NIST Technical Note 2135

\title{
A Case Study of the Camp Fire - Fire Progression Timeline
}

Alexander Maranghides

Eric Link

William "Ruddy" Mell (USFS)

Steven Hawks (CAL FIRE)

Mike Wilson (CAL FIRE)

Will Brewer (CAL FIRE)

Chris Brown

Bob Vihnaneck (University of Washington)

William D. Walton (University of Maryland)

This publication is available free of charge from: https://doi.org/10.6028/NIST.TN.2135
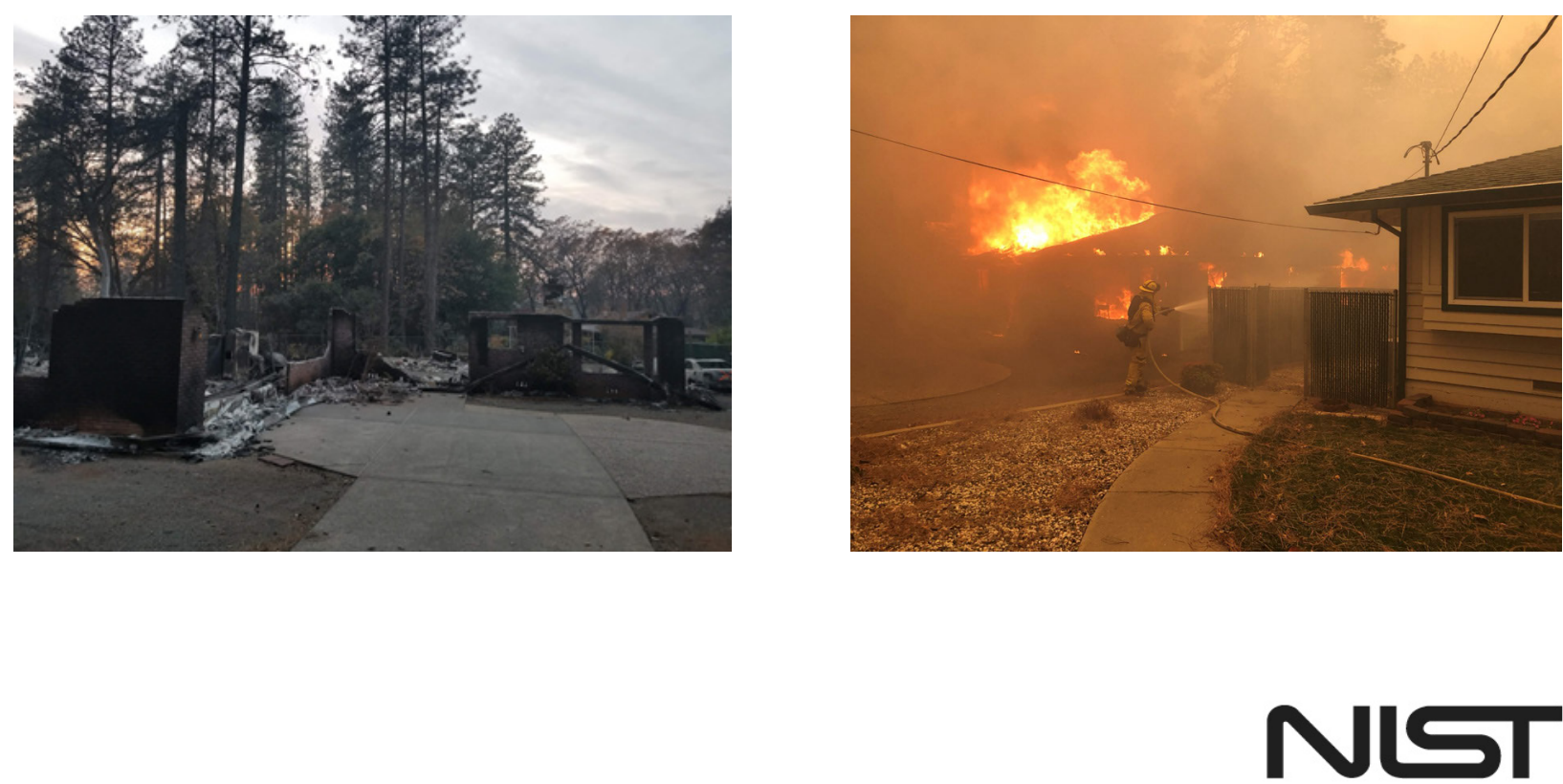

National Institute of Standards and Technology

U.S. Department of Commerce 


\title{
NIST Technical Note 2135
}

\section{A Case Study of the Camp Fire - Fire Progression Timeline}

\author{
Alexander Maranghides \\ Eric Link \\ Engineering Laboratory, NIST \\ William "Ruddy" Mell \\ Fire and Environmental Research Applications, USFS \\ Steven Hawks \\ Mike Wilson \\ Will Brewer \\ Office of State Fire Marshal, CAL FIRE \\ Chris Brown \\ Engineering Laboratory, NIST \\ Bob Vihnaneck \\ University of Washington \\ William D. Walton \\ University of Maryland
}

This publication is available free of charge from:

https://doi.org/10.6028/NIST.TN.2135

January 2021

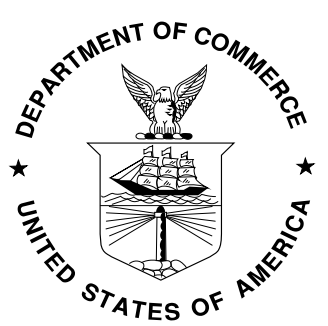

U.S. Department of Commerce Wilbur L. Ross, Jr., Secretary

National Institute of Standards and Technology Walter Copan, NIST Director and Undersecretary of Commerce for Standards and Technology 
Certain commercial entities, equipment, or materials may be identified in this document in order to describe an experimental procedure or concept adequately. Such identification is not intended to imply recommendation or endorsement by the National Institute of Standards and Technology, nor is it intended to imply that the entities, materials, or equipment are necessarily the best available for the purpose.

National Institute of Standards and Technology Technical Note 2135 Natl. Inst. Stand. Technol. Tech. Note 2135, 406 pages (January 2021) CODEN: NTNOEF

This publication is available free of charge from: https://doi.org/10.6028/NIST.TN.2135 


\begin{abstract}
The Camp Fire ignited on November 8, 2018 in the foothills of the Sierra Nevada in Butte County, California. The first 24 hours were characterized by a fast-moving fire with initial spread driven by high winds up to $22 \mathrm{~m} / \mathrm{s}(50 \mathrm{mi} / \mathrm{h}$ ) and long-range spotting up to $6.3 \mathrm{~km}$ (3.9 mi) into the community. The fire quickly impacted the communities of Concow, Paradise, and Magalia. The Camp Fire became the most destructive and deadly fire in California history, with over 18000 destroyed structures, 700 damaged structures, and 85 fatalities. After a preliminary reconnaissance, it was determined that abundant data was available to support an in-depth case study of this devastating wildland-urban interface (WUI) fire to increase our understanding of WUI fire spread, fire behavior, evacuation, and structure response. The methodology guiding the case study and a detailed timeline reconstruction of the fire progression and fire behavior are presented. Over 2200 observations about fire spread and behavior were collected during the case study. Subsequent reports will detail additional aspects of the incident including emergency response and evacuation, and defensive actions and structure response. This study has identified that Butte County and the Town of Paradise were well prepared to respond to a WUI fire, that the Camp Fire grew and spread rapidly and that multiple factors contributed to the rapid growth and spread of the Camp Fire. Additionally, this study identified the importance of the wildland fire ignition location relative to the community, that multiple parcel-level fire spread pathways caused structure ignitions, and that WUI fire spread impacted the affected communities in multiple ways beyond the destruction of residential and commercial properties.
\end{abstract}

\title{
Key words
}

burnover; community hazard reduction; disaster resilience; entrapment; field data collection; large outdoor fires; wildfire; wildland-urban interface; WUI; WUI data collection methodology; WUI fire spread 
Table of Contents

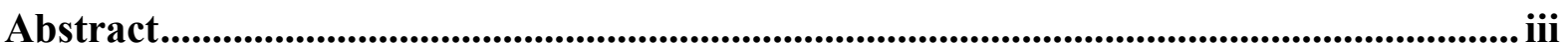

Table of Contents .......................................................................................................... iv

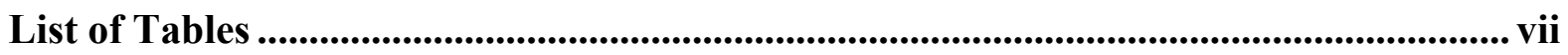

List of Figures................................................................................................................ ix

List of Maps ......................................................................................................................... xiii

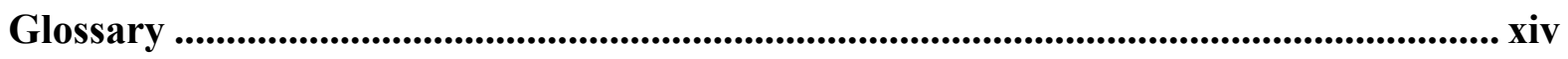

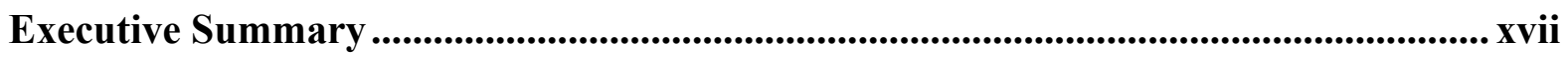

1. NIST Wildland-Urban Interface Fire Research Background .......................................... 1

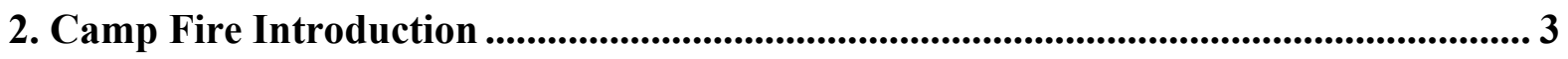

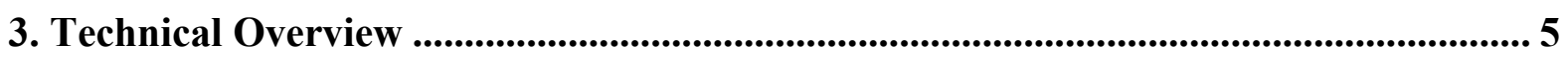

4. WUI Characteristics of Paradise, Magalia, and Concow, CA ......................................... 8

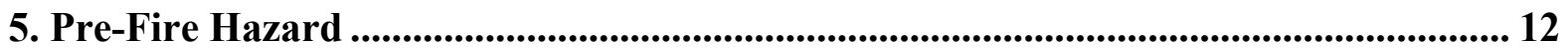

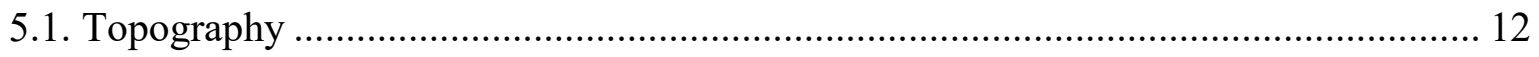

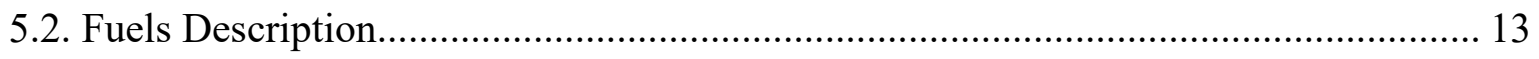

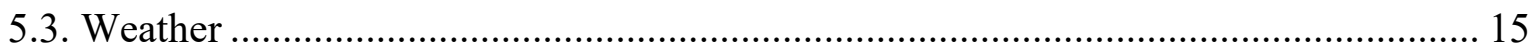

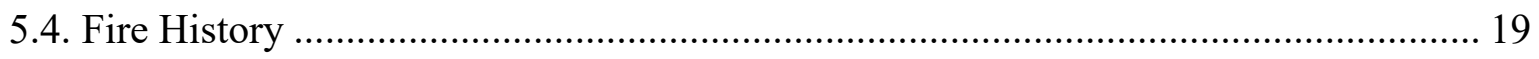

6. Pre-Fire Response Preparations ........................................................................ 21

6.1. Town and County Preparedness ...................................................................... 21

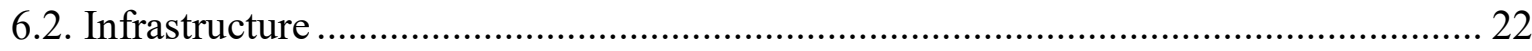

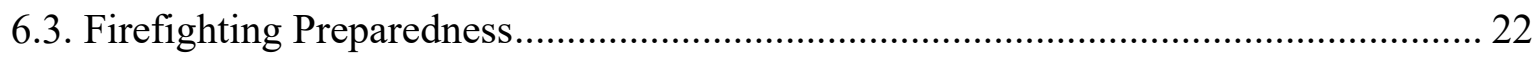

7. Data Collection and Analysis Methodologies ........................................................ 23

7.1. Data Collection....................................................................................................... 23

7.2. Resources Accounted for in First Responder Technical Discussions ........................ 25

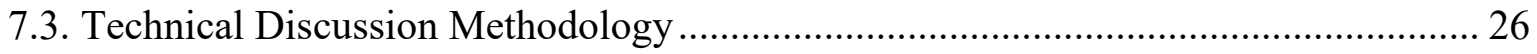

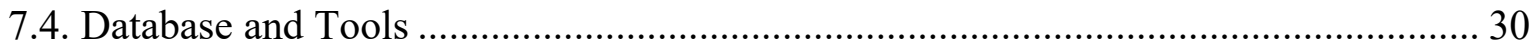

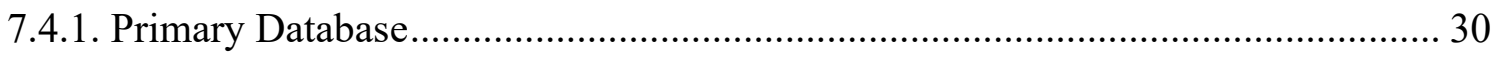

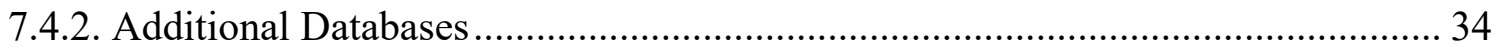

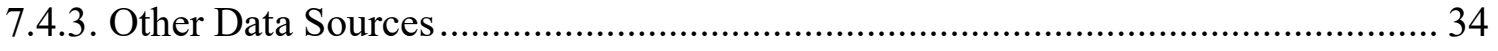

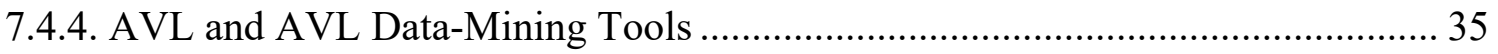

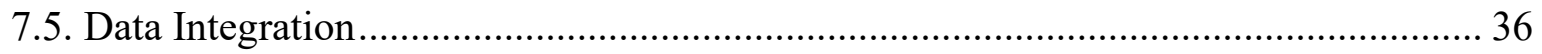

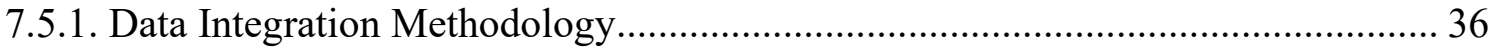

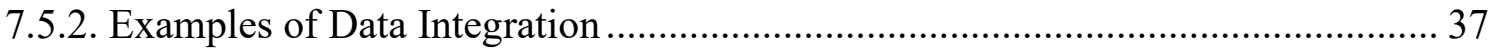

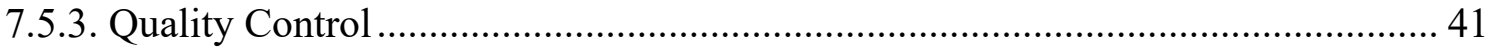




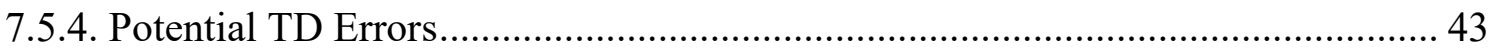

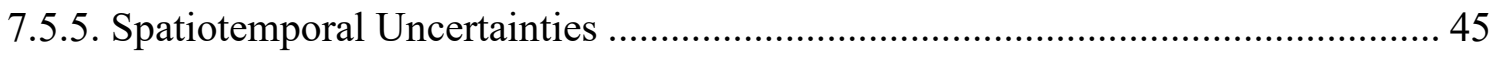

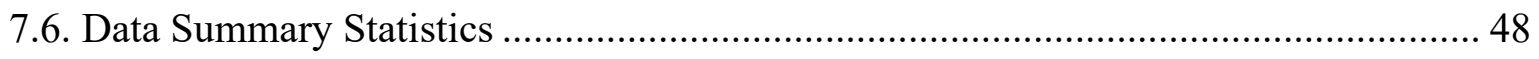

8. Incident Commander Overview for November 8, 2018 ................................................... 51

9. Fire Timeline Reconstruction ................................................................................................ 55

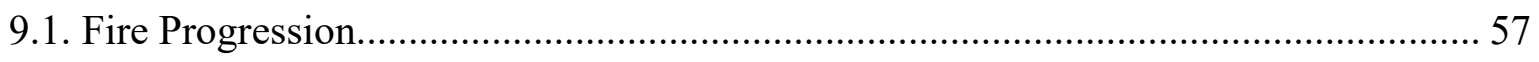

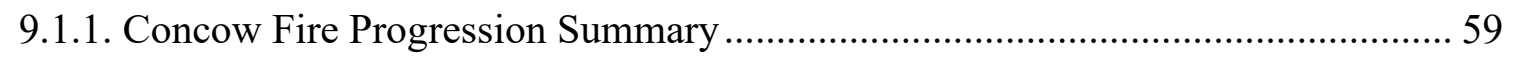

9.1.2. Pentz Road Fire Progression Summary ............................................................ 63

9.1.3. Feather River Hospital (FRH) Fire Progression Summary …………………….. 72

9.1.4. Wagstaff Road Fire Progression Summary ......................................................... 75

9.1.5. Bille Road Fire Progression Summary ……………............................................ 78

9.1.6. Elliott Road Fire Progression Summary ............................................................. 81

9.1.7. Pearson Road and Buschmann Road Fire Progression Summary ......................... 83

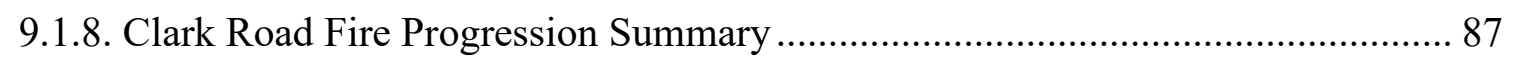

9.1.9. Skyway Fire Progression Summary .................................................................. 94

9.1.10. Neal Road Fire Progression Summary .......................................................... 100

9.1.11. Butte Creek Canyon and Lower Skyway Fire Progression Summary............... 102

9.1.12. Valley View Drive Fire Progression Summary ................................................ 104

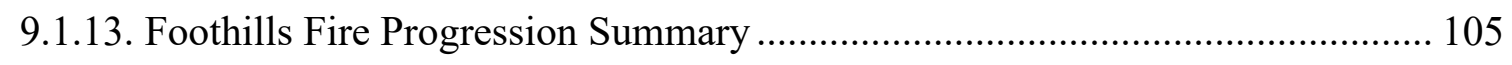

9.1.14. Nelson Bar Road and Highway 70 Fire Progression Summary ........................ 107

9.1.15. Magalia and Coutolenc Road Fire Progression Summary................................ 110

9.2. Fire Observation Histograms ………………………...................................... 113

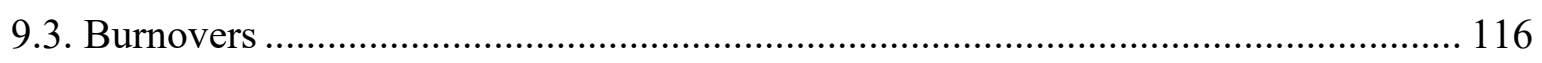

9.4. Impact of Winds, Wildland Fuels, and Terrain on Fire Behavior.............................. 122

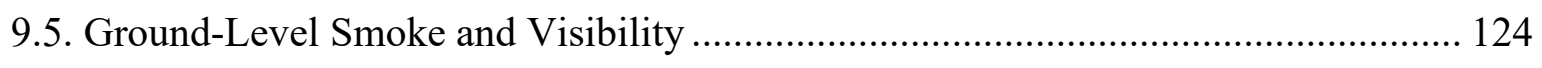

10. Fire Spread Maps................................................................................................................. 126

11. General Fire Behavior and Structure Ignitions ............................................................ 128

11.1. Fire Behavior Across the Community........................................................... 128

11.2. Fire Behavior Across and Within Residential Parcels ........................................... 130

12. Analysis of First Responder Comments.......................................................................... 134

13. Primary Drivers Influencing the Extent of Damage and Destruction ...................... 135

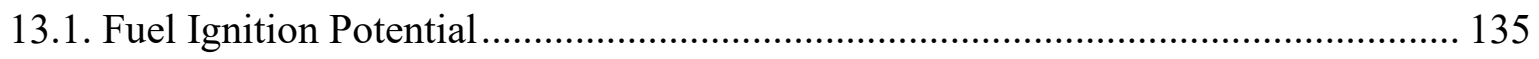

13.2. Density of Vegetative and Structural Fuels........................................................ 135

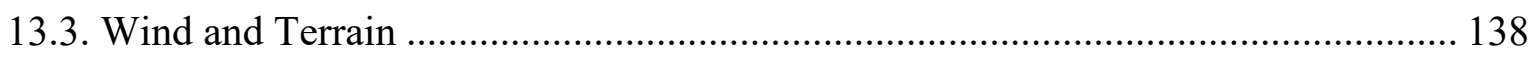


13.4. Extent/Size of Fire Front Reaching the Communities 138

14. Hazard Reduction Pathways................................................................................................ 140

14.1. Community-Level Hazard Reduction Pathways ..................................................... 140

14.2. Reducing the Density of Vegetative and Structural (Community) Fuels and the Fuel

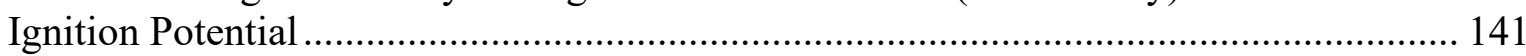

15. Community WUI Fire Hazard Framework ..................................................................... 143

16. Summarized Technical Findings ...................................................................................... 144

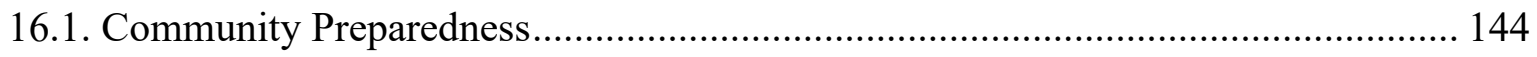

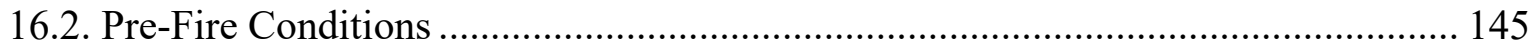

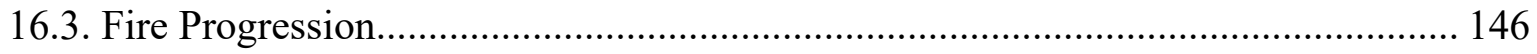

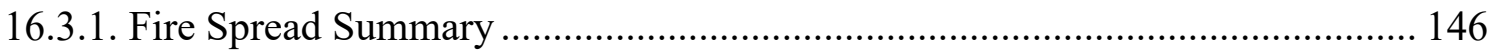

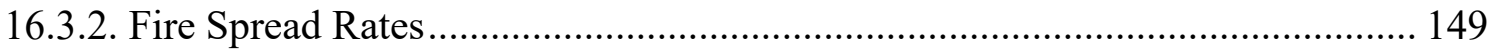

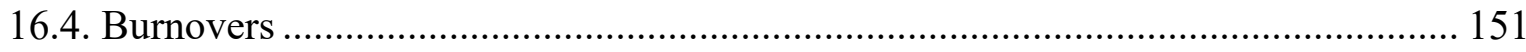

16.5. Wildland Fire Ignition Relative to the Community ............................................... 152

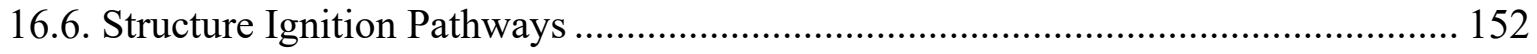

16.7. Community Attribute Impacts........................................................................... 153

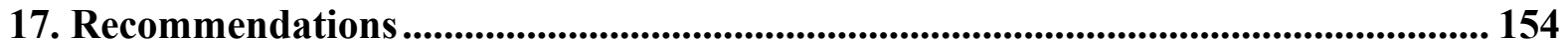

18. NIST Camp Fire Case Study Reports............................................................................ 155

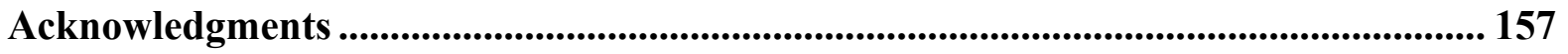

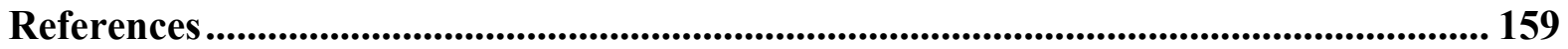

Appendix A. Incident Fire Progression Map, November 22, 2018.................................... 164

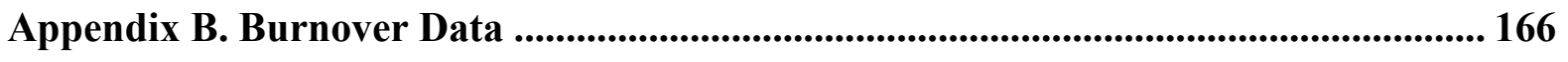

Appendix C. Community WUI Fire Hazard Evaluation Framework ............................... 230

Appendix D. National Weather Service Presentation ........................................................ 236

Appendix E. Identified Successes and Future Improvements to Data Collection and Analysis Methods ................................................................................................................... 255

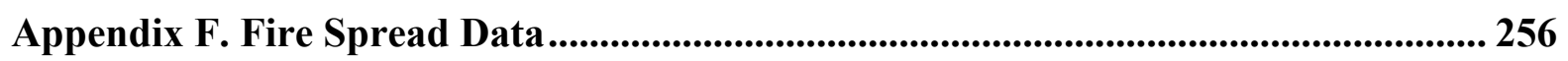

Appendix G. Technical Discussion Comments.............................................................. 367 


\section{List of Tables}

Table 1. Camp Fire Damage Assessment Summary.................................................. 4

Table 2. Population and structure density statistics. ....................................................... 9

Table 3. Variation of structure density in Paradise. ........................................................ 10

Table 4. Distribution of TDs by organization type. ........................................................... 24

Table 5. Tools, "hooks," and methods used to define/refine the event timeline during and after technical discussions.....

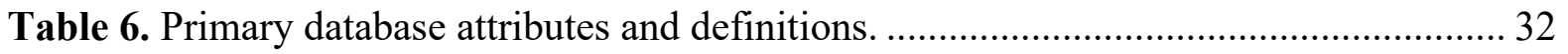

Table 7. Other data sources and tools that provided location, time, or other supporting information.

Table 8. Excerpt of preliminary data along Clark Rd (yellow=traffic direction actions by first responders, red=road closure due to fire activity).

Table 9. Uncertainty ranges of various data sources...................................................... 46

Table 10. Incident Commander Technical Discussion....................................................... 51

Table 11. Summary of fire progression in Concow.

Table 12. Summary of fire progression on Pentz Rd between Apple View Way and Dean Rd.

Table 13. Summary of fire progression on Pentz Rd between Merrill Rd and Wagstaff Rd. 65

Table 14. Summary of fire progression on Pentz Rd between Bille Rd and FRH............... 67

Table 15. Summary of fire progression on Pentz Rd between FRH and Pearson Rd........... 69

Table 16. Summary of fire progression on Pentz Rd between Pearson Rd and Kunkle

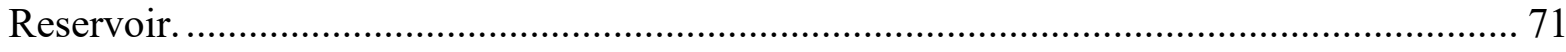

Table 17. Summary of fire progression at Feather River Hospital. ................................... 74

Table 18. Summary of fire progression on Wagstaff $\mathrm{Rd}$............................................. 77

Table 19. Summary of fire progression on Bille $\mathrm{Rd}$................................................... 80

Table 20. Summary of fire progression on Elliott Rd.................................................... 82

Table 21. Summary of fire progression on Pearson Rd and Buschmann Rd...................... 85

Table 22. Summary of fire progression on Clark Rd between Skyway and CMA Church. .. 87

Table 23. Summary of fire progression on Clark Rd between CMA Church and Nunneley $\mathrm{Rd}$.

Table 24. Summary of fire progression on Clark Rd between Nunneley Rd and Airport Rd.

Table 25. Summary of fire progression on Skyway between Coutolenc $\mathrm{Rd}$ and Bille $\mathrm{Rd}$.... 95

Table 26. Summary of fire progression on Skyway between Bille Rd and Lookout Point. .. 98

Table 27. Summary of fire progression on Neal Rd between Skyway and Goa Way. ........ 101

Table 28. Summary of fire progression in Butte Creek Canyon and on lower Skyway...... 103 
Table 29. Summary of fire progression on Valley View Dr. ......................................... 104

Table 30. Summary of fire progression in the foothills between Paradise and Hwy 99..... 106

Table 31. Summary of fire progression on Nelson Bar Rd and Highway 70. .................. 109

Table 32. Summary of fire progression in Magalia and on Coutolenc Rd......................... 111

Table 33. List of identified burnover locations by time of occurrence and risk of injury or

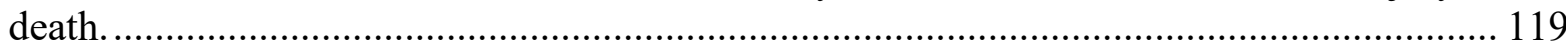

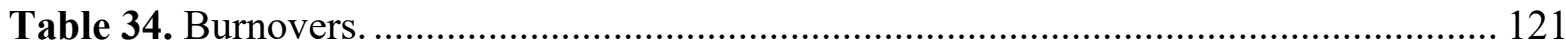

Table 35. Residential structure ignition pathways identified by direct observation........... 133

Table 36. List of topics and frequency counts of fire-related first responder comments..... 134

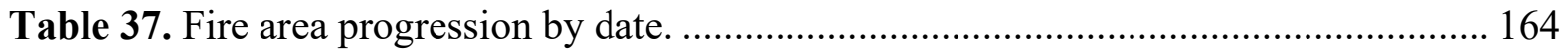

Table 38. List of TD-identified burnover events and information source summary........... 167

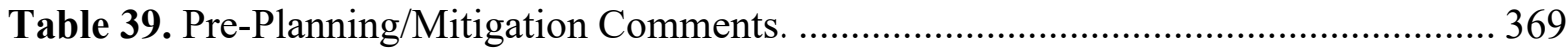

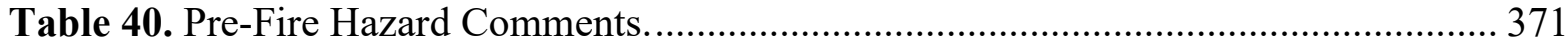

Table 41. Fire Behavior Comments. ................................................................................. 373 


\section{List of Figures}

Figure 1. Location of Butte County, California and the Camp Fire. .................................. 8

Figure 2. Homes within Paradise display a wide range of structure-to-structure separation. Representative images show progressive reductions in structure density from locations; a) Apple Tree Village Mobile Home Park, b) Lancaster Dr, c) Valley Ridge Dr, and d) Round Valley Ranch Rd. Also note the variability in vegetative fuel density.....

Figure 3. Excerpt of the FRAP fire hazard severity zone map [32] of northern Butte County indicating, in red, Very High Fire Hazard Severity Zone (VHFHSZ) on the Paradise ridge and surrounding areas. Paradise is a "Local Responsibility Area" and is recommended by the state as VHFHSZ, shown in the inset [33]....

Figure 4. The energy release component measured among a special interest group (SIG) of nearby fire weather stations representative of the Camp Fire exceeded the historic record high for early November (60) and was in the $90^{\text {th }}$ percentile (80) for the previous 10 years. [35]

Figure 5. National Fire Danger Rating System map [36] indicating Very High to Extreme fire danger in Butte County and northern California.

Figure 6. Percent average precipitation across northern California for a) 1 month $(<25 \%)$, b) 6 months $(<25 \%)$, and c) 1 year $(<70 \%)$ prior to the Camp Fire. Figures from Western Regional Climate Center [39]. Overlaid arrows highlight Butte County.

Figure 7. NWS Sacramento published forecast graphics [40, 41] on November 7 highlighting a) widespread Red Flag Warnings for November 8, and b) wind gust forecast showing peak winds exceeding $22 \mathrm{~m} / \mathrm{s}(50 \mathrm{mi} / \mathrm{h})$.

Figure 8. Wind and temperature observations at the Jarbo Gap RAWS on Highway 70 [37].

The vertical dashed line indicates the ignition time.

Figure 9. Wind and temperature observations at the Openshaw RAWS on Highway 149 in the Sacramento Valley [42]. The vertical dashed lines indicate the ignition time and the wind shift. 18

Figure 10. Historic fire perimeters in northern Butte County (1911-2018) [43] are overlaid to show a) the number of times each area has burned and b) the number of years since the last fire. The Camp Fire is highlighted and outlined in red for comparison. ............................ 20

Figure 11. Locations of TDs across northern California. ............................................... 24

Figure 12. NIST Field Team with CAL FIRE personnel at Fire Station 35 in Paradise. ..... 28

Figure 13. Annotated Paradise Overview Map from TD-064. ....................................... 29

Figure 14. A flowchart illustrating an example of data integration and the method of crossreferencing multiple data sources for TD refinement. 38

Figure 15. a) An unidentified engine in a photograph from TD-041 matches scorch marks on E2390 seen in b) an interview on 60 Minutes. 39 
Figure 16. TD-106 described a fire whirl as they were driving south on Neal Rd and mentioned that a news crew recorded the event. News reporter Laura Anthony/KGO-TV captured a video of the event at 17:18, and the location was confirmed using Google Street View imagery.

Figure 17. Cross-referencing TD and DINS data; a) section of TD-207 map indicating a defended structure marked as 207-24 b) DINS image confirming the identification of the described structure.

Figure 18. An example of cross-referencing: a) video data shows a rising smoke column.

b) Landsat data used in the quality control process identified an adjustment of $300 \mathrm{~m}$ to the original placement of the spot fire observation.

Figure 19. Example of a longitude coordinate transcription error identified during the quality control process. 45

Figure 20. Distribution of fire observation data sources.

Figure 21. Cumulative fraction of fire observations as a function of time (hours greater than 24:00 correspond to November 9) and distribution of time source for fire observations....... 50

Figure 22. Generalized fire spread vector map indicating the direction of fire progression from the origin northeast of Concow. 56

Figure 23. Map of 15 fire timeline focus regions. Some regions overlap slightly indicated by relative discoloration. 58

Figure 24. View of the fire looking north from Highway 70 at the Caltrans Pulga Maintenance Yard at 07:23. Panorama created from video recording.

Figure 25. Strong wind gusts blew dirt and rocks whipping across the ridgetop at Rim Road.

Figure 26. Scenes from a Paradise Police Department dashboard camera show how rapidly conditions can change and impact evacuation routes, as fire is seen impacting evacuating vehicles on Pentz Rd at Merrill Rd.

Figure 27. Body camera recording shows the initial stages of the spot fire off Lowry Ln and Riverside Dr. 68

Figure 28. View of everything burning at the intersection of Pentz Rd and Riverview Dr. View west at 09:42.

Figure 29. a) Fire burning on the Feather River Hospital campus before 08:54. b) Blackout conditions and heavy showers of large embers at 09:08. The video documents ember showers coming from the west as the fire front arrived from the east.

Figure 30. Spot fires in vegetation threatened FRH and generated additional ember showers.

Figure 31. The cardiology section of FRH was destroyed. Extensive firefighting efforts prevented spread to other portions of the facility.

Figure 32. Midnight darkness, swirling winds, heavy ember showers, and fully involved structures at the intersection of Oak Way and Wagstaff Rd at 10:17. View north. 76 
Figure 33. A structure on Wagstaff Rd just east of Clark Rd (behind Save Mart) is burning at 10:22. View south. 76

Figure 34. Abandoned vehicles on Bille Rd, seen after the fire, pushed aside by a bulldozer. Evacuees were overrun by fire around 09:50. View west. .... 78

Figure 35. Fire activity on Bille Rd near Lucky John Rd, west of Skyway, at 17:14. Numerous structures are fully involved, while others are burned down or just starting to ignite.

Figure 36. Intense fire activity in the drainage at Pearson Rd and Hilbe Dr while civilians and first responders are stuck in the area. Views are eastbound, a) just east of Hilbe Dr, and b) just east of Hilltop Dr at the tail end of the traffic jam. 83

Figure 37. A fully involved parcel on Pearson Rd at Sierra Park Dr. 84

Figure 38. Commercial structures burning along Clark Rd at Central Park Dr. View north. 89 Figure 39. Heavy fire exposure from the canyon burns over Clark Rd just north of Airport $\mathrm{Rd}$, delaying civilian evacuation and first responder access. View north at 11:20. 92

Figure 40. Skyway was burned over during the middle of evacuation efforts. Conditions are seen here at 10:44 just west of the lane divide at the town limits.

Figure 41. A view into Butte Creek Canyon from Lookout Point on Skyway shows the steep canyon walls. View north. Photo March 2019. 102

Figure 42. View west from Nelson Bar Rd where plumes of smoke are seen coming from beyond the ridge in the Concow Creek drainage, and beyond to Paradise (background, left).

Figure 43. Fire activity increased in the drainage area, and the front rapidly spread south and east toward Nelson Bar Rd. 108

Figure 44. View south from the Magalia Reservoir dam as flames shoot up from the West Branch Feather River canyon over the ridge and Coutolenc Rd.

Figure 45. Fire observation histograms shaded by type of fire observation $(\mathrm{S}=$ spot, $\mathrm{V}=$ vegetation, $\mathrm{O}=$ other, $\mathrm{R}=$ residential structure, $\mathrm{C}=$ commercial structure) for Pentz $\mathrm{Rd}$, Clark Rd, and Skyway focus regions, binned as a function of time of day on November 8. Note the early number of spot fire observations and the differences in time of peak observation counts.

Figure 46. Snapshot from PPD dashboard camera showing representative conditions throughout a $1 \mathrm{~km}(0.6 \mathrm{mi})$ stretch of Clark Rd near Forest Service Rd at 11:57.

Figure 47. Map of all identified and documented burnover locations.

Figure 48. Image sequence from a video recording showing visibility and wind conditions along Pentz $\mathrm{Rd}$, heading south at 10:52. Visibility is intermittent and wind directions shift $180^{\circ}$ over short distances and time periods.

Figure 49. Wall of smoke observed on Pentz Rd, going north, at Dry Creek Rd. This abrupt change in conditions was described by multiple individuals. 125 
Figure 50. Statistics related to spot fire ignition frequency and location in Paradise:

a) distribution of distance into the community of the 65 documented spot fires and

b) cumulative number of spot fires before 10:30.

Figure 51. Map of the 65 documented spot fire ignitions in Paradise before 10:30. The red symbols $(\mathrm{N}=30)$ are spot fires that ignited between 07:49 and 08:30, mostly within $1 \mathrm{~km}$ from the edge of the community, but as far as $5 \mathrm{~km}$ away. Black symbols $(\mathrm{N}=35)$ are spot fires that ignited between 08:30 and 10:30

Figure 52. A defended structure on Lewis Ranch $\mathrm{Rd}$ where the burning vehicle was igniting the structure, showing a) a dozer displaced the vehicle to stop fire spread, b) the associated evidence of the fire ignition and defensive actions encountered during NIST damage assessments.

Figure 53. Structure ignition on Dade $\mathrm{Ct}$ in Magalia. Images are two minutes apart and show fire spread from surface fuels to fence to vegetation to eaves. The combustible fence is estimated to be approximately $1.8 \mathrm{~m}(6 \mathrm{ft})$ away from the structure.

Figure 54. Numerous structure ignition pathways exist from the wildlands and inter- and intra-parcel exposure sources. The ignition pathway for the identified Dade Ct, Magalia structure ignition is highlighted.

Figure 55. Wildland fire pre-plan for Butte County Fire Department Battalion 2.

Figure 56. Fuel treatment around Paradise Irrigation District critical infrastructure: a) prior to fuel treatment, May 2018, b) fuel treatment showing reduced fuel load, c) rapid post-fire vegetative growth in pre-fire fuel treatment areas....

Figure 57. Idealized relationship between ignition location, a) near or b) far, from a WUI community and the fire front and ember exposures reaching the community. The wind is directed from left to right.

Figure 58. Fully involved shed, $8 \mathrm{~m} \times 4 \mathrm{~m}(13 \mathrm{ft} \times 26 \mathrm{ft})$, located $3 \mathrm{~m}(10 \mathrm{ft})$ from the primary structure. Eaves of the primary structure are pyrolyzing (white arrow). 


\section{List of Maps}

Map 1. Camp Fire Points of Interest and Frequently Referenced Roads and Locations

Map 2. Fire Observations 06:25 to $07: 45$, November 8

Map 3. Fire Observations 07:45 to $08: 30$, November 8

Map 4. Fire Observations 08:30 to 09:00, November 8

Map 5. Fire Observations 09:00 to 10:00, November 8

Map 6. Fire Observations 10:00 to 11:00, November 8

Map 7. Fire Observations 11:00 to 12:00, November 8

Map 8. Fire Observations 12:00 to 13:00, November 8

Map 9. Fire Observations 13:00 to 14:00, November 8

Map 10. Fire Observations 14:00 to 16:00, November 8

Map 11. Fire Observations 16:00 to 19:00, November 8

Map 12. Fire Observations 19:00 to 23:00, November 8

Map 13. Fire Observations 23:00, November 8 to 02:00, November 9

Map 14. Fire Observations 02:00 to 09:00, November 9

Maps are large format $(864 \mathrm{~mm} \times 1118 \mathrm{~mm}, 34 \mathrm{in} \times 44 \mathrm{in})$ and are appended at the end of this report. 


\section{Glossary}

\section{Agencies/Organizations}

BCSO Butte County Sheriff's Office

CAL FIRE California Department of Forestry and Fire Protection

Cal OES California Governor's Office of Emergency Services

CHP California Highway Patrol

FEMA Federal Emergency Management Agency

FSC Fire Safe Council

GACC Geographic Area Coordination Center

ICC International Code Council

NASA National Aeronautics and Space Administration

NFPA National Fire Protection Association

NIFC National Interagency Fire Center

NIST National Institute of Standards and Technology

NOPS CAL FIRE Northern Region Operations

NWS National Weather Service

PID Paradise Irrigation District

PPD Paradise Police Department

PPW Paradise Public Works Department

USFS United States Forest Service

USGS United States Geological Survey

CAL FIRE

$\mathrm{BFC}$

Butte Fire Center

BTU

CAL FIRE Butte Unit

LNU

CAL FIRE Sonoma-Lake-Napa Unit

NEU

CAL FIRE Nevada-Yuba-Placer Unit

SHU

CAL FIRE Shasta-Trinity Unit

TGU

CAL FIRE Tehama-Glenn Unit

Unit

operational unit (CA is divided into 21 geographical operational units)

USFS

ENF

Eldorado National Forest

MNF

Mendocino National Forest

PNF

Plumas National Forest

TNF

Tahoe National Forest 


$\begin{array}{ll}\text { Incident Command } \\ \text { Branch } & \text { ICS organization level } \\ \text { Division } & \text { ICS organization level, below Branch } \\ \text { DINS } & \text { Damage Inspection / Damage Inspection Specialist } \\ \text { ECC } & \text { Emergency Command Center } \\ \text { IC } & \text { Incident Command(er) } \\ \text { ICP } & \text { Incident Command Post } \\ \text { ICS } & \text { Incident Command System } \\ \text { IMET } & \text { Incident Meteorologist } \\ \text { ST } & \text { Strike Team, group of resources of same kind and type } \\ \text { Apparatus } \text { Type } \\ \text { AA } & \text { Air Attack } \\ \text { B } & \text { Battalion Chief } \\ \text { D } & \text { Division Chief } \\ \text { DZ } & \text { Dozer } \\ \text { E } & \text { Engine } \\ \text { P } & \text { Fire Prevention Officer } \\ \text { T } & \text { Training Officer } \\ \text { TD } & \text { Dozer Transport } \\ \text { WT } & \text { Water Tender } \\ \end{array}$




\section{Other}

ANSI E-size American National Standards Institute drawing size, $1118 \mathrm{~mm} \times 864 \mathrm{~mm}$ (44 in $\times 34$ in)

AVL automatic vehicle locator

BO burnover

CWPP Community Wildfire Protection Plan

ERC Energy Release Component, a measure of fuel energy availability

FDS Fire Dynamics Simulator

FF fire fighter

FR first responder

FRH Feather River Hospital

GIS geographic information system

LANDFIRE U.S. Government program providing landscape scale geospatial products describing vegetation and wildland fuel across the U.S.

LE law enforcement

NFDRS National Fire Danger Rating System

RAWS Remote Automated Weather Station

ROS rate of spread

SIG special interest group

SSD structure separation distance

TD technical discussion

TRA temporary refuge area

VHFHSZ Very High Fire Hazard Severity Zone

VTD "virtual" technical discussion

WUI wildland-urban interface 


\section{Executive Summary}

The wildland-urban interface (WUI) is defined as the location where structures and communities meet or intermingle with undeveloped wildland. In the United States, over 44 million homes, housing $32 \%$ of the US population, were in the WUI in 2010. WUI areas that experience wildland fires are vulnerable to significant fire exposures, causing significant loss of life and property. In the early 2000 s, over one thousand structures per year on average were lost to WUI fires in California alone. The WUI fire problem is growing nationally each year; in the 2010s, multiple single fire events have caused losses in the thousands of structures. In 2018, the Camp Fire became the deadliest and most destructive fire in California history.

The Camp Fire started near Camp Creek Road and Pulga Road in Butte County, California, in the Feather River Canyon north of Jarbo Gap, at approximately 06:20 on the morning of November 8, 2018. The agencies responsible for unified command of the incident included the California Department of Forestry and Fire Protection (CAL FIRE), Butte County Sheriff's Office, Paradise Police Department, and the U.S. Forest Service. At peak daily staffing, total personnel involved in firefighting exceeded 5600, including 900 pieces of apparatus (620 engines, 101 hand crews, 102 dozers, and 77 water tenders).

The Camp Fire consumed 153336 acres and destroyed 18804 structures in the towns of Paradise, Magalia, and Concow-equivalent to three times the losses of the 2017 Tubbs Fire (5636 structures) or six times the losses of the 1991 Oakland Hills Fire (2900 structures). Eighty-five percent of the structures in the Town of Paradise were destroyed. In addition to the destroyed structures, the Camp Fire damaged a total of 754 structures. The fire resulted in 5 documented major firefighter injuries and 85 civilian fatalities. Afterwards, 3266 missing persons were located. The fire was declared $100 \%$ contained on November 25, 2018, after burning for 18 days. Initial estimates suggested the Camp Fire would be the most destructive fire in California history at a cost of $\$ 11$ billion to $\$ 13$ billion in losses and $\$ 3$ billion for debris clean up. A more recent assessment determined that the Camp Fire was the costliest natural disaster worldwide in 2018 , with overall losses of $\$ 16.6$ billion.

The catastrophic losses from the Camp Fire have led to the identification of multiple research questions to help understand this WUI fire and provide lessons learned that may be used to reduce losses in other WUI communities in the future. The five overarching research questions are:
a. How can a fire event of the scale of the Camp Fire be documented to facilitate the extraction of information for reducing future losses?
b. How did the fire spread to and within Paradise?
c. What were the primary causes of the extensive devastation?
d. What fire spread pathways caused structural ignitions?
e. How unique is Paradise as a community at risk of WUI fires?

Additional research questions related to topics of emergency notification, evacuation, Temporary Refuge Areas, emergency response, defensive actions, and damaged structures will be addressed in subsequent reports. 


\section{a. How can a fire event of the scale of the Camp Fire be documented to facilitate the extraction of information for reducing future losses?}

Post-fire data includes fire observations, structural losses, emergency notification and evacuation details, and response particulars. Collection and dissemination of this information along with relevant pre-fire data can be used to develop lessons learned, with the goal of reducing losses in future WUI fires and improving community resilience. To address this question, a WUI data collection, analysis, and documentation framework was developed and utilized to document the Camp Fire. The methodology is based on the lessons learned from previous National Institute of Standards and Technology (NIST) WUI fire case studies. The methodology includes a field data collection process and a procedure for reconstructing the Camp Fire using the fire timeline as the baseline.

\section{b. How did fire spread to and within Paradise?}

The NIST-developed post-fire data collection methodology is based on the observations and knowledge of first responders, local officials, and utilities personnel. During the data collection phase of this case study 157 individuals participated in technical discussions where they provided their unique first-hand perspective of the incident. Over 2200 data points related to fire observations were recorded from these discussions and other data sources, including photos, videos, 911 calls, and radio transcripts. The integration of these data points in space and time resulted in the reconstruction of the fire timeline presented here, focusing on the first 24 hours of the event when the majority of destruction occurred. Thousands of additional data points regarding evacuation, rescues, traffic, and defensive actions were also recorded and will be detailed in subsequent reports.

\section{Fire Spread Summary}

\section{November 8, 06:25 to 10:00}

The Camp Fire was first reported via calls to 911 beginning at 06:25. The caller indicated that the fire was burning on the west side of the Feather River near Poe Dam on Highway 70. The fire quickly became well-established in the steep canyon terrain, spreading from the origin toward Pulga. Shortly after 07:00, the fire was cresting the ridge and pushing towards Concow. By 07:25 the first structures started burning in Concow, $5 \mathrm{~km}(3 \mathrm{mi})$ from the origin.

The fire continued growing in Concow, moving westward and spotting over Concow Reservoir and Sawmill Peak. The first spot fires from the Camp Fire arrived in Paradise at $07: 44,12 \mathrm{~km}(7.5 \mathrm{mi})$ from the origin. The main fire front reached Pentz Road around 08:30, resulting in a significant number of distinct spot fires within Paradise. A total of 30 spot fires before 08:30 were identified during the data analysis, with spots reaching as far as $3.4 \mathrm{~km}(2.1 \mathrm{mi})$ into the town. Most of these spots (18) were within the first $1 \mathrm{~km}$ $(0.6 \mathrm{mi})$ from the wildlands. The fire front reached Pentz Road between Apple View Way and Lowry Lane. Spot fires in and across town before 08:30 were most likely from the wildland fire front and a limited number of structure ignitions in Concow. By 08:45 there were two separate spot fires that had started in the vegetation far ahead of the main fire 
front. One was burning in the drainage east of Clark Road near American Way, $3 \mathrm{~km}$ (1.9 mi) southwest from the Lowry Lane, spotted near Feather River Hospital. The second spot ignited in Honey Run Canyon, located on the west side of Paradise, $6.3 \mathrm{~km}$ (3.9 mi) from Lowry Lane.

Between 09:00 and 10:00 in Concow, the head of the fire was hung up on the east side of Concow Reservoir, burning to the north of Ishi Trail. Spot fires were igniting in pine and leaf litter $1.6 \mathrm{~km}(1 \mathrm{mi})$ ahead of the fire front. During that same time in Paradise, the fire intensified along both sides of Pentz Road. Initial spot fires deep within town were well established, and the fire was starting to spread to the west impacting Wagstaff, Bille, and Pearson Roads. By 10:00, fire was impacting Pentz, Bille, and Pearson Roads, where civilians were stuck in traffic and trapped in their vehicles. The fire continued to get deep-seated along both sides of Pentz while the earlier spots in town also grew.

\section{November 8, 10:00 to 12:00}

Between 10:00 and 11:00 on Pentz Road, peak vegetation fire activity had subsided, but significant fire remained. Most structures and heavy fuels were still burning on both sides of the road. The road was passable with variable visibility. The intersection of Pentz Road and Pearson Road remained fully involved, continuing to impact evacuations.

By 10:00, fire was impacting Clark Road in multiple locations, preventing passage while people were attempting to evacuate. The fire overtook vehicles evacuating on Clark Road at Buschmann Road with wind blowing flames "like a blow torch," and fire jumped to the west side of Clark Road. Clark Road became barely passable again near the town limits for a brief time. However, another flare-up between 11:00 and 11:30 closed the roadway again as $15 \mathrm{~m}$ (50 ft) flames crossed Clark Road near Round Valley Ranch Road, and fire again crossed the roadway near American Way. Further down Clark Road at Airport Road, fire also burned over the roadway, delaying access of arriving strike teams as they waited for conditions to abate. The fire continued with high intensity south of the airport into the afternoon, where it paused and hung up for a period of time between about 13:00 and 15:00, before again advancing down into the flats south of Circle J Road.

Between 10:00 and 11:00, the spot fire in Honey Run Canyon, between Russell Drive and Redbud Drive, grew and became well established. Fire ran south up out of the canyon and burned over Skyway. Significant ember showers and fire activity on both sides of Skyway impacted evacuating vehicles.

By noon, intense fire was burning on the ridge and in the canyons near Jordan Hill Road. Flame lengths of $30 \mathrm{~m}$ to $45 \mathrm{~m}(100 \mathrm{ft}$ to $150 \mathrm{ft})$ were observed. Engines looking for civilians had to drive through fire to escape back to Concow Road. At the same time, the northern flank of the fire was hung up between Coutolenc Road and Pentz Road. In Paradise, the main fire was pushing south down Berkshire Avenue, spreading to structures. Fire spread from structure to structure through Skyway Villa Mobile Home Park. The main fire activity along Pentz Road had passed; structures were burned down, vegetation had burned through, and Pentz Road was passable. Fire was well-established on the west side of northern Pentz Road, burning heavy brush, trees, and structures. 
Structures began igniting on Sweetbriar Lane, and the fire spread west from structure to structure. Before noon, fire was approaching the Walgreens store and the intersection of Bille Road and Skyway from multiple directions. Structures were burning south and east of Skyway in the area of Almond Street and Fir Street. At the same time, fire activity at the Skyway split was still active on both sides of the roadway, but Skyway was passable. Fire was encroaching on Neal Road and Roe Road from the north, as a large area of fire burned over Skyway.

November 8, 12:00 to 17:00

Between noon and 15:00 in Concow, the southern extent of the fire continued to burn in the Concow Creek canyon northwest of Nelson Bar Road and north of Comfort Lane on both sides of Concow Road. In Paradise, the fire was well established through most of the town and began impacting the downtown area. By 13:00, 10 to 15 structures were burning at the south end of Andover Drive and on Adrian Drive. On the northern end of Paradise, fire was coming toward the Clark Road and Skyway intersection from the canyon to the west. Structures on the east side of Skyway were burning intensely, and fire was coming from the north through residential structures, threatening commercial structures where trapped civilians were taking temporary refuge. Many homes were on fire near Clark Road and Cabernet Lane. To the southwest, fire in Honey Run Canyon was moving down the canyon toward Centerville Road with a moderate rate of spread. On the ridgetops, flames were shooting out of the canyon with $30 \mathrm{~m}$ to $60 \mathrm{~m}$ (100 ft to $200 \mathrm{ft}$ ) flame lengths. In the canyon, flames were $2 \mathrm{~m}$ to $3 \mathrm{~m} \mathrm{(6ft} \mathrm{to} 10 \mathrm{ft})$ long. Ember showers and flames were threatening multiple structures.

Between 14:00 and 17:00, fire was embedded in the structures in the area on the southern end of South Park Drive and Adrian Drive. Fire was burning in Little Butte Creek Canyon, wrapping around to the west, and burning in ravines uphill into the prevailing wind, toward West Park Drive.

By 15:00, heavy fire was burning everything on the west side of Skyway between Black Olive Drive and Jewell Road, including a burning woodpile that was threatening Town Hall. Torching shrubs and junipers were threatening additional nearby structures. Skyway between Pearson Road and Neal Road was being encroached upon from both east and west; fire was spreading uphill and upwind in Honey Run Canyon into structures on the west side of Skyway, and the main fire front was pushing west from Pearson Road. Structures were burning along Pearson Road, Almond Street, and Black Olive Drive, approaching Skyway.

Between 15:00 and 17:00 the fire approached Nelson Bar Road. To the north, the fire remained burning to the south of Magalia. In downtown Paradise, fire was wellestablished in multiple commercial structures at Skyway on Fir Street, and fire continued to burn structures in the area of Fire Station 81.

November 8, 17:00 to 24:00

Around sunset (16:56) in Concow, an intense fire front with $15 \mathrm{~m}$ to $30 \mathrm{~m}(50 \mathrm{ft}$ to $100 \mathrm{ft}$ ) flames burned through the forest into the grasslands, impacting structures along the west 
side of Nelson Bar Road. Numerous short-range spot fires were observed ahead of the fire front. At the same time in Magalia, fire was backing up out of the canyon, impinging on structures on Andover Drive with creeping fire behind homes. In Paradise, structures continued to burn. Large trees and power poles continued burning and threatened or blocked roadways. Also, around sunset, fire activity at Neal Road and Wayland Road increased, pushing into the area from the northeast. The fire then ran down into the foothills toward Highway 99.

Between 18:00 and midnight, the evening was a period of generally reduced fire behavior in the upper part of Little Butte Creek Canyon near Magalia. Different portions of Andover Drive were threatened throughout the evening period. By 22:00, fire had moved up out of Stilson Canyon and was coming up over Humboldt Road approaching Highway 32. Fire had also burned through the Cory Creek area, destroying multiple structures. Residual fire continued to threaten communities along Durham-Pentz Road.

November 9, 00:00 to 08:00

Between midnight and 02:00 on November 9, the fire flared up out of the West Branch Feather River Canyon with $30 \mathrm{~m}$ (100 ft) flames pushed by strong winds, estimated at $22 \mathrm{~m} / \mathrm{s}$ (50 mi/h). Softball-sized embers blew across Coutolenc Road and Skyway into Magalia and Old Magalia. Several spot fires were established on the west side of Magalia Reservoir, and fire was spreading uphill toward Lakeridge Circle. Intense fire blocked Skyway south of the dam.

Between 02:00 and sunrise, at 06:44, the fire became well established in Magalia and consumed hundreds of structures. During the night in Concow fire was between Nelson Bar Road and Highway 70. Fire intensity was low to moderate, making local runs and overtaking dozer lines towards Lake Oroville.

The fire activity intensified dramatically at several locations at sunrise. In Concow, fire was burning across Pinkston Canyon Road towards Concow Road. Firefighters were worried about getting hemmed in by fire on both sides on Concow Road. Butte County Fire Station 37 on Concow Road was hit hard by the fire. At the same time in Magalia, a rapid increase in fire activity on the west end of Ponderosa Way impacted the south and west. Firefighters had to drive through fire to reach the safety zone of the parking lot at Pine Ridge School, where fire also approached from the east.

\section{General}

The fire timeline reconstruction has identified over a dozen entrapment/burnover events, life-threatening situations when fire traps or overtakes people or equipment and compromises escape routes. These events affected civilian and/or first responder evacuation and movement. The presence of primarily wildland vegetation along evacuation routes and some secondary roadways, likely amplified by local topography and wind, resulted in entrapments/burnovers in different locations and at different times.

Many of the entrapments/burnovers significantly impacted evacuation and required the formation of Temporary Refuge Areas (TRAs) to maintain life safety for residents and 
firefighters. In at least two cases fire shelters were deployed by first responders to reduce radiative exposures to civilians and first responders. Several entrapments/burnovers resulted in civilian or first responder injuries and civilian fatalities. The relationships among entrapments/burnovers, evacuation of residents, and TRAs will be documented and analyzed in NIST Camp Fire Report \#4.

\section{c. What were the primary causes of the extensive devastation?}

There are many factors that may impact individual structure survivability and the effectiveness of defensive actions at a parcel level. When viewing the Camp Fire in its entirety, four factors were identified that most significantly influenced overall fire losses:

i. Fuel ignition potential,

ii. Density of vegetative and structural fuels,

iii. Wind and terrain, and

iv. Extent/size of fire front reaching the communities.

\section{Fuel Ignition Potential}

Fuel receptivity to embers and ignition potential was a result of over 200 days with almost no precipitation. Fuel moisture contents were at or near record low for the time of year. The presence of fine fuels, including but not limited to pine needles and ornamental vegetation stressed by limited precipitation, enabled a number of spot ignitions by embers traveling well ahead of the fire front. Fuel receptivity and ignition from embers was clearly conveyed in multiple first responder statements reporting " $100 \%$ ember ignitions." It was this fuel receptiveness that caused the large number of ignitions within the communities. In Paradise, these ignitions started approximately $30 \mathrm{~min}$ to $40 \mathrm{~min}$ before the arrival of the fire front and rapidly grew in number when the front reached the community.

\section{Density of Vegetative and Structural Fuels}

All three communities, Concow, Paradise, and Magalia, are intermix communities that have developed over decades among the local wildland vegetation. Concow can be considered low population density intermix with 10 people $/ \mathrm{km}^{2}\left(26 \mathrm{p} / \mathrm{mi}^{2}\right)$, while Paradise and Magalia can be classified as high-density intermix communities with $552 \mathrm{p} / \mathrm{km}^{2}$ and $312 \mathrm{p} / \mathrm{km}^{2}\left(1433 \mathrm{p} / \mathrm{mi}^{2}\right.$ and $\left.808 \mathrm{p} / \mathrm{mi}^{2}\right)$ respectively.

The absence of fire within most of Paradise and Magalia for many decades had resulted in significant vegetative fuel accumulation. The vegetative fuel loading was further increased by diseased vegetation (specifically pines). Seasonal needle dropping, combined with diseased trees and further enhanced by high winds, resulted in extensive needle accumulation before and during the fire. The historic growth of Paradise and surrounding communities, going back over a century, resulted in many structures placed on smaller lots. The short structure separation distances, together with the vegetative fuel loading, enabled rapid structure-to-structure fire spread.

Concow had been experiencing wildfires about every ten years; these fires have resulted in a modification of the local wildland fuels from timber to brush and grass. After the 1996-98 and 2008 fires, fuel loading around Concow was estimated at $2.24 \mathrm{~kg} / \mathrm{m}^{2}$ to 
$3.36 \mathrm{~kg} / \mathrm{m}^{2}$ (10 ton/ac to $15 \mathrm{ton} / \mathrm{ac}$ ), which allowed the fire to maintain a high intensity and move rapidly through the community.

Fuel treatments have been used extensively to compartmentalize the landscape in the area around Paradise, Magalia, and Concow. The intent was to provide access for firefighting operations and reduce the total impact of wildfires by reducing the total acreage burned.

Fuel treatments were used not only to influence wildland fire behavior but also to protect critical infrastructure such as the primary pumping station and treatment plant of the Paradise Irrigation District. Together with defensive actions, these specific fuel treatments met their objectives during the Camp Fire, and the critical infrastructure was undamaged. This specific fuel treatment example is included here to highlight the value of pre-fire preparation and vegetative fuel reduction in protecting critical infrastructure. The systematic analysis of the effectiveness of fuel treatments and their impact on fire behavior are beyond the scope of this report.

\section{Wind and Terrain}

The terrain of eastern Butte County is defined by the Sierra Nevada foothills and numerous deep river canyons and ravines.

The Feather River Canyon and Jarbo Gap, near the fire's origin, are known for their particularly high winds. Ridgetop gusts over $22 \mathrm{~m} / \mathrm{s}(50 \mathrm{mi} / \mathrm{h})$ are not uncommon, and the downslope north winds bring dry air through the foothills and the Town of Paradise.

The north wind event that occurred in the early morning on November 8 combined with receptive fuels, and the restricted access associated with topography contributed to the rapid growth of the fire, exceeding the ability for initial containment.

\section{Extent/Size of Fire Front Reaching the Communities}

All three communities were impacted by large fire fronts. The fire front that reached Concow was estimated to be between $0.8 \mathrm{~km}$ and $1.6 \mathrm{~km}(0.5 \mathrm{mi}$ and $1 \mathrm{mi})$ long. This front impacted most of the community and, in combination with the three factors discussed above, caused very dangerous conditions that rapidly impacted life safety and evacuation.

The fire front that reached Paradise at 08:30 reached from Apple View Way to Merrill Road, a distance of $1 \mathrm{~km}(0.6 \mathrm{mi})$. Shortly after, the southern end of the approaching front progressed south and impacted the area between Merrill Road and Feather River Hospital. In a little over $40 \mathrm{~min}$ after the onset of spot fires, Paradise experienced a direct hit by a fire front with a length of $2.8 \mathrm{~km}(1.9 \mathrm{mi})$. The extent and severity of the initial fire exposure required civilian evacuations and life safety to become the top priorities of the early first responder resources on the scene. Rescues and life safety operations, including emergency notification, will be discussed in NIST Camp Fire Report \#4.

The rapid increase in fire intensity around 24:00 on November 8 also resulted in a fire front over $1.6 \mathrm{~km}(1 \mathrm{mi})$ long that impacted the Magalia community. The extent of the front, coupled with the extensive ember cast and very strong winds estimated at $22 \mathrm{~m} / \mathrm{s}$ 
(50 $\mathrm{mi} / \mathrm{h})$, challenged the large number of available resources on the scene. The intensity of the fire exposure together with the receptivity of the fuels to embers resulted in an uncontainable situation that eventually resulted in most of the structural losses in Magalia.

It is the confluence of these four factors (fuel ignition potential, high fuel density, wind and terrain, and extent of the fire front reaching the communities) that caused the aggressive fire behavior resulting in dangerous conditions for residents and first responders and in extensive damage and destruction.

\section{d. What fire spread pathways caused structural ignitions?}

Documenting structure ignition vulnerabilities and structure ignition pathways is critical to improving building codes, standards, and best practices. Post-fire field data collection by NIST, together with CAL FIRE, USFS, and the Federal Emergency Management Agency (FEMA), captured structure damage and ignition vulnerabilities from 132 damaged structures. During the timeline reconstruction, first responder observations indicated that fuels on residential parcels, such as fences, vehicles, and furniture, could act as wicks to bring fire to the residential structures. Parcel-level exposures that resulted in damage of the 132 documented structures will be analyzed in NIST Camp Fire Report \#5. The findings from this subsequent report will be used to guide future WUI fire research, building codes and standards, and best practices for WUI hazard reduction.

\section{e. How unique is Paradise as a community at risk of WUI fires?}

This question was frequently asked by first responders, as well as state and federal officials, during the data collection and analysis phases of the Camp Fire case study. Currently there is no single standard way to capture a community's overall pre-WUI fire hazard that includes particulars of fuel and terrain, in addition to preparedness issues such as emergency notification and evacuation. Similarly, no standard framework yet exists that provides a clear and concise overview of fire response-related parameters for use by incident commanders and first responders during an event. While some of these data may be available from various sources including Community Wildfire Protection Plans (CWPP) and evacuation plans, summarizing the information in an easy-to-interpret format would help the community at hand, inform state and federal officials, and enhance the impact of state and federal hazard mitigation funds. A preliminary Community WUI Fire Hazard Framework is presented in this report as a first step towards highlighting community characteristics that should be considered when evaluating communities at risk of WUI fire.

\section{Fuels and Terrain}

The extensive vegetative fuels in Paradise, Magalia, and Concow may be representative of an older intermix community. A lifestyle of "living in the forest" may have attracted many residents to the community and may be a quality present in many communities across the WUI. The limited fire history of the Paradise area further contributed to the pre-fire vegetative loading. Vegetation fires along roadways and downed powerlines and power poles were the two primary factors that impacted evacuation. These factors will be further discussed in a subsequent report (Camp Fire Report \#4) detailing emergency 
notification and evacuation. Seasonal and multiyear drought conditions are common to many areas of the western United States. Extremely low fuel moisture conditions similar to those during the Camp Fire may also be representative of many WUI communities.

The topography of Paradise is characterized by numerous deep canyons and ravines which lead down slope to the Sacramento Valley. Similar terrain can be found throughout the western states. In addition to the direct influence of terrain on fire spread, many foothill and mountain communities may have similar topography-induced challenges to Paradise, including difficult-to-access areas, increased travel time due to indirect routes and mountain roads, and gusty ridgetop and down-canyon winds. Numerous regions across the west experience similar downslope wind events that characterize the Camp Fire and numerous other destructive wildland and WUI fires.

\section{Preparedness}

The risk of WUI fire in the communities affected by the Camp Fire had been recognized by local officials for many years. Butte County and the Town of Paradise put into place several programs to reduce WUI fire hazard within and around Paradise, Magalia and Concow. These programs and the actions they promoted helped these communities prepare for a fire event by reducing fuels within and around the communities, enhancing communications, and ensuring an operating water supply and distribution system.

The Butte County CWPP addressed vegetation and structure ignitability and included a vegetation management component that incorporated fuels modifications and specifically highlighted topography, weather, and fire history. Paradise also had a town ordinance enabling residents to remove vegetation up to $23 \mathrm{~cm}$ (9 in) in diameter without any permit requirement. Infrastructure protection was specifically addressed in pre-fire preparation. Examples included fuel treatments around Pine Ridge School in Magalia and around Paradise Irrigation District (PID) critical infrastructure.

At the time of the fire, additional preparedness efforts related to emergency notification and evacuation were also in place. The Town of Paradise addressed emergency notification through a detailed evacuation plan and an opt-in Reverse 911 call system. Residents were encouraged to participate in the notification system through the local Fire Safe Council, and notices/reminders about the evacuation plan had been recently mailed to households. To facilitate evacuation, traffic lights at major intersections were equipped with battery backups to allow the signals to continue operating in the event of power loss.

The Paradise Public Works Department (PPW) was well prepared to respond to WUI fires. Measures were taken to prepare the town for the forecasted high wind event, including street sweeping and installation of battery backups. Equipment to facilitate evacuation, such as signage and traffic cones, was also prepared. PPW personnel also had selective fire training, including how to respond to burnovers.

Pre-fire firefighting preparedness and the emergency response to the Camp Fire, including fire department staffing in Paradise and Butte County, as well as preparations and coordination with the Geographic Area Coordination Center (GACC) will be 
discussed in Camp Fire Report \#5. Regional fire activity and US Forest Service (USFS) staffing will also be discussed in the same report.

\section{Summary of Findings}

The data collection, analysis and quality control methodology used in this case study have made the spatiotemporal timeline reconstruction of the first 24 hours of the Camp Fire possible. This fire spread information enables an in-depth understanding of overall fire progression, including examples of local fire behavior and characterization of numerous entrapment/burnover events. The fire progression timeline forms the baseline for additional studies on community evacuation and life safety issues as well as the effectiveness of defensive actions and the impact of fire on structures and infrastructure. Future NIST reports will rely on this fire timeline to address those topics.

There are 23 findings distributed among seven categories related to the fire progression of the Camp Fire:

\section{Butte County and Paradise Were Well Prepared to Respond to a WUI Fire}

F1. Communities did have multiple programs in place to increase awareness of and reduce fire hazards associated with WUI fires.

F2. The Town of Paradise did have an emergency notification and evacuation plan.

F3. Paradise Public Works staff had received training in how to respond to a WUI fire.

F4. Infrastructure was specifically addressed in pre-fire preparations.

\section{Multiple Factors Contributed to the Rapid Growth and Spread of the Camp Fire}

F5. Dry winds, with recorded gusts at Jarbo Gap exceeding $22 \mathrm{~m} / \mathrm{s}$ ( $50 \mathrm{mi} / \mathrm{h})$ from the northeast, increased fire spread in vegetative and structural fuels.

F6. Steep topographical features including river canyons and creek drainages channeled north winds and accelerated fire spread through vegetative fuels.

F7. Extremely dry vegetative fuels, associated with over 200 days without any significant precipitation, increased the fuel ignition potential around and within Concow, Paradise, and Magalia.

F8. Fire spread toward Paradise from Concow was fueled by heavy conifer forests with brush understory. At lower elevations oak woodlands and savannah grass were primary fuels.

\section{The Camp Fire Grew and Spread Rapidly}

F9. Fire ignited near Pulga and Concow, was pushed by gusty wind across steep terrain toward Paradise, swept through Paradise, and then spread into Magalia.

F10. Extensive intermediate- and long-range firebrand spotting caused multiple ignitions ahead of the main fire line and resulted in different exposures to fire conditions. 
F11. The fire travelled and/or spotted more than $11 \mathrm{~km}(7 \mathrm{mi})$ downwind of the origin to reach Paradise in less than 1.5 hours after ignition.

F12. Fire consumed a significant fraction of the Town of Paradise over a period of 6 hours, between 08:30 and 14:30.

F13. Fire spread down slope through the foothills at an average $1 \mathrm{~m} / \mathrm{s}(2.2 \mathrm{mi} / \mathrm{h}, 180 \mathrm{ch} / \mathrm{h}$ (chain per hour $\left.{ }^{1}\right)$ ) through grassy wildland fuels south and west of Paradise.

F14. Fire spread rates for Paradise and Magalia could not be readily computed due to extensive spotting fire behavior.

The first spot fires from the Camp Fire arrived in Paradise at 07:50. The main fire front reached Pentz Road 40 min later, around 08:30. A total of 30 spot fires before 08:30 were identified, with spots reaching as far as $3.4 \mathrm{~km}(2.1 \mathrm{mi})$ into the town. The combination of numerous spot fires and a $1.5 \mathrm{~km}(1 \mathrm{mi})$ long fire front resulted in the fire rapidly becoming well-established throughout Paradise.

\section{Burnovers Impacted Civilian Evacuations and First Responder Operations}

F15. Multiple burnovers occurred during the Camp Fire.

F16. Burnovers adversely affected pre-planned evacuation routes and led to use of Temporary Refuge Areas.

F17. Intense vegetation and structure fires occurred along roadways and resulted in multiple road closures which adversely impacted response and evacuation activities.

F18. Fire resulted in downed utility poles along roadways and throughout the communities. The downed poles, along with the associated electrical and utility lines, blocked multiple streets and impaired access for response and evacuation.

Burnovers were identified and documented in nineteen different locations and occurred throughout the first 24 hours of the incident. The first two burnovers occurred at approximatively 07:50 on November 8 on Hoffman Road and Concow Road in Concow, and the last two recorded burnovers occurred at 07:15 on November 9 on Ponderosa Way in Magalia and on Concow Road in Concow. Multiple roadways were burned over before 10:00 on November 8, impacting evacuation and life safety of residents and first responders. Most burnover events lasted between 1 hour and 2 hours in duration.

\section{The Location of Wildland Fire Ignition Relative to the Community is Important}

F19. The ignition of the fire in wildland fuels over $11 \mathrm{~km}(7 \mathrm{mi})$ from Paradise allowed the fire to grow in intensity and size before reaching the affected communities.

Fire suppression capacity can be rapidly exceeded by large fire front lengths and/or extensive spotting throughout the community. The intense and long fire front and numerous spot fires that reached Paradise also impacted large-scale evacuations. This

\footnotetext{
${ }^{1}$ The chain is a unit of length commonly used in wildland firefighting ( $1 \mathrm{ch}=66 \mathrm{ft} \approx 20.1 \mathrm{~m}$ ).
} 
points to the threat posed by a potentially dangerous region located upwind and some distance away from the communities. Ignitions in the dangerous region that cannot be rapidly suppressed (due to terrain and or wind) may quickly cause dangerous conditions for communities many kilometers (miles) downwind. Far-away ignitions can develop into large fire fronts that can threaten entire communities. In adverse conditions, such as dry conditions and/or locations with high vegetative fuel loads, spot fires developing near or within communities kilometers (miles) ahead of the fire front can impact local conditions and potentially affect evacuation routes.

\section{Multiple Parcel-Level Fire Spread Pathways Caused Structure Ignitions}

F20. Post-fire field data collection and first responder observations identified structure ignition vulnerabilities including structure-to-structure ignition pathways.

F21. Fire spread through Paradise, and subsequently Magalia, was fueled by vegetative fuels, including ornamental shrubs, bushes, and trees; structural fuels, including homes, garages, detached auxiliary buildings, commercial occupancies; and cars, trucks, and campers.

F22. Separation distances between fuel packages within a parcel as well as between parcels did not prevent rapid fire spread.

\section{WUI Fire Spread Impacts Communities in Multiple Ways During Fire Events}

F23. A standardized community wildland-urban interface hazard evaluation framework would improve assessment of fire risk for communities.

The documentation and quantification of the effects of the Camp Fire on Paradise, Magalia, and Concow highlight the issue that WUI fire spread has significant impact on communities well beyond the loss of structures, including community evacuation and incident response. The data begins to demonstrate the relationship between community preparedness and how a WUI fire event unfolds. Pre-fire planning and hazard mitigation impact how the fire develops, how the life safety of residents and first responders is impacted during evacuations, and the extent of structural and infrastructure losses.

The rapid spread of the Camp Fire through Concow, Paradise, and Magalia suggests that WUI community preparedness may benefit from a holistic approach to hazard assessment. The successful pre-fire planning by Butte County and Paradise suggests that a community's hazard assessment and preparedness for WUI fires can benefit from the inclusion of information on the fire history of the community and surroundings, vegetative and structural fuel loading information, as well as evacuation and response plans. 


\section{Recommendations}

There are nine recommendations made in this report. The recommendations are aimed at improving resident and first responder life safety $(\mathrm{R} 1)$ and reducing structural losses during WUI fires (R2-R9).

R1. Characterize fire behavior that leads to burnovers and quantify burnover severity. This information will inform fuel setback guidance for primary egress arteries and provide technical input to evacuation plans. ( $F 15, F 16, F 17, F 18)$

R2. Develop technical guidance to quantify parcel level exposures. (F20, F21, F22)

R3. Quantify fire spread within parcels with focus on fire exposures. (F20, F21, F22)

R4. Quantify exposures from adjacent parcels, specifically from neighboring structures, and develop design guidance for structure separation distances. (F20, F21, F22)

R5. Develop methodology to connect field-collected ember data, such as ember flux and size distribution, to laboratory scales and develop worst case ember exposure criteria. (F7, F10, F11)

R6. Develop spacing/hardening cost benefit relationships for high energy release sources (fences, wood piles, sheds, vehicles, RVs, and residences) and target structures (residential and commercial). (F20, F21, F22)

R7. Characterize the relationships among fire history, fuel treatments, and fire behavior. (F5, F6, F7, F8, F9, F10, F11, F12, F13, F17, F19, F21, F22)

R8. Develop a standardized methodology for assessing the exposures from ornamental vegetation. (F20, F21, F22)

R9. Develop a plant list for vegetation with unacceptably high fire hazard for northern California and other locations with WUI fire risks. (F20, F21, F22) 


\section{NIST Wildland-Urban Interface Fire Research Background}

Recent years have repeatedly shown that wildland-urban interface (WUI) fires pose a significant threat to life safety and property in the United States. In just the last five years, the State of California, in particular, has seen some of the largest, most destructive, and deadliest fires in its history. Five of those fires are among the top 25 largest fire losses (of any fire type) on a list compiled by the National Fire Protection Association (NFPA) [1]. Twelve of the 25 are WUI fires. Eight of the top 20 most destructive California fires [2] occurred during the 2017 and 2018 fire seasons, causing a combined 138 fatalities.

Defined as the location where structures and communities meet or intermingle with undeveloped wildland, the WUI is prevalent in the United States. Analysis of the 2010 U.S. Census data determined that over 44 million homes, housing $32 \%$ of the US population, were located in the WUI [3]. Since 2010, development into wildlands has not slowed, and neither has the number of WUI fires.

In the early 2000s over one thousand structures per year on average were lost to WUI fires in California alone. In the 2010s, seven individual WUI fire events each caused losses of more than one thousand structures. In 2017, the Tubbs Fire destroyed and damaged 5636 structures - double the losses from the 1991 Tunnel Fire (Oakland Hills Fire), which at 2900 structures was the most destructive California fire to date [2]. One year later, the Camp Fire tripled the mark, destroying 18804 structures [2, 4]. Eighty-five people perished [5-7].

An improved understanding of WUI fire dynamics and structure ignition mechanisms is critical to improving structure and community resistance to WUI fires (the "WUI fire problem"). The National Institute of Standards and Technology (NIST) WUI Fire Hazard Mitigation research effort comprises laboratory and field research projects to address this national fire problem. Additionally, the NIST Disaster and Failure Studies Program provides a platform for research on building and infrastructure performance and emergency response and evacuation procedures.

The NIST Wildland-Urban Interface (WUI) Fire Data Collection on Parcel Vulnerabilities Project is focused on understanding how WUI fire behavior is driven by the interactions among fuel, weather, and topography and the roles played by heat flux, embers, and direct flame impingement. The WUI Hazard Exposure Scale [8] characterizes these interactions and provides a framework that allows improved understanding of how communities are exposed to fire and embers during a WUI fire. Building and community vulnerabilities identified through post-fire analysis [9-13] are further investigated through laboratory experiments. Post-fire analysis also shows how fire behavior is modified by active and passive defensive actions. Additionally, field-scale experiments provide data for development and validation of the NIST-developed Fire Dynamic Simulator (FDS) computer fire model [14].

NIST WUI research is conducted in partnership with other federal agencies, including the US Forest Service (USFS), Federal Emergency Management Agency (FEMA), US Department of Homeland Security (DHS), and US Fire Administration (USFA); state agencies, including California Department of Forestry and Fire Protection (CAL FIRE) and Texas Forest Service; fire service organizations including Western Fire Chiefs Association, International 
Association of Fire Fighters (IAFF), and International Association of Fire Chiefs (IAFC); building codes and standards organizations, such as National Fire Protection Association (NFPA) and International Code Council (ICC); and many academic institutions. Research findings are used directly to guide the development of new standards and to provide the scientific basis for new performance-based requirements, with the intent to make structures and communities more resistant to fire and ember exposures. 


\section{Camp Fire Introduction}

The Camp Fire started near Camp Creek Road and Pulga Road in Butte County, California, in the Feather River Canyon north of Jarbo Gap, at approximately 06:20 on November 8, 2018. The first report was called in to 911 at $06: 25$, and the initial response was immediately dispatched to the vegetation fire. The fire quickly became well-established in steep canyon terrain, spreading from the origin toward the small community of Pulga. Shortly after 07:00, the fire crested the ridge west of Pulga and pushed towards Concow. Strong east winds drove the fire $12 \mathrm{~km}(7.5 \mathrm{mi})$ from the origin to the Town of Paradise. Within the next five hours, most of the town was destroyed. Fire continued to spread, impacting the foothills south of Paradise to Highway 99 and the outskirts of Chico, destroying a large portion of Magalia, and burning communities in Yankee Hill and Cherokee. Section 9.1, Fire Progression, describes the first 24 hours of fire progression in detail.

The fire burned for 18 days before being declared $100 \%$ contained on November 25 . The daily progression for the duration of the fire is documented in Appendix A, which was produced by the incident management team near the end of the incident. The agencies responsible for the unified command of the incident included CAL FIRE, Butte County Sheriff's Office, Paradise Police Department, and the U.S. Forest Service. At peak daily staffing, total personnel involved in firefighting exceeded 5600, including 900 pieces of apparatus (620 engines, 101 hand crews, 102 dozers, and 77 water tenders) [15].

The Camp Fire consumed 62053 ha (153 336 acres) and destroyed 18804 structures, including 13696 single-family residences [4]. The fire resulted in 85 civilian fatalities [5-7, 16] and 5 reported major firefighter injuries [17]. After the fire, 3266 missing persons were located [18].

The extent of the damage was surveyed by the CAL FIRE damage inspection team [4] and is categorized by structure type and level of damage in Table 1. Initial estimates suggested the Camp Fire would be the most destructive fire in California history at a cost between $\$ 11$ billion and $\$ 13$ billion in losses [19] and \$3 billion for debris clean up [20]. A more recent assessment determined that the Camp Fire was the costliest natural disaster worldwide in 2018, with overall losses of $\$ 16.6$ billion [21].

NIST deployed a team to conduct a preliminary reconnaissance of the Camp Fire [22]. The primary objective of the reconnaissance was to determine if the Camp Fire offered unique data that, if collected and analyzed, could provide new technical insight into the US WUI fire problem. After the preliminary reconnaissance, it was determined this larger case study was warranted. 
Table 1. Camp Fire Damage Assessment Summary.

\begin{tabular}{|c|c|c|c|c|c|}
\hline Category of Damage $^{a}$ & $\begin{array}{c}\text { Affected } \\
(1 \% \text { to } \\
9 \%)\end{array}$ & $\begin{array}{c}\text { Minor } \\
(10 \% \text { to } \\
25 \%)\end{array}$ & $\begin{array}{c}\text { Major } \\
(26 \% \text { to } \\
50 \%)\end{array}$ & $\begin{array}{c}\text { Destroyed } \\
(>50 \%)\end{array}$ & Total \\
\hline Single Residence & 439 & 47 & 3 & 13696 & 14185 \\
\hline Multiple Residence & 21 & 3 & 1 & 276 & 301 \\
\hline Mixed Commercial/Residential & 1 & 1 & 0 & 11 & 13 \\
\hline Non-residential Commercial & 76 & 18 & 8 & 528 & 630 \\
\hline “Other” Minor Structures ${ }^{\mathrm{b}}$ & 87 & 32 & 13 & 4286 & 4418 \\
\hline Infrastructure $^{c}$ & 2 & 0 & 2 & 7 & 11 \\
\hline Total & 626 & 101 & 27 & 18804 & 19558 \\
\hline
\end{tabular}




\section{Technical Overview}

The catastrophic losses from the Camp Fire have led to the identification of multiple research questions to help understand this WUI fire and provide lessons learned that may be used to reduce losses in other WUI communities in the future. A detailed case study of the Camp Fire is presented through a series of five reports. Two reports have been published. Report \#1 [22] describes preliminary reconnaissance deployments to the Camp Fire while Report \#2 [24] contains preliminary data collected during those deployments. The remaining three reports categorize the research questions into three groups:

Report \#3 (this report): fire progression and fire behavior, Report \#4: emergency notification, evacuation, and Temporary Refuge Areas, Report \#5: emergency response, defensive actions, and damaged structures.

The research questions addressed in this report are:

a. How can a fire event of the scale of the Camp Fire be documented to facilitate the extraction of information for reducing future losses?

b. How did the fire spread to and within Paradise?

c. What were the primary causes of the extensive devastation?

d. What fire spread pathways caused structural ignitions?

e. How unique is Paradise as a community at risk of WUI fires?

\section{a. How can a fire event of the scale of the Camp Fire be documented to facilitate the extraction of information for reducing future losses?}

Post-fire data includes fire observations, structural losses, emergency notification and evacuation details, and response particulars. Collection and dissemination of this information along with relevant pre-fire data can be used to develop lessons learned, with the goal of reducing losses in future WUI fires and improving community resilience. To address this question, a WUI data collection, analysis, and documentation framework, described in Section 7, was developed and utilized to document the Camp Fire. This methodology was based on the lessons learned from previous NIST WUI fire case studies. The methodology includes a field data collection process and a procedure for reconstructing the Camp Fire using the fire timeline as the baseline. Subsequent analysis of evacuation and response will be linked to and interpreted in relation to fire progression in Reports \#4 and \#5.

\section{b. How did the fire spread to and within Paradise?}

The NIST-developed post-fire data collection methodology is based on the observations and knowledge of first responders, local officials, and utilities personnel. Their input was collected, compared, and integrated to reconstruct and capture fire activity in space and time, focusing on the first 24 hours of the event when the majority of the damage occurred. The fire timeline was developed using the available data; fire observations were directly linked to the locations and density of observers. Technical discussions with first responders, together with Automatic Vehicle Location (AVL), photographic images, videos, 911 calls, and radio transcripts were some of the tools used to develop the fire progression timeline. To facilitate the comprehension of the data, fire progression during 
the first 24 hours after ignition was divided into 15 distinct geographic areas in this report. A summarized version for each of the 15 areas is presented in Section 9.1, Fire Progression. This section is further summarized in Section 16.3, in the Summarized Technical Findings. The fire timeline reconstruction has identified over a dozen entrapment/burnover events, life-threatening situations when fire traps or overtakes people or equipment and compromises escape routes, possibly resulting in injuries and/or fatalities [25-27]. Due to the similarities and uncertainties in the distinction between entrapments and burnovers, these events are all referred to as burnovers in this report. These events are summarized in spatiotemporal detail in Section 9.3, Burnovers, and further documented in Appendix B.

\section{c. What were the primary causes of the extensive devastation?}

There are many factors that may impact individual structure survivability and the effectiveness of defensive actions at a parcel level. When viewing the Camp Fire in its entirety, four factors were identified that most significantly influenced overall fire losses:
i. $\quad$ Fuel ignition potential,
ii. Density of vegetative and structural fuels,
iii. Wind and terrain, and
iv. Extent/size of fire front reaching the communities.

It was the confluence of these four factors that caused the aggressive fire behavior resulting in dangerous conditions for residents and first responders and in extensive damage and destruction. The primary causes responsible for the extensive devastation are discussed in Section 13.

\section{d. What fire spread pathways caused structural ignitions?}

Documenting structure ignition vulnerabilities and structure ignition pathways is critical to improving building codes, standards, and best practices. Post-fire field data collection by NIST, together with CAL FIRE, USFS, and the Federal Emergency Management Agency (FEMA), captured structure damage and ignition vulnerabilities from 132 damaged structures. First responder observations presented in Section 11 indicate that fuels on residential parcels, such as fences, vehicles, and furniture, can act as wicks to bring fire to residential structures.

Parcel-level exposures and structure damage will be further analyzed in NIST Camp Fire Report \#5. This information, together with that collected from first responders during the timeline reconstruction effort, will connect fire and ember exposures to specific damage vulnerabilities to inform future WUI fire research, building codes and standards, and best practices for WUI hazard reduction.

\section{e. How unique is Paradise as a community at risk of WUI fires?}

This question was frequently asked by first responders, as well as state and federal officials, during the data collection and analysis phases of the Camp Fire case study. Currently there is no single standard way to capture a community's overall pre-WUI fire hazard that includes particulars of fuel and terrain, in addition to preparedness issues such as emergency notification and evacuation. Similarly, no document yet exists that provides 
a clear and concise overview of fire response-related parameters for use by incident commanders and first responders during an event. While some of these data may be available from various sources, including the community's Community Wildfire Protection Plan (CWPP) and evacuation plans, summarizing the information in an easyto-interpret format can help the community at hand, inform state and federal officials, and enhance the impact of state and federal hazard mitigation funds. A preliminary Community WUI Fire Hazard Evaluation framework is presented in Section 15, and further explained in Appendix C, as a first step towards highlighting community characteristics that should be considered when evaluating communities at risk of WUI fire. 


\section{WUI Characteristics of Paradise, Magalia, and Concow, CA}

Butte County, approximately $130 \mathrm{~km}(80 \mathrm{mi})$ north of Sacramento, is located in the northern part of California, stretching from the northeastern Sacramento Valley into the Sierra Nevada mountains. Figure 1 shows the location of Butte County and the Camp Fire perimeter (in red) in relation to the state.

The Town of Paradise is located in the foothills of the Sierra Nevada at an elevation of $542 \mathrm{~m}$ (1778 ft). Magalia, further up the ridge just north of Paradise, is at an elevation of $711 \mathrm{~m}$ $(2333 \mathrm{ft})$. To the east, Concow lies in a topographic bowl at an elevation of $611 \mathrm{~m}(2005 \mathrm{ft})$. Before the Camp Fire, Paradise was the second-largest population center in Butte County, with a 2014-2018 American Community Survey (ACS) 5-year population estimate [28] of 26543 people. Magalia and Concow were smaller unincorporated communities with populations of 12671 in Magalia, and 743 in Concow.

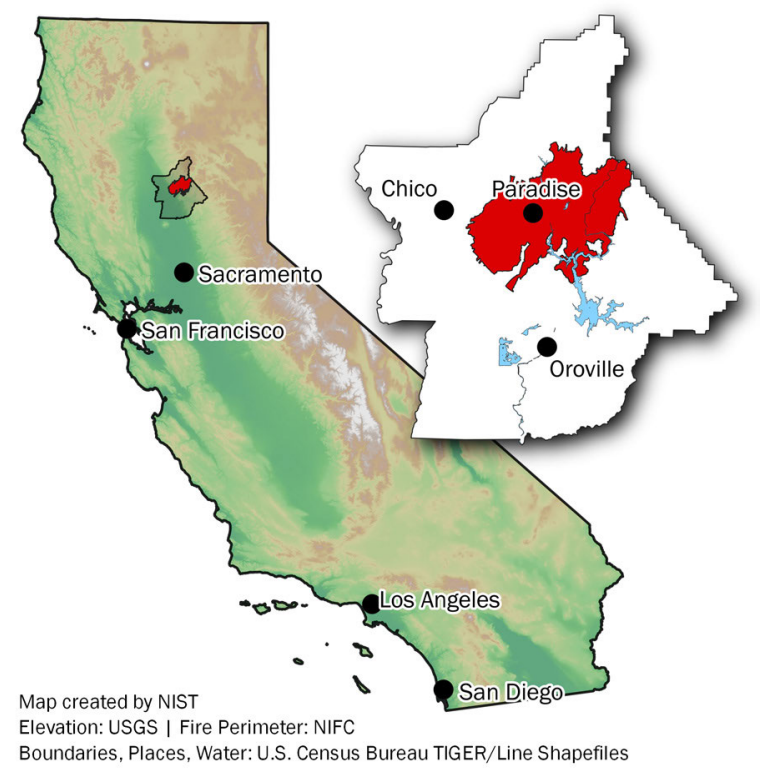

Figure 1. Location of Butte County, California and the Camp Fire.

WUI is defined in two primary categories, interface and intermix, depending on population or structure density and the extent of wildland vegetation. This classification of WUI does not directly translate to the level of hazard, although it may suggest potential differences in fire behavior and/or community mitigation and preparedness capabilities (e.g., details related to evacuation or structure-to-structure ignition potential).

The Town of Paradise had a population density of 559 persons $/ \mathrm{km}^{2}\left(\mathrm{p} / \mathrm{km}^{2}\right)\left(1450 \mathrm{p} / \mathrm{mi}^{2}\right)$. Using the definitions provided by the U.S. Department of Agriculture and the Department of the Interior in their 2001 Federal Register notice [29], the town exceeded the $97 \mathrm{p} / \mathrm{km}^{2}$ $\left(250 \mathrm{p} / \mathrm{mi}^{2}\right)$ minimum threshold and qualified as an interface community based on population density. Magalia similarly met the population density threshold of an interface community. 
The CAL FIRE Damage Inspection (DINS) efforts documented all destroyed, damaged, and undamaged structures (over 22000 structures) in Paradise, Magalia, and Concow (a combination of residential, commercial, and other auxiliary structures greater than $11 \mathrm{~m}^{2}$ $\left.\left(120 \mathrm{ft}^{2}\right)\right)$ [30]. The distribution of these structures within the boundaries of the three communities is tabulated in Table 2. Using the 16520 assessed structures within the Paradise town limits and the $74.5 \mathrm{~km}^{2}$ area, the town-wide nominal structure density was estimated to be 3.5 structures/hectare $(\mathrm{s} / \mathrm{ha})(1.8 \mathrm{~s} / \mathrm{ac})$. This is below the $7.4 \mathrm{~s} / \mathrm{ha}(3 \mathrm{~s} / \mathrm{ac})$ structure density aspect of the definition for interface listed in the Federal Register [29]. However, an effective structure density of $6.4 \mathrm{~s} / \mathrm{ha}(2.6 \mathrm{~s} / \mathrm{ac})$ within the central area of Paradise approached the interface threshold of $7.4 \mathrm{~s} / \mathrm{ha}(3 \mathrm{~s} / \mathrm{ac})$. Examples of this structure density include the residential areas west of Skyway in the vicinity of Bille and Wagstaff Roads and around Lancaster Drive. Structure density reached $17 \mathrm{~s} /$ ha $(7 \mathrm{~s} / \mathrm{ac})$ locally, including several mobile home parks, some of which abutted directly to wildlands. Table 3 lists examples of effective structure densities in selected sections throughout Paradise to illustrate the variability. Effective structure density in Magalia was higher than Paradise at $8.2 \mathrm{~s} / \mathrm{ha}$ $(3.3 \mathrm{~s} / \mathrm{ac})$ and was considered interface.

Table 2. Population and structure density statistics.

\begin{tabular}{|c|c|c|c|c|c|c|}
\hline Location & Pop. & $\begin{array}{c}\text { Area } \\
\mathbf{k m}^{2}\left(\mathbf{m i}^{2}\right)\end{array}$ & $\begin{array}{l}\text { Pop. Density } \\
\mathbf{p} / \mathbf{k m}^{2}\left(\mathbf{p} / \mathbf{m i}^{2}\right)\end{array}$ & $\begin{array}{c}\text { DINS } \\
\text { Struct. Count }\end{array}$ & $\begin{array}{c}\text { Nominal } \\
\text { Struct. Density } \\
\text { s/ha (s/ac) }\end{array}$ & $\begin{array}{c}\text { Effective } \\
\text { Struct. Density } \\
\text { s/ha (s/ac) }\end{array}$ \\
\hline Paradise & 26543 & $\begin{array}{c}47.5 \\
(18.3)\end{array}$ & $\begin{array}{c}559 \\
(1450)\end{array}$ & 16520 & $\begin{array}{c}3.5 \\
(1.4)\end{array}$ & $\begin{array}{c}6.4 \\
(2.6)\end{array}$ \\
\hline Magalia & 12671 & $\begin{array}{c}36.3 \\
(14.0)\end{array}$ & $\begin{array}{c}349 \\
(905)\end{array}$ & $3466^{\mathrm{a}}$ & $\begin{array}{l}6.4^{\mathrm{a}} \\
(2.6)\end{array}$ & $\begin{array}{c}8.2 \\
(3.3)\end{array}$ \\
\hline Concow & 743 & $\begin{array}{c}72.0 \\
(27.8)\end{array}$ & $\begin{array}{l}10 \\
(27)\end{array}$ & 684 & $\begin{array}{c}0.1 \\
(0.04)\end{array}$ & $\begin{array}{c}0.6 \\
(0.25)\end{array}$ \\
\hline
\end{tabular}

${ }^{a}$ Only the fire-impacted southern portion of Magalia was included in structure damage inspection data; the entire structure count is unavailable. Area was truncated at the extent of available data.

Concow, with a population of 743 , had a population density of $10 \mathrm{p} / \mathrm{km}^{2}\left(27 \mathrm{p} / \mathrm{mi}^{2}\right)$ and by the Federal definition was an intermix area. Housing density in Concow was estimated at $0.1 \mathrm{~s} / \mathrm{ha}(0.04 \mathrm{~s} / \mathrm{ac})$, or one structure every $10 \mathrm{ha}(25 \mathrm{ac})$. This is above the lower threshold for intermix which is defined as one house every 16 ha (40 ac). Note that this nominal structure density includes significant areas of relatively undeveloped wildland. An effective structure density for the developed area clustered around the Camelot Lane and Concow Road intersection was much higher at $0.6 \mathrm{~s} / \mathrm{ha}(0.25 \mathrm{~s} / \mathrm{ac})$, or $1.6 \mathrm{ha}(4 \mathrm{ac})$ for each structure.

To more accurately identify WUI areas [3], some additional vegetative constraints have been combined with the Federal Register definitions of WUI. Stewart et al. [31] defines intermix as "the area where houses exist at more than 1 housing unit per 40 ac and wildland vegetation covers more than $50 \%$ of the land area" and interface as "wildland vegetation covers less 
than $50 \%$ of the land area, but a large area (over 1235 ac) [500 ha] covered with more than $75 \%$ wildland vegetation is within $1.5 \mathrm{mi}[2.4 \mathrm{~km}] . "$

The definitions provided by Stewart et al. include the wildland vegetative component, which provides important context related to wildland fire. An important factor that is not considered in either definition (Federal Register or USFS) is a characterization of vegetative fuel loading on the residential parcels. The Town of Paradise was a community built in the forest, and the distinction between wildland vegetation and residential vegetation can be ambiguous. A distribution of pine trees on a residential parcel that results in extensive needle cast can have significant impact on fire behavior, independent of housing density or population density. This important vegetative component is not directly captured by either set of definitions and highlights the challenge of trying to address the WUI fire hazard problem across multiple physical scales from community to residential parcel.

Figure 2 shows four different areas in Paradise, also listed in Table 3, that had very different housing and vegetative densities, further highlighting the complexities of defining and quantifying the WUI fire hazard problem. Housing densities in the pictured areas vary by an order of magnitude, ranging from $17 \mathrm{~s} / \mathrm{ha}(7 \mathrm{~s} / \mathrm{ac})$ down to $0.7 \mathrm{~s} / \mathrm{ha}(0.3 \mathrm{~s} / \mathrm{ac})$. Additionally, differences in vegetation density are apparent, with limited vegetation seen in Figure $\mathbf{2 a}$ and predominately vegetation seen in Figure 2d. Green lawns and extensive non-combustible areas (e.g., driveways and pools) are common in Figure 2c.

Table 3. Variation of structure density in Paradise.

\begin{tabular}{lccc}
\hline $\begin{array}{l}\text { Selected Location } \\
\text { [Cross Street or Bounding Streets] }\end{array}$ & $\begin{array}{c}\text { DINS } \\
\text { Struct. Count }\end{array}$ & $\begin{array}{c}\text { Selected Area } \\
\text { ha (ac) }\end{array}$ & $\begin{array}{c}\text { Struct. Density } \\
\text { s/ha (s/ac) }\end{array}$ \\
\hline $\begin{array}{l}\text { Ridgewood Mobile Home Park } \\
\text { [Pentz Rd] }\end{array}$ & 98 & 5.6 & 17 \\
$\begin{array}{l}\text { Apple Tree Village Mobile Home Park } \\
\text { [Clark Rd] }\end{array}$ & 168 & 9.7 & $(7)$ \\
Lancaster Dr & & $(24)$ & 17 \\
[Country Oak/Himmel/Bille/Sawmill] & 130 & 18 & 7 \\
Bille Rd & & $(45)$ & $(2.9)$ \\
[Wagstaff/Graham/Bille/Lucky John Rd] & 206 & 32 & 6 \\
Nunneley Rd & & $(80)$ & $(2.6)$ \\
[Elliott/Clark/Pearson/Sawmill Rd] & 872 & 142 & 6 \\
Valley View Dr & & $(350)$ & $(2.5)$ \\
[Valley View Dr et al. west of Oliver Rd] & 608 & 172 & 3.5 \\
Round Valley Ranch Rd & & $(425)$ & $(1.4)$ \\
[Clark Rd] & 87 & 137 & 0.7 \\
\hline
\end{tabular}




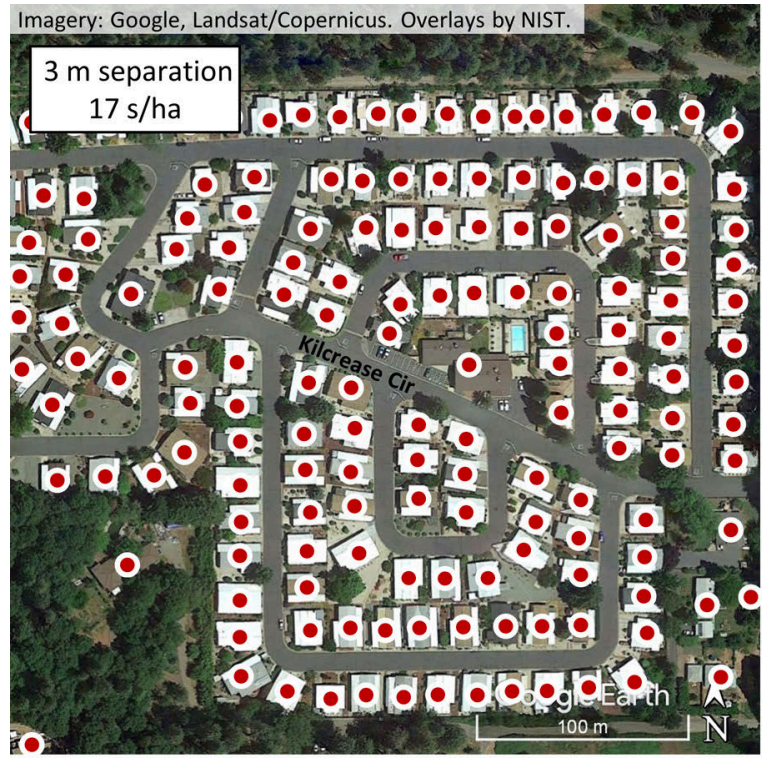

a)

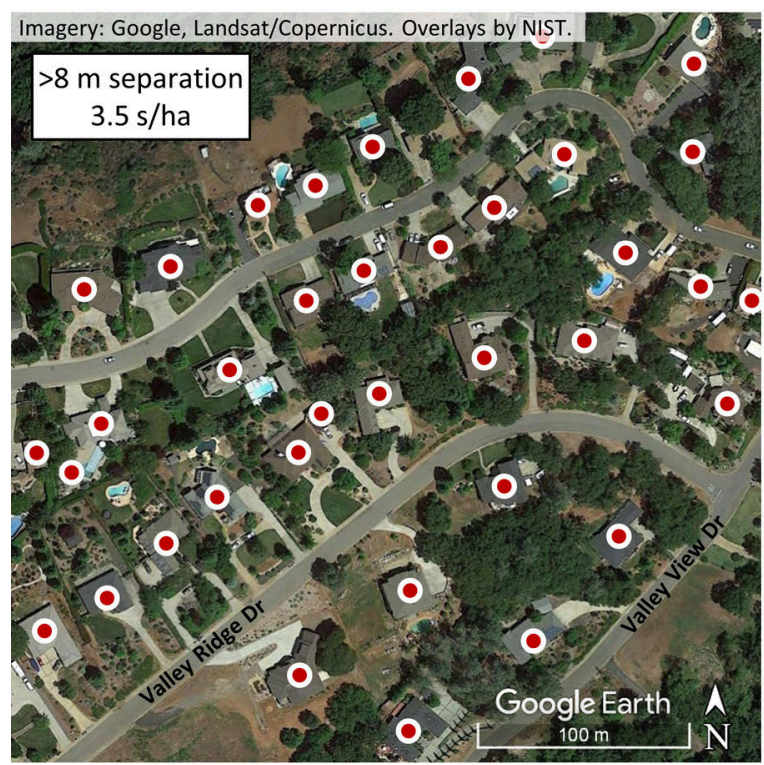

c)

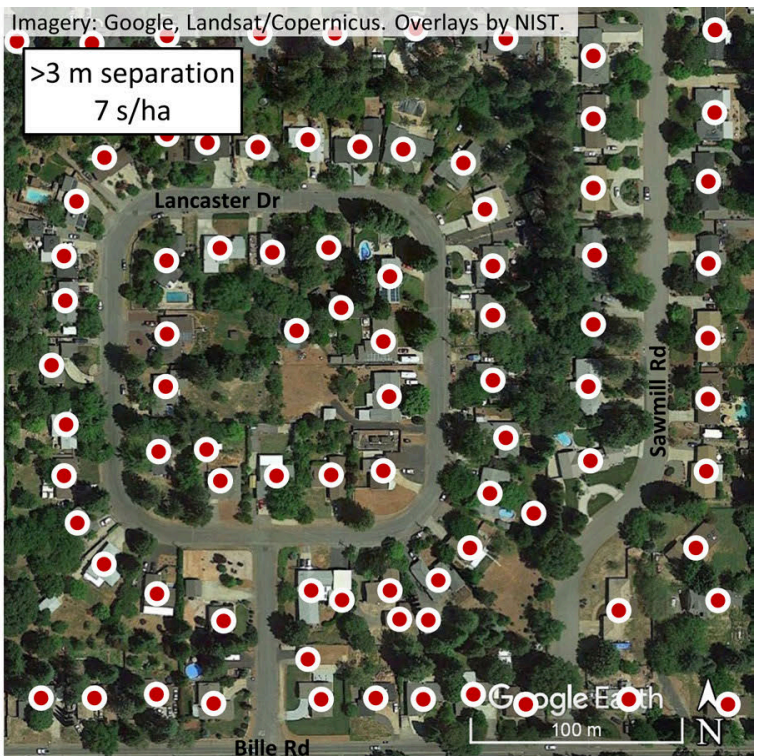

b)

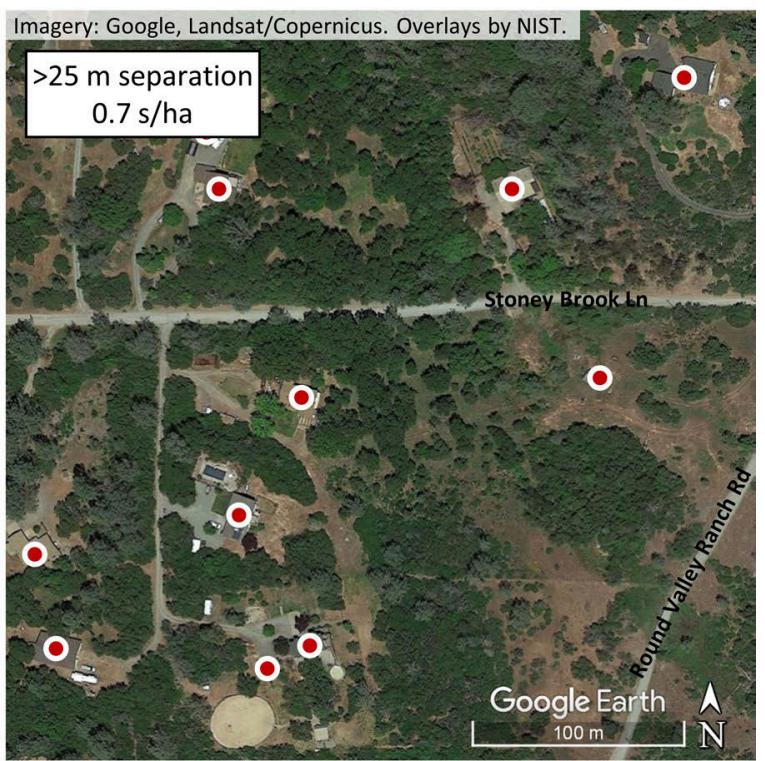

d)

Figure 2. Homes within Paradise display a wide range of structure-to-structure separation. Representative images show progressive reductions in structure density from locations; a) Apple Tree Village Mobile Home Park, b) Lancaster Dr, c) Valley Ridge Dr, and d) Round Valley Ranch Rd. Also note the variability in vegetative fuel density. 


\section{Pre-Fire Hazard}

The California Department of Forestry and Fire Protection's Fire and Resource Assessment Program (FRAP) assesses the amount and extent of California's forests and rangelands, analyzes their conditions, and identifies alternative management and policy guidelines. The FRAP program assesses the wildland fire hazard throughout the state and, in conjunction with the Office of the State Fire Marshal, establishes Fire Hazard Severity Zones (FHSZ). In addition to classifying the fire hazard, these FHSZs drive the building codes and mitigation strategies in WUI areas. Figure 3 shows an excerpt of the Butte County Fire Hazard Severity Zone map [32, 33], last updated in 2007. Magalia, Concow, and Paradise ${ }^{2}$ are all identified as Very High Fire Hazard Severity Zones (VHFHSZ).

Fire hazard is determined by a number of factors, including fuels, topography, weather, and fire history. These factors are discussed in the following sections as they relate to the Camp Fire.

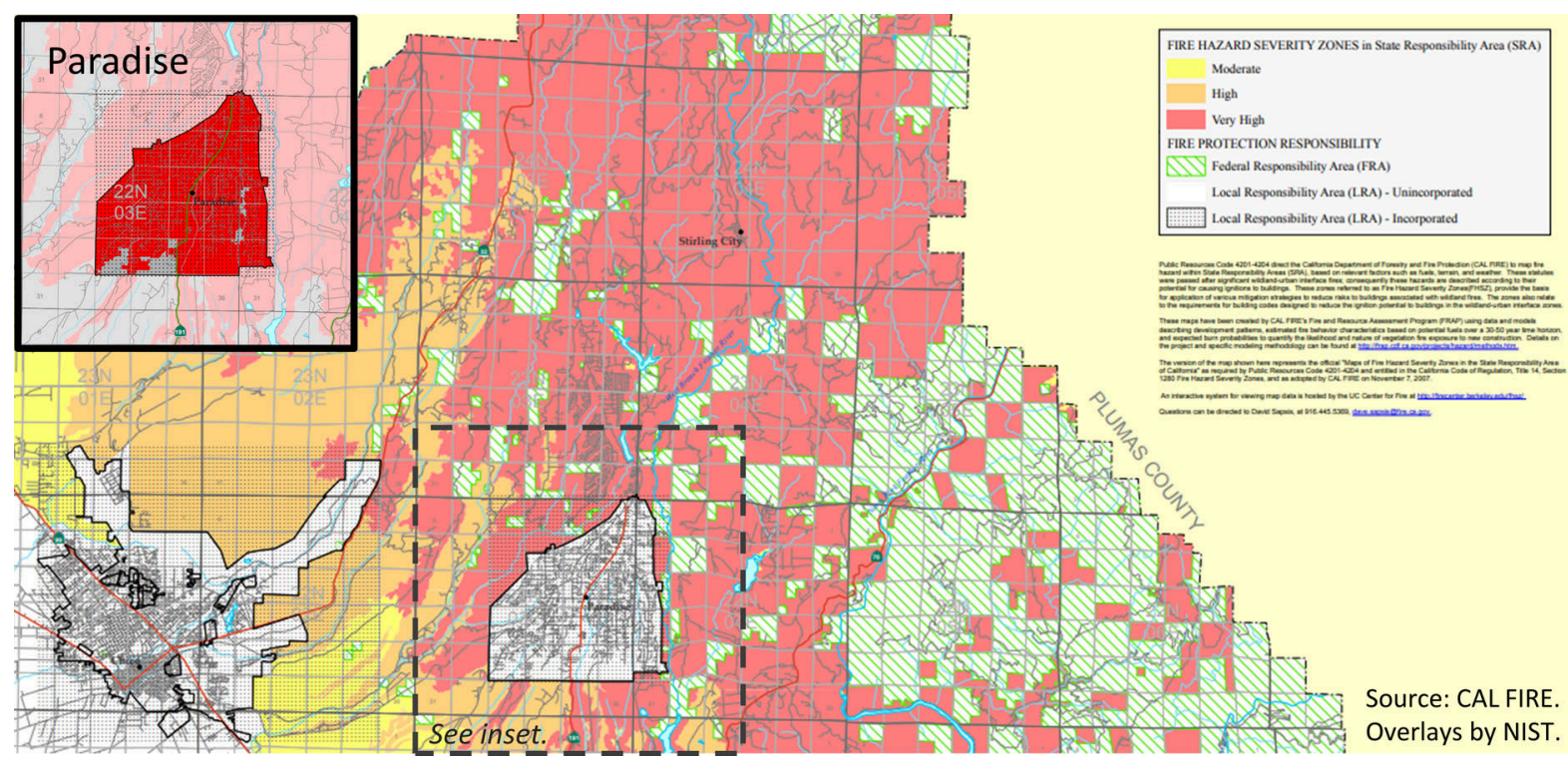

Figure 3. Excerpt of the FRAP fire hazard severity zone map [32] of northern Butte County indicating, in red, Very High Fire Hazard Severity Zone (VHFHSZ) on the Paradise ridge and surrounding areas. Paradise is a "Local Responsibility Area" and is recommended by the state as VHFHSZ, shown in the inset [33].

\subsection{Topography}

The terrain around the Camp Fire is characterized by the rising foothills of the Sierra Nevada and numerous steep river canyons and creek drainages. The Feather River Canyon, where the fire originated, the canyon of the West Branch Feather River along the east side of Paradise, and the Butte Creek Canyons to the west, define the region. Map 1 shows a shaded relief

\footnotetext{
${ }^{2}$ The FHSZ are applicable on lands where the state is responsible for wildland fire protection (State Responsibility Area). FHSZ are recommended for Local Responsibility Areas, including Paradise and Chico. The recommended FHSZ for Paradise is Very High, as seen in the inset of Figure 3. Federal lands are not classified by FRAP.
} 
topographic map of Paradise and Concow, along with several labels of topographic features and locations frequently referenced in this report.

The fire started in the Feather River Canyon at an elevation of $550 \mathrm{~m}(1800 \mathrm{ft})$ and climbed the west wall of the canyon and the deep Flea Valley up to Rim Road, along the ridge to the

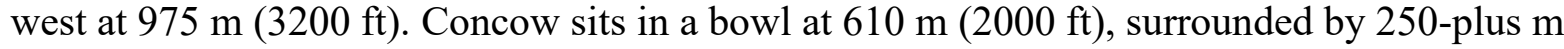
(800-plus $\mathrm{ft}$ ) tall ridges. A few gaps in the ridge lead west toward Paradise. The dramatic 250 m deep West Branch canyon separates Paradise from Concow.

Paradise is relatively flat east to west, with a north to south downhill slope from $700 \mathrm{~m}$ to $60 \mathrm{~m}(2300 \mathrm{ft}$ to $200 \mathrm{ft})$ over a distance between $15 \mathrm{~km}$ and $20 \mathrm{~km}$ (9 mi and $12 \mathrm{mi})$ into the Sacramento Valley. South of town, the landscape is divided by dozens of fingering creek drainages and valleys.

The west side of Paradise is defined by the Butte Creek and Little Butte Creek Canyons. In some locations there is a $300 \mathrm{~m}(1000 \mathrm{ft})$ drop-off to the bottom.

\subsection{Fuels Description}

Fuels around the point of origin and downwind towards and within Paradise and Magalia consisted of heavy conifer timber with brush understory. At lower elevations, oak woodland and grass savannah were the primary fuels. The area near the fire origin had burned previously in 2008; however, fuels west of the West Branch of the Feather River, in Paradise and Magalia, had not burned in recorded history (see Section 5.4). Timber was characterized by close crown spacing with heavy manzanita and oak cover underneath.

Fuel moisture levels were uncharacteristically low for the time of year due to the protracted dry period and late arrival of rain beginning the wet season. Fuel moisture levels [34] for 1000-hour time lag fuels measured at the Pike County Lookout south east of the fire area were at $5 \%$ on November 1 , well below the $17 \%$ average for the Northern Sierras in November. Live fuel moisture in manzanita was $74 \%$; the critical level, in terms of fire hazard, for manzanita is $80 \%$. The average for November is $93 \%$ [TD-131]. ${ }^{3}$

The Energy Release Component (ERC) output by the National Fire Danger Rating System (NFDRS), a measure related to the total fuel energy availability per unit area $\left(\mathrm{J} / \mathrm{m}^{2}, \mathrm{Btu} / \mathrm{ft}^{2}\right)$, which increases as fuels cure/dry, trended slightly above average for the northern Sierras during the summer, but in early October it began trending well above average. On the day of the fire the ERC calculated amongst a grouping of nearby fire weather stations was 80 , above the historic record for the date (60) and above the 90th percentile for all dates in the previous 10 years (80). ERC values are presented in Figure 4, developed by Aviva Braun from the National Weather Service. A slideshow by Ms. Braun on the weather conditions during the Camp Fire is presented in Appendix D [35].

\footnotetext{
${ }^{3}$ References to [TD-\#\#\#] correspond to information provided in technical discussions with first responders and local officials further described in Section 7.
} 
The NFDRS Fire Danger Rating category was Very High or Extreme in the northern Sierras at the four reporting stations in Butte County, indicating the relative potential for high intensity, fast spreading fires. Figure 5 shows the NFDRS map of the observed Fire Danger Ratings on November 8 [36].

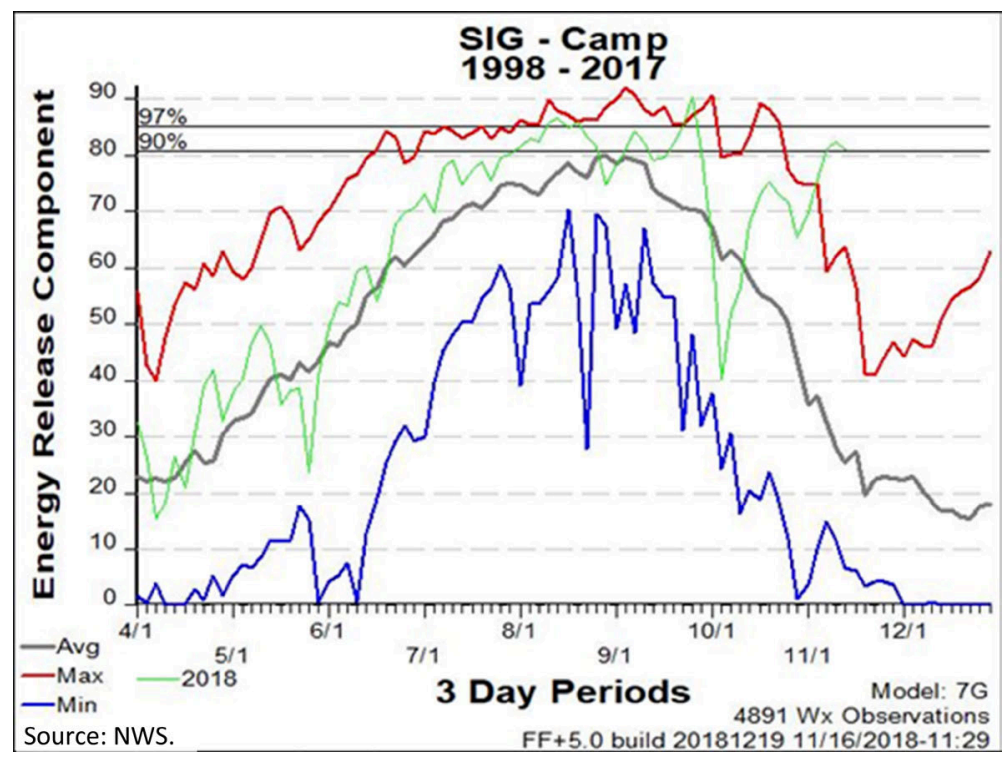

Figure 4. The energy release component measured among a special interest group (SIG) of nearby fire weather stations representative of the Camp Fire exceeded the historic record high for early November (60) and was in the $90^{\text {th }}$ percentile (80) for the previous 10 years [35].

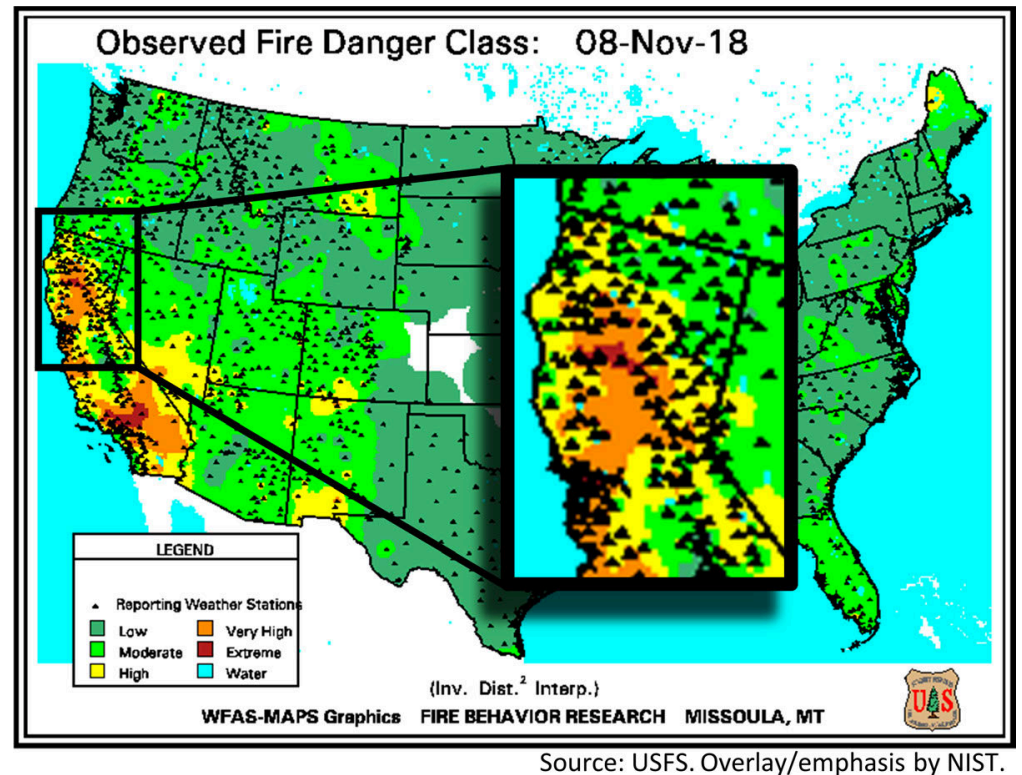

Figure 5. National Fire Danger Rating System map [36] indicating Very High to Extreme fire danger in Butte County and northern California. 


\subsection{Weather}

Weather before and during the Camp Fire, as for many rapidly spreading fires, was characterized by dry and windy conditions. In California, the windy conditions are often brought by downslope north wind events, bringing warm, dry air through fire prone regions. Jarbo Gap is known for locally high winds, ${ }^{4}$ particularly during north wind events which align with the Feather River Canyon. The Big Bend of the Feather River channels and forces winds up and over the ridge at Jarbo Gap. While dry or windy conditions are not unusual in Butte County, the overlap of late season dryness with a north wind event was relatively uncommon. Wetting rains typically begin in September before the frequency of north wind events increases in November and December [TD-003, TD-131].

It was very unusual to have fuel dryness levels so low in November in Butte County. In most years significant rain would have fallen by November, dampening fine fuels and lowering the ignition hazard. However, with the exception of a small amount of rain in early October leading up to the Camp Fire, it had been over 200 days since $13 \mathrm{~mm}$ ( $0.5 \mathrm{in}$ ) or more of rain had fallen at the lower elevations of Butte County. The U.S. Drought Monitor [38] reported much of Butte County in the "D0 Abnormally Dry" condition for the 19 weeks leading up to the fire, between June 26 and November 6, moving into "D1 Moderate Drought" on November $13^{5}$. The percentages of average precipitation in Butte County for the periods 1 month, 6 months, and 1 year prior to the Camp Fire were well below average, indicated by the red areas in Figure 6 [39].

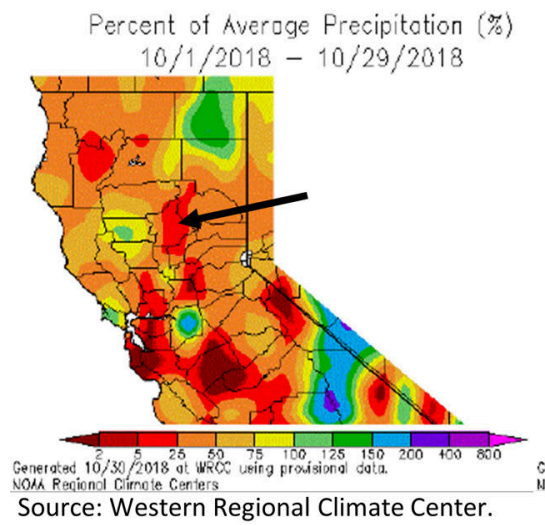

a)

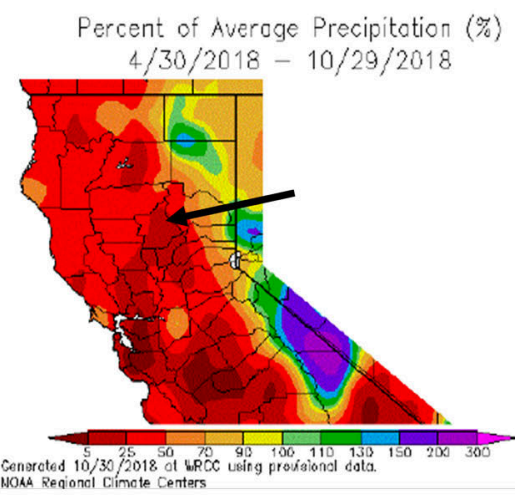

b)

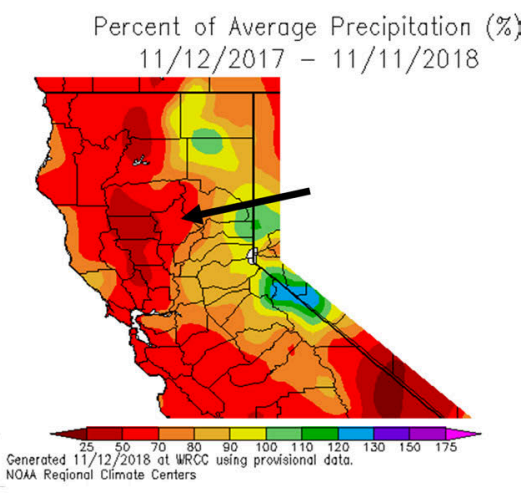

c)

Figure 6. Percent average precipitation across northern California for a) 1 month $(<25 \%)$, b) 6 months $(<25 \%)$, and c) 1 year $(<70 \%)$ prior to the Camp Fire. Figures from Western Regional Climate Center [39]. Overlaid arrows highlight Butte County.

A well-forecasted north wind event and critical fire weather period affected northern California on Thursday, November 8 . The potential wind event was mentioned in the Day 3-8 Fire Weather Outlook issued by the National Weather Service (NWS) a week before the fire. Subsequently, the first Fire Weather Watch was issued Monday, November 5 ,

\footnotetext{
${ }^{4}$ Wind gusts over $13 \mathrm{~m} / \mathrm{s}(30 \mathrm{mi} / \mathrm{h})$ were recorded on $30 \%$ of days in the 10 years prior to the Camp Fire (data from Ref. [37]).

${ }^{5}$ The U.S. Drought Monitor is issued weekly.
} 
followed by a Red Flag Warning on Tuesday, effective for Wednesday night through Friday morning (November 7-9). Forecast graphics [40,41] from the NWS office in Sacramento are shown in Figure 7, highlighting the Red Flag conditions and forecasted wind gusts exceeding $22 \mathrm{~m} / \mathrm{s}(50 \mathrm{mi} / \mathrm{h})$ across the Sierras. Thursday morning's Fire Weather Forecast for the foothills predicted north to northeast winds at $7 \mathrm{~m} / \mathrm{s}$ to $12 \mathrm{~m} / \mathrm{s}(15 \mathrm{mi} / \mathrm{h}$ to $27 \mathrm{mi} / \mathrm{h})$, gusts to $22 \mathrm{~m} / \mathrm{s}(50 \mathrm{mi} / \mathrm{h})$, and single-digit relative humidity. Winds in the valley (i.e., Chico) were forecast to come from the northwest, indicated in Figure 7b.

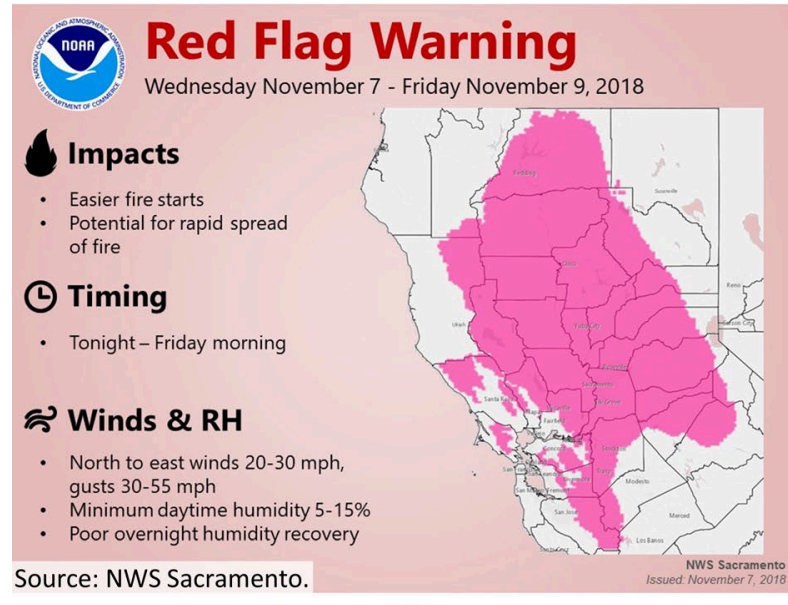

a)

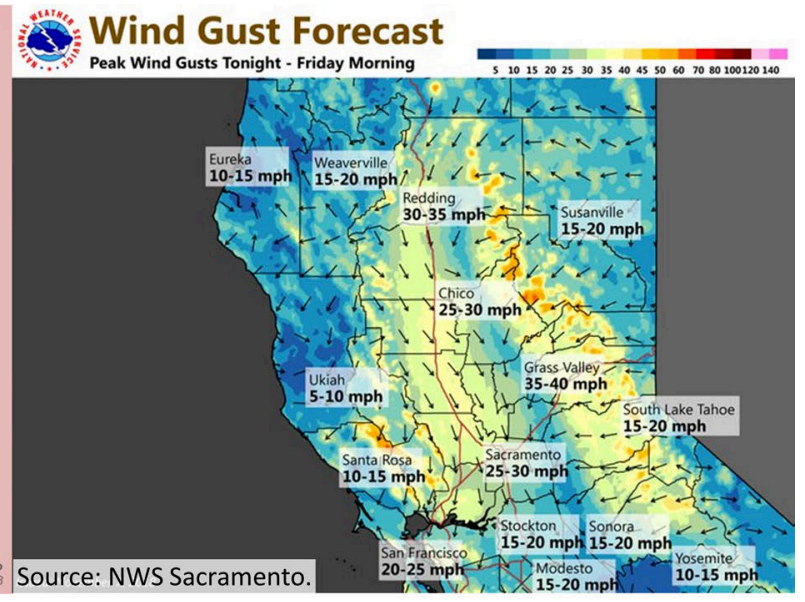

b)

Figure 7. NWS Sacramento published forecast graphics [40, 41] on November 7 highlighting a) widespread Red Flag Warnings for November 8 , and b) wind gust forecast showing peak winds exceeding $22 \mathrm{~m} / \mathrm{s}(50 \mathrm{mi} / \mathrm{h})$.

Gusty winds were measured at the Jarbo Gap Remote Automated Weather Station (RAWS) [37] starting around 19:00 on November 7, becoming very strong by 21:00. Sustained winds of $12 \mathrm{~m} / \mathrm{s}(27 \mathrm{mi} / \mathrm{h})$ continued overnight with gusts over $22 \mathrm{~m} / \mathrm{s}(50 \mathrm{mi} / \mathrm{h})$. At the time of ignition on November 8 , the RAWS station reported $8 \mathrm{~m} / \mathrm{s}(18 \mathrm{mi} / \mathrm{h})$ winds gusting to $18 \mathrm{~m} / \mathrm{s}$ ( $40 \mathrm{mi} / \mathrm{h}$ ) with relative humidity of $23 \%$. Wind direction across the foothills and ridgetops was almost exclusively from the northeast, driving the fire toward Concow and Paradise. Wind gusts during the day on November 8 were around $13 \mathrm{~m} / \mathrm{s}(30 \mathrm{mi} / \mathrm{h})$ with sustained winds of $5 \mathrm{~m} / \mathrm{s}$ to $9 \mathrm{~m} / \mathrm{s}(12 \mathrm{mi} / \mathrm{h}$ to $20 \mathrm{mi} / \mathrm{h})$ from the northeast. Relative humidity dropped to $10 \%$ during the day. Figure 8 shows the wind and temperature observations recorded at the Jarbo Gap RAWS. The vertical dashed line indicates the ignition time. Fire impacted the weather station in the early morning hours of November 9 [TD-008, TD-028, TD-131] and is indicated by spikes in temperature and wind gusts. Data after this time is questionable.

Weather in the Sacramento Valley, on the southwest side of the fire, could be observed from the Openshaw RAWS [42] on Highway 149 near Highway 70. Observations are plotted in Figure 9. As anticipated, winds in the valley were slightly lower than in the foothills and from the northwest on November 8 at $5 \mathrm{~m} / \mathrm{s}$ to $7 \mathrm{~m} / \mathrm{s}$ with gusts to $10 \mathrm{~m} / \mathrm{s}(12 \mathrm{mi} / \mathrm{h}$ to $16 \mathrm{mi} / \mathrm{h}$, with gusts to $22 \mathrm{mi} / \mathrm{h}$ ). Around sunset between the $16: 00$ and 17:00 observations, the wind direction shifted, coming downslope from the northeast. A sharp drop in relative humidity came with the wind shift. 
Critical fire weather conditions of breezy north-to-east winds and low relative humidity continued over the fire area for several days, including an additional Red Flag Warning on November 10 and 11 for conditions similar to November 8. After Monday, November 12, fire weather conditions slowly improved each day as the wind became less widespread, and relative humidity began to increase. Finally, significant rain arrived in the area on November 21 , helping firefighters fully contain the fire.

Additional weather information is provided in Appendix D.

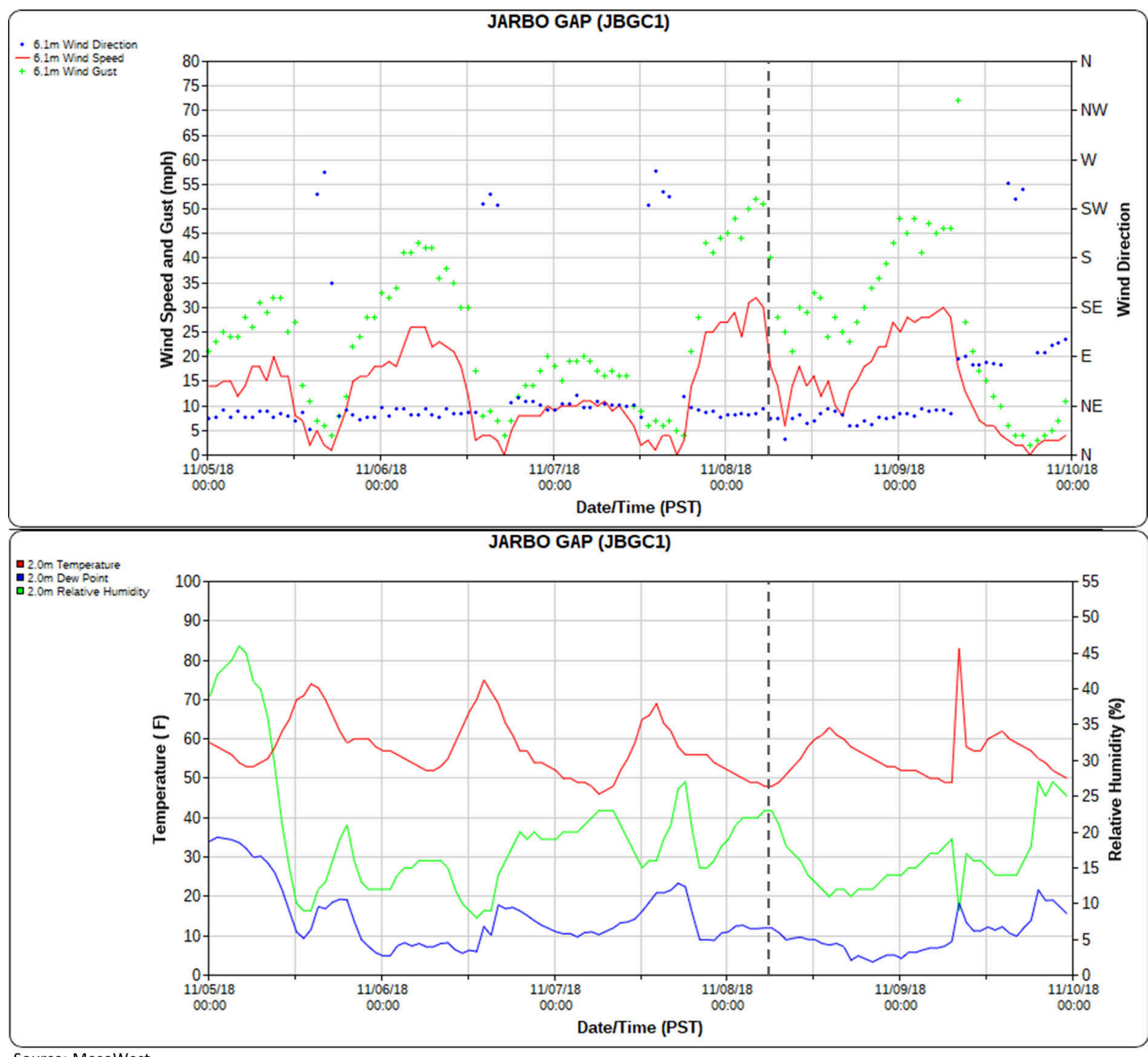

Figure: Mesowest Wind and temperature observations at the Jarbo Gap RAWS on Highway 70 [37]. The vertical dashed line indicates the ignition time. 


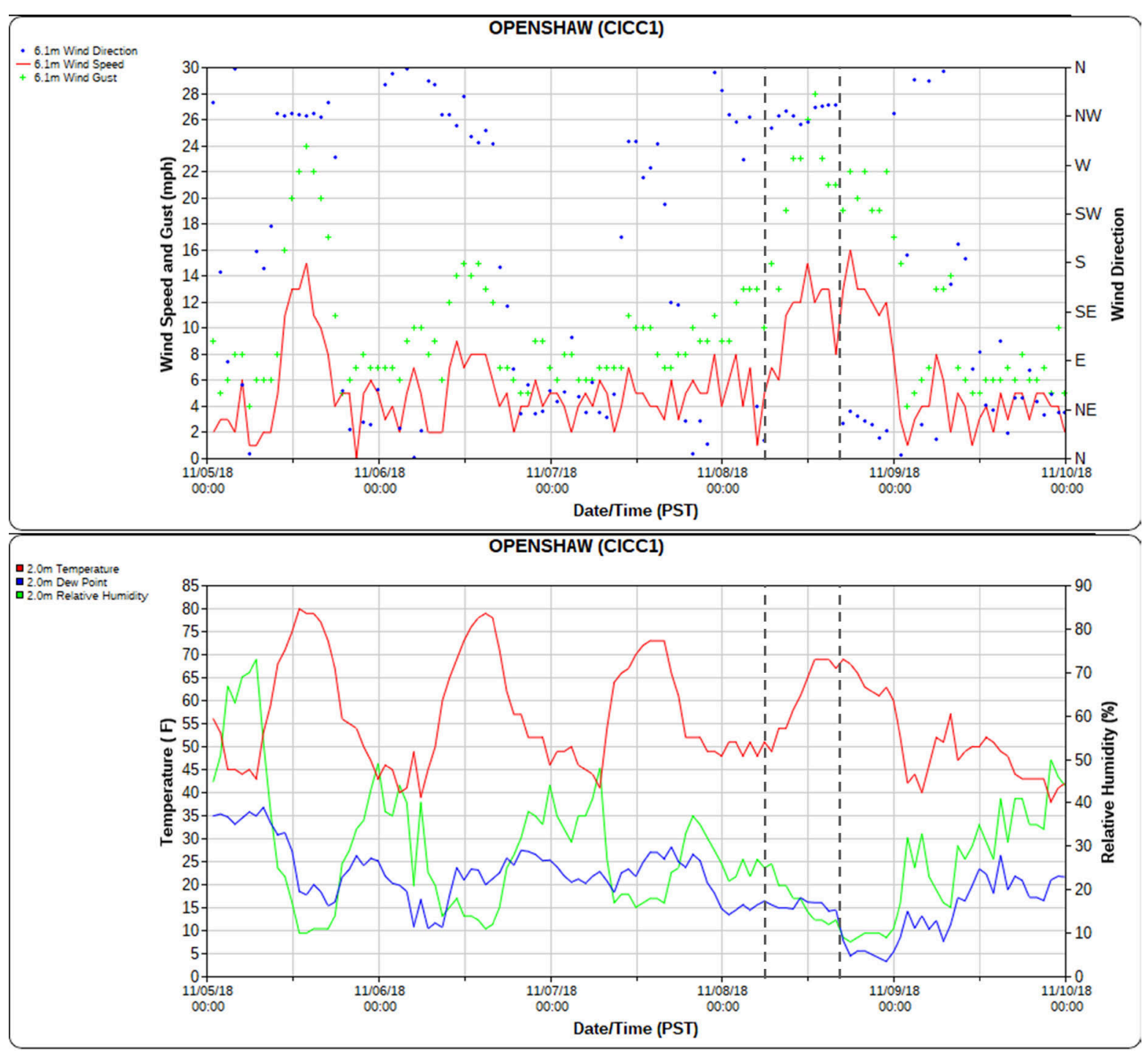

Source: MesoWest

Figure 9. Wind and temperature observations at the Openshaw RAWS on Highway 149 in the Sacramento Valley [42]. The vertical dashed lines indicate the ignition time and the wind shift. 


\subsection{Fire History}

Butte County has an extensive fire history, as shown on the maps in Figure 10 developed using data from the CAL FIRE historic fire perimeter database [43]. A significant portion $(58 \%)$ of the region burned during the Camp Fire had a previous fire history. Figure 10a indicates the number of times areas within and surrounding the Camp Fire had burned between 1911 and 2018. Notably, Paradise and Magalia have no recorded fire history despite the numerous nearby fires. Fires in Concow had historically been kept to the east side of the West Branch of the Feather River, including the 2008 BTU Lightning Complex. To the southwest, fires had been limited to the canyons and the foothills on the edge of Paradise town limits. Additional areas on the east side of the fire also had no fire history or had not burned in over 50 years. More frequent fire activity has been observed along the Feather River Canyon, in the foothills southwest of Paradise, and in Butte Creek Canyon.

In 17 of the 20 years prior to the Camp Fire there had been at least one fire recorded within the Camp Fire perimeter. Figure 10b highlights the number of years since the most recent fire activity. The most prominent fires within the Camp Fire perimeter burned within the last 10 years to 19 years, including the Humboldt Fire (southwest of Paradise) in 2008, the BTU Lightning Complex (in Concow and northeast) in 2008, and the Poe Fire in 2001 that burned through Yankee Hill. In addition to the Humboldt Fire, Butte Creek Canyon previously burned in other fires including the Bidwell Fire in 1984 and the Doe Mill Fire in 1999. Several recent fires near the town limits were contained outside of Paradise, including the Saddle Fire in 2016 and the Honey Fire in 2017.

While selective fuel treatments were conducted in and around both communities (see Section 13.2), the lack of fire history throughout Paradise and Magalia was directly connected to the vegetative fuel loading in both communities. 


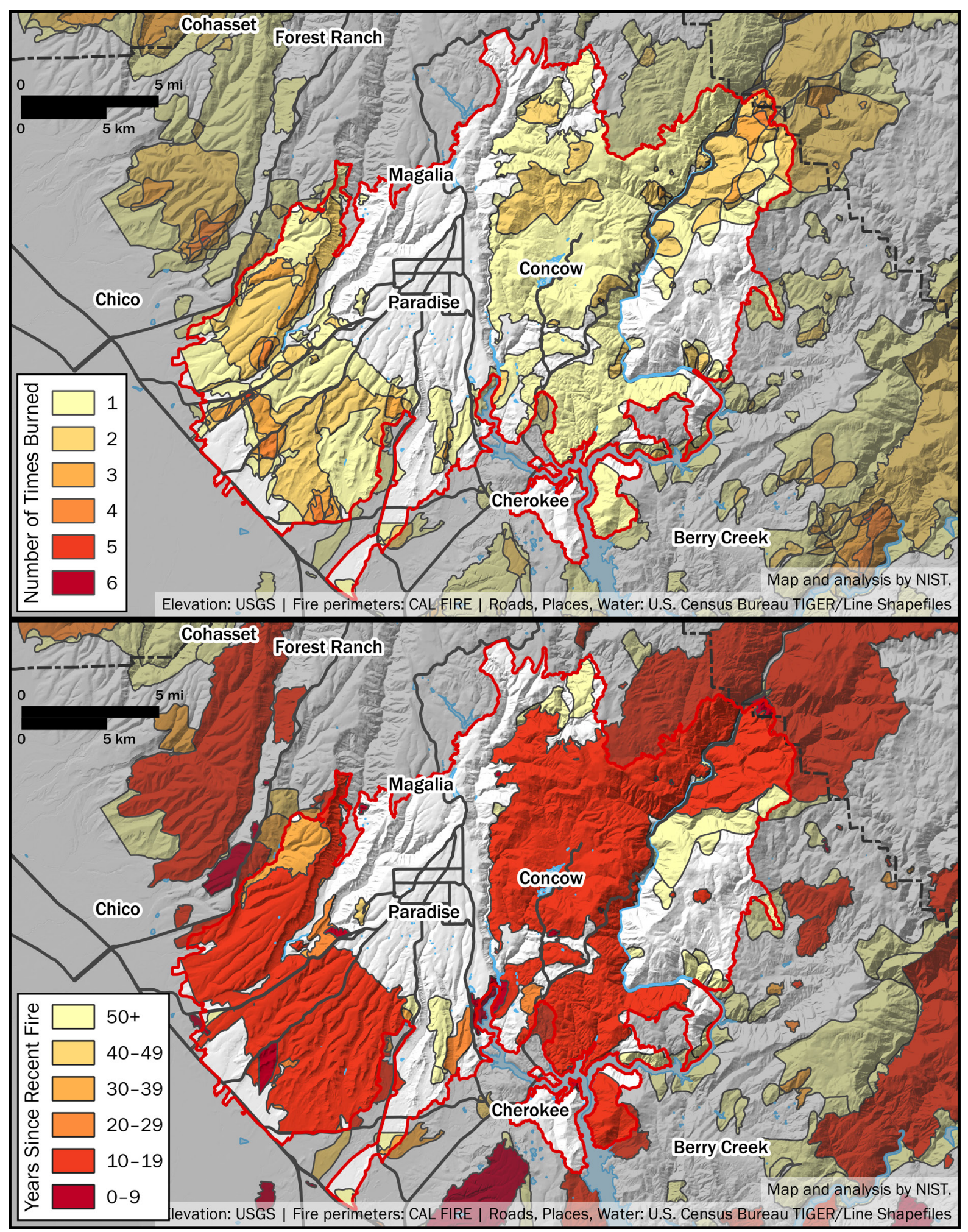

Figure 10. Historic fire perimeters in northern Butte County (1911-2018) [43] are overlaid to show a) the number of times each area has burned and b) the number of years since the last fire. The Camp Fire is highlighted and outlined in red for comparison. 


\section{Pre-Fire Response Preparations}

\subsection{Town and County Preparedness}

Butte County and the Town of Paradise had a number of programs in place at the time of the Camp Fire to communicate the risk of WUI fires and enable residents to reduce WUI fire hazards within and around Paradise, Magalia, and Concow. As described in the 2015-2020 Butte County Community Wildfire Protection Plan (CWPP) [44], the Town of Paradise had been identified as a Community at Risk going back to 2001. The CWPP addressed structure ignitability, including the concept of the Home Ignition Zone. The CWPP also included a vegetation management component that incorporated fuel modifications and specifically highlighted topography, weather, and fire history.

The Town of Paradise and Butte County addressed emergency notification through opt-in Reverse 911 call systems and an evacuation plan. The emergency notification and evacuation plan details will be discussed in NIST Camp Fire Report \#4.

The Paradise Public Works (PPW) played an active role in monitoring and preparing for a potential fire in the days leading to November 8. PPW and the Town Hall monitored the weather forecasts and were aware of the potential fire hazard. PPW prepared to respond to a WUI fire through selective fire training for personnel, including how to respond to burnovers [TD-035]. Backup batteries at their communication towers had been replaced on the evening of November 7, and in the week prior to the fire PPW had conducted a road sweep through Paradise to remove pine needles and other vegetative debris. Additionally, during the first week of November, yard debris could be delivered to the town recycling center to facilitate vegetative fuels maintenance at no cost to the residents. A Town of Paradise ordinance enabled residents to remove vegetation up to $23 \mathrm{~cm}$ (9 in) in diameter without any permit requirement [45].

Butte County has a Vegetation Management Program and a Fire Prevention Bureau. The Vegetation Management Program designs, executes, and maintains vegetative fuel treatments in and around Paradise, Magalia, and Concow. A few examples of this type of work are the fuel mastication program executed around Pine Ridge School in Magalia, the fuel treatment between Magalia Reservoir and Coutolenc Road, and the fuel treatment around Paradise Irrigation District (PID) critical infrastructure [46]. Fuel treatments are further discussed in Section 13.2, Density of Vegetative and Structural Fuels.

Butte County also has an active Fire Safe Council (FSC) [47]. FSC activities include a Chipper Program, which offers a monthly service available to residents who are working on their wildfire safety clearance. The program provides an alternative to burning or hauling fire-hazardous brush and has been in operation for over fourteen years [48].

The above-mentioned hazard mitigation programs and actions reduced fire hazard in the Camp Fire-affected communities by promoting and enabling fuels reduction within and around the communities. They also helped the communities prepare for the fire event through education outreach and enhanced communications. The extensive vegetative fuels are possibly representative of an older intermix community that had not experienced fire in decades. This lifestyle of living in the forest is what attracted many residents to the 
community [TD-025]. Additionally, the immediate community of Paradise has had limited recent fire history, further contributing to the pre-fire vegetative fuel loading.

\subsection{Infrastructure}

Paradise Irrigation District (PID) [49] services the Town of Paradise, while Magalia and areas south of Paradise are serviced by the Del Oro Water Company [50]. Pre-fire preparations included maintaining all water storage tanks at full capacity, with additional water available in the supplying reservoirs. Additional details of the water systems and their response to the fire will be discussed in NIST Camp Fire Report \#5.

To facilitate evacuation during power outages, the traffic lights at major intersections in the Town of Paradise were equipped with battery backups. There are four egress arteries to the south and one to the north of Paradise. Traffic flow through town and evacuation will also be discussed in NIST Camp Fire Report \#4. The impact of vegetation clearance around primary egress arteries on burnovers is briefly discussed in Section 9.3 and will be further discussed in NIST Camp Fire Report \#5.

The vast majority of electric utilities in Paradise were above ground. Power poles and power lines caused evacuation problems during the Camp Fire. Many poles burned and fell over; on others the cross bar burned through and caused power lines to fall. Some power lines partially fell and prevented or slowed traffic while others fell onto civilian vehicles and first responder apparatus. The impact of power pole failures on evacuation will be further discussed in NIST Camp Fire Report \#4.

Pre-fire cell phone coverage in Paradise was available throughout town except for some unreliable coverage on Pentz Road south of Feather River Hospital and in the Pentz-Pearson Road intersection area. Good cell coverage in town significantly aided first responder operation and communication for civilian notification and during evacuation, although reception was intermittent depending on time and location during the Camp Fire. Notification and evacuation during the Camp Fire will be further discussed in NIST Camp Fire Report \#4. Comments from local first responders and town officials did not reveal any pre-fire limited cell phone coverage in Magalia. The complex topography in and around Concow resulted in variable coverage in that area.

In terms of overall infrastructure preparedness in the communities affected by the Camp Fire, all tanks in the water system were topped off, traffic lights were ready for a power outage, and multiple egress arteries were available to move civilians out of town and enable first responder access. Power lines and vegetation fires around roadways were the two primary factors that impacted evacuation, which will be further discussed in the Camp Fire Report \#4.

\subsection{Firefighting Preparedness}

Pre-fire firefighting preparedness, including staffing in Paradise and Butte County and preparations and coordination with the Geographic Area Coordination Center (GACC) will be discussed in Report \#5, as will regional fire activity and USFS staffing. 


\section{Data Collection and Analysis Methodologies}

This section details the data collection and analysis methodologies that were used to integrate the various data sources and reconcile them in space and time in order to produce a unified timeline of the Camp Fire. The extent of the data collection is briefly described, followed by details of the data collection process, database construction, data integration and reconciliation, quality control procedures, and uncertainties in the data. Improvements and successes identified during the data collection and analysis are presented in Appendix E.

\subsection{Data Collection}

Data collection was accomplished in 11 field deployments, each averaging two weeks long, with two to six personnel on each deployment. Data collection focused on perishable data first $[22,24]$, including field data on damaged structures, Automatic Vehicle Locator (AVL) GPS time-stamped data, and dashboard camera video. Such data are only stored for finite time periods before being overwritten due to limited data storage.

Much of the data relies on direct first-hand observation accounts. A total of 151 technical discussions (TDs) with 157 individuals were conducted to collect accounts of first responders and other personnel directly involved in the event. In addition, photos and videos captured during the event provided detail and significant context to the observations.

Technical discussions were conducted with the Incident Commander (IC), Division Supervisors and Branch Chiefs, and personnel on apparatus including air attack, engines, dozers, water tenders, and hand crews. Initial focus was on resources located in Butte County that were first on the scene. TDs expanded to include out-of-unit CAL FIRE personnel, the California Governor's Office of Emergency Services (Cal OES), and other mutual aid response such as the US Forest Service and local government engine strike teams. TDs with law enforcement (LE) organizations included the Paradise Police Department (PPD), Butte County Sheriff's Office (BCSO), and California Highway Patrol (CHP). Non-emergency personnel also participated, including infrastructure-related organizations in public works and transportation.

Table 4 lists the number of TDs by the type of organization. A full listing of departments and agencies is found in the Acknowledgments section. Emergency personnel responded from all over the state; Figure 11 shows the locations where TDs were conducted and/or the location of the participating departments. The circle marks a $160 \mathrm{~km}$ (100 mi) radius to show scale; however, TD participants were not limited to this radius. 
Table 4. Distribution of TDs by organization type.

\begin{tabular}{lc}
\hline Organization Type & TD Count \\
\hline Fire Department $(n=100)$ & 14 \\
Local & 72 \\
State & 14 \\
Federal & \\
Law Enforcement $(n=19)$ & 12 \\
PPD & 3 \\
PPD Dispatch & 3 \\
$\quad$ BCSO & 1 \\
CHP & 1 \\
Emergency Medical Service & 8 \\
Town of Paradise & 2 \\
Water District & 13 \\
Transportation & 1 \\
National Weather Service & 7 \\
Resident & 151 \\
\hline TOTAL & \\
\hline an some cases, data was collected from more than \\
one person during a TD.
\end{tabular}

Basemap data: Esri, GEBCO, DeLorme, NaturalVue | Esri, GEBCO, IHO-IOC GEBCO, DeLorme, NGS. Overlays by NIST.

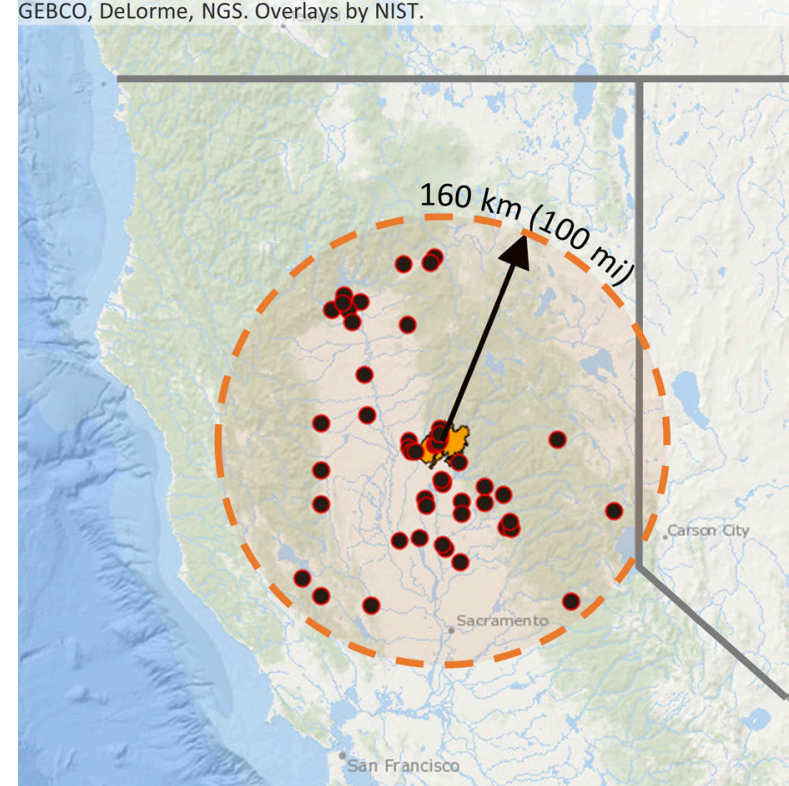

Figure 11. Locations of TDs across northern California. 


\subsection{Resources Accounted for in First Responder Technical Discussions}

A significant fraction of the state's firefighting resources in northern CA responded to the Camp Fire. Within the first hour of ignition, the IC placed one of the largest resource orders in California history, including 90 engines, 38 hand crews, and 24 dozers, on top of the initial dispatch. Field deployment constraints limited the number of first responders that could be contacted for this case study. However, the approach of reconstructing the event starting from the initial dispatch and focusing first on local responders helped prioritize data collection.

The information gathered from the TDs, with the help of AVL and radio log data, allowed estimation of the number of resources involved in the early stages of the incident. Based on the estimated number of resources tracked and the low number of unknown cross-references in the TD data, the collected data provided a representative coverage of the responding apparatus throughout the geographic area covered by the fire in the first 24 hours. Analysis of the response in terms of defensive actions will be further discussed in Report \#5.

TDs were conducted with a large fraction of fire personnel who were on the scene early (before 10:00). TDs were conducted with the IC and all of the Division Supervisors and Branch Directors involved on November 8, along with at least one fire fighter from $60 \%$ of CAL FIRE engines from the local Butte Unit (BTU) that were involved in the incident. Of the 100 TDs with fire department personnel (from any department), 86 unique apparatus were covered, including 3 strike team leaders who were responsible for the operations of the entire team of engines.

Two additional CAL FIRE engine strike teams (without AVL) were known to have arrived before 10:30, based on information in the radio log and technical discussions. AVL data from 6 additional CAL FIRE engine strike teams assigned to the fire line between 14:00 and 20:00 located these additional units in areas where other TD participants were working; therefore, significant changes to the timeline are not expected even if there had been an opportunity to include these engines in the study.

In addition to the apparatus previously mentioned, approximately 45 additional fire apparatus (including engines, dozers, water tenders, hand crews, and others) were identified as having been assigned to the incident before 11:00, based on AVL, radio log, and technical discussion details. According to the IC, 252 engines, 19 water tenders, 35 hand crews, and 17 dozers were deployed to the fire line by 20:30. Based on the information collected from the 151 TDs, the spatial distribution of TD participants in relation to the fire, and the small number of cross-references that could not be verified or followed up, it is expected that all significant fire progression activity is accounted for in the dataset, even as the day progressed and more apparatus arrived at the fire line.

In addition to the fire response, there was also a massive law enforcement and medical transport response. Dozens of agencies responded. TDs were carried out with 12 of the 21 PPD officers and three dispatchers, about half of the PPD personnel who were involved during the first day. Technical discussions with personnel from the Butte County Sheriff's Office and California Highway Patrol were focused on the broader picture of law 
enforcement response, as opposed to detailed accounts of local observations. It is estimated that TDs with law enforcement represent between $10 \%$ and $20 \%$ of personnel on location and therefore do not represent all law enforcement activities. From the limited number of law enforcement TDs, it was determined that law enforcement was present in most, if not all, major intersections throughout the fire directing traffic from very early on. The fire behavior data collected from law enforcement TDs is included in the timeline data and maps; however, the identified locations of law enforcement officers do not capture all of the law enforcement personnel present.

\subsection{Technical Discussion Methodology}

Technical discussions (TDs) with personnel involved in the fire were the primary method to collect firsthand information from the incident. This section describes the methodology employed to guide each TD. Every TD was unique not only because of the information shared but also because TDs were conducted with personnel with different roles and from different agencies, including fire, law enforcement, local government officials, and transportation and public works officials. Even in the case of two apparently similar sources, such as TDs with two Captains from two different fire engines, the data collected could be very different if one was involved in early civilian rescues while the other was on initial attack. TDs were held with personnel in the fire service ranging from the Geographic Area Coordination Center to fire apparatus personnel (Captains and/or Firefighters). Town employees ranged from Paradise Town Hall officials to Paradise Public Works personnel, and law enforcement included officials from several local and state agencies.

Each TD started with an introduction by the TD Lead. The TD Lead was either a NIST or USFS team member with field experience in NIST WUI case studies. The TD Lead outlined the scope of the Case Study and highlighted the non-regulatory role of NIST and the type of anticipated product. The previous three NIST WUI Case Studies [9-13] were used (hard copies were available during each TD) to familiarize the TD participant with the NIST WUI fire research program. A brochure was provided to the TD participant, and the key aspects of the NIST technical work were highlighted. The TD participant signed-in, and the information was stored by the NIST Principal Investigator (lead science researcher) to ensure safekeeping of personally identifiable information.

The workflow for the TD was explained to the Participant. They were asked to share with the NIST team their involvement during the event, with emphasis on fire and rescue/evacuation observations, actions they took, and contacts they made with other first responders during the event. The NIST Lead provided examples of tools that could be used to help build the timeline during the narration, such as pictures and videos or other time-stamped events (e.g., a text message) that might be used to refine the timeline of the narration. Emphasis was also given to contacts with other first responders, even if these interactions were brief. Examples of how this information might be used to refine the event timeline were provided to the TD participant.

If GPS tracking data was available (Automatic Vehicle Locator data is discussed in Section 7.4.4), the data was prepared in advance to facilitate access during the TD. GPS data was not used to lead the discussion but was available in the event the TD participant wanted 
to clarify a sequencing question during their narration. Table 5 lists, roughly in the order of accuracy, the tools used to define/refine the event(s) timeline for observations presented in technical discussions.

The NIST Lead assigned the participant a number, and the number was recorded along with their contact information. ${ }^{6}$ The TD participant was told that only the TD numbers would appear in the NIST Case Study, and that they would be able to track their contributions by their TD number. TDs frequently took place around a large table so that large maps could be spread out as seen in Figure 12.

Table 5. Tools, "hooks," and methods used to define/refine the event timeline during and after technical discussions.

\begin{tabular}{|c|c|c|}
\hline Tool & Source & Primary Value Added \\
\hline AVL & $\begin{array}{l}\text { Electronic database or } \\
\text { prepared route of travel } \\
\text { summary }\end{array}$ & Timestamp, location \\
\hline Pictures and/or videos & Participant & $\begin{array}{l}\text { Usually timestamp and } \\
\text { location, as well as } \\
\text { visual context or audio }\end{array}$ \\
\hline Radio communication & Radio log & Timestamp, context \\
\hline Phone or Text Message & Participant & Timestamp \\
\hline $\begin{array}{l}\text { Meeting with other apparatus } \\
\text { that has AVL }\end{array}$ & $\begin{array}{l}\text { AVL (can be used even if TD } \\
\text { for that apparatus is not } \\
\text { available) }\end{array}$ & Timestamp, location \\
\hline $\begin{array}{l}\text { Participant's notes taken during } \\
\text { event }\end{array}$ & $\begin{array}{l}\text { Participant (frequently from } \\
\text { Battalion Chiefs, Division } \\
\text { Supervisors and Branch } \\
\text { Chiefs) }\end{array}$ & $\begin{array}{l}\text { Possibly timestamp, } \\
\text { additional details }\end{array}$ \\
\hline $\begin{array}{l}\text { Meeting with another first } \\
\text { responder }\end{array}$ & $\begin{array}{l}\text { Primary Database - used } \\
\text { after the TD }\end{array}$ & Cross-reference \\
\hline Unique visual observation $^{\mathrm{a}}$ & $\begin{array}{l}\text { Primary Database - used } \\
\text { after the TD }\end{array}$ & Cross-reference \\
\hline
\end{tabular}

\footnotetext{
${ }^{a}$ e.g., traffic conditions, presence or absence of civilians, presence or absence of fire behavior, presence or absence of other first responders
}

Two printed ANSI E-size maps, with an area of $112 \mathrm{~cm} \times 86 \mathrm{~cm}(34 \mathrm{in} \times 44 \mathrm{in})$, were used for each TD. ${ }^{7}$ One map included the entire Camp Fire perimeter and one zoomed in on Paradise. The map files were created by CAL FIRE and included all the Damage Inspection information color-coded by status of structures (destroyed, damaged, and undamaged). The participant TD number was marked on both maps.

\footnotetext{
${ }^{6}$ The number was marked on the cover of the NIST WUI Brochure provided to TD Participants.

${ }^{7}$ A new set of E-size maps was used for each TD.
} 
The TD participant started the narration of the day's event and the NIST Lead annotated the maps. Figure 13 shows an annotated map from TD-064. Sequential numbering (e.g., for TD-064 the map is annotated with 64-1,64-2, etc.) was used to link the map and scribed accounts. Two scribes from the NIST Field Team captured the information shared by the TD participant (TDs were not audio or video recorded). The maps and TD notes were later used to assemble the TD timeline in the Primary Database (see Section 7.4.1). The session continued until the participant had completed his or her narration of their perspective and contribution to the event. The accounts, contributions, and perspectives differed among TDs, and therefore any clarification or follow-up questions that might be asked were not standardized. Questions might also arise based on the accumulated knowledge from prior TDs to determine if certain information needed clarification. If the TD participant had pictures or videos they wished to share, file sharing was set up. ${ }^{8}$

The NIST Lead then asked if there were any general comments, including lessons learned, that the participant might wish to share about the entire event. The comments were documented by the NIST Field Team. At the end of the field data collection, after all the TDs were completed, all of these comments were assembled, sorted, and analyzed (see Section 12).

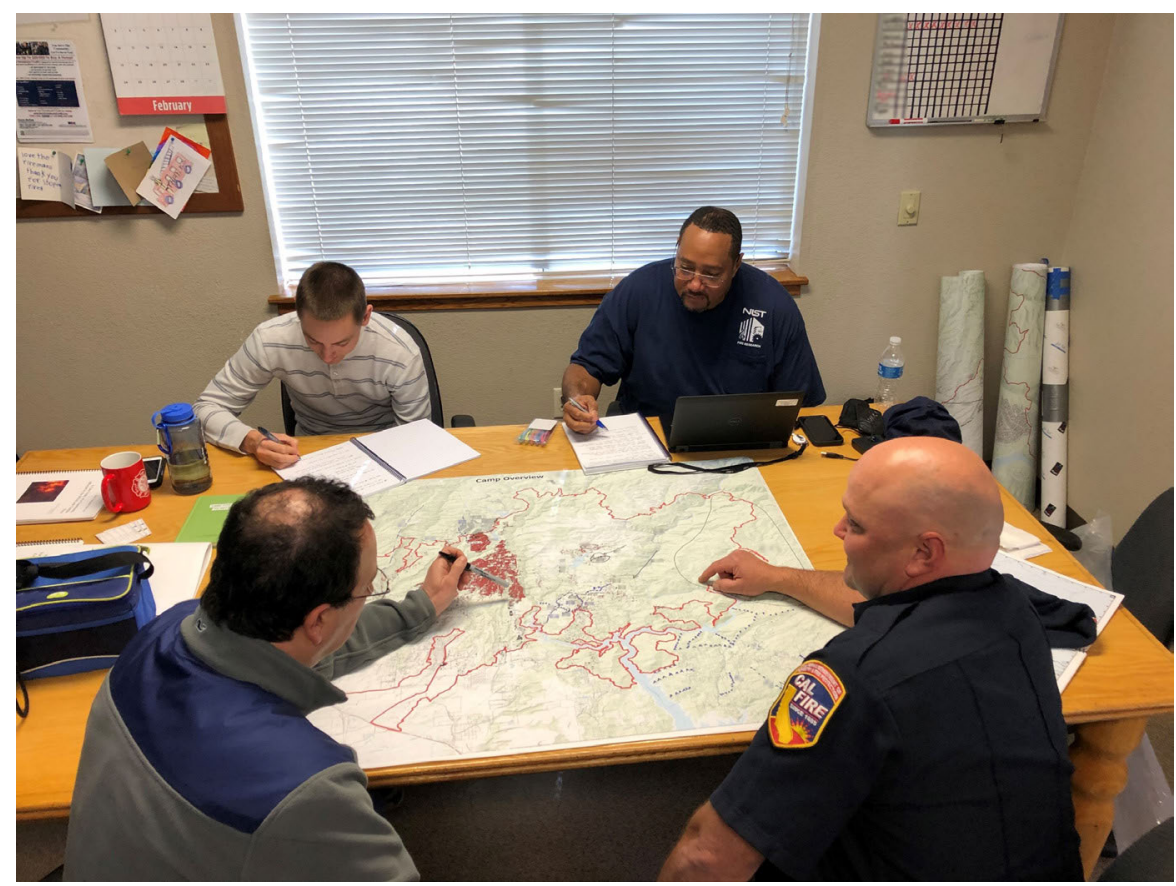

Figure 12. NIST Field Team with CAL FIRE personnel at Fire Station 35 in Paradise.

\footnotetext{
${ }^{8}$ There were numerous ways to share photos and videos, and they were often hardware/operating system specific.
} 


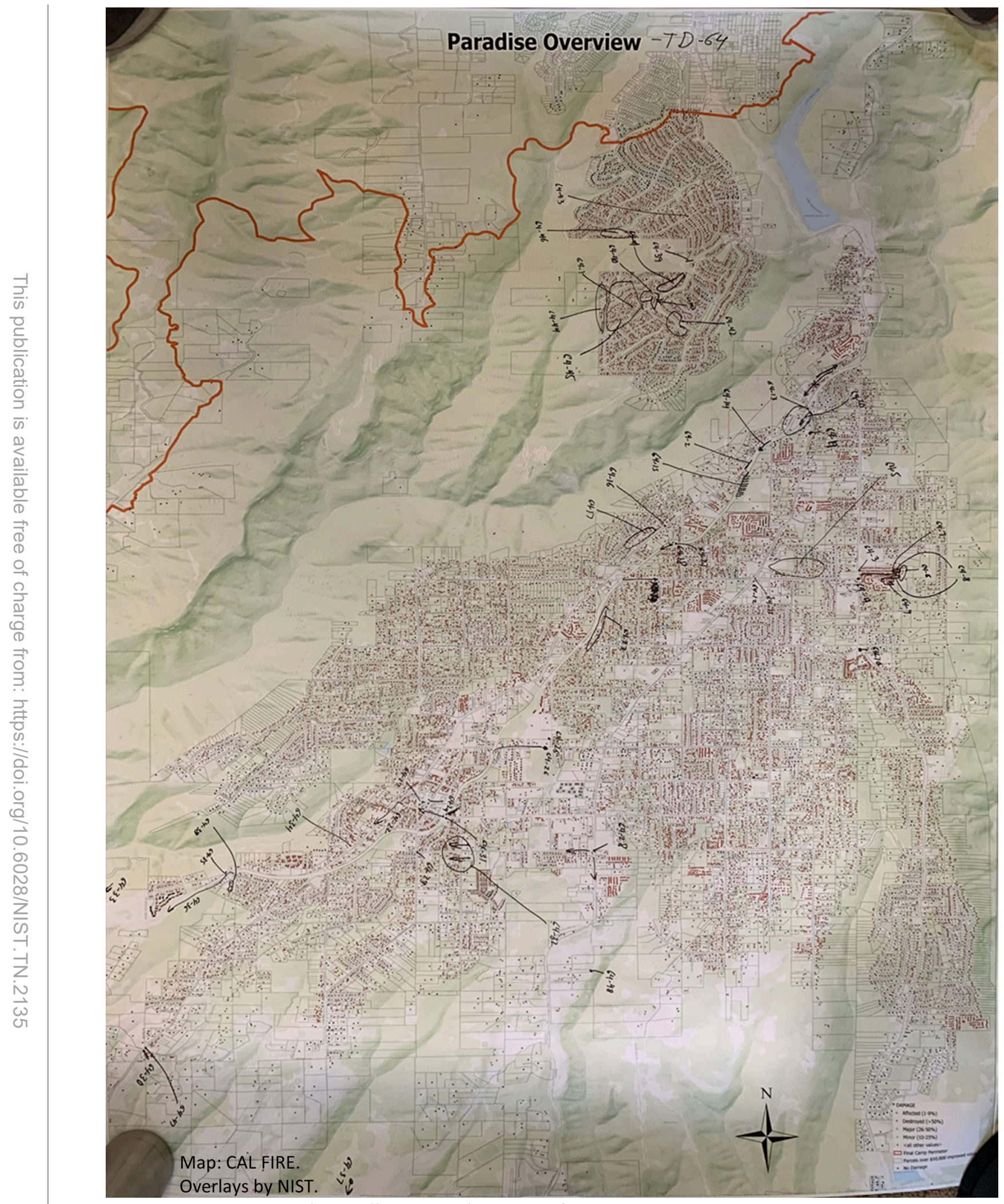

Figure 13. Annotated Paradise Overview Map from TD-064. 


\subsection{Database and Tools}

Database construction and reconciliation were facilitated by several different data sources and cross-referencing methods. Multiple databases were developed to organize the data; the main framework built on the content of the technical discussions is labeled here as the Primary Database. Other timeline-related data were tabulated by adapting the primary database. To facilitate data refinement, integration, timing, and positioning, various other tools and data were also utilized.

\subsubsection{Primary Database}

The primary database was built from the contents of the technical discussions. Each observation was binned into the following categories:

\section{a. Fire and fire behavior}

Fire observations ranged from basic statements of fire burning at a particular location to detailed accounts of observed fire behavior, such as ignitions, fuels detail, fire spread rates and pathways, ember showers, fire whirls, and other fire phenomena.

b. No fire In some cases, a lack of fire was also an important observation. Examples include neighboring structures that were not yet burning, unburned islands, or the fire flanks.

c. Evacuation/people

The evacuation/people category was particularly wide-ranging. To support further analysis, each entry was coded by the following categories: evacuation, rescue, or emergency notification; traffic conditions; whether a roadway was blocked or otherwise impassable; and description of a temporary refuge area (TRA). These observations will be further detailed in Report \#4.

d. Defensive actions

In the context of this case study, defensive actions were defined as any action taken to reduce or influence the fire behavior. Structure preparation, fuel reduction or relocation, fire attack or suppression, exposure protection, and dozer or hand lines were all considered defensive actions. These actions will be further detailed in Report \#5.

e. Weather

Observations of wind speed or direction and visibility were placed in the weather category.

In addition to the observations itself, other attributes included information about time, location, and cross-referencing information. Table 6 lists and describes each of the columns included in the database. Many are intuitive; however, a few will be highlighted here.

Keeping track of time and location was the basis of the dataset, thus the time and location source were noted within a hierarchy. Location was specifically listed in two forms: the location of the observer and the location of the observation. In many cases these were the same; however, if a structure was burning or fire was visible across a ravine or down the street from the position of the observer, the specific location of the observation superseded the location of the person. 
Fire behavior observations were also supplemented with additional metadata, including a classification of the type of fire, whether the observation described residual fire conditions, and whether structure-to-structure fire spread was observed. Fire observations were categorized into five types:

- Spot fire (S): described as a spot fire or other small isolated fire not burning structures

- Vegetation (V): specifically described as burning vegetation or burning wildland areas

- Residential structure (R): residential structure was burning (other fuels might also be burning on a parcel)

- Commercial structure (C): commercial structure was burning (other fuels might also be burning on a parcel)

- Other $(\mathrm{O})$ : category for undetermined or general statements of fire, or specific indication of other fuels such as sheds, vehicles, or fences.

Residual fire conditions were considered to apply if the observation was of reduced fire activity after passage of the fire front, such as lightly flaming structural rubble or isolated heavy fuels burning among already burned finer fuels with no significant threat to continued fire spread, or completely burned areas with no flaming observed.

Defensive actions influenced the final status of structures and were critical to provide context and explanation of surviving structures. Each structure that was identified as having been defended at some point was logged in the database into one of three categories. The most confidence was placed in structures that were "confirmed defended," meaning that the TD participant specifically described or identified a particular structure, or that there was photographic record of such actions taking place. A structure was listed in the "assumed defended" category if defensive actions were specified without a specific address or photographs showed unspecific firefighting activity in an area. In these cases, AVL (if available) and/or Damage Inspection (DINS) data [30] were consulted to identify the structure. The third category was defined as "inferred." This classification was reserved for cases where defensive actions likely took place based on AVL or radio data, or photos showed signs of probable action, but there was no direct record of such actions. Report \#5 will further discuss the defensive actions and damaged structures.

Additional comments provided by TD participants that were descriptive of general observations without specific times and locations, challenges, successes, recommendations, or lessons learned were tabulated separately. These comments are summarized and discussed in Section 12. 
Table 6. Primary database attributes and definitions.

\begin{tabular}{|c|c|}
\hline \multicolumn{2}{|r|}{ Time Information } \\
\hline Column Title & Definition \\
\hline TD\# & Technical discussion identification number \\
\hline Date & Date of observation \\
\hline $\begin{array}{l}\text { Time: } \\
\text { start } \mid \text { end }\end{array}$ & $\begin{array}{l}\text { Time that an observation occurred, or a time period during } \\
\text { which the observation could have occurred }\end{array}$ \\
\hline Time Source & How the time of observation was determined \\
\hline Observation Window (min) & $\begin{array}{l}\text { Duration of the observation, or time window in which the } \\
\text { observation occurred (End time - Start time) }\end{array}$ \\
\hline \multicolumn{2}{|r|}{ Observation Information } \\
\hline Column Title & Definition \\
\hline Notes & Full description of the observation \\
\hline Information Source & Where the information came from \\
\hline Notes/Map \# & $\begin{array}{l}\text { Bookmark or tag number from the TD map annotation to } \\
\text { identify location on the map and in the notes }\end{array}$ \\
\hline \multicolumn{2}{|r|}{ Location Information } \\
\hline Column Title & Definition \\
\hline $\begin{array}{l}\text { Observer: } \\
\text { Latitude | Longitude }\end{array}$ & Where the observer was physically located \\
\hline Observer Source & How the location of the observer was determined \\
\hline $\begin{array}{l}\text { Observation: } \\
\text { Latitude | Longitude }\end{array}$ & True location of the observation \\
\hline Observation Source & How the location of the observation was determined \\
\hline $\begin{array}{l}\text { Map: } \\
\text { Latitude | Longitude }\end{array}$ & $\begin{array}{l}\text { The final record of where an observation is located. If } \\
\text { different, the observation location supersedes the observer } \\
\text { location. }\end{array}$ \\
\hline Area/Line Location & $\begin{array}{l}\text { Check box: does the location of the observation describe a } \\
\text { large area or line/path }\end{array}$ \\
\hline Description & Description of the area or line location of the observation \\
\hline \multicolumn{2}{|r|}{ Cross-Reference Information } \\
\hline Column Title & Definition \\
\hline Accompanied by & $\begin{array}{l}\text { List of other apparatus or people that were mentioned or } \\
\text { known to be in the same location that could be used as cross- } \\
\text { references }\end{array}$ \\
\hline Verified Cross Reference & List of TD\# that cross-reference the same observation \\
\hline Related TD & $\begin{array}{l}\text { List of TD\# that have related observations but have not been } \\
\text { specifically cross-referenced }\end{array}$ \\
\hline
\end{tabular}


(Table 6 cont.)

Categorized Observation Details

\begin{tabular}{|c|c|}
\hline Column Title & Definition \\
\hline Fire Behavior Observations & Details of fire observations; from the Notes column \\
\hline $\begin{array}{l}\text { Type of Fire } \\
(S / V / R / C / O)\end{array}$ & $\begin{array}{l}\text { Letter code categorization of the type of fire observation } \\
\text { (spot, vegetation, residential structure, commercial structure, } \\
\text { or other) }\end{array}$ \\
\hline Residual Fire? & $\begin{array}{l}\text { Check box: does the observation describe fire activity that is } \\
\text { lingering after fuels have burned? }\end{array}$ \\
\hline $\begin{array}{l}\text { Documented Structure } \\
\text { to Structure Ignition }\end{array}$ & $\begin{array}{l}\text { Check box: does this observation specifically describe } \\
\text { structure-to-structure fire spread }\end{array}$ \\
\hline No Fire Observations & $\begin{array}{l}\text { Details of comments related to areas where there is no fire } \\
\text { observed at the time; from the Notes column }\end{array}$ \\
\hline $\begin{array}{l}\text { Evacuation/People } \\
\text { Observations }\end{array}$ & $\begin{array}{l}\text { Details of observations relating to civilian evacuations, } \\
\text { rescues, temporary refuge areas, emergency notification, } \\
\text { traffic; from the Notes column }\end{array}$ \\
\hline Road Blocked & $\begin{array}{l}\text { Check box: does this observation describe a roadway being } \\
\text { blocked and impassable, by fire, vehicles, power lines or } \\
\text { poles? }\end{array}$ \\
\hline Traffic Conditions & Check box: does this observation describe traffic conditions? \\
\hline $\begin{array}{l}\text { Evacuation/ Rescuel } \\
\text { Notification }\end{array}$ & $\begin{array}{l}\text { Check box: does this observation describe emergency } \\
\text { notification, evacuation (excluding traffic), or a rescue } \\
\text { attempt? }\end{array}$ \\
\hline$T R A$ & $\begin{array}{l}\text { Check box: does this observation describe or relate to a } \\
\text { temporary refuge area? }\end{array}$ \\
\hline Defense Actions & $\begin{array}{l}\text { Details of observations describing actions taken to protect, } \\
\text { defend, or suppress structures or unburned areas }\end{array}$ \\
\hline Water / Hydrants & $\begin{array}{l}\text { Check box: does this observation describe the use, or attempt } \\
\text { to use, a fire hydrant or other water source }\end{array}$ \\
\hline Weather Observation & $\begin{array}{l}\text { Details of observations related to weather, most commonly } \\
\text { wind and visibility }\end{array}$ \\
\hline Key statements & $\begin{array}{l}\text { Includes any other non-categorized observation or comment } \\
\text { that contributes to understanding of the incident, conditions, } \\
\text { response, or critical situation }\end{array}$ \\
\hline & Defended Structure Details \\
\hline Column Title & Definition \\
\hline $\begin{array}{l}\text { Defended } \\
\text { (Address Confirmed) }\end{array}$ & $\begin{array}{l}\text { Address of structure that was specifically identified in the TD } \\
\text { as being defended in some way }\end{array}$ \\
\hline $\begin{array}{l}\text { Defended } \\
\text { (Address Assumed) }\end{array}$ & $\begin{array}{l}\text { Address of structure that was defended, was only generally } \\
\text { identified in the TD, and was confirmed using other data } \\
\text { sources as being the specific structure }\end{array}$ \\
\hline $\begin{array}{l}\text { Inferred Defended } \\
\text { (stop not specific in TD) }\end{array}$ & $\begin{array}{l}\text { Address of structure that was possibly defended, as } \\
\text { determined by AVL, radio log, but had no specific record or } \\
\text { comment of TD comment }\end{array}$ \\
\hline $\begin{array}{l}\text { Defended Structure } \\
\text { Latitude | Longitude }\end{array}$ & Location of identified structure \\
\hline
\end{tabular}




\subsubsection{Additional Databases}

Additional timeline-related data from audio-visual sources were entered into supplemental databases according to the data source. These data included photos and videos shared by the TD participants, dashboard/body camera video recordings from PPD, 911 call recordings, and publicly available photos and videos from the internet. Each audio-visual file could be interpreted as an independent TD, and multiple observations were often documented from a single photo or video. All observation details remained the same as those presented in Section 7.4.1 above, with the exception of another suitable identifier (e.g., filename) replacing the TD\#.

A large amount of information was available online through public social media sites, including YouTube and Twitter. Civilians who took photos or videos during the Camp Fire and shared them online provided valuable supplementary firsthand observations. Additionally, several documentary programs have been produced using videos from inside the Camp Fire. Numerous news agencies also published videos and photos during their coverage of the event.

These media were searched to identify additional observations; these were referred to as "virtual" technical discussions (VTD). This effort was made possible by significant crossreferencing to previously known information in the primary database and familiarization with the event and geography of the area. While dozens of videos and photos were available, most did not provide enough context to reliably identify time and/or location. A total of 30 VTDs were documented, incorporating observations from 36 photos and videos.

\subsubsection{Other Data Sources}

Numerous additional data sources, listed in Table 7, were utilized as tools to facilitate data refinement and timeline reconstruction. While these sources did not provide direct observations (aside from the VTD and PPD videos previously mentioned), they provide additional information for identifying locations and clarification/confirmation of other data. 
Table 7. Other data sources and tools that provided location, time, or other supporting information.

\begin{tabular}{|c|c|}
\hline Data Type & Data Source \\
\hline CAL FIRE DINS data & CAL FIRE \\
\hline CAL FIRE radio log & CAL FIRE \\
\hline CAL FIRE AVL & CAL FIRE \\
\hline 911 call recordings & CAL FIRE, PPD \\
\hline PPD dashboard/body camera recordings & PPD \\
\hline Butte County property parcel information & $\begin{array}{l}\text { Butte County; } \\
\text { http://gis.buttecounty.net/Public/index.html?vi } \\
\text { ewer=dssearch }\end{array}$ \\
\hline Butte County post fire drone imagery & $\begin{array}{l}\text { https://www.arcgis.com/home/webmap/viewer } \\
\text { html?useExisting=1\&layers=eaed23c1b71540 } \\
\text { 91896c572b6bc9b6fd }\end{array}$ \\
\hline $\begin{array}{l}\text { Google Earth (satellite imagery, mapping } \\
\text { tools) }\end{array}$ & $\overline{\text { Google }}$ \\
\hline Google Maps (map, Street View images) & https://www.google.com/maps \\
\hline Bing Maps (map, Streetside images) & https://www.bing.com/maps \\
\hline YouTube videos & $\begin{array}{l}\text { Various public videos uploaded to } \\
\text { https://www.youtube.com }\end{array}$ \\
\hline News media & $\begin{array}{l}\text { Various newspapers and television clips } \\
\text { accessed online }\end{array}$ \\
\hline $\begin{array}{l}\text { Social media (e.g., Facebook and } \\
\text { Twitter) }\end{array}$ & $\begin{array}{l}\text { Various public posts on social media } \\
\text { discovered by searching for Camp Fire related } \\
\text { content }\end{array}$ \\
\hline $\begin{array}{l}\text { NIST-collected damaged structure field } \\
\text { data }\end{array}$ & NIST Preliminary Reconnaissance \\
\hline
\end{tabular}

\subsubsection{AVL and AVL Data-Mining Tools}

Automatic Vehicle Location (AVL) data provided a critical dataset and tool for developing the timeline. At the time of the Camp Fire, a large number of CAL FIRE apparatus were equipped with the technology. ${ }^{9}$ During the first 48 hours of the incident, over 725000 data points describe the location of 261 unique apparatus, including fire chief vehicles, engines, crew transports, dozers and transports, and aircraft.

TDs were conducted with personnel from 44 apparatus equipped with AVL. During data entry, three types of AVL discontinuities were encountered. They included:

1. A nearly system-wide loss of data recording from 11:35 to 11:50 on November 8 .

2. Individual dropouts of several minutes (possibly due to reduction in connectivity related to location).

3. No data recordings when the system (vehicle) was turned off.

\footnotetext{
${ }^{9}$ CAL FIRE is in the process of implementing AVL in state-owned apparatus. Local and federal fire apparatus as well as law enforcement were not equipped with AVL, or data was not available.
} 
Of the three discontinuities, the first one was particularly notable. The dropout affected over $50 \%$ of all active apparatus, including over $66 \%$ of apparatus located within the Paradise town limits. It was unclear what caused the dropout, although it may have been related to localized fire and smoke column conditions under the plume, or to an interruption in cell tower communications equipment or frequency.

In addition to geolocating the data points on a map and using this data to directly identify time and location of observations from TDs with AVL, a few tools were developed to facilitate searching through the AVL data. These calculation tools allowed the identification of nearby apparatus and determinations of when two specific apparatus crossed paths, how close an apparatus was to a particular location, and the arrival time of apparatus at a particular location. These search tools allowed for various queries of the data depending on the known information in each situation.

\subsection{Data Integration}

\subsubsection{Data Integration Methodology}

The data integration process utilized all the available data to refine actions and observations in both time and space. Data entry was performed in a sequence with decreasing spatiotemporal information as follows:

1. TD with AVL

2. PPD video, audio

3. TD with photos but no AVL

4. TD with no photos and no AVL

5. VTD

Technical discussions accompanied by AVL records contained the most complete information, providing direct time and location of each observation. These were added to the database first in order to provide a sound initial timeline of the events during the fire. PPD videos were reviewed next, as these recordings also provided direct time and location information (through visual identification). They were also accompanied by radio communications that could be heard through most of the videos.

Technical discussions with photos but no AVL were evaluated third. The photos provided discrete points in the narrative that anchored time and location. The rest of the observations in these TDs relied on participant-provided times and locations or other cross-references to fit between the anchor points.

The TDs without photos or AVL relied on the participant-provided times and locations and on the accumulated knowledge of the researcher to identify cross-reference "hooks" to information and events previously entered in the database or available through the tools listed in Table 7. Examples of these known events included face-to-face meetings or unique observations (specific evacuation action, traffic activity, fire behavior or defensive action) which could narrow down the potential time window or identify a specific location. 
Additionally, the "accompanied by" column, described in Table 6 helped to keep track of other mentions of specific apparatus/personnel. TDs without accompanying AVL or photos were held for last so that the prior TDs could be leveraged to supplement the details provided by the TD participant.

Virtual TDs typically did not include readily defined times or locations. These attributes had to be deduced by using "hooks" to known information. For example, driving past an engine with AVL could provide time and location, enabling the use of all observations within the same continuous video.

All the above data was used to refine and integrate the details of events described in the technical discussions and improve the timeline and spatial resolution. The process was iterative, with a specific event first entered into the database with often limited details, and then built upon as additional details supplemented the initial data.

\subsubsection{Examples of Data Integration}

In the primary database, AVL was used to fill-in the driving directions/sequence when assembling a TD. For the TDs that did not have AVL, estimates of drive time were used when necessary to refine the TD timeline.

Figure 14 illustrates a specific example of data integration. In this case, TD-127 reported taking defensive actions on an unspecified residential structure, with the assistance of TD-061, while it was still daylight, estimated between 15:00 and 16:00. While TD-061 did not mention this action (\#1), the AVL was used to place TD-061 at a structure near the location described by TD-127 (\#2). Additional data from the DINS database confirmed the structure by matching the color and damage of the structure described by TD-127 (\#3). The combination of TD, AVL, and DINS data sources refined the initial observation of a nonspecific location and time to a valuable account of a defended and saved structure while also providing context and support for the individual timelines of each TD account.

Figure 15 shows a photo of an unidentified engine taken by a TD participant. Multiple engines were in the area at the same time, and several TDs reported fire damage to apparatus, so confirmation of the engine was not possible. However, the photo was later matched to an engine seen in a 60 Minutes television program about the Camp Fire, confirming the information in the original photo.

Another example of data integration and refinement is shown in Figure 16. TD-106 described encountering a fire whirl when they were driving south on Neal Road at an unspecified time in the afternoon. The time was originally estimated to be sometime between 17:30 and 18:30 using additional cross references with other TDs. However, TD-106 also mentioned that a news crew was present and recorded the event. Figure 16 shows an image of a fire whirl that was captured on video by news reporter Laura Anthony, KGO-TV. Its location was determined to be on Neal Road by comparing to Google Street View images. The earliest possible time of the observation was identified by a Twitter post by Ms. Anthony at 17:53. Follow-up with Ms. Anthony further refined the time of the observation to 17:18. 
The data integration methodology enabled the creation of a database of time-resolved series of events that can be queried both in time and space.

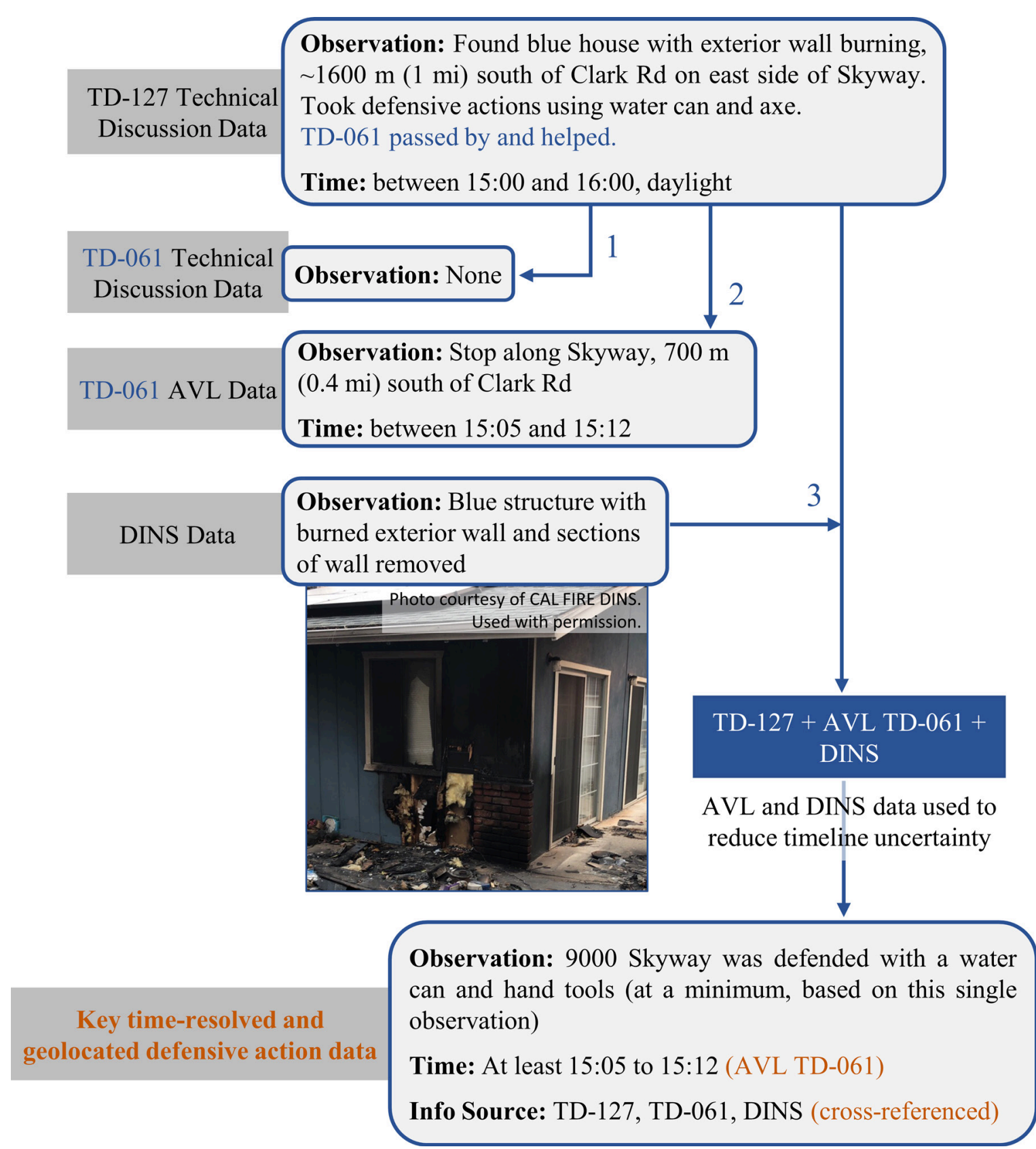

Figure 14. A flowchart illustrating an example of data integration and the method of crossreferencing multiple data sources for TD refinement. 


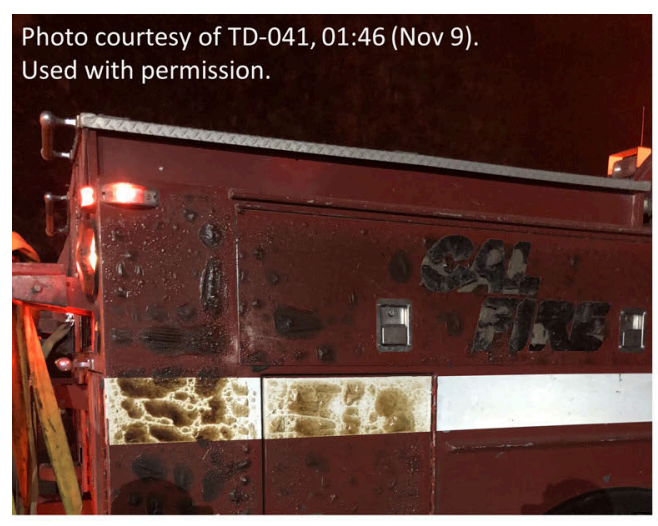

a)

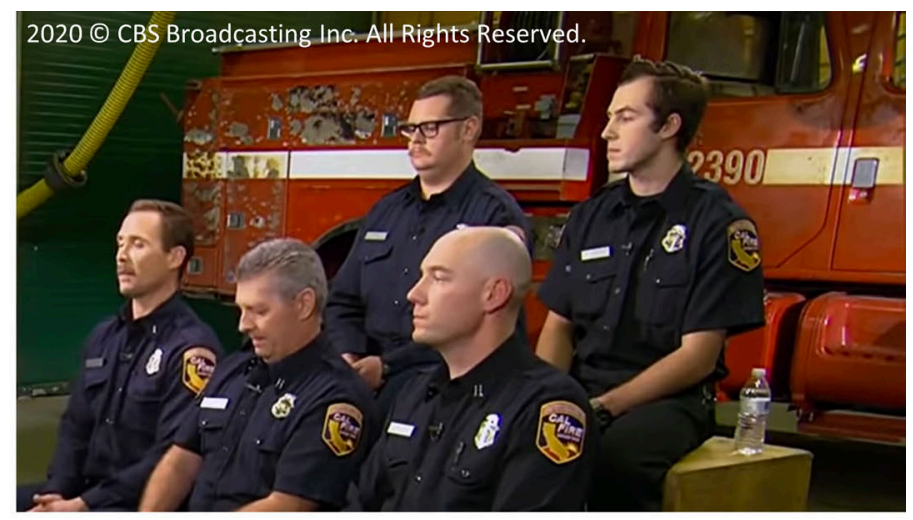

b)

Figure 15. a) An unidentified engine in a photograph from TD-041 matches scorch marks on E2390 seen in b) an interview on 60 Minutes.

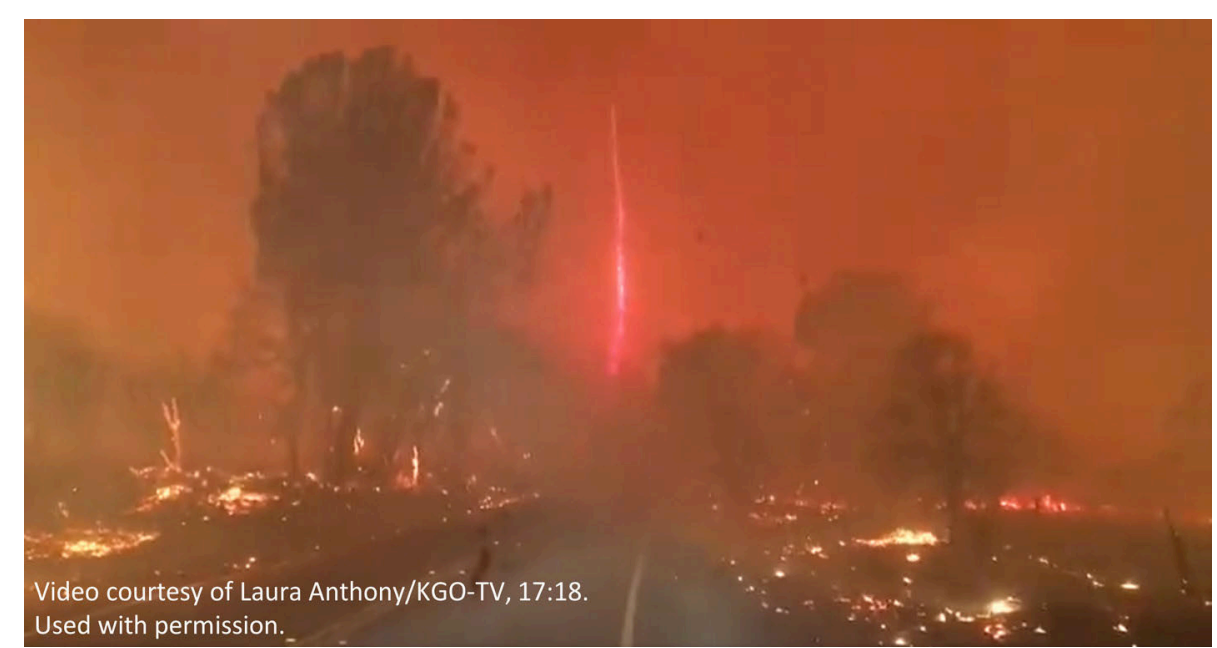

Figure 16. TD-106 described a fire whirl as they were driving south on Neal Rd and mentioned that a news crew recorded the event. News reporter Laura Anthony/KGO-TV captured a video of the event at 17:18, and the location was confirmed using Google Street View imagery.

Table 8 is an example of the type of data that was extracted at the completion of the data integration and documentation effort. The table includes a time summary of the events on Clark Road, one of the four primary egress arteries from Paradise. The road was temporarily closed due to fire exposures during the Camp Fire evacuations. Events are listed in the order of time when they occurred, with the column "Source" listing the primary source of data. The yellow highlighted cells represent data relevant to traffic control actions by first responders and red highlighted cells represent road closures due to fire activity. Traffic and evacuation data will be analyzed in NIST Camp Fire Report \#4 and the defensive actions will be analyzed in NIST Camp Fire Report \#5. 
Table 8. Excerpt of preliminary data along Clark Rd (yellow=traffic direction actions by first responders, red=road closure due to fire activity).

\begin{tabular}{|c|c|}
\hline Time & Event $^{\mathrm{a}}$ \\
\hline 08:45 & Clark Rd at Wagstaff $\mathrm{Rd}$ is gridlocked. \\
\hline 08:53 & Clark Rd is fouled up along the entire length. \\
\hline 08:59 & Clark Rd south of Pearson Rd is normal traffic. \\
\hline 08:59 & Traffic at Clark Rd and Pearson Rd is directed by PPD. \\
\hline 09:03 & Clark Rd southbound is bumper-to-bumper Pearson Rd to Wagstaff Rd. \\
\hline 09:09 & Clark Rd at Wagstaff Rd is completely blocked. \\
\hline 09:13 & Clark Rd and Wagstaff Rd is gridlocked. \\
\hline 09:19 & Clark Rd and Wagstaff Rd: people are beginning to drive southbound in northbound lanes. \\
\hline 09:23 & Clark Rd and Bille $\mathrm{Rd}$ is complete gridlock. \\
\hline 09:25 & Clark Rd and Skyway is jammed - traffic is driving down the bike path. \\
\hline 09:31 & Clark Rd is completely packed. All lanes are southbound at Nunneley Rd. \\
\hline 09:34 & There is need for additional traffic direction at Pearson Rd and Clark Rd. Get all lanes southbound. \\
\hline 09:47 & Clark Rd and Wagstaff Rd is still total gridlock. \\
\hline 09:55 & There is heavy traffic southbound on Clark Rd south of the airport. \\
\hline 10:02 & Fire is burning the west side of Clark Rd at American Way. \\
\hline 10:06 & Traffic is backed up, 5 lanes southbound on Clark Rd. \\
\hline 10:15 & $\begin{array}{l}\text { Clark Rd south of Pearson Rd is one lane southbound, bumper-to-bumper the whole way from } \\
\text { Durham-Pentz Rd. }\end{array}$ \\
\hline 10:18 & $\begin{array}{l}\text { Need to detour Buschmann Rd over to Skyway; no more traffic southbound on Clark Rd [due to } \\
\text { fire]. }\end{array}$ \\
\hline 10:25 & Gridlock is freed at Clark Rd and Wagstaff Rd and traffic is flowing all lanes southbound. \\
\hline 10:27 & Clark Rd southbound is closed. \\
\hline $10: 32$ & There is no traffic southbound on Clark Rd beyond Buschmann Rd. \\
\hline $10: 46$ & First responders are reopening one lane on Clark Rd for southbound. \\
\hline 10:51 & Repeat: one lane is open southbound on Clark Rd. \\
\hline 10:56 & Traffic is locked up at Elliott Rd and Clark Rd. \\
\hline 11:00 & Trying to get all lanes southbound at Elliott Rd. \\
\hline $11: 12$ & Firefighters are turning around southbound vehicles on Clark Rd at American Way due to fire. \\
\hline $11: 18$ & Clark Rd northbound at Skyway is blocked. \\
\hline $11: 22$ & There is no traffic on Clark Rd between Elliott Rd and Bille Rd. \\
\hline $11: 23$ & Most traffic on Clark Rd has made it south of Nunneley Rd. \\
\hline $11: 30$ & Arriving engines must stop and wait for fire to clear Clark Rd, at Airport Rd and at American Way. \\
\hline $11: 32$ & $\begin{array}{l}\text { Fire is burning really close to Clark Rd. Need to divert vehicles on Buschmann Rd north and south } \\
\text { on Foster Rd to clear backup. }\end{array}$ \\
\hline $11: 33$ & $\begin{array}{l}\text { Skyway at Bille Rd is jammed and backed up on Bille Rd. Vehicles are being turned around back } \\
\text { toward Clark Rd. }\end{array}$ \\
\hline
\end{tabular}




\begin{tabular}{ll}
\hline Time & Event $^{\text {a }}$ \\
\hline 11:35 & Civilians begin abandoning vehicles at Skyway and Clark Rd. \\
11:36 & There is no traffic at Clark Rd and Elliott Rd. \\
11:42 & A steady stream of cars (one by one) is heading southbound on Clark Rd at Central Park Dr. \\
11:44 & $\begin{array}{l}\text { Fire officials are about to start sending vehicles trapped at Bille Rd/Pentz Rd into Kmart parking lot } \\
\text { 11:45 }\end{array}$ No vehicles are travelling on Clark Rd at Wagstaff Rd. \\
11:53 & Clark Rd south of Buschmann Rd is clearly engulfed in flames. \\
11:57 & Intense fire cuts off Clark Rd at Fire Station 35. Powerlines are falling. \\
12:26 & Clark Rd is passable from Pearson Rd to the south past the airport. \\
12:26 & Reroute Pearson Rd traffic back down Clark Rd. \\
12:26 & Heavy fire at Central Park Dr and Clark Rd. \\
12:28 & Zero visibility at Clark Rd and Pearson Rd. \\
13:45 & Clark Rd is clear of traffic. \\
15:40 & All traffic has cleared out. There are no cars on Pearson Rd or Clark Rd or Skyway. \\
\hline
\end{tabular}

${ }^{a}$ Observations related to evacuation and traffic have not yet been quality controlled or cross-referenced as have been the fire observations detailed in this report. They are provided as-is and are subject to revision.

This type of data enables the reconstruction of the event in terms of fire progression, evacuation (traffic/gridlock information, burnovers, Temporary Refuge Areas (TRAs)), and defensive actions.

\subsubsection{Quality Control}

Technical discussion notes and maps were entered into the Primary Database in chronological sequence, along with the location of each observation. This was accomplished by keeping track of time, including reported actions or meetings with other first responders and accounting for drive times as needed. All available data sources were used to crossreference with other actions and observations in time and in space. This was achieved by searching the database for key words or through visual analysis of mapped data to identify related data points.

The database captured the information collected during TDs and from other sources. In several cases, the data from the TD offered only a fraction of the event because of spatial situational awareness during the event. Because of this, data integration required an in-depth understanding of the incident to allow consistent and repeatable utilization of the data. An example is provided to illustrate this. Data collected from PPD video on Pentz Road indicated that there was "no access to Pearson Road" at a specific time without making any mention of the reason. Additional information in the database confirmed that intense fire was burning on Pearson Road at that same time. These separate pieces of information, when used together, provided a clearer picture of the events that took place at that location and time.

The quality control methodology was aimed at capturing spatial and temporal errors. The visualization of the data enabled the identification of spatial errors. An example is provided 
in Section 7.5.4, Potential TD Errors. The TDs were checked for continuity in location and time using geographic information systems (GIS). Spatial discontinuities were identified and resolved by mapping each data point. The data was then animated in GIS based on the time of observation and visualized sequentially. The animation of the data enabled temporal quality control on the data. As an example, TD-034 reported "fire approaching the area" near Bushman at 11:00 $\pm 15 \mathrm{~min}$. Based on the timeline visualization TD-065 reported fire in the same area at 10:45. The GIS animation was used to identify the discontinuity and the TD-034 time was adjusted to 10:45, which fell within its original time window.

Quality control also included the cross refencing of TD information with other data sources to confirm the event location, time, or both. An example is provided here to illustrate the methodology. During TD-207, the first responder described a defensive action on a structure on Joplin Court in Magalia where the "deck had caught fire." This was captured in the TD map as 207-24; however, the precise structure out of the three structures circled was not known. Figure 17 shows a zoomed-in portion of the annotated map from TD-207. The DINS data, including a photo of the damaged structure, was used to confirm the TD-207 statement and identify the structure with the burned deck.

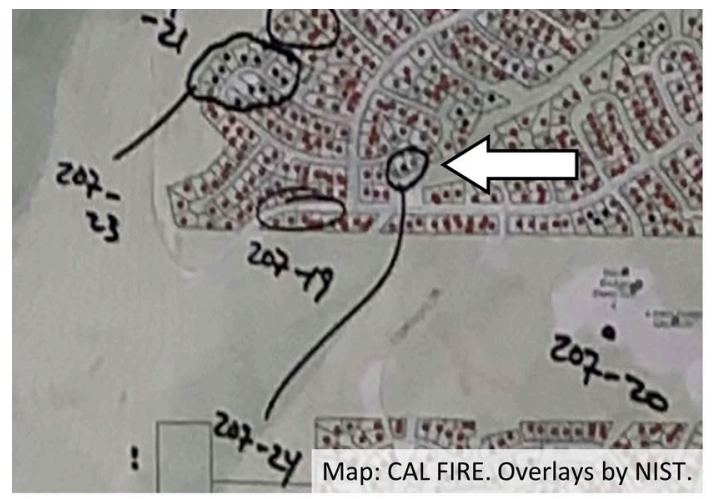

a)

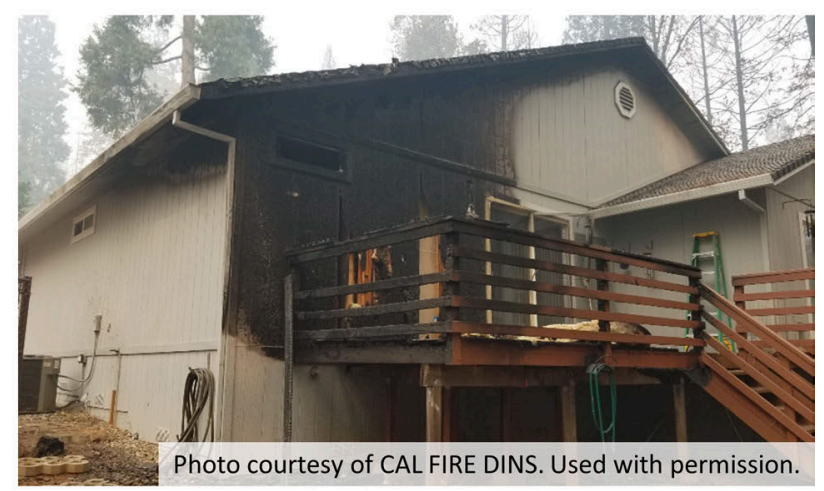

b)

Figure 17. Cross-referencing TD and DINS data; a) section of TD-207 map indicating a defended structure marked as 207-24 b) DINS image confirming the identification of the described structure.

Two examples illustrate the use of satellite imagery. A virtual TD (VTD) video source observed a distinct smoke column rising from the canyon beyond some trees. The original point was assigned an estimated location based on the video. The video was taken at the same time as a multispectral image of the fire was taken by the Landsat satellite, highlighting the active fire perimeter [51]. Cross-referencing with the Landsat imagery adjusted the location of the original point estimated from the video by $300 \mathrm{~m}$ to correspond with the Landsat-observed spot fire (Figure 18). In a second case, the Landsat perimeter was compared to video observation on Skyway at the southwest head of the fire. In this case, the Landsat perimeter was within $60 \mathrm{~m}(200 \mathrm{ft})$ of the video-recorded direct observation of the fire. A broader comparison of the Landsat perimeter and the collected data can be seen in Map 6, which includes all data points between 10:00 and 11:00, including the Landsat observation at 10:45. 


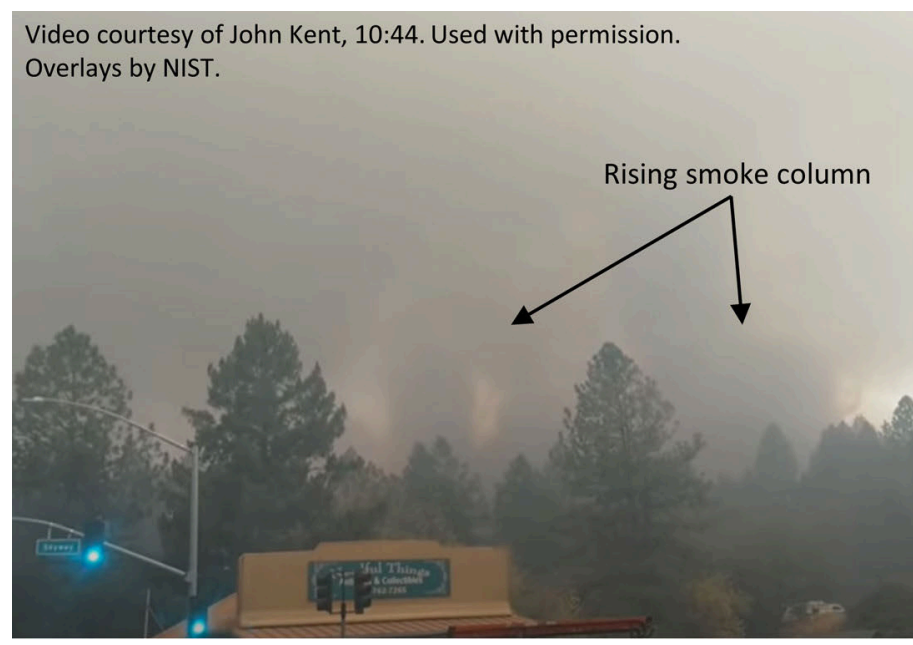

a)
Elevation: USGS | Fire Perimeter: NASA Imagery, NIST Overlay $300 \mathrm{~m}$ Roads, Water: U.S. Census Bureau TIGER/Line Shapefile $300 \mathrm{~m}$ Map and overlays by NIST

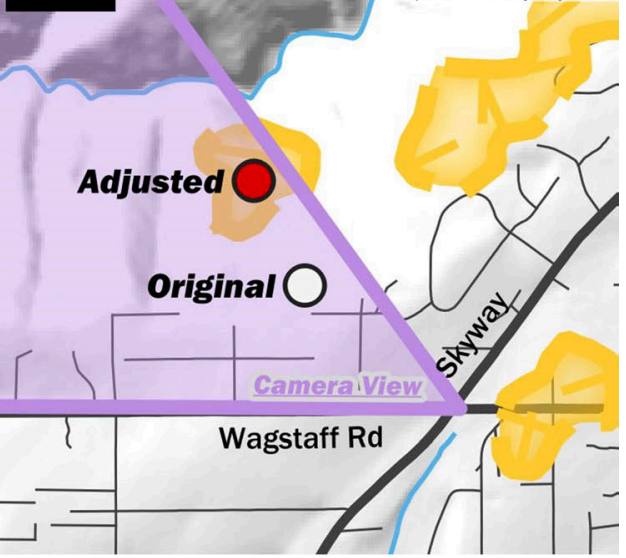

b)

Figure 18. An example of cross-referencing: a) video data shows a rising smoke column. b) Landsat data used in the quality control process identified an adjustment of $300 \mathrm{~m}$ to the original placement of the spot fire observation.

\subsubsection{Potential TD Errors}

There are four different types of errors that could occur during TDs as well during the data transfer process into the primary database: temporal, spatial, narration transcription, and coordinate transcription errors.

\section{Temporal Errors}

These errors occurred when a TD participant confused the sequencing of events. The tools identified in Table 5 were used during and after the TD to help identify a number of these errors. There were cases, however, where there were no usable "time hooks" to anchor the $\mathrm{TD}$, and large time windows represented several observations or actions that could not be further pinpointed in time. In these cases, the observation time was assigned the entire time window in which it could have occurred.

\section{Spatial Errors}

Misplaced information on the TD maps could result from marking the wrong place (by the TD Lead), from misreading the map (by TD participants), or from getting the location of the event wrong (by TD participants). The documentation and descriptions within the TD were used to identify and rectify this type of error. However, there were cases where there was only a single observer of an event/action at a specific location, meaning that errors might be introduced that could not be tracked and rectified. The tracking and cross-referencing of events during database assembly was intended specifically to reduce the occurrence of these potential errors.

Another potential spatial error source resulted from the difficulty of precisely estimating spot fire areas while in the field. This problem was confounded when rapidly burning fires moved through light fuels. The following example illustrates this. A spot fire that began in the field 
at Merrill Road and Pentz Road was reported by two different first responders at 08:16 and 08:21. The first observation described a one-acre fire, and the second report, five minutes later, was of a half-acre fire. While estimate uncertainty was a possible explanation, it was also possible that the flaming area or its visibility decreased over the span of five minutes, with the result that the fire appeared to be smaller at the later time. More information would be required to reconcile these two statements. The same issue was a problem for larger spot fires seen from a distance.

\section{Narration Transcription Errors}

Narration transcription errors were a possibility. This issue was addressed by having more than one experienced scribe taking notes during the TDs. Data collection for the previous NIST studies had identified that three is the optimal number of TD scribes. While several TDs were conducted with two scribes, it also should be noted that one scribe was insufficient to capture all the information provided by TD participants. An experienced scribe who had also participated in the field reconnaissance and data collection activities had a better awareness of the locations and could capture TD information more reliably than a person who was unfamiliar with the locations and streets described during the TD.

\section{Coordinate Transcription Errors}

The data documented on the E-size maps was transcribed into the primary database. Geolocation tools, including Google Earth, Google Maps, Bing Maps, and ArcGIS Online, were used to get the coordinates for the identified point. ${ }^{10}$ A number of these tools permitted a seamless "cut-and-paste" of the coordinates while some required manual input, which could result in transcription errors. The visual data integration as part of the Quality Control process could identify this type of error. Figure 19 illustrates a transcription error identified during the quality control process. The erroneous point location was identified as an outlier on the map and the associated note indicated the data point corresponded to 6166 Clark Road in Paradise, $21 \mathrm{~km}(13 \mathrm{mi})$ to the west. The arrow illustrates the transcription error in longitude, in this case $121.360^{\circ} \mathrm{W}$ was initially recorded instead of $121.603^{\circ} \mathrm{W}$.

\footnotetext{
${ }^{10}$ Certain commercial entities, equipment, or materials may be identified in this document in order to describe an experimental procedure or concept adequately. Such identification is not intended to imply recommendation or endorsement by the National Institute of Standards and Technology, nor is it intended to imply that the entities, materials, or equipment are necessarily the best available for the purpose.
} 


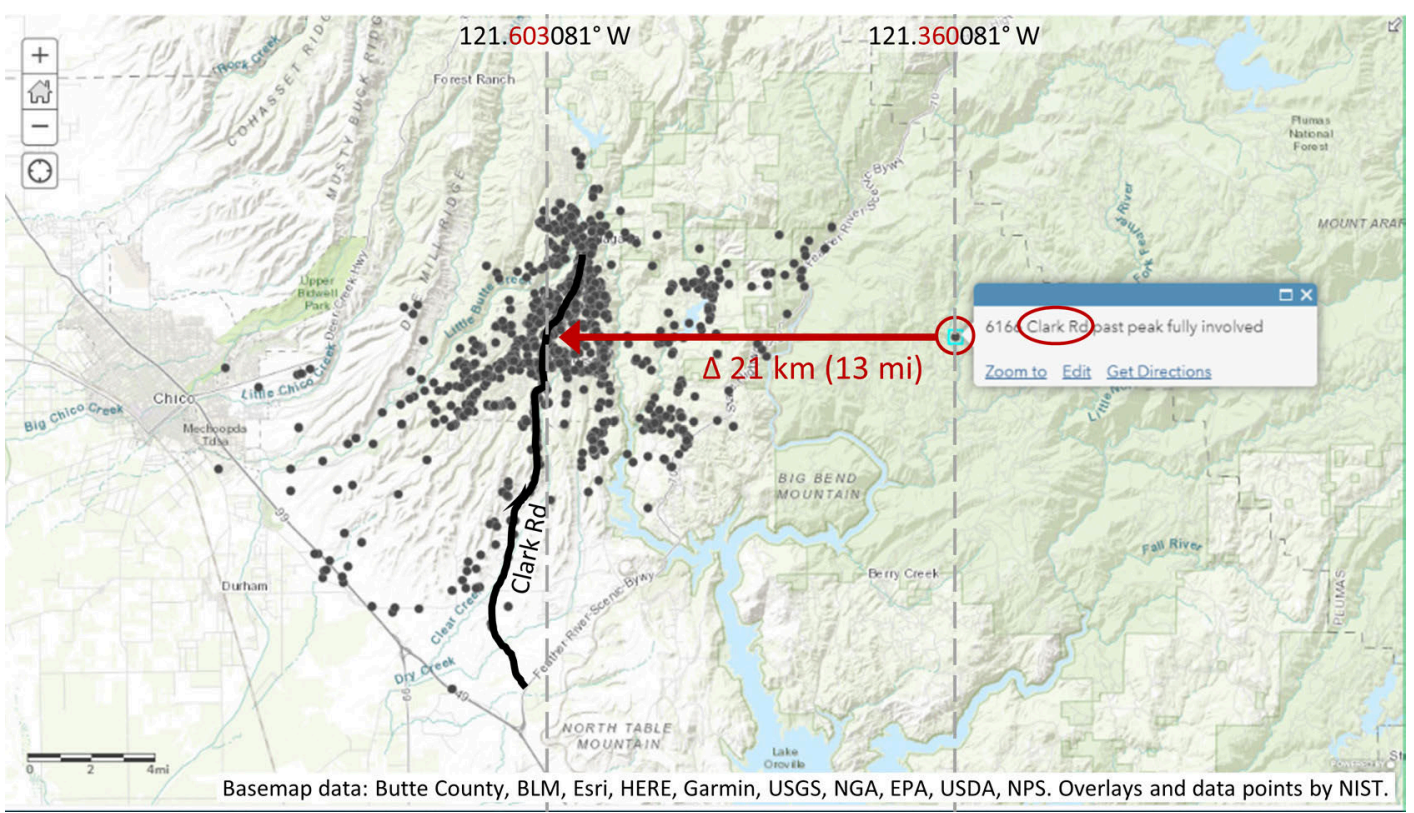

Figure 19. Example of a longitude coordinate transcription error identified during the quality control process.

\subsubsection{Spatiotemporal Uncertainties}

There is a range of spatial and temporal uncertainties within the data. AVL and geolocated/time-stamped images ${ }^{11}$ provided very precise statements about the event. Although many images may be geotagged by cameras or cell phones, care was needed to ensure that an accurate location was recorded, especially in difficult terrain and smoky conditions. All photos used in this study were individually re-geotagged to precise locations based on the contents of the photos. Some photos provided from the TD participants were not geotagged and were not descriptive enough to deduce the location; information from such photos was not captured in the datasets.

Radio log data could also be very precise; however, sometimes statements by Division Supervisors and other ICS personnel were more general in nature. Defensive actions conveyed to the NIST data collection team by Division Supervisors and Strike Team Leaders (STLs) were often longer or shorter than what was reported. ${ }^{12}$ Cross referencing of these defensive actions was used when available to further refine the temporal component of the statement.

TDs without AVL or accompanying photos had the widest range of temporal and spatial uncertainties of all the data collected. By utilizing the methodology described in Section 7.5.1, the TD observations could be refined in space and time.

\footnotetext{
${ }^{11}$ All images were from cell phones or body/dashboard cameras with accurate times. A few images were copies with altered time and date and were adjusted if possible, otherwise they were not included in the dataset.

${ }^{12}$ This is because the Division Supervisors and STLs frequently travelled between resources and surrounding areas to maintain situational awareness.
} 
Table 9 lists the range of uncertainties that were expected within the different data types. Overall, Type B evaluation of uncertainties [52] was implemented based on scientific judgment, review of visual data, and the recording intervals of timestamped data. Further discussion about the variable uncertainties related to TD observations follows.

Table 9. Uncertainty ranges of various data sources.

\begin{tabular}{llcc}
\hline Data Source & Data Attributes & $\begin{array}{c}\text { Temporal } \\
\text { Uncertainty }\end{array}$ & $\begin{array}{c}\text { Spatial } \\
\text { Uncertainty }\end{array}$ \\
\hline Picture/video & $\begin{array}{l}\text { Geolocated } \\
\text { Timestamped }\end{array}$ & $\pm 1 \mathrm{~min}$ & $\pm 5 \mathrm{~m}$ \\
AVL position & $\begin{array}{l}\text { Geolocated } \\
\text { Timestamped }\end{array}$ & $\pm 1 \mathrm{~min}$ & $\pm 10 \mathrm{~m}$ \\
Radio log (fire or PPD) & $\begin{array}{l}\text { Variable location } \\
\text { Timestamped }\end{array}$ & $\pm 1 \mathrm{~min}-$ & $\pm 0 \mathrm{~m}-$ \\
Picture/video & Geolocated & $\pm 1 \mathrm{~min}-$ & Variable \\
TD observation & No timestamp & Variable & $\pm 5 \mathrm{~m}$ \\
TD Inferred time & Location estimated & Variable & Variable \\
DINS Post Fire Damage Pictures & Gime estimated & Variable & $\mathrm{n} / \mathrm{a}$ \\
NIST Post-fire Pictures & Gime estimated & $\mathrm{n} / \mathrm{a}{ }^{\mathrm{a}}$ & $\begin{array}{c}\text { Linked to } \\
\text { structure }\end{array}$ \\
Drone and Satellite Imagery & Geolocated & $\mathrm{n} / \mathrm{a}$ & $\pm 5 \mathrm{~m}$ \\
\hline
\end{tabular}

${ }^{\text {a }}$ Data without temporal information (such as DINS, drone, and NIST post fire images) were used as supplemental information to cross-reference and confirm events in time.

${ }^{b}$ For a limited area on the west edge of fire east of Chico, there was an imagery "stitching" offset.

\subsubsection{Temporal uncertainty of all observations}

The observations with a temporal window fell into two distinct categories. They either encompassed a general action, such as "we were parked here for two hours and during that time defended these five structures," or they described a more specific action such as "we defended this one house for two hours." In the first case, the different structures were defended sometime within the time window without specification of individual duration or sequence, whereas in the second case the action took place over the entirety of the duration.

Large temporal windows were common for locations where the density of first responders was low. This was typical in low population density areas or wildland areas that were not critical to evacuation, life safety, or the containment of the fire. One example was a statement from the heel of the fire, near Pulga, where fire jumped onto the east side of Highway 70. The collected data placed the event between 12:35 and 23:30. The large window was associated with the limited available data. In this case there were a limited number of firefighters in the area and limited anchor points to narrow down the event time window. The 11 hour time window was an outlier in the dataset; typical time windows and uncertainties are provided in Table 9 and Section 7.6, Data Summary Statistics. 
The time of a photo without a timestamp was often determined by the content of the photo. The content could set the photo at a specific time, such as with AVL positioning of a visible apparatus, or could be set within a time window of possibility. Therefore, these data sources had variable time uncertainties.

Another source of temporal uncertainty was associated with defensive actions performed by residents who stayed behind and defended their property. Specific actions have not been systematically collected from the public in this study; instead, information about civilian structure defense was determined through TDs and VTDs in which such actions were observed. Therefore, to address this temporal issue, generalized defensive actions by civilians (e.g. "a resident defended this property") were listed with a time window extending all day unless more specific details were known to narrow down the time of the action. While not time-resolved, the location and action were known; the fact that a structure was defended provided critical information to understanding structure survival.

Some times were noted as "inferred" times. While this indicated that a time was not stated or identified for a particular observation, there was data supporting the time window. For example, an observation or sequence of events might be provided in a TD or VTD without a specific time. By identifying cross-references, time windows could be determined for these other observations. Another example was the refinement of a time window by approximating travel time between two known locations. These inferred times may have uncertainties similar to AVL times or videos, which were very precise, or may span larger time windows like some TD-provided time estimates.

\subsubsection{Geolocation uncertainty of fire observations}

TDs provided information on operations, fire behavior, and the presence of fire. Fire observations included information on spot fires, building fires, vegetation fires, and fire line extent and location. The information was provided verbally during the TD, and the TD map was annotated as described in Section 7.3. TD statements about evacuation, notification, and traffic will be further discussed in NIST Camp Fire Report \#4. TD statements about defensive actions will be further discussed in NIST Camp Fire Report \#5.

TD statements on fire observations and their associated TD map locations were associated with a broad range of spatial uncertainties determined by a combination of data crossreferencing and engineering judgment, as described below.

\section{Spot Fires}

Spot fires fell into two categories: spot fires in developed areas and spot fires in the wildlands. Spot fires sometimes involved auxiliary structures such as fences or sheds and could also include vegetation. In town, streets and other landmarks were typically used to locate the spot fire, and frequently there was more than one observation. Early on during the incident (before 10:00 on November 8), spot fire information from first responders was frequently also reported by civilians via 911 calls before or during their evacuation. Spot fires in town were estimated to be within $15 \mathrm{~m}$ to $45 \mathrm{~m}$ ( $50 \mathrm{ft}$ to $150 \mathrm{ft}$ ) of their actual location. For the wildland spot fires, the spatial uncertainly was estimated at $0.1 \mathrm{~km}$ to $0.5 \mathrm{~km}(0.06 \mathrm{mi}$ to $0.3 \mathrm{mi})$. The observations of spot fires in limited access locations were 
associated with increased uncertainties, as were the size estimates for spot fires. An example was provided in Figure 18 in Section 7.5.3, demonstrating the use of different data sources to reduce the spatial uncertainty of a spot fire in wildland fuels.

\section{Structure Fires}

Structure fires included both residential and commercial structures. These two categories are further subdivided in the timeline fire progression maps in Section 10. Building fires, like spot fires in town, were typically very precisely geolocated. When commercial buildings were involved, there was little ambiguity about the exact building. When residential buildings were involved, there was sometimes uncertainty about the precise building on a cul-de-sac or block of a street. Multiple tools were used to identify the specific building; in the majority of cases this was accomplished successfully. An example of this was shown in Figure 17 in Section 7.5.3. The estimated spatial uncertainty for structure fires ranged from $0 \mathrm{~m}$ to $45 \mathrm{~m}(0 \mathrm{ft}$ to $150 \mathrm{ft})$.

\section{Vegetation Fires}

Vegetation fires encompassed specific statements about fire activity in ornamental or wildland vegetation and specifically did not include any burning of structures (auxiliary, residential or commercial). Like spot fires, vegetation fires fell into two categories: fires in developed areas and fires in the wildlands. In the wildlands, this category described the fire location. In developed areas, observations were categorized as vegetation fires only if the description was specifically limited to vegetative fuels. Spatial uncertainties for vegetation fires were similar to those for spot fires. In developed areas, the spatial uncertainty range was estimated to be within $15 \mathrm{~m}$ to $45 \mathrm{~m}(50 \mathrm{ft}$ to $150 \mathrm{ft})$ of their actual location. For wildland vegetation fires, the spatial uncertainty was estimated to be $0.1 \mathrm{~km}$ to $0.5 \mathrm{~km}(0.06 \mathrm{mi}$ to $0.3 \mathrm{mi})$.

\section{Other Fires}

Fires included in this category encompassed fire activity that was not explicitly listed as spot fire, vegetation fire or building fire (commercial or residential). These included statements like "Fire reached the east side of Clark between Pearson and Elliott," or "there is fire behind the Ace Hardware." A range of spatial uncertainties was associated with these fire observations. In this category, there was no distinct difference between "in town" and "in the wildlands". If the observation was described as occurring across a spatial range, the location used was the geographic center of the observation area. The annotated TD maps were used along with other data sources to refine the location if possible. Spatial uncertainty for other fires was estimated to be $0.1 \mathrm{~km}$ to $0.5 \mathrm{~km}(0.06 \mathrm{mi}$ to $0.3 \mathrm{mi})$.

\subsection{Data Summary Statistics}

As described in the sections above, multiple databases were developed for different sources of data. Sources included TDs, of which nominally one-third were supplemented with photos/videos, VTDs from civilian videos and other news sources, dashboard camera recordings from the Paradise Police Department, and 911 call recordings. Combined, these sources yielded 2260 fire observation data points. Thousands of additional observations 
related to evacuation/emergency notification and defensive actions will be detailed in subsequent reports.

The distribution of data sources is shown in Figure 20. Technical discussions comprise a majority of the database, contributing $59 \%$ of all fire observations. Accompanying photos and videos from TD participants yielded $21 \%$ of the data, plus $8 \%$ of fire observations from PPD video recording. Contributing $6 \%$ of the observations each, 911 calls and VTDs proved tremendously valuable. The 911 calls that were included in this case study were all made before 09:30 and described the early stages of the fire. VTDs provided additional information from a civilian perspective, sometimes providing information from locations otherwise not covered by other data sources, or by providing supplementary information and context to first responder observations.

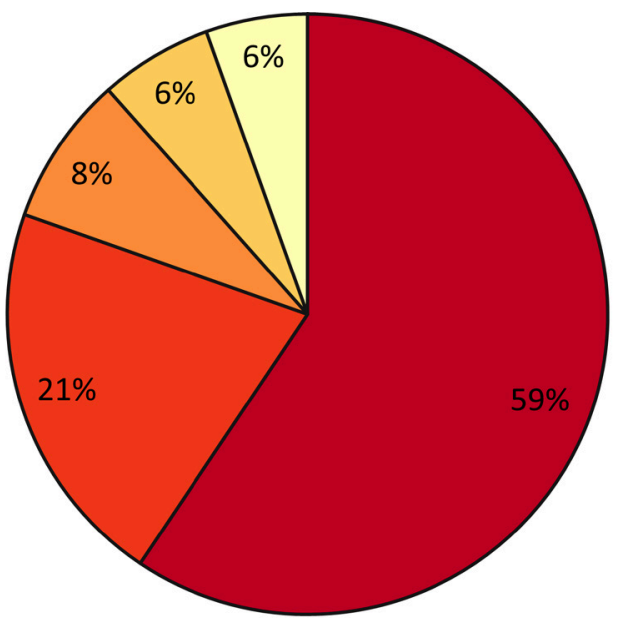

TD $\square$ TD Photo/Video $\square$ PPD Video $\square$ VTD $\square 911$

Figure 20. Distribution of fire observation data sources.

Figure 21 plots the cumulative fraction of fire observations as a function of time of day (hours greater than 24 indicate time on November 9, e.g., 25 is 01:00). This plot indicates how quickly fire overtook the town, with over $80 \%$ of recorded fire observations occurring before 18:00, within the first 12 hours of the incident. Steeper portions of the line indicate more frequent observations, notably from 08:00 to 09:00 and from 13:30 to 14:30. The earlier window, 08:00 to 09:00, is characterized by a rapid increase in fire activity and a large number of resources (i.e., TD participants) arriving to the scene. The afternoon increase can be attributed to fire activity along Clark Road and northern Skyway. After a relative lull from 18:00 to 24:00, another smaller increase is seen from 24:00 to 26:00 (00:00 to 02:00 on November 9) as fire activity increased in Magalia.

Figure 21 also illustrates the distribution of time sources for each observation. Note that $71 \%$ of observations were placed in time using cross-referenced timestamps, including photos or videos, AVL, radio log transcriptions, or 911 calls. The inferred times were usually also well-defined in time and were often similarly linked to cross-referenced times. 
Time resolution of the observations was very precise. Sixty-three percent of the observations were known within a zero- or one-minute observation window. This does not necessarily indicate that a majority of the observations were instantaneous; the observations often related to conditions that existed before and/or after the particular observation. Eighty percent of the observations were bounded within a 30 -minute period.

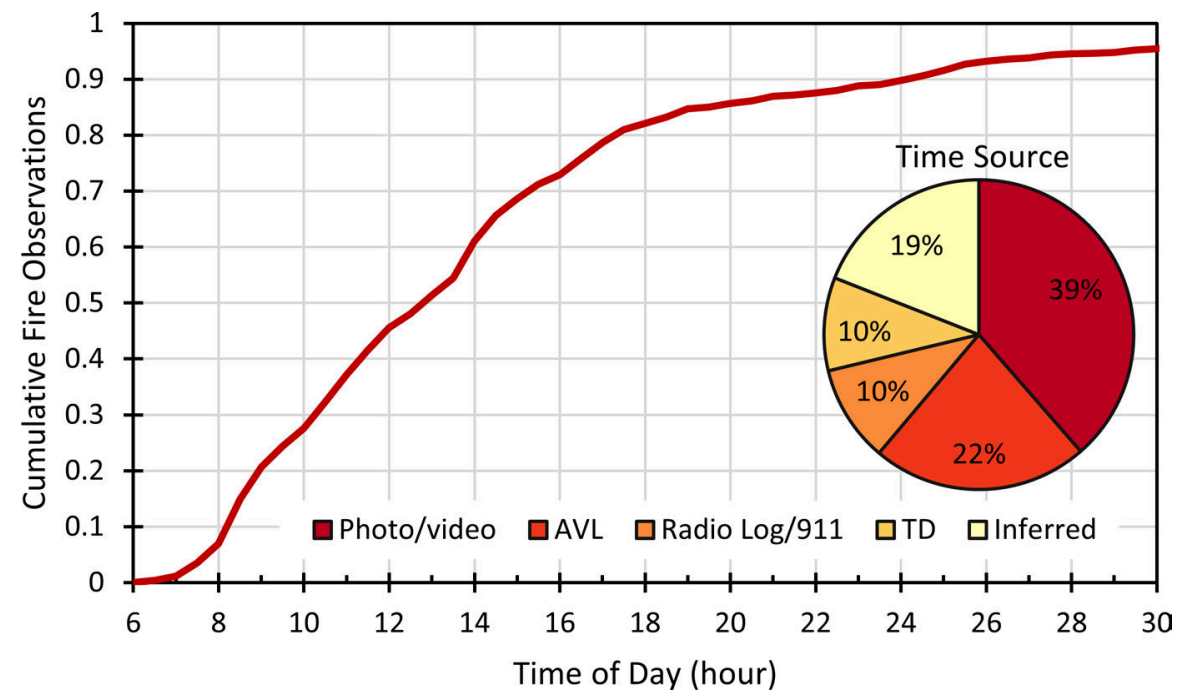

Figure 21. Cumulative fraction of fire observations as a function of time (hours greater than 24:00 correspond to November 9) and distribution of time source for fire observations. 


\title{
8. Incident Commander Overview for November 8, 2018
}

An incident timeline from the perspective of the Incident Commander (IC) is presented in Table 10. The summary contains the transcribed notes from the technical discussion with the Camp Fire IC, in which he described the first 18 hours after ignition. The bulk of observations were made between ignition at 06:30 and 09:00, illustrating the rapid development of the fire. Beyond this time period, the scope of the incident expanded dramatically. Rows are shaded gray and white to visually separate each hour. Italics are explanations of specific points/events and italics in blue are additional key events related to evacuation that were determined during the fire timeline reconstruction. The table contains the original transcription of the TD, including thoughts of the IC and snippets of radio communications, to provide a brief introduction to the incident timeline, which will be described in further detail in the following sections. The notes also provide insight to the situational awareness challenges presented to the IC.

Table 10. Incident Commander Technical Discussion.

\author{
IC Technical Discussion \\ 06:31 First dispatch by/under power lines, dispatch B2118, P2121, T2107, E2176, E2161, E2167, E2186, \\ E2182, E2162, Company 67, WT37, WT67, TD2140, TD2142, BFC2, BFC3. These were all sent up \\ to NOPS. \\ 06:44 First engine confirms fire off Camp Creek Road, $35 \mathrm{mi} / \mathrm{h}$ sustained wind. \\ 06:44 ECC places request for 15 additional engines, 4 dozers, 2 water tenders, and 4 strike teams of hand \\ crews. \\ 06:45 Received call at home. BC informed me of the incident. Cool morning $40^{\circ} \mathrm{F}$. Fire appears on Flea \\ Mountain camera. \\ 06:54 E2161 request a mandatory evacuation order for Pulga and stage resources at Scooters. \\ 06:55 ECC called BCSO and requested Mandatory Evacuation order for Pulga.
}

07:02 Duty Chief calls. IC send him to Concow.

07:10 Duty Chief calls back, reports flames visible from Hwy 149.

07:14 B2118 assumes IC.

07:21 Camp IC - "Pulga has been evacuated. If you could make notifications, request representative to Scooters. Have the Sheriff respond to Camelot area for evacuations."

07:22 Camp IC - "Request evacuation warning for the Concow area - working on exact area and warning/order."

07:22 ECC called BCSO requesting mandatory evacuation warning for Concow Immediately.

07:26 Camp IC - "shut down Hwy 70 and standby for resource order. Close Hwy 70 from Pentz to Belden."

07:30 Requests to early up all aircraft - Paradise burning not being considered at that time.

07:32 EVAC warning Pentz Rd west side.

07:33 Resource order for an additional 15 engine strike teams, 15 hand crew strike teams, 10 dozer strike teams, with appropriate overhead.

07:40 T2107 needs 5 engine strike teams on Hoffman Rd can't get ahold of Camp IC - request relay info.

07:44 ECC takes call at 1900 Drayer Dr/Pentz Rd reporting fire on the Paradise side of canyon - reporting 3 spots.

07:45 At ICP develop incident objectives, box it in: North of Hwy 70, east of Pentz, then west of Pulga and south of Empire Creek. Before objectives are announced on the radio, there are spot fires reported outside the box.

07:44 IC change over to new IC - for remainder of first day.

07:45 Camp IC - "We are extending the mandatory evac zone to east of Pentz Rd 3, 8, 14 and everything east of Pentz Rd and everything north of Hwy 70."

07:46 ECC calls BCSO requesting the above Evacuation Warning. Not thinking spot fires is a crazy issue, spot fires are normal. 


\section{IC Technical Discussion}

07:50 T2107 relaying 10 to 15 large spots on the backside of Sawmill Peak Jordan Hill Rd area currently. Consider putting Pentz zones in evacuation warning.

07:52 AA210: "Off Chico [Airport] showing about 1000 ac. Request a total of 6 tankers, 1 lead plane, 6 Type 1 helicopters. [Personnel] en route to Oroville Airport to setup Oroville Helibase. Have all rotary wing aircraft report to Oroville Airport."

08:01 Camp Air Attack (AA) via radio: "The fire is now in Paradise. You are going to have significant structure threat issues. About 2000 ac along Pentz Rd. Dangerous to Critical ROS" - well into Paradise Zones 2, 7 and Morgan Ridge.

Information on fire spread is coming in from 911 calls. Traditional information from fire fighters is broken because they are saving lives.

08:01 D2102 -CAMP IC going to evacuate orders - expand to Zone 2, 7, 13, Morgan Ridge. Everything west of that will be an evacuation warning.

08:02 ECC calls BCSO Immediate Mandatory Evacuations for all of Paradise.

08:02 Go into rescue mode.

08:07 60 civilians sheltered in creek and field, burn injuries, medivac request made.

Think Skyway could be line, don't give up fire control when evacs are done plan B is suppression.

08:15 FF report of new 10 ac fire in Paradise on Merrill Road, homes burning, wildfire response and 10 engines requested. Kids getting dropped off at Paradise Elementary School - FFs did not realize at the time that this was the Camp Fire.

08:15 Contacted Paradise CAL FIRE Chief and said: "evacuate the whole town." Chief replied, "you will break the system."

08:15 Camp IC - "ready to copy resource request...30 strike teams of engines, any type, immediate need, 10 strike teams of dozers, 10 strike teams of crews, 5 Dozer Bosses. That's on top of what's already been ordered."

08:16 Mandatory evacuations ordered (on the radio) for Zones 3, 2, 7, 8, 13, 14, Morgan Ridge, and Lower Pentz.

Main fire is still in Concow but not aware how fast and widespread spot fires were.

ECC called Town PD and instructed them to "evacuate the whole town." ECC calls Sheriff, Sheriff calls his dispatch and informs of evacuation - this was not the exact order from IC, but the town initiated a full evacuation to be conservative.

IC not getting much info, call volume $\sim 200$ calls/hour.

08:21 Multiple spot fires off Shay Ln and June Way area multiple structures threatened E82 assisting with evacuations.

08:25 Fire is at the Feather River Hospital, need to evacuate hospital, people are in surgery. Few resources in the area, coordinate air evacuation (helicopters are flying to move patients) with fire in the area.

08:30-10:00 First evacuation convoy of buses up to Paradise.

08:40 IC told LE to start contraflow all roads, except Clark and Neal, told engines responding that driving uphill to not push civilians off the road to go north, let evacuation happen, concede the town is burning - maintaining two way traffic was difficult.

08:42 Camp IC changes staging at Spring Valley School - improving staging and communications. Stayed in Spring Valley School briefly before moving to Butte College.

08:45 Camp AA - Information: fire progressed approx. halfway through Paradise. Picking up spot fires halfway through Paradise and spot fires in the community in Old Magalia with a threat to the lower end of Paradise Pines. Suggest also consider evacuation warnings in the Butte Creek Canyon area; it should be impacted in the next few hours. Clark Rd is currently a Warning. Do you recommend an Order. Camp AA suggest everything west of Steiffer Rd an Order - Decide to go all rescue, town is lost.

08:45 Camp IC (calls): orders no firefighting, all life safety and evacuation protection "save lives, keep evacuation moving."

08:49 Camp IC advises ECC new Evacuation Orders from Steiffer Rd to town limits. Evacuation Zones 2, 1, 4, 5, 5, 12, 11. Put Evac Warning Butte Creek Canyon/Centerville. BCSO is advised of the plan this is for PPD.

08:49 BCSO Officer radioed in the above Evacuation orders(s) on their frequency to their dispatch.

08:51 ECC calls PPD and advises them of the above Evacuation. 


\section{IC Technical Discussion}

08:53 Branch II advises IC that Pentz Rd is a parking lot. We cannot get engines up and down we need to get PPD in here or to start working on safe refuge zones. At the very least get one lane open for fire.

09:00-10:00 Reports begin coming in about evacuation routes being blocked, traffic is now a big issue, civilians with luggage etc. leaving vehicles even if not in immediate need. Vehicles blocking roads impacting evaluation and rescues.

09:14 E8332 lets ECC know fire is established in the Butte Creek Canyon while responding to Paradiseprobably approximate to Pearson Rd. (Butte Creek Canyon was under Evacuation Warning since 08:49) - first time IC hears about this spot fire.

$\sim 09: 30$ Power and gas disabled before this time.

09:30-10:00 Realize the intersection in Chico is jammed.

09:33 Camp IC -“... there is a handful of people trapped in the basement of FRH. Copy, right now the Hospital is secure. Actually, the safest place to be right now. Relay to PPD that we need to start sheltering people in place at the Hospital if we can to try evacuate clogging the road. We need to keep people in place the fire has moved past the hospital right now so it's the safest place."

09:40 Camp AA: $6000 \mathrm{ac}$, dangerous to critical rate of spread.

10:00 First Convoy back to Butte College [TD-057, TD-059, TD-046].

10:00 Second Convoy up to Paradise.

10:00-11:00 Calls of walking people, jammed roads. Hearing officer traffic of trapped officers, $12 \mathrm{LE}$ helicopters on the scene.

$\sim 10: 00$ ordered 50 ambulances and 10 medivac helicopters by phone.

11:21 About 1000 cars stuck up town due to stalled and abandoned vehicles. Rounding people up and setting up multiple TRAs up.

11:30 Water pressure issues start being reported.

12:00 Did not know how many structures were burned, just that there were a lot, maybe $\sim 1000$.

12:00-14:00 cell phone call to engage in critical infrastructure fires.

13:00 No water.

13:21 Third Convoy preparing to send BCSO and one small B-Line convoy with USFS engine escort up

Clark Rd-Convoy turned around because of fire blocking Clark Rd [TD-046, TD-054].

13:30 Second Convoy back to Butte College [TD-059].

14:49 Fourth Convoy up Clark to Paradise with BCSO buses [Radio log, IC].

$\sim 15: 38$ Fifth Convoy B-Line buses with Dozer and Engine escort up Skyway to Paradise and Magalia [BLine, IC].

16:06 Establish division for Butte Creek Canyon with 15 engines.

17:00-18:00 Wind pattern picked up again, wind shifts from $\mathrm{N}$ to $\mathrm{E}$.

18:50 Fire reaches Hwy 99.

Resources on way to ICP on Durham Pentz put out fire off the highway before checking in.

19:43 Fire reaches Stilson Canyon.

20:27 Fire reaches Hwy 149.

$\sim 21: 00$ Estimated 83000 ac.

21:08 Division in Butte Creek is overrun, 2 civilian fatalities, (civilians) fought with fire fighters - refusing to evacuate.

23:23 Fire activity begins increasing at Coutolenc Rd, Magalia Reservoir, then impacts Magalia structures. 
The information provided by the Camp Fire IC highlights the rapid development of the event and the need for having access to real-time situational awareness and fire location information. There is potentially a readily available data source of early fire spread information, namely early 911 reports. If this information could be geolocated and made available to the IC in real-time in a readily accessible format that could be displayed in an engine's or vehicle's mobile data system, this information would enhance the early situation assessment of the incident. 


\section{Fire Timeline Reconstruction}

A detailed summary of the reconstructed timeline and discussion of additional fire behavior findings are presented in this section. A progression map shown in Figure 22 presents a summary of the fire spread data over the first 24 hours of the Camp Fire. The final perimeter is indicated by the red outline. The extent of fire progression on the evening of November 9 is indicated by the yellow outline. While 12 hours beyond the extent of the data presented in this report, the evening perimeter on November 9 provides context to the outlying areas of the fire perimeter which burned over the course of the following two weeks. Arrows indicate primary spread directions identified from the fire observation data as the fire progressed from the origin northeast of Concow. Additional details, including the time and sequence of the fire spread, are provided in the following sections and tables, and detailed annotated fire progression maps are presented in Section 10.

Fire spread data collected and represented in this report were restricted by the number of first responder TDs (and VTDs) as well as the location of those individuals throughout the incident. TDs were not conducted with all fire personnel on scene, and fire spread data were not available for every location within the perimeter. However, the data collection process resulted in only a few major key events that were described by a single TD; most were crossreferenced and further supported by the collective dataset. Therefore, it is believed that the extent of the data collected is representative of the overall fire progression through the first 24 hours.

Additional findings include numerous times when fire burned over civilians and/or firefighters and when evacuation routes were blocked due to fire conditions. These events are presented in Section 9.3. The impact of winds, fuels, and terrain on fire behavior is discussed in Section 9.4. Comments about ground-level smoke and reduced visibility caused by the fire are offered in Section 9.5. 


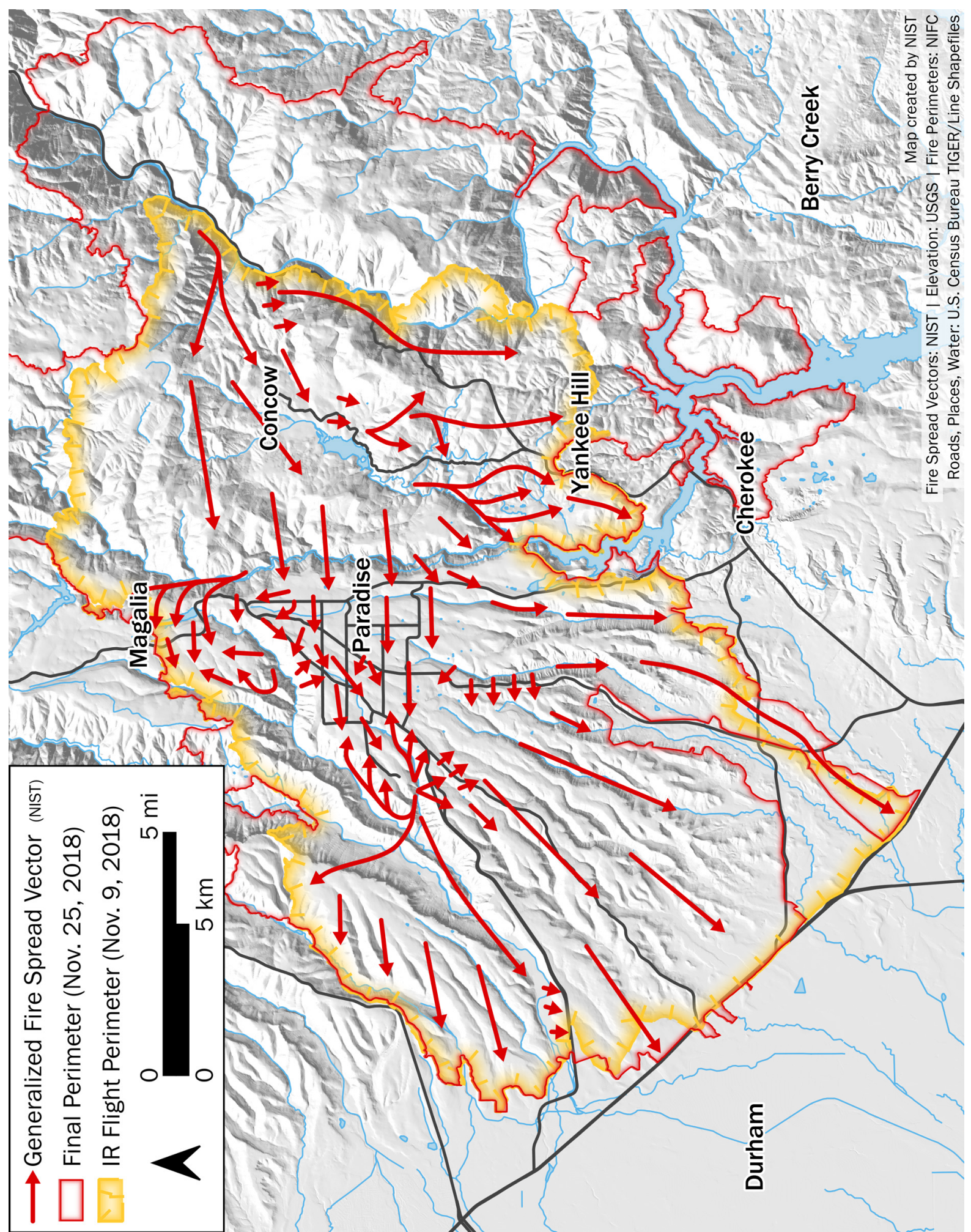

Figure 22. Generalized fire spread vector map indicating the direction of fire progression from the origin northeast of Concow. 


\subsection{Fire Progression}

Fire progression data is presented in three layers of detail. Due to the fire's large geographic area and multiple concurrent events, the data are divided into 15 geographic focus regions. A detailed summary of fire progression for each of the 15 regions is presented in this section. An abridged incident-wide summary can be found in Section 16.3 of the Summarized Technical Findings. Finally, all 2260 fire observations are listed in Appendix F.

The geographic focus areas are identified in Figure 23. They are presented in a semichronological order based on the time of day that significant fire occurred within each region; however, many of the observations were concurrent. In the sections detailing each focus region, fire activity is summarized and accompanied by a timeline table (Table 11 to Table 32). The data displayed in the Fire Progression Timeline tables are aimed at providing an overview of the event, using data excerpted and condensed from the full dataset.

Map 1, Camp Fire Points of Interest, labels roads and locations frequently referenced in this report. Map 1 also includes each geographic focus area. Maps illustrating the fire progression timeline are presented in Section 10 and include all the collected data points.

Toward the east, Section 9.1.1 covers the area for Concow, including the ignitions near Pulga. In Paradise, Pentz Road from Old Magalia to Kunkle Reservoir is presented in Section 9.1.2, which is further divided into five subsections. Feather River Hospital is described separately from its location on Pentz Road, is described in Section 9.1.3.

There are four Sections associated with the east-west traffic arteries in Paradise; Wagstaff Road (Section 9.1.4), Bille Road (Section 9.1.5), Elliot Road, also including Nunneley Road (Section 9.1.6), and Pearson Road (Section 9.1.7). Three subsections divide Clark Road between Skyway and Airport Road in Section 9.1.8. Skyway (Section 9.1.9) was also divided into multiple subsections between Coutolenc Road and the overlook at Lookout Point $3.2 \mathrm{~km}$ (2 mi) southwest of the town limits.

Neal Road, from Skyway to Goa Way, is summarized in Section 9.1.10. Butte Creek Canyon and Skyway south of Lookout Point all the way to Chico are covered in Section 9.1.11. In Paradise, neighborhoods off Valley View Drive are covered in Section 9.1.12. The Foothills, from Lookout Point, Airport Road, and Kunkle Reservoir south to Highways 99 and 70, are covered in Section 9.1.13. The area surrounding Nelson Bar Road and Highway 70 is documented in Section 9.1.14. To the north, Magalia and Coutolenc Road are covered by Section 9.1.15.

Observations are occasionally located at the intersection of two focus regions (e.g., Pearson Road and Skyway). In these cases, observations are listed in the data tables of both focus regions. This data is displayed in italics to facilitate locating it between tables to follow the progression. 
The data included in Table 11 to Table 32 list the start time and/or time range of the observation. If no end time is listed, the information collected was placed precisely in time. If both values are used, the observation took place within that window. ${ }^{13}$ Times in the tables were rounded to $5 \mathrm{~min}$ windows for ease of dissemination. The timeline tables also include a general description of the location as well as the identification of the contributing sources. Appendix F contains additional information, including the precise observation times and geographic coordinates, along with time and location source information. The fire spread information in this section and in Appendix F represents all the fire observation data collected during the Camp Fire reconstruction; however, the data does not include all fire activity that occurred within the fire perimeter. The observations of surface/ground level winds were included when available.

Temporary Refuge Areas (TRAs), together with traffic and evacuation data, findings, and recommendations, will be presented in NIST Camp Fire Report \#4. Defensive actions and findings from the NIST documented damaged structures will be addressed in NIST Camp Fire Report \#5.

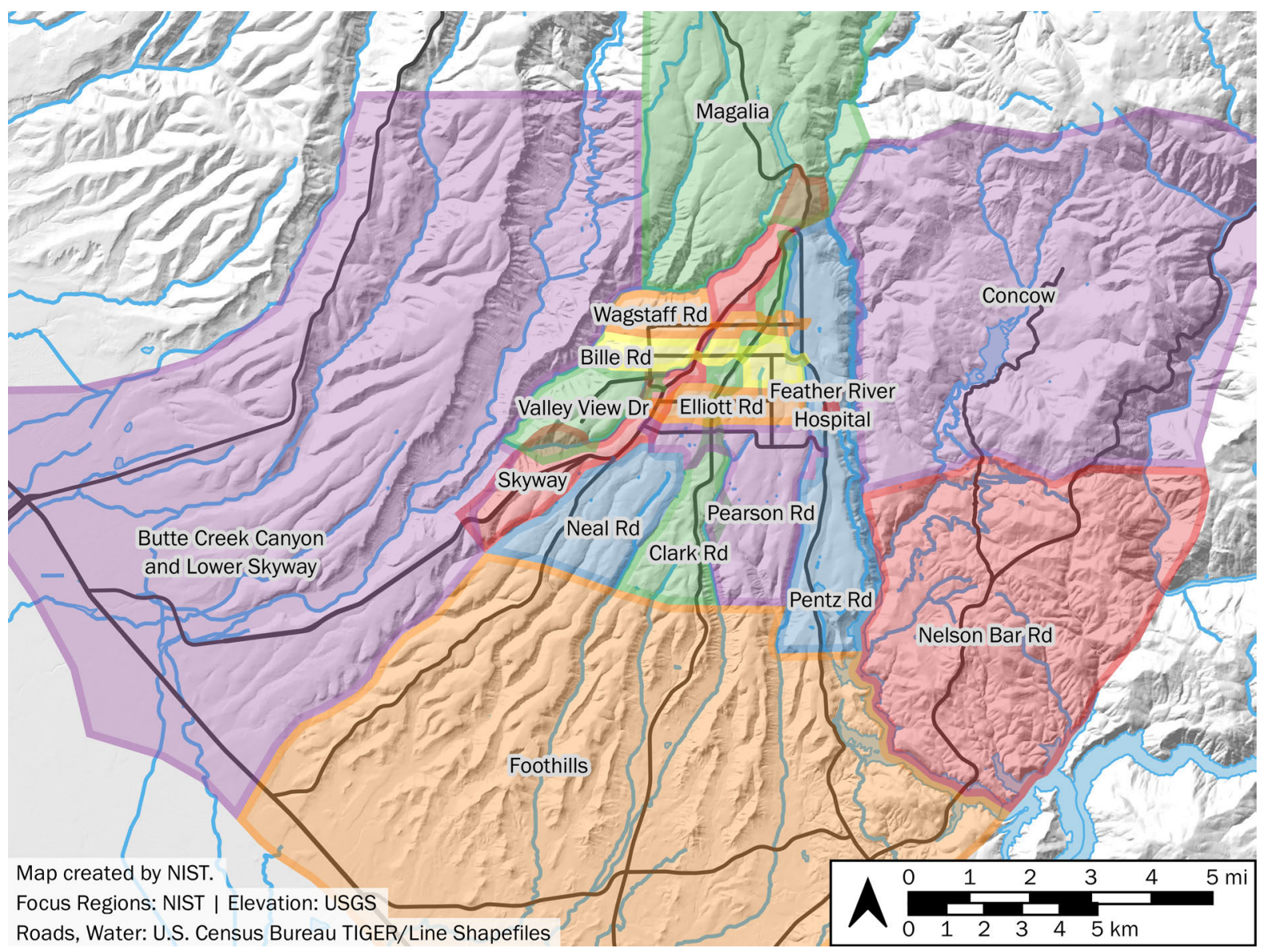

Figure 23. Map of 15 fire timeline focus regions. Some regions overlap slightly indicated by relative discoloration.

\footnotetext{
${ }^{13}$ An observation in a time window, as discussed in Section 7.5.5.1, does not necessarily imply that this is the only time the event took place.
} 


\subsubsection{Concow Fire Progression Summary}

At 06:25 on November 8, 2018, the first 911 call was received reporting a vegetation fire in the Feather River Canyon near the Poe Dam, approximately $10 \mathrm{~km}(6 \mathrm{mi})$ north of Jarbo Gap. Initial reports indicated the size of the fire was $30 \mathrm{~m} \times 30 \mathrm{~m}(100 \mathrm{ft} \times 100 \mathrm{ft})$, burning underneath electrical transmission lines on the north side of the river. Multiple callers reported the fire and indicated there were significant winds in the canyon. The initial dispatch was sent at 06:31.

The first engines, arriving from Fire Station 36 at Jarbo Gap (10 min travel time), observed the fire and gave an initial report of conditions at 06:44.

"We have eyes on the vegetation fire. It's going to be very difficult access; Camp Creek Road is nearly inaccessible. It is on the west side of the river underneath the transmission lines. It's got about a $35 \mathrm{mi} / \mathrm{h}$ sustained wind on it. We'll keep working on access. I'm going to go up the highway to try and get a better idea about how to get to it. It's a possibility we may have to come in off the top of Concow Road; Flea Mountain... This has got potential for a major incident. Request 15 additional engines, 4 additional dozers, 2 water tenders, 4 strike teams of hand crews. I'll get back to you on a reporting location."

Within 20 minutes of the first report of ignition, the fire was threatening structures in Pulga.

At 07:04, the IC was notified about a possible second fire ignition on Rim Road between Pulga and Concow. Post-fire investigation [5] confirmed a second ignition occurred at approximately 06:45 when the first engines were arriving on Highway 70 .

By 07:10, estimates put the fire between 80 ha and 120 ha ( 200 ac to 300 ac), burning in the Flea Valley and Pulga areas with a rapid rate of spread toward Concow. Sustained winds of over $15 \mathrm{~m} / \mathrm{s}(35 \mathrm{mi} / \mathrm{h})$ were observed in the canyon. Over the next 15 minutes the fire pushed westward out of Flea Valley and spotted west of Rim Road into Concow and across Concow Reservoir. Figure 24 shows a view looking north from the Caltrans Pulga Maintenance Yard on Highway 70 at $07: 23$. By 07:25 the fire had spotted up to $8 \mathrm{~km}(5 \mathrm{mi})$ ahead of the main fire.

At approximately the same time, 07:20, engines responding to the north flank via Rim Road encountered multiple rapidly growing spot fires west of Rim Road with very strong winds on the ridgetop. Figure 25 shows a snapshot from a video taken from the ridgetop. Firefighters described softball-sized rocks pelting the side of their engine.

Calls to 911 reporting fire burning in yards in Concow started at approximately 07:30. Conditions in Concow deteriorated as the fire continued to spread and involve the Concow geographical bowl. Shortly after, residents in Paradise began reporting spot fires on the west side of Sawmill Peak. Before 08:00, air attack was providing information on fire conditions and spread from the air. 


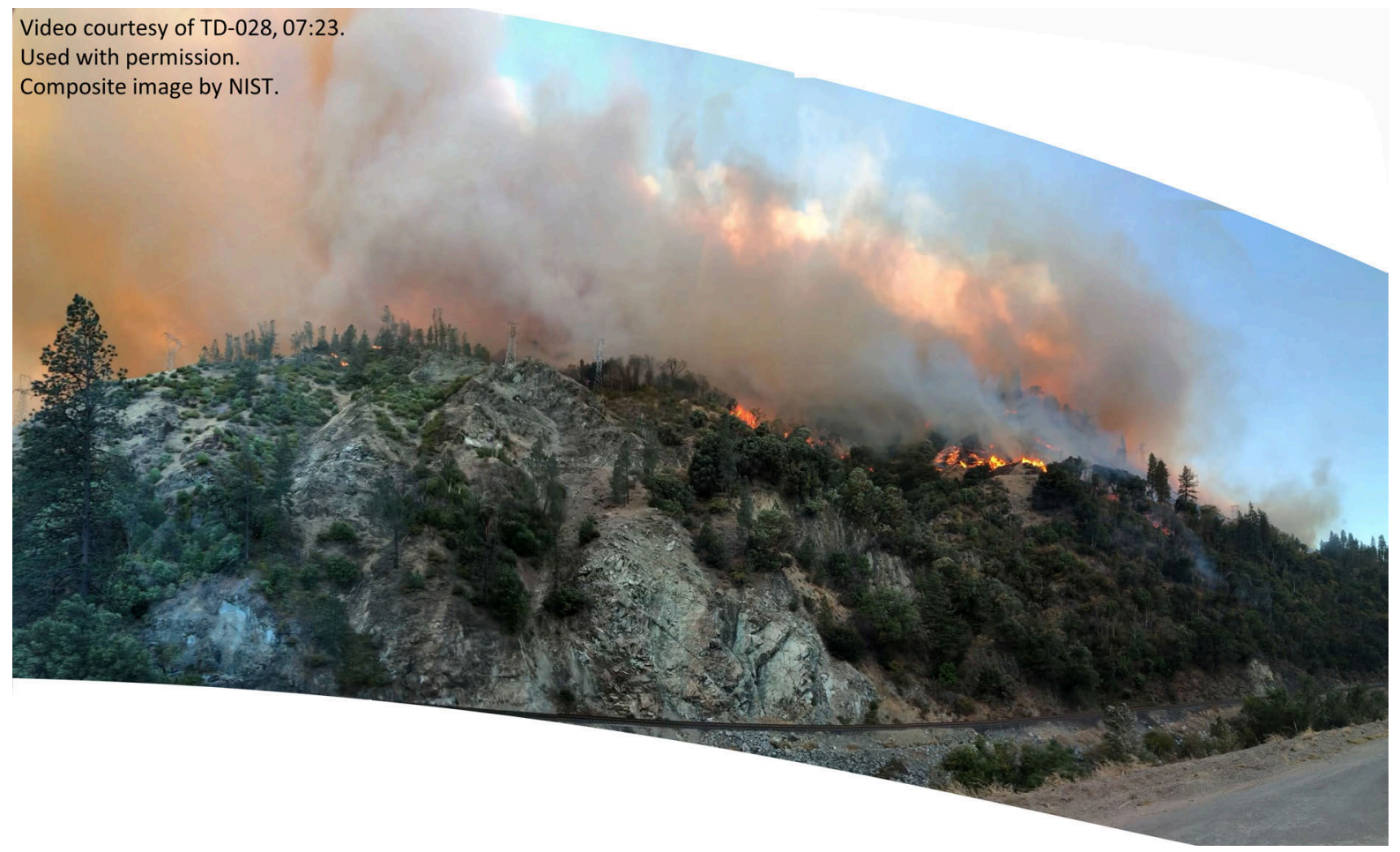

Figure 24. View of the fire looking north from Highway 70 at the Caltrans Pulga Maintenance Yard at 07:23. Panorama created from video recording.

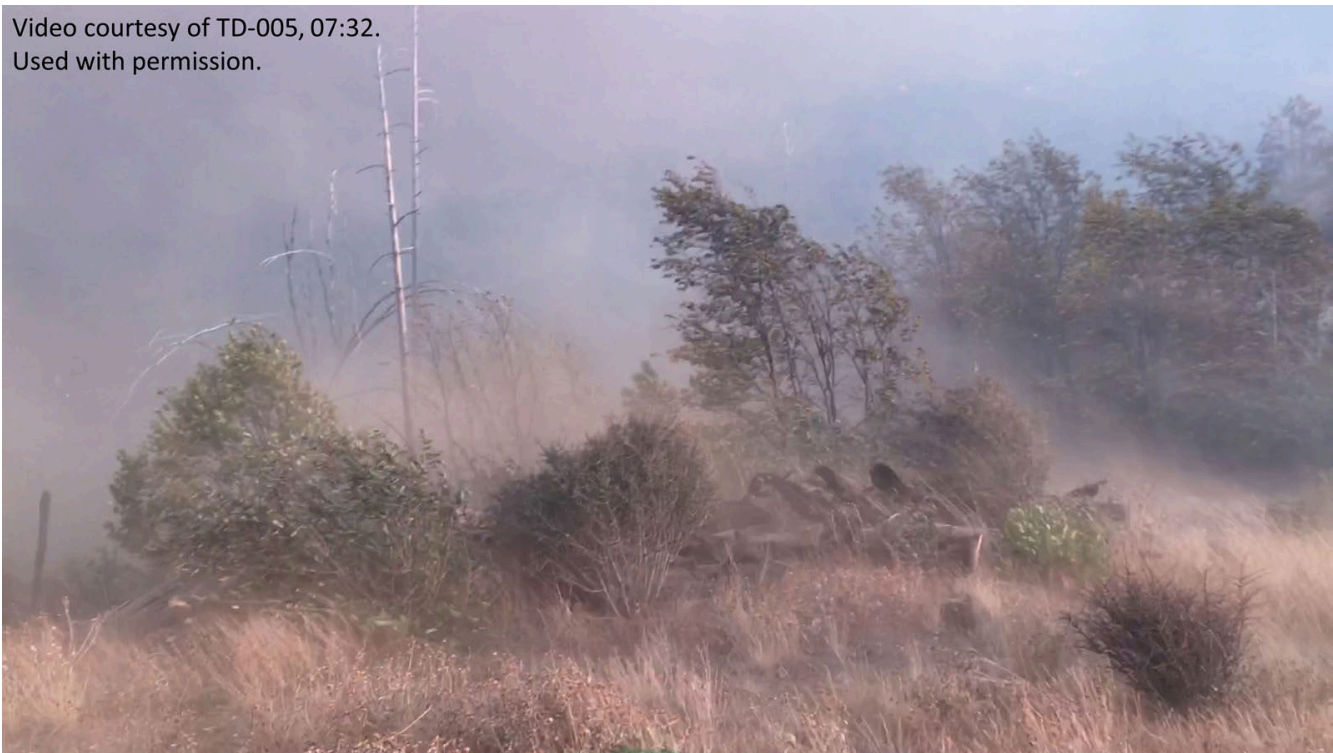

Figure 25. Strong wind gusts blew dirt and rocks whipping across the ridgetop at Rim Road. 
Around 09:20, the fire was hung up on the east side of Concow Reservoir and burning north of Ishi Trail. Fires on the west side of Concow Reservoir continued to grow and were spreading toward the south end of the reservoir.

There was limited data on fire spread south of Concow between 10:00 and 11:00 because first responders were located within the fire working on rescues and evacuations. After 11:00, the fire continued spreading south of Jeffrey Pine Lane and reached the south end of the reservoir by 12:00.

About the same time at 11:30, intense fire reached the intersection of Jordan Hill Road and Granite Ridge Road, where $30 \mathrm{~m}$ to $45 \mathrm{~m}$ (100 ft to $150 \mathrm{ft}$ ) flames were observed. Engines on Jordan Hill Road looking for civilians drove through fire and sustained damage while escaping to Concow Road with civilians following.

Throughout the morning, the fire continued burning near the origin, backing into the wind and starting multiple spots from rollouts down the hill. After noon and into the night, the fire became well established along Highway 70 and began running southwest down the canyon towards Jarbo Gap. The fire was approximately $2 \mathrm{~km}$ (1 mi to $2 \mathrm{mi}$ ) from Jarbo Gap (Fire Station 36) shortly after midnight into November 9.

Table 11 contains a summary of fire progression data in Concow. Common for tables throughout Section 9.1, the table lists the date and time window of selected fire observations along with a brief description of the location and the contributing source of the observation. When an observation was confirmed by multiple independent sources, or the description is a combination of multiple related observations, each independent data source identifier is listed (911-\#\#\#-\# indicates data from a recorded call to 911. TD and VTD indicate technical discussions and "virtual" technical discussions, respectively. PPD indicates information obtained from video recordings from Paradise Police Department).

Table 11. Summary of fire progression in Concow.

\begin{tabular}{|c|c|c|c|c|}
\hline Date & Time Range & Fire Behavior Observations & Location & Source \# \\
\hline $11 / 8$ & $06: 25 \quad 06: 40$ & $\begin{array}{l}\text { First report of vegetation fire via 911. Caller reports fire under } \\
\text { electric transmission lines within } 6 \mathrm{~m}(20 \mathrm{ft}) \text { of tower, estimated } \\
\text { size } 30 \mathrm{~m} \times 30 \mathrm{~m}(100 \mathrm{ft} \times 100 \mathrm{ft}) \text {. Others call to report same fire. }\end{array}$ & $\begin{array}{l}\text { West side Feather River, } \\
\text { CA Hwy } 70 \text { at Poe Dam }\end{array}$ & $\begin{array}{l}911-001-1 \\
911-002-1 \\
911-004-1\end{array}$ \\
\hline $11 / 8$ & $06: 45$ & $\begin{array}{l}\text { First engine gets sight of well-established fire, reports difficult } \\
\text { access in nearly inaccessible location. Approximately } 15 \mathrm{~m} / \mathrm{s} \\
(35 \mathrm{mi} / \mathrm{h}) \text { sustained winds. Captain declares potential for a major } \\
\text { incident. }\end{array}$ & $\begin{array}{l}\text { West side Feather River, } \\
\text { CA Hwy } 70 \text { at Poe Dam }\end{array}$ & TD-028 \\
\hline $11 / 8$ & $06: 45$ & $\begin{array}{l}\text { Investigators determined a second power line ignition started } \\
\text { another fire which was enveloped in the Camp Fire. }\end{array}$ & $\begin{array}{l}\text { Near intersection of Rim } \\
\text { Rd and Concow Rd }\end{array}$ & VTD-28 \\
\hline $11 / 8$ & $06: 45$ & Fire begins threatening structures in Pulga. & Pulga & TD-029 \\
\hline $11 / 8$ & 07:10 & $\begin{array}{l}\text { Engine reports fire is now } 80 \text { ha to } 120 \text { ha }(200 \mathrm{ac} \text { to } 300 \mathrm{ac}) \text { with } \\
\text { rapid rate of spread toward Concow Reservoir. }\end{array}$ & Pulga & TD-028 \\
\hline $11 / 8$ & 07:15 & $\begin{array}{l}\text { Fire spread SW from origin and got established in Flea Valley } \\
\text { above Pulga. }\end{array}$ & Pulga & TD-028 \\
\hline $11 / 8$ & 07:20 & $\begin{array}{l}\text { Wind pushing fire up slope W, WSW; fire extending up slope and } \\
\text { well beyond ridge to W. }\end{array}$ & Pulga & TD-028 \\
\hline $11 / 8$ & 07:20 & $\begin{array}{l}\text { Multiple (5) small spot fires }(3 \mathrm{~m} \times 3 \mathrm{~m}, 10 \mathrm{ft} \times 10 \mathrm{ft}) \text { visible on east } \\
\text { facing slopes west of Concow Reservoir. }\end{array}$ & $\begin{array}{l}\text { West side of Concow } \\
\text { Reservoir }\end{array}$ & TD-013 \\
\hline
\end{tabular}




\begin{tabular}{|c|c|c|c|c|}
\hline Date & Time Range & Fire Behavior Observations & Location & Source \# \\
\hline $11 / 8$ & 07:20 & $\begin{array}{l}\text { Engines attempting access to the north flank of the fire encounter } \\
\text { large, a well-established spot fire, } 0.1 \text { ha to } 0.2 \text { ha }(0.25 \text { ac to } \\
0.5 \text { ac). }\end{array}$ & $\begin{array}{l}\text { Rim Rd between Concow } \\
\text { and Pulga }\end{array}$ & TD-005 \\
\hline $11 / 8$ & 07:25 & Spot fires are igniting in Concow and homes start to catch fire. & Concow & TD-062 \\
\hline $11 / 8$ & $07: 30$ & $\begin{array}{l}\text { Engines responding to Concow encounter } 6 \mathrm{~m} \times 6 \mathrm{~m}(20 \mathrm{ft} \times 20 \mathrm{ft}) \\
\text { spot fire burning upwind, threatening homes. }\end{array}$ & $\begin{array}{l}\text { Concow Rd at } \\
\text { Cribbage Ln }\end{array}$ & TD-013 \\
\hline $11 / 8$ & $07: 30$ & First 911 call reporting active fire in yard. & Concow & $911-037-1$ \\
\hline $11 / 8$ & 07:30 & $\begin{array}{l}\text { Spot fires up on Rim Rd have grown to several acres within } 10 \mathrm{~min} \text {, } \\
\text { spreading up slope, consuming the draw. }\end{array}$ & $\begin{array}{l}\text { Rim Rd between Concow } \\
\text { and Pulga }\end{array}$ & TD-005 \\
\hline $11 / 8$ & 07:40 07:45 & $\begin{array}{l}\text { Multiple } 911 \text { calls report multiple spot fires just below Sawmill } \\
\text { Peak, burning on the Paradise side. }\end{array}$ & Sawmill Peak & $\begin{array}{l}911-048-1 \\
911-058-1\end{array}$ \\
\hline $11 / 8$ & 07:50 & $\begin{array}{l}\text { Fire is well-established in Concow. Multiple structures are burning, } \\
\text { and fire is impacting evacuation. }\end{array}$ & Concow & $911-075-1$ \\
\hline $11 / 8$ & 08:00 $\quad 08: 30$ & $\begin{array}{l}\text { Hoffman Rd burnover event (see Section 9.3). Heavy fire is burning } \\
\text { in the Hoffman Rd area, blocking the road. Civilian evacuation } \\
\text { impacted. }\end{array}$ & Hoffman Rd & TD-013 \\
\hline $11 / 8$ & 08:00 $\quad 08: 30$ & $\begin{array}{l}\text { Concow Rd burnover event (see Section 9.3). Flame front too } \\
\text { intense to pass, burning vehicles in road. Crown, timber, } 3 \mathrm{~m} \text { to } \\
4.5 \mathrm{~m}(10 \mathrm{ft} \text { to } 15 \mathrm{ft}) \text { brush burning; } 18 \mathrm{~m} \text { to } 24 \mathrm{~m}(60 \mathrm{ft} \text { to } 80 \mathrm{ft}) \\
\text { flames. }\end{array}$ & $\begin{array}{l}\text { Concow Rd near Cribbage } \\
\text { Ln }\end{array}$ & TD-008 \\
\hline $11 / 8$ & 08:15 & $\begin{array}{l}\text { Intense fire conditions, embers blowing across roadway, trees } \\
\text { torching, fire up against roadway. }\end{array}$ & $\begin{array}{l}\text { Concow Rd between } \\
\text { Hoffman Rd and } \\
\text { Cribbage Ln }\end{array}$ & TD-110 \\
\hline $11 / 8$ & 08:30 & Most structures in Camelot are already burning. & Concow & TD-062 \\
\hline $11 / 8$ & 08:30 & Fire burning the hills on the west side of Concow Reservoir. & $\begin{array}{l}\text { West side of Concow } \\
\text { Reservoir }\end{array}$ & TD-115 \\
\hline $11 / 8$ & 09:20 10:00 & $\begin{array}{l}\text { Head of fire is hung up on east side of Concow Reservoir, burning } \\
\text { to the north of Ishi Tr. Spot fires are igniting in pine and leaf litter } \\
1.6 \mathrm{~km}(1 \mathrm{mi}) \text { ahead of fire front. }\end{array}$ & Concow Rd near Ishi Tr & $\begin{array}{l}\text { TD-013, TD-090 } \\
\text { TD-115 }\end{array}$ \\
\hline $11 / 8$ & $11: 00$ & $\begin{array}{l}\text { Fire is intensifying, moving south, burning both sides of } \\
\text { Concow Rd near Jeffrey Pine Ln. }\end{array}$ & $\begin{array}{l}\text { Concow Rd near Jeffrey } \\
\text { Pine Ln }\end{array}$ & TD-062 \\
\hline $11 / 8$ & $11: 20 \quad 11: 40$ & $\begin{array}{l}\text { Intense fire is burning on the ridge and in the canyons near Jordan } \\
\text { Hill Rd. Flame lengths of } 30 \mathrm{~m} \text { to } 45 \mathrm{~m} \text { ( } 100 \mathrm{ft} \text { to } 150 \mathrm{ft} \text { ) observed. } \\
\text { Engines looking for civilians must drive through fire to escape to } \\
\text { Concow Rd. }\end{array}$ & $\begin{array}{l}\text { Jordan Hill Rd and } \\
\text { Granite Ridge Rd }\end{array}$ & TD-031, TD-062 \\
\hline $11 / 8$ & 12:00 14:00 & $\begin{array}{l}\text { South flank of the fire reaches the south end of Concow Reservoir } \\
\text { in the early afternoon. }\end{array}$ & Concow & TD-027 \\
\hline $11 / 8$ & 12:00 $12: 30$ & $\begin{array}{l}\text { At the heel, fire is backing into wind burning in steep terrain in the } \\
\text { canyons near the origin. Numerous small spots are igniting from } \\
\text { rollout down the hill. }\end{array}$ & $\begin{array}{l}\text { West side of Feather River } \\
\text { near Caltrans yard, } \\
\text { CA Hwy } 70 .\end{array}$ & $\begin{array}{l}\text { TD-008, TD-028 } \\
\text { TD-108 }\end{array}$ \\
\hline $11 / 8$ & 12:00 23:00 & $\begin{array}{l}\text { At some point after noon fire crossed Hwy } 70 \text {. Later at night, began } \\
\text { making runs along the canyon to the southwest. }\end{array}$ & $\begin{array}{l}\text { CA Hwy } 70,5 \mathrm{~km} \text { to } 8 \mathrm{~km} \\
(3 \mathrm{mi} \text { to } 5 \mathrm{mi}) \text { north of } \\
\text { Jarbo Gap }\end{array}$ & TD-013, TD-028 \\
\hline $11 / 9$ & $00: 30$ & $\begin{array}{l}\text { Fire gets well established } 1.6 \mathrm{~km} \text { to } 3 \mathrm{~km}(1 \mathrm{mi} \text { to } 2 \mathrm{mi}) \text { below } \\
\text { Station } 36 \text {. Engines drive through fire on Hwy } 70 \text { to return to } \\
\text { Station } 36 \text { for structure prep. }\end{array}$ & $\begin{array}{l}\text { CA Hwy } 70,1.6 \mathrm{~km} \text { to } 3 \\
\mathrm{~km}(1 \mathrm{mi} \text { to } 2 \mathrm{mi}) \text { north of } \\
\text { Jarbo Gap }\end{array}$ & TD-028, TD-029 \\
\hline
\end{tabular}




\subsubsection{Pentz Road Fire Progression Summary}

The initial impact on Paradise was primarily focused along the Pentz Road corridor. To convey the various concurrent events, fire progression along Pentz Road is divided into five separate regions. From the north, the five sections of Pentz Road are:

- Apple View Way to Dean Road,

- Merrill Road to Wagstaff Road,

- Bille Road to Feather River Hospital (FRH),

- FRH to Pearson Road, and

- Pearson Road to Kunkle Reservoir.

Fire was visible up on the Paradise side of Sawmill Peak by 07:40. Shortly after, the first 911 call reporting fire in Paradise was at 07:49 on Lowry Lane off Pentz Road. Between 07:50 and 08:20, there were an additional 16 spot fires reported between Apple View Way and Lowry Lane. The early spots intensified as the fire front arrived from the east at 08:30. Structures began igniting on the east side of Pentz Road between 08:30 and 09:00, and the fire crossed Pentz Road between 09:00 and 09:15 at numerous locations north of Pearson Road.

Fire reached the Bille Road intersection and vehicles on Bille Road started igniting just before 10:00, significantly impacting civilian evacuation. At the same time, another burnover occurred between Bille Road and Feather River Hospital (FRH). This burnover further restricted traffic flow on Pentz Road. At the same time, between 09:00 and 10:00 there was intense fire activity on Pentz Road south of FRH limiting traffic flow to the south towards Pearson Road or Pentz Road out of town. These burnover events are further described in Section 9.3. By 10:30, fire had burned through the vegetation, and many structures along Pentz Road were already burned. The Pearson Road intersection remained fully involved at 10:40, and there was active fire to the south. Bille Road access will be further discussed in Section 9.1.5.

South of Pearson Road, fire activity on Pentz Road increased significantly between 09:20 and 11:00. The fire spread west out of the West Branch canyon in the area south of the town limits before 11:00. Between 11:30 and noon, $6 \mathrm{~m}(20 \mathrm{ft})$ tall flames were hopping the $9 \mathrm{~m}$ (30 ft) wide dozer lines and threatening structures to the east and south of Lago Vista Way. The fire reached the Kunkle Reservoir by 12:15, and by 16:00 the main fire activity had passed through that area. 


\subsubsection{Apple View Way to Dean Road Fire Progression Summary}

Between 07:50 and 08:00, multiple residents called 911 reporting a spot fire in the Noble Orchard, with additional spots reported between 08:00 and 08:10. At approximately 08:30, the wind picked up, and the approaching fire front "sounded like a freight train or 747 on full power" [TD-040]. Between 08:30 and 10:30 local visibility decreased to zero and fire activity increased rapidly in the area with propane tanks exploding. By 09:15 the fire crossed to the west side of Pentz Road, where it was well established by 11:00, igniting structures. Table 12 contains a summary of fire progression on Pentz Road between Apple View Way and Dean Road.

Table 12. Summary of fire progression on Pentz Rd between Apple View Way and Dean Rd.

\begin{tabular}{|c|c|c|c|c|}
\hline Date & Time Range & Fire Behavior Observations & Location & Source \# \\
\hline $11 / 8$ & 07:50 08:00 & $\begin{array}{l}\text { Multiple residents call to report a spot fire burning in Noble } \\
\text { Orchard. Fire begins approximately } 6 \mathrm{~m} \times 6 \mathrm{~m}(20 \mathrm{ft} \times 20 \mathrm{ft}) \text { with } \\
3 \mathrm{~m} \text { ( } 10 \mathrm{ft} \text { ) flames in } 1 \mathrm{~m} \text { to } 1.5 \mathrm{~m}(3 \mathrm{ft} \text { to } 5 \mathrm{ft}) \text { tall dead brown } \\
\text { grass. Spot consumes } \sim 0.4 \text { ha }(1 \mathrm{ac}) \text { by } 08: 10 \text {. }\end{array}$ & end of Apple View Way & $\begin{array}{c}\text { TD-021, TD-022 } \\
\text { TD-023, TD-040 } \\
911-074-1 \\
911-082-1 \\
911-086-4\end{array}$ \\
\hline $11 / 8$ & 08:00 08:10 & Additional spot fires continue to be reported. & $\begin{array}{l}\text { area of Dean Rd, east of } \\
\text { Pentz Rd }\end{array}$ & $\begin{array}{l}\text { TD-024, TD-042 } \\
\text { 911-141-1 } \\
911-144-1\end{array}$ \\
\hline $11 / 8$ & 08:30 & $\begin{array}{l}\text { Wind increases dramatically and ignites numerous }(10+) \text { additional } \\
\text { spot fires in Noble Orchard as fire comes out of the Feather River } \\
\text { Canyon. }\end{array}$ & Apple View Way & TD-021 \\
\hline $11 / 8$ & $08: 35 \quad 10: 30$ & $\begin{array}{l}\text { Fire coverage and intensity greatly increases. Fire is well- } \\
\text { established and threatening structures. Fire spreads all around, } \\
\text { visibility drops to zero, propane tanks begin exploding, and } \\
\text { structures ignite. }\end{array}$ & Chapman Ln and Dean Rd & TD-040, TD-042 \\
\hline $11 / 8$ & 09:15 09:30 & Spot fires begin on west side of Pentz Rd. & $\begin{array}{l}\text { Pentz Rd near Dean Rd } \\
\text { and Apple View Way }\end{array}$ & PPD-02 \\
\hline $11 / 8$ & 09:45 & $\begin{array}{l}\text { Beyond Fitness gym building is igniting and the Children's } \\
\text { Community Charter School is burning. }\end{array}$ & Pentz Rd & TD-086 \\
\hline $11 / 8$ & $10: 20$ & $\begin{array}{l}\text { Multiple spot fires ignite around Paradise Ridge Southern Baptist } \\
\text { Church and the fire wraps around and becomes established to the } \\
\text { west toward Clark Rd. }\end{array}$ & $\begin{array}{l}\text { Paradise Ridge Southern } \\
\text { Baptist Church, west side } \\
\text { of Pentz Rd }\end{array}$ & TD-079, TD-089 \\
\hline $11 / 8$ & $10: 30$ & $\begin{array}{l}\text { Fire continues to involve structures on Apple View Way throughout } \\
\text { the day after the main fire front has passed. }\end{array}$ & Apple View Way & $\begin{array}{l}\text { TD-023, TD-040 } \\
\text { TD-084, TD-089 }\end{array}$ \\
\hline $11 / 8$ & 11:00 & $\begin{array}{l}\text { Fire is well-established on west side of Pentz Rd burning heavy } \\
\text { brush, trees, structures. Structures begin igniting on Sweetbriar Ln } \\
\text { and spreading west structure to structure. Blue Spruce Mobile } \\
\text { Estates is burning. }\end{array}$ & Sweetbriar Ln & $\begin{array}{l}\text { TD-060, TD-079 } \\
\text { TD-083 }\end{array}$ \\
\hline
\end{tabular}




\subsubsection{Merrill Road to Wagstaff Road Fire Progression Summary}

Spot fires were reported via 911 calls around the Merrill Road area, simultaneously with the spot fire on Apple View Way, between 07:50 and 08:10. The number of spots continued to increase between 08:10 and 08:20, when structures began igniting on the east side of Pentz Road. Fire spotted across Pentz Road between 08:40 and 08:50. Figure 26 shows the progression of fire as it impacted Pentz Road at Merrill Road. Figure 26a shows traffic observed travelling both directions on Merrill Road, with southbound traffic backed up and a fire engine heading south. Twenty seconds later, the roadway was impacted by intense flame and ember exposure and low visibility (Figure 26b/c/d). Figure 26e shows the view south down Pentz Road as the officer responded to attempt to escort vehicles to safety. Details about response, traffic, and evacuation will be detailed in subsequent reports.

By 09:00, fire had burned through Ridgewood and Ponderosa Mobile Home Parks near Wagstaff Road and was impacting Pentz Road, threatening evacuating vehicles. Structures began igniting on the west side of Pentz Road shortly after 11:00. Before 12:30, the mobile home parks were burned down, vegetation had burned through, and the main fire activity in the area was over. Table 13 contains the fire progression summary for Merrill and Wagstaff Roads.

Table 13. Summary of fire progression on Pentz Rd between Merrill Rd and Wagstaff Rd.

\begin{tabular}{|c|c|c|c|c|}
\hline Date & Time Range & Fire Behavior Observations & Location & Source \# \\
\hline $11 / 8$ & $07: 50 \quad 08: 10$ & $\begin{array}{l}\text { Multiple } 911 \text { calls report widespread spot fires scattered on the east } \\
\text { side of Pentz Rd. }\end{array}$ & $\begin{array}{l}\text { Merrill Rd, Stark Ln and } \\
\text { cross streets }\end{array}$ & $\begin{array}{c}911-077-3 \\
911-088-1 \\
911-110-1 \\
911-1026-1 \\
911-1027-1 \\
911-1034-2 \\
911-1040-1 \\
911-1046-4\end{array}$ \\
\hline $11 / 8$ & 08:10 08:20 & $\begin{array}{l}\text { The number of spot fires in the area continues to increase. Two spot } \\
\text { fires have become well-established in grass and manzanita, rapidly } \\
\text { spreading and threatening structures. }\end{array}$ & $\begin{array}{l}\text { Merrill Rd, Stark Ln and } \\
\text { cross streets }\end{array}$ & $\begin{array}{c}\text { TD-020, TD-022 } \\
\text { TD-061 } \\
911-1049-8 \\
911-1049-6 \\
911-1048-2 \\
911-1053-4\end{array}$ \\
\hline $11 / 8$ & $08: 20 \quad 08: 40$ & $\begin{array}{l}\text { Spot fire in } 0.6 \mathrm{~m} \text { ( } 2 \mathrm{ft}) \text { tall grass field continues to spread west and } \\
\text { north, consuming field. Structures begin igniting along Merrill Rd. }\end{array}$ & $\begin{array}{l}\text { Merrill Rd, Stark Ln and } \\
\text { cross streets }\end{array}$ & $\begin{array}{l}\text { TD-014, TD-022 } \\
\text { TD-043, TD-045 } \\
\text { TD-061, TD-143 }\end{array}$ \\
\hline $11 / 8$ & $08: 40 \quad 08: 50$ & $\begin{array}{l}\text { Fire begins spotting west of Pentz Rd. Mobile Homes in Ridgewood } \\
\text { Mobile Home Park are on fire. Heavy fire from the field impacts } \\
\text { Pentz Rd. }\end{array}$ & $\begin{array}{l}\text { Pentz Rd between Merrill } \\
\text { Rd and Wagstaff Rd }\end{array}$ & $\begin{array}{l}\text { TD-014, TD-042 } \\
\text { TD-064, TD-067 } \\
\text { PPD-02 }\end{array}$ \\
\hline $11 / 8$ & 09:00 & $\begin{array}{l}\text { Fire has burned through Ridgewood and Ponderosa Mobile Home } \\
\text { Parks and is impacting Pentz Rd, threatening evacuating vehicles. } \\
\text { Spot fires ignite in the Ponderosa Elementary School parking lot. }\end{array}$ & Pentz Rd and Wagstaff Rd & $\begin{array}{l}\text { TD-021, TD-043 } \\
\text { TD-067, TD-085 } \\
\text { PPD-02, PPD-04 }\end{array}$ \\
\hline $11 / 8$ & 09:10 & $\begin{array}{l}\text { Fire impacts structures on Chris Ct from the southeast. Sheds and } \\
\text { fences are burning, homes are igniting. }\end{array}$ & Chris Ct & TD-045 \\
\hline $11 / 8$ & 11:05 & Buildings at Ponderosa Elementary School are on fire. & $\begin{array}{l}\text { Ponderosa Elementary } \\
\text { School }\end{array}$ & TD-014, TD-015 \\
\hline $11 / 8$ & $12: 15$ & $\begin{array}{l}\text { Portable classroom buildings have burned, and the cafeteria is on } \\
\text { fire. }\end{array}$ & $\begin{array}{l}\text { Ponderosa Elementary } \\
\text { School }\end{array}$ & TD-021 \\
\hline $11 / 8$ & $12: 30$ & $\begin{array}{l}\text { Before } 12: 30 \text {, the mobile home parks are burned down, vegetation } \\
\text { has burned through, and the main fire activity in the area is over. }\end{array}$ & $\begin{array}{l}\text { Pentz Rd between Merrill } \\
\text { Rd and Wagstaff Rd }\end{array}$ & TD-043 \\
\hline
\end{tabular}




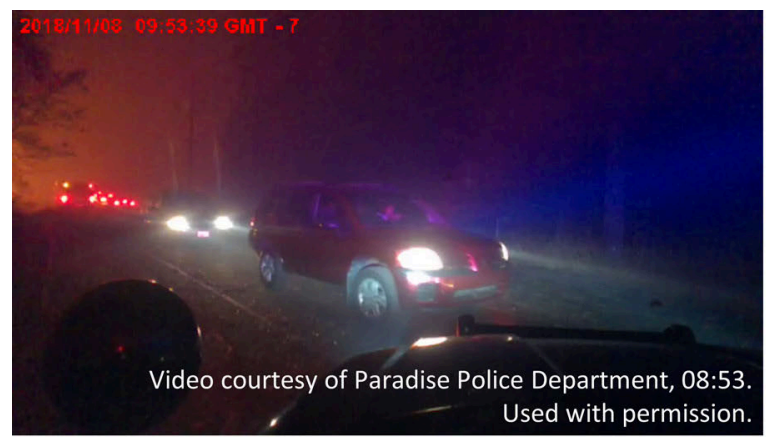

a) $t=0 \mathrm{~s}$

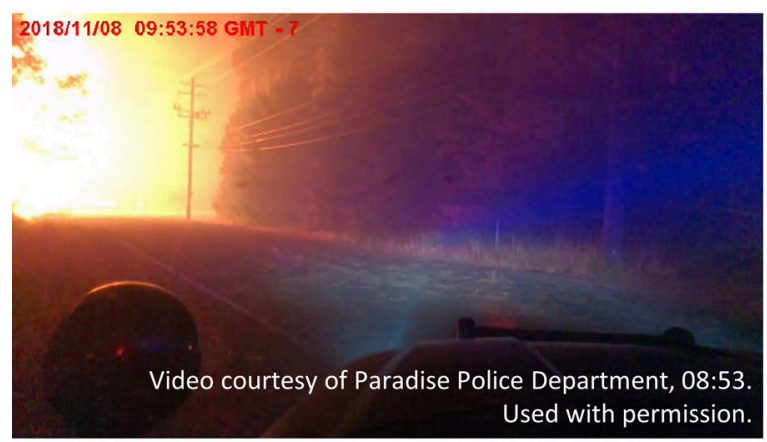

c) $t=19 \mathrm{~s}$

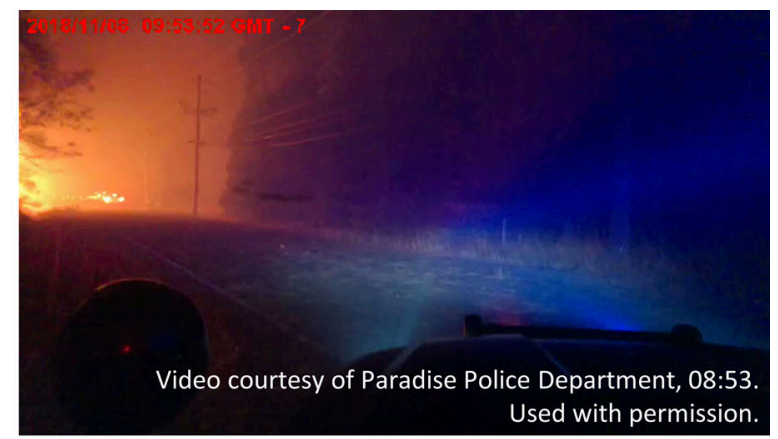

b) $t=13 \mathrm{~s}$

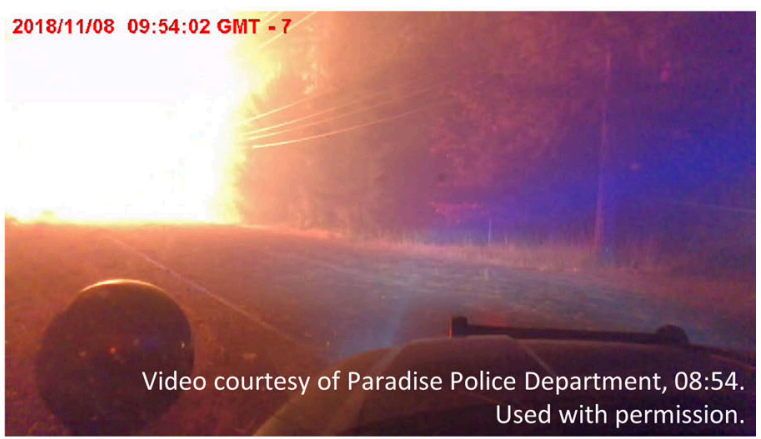

d) $t=23 \mathrm{~s}$

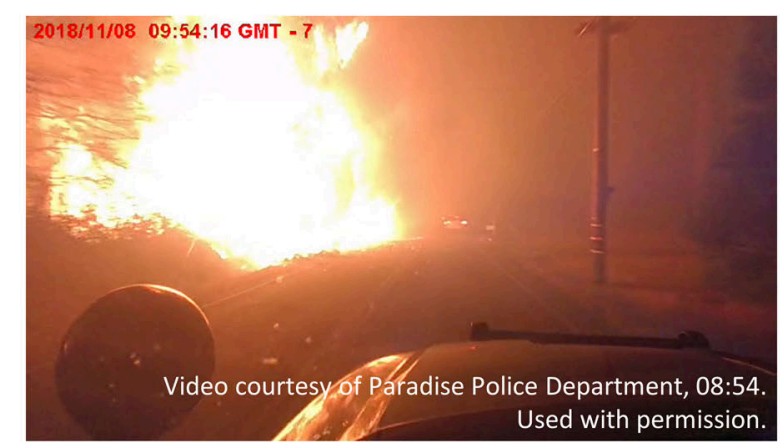

e) $t=37 \mathrm{~s}$

Figure 26. Scenes from a Paradise Police Department dashboard camera show how rapidly conditions can change and impact evacuation routes, as fire is seen impacting evacuating vehicles on Pentz Rd at Merrill Rd. 


\subsubsection{Bille Road to Feather River Hospital Fire Progression Summary}

The 911 calls from residents reporting burning sticks falling from the sky started at 08:00, and spot fires began at 08:10 just east of Feather River Hospital (see Section 9.1.3). Fire impacted civilians and first responders on Pentz Road between Bille Road and Norwood Drive starting shortly after 09:00. The burnover was characterized by sideways flames, torching trees, evacuating vehicles on fire, civilian's hair igniting, and tires on a fire engine melting. The burnover is further described in Section 9.3. By 09:20 structures were igniting on the east side of Pentz Road between Norwood Drive and Peach Lane. Structures ignited on the west side of Pentz Road by 09:35, and by 09:50 vehicles in the traffic jam at Bille Road ignited. The main fire activity in this part of Pentz Road had passed by 11:15 as the fire front moved to the southwest. Table 14 summarizes the fire progression along Pentz Road between Bille Road and the Feather River Hospital.

Table 14. Summary of fire progression on Pentz Rd between Bille Rd and FRH.

\begin{tabular}{|c|c|c|c|c|}
\hline Date & Time Range & Fire Behavior Observations & Location & Source \# \\
\hline $11 / 8$ & 08:00 & $\begin{array}{l}\text { Calls to } 911 \text { report burning sticks falling from the sky and spot } \\
\text { fires. }\end{array}$ & Pentz Rd near Bille Rd & $\begin{array}{l}911-085-2 \\
911-095-1 \\
911-098-1 \\
911-100-1\end{array}$ \\
\hline $11 / 8$ & 08:00 & $\begin{array}{l}\text { Fire is burning within feet of structures at the end of Canyon View } \\
\text { Dr at the edge of the canyon. }\end{array}$ & Canyon View Dr & $\begin{array}{c}911-086-3 \\
911-1035-1\end{array}$ \\
\hline $11 / 8$ & $08: 10$ & $\begin{array}{l}\text { Spot fires begin on Feather River Hospital campus. See Section } \\
\text { 9.1.3 for additional details related to the hospital. }\end{array}$ & Feather River Hospital & $911-1047-1$ \\
\hline $11 / 8$ & 09:00 & $\begin{array}{l}\text { Dangerous fire between Bille Rd and Norwood Dr. East side of } \\
\text { Pentz Rd is more heavily involved than west side. Flames are } \\
\text { sideways, trees are torching, evacuating vehicles are on fire, } \\
\text { civilian's hair is igniting, and tires on the engine are melting. See } \\
\text { Section } 9.3 \text { for burnover event details. }\end{array}$ & $\begin{array}{l}\text { Pentz Rd between Bille } \\
\text { Rd and Norwood Dr }\end{array}$ & $\begin{array}{l}\text { TD-015, TD-060 } \\
\text { TD-079, TD-083 } \\
\text { TD-116 }\end{array}$ \\
\hline $11 / 8$ & 09:00 & $\begin{array}{l}\text { Numerous spot fires begin igniting along Pentz Rd between } \\
\text { Norwood Dr and Peach Ln. }\end{array}$ & $\begin{array}{l}\text { Pentz Rd between } \\
\text { Norwood Dr and Peach } \\
\text { Ln }\end{array}$ & TD-015, VTD-23 \\
\hline $11 / 8$ & $09: 20$ & $\begin{array}{l}\text { Structures between Norwood Dr and Peach Ln are igniting. } \\
\text { Evacuating vehicles are exposed to intense fire. Dark as night, } \\
\text { visibility in places drops to zero. }\end{array}$ & $\begin{array}{l}\text { Pentz Rd between } \\
\text { Norwood Dr and Peach } \\
\text { Ln }\end{array}$ & $\begin{array}{l}\text { TD-069, TD-090 } \\
\text { VTD-23, PPD-05 } \\
\text { 911-234-1 }\end{array}$ \\
\hline $11 / 8$ & $09: 35$ & $\begin{array}{l}\text { Structures on the west side of Pentz Rd ignite, including mobile } \\
\text { homes in Eden Roc Estates. }\end{array}$ & Pentz Rd at Bille Rd & TD-060, TD-079 \\
\hline $11 / 8$ & $09: 50$ & $\begin{array}{l}\text { Vehicles in traffic jam on Bille Rd catch fire as fire front } \\
\text { progresses west-southwest. Structures continue to burn. See } \\
\text { Section } 9.3 \text { for description of the burnover event. }\end{array}$ & $\begin{array}{l}\text { Bille Rd just west of Pentz } \\
\text { Rd }\end{array}$ & $\begin{array}{l}T D-021, T D-060 \\
T D-079 \\
P P D-02, P P D-05\end{array}$ \\
\hline $11 / 8$ & $11: 00$ & $\begin{array}{l}\text { Structures on Del Rio Way are burned and collapsed. Yards, } \\
\text { fences, and one structure are burning on Vineyard Dr. }\end{array}$ & $\begin{array}{l}\text { East side of Pentz Rd near } \\
\text { hospital; Del Rio Way, } \\
\text { Vineyard Dr }\end{array}$ & TD-005 \\
\hline $11 / 8$ & $11: 15$ & $\begin{array}{l}\text { Main fire activity along Pentz Rd has passed; structures are burned } \\
\text { down; vegetation has burned through. Pentz Rd is passable. }\end{array}$ & $\begin{array}{l}\text { Pentz Rd between Bille } \\
\text { Rd and Feather River } \\
\text { Hospital }\end{array}$ & $\begin{array}{l}\text { TD-015, TD-090, } \\
\text { TD-111, PPD-08 }\end{array}$ \\
\hline
\end{tabular}




\subsubsection{Feather River Hospital to Pearson Road Fire Progression Summary}

The first call reporting a spot fire in Paradise was placed at 07:49 off Lowry Lane. Paradise Police responded to the area, and body camera video recording captured the plume from the initial spot fire, seen in Figure 27.

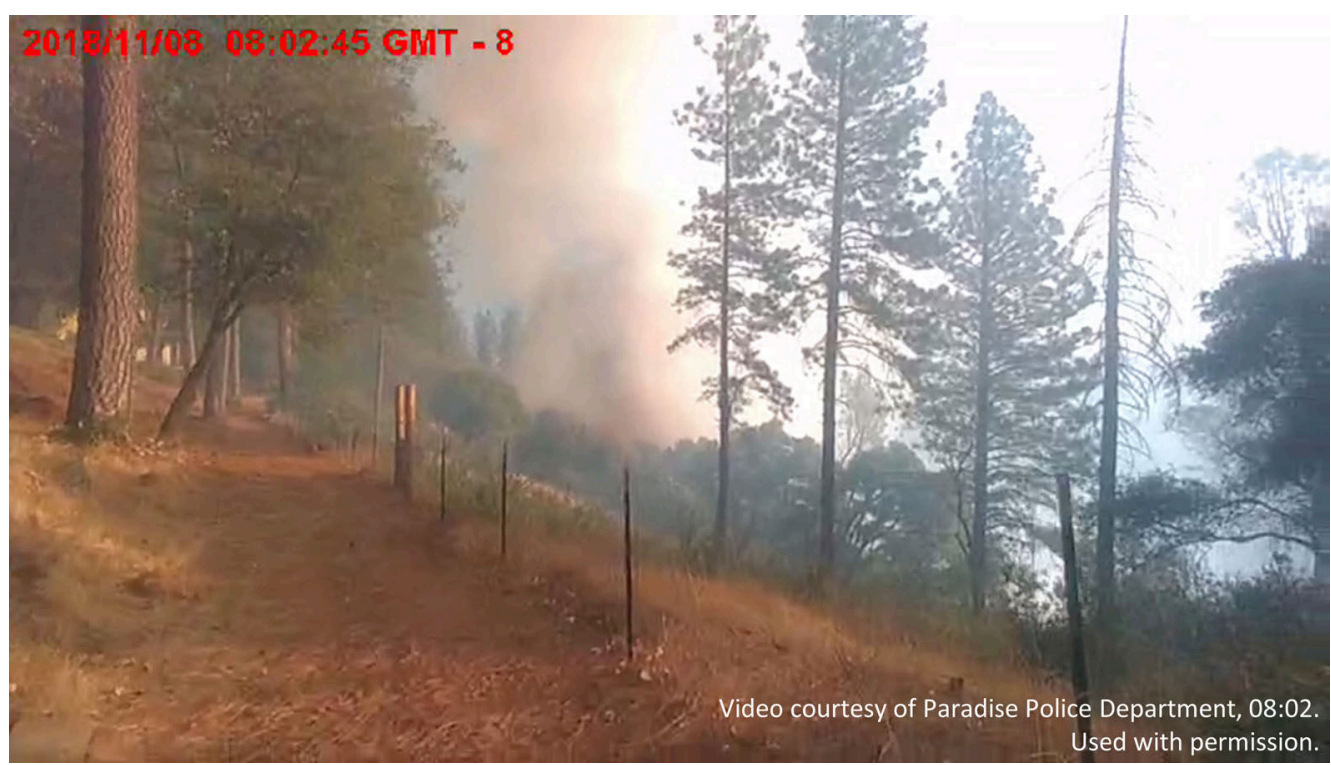

Figure 27. Body camera recording shows the initial stages of the spot fire off Lowry Ln and Riverside Dr.

Additional spot fires ignited along the west side of the river as the initial fire grew. Fire reached Pentz Road by 08:30, burning structures and vegetation. Between 09:00 and 10:00, everything along Pentz Road was on fire between FRH and Chaney Lane. Figure 28 shows a picture taken in this area at 09:42, showing structures burning and smoky conditions. The initial spot grew to an estimated area of 24 ha $(60 \mathrm{ac})$ in approximately 2 hours.

The fire continued to expand into the drainage to the north of Pearson Road by 09:30, where it soon flared up and burned over evacuees (see Section 9.1.7 detailing Pearson Road and Section 9.3 discussing burnovers). Some structures continued to burn; however, by 10:30 the main fire had subsided between FRH and Pearson Road. The Pearson Road intersection remained fully involved at 10:40, and there was more active fire to the south.

Table 15 summarizes the fire progression on Pentz Road from FRH to Pearson Road. 


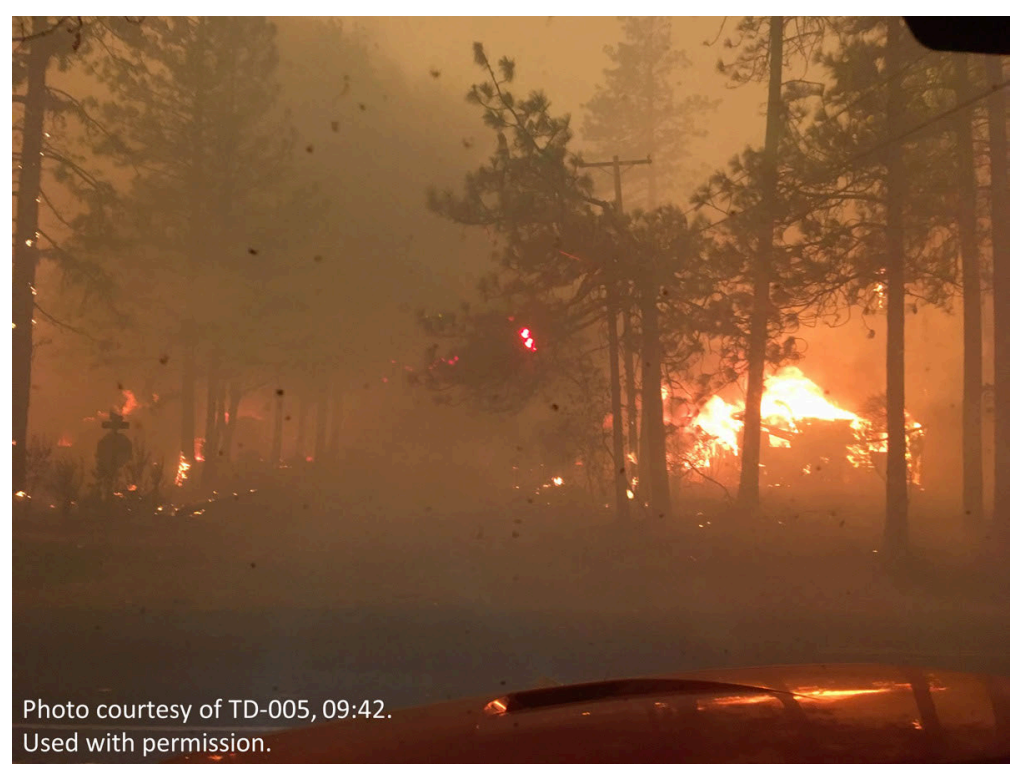

Figure 28. View of everything burning at the intersection of Pentz Rd and Riverview Dr. View west at 09:42.

Table 15. Summary of fire progression on Pentz Rd between FRH and Pearson Rd.

\begin{tabular}{|c|c|c|c|c|}
\hline Date & Time Range & Fire Behavior Observations & Location & Source \# \\
\hline $11 / 8$ & 07:50 08:00 & $\begin{array}{l}\text { Multiple } 911 \text { calls and PPD officer report a spot fire on the west } \\
\text { side of the canyon behind homes on Lowry Ln and Riverview Dr. }\end{array}$ & Lowry Ln, Riverview Dr & $\begin{array}{c}911-064-1 \\
911-066-1 \\
911-071-1 \\
911-084-1 \\
\text { TD-063 } \\
\text { PPD-01 }\end{array}$ \\
\hline $11 / 8$ & 08:10 08:20 & Fire is burning vegetation around homes on east side of Pentz Rd. & Riverview Dr & $\begin{array}{c}\text { TD-063 } \\
911-104-1 \\
911-1054-2\end{array}$ \\
\hline $11 / 8$ & 08:30 $08: 40$ & $\begin{array}{l}\text { Fire is established on east side, spotting to west side of Pentz Rd. } \\
\text { Spot fires are growing bigger than "back pump size" in seconds. } \\
\text { Flames are blowtorching and embers are flying everywhere. Yard } \\
\text { decorations not typically observed burning are on fire. }\end{array}$ & Riverview Dr & $\begin{array}{l}\text { TD-005, TD-016 } \\
\text { TD-084, TD-143 }\end{array}$ \\
\hline $11 / 8$ & 08:40 09:00 & $\begin{array}{l}\text { Homes are threatened by fire, many are igniting and burning both } \\
\text { sides of Pentz Rd. Bumpers of evacuating vehicles are igniting. } \\
\text { " } 100 \% \text { of embers are igniting spot fires when they land." }\end{array}$ & $\begin{array}{l}\text { between Riverview Dr and } \\
\text { Chaney Ln }\end{array}$ & $\begin{array}{c}\text { TD-005, TD-014 } \\
\text { TD-016, TD-060 } \\
\text { TD-079, TD-084 } \\
\text { TD-103, TD-109 } \\
\text { TD-122, TD-123 } \\
\text { TD-124, TD-209 } \\
\text { PPD-04 }\end{array}$ \\
\hline $11 / 8$ & 09:00 09:30 & $\begin{array}{l}\text { Spot fire becomes well-established and begins to consume the } \\
\text { drainage on Pearson Rd at Hilbe Dr, burning up behind homes on } \\
\text { Fickett Ln. The fire in the drainage results in the burnover event on } \\
\text { Pearson Rd. See Section } 9.3 \text { for description of the burnover event. }\end{array}$ & $\begin{array}{l}\text { west of Fickett Ln towards } \\
\text { Hilbe Dr }\end{array}$ & $\begin{array}{l}\text { TD-016, TD-123 } \\
\text { TD-129, TD-209 }\end{array}$ \\
\hline $11 / 8$ & 09:00 10:00 & $\begin{array}{l}\text { Everything along Pentz Rd is burning, intense fire both sides of } \\
\text { roadway, heavy ember showers, wind is variable }\end{array}$ & Hospital to Chaney Ln & $\begin{array}{l}\text { TD-063, VTD-17 } \\
\text { VTD-21, VTD-23 }\end{array}$ \\
\hline $11 / 8$ & $10: 30$ & $\begin{array}{l}\text { Vegetation has been burned through, many structures have been } \\
\text { destroyed, others are still actively burning. }\end{array}$ & Hospital to Pearson Rd & $\begin{array}{l}\text { TD-037, TD-103 } \\
\text { TD-209 }\end{array}$ \\
\hline
\end{tabular}




\subsubsection{Pearson Road to Kunkle Reservoir Fire Progression Summary}

The lower part of Pentz Road from Pearson Road to Kunkle Reservoir saw fire almost one hour after the first spots were reported on Apple View Way and Merrill Road. Fire was well established north of Pearson Road at Chaney Lane by 08:40. Between 08:40 and 09:00 there were several fingers of fire burning across Pentz Road between York Towne Manor and Malibu Drive, and by 09:20 there were structures reported burning on York Towne Manor. Shortly after, between 09:40 and 09:50, fire encroached on the intersection of Pentz Road and Pearson Road from all directions. The intersection remained fully involved until approximately 10:40. The structures south of town limits on Lago Vista Way and Sierra del Sol were threatened in the late morning, with structures burning on both sides of Pentz Road by $10: 50$.

The fire spread west out of the Feather River Canyon in the area south of the town limits before 11:00. Between 11:30 and noon, $6 \mathrm{~m}$ (20 ft) tall flames were hopping the $9 \mathrm{~m}(30 \mathrm{ft})$ wide dozer lines and threatening structures to the east and south of Lago Vista Way. The fire reached Kunkle Reservoir by 12:15. Fire progression slowed down in the afternoon. By 16:00 the main fire activity had passed. Table $\mathbf{1 6}$ summarizes the fire progression in this focus area. 
Table 16. Summary of fire progression on Pentz Rd between Pearson Rd and Kunkle Reservoir.

\begin{tabular}{|c|c|c|c|c|}
\hline Date & Time Range & Fire Behavior Observations & Location & Source \# \\
\hline $11 / 8$ & $08: 40$ & Fire is well-established north of Chaney Ln. (Table 15) & $\begin{array}{l}\text { Pentz Rd north of Chaney } \\
\text { Ln }\end{array}$ & $\begin{array}{l}T D-005, T D-016 \\
T D-123, T D-122\end{array}$ \\
\hline $11 / 8$ & 09:00 & $\begin{array}{l}\text { Several fingers of fire are burning across Pentz Rd between York } \\
\text { Towne Manor and Malibu Dr. A defined wall of flames and smoke } \\
\text { marks the southern edge across Pentz Rd at Malibu Dr. }\end{array}$ & $\begin{array}{l}\text { Pentz Rd between York } \\
\text { Towne Manor and Malibu } \\
\text { Dr }\end{array}$ & $\begin{array}{l}\text { TD-079, TD-122 } \\
\text { TD-129, TD-209 }\end{array}$ \\
\hline $11 / 8$ & 09:20 & $\begin{array}{l}\text { The first report of structures on fire south of Pearson Rd is on } \\
\text { Yorke Town Manor. There is a wall of flames and heavy ember } \\
\text { cast. }\end{array}$ & York Towne Manor & TD-086 \\
\hline $11 / 8$ & 09:30 & Fire crosses Pentz Rd between York Towne Manor and Malibu Dr & $\begin{array}{l}\text { Pentz Rd between York } \\
\text { Towne Manor and Malibu } \\
\text { Dr }\end{array}$ & TD-009 \\
\hline $11 / 8$ & $09: 40 \quad 09: 50$ & $\begin{array}{l}\text { Fire encroaches on the intersection of Pentz Rd and Pearson Rd } \\
\text { from all directions. }\end{array}$ & Pentz Rd at Pearson Rd & $\begin{array}{l}\text { TD-122, TD-129 } \\
\text { VTD-21, VTD-23 }\end{array}$ \\
\hline $11 / 8$ & 10:00 & $\begin{array}{l}\text { Fire is burning in on the edge of the canyon south of town limits, } \\
\text { east of Lago Vista Dr. }\end{array}$ & east of Lago Vista Dr & TD-086 \\
\hline $11 / 8$ & $10: 40$ & $\begin{array}{l}\text { The intersection of Pentz } R d \text { and Pearson Rd remains fully } \\
\text { involved. (Table 21) }\end{array}$ & Pentz Rd and Pearson Rd & $T D-037$ \\
\hline $11 / 8$ & $10: 50$ & $\begin{array}{l}\text { Peak vegetation fire activity has subsided, but significant fire } \\
\text { remains. Most structures and heavy fuels are burning on both sides } \\
\text { of Pentz Rd. The road is passable with variable visibility. }\end{array}$ & $\begin{array}{l}\text { Pentz Rd between Pearson } \\
\text { Rd to Malibu Dr }\end{array}$ & $\begin{array}{l}\text { TD-020, TD-090 } \\
\text { TD-209 }\end{array}$ \\
\hline $11 / 8$ & $11: 30 \quad 12: 00$ & $\begin{array}{l}\text { Fire activity in thick, } 3.6 \mathrm{~m}(12 \mathrm{ft}) \text { brush and grass is increasing and } \\
\text { spreading west toward Lago Vista Dr. } 6 \mathrm{~m}(20 \mathrm{ft}) \text { tall flames are } \\
\text { hopping } 9 \mathrm{~m}(30 \mathrm{ft}) \text { wide dozer lines and threatening structures. }\end{array}$ & east of Lago Vista Dr & TD-086 \\
\hline $11 / 8$ & $11: 45 \quad 12: 15$ & $\begin{array}{l}\text { The southern extent of fire has reached Sierra del Sol and Kunkle } \\
\text { Reservoir. }\end{array}$ & $\begin{array}{l}\text { Pentz Rd and Sierra del } \\
\text { Sol }\end{array}$ & $\begin{array}{l}\text { TD-086, TD-118 } \\
\text { PPD-08 }\end{array}$ \\
\hline $11 / 8$ & $13: 00$ & $\begin{array}{l}\text { Fire continues west, spotting over dozer lines toward structures on } \\
\text { Pentz Rd south of Lago Vista Dr. }\end{array}$ & Pentz Rd at Lago Vista Dr & TD-086 \\
\hline $11 / 8$ & $14: 00$ & $\begin{array}{l}\text { Fire is actively crossing to west of Pentz Rd at Dry Creek Rd; } \\
\text { numerous spot fires are burning in Sierra del Sol. Fire continues } \\
\text { spreading south and threatening rural structures south of Sierra del } \\
\text { Sol. }\end{array}$ & Kunkle Reservoir & $\begin{array}{l}\text { TD-086, TD-115 } \\
\text { TD-121 }\end{array}$ \\
\hline $11 / 8$ & $16: 00$ & $\begin{array}{l}\text { Main fire activity has passed. Multiple structures have burned to } \\
\text { foundations. A few scattered structures are fully involved. }\end{array}$ & $\begin{array}{l}\text { Sunset Oaks Dr and Sierra } \\
\text { del Sol }\end{array}$ & VTD-27 \\
\hline $11 / 8$ & $17: 00$ & $\begin{array}{l}\text { Fire activity increases and blows westward across Pentz at Kunkle } \\
\text { Reservoir. Fire quickly spreads south/southwest down the canyon. } \\
\text { (Table 30) }\end{array}$ & south of Sierra del Sol & $T D-121$ \\
\hline
\end{tabular}




\subsubsection{Feather River Hospital (FRH) Fire Progression Summary}

The first spot fire reported in the vicinity of the hospital was the Lowry Lane spot at 07:50, and fire subsequently approached the hospital campus. The first 911 calls reporting hospital buildings on fire were received at 08:30. Figure 29 shows conditions on the FRH campus as evacuations were nearing completion at 08:54, with structures seen burning in the background. Within a short time period, blackout conditions prevailed as ember showers impacted the campus.

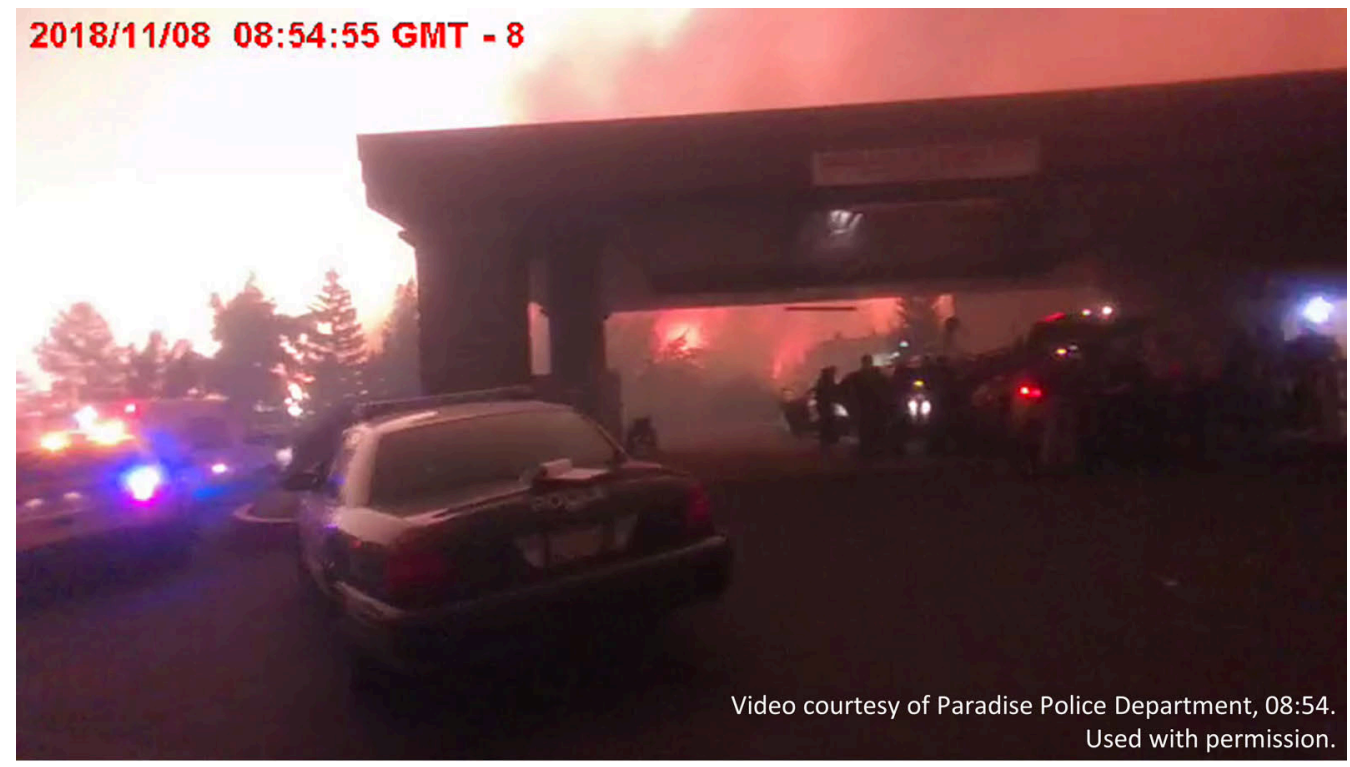

a)

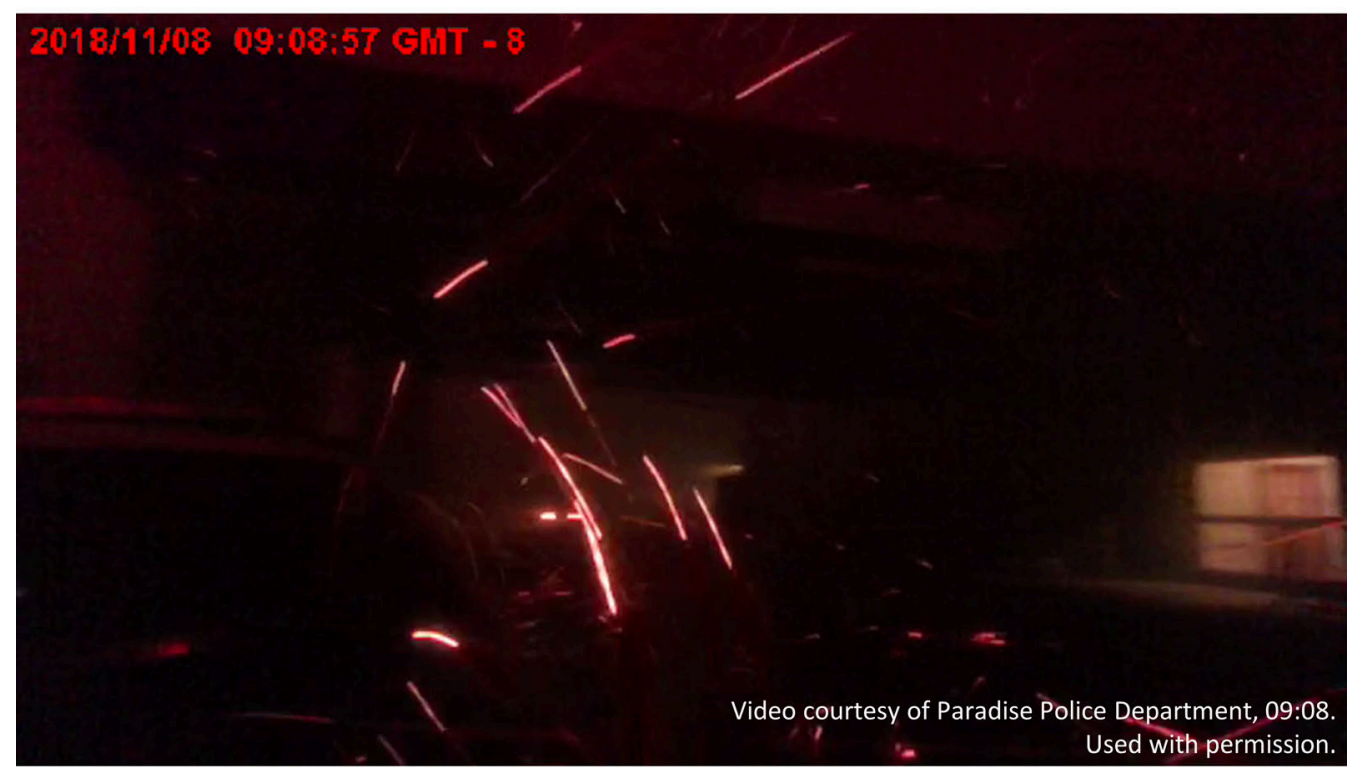

b)

Figure 29. a) Fire burning on the Feather River Hospital campus before 08:54. b) Blackout conditions and heavy showers of large embers at 09:08. The video documents ember showers coming from the west as the fire front arrived from the east. 
Between 08:30 and 13:30, multiple buildings on the FRH campus ignited; many were defended. Figure 30 illustrates the morning conditions at FRH as spot fires started in vegetation, threatening the structures and generating embers. The main clinic building was destroyed, and other buildings were damaged. A large portion of the hospital, the cardiology building, ignited in the late morning and fire became established inside, as shown in Figure 31. Much of the building was destroyed, but the overall hospital structure was saved from burning. The defensive actions at the FRH will be detailed in NIST Camp Fire Report \#5. Table 17 summarizes the fire progression at FRH.

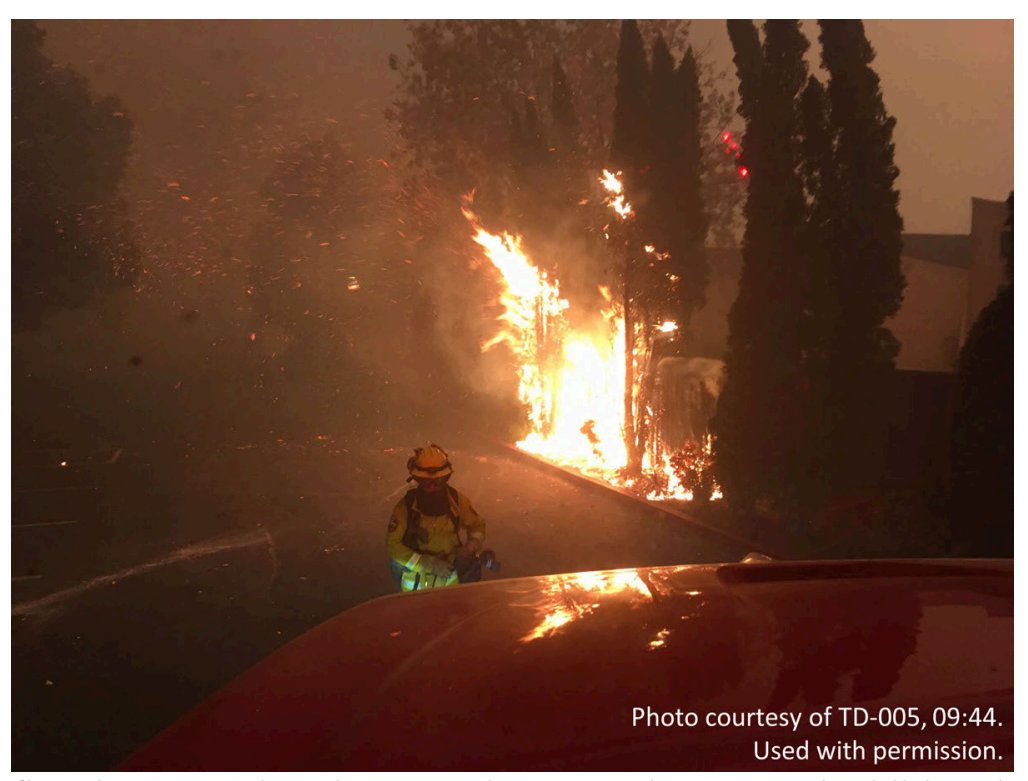

Figure 30. Spot fires in vegetation threatened FRH and generated additional ember showers.

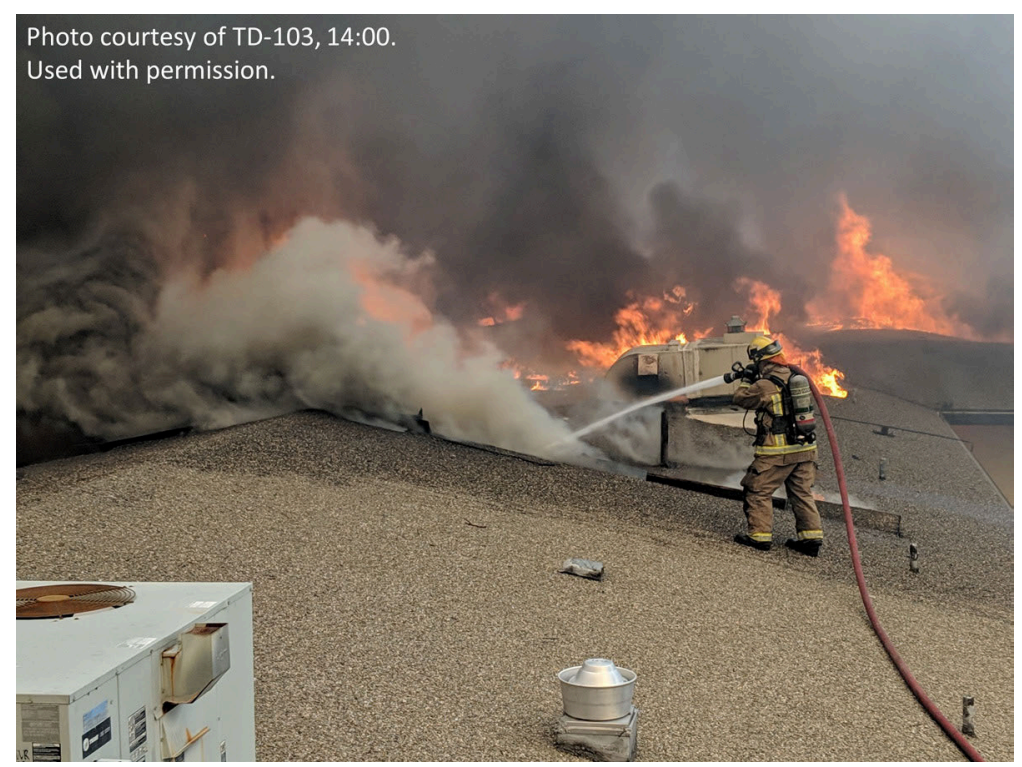

Figure 31. The cardiology section of FRH was destroyed. Extensive firefighting efforts prevented spread to other portions of the facility. 
Table 17. Summary of fire progression at Feather River Hospital.

\begin{tabular}{|c|c|c|c|c|c|}
\hline Date & Time & Range & Fire Behavior Observations & Location & Source \# \\
\hline $11 / 8$ & 07:50 & 08:00 & $\begin{array}{l}\text { Multiple } 911 \text { calls and PPD officer report a spot fire on the west } \\
\text { side of the canyon behind homes on Lowry Ln and Riverview Dr. }\end{array}$ & $\begin{array}{l}\text { Lowry Ln, Riverview Dr, } \\
\text { just south of FRH }\end{array}$ & a \\
\hline $11 / 8$ & 08:00 & 08:10 & $\begin{array}{l}\text { Fire approaches the hospital campus from the canyon by the } \\
\text { retirement home and from the spot fire near Lowry Ln. Spot fires } \\
\text { also ignite on campus. }\end{array}$ & Feather River Hospital & a \\
\hline $11 / 8$ & $08: 30$ & & The first 911 calls reporting hospital buildings on fire are received. & Feather River Hospital & a \\
\hline $11 / 8$ & $08: 40$ & & $\begin{array}{l}\text { The clinic building is on fire to the southeast of the main hospital } \\
\text { building. }\end{array}$ & Clinic & a \\
\hline $11 / 8$ & 08:40 & & Fire is burning on the patio of the OB unit. & Birth Day Place & a \\
\hline $11 / 8$ & 09:10 & & $\begin{array}{l}\text { Ember showers increase dramatically. Embers are exploding and } \\
\text { skittering across pavement. Multiple spot fires ignite in mulch and } \\
\text { bushes. There is widespread surface fire burning on the west side of } \\
\text { Pentz Rd, southwest of the hospital. }\end{array}$ & Feather River Hospital & a \\
\hline $11 / 8$ & 09:20 & & $\begin{array}{l}\text { Pentz Rd is inaccessible due to heavy fire and fire engine activity } \\
\text { south of hospital. (Table 15) }\end{array}$ & Pentz Rd south of FRH & a \\
\hline $11 / 8$ & 09:30 & & $\begin{array}{l}\text { Flames are showing from the HVAC support building. The building } \\
\text { continues to burn and flare-up over the next } 24 \text { hours. }\end{array}$ & HVAC/utility building & a \\
\hline $11 / 8$ & 09:43 & & $\begin{array}{l}\text { A spot fire against the building alcoves is torching juniper trees and } \\
\text { a fence, spewing embers. }\end{array}$ & Birth Day Place & a \\
\hline $11 / 8$ & 10:00 & $10: 30$ & There is a fire in attic of the cancer center. & Cancer Center & a \\
\hline $11 / 8$ & $10: 15$ & $11: 30$ & $\begin{array}{l}\text { There is a small fire on the roof of the main building of the } \\
\text { retirement home. Bark mulch against the building is burning and } \\
\text { igniting OSB underneath the vinyl and shows rapid fire growth. All } \\
\text { condo units are burned to foundation. Multiple auxiliary buildings } \\
\text { are burning. The main fire activity in the surrounding area is over. }\end{array}$ & $\begin{array}{l}\text { Feather Canyon } \\
\text { Retirement Home }\end{array}$ & a \\
\hline $11 / 8$ & $10: 30$ & & $\begin{array}{l}\text { Fire begins in the eaves and gutters of the lower portion of the } \\
\text { hospital cardiology wing. Fire spreads in the roof. Throughout the } \\
\text { day, wind directed straight down the hallways would flare-up } \\
\text { through trench cuts in the roof. }\end{array}$ & Cardiology & a \\
\hline $11 / 8$ & $11: 45$ & $12: 00$ & $\begin{array}{l}\text { A patient room catches fire in the Family Health Center and } \\
\text { damages the patient room and exterior wall. }\end{array}$ & Family Health Center & a \\
\hline $11 / 8$ & $13: 30$ & & $\begin{array}{l}\text { The cardiology building is well involved, beginning to threaten the } \\
\text { main hospital. }\end{array}$ & Cardiology & a \\
\hline $11 / 8$ & $13: 30$ & & $\begin{array}{l}\text { Multiple structures are still burning, fully involved on the west side } \\
\text { of Pentz Rd. Others have already burned down. }\end{array}$ & $\begin{array}{l}\text { Eastwoods Professional } \\
\text { Park }\end{array}$ & a \\
\hline $11 / 8$ & $15: 00$ & & $\begin{array}{l}\text { The cardiology building is still burning, and the north end is } \\
\text { partially collapsed. The building continues to burn overnight. }\end{array}$ & Cardiology & a \\
\hline
\end{tabular}

a Information sources for the fire events at Feather River Hospital include:

TD-005, TD-014, TD-016, TD-020, TD-055, TD-063, TD-069, TD-090, TD-103, TD-109, TD-111, TD-112, TD-124, TD-130, TD-143,

VTD-17, PPD-01, PPD-04, PPD-05, 911-064-1, 911-066-1, 911-071-1, 911-084-1, 911-086-3, 911-1035-1, 911-104-1, 911-1047-1, 911-

1054-2, 911-131-1, 911-134-1, 911-137-1, 911-179-1, 911-208-1, 911-210-1 


\subsubsection{Wagstaff Road Fire Progression Summary}

Wagstaff Road was affected by multiple spot fire ignitions. The first report was at 07:55 at the Ridgewood Mobile Home Park on Pentz Road as the fire started becoming established along the Pentz Road corridor. At 08:30, a wave of spot fires ignited along the length of Wagstaff Road, including one west of Skyway in Little Butte Creek Canyon (2.5 km, 1.6 mi, west of Pentz Road), several near Rocky Lane and the bike path, and several around the intersection with Clark Road. Each of these spot fires grew and caused significant impacts. The first structure fire was also observed at 08:30, reported via 911 on Harvey Road.

The main fire front impacted Pentz Road at Wagstaff Road by 09:00 and was consuming the mobile home parks and threatening evacuating vehicles. At the same time, the spot fire near Rocky Lane was becoming well-established, burning toward the intersection of Wagstaff Road and Skyway and overrunning evacuees by 09:30.

At 10:00, there were multiple areas of significant fire on Wagstaff Road with numerous structures burning. These included the intersection of Pentz Road, the residential structures behind (east and south of) the Save Mart and Kmart at Paradise Plaza shopping center, and the area near Skyway at Berkshire Avenue and Oak Way. Figure 32 shows an image from a video recorded at Oak Way at 10:17. The image shows significant fire activity, airborne embers, and dark, smoky conditions. Figure 33 is a photograph taken five minutes later at 10:22 behind the Save Mart, just over $1 \mathrm{~km}(0.75 \mathrm{mi})$ east of the location in Figure 32. There was a significant difference in visibility and fire activity in a short distance. Spot fires began behind the structures seen in Figure 33 between 08:35 and 08:45.

At 11:00, there was significant fire impacting the area north and west of the Skyway intersection. The spot fires that began in Little Butte Creek Canyon had grown and were consuming structures between the canyon and Wagstaff Road. The fire continued to spread through the area west of Skyway. By 16:00, the main fire activity along Wagstaff Road was over; however, structures were threatened throughout the evening. Table 18 contains the fire progression summary for Wagstaff Road. 


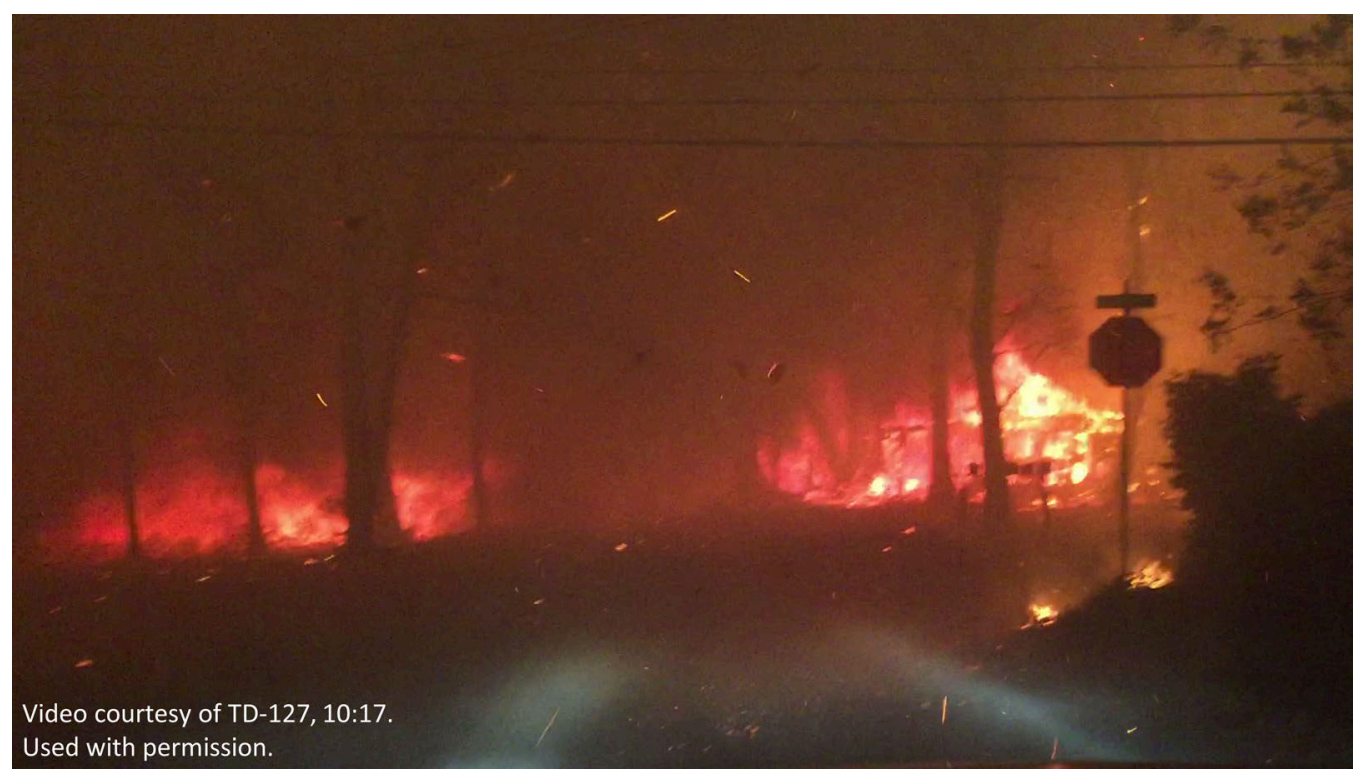

Figure 32. Midnight darkness, swirling winds, heavy ember showers, and fully involved structures at the intersection of Oak Way and Wagstaff Rd at 10:17. View north.

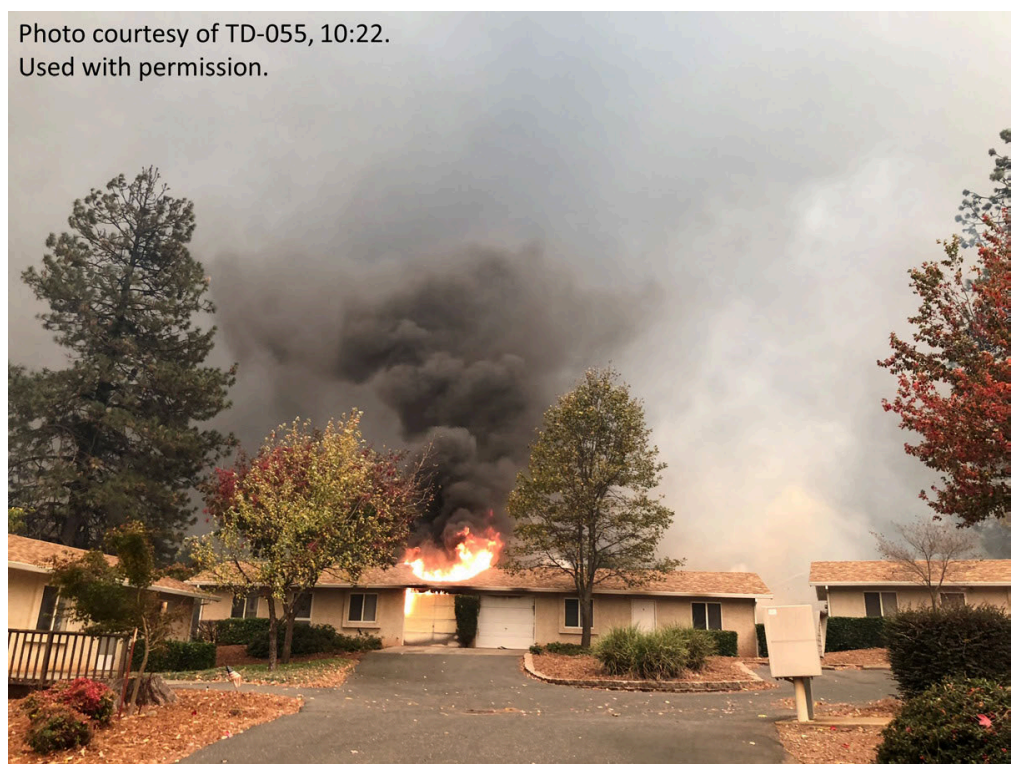

Figure 33. A structure on Wagstaff Rd just east of Clark Rd (behind Save Mart) is burning at 10:22. View south. 
Table 18. Summary of fire progression on Wagstaff Rd.

\begin{tabular}{|c|c|c|c|c|}
\hline Date & Time Range & Fire Behavior Observations & Location & Source \# \\
\hline $11 / 8$ & $07: 55$ & $\begin{array}{l}\text { A call to } 911 \text { reports the first spot fire in vegetation in Ridgewood } \\
\text { Mobile Home Park. (Table 13) }\end{array}$ & Wagstaff Rd and Pentz Rd & $911-077-3$ \\
\hline $11 / 8$ & 08:25 & $\begin{array}{l}\text { The first spot fire west of Clark Rd, located near Rocky Ln and } \\
\text { Wagstaff Rd, is called in to } 911 .\end{array}$ & $\begin{array}{l}\text { Wagstaff Rd and } \\
\text { Rocky Ln }\end{array}$ & $\begin{array}{l}911-128-1 \\
911-129-1\end{array}$ \\
\hline $11 / 8$ & 08:30 & $\begin{array}{l}\text { Additional spot fires start on the north side of Wagstaff Rd between } \\
\text { Clark Rd and Pentz Rd. }\end{array}$ & $\begin{array}{l}\text { Wagstaff Rd between } \\
\text { Clark Rd and Pentz Rd }\end{array}$ & TD-064 \\
\hline $11 / 8$ & 08:30 & A citizen reports a house on fire on Harvey Rd. & Harvey Rd & $911-141-2$ \\
\hline $11 / 8$ & 08:35 $08: 45$ & $\begin{array}{l}\text { A spot fire begins in a grass field behind (east of) Save Mart and } \\
\text { spread to pine trees. At the same time, an additional spot fire is } \\
\text { starting at the Paradise United Methodist Church and the School } \\
\text { District office. (Table 22) }\end{array}$ & $\begin{array}{l}\text { Wagstaff Rd east of } \\
\text { Clark Rd }\end{array}$ & $\begin{array}{l}\text { TD-067, TD-075 } \\
\text { PPD-02 } \\
911-157-1 \\
911-158-1\end{array}$ \\
\hline $11 / 8$ & 08:40 & Smoke is seen rising from a spot fire in Little Butte Creek Canyon. & $\begin{array}{l}\text { Little Butte Creek Canyon } \\
\text { north of Wagstaff Rd }\end{array}$ & $911-163-1$ \\
\hline $11 / 8$ & 08:40 $08: 50$ & $\begin{array}{l}\text { Multiple citizens report a new spot fire in the area of Wagstaff Rd } \\
\text { and the bike path, near Berkshire Ave. (Table 25) }\end{array}$ & $\begin{array}{l}\text { Wagstaff Rd and } \\
\text { Berkshire Ave }\end{array}$ & $\begin{array}{l}T D-015 \\
911-162-1 \\
911-169-1 \\
911-178-2 \\
911-195-4\end{array}$ \\
\hline $11 / 8$ & 08:40 & $\begin{array}{l}\text { The main fire front is approaching Pentz Rd. Multiple spot fires are } \\
\text { burning in the area of Pentz Rd and Wagstaff Rd. Half of } \\
\text { Ridgewood Mobile Home Park is burning. (Table 12) }\end{array}$ & Wagstaff Rd and Pentz Rd & $\begin{array}{l}T D-014, T D-042 \\
T D-043, T D-067 \\
\quad P P D-02\end{array}$ \\
\hline $11 / 8$ & 08:50 09:00 & $\begin{array}{l}\text { The fire reaches Pentz Rd. Ridgewood and Ponderosa Mobile } \\
\text { Home Parks are burning. Trees are igniting at the intersection and } \\
\text { fire is threatening evacuating vehicles. }\end{array}$ & Wagstaff Rd and Pentz Rd & $\begin{array}{l}\text { TD-043, TD-085 } \\
\text { PPD-02 }\end{array}$ \\
\hline $11 / 8$ & 08:50 09:15 & $\begin{array}{l}\text { Fire is pinching Wagstaff Rd between Skyway and Clark Rd. Fire is } \\
\text { burning from the NE into the area of Rocky Ln, and the spot near } \\
\text { the bike path is well established. The intersection of Skyway and } \\
\text { Wagstaff Rd will be impacted soon. Multiple cars are on fire. } \\
\text { (Table 25) }\end{array}$ & $\begin{array}{l}\text { Wagstaff Rd between } \\
\text { Skyway and Clark Rd }\end{array}$ & $\begin{array}{l}\text { TD-017, TD-042 } \\
T D-053, T D-111 \\
\quad T D-127\end{array}$ \\
\hline $11 / 8$ & $09: 30 \quad 09: 45$ & $\begin{array}{l}\text { Additional pine trees torch behind Save Mart and fire wraps south } \\
\text { around the shopping center. }\end{array}$ & $\begin{array}{l}\text { Wagstaff Rd east of } \\
\text { Clark Rd }\end{array}$ & TD-052, VTD-18 \\
\hline $11 / 8$ & $09: 35$ & $\begin{array}{l}\text { Structures are burning and vehicles are about to be overrun by fire } \\
\text { on Wagstaff Rd near Skyway and the bike path as fire spreads } \\
\text { across to south of Wagstaff Rd. (Table 25) }\end{array}$ & $\begin{array}{l}\text { Wagstaff Rd and } \\
\text { Berkshire Ave }\end{array}$ & $T D-055, T D-127$ \\
\hline $11 / 8$ & 10:00 & $\begin{array}{l}\text { The general area of Wagstaff Rd and Oak Way is fully involved. } \\
\text { Everything is burning and considerable ember showers are swirling. } \\
\text { The fire continues pushing S and W. }\end{array}$ & $\begin{array}{l}\text { Wagstaff Rd between } \\
\text { Berkshire Ave and } \\
\text { Rocky Ln }\end{array}$ & $\begin{array}{l}\text { TD-022, TD-014 } \\
\text { TD-127, VTD-26 }\end{array}$ \\
\hline $11 / 8$ & $10: 45$ & $\begin{array}{l}\text { The spot fire(s) in the canyon has become more established and is } \\
\text { generating a noticeable smoke plume. }\end{array}$ & $\begin{array}{l}\text { Little Butte Creek Canyon } \\
\text { north of Wagstaff Rd }\end{array}$ & VTD-26 \\
\hline $11 / 8$ & $11: 00$ & $\begin{array}{l}\text { Structures and vegetation north of Wagstaff Rd on the edge of the } \\
\text { canyon are engulfed in intense fire. Embers enter vehicle when } \\
\text { opening the door. }\end{array}$ & $\begin{array}{l}\text { Wagstaff Rd and } \\
\text { Paragalia Way }\end{array}$ & TD-017 \\
\hline $11 / 8$ & $11: 30$ & $\begin{array}{l}\text { Fire continues to spread through area of Wagstaff Rd west of } \\
\text { Skyway. }\end{array}$ & $\begin{array}{l}\text { Wagstaff Rd west of } \\
\text { Skyway }\end{array}$ & TD-127 \\
\hline $11 / 8$ & $11: 30 \quad 13: 00$ & $\begin{array}{l}\text { Kmart and the shopping center are threatened as fire burns } \\
\text { structures around the perimeter. Shrubs are igniting from embers } \\
\text { throughout the parking lot. }\end{array}$ & Wagstaff Rd and Clark Rd & $\begin{array}{l}\text { TD-015, TD-017 } \\
\text { TD-043, VTD-18 }\end{array}$ \\
\hline $11 / 8$ & $12: 00 \quad 13: 00$ & $\begin{array}{l}\text { Fire continues impacting more structures along Wagstaff Rd. Most } \\
\text { activity is to the west side of Clark Rd by this time. }\end{array}$ & $\begin{array}{l}\text { Wagstaff Rd west of } \\
\text { Clark Rd }\end{array}$ & $\begin{array}{l}\text { TD-065, TD-100 } \\
\text { TD-127, VTD-18 }\end{array}$ \\
\hline $11 / 8$ & $16: 00$ & $\begin{array}{l}\text { The main fire activity is over, and the majority of structure } \\
\text { destruction has already occurred. Remaining fire activity continues } \\
\text { to threaten surviving structures for several hours. }\end{array}$ & Wagstaff Rd & $\begin{array}{l}\text { TD-014, TD-065 } \\
\text { TD-108, TD-127 } \\
\text { TD-200, TD-202 } \\
\text { TD-205, TD-207 }\end{array}$ \\
\hline
\end{tabular}




\subsubsection{Bille Road Fire Progression Summary}

Multiple calls to 911 and observations by first responders reported fires along Bille Road between 08:30 and 09:00, including one on the west side of Skyway. By 09:00, several scattered structures were burning in this region ahead of the main fire, which was located on Pentz Road. At approximately 09:30, the main fire front impacted the intersection of Bille Road and Pentz Road. Shortly after, fire impacted traffic that was stuck near Tyden Way. Figure 34 shows the burned vehicles 48 hours after the burnover and after vehicles were moved by a bulldozer to clear the roadway. Heavy fire conditions surrounded the intersection, burning structures and vehicles until 11:30. Section 9.3 describes the burnover event in more detail.

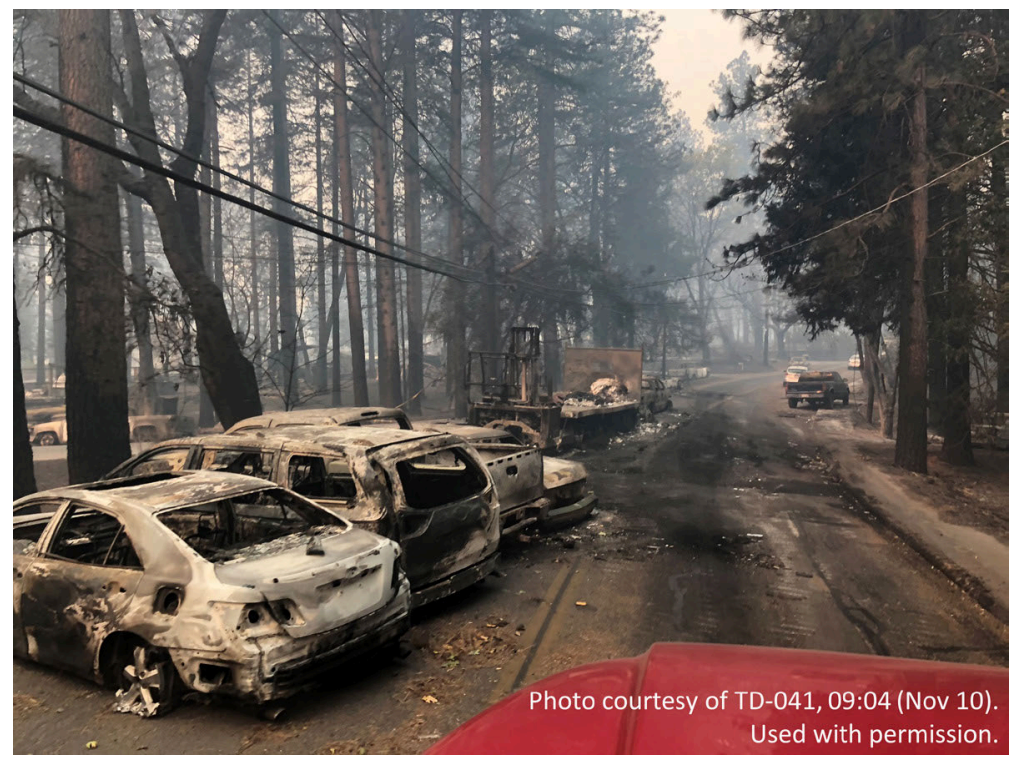

Figure 34. Abandoned vehicles on Bille Rd, seen after the fire, pushed aside by a bulldozer. Evacuees were overrun by fire around 09:50. View west.

Spot fires between Skyway and Clark Road grew, and fire spread south from the established fire on Wagstaff Road between 10:00 and 11:00. Shortly after 11:30, fire was encroaching on the intersection of Skyway and Bille Road. At the same time, fire was also impacting Bille Road west of Skyway. Vehicles stuck in traffic were igniting, and structures were burning in the area north of Bille Road between Oliver Road and Skyway.

Throughout the early afternoon, fires continued burning more structures, merging, and filling in the unburned areas along Bille Road west of Clark Road. In the evening, most fire activity was on the west end of Bille Road; Figure 35 shows the view east on Bille Road at Lucky John Road. Fire activity increased in the Little Butte Creek Canyon, and wind driven flames torched the area of Cliff Drive and burned toward Oliver Road.

Surviving structures east of Clark Road were threatened again overnight around Lancaster Drive, as indicated in the radio transcription. Based on radio communications, 7 or 8 engines were sent to the area. Many structures survived. Table 19 contains the fire progression summary for Bille Road. 


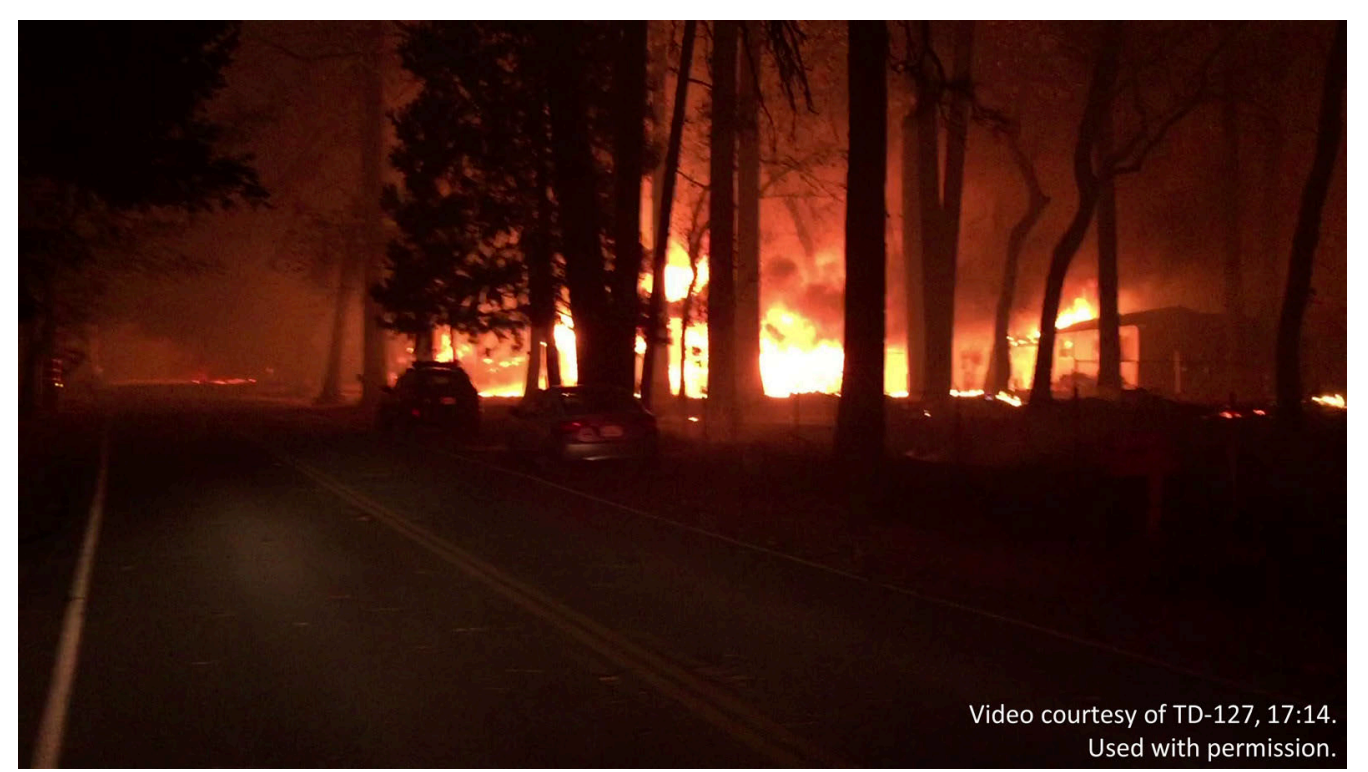

Figure 35. Fire activity on Bille Rd near Lucky John Rd, west of Skyway, at 17:14. Numerous structures are fully involved, while others are burned down or just starting to ignite. 
Table 19. Summary of fire progression on Bille Rd.

\begin{tabular}{|c|c|c|c|c|c|}
\hline Date & Time & Range & Fire Behavior Observations & Location & Source \# \\
\hline $11 / 8$ & 08:30 & & Spot fire west of Skyway & west of Skyway & $911-143-1$ \\
\hline $11 / 8$ & 08:40 & 09:00 & Multiple spot fires have started between Skyway and Clark Rd. & $\begin{array}{l}\text { Bille Rd between Skyway } \\
\text { and Clark Rd }\end{array}$ & $\begin{array}{l}\text { TD-105, TD-111 } \\
911-170-2 \\
911-195-4\end{array}$ \\
\hline $11 / 8$ & 08:45 & & $\begin{array}{l}\text { Call to } 911 \text { reports a spot fire burning a fence toward the east end } \\
\text { of Bille Rd. }\end{array}$ & Bille Rd near Pentz Rd & $911-174-1$ \\
\hline $11 / 8$ & $08: 50$ & & $\begin{array}{l}\text { A spot fire is burning behind the Paradise Irrigation District offices } \\
\text { on Clark Rd. (Table 23) }\end{array}$ & Bille Rd and Clark Rd & $\begin{array}{l}T D-077, T D-111 \\
\quad 911-183-4\end{array}$ \\
\hline $11 / 8$ & 09:00 & & $\begin{array}{l}\text { Two structures are burning, fully involved, ahead of the fire front. } \\
\text { The main fire is east of Pentz Rd at this time. }\end{array}$ & $\begin{array}{l}\text { Bille Rd and Vista Knolls } \\
\text { Dr }\end{array}$ & TD-116 \\
\hline $11 / 8$ & 09:00 & & Heavy ember cast is impacting Pentz Rd. & Bille Rd and Pentz Rd & TD-116 \\
\hline $11 / 8$ & 09:00 & & $\begin{array}{l}\text { A structure is burning fully involved behind the post office } \\
\text { somewhere near Harvey Rd. }\end{array}$ & $\begin{array}{l}\text { Bille Rd west of Clark Rd, } \\
\text { near Harvey Rd }\end{array}$ & PPD-02 \\
\hline $11 / 8$ & 09:25 & & $\begin{array}{l}\text { Homes are igniting on the east side of Pentz Rd. Fire is about to } \\
\text { impact Bille Rd. }\end{array}$ & Pentz Rd and Bille Rd & TD-021, TD-038 \\
\hline $11 / 8$ & 09:35 & $11: 15$ & $\begin{array}{l}\text { Fire is burning through and around the Bille Rd and Pentz Rd } \\
\text { intersection. Mobile homes in Eden Roc Estates ignite and burn. }\end{array}$ & Pentz Rd and Bille Rd & $\begin{array}{l}\text { TD-015, TD-021 } \\
\text { TD-060, TD-079 } \\
\text { PPD-02 }\end{array}$ \\
\hline $11 / 8$ & 09:50 & & $\begin{array}{l}\text { In the curve on the east end of Bille Rd, fire is impacting vehicles } \\
\text { stuck and abandoned on road. See Section } 9.3 \text { for description of the } \\
\text { burnover event. }\end{array}$ & Pentz Rd and Bille Rd & $\begin{array}{l}\text { TD-021, TD-060 } \\
\text { TD-079, PPD-05 }\end{array}$ \\
\hline $11 / 8$ & 09:55 & & Fire is burning on the east side of the bike path near Berkshire Ave. & $\begin{array}{l}\text { Bille Rd and Berkshire } \\
\text { Ave }\end{array}$ & TD-064 \\
\hline $11 / 8$ & $10: 15$ & & $\begin{array}{l}\text { Fire is now pushing SW from Wagstaff Rd toward Bille Rd } \\
\text { between Skyway and Clark Rd. }\end{array}$ & $\begin{array}{l}\text { Bille Rd between Skyway } \\
\text { and Clark Rd }\end{array}$ & TD-014, TD-127 \\
\hline $11 / 8$ & $10: 30$ & & Structures are burning at Bille Rd and Harvey Rd. & Bille Rd and Harvey Rd & PPD-02 \\
\hline $11 / 8$ & $11: 00$ & & $\begin{array}{l}\text { The main fire is pushing south down Berkshire Ave, spreading to } \\
\text { structures. Fire spreads from structure to structure through Skyway } \\
\text { Villa Mobile Home Park. }\end{array}$ & $\begin{array}{l}\text { Bille Rd and Berkshire } \\
\text { Ave }\end{array}$ & $\begin{array}{l}\text { TD-022, TD-055 } \\
\text { TD-116 }\end{array}$ \\
\hline $11 / 8$ & 11:00 & & $\begin{array}{l}\text { Vehicles west of Skyway are igniting. Fire is burning the area north } \\
\text { of Bille Rd between Oliver Rd and Skyway. }\end{array}$ & $\begin{array}{l}\text { Bille Rd between Oliver } \\
\text { Rd and Skyway }\end{array}$ & TD-030 \\
\hline $11 / 8$ & $11: 30$ & $12: 30$ & $\begin{array}{l}\text { Fire is approaching and pinching the Walgreens and intersection } \\
\text { of Bille Rd and Skyway. Bushes and vegetation are igniting around } \\
\text { the area. (Table 25) }\end{array}$ & Bille Rd and Skyway & $T D-127$ \\
\hline $11 / 8$ & 12:00 & & $\begin{array}{l}\text { Vehicles are burning on Bille Rd east of Sawmill Rd. It sounds like } \\
\text { another push of fire is coming. }\end{array}$ & $\begin{array}{l}\text { Bille Rd between Sawmill } \\
\text { Rd and Pentz Rd }\end{array}$ & TD-118 \\
\hline $11 / 8$ & $12: 30$ & & $\begin{array}{l}\text { Areas along Bille Rd that initially experienced only scattered spot } \\
\text { fires are beginning to merge and fill in. }\end{array}$ & $\begin{array}{l}\text { Bille Rd between Skyway } \\
\text { and Clark Rd }\end{array}$ & TD-101, PPD-08 \\
\hline $11 / 8$ & $14: 45$ & & $\begin{array}{l}\text { Vehicles are still burning on Bille Rd, but now the roadway is } \\
\text { passable at this time. }\end{array}$ & Bille Rd near Pentz Rd & TD-069 \\
\hline $11 / 8$ & 14:00 & $15: 00$ & $\begin{array}{l}\text { Most structures along Bille Rd near Skyway are fully involved. } \\
\text { Some vehicles are burning and blocking the roadway. }\end{array}$ & $\begin{array}{l}\text { Bille Rd between Lucky } \\
\text { John Rd and Skyway }\end{array}$ & TD-066, PPD-15 \\
\hline $11 / 8$ & $16: 30$ & & The fire activity is past peak, and many structures are burned down. & Bille Rd and Clark Rd & VTD-18 \\
\hline $11 / 8$ & $16: 30$ & $17: 30$ & $\begin{array}{l}\text { The main fire activity is on the west end of Bille Rd. Fire is burning } \\
\text { out of the Little Butte Creek Canyon with } 90 \mathrm{~m} \text { ( } 300 \mathrm{ft}) \text { flames. } \\
\text { Many structures are burning. Embers are blowing around like a } \\
\text { blizzard, wind is blow-torching flames. Homes on Cliff Dr were } \\
\text { first to burn down. }\end{array}$ & $\begin{array}{l}\text { Cliff Dr, Bille Rd, Oliver } \\
\text { Rd, Valley View Dr }\end{array}$ & $\begin{array}{l}\text { TD-014, TD-044 } \\
\text { TD-111 }\end{array}$ \\
\hline $11 / 8$ & 23:30 & & $\begin{array}{l}\text { Surviving structures in the Lancaster Dr area are again threatened } \\
\text { by fire. }\end{array}$ & Bille Rd and Lancaster Dr & TD-008 \\
\hline
\end{tabular}




\subsubsection{Elliott Road Fire Progression Summary}

Spot fires in this focus area began at 08:00, east of Clark Road. The first spot was reported by multiple 911 calls and Paradise Police officers on Nunneley Road near Ingalls Road. This spot expanded during the morning until it was enveloped by the main fire front. Between 08:00 and 09:00, numerous additional spot fires were reported east of Sawmill Road as the fire burned intensely along Pentz Road further east. By 10:00, multiple structures were burning on Sawmill Road. Spot fire coverage increased during this time to affect the area between the early, now well-established fire on Nunneley Road and the main fire front now on Sawmill Road. By 11:00, fire was burning up to the back of the Safeway and other buildings in the Old Town Plaza shopping center at the intersection of Elliott Road and Clark Road. Most fire activity east of Clark Road was over, and structures had burned before 13:15.

In the early afternoon, the main fire activity shifted to the west side of Clark Road as fire progressed toward Skyway. By 15:00, the fire front was near the Holiday Market, burning along Maxwell Drive and affecting Paradise High School. Around 16:00, the fire impacted the downtown area of Skyway.

Note that while the main fire activity accounted for a large majority of the destruction, residual fires and scattered structure fires continued to threaten localized unburned areas and structures for an extended period of time. For example, at 01:45 November 9, a surviving structure on the east end of Elliott Road was discovered to be just starting to ignite and was able to be saved. Table 20 contains the fire progression summary for Elliot Road. 
Table 20. Summary of fire progression on Elliott Rd.

\begin{tabular}{|c|c|c|c|c|}
\hline Date & Time Range & Fire Behavior Observations & Location & Source \# \\
\hline $11 / 8$ & 08:00 & $\begin{array}{l}\text { A spot fire begins on Nunneley Rd. A large tree is burning, flames } \\
\text { are } 2 \mathrm{~m}(6+\mathrm{ft}) \text { tall. Pine needles are built up against structures. } \\
\text { Matchbox-sized embers are reaching at least as far west as Clark } \\
\text { Rd. }\end{array}$ & $\begin{array}{l}\text { Nunneley Rd between } \\
\text { Copeland Rd and } \\
\text { Ingalls Rd }\end{array}$ & $\begin{array}{l}\text { TD-035, TD-065 } \\
\text { TD-067, TD-074 } \\
\text { PPD-01 } \\
911-1030-10 \\
911-1041-1 \\
911-1051-1\end{array}$ \\
\hline $11 / 8$ & 08:00 & A structure is reportedly burning on Sawmill Rd. & $\begin{array}{l}\text { Sawmill Rd, north of } \\
\text { Elliott Rd }\end{array}$ & TD-069 \\
\hline $11 / 8$ & 08:20 09:00 & $\begin{array}{l}\text { Multiple } 911 \text { calls report numerous scattered spot fires between } \\
\text { Sawmill Rd and Pentz Rd. }\end{array}$ & $\begin{array}{l}\text { between Sawmill Rd and } \\
\text { Pentz Rd }\end{array}$ & $\begin{array}{c}\text { TD-013, TD-015 } \\
\text { PPD-04 } \\
911-127-1 \\
911-156-1 \\
911-148-1 \\
911-186-1 \\
911-195-1\end{array}$ \\
\hline $11 / 8$ & 09:20 & $\begin{array}{l}\text { The early spot fire on Nunneley Rd has spread. Additional } 911 \text { calls } \\
\text { report fire on Nunneley Rd east of Clark Rd is impacting the } \\
\text { evacuating traffic. }\end{array}$ & $\begin{array}{l}\text { Nunneley Rd near } \\
\text { Newland Rd }\end{array}$ & $\begin{array}{l}911-230-2 \\
911-230-4\end{array}$ \\
\hline $11 / 8$ & $10: 10$ & $\begin{array}{l}\text { Fire is blocking Sawmill Rd north of Nunneley Rd. Structures on } \\
\text { the east side of Sawmill Rd are burning. }\end{array}$ & $\begin{array}{l}\text { Sawmill Rd and } \\
\text { Nunneley Rd }\end{array}$ & $\begin{array}{l}\text { TD-070, TD-123 } \\
\text { PPD-05 }\end{array}$ \\
\hline $11 / 8$ & $10: 25$ & $\begin{array}{l}\text { Widespread fire is affecting the area east of Clark Rd, north of } \\
\text { Nunneley Rd. Spot fires are numerous in the area of Nunneley Rd } \\
\text { and Middle Libby Rd. }\end{array}$ & $\begin{array}{l}\text { Nunneley Rd east of } \\
\text { Clark Rd }\end{array}$ & TD-112, PPD-02 \\
\hline $11 / 8$ & $10: 50 \quad 11: 20$ & $\begin{array}{l}\text { Fire is right behind (east of) Safeway. Spots are burning west of } \\
\text { Clark Rd. }\end{array}$ & $\begin{array}{l}\text { Clark Rd and } \\
\text { Nunneley Rd }\end{array}$ & $\begin{array}{l}\text { TD-035, TD-037 } \\
\text { TD-068, TD-070 } \\
\text { VTD-26 } \\
\text { PPD-02, PPD-08 }\end{array}$ \\
\hline $11 / 8$ & $11: 20$ & $\begin{array}{l}\text { The fire front is progressing west from Sawmill Rd. Structures east } \\
\text { of Ingalls Rd, previously unaffected by the early spot fire, are } \\
\text { starting to burn west of Sawmill Rd on Nunneley Rd. }\end{array}$ & $\begin{array}{l}\text { Nunneley Rd between } \\
\text { Ingalls Rd and } \\
\text { Sawmill Rd }\end{array}$ & TD-037, TD-112 \\
\hline $11 / 8$ & $12: 45$ & $\begin{array}{l}\text { Structures are burning south and east of Skyway in the area of } \\
\text { Almond St and Fir St. (Skyway) }\end{array}$ & Almond St and Fir St & $T D-026$ \\
\hline $11 / 8$ & $13: 15$ & $\begin{array}{l}\text { Heavy fire activity is mainly west of Clark Rd. Multiple active } \\
\text { structure fires are burning along Nunneley Rd. }\end{array}$ & $\begin{array}{l}\text { Nunneley Rd west of } \\
\text { Clark Rd }\end{array}$ & TD-021, TD-130 \\
\hline $11 / 8$ & 13:15 & Structures on Elliott Rd east of Clark Rd have already burned. & $\begin{array}{l}\text { Nunneley Rd east of } \\
\text { Clark Rd }\end{array}$ & TD-210 \\
\hline $11 / 8$ & 14:00 & $\begin{array}{l}\text { Main fire activity is west of Clark Rd; commercial structures on } \\
\text { Clark Rd are burning. (Table 23) }\end{array}$ & $\begin{array}{l}\text { Clark Rd between } \\
\text { Elliott Rd and Pearson Rd }\end{array}$ & $\begin{array}{l}T D-055, T D-108 \\
T D-133, T D-141\end{array}$ \\
\hline $11 / 8$ & $14: 30 \quad 15: 30$ & $\begin{array}{l}\text { The active fire front is approaching Skyway from the east. } \\
\text { Significant structure fires are burning on Almond St. Fire is } \\
\text { approaching the rear of Holiday Market (east) from the bike path. } \\
\text { East of Maxwell Dr, structures have already burned down, and fire } \\
\text { activity is past peak. Residential structures on Maxwell Dr north of } \\
\text { Elliott Rd are burning. }\end{array}$ & Skyway and Elliott Rd & $\begin{array}{l}\text { TD-014, TD-066 } \\
\text { TD-132, TD-135 } \\
\text { PPD-15 }\end{array}$ \\
\hline $11 / 8$ & $15: 00$ & $\begin{array}{l}\text { The downtown commercial area between Pearson Rd and Elliott } \\
\text { Rd gets heavily impacted by the fire front. (Table 26) }\end{array}$ & $\begin{array}{l}\text { Skyway between Elliott Rd } \\
\text { and Pearson Rd }\end{array}$ & $T D-014, T D-142$ \\
\hline $11 / 8$ & $15: 30$ & $\begin{array}{l}\text { Fire is burning on the high school campus. Portable classrooms are } \\
\text { burning, and a fire is on the roof of the main building. }\end{array}$ & $\begin{array}{l}\text { Paradise High School, } \\
\text { Maxwell Rd }\end{array}$ & $\begin{array}{l}\text { TD-015, TD-132 } \\
\text { TD-133, TD-141 }\end{array}$ \\
\hline $11 / 9$ & 01:42 & A structure is found to be just igniting on east end of Elliott Rd. & Elliott Rd and Nielsen Dr & TD-014 \\
\hline $11 / 9$ & 09:55 & Shadowbrook Apartments are burning. & Shadowbrook Way & TD-030, TD-111 \\
\hline
\end{tabular}




\subsubsection{Pearson Road and Buschmann Road Fire Progression Summary}

The first recorded observation of fire activity along Pearson Road was well into town at Paradise Elementary School before 08:30. Additional data about this observation was not found in this study, and the effects and timing of this fire observation are not known.

Around 09:00, spot fires first ignited in the drainage in the area of Stearns Road and Hilbe Drive as the main fire activity in Paradise was heavily impacting the Pentz Road corridor to the east. Before 09:30, multiple spots also started along Pearson Road as far west as Sawmill Road. The spot fires in the drainage grew rapidly, and by 09:40 the drainage was overcome with intense fire and ember showers, as seen in Figure 36a. Dozens of civilian vehicles were trapped on the roadway, seen in Figure 36b, and exposed to intense flames and large embers. Section 9.3 describes the burnover event in more detail.

The areas east of Sawmill Road were heavily impacted by fire during this time. The fire progressed westward down Pearson Road, with localized areas burning between Clark Road and Sawmill Road until about 11:30, after which fire had filled in and everything was burning or already burned. The majority of destruction and fire activity east of Clark Road was over by 14:00.

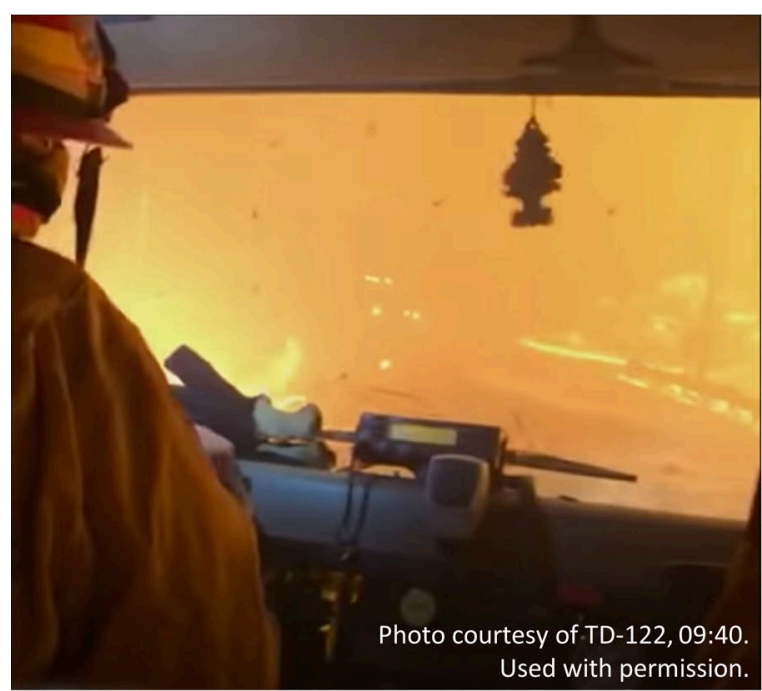

a)

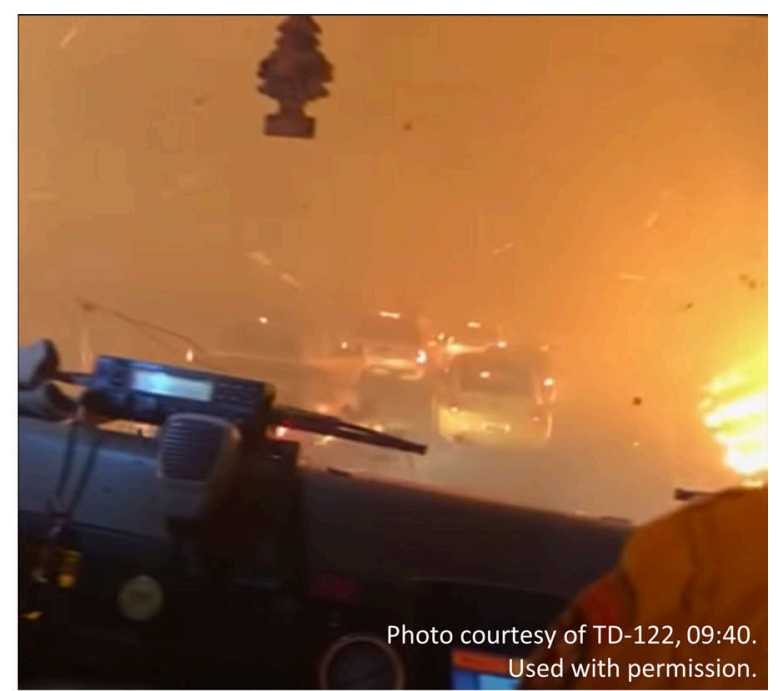

b)

Figure 36. Intense fire activity in the drainage at Pearson Rd and Hilbe Dr while civilians and first responders are stuck in the area. Views are eastbound, a) just east of Hilbe Dr, and b) just east of Hilltop Dr at the tail end of the traffic jam.

The area along Buschmann Road was affected earlier than the rest of Pearson Road west of Clark Road. Intense fire and ember showers impacted the intersection of Clark Road and Buschmann Road between 10:00 and 11:00, as fire from further south on Clark Road spread north and west into the area. This fire activity had significant impact on evacuating vehicles using Clark Road and Buschmann Road. 
After noon, the fire continued its push west and involved the areas west of Clark Road toward Skyway. Widespread and intense fire activity burning vegetation and structures was observed between 14:00 and 16:00 on western Pearson Road, particularly between Skyway and Academy Drive. Figure 37 shows representative conditions along this stretch of Pearson Road, with black out conditions and intense fire activity on fully involved parcels. By 16:00, there were approximately equal numbers of standing, burning, and destroyed structures visible on Pearson Road west of Clark Road. The majority of active fire spread had now moved to Skyway and the downtown portion of Paradise. Table 21 contains the fire progression summary for Pearson Road.

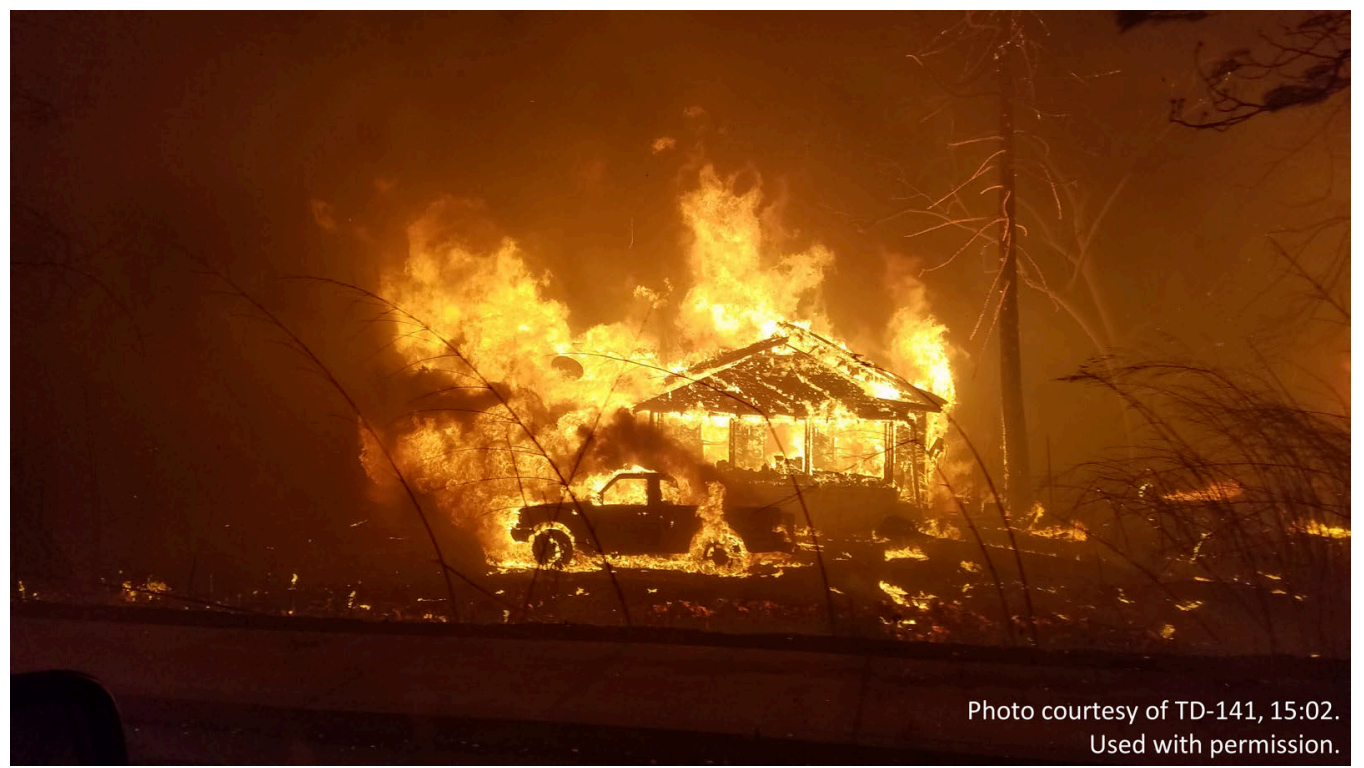

Figure 37. A fully involved parcel on Pearson Rd at Sierra Park Dr. 
Table 21. Summary of fire progression on Pearson Rd and Buschmann Rd.

\begin{tabular}{|c|c|c|c|c|c|}
\hline Date & Time & Range & Fire Behavior Observations & Location & Source \# \\
\hline $11 / 8$ & $08: 15$ & $08: 30$ & Report of flames ${ }^{\mathrm{a}}$ visible in area of Paradise Elementary School. & $\begin{array}{l}\text { Paradise Elementary } \\
\text { School }\end{array}$ & TD-054 \\
\hline $11 / 8$ & $08: 30$ & & $\begin{array}{l}\text { A spot fire, estimated about } 12 \text { ha ( } 30 \mathrm{ac}) \text {, is established in the } \\
\text { drainage east of Clark Rd near American Way. }\end{array}$ & $\begin{array}{l}\text { drainage east of Clark Rd } \\
\text { near American Way }\end{array}$ & TD-100 \\
\hline $11 / 8$ & $08: 30$ & 09:00 & $\begin{array}{l}\text { An ember storm is impacting the east end of Pearson Rd at Pentz } \\
R d \text {. Propane tanks and ammunition are heard exploding as Pentz } \\
R d \text { is impacted by the fire. (Table 15, Table 16) }\end{array}$ & Pearson Rd and Pentz Rd & $\begin{array}{l}T D-005, T D-034 \\
T D-036, T D-123\end{array}$ \\
\hline $11 / 8$ & 09:00 & & $\begin{array}{l}\text { Spot fire(s) ignite and become established in drainage south of } \\
\text { Pearson Rd in the area of Stearns Rd and Hilbe Dr. }\end{array}$ & Pearson Rd and Hilbe Dr & TD-037, TD-100 \\
\hline $11 / 8$ & 09:15 & & $\begin{array}{l}6 \mathrm{~m} \text { to } 9 \mathrm{~m} \text { ( } 20 \mathrm{ft} \text { to } 30 \mathrm{ft} \text { ) flames are observed in the drainage near } \\
\text { Hilbe Dr. }\end{array}$ & Pearson Rd and Hilbe Dr & TD-068 \\
\hline $11 / 8$ & 09:20 & $09: 30$ & $\begin{array}{l}\text { The first spot fire, } 6 \mathrm{~m} \times 6 \mathrm{~m}(20 \mathrm{ft} \times 20 \mathrm{ft}) \text { in pine needles and leaf } \\
\text { litter, is observed along Pearson Rd near Edgewood Ln. To the east, } \\
\text { fire is consuming the drainage including Stearns Rd, Pearson Rd, } \\
\text { and Hilbe Dr. }\end{array}$ & $\begin{array}{l}\text { Pearson Rd east of } \\
\text { Sawmill Rd }\end{array}$ & TD-037, TD-087 \\
\hline $11 / 8$ & $09: 35$ & & $\begin{array}{l}\text { Homes are burning on Henson Rd. This is the first report of burning } \\
\text { structures along Pearson Rd east of Sawmill Rd. }\end{array}$ & $\begin{array}{l}\text { Henson Rd; north and east } \\
\text { of Pearson Rd and } \\
\text { Sawmill Rd }\end{array}$ & TD-111 \\
\hline $11 / 8$ & 09:40 & 10:00 & $\begin{array}{l}\text { Intense fire consumes the drainage. Heavy fire in vegetative fuels } \\
\text { on both sides of the road with gusty NW winds produce extensive } \\
\text { ember showers that sound like pebbles. Fire burns through ground } \\
\text { fuels, debris in pickup truck bed ignites, fire overtakes civilian } \\
\text { vehicles and fire engine. Fire shelters were placed over windows, } \\
\text { engine gets torched, blew diesel tank vents. Structures begin } \\
\text { igniting from pine needles, propane tanks are exploding, and } \\
\text { vehicles melt and catch fire. Several civilians and law enforcement } \\
\text { officers escape on foot surrounded by heavy vegetation fire and } \\
\text { ember showers. See Section } 9.3 \text { for a description of the burnover } \\
\text { event. }\end{array}$ & $\begin{array}{l}\text { Pearson between Cherry } \\
\text { Ln and Pentz Rd }\end{array}$ & $\begin{array}{l}\text { TD-087, TD-122 } \\
\text { TD-129 } \\
\text { VTD-23 } \\
\text { VTD-24 } \\
\text { VTD-16 } \\
\text { PPD-05 }\end{array}$ \\
\hline $11 / 8$ & 10:00 & & Fires are observed on Angel Dr south of Pearson Rd. & Pearson Rd and Angel Dr & PPD-05 \\
\hline $11 / 8$ & 10:00 & & Pearson Rd is blocked by fire across roadway at Sawmill Rd. & $\begin{array}{l}\text { Pearson Rd and Sawmill } \\
\text { Rd }\end{array}$ & TD-070 \\
\hline $11 / 8$ & $\underset{\mathrm{b}}{10: 00}$ & & $\begin{array}{l}\text { Numerous spot fires, ember showers, and strong winds begin on } \\
\text { Buschmann Rd. Conditions last for several hours, threatening and } \\
\text { destroying structures. }\end{array}$ & Buschmann Rd & VTD-02 \\
\hline $11 / 8$ & 10:00 & $10: 20$ & $\begin{array}{l}\text { All structures around Pearson Rd and Stearns Rd are burning. } \\
\text { Quarter sized embers are falling. The main fire activity passes by } \\
\text { 10:20. See Section } 9.3 \text { for a description of the burnover event. }\end{array}$ & $\begin{array}{l}\text { Pearson Rd and Stearns } \\
\mathrm{Rd}\end{array}$ & $\begin{array}{l}\text { TD-087, TD-123 } \\
\text { VTD-23 }\end{array}$ \\
\hline $11 / 8$ & $10: 25$ & & $\begin{array}{l}\text { Scattered structure fires and woodpiles are burning along South } \\
\text { Libby Rd between Pearson Rd and Keller Ln. }{ }^{\mathrm{c}}\end{array}$ & South Libby Rd & TD-020 \\
\hline $11 / 8$ & $10: 30$ & $10: 45$ & $\begin{array}{l}\text { Fire overtakes vehicles evacuating on Clark Rd at Buschmann Rd. } \\
\text { Wind is blowing flames like a blow torch, spot fires and trees ignite. } \\
\text { Fire jumps to the west side of Clark Rd. Spot fires and scattered } \\
\text { structures begin burning west toward Scottwood Rd. (Table 24) }\end{array}$ & Buschmann Rd & $\begin{array}{l}T D-034, T D-065 \\
\quad P P D-02\end{array}$ \\
\hline $11 / 8$ & 11:00 & $11: 15$ & $\begin{array}{l}\text { Structures are igniting along Pearson Rd between Clark Rd and } \\
\text { South Libby Rd. The area is not fully involved yet, but fire is } \\
\text { present. Heavy fire is east of Middle Libby Rd; structures, } \\
\text { vegetation, and fences are all burning. Propane tanks are exploding } \\
\text { about } 1 \text { per minute. }\end{array}$ & $\begin{array}{l}\text { Pearson Rd between Clark } \\
\text { Rd and Sawmill Rd }\end{array}$ & $\begin{array}{l}\text { TD-020, TD-124 } \\
\text { TD-130 }\end{array}$ \\
\hline $11 / 8$ & $11: 30$ & & $\begin{array}{l}\text { Houses on the east side of Pearson Rd and South Libby Rd are } \\
\text { burning. Enchanted Forest Mobile Home Park is burning, and fire } \\
\text { continues pushing westward. }\end{array}$ & $\begin{array}{l}\text { Pearson Rd and South } \\
\text { Libby Rd }\end{array}$ & TD-37, TD-123 \\
\hline $11 / 8$ & 11:45 & 12:00 & $\begin{array}{l}\text { Fire approaches Pearson } R d \text { and Clark Rd and becomes } \\
\text { established in the area around the intersection. Spot fires, areas of } \\
\text { surface fires in heavy brush with } 4.5 \mathrm{~m}(15 \mathrm{ft} \text { ) flames and blowing } \\
\text { embers threaten Ace Hardware and ignite the Mobil gas station } \\
\text { and mobile homes. (Table 24) }\end{array}$ & Pearson Rd and Clark Rd & $\begin{array}{l}T D-037, T D-074 \\
T D-130\end{array}$ \\
\hline
\end{tabular}




\begin{tabular}{|c|c|c|c|c|}
\hline Date & Time Range & Fire Behavior Observations & Location & Source \# \\
\hline $11 / 8$ & $13: 00$ & $\begin{array}{l}\text { Significant fire activity on both sides of Pearson Rd between Clark } \\
\text { Rd and Libby Rd make the road barely passable. Enchanted Forest } \\
\text { Mobile Home Park is fully involved. The area south of Pearson Rd } \\
\text { on Newland Rd and Garden View Ln is a furnace; everything is } \\
\text { burning. }\end{array}$ & $\begin{array}{l}\text { Pearson Rd between Clark } \\
\text { Rd and South Libby Rd }\end{array}$ & $\begin{array}{l}\text { TD-014, TD-020 } \\
\text { TD- } 111, \text { TD- } 130 \\
\quad \text { TD- } 210\end{array}$ \\
\hline $11 / 8$ & $12: 00$ & $\begin{array}{l}\text { At the end of South Libby, timber and heavy fuels are still burning. } \\
\text { Structures are burning and some have already burned to the ground. }\end{array}$ & $\begin{array}{l}\text { south end of South Libby } \\
\text { Rd }\end{array}$ & $\begin{array}{l}\text { TD-014, TD-020 } \\
\text { TD-111, TD-123 }\end{array}$ \\
\hline $11 / 8$ & $13: 00$ & $\begin{array}{l}\text { Paradise Community Park is burning and } 10 \mathrm{~cm} \text { to } 13 \mathrm{~cm} \text { ( } 4 \text { in to } \\
5 \text { in) diameter embers are falling. Structures to the north of Paradise } \\
\text { PD are burning. }\end{array}$ & $\begin{array}{l}\text { Black Olive Dr and Birch } \\
\text { St }\end{array}$ & TD-026, TD-064 \\
\hline $11 / 8$ & $13: 00$ & Areas previously burned are observed burning a second time. & Pearson Rd and Hilbe Dr & TD-014 \\
\hline $11 / 8$ & $13: 45 \quad 14: 15$ & $\begin{array}{l}\text { The main fire activity is over east of Clark Rd. There is minimal } \\
\text { fire activity and most structures are burning rubble by this time. }\end{array}$ & $\begin{array}{l}\text { Pearson Rd between Clark } \\
\text { Rd and Pentz Rd }\end{array}$ & TD-130, TD-209 \\
\hline $11 / 8$ & $14: 50 \quad 15: 00$ & $\begin{array}{l}\text { The main fire activity on Pearson Rd is now west of Clark Rd. A } \\
\text { majority of structures are burning along Pearson Rd, including } \\
\text { Paradise Elementary School. Intense fire is burning on both sides of } \\
\text { Pearson Rd between Black Olive Dr and Academy Dr, including } \\
\text { many structures fully involved. }\end{array}$ & $\begin{array}{l}\text { Pearson Rd between } \\
\text { Skyway and Academy Dr }\end{array}$ & $\begin{array}{l}\text { TD-055, TD-069 } \\
\text { TD-100, TD-101 } \\
\text { TD-132, TD-141 } \\
\quad \text { PPD-15 }\end{array}$ \\
\hline $11 / 8$ & $15: 00$ & $\begin{array}{l}\text { A spot fire is observed burning against a commercial structure at } \\
\text { Skyway and Foster Rd. Smoke may be coming from the building. } \\
\text { (Table 26) }\end{array}$ & Skyway and Foster Rd & $T D-132$ \\
\hline $11 / 8$ & $15: 20$ & $\begin{array}{l}\text { A building is fully involved at Skyway and Foster Rd and there is no } \\
\text { other fire around. Waves of golf ball-sized embers are blowing } \\
\text { along the roadway. (Table 26) }\end{array}$ & Skyway and Foster Rd & $P P D-15$ \\
\hline $11 / 8$ & $15: 45$ & $\begin{array}{l}\text { Pearson Rd is passable between Skyway and Clark Rd. Structures } \\
\text { are equal parts burned to foundation, fully involved, or unburned } \\
\text { and standing. }\end{array}$ & $\begin{array}{l}\text { Pearson Rd between } \\
\text { Skyway and Clark Rd }\end{array}$ & PPD-15 \\
\hline $11 / 8$ & $16: 45$ & $\begin{array}{l}\text { Fire gets well-established in multiple commercial structures at } \\
\text { Skyway at Fir St, and fire continues to burn structures in the area } \\
\text { of Fire Station } 81 .(\text { Table 26) }\end{array}$ & $\begin{array}{l}\text { northeast of Pearson Rd } \\
\text { and Skyway }\end{array}$ & $T D-111, T D-142$ \\
\hline
\end{tabular}

${ }^{\text {a }}$ This observation is an outlier from a single source. It is possible that there are early spot fires in this area.

${ }^{\mathrm{b}}$ Time is a general estimate provided by single source VTD.

${ }^{c}$ Conditions further south on South Libby Rd were not described and fire may extend further than Keller Ln. 


\subsubsection{Clark Road Fire Progression Summary}

Much of the fire activity on Clark Road occurred simultaneously, as numerous spot fires ignited along this corridor, and the main fire front also passed through within roughly an hour on either side of 12:00 noon, with most significant destruction completed around 14:00. Clark Road is divided into three sections for added clarity. Table 22-Table 24 contain the fire progression summary for Clark Road.

\subsubsection{Skyway to CMA Church near Bille Road}

The first spot fires along Clark Road north of Bille Road ignited before 08:30 in the area of Apple Tree Village Mobile Home Park. Shortly after, a spot fire also began a mile north near the intersection with Skyway. Before 09:00, additional spots ignited near Wagstaff Road at the School District Office and east of the Save Mart in Paradise Plaza shopping center. Soon after, trees and vegetation were torching around the rear of the commercial buildings as fire wrapped around the southeast corner. Several residential structures were destroyed before 11:00.

Around the same 09:00 timeframe, a spot fire was becoming well-established in timber west of the CMA Church, between Wagstaff Road and Bille Road, working its way south toward Bille Road. Initial estimates were that it was already 0.4 ha (1 ac) in size.

At 11:00, fire had burned through surface fuels in the area of Clark Road and Forest Service Road near Fire Station 35. Mobile homes in Apple Tree Village were burning. Fire intensity increased between Adams Road and Kimberly Lane. By noon, the fire had spread north, with active fire now burning on both sides of Clark Road north of Kimberly Lane. The area immediately around the Skyway and Cabernet Lane intersections were still unburned; however, fire was moving closer to this area. Fire activity peaked around Clark Road and Skyway in the afternoon at about 14:30.

Through the evening, additional structures throughout the area were still burning. Trees and power poles blocked roadways in multiple locations. The area west of the Paradise Plaza, including the Pine Grove Mobile Home Park was generally unburned until 18:30, when fire got established and spread through the park, becoming fully involved by 20:00.

Table 22. Summary of fire progression on Clark Rd between Skyway and CMA Church.

\begin{tabular}{|c|c|c|c|c|}
\hline Date & Time Range & Fire Behavior Observations & Location & Source \# \\
\hline $11 / 8$ & $08: 15 \quad 08: 30$ & $\begin{array}{l}\text { Multiple spot fires are burning in and around Apple Tree Village } \\
\text { Mobile Home Park. }\end{array}$ & $\begin{array}{l}\text { Clark Rd and Kilcrease } \\
\text { Cir }\end{array}$ & $\begin{array}{l}\text { TD-015,VTD-09 } \\
911-161-2\end{array}$ \\
\hline $11 / 8$ & $08: 30$ & $\begin{array}{l}\text { A spot fire ignites on the south side of the intersection between } \\
\text { Skyway and Clark Rd, estimated initially at } 0.1 \text { ha }(0.25 \text { ac). } \\
\text { Multiple citizens report the fire to } 911 \text {. Trees are also observed on } \\
\text { fire at the northern end of Clark Rd. (Table 25) }\end{array}$ & Clark Rd and Skyway & $\begin{array}{c}\text { TD-058 } \\
911-141-1 \\
911-141-2 \\
911-152-1 \\
911-153-1 \\
911-155-1 \\
911-164-1\end{array}$ \\
\hline $11 / 8$ & $08: 35 \quad 08: 45$ & $\begin{array}{l}\text { A small spot fire is starting in grass at the Paradise United } \\
\text { Methodist Church and the School District office. A spot fire also } \\
\text { begins in a grass field behind (east of) Save Mart and spreads to } \\
\text { pine trees. (Table 18) }\end{array}$ & Wagstaff Rd and Clark Rd & $\begin{array}{l}T D-067, T D-075 \\
P P D-02 \\
911-157-1 \\
911-158-1\end{array}$ \\
\hline
\end{tabular}




\begin{tabular}{|c|c|c|c|c|}
\hline Date & Time Range & Fire Behavior Observations & Location & Source \# \\
\hline $11 / 8$ & 08:50 09:20 & $\begin{array}{l}\text { A spot fire is observed in trees and vegetation behind the CMA } \\
\text { church (west). The fire is about } 0.4 \text { ha }(1 \mathrm{ac}) \text {, burning in timber, and } \\
\text { working its way south toward Bille Rd. }\end{array}$ & $\begin{array}{l}\text { Clark Rd at Paradise } \\
\text { Alliance CMA Church }\end{array}$ & $\begin{array}{l}\text { TD-017 } \\
911-188-2\end{array}$ \\
\hline $11 / 8$ & 09:00 09:30 & $\begin{array}{l}\text { The spot fire east of Save Mart grows. Trees are torching and fire is } \\
\text { becoming well-established in area of Wagstaff Rd. Structures to } \\
\text { east are burning. }\end{array}$ & $\begin{array}{l}\text { Wagstaff Rd east of Save } \\
\text { Mart }\end{array}$ & $\begin{array}{l}\text { TD-017, TD-052 } \\
\text { TD-053, TD-055 } \\
\text { TD-058,VTD-18 }\end{array}$ \\
\hline $11 / 8$ & $09: 30$ & $\begin{array}{l}\text { The surface fuels in the wedge between Skyway and Clark Rd at } \\
\text { the intersection have burned through and the main fire activity has } \\
\text { subsided in immediate area and moved south along Skyway. }\end{array}$ & Clark Rd and Skyway & TD-067 \\
\hline $11 / 8$ & $10: 15 \quad 10: 45$ & $\begin{array}{l}\text { Fire is burning around Fire Station } 35 \text { on the west side of Clark Rd. } \\
\text { On the east side, Pine Springs Mobile Home Park being impacted. } \\
\text { Most active fire is on east side of Clark Rd between Kimberly Ln } \\
\text { and Adams Rd. Spot fires are burning throughout Clark Rd north of } \\
\text { Wagstaff Rd. }\end{array}$ & $\begin{array}{l}\text { Clark Rd near Forest } \\
\text { Service Rd }\end{array}$ & $\begin{array}{l}\text { TD-037, TD-043 } \\
\text { VTD-13 }\end{array}$ \\
\hline $11 / 8$ & $10: 50$ & $\begin{array}{l}\text { Residential structures around Save Mart and Kmart have been } \\
\text { burning. Several are fully involved and beginning to collapse. }\end{array}$ & $\begin{array}{l}\text { Paradise Plaza, Clark Rd } \\
\text { and Wagstaff Rd }\end{array}$ & VTD-18 \\
\hline $11 / 8$ & $10: 55$ & $\begin{array}{l}\text { Surface fuels around Fire Station } 35 \text { have already burned. Mobile } \\
\text { homes in Apple Tree Village are catching fire. }\end{array}$ & $\begin{array}{l}\text { Clark Rd and Forest } \\
\text { Service Rd }\end{array}$ & $\begin{array}{l}\text { TD-009, TD-041 } \\
\text { TD-043 }\end{array}$ \\
\hline $11 / 8$ & $11: 30 \quad 12: 30$ & $\begin{array}{l}\text { Spot fires are burning in juniper bushes on both sides of Clark Rd } \\
\text { south of Wagstaff at the Kmart and the CMA church. }\end{array}$ & $\begin{array}{l}\text { Clark Rd between } \\
\text { Wagstaff Rd and Bille Rd }\end{array}$ & $\begin{array}{l}\text { TD-015, TD-017 } \\
\text { VTD-18 }\end{array}$ \\
\hline $11 / 8$ & $11: 40$ & Structures on Gate Ln are igniting and spreading south. & Gate Ln & TD-041 \\
\hline $11 / 8$ & $11: 45$ & $\begin{array}{l}\text { Intense fire conditions between Kimberly Ln and Adams Rd. North } \\
\text { of Kimberly Ln, numerous spot fires are burning mostly on the east } \\
\text { side of Clark Rd in surface vegetation and fences. South of Adams } \\
\text { Rd to Wagstaff Rd there are still only a few spot fires. }\end{array}$ & $\begin{array}{l}\text { Clark Rd north of } \\
\text { Wagstaff Rd }\end{array}$ & PPD-08 \\
\hline $11 / 8$ & $12: 00$ & $\begin{array}{l}\text { Spot fires on the north side of the storage facility at Skyway and } \\
\text { Clark Rd, Bader Mine Rd. }\end{array}$ & $\begin{array}{l}\text { Clark Rd and Skyway, } \\
\text { Bader Mine Rd }\end{array}$ & $\begin{array}{l}\text { TD-042, TD-075 } \\
\text { PPD-10, PPD-12 }\end{array}$ \\
\hline $11 / 8$ & $12: 00$ & $\begin{array}{l}\text { Fire has become more established north of Kimberly } \mathrm{Ln} \text { and is } \\
\text { beginning to spread significantly west of Clark Rd. }\end{array}$ & $\begin{array}{l}\text { Clark Rd north of } \\
\text { Kimberly Ln }\end{array}$ & PPD-08 \\
\hline $11 / 8$ & $12: 30$ & $\begin{array}{l}\text { Multiple structures are burning on Wagstaff Rd just west of Clark } \\
\text { Rd. Several spot fires are burning around the intersection and } \\
\text { Paradise Plaza shopping center. (Table 18) }\end{array}$ & Clark Rd and Wagstaff Rd & $V T D-18$ \\
\hline $11 / 8$ & 13:00 & Clark Rd north of Wagstaff Rd is burning. & $\begin{array}{l}\text { Clark Rd north of } \\
\text { Wagstaff Rd }\end{array}$ & TD-015 \\
\hline $11 / 8$ & 13:15 $14: 15$ & $\begin{array}{l}\text { Fire is coming toward the Clark Rd and Skyway intersection from } \\
\text { the canyon to the west. Structures on the east side of Skyway are } \\
\text { burning intensely, fire is coming from the north through structures, } \\
\text { threatening Optimo and Fastrip. (Skyway) Many homes are on fire } \\
\text { near Clark Rd and Cabernet Ln. }\end{array}$ & Clark Rd and Skyway & $\begin{array}{l}T D-041, T D-067 \\
T D-127, T D-111 \\
T D-200, T D-207 \\
\quad P P D-13\end{array}$ \\
\hline $11 / 8$ & $14: 00$ & $\begin{array}{l}\text { Residential structures south of Kmart continue to burn and ignite } \\
\text { additional homes. }\end{array}$ & $\begin{array}{l}\text { Clark Rd south of } \\
\text { Wagstaff Rd }\end{array}$ & VTD-18 \\
\hline $11 / 8$ & $14: 30$ & $\begin{array}{l}\text { Peak fire activity around Clark Rd and Skyway, at the Optimo and } \\
\text { Fastrip. (Table 25) }\end{array}$ & Clark Rd and Skyway & $\begin{array}{l}T D-067, T D-075 \\
T D-041, T D-127 \\
T D-200, T D-205 \\
\quad P P D-14\end{array}$ \\
\hline $11 / 8$ & $15: 00$ & $\begin{array}{l}\text { Peak fire activity around Optimo is subsiding, but multiple } \\
\text { structures are still burning in area. Fire continues to burn for several } \\
\text { hours. A few homes are also burning on Gate Ln. }\end{array}$ & Clark Rd and Skyway & $\begin{array}{l}\text { TD-108, TD-111 } \\
\text { TD-114, PPD-15 }\end{array}$ \\
\hline $11 / 8$ & $17: 00$ & $\begin{array}{l}\text { Structures up and down Clark Rd and on side roads continue to } \\
\text { burn. Large trees and power poles are also burning and threaten or } \\
\text { block roadways. }\end{array}$ & $\begin{array}{l}\text { Clark Rd north of } \\
\text { Wagstaff Rd }\end{array}$ & $\begin{array}{l}\text { TD-014, TD-108 } \\
\text { TD-114 }\end{array}$ \\
\hline $11 / 8$ & $18: 30$ & $\begin{array}{l}\text { An island of unburned area SW of Wagstaff Rd and Clark Rd } \\
\text { begins to be affected by fire. Mobile homes in Pine Grove Mobile } \\
\text { Home Park begin to ignite. }\end{array}$ & $\begin{array}{l}\text { Pine Grove Mobile Home } \\
\text { Park, Clark Rd between } \\
\text { Wagstaff Rd and CMA } \\
\text { church }\end{array}$ & TD-108, TD-114 \\
\hline $11 / 8$ & 20:00 & $\begin{array}{l}\text { Pine Grove Mobile Home Park is completely burning and other } \\
\text { structures surrounding the park are also beginning to burn. }\end{array}$ & $\begin{array}{l}\text { Pine Grove Mobile Home } \\
\text { Park, Clark Rd between } \\
\text { Wagstaff Rd and CMA } \\
\text { church }\end{array}$ & $\begin{array}{l}\text { TD-108, TD-205 } \\
\text { TD-207 }\end{array}$ \\
\hline
\end{tabular}




\subsubsection{CMA Church to Nunneley Road}

This region of Clark Road was impacted early. Matchbook-sized embers were observed at Clark Road and Elliott Road as early as 08:00. The first spot fire was established within the hour, burning east of the Paradise Irrigation District office just south of Bille Road by 08:50.

Significant fire activity was observed before noon. The localized area near Central Park Drive was impacted first around 10:00 when multiple commercial structures were burning on both sides of Clark Road. Figure 38 shows buildings continuing to burn at 11:43, with flames blowing and encroaching on the roadway. Some structures had already burned down by this time.

By 11:00, fire was moving west down Elliott Road and burning up against the Safeway. Around 12:00, a majority of the area along Clark Road between Bille Road and Nunneley Road had been impacted. By 14:00, many structures had burned and collapsed.

As an example of the continual threat of ignition even after the fire front had passed, structures in this area were still igniting many hours later. The Lisa Family Pharmacy was burning around 01:45 on November 9 and threatening the nearby Masonic Lodge and library buildings. Even in the mid-morning of November 9, structures at the Shadowbrook Apartments were burning.

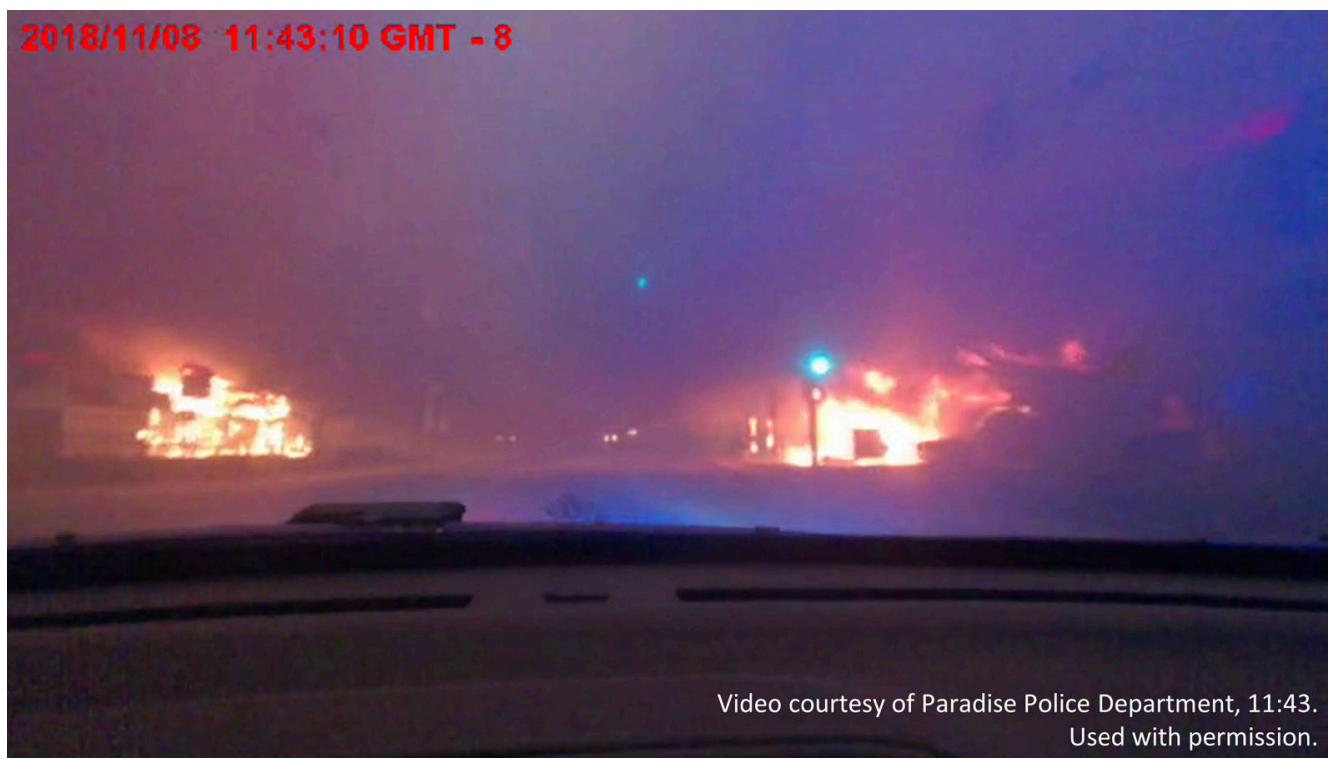

Figure 38. Commercial structures burning along Clark Rd at Central Park Dr. View north. 
Table 23. Summary of fire progression on Clark Rd between CMA Church and Nunneley Rd.

\begin{tabular}{|c|c|c|c|c|}
\hline Date & Time Range & Fire Behavior Observations & Location & Source \# \\
\hline $11 / 8$ & 08:00 & Matchbox-sized embers are landing at Clark Rd and Elliott Rd. & Clark Rd and Elliott Rd & TD-065, TD-074 \\
\hline $11 / 8$ & 08:50 & $\begin{array}{l}\text { A significant spot fire is burning a field just east of Paradise } \\
\text { Irrigation District office. }\end{array}$ & Clark Rd and Rossi Ln & $\begin{array}{l}\text { TD-077, TD-111 } \\
\text { 911-183-4 }\end{array}$ \\
\hline $11 / 8$ & $09: 50$ & $\begin{array}{l}\text { Fire is burning in the area of the medical complex on the west side } \\
\text { of Clark Rd. (Table 19) }\end{array}$ & $\begin{array}{l}\text { Clark Rd just south of } \\
\text { Bille Rd }\end{array}$ & $P P D-05$ \\
\hline $11 / 8$ & $10: 00$ & $\begin{array}{l}\text { Fire is beginning to burn both sides of Clark Rd in buildings and } \\
\text { vegetation. }\end{array}$ & $\begin{array}{l}\text { Clark Rd near Central } \\
\text { Park Dr }\end{array}$ & TD-009 \\
\hline $11 / 8$ & $10: 25$ & $\begin{array}{l}\text { The area north of Nunneley Rd, east of Clark Rd is catching fire. } \\
\text { (Table 20) }\end{array}$ & $\begin{array}{l}\text { Clark Rd and Nunneley } \\
R d\end{array}$ & PPD-02 \\
\hline $11 / 8$ & $10: 30 \quad 11: 00$ & $\begin{array}{l}\text { Fire impacts structures from the east and everything is burning. } \\
\text { Intense fire consumes the area of Central Park Dr. Surface fuels } \\
\text { burn through first, while heavy fuels, including landscape timbers } \\
\text { and structures, continue to burn. }\end{array}$ & $\begin{array}{l}\text { Clark Rd between Elk Ln } \\
\text { and Saxberg Dr }\end{array}$ & $\begin{array}{l}\text { TD-037, TD-041 } \\
\text { TD-058, TD-070 } \\
\text { VTD-26,PPD-08 }\end{array}$ \\
\hline $11 / 8$ & $10: 45$ & $\begin{array}{l}\text { Numerous spot fires are burning in parking lot vegetation at the } \\
\text { intersection of Clark Rd and Bille Rd. }\end{array}$ & Clark Rd and Bille Rd & VTD-26 \\
\hline $11 / 8$ & $10: 50$ & $\begin{array}{l}\text { Fire is impacting the rear (east side) of the Safeway shopping } \\
\text { center. (Table 20) }\end{array}$ & Clark Rd and Elliott Rd & $\begin{array}{l}T D-037, T D-068 \\
\quad P P D-02\end{array}$ \\
\hline $11 / 8$ & 11:00 & $\begin{array}{l}\text { Spot fires are burning in vegetation at the Arco gas station. Fire is } \\
\text { now approaching from the west. }\end{array}$ & Clark Rd and Elliott Rd & $\begin{array}{l}\text { TD-034, TD-035 } \\
\text { TD-070 }\end{array}$ \\
\hline $11 / 8$ & $12: 00$ & Areas west of Clark Rd are burning as fire pushes further west. & $\begin{array}{l}\text { Clark Rd and Nunneley } \\
\text { Rd }\end{array}$ & TD-118, PPD-08 \\
\hline $11 / 8$ & $12: 20$ & $\begin{array}{l}\text { A lot of damage has been done on Clark Rd around Central Park } \\
\text { Dr. Vegetative surface fires are burned through. Remaining } \\
\text { structures continue to ignite and burn. }\end{array}$ & $\begin{array}{l}\text { Clark Rd near Central } \\
\text { Park Dr }\end{array}$ & TD-101, PPD-08 \\
\hline $11 / 8$ & $12: 20$ & Structures on Bille Rd are burning just west of Clark Rd. (Table 19) & Clark Rd and Bille Rd & $T D-101$ \\
\hline $11 / 8$ & $12: 30$ & $\begin{array}{l}\text { There are several moderately active surface fires between Elliott Rd } \\
\text { and Nunneley Rd. Limited structures are burning close to roadway } \\
\text { due to the numerous parking lots. }\end{array}$ & $\begin{array}{l}\text { Clark Rd between Elliott } \\
\text { Rd and Nunneley Rd }\end{array}$ & PPD-08 \\
\hline $11 / 8$ & 13:00 & $\begin{array}{l}\text { Fire is blowing across Clark Rd at Tahoe Way, just south of Bille } \\
\text { Rd. }\end{array}$ & Clark Rd and Tahoe Way & TD-038 \\
\hline $11 / 8$ & 14:00 & $\begin{array}{l}\text { The main fire activity has moved on mainly west of Clark Rd, } \\
\text { burning on Central Park Dr, Elliott Rd, and Nunneley Rd where } \\
\text { structures continue to burn. Many structures along Clark Rd are } \\
\text { past peak and have collapsed. }\end{array}$ & $\begin{array}{l}\text { Clark Rd between CMA } \\
\text { and Nunneley Rd }\end{array}$ & $\begin{array}{l}\text { TD-069, TD-118 } \\
\text { TD-141, PPD-15 }\end{array}$ \\
\hline $11 / 8$ & $15: 30$ & There is fire on the roof of Rite Aid. & Clark Rd and Elliott Rd & TD-122, TD-124 \\
\hline $11 / 9$ & 01:45 & $\begin{array}{l}\text { Structures continue to ignite throughout town. Lisa Family } \\
\text { Pharmacy has smoke coming from the attic, and the Masonic Lodge } \\
\text { and library are threatened. }\end{array}$ & Clark Rd and Elliott Rd & TD-022, TD-110 \\
\hline $11 / 9$ & 09:55 & Shadowbrook Apartments are burning. & Shadowbrook Way & TD-030, TD-111 \\
\hline
\end{tabular}




\subsubsection{Nunneley Road to Airport Road}

Impacts on the southern portions of Clark Road within Paradise began as early as 07:45 when hot embers were observed falling on American Way, and by 08:30, a spot fire was established in the drainage east of American Way. Spot fires and a structure burning on the west side of Clark Road near Easy St were reported as early as 08:45.

By 10:00, fire was impacting Clark Road in multiple locations while people were attempting to evacuate. Near the "S"-curve and near American Way, flames were burning across the roadway. At this time, fire was burning as far south as Meadow Song Drive, with flames also right against the roadway. Within the hour, by 10:45, most structures along Clark Road south of Buschmann Road were burning. Conditions deteriorated at the intersection with Buschmann Road as intense wind-driven flames spread across Clark Road.

Clark Road became barely passable again near the town limits for a brief time window. However, another flare-up between 11:00 and 11:30 closed the roadway again as $15 \mathrm{~m}(50 \mathrm{ft})$ flames crossed Clark Road near Round Valley Ranch Road, and fire again crossed the roadway near American Way. Further down Clark Road at Airport Road, fire also burned over the roadway, delaying access of the arriving strike teams as they waited for conditions to abate, seen in Figure 39. The fire continued with high intensity south of the airport, where it paused and hung up for a period of time between about 13:00 and 15:00 before again advancing down into the flats south of Circle J Road as described in Section 9.1.13.

Around 12:00, the intersection of Clark Road and Pearson Road was impacted as the fire front moved in from the east and also spread up from Buschmann Road. Structures burned all afternoon, but by 14:00 the main fire activity along Clark Road was over and most structures were already destroyed. 


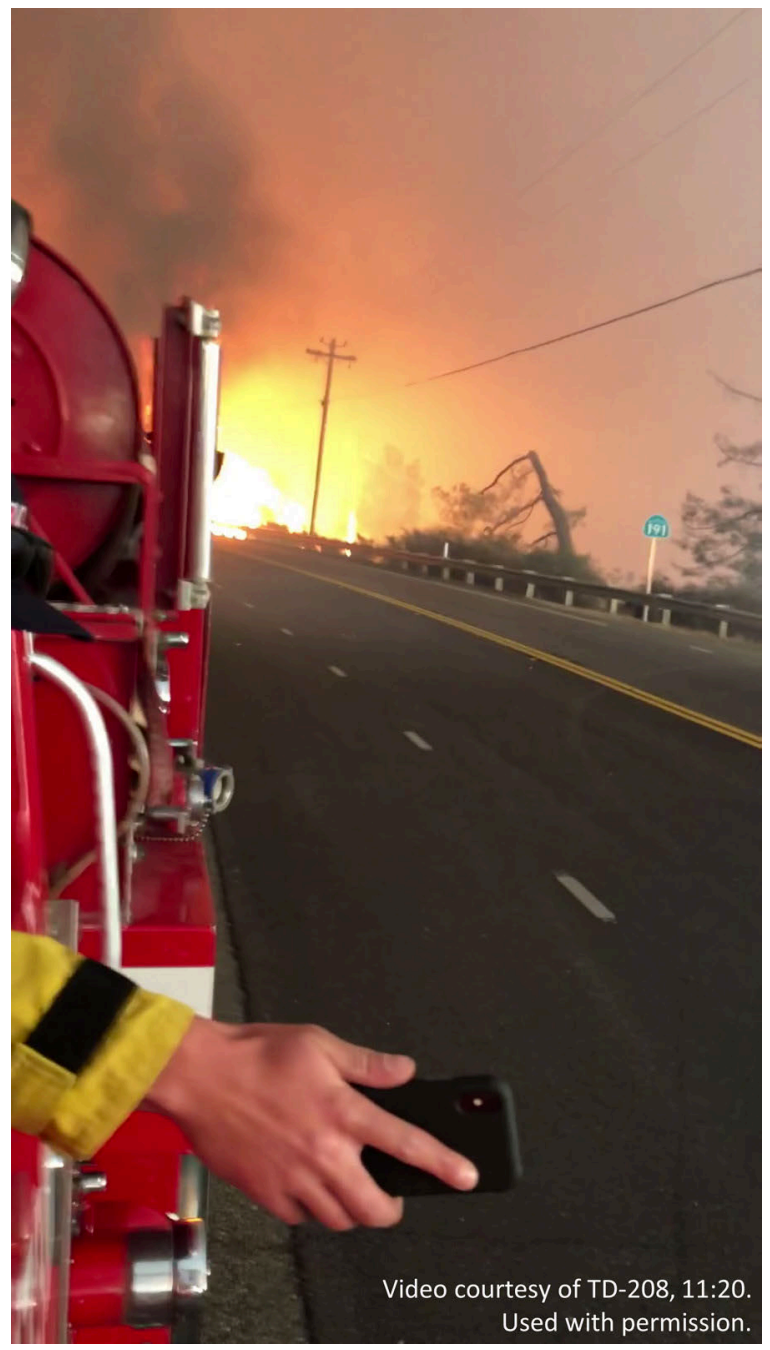

Figure 39. Heavy fire exposure from the canyon burns over Clark Rd just north of Airport Rd, delaying civilian evacuation and first responder access. View north at 11:20. 
Table 24. Summary of fire progression on Clark Rd between Nunneley Rd and Airport Rd.

\begin{tabular}{|c|c|c|c|c|c|}
\hline Date & Time I & Range & Fire Behavior Observations & Location & Source \# \\
\hline $11 / 8$ & $07: 45$ & & $\begin{array}{l}\text { Hot embers are observed falling at American Way at the south end } \\
\text { of town. }\end{array}$ & American Way & TD-035 \\
\hline $11 / 8$ & $08: 30$ & & $\begin{array}{l}\text { A large spot fire east of Clark is established in drainage, estimated } \\
\text { up to } 12 \text { ha }(30 \mathrm{ac}) \text {. }\end{array}$ & $\begin{array}{l}\text { between Clark Rd and } \\
\text { Morgan Ridge Rd }\end{array}$ & TD-100 \\
\hline $11 / 8$ & $08: 45$ & & $\begin{array}{l}\text { Fire is spotting onto the west side of Clark Rd near the town limits. } \\
\text { A structure is burning. }\end{array}$ & Clark Rd near Easy St & TD-105 \\
\hline $11 / 8$ & 09:30 & & $\begin{array}{l}\text { Fire from the drainage east of Clark Rd is spreading uphill towards } \\
\text { Lanser Dr and American Way. }\end{array}$ & Clark Rd "S"-curve & $\begin{array}{l}\text { TD-034, TD-077 } \\
911-201-1\end{array}$ \\
\hline $11 / 8$ & $10: 00$ & & $\begin{array}{l}\text { Fire impacting Clark Rd at the south end of town at the S-curve } \\
\text { near American Way and further south near the town limits. } \\
\text { Vehicles are burning and flames are fully or partially blocking the } \\
\text { roadway. See Section } 9.3 \text { for a description of the burnover event. }\end{array}$ & Clark Rd "S"-curve & $\begin{array}{l}\text { TD-009, TD-041 } \\
\text { TD-049, TD-065 } \\
\quad \text { PPD-02 }\end{array}$ \\
\hline $11 / 8$ & $10: 00$ & & $\begin{array}{l}\text { Fire has reached as far south as Meadow Song Dr, burning in } \\
\text { vegetation. }\end{array}$ & $\begin{array}{l}\text { Clark Rd and Meadow } \\
\text { Song Dr, south of town } \\
\text { limits }\end{array}$ & TD-014 \\
\hline $11 / 8$ & $10: 30$ & & $\begin{array}{l}\text { Spot fire ignitions are increasing on the west side of Clark Rd } \\
\text { down Round Valley Ranch Rd. The main fire activity now extends } \\
\text { as far south as Airport Rd on the east side of Clark Rd. }\end{array}$ & $\begin{array}{l}\text { Round Valley Ranch Rd } \\
\text { and south }\end{array}$ & TD-100, TD-110 \\
\hline $11 / 8$ & $10: 45$ & & $\begin{array}{l}\text { All structures are burning along Clark Rd between Buschmann Rd } \\
\text { and Lanser Dr. }\end{array}$ & $\begin{array}{l}\text { Clark Rd between } \\
\text { Buschmann Rd and } \\
\text { Lanser Dr }\end{array}$ & TD-110 \\
\hline $11 / 8$ & $10: 45$ & & $\begin{array}{l}\text { Conditions at Clark Rd and Buschmann Rd deteriorate. The field } \\
\text { on the east side is burning, flames are being blown like a } \\
\text { blowtorch, and fire is jumping to the west side of Clark Rd. } \\
\text { (Table 21) }\end{array}$ & $\begin{array}{l}\text { Clark Rd and Buschmann } \\
\text { Rd }\end{array}$ & $T D-034, T D-065$ \\
\hline $11 / 8$ & $10: 45$ & & $\begin{array}{l}\text { Clark Rd is barely passable again using a single lane at Round } \\
\text { Valley Ranch Rd. Fire is burning both sides, with the more intense } \\
\text { fire on the east side burning up from the drainage. Some active } \\
\text { areas of vegetation fire are up against the roadway, other areas } \\
\text { already burned through with spot fires still active on heavier fuels. }\end{array}$ & $\begin{array}{l}\text { Clark Rd south of Round } \\
\text { Valley Ranch Rd }\end{array}$ & $\begin{array}{l}\text { TD-130, TD-210 } \\
\text { PPD-02 }\end{array}$ \\
\hline $11 / 8$ & 11:00 & $11: 30$ & $\begin{array}{l}\text { Fire is burning over Clark Rd again at multiple locations at the } \\
\text { south edge of town, re-closing the roadway preventing evacuations. } \\
15 \mathrm{~m}(50 \mathrm{ft}) \text { flames are crossing Clark Rd at Round Valley Ranch } \\
\mathrm{Rd} \text {, and fire is blocking Clark Rd at American Way again. }\end{array}$ & $\begin{array}{l}\text { Clark Rd south of the S- } \\
\text { curve }\end{array}$ & $\begin{array}{l}\text { TD-100, TD-208 } \\
\text { TD-211 }\end{array}$ \\
\hline $11 / 8$ & $11: 00$ & $11: 30$ & $\begin{array}{l}\text { Intense vegetation fire is burning up out of the canyon, with heavy } \\
\text { fire near Airport Rd threatening structures on Good View Ln. }\end{array}$ & Clark Rd and Airport Rd & TD-110, TD-208 \\
\hline $11 / 8$ & $11: 15$ & & Structures are burning on Round Valley Ranch Rd. & Round Valley Ranch Rd & TD-110 \\
\hline $11 / 8$ & $11: 30$ & $12: 00$ & $\begin{array}{l}\text { Fire makes another push across Clark Rd between Pearson Rd and } \\
\text { Lanser Dr, burning many structures and threatening others. Clark is } \\
\text { impassable at Buschmann Rd. }\end{array}$ & $\begin{array}{l}\text { Clark Rd between Pearson } \\
\text { Rd and the S-curve }\end{array}$ & $\begin{array}{l}\text { TD-035, TD-130 } \\
\text { TD-208, TD-211 } \\
\text { PPD-08 }\end{array}$ \\
\hline $11 / 8$ & 11:45 & 12:00 & $\begin{array}{l}\text { The intersection of Clark Rd and Pearson Rd is impacted. Fire gets } \\
\text { established, burning structures. (Table 21) }\end{array}$ & Clark Rd and Pearson Rd & $\begin{array}{l}T D-037, T D-074 \\
T D-130, T D-210 \\
\quad P P D-08\end{array}$ \\
\hline $11 / 8$ & $12: 30$ & $12: 45$ & $\begin{array}{l}\text { The main fire front continues pushing south along Clark Rd } \\
\text { beyond Airport Rd. Guardrail posts are burning, burning debris is } \\
\text { in the roadway, heavy fire is coming from structures on Good } \\
\text { View Dr. } 30 \mathrm{~m}(100 \mathrm{ft}) \text { flames are burning up the canyon walls } \\
\text { west toward the airport. }\end{array}$ & Clark Rd and Airport Rd & $\begin{array}{l}\text { TD-035, TD-208 } \\
\text { VTD-06,PPD-08 }\end{array}$ \\
\hline $11 / 8$ & 13:00 & & $\begin{array}{l}\text { There are heavy fire conditions in commercial structures along } \\
\text { Clark Rd north of Pearson Rd. }\end{array}$ & $\begin{array}{l}\text { Clark Rd north of Pearson } \\
\text { Rd }\end{array}$ & $\begin{array}{l}\text { TD-021, TD-108 } \\
\text { TD-130, TD-132 } \\
\text { TD-141, TD-142 }\end{array}$ \\
\hline $11 / 8$ & 13:00 & $14: 00$ & $\begin{array}{l}\text { The main fire activity is over at the south end of town and many } \\
\text { structures are already destroyed. Structures continue to burn all } \\
\text { afternoon. }\end{array}$ & $\begin{array}{l}\text { Clark Rd south of Pearson } \\
\text { Rd }\end{array}$ & $\begin{array}{l}\text { TD- } 014, \text { TD-020 } \\
\text { TD-108, TD-112 } \\
\text { TD-122, TD-123 } \\
\text { TD-126, TD-133 } \\
\text { TD-142, TD-209 } \\
\text { TD-211, TD-18 }\end{array}$ \\
\hline
\end{tabular}

a This early observation is an outlier point that was not verifiable through cross-reference at this time of day. 


\subsubsection{Skyway Fire Progression Summary}

Due to the length of the road and the number of simultaneous events on the north and south ends of Paradise, Skyway is divided into two sub-regions; north of Bille Road in Table 25 and south of Bille Road in Table 26.

\subsubsection{Coutolenc Road to Bille Road Fire Progression Summary}

At the north end of Paradise, numerous spot fires ignited in the 08:30 to 09:00 window. These included a fire just south of the intersection with Clark Road, a fire off of Rocky Lane near the bike path, a fire a little further south at Wagstaff Road and Berkshire Avenue, and also already several spots west of town on the Paradise side of Little Butte Creek Canyon. By 09:00, fire was also burning in Old Magalia, influencing the ability to travel north on Skyway from Paradise.

By 09:30, the four major spot fires were well-established, igniting structures and impacting evacuating vehicles. The area of Skyway south of Clark Road near Lofty Lane was particularly intense between 09:30 and 10:30. By 10:30, nearly all of Skyway north of Wagstaff Road was about to be impacted by fire from both the east (Rocky Lane spot fire and Clark Road spot fire) and from the west (spot fires now pushing up from the canyon burning structures on Montna Drive). South of Clark Road, evacuees and first responders were overrun by fire as they were stuck in traffic. Further south, the area of Wagstaff Road just east of Skyway at Berkshire Avenue and Oak Way was heavily involved, with intense ember showers and multiple structures burning.

Before 11:00, the escape routes from the unburned area surrounding the intersection of Skyway and Clark Road were blocked by fire. By 13:00, fire activity was increasing north of Clark Road, with fire encroaching on civilians sheltered at the Optimo restaurant parking lot and threatening commercial buildings, including the Fastrip gas station.

Between 12:00 and 15:00, nearly every structure was fully involved in the area between Wagstaff Road and Clark Road, and dozens of abandoned vehicles were burning in the roadway. Engine strike teams had to wait for fire to subside before they could pass through, while everything was still burning.

By 14:30, Skyway between Wagstaff Road and Bille Road had been completely destroyed. Although foundations and rubble were still flaming, the main fire had moved further south and west. At the same time, fire activity was wrapping around the intersection at Clark Road and burning structures along Skyway and on Gate Lane and Cabernet Lane.

After 15:00, the fire activity on Skyway north of Bille Road had passed by, and the downtown areas of Skyway south of Bille Road were impacted. See Table 26 describing that region.

During the early morning hours on November 9, fire activity blew up in the West Branch canyon, sending intense fire west over the ridge of Skyway and Coutolenc Road directly toward Magalia. This blow up is further detailed in the Magalia section, Table 32, and the burnover section, Section 9.3. 
Table 25. Summary of fire progression on Skyway between Coutolenc Rd and Bille Rd.

\begin{tabular}{|c|c|c|c|c|}
\hline Date & Time Range & Fire Behavior Observations & Location & Source \# \\
\hline $11 / 8$ & 08:00 & $\begin{array}{l}\text { Spot fires have started on the west side of the Feather River } \\
\text { Canyon by Sawmill Peak. }\end{array}$ & Skyway and Pentz Rd & $911-092-1$ \\
\hline $11 / 8$ & $08: 25$ & $\begin{array}{l}\text { A spot fire has started on the bike path at Rocky Ln and is burning } \\
\text { in backyards. }\end{array}$ & Rocky Ln & $911-128-1$ \\
\hline $11 / 8$ & 09:00 & $\begin{array}{l}3 \text { to } 4 \text { spot fires start down in Little Butte Creek Canyon west of } \\
\text { Skyway, spreading uphill towards Montna Dr. }\end{array}$ & $\begin{array}{l}\text { in canyon NW of Skyway } \\
\text { and Wagstaff Rd }\end{array}$ & $\begin{array}{l}\text { TD-113 } \\
911-183-2 \\
911-163-1 \\
911-205-1\end{array}$ \\
\hline $11 / 8$ & $08: 30$ & $\begin{array}{l}\text { A spot fire ignites on the south side of the intersection between } \\
\text { Skyway and Clark Rd, estimated initially at } 0.1 \text { ha }(0.25 \mathrm{ac}) \text {. } \\
\text { Multiple citizens report the fire to } 911 \text {. Trees are also observed on } \\
\text { fire at the northern end of Clark } R d \text {. (Table 22) }\end{array}$ & Clark Rd and Skyway & $\begin{array}{c}T D-058 \\
911-141-1 \\
911-141-2 \\
911-152-1 \\
911-153-1 \\
911-155-1 \\
911-164-1\end{array}$ \\
\hline $11 / 8$ & $08: 50$ & $\begin{array}{l}\text { Multiple citizens report a new spot fire in the area of Wagstaff Rd } \\
\text { and the bike path, near Berkshire Ave. (Table 18) }\end{array}$ & $\begin{array}{l}\text { Wagstaff Rd and } \\
\text { Berkshire Ave }\end{array}$ & $\begin{array}{l}T D-015 \\
911-162-1 \\
911-169-1 \\
911-178-2 \\
911-195-4\end{array}$ \\
\hline $11 / 8$ & 08:40 & Spot fires are burning in Old Magalia. & Old Magalia & $\begin{array}{l}\text { TD-006 } \\
911-207-1\end{array}$ \\
\hline $11 / 8$ & 08:50 & $\begin{array}{l}\text { Another spot fire, estimated at } 0.1 \mathrm{ha}(0.25 \mathrm{ac}) \text {, is burning in the } \\
\text { ball field between Skyway and Clark Rd. }\end{array}$ & $\begin{array}{l}\text { Moore Rd ballfield } \\
\text { between Skyway and } \\
\text { Clark Rd }\end{array}$ & $\begin{array}{l}\text { TD-064 } \\
911-188-1\end{array}$ \\
\hline $11 / 8$ & 09:00 & $\begin{array}{l}\text { The upper portion of Skyway, parallel with the bike path, is fully } \\
\text { involved in fire both sides of roadway. }\end{array}$ & Skyway near Lofty Ln & TD-064 \\
\hline $11 / 8$ & $10: 00$ & $\begin{array}{l}\text { A large spot fire is burning on both sides of Skyway north of Pentz } \\
\text { Rd blocking traffic. Structures are burning in Old Magalia. Dense } \\
\text { white, light gray smoke is drifting across roadway, north of Pentz. }\end{array}$ & Old Magalia & $\begin{array}{l}\text { PPD-02 } \\
911-217-1 \\
911-230-1\end{array}$ \\
\hline $11 / 8$ & $08: 50 \quad 09: 15$ & $\begin{array}{l}\text { Fire is pinching Wagstaff Rd between Skyway and Clark Rd. Fire } \\
\text { is burning from the NE into the area of Rocky Ln, and the spot near } \\
\text { the bike path is well established. The intersection of Skyway and } \\
\text { Wagstaff Rd will be impacted soon. Multiple cars are on fire. } \\
\text { (Table 18) }\end{array}$ & $\begin{array}{l}\text { Wagstaff Rd between } \\
\text { Skyway and Clark Rd }\end{array}$ & $\begin{array}{l}T D-017, T D-042 \\
T D-053, T D-111 \\
T D-127\end{array}$ \\
\hline $11 / 8$ & 09:20 & $\begin{array}{l}\text { The initial spot fire burned through surface fuels in the area at } \\
\text { Skyway and Clark and the fire activity is increasing near Lofty Ln. }\end{array}$ & Skyway and Clark Rd & TD-067, PPD-02 \\
\hline $11 / 8$ & 09:30 & $\begin{array}{l}\text { Fire is burning in } 4 \text { large areas along Skyway. One spot to the west } \\
\text { in the area of Montna Dr, one to the east at Wagstaff Rd and Rocky } \\
\mathrm{Ln} \text {, one spot further to the east at Station 35, as well as the initial } \\
\text { spot location near the intersection of Clark Rd. }\end{array}$ & $\begin{array}{l}\text { Skyway north of Wagstaff } \\
\text { Rd }\end{array}$ & TD-064 \\
\hline $11 / 8$ & 09:55 & $\begin{array}{l}\text { Vegetation fire is established at the west end of Pheasant Ridge Dr. } \\
\text { On Skyway, fire is still burning intensely near Lofty Ln. Sheeting } \\
\text { flames are impacting vehicles. }\end{array}$ & Skyway near Lofty Ln & TD-022 \\
\hline $11 / 8$ & $10: 30$ & $\begin{array}{l}\text { Structures are now burning in the area of Skyway and Kemen Ln } \\
\text { and west of Skyway on Montna Dr. A fire front is coming hard } \\
\text { from Little Butte Creek Canyon. }\end{array}$ & $\begin{array}{l}\text { Skyway between } \\
\text { Wagstaff Rd and } \\
\text { Firland } \mathrm{Dr}\end{array}$ & TD-014, TD-113 \\
\hline $11 / 8$ & 11:00 & $\begin{array}{l}\text { Fire burning south east of Skyway through Berkshire Ave and } \\
\text { Skyway Villa Mobile Home Park, pushing south and west toward } \\
\text { Bille Rd }\end{array}$ & Skyway near Bille Rd & $\begin{array}{l}\text { TD-116, TD-030 } \\
\text { TD-127 }\end{array}$ \\
\hline $11 / 8$ & $11: 00 \quad 13: 00$ & $\begin{array}{l}\text { The fire stalls north of Pentz Rd. The north flank of the main fire is } \\
\text { on Skyway between Pentz Rd and Coutolenc Rd. There are some } \\
\text { spot fires down in canyon to the east. }\end{array}$ & $\begin{array}{l}\text { Skyway between Pentz } \\
\text { Rd and Coutolenc Rd }\end{array}$ & $\begin{array}{l}\text { TD-009, TD-041 } \\
\text { TD-060, TD-079 }\end{array}$ \\
\hline $11 / 8$ & $11: 25$ & $\begin{array}{l}\text { Heavy fire continues on Skyway south of Clark Rd. Civilians are } \\
\text { encircled in the upper portion of town with fire compromising all } \\
\text { roads. }\end{array}$ & Skyway and Clark Rd & TD-041, PPD-02 \\
\hline $11 / 8$ & $11: 35$ & $\begin{array}{l}\text { Evacuating vehicles and law enforcement officers are trapped and } \\
\text { surrounded by fire in the area of Skyway and Coldren Rd, south of } \\
\text { Clark Rd. }\end{array}$ & Skyway and Coldren Rd & PPD-08 \\
\hline $11 / 8$ & $11: 45$ & $\begin{array}{l}\text { Skyway is overtaken by fire and everything is burning between } \\
\text { Wagstaff Rd and Bille Rd. }\end{array}$ & $\begin{array}{l}\text { Skyway between } \\
\text { Wagstaff Rd and Bille Rd }\end{array}$ & TD-127, PPD-08 \\
\hline
\end{tabular}




\begin{tabular}{|c|c|c|c|c|c|}
\hline Date & Time & Range & Fire Behavior Observations & Location & Source \# \\
\hline $11 / 8$ & $12: 00$ & & $\begin{array}{l}\text { Multiple spot fires and structures are burning on the east side of } \\
\text { Skyway north of Clark Rd and on Bader Mine Rd. Structures in } \\
\text { Old Magalia, Ishi Dr and Indian Dr, are burning. The old fire } \\
\text { station in Old Magalia near the Magalia Community Church on } \\
\text { Old Skyway is impacted. }\end{array}$ & Skyway north of Clark Rd & $\begin{array}{l}\text { TD-041, TD-060 } \\
\text { TD-075, TD-079 } \\
\text { TD-083 } \\
\text { PPD-10, PPD-12 }\end{array}$ \\
\hline $11 / 8$ & $12: 20$ & $15: 00$ & $\begin{array}{l}\text { There is a significant period of intense fire between Wagstaff Rd } \\
\text { and Clark Rd. Crowning fire pushes from west of Skyway and fire } \\
\text { closes in on both sides of roadway. Vehicles and structures are } \\
\text { burning. The area is like a furnace. }\end{array}$ & $\begin{array}{l}\text { Skyway between Clark } \\
\text { Rd and Wagstaff Rd }\end{array}$ & $\begin{array}{l}\text { TD-015, TD-061 } \\
\text { TD-111, TD-113 } \\
\text { TD-127, TD-128 } \\
\text { TD-200, TD-205 } \\
\text { TD-207, PPD-08 }\end{array}$ \\
\hline $11 / 8$ & $13: 00$ & & $\begin{array}{l}\text { Fire activity increases around Optimo, with fire coming up from } \\
\text { the west along Bader Mine Rd. Structures on east side Skyway } \\
\text { burning, fully involved. }\end{array}$ & Skyway and Clark Rd & $\begin{array}{l}\text { TD-041, TD-067 } \\
\text { TD-127, PPD-13 }\end{array}$ \\
\hline $11 / 8$ & $13: 00$ & & All structures on Ishi Dr are burning in Old Magalia. & $\begin{array}{l}\text { Ishi Dr and Indian Dr, Old } \\
\text { Magalia }\end{array}$ & TD-079 \\
\hline $11 / 8$ & $13: 20$ & & $\begin{array}{l}\text { There is significant fire in the area of Skyway and Wagstaff Rd. } \\
\text { Skyway Villa Mobile Home Park is burning, and structures are } \\
\text { fully involved on Bille Rd and Berkshire Ave. }\end{array}$ & Skyway and Wagstaff Rd & $\begin{array}{l}\text { TD-011, TD-030 } \\
\text { TD-055 }\end{array}$ \\
\hline $11 / 8$ & $14: 00$ & $14: 30$ & $\begin{array}{l}\text { Many homes are on fire near Cabernet Ln down Clark Rd. Most } \\
\text { structures are burning on Skyway north of Clark Rd. Commercial } \\
\text { buildings, including the propane facility and storage units, are } \\
\text { burning. Fastrip and Optimo are threatened. }\end{array}$ & Skyway and Clark Rd & $\begin{array}{l}\text { TD-041, TD-067 } \\
\text { TD-075, TD-111 } \\
\text { TD-127, TD-200 } \\
\quad \text { TD-207 }\end{array}$ \\
\hline $11 / 8$ & $14: 20$ & & $\begin{array}{l}\text { The area of Skyway between Wagstaff Rd and Bille Rd is } \\
\text { completely destroyed. Foundations are still flaming, but the main } \\
\text { fire activity is over. Burning power poles and power lines and local } \\
\text { flare-ups occasionally make passage difficult. }\end{array}$ & $\begin{array}{l}\text { Skyway between } \\
\text { Wagstaff Rd and Bille Rd }\end{array}$ & TD-055, TD-065 \\
\hline $11 / 8$ & $14: 20$ & & $\begin{array}{l}\text { Vehicles in the roadway are burning. Structures are destroyed, with } \\
\text { some still burning fully involved. Surface fuels have been } \\
\text { completely consumed. }\end{array}$ & $\begin{array}{l}\text { Skyway north of Wagstaff } \\
\text { Rd }\end{array}$ & TD-055 \\
\hline $11 / 8$ & $15: 00$ & & $\begin{array}{l}\text { One structure is still burning but everything else is pretty much } \\
\text { done around Optimo, Clark Rd and Skyway. }\end{array}$ & Skyway and Clark Rd & PPD-15 \\
\hline $11 / 8$ & $15: 00$ & & Everything has burned north of Bille Rd to Clark Rd. & $\begin{array}{l}\text { Skyway between Clark } \\
\text { Rd and Bille Rd }\end{array}$ & TD-108, TD-205 \\
\hline $11 / 8$ & $16: 30$ & $18: 00$ & $\begin{array}{l}\text { Fire activity south of Skyway down Clark Rd picks up again. } \\
\text { Structures continue igniting and burning on Clark Rd, Cabernet Ln, } \\
\text { and Gate Ln. }\end{array}$ & $\begin{array}{l}\text { Clark Rd, Cabernet Ln, } \\
\text { Gate Ln }\end{array}$ & TD-108, TD-114 \\
\hline $11 / 8$ & $17: 30$ & & $\begin{array}{l}\text { South of Bille Rd, commercial structures along Skyway in the } \\
\text { downtown area are threatened. (Table 26) }\end{array}$ & Skyway south of Bille Rd & $T D-127$ \\
\hline $11 / 8$ & $18: 30$ & & $\begin{array}{l}\text { Fire in the drainage is burning heavy brush, pushing NE uphill } \\
\text { toward Ishi Dr from Little Butte Creek Canyon toward a few } \\
\text { unburned homes. }\end{array}$ & Old Magalia, Ishi Dr & $\begin{array}{l}\text { TD-079, TD-085 } \\
\text { TD-087, TD-089 }\end{array}$ \\
\hline $11 / 8$ & 21:00 & & $\begin{array}{l}\text { Low-intensity fire is burning east of Skyway in the Feather River } \\
\text { Canyon. Fire is bumping scattered structures. }\end{array}$ & $\begin{array}{l}\text { Skyway between } \\
\text { Coutolenc Rd and Pentz } \\
\text { Rd }\end{array}$ & TD-043, TD-045 \\
\hline $11 / 9$ & 00:00 & 01:00 & $\begin{array}{l}\text { Fire runs up out of the West Branch canyon and pushes hard } N \text { and } \\
\text { W into Magalia with strong winds and large, softball-size embers. } \\
\text { (Table 32) }\end{array}$ & $\begin{array}{l}\text { Skyway and Coutolenc } \\
\text { Rd, and north }\end{array}$ & $\begin{array}{c}T D-007, T D-045 \\
T D-061, T D-115 \\
T D-125, T D-126 \\
T D-209\end{array}$ \\
\hline $11 / 9$ & $01: 30$ & & $\begin{array}{l}\text { Areas of northern Old Magalia are hit hard again by lots of } \\
\text { scattered spot fires and fire pushing hard out of canyons from all } \\
\text { directions. }\end{array}$ & $\begin{array}{l}\text { Old Skyway, Sugar Pine } \\
\text { Rd }\end{array}$ & $\begin{array}{c}\text { TD-043, TD-087 } \\
\text { TD-089 }\end{array}$ \\
\hline
\end{tabular}




\subsubsection{Bille Road to Lookout Point Fire Progression Summary}

Early fire activity on Skyway south of Bille Road was related to the burnover of Skyway near the town limits. At 08:45, a spot fire began in the Honey Run Canyon between Skyway and Redbud Drive. After becoming well-established in the canyon, it made a run south up the canyon walls toward the Canyon View Apartments and burned over Skyway beginning around 10:15. During this time, Skyway was full of heavy, slow-moving traffic from evacuating vehicles. Incoming emergency vehicles and outgoing citizens were overrun by fire burning across the roadway. Figure $\mathbf{4 0}$ shows conditions experienced by evacuating civilians on Skyway as they travelled southbound in the northbound lanes because of burned trees and power poles blocking the normal southbound traffic lanes. Peak fire activity along this part of Skyway occurred between 10:15 and 11:15, with significant ember showers and burning of vegetation, fences, power poles, and structures on both sides of Skyway. Fire continued pushing into the neighborhood of Princeton Way, the drainage between Skyway and Neal Road, and westward beyond Skyway Crossroad. By noon, fire was well involved on Neal Road (see Table 27).

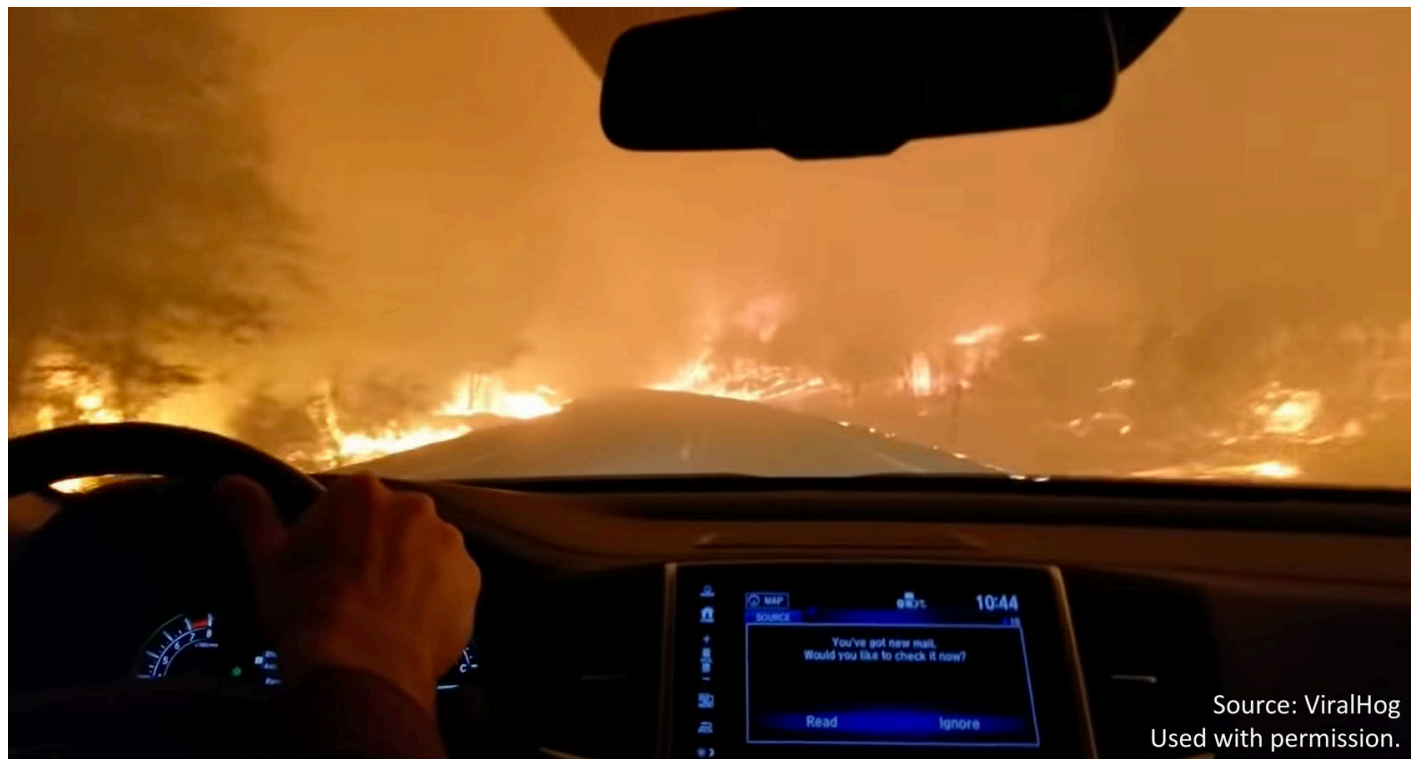

Figure 40. Skyway was burned over during the middle of evacuation efforts. Conditions are seen here at 10:44 just west of the lane divide at the town limits.

Further north, fire pushed into the Skyway area at Bille Road around 11:00 to 11:30 as it spread from initial spot fires on Wagstaff Road and Bille Road. After noon, structures east of Skyway in the area of Fir Street and Almond Street began burning.

Spot fires began affecting the area of Skyway between Pearson Road and Neal Road around 12:30, which up to this point had not seen fire activity. The Honey Run spot fire, while initially running south over Skyway, had also been progressing up the drainage north of Skyway along Honey Run Road, burning structures behind the medical center and Town Hall. By 15:00, fire was burning toward Skyway from multiple directions: from Honey Run Road to the west and from Pearson Road, Almond Street, and Black Olive Drive to the east. 
The first commercial structure in the area was in the early stages of burning at 15:00 at Skyway and Foster Road. Downtown structures were increasingly threatened as fire closed in on the area, and heavy fire conditions were observed between 15:30 and 18:00 when many structures were destroyed between Bille Road and Neal Road. Fires continued to burn after 18:00 and through the night. Table 26 has additional details.

Table 26. Summary of fire progression on Skyway between Bille Rd and Lookout Point.

\begin{tabular}{|c|c|c|c|c|}
\hline Date & Time Range & Fire Behavior Observations & Location & Source \# \\
\hline $11 / 8$ & $08: 45$ & $\begin{array}{l}\text { A spot fire ignites in Honey Run Canyon and becomes well- } \\
\text { established.(Table 29) }\end{array}$ & $\begin{array}{l}\text { Honey Run Canyon } \\
\text { between Redbud Dr and } \\
\text { Skyway }\end{array}$ & $\begin{array}{c}\text { TD-006, TD-038 } \\
\text { TD-055, TD-111 } \\
911-182-1 \\
911-200-1 \\
911-202-1 \\
911-204-1 \\
911-218-1 \\
911-221-1 \\
911-225-1\end{array}$ \\
\hline $11 / 8$ & $10: 10$ & $\begin{array}{l}\text { Fire is well established in Honey Run Canyon just below Canyon } \\
\text { View. Multiple spots are running back up towards Canyon View } \\
\text { Apartments and will impact Skyway. (Table 29) }\end{array}$ & $\begin{array}{l}\text { Honey Run Canyon } \\
\text { between Redbud Dr and } \\
\text { Skyway }\end{array}$ & $\begin{array}{l}\text { TD-007 } \\
\text { Radio Log }\end{array}$ \\
\hline $11 / 8$ & $10: 15$ & $\begin{array}{l}\text { Skyway is burned over at the southwest end of town (see Section } \\
9.3 \text { ). Significant ember showers and fire activity on both sides of } \\
\text { Skyway is impacting evacuating vehicles. Fences, power poles, } \\
\text { structures, and vegetation are all burning. Structures in the split } \\
\text { between the NB and SB lanes are burning. Fire is spreading south } \\
\text { of Skyway toward Neal Rd. }\end{array}$ & $\begin{array}{l}\text { Skyway between Neal Rd } \\
\text { and just west of the } \\
\text { Crossroad. }\end{array}$ & $\begin{array}{l}\text { TD-011, TD-025 } \\
\text { TD-068, TD-155 } \\
\text { VTD-13 } \\
\text { VTD-14 }\end{array}$ \\
\hline $11 / 8$ & $11: 00$ & $\begin{array}{l}\text { Fire is pushing south and west toward Bille Rd, threatening } \\
\text { structures on Skyway. }\end{array}$ & Skyway and Bille Rd & TD-030, TD-127 \\
\hline $11 / 8$ & $11: 15$ & $\begin{array}{l}\text { Fire activity at the Skyway split is still active on both sides of } \\
\text { roadway, but Skyway is passable. Heavy flaming activity has } \\
\text { subsided immediately against the road. Structures to the south of } \\
\text { Skyway are fully involved. North of Skyway is also burning, down } \\
\text { into the Honey Run Canyon west of the health center. A burned } \\
\text { power pole is blocking SB lanes at the split. }\end{array}$ & Skyway near the lane split & $\begin{array}{l}\text { TD-011, TD-058 } \\
\text { VTD-13 } \\
\text { VTD-26 }\end{array}$ \\
\hline $11 / 8$ & $11: 15$ & $\begin{array}{l}\text { The western extent of the fire is past the crossroad to where the } \\
\text { lanes rejoin. }\end{array}$ & $\begin{array}{l}\text { Skyway, } 800 \mathrm{~m}(0.5 \mathrm{mi}) \\
\text { out of town }\end{array}$ & VTD-26 \\
\hline $11 / 8$ & $12: 15$ & $\begin{array}{l}\text { Fire activity is increasing from Honey Run Canyon, moving behind } \\
\text { the health center north of Skyway at Neal Rd. }\end{array}$ & $\begin{array}{l}\text { Honey Run Canyon, } \\
\text { Skyway near Neal Rd }\end{array}$ & TD-070 \\
\hline $11 / 8$ & $12: 30$ & $\begin{array}{l}\text { Spot fires are beginning along Skyway between Pearson Rd and } \\
\text { Neal Rd. }\end{array}$ & $\begin{array}{l}\text { Skyway between Pearson } \\
\text { Rd and Neal Rd }\end{array}$ & TD-066 \\
\hline $11 / 8$ & $12: 45$ & $\begin{array}{l}\text { Structures are burning south and east of Skyway in the area of } \\
\text { Almond St and Fir St. (Table 20) }\end{array}$ & Almond St and Fir St & $T D-026$ \\
\hline $11 / 8$ & $13: 15$ & $\begin{array}{l}\text { Paradise Community Park is burning and } 10 \mathrm{~cm} \text { to } 13 \mathrm{~cm} \text { ( } 4 \text { in to } \\
5 \text { in) diameter embers are falling. Structures to the north of } \\
\text { Paradise PD are burning. (Table 21) }\end{array}$ & $\begin{array}{l}\text { Pearson Rd and Black } \\
\text { Olive } D r\end{array}$ & $T D-026, T D-064$ \\
\hline $11 / 8$ & $14: 00$ & $\begin{array}{l}\text { Fire is threatening structures in the downtown area of Pearson Rd } \\
\text { and Almond St. At town hall, a large woodpile and fence are } \\
\text { burning and threatening the building. }\end{array}$ & $\begin{array}{l}\text { Skyway between Elliott } \\
\text { Rd and Neal Rd }\end{array}$ & $\begin{array}{l}\text { TD-011, TD-015 } \\
\text { TD-017, TD-064 } \\
\text { PPD-15 }\end{array}$ \\
\hline $11 / 8$ & $14: 00$ & $\begin{array}{l}\text { Fire down in Honey Run Canyon is moving SW with moderate rate } \\
\text { of spread. On the ridgetops, flames are shooting out of the canyon } \\
\text { with } 30 \mathrm{~m} \text { to } 60 \mathrm{~m}(100 \mathrm{ft} \text { to } 200 \mathrm{ft}) \text { flame lengths. }\end{array}$ & $\begin{array}{l}\text { Honey Run Rd north of } \\
\text { Centerville Rd }\end{array}$ & TD-117 \\
\hline $11 / 8$ & $14: 00$ & $\begin{array}{l}\text { Spot fires are burning along the ridge east of Skyway, south of } \\
\text { town. In town, fire along Skyway south of Neal Rd is past peak, } \\
\text { but some structures are still burning. }\end{array}$ & Skyway south of Neal Rd & $\begin{array}{l}\text { TD-011, TD-118 } \\
\text { VTD-20 }\end{array}$ \\
\hline $11 / 8$ & $14: 30$ & $\begin{array}{l}\text { Midtown, fire is approaching Skyway from the east. Spot fires and } \\
\text { trees are torching near Holiday Market. }\end{array}$ & Skyway near Oliver Dr & $\begin{array}{l}\text { TD-064, TD-066 } \\
\text { TD-071 }\end{array}$ \\
\hline
\end{tabular}




\begin{tabular}{|c|c|c|c|c|}
\hline Date & Time Range & Fire Behavior Observations & Location & Source \# \\
\hline $11 / 8$ & $15: 00$ & $\begin{array}{l}\text { Heavy fire activity is burning everything on the west side of } \\
\text { Skyway between Black Olive Dr and Jewell Rd. The burning } \\
\text { woodpile continues threatening town hall; shrubs and junipers are } \\
\text { torching, threatening additional structures. Skyway between } \\
\text { Pearson Rd and Neal Rd is being pinched from both east and west: } \\
\text { Fire is spreading uphill, upwind in Honey Run Canyon into } \\
\text { structures on the west side of Skyway. The main fire front is } \\
\text { pushing west from Pearson Rd. Structures are burning along } \\
\text { Pearson Rd, Almond St, and Black Olive Dr, approaching Skyway. }\end{array}$ & $\begin{array}{l}\text { Skyway between Pearson } \\
\text { Rd and Neal Rd }\end{array}$ & $\begin{array}{l}\text { TD-015, TD-055 } \\
\text { TD-101, TD-132 } \\
\text { VTD-20 } \\
\text { PPD-15 }\end{array}$ \\
\hline $11 / 8$ & $15: 00$ & $\begin{array}{l}\text { Fire is threatening downtown structures, approaching Skyway from } \\
\text { the east. So far, a single commercial building on Skyway in the } \\
\text { downtown area is burning. Additional structures burn shortly } \\
\text { thereafter. Waves of golf ball-sized embers from burning structures } \\
\text { are blowing and bouncing down the street. }\end{array}$ & $\begin{array}{l}\text { Skyway between Elliott } \\
\text { Rd and Pearson Rd }\end{array}$ & TD-135, PPD-15 \\
\hline $11 / 8$ & $15: 30$ & $\begin{array}{l}\text { Heavy ember showers and fire are everywhere downtown, Bille Rd } \\
\text { to Neal Rd. Commercial structures are fully involved and burning } \\
\text { down. }\end{array}$ & $\begin{array}{l}\text { Skyway between Bille Rd } \\
\text { and Neal Rd }\end{array}$ & $\begin{array}{l}\text { TD-014, TD-030 } \\
\text { TD-049, TD-111 } \\
\text { TD-114, TD-116 } \\
\text { TD-122, TD-123 } \\
\text { TD-124, TD-127 } \\
\text { TD-142, TD-201 } \\
\text { PPD-15 }\end{array}$ \\
\hline $11 / 8$ & $18: 00$ & $\begin{array}{l}\text { Many structures are destroyed by this time. Residual fire continues } \\
\text { threatening downtown structures overnight. }\end{array}$ & $\begin{array}{l}\text { Skyway between Bille Rd } \\
\text { and Neal Rd }\end{array}$ & $\begin{array}{l}\text { TD-017, TD-122 } \\
\text { TD-123 }\end{array}$ \\
\hline
\end{tabular}




\subsubsection{Neal Road Fire Progression Summary}

The first recorded observations of fire in this region were between 08:30 and 09:00 when fire was burning in the drainage east of Foster Road between Eldridge Drive and Scottwood Road and working into backyards on the side streets on the east side of Foster Road.

At 10:30, spot fires were burning along Red Sky Lane off Neal Road, near Wayland Road. It is unclear if these spot fires were from the main fire to the east or from the fire that was burning over Skyway just to the north of this location. However, at 11:00, flames were burning closer to Neal Road; the fire was burning in the canyons to the west, along Indian Springs Lane and Red Sky Lane. Fire impacted along Neal Road between 11:45 and 12:15 as fire came from the canyon north and west of Neal Road. Fire burned over Neal Road north of Wayland Road, impacting evacuating vehicles and burning structures. Throughout the afternoon into early evening, fire was widespread north of Wayland Road.

By 14:00, structures off Foster Road were burning, and Foster Road was being encroached upon by fire to the east and west of the ridge. Fire continued to close in on the ridge, and structures burned through the afternoon and overnight. Limited direct observations in the area between Neal Road and Scottwood Road are supported by the overall observation dataset in finding that fire encroached upon this area in the early afternoon hours as fire spread into the area from both the east and west.

In the evening, from 17:00 to 17:30, fire activity at Neal Road and Wayland Road increased, and the fire ran south and west down into the lighter fuels of the foothills. Table 27 contains the fire progression summary for Neal Road. 
Table 27. Summary of fire progression on Neal Rd between Skyway and Goa Way.

\begin{tabular}{|c|c|c|c|c|}
\hline Date & Time Range & Fire Behavior Observations & Location & Source \# \\
\hline $11 / 8$ & $08: 30^{\text {a }}$ & $\begin{array}{l}\text { Fire in the canyon is burning westward into backyards at end of } \\
\text { Eldridge Dr }\end{array}$ & $\begin{array}{l}\text { drainage east of Eldridge } \\
\text { Dr, Foster Rd }\end{array}$ & TD-104 \\
\hline $11 / 8$ & $09: 00^{\text {a }}$ & Backyards are igniting. Embers and ash are falling. & $\begin{array}{l}\text { drainage east of Eldridge } \\
\text { Dr, Foster Rd }\end{array}$ & TD-104 \\
\hline $11 / 8$ & $10: 30$ & $\begin{array}{l}\text { Spot fires are burning in the area of Neal Rd and Wayland Rd, Red } \\
\text { Sky Ln. }\end{array}$ & Neal Rd and Wayland Rd & TD-106 \\
\hline $11 / 8$ & $11: 00$ & $\begin{array}{l}\text { Flames are coming up Red Sky Ln toward Neal Rd. Fire is on the } \\
\text { NW side of the road, with glow of significant fire coming from } \\
\text { drainage to west. }\end{array}$ & Neal Rd and Wayland Rd & $\begin{array}{l}\text { TD-053, TD-068 } \\
\text { TD-078, PPD-02 }\end{array}$ \\
\hline $11 / 8$ & $11: 30$ & $\begin{array}{l}\text { Flames very close to Neal Rd at Wayland Rd; north of Wayland Rd, } \\
\text { fire activity on both sides of Neal Rd. }\end{array}$ & Neal Rd and Wayland Rd & $\begin{array}{l}\text { TD-066, TD-073 } \\
\text { PPD-08 }\end{array}$ \\
\hline $11 / 8$ & $11: 45$ & $\begin{array}{l}\text { The south edge of the fire is burning on ridge west of Neal Rd. This } \\
\text { fire is spreading from the Skyway area toward Neal Rd and south } \\
\text { down the drainages. }\end{array}$ & $\begin{array}{l}\text { Indian Springs Ln and } \\
\text { Red Sky Ln }\end{array}$ & TD-205 \\
\hline $11 / 8$ & $11: 45$ & $\begin{array}{l}\text { Fire encroaching on Neal Rd and Roe Rd from the north, large area } \\
\text { of fire burned over Skyway. }\end{array}$ & Neal Rd and Roe Rd & PPD-08 \\
\hline $11 / 8$ & $12: 00$ & $\begin{array}{l}\text { Fire is bumping structures along Neal Rd, burning all around the } \\
\text { intersection of Neal Rd and Wayland Rd. Structures on Red Sky Ln } \\
\text { are also threatened. }\end{array}$ & Neal Rd and Wayland Rd & $\begin{array}{l}\text { TD-050, TD-073 } \\
\text { TD-091, TD-092 } \\
\text { TD-106 }\end{array}$ \\
\hline $11 / 8$ & $12: 00$ & $\begin{array}{l}\text { Fire is all around Neal Rd and Roe Rd north toward Skyway. } \\
\text { Vehicles are being overrun by fire. Some vehicles are burning. }\end{array}$ & Neal Rd and Roe Rd & $\begin{array}{l}\text { TD-014, TD-066 } \\
\text { TD-200 }\end{array}$ \\
\hline $11 / 8$ & $12: 00$ & $\begin{array}{l}\text { Intense fire activity is moving up hill in vegetation, east toward } \\
\text { Grinding Rock Rd. Fire is burning in the backyards on the south } \\
\text { side of the street threatening structures. Flames are } 40 \mathrm{ft} \text { tall, and } \\
\text { trees are torching. }\end{array}$ & Grinding Rock Rd & $\begin{array}{l}\text { TD-128, TD-205 } \\
\text { TD-207 }\end{array}$ \\
\hline $11 / 8$ & $12: 15$ & $\begin{array}{l}\text { Fire is crossing lower Neal Rd north of Wayland Rd, jumping dozer } \\
\text { lines. }\end{array}$ & $\begin{array}{l}\text { Neal Rd between } \\
\text { Grinding Rock Rd and } \\
\text { Wayland Rd }\end{array}$ & TD-091, PPD-08 \\
\hline $11 / 8$ & 13:00 14:00 & $\begin{array}{l}\text { Fire is heading S/SW down drainages to west of Neal Rd, burning } \\
\text { behind structures. The fire activity on Neal Rd is still to the north } \\
\text { towards Wayland Rd. }\end{array}$ & $\begin{array}{l}\text { Neal Rd and Indian } \\
\text { Springs Rd }\end{array}$ & VTD-05 \\
\hline $11 / 8$ & 13:45 & $\begin{array}{l}\text { Structures are burning on the east end of Eldridge Rd (east of Foster } \\
\text { Rd). }\end{array}$ & $\begin{array}{l}\text { Foster Rd and Eldridge } \\
\text { Rd }\end{array}$ & TD-104 \\
\hline $11 / 8$ & 14:00 & $\begin{array}{l}\text { Fire is pinching Foster Rd from the east and west. Fire in the } \\
\text { drainage between Neal Rd and Foster Rd is intense and sounds like } \\
\text { a freight train or jet engine. Large flaming embers are flying. }\end{array}$ & Foster Rd near Apple Ln & TD-104 \\
\hline $11 / 8$ & $14: 00^{\mathrm{a}}$ & $\begin{array}{l}\text { Golf ball sized embers arrived with the fire front. Wood shake roof } \\
\text { on a shed ignited first. Residential structure ignited at roof-wall } \\
\text { intersection. }\end{array}$ & $\begin{array}{l}\text { Filbert St area between } \\
\text { Roe Rd and Neal Rd }\end{array}$ & TD-002 \\
\hline $11 / 8$ & $14: 00 \quad 17: 30$ & Structures continue to ignite and burn on Neal Rd and cross streets. & $\begin{array}{l}\text { Neal Rd between Roe Rd } \\
\text { and Wayland Rd }\end{array}$ & TD-091, TD-092 \\
\hline $11 / 8$ & $15: 00$ & $\begin{array}{l}\text { Commercial structures and vegetation are burning at Neal Rd and } \\
\text { Skyway. }\end{array}$ & Neal Rd and Skyway & $\begin{array}{l}\text { TD-066,VTD-20 } \\
\text { PPD-15 }\end{array}$ \\
\hline $11 / 8$ & $15: 30$ & Several structures along Foster Rd are burning. & Foster Rd near Apple Ln & TD-104 \\
\hline $11 / 8$ & $17: 30$ & $\begin{array}{l}\text { Fire activity at Neal and Wayland increases, pushing into area } \\
\text { from the northeast. The fire then runs down into the Foothills } \\
\text { (Table 30). }\end{array}$ & $\begin{array}{l}\text { Neal Rd south of Wayland } \\
\text { Rd }\end{array}$ & $\begin{array}{l}T D-091, T D-092 \\
T D-106, V T D-01\end{array}$ \\
\hline
\end{tabular}

${ }^{a}$ Observations were in locations with low data density and rely on estimated times from single TDs. They were unable to be directly cross-referenced. 


\subsubsection{Butte Creek Canyon and Lower Skyway Fire Progression Summary}

Fire activity in Butte Creek Canyon began with an 08:45 spot fire on Honey Run Road that impacted Skyway by 10:00. Additional impacts to lower Skyway south of town limits and the canyons were limited until after noon.

At 13:00, additional spot fires were encountered along Honey Run Road north of Centerville Road. Fire activity picked up through the afternoon, and at 14:00 fire was spreading southwest down the canyon and up on the ridgetops. By 16:00, fire progressed halfway down Skyway in the lighter fuels of the foothills, reaching Tuscan Ridge. Spot fires were also beginning to impact Centerville Road and further west into the Wilder Drive and Doe Mill Ridge area. Around 18:00, $30 \mathrm{~m}$ to $60 \mathrm{~m}(100 \mathrm{ft}$ to $200 \mathrm{ft})$ flames broke out of the canyon onto Wilder Drive and fire became well established up on the ridge. Figure 41 shows a view north into Butte Creek Canyon from the Lookout Point overlook on Skyway showing the steep canyon walls. Wilder Drive is on the ridge to the left side of the photo.

By 20:00, the fire was burning towards Highway 99 between Skyway and Neal Road. Containment efforts in Butte Creek Canyon were unable to keep up with the fire, and many structures were lost. North of Honey Run Road, fire continued pushing west out of the canyon, reaching Stilson Canyon, Humboldt Road, and Highway 32 by 22:00. Additional structures were threatened in the subdivisions of Spanish Garden Drive, Oak Ridge Drive, and Eagle Nest Drive of Skyway around midnight. Table 28 contains the fire progression summary for Butte Creek Canyon and lower Skyway south of Lookout Point.

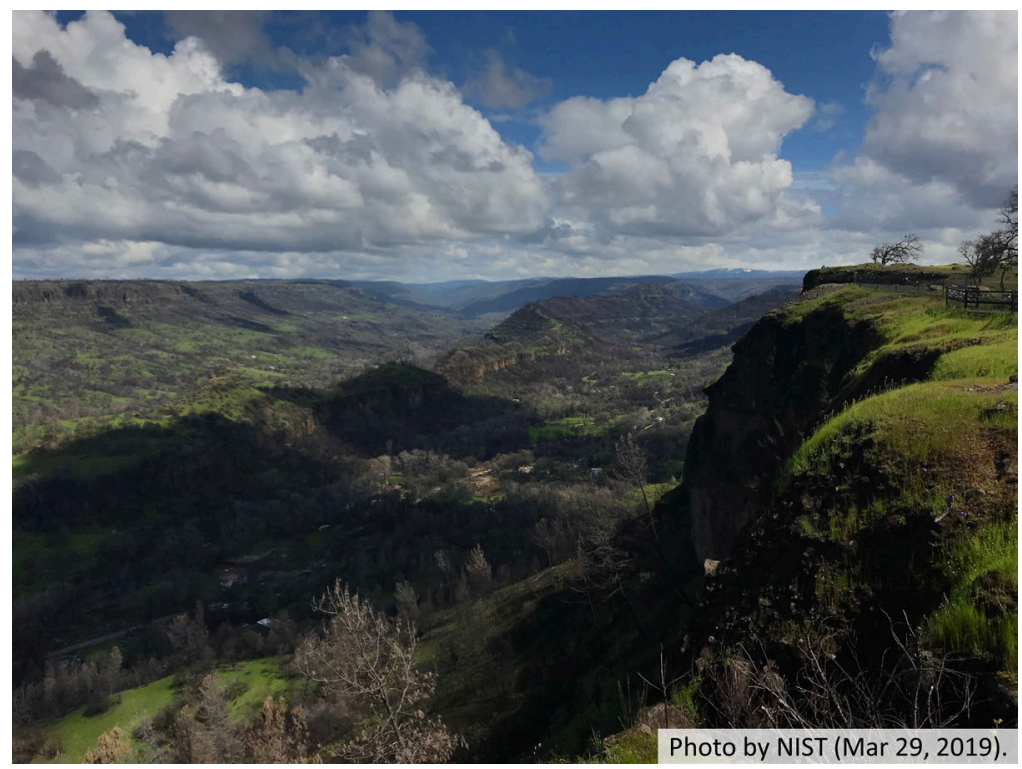

Figure 41. A view into Butte Creek Canyon from Lookout Point on Skyway shows the steep canyon walls. View north. Photo March 2019. 
Table 28. Summary of fire progression in Butte Creek Canyon and on lower Skyway.

\begin{tabular}{|c|c|c|c|c|}
\hline Date & Time Range* & Fire Behavior Observations & Location & Source \# \\
\hline $11 / 8$ & $08: 45 \quad 09: 15$ & $\begin{array}{l}\text { A spot fire ignites in Honey Run Canyon between Redbud Dr and } \\
\text { Skyway and becomes well-established. (Table 26, Table 29) }\end{array}$ & $\begin{array}{l}\text { Honey Run Canyon } \\
\text { between Redbud Dr and } \\
\text { Skyway }\end{array}$ & $\begin{array}{c}\text { TD-006, TD-038 } \\
\text { TD-055, TD-111 } \\
911-182-1 \\
911-200-1 \\
911-202-1 \\
911-204-1 \\
911-218-1 \\
911-221-1 \\
911-225-1\end{array}$ \\
\hline $11 / 8$ & 09:10 & $\begin{array}{l}\text { Another spot fire is reported on Honey Run Rd about } 1.6 \text { km (1 mi) } \\
\text { north of Centerville Rd. }\end{array}$ & $\begin{array}{l}\text { Honey Run Rd north of } \\
\text { Centerville Rd, off } \\
\text { Lookout Point }\end{array}$ & $911-223-1$ \\
\hline $11 / 8$ & $10: 10$ & $\begin{array}{l}\text { Fire is well established in Honey Run Canyon just below Canyon } \\
\text { View. Multiple spots are running back up towards Canyon View } \\
\text { Apartments and will impact Skyway. (Table 26, Table 29) }\end{array}$ & $\begin{array}{l}\text { Honey Run Canyon } \\
\text { between Redbud Dr and } \\
\text { Skyway }\end{array}$ & $\begin{array}{l}\text { TD-007 } \\
\text { Radio Log }\end{array}$ \\
\hline $11 / 8$ & $10: 55 \quad 12: 45$ & $\begin{array}{l}\text { On Skyway, an evacuating pickup truck is on fire. The fire is } \\
\text { prevented from spreading to vegetation. }\end{array}$ & $\begin{array}{l}\text { Skyway just west of } \\
\text { Lookout Point }\end{array}$ & TD-014, TD-026 \\
\hline $11 / 8$ & 13:00 & Spot fires are observed on both sides of Honey Run Rd. & $\begin{array}{l}\text { Honey Run Rd near } \\
\text { Centerville Rd }\end{array}$ & Radio Log \\
\hline $11 / 8$ & $14: 00$ & $\begin{array}{l}\text { Fire is spreading SW down canyon toward Centerville Rd. Ember } \\
\text { showers and flames are threatening multiple structures. In the } \\
\text { canyon flames are } 2 \mathrm{~m} \text { to } 3 \mathrm{~m}(6 \mathrm{ft} \text { to } 10 \mathrm{ft}) \text { long. Flames are } 30 \mathrm{~m} \\
\text { to } 60 \mathrm{~m}(100 \mathrm{ft} \text { to } 200 \mathrm{ft}) \text { long burning up the canyon walls and on } \\
\text { the ridgetops. }\end{array}$ & Little Butte Creek Canyon & TD-117 \\
\hline $11 / 8$ & $15: 40$ & Spot fires are beginning in the Wilder Dr area west of Butte Creek. & Wilder Dr & TD-007 \\
\hline $11 / 8$ & $16: 00$ & $\begin{array}{l}\text { Fast moving fire fronts are merging from the ridgetops down into } \\
\text { Honey Run Canyon. Fire is moving west over into Centerville Rd } \\
\text { and Butte Creek Canyon. Homes are burning. }\end{array}$ & $\begin{array}{l}\text { Butte Creek Canyon, } \\
\text { Honey Run Rd, } \\
\text { Centerville Rd }\end{array}$ & TD-117 \\
\hline $11 / 8$ & $16: 00$ & $\begin{array}{l}\text { On Skyway, fire has progressed west to near Tuscan Ridge on } \\
\text { Skyway (approximately } 3.5 \mathrm{mi} \text { from Hwy 99). }\end{array}$ & $\begin{array}{l}\text { Skyway and Tuscan } \\
\text { Ridge }\end{array}$ & TD-114 \\
\hline $11 / 8$ & $16: 30$ & $\begin{array}{l}\text { A } 10 \text { ac to } 20 \text { ac spot fire is burning in Butte Creek Canyon, west } \\
\text { of Centerville Rd. }\end{array}$ & $\begin{array}{l}\text { Centerville Rd and } \\
\text { McClure Ln }\end{array}$ & TD-076 \\
\hline $11 / 8$ & $18: 00$ & $\begin{array}{l}\text { Intense fire is licking up canyon walls into the Wilder Dr area. } \\
\text { Flames are } 30 \mathrm{~m} \text { to } 60 \mathrm{~m}(100 \mathrm{ft} \text { to } 200 \mathrm{ft}) \text { coming out of the } \\
\text { canyon. Flames are laying down into thick brush, sheeting with } 15 \\
\mathrm{~m} \text { to } 18 \mathrm{~m}(50 \mathrm{ft} \text { to } 60 \mathrm{ft}) \text { flame lengths. }\end{array}$ & Wilder Dr & TD-012 \\
\hline $11 / 8$ & 20:00 & $\begin{array}{l}\text { Fire approaching within } 1.6 \mathrm{~km}(1 \mathrm{mi}) \text { of Hwy } 99 \text { near Skyway and } \\
\text { Spanish Garden Dr. }\end{array}$ & $\begin{array}{l}\text { Skyway and Spanish } \\
\text { Garden Dr }\end{array}$ & TD-201 \\
\hline $11 / 8$ & 21:00 & $\begin{array}{l}\text { Fire has overcome containment efforts on Honey Run Rd to } \\
\text { Centerville Rd. Many structures are lost. }\end{array}$ & $\begin{array}{l}\text { Honey Run Rd between } \\
\text { Skyway and Centerville } \\
\text { Rd }\end{array}$ & TD-009, TD-117 \\
\hline $11 / 8$ & 22:00 & $\begin{array}{l}\text { North of Honey Run Rd, fire is spreading west down slopes } \\
\text { through grass toward east Chico. }\end{array}$ & $\begin{array}{l}\text { between Honey Run Rd } \\
\text { and Stilson Canyon Rd }\end{array}$ & TD-117 \\
\hline $11 / 8$ & $22: 00$ & $\begin{array}{l}\text { Fire has moved up out of Stilson Canyon and is coming up over } \\
\text { Humboldt Rd approaching Hwy } 32 \text {. The fire spots into tall grass. }\end{array}$ & $\begin{array}{l}\text { Humboldt Rd and Stilson } \\
\text { Canyon Rd }\end{array}$ & TD-009, TD-012 \\
\hline $11 / 8$ & $23: 30$ & Fire activity has decreased along Humboldt Rd. & $\begin{array}{l}\text { Humboldt Rd and Stilson } \\
\text { Canyon Rd }\end{array}$ & TD-009 \\
\hline $11 / 8$ & $23: 30$ & $\begin{array}{l}\text { Subdivisions off Skyway, at Spanish Garden Dr and Oak Ridge Dr } \\
\text { are threatened by fire. }\end{array}$ & $\begin{array}{l}\text { Skyway and Oak Ridge } \\
\text { Dr / Spanish Garden Dr }\end{array}$ & TD-201 \\
\hline
\end{tabular}




\subsubsection{Valley View Drive Fire Progression Summary}

At 08:45, a long-range spot fire started down in the Honey Run Canyon between Redbud Drive and Russell Drive to the south on Skyway. The fire became well-established, and by 10:00 it was spreading south out of the canyon and overran Skyway. The fire did not spread up and impact the Valley View Drive area directly; it slowly worked west around the ridge, and at 13:30 the fire was burning along the ridge at the end of Point West Drive.

Flames were observed in the Little Butte Creek Canyon, west of Valley Ridge Drive, an hour later around 14:30. The fire spread up out of the canyon toward homes on Valley Ridge Drive and Valley View Drive. By 17:00, most of the homes along Valley Ridge Drive had been destroyed. The fire pushed through the Valley View Drive area from the canyon to the west and from Oliver Drive to the east. Structures throughout the area continued to ignite during the evening hours and overnight. Table 29 contains the fire progression summary for Valley View Drive.

Table 29. Summary of fire progression on Valley View Dr.

\begin{tabular}{|c|c|c|c|c|}
\hline Date & Time Range & Fire Behavior Observations & Location & Source \# \\
\hline $11 / 8$ & $09: 15$ & $\begin{array}{l}\text { A spot fire ignites in Honey Run Canyon and becomes well- } \\
\text { established. }\end{array}$ & $\begin{array}{l}\text { Honey Run Canyon } \\
\text { between Redbud Dr and } \\
\text { Skyway }\end{array}$ & $\begin{array}{c}\text { TD-006, TD-038 } \\
\text { TD-055, TD-111 } \\
911-182-1 \\
911-200-1 \\
911-202-1 \\
911-204-1 \\
911-218-1 \\
911-221-1 \\
911-225-1\end{array}$ \\
\hline $11 / 8$ & $10: 10$ & $\begin{array}{l}\text { Fire is well established in Honey Run Canyon just below Canyon } \\
\text { View. Multiple spots are running back up towards Canyon View } \\
\text { Apartments and will impact Skyway (Table 26). }\end{array}$ & $\begin{array}{l}\text { Honey Run Canyon } \\
\text { between Redbud Dr and } \\
\text { Skyway }\end{array}$ & $\begin{array}{l}\text { TD-007 } \\
\text { Radio Log }\end{array}$ \\
\hline $11 / 8$ & $13: 30$ & $\begin{array}{l}\text { Fire is burning on the ridge at the end of Point West Dr on the west } \\
\text { side of Paradise. }\end{array}$ & $\begin{array}{l}\text { Point West Dr, end of } \\
\text { Valley Ridge Dr }\end{array}$ & TD-012 \\
\hline $11 / 8$ & $14: 30$ & $\begin{array}{l}\text { Flames are observed down in Little Butte Creek Canyon, west of } \\
\text { Valley Ridge Dr. }\end{array}$ & Little Butte Creek Canyon & TD-044 \\
\hline $11 / 8$ & $16: 55$ & $\begin{array}{l}\text { Fire is burning all around the intersection of Valley View Dr and } \\
\text { Oliver Dr. Structures are also burning on Castle Dr to the north of } \\
\text { Valley View Dr (Table 19, Table 26). }\end{array}$ & $\begin{array}{l}\text { Valley View Dr and } \\
\text { Oliver Dr }\end{array}$ & $T D-014$ \\
\hline $11 / 8$ & $17: 00$ & $\begin{array}{l}\text { Fire is making a hard run out of the canyon toward Valley Ridge } \\
\text { Dr. All but } 3 \text { structures on the north loop are burned to foundations } \\
\text { and flaming. Two are standing, one other is well-involved. }\end{array}$ & Valley Ridge Dr & TD-014, TD-020 \\
\hline $11 / 8$ & 19:00 & $\begin{array}{l}\text { Structures further east of the canyon rim are being threatened and } \\
\text { burning now and there are heavy ember showers. The handful of } \\
\text { surviving structures on Valley Ridge Dr continue to be threatened } \\
\text { by residual fire activity in the area. }\end{array}$ & $\begin{array}{l}\text { Valley Ridge Dr and } \\
\text { Valley View Dr }\end{array}$ & TD-044, TD-111 \\
\hline $11 / 8$ & 20:00 & $\begin{array}{l}\text { Multiple structures are burning, and fire is widespread south and } \\
\text { east of Valley View Dr on Crestmoor Dr, Crestview Dr, and } \\
\text { surrounding neighborhood. }\end{array}$ & $\begin{array}{l}\text { Crestmoor Dr and } \\
\text { surrounding neighborhood }\end{array}$ & TD-109 \\
\hline $11 / 8$ & $22: 30$ & $\begin{array}{l}\text { Additional structures ignite on Valley Ridge Dr near Valley View } \\
\text { Dr. }\end{array}$ & $\begin{array}{l}\text { Valley Ridge Dr and } \\
\text { Valley View Dr }\end{array}$ & TD-044 \\
\hline $11 / 8$ & 23:00 & $\begin{array}{l}\text { Structures continue to be threatened in the Valley View Dr and } \\
\text { Redbud Dr area. Fences, sheds, and homes are burning. }\end{array}$ & Redbud Dr & $\begin{array}{l}\text { TD-017, TD-030 } \\
\text { TD-044 }\end{array}$ \\
\hline
\end{tabular}




\subsubsection{Foothills Fire Progression Summary}

Fire reached the foothills south of town in the afternoon. In the early afternoon, the fire was generally hung up north of an arc connecting Kunkle Reservoir on Pentz Road, north of Circle J Road on Clark Road south of the airport, and north of Wayland Road on Neal Road. Fingers of fire were burning in the numerous drainages and ridges south of town.

The fire spread beyond this general line around 15:00 along Clark Road. After the fire paused south of the airport, a wind shift pushed fire quickly into the grassy flats along Clear Creek, east of Clark Road. Three firefighters were injured in a burnover on Rattlesnake Flats Road [17]. On the west side of Clark Road, fire was spreading down slope toward Circle J Road.

Increased fire activity was observed across the entire fire front around 17:00 (sunset was at 16:56). On Pentz Road, fire picked up and spread quickly through structures near Pardes Way and Silvera Court and burned into the Dry Creek drainage and the Messilla Valley Road area. Activity along the west side of Clark Road pushed fire along the ridgetops, burning up against structures on the cross streets of Clark Road south of Circle J Road and over the ridge into the Cory Canyon area. Further west, along Neal Road, fire activity increased at the edge of town near Wayland Road, and fire spread quickly downwind and down canyon. A fire whirl was documented at this time along Neal Road, as shown in Figure 16. The increase in fire activity was likely due to the diurnal wind shift at sunset, captured in the observations of the Openshaw RAWS shown in Figure 9. The wind shifted from the northwest to the northeast, bringing dry air with it and accelerating fire spread down slope.

By 19:00, fire had jumped Durham-Pentz Road near Highway 99 as well as east of Clark Road. Fire spread between 17:00 and 19:00 showed an average rate of spread nominally $0.9 \mathrm{~m} / \mathrm{s}(2 \mathrm{mi} / \mathrm{h}$ or $160 \mathrm{ch} / \mathrm{h})$ downslope through the grasslands. Fire did slop over Highway 99, burning in three different places.

Fire spread away from structures along Clark Road, jumped south of Durham-Pentz Road, and crossed to the west side of Clark Road around 19:30. By 20:30, the fire had reached Highway 149 near Shippee Road. Again, the rate of spread through the grass was nominally $0.9 \mathrm{~m} / \mathrm{s}$ based on these observations. Table 30 contains the fire progression summary for the Foothills. 
Table 30. Summary of fire progression in the foothills between Paradise and Hwy 99.

\begin{tabular}{|c|c|c|c|c|c|}
\hline Date & Time & Range & Fire Behavior Observations & Location & Source \# \\
\hline $11 / 8$ & $13: 30$ & & $\begin{array}{l}\text { The fire front has slowed down on Clark Rd south of the airport. } \\
\text { Lower intensity fire is burning on both sides of Clark Rd (Table } \\
\text { 24). }\end{array}$ & $\begin{array}{l}\text { Clark } R d, 1.5 \text { mi south of } \\
\text { Airport } R d\end{array}$ & $\begin{array}{l}T D-035, T D-046 \\
T D-110, T D-132 \\
T D-133, T D-141 \\
\quad T D-210\end{array}$ \\
\hline $11 / 8$ & $14: 00$ & & $\begin{array}{l}\text { Fire is working further south on ridgetops east of Clark Rd, as far } \\
\text { south as Dulcinea Dr. }\end{array}$ & ridgetop east of Clark Rd & TD-132, TD-141 \\
\hline $11 / 8$ & $14: 00$ & & $\begin{array}{l}\text { On Pentz Rd, fire is spreading south beyond Kunkle Reservoir, } \\
\text { threatening structures near Zephyr Point Rd. (Table 16) }\end{array}$ & $\begin{array}{l}\text { Pentz Rd and Zephyr } \\
\text { Point Rd }\end{array}$ & $T D-121$ \\
\hline $11 / 8$ & $15: 00$ & & $\begin{array}{l}\text { A wind shift in the afternoon blows fire down the drainage through } \\
\text { the flats on the east side of Clark Rd. }\end{array}$ & $\begin{array}{l}\text { Clark Rd between Clear } \\
\text { Creek Cemetery Rd and } \\
\text { Circle J Rd }\end{array}$ & TD-110 \\
\hline $11 / 8$ & $15: 00$ & $15: 30$ & $\begin{array}{l}\text { With the wind, fire spreads quickly south through grass east of } \\
\text { Clark Rd. Crews and engines get trapped and burned over on } \\
\text { Rattlesnake Flats Rd (see Section 9.3). Several spot fires start on } \\
\text { the west side of Clark Rd near Clear Creek Cemetery Rd. }\end{array}$ & $\begin{array}{l}\text { Clark Rd between Clear } \\
\text { Creek Cemetery Rd and } \\
\text { Circle J Rd }\end{array}$ & TD-208, TD-210 \\
\hline $11 / 8$ & $15: 30$ & $16: 00$ & $\begin{array}{l}\text { On the west side of Clark Rd, fire is moving down slope from the } \\
\text { airport and Round Valley Ranch Rd into the Circle J Rd area. }\end{array}$ & Circle J Rd, Clark Rd & TD-102, TD-110 \\
\hline $11 / 8$ & $17: 00$ & $21: 00$ & $\begin{array}{l}\text { Fire activity increases on ridges west of Clark Rd; structures at the } \\
\text { ends of side streets are threatened and destroyed. The fire front } \\
\text { burns further south and west into Cory Canyon. }\end{array}$ & $\begin{array}{l}\text { Clark Rd between } \\
\text { Durham-Pentz Rd and } \\
\text { Circle J Rd; Cory Canyon } \\
\text { Rd }\end{array}$ & $\begin{array}{l}\text { TD-065, TD-102 } \\
\text { TD-119, TD-120 }\end{array}$ \\
\hline $11 / 8$ & $17: 30$ & 18:00 & $\begin{array}{l}\text { Fire activity increases and pushes down Neal Rd to the recycling } \\
\text { and waste facility. Fire is aligning with drainages (Table 27). }\end{array}$ & Neal Rd & TD-091, TD-092 \\
\hline $11 / 8$ & $17: 30$ & & $\begin{array}{l}\text { Fire is quickly moving south along Pentz Rd, near Pardes Way and } \\
\text { Silvera Ct, threatening structures. Fire is also burning south in the } \\
\text { Dry Creek drainage, along Dry Creek Rd. }\end{array}$ & $\begin{array}{l}\text { Pentz Rd and Pardes Way, } \\
\text { Dry Creek Rd }\end{array}$ & TD-121 \\
\hline $11 / 8$ & $18: 30$ & & $\begin{array}{l}\text { Fingers of fire are spreading through the grass foothills towards } \\
\text { Hwy 99, and consuming the rest of the hillside east of Neal Rd. }\end{array}$ & south and east of Neal Rd & TD-091, TD-092 \\
\hline $11 / 8$ & $18: 45$ & & $\begin{array}{l}\text { Fire jumps Durham-Pentz Rd east of Clark Rd, pushing SW } \\
\text { through the grass. }\end{array}$ & $\begin{array}{l}\text { Durham-Pentz Rd just } \\
\text { east of Clark Rd }\end{array}$ & $\begin{array}{l}\text { TD-071, TD-076 } \\
\text { TD-110, TD-211 }\end{array}$ \\
\hline $11 / 8$ & $18: 50$ & & $\begin{array}{l}\text { Fire has reached Hwy 99. Flames are bumping Hwy } 99 \text { between } \\
\text { Neal Rd and Durham-Pentz Rd. Fire also jumps Durham-Pentz Rd } \\
\text { near Hwy } 99 \text {. }\end{array}$ & $\begin{array}{l}\text { Hwy } 99 \text { between Neal Rd } \\
\text { and Durham-Pentz Rd }\end{array}$ & $\begin{array}{l}\text { TD-106 } \\
\text { Radio Log }\end{array}$ \\
\hline $11 / 8$ & $19: 00$ & 20:00 & $\begin{array}{l}\text { Fire spots over Hwy } 99 \text { in several places. The spot fires grow and } \\
\text { burn several acres of slopover west of Hwy } 99 \text {. Fire is burning in } \\
\text { fingery patterns through grass, with winds } 11 \mathrm{~m} / \mathrm{s} \text { to } 13 \mathrm{~m} / \mathrm{s} \\
(25 \mathrm{mi} / \mathrm{h} \text { to } 30 \mathrm{mi} / \mathrm{h}) \text {. }\end{array}$ & $\begin{array}{l}\text { Hwy } 99 \text { between Neal Rd } \\
\text { and Durham-Pentz Rd }\end{array}$ & $\begin{array}{l}\text { TD-042, TD-091 } \\
\text { TD-092, TD-106 } \\
\text { TD-201, TD-211 } \\
\text { VTD-01 }\end{array}$ \\
\hline $11 / 8$ & 19:30 & & Fire is about to jump Clark Rd south of Durham-Pentz Rd. & $\begin{array}{l}\text { Clark Rd } 1.6 \mathrm{~km}(1 \mathrm{mi}) \\
\text { south of Durham-Pentz }\end{array}$ & TD-102, TD-110 \\
\hline $11 / 8$ & 19:30 & & $\begin{array}{l}\text { Fire is threatening communities off Pentz Rd on Sunview Dr and } \\
\text { Messilla Valley Rd. }\end{array}$ & $\begin{array}{l}\text { Pentz Rd and Messilla } \\
\text { Valley Rd }\end{array}$ & TD-020, TD-121 \\
\hline $11 / 8$ & $20: 30$ & & $\begin{array}{l}\text { Fire has reached Hwy } 149 \text { and Shippee Rd, } 3 \mathrm{~km}(2 \mathrm{mi}) \mathrm{SW} \text { from } \\
\text { Clark Rd, and is threatening to jump Hwy } 149 .\end{array}$ & Hwy 149 and Shippee Rd & Radio Log \\
\hline $11 / 8$ & $22: 00$ & & $\begin{array}{l}\text { By this time, fire has gone through the Cory Creek area. Several } \\
\text { structures destroyed. Residual fire continues to threaten } \\
\text { communities along Durham-Pentz Rd. }\end{array}$ & Durham-Pentz Rd & TD-102 \\
\hline
\end{tabular}




\subsubsection{Nelson Bar Road and Highway 70 Fire Progression Summary}

As the fire progressed beyond the south end of Concow Reservoir into the Nelson Bar Road focus region in the early afternoon, observations of the fire spread became limited due to first responder locations and the topography. In the late morning the fire became hung up by wind/topography/fuel interactions beyond the south end of Concow Reservoir, burning north of Deadwood Road and in the Concow Creek drainage.

The fire continued to build in the drainages during the afternoon hours. Figure $\mathbf{4 2}$ shows the view seen during the afternoon by first responders in the Nelson Bar Road area, with smoke coming from the Concow Creek drainage and West Branch canyons.

Fire activity dramatically increased around 17:00, and intense fire came out of the drainages ${ }^{14}$ and toward Nelson Bar Road with flame heights of $15 \mathrm{~m}$ to $30 \mathrm{~m}$ (50 ft to $100 \mathrm{ft}$ ). Numerous spot fires aided the spread of fire through the flatter grasslands in the area. Figure 43, a panorama compiled from a video recording, shows the fire front and spot fires from nearly the same position seen in Figure 42.

The fire front passed and was burning on the east side of Nelson Bar Road and toward Lunt Road by 19:00. The fire continued to burn the area between Nelson Bar Road, Lunt Road, and Concow Road during the overnight hours. At approximately 03:30 on November 9, strong winds estimated at $20 \mathrm{~m} / \mathrm{s}(45 \mathrm{mi} / \mathrm{h})$ sent the fire front south of Lunt Road, jumping containment lines and backfiring operations. Around the same time, Fire Station 36 at Jarbo Gap was impacted by slope- and wind-driven fire as the front pushed south down the Feather River Canyon toward Big Bend.

Down on Concow Road near Shuman Lane and Fire Station 37, fire activity subsided overnight. However, around sunrise, fire activity dramatically increased again, threatening firefighters in the area and preventing travel to safety via Concow Road. After a period of sheltering, firefighters were able to progress back to Highway 70 .

At approximately 08:00 on November 9, fire continued south and east from Concow Road, jumping Highway 70 and running toward Yankee Hill. Table 31 contains the fire progression summary for Nelson Bar Road and Highway 70.

\footnotetext{
${ }^{14}$ Local fire behavior in the Concow Creek and Nelson Bar Road area was influenced by slope and wind throughout the afternoon resulting in upslope spread into the wind and downslope wind-driven spread.
} 


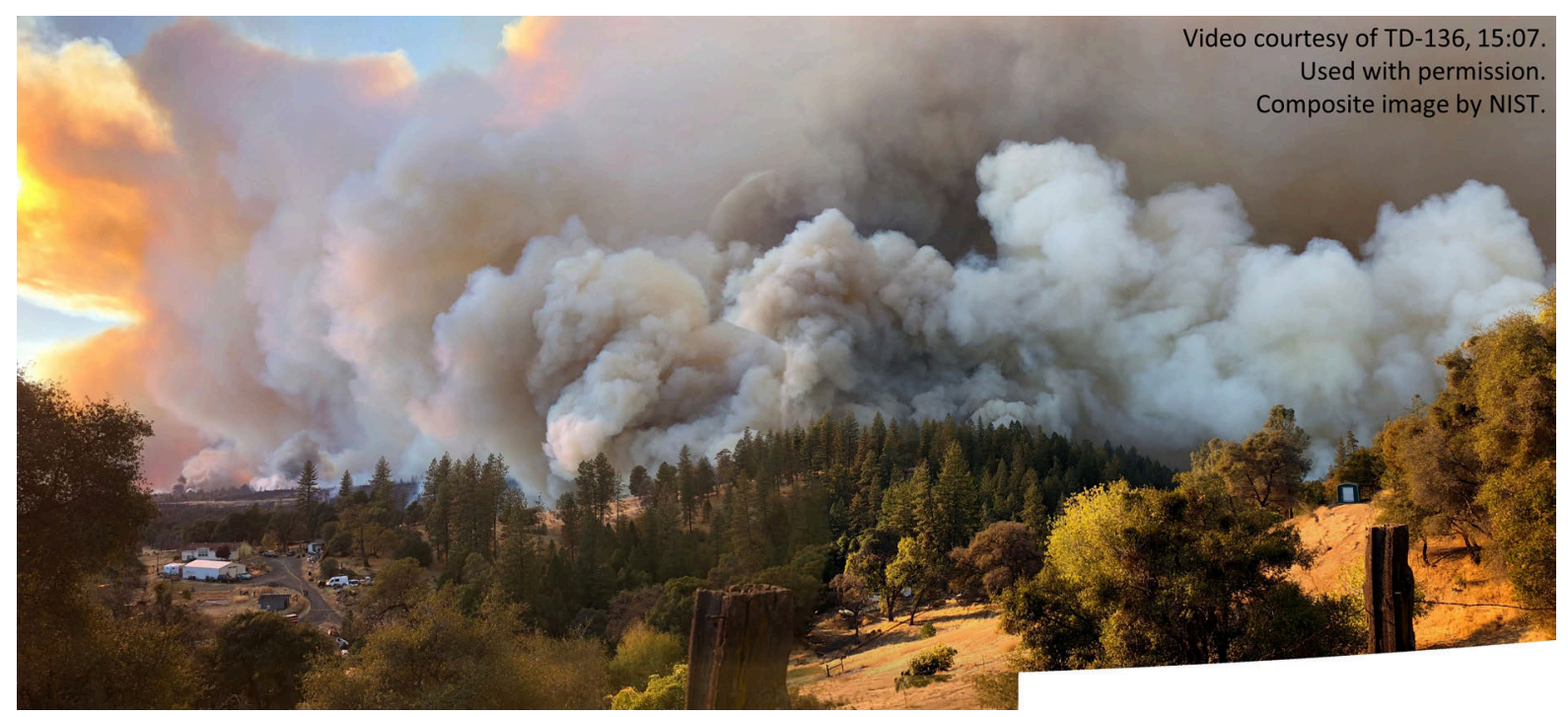

Figure 42. View west from Nelson Bar Rd where plumes of smoke are seen coming from beyond the ridge in the Concow Creek drainage, and beyond to Paradise (background, left).

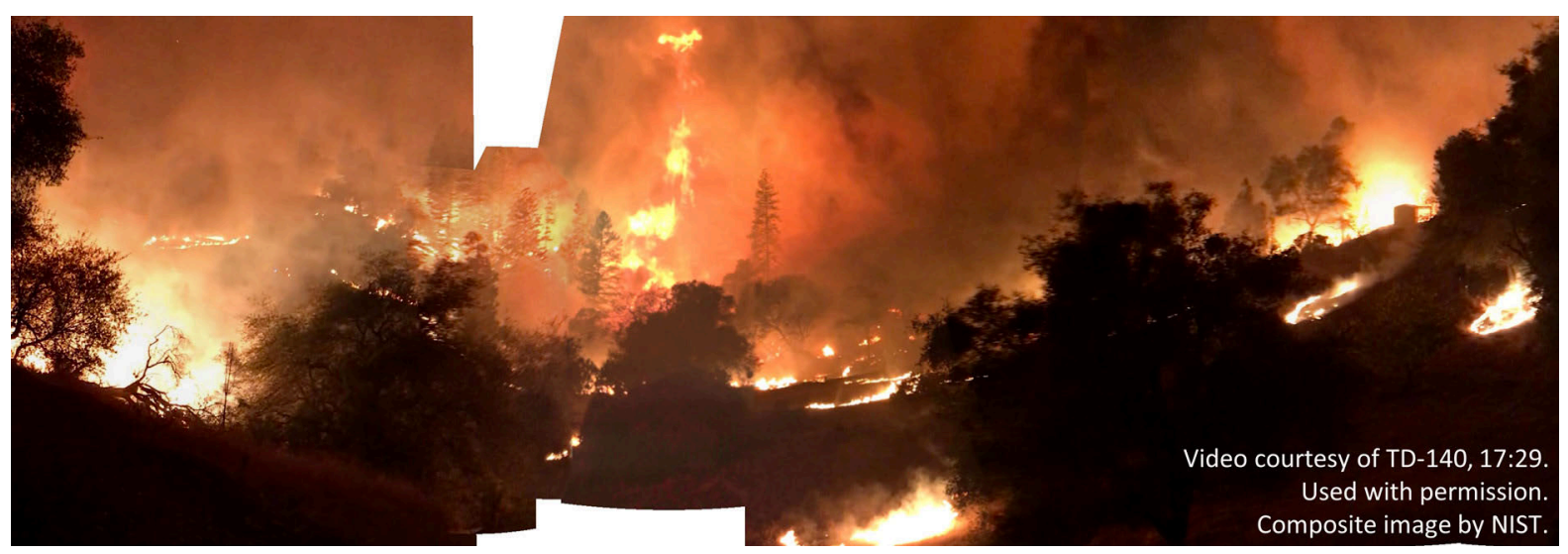

Figure 43. Fire activity increased in the drainage area, and the front rapidly spread south and east toward Nelson Bar Rd. 
Table 31. Summary of fire progression on Nelson Bar Rd and Highway 70.

\begin{tabular}{|c|c|c|c|c|}
\hline Date & Time Range & Fire Behavior Observations & Location & Source \# \\
\hline $11 / 8$ & $11: 00$ & $\begin{array}{l}\text { Fire is established in the West Branch Feather River Canyon where } \\
\text { the river turns into the lake. }\end{array}$ & $\begin{array}{l}\text { Feather River Canyon east } \\
\text { of Kunkle Reservoir }\end{array}$ & TD-008 \\
\hline $11 / 8$ & $12: 30 \quad 17: 00$ & $\begin{array}{l}\text { The southern extent of the fire remains hung up burning in the } \\
\text { Concow Creek Canyon northwest of Nelson Bar Rd, and on both } \\
\text { sides of Concow Rd north of Comfort Ln. }\end{array}$ & $\begin{array}{l}\text { Concow Rd and } \\
\text { Deadwood Rd }\end{array}$ & $\begin{array}{l}\text { TD-013, TD-031 } \\
\text { TD-108, TD-136 } \\
\text { TD-137, TD-140 }\end{array}$ \\
\hline $11 / 8$ & $14: 40$ & $\begin{array}{l}\text { The fire front is creeping south and is approaching structures on } \\
\text { Concow Rd and Deadwood Rd }\end{array}$ & $\begin{array}{l}\text { Concow Rd and } \\
\text { Deadwood Rd }\end{array}$ & TD-027 \\
\hline $11 / 8$ & $15: 45$ & Fire is threatening structures in the Miller Peak area. & $\begin{array}{l}\text { Miller Peak between } \\
\text { Concow Rd and Hwy } 70\end{array}$ & $\begin{array}{l}\text { TD-013, TD-031 } \\
\text { TD-136, TD-137 } \\
\text { TD-140 }\end{array}$ \\
\hline $11 / 8$ & $16: 00$ & The fire front has progressed south of Deadwood Rd. & $\begin{array}{l}\text { Concow Rd and } \\
\text { Deadwood Rd }\end{array}$ & TD-027 \\
\hline $11 / 8$ & $17: 00$ & $\begin{array}{l}\text { Intense fire comes out of the Concow Creek Canyon towards } \\
\text { Nelson Bar Rd. Fire is spotting across the flat grassy areas. }\end{array}$ & $\begin{array}{l}\text { Nelson Bar Rd near } \\
\text { Stage Coach Ln }\end{array}$ & $\begin{array}{l}\text { TD-027, TD-062 } \\
\text { TD-136, TD-137 } \\
\text { TD-140 }\end{array}$ \\
\hline $11 / 8$ & $17: 20$ & $\begin{array}{l}\text { An intense fire front with } 15 \mathrm{~m} \text { to } 30 \mathrm{~m}(50 \mathrm{ft} \text { to } 100 \mathrm{ft}) \text { flames } \\
\text { burns through the forest into the grasslands, impacting structures } \\
\text { along the west side of Nelson Bar Rd. Numerous short-range spot } \\
\text { fires are observed ahead of the front. }\end{array}$ & $\begin{array}{l}\text { Nelson Bar Rd near } \\
\text { Stage Coach Ln }\end{array}$ & $\begin{array}{l}\text { TD-137, TD-139 } \\
\text { TD-140 }\end{array}$ \\
\hline $11 / 8$ & 18:00 & $\begin{array}{l}\text { Fire jumps south of Nelson Bar Rd between Concow Rd and Lunt } \\
\text { Rd. }\end{array}$ & $\begin{array}{l}\text { Nelson Bar Rd between } \\
\text { Concow Rd and Lunt Rd }\end{array}$ & $\begin{array}{l}\text { TD-013, TD-031 } \\
\text { TD-139, TD-140 } \\
\text { TD-008 }\end{array}$ \\
\hline $11 / 8$ & $19: 15$ & $\begin{array}{l}\text { The fire front has passed through structures on Nelson Bar Rd north } \\
\text { of Lunt Rd. Widespread scattered fires remain. Some structures } \\
\text { have been destroyed. }\end{array}$ & $\begin{array}{l}\text { Nelson Bar Rd between } \\
\text { Concow Rd and Lunt Rd }\end{array}$ & $\begin{array}{l}\text { TD-008, TD-137 } \\
\text { TD-138, TD-139 } \\
\text { TD-140, }\end{array}$ \\
\hline $11 / 8$ & 22:00 $03: 30$ & $\begin{array}{l}\text { Overnight, fire is burning west of Nelson Bar Rd, north of Lunt Rd, } \\
\text { and west of Concow Rd. }\end{array}$ & $\begin{array}{l}\text { Nelson Bar Rd between } \\
\text { Concow Rd and Lunt Rd }\end{array}$ & $\begin{array}{l}\text { TD-013, TD-031 } \\
\text { TD-062, TD-136 }\end{array}$ \\
\hline $11 / 9$ & 02:00 & The fire front is burning close to Fire Station 36 at Jarbo Gap. & $\begin{array}{l}\text { Hwy } 70 \text { and Deadwood } \\
\text { Rd }\end{array}$ & $\begin{array}{l}\text { TD-027, TD-028 } \\
\text { TD-029 }\end{array}$ \\
\hline $11 / 9$ & 03:30 & $\begin{array}{l}\text { Strong winds, } 18 \mathrm{~m} / \mathrm{s} \text { to } 22 \mathrm{~m} / \mathrm{s} \text { ( } 40 \mathrm{mi} / \mathrm{h} \text { to } 50 \mathrm{mi} / \mathrm{h}) \text {, push the main } \\
\text { fire front south of Lunt Rd and fire runs WSW. Flames are laying } \\
\text { down and consuming } 2 \mathrm{~m} \text { to } 3 \mathrm{~m}(6 \mathrm{ft} \text { to } 10 \mathrm{ft} \text { ) tall brush fuels. }\end{array}$ & Lunt Rd & $\begin{array}{l}\text { TD-008, TD-013 } \\
\text { TD-031 }\end{array}$ \\
\hline $11 / 9$ & 04:00 & $\begin{array}{l}\text { Fire wraps around and impacts Fire Station } 36 \text {. Fire is both slope- } \\
\text { and wind-driven from the canyon. The fire continues running south } \\
\text { toward Big Bend Mountain Mobile Home Park. }\end{array}$ & $\begin{array}{l}\text { Hwy } 70 \text { and Deadwood } \\
\text { Rd }\end{array}$ & TD-008, TD-02 \\
\hline $11 / 9$ & 07:20 & $\begin{array}{l}\text { Sunrise causes fire intensity to pick up dramatically; visibility } \\
\text { decreases, suddenly everything is burning again: trees, needles, and } \\
\text { houses. Fire is burning across Pinkston Canyon Rd towards } \\
\text { Concow Rd, coming hard toward Concow Pool. Firefighters are } \\
\text { worried about getting pinched from fire from both sides of Concow } \\
\text { Rd. Fire Station } 37 \text { is hit hard by fire (see Section 9.3) }\end{array}$ & $\begin{array}{l}\text { Concow Rd and Shuman } \\
\text { Ln }\end{array}$ & $\begin{array}{l}\text { TD-136, TD-137 } \\
\text { TD-138, TD-139 } \\
\text { TD-140 }\end{array}$ \\
\hline $11 / 9$ & $07: 45$ & $\begin{array}{l}\text { Fire is burning along Hwy } 70 \text { north of Concow Rd with } 6 \mathrm{~m}(20 \mathrm{ft}) \\
\text { flames up against Hwy } 70 .\end{array}$ & Hwy 70 and Concow Rd & $\begin{array}{l}\text { TD-013, TD-136 } \\
\text { TD-139, TD-140 }\end{array}$ \\
\hline $11 / 9$ & $08: 40$ & $\begin{array}{l}\text { Fire is well established on the east side of Hwy } 70 \text { at Concow Rd } \\
\text { and runs through Yankee Hill. }\end{array}$ & Hwy 70 and Concow Rd & TD-138, TD-140 \\
\hline
\end{tabular}




\subsubsection{Magalia and Coutolenc Road Fire Progression Summary}

Old Magalia, in the area of Old Skyway and Indian Drive, was the earliest area of Magalia to be affected by fire. Observations from the air and from multiple 911 calls indicated spot fires were burning in Old Magalia at 08:40 and structures were burning by 09:20 (see Section 9.1.9.1). Most structures in the Indian Drive and Ishi Drive areas were burning around 12:30.

It was described multiple times that the northern flank of the fire was hung up east to west in the area on Skyway between Pentz Road and Coutolenc Road. Aggregated observations indicated that the area of fire in Old Magalia was initially a large spot fire burning ahead of the main fire. South of this line, fire was not continuous, and several pockets remained unburned, including the area along Skyway and Gate Lane between Clark Road and Pentz Road. Additional spot fires were also burning north of this line in the Andover Drive and South Park Drive areas in the late morning.

Due to the initial response to Concow and Paradise and the impeded access to Magalia, the first documented observation of conditions in Magalia was at 13:00. At this time in the early afternoon, 10 to 15 structures were already burning on South Park Drive, Andover Drive, and Adrian Drive. Landsat imagery taken at 10:45 shows a large spot fire burning in Little Butte Creek Canyon up into the south end of Andover Drive.

Observations throughout greater Magalia are limited as fire fighters focused efforts on the large fire toward the south end of Andover Drive. Observations around 15:00 indicate that structures on the north end of Andover Drive had also been destroyed, and fire was burning in the canyon below the dam. Fire progressed through the canyons and drainages to the south and east, but generally held steady on the perimeter of the community through the evening hours. Fire activity along Andover Drive increased around 23:00, with fire fingering up into structures and jumping burn-out operations. To the east, activity also increased, with spot fires becoming established on the ridge near Coutolenc Road.

After midnight, fire made a significant run across the ridge with $30 \mathrm{~m}(100 \mathrm{ft})$ flames and $22 \mathrm{~m} / \mathrm{s}(50 \mathrm{mi} / \mathrm{h})$ winds blowing fire directly over the dam and into Magalia, seen in Figure 44. Fire became well-established on the west side of the Magalia Reservoir and burned uphill into Lakeridge Circle and Skyway between Creston Road and Ponderosa Way. Fire spread throughout the residential areas west of Skyway overnight. Between 02:00 and 07:00 on November 9, additional structures burned throughout the majority of Magalia. Fire was continuing to burn with significant intensity.

Another flare-up was observed at approximately 07:20 on November 9 on Ponderosa Way. Fire activity rapidly increased, forcing firefighters to seek safety at the Pine Ridge School. The increase in fire activity led to additional structure ignitions of surviving homes on Ponderosa Way. Throughout the day on November 9, fire continued to threaten structures west of Skyway and south of Cumberland Road. Table 32 contains the fire progression summary for Magalia including Coutolenc Road. 


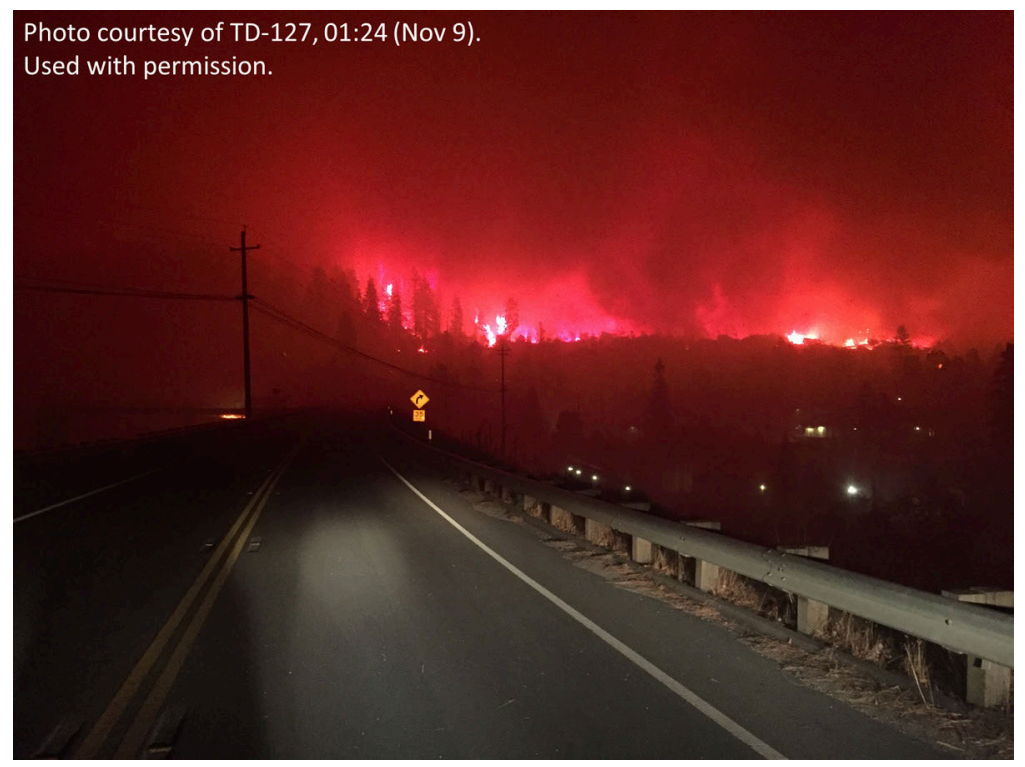

Figure 44. View south from the Magalia Reservoir dam as flames shoot up from the West Branch Feather River canyon over the ridge and Coutolenc Rd.

Table 32. Summary of fire progression in Magalia and on Coutolenc Rd.

\begin{tabular}{|c|c|c|c|c|}
\hline Date & Time Range & Fire Behavior Observations & Location & Source \# \\
\hline $11 / 8$ & 08:40 & $\begin{array}{l}\text { Spot fires have started in Old Magalia. Structures are burning by } \\
09: 20 .\end{array}$ & $\begin{array}{l}\text { Old Skyway and Indian } \\
\text { Dr }\end{array}$ & $\begin{array}{l}\text { TD-006 } \\
911-207-1 \\
911-217-1 \\
911-230-1 \\
911-240-1\end{array}$ \\
\hline $11 / 8$ & $11: 00 \quad 12: 00$ & $\begin{array}{l}\text { The northern flank of the fire is hung up between Coutolenc Rd and } \\
\text { Pentz Rd. There are some noticeable spot fires down in the West } \\
\text { Branch canyon. }\end{array}$ & $\begin{array}{l}\text { Skyway between } \\
\text { Coutolenc Rd and Pentz } \\
\text { Rd }\end{array}$ & $\begin{array}{l}\text { TD-009, TD-041 } \\
\text { TD-060 }\end{array}$ \\
\hline $11 / 8$ & $12: 30$ & $\begin{array}{l}\text { There is a period of increased fire activity in Old Magalia when } \\
\text { additional structures begin burning. }\end{array}$ & Indian Dr and Ishi Dr & $\begin{array}{l}\text { TD-060, TD-079 } \\
\text { TD-083 }\end{array}$ \\
\hline $11 / 8$ & 13:00 & $\begin{array}{l}10 \text { to } 15 \text { structures are burning at the south end of Andover Dr and } \\
\text { on Adrian Dr. }\end{array}$ & $\begin{array}{l}\text { Andover Dr and Adrian } \\
\text { Dr }\end{array}$ & $\begin{array}{l}\text { TD-040, TD-060 } \\
\text { TD-079 }\end{array}$ \\
\hline $11 / 8$ & $14: 00 \quad 17: 00$ & $\begin{array}{l}\text { Active fire is in the structures in the area on the southern end of } \\
\text { South Park Dr and Adrian Dr. Fire is burning in the Little Butte } \\
\text { Creek Canyon and wrapping around to the west and burning up } \\
\text { drainages toward West Park Dr. }\end{array}$ & $\begin{array}{l}\text { Athens Way and Adrian } \\
\text { Dr }\end{array}$ & $\begin{array}{l}\text { TD-045, TD-060 } \\
\text { TD-079, TD-084 } \\
\text { TD-085, TD-089 } \\
\text { TD-113, TD-126 }\end{array}$ \\
\hline $11 / 8$ & $15: 00$ & $\begin{array}{l}\text { First recorded observation that structures on east side of the north } \\
\text { end of Andover Dr are already burned down. Fire is burning in the } \\
\text { canyon east of Andover Dr and south of the dam. }\end{array}$ & $\begin{array}{l}\text { Andover Dr near Huron } \\
\mathrm{Ct}\end{array}$ & TD-041, TD-100 \\
\hline $11 / 8$ & $16: 30$ & $\begin{array}{l}\text { First recorded observation that some structures on South Park Dr } \\
\text { near Skyway have already been destroyed. }\end{array}$ & $\begin{array}{l}\text { South Park Dr and } \\
\text { Andover Dr }\end{array}$ & TD-143 \\
\hline $11 / 8$ & $17: 15$ & $\begin{array}{l}\text { Fires are burning in the area around Sav-Mor Foods and Lakeridge } \\
\text { Cir. }\end{array}$ & Lakeridge Cir and Skyway & TD-114 \\
\hline $11 / 8$ & 17:00 23:00 & $\begin{array}{l}\text { The evening is a period of generally reduced fire behavior in the } \\
\text { Little Butte Creek Canyon. Fire is backing up out of canyon, } \\
\text { bumping structures on Andover Dr with creeping fire behind } \\
\text { homes. Different portions of Andover Dr are threatened throughout } \\
\text { the evening period. }\end{array}$ & Andover Dr & $\begin{array}{l}\text { TD-040, TD-060 } \\
\text { TD-061, TD-084 } \\
\text { TD-085, TD-125 } \\
\text { TD- } 126\end{array}$ \\
\hline $11 / 8$ & 19:00 & $\begin{array}{l}\text { Fire is making significant pushes up drainages. Structures are } \\
\text { burning on Andover Dr, South Park Dr, and along Skyway by Rite } \\
\text { Aid. South Park Dr is inaccessible from Skyway. }\end{array}$ & $\begin{array}{l}\text { Skyway and South Park } \\
\text { Dr }\end{array}$ & TD-014 \\
\hline $11 / 8$ & 21:00 & $\begin{array}{l}\text { Fire has burned areas predominantly south of the dam, burning in } \\
\text { Magalia and Old Magalia. To the east, active fire is still on the east } \\
\text { side of the West Branch in the drainages and up on Sawmill Peak. }\end{array}$ & Skyway and Coutolenc Rd & $\begin{array}{l}\text { TD-015, TD-043 } \\
\text { TD-045, TD-061 }\end{array}$ \\
\hline
\end{tabular}




\begin{tabular}{|c|c|c|c|c|}
\hline Date & Time Range & Fire Behavior Observations & Location & Source \# \\
\hline $11 / 8$ & 23:00 & $\begin{array}{l}\text { Fire activity increased from Little Butte Creek Canyon, with fire } \\
\text { fingering up into structures and jumping over burn-out operations. }\end{array}$ & Andover Dr & $\begin{array}{l}\text { TD-060, TD-084 } \\
\text { TD-126 }\end{array}$ \\
\hline $11 / 8$ & $23: 30$ & $\begin{array}{l}\text { An active spot fire has established in the drainage below Coutolenc } \\
\text { Rd off Ridgway and is moving uphill threatening structures. The } \\
\text { main fire to east of reservoir is still burning up on the ridge north of } \\
\text { Sawmill Peak on the east side of the West Branch. }\end{array}$ & $\begin{array}{l}\text { Coutolenc Rd and } \\
\text { Ridgeway }\end{array}$ & TD-061, TD-126 \\
\hline $11 / 9$ & 00:30 $02: 00$ & $\begin{array}{l}\text { The fire blows up out of the West Branch canyon with } 30 \mathrm{~m}(100 \mathrm{ft}) \\
\text { flames, pushed by strong winds, estimated at }(22 \mathrm{~m} / \mathrm{s}) 50 \mathrm{mi} / \mathrm{h} \text {. } \\
\text { Softball-sized embers blow across Coutolenc Rd and Skyway into } \\
\text { Magalia and Old Magalia. Several spot fires are established on the } \\
\text { west side of the reservoir and fire is working uphill toward } \\
\text { Lakeridge Cir. Intense fire blocks Skyway south of the dam (see } \\
\text { Section 9.3). }\end{array}$ & Skyway and Coutolenc Rd & $\begin{array}{l}\text { TD-007, TD-040 } \\
\text { TD-041, TD-043 } \\
\text { TD-045, TD-061 } \\
\text { TD-087, TD-089 } \\
\text { TD-115, TD-125 } \\
\text { TD-126, TD-127 } \\
\text { TD-209 }\end{array}$ \\
\hline $11 / 9$ & 00:30 $02: 00$ & $\begin{array}{l}\text { Spot fire activity dramatically increases in Magalia on Andover Dr } \\
\text { and South Park Dr as fire activity blows up to the east. Fires begin } \\
\text { burning along Skyway near the commercial areas on Lakeridge Cir. }\end{array}$ & $\begin{array}{l}\text { Andover Dr / Lakeridge } \\
\text { Cir }\end{array}$ & $\begin{array}{l}\text { TD-040, TD-041 } \\
\text { TD-060, TD-122 } \\
\text { TD-127, TD-209 }\end{array}$ \\
\hline $11 / 9$ & 00:30 $\quad 02: 00$ & $\begin{array}{l}\text { Fire activity also increases in the Little Butte Creek Canyon and fire } \\
\text { pushes up into Old Magalia. Fire impacts the water treatment plant } \\
\text { and pinches Skyway and Old Magalia from both east and west. }\end{array}$ & $\begin{array}{l}\text { Old Skyway and Sugar } \\
\text { Pine Dr }\end{array}$ & TD-089 \\
\hline $11 / 9$ & 02:00 & $\begin{array}{l}\text { Significant fire activity reaches Skyway at Ponderosa Way. There } \\
\text { are heavy ember showers and fire burning in vegetation and } \\
\text { structures. Structure-to-structure fire spread is observed west of } \\
\text { Skyway. }\end{array}$ & $\begin{array}{l}\text { Skyway and Ponderosa } \\
\text { Way }\end{array}$ & $\begin{array}{l}\text { TD-009, TD-041 } \\
\text { TD-045, TD-060 } \\
\text { TD-061, TD-084 } \\
\text { TD-109, TD-122 } \\
\text { TD-123, TD-124 } \\
\text { TD-127, TD-143 } \\
\text { TD-209 }\end{array}$ \\
\hline $11 / 9$ & $02: 30$ & $\begin{array}{l}\text { Fire pushes into the West Park Dr area towards Pine Ridge School } \\
\text { from the east and south. Fire also pushes west of Skyway into the } \\
\text { Creston Rd area. }\end{array}$ & $\begin{array}{l}\text { west of Skyway on West } \\
\text { Park Dr and Creston Rd }\end{array}$ & TD-041, TD-123 \\
\hline $11 / 9$ & 02:30 07:00 & $\begin{array}{l}\text { Additional structures burn throughout the majority of Magalia. Fire } \\
\text { is continuing to burn with significant intensity. }\end{array}$ & $\begin{array}{l}\text { Magalia, south of Creston } \\
\text { Rd }\end{array}$ & $\begin{array}{l}\text { TD-009, TD-041 } \\
\text { TD-045, TD-060 } \\
\text { TD-061, TD-079 } \\
\text { TD-084, TD-087 } \\
\text { TD-089, TD-123 } \\
\text { TD-124, TD-127 } \\
\text { TD-128, TD-143 } \\
\text { TD-209 }\end{array}$ \\
\hline $11 / 9$ & 06:00 & $\begin{array}{l}\text { Intense fire activity is burning structures on Chestnut Cir. A } \\
\text { propane tank explosion injures firefighters (see Section 9.3). }\end{array}$ & $\begin{array}{l}\text { Ponderosa Way and } \\
\text { Chestnut Cir }\end{array}$ & TD-127, TD-209 \\
\hline $11 / 9$ & 07:20 & $\begin{array}{l}\text { A rapid increase in fire activity on the west end of Ponderosa Way } \\
\text { impacts from the south and west. Firefighters must drive through } \\
\text { fire to reach the relative safety of Pine Ridge School, where fire } \\
\text { also hits from the east. Portable school buildings ignite, and the } \\
\text { main buildings are threatened. }\end{array}$ & $\begin{array}{l}\text { Ponderosa Way and } \\
\text { Compton Dr }\end{array}$ & $\begin{array}{l}\text { TD-127, TD-128 } \\
\text { TD-200, TD-202 } \\
\text { TD-205, TD-207 }\end{array}$ \\
\hline $11 / 9$ & 07:20 $10: 00$ & $\begin{array}{l}\text { Homes throughout Magalia continue to burn with localized areas of } \\
\text { high fire activity. }\end{array}$ & $\begin{array}{l}\text { Magalia, south of Creston } \\
\text { Rd }\end{array}$ & $\begin{array}{l}\text { TD-041, TD-200 } \\
\text { TD-203, TD-205 }\end{array}$ \\
\hline $11 / 9$ & $10: 00$ & $\begin{array}{l}\text { Fire is affecting homes on the west edge of Ponderosa Way, } \\
\text { Creston Rd, Brevard Cir area. Unburned structures are igniting or } \\
\text { threatened throughout the day. }\end{array}$ & Magalia & $\begin{array}{l}\text { TD-128, TD-205 } \\
\text { TD-207 }\end{array}$ \\
\hline
\end{tabular}




\subsection{Fire Observation Histograms}

The three histograms in Figure 45 summarize the number and type of fire observations (described in Section 7.4) in Paradise on Pentz Road, Clark Road, and Skyway throughout the day, and illustrate the general progression and timeline of fire in Paradise from east to west. The data illustrate the number of early spot fires in each of the zones, how the fire moved on from Pentz Road by 10:00 and picked up activity on Clark Road by 10:30. The fire then moved east from Clark Road to Skyway where there were a significant number of fire observations after 13:30, starting to tail off at 16:30. The shift in the observation count is also a function of TD first responder location; however, this is also influenced by fire activity. Note that this figure provides a general sense of the location of fire activity and does not directly indicate the severity or extent of fire for each observation. Some context and interpretation are discussed here, and the reader is directed back to the relevant portions of Section 9.1 for more specifics of individual observations. For the spatial component of the observations in more detail than conveyed by the specified roadway corridors in Figure 45, see the individual fire spread maps described in Section 10.

The dark red portions of the bars in Figure 45 show the frequency of spot fire observations (denoted by " $\mathrm{S}$ " in the figure legend) early in the morning in all three zones, but predominantly in the Pentz Road area, peaking in the 08:30 to 08:45 time window as the fire front entered along the east side of Paradise. As the fire grew from each of these spots to include more widespread vegetation (denoted by " $\mathrm{V}$ " in the figure legend) and/or structures, the fraction of fire observations that were spot fires decreased.

The observations on Pentz Road were characterized by a relatively short but intense time window corresponding to the near simultaneous impact from the large extent of the fire front. Before 08:30, much of the observations described spot fires. Once the spots became established and the fire front hit, the observations were dominated by the "other" or "residential structure" categories (denoted by " $O$ " and "R," respectively, in the figure legend) until fire observations and fire activity tapered off by 12:00. The relatively high portion of "other" categorized observations could be attributed to the rapid development of the fire from the wildlands into the community where TD participants reported widespread fire observations without specification of exact fuels. Additionally, note that the large number of observations in this time window was also a function of TD first responder (primarily firefighter) locations, as the initial response was focused on the Pentz Road corridor.

Along Clark Road, the increase in fire observations after 10:30 was attributed to the expansion of fires in the Central Park Drive area and the fire impacting evacuations at the south end of town between American Way and Airport Road. Subsequently, fire impacted Clark Road north of Wagstaff Road, followed by Clark Road between Central Park Drive and Pearson Road. A spike in "commercial structure" category observations (denoted by "C" in the figure legend) was notable in the early afternoon. This was the period in which a majority of commercial structures were burning or already burned down. The spike was also influenced in part by the arrival of additional engine strike teams accessing Paradise via Clark Road from Butte College. As these engines arrived, some of their first observations were burning or destroyed commercial structures. 
At first glance, Skyway appears to be dominated by afternoon activity. However, the raw number of individual observations (not the quality or resolution of observations) on Skyway may be underrepresented compared to Pentz Road due to the spatial distribution of TD sources. Figure 45 also does not highlight the severity of the observations by first responders in the mid-morning hours when the Honey Run spot fire burned over Skyway.

Before 09:30, fire observations on Skyway were dominated by spot fires; 40/44 (91\%) of fire observations were categorized as such. This fire activity was primarily in Honey Run Canyon and near the Skyway/Clark Road intersection. Beyond 09:30, only 23/350 (6\%) of observations were categorized as spot fires along Skyway. This may have been a function of two contributing factors: 1) location of first responder TD participants and 2) true differences in general fire behavior. If the observations shared by first responders occurred after the initial fire ignitions and fire spread along Skyway, it may have been the case that spot fires occurred prior to the bulk of observations in the afternoon, which indicated structures burning rather than spot fires (56\% of fire observations between 13:15 and 15:15 were categorized as residential or commercial structure fires). Alternatively, there might have been a difference in fire behavior in this region, characterized more by linear fire progression (spreading from the numerous initial morning spot fire ignitions and the main fire front in the evening) rather than by spot fire behavior comparable to that seen on Pentz Road.

The peak number of observations in the early afternoon relates primarily to the portion of Skyway north of Wagstaff Road where intense fire was burning residential structures. The increase in "commercial structure" observations in the 17:30 timeframe was related to fire impact on the downtown area between Pearson Road and Bille Road.

The tails in all three histograms indicate that fire remained in the area for many hours after the main fire activity had passed. The remaining fires and associated ember exposures threaten surviving structures for many hours, which frequently results in structure losses if first responders are not locally available to prevent or suppress the ignitions. 


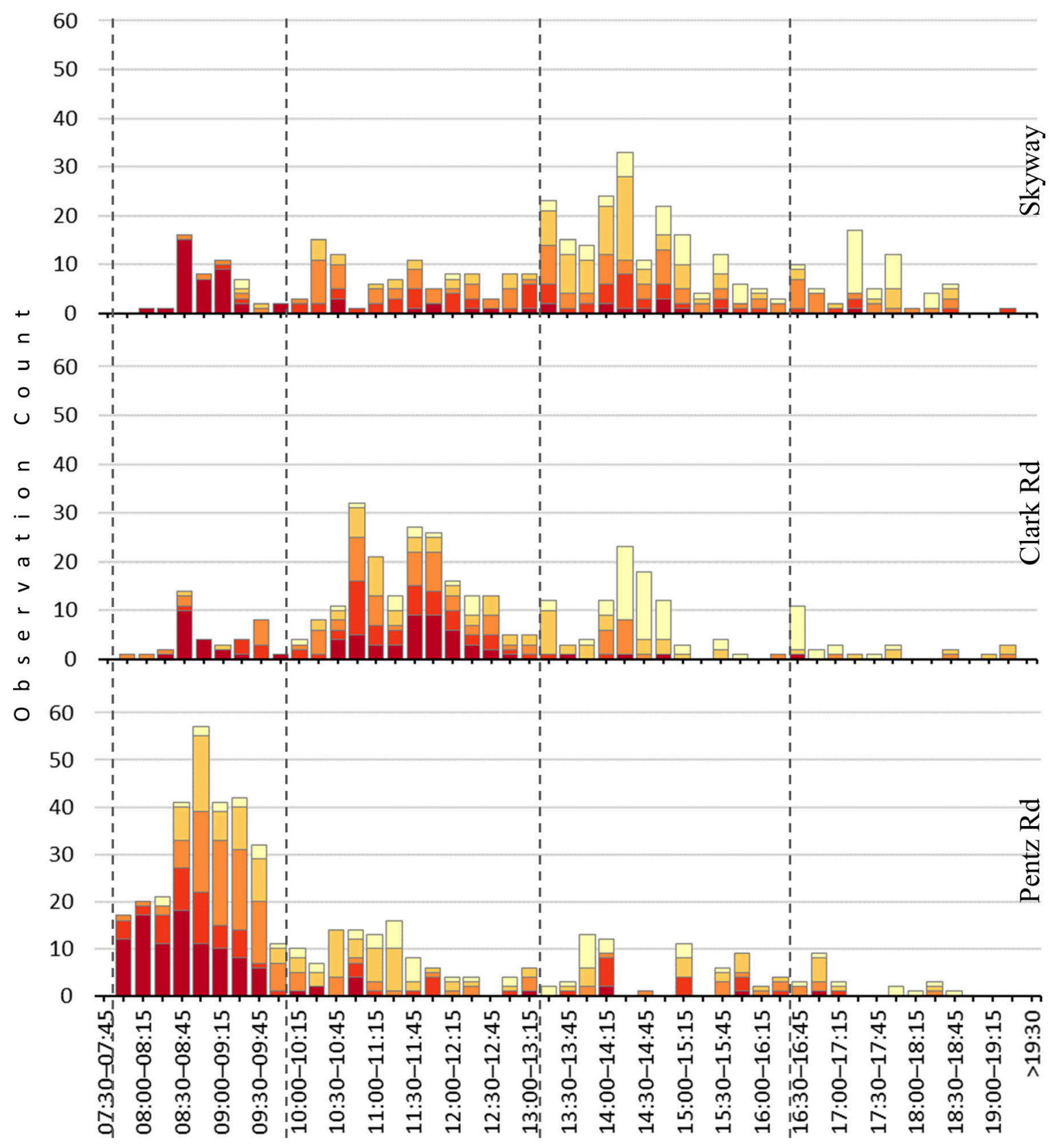

$\square \mathrm{S} \square \mathrm{V} \square \mathrm{O} \square \mathrm{R} \square \mathrm{C}$

Figure 45. Fire observation histograms shaded by type of fire observation ( $\mathrm{S}=$ spot, $\mathrm{V}=$ vegetation, $\mathrm{O}=$ other, $\mathrm{R}=$ residential structure, $\mathrm{C}=$ commercial structure) for Pentz $\mathrm{Rd}$, Clark Rd, and Skyway focus regions, binned as a function of time of day on November 8 . Note the early number of spot fire observations and the differences in time of peak observation counts. 


\subsection{Burnovers}

A burnover is defined by the National Wildfire Coordinating Group (NWCG) [25] as "an event in which a fire moves through a location or overtakes personnel or equipment where there is no opportunity to utilize escape routes and safety zones, often resulting in personal injury or equipment damage." During the Camp Fire, several events occurred where fire temporarily restricted through-access on a major traffic artery or a secondary road, or trapped civilians or first responders amid dangerous conditions. The events varied in intensity and duration. Some impacted civilian evacuation while others impacted first responders only. Burnovers resulted in civilian fatalities, civilian and first responder injuries, and destruction and damage of civilian and first responder vehicles. In several cases, a burnover occurred that did not result in fatalities, injuries, or damage. These were instances in which fire blocked the road and civilians caught in traffic and/or first responders attempting to access the scene either waited it out or opted to take another route if available. These events could be interpreted as entrapments or "near misses" with respect to the NWCG definitions but are included in this report as they have significant impact on civilian and first responder life safety. Identified events are grouped and labeled as burnovers in this report.

Burnovers were identified and documented in nineteen different locations. The first two burnovers occurred at approximatively 07:50 on November 8 on Hoffman Road and Concow Road in Concow, and the last two recorded burnovers occurred at 07:15 on November 9 on Ponderosa Way in Magalia and on Concow Road in Concow. Additional burnovers occurred but were not captured during the data collection process because:

a. no personnel (first responder or civilian) was present to witness the event, or

b. the event was witnessed by first responder(s) and/or civilian(s), but data was not captured because no TD took place with these individuals.

While documenting the burnovers that occurred during the Camp Fire, it was identified that the severity of the exposure from the burnovers impacted how the first responders assessed the situation. In this context, exposure can be expressed as the integral (or sum) of total heat flux $\left(\mathrm{kW} / \mathrm{m}^{2}\right)$ over time. Two different burnovers could subject vehicles to similar exposures even through the fire intensities were different, due to a difference in residence time. The amount of traffic and the driving speed though the burnover could have significant impact on the outcome. This was manifested in the burnovers that occurred on Pearson Road and on Skyway, where gridlocked traffic resulted in fatalities, injuries, and/or damage to vehicles. Additional factors that might have affected the decision to drive through a burnover were visibility and whether the extent of the burnover conditions were known.

Burnover situations were assessed differently by civilians, first responders, and first responders escorting civilians. A hardened fire engine with trained personnel might elect to drive through an area that they would not allow civilians to drive though. An example of this occurred on Clark Road, where a fire engine, having driven through a high intensity area, informed a police officer that they could get through if they "drive fast," while civilians were kept in a Temporary Refuge Area (TRA) until the hazard subsided. Figure 46 shows conditions that first responders drove through but were considered unsafe for civilians. 


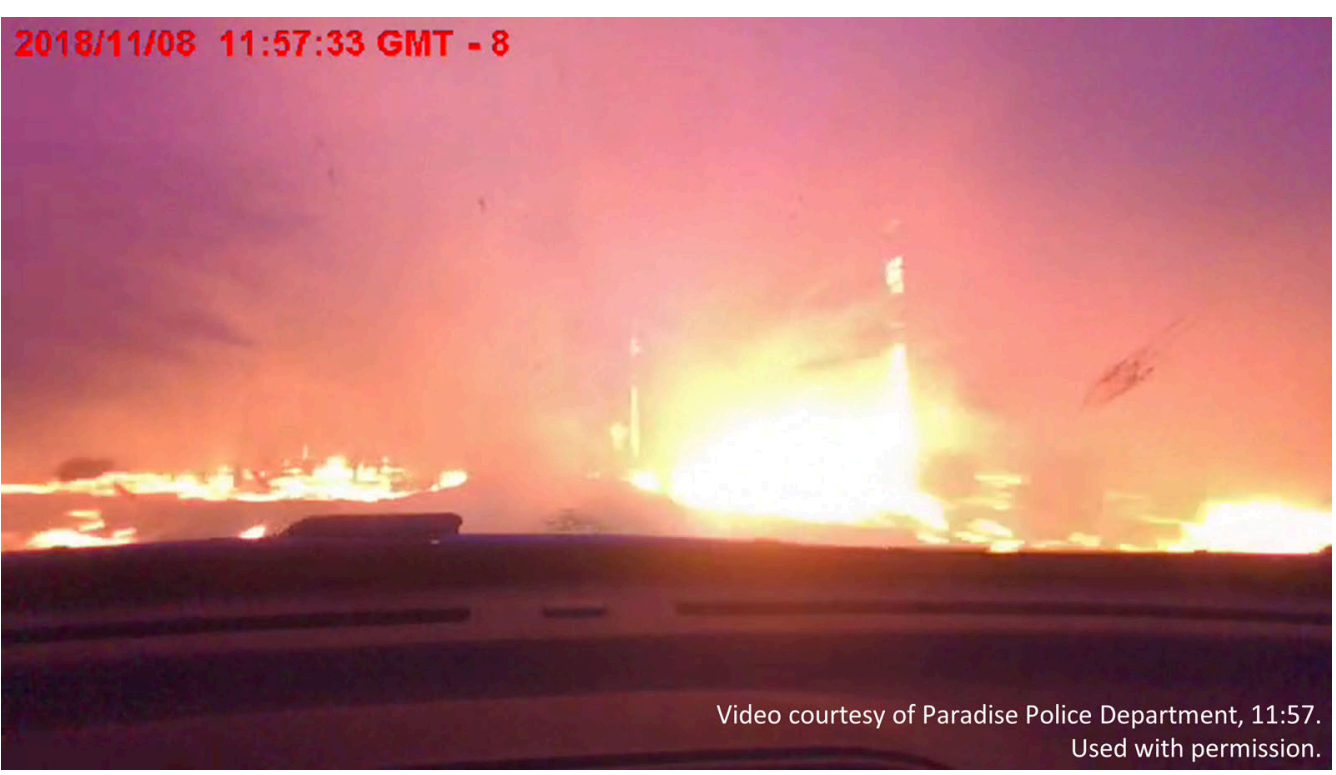

Figure 46. Snapshot from PPD dashboard camera showing representative conditions throughout a $1 \mathrm{~km}(0.6 \mathrm{mi})$ stretch of Clark Rd near Forest Service Rd at 11:57.

The identified burnovers were divided into two categories with respect to risk of injury or death. Listed in Table 33, eleven burnovers were identified as "Category 1," representing the highest potential of death/injury (highlighted in red), and seven as less-hazardous "Category 2" events. The burnovers are documented in Table 33, Table 34, and Appendix B to convey the range of different conditions under which burnovers occurred. 
Table 34 summarizes the burnover data on the nineteen identified burnovers, which occurred throughout the fire area and are mapped in Figure 47. Timeline details associated with fire behavior for all the burnovers are documented in Appendix B, along with pre and post-fire street view images and overview imagery. Of the nine burnovers that occurred before 10:00 on November 8, seven were listed as Category 1, and two as Category 2. Most of the Category 1 burnovers on the morning of November 8 significantly impacted civilian evacuations. Of the eleven Category 1 burnovers, six resulted in the formation of Temporary Refuge Areas (TRAs). Details of traffic conditions and access to the TRAs will be discussed in NIST Camp Fire Report \#4.

Local conditions dictated the spatial and temporal extent of each burnover. Burnover durations typically ranged between 1 hour and 2 hours and were influenced by the type and quantity of vegetative and other fuels in the area. Road widths ranged from $3 \mathrm{~m}$ to $23 \mathrm{~m}$ $(10 \mathrm{ft}$ to $75 \mathrm{ft})$, and vegetation setbacks ranged from $0 \mathrm{~m}$ to $10 \mathrm{~m}(0 \mathrm{ft}$ to $33 \mathrm{ft})$. The length of road impacted by burnovers ranged from $150 \mathrm{~m}$ to $3000 \mathrm{~m}$ (500 $\mathrm{ft}$ to $2 \mathrm{mi})$.

Thirteen burnovers impacted the evacuation of civilians, eight of which occurred before 10:00 on November 8. The final documented burnover that impacted civilian evacuation occurred on Ponderosa Way in Magalia at 07:15 on November 9. Of the nineteen burnovers, only the Rattlesnake Flats incident involved firefighting hand crews. This burnover resulted in serious injuries and has been documented in a CAL FIRE Green Sheet Report [17]. This was the shortest duration burnover event, with the fire driven by wind through flashy vegetative fuels (readily ignitable fuels that burn rapidly). A propane tank explosion resulted in additional firefighter injuries to an engine crew, which was also documented in Ref. [17].

Fire shelters were deployed in two cases: during the Hoffman Road and the Pearson Road burnovers. During the Hoffman Road burnover, a fire shelter was used to shield a first responder and civilians from radiation during rescue operations. The second use of fire shelters occurred during the burnover on Pearson Road. In this case the shelter was deployed inside the fire engine against the window to limit radiation to firefighters and rescued civilians refuging inside. The exterior of the engine was damaged from the fire exposure.

The last two documented burnovers, at Ponderosa Way in Magalia and on Concow Road in Concow, both occurred at approximately 07:15, half an hour after sunrise at 06:44. First responders explicitly attributed the Concow burnover to the increased fire intensity associated with daybreak. 
Table 33. List of identified burnover locations by time of occurrence and risk of injury or death.

\begin{tabular}{|c|c|c|c|}
\hline ID & Burnover Location & Time & $\begin{array}{c}\text { Risk of } \\
\text { Injury/Death } \\
\text { Category }\end{array}$ \\
\hline 1 & Hoffman Rd & $07: 50$ & 1 \\
\hline 2 & Concow Rd & $07: 50$ & 2 \\
\hline 3 & Chapman Ln & $08: 30$ & 1 \\
\hline 4 & $\begin{array}{l}\text { Skyway (upper, between Clark Rd } \\
\text { and Wagstaff Rd) }\end{array}$ & $08: 30$ & 1 \\
\hline 5 & Windermere Ln & $08: 35^{\mathrm{a}}$ & 1 \\
\hline 6 & Pentz Rd & $08: 45$ & 1 \\
\hline 7 & Pearson Rd & $09: 15$ & 1 \\
\hline 8 & Bille $\mathrm{Rd}$ & $09: 25$ & 1 \\
\hline 9 & Wagstaff $\mathrm{Rd}$ & $09: 30$ & 2 \\
\hline 10 & Clark Rd / American Way & $10: 00$ & 2 \\
\hline 11 & Clark Rd / Airport Rd & $10: 00$ & 2 \\
\hline 12 & $\begin{array}{l}\text { Skyway (lower, west of Princeton } \\
\text { Way) }\end{array}$ & $10: 15$ & 2 \\
\hline 13 & Jordan Hill Rd /Granite Hill Rd & $11: 30$ & 1 \\
\hline 14 & Clark Rd / Black Bear Diner & $13: 10$ & 2 \\
\hline 15 & Rattlesnake Flats Rd & $15: 15$ & 1 \\
\hline 16 & Coutolenc Rd & $00: 00^{\mathrm{b}}$ & 2 \\
\hline 17 & Chestnut Cir & $06: 00^{b}$ & 1 \\
\hline 18 & Ponderosa Way & $07: 15^{b}$ & 2 \\
\hline 19 & Concow Fire Station 37 & $07: 15^{b}$ & 1 \\
\hline
\end{tabular}

a Burnover conditions existed prior to the first recorded observation.

${ }^{\mathrm{b}}$ November 9. 


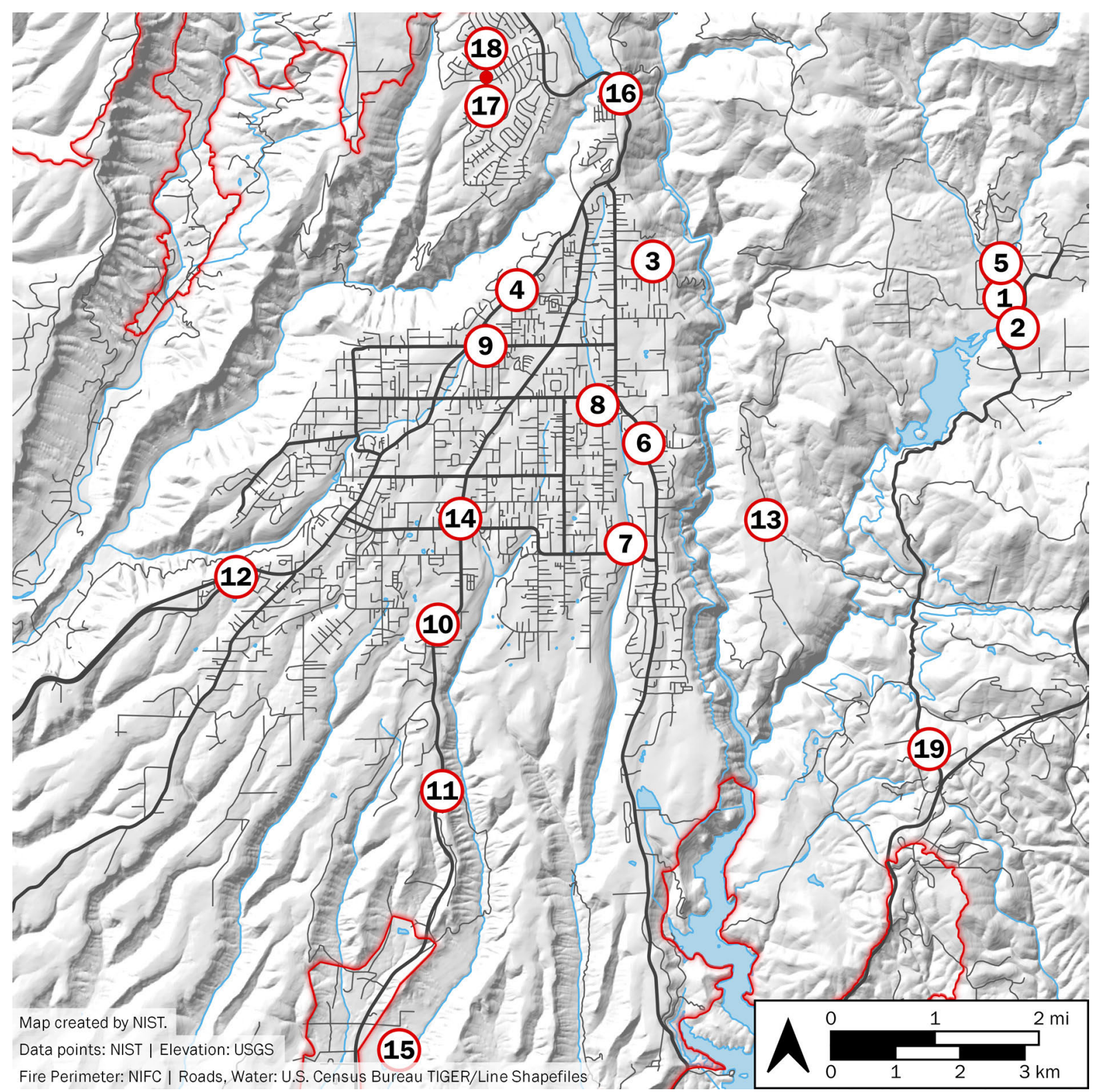

Figure 47. Map of all identified and documented burnover locations. 
Table 34. Burnovers.

\begin{tabular}{|c|c|c|c|c|c|c|c|c|c|}
\hline ID & Location & $\begin{array}{l}\text { Burnover } \\
\text { Initiation }\end{array}$ & $\begin{array}{l}\text { Burnover } \\
\text { Duration }\end{array}$ & $\begin{array}{l}\text { Road } \\
\text { Width } \\
\text { (m) }\end{array}$ & $\begin{array}{c}\text { Vegetation } \\
\text { Setback } \\
\text { (m) }\end{array}$ & $\begin{array}{l}\text { Roadway } \\
\text { Length } \\
\text { Affected }{ }^{\mathrm{a}} \\
\quad(\mathrm{m})\end{array}$ & $\begin{array}{c}\text { Impacted } \\
\text { Civilian } \\
\text { Evacuation } \\
\text { (Y if yes) }\end{array}$ & \begin{tabular}{l}
\multicolumn{1}{c}{ Fire } \\
Shelter(s) \\
Deployed \\
(Y if yes)
\end{tabular} & $\begin{array}{c}\text { TRA } \\
\text { Formed } \\
\text { (Y if yes) }\end{array}$ \\
\hline 1 & Hoffman Rd & 07:50 & $40 \mathrm{~min}$ & 3 & $\begin{array}{c}0-2, \\
\text { more at } \\
\text { creek }\end{array}$ & 250 & Y & Y & Y \\
\hline 2 & Concow Rd & $07: 50$ & $70 \mathrm{~min}$ & 7 & $0-1$ & 1000 & Y & & \\
\hline 3 & Chapman Ln & 08:30 & $\mathrm{n} / \mathrm{d}^{\mathrm{b}}$ & 3 & $0-3$ & 250 & & & \\
\hline 4 & $\begin{array}{l}\text { Skyway } \\
\text { (upper) }\end{array}$ & $08: 30$ & $360 \mathrm{~min}$ & 8 & $0-10$ & 2600 & $\begin{array}{c}\mathrm{Y} \\
\text { (street was } \\
\text { gridlocked) }\end{array}$ & & $\mathrm{Y}$ \\
\hline 5 & Windermere Ln & $08: 35^{c}$ & $\mathrm{n} / \mathrm{d}$ & 4 & $0-2$ & 1100 & $\mathrm{Y}$ & & \\
\hline 6 & Pentz Rd & $08: 45$ & $150 \mathrm{~min}$ & 8 & $0-1$ & 1300 & $\begin{array}{c}\text { Y } \\
\text { (street was } \\
\text { gridlocked) }\end{array}$ & & $\mathrm{Y}$ \\
\hline 7 & Pearson Rd & $09: 15$ & $60 \mathrm{~min}$ & 11 & $1-3$ & 800 & $\begin{array}{c}\mathrm{Y} \\
\text { (street was } \\
\text { gridlocked) }\end{array}$ & Y & $\mathrm{Y}$ \\
\hline 8 & Bille Rd & $09: 25$ & $140 \mathrm{~min}$ & 8 & $0-2$ & 500 & $\begin{array}{c}\mathrm{Y} \\
\text { (street was } \\
\text { blocked) }\end{array}$ & & $\mathrm{Y}$ \\
\hline 9 & Wagstaff Rd & 09:30 & $60 \mathrm{~min}$ & 8 & $0-3$ & 500 & $\mathrm{Y}$ & & \\
\hline 10 & $\begin{array}{l}\text { Clark Rd / } \\
\text { American Way }\end{array}$ & $10: 00$ & $120 \mathrm{~min}$ & 11 & $1-3$ & 700 & $\mathrm{Y}$ & & \\
\hline 11 & Clark Rd / Airport Rd & $10: 00$ & $90 \mathrm{~min}$ & 9 & 1 & 1500 & Y & & \\
\hline 12 & $\begin{array}{l}\text { Skyway } \\
\text { (lower) }\end{array}$ & $10: 15$ & $90 \mathrm{~min}$ & $7-20$ & $1-3$ & 1000 & Y & & \\
\hline 13 & $\begin{array}{l}\text { Jordan Hill Rd / } \\
\text { Granite Hill Rd }\end{array}$ & $11: 30$ & $\mathrm{n} / \mathrm{d}$ & 5 & $0-4$ & 800 & Y & & \\
\hline 14 & $\begin{array}{l}\text { Clark Rd / } \\
\text { Black Bear Diner }\end{array}$ & $13: 10^{\mathrm{c}}$ & $\mathrm{n} / \mathrm{d}$ & 23 & $\begin{array}{c}3 \\
\text { (structure) }\end{array}$ & 150 & & & \\
\hline 15 & Rattlesnake Flats Rd & $15: 15$ & $15 \mathrm{~min}$ & 3 & 0 & 300 & & & \\
\hline 16 & Coutolenc $\mathrm{Rd}$ & $\begin{array}{c}00: 00 \\
\text { (Nov 9) }\end{array}$ & $120 \mathrm{~min}$ & 7 & $0-2$ & 3000 & & & $\mathrm{Y}$ \\
\hline 17 & Chestnut Cir & $\begin{array}{c}06: 00 \\
\text { (Nov 9) }\end{array}$ & $\mathrm{n} / \mathrm{a}$ & 9 & $0-1$ & 150 & & & \\
\hline 18 & Ponderosa Way & $\begin{array}{c}07: 15 \\
\text { (Nov 9) }\end{array}$ & $\mathrm{n} / \mathrm{d}$ & 12 & $0-3$ & 400 & Y & & $\mathrm{Y}$ \\
\hline 19 & Concow Fire Station 37 & $\begin{array}{c}07: 15 \\
\text { (Nov 9) }\end{array}$ & $\mathrm{n} / \mathrm{d}$ & 9 & $0-3$ & 600 & & & $\mathrm{Y}$ \\
\hline
\end{tabular}

${ }^{a}$ The roadway segment affected by each burnover was estimated from the technical discussions.

${ }^{\mathrm{b}}$ No data.

${ }^{\mathrm{c}}$ First time of observation. Burnover conditions existed prior to the first recorded observation. 


\subsection{Impact of Winds, Wildland Fuels, and Terrain on Fire Behavior}

Section 5.3 in this report presents an overview of the weather during the Camp Fire. Local observations and video documentation provided additional resolution and information on how the wind affected local fire behavior. Firsthand observations on Rim Road at 07:20 on November 8 talked of "softball size rocks hitting the engine" [TD-005]. These reports were consistent with the short video from the TD and likely indicated local winds in the range of $22 \mathrm{~m} / \mathrm{s}$ to $27 \mathrm{~m} / \mathrm{s}(50 \mathrm{mi} / \mathrm{h}$ to $60 \mathrm{mi} / \mathrm{h})$. These values agree with the forecasted ridgetop winds.

Within 30 minutes of these firsthand observations, shortly before $08: 00$, the spot fires that ignited on the east side of Pentz Road in Paradise were reported as burning under almost calm conditions [PPD video, TD-042, TD-023, VTD-17, VTD-23], although in some locations winds did dramatically increase as the fire front hit. These local low wind observations confirm the significant range of conditions within small spatial distances. The embers that reached Paradise, between the wildlands and Pentz Road, came from the approaching fire front, but there was no way to pinpoint their exact origin. While most of the fuels upwind were vegetative, there were also a limited number of structures that had just ignited in Concow that might have contributed to the ember generation that reached into Paradise.

By 08:30 the main front had reached Paradise from approximately Apple View Way to Merrill Road, a distance of $1 \mathrm{~km}(0.6 \mathrm{mi})$. Shortly afterwards, the southern end of the approaching front progressed south and impacted the area between Merrill Road and FRH. A little over 70 minutes later, Paradise was experiencing a direct fire front hit $2.8 \mathrm{~km}(1.9 \mathrm{mi})$ in length.

Given the local conditions and the lack of local weather data, it was not possible to determine whether the arrival of the fire front was driven primarily by an increase in local wind, by fire generating its own wind going upslope, or by some combination of the two. The conditions observed in videos taken during the fire indicate that within Paradise the wind never reached the high velocities observed on Rim Road. Wind observations in town ranged from calm to an estimated $9 \mathrm{~m} / \mathrm{s}$ to $13 \mathrm{~m} / \mathrm{s}(20 \mathrm{mi} / \mathrm{h}$ to $30 \mathrm{mi} / \mathrm{h})$ [TD-021, TD-042, PPD Video]. These ambient winds enhanced fire spread in Paradise. As the fire became deep-seated, the increased fire intensity might have generated its own fire induced winds, as appeared to be the case with the approaching fire front. Given the lack of high-resolution spatiotemporal wind data, it was not possible to say if the predominant influence was regional and local winds or the fire-induced winds. An example of the influence of local wind conditions was observed at FRH at 09:08 when a video recording shows embers blowing from the west while the fire front arrived from the east, shown in Figure 29.

Other significant wind observations were made during the Coutolenc Road burnover that occurred near 00:30 on November 9 . First responders reported very strong, gusty winds coming up from the West Branch canyon with estimates of $22 \mathrm{~m} / \mathrm{s}(50 \mathrm{mi} / \mathrm{h}$ ) [TD-041, TD-061, TD-209]. The estimates, while not precise, conveyed that this wind event was different from the rest of the wind experienced in Paradise up to that time. 
The Feather River Canyon, Concow, and Pulga have experienced a nominal 10-year burn cycle. Significant fires occurred there in 1999 and 2000, 2008, and now 2018. Historically these fires did not cross the Feather River Canyon. The periodic reentry of fire in high country has prevented the regrowth of conifers, gradually converting timber to grass and brush fuels [TD-008]. In Pulga, brush height ranged from $2.5 \mathrm{~m}$ to $4.3 \mathrm{~m}$ ( $8 \mathrm{ft}$ to $14 \mathrm{ft}$ ) tall. The last two fire cycles (prior to 2018) caused extensive tree mortality and a significant number of fallen trees, resulting in a high loading of dead and down 1000-hour fuels. PreCamp Fire fuel-loading estimates around Concow were $2.2 \mathrm{~kg} / \mathrm{m}^{2}$ to $3.4 \mathrm{~kg} / \mathrm{m}^{2}$ (10 ton/ac to 15 ton/ac) with a timber overstock of $125 \%$ [TD-008]. These decaying 1000-hour fuels, together with the fast-growing brush and the strong winds, generated very large heat release rates and long-distance spotting. ${ }^{15}$

Terrain also directly impacted fire behavior, resulting in dramatic fire behavior as observed around 18:00 on November 8, with flame lengths of $30 \mathrm{~m}$ to $60 \mathrm{~m}(100 \mathrm{ft}$ to $200 \mathrm{ft})$ breaking out of the Butte Creek Canyon into Wilder Drive [TD-117]. Similar effects of topography, compounded with high fuel loading and possible alignment with local winds, resulted in significant fire activity in other areas within the fire perimeter, including the drainages to the north of Nelson Bar Road where flame lengths of $15 \mathrm{~m}$ to $30 \mathrm{~m}$ (50 ft to $100 \mathrm{ft}$ ) were reported.

The terrain also impacted fire spread indirectly by restricting or slowing down access by first responders. An example is provided here to illustrate the impact of topography on access. A straight line from Rim Road (39 47'34.89” N, $121^{\circ} 28^{\prime} 24.00^{\prime \prime} \mathrm{W}$ ) to the intersection of Pentz Road and Skyway is $9.3 \mathrm{~km}(5.75 \mathrm{mi})$; however, it takes $40 \mathrm{~km}(25 \mathrm{mi})$ and 43 minutes of drive time to get there. The fire is thus able to travel much faster than ground suppression forces. Further information on incident response and defensive actions will be presented in NIST Camp Fire Report \#5.

${ }^{15}$ Efforts are underway by CAL FIRE, in collaboration with federal agencies, to widen and connect fuel breaks in Butte County. Connecting fuel breaks will compartmentalize the landscape to reduce fire intensity and facilitate fire control in the future [TD-008]. 


\subsection{Ground-Level Smoke and Visibility}

Ground-level smoke and visibility varied significantly in both space and time throughout the incident. The variability in light levels and visibility was influenced by local conditions as well as by the overhead smoke plume. By mid-morning on November 8 , areas of the fire were experiencing nighttime darkness as the high-level smoke column to the east blocked out the sunlight. Photos taken at noon could easily be confused with midnight. In these cases, ground visibility might still be clear despite the darkness.

At other times, ground-level smoke affected light levels block by block, with local smoke curtains created by burning structures or vegetation. Video footage from a dozer operator driving south on Pentz Road highlights the extent of this spatiotemporal variability in Figure 48. Visibility changed from relatively clear and light to barely being able to see the hood of the transport in less than one minute while moving $220 \mathrm{~m}(720 \mathrm{ft})$. Ground visibility was often influenced by local wind variability. Arrows in Figure $\mathbf{4 8}$ highlight the $180^{\circ}$ reversal in wind direction within a $400 \mathrm{~m}(0.25 \mathrm{mi})$ distance. The variability illustrated was representative of conditions though Concow, Paradise, and Magalia at different locations and times. Reduced ground level visibility conditions could be attributed to the high smoke yield of multiple fully involved structures and/or large quantities of vegetative fuels burning simultaneously.

At the edge of the fire, first responders driving up Pentz Road reported a "wall of smoke" north of Kunkle Reservoir, seen in one case in Figure 49. The clear boundary resulted in rapid transition from a clear, no smoke environment to significant reduction in light intensity and visibility. In several cases visibility was less than a few meters and pitch black once past the "wall." The transition was almost instantaneous over a course of a few meters (10 ft).The conditions along Pentz Road seen in Figure 49 were described by multiple TDs through the early afternoon [TD-009, TD-079, TD-084, TD-086, TD-090, TD-115, TD-118]. This welldefined "wall of smoke" migrated to the south and eventually became less well-defined.

The early burnovers in Concow (Hoffman Road) and in Paradise (Pearson Road) were accompanied by significant reduction in visibility. On Hoffman Road, first responders reported blackout conditions with glowing fire showing through the blackout and difficulty seeing the headlights on the approaching bulldozer. On Pearson Road, smoke obscuration also reduced visibility to zero. A picture during the burnover, after the initial flaming event and accompanying low visibility, shows an orange glow resembling the interior of a furnace (Figure 36). Similar conditions occurred in the other burnovers. 


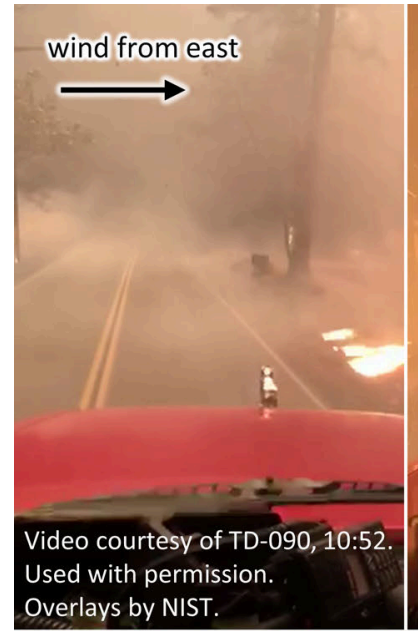

a) $t=0 \mathrm{~s}$ $x=0 \mathrm{~m}$

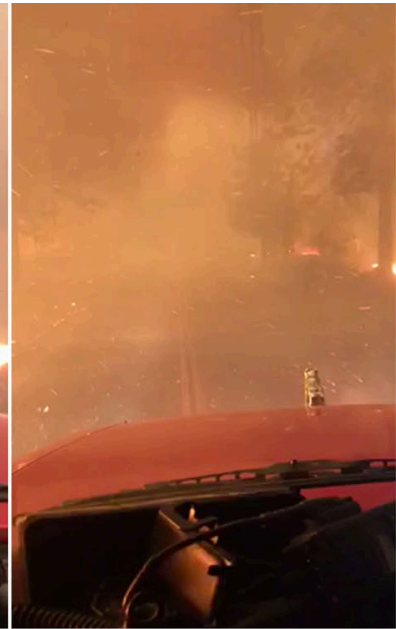

b) $t=20 \mathrm{~s}$ $x=120 \mathrm{~m}$

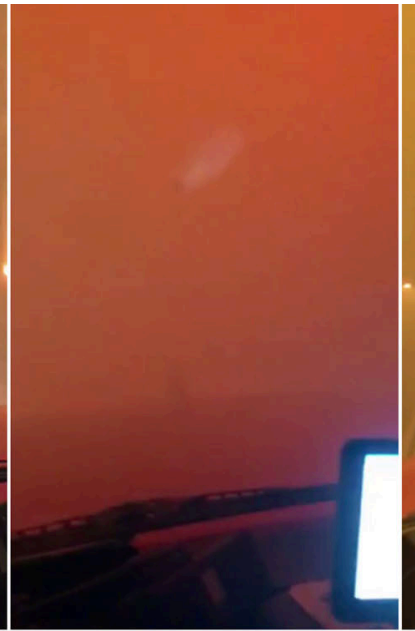

c) $t=46 \mathrm{~s}$ $x=220 \mathrm{~m}$

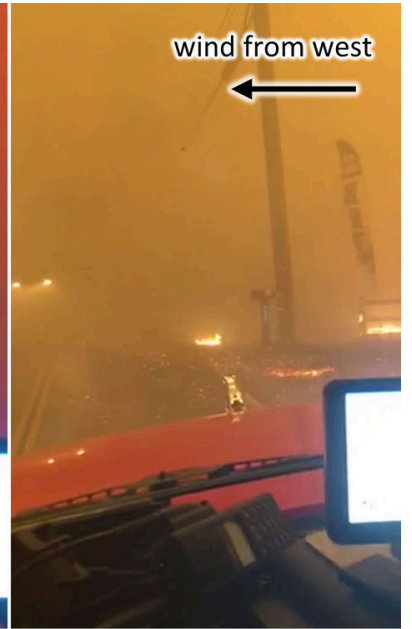

d) $t=93 \mathrm{~s}$ $x=350 \mathrm{~m}$

Figure 48. Image sequence from a video recording showing visibility and wind conditions along Pentz Rd, heading south at 10:52. Visibility is intermittent and wind directions shift $180^{\circ}$ over short distances and time periods.

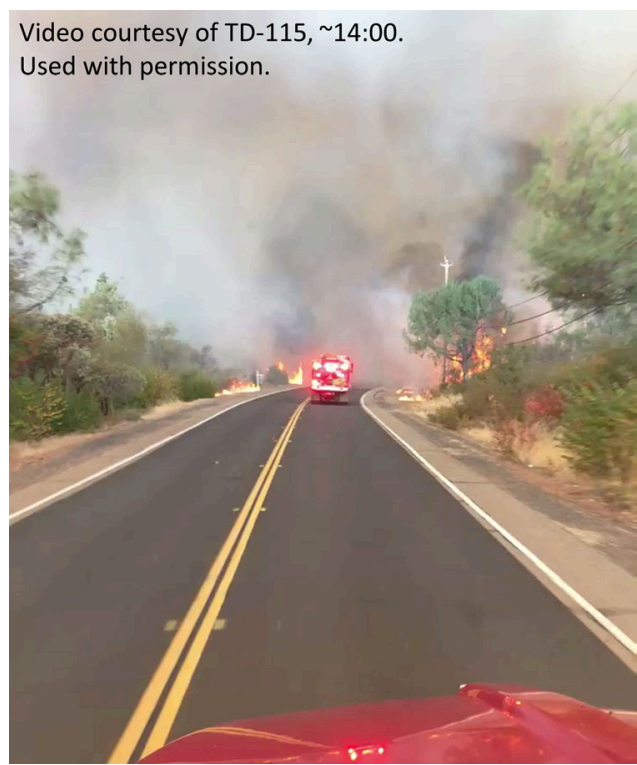

Figure 49. Wall of smoke observed on Pentz Rd, going north, at Dry Creek Rd. This abrupt change in conditions was described by multiple individuals. 


\section{Fire Spread Maps}

Fire progression is further documented in an accompanying map book. Map 1 includes frequently referenced locations and roads in the Concow, Paradise, and Magalia region. The 15 geographic focus regions are also marked for reference. Map 2-Map 14 provide a look at the entire fire observation data set divided into smaller successive time windows. The maps include annotations to describe highlights of the fire spread within the resolution permitted by the collected data. Figure $\mathbf{2 2}$ includes an overview of the fire spread vectors during the spread of the fire over the first 24 hours.

Each successive map contains the accumulated observation points from previous time windows. Current observations are displayed in full color, while previous observations are faded. The faded symbols from previous time frames remain to facilitate the viewing/interpretation of the data and to visualize the fire progression.

Data point shapes correspond to the different type of fire observations described in Section 7.4.1: spot fire; vegetation fire; residential structure; commercial structure; or other. The size of the symbol in figures is not related to the size of the actual fire but rather indicates a representative location for each observation.

Fire observations are displayed at the time window they occurred in; therefore, a TD observation based on AVL that has a precise time of 09:55 is displayed in the 09:00 to 10:00 map. Data that have a time range associated with them are displayed on every relevant time map, i.e., a TD observation with a time range between 15:00 and 17:00 is displayed on the 14:00 to 16:00 map as well as the 16:00 to 19:00 map.

The maps are presented with the time divisions as follows.

Map 1. Camp Fire Points of Interest and Frequently Referenced Roads and Locations

Map 2. Fire Observations 06:25 to 07:45, November 8

Map 3. Fire Observations 07:45 to 08:30, November 8

Map 4. Fire Observations 08:30 to 09:00, November 8

Map 5. Fire Observations 09:00 to 10:00, November 8

Map 6. Fire Observations 10:00 to 11:00, November 8

Map 7. Fire Observations 11:00 to 12:00, November 8

Map 8. Fire Observations 12:00 to 13:00, November 8

Map 9. Fire Observations 13:00 to 14:00, November 8

Map 10. Fire Observations 14:00 to 16:00, November 8

Map 11. Fire Observations 16:00 to 19:00, November 8

Map 12. Fire Observations 19:00 to 23:00, November 8

Map 13. Fire Observations 23:00, November 8 to 02:00, November 9

Map 14. Fire Observations 02:00 to 09:00, November 9 
Two maps contain unique comparisons to additional fire perimeter data sources. NASA/USGS's Landsat 8 satellite captured an image of the Camp Fire at 10:45 on November 8 [51] using a combination of visible and short-wave infrared lights. Map 6 includes a digitized perimeter traced from the overlaid satellite image. Overall, the collected data was further validated by the satellite imagery. In fact, the collected data indicated more detail than the data captured by the infrared (IR) imaging. Much of the eastern half of the fire showed the fire perimeter with good contrast to unburned areas; however, the western half of the fire was obscured by the towering smoke plume. This was the case particularly on Clark Road south of Buschmann Road to Round Valley Ranch Road near the town limits. Data indicated that the fire was more widespread and was impacting Clark Road through this area.

An IR perimeter mapping flight was conducted beginning at 17:54 on November 8. Map 11 includes this observed fire perimeter [53]. Comparison of the collected data with the IR fire perimeter shapefile was favorable. Observation density dropped as the fire spread beyond the developed area of Paradise into the foothills. The fire perimeter provided a good sense of the extent of the fire as it ran toward Highway 99, Durham-Pentz Road, and across Butte Creek Canyon. The fire spread quickly through the lighter fuels south and west of Paradise, and observations within the 16:00 to 19:00 time window shown on Map 11 indicated the fire quickly spread beyond the perimeter observed during the IR overflight. 


\section{General Fire Behavior and Structure Ignitions}

\subsection{Fire Behavior Across the Community}

Fire and ember exposures varied across the fire both spatially and temporally. Exposure conditions ranged from severe at the burnover locations and at the Butte Creek Canyon in the vicinity of Wilder Drive where flames reached $30 \mathrm{~m}$ to $60 \mathrm{~m}$ (100 ft to $200 \mathrm{ft})$ [TD-117], to creeping surface fires with little to no wind [TD-012, TD-022, TD-045, TD-79, TD-102, TD-126, TD-136].

Spotting ranged from a few meters to several kilometers downwind. Technical discussions, 911 calls, and radio logs were used to identify that spotting was extensive in Paradise by 08:30 on November 8. Many spot fires reached as far as $3.4 \mathrm{~km}(2.1 \mathrm{mi})$ west into the town from the edge of the community along the West Branch; $75 \%$ were located within $3 \mathrm{~km}$ from the edge of the community. The spot fire in Honey Run Canyon, which was first observed at 08:41 and which ultimately burned over Skyway, was $7.4 \mathrm{~km}$ (4.6 mi) from the eastern edge of the community. Figure 50a shows the distribution of spot fire distances into the community.

A total of 30 spot fires before 08:30 were identified during the data analysis. Figure 50b shows the cumulative number of spot fires as a function of time. The initial wave, mainly before 08:00, was focused along Pentz Road, mostly within $1 \mathrm{~km}(0.6 \mathrm{mi})$ from the edge of the community. A second wave of spot fires hit after 08:30, extending deeply into and across town. An additional 35 spot fires were identified between 08:30 and 10:30. Figure 51 shows a map indicating the locations of spot fire ignitions within Paradise before 10:30. Red symbols mark spot fires before 08:30 along Pentz Road and throughout town. Black symbols mark spot fires that ignited between 08:30 and 10:30. Distance was measured from a straight north-south line along the edge of the canyon.

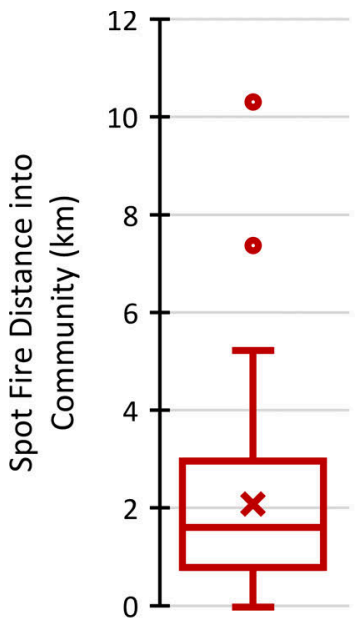

a)

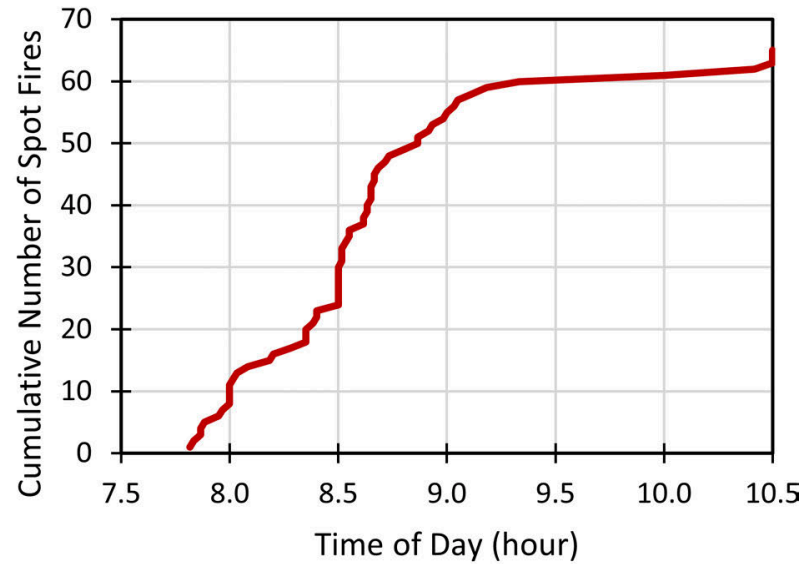

b)

Figure 50. Statistics related to spot fire ignition frequency and location in Paradise: a) distribution of distance into the community of the 65 documented spot fires and b) cumulative number of spot fires before 10:30. 


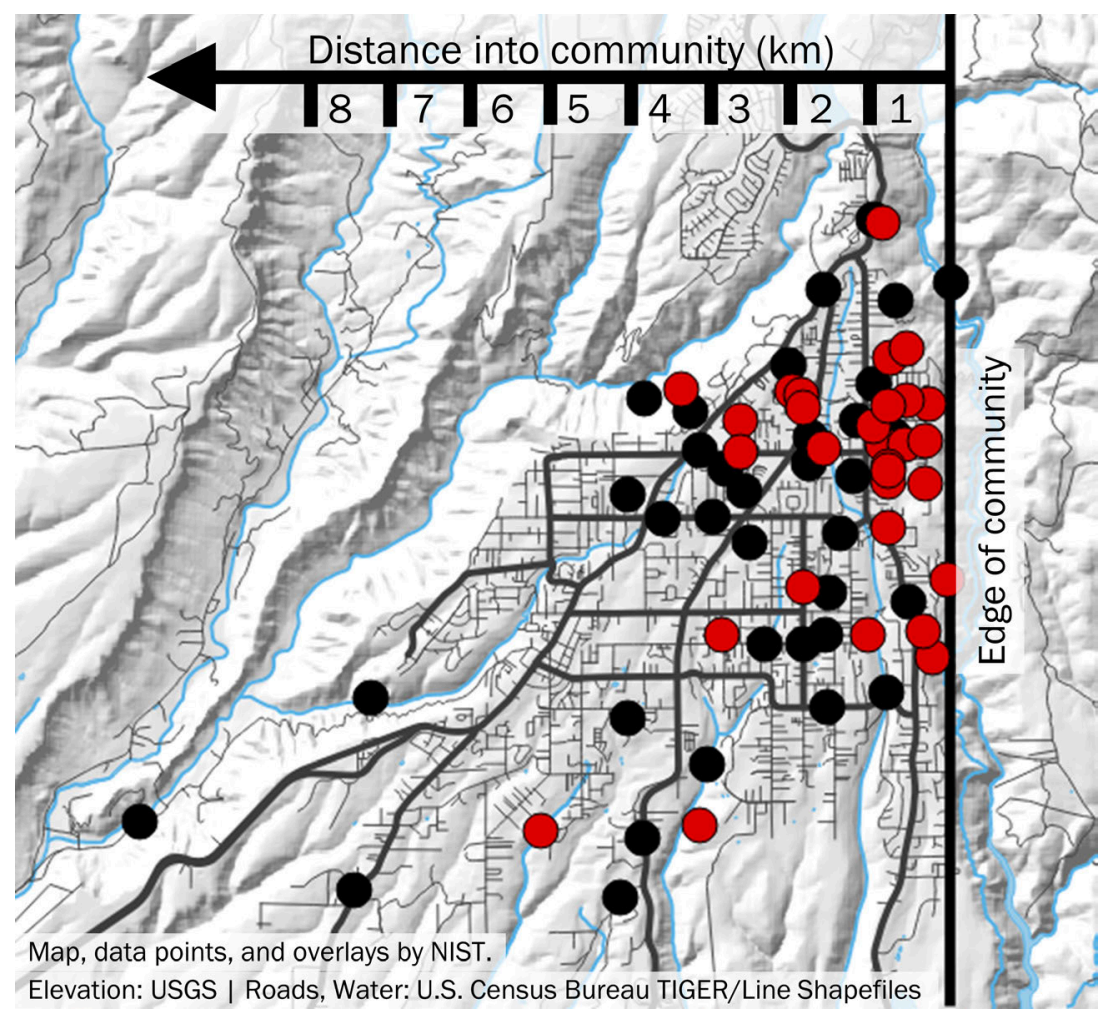

Figure 51. Map of the 65 documented spot fire ignitions in Paradise before 10:30. The red symbols $(\mathrm{N}=30)$ are spot fires that ignited between 07:49 and 08:30, mostly within $1 \mathrm{~km}$ from the edge of the community, but as far as $5 \mathrm{~km}$ away. Black symbols $(\mathrm{N}=35)$ are spot fires that ignited between 08:30 and 10:30.

The extensive spotting, caused by ember transport and the low ignition threshold of abundant dry vegetative fuels, such as pine needles, discussed below, resulted in multiple ignitions of vegetation and structures that quickly spread and overwhelmed the available firefighting resources. The spot fires then grew and "backfilled," causing severe local fire exposures in many cases. These high intensity exposures might have then generated strong local winds and blackout conditions downwind.

Needle drop associated with drought-stressed vegetation, time of year, and disease resulted in piles of needles throughout town, even though the Town of Paradise had just swept the streets. The same buildup also occurred on properties and roofs that had been recently cleaned. This further accentuated the hazard on properties that might not have been recently maintained. First responder reports of needles piling up against walls or "tumbleweed"-type needle piles burning as they were blown by the wind further highlight the fire hazard associated with pine trees and how this hazard is compounded by drought and disease. TDs identified that the same area surrounding Fire Station 35 in Paradise burned three separate times as needles fell, accumulated, ignited, and carried fire across the surface within and between parcels. These fires may then have resulted in additional vegetation ignitions and potentially caused either direct or indirect structural ignitions. This fire behavior illustrates the difficulties of maintaining defensible space during high-wind events with this type of surrounding vegetation. Station 35 was not the only location to experience a second 
documented fire front. Eastern Pearson Road, near Stearns Road and Hilbe Drive, was also observed burning as a second front moved through at 13:15 [TD-014], after initially burning between 09:00 and 10:30.

Winds and exposure varied in space and time and impacted burnovers and fire behavior in and around Concow, Paradise, and Magalia. The first burnovers occurred on Hoffman Road and on Concow Road at around 07:50 on November 8, followed by the Windermere Lane burnover at 08:35 and the Pearson Road burnover at 09:56. These events were the result of wildland fuel conflagrations (similar to many other burnovers), and they highlight the local impacts of fuel, topography, and weather. TDs often reported very high thermal radiation causing heat damage and ignitions of trapped vehicles.

Severe fire behavior occurred in burnovers and other locations within the fire perimeter. TD-040 and TD-104 reported very loud noise prior to the arrival of the fire front that sounded like jet engines or a freight train. The arrival of high intensity exposures occurred within minutes of first hearing the loud noise. In the case of Apple View Way [TD-040], the approaching fire front was from the east out of the West Branch canyon, while in another location [TD-104] the direction was not identified.

\subsection{Fire Behavior Across and Within Residential Parcels}

Differences in fire behavior at the parcel level result in a range of fire exposures to structures, from large flames in high exposure areas due to high vegetative fuel loading or the proximity of nearby burning structures, to low energy smoldering or creeping spot fires. Structures may ignite due to thermal radiation or convection due to flames, from direct flame contact, or from deposition of embers (from vegetation, upwind structures, or other combustibles) [54]. In the WUI, these fire and ember exposures threatening residential structures may originate from fuels located within a single parcel (intra-parcel exposures) or from adjacent parcels (inter-parcel exposures).

Direct observations of structure ignitions were identified in several TDs, videos, and photos, and highlighted several different ignition pathways. The data presented in Table 35 illustrate the inter- and intra-parcel ignition pathways that were specifically identified through direct observations. Figure 52 and Figure 53 present photos from two structure ignition events with known pathways. Figure 52a shows a burning vehicle that was initially located approximately $2 \mathrm{~m}(6.5 \mathrm{ft})$ from the building and was moved by a dozer because it was igniting the side of the structure. Figure 52 b shows a view of the damage as it appeared when surveyed by the NIST team during the field data collection effort. Evidence of ignition and defensive actions were confirmed by TD-091. Figure 53 shows a structure ignition in Magalia as fire spread from vegetation and combustible fencing. Figure 53a and $\mathbf{b}$ were taken two minutes apart, and show the rapid fire spread to the eaves of the structure.

Figure 54 illustrates parcel-level fire vulnerabilities and hazards and highlights the structure ignition pathway for the case shown in Figure 53.

Additional ignition pathways may be identified through post-fire analysis of damaged structures. NIST/USFS/FEMA data collection, in coordination with CAL FIRE, was conducted on 132 damaged residential structures. The relationship between known defensive 
actions and damaged structures will be further analyzed in NIST Camp Fire Report \#5. The report will also contain documentation and analysis of the exposure data collected as outlined in NIST Camp Fire Preliminary Reconnaissance and Preliminary Data reports [22, 24].

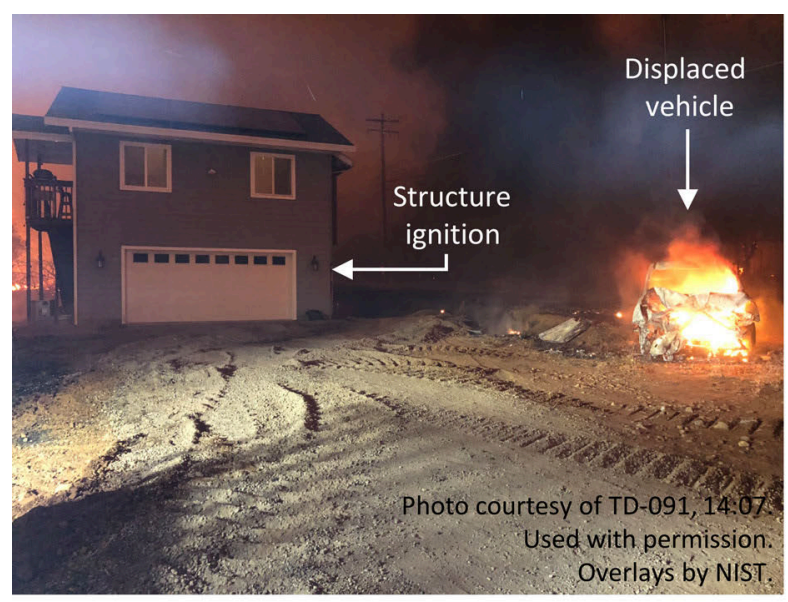

a)

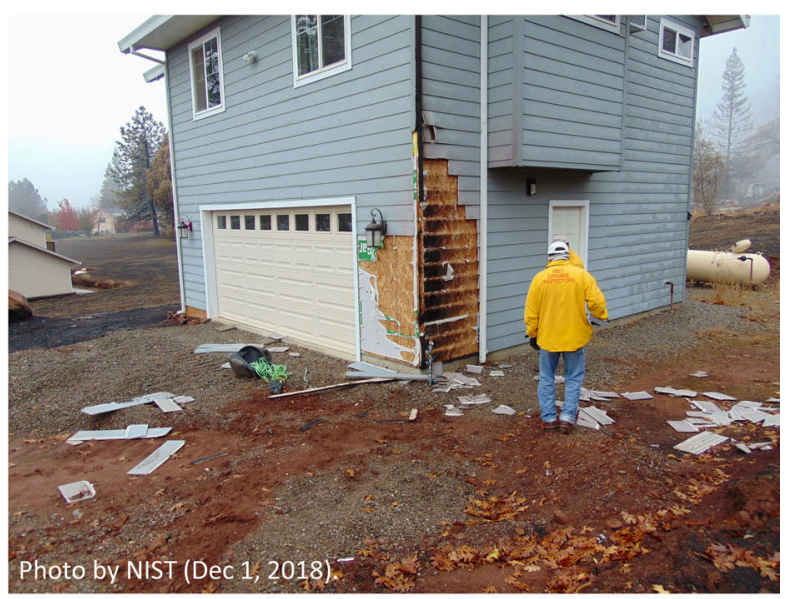

b)

Figure 52. A defended structure on Lewis Ranch Rd where the burning vehicle was igniting the structure, showing a) a dozer displaced the vehicle to stop fire spread, b) the associated evidence of the fire ignition and defensive actions encountered during NIST damage assessments.

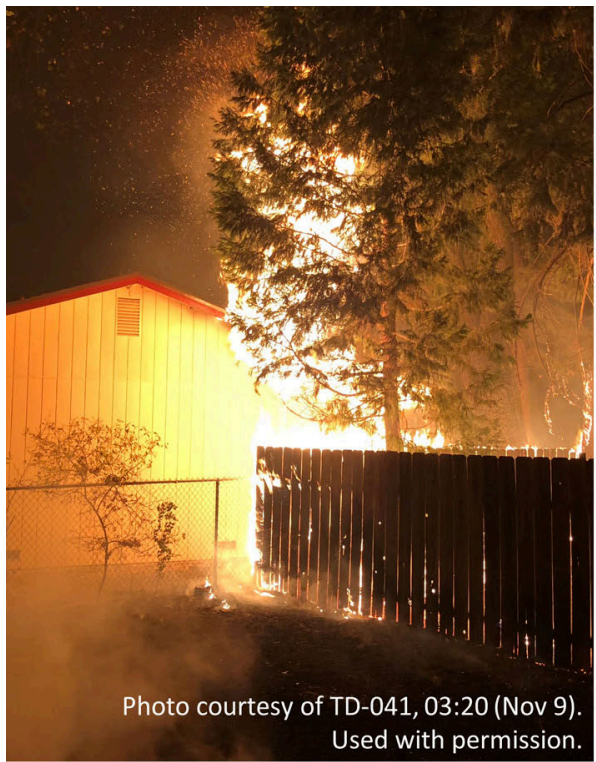

a) $t=0 \mathrm{~s}$

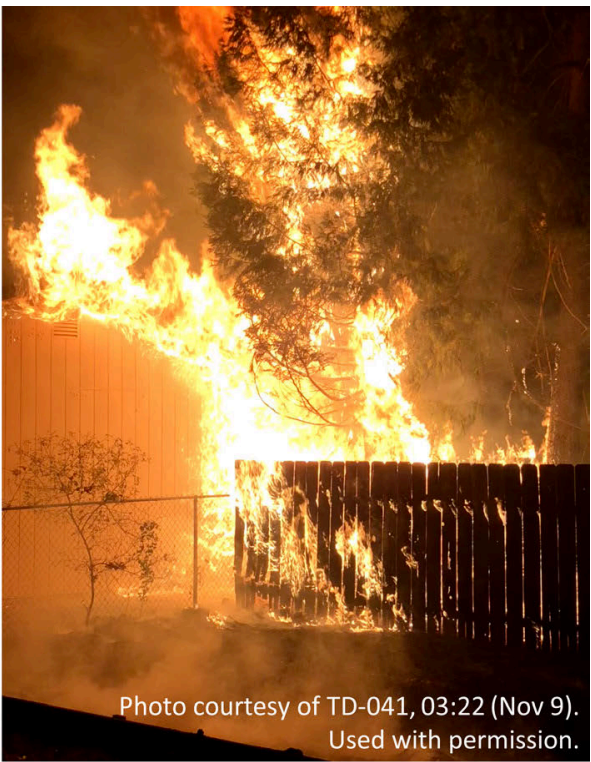

b) $t=139 \mathrm{~s}$

Figure 53. Structure ignition on Dade $\mathrm{Ct}$ in Magalia. Images are two minutes apart and show fire spread from surface fuels to fence to vegetation to eaves. The combustible fence is estimated to be approximately $1.8 \mathrm{~m}(6 \mathrm{ft})$ away from the structure. 


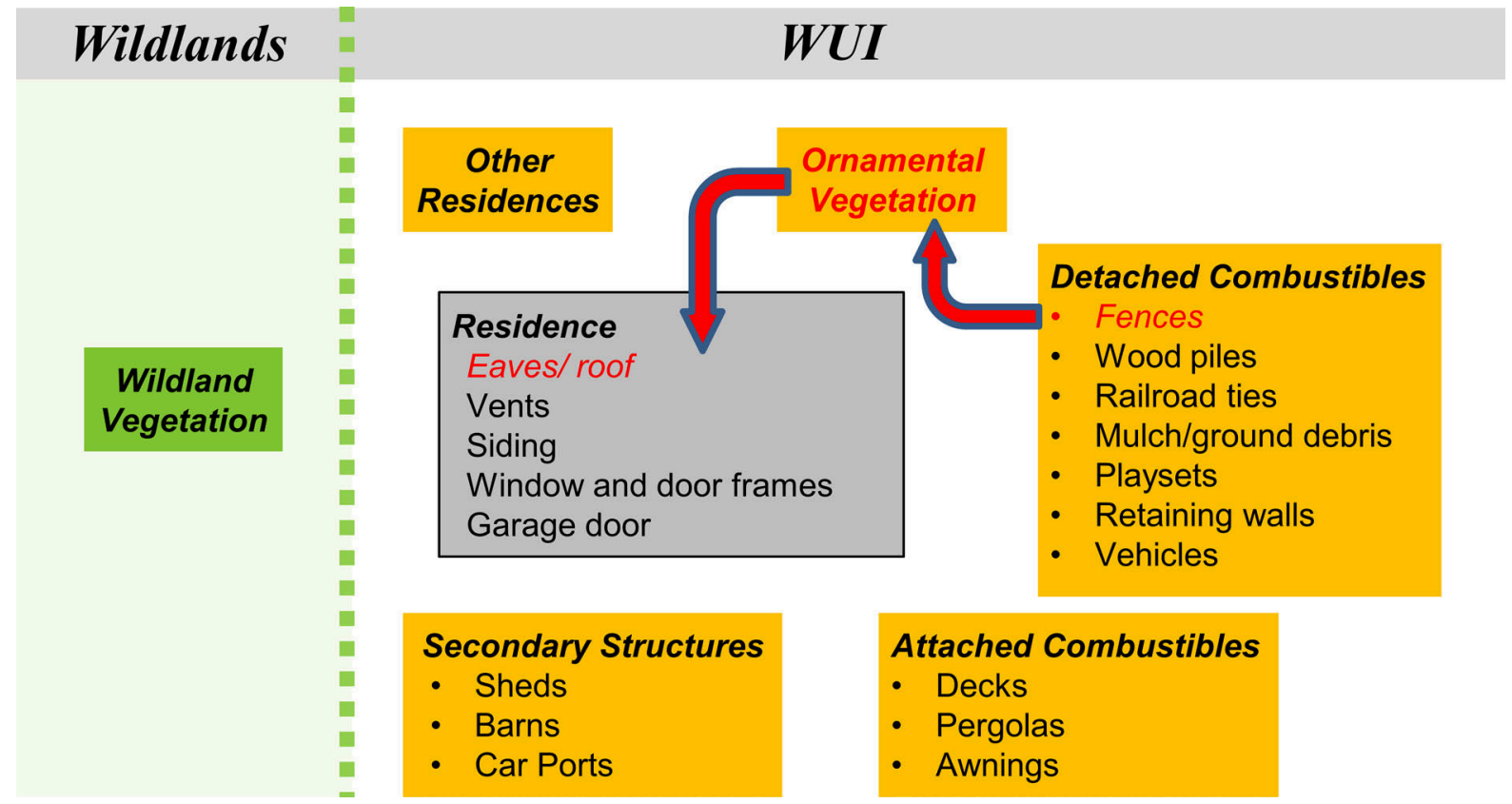

Figure 54. Numerous structure ignition pathways exist from the wildlands and inter- and intra-parcel exposure sources. The ignition pathway for the identified Dade Ct, Magalia structure ignition is highlighted. 
Table 35. Residential structure ignition pathways identified by direct observation.

\begin{tabular}{|c|c|c|c|c|c|}
\hline \multirow{2}{*}{$\begin{array}{l}\text { Data } \\
\text { Source }\end{array}$} & \multirow{2}{*}{$\begin{array}{l}\text { Time } \\
\text { of Obs }\end{array}$} & \multirow[b]{2}{*}{ Location $^{a}$} & \multirow[b]{2}{*}{ Building Ignition Pathway } & \multicolumn{2}{|c|}{$\begin{array}{c}\text { Source to Target } \\
\text { Distance }\end{array}$} \\
\hline & & & & $\mathbf{m}$ & $\mathrm{ft}$ \\
\hline TD-045 & 09:10 & Chris $\mathrm{Ct}$ & Shed to fence to shed to house $\mathrm{e}^{\mathrm{b}}$ & 2.7 & 9 \\
\hline TD-005 & $10: 20$ & Canyon View Dr & $\begin{array}{l}\text { Bark mulch to wall of house (OSB } \\
\text { and vinyl) }\end{array}$ & \multicolumn{2}{|c|}{ unknown } \\
\hline TD-060 & 11:06 & Sweetbriar Ln & $\begin{array}{l}\text { Structure ignition via radiation } \\
\text { from neighboring structure on fire }\end{array}$ & 11 & 35 \\
\hline TD-092 & $13: 52$ & Neal Rd & Burning car to shed to house & \multicolumn{2}{|c|}{ unknown } \\
\hline TD-091 & 14:06 & Lewis Ranch Rd & Burning car to side of house & $1.5-2.4$ & $5-8$ \\
\hline TD-091 & $14: 06$ & Neal Rd & Mulch to garage & \multicolumn{2}{|c|}{ unknown } \\
\hline $\begin{array}{c}\text { TD-015 } \\
\text { TD-017 } \\
\text { TD-064 } \\
\text { PPD }\end{array}$ & $14: 37$ & Skyway & Fence to wall of building & 2.4 & 8 \\
\hline $\begin{array}{l}\text { TD-100 } \\
\text { TD-101 }\end{array}$ & $14: 53$ & Pearson Rd & $\begin{array}{l}\text { Commercial structure to } \\
\text { commercial structure roof to eave }\end{array}$ & 0.7 & 2 \\
\hline TD-036 & $14: 58$ & Skyway & Juniper vegetation to eave & \multicolumn{2}{|c|}{ against house } \\
\hline TD-108 & 17:01 & Clark Rd & Juniper vegetation to house & 1.3 & 4 \\
\hline TD-091 & 17:09 & Neal Rd & $\begin{array}{l}\text { Burning bark mulch into subfloor } \\
\text { vents of house }\end{array}$ & \multicolumn{2}{|c|}{ unknown } \\
\hline TD-091 & $17: 23$ & Sutter Rd & $\begin{array}{l}8 \mathrm{~m} \times 4 \mathrm{~m}(26 \mathrm{ft} \times 13 \mathrm{ft}) \text { shed to } \\
\text { house eaves }\end{array}$ & 2.4 & 8 \\
\hline TD-044 & 19:00 & Valley Ridge Dr & Fence to boat to house & $2.7-3.6$ & $9-12$ \\
\hline TD-205 & $20: 12$ & Clark Rd & Boat on fire to eaves of house & 2.5 & 8 \\
\hline TD-044 & $22: 30$ & Valley Ridge Dr & Woodpile to house & $0.3-0.7$ & $1-2$ \\
\hline TD-041 & $03: 20^{\mathrm{c}}$ & Dade Ct, Magalia & $\begin{array}{l}\text { Fence/ground fuel to tree to eaves } \\
\text { of house }\end{array}$ & 1.5 & 5 \\
\hline
\end{tabular}

${ }^{\mathrm{a}}$ Location in Paradise unless noted.

${ }^{\mathrm{b}}$ Second shed fire resulted in an explosion that caused a firefighter injury.

${ }^{\mathrm{c}}$ November 9. 


\section{Analysis of First Responder Comments}

Technical discussions (TD) often included statements or comments about the incident or WUI fire in general that were not directly related to establishing the incident timeline or linked to a specific observation. The comments came from a broad range of perspectives and contain a plethora of valuable observations from a range of different first responders.

The TD comments were subdivided into ten categories. Pre-Planning/Mitigation, Pre-Fire Hazard, and Fire Behavior categories are included in this report. The remaining categories will be included in the subsequent NIST Camp Fire reports on Evacuation/Notification and Response. TD comments may fall into more than one category and may therefore be listed more than once.

The full listing of Pre-Planning/Mitigation, Pre-Fire Hazard and Fire Behavior comments are contained in Appendix G. Table 36 summarizes the comments using subcategories. Comments tagged with the subcategory/keyword Vegetation dominated the Pre-Fire Planning/Mitigation category (60\% occurrence), with the second most common keyword, Water, appearing only five times (12.5\% occurrence). In the Pre-Fire Hazard category, Vegetation also dominated the comments with $44 \%$ occurrence, with Pine Needles being the second most common keyword with 4 entries (10\% occurrence). Out of 106 Fire Behavior comments, the three most frequently used keywords were Wind, Conditions, and Embers, with 24,23 , and 19 occurrences respectively.

Table 36. List of topics and frequency counts of fire-related first responder comments.

\begin{tabular}{lc}
$\begin{array}{l}\text { Pre-Fire Planning/ } \\
\text { Mitigation }\end{array}$ & Count \\
\hline Vegetation & 24 \\
Water & 5 \\
TRA & 4 \\
Utilities & 3 \\
WUI & 2 \\
Research & 1 \\
Resources & 1 \\
\hline Total & $\mathbf{4 0}$ \\
\hline
\end{tabular}

\begin{tabular}{lc} 
Pre-Fire Hazard & Count \\
\hline Vegetation & 18 \\
Pine needles & 4 \\
Infrastructure & 3 \\
Wind & 2 \\
Clearance & 1 \\
Conditions & 1 \\
Defensive space & 1 \\
Egress & 1 \\
Embers & 1 \\
Fences & 1 \\
Fuel model & 1 \\
Inspection & 1 \\
Regulation & 1 \\
Research & 1 \\
Structure & 1 \\
Visibility & 1 \\
Windows & 1 \\
\hline Total & $\mathbf{4 0}$ \\
\hline
\end{tabular}

\begin{tabular}{lc} 
Fire Behavior & Count \\
\hline Wind & 24 \\
Conditions & 23 \\
Embers & 19 \\
Hazards & 11 \\
Fire history & 7 \\
Flames & 6 \\
Structure & 6 \\
Topography & 5 \\
Vegetation & 3 \\
Pine needles & 2 \\
\hline Total & $\mathbf{1 0 6}$ \\
\hline
\end{tabular}




\section{Primary Drivers Influencing the Extent of Damage and Destruction}

During the Camp Fire, there were many factors that impacted individual structure survivability and effectiveness of defensive actions at a parcel level. However, when viewing the incident in its entirety, based on all fire observations and additional comments provided in the TDs, four factors have been identified to be the most significant for influencing the extent of damage and destruction during the Camp Fire. They are:

1. Fuel ignition potential

2. Density of vegetative and structural fuels

3. Wind and terrain

4. Extent/size of fire front reaching the communities

It was the confluence of these four factors that resulted in the very aggressive fire behavior that caused dangerous conditions for residents and fire fighters and extensive damage and destruction.

\subsection{Fuel Ignition Potential}

Fuel receptivity to embers and ignition potential was a result of over 200 days with almost no precipitation (see Section 5.3). The presence of fine fuels, including pine needles and ornamental vegetation stressed by limited precipitation, enabled far-field embers to cause a number of ignitions well ahead of the fire front. Fuel receptivity and ignition by embers were clearly conveyed in multiple first responder statements of " $100 \%$ ember ignitions" [TD-041, TD-079]. It is this receptivity within the communities that caused the large number of spot fire ignitions. In Paradise, these ignitions started approximately $30 \mathrm{~min}$ to $40 \mathrm{~min}$ before the arrival of the fire front and rapidly grew in number when the front reached the community.

\subsection{Density of Vegetative and Structural Fuels}

All three communities, Concow, Paradise, and Magalia, are wildland-urban intermix communities that have developed over decades within the local wildland vegetation. Concow can be considered low population density intermix with 10 people $/ \mathrm{km}^{2}\left(26 \mathrm{p} / \mathrm{mi}^{2}\right)$, while Paradise and Magalia can be classified as high-density intermix communities with $552 \mathrm{p} / \mathrm{km}^{2}$ and $312 \mathrm{p} / \mathrm{km}^{2}\left(1433 \mathrm{p} / \mathrm{mi}^{2}\right.$ and $\left.808 \mathrm{p} / \mathrm{mi}^{2}\right)$ respectively; however, effective densities varied significantly within all three communities as discussed in Section 4.

The absence of fire within most of Paradise for many decades had resulted in significant accumulation of vegetative fuels. The vegetative fuel loading was further impacted by diseased vegetation (specifically conifers) [TD-035]. Seasonal needle dropping, combined with diseased trees and enhanced by wind, resulted in extensive needle accumulation before and during the fire. The historic growth of Paradise and surrounding communities, going back over a century, resulted in many structures on smaller lots, with small structure separation distances. Combined with the vegetative fuel loading, this enabled rapid structureto-structure fire spread.

Concow has recently experienced wildfires about every ten years. These recent fires have resulted in modification of the local wildland fuels from timber to brush and grass. After the 1999, 2000, and 2008 fires, fuel loading around Concow was estimated at $2.2 \mathrm{~kg} / \mathrm{m}^{2}$ to 
$3.4 \mathrm{~kg} / \mathrm{m}^{2}$ (10 ton $/ \mathrm{ac}$ to $15 \mathrm{ton} / \mathrm{ac}$ ), which allowed the fire to maintain a high intensity and move rapidly through the community [TD-008].

Fuel treatments have been used extensively to compartmentalize the landscape in the area around Paradise, Magalia, and in Concow [TD-008]. The goal of fuel treatments is to provide access for firefighting operations and reduce the total impact of wildfires by reducing the total acreage burned. Figure 55 is an excerpt from the Butte County Wildland Fire Pre-Plan that illustrates fuel treatments around Paradise and Magalia. Fuel treatments have been used to influence wildland fire behavior and to protect critical infrastructure.

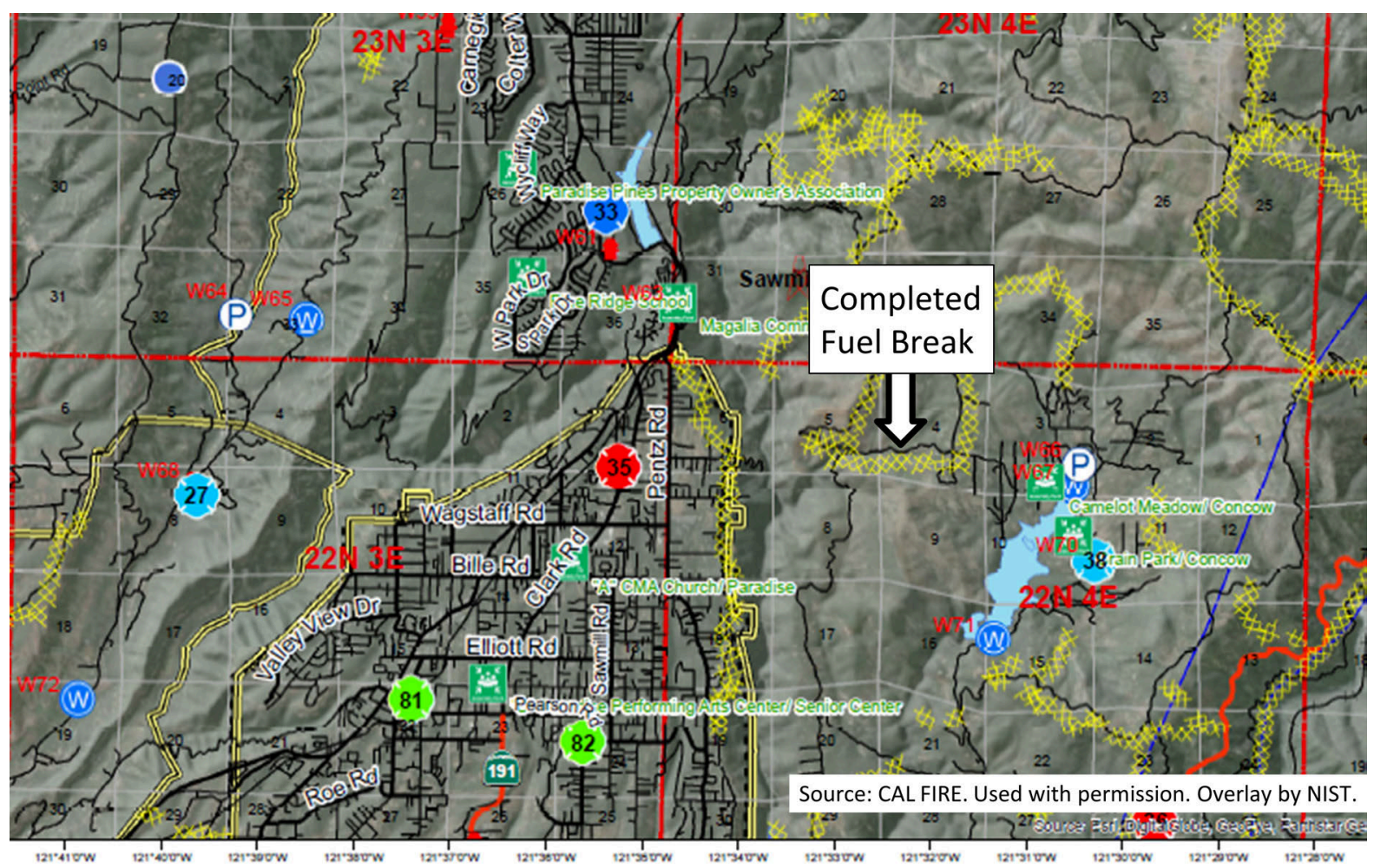

Figure 55. Wildland fire pre-plan for Butte County Fire Department Battalion 2.

The fuel treatment around Paradise Irrigation District (PID) critical infrastructure, illustrated in Figure 56, was successful in protecting the facility when combined with defensive actions [TD-008]. This specific fuel treatment highlights pre-fire preparation and vegetative fuel reduction aimed at protecting critical infrastructure. The systematic analysis of the effectiveness of fuel treatments and their impact on fire behavior are beyond the scope of this report. There is a need for a detailed study to assess the impact of fuel treatments on wildland fire behavior and on their contributions to structure survivability, particularly when coupled with defensive actions.

At the residential parcel level, the quantification of exposures from various burning vegetative fuels can provide further information to guide defensible space guidance and hazard mitigation efforts. Intermix communities may be particularly vulnerable to the presence of high vegetative fuel loading on residential and commercial properties. While 
drought affects all non-irrigated plants, highly flammable plants like juniper can generate severe fire and ember exposures that threaten surrounding structures. While there are a number of plant lists available, there is currently no standard way to assess the hazard associated with a specific plant. As a result, different lists may present different levels of unquantified hazard reduction. There is a need to develop a standardized methodology for assessing the exposures from ornamental vegetation. Such a methodology can then be used to develop a prohibited plant list based on an unacceptably high fire hazard, in order to limit the exposures to residential and commercial structures, specifically in Very High Fire Hazard Severity Zones.

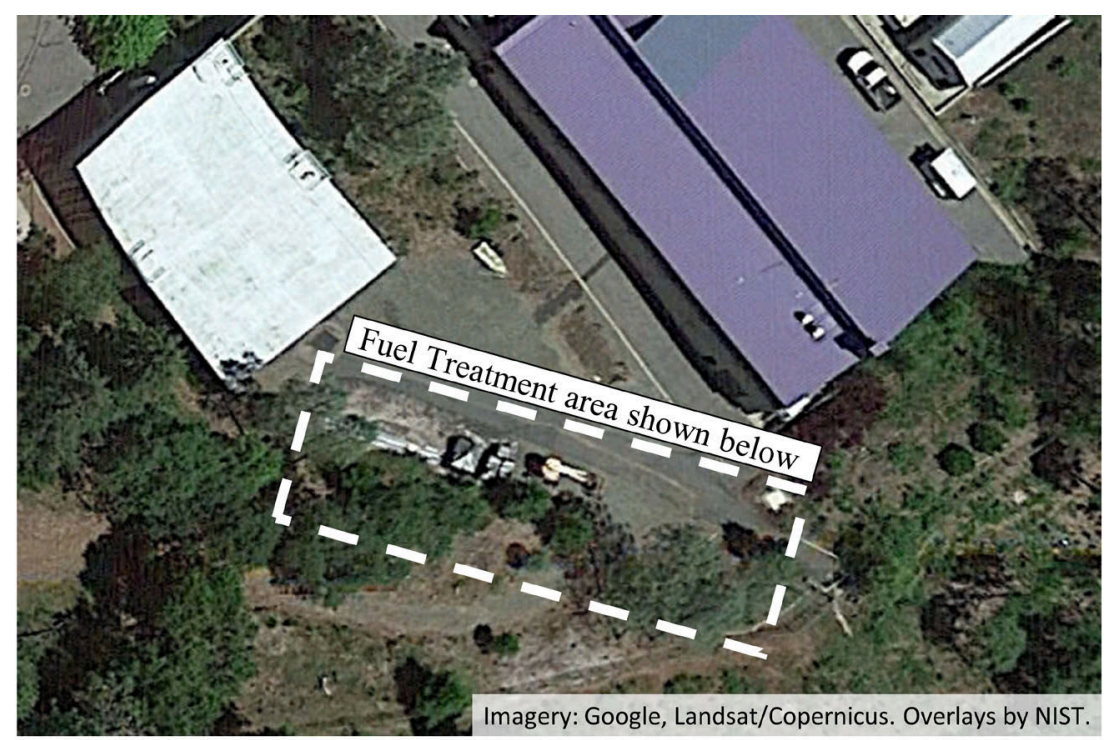

a)

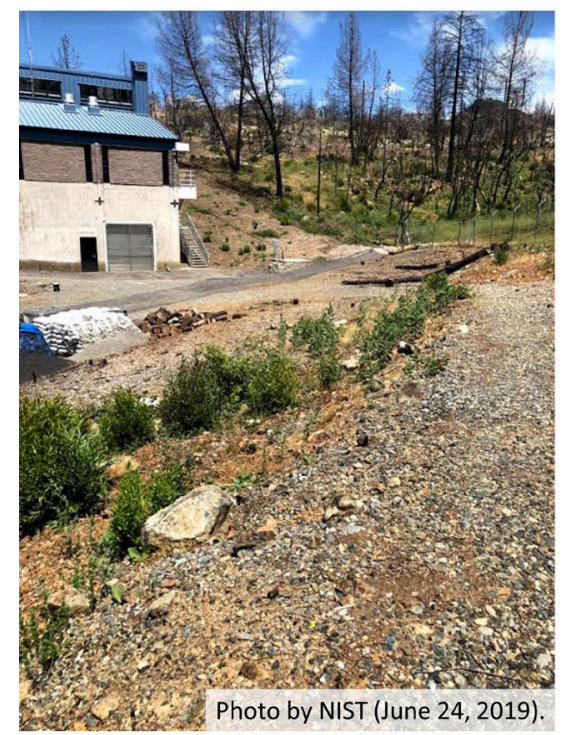

b)

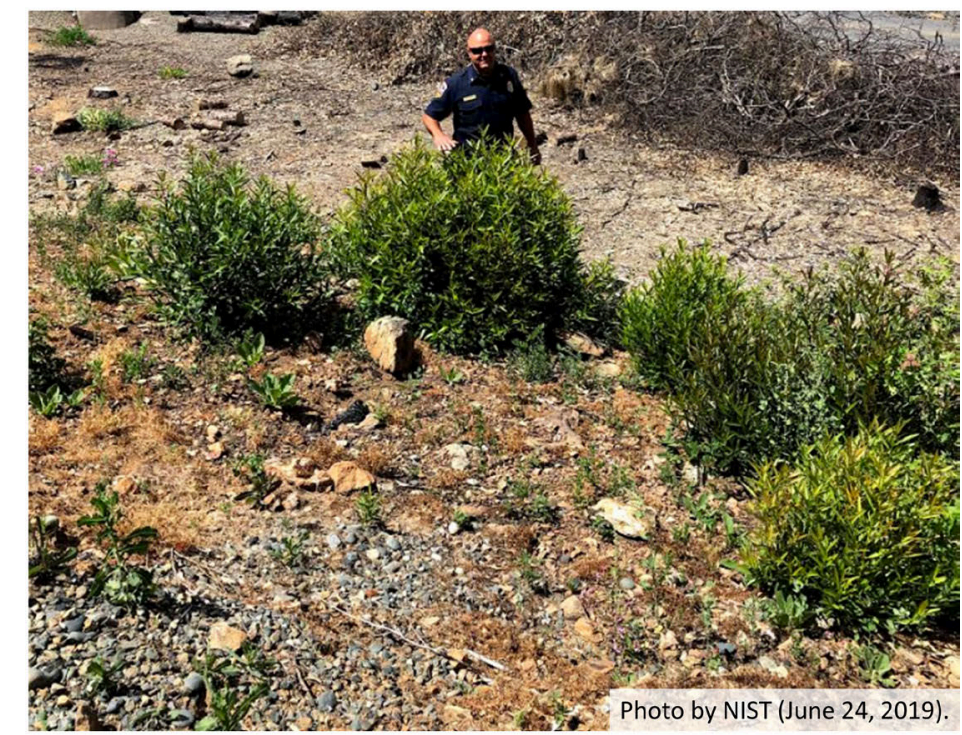

c)

Figure 56. Fuel treatment around Paradise Irrigation District critical infrastructure: a) prior to fuel treatment, May 2018, b) fuel treatment showing reduced fuel load, c) rapid post-fire vegetative growth in pre-fire fuel treatment areas. 


\subsection{Wind and Terrain}

The impact of wind and terrain on the fire spread was discussed in detail in Section 9.4. Jarbo Gap is known for its high winds [TD-003, TD-008]. The wind event that occurred in the early morning on November 8 , combined with the restricted access associated with topography, resulted in the fire not being contained soon after ignition. The wind, augmented by the local topography and fueled by very dry vegetation, caused the fire to grow very rapidly.

\subsection{Extent/Size of Fire Front Reaching the Communities}

All three communities were impacted by large fire fronts. The front length, driving fire over very dry fuels in complex terrain with wind, resulted in fire behavior that could not be readily contained.

The fire front that reached Concow was estimated to be between $0.8 \mathrm{~km}$ and $1.6 \mathrm{~km}(0.5 \mathrm{mi}$ to $1 \mathrm{mi}$ ) long. This front impacted most of the community and, in combination with the above three factors, caused very dangerous conditions that rapidly impacted life safety and evacuation (see Section 9.3, Burnovers). The fire front that reached Paradise at 08:30 on November 8 extended from approximately Apple View Way to Merrill Road, a distance of $1 \mathrm{~km}(0.6 \mathrm{mi})$. Shortly after, the southern end of the approaching front progressed south and impacted the area between Merrill Road and Feather River Hospital.

In a little over $40 \mathrm{~min}$ after the initial spot fires reached the community, Paradise was experiencing a direct fire front hit $2.8 \mathrm{~km}(1.9 \mathrm{mi})$ in length. The extent and severity of that initial exposure, as in Concow, resulted in civilian evacuations and life safety becoming the top priorities of the early first responder resources on the scene. The initial fire front expanded to the south, and by late morning the exposure to Paradise was along the entire town boundary along the West Branch canyon, approximately $8 \mathrm{~km}(5 \mathrm{mi})$ in length.

Figure 57 illustrates idealized fire spread scenarios with two different ignition locations away from the WUI community edge. In both cases the fire is not contained by the first responders before reaching the community. In the case where the ignition occurs near the community, the fire front length (FFL) represents only a small fraction of the community interface length (IL). The resulting initial impact on the community is relatively small, FFL/IL $<<1$, and therefore the high ember exposure zone downwind of the initial fire front also covers a small area of the WUI community.

The second (lower) scenario illustrated represents an idealized version of the Camp Fire. In this scenario, the wildland fire ignition occurs far from the community, and the fire has enough fuel and distance to develop a fire front that represents a large fraction of the interface length of the community. In this case, in addition to the extended direct fire front assault, the high ember exposure zone represents a large fraction of the community and is illustrated as having a longer and deeper reach into the community. This deeper reach is related to the higher overall intensity of the fire front. The increased area of initial high ember flux exposure has the potential to easily overwhelm fire-fighting resources and enables the fire to become well established throughout the community. 
The rapid increase in fire intensity that caused the Coutolenc Burnover around midnight on November 8 also resulted in a fire front over $1.6 \mathrm{~km}(1 \mathrm{mi})$ long that impacted Magalia. The extent of the fire front coupled with the extensive ember cast and very strong winds estimated at $22 \mathrm{~m} / \mathrm{s}(50 \mathrm{mi} / \mathrm{h})$ challenged the large number of available resources on the scene. The intensity of the exposure and the fuel's receptivity to embers led to an uncontainable situation that resulted in most of the Magalia structural losses.

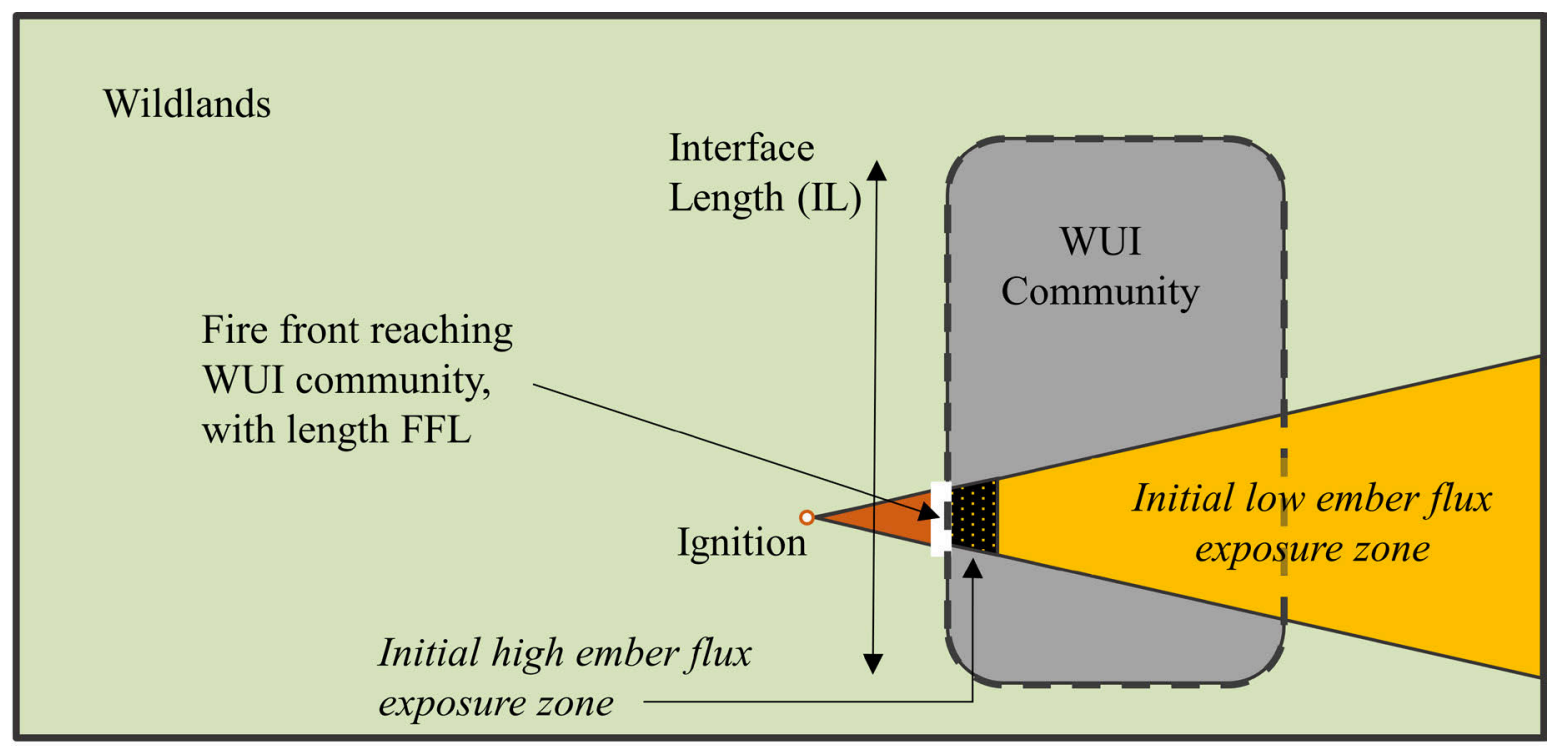

a) Ignition near WUI community - fire front impacting community

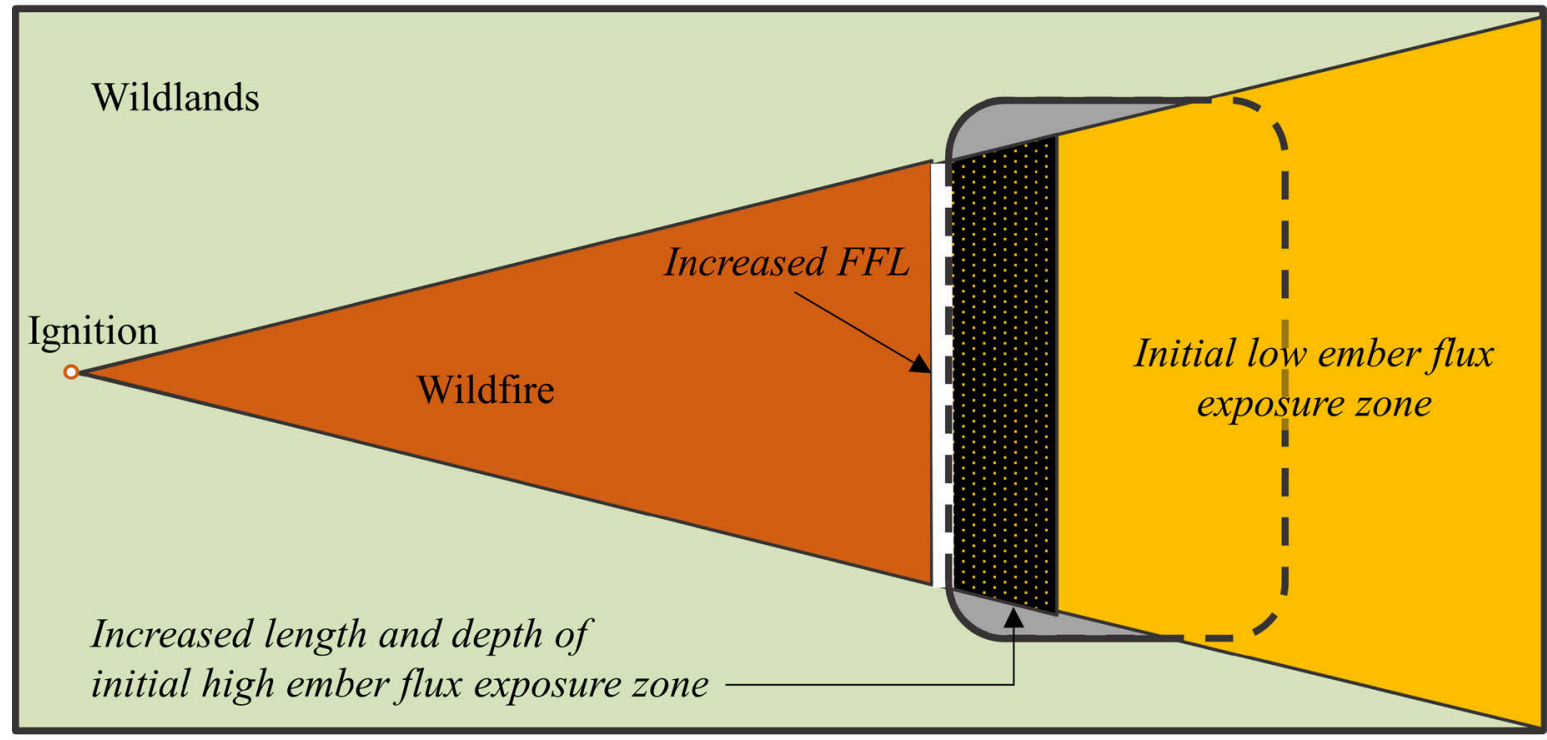

b) Ignition far from WUI community - fire front impacting community

Figure 57. Idealized relationship between ignition location, a) near or b) far, from a WUI community and the fire front and ember exposures reaching the community. The wind is directed from left to right. 


\section{Hazard Reduction Pathways}

\subsection{Community-Level Hazard Reduction Pathways}

Devastating WUI fires frequently occur during short term limited precipitation windows and/or during extensive droughts. In both cases, water availability may be limited, and statewide or regional water usage restrictions may be in place. Such restrictions can result in low vegetative fuel moisture levels within the community, further enhancing the danger presented by the surrounding very dry wildland fuels.

Wildfires up to 300 ac (size class D) [55] are successfully contained early $97 \%$ of the time [56]. This is achieved by utilizing several pre-fire hazard mitigation techniques such as vegetative fuel treatments and active suppression and containment techniques. Fuel treatments are a critical tool in containing wildland fires in low and moderate wind speeds.

Fuel treatments around communities are a key strategy in reducing WUI community hazard. The fuel treatments serve several purposes. While there is limited scientific information quantifying fire and ember exposure reductions from fuel treatments around communities, fuel treatments can reduce local fire exposures and enable first responders to safely defend the structures along the perimeter of a community. This can be viewed as an extension of the parcel-level defensible space concept to the community and could be a high impact hazard mitigation solution for low and moderate wind WUI fires. When fire ignition occurs near the community under low and moderate wind conditions, these treatments can be very beneficial by enabling effective suppression and reduction of structure ignitions and rapid containment of the fire.

However, fuel treatments around communities may not be able to significantly reduce ember exposures. In WUI fires that occur under severe conditions (with challenging topography, low vegetative fuels moisture, and high wind speeds) the ember assault can potentially result in catastrophic life and property losses in communities with a high density of vegetative and structural fuels. In the case of the Camp Fire, the initial high ember flux zone in Paradise reached $1 \mathrm{~km}(0.6 \mathrm{mi})$ into the community, with additional significant spot fires extending to $3.4 \mathrm{~km}$ (2.1 mi) into the community. To significantly reduce ember exposure for

communities with high fuel ignition potential, such as in the case of the Camp Fire, extensive fuel treatments reaching hundreds of meters from the community would be required. A fuel treatment on that scale would have very significant environmental and financial impacts and would be difficult to initially implement and subsequently maintain.

A review of the four primary drivers influencing extent of damage and destruction described in Section 13 reveals that only two can be readily addressed to potentially reduce losses in existing WUI communities. For communities that are built in regions with complex terrain and strong winds, the density of vegetative and structural (community) fuels and the fuel ignition potential are the two drivers that can be impacted by proactive pre-fire hazard reduction methods. Hazard reduction pathways based on these two drivers are further described in Section 14.2 below. 


\subsection{Reducing the Density of Vegetative and Structural (Community) Fuels and the Fuel Ignition Potential}

Section 14.1 identified that the two high impact approaches for reducing structure ignitions under severe exposure conditions are the reduction of fuels within the community and reduction in the ignition potential of these fuels. The ignition of a structure results from the relationship between exposure of a structural component or assembly and its response. Uncoupling the exposure problem into flame and ember components can help clarify the path forward to reduce structure ignitions.

The Camp Fire can be viewed as an example of a severe exposure scenario for a WUI community. This fire resulted in a significant ember exposure from the wildlands reaching $0.8 \mathrm{~km}(0.5 \mathrm{mi})$ into the community. In many cases, these wildland embers then ignited other fuels, causing direct or indirect structure ignitions. ${ }^{16}$ The exposure from these newly ignited fuels could themselves be further subdivided into embers and fire. In general terms, the end result is two ember exposure sources: wildland fuels and fuels within the community.

In agreement with the other NIST case studies of WUI fires, the Camp Fire has demonstrated that embers can have significant impact on WUI communities. Laboratory and field work by NIST [57] has demonstrated that embers with enough energy to cause ignitions are readily generated from parcel-level combustibles such as landscaping mulch, fences, and firewood piles. These parcel-level fuels can cause ignitions over $40 \mathrm{~m}(130 \mathrm{ft})$ downwind. Ember ignitions downwind from parcel-level combustibles enable fire to readily spread from parcel to parcel. In high hazard areas, WUI structures therefore need to be able to withstand the exposures generated from both wildland and parcel-level combustibles. ${ }^{17}$

Measurement science can be used to quantify these exposures and develop a realistic worstcase ember exposure flux. Experiments will need to be conducted to obtain ember flux data from different types of fuels present in and around WUI. ${ }^{18}$ To define a worst case ember exposure flux, field-collected ember flux data will need to be compared to laboratory ember ignition studies in order to identify the ember attributes of interest that yield enhanced ignition potential. This realistic worst-case ember exposure flux can then be used as the "Design Ember Flux" that residential and commercial properties in high hazard WUI areas will need to withstand. The proposed approach will harden structures against embers from wildland and community fuels.

Structure-to-structure fire spread was observed during the Camp Fire [TD-045, TD-060, TD-061, TD-089, TD-091, TD-100, TD-101, TD-108] and has been identified as an issue in previous NIST WUI case studies [9-13]. This issue applies to primary residences as well as auxiliary dwelling units (ADUs) and utility buildings. All three types of structures can directly spread fire to primary residences. Figure $\mathbf{5 8}$ shows a photo from the Camp Fire in which a primary structure is being exposed to significant radiation from a large shed $3 \mathrm{~m}$ $(10 \mathrm{ft})$ from the primary structure and the eaves are pyrolyzing (white arrow). Wind is from right to left; however, direct flame contact would easily occur if wind were from left to right.

\footnotetext{
${ }^{16}$ Structure vulnerabilities to embers will be discussed in Report \#5.

${ }^{17}$ The definition of these exposures requires further measurement science development and field data collection in different settings with different wildland fuels.

${ }^{18}$ The ember exposure flux must contain specifics on the ember size, material, energy release, and time.
} 


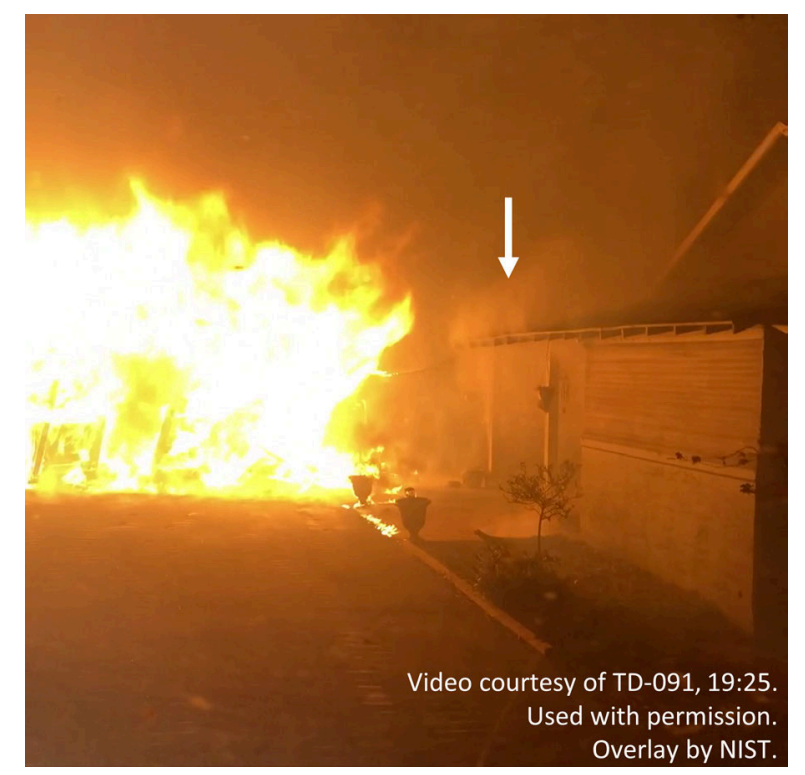

Figure 58. Fully involved shed, $8 \mathrm{~m} \times 4 \mathrm{~m}(13 \mathrm{ft} \times 26 \mathrm{ft})$, located $3 \mathrm{~m}$ $(10 \mathrm{ft})$ from the primary structure. Eaves of the primary structure are pyrolyzing (white arrow).

The hardening of both residential and non-residential structures to resist ignition from direct flame exposures can be addressed using two different technical approaches: 1) the fuels (exposure sources) can be displaced or 2) the target structure can be hardened. Because radiation and convection heat fluxes from a fire are near-field hazards, it is frequently possible to displace the relevant source term. This can be achieved by a vegetative fuel treatment on the perimeter of the community, by displacement of fuels within a parcel, such as locating a combustible shed away from the residence, or by increasing the structure setback from the property line, thus effectively increasing the structure separation distance (SSD). All three pathways can result in reduced ignitions.

Quantifying fire (radiative and convective) exposures from wildland fuels as well as interand intra-parcel level combustibles will enable the development of spacing/hardening costbenefit relationships. These functions can then be used to reduce the overall implementation burden by providing balanced solutions to issues posed by structure hardening versus increased SSD.

The above approach provides a technical outline to address both the flame and ember structure ignition threats. The proposed approach focuses on using large scale field data to develop test methods that together with cost-benefit tools can enhance cost-effective hazard reduction solutions for WUI communities. By addressing both ember and flame hardening of structures, WUI losses can be significantly reduced.

The data presented in Table 2 for communities affected by the Camp fire indicates how parcel sizes may vary between and within communities. Hazard mitigation solutions in low housing density, where large parcels may allow for parcel-level fuel displacement, may not be implementable in high density construction. Hazard reduction in high density construction will require both fuel removal and hardening of the structures because of the proximity of residential structures and the fire exposures generated from detached combustibles. 


\section{Community WUI Fire Hazard Framework}

WUI fire spread has significant impact on communities well beyond the loss of structures, including community evacuation and incident response. Pre-fire planning and hazard mitigation impact how the fire develops, how the life safety of residents and first responders is impacted during evacuations, and the extent of structural and infrastructure losses. There is a need to document pre-fire hazard in a way that assesses the fire impact beyond potential structural losses.

Appendix C contains a preliminary Community WUI Fire Hazard Framework as a suggested methodology to begin to address the question of "How unique is Paradise as a community at risk of WUI fires, " by providing common metrics for comparisons and to support communities at risk in the identification of their unique hazards. This preliminary framework includes information on community size, population, and fuels; on notification and evacuation; and on the community infrastructure and firefighting response potential. Aspects of this framework may already be included in various community-level documents, such as CWPPs or evacuation plans. Development of a standard framework will l) consolidate relevant WUI fire hazard and planning information in one place, and 2) allow for crosscommunity comparisons.

The evaluation required to implement this framework would support pre-fire hazard assessment and during-fire response operations. An increased understanding of the relationships between fire-evacuation, fire-structural response, and fire-defensive actions is needed to assess the overall community WUI fire hazard. The quantification of these relationships will enable communities to optimize the community-level response to WUI fire hazards in a more integrated way with the intended result of increased life safety and reduced losses. 


\section{Summarized Technical Findings}

\subsection{Community Preparedness}

F1. Communities did have multiple programs in place to increase awareness of and reduce fire hazards associated with WUI fires.

F2. The Town of Paradise did have an emergency notification and evacuation plan.

F3. Paradise Public Works staff had received training in how to respond to a WUI fire.

F4. Infrastructure was specifically addressed in pre-fire preparations.

Butte County and the Town of Paradise had a number of programs in place at the time of the Camp Fire to reduce the WUI fire hazard within and around communities. The Butte County Community Wildfire Protection Plan (CWPP) addressed vegetation and structure ignitability, including a vegetation management component that incorporated fuel modifications and specifically highlighted topography, weather, and fire history.

The Town of Paradise addressed notification through a detailed evacuation plan and an opt-in Reverse 911 call system. To facilitate the town evacuation during power outages, Paradise equipped traffic lights at major intersections with battery backups to allow the signals to continue operating in the event of power loss.

The Paradise Public Works Department (PPW) was well prepared to respond to WUI fires and took measures to prepare the town as the high wind event of November 7-9 was forecasted. PPW personnel also had selective fire training including how to respond to burnovers. A Town of Paradise ordinance [45] enabled residents to remove vegetation up to $23 \mathrm{~cm}$ (9 in) in diameter without any permit requirement.

Infrastructure was specifically addressed in pre-fire preparations. Examples included the fuel treatments around Pine Ridge School in Magalia and Paradise Irrigation District (PID) critical infrastructure. Pre-fire preparations included having all water storage tanks at full capacity with additional water available in the supplying reservoirs.

All the above-mentioned hazard mitigation programs and actions reduced fire hazard in the Camp Fire-affected communities by promoting and enabling fuels reduction within and around the communities and prepared the communities for a fire event by enabling enhanced communications.

Vegetation fires around roadways and downed powerlines and power poles were the two primary factors that impacted evacuation. These factors will be further discussed in a subsequent report (Camp Fire Report \#4) detailing emergency notification and evacuation.

Pre-fire firefighting preparedness, including staffing in Paradise and Butte County, as well as preparations and coordination with the Geographic Area Coordination Center (GACC) will be discussed in Camp Fire Report \#5. Regional fire activity and US Forest Service (USFS) staffing will also be discussed in the same report. 
The extensive vegetative fuels in Paradise, Magalia, and Concow may be representative of an older intermix community. A lifestyle of "living in the forest" might have attracted many residents to the community and may be a quality present in many WUI communities. The limited fire history of the Paradise area further contributed to the pre-fire vegetative loading.

\subsection{Pre-Fire Conditions}

F5. Dry winds, with recorded gusts at Jarbo Gap exceeding $22 \mathrm{~m} / \mathrm{s}$ ( $50 \mathrm{mi} / \mathrm{h}$ ) from the northeast, increased fire spread in vegetative and structural fuels.

F6. Steep topographical features including river canyons and creek drainages channeled north winds and accelerated fire spread through vegetative fuels.

F7. Extremely dry vegetative fuels, associated with over 200 days without any significant precipitation, increased the fuel ignition potential around and within Concow, Paradise, and Magalia.

F8. Fire spread toward Paradise from Concow was fueled by heavy conifer forests with brush understory. At lower elevations oak woodlands and savannah grass were the primary fuels.

Pre-fire conditions were hazardous, with the Fire Danger Rating of Very High to Extreme in the northern Sierras. The combination of extremely dry fuels and a north wind event, bringing gusty dry winds, were the cause for Red Flag Warnings and critical fire weather conditions. The terrain around the Camp Fire is characterized by the rising foothills of the Sierra Nevada and numerous steep river canyons and creek drainages that are aligned with the north wind in many cases, channeling and accelerating the local winds.

It was very unusual to have fuel dryness levels so low in November in Butte County. In most years significant rain would have fallen by November, dampening fine fuels and lowering the ignition hazard. However, in the time leading up to the Camp Fire it had been over 200 days since $13 \mathrm{~mm}(0.5 \mathrm{in})$ or more rain had fallen at the lower elevations of Butte County, with the exception of a small amount of rain in early October. Fuel moisture levels were uncharacteristically low for the time of year due to the protracted dry period and late arrival of wet season rain. Fuel moisture levels [34] for 1000-hour time lag fuels measured at the Pike County Lookout southeast of the fire area were at $5 \%$ on November 1 , well below the $17 \%$ historical average for the Northern Sierras in November. Live fuel moisture in manzanita was $74 \%$; the critical level for manzanita is $80 \%$. The average for November is $93 \%$.

Fuels around the point of origin and downwind toward Paradise consisted of heavy conifer timber with brush understory. At lower elevations, oak woodland and grass savannah were the primary fuels. The area near the origin had burned previously in 2008; however, fuels west of the West Branch of the Feather River had not burned in recorded history (see Section 5.4). The most prominent fires within the Camp Fire perimeter include the Humboldt and BTU Lightning Complex fires in 2008 and the Poe Fire in 2001. Butte Creek Canyon previously burned in the Bidwell Fire in 1984 and the Doe Mill Fire in 1999. Several recent 
fires near the town limits were contained outside of Paradise, including the Saddle Fire in 2016 and the Honey Fire in 2017.

\subsection{Fire Progression}

F9. Fire ignited near Pulga and Concow, was pushed by gusty wind across steep terrain toward Paradise, swept through Paradise, and then spread into Magalia.

F10. Extensive intermediate- and long-range firebrand spotting caused multiple ignitions ahead of the main fire line and resulted in different exposures to fire conditions.

F11. The fire travelled and/or spotted more than $11 \mathrm{~km} \mathrm{(7} \mathrm{mi)} \mathrm{downwind} \mathrm{of} \mathrm{the} \mathrm{origin} \mathrm{to}$ reach Paradise in less than 1.5 hours after ignition.

F12. Fire consumed a significant fraction of the Town of Paradise over a period of 6 hours, between 08:30 and 14:30.

F13. Fire spread down slope through the foothills at an average $1 \mathrm{~m} / \mathrm{s}(2.2 \mathrm{mi} / \mathrm{h}$, $180 \mathrm{ch} / \mathrm{h}$ ) through grassy wildland fuels south and west of Paradise.

F14. Fire spread rates for Paradise and Magalia could not be readily computed due to extensive spotting fire behavior.

\subsubsection{Fire Spread Summary}

This section summarizes the fire spread on November 8, 2018 from the origin to Concow, when and how the Camp Fire reached Paradise, how rapidly the fire progressed through town, and the fire activity extending into the morning of November 9. The fire spread information presented here, as in Section 9 and Appendix F, represents all the data collected during the Camp Fire reconstruction. The summarized data does not include all fire activity within the fire perimeter.

The Camp Fire started in the Feather River Canyon and climbed the west wall of the canyon rapidly. The fire moved across the Concow Basin and then crossed the West Fork of the Feather River into Paradise. The fire then went downslope with the wind into the lower elevation areas and agricultural areas east of Chico. It also progressed westerly with a flanking spread across Butte Creek Canyon.

November 8, 06:25 to 10:00

The Camp Fire was first reported via calls to 911 beginning at 06:25. The caller indicated that the fire was burning on the west side of the Feather River near Poe Dam on Highway 70. The fire quickly became well-established in the steep canyon terrain, spreading from the origin toward Pulga. Shortly after 07:00, the fire was cresting the ridge and pushing towards Concow. By 07:25, the first structures started burning in Concow, $5 \mathrm{~km}$ (3 mi) from the origin.

The fire continued growing in Concow, moving westward and spotting over Concow Reservoir and Sawmill Peak. The first spot fires from the Camp Fire arrived in Paradise at 07:50, $12 \mathrm{~km}$ (7.5 mi) from the origin. The main fire front reached Pentz Road around 08:30, resulting in a significant number of distinct spot fires within Paradise. A total of 30 spot fires before 08:30 were identified during the data analysis, with spots reaching as far as $3.4 \mathrm{~km}$ 
(2.1 $\mathrm{mi})$ into the town. Most of these spots (18) were within the first $1 \mathrm{~km}(0.6 \mathrm{mi})$ from the wildlands. The fire front reached Pentz Road between Apple View Way and Lowry Lane. Spot fires in and across town before 08:30 were most likely from the wildland fire front and a limited number of structure ignitions in Concow. By 08:45 there were two separate spot fires that had started in the vegetation far ahead of the main fire front. One was burning in the drainage east of Clark Road near American Way, $3 \mathrm{~km}$ (1.9 mi) southwest from the Lowry Lane, spotted near Feather River Hospital. The second spot ignited in Honey Run Canyon, located on the west side of Paradise, $6.3 \mathrm{~km}$ (3.9 mi) from Lowry Lane.

Between 09:00 and 10:00 in Concow, the head of the fire was hung up on the east side of Concow Reservoir, burning to the north of Ishi Trail. Spot fires were igniting in pine and leaf litter $1.6 \mathrm{~km}(1 \mathrm{mi})$ ahead of the fire front. During that same time in Paradise, the fire intensified along both sides of Pentz Road. Initial spot fires deep within town were well established, and the fire was starting to spread to the west impacting Wagstaff, Bille, and Pearson Roads. By 10:00, fire was impacting Pentz, Bille, and Pearson Roads, where civilians were stuck in traffic and trapped in their vehicles. The fire continued to get deepseated along both sides of Pentz while the earlier spots in town also grew.

November 8, 10:00 to 12:00

Between 10:00 and 11:00 on Pentz Road, peak vegetation fire activity had subsided, but significant fire remained. Most structures and heavy fuels were still burning on both sides of the road. The road was passable with variable visibility. The intersection of Pentz Road and Pearson Road remained fully involved, continuing to impact evacuations.

By 10:00, fire was impacting Clark Road in multiple locations, preventing passage while people were attempting to evacuate. The fire overtook vehicles evacuating on Clark Road at Buschmann Road with wind blowing flames "like a blow torch," and fire jumped to the west side of Clark Road. Clark Road became barely passable again near the town limits for a brief time. However, another flare-up between 11:00 and 11:30 closed the roadway again as $15 \mathrm{~m}$ $(50 \mathrm{ft})$ flames crossed Clark Road near Round Valley Ranch Road, and fire again crossed the roadway near American Way. Further down Clark Road at Airport Road, fire also burned over the roadway, delaying access of arriving strike teams as they waited for conditions to abate. The fire continued with high intensity south of the airport into the afternoon, where it paused and hung up for a period of time between about 13:00 and 15:00, before again advancing down into the flats south of Circle J Road.

Between 10:00 and 11:00, the spot fire in Honey Run Canyon, between Russell Drive and Redbud Drive, grew and became well established. Fire ran south up out of the canyon and burned over Skyway. Significant ember showers and fire activity on both sides of Skyway impacted evacuating vehicles.

By noon, intense fire was burning on the ridge and in the canyons near Jordan Hill Road. Flame lengths of $30 \mathrm{~m}$ to $45 \mathrm{~m}$ (100 ft to $150 \mathrm{ft})$ were observed. Engines looking for civilians had to drive through fire to escape back to Concow Road. At the same time, the northern flank of the fire was hung up between Coutolenc Road and Pentz Road. In Paradise, the main fire was pushing south down Berkshire Avenue, spreading to structures. Fire spread from 
structure to structure through Skyway Villa Mobile Home Park. The main fire activity along Pentz Road had passed; structures were burned down, vegetation had burned through, and Pentz Road was passable. Fire was well-established on the west side of northern Pentz Road, burning heavy brush, trees, and structures. Structures began igniting on Sweetbriar Lane, and the fire spread west from structure to structure. Before noon, fire was approaching the Walgreens store and the intersection of Bille Road and Skyway from multiple directions. Structures were burning south and east of Skyway in the area of Almond Street and Fir Street. At the same time, fire activity at the Skyway split was still active on both sides of the roadway, but Skyway was passable. Fire was encroaching on Neal Road and Roe Road from the north, as a large area of fire burned over Skyway.

November 8, 12:00 to 17:00

Between noon and 15:00 in Concow, the southern extent of the fire continued to burn in the Concow Creek canyon northwest of Nelson Bar Road and north of Comfort Lane on both sides of Concow Road. In Paradise, the fire was well established through most of the town and began impacting the downtown area. By 13:00, 10 to 15 structures were burning at the south end of Andover Drive and on Adrian Drive. On the northern end of Paradise, fire was coming toward the Clark Road and Skyway intersection from the canyon to the west. Structures on the east side of Skyway were burning intensely, and fire was coming from the north through residential structures, threatening commercial structures where trapped civilians were taking temporary refuge. Many homes were on fire near Clark Road and Cabernet Lane. To the southwest, fire in Honey Run Canyon was moving down the canyon toward Centerville Road with a moderate rate of spread. On the ridgetops, flames were shooting out of the canyon with $30 \mathrm{~m}$ to $60 \mathrm{~m}$ (100 ft to $200 \mathrm{ft}$ ) flame lengths. In the canyon, flames were $2 \mathrm{~m}$ to $3 \mathrm{~m}$ ( $6 \mathrm{ft}$ to $10 \mathrm{ft}$ ) long. Ember showers and flames were threatening multiple structures.

Between 14:00 and 17:00, fire was embedded in the structures in the area on the southern end of South Park Drive and Adrian Drive. Fire was burning in Little Butte Creek Canyon, wrapping around to the west, and burning in ravines uphill into the prevailing wind, toward West Park Drive.

By 15:00, heavy fire was burning everything on the west side of Skyway between Black Olive Drive and Jewell Road, including a burning woodpile that was threatening Town Hall. Torching shrubs and junipers were threatening additional nearby structures. Skyway between Pearson Road and Neal Road was being encroached upon from both east and west; fire was spreading uphill and upwind in Honey Run Canyon into structures on the west side of Skyway, and the main fire front was pushing west from Pearson Road. Structures were burning along Pearson Road, Almond Street, and Black Olive Drive, approaching Skyway.

Between 15:00 and 17:00 the fire approached Nelson Bar Road. To the north, the fire remained burning to the south of Magalia. In downtown Paradise, fire was well-established in multiple commercial structures at Skyway on Fir Street, and fire continued to burn structures in the area of Fire Station 81. 
November 8, 17:00 to $24: 00$

Around sunset (16:56) in Concow, an intense fire front with $15 \mathrm{~m}$ to $30 \mathrm{~m}$ (50 ft to $100 \mathrm{ft}$ ) flames burned through the forest into the grasslands, impacting structures along the west side of Nelson Bar Road. Numerous short-range spot fires were observed ahead of the fire front. At the same time in Magalia, fire was backing up out of the canyon, impinging on structures on Andover Drive with creeping fire behind homes. In Paradise, structures continued to burn. Large trees and power poles continued burning and threatened or blocked roadways. Also, around sunset, fire activity at Neal Road and Wayland Road increased, pushing into the area from the northeast. The fire then ran down into the foothills toward Highway 99.

Between 18:00 and midnight, the evening was a period of generally reduced fire behavior in the upper part of Little Butte Creek Canyon near Magalia. Different portions of Andover Drive were threatened throughout the evening period. By 22:00, fire had moved up out of Stilson Canyon and was coming up over Humboldt Road approaching Highway 32. Fire had also burned through the Cory Creek area, destroying multiple structures. Residual fire continued to threaten communities along Durham-Pentz Road.

November 9, 00:00 to 08:00

Between midnight and 02:00 on November 9, the fire flared up out of the West Branch Feather River Canyon with $30 \mathrm{~m}$ (100 ft) flames pushed by strong winds, estimated at $22 \mathrm{~m} / \mathrm{s}$ (50 mi/h). Softball-sized embers blew across Coutolenc Road and Skyway into Magalia and Old Magalia. Several spot fires were established on the west side of Magalia Reservoir, and fire was spreading uphill toward Lakeridge Circle. Intense fire blocked Skyway south of the dam.

Between 02:00 and sunrise, at 06:44, the fire became well established in Magalia and consumed hundreds of structures. During the night in Concow fire was between Nelson Bar Road and Highway 70. Fire intensity was low to moderate, making local runs and overtaking dozer lines towards Lake Oroville.

The fire activity intensified dramatically at several locations at sunrise. In Concow, fire was burning across Pinkston Canyon Road towards Concow Road. Firefighters were worried about getting hemmed in by fire on both sides on Concow Road. Butte County Fire Station 37 on Concow Road was hit hard by the fire. At the same time in Magalia, a rapid increase in fire activity on the west end of Ponderosa Way impacted the south and west. Firefighters had to drive through fire to reach the safety zone of the parking lot at Pine Ridge School, where fire also approached from the east.

\subsubsection{Fire Spread Rates}

The data presented in Section 9.1 describes the Camp Fire spread in the first 24 hours from its origin until it reached Highway 99 to the southwest, Route 32 to the west, Magalia to the north, and Highway 70 to the south and east.

In reviewing the topography and fuels, the fire can be divided into three distinct sections. From the origin near Pulga to the eastern edge of Paradise along the Feather River Canyon, 
the fire burned in primary wildland fuels with the exception of Concow, where the community was low to moderate density intermix. In Paradise and Magalia, both high density intermix communities (see Section 4), the fire burned and consumed almost 20000 buildings along with wildland and ornamental vegetation. In the Foothills, the fire moved through clusters of residential areas spread out among mostly wildland vegetation that was predominantly grass. In Butte Creek Canyon to the west, the fire moved through a combination of low-density structures and a mixture of wildland fuels including some locally dense forested area. In Concow between Concow Reservoir and Highway 70, wildland vegetation represented the primary fuel. Fuels consisted of forested lands with some grasslands, primarily in the vicinity of the southern end of Nelson Bar Road.

The overall fire spread rate from Pulga to Highway 99 was estimated at approximately $0.55 \mathrm{~m} / \mathrm{s}(30 \mathrm{~km} / 15 \mathrm{~h})$, or a little over $1 \mathrm{mi} / \mathrm{h}(80 \mathrm{ch} / \mathrm{h})$. However, given the wide variety of fuels and the extensive spotting documented in the previous sections, an overall fire spread might not capture the varying fire behavior in the first 12 to 24 hours of fire spread after ignition.

Breaking down the fire spread rate into three distinct geographic areas may provide additional insight into fire behavior. Within one hour from the first ignition, there were reports of structures burning in Concow. The time interval between the second ignition on Rim Road and the first structures burning was $40 \mathrm{~min}$. Using the location of structures burning near Pine Cluster Lane, fire spread from the origin was estimated at $1.1 \mathrm{~m} / \mathrm{s}$ $(2.5 \mathrm{mi} / \mathrm{h}$, or $200 \mathrm{ch} / \mathrm{h})$. Within $15 \mathrm{~min}$ from the time of the first reported structure ignitions in Concow, by 07:50, the fire had spotted to the west side of Sawmill Peak and the east side of Paradise, extending from the orchard on Apple View Way all the way to Lowry Lane, just south of Feather River Hospital. This spotting was approximately $7 \mathrm{~km}(4.5 \mathrm{mi})$ ahead of the fire activity in Concow, yielding an effective fire spread rate of $7.8 \mathrm{~m} / \mathrm{s}(18 \mathrm{mi} / \mathrm{h})$. The spots on the west of Paradise became well established, and by 08:30 the community experienced the arrival of the main fire front. However, it was also possible that the front that hit Paradise at 08:30 might have arrived from Concow traveling $7 \mathrm{~km}(4.5 \mathrm{mi})$ in 1 hour. This four-fold range in the rate of spread illustrates the difficulty of generating representative values for fire spread, particularly when a fire generates extensive intermediate and long-range ember transport to highly ignition-receptive fuels. Shortly after 08:30, the flank of the main fire front stalled near Ishi Road in Concow into the early afternoon, highlighting the large range in fire behavior over small geographic scales on the order of $5 \mathrm{~m}$ to hundreds of meters ( $15 \mathrm{ft}$ to hundreds of $\mathrm{ft}$ ). This range of fire behaviors over short geographic scales has also been observed in the previous NIST WUI fire case studies, as fuels, topography, and wind can vary widely at those scales.

In general terms, the fire in Paradise progressed from east to west or southwest. However, as in the wildlands, the extensive spotting in town resulted in areas or clusters of high intensity burning adjacent to other areas that backfilled at a much later time. In WUI areas like Paradise, fire spread estimates can be made by looking at spots or high intensity fire activity. However, given the spotty nature of the fire progression and the highly variable residence times at different locations, these estimates will have very large uncertainties and will not easily capture the local conditions. After the main fire activity moved through Paradise, in 
the open areas of the Foothills, fire spread in grass was estimated at $1 \mathrm{~m} / \mathrm{s}(2.2 \mathrm{mi} / \mathrm{h}$, $180 \mathrm{ch} / \mathrm{h}$ ) with significant variations based on local conditions.

The location and density of spot fires ahead of the main front can have many different outcomes depending on local conditions. Spot fires can grow and generate new fronts ahead of the main front or result in other local disturbances that significantly impact the development of the incident. The spot fire in Honey Run Canyon at 08:45 further illustrates that fire spread rates may not be a valid metric for documenting overall fire behavior. The spot grew rapidly and spread upwind, not with the prevailing wind, because of local conditions. This spot ended up impacting community evacuation.

In summary, fire behavior in varying fuels with complex topography and varying local winds, coupled with extensive intermediate and long-range spotting, results in fire spread rates that can vary locally by almost an order of magnitude. The documentation of this variability is driven by the density of the available data, which almost always lacks quantifiable wind velocity data. This variability is further complicated by the introduction of defensive actions, which impact fire spread; this will be further discussed in NIST Camp Fire Report \#5. Together, these complexities and defensive actions point to the challenges of trying to reliably predict or even simulate post-incident, incident-scale fire behavior in the WUI.

\subsection{Burnovers}

F15. Multiple burnovers occurred during the Camp Fire.

F16. Burnovers adversely affected pre-planned evacuation routes and led to use of Temporary Refuge Areas.

F17. Intense vegetation and structure fires occurred along roadways and resulted in multiple road closures which adversely impacted response and evacuation activities.

F18. Fire resulted in downed utility poles along roadways and throughout the communities. The downed poles, along with the associated electrical and utility lines, blocked multiple streets and impaired access for response and evacuation.

The presence of primarily wildland vegetation along egress arteries as well as some secondary roadways, likely amplified by local topography and wind, caused burnovers in different locations during the incident.

Many of the burnovers significantly impacted evacuation and required the formation of Temporary Refuge Areas (TRAs). TRAs were necessary to maintain life safety for residents and firefighters. Burnovers resulted in injuries and fatalities. In at least two cases, fire shelters were deployed by first responders to reduce radiative exposures to civilians and first responders. The relationships between burnovers, evacuation of residents, and TRAs will be documented and analyzed in NIST Camp Fire Report \#4. 
There is limited technical information to provide reliable guidance on the relationship among vegetative fuel type, density, and setback from the roadway, along with topography and exposures, that can be used to develop reliable guidance for the protection of egress arteries against burnovers. This is an important area of study as the frequency of fast-moving fires requiring large-scale last-minute evacuations increases.

\subsection{Wildland Fire Ignition Relative to the Community}

F19. The ignition of the fire in wildland fuels over $11 \mathrm{~km} \mathrm{(7} \mathrm{mi)} \mathrm{from} \mathrm{Paradise} \mathrm{allowed}$ the fire to grow in intensity and size before reaching the affected communities.

Fire suppression capacity can be rapidly exceeded by large fire front lengths and/or extensive spotting throughout the community. The intense and long fire front and numerous spot fires that reached Paradise also impacted large-scale evacuations. This points to the threat posed by a potentially dangerous region located upwind and some distance away from the communities. Ignitions in the dangerous region that cannot be rapidly suppressed (due to terrain and or wind) may quickly cause dangerous conditions for communities many kilometers (miles) downwind. Far-away ignitions can develop into large fire fronts that can threaten entire communities. In adverse conditions, such as dry conditions and/or locations with high vegetative fuel loads, spot fires developing near or within communities kilometers (miles) ahead of the fire front can impact local conditions and potentially affect evacuation routes.

\subsection{Structure Ignition Pathways}

F20. Post-fire field data collection and first responder observations identified structure ignition vulnerabilities including structure-to-structure ignition pathways.

F21. Fire spread through Paradise, and subsequently Magalia, was fueled by vegetative fuels, including ornamental shrubs, bushes, and trees; structural fuels, including homes, garages, detached auxiliary buildings, commercial occupancies; and cars, trucks, and campers.

F22. Separation distances between fuel packages within a parcel as well as between parcels did not prevent rapid fire spread.

Documenting structure ignition vulnerabilities and structure ignition pathways is critical to developing technical guidance for improving building codes, standards, and best practices to reduce future losses. During the data analysis, several structure ignitions were identified to have been directly observed by first responders, providing firsthand information about structure ignition pathways. Their observations indicated that fuels on residential parcels can act as wicks to bring fire to the residential structures. Additionally, post-fire field data collection by NIST, together with CAL FIRE, USFS, and FEMA, captured structure damage and ignition vulnerabilities from 132 damaged structures within the Camp Fire perimeter. Parcel-level exposures that resulted in structure damage and structure damage data of these documented structures will be analyzed in NIST Camp Fire Report \#5. 
Home exposures may be divided into inter- and intra-parcel categories, defined as coming from objects outside and inside the parcel respectively. In this way, exposures that may be controlled by the individual homeowner are separated from those that require decisionmaking on a community level. Additionally, there is a need to quantify inter- and intra-parcel exposures specifically from neighboring structures and to develop design guidance in the form of minimum structure separation distances necessary to prevent fire spread from structure to structure. Reduction of structural losses from direct fire exposures (radiation and convection) can be achieved by increasing the spacing between the source term (e.g., shed) and the target (residential structure), hardening the structure to provide additional ignition resistance, or a combination of both approaches. Quantifying inter- and intra-parcel fire exposure information would serve as the technical framework for the development of spacing/hardening cost-benefit tools for high energy release sources (i.e., fences, wood piles, sheds, vehicles, RVs, and residences) and the target (residential and commercial) structures.

\subsection{Community Attribute Impacts}

F23. A standardized community wildland-urban interface hazard evaluation framework would improve assessment of fire risk for communities.

The documentation and quantification of the effects of Camp Fire on Paradise, Magalia, and Concow highlight the issue that WUI fire spread has significant impact on communities well beyond the loss of structures, including community evacuation and incident response. The data begins to demonstrate the relationship between community preparedness and how a WUI fire event unfolds. Pre-fire planning and hazard mitigation impact how the fire develops, how the life safety of residents and first responders is impacted during evacuations, and the extent of structural and infrastructure losses.

The rapid spread of the Camp Fire through Concow, Paradise, and Magalia suggests that WUI community preparedness may benefit from a holistic approach to hazard assessment. The successful pre-fire planning by Butte County and Paradise suggests that a community's hazard assessment and preparedness for WUI fires can benefit from the inclusion of information on the fire history of the community and surroundings, vegetative and structural fuel loading information, as well as evacuation and response plans. 


\section{Recommendations}

There are nine recommendations made in this report. The recommendations are aimed at improving resident and first responder life safety (R1) and reducing structural losses during WUI fires (R2-R9).

R1. Characterize fire behavior that leads to burnovers and quantify burnover severity. This information will inform fuel setback guidance for primary egress arteries and provide technical input to evacuation plans. (Section 9.3, F15, F16, F17, F18)

R2. Develop technical guidance to quantify parcel level exposures. (Section 11.2, F20, F21, F22)

R3. Quantify fire spread within parcels with focus on fire exposures. (Section 11.2, F20, F21, F22)

R4. Quantify exposures from adjacent parcels, specifically from neighboring structures, and develop design guidance for structure separation distances. (Section 11.2, F20, $F 21, F 22)$

R5. Develop methodology to connect field-collected ember data, such as ember flux and size distribution, to laboratory scales and develop worst case ember exposure criteria. (Section 14.2, F7, F10, F11)

R6. Develop spacing/hardening cost benefit relationships for high energy release sources (fences, wood piles, sheds, vehicles, RVs, and residences) and target structures (residential and commercial). (Section 14.2, F20, F21, F22)

R7. Characterize the relationships among fire history, fuel treatments, and fire behavior. (Section 13.2, Section 14.1, F5, F6, F7, F8, F9, F10, F11, F12, F13, F17, F19, F21, F22)

R8. Develop a standardized methodology for assessing the exposures from ornamental vegetation. (Section 11.2, F20, F21, F22)

R9. Develop a plant list for vegetation with unacceptably high fire hazard for northern California and other locations with WUI fire risks. (Section 11.2, F20, F21, F22) 


\section{NIST Camp Fire Case Study Reports}

The set of reports on the NIST Camp Fire Case Study, including two follow-on reports and a web-based data visualization tool, are outlined below:

Camp Fire Report \#1: Camp Fire Preliminary Reconnaissance [22]

NIST Camp Fire Report \#1 focused on the initial reconnaissance deployment and field data collection and includes:

- $\quad$ NIST Disaster and Failure Studies Preliminary Reconnaissance Decision Criteria worksheet

- Preliminary Reconnaissance objectives

- Field deployment timeline

- Initial data collection summary

- Initial findings

Camp Fire Report \#2: Preliminary Data Collected from the Camp Fire Reconnaissance [24]

NIST Camp Fire Report \#2 focused on data collected from the Preliminary Reconnaissance and includes:

- NIST Damage Assessments of 132 damaged residential structures

- Photographs of structure damage

- Automatic vehicle location (AVL) data

- Radio transcripts

- Incident-related maps

Camp Fire Report \#3: Fire Progression Timeline (this report)

NIST Camp Fire Report \#3, this report, focuses on the methodology and the fire progression details, and includes:

- Introduction to the Camp Fire and affected WUI communities

- Pre-fire hazard and preparation

- Data collection and analysis methodology details

- Fire progression details and timeline

- First responder comments

- Technical findings summary

- Recommendations 
Camp Fire Report \#4: Notification, Evacuation, and Temporary Refuge Areas, and Burnovers

NIST Camp Fire Report \#4 will focus on notification, evacuation, and TRAs.

Specifically, the report will include:

- Notification timeline and tie-ins with fire progression (Report \#3)

- Evacuation timeline and traffic (by artery)

- Summary of each burnover and connection to TRA

- Summary of each TRA

- Summary of known rescues

- First responder comments

- Technical findings summary

- Recommendations

\section{Camp Fire Report \#5: Emergency Response and Defensive Actions}

NIST Camp Fire Report \#5 will focus on Fire and Law Enforcement response and infrastructure response, including water systems. The report will include:

- An overview of Fire and LE resources on the scene

- Infrastructure response

- Defensive actions: ground operations

- Defensive actions: aerial operations

- Defended structures

- Exposures to NIST-documented damaged structures

- First responder comments

- Technical findings summary

- Recommendations

\section{Camp Fire Case Study Data Visualization Tool}

A web-based tool will be provided that will enable users to navigate the Camp Fire in both space and time. All the data presented in NIST Camp Fire Reports \#3, \#4 and \#5 will be included in the tool. 


\section{Acknowledgments}

This case study would not have been possible without the collaboration and support of CAL FIRE and the first responders that participated in the incident, including the Paradise Fire and Police Departments. Specifically, the authors would like to acknowledge the support of the California State Fire Marshall, Dennis Mathisen (since retired). Chief Mathisen and the CAL FIRE DINS team enabled the NIST/USFS/FEMA Team to effectively access the scene and collect perishable data from the Camp Fire with the help of CAL FIRE damage assessment data. The authors would like to also acknowledge California State Fire Marshall Michael Richwine for the continuing support of this timeline reconstruction effort.

The authors would like to acknowledge every department/organization that participated in the Technical Discussions:

American Medical ResponseShasta County

B-Line Butte Regional Transit

BTU Station 35-Paradise

BTU Station 62-Harts Mill

BTU Station 63-Oroville

BTU-Butte Fire Center

BTU-Unit Headquarters

Burney Fire District Station 17

Butte County Emergency

Command Center

Butte County Fire Safe Council

Butte County Fire Station 33Upper Ridge

Butte County Fire Station 42-North Chico

Butte County Fire Station 44-South Chico

Butte County Fire Station 55Bangor

Butte County Fire Station 73-Biggs

Butte County Fire Station 74Gridley

Butte County Sheriff's Office

CAL FIRE-Law Enforcement Division

California Highway Patrol-Chico

Chico Fire DepartmentHeadquarters
Del Oro Water Company

Grass Valley Emergency Command Center

Grass Valley Fire Department Station 2

Linda Fire Protection District

LNU-Brooks Forest Fire Station

LNU-Konocti Conservation Camp

Meridian Fire Protection

National Weather Service

NEU Station 61-Loma Rica

NEU-Dobbins Forest Fire Station

NEU-Nevada City Forest Fire Station

Nevada County Consolidated Fire

District

Northern California Geographic Area Coordination Center

Olivehurst Fire Department

Paradise Fire Station 81-Paradise

Fire Department

Paradise Irrigation District

Paradise Police Department

Shasta County Fire Station 33-

Bella Vista

Shasta Lake Fire Protection District

SHU Station 14-Burney

SHU Station 22-Shingletown

SHU Station 58-Shasta
SHU Station 75-Hillcrest

South Lake County Fire Protection District Station 63-Hidden Valley

Sutter County Fire Department Station 6-Sutter

TGU Station 12-Corning

TGU Station 1-Red Bluff

TGU-Elk Creek Station

TGU-Paskenta Station

Town of Paradise

Town of Paradise-Department of Public Works

USFS CA-ENF-Pacific Ranger District, Pollock Pines

USFS CA-MNF-Stonyford Work Center

USFS CA-PNF-Beckwourth Ranger District, Blairsden

USFS CA-PNF-Challenge Visitor Center, Challenge

USFS CA-PNF-Feather River Ranger District, Oroville

USFS CA-TNF-Truckee Ranger District, Truckee

USFS CA-TNF-Yuba River Ranger District, Camptonville

Wheatland Fire Authority 
The authors would also like to specifically acknowledge Paradise Irrigation District and the Del Oro Water Companies for providing important information for the timeline reconstruction.

Additionally, the field data collection would not have been possible without the participation of Engineering Laboratory and Fire Research Division staff, including Ms. Nicole Cooper, Dr. Ryan Falkenstein-Smith, Ms. Lucy Fox, Mr. Cartier Murrill, and Ms. Rebecca Turnbull. Additional data collection support from Ms. Nicole LaRosa of FEMA is also appreciated.

Special thanks to Aviva Braun of NWS for presentation materials presented in Appendix D.

The authors would like to acknowledge CAL FIRE Butte Unit Chief and Butte County Fire Department Fire Chief John Messina, Ms. Karen Ridenour of Texas Forest Service (Retired), Ms. Colette Curtis, Paradise Town Council and the town management, Paradise Police Department, Dr. Kathryn Butler of NIST, NIST WUI Group Leader Jiann Yang, NIST Fire Research Division Chief Nelson Bryner, NIST Engineering Laboratory Director Dr. Howard Harary, NIST Associate Division Chief of Materials and Structure Systems Dr. Judith Mitrani-Reiser, and the NIST Office of the Chief Counsel for providing input to the report and participating in the review process. 


\section{References}

[1] National Fire Protection Association (2019) Largest fire losses in the United States. (Updated September 2019) Available at https://www.nfpa.org/News-and-

Research/Data-research-and-tools/US-Fire-Problem/Large-loss-fires-in-the-UnitedStates/Largest-fire-losses-in-the-United-States. Accessed: August 2020.

[2] CAL FIRE (2019) Top 20 Most Destructive California Wildfires. (Updated August 8, 2019) Available at https://www.fire.ca.gov/media/5511/top20 destruction.pdf. Accessed: August 2019.

[3] Martinuzzi S., et al. (2015) The 2010 wildland-urban interface of the conterminous United States (NRS-RMAP-8). U.S. Department of Agriculture, Forest Service, Newtown Square, PA. https://doi.org/10.2737/NRS-RMAP-8

[4] Wallingford N. (2018) Camp Incident Damage Inspection Report. CAL FIRE, Sacramento, CA.

[5] Butte County District Attorney (2020) The Camp Fire Public Report: A Summary of the Camp Fire Investigation. Butte County District Attorney, Oroville, CA. https://www.buttecounty.net/Portals/30/CFReport/PGE-THE-CAMP-FIRE-PUBLICREPORT.pdf?ver=2020-06-15-190515-977. Accessed: October 2020.

[6] Butte County Sheriff (2019) Camp Fire Update [Press release, September 25, 2019]. Retrieved from http://www.buttecounty.net/sheriffcoroner/NewsCenter/ArtMID/4964/ArticleID/1370/Camp-Fire-Update. Accessed: August 2020.

[7] CAL FIRE (2019) Top 20 Deadliest California Wildfires. (Updated August 8, 2019) Available at https://www.fire.ca.gov/media/5512/top20_deadliest.pdf. Accessed: August 2019.

[8] Maranghides A., Mell W. (2013) Framework for Addressing the National Wildland Urban Interface Fire Problem - Determining Fire and Ember Exposure Zones using a WUI Hazard Scale. NIST Technical Note 1748. National Institute of Standards and Technology, Gaithersburg, MD. https://doi.org/10.6028/NIST.TN.1748

[9] Maranghides A. , Mell W. (2009) A Case Study of a Community Affected by the Witch and Guejito Fires. NIST Technical Note 1635. National Institute of Standards and Technology, Gaithersburg, MD. https://doi.org/10.6028/NIST.TN.1635

[10] Maranghides A., et al. (2013) A Case Study of a Community Affected by the Witch and Guejito Fires Report: \#2 - Evaluating the Effects of Hazard Mitigation Actions on Structure Ignitions. NIST Technical Note 1796. National Institute of Standards and Technology, Gaithersburg, MD. https://doi.org/10.6028/NIST.TN.1796

[11] Maranghides A., et al. (2011) Initial Reconnaissance of the 2011 Wildland-Urban Interface Fires in Amarillo, Texas. NIST Technical Note 1708. National Institute of Standards and Technology, Gaithersburg, MD. https://doi.org/10.6028/NIST.TN.1708

[12] Maranghides A. , McNamara D. (2016) 2011 Wildland Urban Interface Amarillo Fires Report \#2 - Assessment of Fire Behavior and WUI Measurement Science. NIST 
Technical Note 1909. National Institute of Standards and Technology, Gaithersburg, MD. https://doi.org/10.6028/NIST.TN.1909

[13] Maranghides A., et al. (2015) A Case Study of a Community Affected by the Waldo Fire - Event Timeline and Defensive Actions. NIST Technical Note 1910. National Institute of Standards and Technology, Gaithersburg, MD. https://doi.org/10.6028/NIST.TN.1910

[14] National Institute of Standards and Technology (2020) Fire Dynamics Simulator (FDS) and Smokeview (SMV). Available at https://pages.nist.gov/fds-smv/. Accessed: August 2020.

[15] CAL FIRE (2018) Camp Fire Incident Update (November 17, 2018 7:00 a.m.). Available at https://www.twitter.com/CALFIRE ButteCo/status/1063809226458357761. Accessed: August 2020.

[16] Butte County Grand Jury (2019) 2018-2019 Butte County Grand Jury Report. Oroville, CA. https://www.buttecourt.ca.gov/GrandJury/reports/20182019\%20Grand\%20Jury\%20Report.pdf. Accessed: August 2020.

[17] CAL FIRE (2018) Informational Summary Report of Serious or Near Serious CAL FIRE Injuries, Illnesses and Accidents (Green Sheet). https://www.firefighterclosecalls.com/wp-content/uploads/2018/12/18-CA-BTU016737-Camp-Green-Sheet.pdf. Accessed: August 2020.

[18] Butte County Sheriff (2018) Camp Fire Update [Press release, December 19, 2018]. Retrieved from http://www.buttecounty.net/Portals/24/pdf/Press\%20Releases\%20sent\%20during\%20 the\%20Camp\%20Fire\%202.pdf?ver=2019-01-03-073238-227. Accessed: August 2020.

[19] Ellingson A. (2018) Camp, Woolsey wildfires property losses could reach $\$ 19$ billion. LA Biz (American City Business Journals). Available at https://www.bizjournals.com/losangeles/news/2018/11/27/calif-wildfires-propertylosses-could-reach-19b.html. Accessed: October 2019.

[20] Elias P. (2018) Correction: California Wildfires-Cleanup story. Associated Press, December 12, 2018. Available at https://www.apnews.com/a51b655eff3848a9b90783e05a33d400. Accessed: October 2019.

[21] Löw P. (2019) The natural disasters of 2018 in figures. Munich Re. Available at https://www.munichre.com/topics-online/en/climate-change-and-naturaldisasters/natural-disasters/the-natural-disasters-of-2018-in-figures.html Accessed: August 2020.

[22] Maranghides A., et al. (2020) Camp Fire Preliminary Reconnaissance. NIST Technical Note 2105. National Institute of Standards and Technology, Gaithersburg, MD. https://doi.org/10.6028/NIST.TN.2105 
[23] Federal Emergency Management Agency (2016) Damage Assessment Operations Manual. https://www.fema.gov/media-library-data/1459972926996a31eb90a2741e86699ef34ce2069663a/PDAManualFinal6.pdf. Accessed: October 2019.

[24] Maranghides A., et al. (2020) Preliminary Data Collected from the Camp Fire Reconnaissance. NIST Technical Note 2128. National Institute of Standards and Technology, Gaithersburg, MD. https://doi.org/10.6028/NIST.TN.2128

[25] National Wildfire Coordinating Group (n.d.) Burnover. Available at https://www.nwcg.gov/term/glossary/burnover. Accessed: August 2020.

[26] National Wildfire Coordinating Group (n.d.) Entrapment. Available at https://www.nwcg.gov/term/glossary/entrapment. Accessed: August 2020.

[27] Page W.G., Freeborn P.H. (2019) Entrapment. In: Manzello S (eds) Encyclopedia of Wildfires and Wildland-Urban Interface (WUI) Fires. Springer, Cham. https://doi.org/10.1007/978-3-319-51727-8_183-1

[28] U.S. Census Bureau (2019) 2014-2018 ACS 5-Year Data Profile (place search: Paradise town, Magalia CDP, Concow CDP, California). Available at https://www.census.gov/acs/www/data/data-tables-and-tools/data-profiles/2018/. Accessed: January 2021.

[29] US Department of Agriculture, US Department of Interior (2001) Urban Wildland Interface Communities Within the Vicinity of Federal Lands That Are at High Risk From Wildfire. Federal Register 66(3):751-777. https://www.federalregister.gov/d/01-52

[30] CAL FIRE (2018) Camp Fire Structure Status. Available at https://calfireforestry.maps.arcgis.com/apps/webappviewer/index.html?id=5306cc8cf38c4252830a 38d467d33728. Accessed: August 2020.

[31] Stewart S.I., et al. (2007) Defining the Wildland-Urban Interface. Journal of Forestry 105(4):201-207. https://doi.org/10.1093/jof/105.4.201/

[32] CAL FIRE (2007) Fire Hazard Severity Zones in SRA; Butte County map. (Updated November 5, 2007) Available at https://osfm.fire.ca.gov/media/6652/fhszs map4.pdf. Accessed: November 2020.

[33] CAL FIRE (2008) Very High Fire Hazard Severity Zones in LRA; Butte County map. (Updated May 28, 2008) Available at https://osfm.fire.ca.gov/media/6650/fhszl_map4.pdf. Accessed: November 2020.

[34] US Forest Service (2018) National Fuel Moisture Database. Available at https://www.wfas.net/index.php/national-fuel-moisture-database-moisture-drought103. Accessed: August 2020.

[35] Braun A. (2019) Antecedent Conditions and Support Services on the Camp Fire: An Incident Meterologist's Perspective. (Powerpoint Presentation, selected slides, see Appendix D). 
[36] U.S. Forest Service (2018) U.S. National Fire Danger Rating Map. (Updated November 8, 2018) Available at https://www.wfas.net/index.php/fire-danger-ratingfire-potential--danger-32. Accessed: August 2019.

[37] MesoWest (n.d.) Weather observations for Jarbo Gap RAWS (JBGC1). Available at https://mesowest.utah.edu/cgi-bin/droman/meso base dyn.cgi?stn=JBGC1.

Accessed: August 2020.

[38] National Drought Mitigation Center (n.d.) U.S. Drought Monitor, Archive. Available at https://droughtmonitor.unl.edu/Maps/MapArchive.aspx. Accessed: August 2020.

[39] Western Regional Climate Center (2018) Percent of Average Precipitation, California. (Updated November 2018) Available at https://wrcc.dri.edu/. Accessed: November 2018.

[40] NWS Sacramento (2018) Wind Gust Forecast graphic. (Updated November 7, 2018) Available at https://www.twitter.com/NWSSacramento/status/1060221126536761347. Accessed: August 2020.

[41] NWS Sacramento (2018) Red Flag Warning graphic. (Updated November 7, 2018) Available at https://www.twitter.com/NWSSacramento/status/1060295966891405312. Accessed: August 2020.

[42] MesoWest (n.d.) Weather observations for Openshaw RAWS (CICC1). Available at https://mesowest.utah.edu/cgi-bin/droman/meso base dyn.cgi?stn=CICC1.

Accessed: August 2020.

[43] CAL FIRE (n.d.) Fire Perimeter Database (GDB file). Available at https://frap.fire.ca.gov/frap-projects/fire-perimeters/. Accessed: October 2020.

[44] Butte County (2015) Butte County Community Wildfire Protection Plan (20152020).

https://www.buttecounty.net/Portals/14/Evac\%20Maps/2015_Countywide_CWPP_FI NAL.pdf. Accessed: August 2020.

[45] Town of Paradise, California (2016) Ordinance No 565. "Felling, removal, destruction, damaging and replacement of trees." Adopted December 13, 2016. Available at https://www.townofparadise.com/index.php/ourgovernment/departments/animal-control/documents/1576-ord-565-an-ordinanceamending-paradise-municipal-code-sections-8-12-020-8-12-040-8-12-050-8-12-0908-12-120-8-12-150-and-8-12-160-relating-to-felling-removal/file. Accessed: August 2020.

[46] Butte County (n.d.) Fire Prevention Bureau. Available at https://www.buttecounty.net/fire/FireFacilities/Prevention/Fire-Prevention-Bureau. Accessed: August 2020.

[47] Butte County Fire Safe Council (n.d.) Available at https://www.buttefiresafe.net/. Accessed: August 2020. 
[48] Butte County Fire Safe Council (2019) Chipper Program. (Updated December 2019) Available at https://www.buttefiresafe.net/chipper-program/. Accessed: August 2020.

[49] Paradise Irrigation District (n.d.) Available at https://www.pidwater.com/. Accessed: August 2020.

[50] Del Oro Water Company (n.d.) Available at http://www.delorowater.com/. Accessed: August 2020.

[51] NASA Earth Observatory (2018) Camp Fire Rages in California. "Landsat 8 image of Camp Fire at 10:45am local time." Available at https://earthobservatory.nasa.gov/images/144225/camp-fire-rages-in-california. Accessed: August 2020.

[52] Taylor B.N. , Kuyatt C.E. (1994) Guidelines for Evaluating and Expressing the Uncertainty of NIST Measurement Results. NIST Technical Note 1297. National Institute of Standards and Technology, Gaithersburg, MD. https://doi.org/10.6028/NIST.TN.1297

[53] National Interagency Fire Center (n.d.) Wildland Fire Open Data; Historic Fire Perimeters. "Camp Fire perimeter 17:54 Nov 18 shapefile." Available at https://datanifc.opendata.arcgis.com/. Accessed: August 2020.

[54] Caton S.E., et al. (2016) Review of Pathways for Building Fire Spread in the Wildland Urban Interface Part I: Exposure Conditions. Fire Technology 53(2):429473. https://doi.org/10.1007/s10694-016-0589-z

[55] National Wildfire Coordinating Group (n.d.) Size Class of Fire. Available at https://www.nwcg.gov/term/glossary/size-class-of-fire. Accessed: August 2020.

[56] Calkin D.E., et al. (2005) Forest Service Large Fire Area Burned and Suppressions Expenditure Trends, 1970-2002 Journal of Forestry 103(4):179-183. https://doi.org/doi.org/10.1093/jof/103.4.179

[57] Johnsson E., Butler K., et al. (2021) Wind-driven Fire Spread to a Structure from Fences and Mulch. NIST Technical Note In Progress. National Institute of Standards and Technology, Gaithersburg, MD. 


\section{Appendix A. Incident Fire Progression Map, November 22, 2018}

The following map, produced by the Incident Management Team on November 22, 2018, shows the fire progression as determined by various infrared flights. Labels have been enhanced for readability at small scale. The colors represent the fire perimeters on successive days transitioning from purple on November 8 to red on November 21. Three perimeters are shown for November 8 , including an estimated perimeter at 12:00, an IR flight perimeter observed at 18:00, and an estimated perimeter at 22:00. Table 37 below lists the daily and cumulative area burned. Over $70 \%$ of the final area was burned by the end of November 10 , three days after ignition. The slower progression after the first few days was located in the remote and rugged wildlands on the north and east sides of the fire.

Table 37. Fire area progression by date.

\begin{tabular}{|c|c|c|c|c|c|}
\hline \multirow{2}{*}{$\begin{array}{l}\text { Map } \\
\text { Color }\end{array}$} & \multirow[b]{2}{*}{ Date } & $\begin{array}{l}\text { Daily } \\
\text { Area }\end{array}$ & $\begin{array}{c}\text { Cumulative } \\
\text { Area }\end{array}$ & $\begin{array}{l}\text { Daily } \\
\text { Area }\end{array}$ & $\begin{array}{l}\text { Cumulative } \\
\text { Area }\end{array}$ \\
\hline & & \multicolumn{2}{|c|}{ ha } & \multicolumn{2}{|c|}{$\mathrm{ac}$} \\
\hline & 2018-11-08 & 12653 & 12653 & 3126 & 31267 \\
\hline & 2018-11-08 & 9512 & 22165 & 2350 & 54771 \\
\hline & 2018-11-08 & 5767 & 27932 & 14250 & 69021 \\
\hline & 2018-11-09 & 13745 & 41677 & 3396 & 102985 \\
\hline & $2018-11-10$ & 2274 & 43951 & 5619 & 108604 \\
\hline & $2018-11-11$ & 6651 & 50602 & 16436 & 125040 \\
\hline & $2018-11-12$ & 1617 & 52219 & 3996 & 129036 \\
\hline & $2018-11-13$ & 3176 & 55395 & $784 \varepsilon$ & 136884 \\
\hline & 2018-11-14 & 2226 & 57621 & 5500 & 142384 \\
\hline & $2018-11-15$ & 1126 & 58747 & 278 & 145167 \\
\hline & 2018-11-16 & 1287 & 60034 & 3180 & 148347 \\
\hline & 2018-11-17 & 946 & 60980 & 2338 & 150685 \\
\hline & 2018-11-18 & 323 & 61303 & 795 & 151484 \\
\hline & 2018-11-19 & 19 & 61322 & 46 & 151530 \\
\hline & $2018-11-20$ & 731 & 62053 & $180 \mathrm{t}$ & 153336 \\
\hline
\end{tabular}

Fire perimeter data are available from the National Interagency Fire Center (NIFC) Wildland Fire Open Data ArcGIS Online interface, previously known as GeoMAC. ${ }^{19,20}$

\footnotetext{
${ }^{19} \mathrm{https} / / /$ data-nifc.opendata.arcgis.com/

${ }^{20}$ Prior to May 2020 this database was known as GeoMAC.
} 


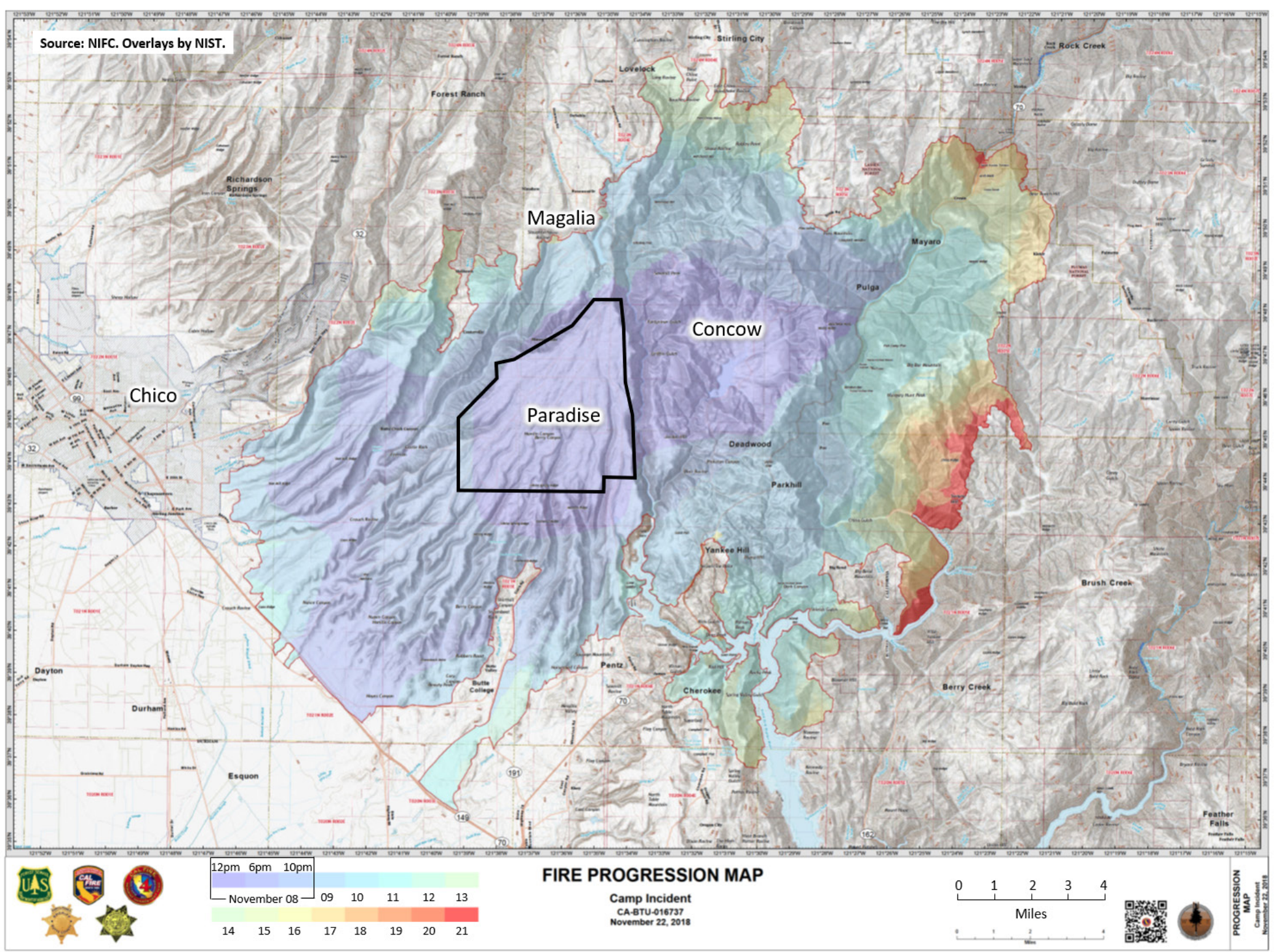




\section{Appendix B. Burnover Data}

Entrapments are defined by the National Wildfire Coordinating Group (NWCG) as:

A situation where personnel are unexpectedly caught in a fire behavior-related, lifethreatening position where planned escape routes or safety zones are absent, inadequate, or compromised. An entrapment may or may not include deployment of a fire shelter for its intended purpose. These situations may or may not result in injury. They include "near misses. ${ }^{21}$

Furthermore, the NWCG defines burnovers as:

An event in which a fire moves through a location or overtakes personnel or equipment where there is no opportunity to utilize escape routes and safety zones, often resulting in personal injury or equipment damage. ${ }^{22}$

Due to the similarities and uncertainties in the distinction between entrapments and burnovers, and with the understanding that details of each event may be incomplete, the identified events are all referred to as burnovers in this report.

This appendix presents further details of the 19 burnover events that were identified during the data collection and analysis that presented such conditions for civilians and/or first responders. Additional burnover events are known to have occurred but did not have enough first-hand data to include, and many more are likely to have occurred which have no documentation. Selected observations from the complete data are presented in the following summaries to provide a brief synopsis of each event based on the collected data.

Observations are largely presented as they were captured and transcribed during the technical discussions. Slight modifications were included for context and clarity, indicated by [italics], as well as incorporation of SI units. Table $\mathbf{3 8}$ lists the burnover events and the technical discussions which contributed data of each event, as well as the page number on which the detailed summary can be found.

The selected observations presented in the following summaries are intended to provide a snapshot of each situation, focusing on fire behavior and progression information of the incidents. Additional information on the impacts to civilian and first responder movements, evacuations, temporary refuge areas, and defensive actions are beyond the scope of the current report.

The start time and duration information is based on the collected observations and may not include the entire time period of dangerous conditions, particularly if the observer moved to a safer location during the incident. Furthermore, durations may include periods of variable exposure conditions as the fire progressed. The start times and durations, as well as the affected areas, are estimated based on the collected data. The affected areas marked on the maps on the following pages indicate a buffer zone approximately $100 \mathrm{~m}(330 \mathrm{ft})$ from the roadway. Hazardous conditions may have existed beyond the marked areas.

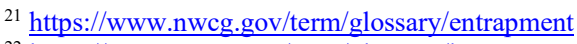

${ }^{22}$ https://www.nwcg.gov/term/glossary/burnover
} 
Table 38. List of TD-identified burnover events and information source summary.

\begin{tabular}{|c|c|c|c|c|c|}
\hline ID & Location & Time & Duration & Source(s) & Page \# \\
\hline 1 & Hoffman Rd & $07: 50$ & $40 \mathrm{~min}$ & $\begin{array}{l}\text { TD-005, TD-007, TD-008, TD-013, TD-027, } \\
\text { TD-062, TD 103, TD-110, TD-137 }\end{array}$ & 168 \\
\hline 2 & Concow Rd & $07: 50$ & $70 \mathrm{~min}$ & $\begin{array}{l}\text { TD-008, TD-013, TD-031, TD-062, TD-103, } \\
\text { TD-110, TD } 115\end{array}$ & 172 \\
\hline 3 & Chapman Ln & $08: 30$ & $\mathrm{n} / \mathrm{d}$ & TD-040, TD-042 & 176 \\
\hline 4 & $\begin{array}{l}\text { Skyway } \\
\text { (upper, between Clark } \\
\text { Rd and Wagstaff Rd) }\end{array}$ & $08: 30$ & $360 \mathrm{~min}$ & $\begin{array}{l}\text { 911-154-1, 911-165-1, 911-167-1, 911-188-1, } \\
\text { 911-191-1, PPD, TD-014, TD-015, TD-022, } \\
\text { TD-041, TD-042, TD-043, TD-055, TD-064, } \\
\text { TD-067, TD-111, TD-127, TD-128, TD-200, } \\
\text { TD-203, TD-205, TD-207, VTD-12 }\end{array}$ & 179 \\
\hline 5 & Windermere Ln & $08: 35^{*}$ & $\mathrm{n} / \mathrm{d}$ & TD-062, TD-110 & 183 \\
\hline 6 & Pentz Rd & $08: 45$ & $150 \mathrm{~min}$ & $\begin{array}{l}\text { 911-221-2, 911-230-5, 911-232-1, PPD, TD-014, } \\
\text { TD-015, TD-020, TD-038, TD-060, TD-063, } \\
\text { TD-069, TD-079, TD-083, TD-084, TD-089, } \\
\text { TD-090, TD-111, VTD-23 }\end{array}$ & 186 \\
\hline 7 & Pearson Rd & $09: 15$ & $60 \mathrm{~min}$ & $\begin{array}{l}\text { PPD, TD-014, TD-037, TD-063, TD-068, TD-070, } \\
\text { TD-071, TD-076, TD-087, TD-100, TD-111, TD- } \\
\text { 122, TD-123, TD-129, VTD-16, VTD-23, VTD-24, } \\
\text { VTD-25 }\end{array}$ & 190 \\
\hline 8 & Bille Rd & $09: 25$ & $140 \mathrm{~min}$ & $\begin{array}{l}\text { PPD, TD-015, TD-021, TD-038, TD-040, TD-060, } \\
\text { TD-069, TD-079, TD-084, TD-089, TD-090, } \\
\text { TD-116, TD-118 }\end{array}$ & 194 \\
\hline 9 & Wagstaff Rd & 09:30 & $60 \mathrm{~min}$ & $\begin{array}{l}\text { 911-129-1, 911-162-1, 911-169-1, 911-178-2, PPD, } \\
\text { TD-009, TD-014, TD-017, TD-022, TD-042, } \\
\text { TD-053, TD-055, TD-064, TD-085, TD-111, } \\
\text { TD-127, VTD-13, VTD-18, VTD-26 }\end{array}$ & 197 \\
\hline 10 & $\begin{array}{l}\text { Clark Rd / } \\
\text { American Way }\end{array}$ & $10: 00$ & $120 \mathrm{~min}$ & $\begin{array}{l}\text { PPD, Radio Log, TD-009, TD-035, TD-041, } \\
\text { TD-049, TD-065, TD-100, TD-110, TD-130, } \\
\text { TD-208, TD-211, VTD-15 }\end{array}$ & 200 \\
\hline 11 & $\begin{array}{l}\text { Clark Rd / } \\
\text { Airport Rd }\end{array}$ & $10: 00$ & $90 \mathrm{~min}$ & $\begin{array}{l}\text { PPD, TD-065, TD-100, TD-101, TD-110, TD-130, } \\
\text { TD-208, TD-210, TD-211 }\end{array}$ & 203 \\
\hline 12 & $\begin{array}{l}\text { Skyway } \\
\text { (lower, west of } \\
\text { Princeton Way) }\end{array}$ & $10: 15$ & $90 \mathrm{~min}$ & $\begin{array}{l}\text { TD-011, TD-025, TD-026, TD-058, TD-070, } \\
\text { TD-155, VTD-13, VTD-14, VTD-22, VTD-26 }\end{array}$ & 206 \\
\hline 13 & $\begin{array}{l}\text { Jordan Hill Rd / } \\
\text { Granite Hill Rd }\end{array}$ & $11: 30$ & $\mathrm{n} / \mathrm{d}$ & TD-008, TD-031, TD-062 & 209 \\
\hline 14 & $\begin{array}{l}\text { Clark Rd / } \\
\text { Black Bear Diner }\end{array}$ & $13: 10$ & $\mathrm{n} / \mathrm{d}$ & PPD, TD-021 & 212 \\
\hline 15 & Rattlesnake Flats Rd & $15: 15$ & $15 \mathrm{~min}$ & TD-208, TD-210 & 215 \\
\hline 16 & Coutolenc Rd & $\begin{array}{c}\text { 00:00 } \\
\text { (Nov 9) }\end{array}$ & $120 \mathrm{~min}$ & $\begin{array}{l}\text { TD-007, TD-040, TD-041, TD-043, TD-045, } \\
\text { TD-061, TD-109, TD-115, TD-122, TD-123, } \\
\text { TD-124, TD-125, TD-126, TD-127, TD-209 }\end{array}$ & 218 \\
\hline 17 & Chestnut Cir & $\begin{array}{c}\text { 06:00 } \\
\text { (Nov 9) }\end{array}$ & $\mathrm{n} / \mathrm{d}$ & TD-127, TD-209 & 221 \\
\hline 18 & Ponderosa Way & $\begin{array}{l}07: 15 \\
\text { (Nov 9) }\end{array}$ & $\mathrm{n} / \mathrm{d}$ & $\begin{array}{l}\text { TD-061, TD-127, TD-128, TD-202, TD-203, TD- } \\
\text { 205, TD-207 }\end{array}$ & 224 \\
\hline 19 & Concow Fire Station 37 & $\begin{array}{l}07: 15 \\
\text { (Nov } 9)\end{array}$ & $\mathrm{n} / \mathrm{d}$ & TD-136, TD-137, TD-138, TD-139, TD-140 & 227 \\
\hline
\end{tabular}




\section{Hoffman Road}

Date/Time: November 8, 07:50-08:30

Location: Hoffman Road, Concow

Coordinates: [39.783963,-121.509288]

Related TRA/ after the Hoffman Rd burnover, civilians went to the Camelot Wildfire Safety Zone: Safety Zone

Summary: $\quad$ Fire activity in the form of a large spot was first reported in the Hoffman $\mathrm{Rd}$ area at 07:35. Within ten minutes conditions deteriorated dramatically, blocking Hoffman Road between the low water crossing and Concow Road, trapping fire fighters and a convoy of civilians trying to evacuate. Evacuees and fire fighters remained at the low water crossing area as the fire burned over the area. Fire shelters were deployed to shield civilians and fire fighters during rescue operations and civilians took refuge in the creek. When local conditions improved the convoy of vehicles migrated towards the intersection of Hoffman Road and Concow Road.

\begin{tabular}{|c|c|c|}
\hline Time & Observation & Source \\
\hline 08:00 & $\begin{array}{l}\text { four civilians running WB on Hoffman Rd at low water crossing, } \\
\text { beard a bit on fire; clothing is burned; civilians advise road ahead } \\
\text { is blocked by fire; civilians jump into creek; visibility } 0 \mathrm{~m} \text { to } 2 \mathrm{~m} \\
(0 \mathrm{ft} \text { to } 7 \mathrm{ft}) \text {, dark }\end{array}$ & TD-013 \\
\hline 08:00 & $\begin{array}{l}\text { park on low water crossing; } 10 \text { to } 15 \text { vehicles of civilians trying } \\
\text { to evacuate are stuck in line behind, [west] up Hoffman Rd }\end{array}$ & TD-013 \\
\hline 08:00 & $\begin{array}{l}\text { small patch of green between Hoffman Rd and lake, fire all } \\
\text { around }\end{array}$ & TD-013 \\
\hline 08:00-08:17 & $\begin{array}{l}\text { vehicles behind [in line to the west] are catching fire; TD- } 027 \\
\text { goes to evacuate people from vehicles using fire shelters as } \\
\text { shields; } 4 \text { trips back and forth to grab people; cannot make it back } \\
\text { to all vehicles; hard to breathe }\end{array}$ & TD-013 \\
\hline 08:00-08:25 & $\begin{array}{l}28 \text { to } 30 \text { civilians in the creek at the rock wall; } 4 \text { to } 5 \text { vehicles are } \\
\text { burning; wind is from the north }\end{array}$ & TD-013 \\
\hline 08:00-08:25 & 3 or 4 homes fully involved; propane tanks exploding & TD-013 \\
\hline $08: 15-08: 29$ & $\begin{array}{l}\text { dozer gains access to clear Hoffman Rd, pushing cars off } \\
\text { roadway }\end{array}$ & TD-008 \\
\hline $08: 15-08: 30$ & $\begin{array}{l}\text { head [toward Hoffman Rd on Concow Rd] with a couple engines } \\
\text { following; most intense fire conditions; flames horizontal over } \\
\text { Hoffman Rd; had to reverse back out of there, engines had } \\
\text { difficulty [turning around on narrow road]; total bottleneck in S- } \\
\text { curve }\end{array}$ & TD-110 \\
\hline
\end{tabular}




\begin{tabular}{|c|c|c|}
\hline Time & Observation & Source \\
\hline $08: 15-08: 30$ & $\begin{array}{l}\text { trees torching down Hoffman Rd, not safe to go down there to get } \\
\text { to TD- } 013\end{array}$ & TD-11C \\
\hline 08:17-08:27 & $\begin{array}{l}\text { plan to get to Camelot Wildfire Safety Zone; stuff all people into } \\
8 \text { vehicles, leave behind the burning vehicles; } 2 \text { civilians in front } \\
\text { seat [of fire pickup truck] plus } 3 \text { in the back seat and TD- } 027 \text { in } \\
\text { the bed camper shell (total of } 7 \text { people in pickup); takes maybe } 40 \\
\text { min to } 60 \text { min from leaving Hoffman Rd to arrive at Camelot } \\
\text { Wildfire Safety Zone }\end{array}$ & TD-013 \\
\hline $08: 23-08: 31$ & $\begin{array}{l}\text { Concow Rd at Hoffman Rd; dozer coming up Hoffman Rd, meet } \\
\text { with TD- } 013 \text { and evacuees; confirm power is dead, and clear } \\
\text { powerlines off Concow Rd with bolt cutters; fire right up against } \\
\text { road; significant } 13 \mathrm{~m} / \mathrm{s} \text { to } 18 \mathrm{~m} / \mathrm{s}(30 \mathrm{mi} / \mathrm{h} \text { to } 40 \mathrm{mi} / \mathrm{h} \text { ) wind }\end{array}$ & TD-062 \\
\hline
\end{tabular}


Topography:

Roadway width:

Vegetation setbacks:

Duration:

Extent of burnover (length of road affected):

Fire direction across road:

Wind intensity:

Fuels:

Fire behavior:

Related TD: low concrete road fording across a creek that feeds into Concow Reservoir, road passes along flat ground

$3 \mathrm{~m}$ to $3.5 \mathrm{~m}$ (10 ft to $12 \mathrm{ft}$ )

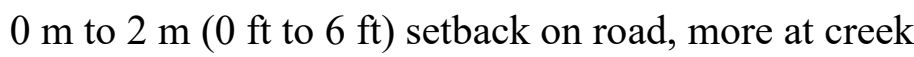
crossing

$40 \mathrm{~min}$

$250 \mathrm{~m}(0.15 \mathrm{mi})$

from northeast to southwest

estimated $13 \mathrm{~m} / \mathrm{s}$ to $18 \mathrm{~m} / \mathrm{s}$ ( $30 \mathrm{mi} / \mathrm{h}$ to $40 \mathrm{mi} / \mathrm{h}$ ) from north brush / trees

surface fire, torching trees, visible flames across road or portion of road

TD-005, TD-007, TD-008, TD-013, TD-027, TD-062, TD-103, TD-110, TD-137

Related streets or keywords: Concow Rd, Concow Creek, Hoffman Rd, Concow Reservoir

Street-level view:

Hoffman Rd looking west at Concow Creek and the low water crossing.

Pre-fire imagery links: $\quad$ Bing Maps Streetside

Post-fire imagery links: $\quad$ No imagery available. See NIST photo below.

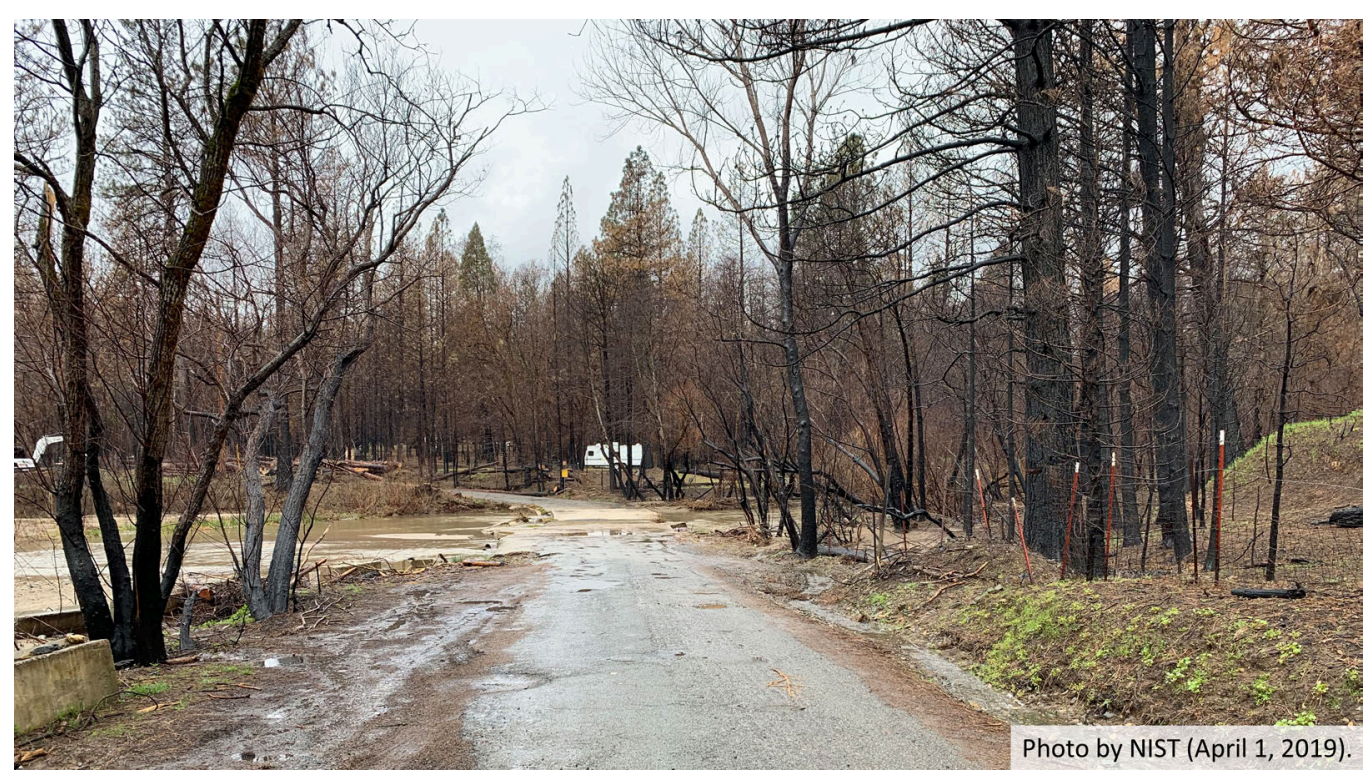




\section{Street map:}

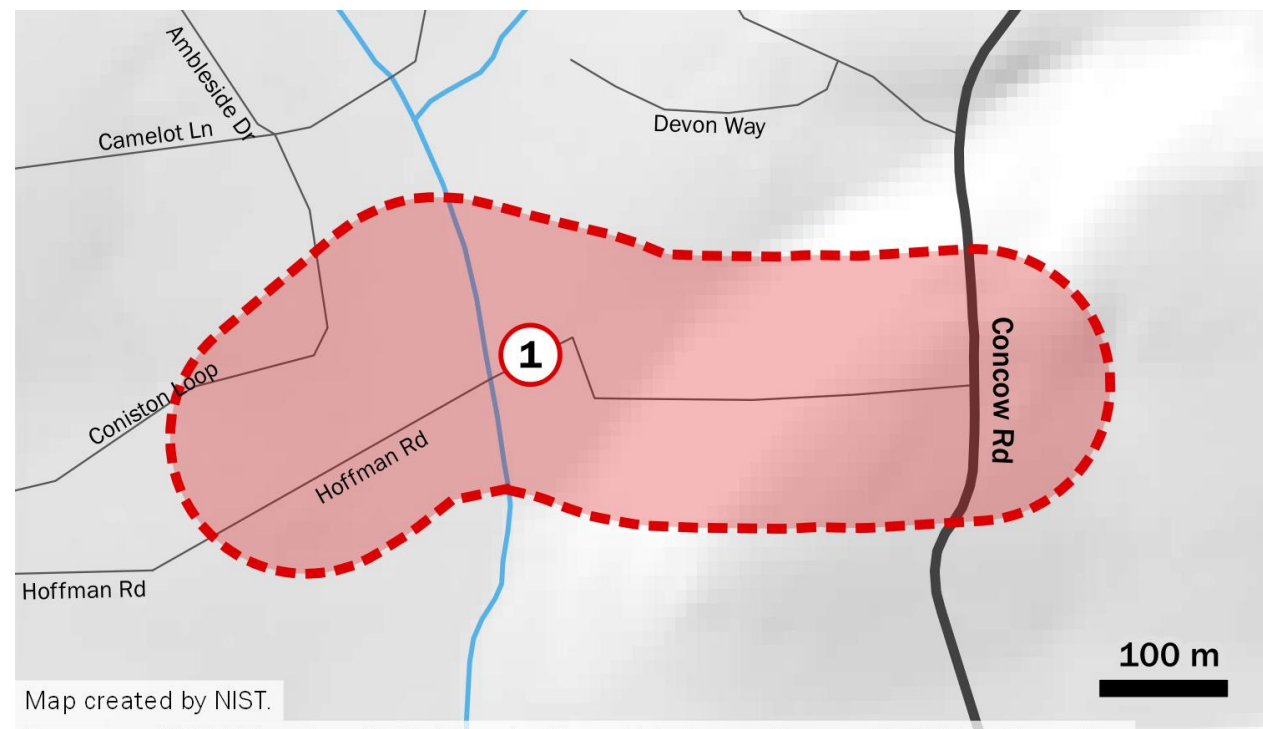

Burnovers: NIST | Elevation: USGS | Roads, Water: U.S. Census Bureau TIGER/Line Shapefiles

\section{Satellite view:}

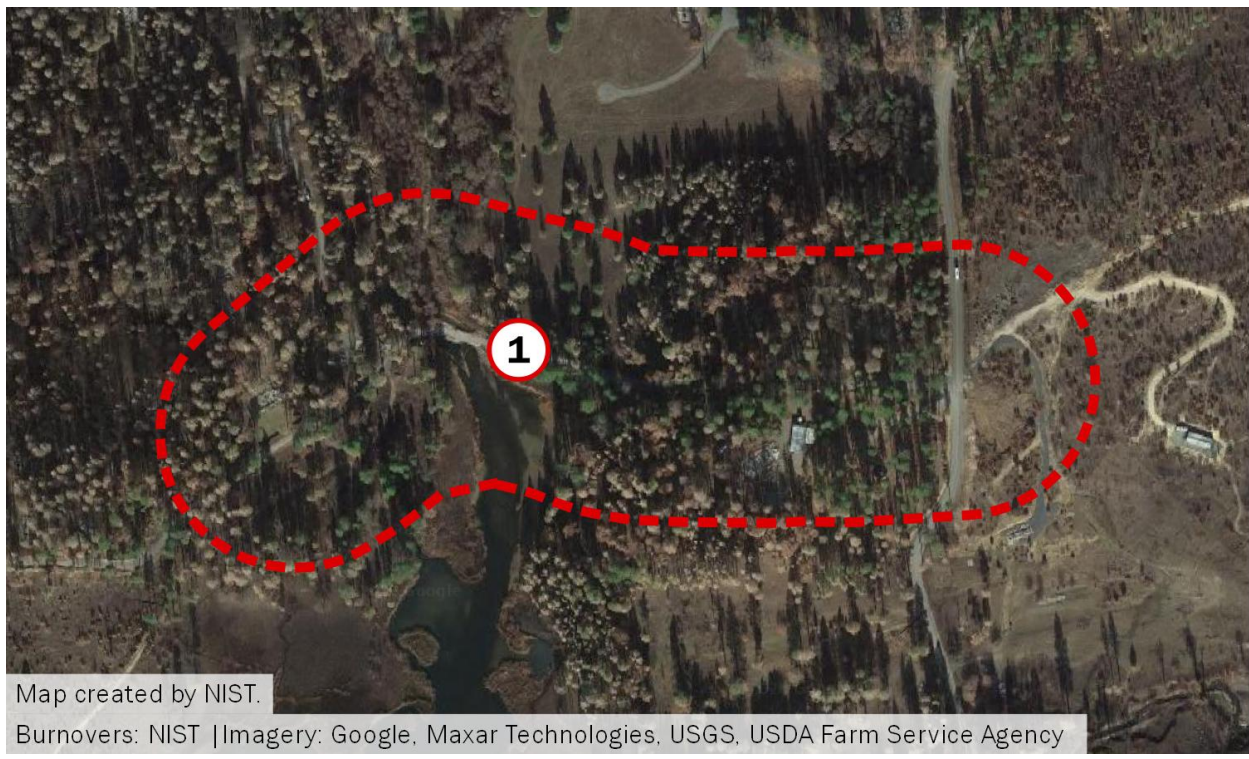




\section{Concow Road}

Date/Time: November 8, 07:50-09:00

Location: Concow Road, Concow

Coordinates: $\quad[39.779816,-121.506844]$

Related TRA/ after the Concow Rd burnover, civilians went to the Camelot Wildfire Safety Zone: Safety Zone

Summary: Concow Road is the main access road in and out of Concow. Fire activity was first reported in the area of Concow Road at Cribbage Lane at 07:30. The fire spread and increased in intensity, resulting in the closure of Concow Road, limiting access for first responders and impeding the evacuation of civilians. Firefighters lined up on Concow Road waiting for fire to pass the roadway before they proceeded north into the burn area. Fire engines ultimately drive through fire to reach trapped civilians and other first responders on Hoffman Road and Camelot Lane. However, almost one hour later, at 08:42, firefighters report that they are still blocked by fire near Cribbage Lane. Road access improved by 10:00 with rescue operations for burn victims.

\begin{tabular}{|c|c|c|}
\hline Time & Observation & Source \\
\hline 07:30-07:40 & $\begin{array}{l}\text { observe } 6 \mathrm{~m} \times 6 \mathrm{~m}(20 \mathrm{ft} \times 20 \mathrm{ft}) \text { spot fire at house near Tweedy } \\
\text { Ln, resident attempting to suppress with hose and shovel; fire } \\
\text { pulling upwind toward house, wind not too strong; help dig quick } \\
\text { line but cannot put out fire with hand tools; dark; no embers } \\
\text { falling }\end{array}$ & TD-013 \\
\hline 07:40-07:50 & wind blowing hard; multiple vehicles leaving Concow & TD-013 \\
\hline 07:45-07:49 & $\begin{array}{l}\text { Concow Rd at Cribbage } \mathrm{Ln} \text {; seeing fire, structures not on fire yet; } \\
\text { black dark with orange glow }\end{array}$ & TD-103 \\
\hline 07:49-08:15 & $\begin{array}{l}\text { lots of resources gathered at Cribbage Ln working on plan of } \\
\text { action (dozer, } 1 \text { or } 2 \text { crews, engine) right on edge of fire and } \\
\text { smoke cloud }\end{array}$ & TD-110 \\
\hline 08:01-08:30 & $\begin{array}{l}\text { parked at Concow Rd and Cribbage } \mathrm{Ln} \text {; flame front too intense to } \\
\text { pass, burning vehicles in road. Crown, timber, } 3 \mathrm{~m} \text { to } 4.5 \mathrm{~m}(10 \mathrm{ft} \\
\text { to } 15 \mathrm{ft}) \text { tall brush [all burning]; } 18 \mathrm{~m} \text { to } 24 \mathrm{~m}(60 \mathrm{ft} \text { to } 80 \mathrm{ft}) \text { tall } \\
\text { flames }\end{array}$ & TD-008 \\
\hline 08:15-08:30 & $\begin{array}{l}\text { embers blowing across roadway; sketchy to drive through but not } \\
\text { crazy; encounter more civilians }\end{array}$ & TD-110 \\
\hline 08:15-08:30 & $\begin{array}{l}\text { head [toward Hoffman Rd on Concow Rd] with a couple engines } \\
\text { following; most intense fire conditions; flames horizontal over } \\
\text { Hoffman Rd; had to reverse back out of there, engines had } \\
\text { difficulty; total bottleneck in S-curve }\end{array}$ & TD-110 \\
\hline
\end{tabular}




\begin{tabular}{|c|c|c|}
\hline Time & Observation & Source \\
\hline 08:15-08:30 & $\begin{array}{l}\text { trees torching down Hoffman Rd, not safe to go down there to get } \\
\text { to TD-013 }\end{array}$ & TD-110 \\
\hline $08: 23-08: 31$ & $\begin{array}{l}\text { Concow Rd at Hoffman Rd; dozer coming up Hoffman Rd, meet } \\
\text { with TD- } 013 \text { and evacuees; confirm power is dead, and clear } \\
\text { powerlines off Concow Rd with bolt cutters; fire right up against } \\
\text { road; significant } 13 \mathrm{~m} / \mathrm{s} \text { to } 18 \mathrm{~m} / \mathrm{s}(30 \mathrm{mi} / \mathrm{h} \text { to } 40 \mathrm{mi} / \mathrm{h}) \text { wind }\end{array}$ & TD-062 \\
\hline $08: 30$ & $\begin{array}{l}\text { house on left at Camelot } \mathrm{Ln} / \text { Concow Rd intersection burning; } \\
\text { vehicle on embankment fully involved; severe ember wash }\end{array}$ & TD-110 \\
\hline 08:30 & $\begin{array}{l}\text { attempt to get to Camelot Wildfire Safety Zone; north of Hoffman } \\
\text { Rd totally black, cannot see intersection to Camelot Ln; moving } \\
\text { slowly to find roadway }\end{array}$ & TD-110 \\
\hline 08:31 & [fire engines] could finally access beyond Hoffman Rd & TD-008 \\
\hline $08: 32-08: 35$ & $\begin{array}{l}\text { vehicle at entrance to Camelot is on fire; most if not all structures } \\
\text { in Camelot already on fire; safety zone is viable; } 5 \text { civilian } \\
\text { vehicles already refuging at safety zone with law enforcement }\end{array}$ & TD-062 \\
\hline $08: 42$ & $\begin{array}{l}\text { stopped by fire on Concow Rd at Cribbage Ln; } 2 \text { crew buses and } \\
\text { a water tender }\end{array}$ & TD-115 \\
\hline
\end{tabular}


Topography:

Roadway width:

Vegetation setbacks:

Duration:

Extent of burnover (length of $1000 \mathrm{~m}(0.6 \mathrm{mi})$ road affected):

Fire direction across road: from northeast to southwest

Wind intensity:

Fuels:

Fire behavior:

Road passes along a hill, hill slopes down from road west towards lake

$7 \mathrm{~m}(23 \mathrm{ft})$

$0 \mathrm{~m}$ to $1 \mathrm{~m}(0 \mathrm{ft}$ to $3 \mathrm{ft})$

$70 \mathrm{~min}$
Related TD:
Fire behavior: ember showers, visible flames across road or portion of road
TD-008, TD-013, TD-031, TD-062, TD-103, TD-110, TD-115

"wind blowing hard" estimated $13 \mathrm{~m} / \mathrm{s}$ to $18 \mathrm{~m} / \mathrm{s}(30 \mathrm{mi} / \mathrm{h}$ to $40 \mathrm{mi} / \mathrm{h}$ )

brush / trees / vehicles

Crowning fire through thick brush and timber, intense

Related streets or keywords: Cribbage Ln, Tweedy Ln, Ishi Tr, Concow Reservoir

$\begin{array}{ll}\text { Street-level view: } & \text { Concow Rd looking north toward Hoffman Rd. } \\ \text { Pre-fire imagery links: } & \text { Bing Maps Streetside } \\ \text { Post-fire imagery links: } & \text { No imagery available. }\end{array}$




\section{Street map:}

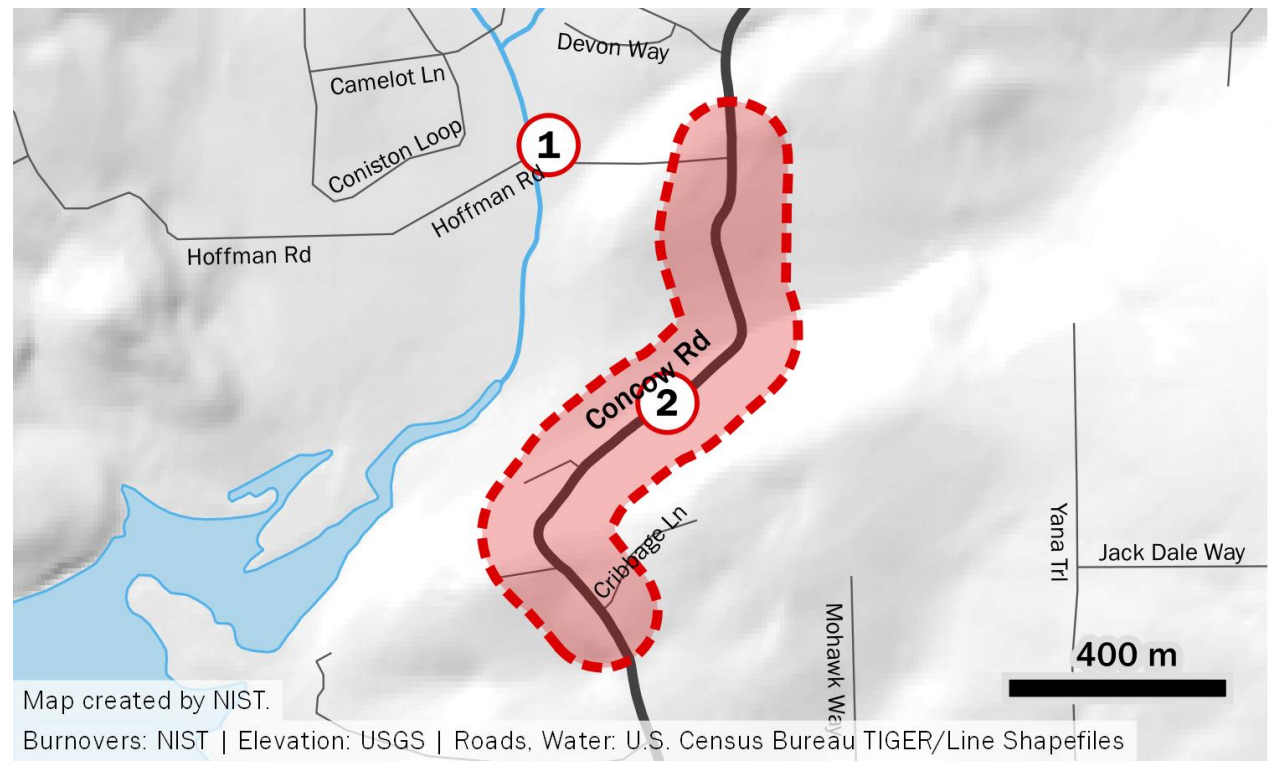

\section{Satellite view:}

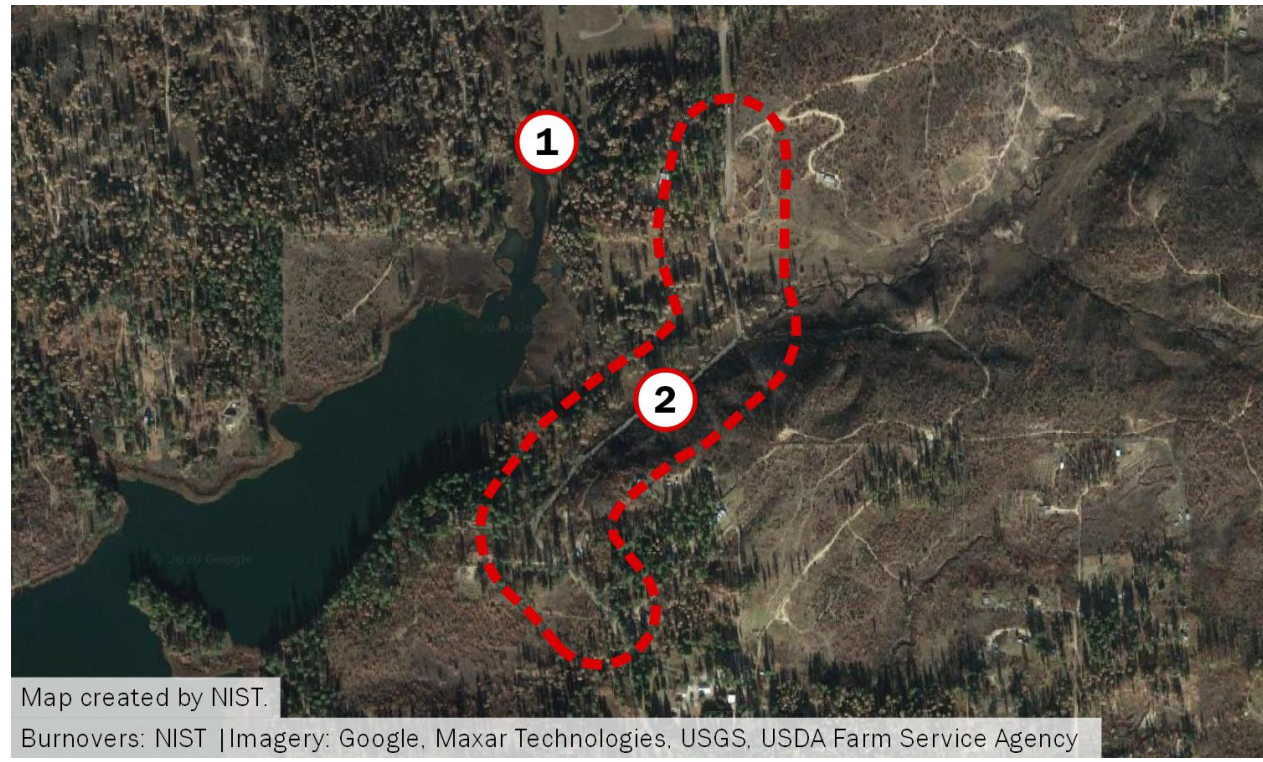




\section{Chapman Ln}

Date/Time: November 8, 08:30

Location: $\quad$ Chapman Ln, Paradise, off Dean Rd

Coordinates: $\quad[39.789343,-121.572755]$

Related TRA: n/a

Summary: At approximatively 08:00 spot fires were reported around Chapman Lane and Dean Road. Firefighters deployed approximately $130 \mathrm{~m}$ (400 ft) of hose from their engine on Chapman Lane to try to reach the various spot fires. Fire activity rapidly increased as the main fire front arrived out of the West Branch Feather River Canyon. Because of the rapidly deteriorating conditions, the firefighters cut the hose from the engine as they evacuated the narrow road. There is insufficient data to determine the temporal extent of this burnover.

\begin{tabular}{|c|c|c|}
\hline Time & Observation & Source \\
\hline 08:00-08:40 & $\begin{array}{l}\text { find another spot off Dean Rd behind the orchard; defended a } \\
\text { number of homes with garden hoses; defensible at the time until } \\
\text { we saw a structure ignite down the street; wind } 5 \mathrm{~m} / \mathrm{s} \text { to } 7 \mathrm{~m} / \mathrm{s} \\
(10 \mathrm{mi} / \mathrm{h} \text { to } 15 \mathrm{mi} / \mathrm{h})\end{array}$ & TD-042 \\
\hline $08: 36$ & $\begin{array}{l}\text { spots starting along Dean Rd; heavy traffic outbound on Dean Rd, } \\
\text { crowded; on loudspeaker for evacuation }\end{array}$ & TD-040 \\
\hline $08: 36-10: 30$ & active fire burning in grass behind Chapman Ln & TD-040 \\
\hline $08: 36-10: 30$ & residents are gone; cut hose and escaped out of Chapman Ln & TD-040 \\
\hline $08: 36-10: 30$ & $\begin{array}{l}\text { visibility zero; stuck on Chapman Ln up against tree; trying to } \\
\text { extend hose lines to fire, run about } 120 \mathrm{~m} \text { ( } 400 \mathrm{ft}) \text { of hose; } \\
\text { propane tanks exploding, fire all around in heavy vegetation and } \\
\text { pine needles; civilians evacuating, block in engine }\end{array}$ & TD-040 \\
\hline 08:36-10:30 & $\begin{array}{l}\text { stretch hose to attack veg fire on lot; structure not burning; ember } \\
\text { cast causing ignitions Dean Rd; got very smoky had to leave }\end{array}$ & TD-040 \\
\hline $08: 40$ & fire all along Dean $\mathrm{Rd}$ & TD-042 \\
\hline
\end{tabular}


Topography:

Roadway width:

Vegetation setbacks:

Duration:

Extent of burnover (length

of road affected):

Fire direction across road:

Wind intensity:

Fuels:

Fire behavior:

Related TD:

Related streets or keywords: Dean Rd, Pentz Rd northeast

$3 \mathrm{~m}(10 \mathrm{ft})$

$\mathrm{n} / \mathrm{d}$

$250 \mathrm{~m}(0.15 \mathrm{mi})$

$\mathrm{n} / \mathrm{d}$

TD-040, TD-042
Flat, slopes to canyon beyond $150 \mathrm{~m}(500 \mathrm{ft})$ to the

$0 \mathrm{~m}$ to $3 \mathrm{~m}(0 \mathrm{ft}$ to $10 \mathrm{ft})$

$5 \mathrm{~m} / \mathrm{s}$ to $7 \mathrm{~m} / \mathrm{s}(10 \mathrm{mi} / \mathrm{h}$ to $15 \mathrm{mi} / \mathrm{h})$

brush/trees, grass, structures

quick increase in fire activity burning in heavy vegetation and pine needles, igniting structures
Street-level view:
View looking north on Chapman Ln from near Dean Rd.
Pre-fire imagery links:
Google Maps Street View, Bing Maps Streetside
Post-fire imagery links:
No imagery available. 


\section{Street map:}

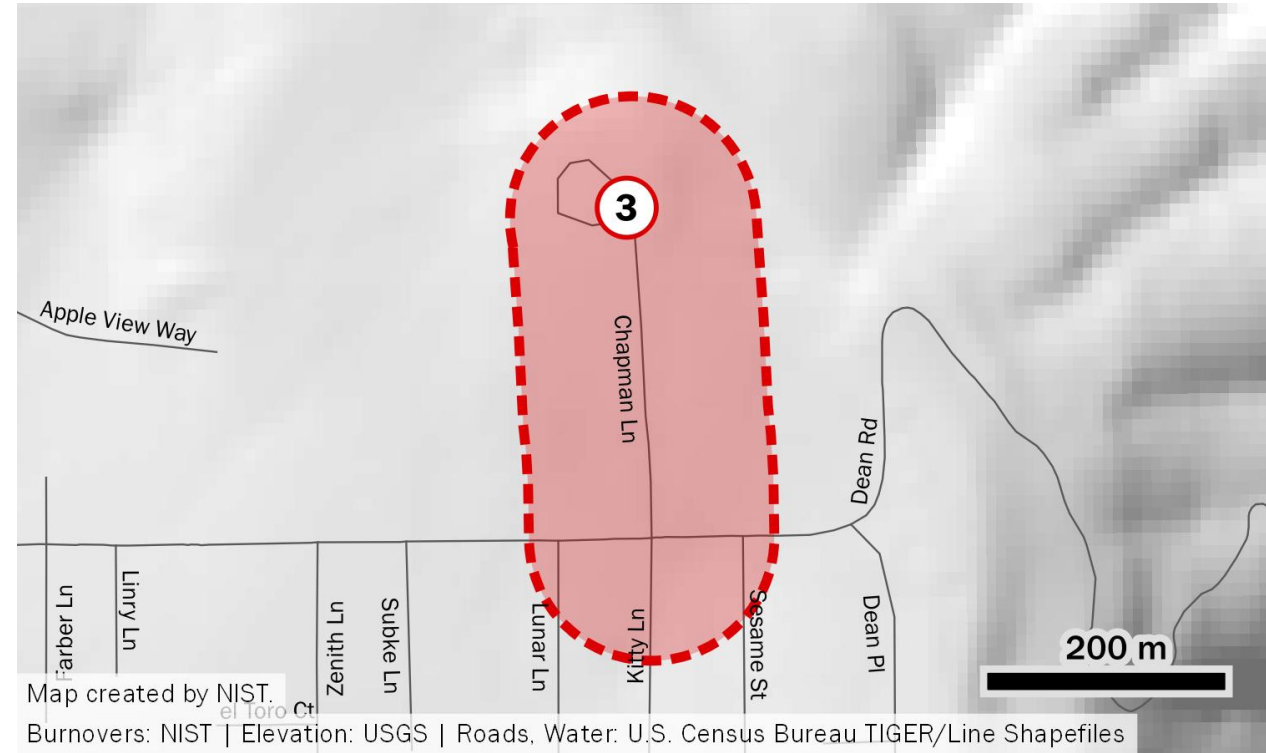

\section{Satellite view:}

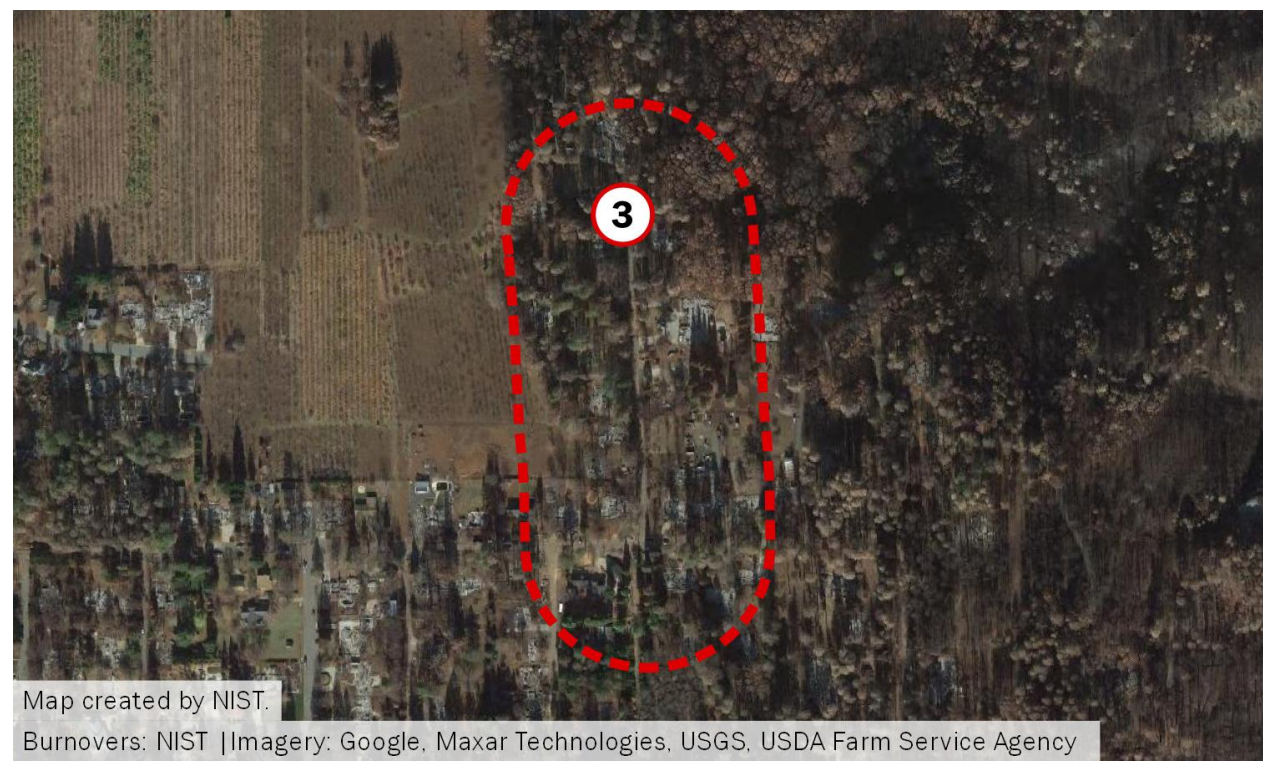




\title{
4. Skyway (upper, north of Wagstaff Road)
}

\author{
Date/Time: November 8, 08:30-14:30
}

Location: $\quad$ Skyway, Paradise, between Wagstaff $\mathrm{Rd}$ and Clark Rd

Coordinates: $\quad[39.785431,-121.597351]$

Related TRA: Walgreens, Optimo

Summary: Multiple segments of Skyway were blocked by fire activity during several time periods the morning of November 8. At 08:35 fire was burning along upper Skyway, north of Lofty Lane with multiple large spots reported in the vicinity of the 9100 Skyway. Fire activity on Skyway increased between Towhee Lane and Clark Road and by 09:00 Skyway became impassable due to extensive fire activity. Fire exposures remained severe through the morning. At 11:37 a law enforcement officer was reported trapped by fire on Skyway at Coldren Road. An hour later, a firefighter managed to get though going northbound at 12:45 and described high heat exposures. Into the early afternoon, intense fire exposures from burning structures and vehicles prevented access between Montna Drive and Towhee Lane. The closing of Skyway impacted civilian evacuations and first responder access. Abandoned cars continued to burn into the afternoon. Burned and unburned (abandoned) vehicles and downed power lines made access difficult even after the fire exposures had diminished.

\begin{tabular}{|c|c|c|}
\hline Time & Observation & Source \\
\hline $08: 35$ & spot fire first reported near intersection of Clark Rd and Skyway & $\begin{array}{c}911- \\
154-1\end{array}$ \\
\hline 08:35-09:59 & large spot fires [in the area of] 9100 Skyway & VTD-12 \\
\hline 08:35-09:59 & $\begin{array}{l}\text { drove through, fire and boulders everywhere; round trips, drivers } \\
\text { would freeze with fire in front; probably got at least } 200 \text { cars } \\
\text { through there }\end{array}$ & VTD-12 \\
\hline 09:00-09:30 & $\begin{array}{l}\text { Skyway SB is gridlocked; NB is clear. Instructing drivers to drive } \\
\text { down middle of roadway; visibility } 1 \text { to } 2 \text { car lengths }\end{array}$ & TD-064 \\
\hline 09:00-09:30 & $\begin{array}{l}\text { fire still to east of bike path south of Bel Air Dr, north of Fire } \\
\text { Station } 35\end{array}$ & TD-064 \\
\hline 09:00-09:30 & bike path and Skyway fully involved in fire, both sides of Skyway & TD-064 \\
\hline 09:30 & $\begin{array}{l}\text { help [law enforcement] direct traffic on Skyway at Quail; sending } \\
\text { vehicles down one lane during fire, then two lanes after intense } \\
\text { fire passed }\end{array}$ & TD-064 \\
\hline $10: 00-10: 15$ & $\begin{array}{l}\text { traffic SB on Skyway } 2 \text { lanes; high heat impacting stuck vehicles } \\
\text { and LE in area; attack vegetation fire with booster line; flames are } \\
\text { sheeting and wind is blustery }\end{array}$ & TD-022 \\
\hline $11: 25$ & heavy fire on Skyway to the south of Clark Rd & TD-041 \\
\hline
\end{tabular}




\begin{tabular}{|c|c|c|}
\hline Time & Observation & Source \\
\hline $11: 37$ & "I'm trapped by fire, Skyway at Coldren $[R d] "$ & PPD \\
\hline $12: 22$ & $\begin{array}{l}\text { "The blockage [stopping traffic] is Skyway below Rocky Ln; } \\
\text { crowning fire activity all to the west side" }\end{array}$ & PPD \\
\hline $12: 45-13: 00$ & $\begin{array}{l}\text { "drove the gauntlet" [through intense fire exposure] to get to } \\
\text { Optimo [Clark Rd] }\end{array}$ & TD-127 \\
\hline $12: 55-13: 01$ & $\begin{array}{l}\text { both sides of Skyway on fire (vehicles and houses burning); } \\
\text { between Wagstaff and Quail Way }\end{array}$ & TD-200 \\
\hline $13: 00-13: 19$ & $\begin{array}{l}\text { Skyway between Wagstaff Rd and Towhee Ln; fire on both sides } \\
\text { of Skyway }\end{array}$ & TD-205 \\
\hline $13: 15-13: 19$ & $\begin{array}{l}\text { Skyway blocked with abandoned vehicles; most did not have } \\
\text { keys and could not be moved; Turned around on Skyway to head } \\
\text { southbound; cars are beginning to ignite - very hot }\end{array}$ & TD-205 \\
\hline $13: 16$ & $\begin{array}{l}\text { fire activity intense on both sides of road; road blocked with } \\
\text { vehicles; an engine strike team was pushing vehicles with engines }\end{array}$ & TD-207 \\
\hline $13: 34-13: 58$ & 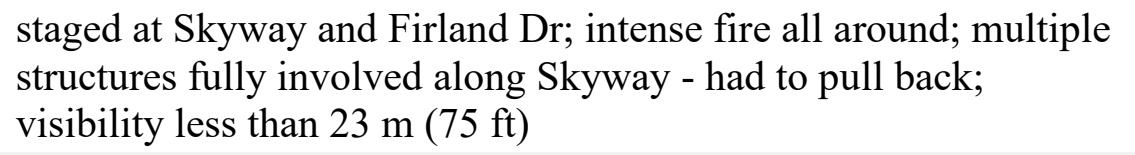 & TD-205 \\
\hline $13: 35-13: 53$ & took refuge in field/general store lot & TD-207 \\
\hline $13: 47-13: 59$ & $\begin{array}{l}\text { north on Skyway, passing Wagstaff Rd, abandoned vehicles; lots } \\
\text { of structures burning, wind pushing hard; wall of flames, cars on } \\
\text { fire }\end{array}$ & TD-111 \\
\hline $14: 00$ & $\begin{array}{l}\text { heavy fire along Skyway, visibility } 3 \mathrm{~m}(10 \mathrm{ft}) \text {, abandoned } \\
\text { vehicles burning }\end{array}$ & TD-128 \\
\hline $14: 26$ & $\begin{array}{l}\text { motorhome in roadway, fully engulfed; exploded when trying to } \\
\text { get past; turn around }\end{array}$ & TD-055 \\
\hline $14: 45$ & $\begin{array}{l}\text { the main issue [preventing civilians from driving through } \\
\text { Skyway] is the abandoned vehicles on Skyway between Clark Rd } \\
\text { and Wagstaff are all burning }\end{array}$ & TD-127 \\
\hline
\end{tabular}


Topography:

Roadway width:

Vegetation setbacks:

Duration:

Extent of burnover (length

of road affected):

Fire direction across road:

Wind intensity:

Fuels:

Fire behavior:

Related TD:

Street-level view:

Pre-fire imagery links:

Post-fire imagery links:

Street-level view:

Pre-fire imagery links:

Post-fire imagery links:
Relatively flat in most sections, along slight ridge near Clark Rd

$8 \mathrm{~m}(26 \mathrm{ft})$

$0 \mathrm{~m}$ to $10 \mathrm{~m}(0 \mathrm{ft}$ to $33 \mathrm{ft})$

$360 \mathrm{~min}$

$2.6 \mathrm{~km}(1.6 \mathrm{mi})$

$\mathrm{n} / \mathrm{d}$, variable

$\mathrm{n} / \mathrm{d}$

Brush / trees, vehicles, structures

initially numerous spot fires, developing into widespread fires in vegetation, structures, and vehicles

911-154-1, 911-165-1, 911-167-1, 911-188-1, 911-191-1, PPD, TD-014, TD-015, TD-022, TD-041, TD-042, TD-043, TD-055, TD-064, TD-067, TD-111, TD-127, TD-128, TD-200, TD-203, TD-205, TD-207, VTD-12

Related streets or keywords: Montna Dr, Quail Way, Towhee Ln, Coldren Rd, Firland Dr, Rocky Ln

Skyway looking north at Firland Dr.

Google Maps Street View, Bing Maps Streetside

Google Maps Street View

Skyway looking north at Towhee Ln.

Google Maps Street View, Bing Maps Streetside

Google Maps Street View 


\section{Street map:}

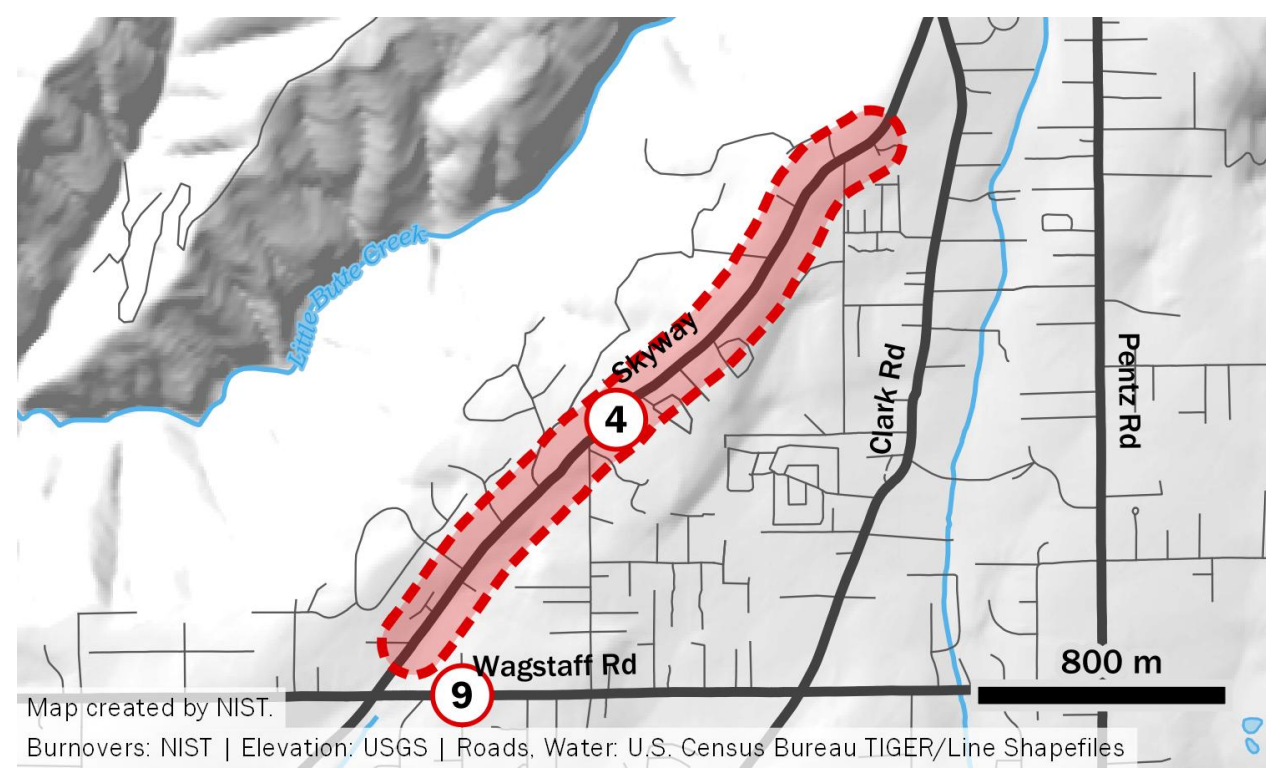

\section{Satellite view:}

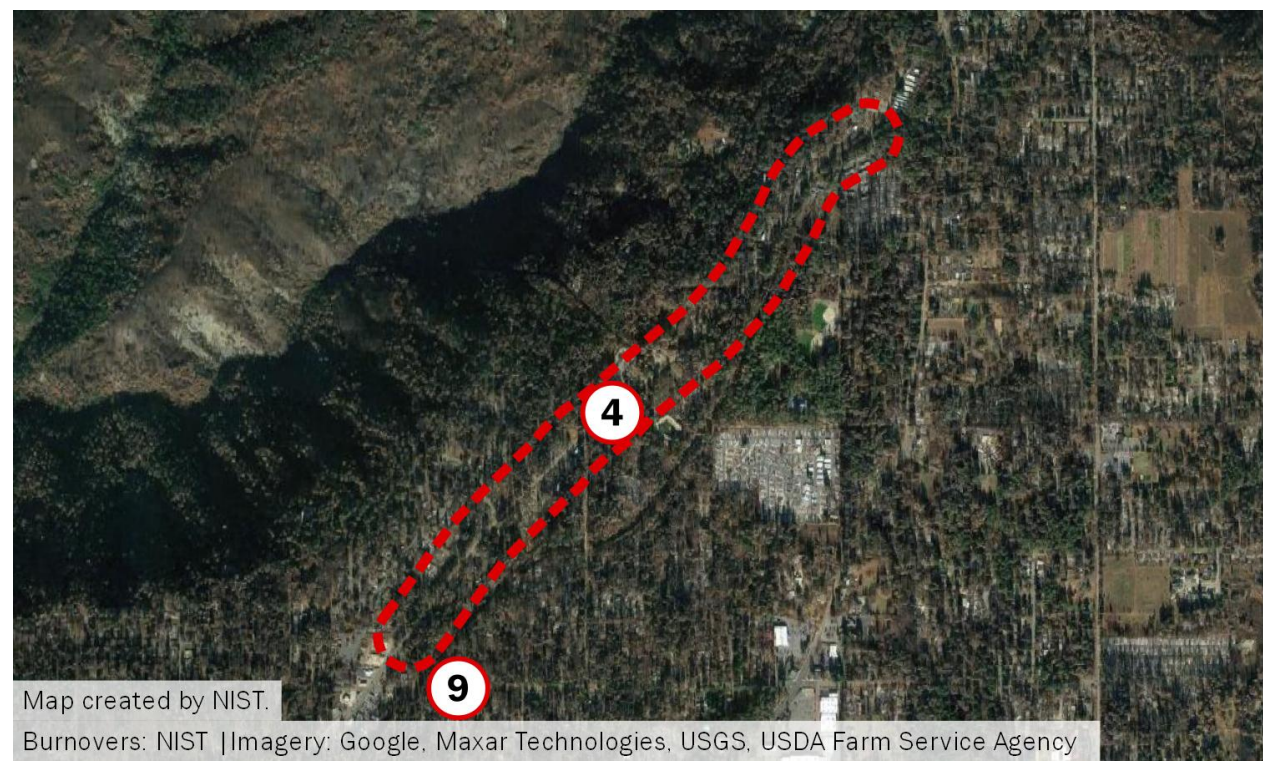




\section{Windermere Lane}

\section{Date/Time: November $8,08: 35-\mathrm{n} / \mathrm{d}$}

Location: Windermere Ln, Concow

Coordinates: $\quad[39.788864,-121.509851]$

Related TRA: Concow, Camelot

Summary: Shortly after 08:30 civilians sheltering in the designated Safety Zone in the Camelot neighborhood of Concow informed first responders of possible civilian entrapments in the Windermere Lane area. First responders made three separate unsuccessful attempts to reach the area between 08:35 and 08:52. Intense fire, lack of visibility, and downed trees and power lines prevented first responders from reaching the Windermere Lane area and conducting search and rescue operations. The full duration of the fire activity and restricted access is undetermined from the collected information.

\begin{tabular}{clc}
\hline \multicolumn{1}{c}{ Time } & Observation & Source \\
\hline 08:32-08:35 & $\begin{array}{l}\text { civilian in safety zone advises about possible entrapment; attempt } \\
3 \text { different routes to access } \\
\text { civilians informed that residents are still trapped in Windermere } \\
\text { area; impossible to access - powerlines down and trees torching; } \\
\text { structures burning; TD-062 attempts rescues } \\
\text { attempt to access address; smoke so thick can't see hood of }\end{array}$ & TD-110 \\
08:35 & TD-062 \\
08:35-08:47 & $\begin{array}{l}\text { engine; all houses and vegetation on fire; propane venting; road } \\
\text { compromised }\end{array}$ & TD-062 \\
08:47-08:52 & $\begin{array}{l}\text { tree blocking roadway; wall of flames } \\
\text { third try to access address; looking for any other evacuees; road } \\
\text { blocked by powerlines and downed trees; propane explosions }\end{array}$ & TD-062 \\
\hline $08: 52-08: 5$
\end{tabular}


Topography:

Roadway width:

Vegetation setbacks:

Duration:

Extent of burnover (length

of road affected):

Fire direction across road: $\quad \mathrm{n} / \mathrm{d}$

Wind intensity:

Fuels:

Fire behavior:

Related TD:

Related streets or keywords: Camelot Ln, Ambleside Dr, St Ives Way flat ground on both sides of roadway

$4 \mathrm{~m}(12 \mathrm{ft})$

$0 \mathrm{~m}$ to $2 \mathrm{~m}(0 \mathrm{ft}$ to $6 \mathrm{ft})$

$\mathrm{n} / \mathrm{d}$

$1100 \mathrm{~m}(0.7 \mathrm{mi})$

$\mathrm{n} / \mathrm{d}$

brush / trees, structures

visible flames across road or portion of road TD-062, TD-110
Street-level view:

Pre-fire imagery links:

Post-fire imagery links:
Windermere Ln looking west at St Ives Way.

Bing Maps Streetside

No imagery available. 


\section{Street map:}

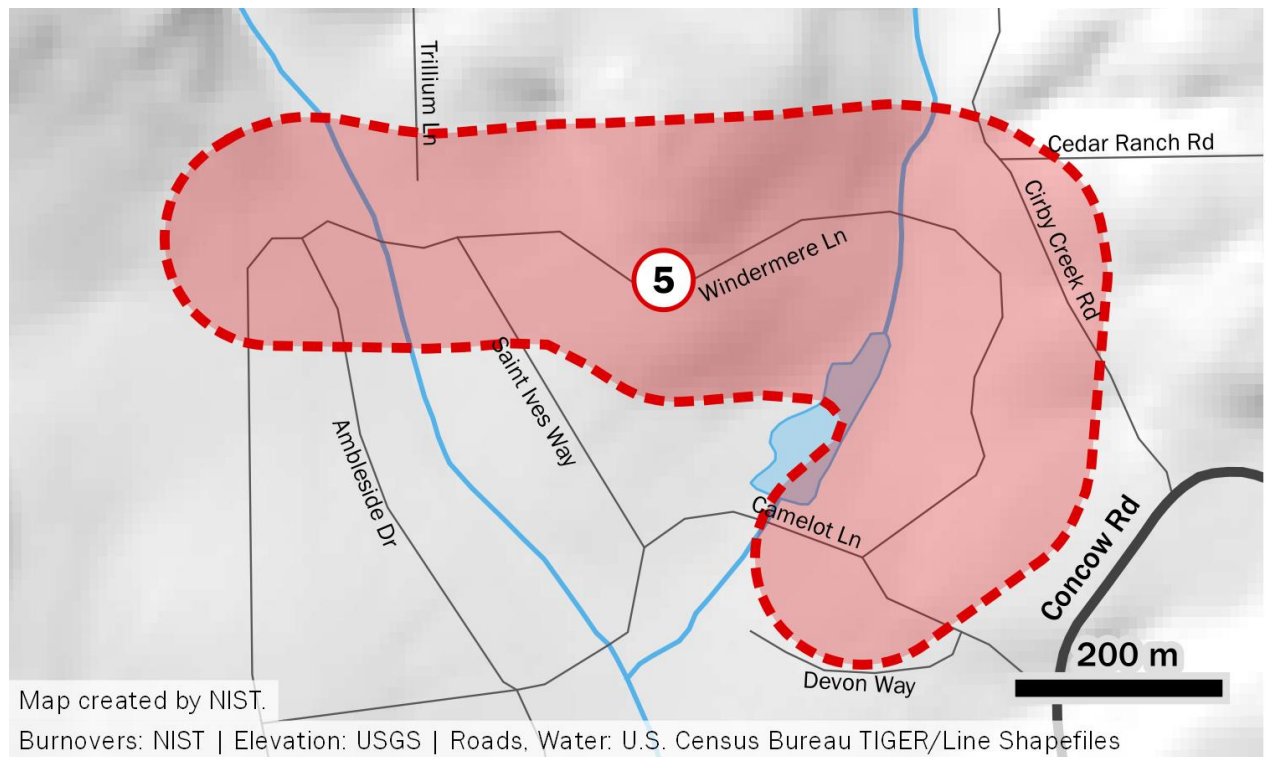

\section{Satellite view:}

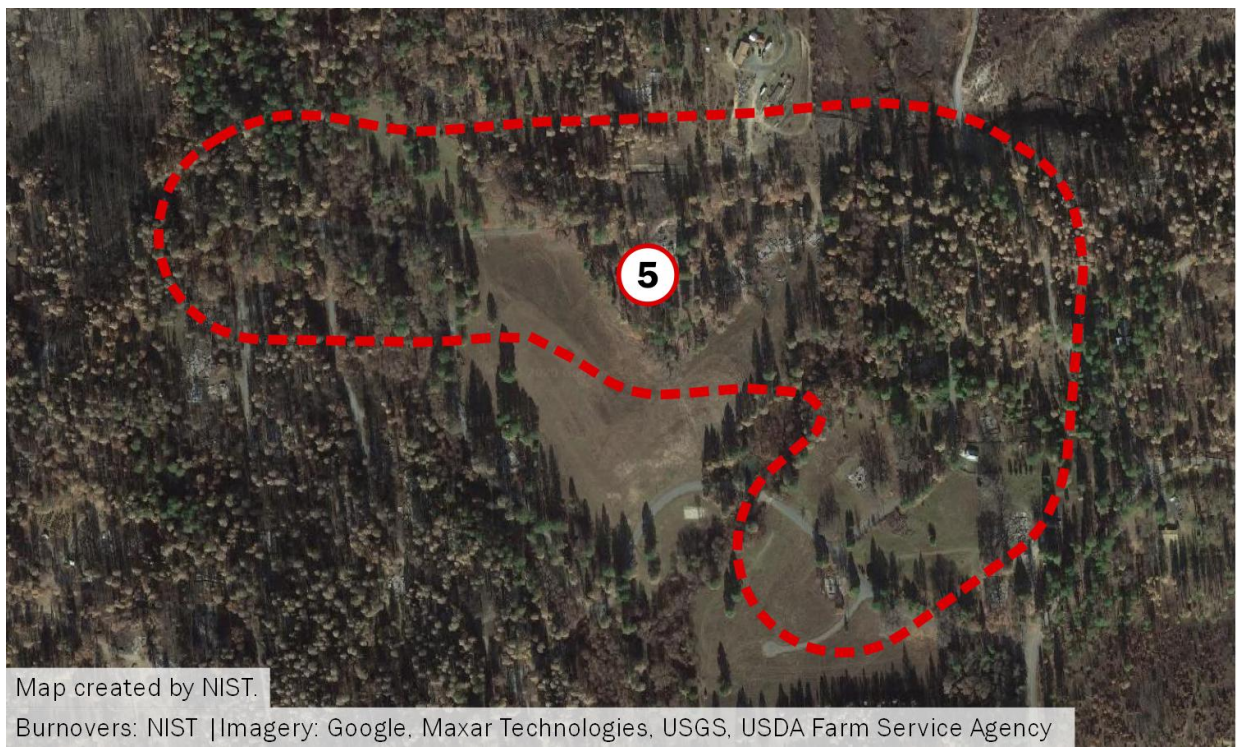




\section{Pentz Road}

Date/Time: November 8, 08:45-11:15

Location: $\quad$ Pentz Rd, Paradise, between Bille Rd and Feather River Hospital (FRH)

Coordinates: $\quad[39.764012,-121.574553]$

Related TRA: Feather River Hospital, Bille Rd

Summary: Pentz Road is one of the four main north-south arteries in Paradise. Fire activity in the form of multiple spot fires were first reported off Pentz Road at Clearbrook Lane by 08:54. Within ten minutes Pentz Road became impassable, causing evacuation traffic to come to a standstill and simultaneously limiting access to first responders. The first vehicle ignition in the data set was reported shortly before 09:20. Multiple vehicles ignited over the next $20 \mathrm{~min}$ to $30 \mathrm{~min}$. Intense fire activity, downed power lines, and burning vehicles resulted in closure of parts of Pentz Road between Bille Road and FRH until approximately 10:45, when fire activity began to subside.

\begin{tabular}{|c|c|c|}
\hline Time & Observation & Source \\
\hline 08:54-08:58 & $\begin{array}{l}\text { Pentz Rd at Clearbrook Ln; spot fires all around; east side heavily } \\
\text { involved; SB Pentz Rd is open, very little traffic. NB Pentz Rd } \\
\text { congested, stop for } 5 \text { min at a time, flowing slowly but steady, } \\
\text { lots of traffic; smoky but visibility okay }\end{array}$ & TD-015 \\
\hline 08:57-09:03 & $\begin{array}{l}\text { Pentz Rd near Del Rio Way; flags blowing in wind, wind speed } \\
\text { variable between calm and } 4.5 \mathrm{~m} / \mathrm{s}(10 \mathrm{mi} / \mathrm{h}) \text { gusting to } 9 \mathrm{~m} / \mathrm{s} \\
(20 \mathrm{mi} / \mathrm{h}) \text { from west }\end{array}$ & VTD-23 \\
\hline 09:00-09:05 & $\begin{array}{l}\text { meet with [firefighter] who is directing traffic; spot fires all } \\
\text { around - east side Pentz Rd heavily involved; civilians evacuating } \\
\text { north }\end{array}$ & TD-015 \\
\hline 09:03-09:23 & $\begin{array}{l}\text { multiple spot fires in area along Pentz Rd at Vineyard Dr; both } \\
\text { sides road }\end{array}$ & VTD-23 \\
\hline 09:03-09:35 & $\begin{array}{l}\text { Pentz Rd is unpassable, fire impacting Pentz Rd north of hospital; } \\
\text { major gridlock; engines arriving }\end{array}$ & TD-014 \\
\hline 09:11 & ambulances trapped by fire & $\begin{array}{c}911- \\
221-2\end{array}$ \\
\hline 09:12-09:21 & $\begin{array}{l}\text { active fire, fire spotting to west side of Pentz Rd. A } \\
\text { drive by with sirens, northbound in southbound lan }\end{array}$ & TD-015 \\
\hline 09:18 & pass burning ambulance at $\mathrm{Chloe} \mathrm{Ct}$; ambulances just igniting & TD-060 \\
\hline 09:24 & $\begin{array}{l}\text { fire is burning on both sides of Pentz Rd; active flames both sides } \\
\text { of road; both lanes of Pentz Rd are NB }\end{array}$ & TD-069 \\
\hline 09:27 & [traffic] has not moved; active vegetation fire against roadway & VTD-23 \\
\hline
\end{tabular}




\begin{tabular}{clc}
\hline Time & Observation & Source \\
\hline 09:33 & $\begin{array}{l}\text { fire starting to impact vehicles right now [Pentz Rd near } \\
\text { Conifer Dr] } \\
\text { civilian says there was fire north of hospital on both sides of }\end{array}$ & PPD \\
09:39 & $\begin{array}{l}\text { Pentz Rd, was instructed by [TD-088] to turn around and come } \\
\text { back to hospital because that's where the fire trucks were }\end{array}$ & PPD \\
09:45-10:40 & vehicles are being driven while on fire \\
parked [vehicle] on Amore Ln; structures are not burning, fire is & TD-090 \\
approaching; powerlines down and sparking & TD-069 \\
still stuck on side street due to fire activity & meet with [TD-020]; smoky, visibility enough to drive slowly, \\
dark as night & PPD \\
advise paramedics [from burning ambulances] to return to & TD-015 \\
hospital parking lot [after taking refuge with patients and & defending residential structure] \\
back to FRH; no traffic trouble on Pentz Rd & TD-015 \\
\hline $11: 22$ & & TD-069 \\
\hline
\end{tabular}


Topography:

Roadway width:

Vegetation setbacks:

Duration:

Extent of burnover (length of road affected):

Fire direction across road:

Wind intensity:

Fuels:

Fire behavior:

Related TD: slight slope, area relatively flat for the first $100 \mathrm{~m} \mathrm{(328 \textrm {ft } )}$ on both sides of the road

$8 \mathrm{~m}(26 \mathrm{ft})$

$0 \mathrm{~m}$ to $1 \mathrm{~m}(0 \mathrm{ft}$ to $3 \mathrm{ft})$

$150 \mathrm{~min}$

$1300 \mathrm{~m}(0.8 \mathrm{mi})$

east to west

variable (observations from calm to gusts of $9 \mathrm{~m} / \mathrm{s}$ $(20 \mathrm{mi} / \mathrm{h})$ )

trees / brush, vehicles, structures

visible flames across road or portion of road

911-221-2, 911-230-5, 911-232-1, PPD,

TD-014, TD-015, TD-020, TD-038, TD-060, TD-063, TD-069, TD-079, TD-083, TD-084, TD-089, TD-090, TD-111, VTD-23

Related streets or keywords: Vineyard Dr, Bille Rd, Pentz Rd, Del Rio Way, Chloe Ct
Pentz Rd looking north, just north of the intersection with Dubarry Ln.

Pre-fire imagery links: $\quad$ Google Maps Street View, Bing Maps Streetside

Post-fire imagery links: $\quad$ Google Maps Street View 


\section{Street map:}

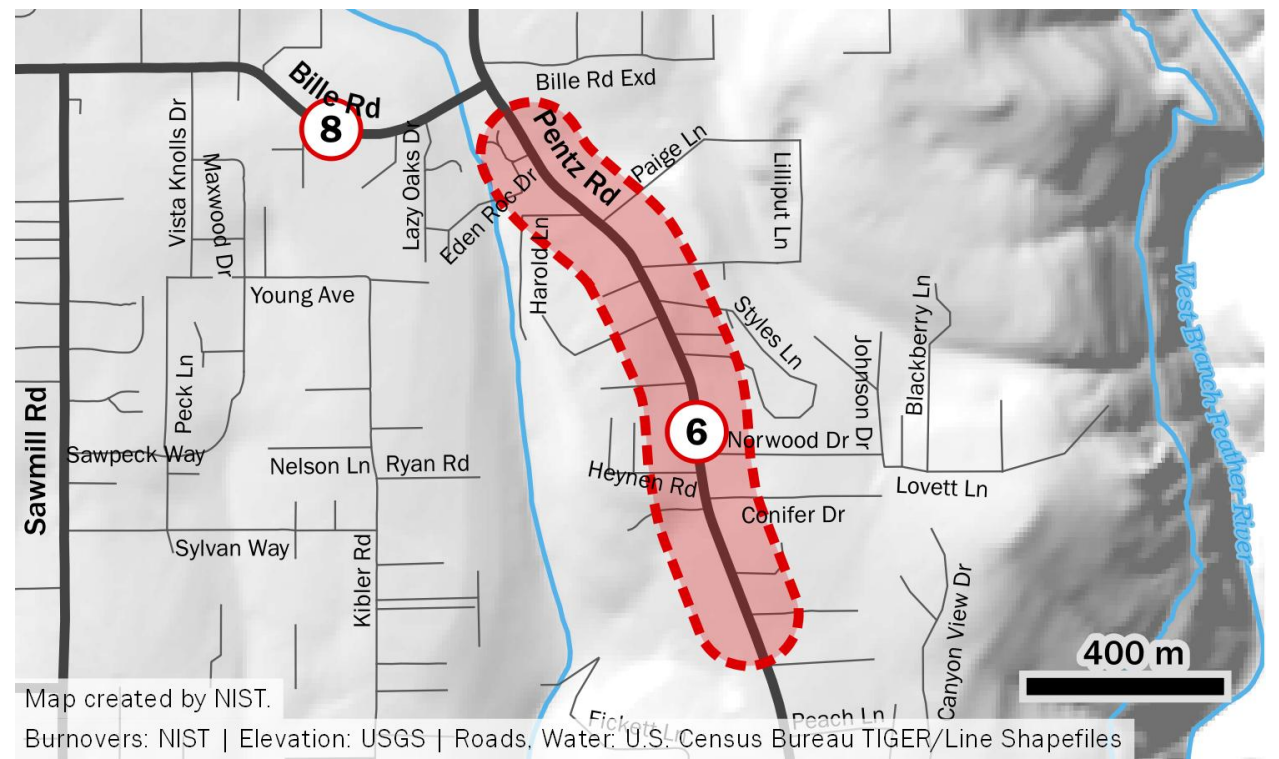

\section{Satellite view:}

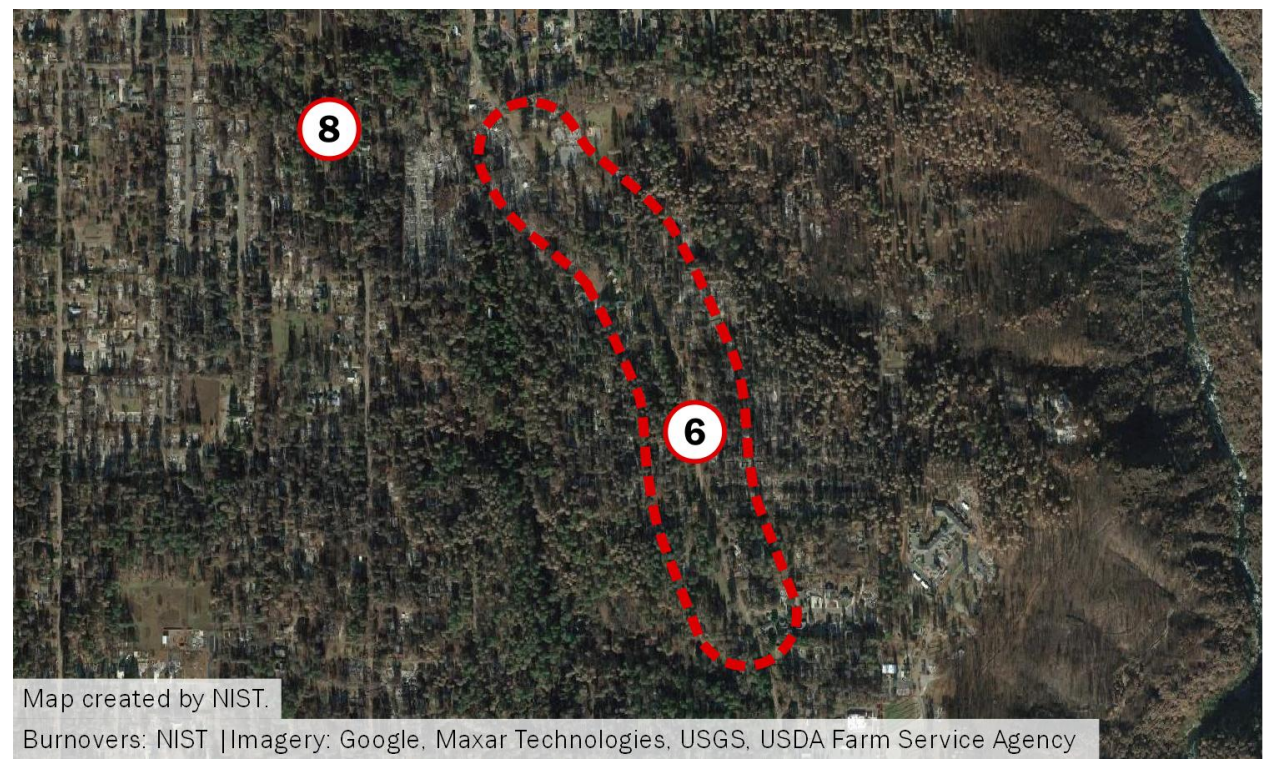




\section{Pearson Road}

\begin{tabular}{|c|c|}
\hline Date/Time: & November $8,09: 15-10: 15$ \\
\hline Location: & Pearson Rd, Paradise, between Hilbe Dr and Cherry Ln \\
\hline Coordinates: & {$[39.749969,-121.577933]$} \\
\hline Related TRA: & Pearson Rd, Feather River Hospital \\
\hline Summary: & $\begin{array}{l}\text { Person Road is one of the four main east-west traffic arteries in Paradise. } \\
\text { Fire was first reported in the drainage off Pearson Road at 09:00, and } \\
\text { quickly became well established. By 09:30, fire overtook the first } \\
\text { responder and civilian vehicles stuck in traffic. Intense fire exposures } \\
\text { caused damage to a fire engine and ignited multiple civilian vehicles. } \\
\text { Swirling winds, heavy embers showers, and intense radiation were } \\
\text { reported during the event. First responders rescued civilians and trapped } \\
\text { law enforcement personnel. Fire shelters were deployed to reduce } \\
\text { radiative exposures to first responders and rescued civilians. At 10:00 a } \\
\text { dozer arrived to support rescue operations, create a Temporary Refuge } \\
\text { Area and clear Person Road of burning vehicles. Pearson Road became } \\
\text { passable again at approximately 10:15. }\end{array}$ \\
\hline
\end{tabular}

\begin{tabular}{|c|c|c|}
\hline Time & Observation & Source \\
\hline 09:00 & $\begin{array}{l}\text { spot fires down in Pearson Rd drainage; put out spots with hand } \\
\text { tools and water, alone in patrol truck with } 190 \text { liters ( } 50 \text { gallons) } \\
\text { water }\end{array}$ & TD-100 \\
\hline 09:00-09:20 & spot fire just becoming established in drainage & TD-037 \\
\hline 09:00-09:20 & can see spot fire on south side Pearson Rd at Stearns Rd & TD-037 \\
\hline 09:00-09:20 & wind is picking up; dark as night & TD-037 \\
\hline $09: 15-09: 30$ & $\begin{array}{l}6 \mathrm{~m} \text { to } 9 \mathrm{~m}(20 \mathrm{ft} \text { to } 30 \mathrm{ft}) \text { flames in Pearson Rd drainage; } \\
\text { visibility } 15 \mathrm{~m}(50 \mathrm{ft})\end{array}$ & TD-068 \\
\hline $09: 26$ & fire established on Pentz Rd at the curves down in the drainage & TD-037 \\
\hline $09: 32$ & $\begin{array}{l}\text { start seeing spot fires; poor visibility, } 15 \mathrm{~m} \text { to } 18 \mathrm{~m}(50 \mathrm{ft} \text { to } \\
60 \mathrm{ft}) \text {; horrendous wind }\end{array}$ & TD-087 \\
\hline $09: 38$ & $\begin{array}{l}\text { moderate to heavy surface fire, single tree torching, heavy ember } \\
\text { shower through the curve }\end{array}$ & VTD-23 \\
\hline 09:40 & $\begin{array}{l}\text { encounter traffic jam both lanes WB on Pearson Rd, hugging } \\
\text { south side of roadway; heavy fire both sides; VTD- } 23 \text { is at end of } \\
\text { line }\end{array}$ & VTD-24 \\
\hline 09:41 & $\begin{array}{l}\text { heavy surface fire, torching trees, ember showers sound like } \\
\text { pebbles, cars honking; wind gusty from NE }\end{array}$ & VTD-23 \\
\hline 09:41-10:00 & see [TD-087] ahead, wind swirling & TD-122 \\
\hline
\end{tabular}




\begin{tabular}{|c|c|c|}
\hline Time & Observation & Source \\
\hline 09:41-10:00 & $\begin{array}{l}\text { fire had cleaned ground fuel; stuck here; fire overtakes engine; } \\
\text { put fire shelters over windows; engine is torched, blew diesel tank } \\
\text { vents }\end{array}$ & TD-122 \\
\hline 09:41-10:00 & cars in front of engine are on fire & TD-122 \\
\hline 09:41-10:00 & $\begin{array}{l}\text { debris in back of pickup truck catches fire; bring } 5 \text { civilians into } \\
\text { engine; ember shower across window }\end{array}$ & TD-122 \\
\hline 09:41-10:00 & ground fuels are gone, torched to limbs & TD-122 \\
\hline 09:45-10:04 & $\begin{array}{l}\text { new spot fire } 9 \mathrm{~m} \times 12 \mathrm{~m}(30 \mathrm{ft} \times 40 \mathrm{ft}) \text { in grass. Vehicles are } \\
\text { melting }\end{array}$ & TD-087 \\
\hline 09:51 & $\begin{array}{l}\text { heavy ember shower, swirling winds, dark with light of glowing } \\
\text { fire, visibility } 0 \mathrm{~m} \text { to } 15 \mathrm{~m}(0 \mathrm{ft} \text { to } 50 \mathrm{ft})\end{array}$ & VTD-16 \\
\hline $09: 53$ & $\begin{array}{l}\text { CHP vehicle not burning but cars next to it are burning; move } \\
\text { burning vehicles off roadway }\end{array}$ & TD-129 \\
\hline $09: 53$ & $\begin{array}{l}\text { visibility } 12 \mathrm{~m}(40 \mathrm{ft}), \text { smoky, everything on fire, extensive ember } \\
\text { cast; moderate to strong winds } 4.5 \mathrm{~m} / \mathrm{s} \text { to } 9 \mathrm{~m} / \mathrm{s}(10 \mathrm{mi} / \mathrm{h} \text { to } 20 \\
\mathrm{mi} / \mathrm{h}) \text {; swirling winds; wind knocking trees over }\end{array}$ & TD-129 \\
\hline 09:53 & $\begin{array}{l}\text { "Pearson Rd W of Pentz Rd, CHP and SO units have disabled } \\
\text { vehicles surrounded by fire trying to get out on foot" }\end{array}$ & PPD \\
\hline $10: 00$ & $\begin{array}{l}\text { push burning cars on south side of road to give distance to } \\
\text { occupied vehicles on the north side of road }\end{array}$ & TD-129 \\
\hline $10: 00-10: 15$ & by the time dozer cut line, fire front had passed & TD-037 \\
\hline $10: 00-10: 15$ & [civilian] had deployed fire shelter inside pickup truck & TD-037 \\
\hline $10: 15$ & dozer verified that Pearson Rd was passable & TD-037 \\
\hline $10: 18$ & after fire front all cars left TRA via Pearson Rd to Pentz Rd & TD-087 \\
\hline
\end{tabular}


Topography: ravine, drainage
Roadway width:
$11 \mathrm{~m}(36 \mathrm{ft})$
Vegetation setbacks:
$1 \mathrm{~m}$ to $3 \mathrm{~m}(2 \mathrm{ft}$ to $10 \mathrm{ft})$
Duration:
$60 \mathrm{~min}$
Extent of burnover (length $800 \mathrm{~m}(0.5 \mathrm{mi})$
of road affected):

Fire direction across road: n/d/variable, generally from northeast

Wind intensity:

multiple estimates: "horrendous", "gusty from NE", "swirling", "moderate to strong", $5 \mathrm{~m} / \mathrm{s}$ to $9 \mathrm{~m} / \mathrm{s}(10 \mathrm{mi} / \mathrm{h}$ to $20 \mathrm{mi} / \mathrm{h}$ )

Fuels:

brush/trees, vehicles, structures

Fire behavior:

spot fires, visible flames across road or portion of road, tree torching, vehicle and structure ignitions
Related TD: $\quad$ PPD, TD-014, TD-037, TD-063, TD-068, TD-070, TD-071, TD-076, TD-087, TD-100, TD-111, TD-122, TD-123, TD-129, VTD-16, VTD-23, VTD-24, VTD-25

Related streets or keywords: Hilbe Dr, Pearson curve

Street-level view: $\quad$ Pearson Rd looking west in the middle of the drainage just west of Hilbe Dr.

Pre-fire imagery links: $\quad$ Google Maps Street View, Bing Maps Streetside

Post-fire imagery links: $\quad$ Google Maps Street View 


\section{Street map:}

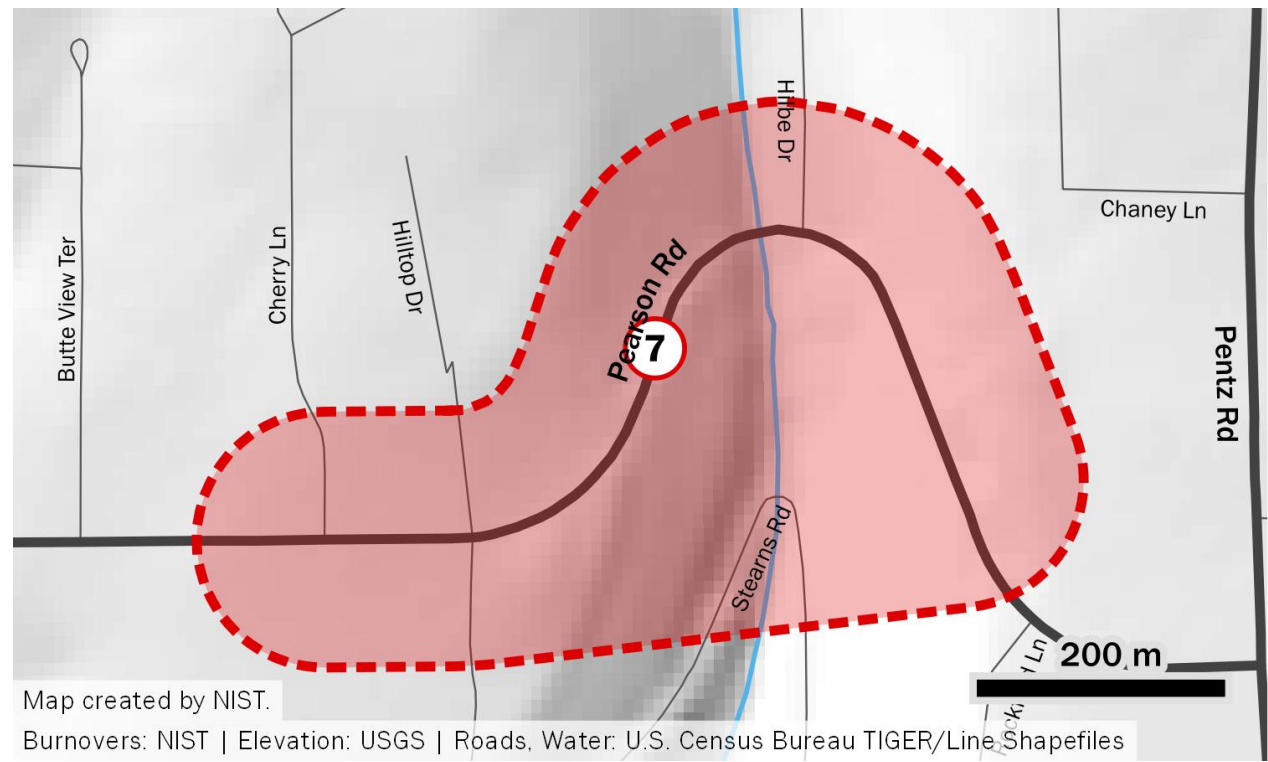

\section{Satellite view:}

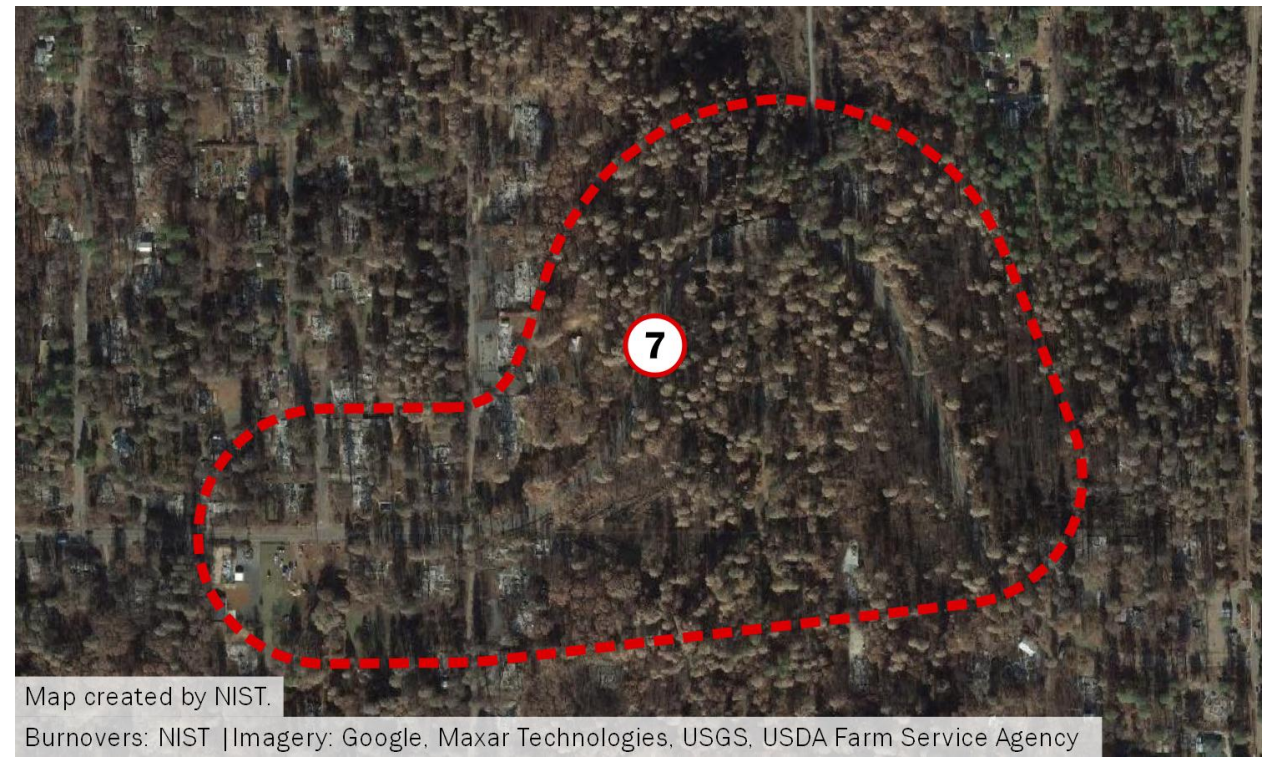




\section{Bille Road}

Date/Time: November 8, 09:25-11:45

Location: Bille Rd near Pentz Rd

Coordinates: $\quad[39.769364,-121.582853]$

Related TRA: Bille Rd

Summary: Bille Road is one of the four main east-west traffic arteries in Paradise. Fire activity at the Bille Road/Pentz Road intersection increased shortly before 09:30. Winds increased, gusting between $9 \mathrm{~m} / \mathrm{s}$ and $13 \mathrm{~m} / \mathrm{s}$ (20 mi/h and $30 \mathrm{mi} / \mathrm{h}$ ). By 09:45 fire was impacting the intersection. Multiple vehicles ignited in gridlocked traffic on Bille Road, between Pebble Lane and Pentz Road. Vehicles in the intersection of Bille Road and Pentz Road were cooled by a deck gun water monitor from a fire engine hooked to a hydrant. At noon, civilians and their vehicles were moved out of the intersection to another Temporary Refuge Area.

\begin{tabular}{|c|c|c|}
\hline Time & Observation & Source \\
\hline 09:23 & [estimate that] fire will be impacting Bille Rd within 5 min & TD-021 \\
\hline 09:23-11:45 & $\begin{array}{l}\text { hook up to hydrant to protect intersection and commercial } \\
\text { structure [using] deck gun (reach of } 30 \mathrm{~m} \text { to } 45 \mathrm{~m}(100 \mathrm{ft} \text { to } \\
150 \mathrm{ft})) \text {; good hydrant pressure; wind gusting } 9 \mathrm{~m} / \mathrm{s} \text { to } 13 \mathrm{~m} / \mathrm{s} \\
(20 \mathrm{mi} / \mathrm{h} \text { to } 30 \mathrm{mi} / \mathrm{h}) \text {; variable visibility }\end{array}$ & TD-021 \\
\hline 09:23-11:50 & homes igniting on east side Pentz Rd & TD-038 \\
\hline 09:35-09:52 & mobile homes igniting at Bille $\mathrm{Rd} / \mathrm{Pentz} \mathrm{Rd}$ & TD-060 \\
\hline 09:49 & $\begin{array}{l}\text { [near] } 1642 \text { Bille } \mathrm{Rd} \text { [there are] active flames about } 14 \mathrm{~m} \\
(15 \mathrm{yd}) \text { from the roadway }\end{array}$ & PPD \\
\hline 09:50 & fire impacting Bille Rd and vehicles abandoned/stuck on road & TD-021 \\
\hline 09:52-10:13 & $\begin{array}{l}\text { conditions on Bille Rd at Pentz Rd; cars i } \\
\text { put out a few vehicles on fire; side of eng }\end{array}$ & TD-060 \\
\hline 09:54-10:13 & $\begin{array}{l}\text { gridlock along Bille Rd, unpassable; direct cars into parking lot; } \\
\text { pickup on fire down the road }\end{array}$ & TD-079 \\
\hline 10:00-10:30 & $\begin{array}{l}\text { mobile homes ignite and burn quickly; not enough resources to } \\
\text { defend }\end{array}$ & TD-021 \\
\hline 10:16 & $\begin{array}{l}\text { "the mobile home park is going up near Pentz Rd, it's not safe up } \\
\text { here now" }\end{array}$ & PPD \\
\hline 11:00 & Bille $\mathrm{Rd}$ is blocked by burning vehicles & TD-021 \\
\hline $11: 16-11: 22$ & $\begin{array}{l}\text { fire all around; Eden Roc mobile home park had already burned; } \\
\text { engine at hydrant had deck gun going, spraying on } 50 \text { vehicles }\end{array}$ & TD-015 \\
\hline 12:02 & $\begin{array}{l}\text { "Bille Rd and Pentz Rd has been cleared, they are moving to } \\
\text { Kmart and the CMA" }\end{array}$ & PPD \\
\hline
\end{tabular}


Topography:

Roadway width:

Vegetation setbacks:

Duration:

Extent of burnover (length

of road affected):

Fire direction across road:

Wind intensity:

Fuels:

Fire behavior:

Related TD: flat, curved, roadway with trees closely lining both sides of road

$8 \mathrm{~m}(26 \mathrm{ft})$

$0 \mathrm{~m}$ to $2 \mathrm{~m}(0 \mathrm{ft}$ to $6 \mathrm{ft})$

$140 \mathrm{~min}$

$500 \mathrm{~m}(0.3 \mathrm{mi})$

north to south, east to west

gusting $9 \mathrm{~m} / \mathrm{s}$ to $13 \mathrm{~m} / \mathrm{s}(20 \mathrm{mi} / \mathrm{h}$ to $30 \mathrm{mi} / \mathrm{h})$

brush / trees, structures

fire front ignited structures and vehicles

PPD, TD-015, TD-021, TD-038, TD-040, TD-060, TD-069, TD-079, TD-084, TD-089, TD-090, TD-116, TD-118

Related streets or keywords: Pentz Rd, Tyden Way

Street-level view: $\quad$ Bille Rd looking west approaching the Tyden Way intersection.

Pre-fire imagery links: $\quad$ Google Maps Street View, Bing Maps Streetside

Post-fire imagery links: Google Maps Street View, TD-041 (below) 


\section{Street map:}

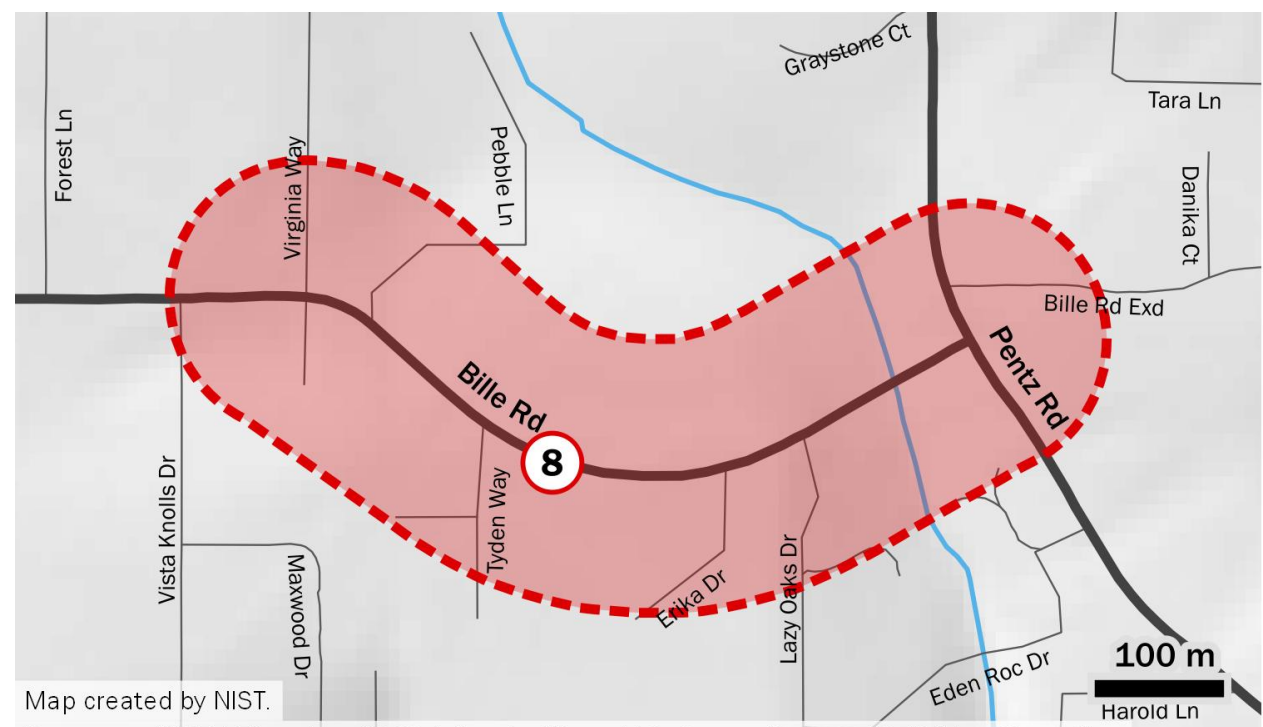

Burnovers: NISTed Elevation: USGS | Roads, Water: U.S. Census Bureau TIGER/Line Shapefiles

\section{Satellite view:}

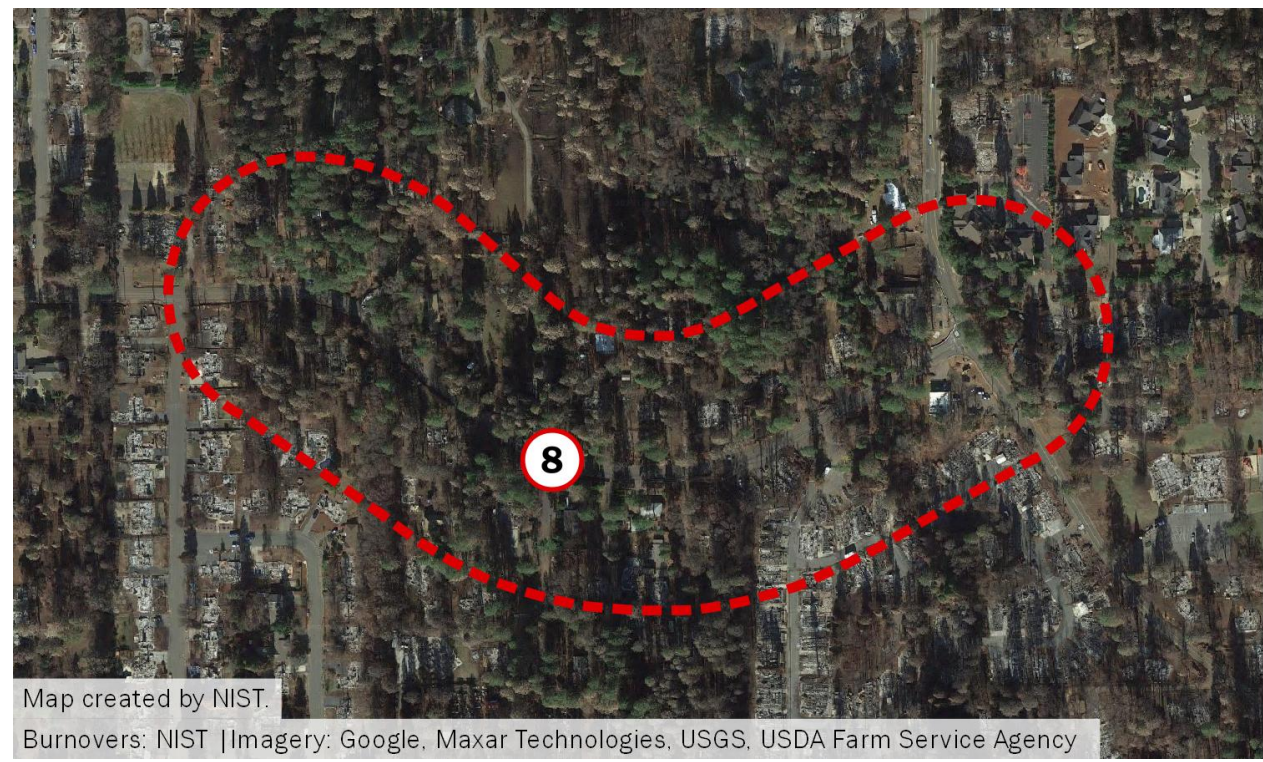




\section{Wagstaff Road}

Date/Time: November 8, 9:30-10:30

Location: Wagstaff Rd, Paradise, between Oak Way and Rocky Ln

Coordinates: $\quad[39.777655,-121.603046]$

Related TRA: n/a

Summary: Wagstaff Road is one of the four main east-west traffic arteries in Paradise. Fire was reported on the bike path at Wagstaff Road at 08:46. Spot fire activity increased and expanded, and at 09:21 multiple cars were reported on fire. Before 10:00 power lines were falling into the roadway. Wagstaff Road and side streets experienced severe fire exposures from burning vegetation and structures, limiting access of first responders. Fire progressed toward the southwest in the late morning and the roadway was passable, with structures still burning, at 10:44.

\begin{tabular}{|c|c|c|}
\hline Time & Observation & Source \\
\hline 08:46 & fire reported on bike path at Wagstaff Rd & $\begin{array}{l}911- \\
178-2\end{array}$ \\
\hline 08:50-09:00 & $\begin{array}{l}\text { Wagstaff Rd; gridlocked, houses burning, trees burning on north } \\
\text { side }\end{array}$ & TD-053 \\
\hline 09:15-10:23 & $\begin{array}{l}\text { spot fires increase [in number along Wagstaff Rd] closer to } \\
\text { Skyway }\end{array}$ & TD-042 \\
\hline 09:17-11:00 & $\begin{array}{l}\text { fire spotting in, pinching Wagstaff Rd between Clark Rd and } \\
\text { Skyway }\end{array}$ & TD-017 \\
\hline 09:21 & $\begin{array}{l}\text { well-established spot fire off Wagstaff Rd near the bike path; } \\
\text { Skyway at Wagstaff Rd about to be threatened, multiple cars on } \\
\text { fire }\end{array}$ & TD-111 \\
\hline 09:30-10:00 & $\begin{array}{l}\text { fire is burning from the NE into area of Rocky Ln and Wagstaff } \\
\text { Rd; [fire engine is] in the area }\end{array}$ & TD-127 \\
\hline 09:37 & stuck in traffic on Wagstaff Rd, structures burning & TD-127 \\
\hline 09:40 & $\begin{array}{l}\text { "[a fire engine is] holding position on Wagstaff }[400 \mathrm{~m}] 0.25 \mathrm{mi} \\
\text { from Skyway; several structures threatened/involved, it will close } \\
\text { off the Wagstaff Rd route; we could use another engine" }\end{array}$ & TD-055 \\
\hline 09:47 & $\begin{array}{l}\text { powerlines coming down into traffic; fire coming across Wagstaff } \\
\text { Rd }\end{array}$ & TD-127 \\
\hline 10:15-10:17 & $\begin{array}{l}\text { WB on Wagstaff Rd to Harvey Rd, turn around; lots of fire, } \\
\text { structures burning both sides of Wagstaff Rd }\end{array}$ & TD-014 \\
\hline 10:17 & $\begin{array}{l}\text { stuck in intersection of Oak Way and Wagstaff Rd waiting for } \\
\text { fire to die down }\end{array}$ & TD-127 \\
\hline
\end{tabular}




\begin{tabular}{clc}
\hline Time & Observation & Source \\
\hline \multirow{2}{*}{ 10:44 } & $\begin{array}{l}\text { multiple structures fully involved; homes to the west of Harvey } \\
\text { Rd on north side of Wagstaff Rd are fully involved, some have } \\
\text { collapsed }\end{array}$ & VTD-13 \\
fire heavily impacting Oak Way and towards Bille Rd & TD-127 \\
\hline
\end{tabular}

Topography:

Roadway width:

Vegetation setbacks:

Duration:

Extent of burnover (length $500 \mathrm{~m}(0.3 \mathrm{mi})$ of road affected):

Fire direction across road:

Wind intensity:

Fuels:

Fire behavior:

Related TD:

Street-level view:

Pre-fire imagery links:

Post-fire imagery links:

Mostly flat

$8 \mathrm{~m}(26 \mathrm{ft})$

$60 \mathrm{~min}$

north to south

$\mathrm{n} / \mathrm{d}$, variable intersection.
$0 \mathrm{~m}$ to $3 \mathrm{~m}(0 \mathrm{ft}$ to $10 \mathrm{ft})$

brush/trees, structures

initial spot fires progressed to structures, with high radiation, flame, and ember exposures

911-129-1, 911-162-1, 911-169-1, 911-178-2, PPD, TD-009, TD-014, TD-017, TD-022, TD-042, TD-053, TD-055, TD-064, TD-085, TD-111, TD-127, VTD-13, VTD-18, VTD-26

Related streets or keywords: Wagstaff Rd, Oak Way, Harvey Rd, Rocky Ln

Wagstaff Rd looking west approaching the Oak Way

Google Maps Street View, Bing Maps Streetside

Google Maps Street View 


\section{Street map:}

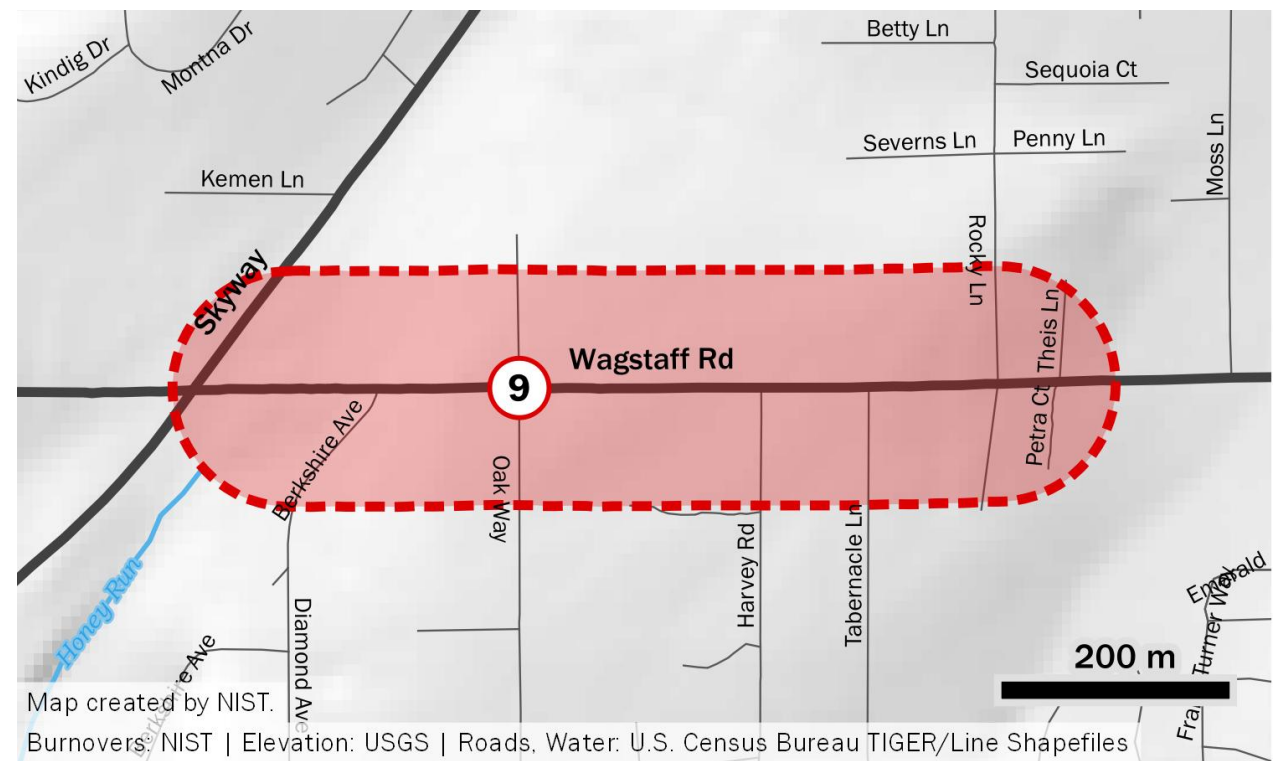

\section{Satellite view:}

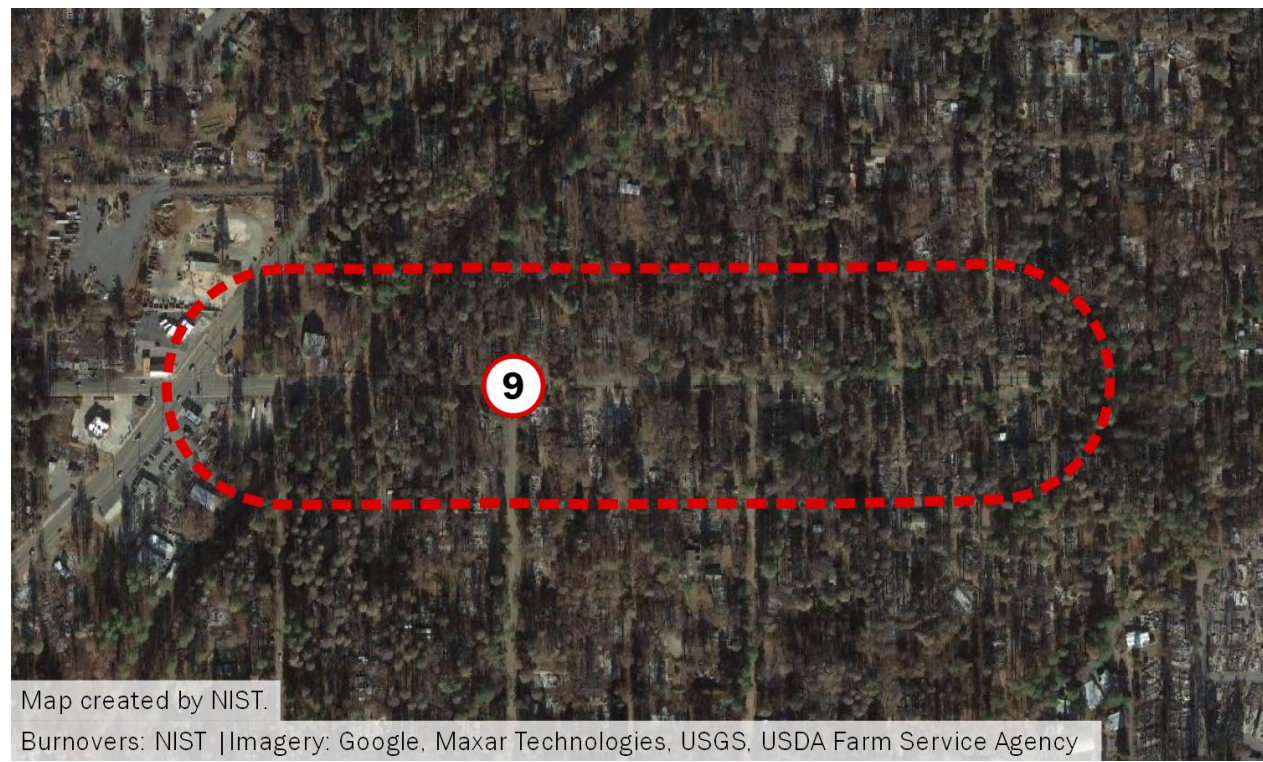




\section{Clark Road/American Way}
Date/Time: $\quad$ November 8,10:00-12:00
Location: $\quad$ Clark Rd, Paradise, near American Way
Coordinates: $\quad[39.738857,-121.611887]$
Related TRA: Best Western, Ace Hardware
Summary: $\quad$ Fire impacted Clark Road between American Way and Lanser Drive around 10:00. Fire was burning on both sides of Clark Rd and erratic winds of $13 \mathrm{~m} / \mathrm{s}$ to $18 \mathrm{~m} / \mathrm{s}(30 \mathrm{mi} / \mathrm{h}$ to $40 \mathrm{mi} / \mathrm{h})$ and fire tornadoes were reported in the area. Flames blocked the road and first responders redirected traffic back toward Paradise. Intense fire activity was reported intermittently until 11:30. Low hanging power lines were reported before the road was fully opened to traffic after noon. See concurrent events further south at Airport Road (page 203).

\begin{tabular}{|c|c|c|}
\hline Time & Observation & Source \\
\hline $10: 00-10: 15$ & $\begin{array}{l}\text { fire on both sides of road; wind very strong, shaking bus; saw fire } \\
\text { tornadoes }\end{array}$ & TD-049 \\
\hline $10: 02$ & fire burning on west side of Clark Rd near American Way & TD-009 \\
\hline $10: 17$ & $\begin{array}{l}\text { Clark Rd [near American Way]; fire had just hit - vehicles are } \\
\text { burning; guardrail posts on fire; flames fully or partially blocking } \\
\text { roadway; } 13 \mathrm{~m} / \mathrm{s} \text { to } 18 \mathrm{~m} / \mathrm{s} \text { ( } 30 \mathrm{mi} / \mathrm{h} \text { to } 40 \mathrm{mi} / \mathrm{h} \text { ) erratic winds; } \\
\text { some vehicles driving SB in NB lanes; zero visibility }\end{array}$ & TD-041 \\
\hline $10: 18$ & $\begin{array}{l}\text { advised that conditions to south are bad; drive down to bend } \\
\text { [Clark Rd near Lanser Dr]; bad fire across roadway }\end{array}$ & TD-065 \\
\hline $10: 21$ & $\begin{array}{l}\text { "vehicle evacuations coming down Clark Rd are really slowing } \\
\text { down and are going to be impacted by fire; fire is impacting line } \\
\text { of traffic" }\end{array}$ & $\begin{array}{l}\text { Radio } \\
\text { Log }\end{array}$ \\
\hline $10: 40-12: 10$ & $\begin{array}{l}\text { all structures are burning; dark, but visibility better than in } \\
\text { Concow }\end{array}$ & TD-110 \\
\hline $11: 08-12: 31$ & $\begin{array}{l}\text { fire coming up from drainage [on east side of Clark Rd]; fire } \\
\text { burning on both sides of Clark Rd; powerlines down }\end{array}$ & TD-211 \\
\hline $11: 12$ & $\begin{array}{l}\text { turning around civilians on Clark Rd at American Way to go back } \\
\text { north toward Paradise; [fire blocking Clark Rd] }\end{array}$ & TD-211 \\
\hline $11: 14-11: 54$ & $\begin{array}{l}\text { open up Clark Rd NB back into Paradise; send vehicles back } \\
\text { north to parking lot at Ace Hardware to get off road }\end{array}$ & TD-100 \\
\hline $11: 14-11: 54$ & $\begin{array}{l}\text { flames blowing across Clark Rd; stuck with } 50 \text { civilian vehicles } \\
\text { between Round Valley Ranch Rd and Lanser Dr at American } \\
\text { Way }\end{array}$ & TD-100 \\
\hline
\end{tabular}




\begin{tabular}{clr}
\hline Time & Observation & Source \\
\hline 11:30-11:34 & $\begin{array}{l}\text { stop and wait for fire front across Clark Rd; then drive through } \\
\text { firec black, everything on fire; foam line on engine burned }\end{array}$ & TD-208 \\
& $\begin{array}{l}\text { up } \\
\text { pitch black as night; everything burning, past peak, Clark Rd } \\
\text { between Buschmann Rd and Old Clark Rd } \\
\text { hear that road is opened up; vehicles from Best Western can be } \\
\text { evacuated }\end{array}$ & VTD-15 \\
\hline
\end{tabular}

Topography:

Roadway width:

Vegetation setbacks:

Duration:

Extent of burnover (length $700 \mathrm{~m}(0.5 \mathrm{mi})$

of road affected):

Fire direction across road:

Wind intensity:

Fuels:

Fire behavior:

Related TD:

Street-level view:

Pre-fire imagery links:

Post-fire imagery links:

$11 \mathrm{~m}(36 \mathrm{ft})$

$120 \mathrm{~min}$

east to west

brush/trees VTD-15 near the top of a ridge, east aspect slope on either side of the roadway down to canyon to east

$1 \mathrm{~m}$ to $3 \mathrm{~m}(2 \mathrm{ft}$ to $10 \mathrm{ft})$

$13 \mathrm{~m} / \mathrm{s}$ to $18 \mathrm{~m} / \mathrm{s}(30 \mathrm{mi} / \mathrm{h}$ to $40 \mathrm{mi} / \mathrm{h})$

flames fully or partially blocking roadway, flames blowing across roadway, fire tornados

PPD, Radio Log, TD-009, TD-035, TD-041, TD-049, TD-065, TD-100, TD-110, TD-130, TD-208, TD-211,

Related streets or keywords: Lanser Dr, Easy St, Round Valley Ranch Rd

Clark Rd looking southwest between Lanser Dr and American Way.

$\underline{\text { Google Maps Street View, Bing Maps Streetside }}$

Google Maps Street View 


\section{Street map:}

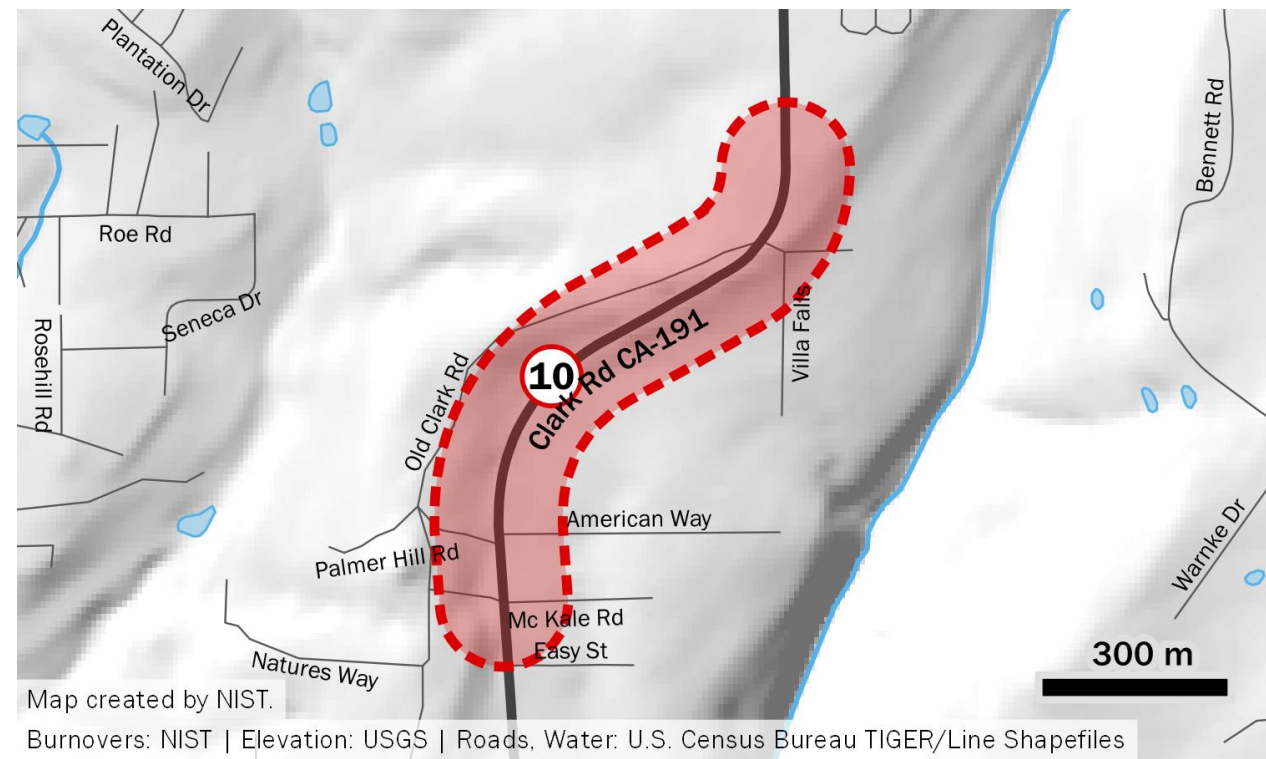

\section{Satellite view:}

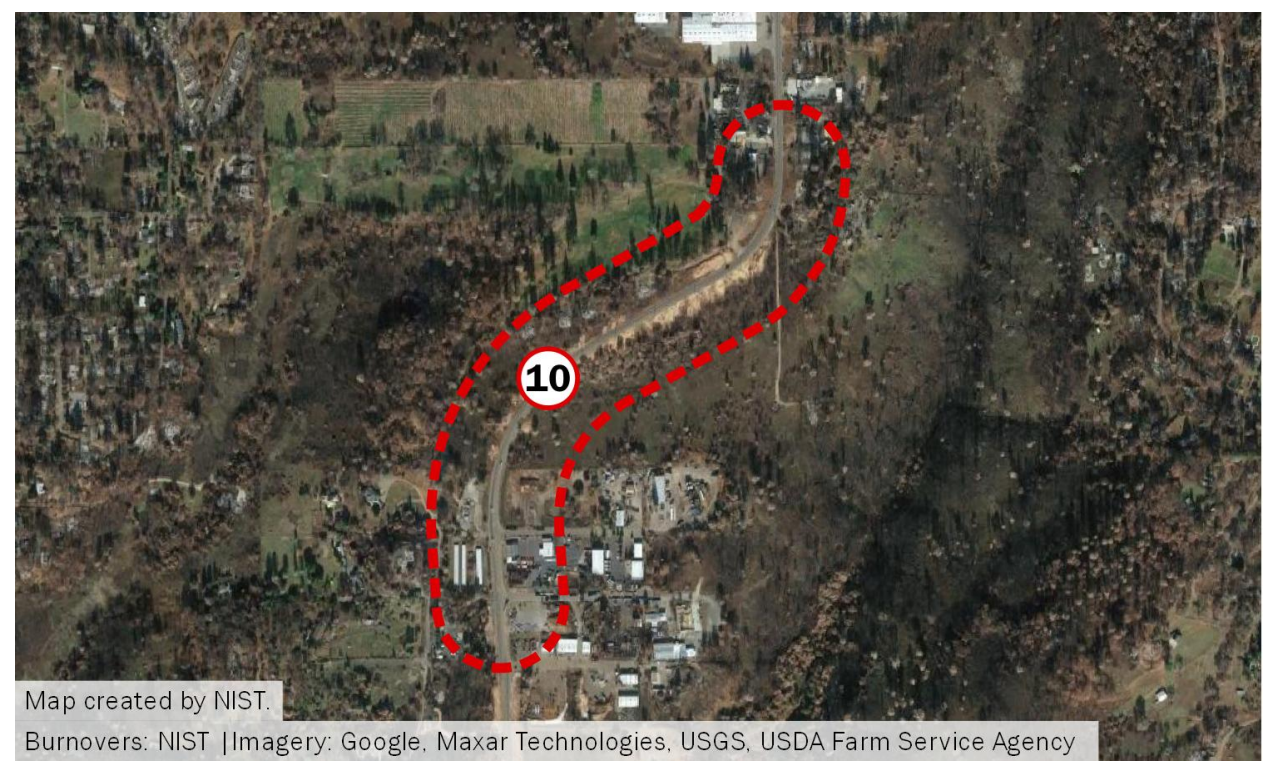




\title{
11. Clark Road/Airport Road
}

\author{
Date/Time: $\quad$ November 8, 10:00-11:30
}

Location: $\quad$ Clark $\mathrm{Rd}$ at Airport $\mathrm{Rd}$, south of Paradise

Coordinates: $\quad[39.715652,-121.611268]$

Related TRA: n/a

Summary: Clark Road is one of the four north-south traffic arteries in Paradise. Fire was impacting Clark Road south of Round Valley Ranch Road by 10:00. Shortly after the road was closed to traffic and remained closed until 10:46 when a single lane of traffic was permitted to drive through. Fire activity intensified again and by 11:13 the road was closed again. Arriving fire engines coming from the south encountered flames blowing across Clark Road at Airport Road and waited for the flames to subside at 11:26. By 13:00 fire activity had subsided along Clark Road, however, downed powerlines/power poles restricted first responder movement until cleared.

\begin{tabular}{|c|c|c|}
\hline Time & Observation & Source \\
\hline 10:18 & $\begin{array}{l}\text { "SB traffic on Clark Rd south of town limits, fire encroaching } \\
\text { roadway; need a detour on Buschmann Rd over to Skyway; no } \\
\text { more traffic SB on Clark Rd" }\end{array}$ & PPD \\
\hline 10:30-10:40 & fire on Clark Rd at Airport Rd & TD-110 \\
\hline $10: 46$ & $\begin{array}{l}\text { drove down Clark Rd toward Round Valley - [a fire fighter] says } \\
\text { Clark Rd SB is passable with a single lane in the center and no } \\
\text { stopping }\end{array}$ & TD-065 \\
\hline $10: 46$ & $\begin{array}{l}\text { "I have fire both sides of roadway but we are safe to have one } \\
\text { lane as long as they stay on the west side of the road and keep } \\
\text { moving near Round Valley; divert Buschmann Rd and SB Clark } \\
\text { Rd to go SB on Clark Rd out of town" }\end{array}$ & PPD \\
\hline 10:52 & $\begin{array}{l}\text { flames coming from the east towards Clark Rd between Airport } \\
\text { Rd and Round Valley Ranch Rd }\end{array}$ & TD-210 \\
\hline $10: 53$ & suddenly gets very dark & TD-130 \\
\hline 11:00-11:15 & $\begin{array}{l}\text { fire all around, } 46 \mathrm{~m}(50 \mathrm{ft}) \text { flames crossing Clark Rd; traffic all } \\
\text { SB on Clark Rd; cannot see oncoming headlights further than } \\
1.5 \mathrm{~m}(5 \mathrm{ft})\end{array}$ & TD-100 \\
\hline $11: 13$ & $\begin{array}{l}\text { [heading } N B \text { and must] turn around due to heavy fire impacting } \\
\text { and blocking roadway on Clark Rd }\end{array}$ & TD-208 \\
\hline 11:14 & $\begin{array}{l}\text { Clark Rd is no longer a safe evacuation route; heavily impacted } \\
\text { fire near the airport }\end{array}$ & TD-110 \\
\hline 11:14-11:54 & $\begin{array}{l}\text { shut down Clark Rd; impassable with zero visibility and flames; } \\
\text { last vehicle through is a trailer, driving through flames }\end{array}$ & TD-100 \\
\hline
\end{tabular}




\begin{tabular}{clc}
\hline Time & Observation & Source \\
\hline $11: 15-11: 26$ & $\begin{array}{l}\text { stop and wait on Clark Rd at airport for fire to die down to } \\
\text { continue north; no traffic north of here } \\
\text { turn around on Clark Rd near Meadowsong Dr; Clark Rd is } \\
\text { impassable }\end{array}$ & TD-208 \\
12:25 & $\begin{array}{l}\text { "just took Clark Rd south from Pearson Rd, I made it past the } \\
\text { airport, it clears up, it's barely passable” } \\
\text { fire burning through guardrail posts; burning branches in } \\
\text { roadway; heavy fire on Good View Dr, structures burning; } \\
\text { visibility poor, dark smoky }\end{array}$ & PPD \\
& & VTD-06 \\
\hline
\end{tabular}

Topography:

Roadway width:

Vegetation setbacks:

Duration:

Extent of burnover (length of road affected):

Fire direction across road: east to west

Wind intensity:

Fuels:

Fire behavior:

Related TD:

$9 \mathrm{~m}(30 \mathrm{ft})$

$1 \mathrm{~m}(3 \mathrm{ft})$

$90 \mathrm{~min}$

$\mathrm{n} / \mathrm{d}$

brush/trees road slightly up hill, steep canyon to the east

$1.5 \mathrm{~km}(0.9 \mathrm{mi})$

$15 \mathrm{~m}$ (50 ft) flames from canyon impacting roadway, burning guardrail posts

PPD, TD-065, TD-100, TD-101, TD-110, TD-130, TD-208, TD-210, TD-211, VTD-06

Related streets or keywords: Good View Rd, Round Valley Ranch Rd

Street-level view:

Clark Rd in area of burnover, north of Airport Rd intersection looking north.

Pre-fire imagery links: $\quad$ Bing Maps Streetside

Post-fire imagery links: $\quad$ Google Maps Street View 


\section{Street map:}

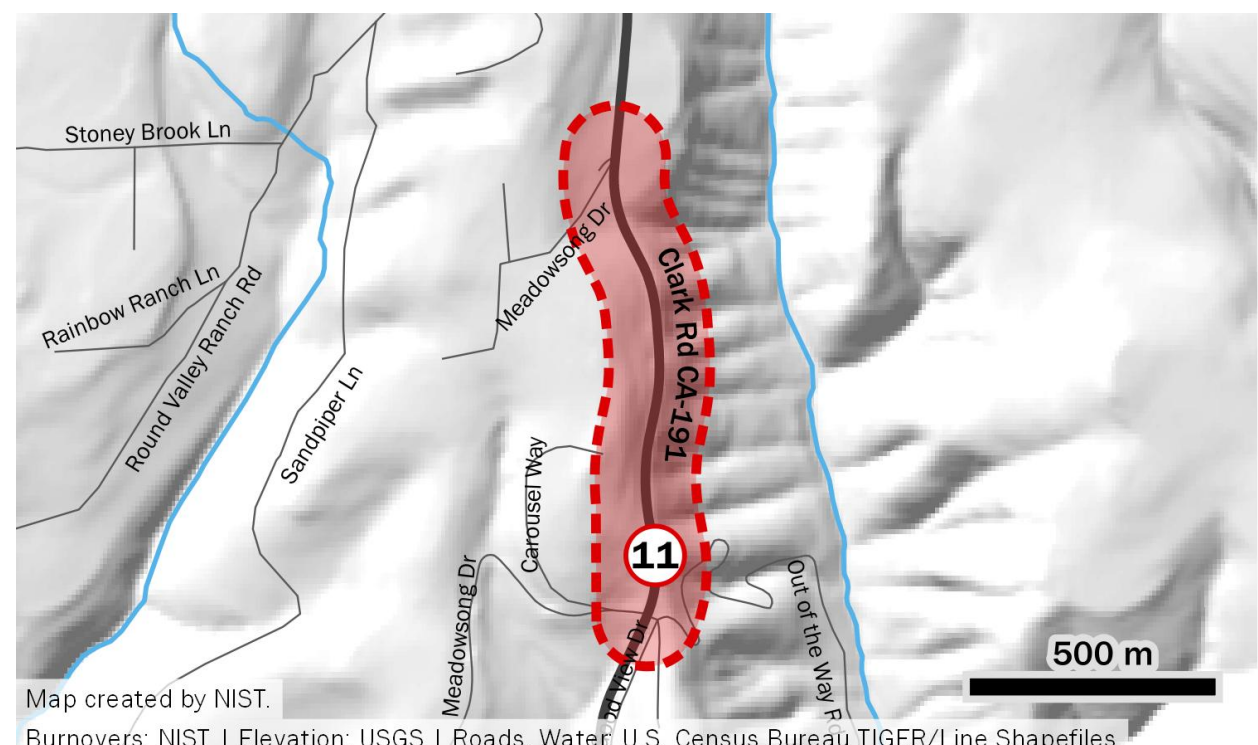

\section{Satellite view:}

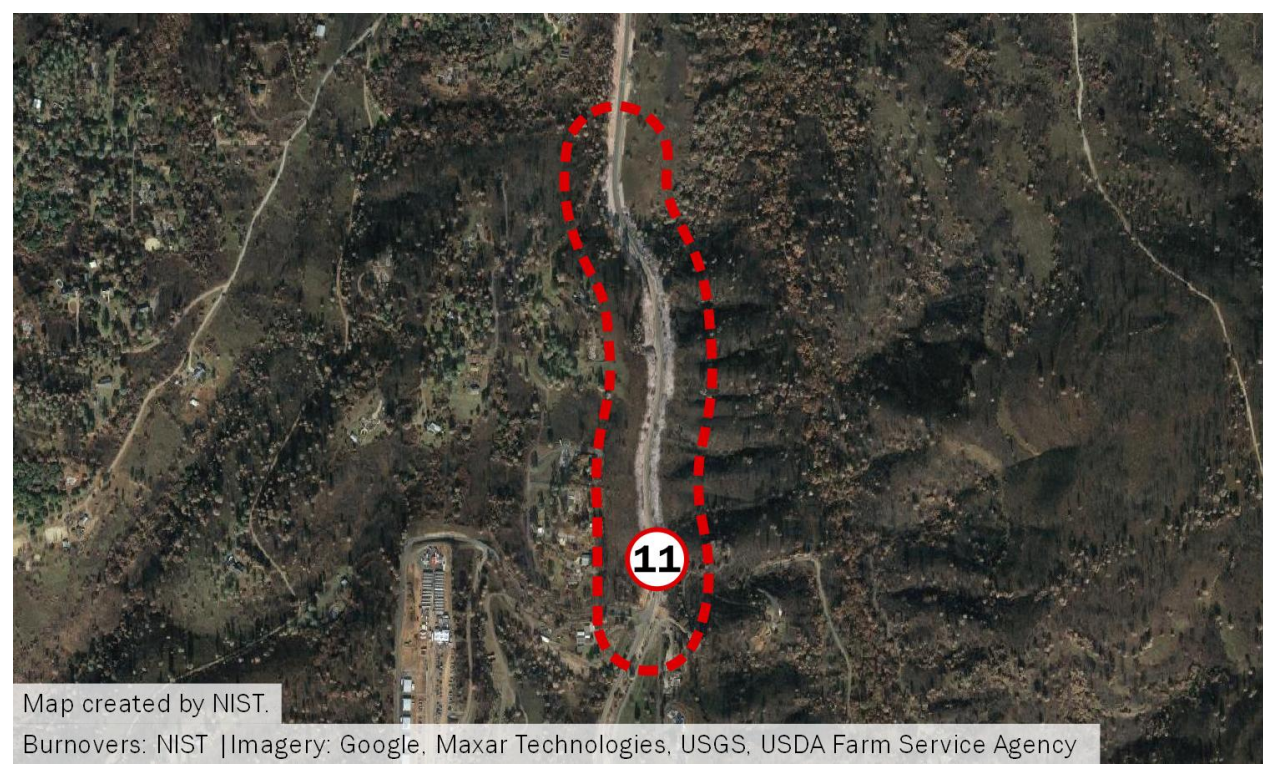




\section{Skyway (lower, west of Princeton Way)}

Date/Time: November 8, 10:15-11:45

Location: $\quad$ Skyway, Paradise, between Skyway Crossroad and Princeton Way

Coordinates: $\quad[39.745615,-121.648307]$

Related TRA: n/a

Summary: Skyway is one of the four north-south traffic arteries in Paradise. Intense fire against the roadway was observed on lower Skyway in the vicinity of the lane divide near the town limits by 10:19. By 10:45 traffic was leaving Paradise using a single lane due to downed power poles. Fire activity in the area increased significantly impacting civilian evacuations until the early afternoon.

\begin{tabular}{|c|c|c|}
\hline Time & Observation & Source \\
\hline 10:19 & $\begin{array}{l}\text { Skyway NB; traffic all lanes SB; fire burning south side Skyway, } \\
\text { fences, structures, vegetation; visibility dark, smoky, } 6 \mathrm{~m}(20 \mathrm{ft})\end{array}$ & TD-155 \\
\hline $10: 22$ & $\begin{array}{l}\text { Cannot continue NB into heavy traffic and heavy fire activity, } \\
\text { turn around and retreat SB }\end{array}$ & TD-155 \\
\hline 10:30-11:00 & drove through fire, everything on fire Skyway & TD-025 \\
\hline $10: 44$ & $\begin{array}{l}\text { vehicles heading single file down Skyway SB using NB lanes at } \\
\text { the split; traffic moving } 40 \mathrm{~km} / \mathrm{h}(25 \mathrm{mi} / \mathrm{h})\end{array}$ & VTD-14 \\
\hline $10: 44$ & structures fully involved on south side Skyway & VTD-14 \\
\hline 10:44 & $\begin{array}{l}\text { heavy intense fire burning both sides Skyway NB lanes between } \\
\text { split and past paradise sign }\end{array}$ & VTD-22 \\
\hline $10: 45-11: 12$ & $\begin{array}{l}\text { left side skyway, heavy vegetation fire; traffic is slow/stopped, } \\
\text { two lanes SB on SB lanes, just south of Feather River Health }\end{array}$ & VTD-13 \\
\hline $11: 12$ & $\begin{array}{l}\text { south side Skyway heavy fire near Princeton Way; traffic moving } \\
\text { quickly down SB lanes; unclear if all traffic heading this way or } \\
\text { also using NB lanes }\end{array}$ & VTD-13 \\
\hline 11:13 & $\begin{array}{l}\text { heavy fire, structures fully involved, both sides roadway between } \\
\text { Skyway split and Skyway Crossroad }\end{array}$ & VTD-13 \\
\hline $11: 30$ & $\begin{array}{l}\text { Skyway split is fully involved both sides; cars are following each } \\
\text { other closely to get out }\end{array}$ & TD-011 \\
\hline $11: 38$ & structures burning in middle of Skyway split & TD-058 \\
\hline $11: 38$ & $\begin{array}{l}\text { everything on fire; trees, cars, houses, telephone poles; power } \\
\text { lines down }\end{array}$ & TD-058 \\
\hline $12: 45$ & $\begin{array}{l}\text { fire on both sides, fully involved, roofs on fire; pitch black; area } \\
\text { of Skyway and Princeton Way }\end{array}$ & TD-026 \\
\hline
\end{tabular}


Topography:

Roadway width:

Vegetation setbacks:

Duration:

Extent of burnover (length $1 \mathrm{~km}(0.6 \mathrm{mi})$

of road affected):

Fire direction across road: northwest to southeast

Wind intensity:

Fuels:

Fire behavior:

Related TD:

$\mathrm{n} / \mathrm{d}$

brush / trees

intense exposure from vegetation fires, torching, ember showers

TD-011, TD-025, TD-026, TD-058, TD-070, TD-155, VTD-13, VTD-14, VTD-22, VTD-26

Related streets or keywords: Skyway split (lane divide), Skyway Crossroad, Princeton Way

Street-level view:

Skyway looking southwest at the lane divide.

Pre-fire imagery links:

Post-fire imagery links:

Street-level view:

Pre-fire imagery links:

Post-fire imagery links:
Google Maps Street View, Bing Maps Streetside

Google Maps Street View

Skyway looking west toward the lane divide, just west of Princeton Way.

Google Maps Street View, Bing Maps Streetside

Google Maps Street View 


\section{Street map:}

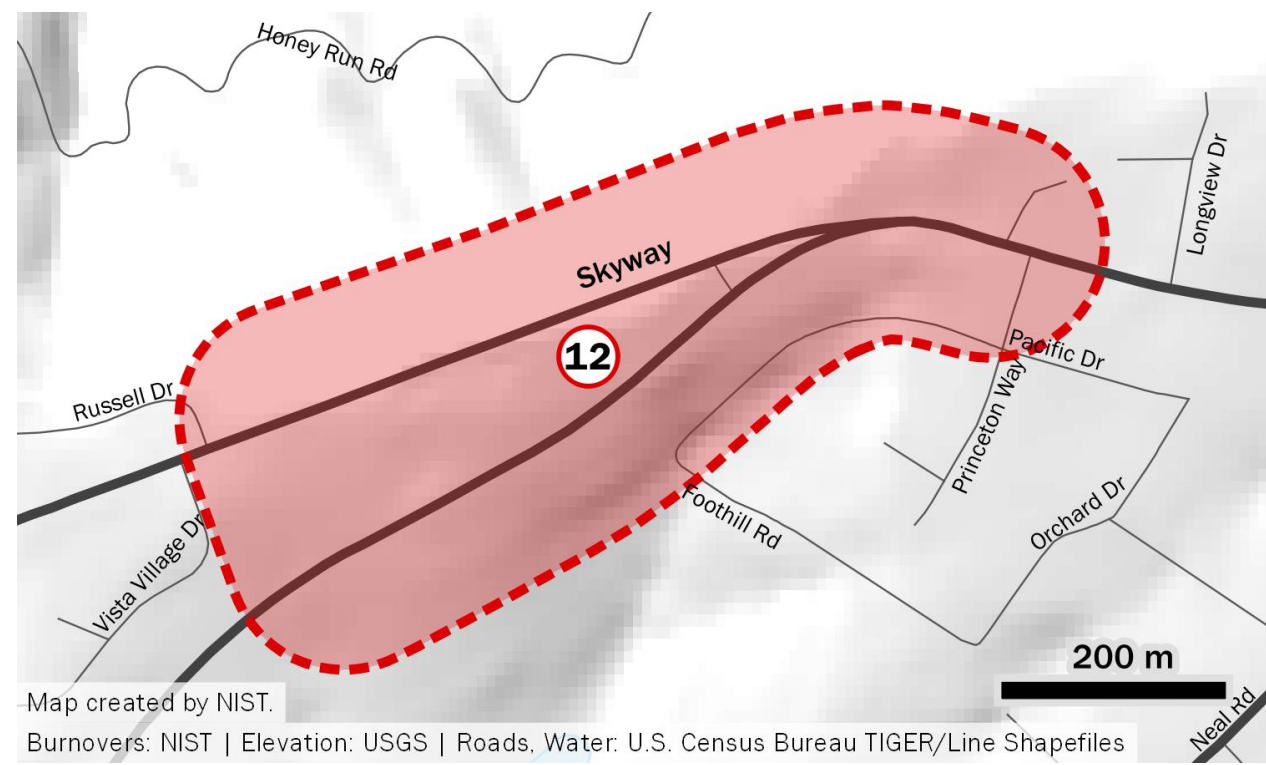

\section{Satellite view:}

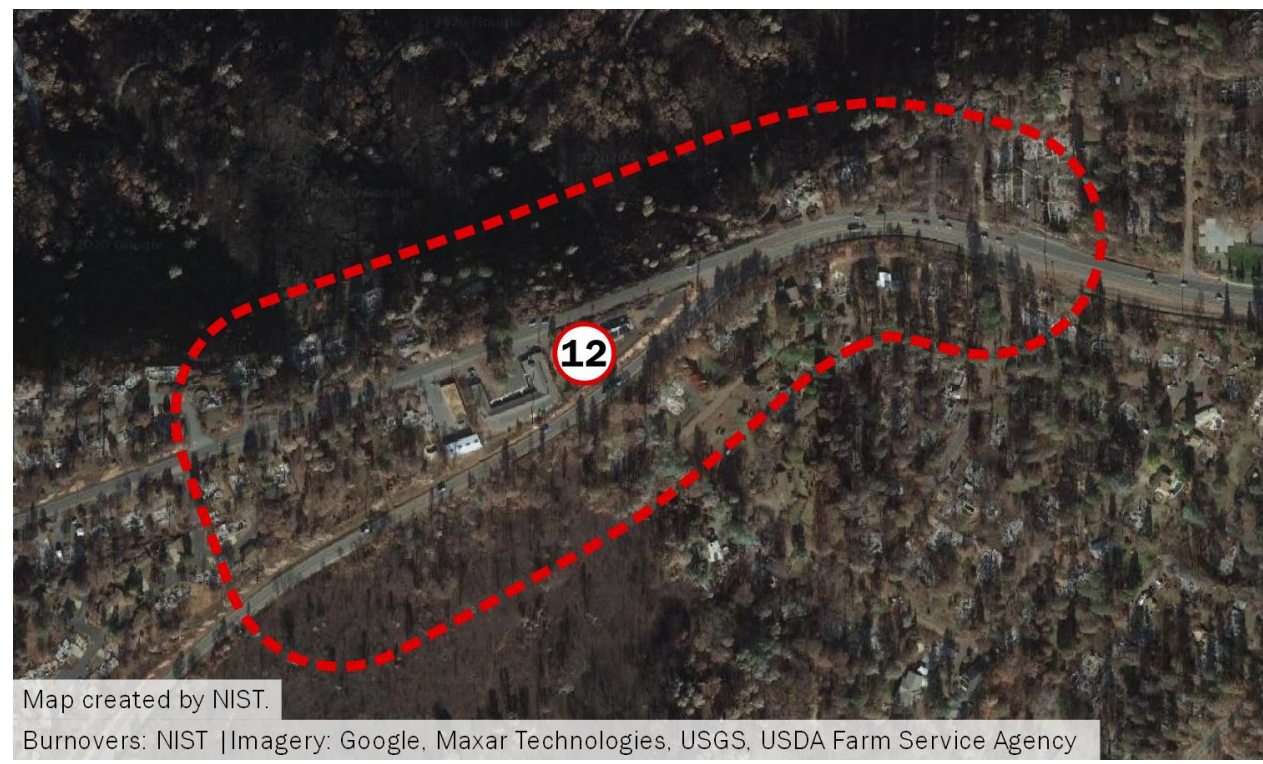




\section{Jordan Hill Road/Granite Ridge Road}

Date/Time: November 8, 11:30

Location: Jordan Hill Rd at Granite Ridge Rd, south of Concow

Coordinates: $\quad[39.753223,-121.552523]$

Related TRA: n/a

Summary: A fire engine responded to Granite Ridge Road at 11:18 in response to a call regarding civilian entrapment. Fire was over the ridge to the northeast of Jordan Hill Road as they arrived. The burnover occurred while first responders were evacuating the Jordan Hill area. On the drive out at 11:32, flame lengths were $30 \mathrm{~m}$ to $45 \mathrm{~m}(100 \mathrm{ft}$ to $150 \mathrm{ft})$ near the road as the fire engine led civilian vehicles out of the fire. All vehicles drove through flames to escape and the engine suffered damage. There is insufficient data to determine the temporal extent of this burnover. The engine returned to Concow Road at 11:40.

\begin{tabular}{clc}
\hline Time & Observation & Source \\
\hline $11: 18$ & $\begin{array}{l}\text { ECC provides notification of entrapment Granite Ridge Rd via } \\
\text { radio }\end{array}$ & TD-008 \\
$11: 18$ & $\begin{array}{l}\text { flames making way over the ridge } \\
\text { observe } 30 \mathrm{~m} \text { to } 45 \mathrm{~m}(100 \mathrm{ft} \text { to } 150 \mathrm{ft}) \text { flame lengths } \\
\text { [approaching Jordan Hill Rd from north] } \\
11: 32\end{array}$ & $\begin{array}{l}\text { TD-062 } \\
\text { as driving out, fire well established in canyon below [Jordan Hill }\end{array}$ \\
\hline
\end{tabular}


Topography:

Roadway width:

Vegetation setbacks:

Duration:

Extent of burnover (length

of road affected):

Fire direction across road:

Wind intensity:

Fuels:

Fire behavior:

Related TD:

Related streets or keywords: n/a

$\mathrm{n} / \mathrm{d}$ steep slope along ravine/canyon

$5 \mathrm{~m}(16 \mathrm{ft})$

$0 \mathrm{~m}$ to $4 \mathrm{~m}(0 \mathrm{ft}$ to $13 \mathrm{ft})$

$\mathrm{n} / \mathrm{d}$, however impact on firefighters and civilians

approximately 10 minutes

$800 \mathrm{~m}(0.5 \mathrm{mi})$

north to south

brush/trees

large flame lengths, $30 \mathrm{~m}$ to $45 \mathrm{~m}(100 \mathrm{ft}$ to $150 \mathrm{ft})$ from overgrown vegetation in canyon

TD-008, TD-031, TD-062
Street-level view:

Pre-fire imagery links:

Post-fire imagery links:

Street-level view:

Pre-fire imagery links:

Post-fire imagery links:
Granite Ridge Rd looking east toward intersection with Jordan Hill Rd.

Bing Maps Streetside

No imagery available.

View northwest on Jordan Hill Rd, midway between Concow $\mathrm{Rd}$ and the ridgetop at Granite Ridge $\mathrm{Rd}$.

Bing Maps Streetside

No imagery available. 


\section{Street map:}

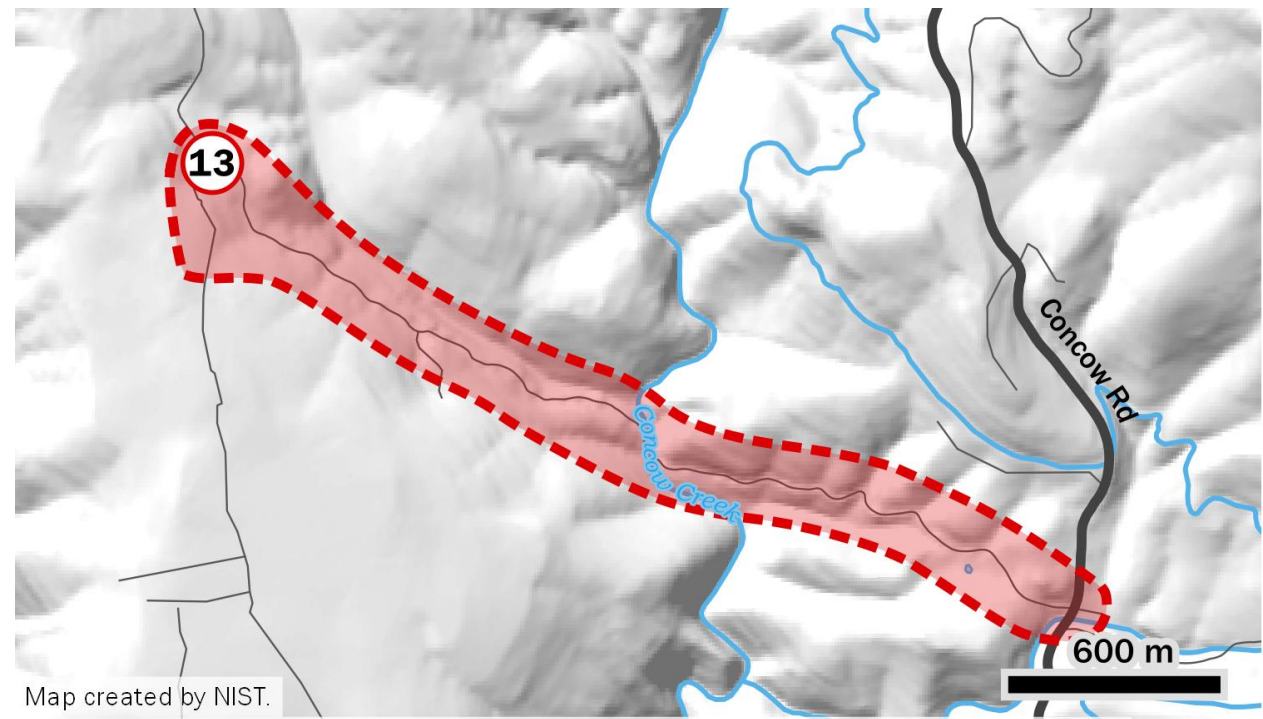

Burnovers: NIST | Elevation: USGS | Roads. Water: U.S. Census Bureau TIGER/Line Shapefiles

\section{Satellite view:}

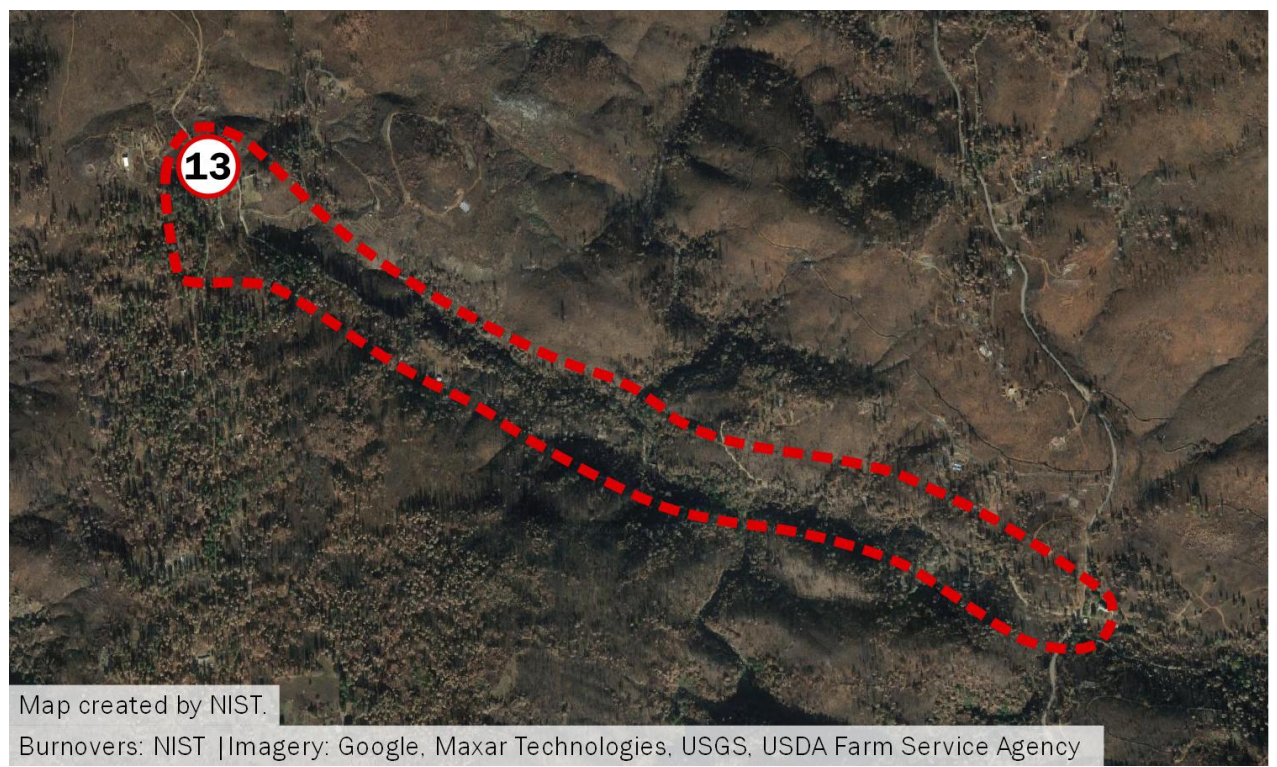




\section{Clark Road/Black Bear Diner}

\section{Date/Time: $\quad$ November 8, 13:10}

Location: $\quad 5791$ Clark Rd, Paradise, at Black Bear Diner

Coordinates: $\quad[39.753598,-121.607740]$

Related TRA: n/a

Summary: At approximately 12:30 there was minimal visible fire activity reported on Clark Road between Nunneley Road and Person Road, however this may be in part due to the observed heavy black smoke and reduced visibility. At 13:10, firefighters attempted to drive south on Clark Road and encountered reduced visibility and heavy fire exposure forcing them to turn around. This event does not meet the NWCG definition of burnover, as first responders were able to backtrack their way out and were not in life-threatening danger. No civilians were impacted by this incident. It is included here, however, to illustrate that even a major artery with a sidewalk to sidewalk width of $23.5 \mathrm{~m}$ (77 ft) can be rendered impassable by the exposures generated from one or more fully involved commercial buildings. There is insufficient data to determine the temporal extent of this burnover.

\begin{tabular}{clc}
\hline Time & Observation & Source \\
\hline 12:28-12:28 & $\begin{array}{l}\text { minimal fire visible between Nunneley Rd and Pearson Rd; } \\
\text { visibility black, zero visibility on Clark Rd } \\
\text { visibility zero, can't see, heavy fire; so turn around and head back } \\
\text { NB on Clark Rd }\end{array}$ & PPD \\
\hline
\end{tabular}


Topography: flat

Roadway width: $\quad 23 \mathrm{~m}(75 \mathrm{ft})$

Vegetation setbacks: $\quad 3 \mathrm{~m}(10 \mathrm{ft})$ structure setback from sidewalk

Duration: $\quad \mathrm{n} / \mathrm{d}$

Extent of burnover (length $150 \mathrm{~m}(500 \mathrm{ft})$

of road affected):

Fire direction across road: primary exposure from structure on west side of road

Wind intensity: $\quad \mathrm{n} / \mathrm{d}$

Fuels: commercial structures, ornamental vegetation

Fire behavior: burning commercial structure

Related TD: $\quad$ PPD, TD-021

Related streets or keywords: $\mathrm{n} / \mathrm{a}$

Street-level view: $\quad$ Clark Rd at Black Bear Diner looking northwest at the diner building.

Pre-fire imagery links: $\quad$ Google Maps Street View, Bing Maps Streetside

Post-fire imagery links: $\quad$ Google Maps Street View 


\section{Street map:}

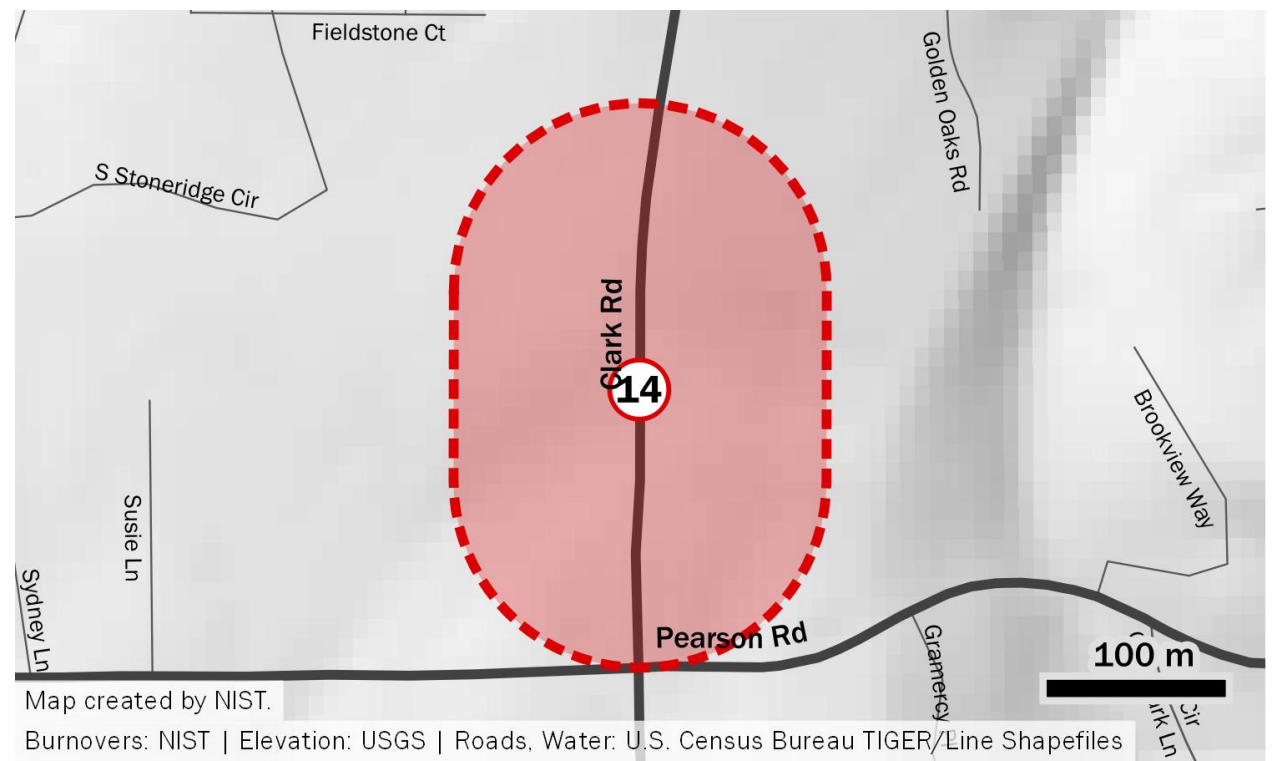

\section{Satellite view:}

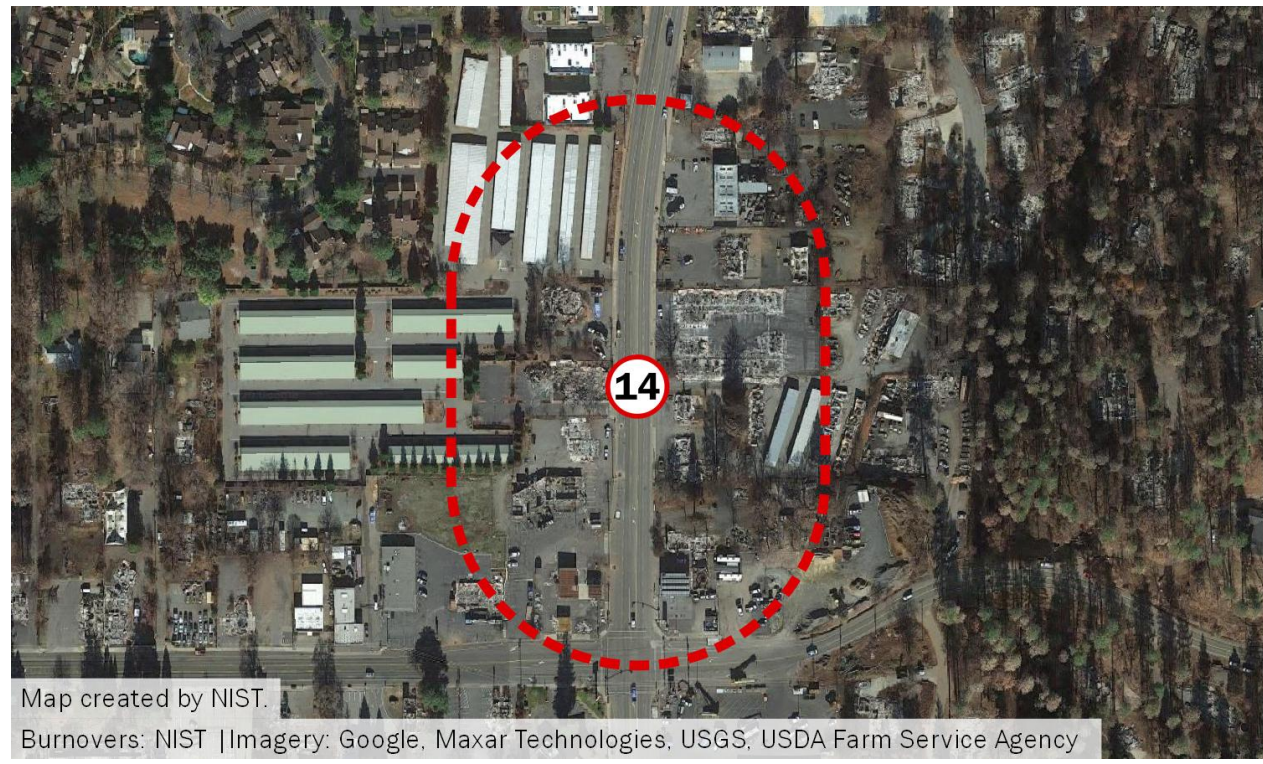




\section{Rattlesnake Flats Road}

\section{Date/Time: $\quad$ November 8, 15:15}

Location: Rattlesnake Flats Rd off Clark Rd, south of Paradise

Coordinates: $\quad[39.679551,-121.619215]$

Related TRA: n/a

Summary: In the mid-afternoon, firefighters and hand crews were planning and conducting firing operations along Clark Road south of Paradise. The area surrounding the location of this burnover was dominated by grassy fuels. A wind shift in the afternoon at around 15:00 and the rapidly changing conditions resulted in accelerated fire spread leading to firefighter injuries. The event only lasted a few minutes but injured three fire fighters. This burnover is further documented in a CALFIRE Green Sheet serious injury report. ${ }^{23}$

\begin{tabular}{clc}
\hline Time & Observation & Source \\
\hline 15:00 & wind shifted in afternoon and blew fire down canyon & TD-110 \\
& $\begin{array}{l}\text { Rattlesnake Flats Rd; flames sheeting } 3 \mathrm{~m} \text { to } 4.5 \mathrm{~m}(10 \mathrm{ft} \text { to } 15 \mathrm{ft}) \\
\text { 15:17-15:19 }\end{array}$ & $\begin{array}{l}\text { in grass; fire went over engine hood; threw engine in reverse to } \\
\text { retreat to Clark Rd; bumper line and nozzle burned up; could } \\
\text { barely see road/grass }\end{array}$ \\
& "I have 2 inmate [firefighters] with minor to moderate burns at \\
the end of Rattlesnake off Clark Rd, I need a code 3 medic unit" & Radio \\
\end{tabular}

\footnotetext{
${ }^{23}$ CAL FIRE (2018), accessed October 2020 from https://www.firefighterclosecalls.com/wp-content/uploads/2018/12/18-CA-BTU-016737Camp-Green-Sheet.pdf
} 
Topography:

Roadway width:

Vegetation setbacks:

Duration:

Extent of burnover (length

of road affected):

Fire direction across road: north to south

Wind intensity:

Fuels:

Fire behavior:

Related TD:

$11 \mathrm{~m} / \mathrm{s}(25 \mathrm{mi} / \mathrm{h})$ grass

wind-driven run through grass, flames $3 \mathrm{~m}$ to $4.5 \mathrm{~m}$ (10 ft to $15 \mathrm{ft}$ )

Related streets or keywords: Clark Rd, Dulcinea Dr

$\begin{array}{ll}\text { Street-level view: } & \text { Rattlesnake Flats Rd looking east from Clark Rd. } \\ \text { Pre-fire imagery links: } & \text { Google Maps Street View, Bing Maps Streetside } \\ \text { Post-fire imagery links: } & \text { Google Maps Street View }\end{array}$

Street-level view: $\quad$ Rattlesnake Flats Rd looking east from Clark Rd.

Post-fire imagery links: Google Maps Street View 


\section{Street map:}

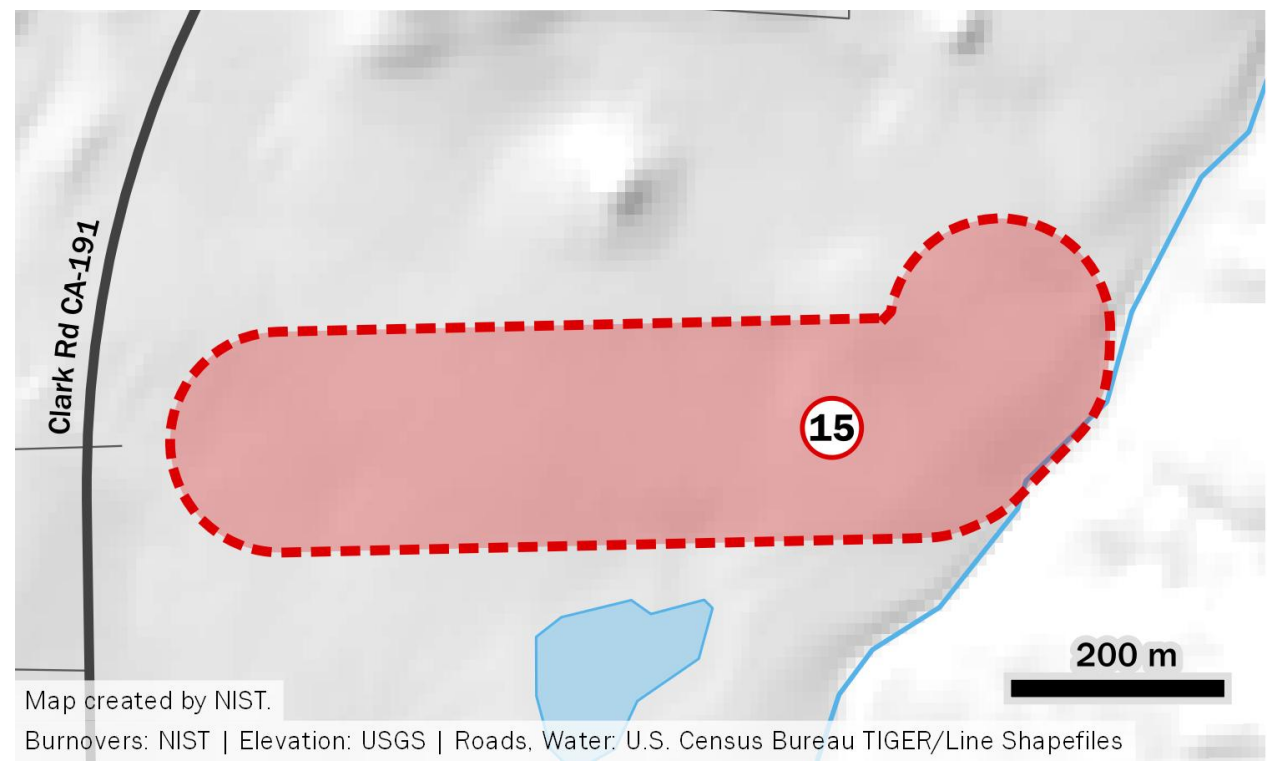

\section{Satellite view:}

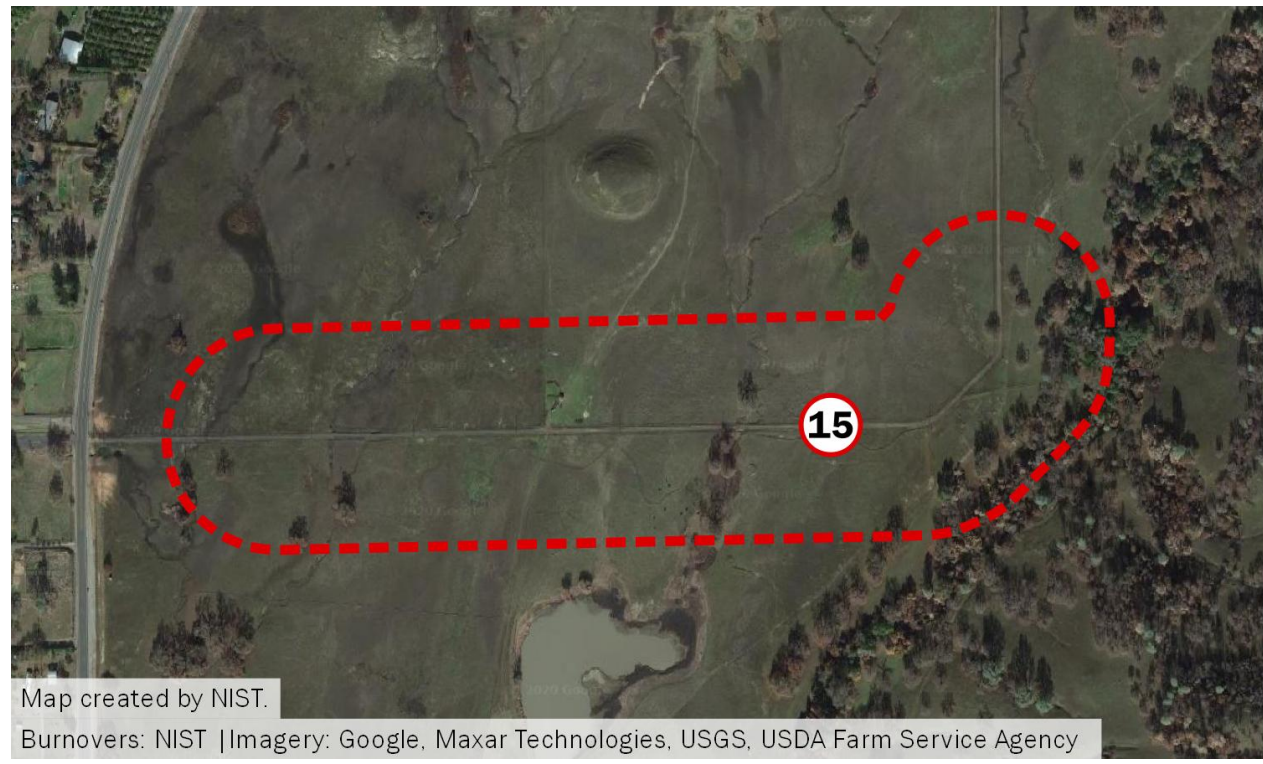




\section{Coutolenc Road}
Date/Time:
November 9, 00:00-02:00
Location: Coutolenc Rd, Magalia, between Skyway and Ridgeway
Coordinates: $\quad[39.812765,-121.578400]$
Related TRA: n/a
Summary: At 23:30 a spot fire was identified in the West Branch Feather River Canyon. Shortly after midnight, into November 9, the wind increased to $15 \mathrm{~m} / \mathrm{s}$ to $27 \mathrm{~m} / \mathrm{s}(35 \mathrm{mi} / \mathrm{h}$ to $60 \mathrm{mi} / \mathrm{h})$ and the spot fire grew rapidly, pushing uphill and west towards Coutolenc Road and Magalia. A strike team working on Coutolenc Road was split up as they escaped the oncoming fire; some engines had to drive north on Coutolenc Road and return through Magalia. The area surrounding the intersection of Coutolenc Road and Skyway remained impassable until at least 01:19, when first responders took refuge in the intersection of Skyway and Coutolenc Road, and on the dam of the Magalia Reservoir. Photos taken at 01:22 indicate continued crown fire activity along Coutolenc Road.

\begin{tabular}{|c|c|c|}
\hline Time & Observation & Source \\
\hline $23: 30-00: 00$ & spot fire down in canyon, can't see it yet & TD-126 \\
\hline 00:07-01:13 & $\begin{array}{l}\text { Skyway at Coutolenc Rd; fire starting to spread to ground but not } \\
\text { fast; fire pushing up canyon, winds } 15 \mathrm{~m} / \mathrm{s} \text { to } 27 \mathrm{~m} / \mathrm{s}(35 \mathrm{mi} / \mathrm{h} \text { to } \\
60 \mathrm{mi} / \mathrm{h}) \text { the whole time }\end{array}$ & TD-209 \\
\hline $00: 30-01: 00$ & fire came over ridge, spotting & TD-043 \\
\hline $00: 37$ & $\begin{array}{l}\text { fire has crossed Coutolenc Rd between Winchester Ln and } \\
\text { Alphys Ln, burning with the wind toward Magalia Reservoir }\end{array}$ & TD-061 \\
\hline $00: 37-00: 53$ & $\begin{array}{l}\text { see fire is coming [over Coutolenc Rd] and advise engines to } \\
\text { leave; } 3 \text { engines south toward Skyway, } 2 \text { cannot make it and must } \\
\text { escape to north }\end{array}$ & TD-126 \\
\hline $00: 53$ & $\begin{array}{l}\text { fire making major run across Coutolenc } \mathrm{Rd}, 13 \mathrm{~m} / \mathrm{s}(30 \mathrm{mi} / \mathrm{h}) \\
\text { winds aligned with drainages }\end{array}$ & TD-061 \\
\hline $00: 53-01: 17$ & $\begin{array}{l}\text { fire hits [at intersection of Skyway] out of east canyon hard; quick } \\
\text { wind increase }\end{array}$ & TD-041 \\
\hline $00: 53-01: 17$ & $\begin{array}{l}\text { main fire front blew straight across Skyway at Coutolenc Rd, } \\
\text { estimate } 22 \mathrm{~m} / \mathrm{s}(50 \mathrm{mi} / \mathrm{h}) \text { winds. Wood guardrails igniting. }\end{array}$ & TD-061 \\
\hline $00: 53-01: 17$ & $\begin{array}{l}\text { fire coming up from canyon, strong wind; softball size embers; } \\
\text { embers igniting houses }\end{array}$ & TD-125 \\
\hline $00: 53-01: 17$ & $\begin{array}{l}\text { fire coming towards house [near intersection with Skyway], fire } \\
\text { blows up; cut hose off engine and get out }\end{array}$ & TD-126 \\
\hline
\end{tabular}




\begin{tabular}{clc}
\hline Time & Observation & Source \\
\hline 00:54 & $\begin{array}{l}\text { 3 Type } 3 \text { strike teams, 1 Type 1 strike team staged; moved all } \\
\text { engines to Skyway for safety }(\sim \text { half of resources went north on } \\
\text { Coutolenc Rd after cut-off by fire) }\end{array}$ & TD-061 \\
01:00-02:00 & $\begin{array}{l}\text { staging for an hour at the dam after the initial fire front } \\
\text { fire burning both sides Skyway north of Dogtown Rd; cannot get } \\
\text { through }\end{array}$ & TD-126 \\
p1:00-02:126 \\
photo to east from Dogtown Rd; crown fire coming from the & TD-127 \\
West Branch toward Coutolenc Rd & pD-061 \\
\hline
\end{tabular}

Topography:

Roadway width:

Vegetation setbacks:

Duration:

Extent of burnover (length $3 \mathrm{~km}(2 \mathrm{mi})$ of road affected):

Fire direction across road:

Wind intensity:

Fuels:

Fire behavior:

Related TD:

Street-level view:

Pre-fire imagery links:

Post-fire imagery links:

Street-level view:

Pre-fire imagery links:

Post-fire imagery links:

$7 \mathrm{~m}(22 \mathrm{ft})$

$120 \mathrm{~min}$

east to west

brush/trees along a ridge, canyon to either side

$0 \mathrm{~m}$ to $2 \mathrm{~m}(0$ to $6 \mathrm{ft})$

$15 \mathrm{~m} / \mathrm{s}$ to $27 \mathrm{~m} / \mathrm{s}(35 \mathrm{mi} / \mathrm{h}$ to $60 \mathrm{mi} / \mathrm{h})$

wind-driven increase of fire pushed up slope through heavy vegetation, crowning fire through trees

TD-007, TD-040, TD-041, TD-043, TD-045, TD-061,

TD-109, TD-115, TD-122, TD-123, TD-124, TD-125,

TD-126, TD-127, TD-209

Related streets or keywords: Skyway, Dogtown Rd

View east to Coutolenc Rd at the intersection with Skyway. Google Maps Street View, Bing Maps Streetside

Google Maps Street View

Coutolenc Rd just north of the intersection with Skyway.

Google Maps Street View, Bing Maps Streetside

No imagery available. 


\section{Street map:}

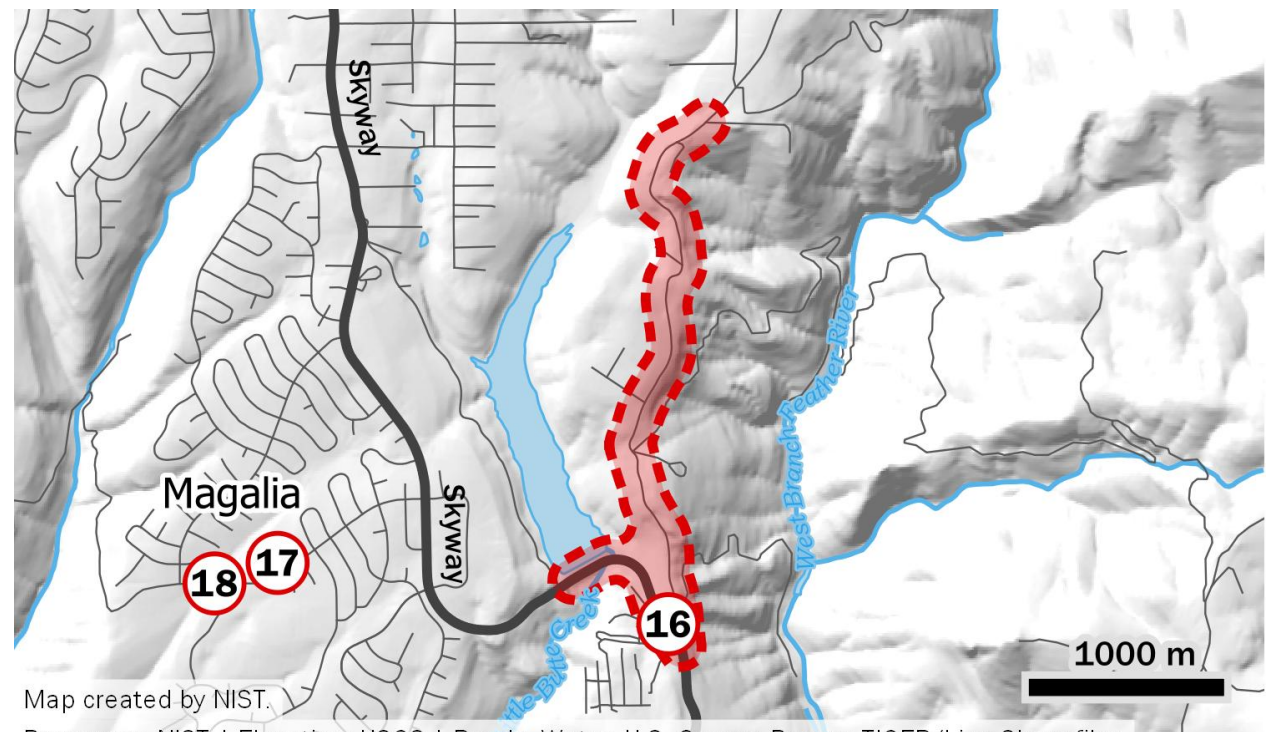

Burnovers: NIST | Elevation: USGS | Roads, Water: U.S. Census Bureau TIGER/Line Shapefiles

\section{Satellite view:}

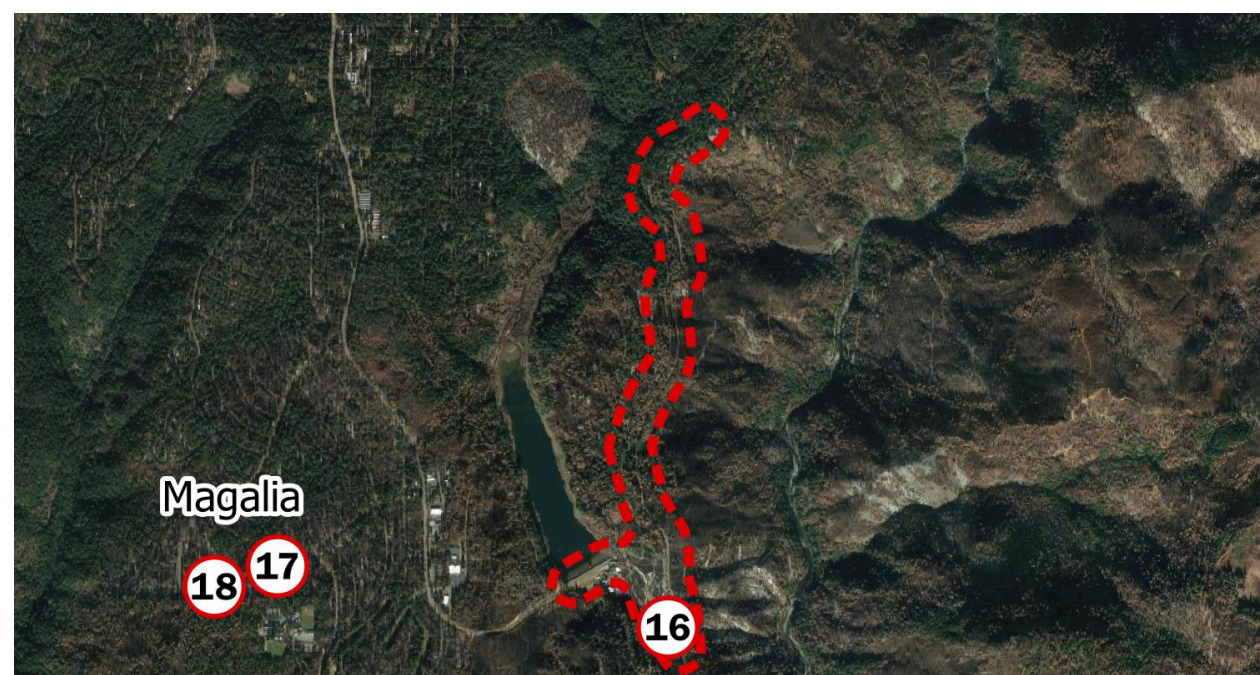

Map created by NIST.

Burnovers: NIST | Imagery: Google, Maxar Technologies, USGS, USDA Farm Service Agency 


\section{Chestnut Circle}

Date/Time: November 9, 06:00

Location: Chestnut Cir, Magalia

Coordinates: $\quad[39.815564,-121.600900]$

Related TRA: n/a

Summary: On November 9, firefighters were protecting structures on Chestnut Circle in Magalia. At approximatively 06:00 there was intense fire activity among structures in the area when a propane tank exploded, injuring two fire fighters. The explosion was located approximately $64 \mathrm{~m}(210 \mathrm{ft})$ east of the crew. The injury is documented in a CALFIRE Green Sheet serious injury report. ${ }^{24}$ While there were still residents in Magalia at this time, this incident is not known to have impacted any civilians.

\begin{tabular}{clc}
\hline Time & Observation & Source \\
\hline 06:00 & BLEVE with firefighters & TD-127 \\
06:00-06:05 & propane tank explodes; retreat to engine; no water & TD-209 \\
06:00-06:05 & $\begin{array}{l}\text { on the left, } 1.5 \mathrm{~m} \times 1.5 \mathrm{~m}(5 \mathrm{ft} \times 5 \mathrm{ft}) \text { spot fire starting; jump out } \\
\text { to handle spot with reel line }\end{array}$ & TD-209 \\
06:00-06:05 & houses inside Chestnut Cir loop engulfed; intense fire activity & TD-209 \\
$06: 07$ & head around corner to put out fire on engine & TD-209 \\
\hline
\end{tabular}

${ }^{24}$ CAL FIRE (2018), accessed October 2020 from https://www.firefighterclosecalls.com/wp-content/uploads/2018/12/18-CA-BTU-016737Camp-Green-Sheet.pdf 
Topography: flat

Roadway width: $\quad 9 \mathrm{~m}(30 \mathrm{ft})$

Vegetation setbacks: $\quad 0 \mathrm{~m}$ to $1 \mathrm{~m}(0 \mathrm{ft}$ to $3 \mathrm{ft})$

Duration: $\quad \mathrm{n} / \mathrm{a}$

Extent of burnover (length $150 \mathrm{~m}(500 \mathrm{ft})$

of road affected):

Fire direction across road: east to west

Wind intensity: $\quad \mathrm{n} / \mathrm{d}$

Fuels: residential propane tank explosion

Fire behavior: surrounding structures burning, spot fires igniting in surface fuels, propane tank explosion

Related TD: $\quad$ TD-127, TD-209

Related streets or keywords: Ponderosa Way

Street-level view: $\quad$ View north on Chestnut Cir at Ponderosa Way.

Pre-fire imagery links: $\quad$ Bing Maps Streetside

Post-fire imagery links: $\quad$ No imagery available. 


\section{Street map:}

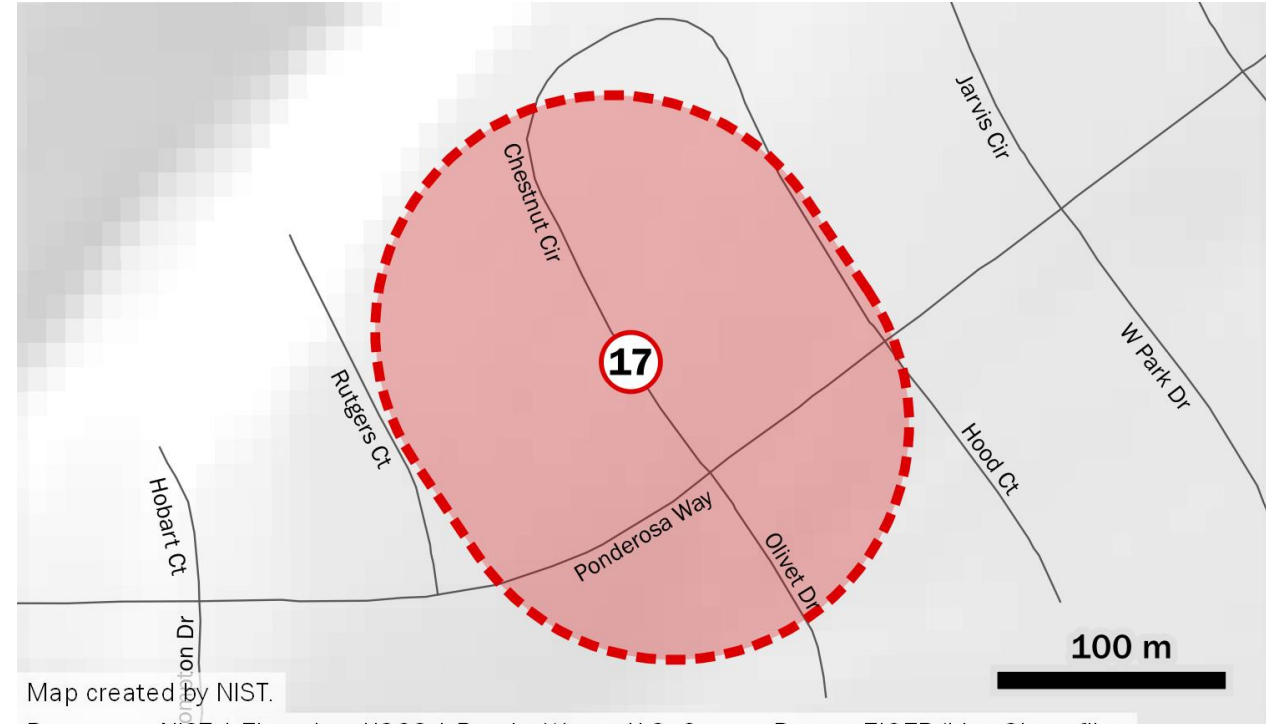

Burnovers: NIST | Elevation: USGS | Roads, Water: U.S. Census Bureau TIGER/Line Shapefiles

\section{Satellite view:}

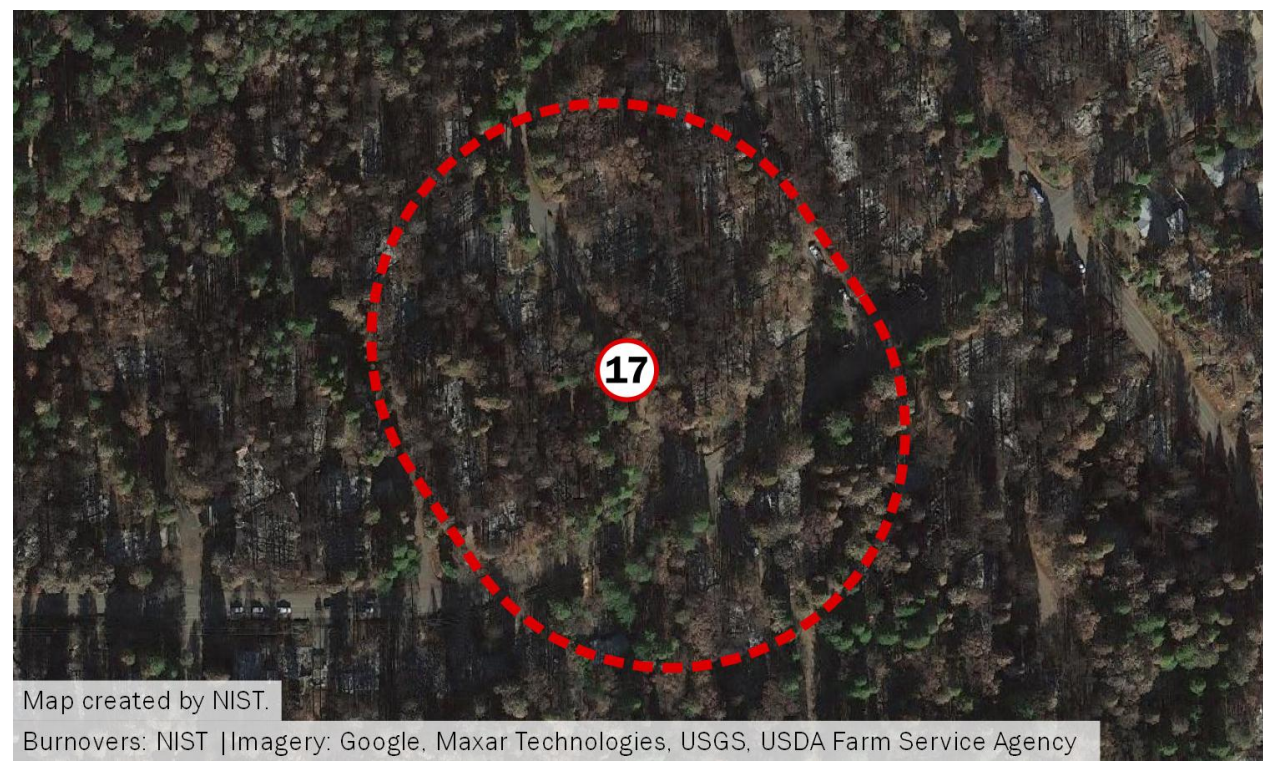




\section{Ponderosa Way}

Date/Time: November 9, 07:15

Location: $\quad$ Ponderosa Way, Magalia, west of Compton Dr

Coordinates: $\quad[39.814665,-121.604539]$

Related TRA: Pine Ridge School

Summary: At approximatively 07:10 on November 9, firefighters were conducting door-to-door evacuations along Ponderosa Way as some civilians were still in the area. Within 10 minutes, by 07:20, fire approached Ponderosa Way from the south and west causing a rapid deterioration of local conditions resulting in fire blowing across Ponderosa Way. Firefighters with an elderly civilian in their engine drove through fire to get to safety. Additional fire engines retreated to a safety zone at Pine Ridge School on Compton Drive. There is insufficient data to determine the temporal extent of this burnover since firefighters left the area.

\begin{tabular}{clc}
\hline Time & Observation & Source \\
\hline 07:10 & end of Ponderosa Way is okay, not burning yet & TD-127 \\
07:11-07:20 & structures not on fire yet & TD-205 \\
07:20 & fire coming into Ponderosa Way from south & TD-127 \\
$07: 20$ & stuck along with [several engines]; wind howling, branches & falling; drove through wind-driven flames \\
$07: 20$ & fire blowing across road from west & TD-128 \\
07:20-07:24 & drove through serious fire to get to safety of school & TD-202 \\
$07: 24-08: 44$ & $\begin{array}{l}\text { intense fire on north side of school property; high winds pushing } \\
\text { fire towards school }\end{array}$ & TD-205 \\
\hline
\end{tabular}


Topography:

Roadway width:

Vegetation setbacks:

Duration:

Extent of burnover (length

of road affected):

Fire direction across road:

Wind intensity:

Fuels:

Fire behavior:

Related TD:

Related streets or keywords: Compton Dr, Creston Rd, Pine Ridge School
Street-level view:

Pre-fire imagery links:

Post-fire imagery links:
Slight southwest aspect near top of canyon/ravine $12 \mathrm{~m}(40 \mathrm{ft})$

$0 \mathrm{~m}$ to $3 \mathrm{~m}(0 \mathrm{ft}$ to $10 \mathrm{ft})$

$\mathrm{n} / \mathrm{d}$

$400 \mathrm{~m}(0.25 \mathrm{mi})$

southwest to northeast

"wind howling", "high winds"

brush/trees

rapid increase in fire activity due to high winds, winddriven fire

TD-061, TD-127, TD-128, TD-202, TD-203, TD-205, TD-207

Ponderosa Way at Compton Dr intersection near Pine Ridge School looking west.

Bing Maps Streetside

No imagery available. 


\section{Street map:}

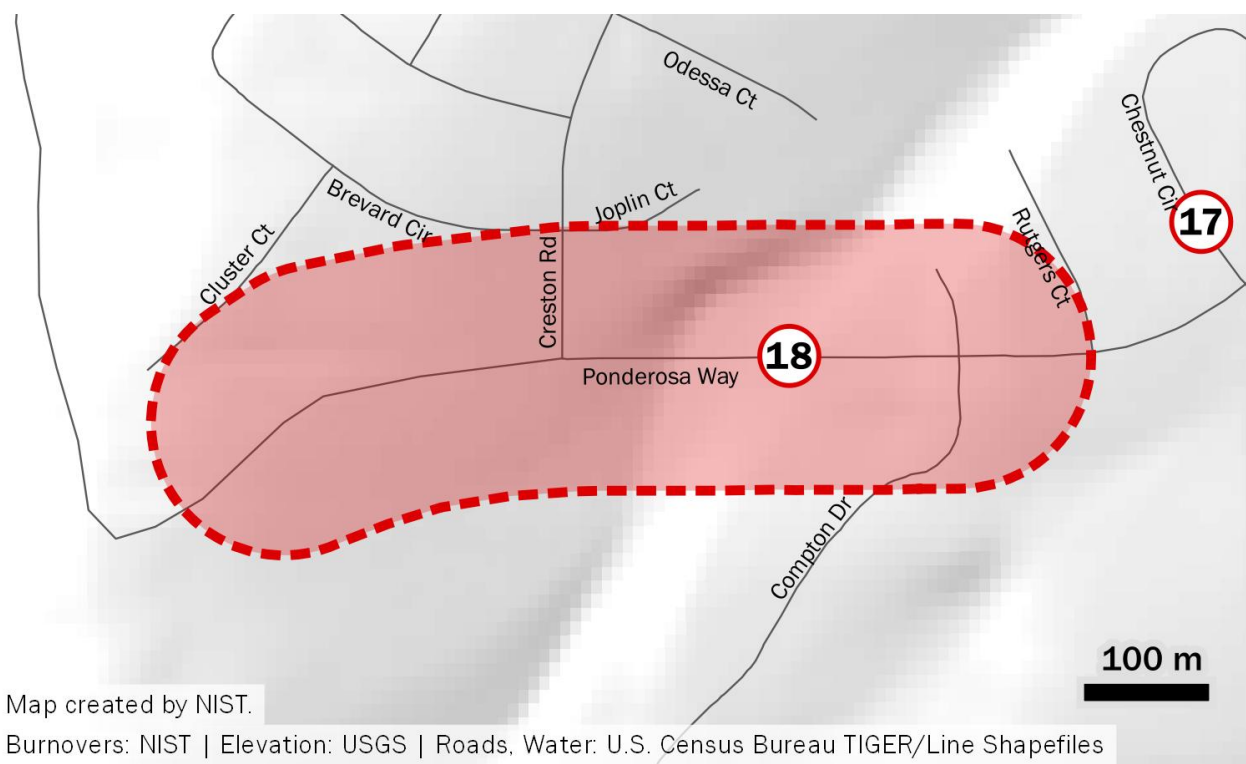

\section{Satellite view:}

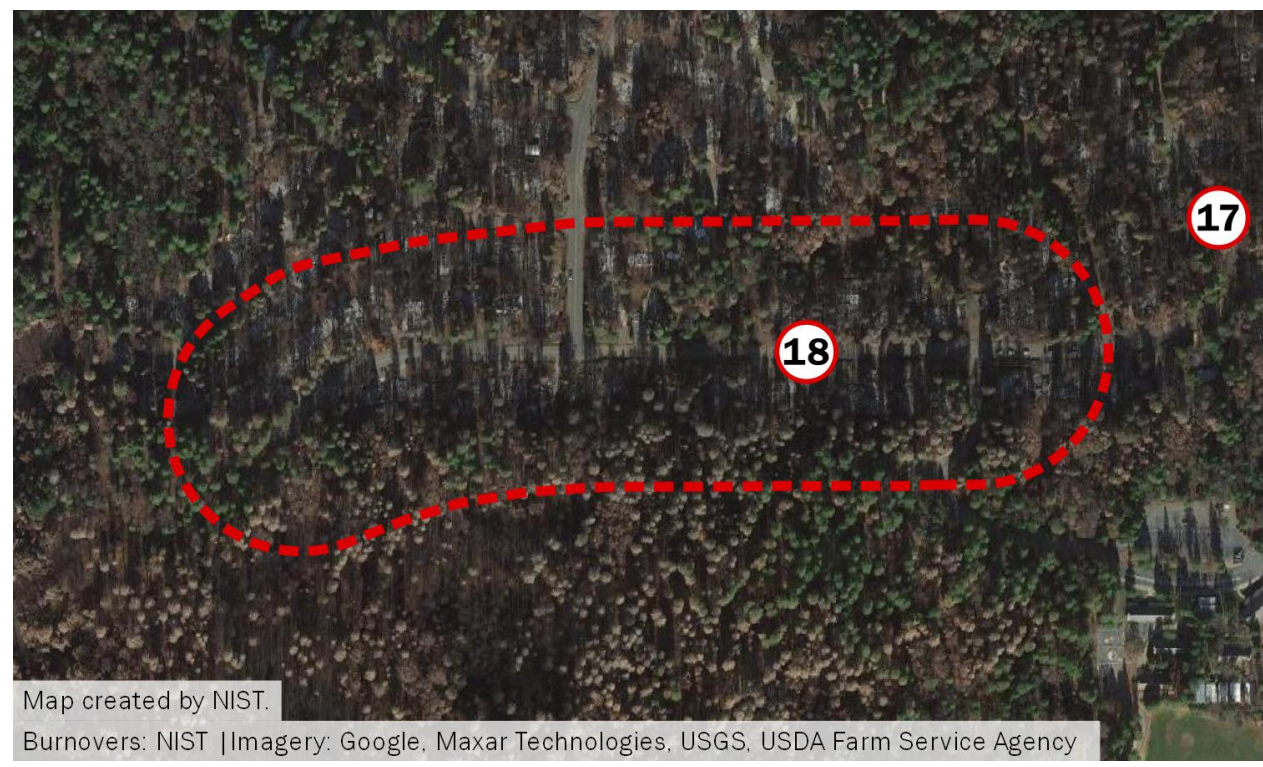




\section{Concow Fire Station 37}

Date/Time: November 9, 07:15

Location: $\quad$ Concow Rd, south of Concow, between Nelson Bar Rd and Hwy 70

Coordinates: $\quad[39.721161,-121.523270]$

Related TRA: n/a

Summary: At 06:40 on November 9, fire was blowing southwest across Pinkston Canyon Road towards Concow Road. Firefighters in the area of Fire Station 37 on Concow Road at Shuman Lane were concerned about getting pinched by the fire. Fire was burning on Shuman Lane at around 07:09 but the activity was not intense. However, over the next 10 minutes the wind increased dramatically to $9 \mathrm{~m} / \mathrm{s}$ to $13 \mathrm{~m} / \mathrm{s}(20 \mathrm{mi} / \mathrm{h}$ to $30 \mathrm{mi} / \mathrm{h})$, fire activity quickly intensified, and Station 37 was surrounded by fire. Concow Road became impassable and only part of the strike team was able to drive though fire to Hwy 70. Other engines in the strike team had to turn around and wait for the fire activity to subside. Concow Road remained impassable until at least 07:50. There is insufficient data to determine the temporal extent of this burnover. This burnover is not known to have impacted any civilians.

\begin{tabular}{|c|c|c|}
\hline Time & Observation & Source \\
\hline 06:40-07:20 & $\begin{array}{l}\text { fire burning across Pinkston Canyon Rd towards Concow Rd; } \\
\text { worried about getting pinched [on Concow Rd] }\end{array}$ & TD-140 \\
\hline 07:09 & $\begin{array}{l}\text { Shuman Ln; fire burning in area, but not intense, piles of pine } \\
\text { needles and slash debris }\end{array}$ & TD-137 \\
\hline 07:20 & fire approaches, wind increases, huge embers, pine needles falling & TD-139 \\
\hline 07:20-07:27 & $\begin{array}{l}\text { wind increases } 9 \mathrm{~m} / \mathrm{s} \text { to } 13 \mathrm{~m} / \mathrm{s}(20 \mathrm{mi} / \mathrm{h} \text { to } 30 \mathrm{mi} / \mathrm{h}) \text { and fire } \\
\text { intensifies quickly; have to leave area }\end{array}$ & TD-137 \\
\hline $07: 20-07: 27$ & $\begin{array}{l}\text { visibility drops to zero, told to retreat to pool parking lot [north } \\
\text { on Concow Rd] but can't make it, roadway blocked by fire }\end{array}$ & TD-137 \\
\hline $07: 20-07: 27$ & $\begin{array}{l}\text { wind shift; fire starts coming down from west side, then east side; } \\
\text { both sides of Concow Rd are burning; firehouse is hit hard }\end{array}$ & TD-140 \\
\hline $07: 27-07: 48$ & $\begin{array}{l}2 \text { fire engines drive past head toward Hwy 70, but can't make it } \\
\text { and come back to wait }\end{array}$ & TD-137 \\
\hline 07:50 & $\begin{array}{l}\text { drive out through fire across Concow Rd; engine takes slight } \\
\text { damage }\end{array}$ & TD-136 \\
\hline $07: 50$ & $\begin{array}{l}\text { wait at Concow Rd and Pinskton Canyon Rd; fire intensity not as } \\
\text { severe }\end{array}$ & TD-137 \\
\hline 09:01 & station is burned down & TD-137 \\
\hline
\end{tabular}


Topography: between ridges, up slope on both sides of roadway

Roadway width: $\quad 9 \mathrm{~m}(30 \mathrm{ft})$

Vegetation setbacks: $\quad 0 \mathrm{~m}$ to $3 \mathrm{~m}(0 \mathrm{ft}$ to $10 \mathrm{ft})$

Duration: $\quad \mathrm{n} / \mathrm{d}$

Extent of burnover (length $600 \mathrm{~m}(0.4 \mathrm{mi})$

of road affected):

Fire direction across road: $\mathrm{n} / \mathrm{d}$

Wind intensity: $\quad 9 \mathrm{~m} / \mathrm{s}$ to $13 \mathrm{~m} / \mathrm{s}(20 \mathrm{mi} / \mathrm{h}$ to $30 \mathrm{mi} / \mathrm{h})$

Fuels: $\quad$ brush/trees

Fire behavior: $\quad$ rapid increase in fire activity during sun rise and shifting winds.

Related TD: $\quad$ TD-136, TD-137, TD-138, TD-139, TD-140

Related streets or keywords: Concow Rd, Shuman Ln, Pinkston Canyon Rd, Concow pool

Street-level view: $\quad$ Concow Rd looking north with fire station on the west side of Concow Rd.

Pre-fire imagery links: Bing Maps Streetside

Post-fire imagery links: Google Maps Street View 


\section{Street map:}

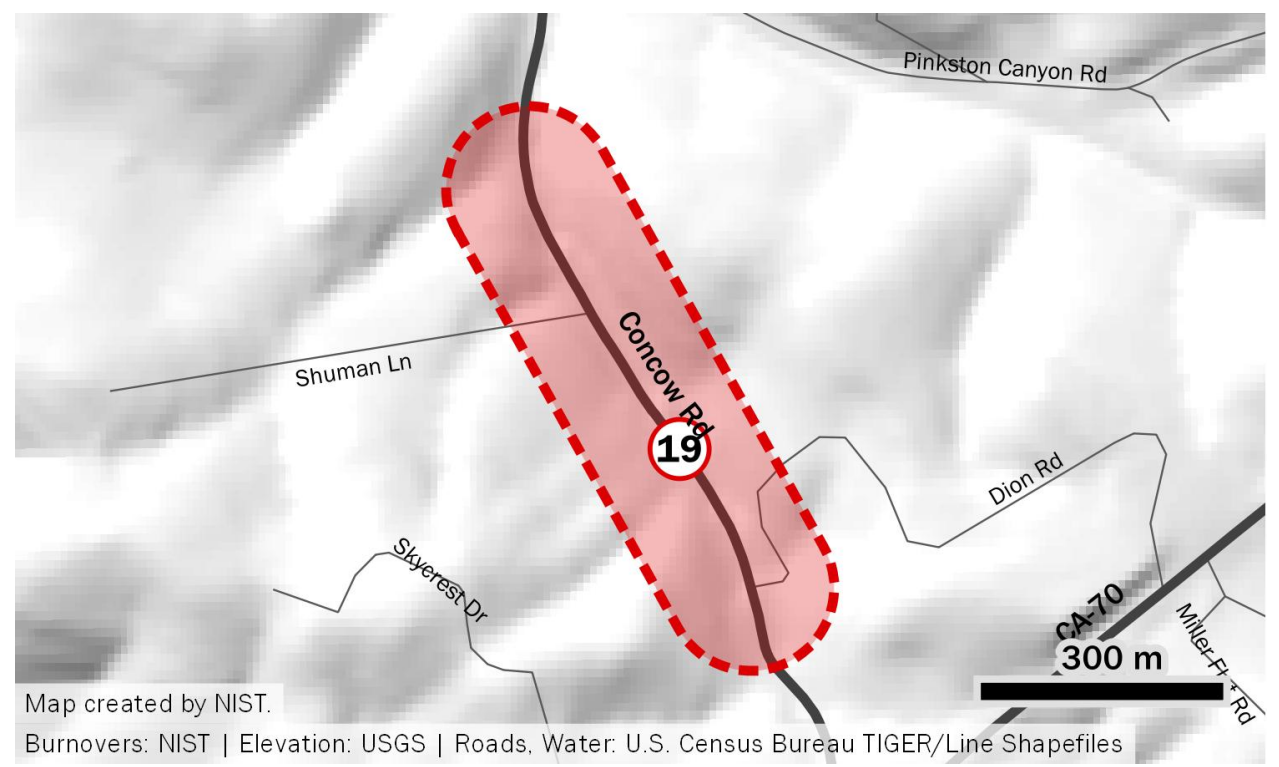

\section{Satellite view:}

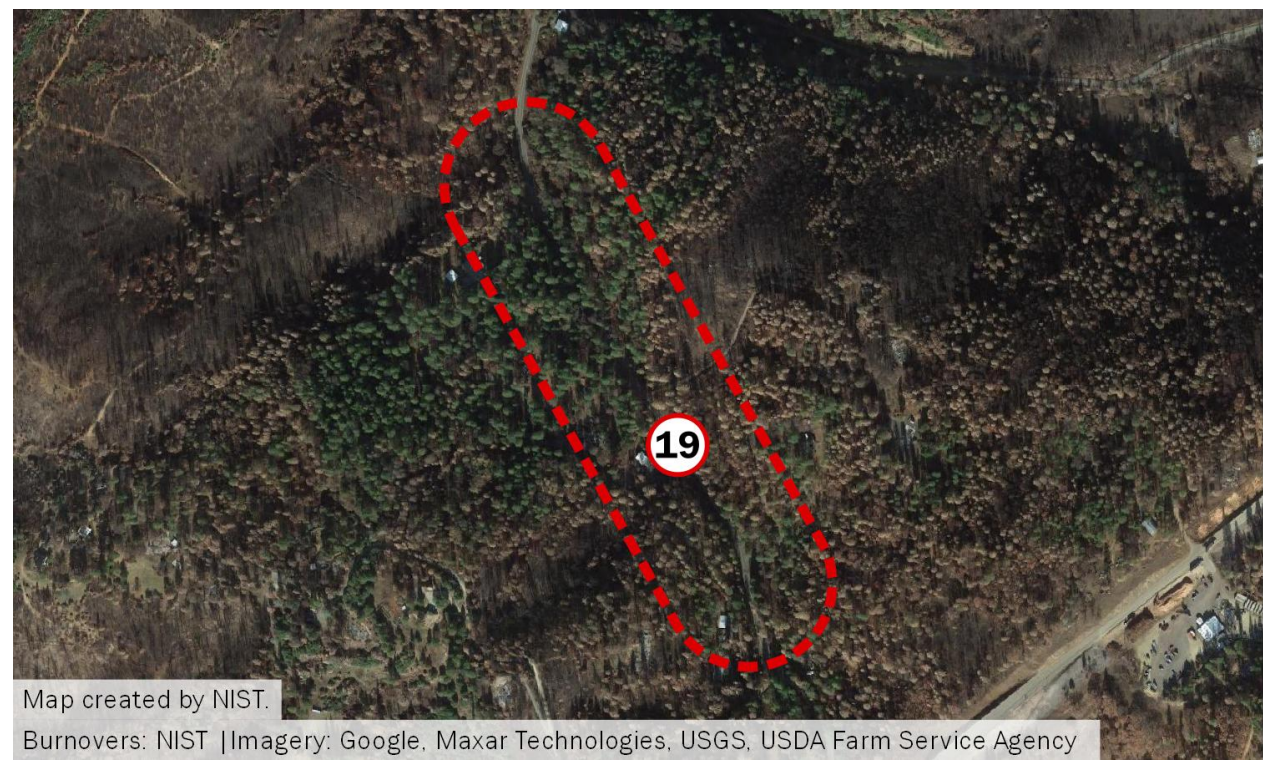




\section{Appendix C. Community WUI Fire Hazard Evaluation Framework}

WUI fire spread has significant impact on communities well beyond the loss of structures, including community evacuation and incident response. Pre-fire planning and hazard mitigation impact how the fire develops, how the life safety of residents and first responders is impacted during evacuations, and the extent of structural and infrastructure losses. There is a need to document pre-fire hazard in a way that assesses the fire impact beyond potential structural losses. Instead of making a recommendation in response to $F 23$, this reconstruction study elected to provide the following preliminary framework.

This appendix contains a preliminary Community WUI Fire Hazard Evaluation Framework as a suggested methodology to begin to support communities at risk in the identification of their unique hazards and to provide common metrics for comparisons between communities. This preliminary framework includes information on community size, population, and fuels; on notification and evacuation; and on the community infrastructure and firefighting response potential. Aspects of this framework may already be included in various community-level documents, such as CWPPs or evacuation plans. Development of a standard framework will consolidate relevant WUI fire hazard and planning information in one place and allow for cross-community comparisons.

The evaluation required to implement this framework will support pre-fire hazard assessment and during-fire response operations. An increased understanding of fire-evacuation, firestructural response, and fire-defensive actions relationships is needed to assess the overall community WUI fire hazard. The quantification of these relationships will enable communities to optimize the community-level response to WUI fire hazards in a more integrated approach and result in increased life safety and reduced losses. 


\begin{tabular}{|c|c|c|}
\hline \multicolumn{3}{|l|}{ Community WUI Fire Hazard Evaluation Framework } \\
\hline Community & Data Type & $\begin{array}{c}\text { Data } \\
\text { Layer } \\
\text { in MDS } \\
\end{array}$ \\
\hline $\begin{array}{l}\text { Community shapefile, geodatabase, or GeoPackage including } \\
\text { topography and geographic attributes, and prevailing weather } \\
\text { patterns (e.g., wind) }\end{array}$ & GIS layer & $\mathrm{x}$ \\
\hline \multicolumn{3}{|l|}{ Fuels } \\
\hline Structure Density (structure separation distances - SSD) & SSD histogram & \\
\hline Age of structures & Histogram & \\
\hline $\begin{array}{l}\text { Vegetative Fuel Loading: } \\
\text { - Fuel type } \\
\text { - Fuel loading }\end{array}$ & $\begin{array}{l}\text { fuel type } \\
\text { tons/acre }\end{array}$ & \\
\hline $\begin{array}{l}\text { Natural and artificial fuel breaks (including fuel treatments } \\
\text { within and around community and year built) }\end{array}$ & List, GIS layer & $\mathrm{x}$ \\
\hline Community hazards (e.g., hazmat and high fuel load facilities) & Specify, GIS layer & $\mathrm{x}$ \\
\hline Fire History & $\begin{array}{l}\text { Frequency of, and most recent, } \\
\text { fires in/around community }\end{array}$ & $\mathrm{x}$ \\
\hline \multicolumn{3}{|l|}{ Population } \\
\hline $\begin{array}{l}\text { Population } \\
\quad \text { - Density } \\
\text { - Permanent/transient ratio }\end{array}$ & $\begin{array}{l}\text { Number, age distribution } \\
\text { Number/acre } \\
\text { p/t ratio }\end{array}$ & \\
\hline \multicolumn{3}{|l|}{ Notification } \\
\hline $\begin{array}{l}\text { Reverse } 911 \\
\quad \text { - Opt-in or Opt-out } \\
\text { - Percent of population enrolled in Reverse } 911\end{array}$ & $\begin{array}{l}\text { Opt-in/Opt-out } \\
\%\end{array}$ & \\
\hline $\begin{array}{l}\text { Sirens or other notification with power backup } \\
\quad \text { - Percent of population within siren coverage range }\end{array}$ & $\begin{array}{l}\text { List } \\
\text { \% population }\end{array}$ & \\
\hline Notification dissemination w/out phone or internet & $\mathrm{y} / \mathrm{n}$ & \\
\hline \multicolumn{3}{|l|}{ Evacuation } \\
\hline Egress Route Capacity (Minimum Throughput Time) & Time (hours) & \\
\hline $\begin{array}{l}\text { Vulnerability of egress arteries: } \\
\text { - Fuel setbacks } \\
\text { - Hazmat/high fuel load facilities affecting evacuation } \\
\text { - Other }\end{array}$ & $\begin{array}{l}\text { fuel setback data, GIS layer } \\
\text { specify, GIS layer }\end{array}$ & $\begin{array}{l}\mathrm{x} \\
\mathrm{x} \\
\mathrm{x}\end{array}$ \\
\hline Hospitals and senior care facilities & specify, number of persons & $\mathrm{x}$ \\
\hline $\begin{array}{l}\text { Community evacuation plan } \\
\text { Safety zones and large crowd assembly areas, capacity } \\
\text { Evacuation drills }\end{array}$ & $\begin{array}{l}\mathrm{y} / \mathrm{n}, \text { specify, GIS layer } \\
\mathrm{y} / \mathrm{n}, \text { number, GIS layer } \\
\mathrm{y} / \mathrm{n}\end{array}$ & $\begin{array}{l}\mathrm{x} \\
\mathrm{x}\end{array}$ \\
\hline $\begin{array}{l}\text { Community in evacuation route of other communities, through- } \\
\text { flow number }\end{array}$ & $\mathrm{y} / \mathrm{n}$, identify, number & \\
\hline \multicolumn{3}{|l|}{ Infrastructure / COOP/COG } \\
\hline Location and needs of key facilities & List & $\mathrm{x}$ \\
\hline $\begin{array}{l}\text { Public water, dependence on power, generator backup, } \\
\text { community owned water }\end{array}$ & $\mathrm{y} / \mathrm{n}, \mathrm{y} / \mathrm{n}, \mathrm{y} / \mathrm{n}, \mathrm{y} / \mathrm{n}$ & \\
\hline Power lines around primary arteries (above ground or below) & above or below & $\mathrm{x}$ \\
\hline Critical infrastructure that requires fuel to keep operating & specify, GIS layer & $\mathrm{x}$ \\
\hline \multicolumn{3}{|l|}{ Fire Fighting Response } \\
\hline $\begin{array}{l}\text { Volunteer vs Career } \\
\text { (availability of first responder resources at station) }\end{array}$ & volunteer/career/combination & \\
\hline $\begin{array}{l}\text { Density of firefighting (ff) responder to number of structures } \\
\text { (ff/structure ratio) }\end{array}$ & ff/structures & \\
\hline $\begin{array}{l}\text { Mutual aid response (engines-hours histogram) and agreements } \\
\text { with mutual aid }\end{array}$ & engines-hours histogram & \\
\hline
\end{tabular}




\section{Primary Community WUI Fire Hazard Evaluation Framework Definitions}

The Community WUI Hazard Evaluation Framework presented here is intended for communities as small as a few hundred to tens of thousands of residents. The methodology is not intended for the documentation of single residences or large cities. It is intended to provide a community with an overview of the overall WUI fire-related hazards and to enable the authority having jurisdiction (AHJ) to compare the relative hazards and preparedness levels of different communities. The information collected can be used by first responders and community and county officials to prioritize hazard mitigation within and around the community and to develop "tabletop" responses to different WUI fire scenarios. In the event of an actual WUI fire, the information collected could be used by first responders and local officials to safely evacuate civilians, to reduce the risk of first responder injuries, and to enhance fire containment. The following are definitions and uses of the different components of the Community WUI Fire Hazard Evaluation Framework. This framework may be expanded to include additional characteristics that are not specifically listed in this preliminary version.

\section{Community}

In the sense of WUI fire hazard, the community should be viewed in the context of evacuation arteries rather than jurisdictional boundaries. As such, the community may have parts that are incorporated or unincorporated. Community size is reported in acres, and the community boundary selected for this hazard evaluation can be provided for use in a geographic information system (GIS) layer in a number of formats, including but not limited to shapefile, geodatabase, or GeoPackage. A topographic overview of the area (community) is used to describe the general conditions using one or more of the following key words: flat terrain, rolling hills, moderate slopes, valleys and steep slopes, and/or plateau.

Information about prevailing weather patterns, such as localized winds or significant wind events (strength and direction), should also be included in the community profile.

\section{Fuels}

The fuels section is intended to provide an overview of the structural, vegetative, and other fuels present in the community. This is not a parcel-level assessment; however, if defensible space assessment data is available, it can be aggregated and utilized within this framework to provide higher resolution assessment of community fire hazard. Structure density is a simple metric to capture structure-to-structure spacing and provide insight on the potential structureto-structure fire spread. For uniform communities a representative structure separation distance (SSD) may be sufficient, whereas nonuniform communities will be better described using a histogram of SSD. The age of structures may also be a factor in structure vulnerability due to changes in building codes associated with structure hardening. Similarly, a community that was built over a short period of time can be represented by a single value representing the decade of construction, while a community that grew and expanded over long periods will be better represented by a histogram of structure ages. 
A database such as LANDFIRE ${ }^{25}$ can provide the vegetative fuel type and fuel loading throughout the community. This data will be limited by the age of the last LANDFIRE overflight and the $30 \mathrm{~m}$ pixel spatial resolution.

Natural and artificial fuel breaks, including fuel treatments within and around the community, should be represented in a geospatial format and should include the year the vegetative fuel treatment was conducted. Fuel treatments should also include any logging activities in the area surrounding the community. Fire history in and around the community will describe the last time the community experienced direct impacts from fire. Shapefiles of the fuel treatments and fire history will allow for spatial documentation of this data. Fuel treatments and fire history should be documented at least $16 \mathrm{~km}(10 \mathrm{mi})$ out from the edge of the community. Local conditions (e.g., fuel, topography, weather, evacuation routes) may require documentation well beyond $16 \mathrm{~km}(10 \mathrm{mi})$. The last large fire in the area of the community perimeter, together with the vegetative fuel loading, will provide information on the potential energy content of the vegetative fuels in the event of a short- or long-term drought.

The documentation of other community hazards such as hazmat or high fuel load facilities (e.g., fixed propane tanks, hazardous material storage and use facilities, ammunition facilities lumber yards, pallet storage, tire storage) is important as they can affect civilians and first responder safety during evacuations, fire containment, and mop-up activities. The information should be provided in the form of a GIS layer and may then be used by first responders to develop "tabletop" responses for emergency preparedness, and to direct response actions during a WUI fire event.

\section{Population}

The population of the selected community will impact, among other factors, the minimum time required for evacuation. Population and population density, expressed as the number of residents per acre, are both important metrics that provide information that can be used for evacuation assessment. The permanent to transient population density ratio is intended to capture the fraction of the community that may be visiting for tourism and may not be aware of community evacuation and other fire related activities.

\section{Notification}

The notification section of the Community WUI Hazard Evaluation is designed to capture the presence and type of mass-notification tools available to emergency managers. It should be noted that reliance on individual notification methods may result in limited notifications. If a Reverse 911 system is in place, the percentage of the community that will potentially receive the notifications from this system will estimate the number of residents that may require different notification(s). Sirens or other fixed notification systems with power backup should also be listed in this section along with the fraction of the population covered by these systems. Additional notification systems that don't require phone or internet are also captured in this section, since WUI events frequently result in power outages or other service interruptions.

\footnotetext{
${ }^{25}$ www.landfire.gov
} 


\section{Evacuation}

This section of the Community WUI Hazard Evaluation is not intended to replace a full community evacuation study or act as a community evacuation plan. The primary purpose of this section is to compute, given a number of assumptions, a Minimum Throughput Time (MTT), to provide an initial idealized order of magnitude time to be considered in the early stages of evacuation pre-planning. This information can be of value to first responders and community emergency planning personnel, as it may potentially highlight critical evacuation bottlenecks inside or outside the community.

The MTT concept is a traffic engineering calculation of roadway capacity to provide an initial lower bound for planning community evacuation. The MTT is intended for isolated and partly isolated interface and intermix communities rather than a city setting with large populations and complex evacuation routes. A community should consider a detailed evacuation study to further enhance the community evacuation plan. There is a significant body of work associated with developing dynamic evacuation models. ${ }^{26}$

The MTT considers two significant factors: bottlenecks within and beyond town, and the total number of vehicles that must be accommodated. Bottlenecks slowing traffic throughput may be located within or outside of jurisdictional boundaries. Bottlenecks occurring well beyond the evacuating community may cause ripple effects significantly impacting community evacuation. In identifying the population for computing the MTT, consideration should be given to neighboring settlements/communities that may share the same evacuation route(s). The MTT should consider the minimum number of traffic lanes (i.e., 8 lanes merging into 2 lanes should be treated as 2 lanes) available for evacuation, the community population, and the average speed limit of the egress routes. Contraflow, the implementation of reverse direction traffic flow, may be considered here, along with provisions for first responder access to the community. The computed Minimum Throughput Time (MTT) does not account for any of the numerous potential hinderances to evacuation traffic, such as road accidents, reduced speed due to smoke obscuration, merging of traffic in town to feed the primary arteries, large vehicles that occupy more space than cars and have reduced maneuverability, or fire activity impacts, such as burnovers, causing evacuation lane(s) closures and potential slowdowns associated with traffic redirections.

The evacuation section is also used to identity vulnerabilities of egress arteries including vegetative fuel setbacks as well as any hazardous material facilities which might affect evacuation. Fuel setback information, collected in $0.25 \mathrm{~km}(0.15 \mathrm{mi})$ increments along egress routes, presented in the form of a histogram and a GIS layer, could help identify vulnerable spots that may potentially impact evacuation and identify candidate locations for fuel treatments.

The presence of a Community Evacuation Plan, the presence and capacity of safety zones and other large crowd assembly areas, and whether or not evacuation drills are performed will contribute to the community evacuation preparedness overview. The number of hospitals

\footnotetext{
${ }^{26}$ An example of a framework which includes coupled fire and evacuation considerations, as well as background on the individual model components, is provided in Ronchi et al. (2019) “An open multi-physics framework for modelling WUI fire evacuations," Safety Science 118:868-880.
} 
and senior care facilities and their total capacity will provide further information to assess overall community evacuation needs.

\section{Infrastructure / COOP / COG}

The locations and needs of key facilities for maintaining continuity of operations (COOP) and continuity of government (COG), such as police, fire, EMS, hospitals, government buildings, cell towers, water sources, water provider infrastructure, electrical utility key infrastructure, and natural gas key infrastructure should be listed and incorporated in this part of the evaluation framework.

Infrastructure characteristics, particularly related to water supply and electric utilities, can impact response and potential pre-fire hazard reduction. The public water system dependence on power supply, including the availability of backup power sources (i.e., generator backup) will provide insight into the resilience of the water system. The location of power lines (i.e., above or below ground) can impact evacuation, as downed power lines can impact evacuation and mobility throughout the community.

\section{Fire Fighting Response}

The type of fire department, whether volunteer, career, or combined, may impact the likely availability and response time of first responder resources. The density of firefighting (ff) responders, as a ratio of the number of personnel on shift to the number of structures (number of ffs/number of structures) will provide information on the maximum possible coverage by the local resources.

In this section, mutual aid resources should be counted only if mutual aid agreements are in place and can ensure rapid deployment. Mutual aid response is captured though a histogram in 1-, 2-, 3-, and 4-hour travel times. This may also be approximated using a geographic radius of distance from the community. The purpose of this information is to provide insight into the minimum response times by mutual aid. 


\section{Appendix D. National Weather Service Presentation}

The following presentation materials on the weather conditions during the Camp Fire were provided by Incident Meteorologist (IMET) Trainee Aviva Braun from the National Weather Service. 


\section{Antecedent Conditions and Support} Services on the Camp Fire: $A n$ Incident Meteorologist's

\section{Perspective}
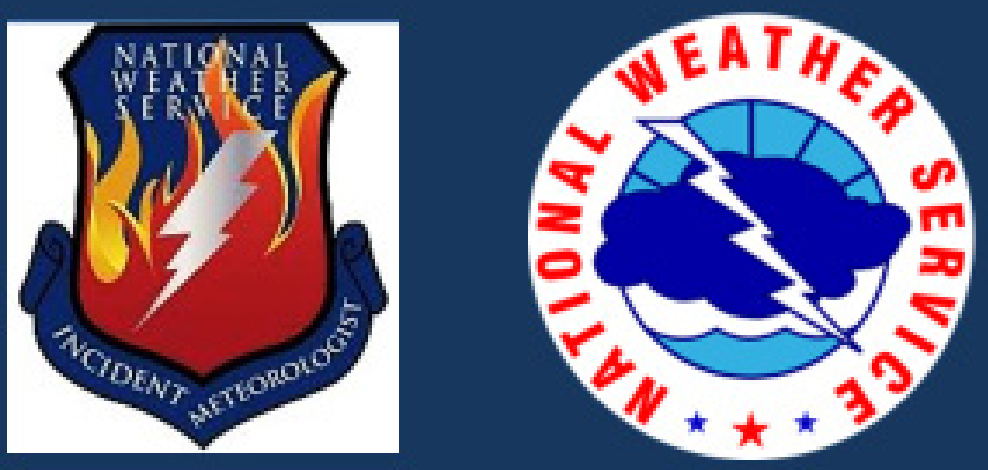

Aviva Braun

January 23, 2019 


\section{Outline}

1. What does the National Weather Service look like?

2. Decision Support Services across NWS

3. The Incident Meteorologist program

4. The Camp Fire

1. Dangerous antecedent conditions

1. Drought, fuels, and topography

2. A Red Flag Warning

3. Weather conditions during the incident 


\section{National Weather Service}
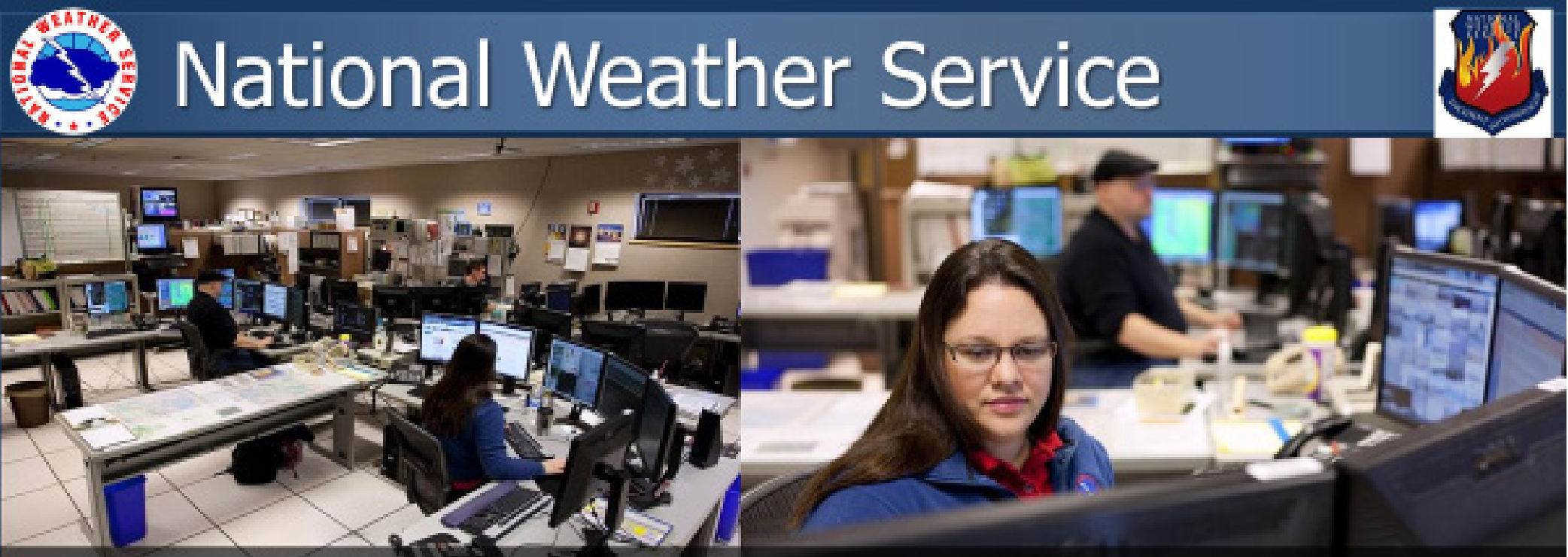

Meteorologists on site 24-hours a day / 365 days a year

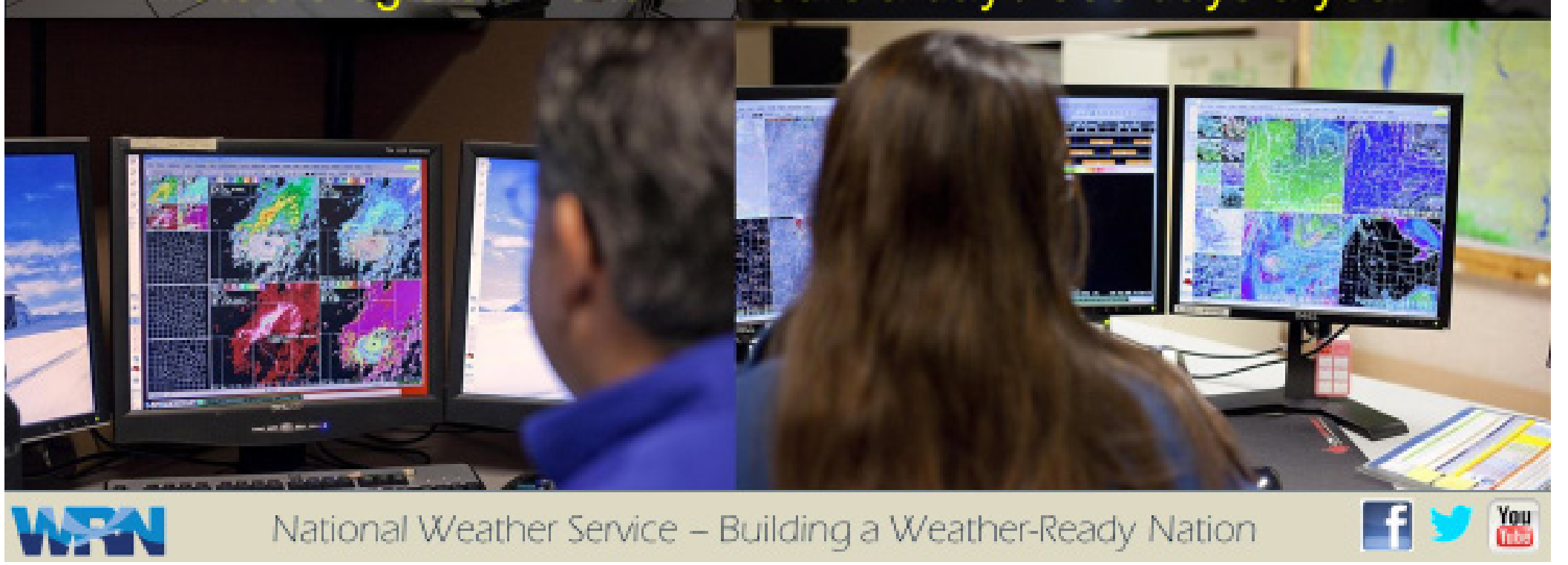




\section{Decision Support Services}

NWS employees can be found at events and incidents across the nation, supporting local partners everywhere.

- University Football Games and Superbowls

- Working in the State EOCs for a significant weather event - river flooding, hurricane landfall, and tornado outbreaks

- Deepwater Horizon Oil Spill

- State fairs

- Salt Lake City Olympics

- Large concerts

- Local exercises in preparation for events and to build relationships: local fire partners, Homeland Security, National Guard, State Emergency Management. 


\section{NWS Meteorologists in Action}
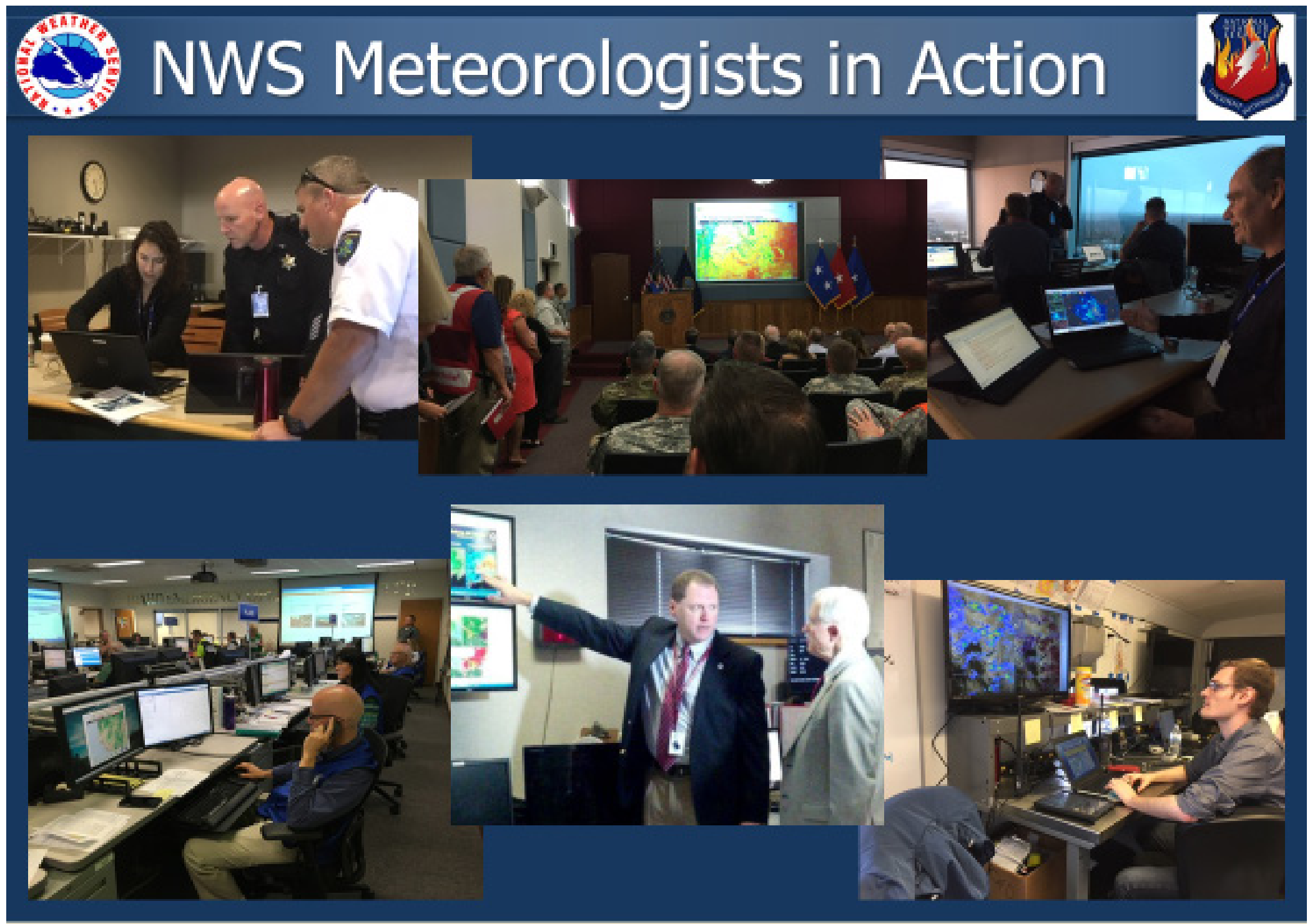

M른 


\section{The Incident Meteorologist}

\section{An IMET is a rare bird}

How Rare?

There is 1 IMET for ever 3,900 firefighters in the US

Less than 2\% of NWS employees are IMETS

Only 250 people have taken up the duty of being an IMET in it's 100 year history 

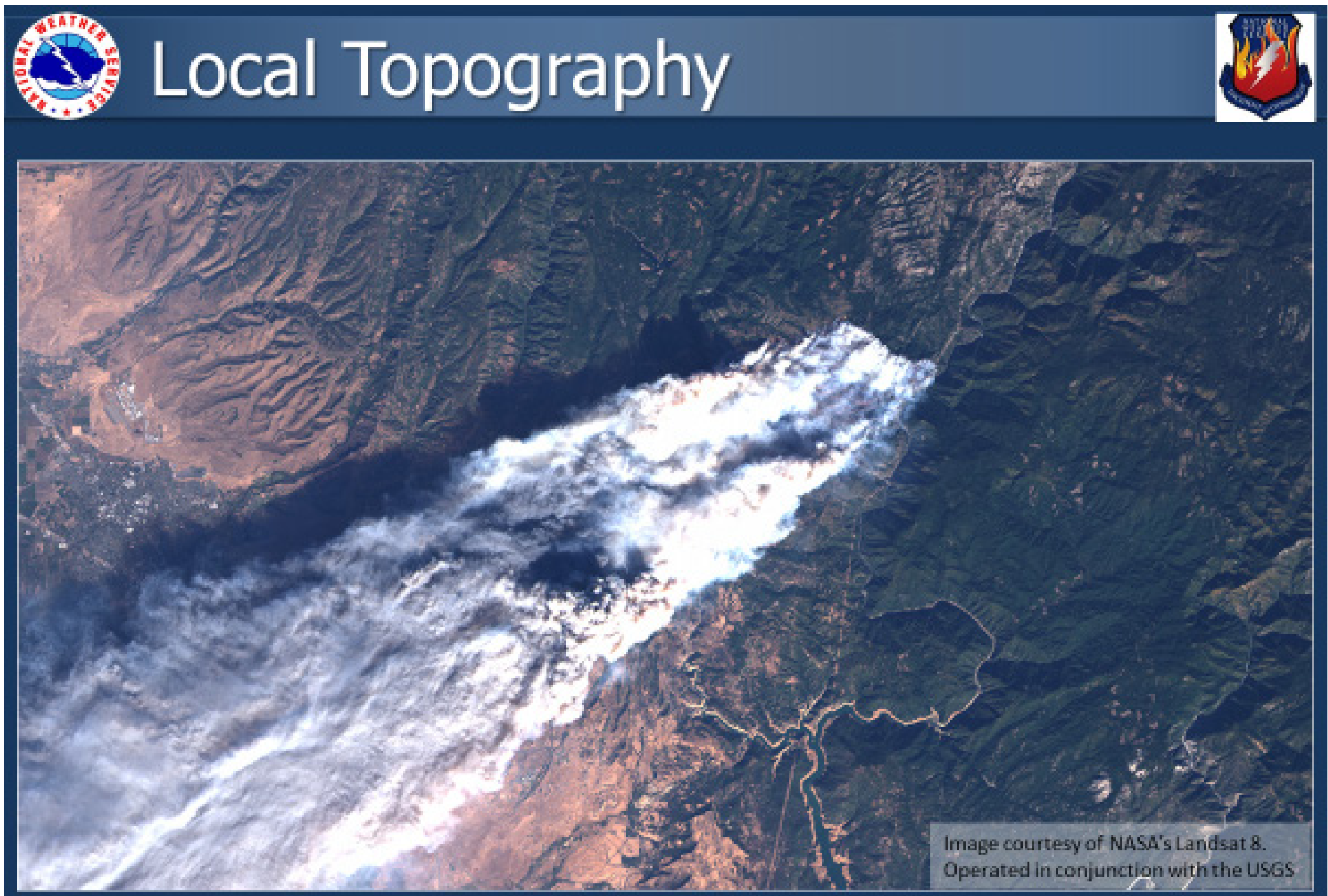

WㅁN

National Weather Service - Building a Weather-Ready Nation

f $y$ y 


\section{Local Topography and Hotspots}

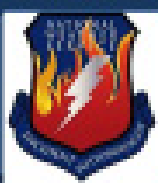

* Image courtesy of NASA's Landsat 8.
- Operated in conjunction with the USGS 


\section{Fire History}

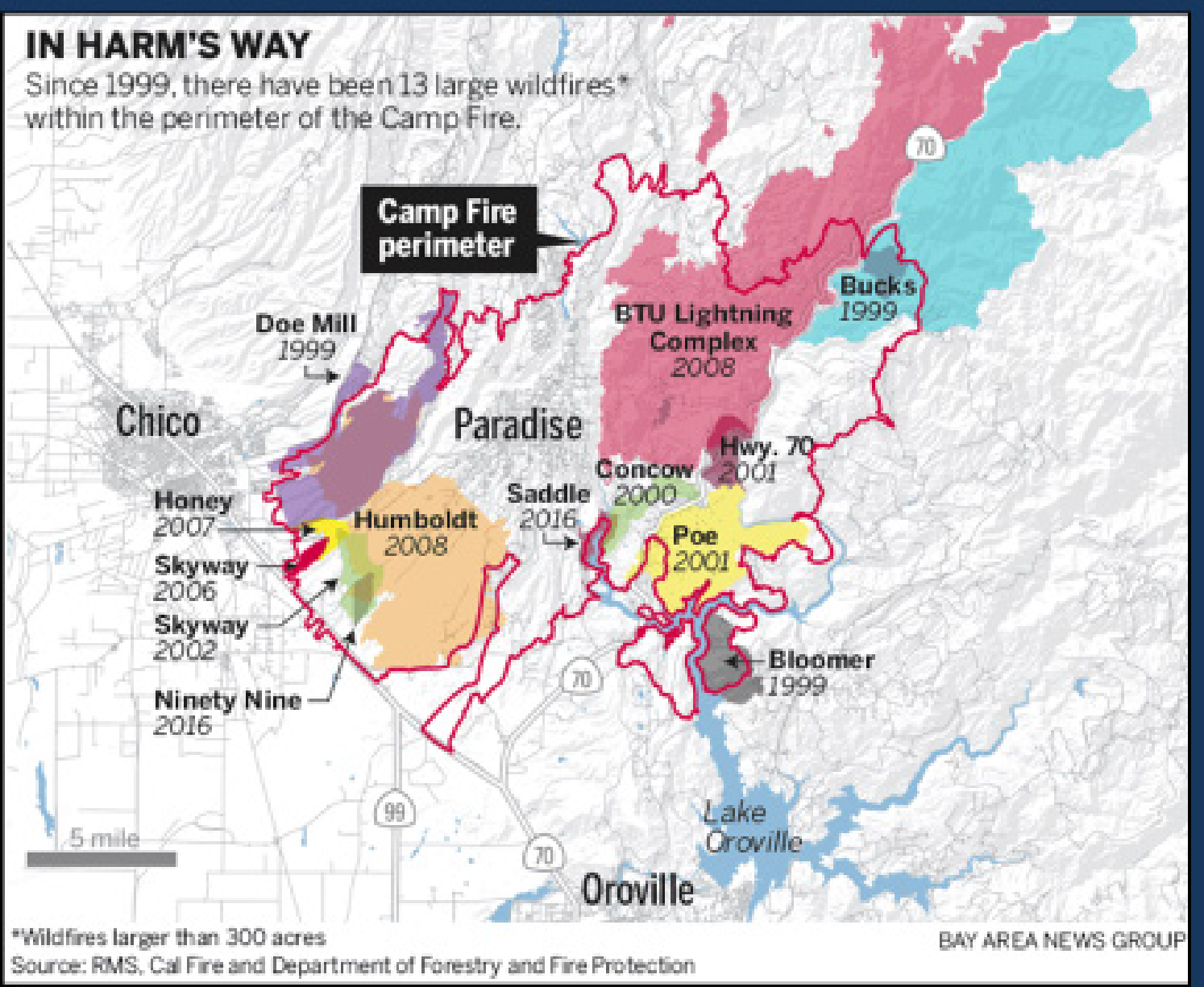




\section{Drought Conditions}

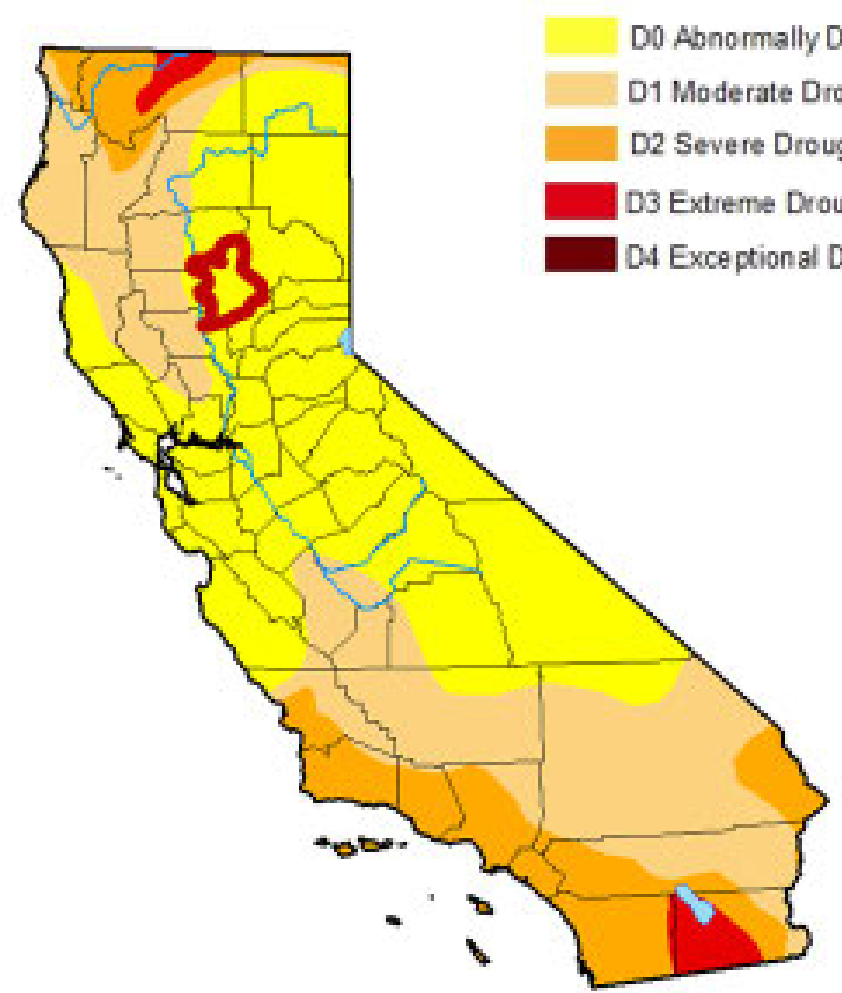

US Drought Monitor for California on November 6, 2018:

Butte County

Abnormally

Dry 


\section{The Fuels}

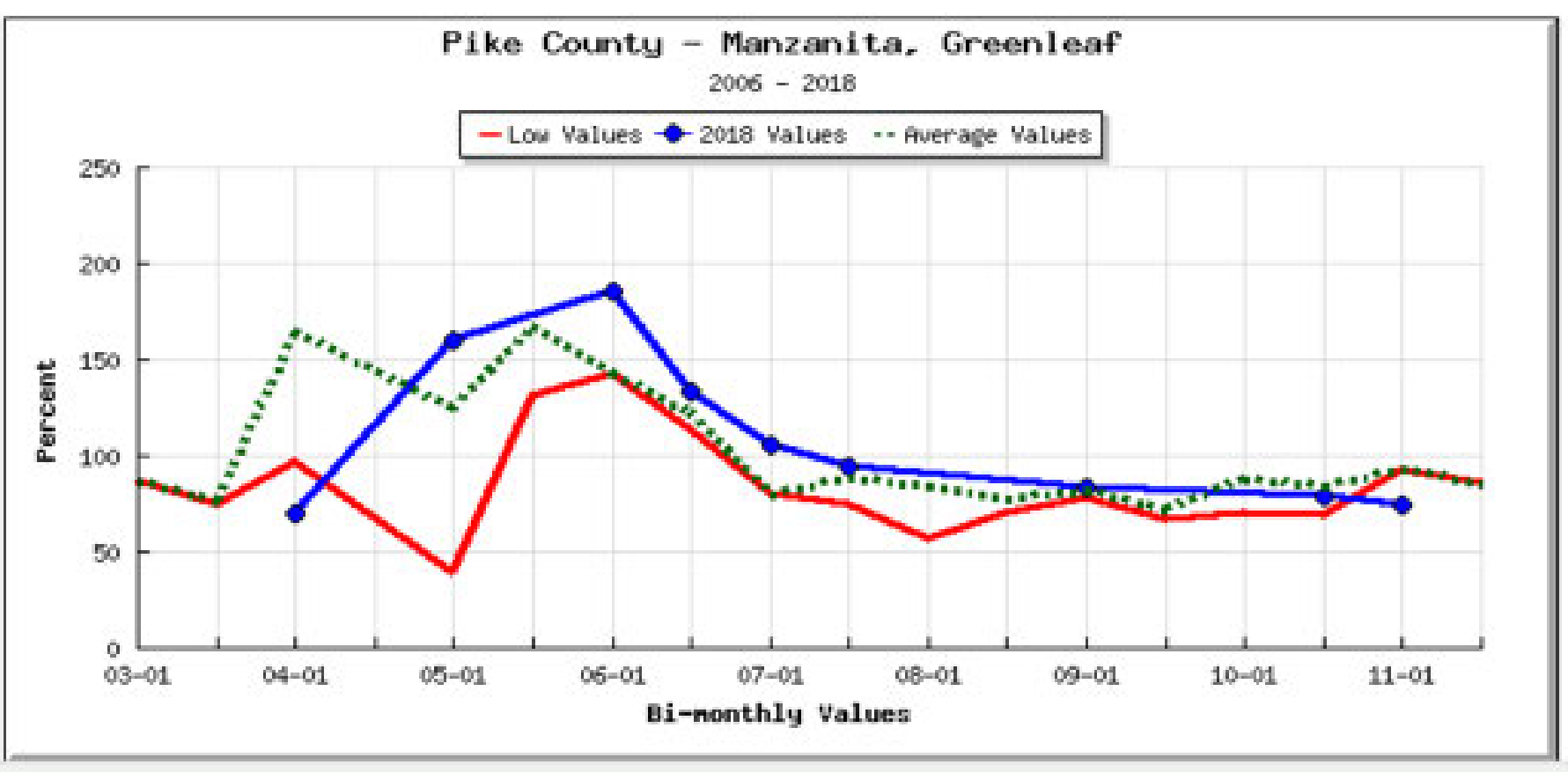

Average for

November is:

(c) 510
Critical level for

Manzanita is:

\section{$80 \%$}

Live fuel moisture in Manzanita was: 


\section{The Energy Release Component}

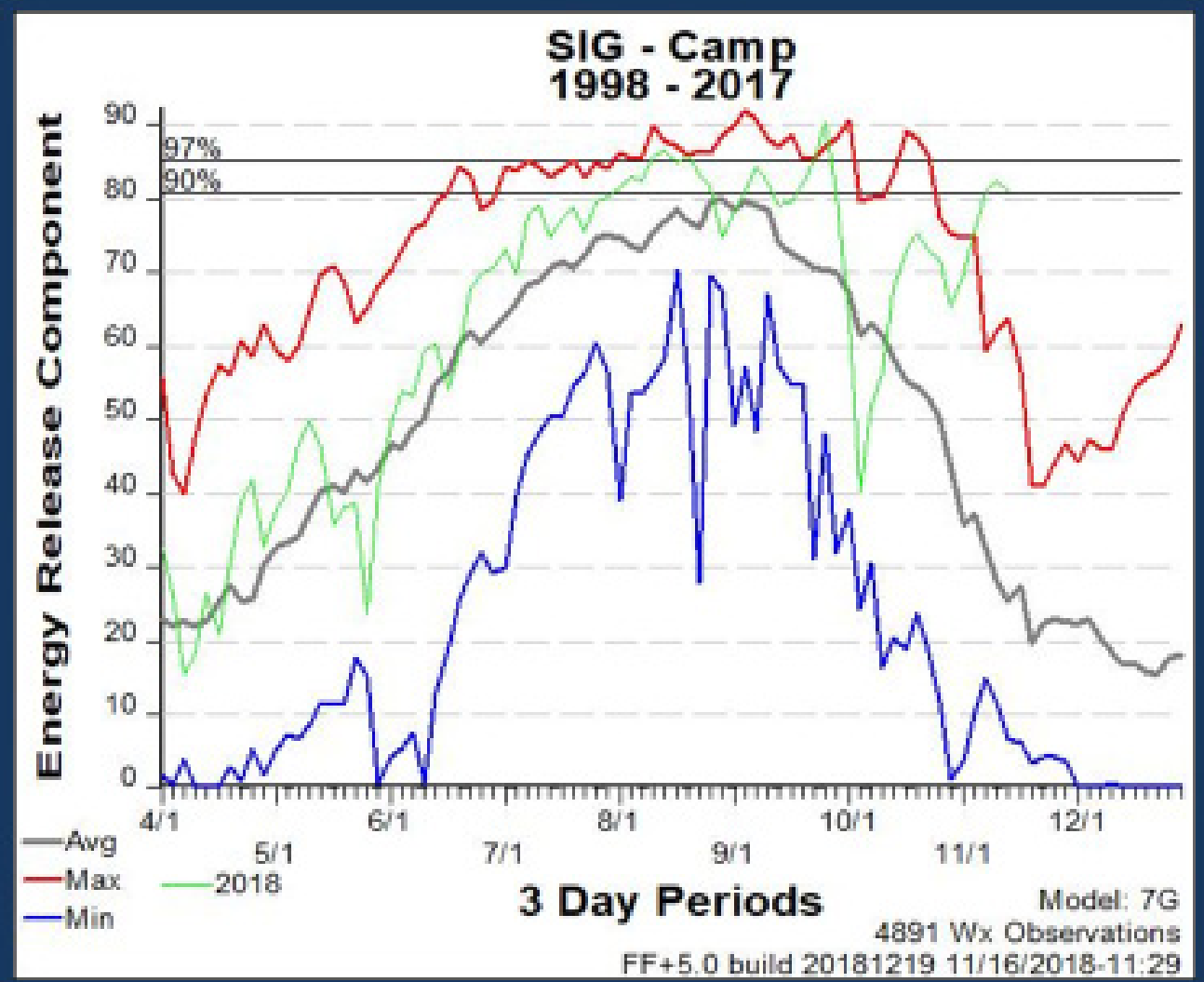

The Energy Release Component (ERC) of the National Fire Danger Rating System is a measure of fuel dryness and flammability.

The ERC was trending slightly above average all summer for the Northern Sierras, but in October it began trending well above average, and continued through to the day of the fire when it was above the historic record for the date and near the $90^{\text {th }}$ percentile for all dates. 


\section{A Structure Fire}
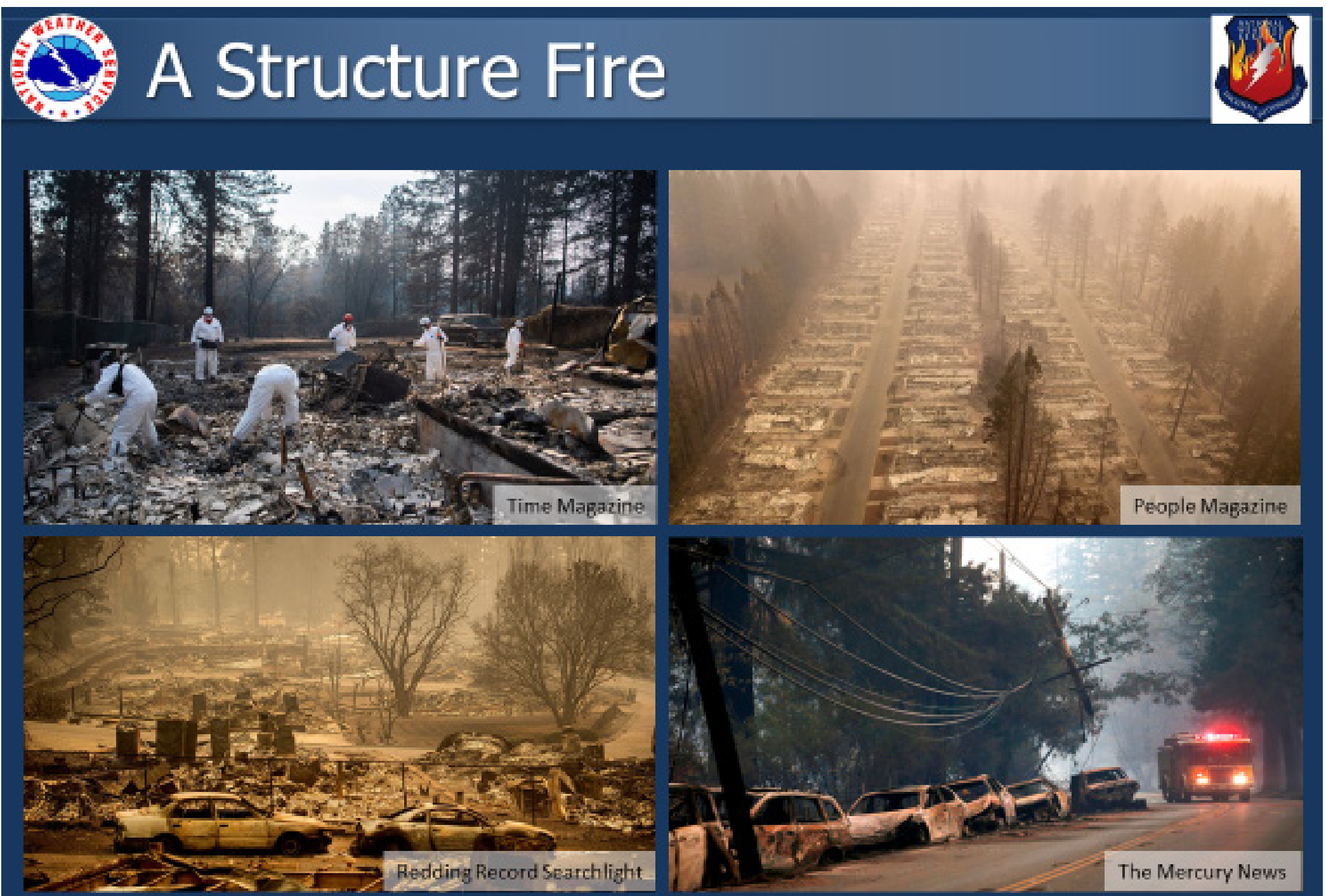

WENN

National Weather Service - Building a Weather-Ready Nation

f $y$ y 


\section{Jarbo Gap RAWS - The Day Before}

A Red Flag

Warning was

issued on

Wednesday night

that would last

through Friday

morning.

Wind gusts to 45

mph were

predicted.
Weatber Condition for JBCC

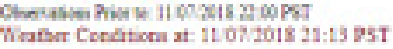

\begin{tabular}{|c|c|c|c|c|c|}
\hline Conghalloh & 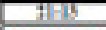 & 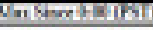 & 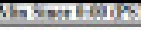 & d & \\
\hline Me Thestaties & $860^{\circ} \mathrm{F}$ & Q6.9ar $14 i 13$ & 560.1613 & 6.0 arlitily & 46.0 ar $6: 13$ \\
\hline 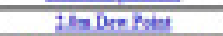 & ghन & 23.3 at $17: 13$ & $9.0=21: 13$ & 233 at $17: 13$ & 9.0 at $21: 13$ \\
\hline 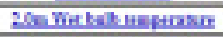 & 38,7 & 47,2 ar 14:13 & 2063013 & 47,2 ar lait3 & 33.5 ar6:13 \\
\hline 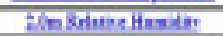 & $15 \%$ & If at IS:DB & 15 at $11-13$ & 2f at $18=13$ & 15at 21:13 \\
\hline 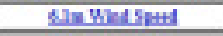 & $28.6 \mathrm{mb}$ & 28,9 ar 2 & $0.0 \times 17: 13$ & 250 at $21: 13$ & 0.0 at $17 ; 13$ \\
\hline Al= Wistati & F5. & 430 at $21: 13$ & $4.0 \mathrm{~A} / \mathrm{K}: 13$ & 49.0 at $21: 19$ & 40 at $15: 19$ \\
\hline Antialdowron & NI & & & 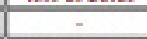 & \\
\hline Sempatalia & 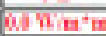 & 5536 al1II3 & Q6A21:13 & B56.6 का IF:13 & 60 क्सा:y \\
\hline Fulfanmirsm & 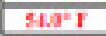 & 75. a ar $1 \mathrm{A:13}$ & EL: $x: t \in: 13$ & 73.0 at 14:13 & 41.0 at $6: 13$ \\
\hline Eard Whasent & $5 \mathrm{sm}$ & & & 5 as 21119 & tack:13 \\
\hline Burrotabse & 12.50 telt & 16.09 at $3: 13$ & 12.00 at $6: 13$ & 16.00 at $9: 13$ & 1270 at $8=13$ \\
\hline
\end{tabular}

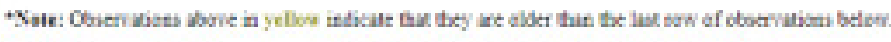

\begin{tabular}{|c|c|c|c|c|c|c|c|c|c|c|c|c|c|}
\hline का & \multicolumn{3}{|c|}{ ता } & \multicolumn{3}{|c|}{ 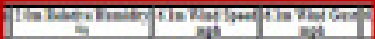 } & \multicolumn{2}{|c|}{ 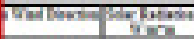 } & \multicolumn{2}{|c|}{ 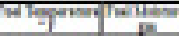 } & 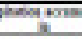 & \multicolumn{2}{|c|}{ tench } \\
\hline 2113 & 566 & 50 & 38.7 & 15 & 250 & 43.0 & SE & 0.6 & 540 & 5 & 0.70 & $12 . \omega$ & $\mathrm{OK}$ \\
\hline 20.13 & 560 & 90 & 38.7 & 15 & 180 & 280 & NE & 00 & 54.0 & 5 & 0.70 & 13.90 & OK \\
\hline $19-13$ & $\$ 60$ & 159 & 398 & 20 & 240 & 210 & NE & 0.0 & 530 & 5 & 0.70 & 13.00 & ov \\
\hline 18.13 & 560 & 225 & 41.5 & 27 & 3.6 & 40 & NE & 0.0 & $\$ 00$ & 5 & 0.70 & 13.20 & $0 \mathrm{~s}$ \\
\hline $17: 13$ & s80 & 253 & 42.7 & 26 & 0.0 & 50 & & 110 & 52.0 & 5 & 9.70 & 13.90 & CW \\
\hline $16: 13$ & 62.6 & 21.6 & 442 & 21 & 40 & 7.0 & $5 W$ & 190 & 60.0 & 5 & 0.70 & 13.58 & $\mathrm{CK}$ \\
\hline $15: 13$ & 640 & 20.9 & 449 & 19 & $\Delta$ & 6.0 & Wsw & 2420 & 63.0 & 5 & 0.30 & 13.50 & OK \\
\hline $1+13$ & 000 & 200 & 472 & & & & $\bar{x}$ & 4530 & 780 & 5 & 0.70 & 13.90 & ok \\
\hline $13: 13$ & 65.6 & 18.5 & 453 & 16 & 3.6 & 60 & $5 W$ & 433.0 & 63.0 & 5 & 0.70 & 13.65 & $\mathrm{OK}$ \\
\hline $12: 13$ & 650 & 162 & 44.4 & 15 & 20 & 9.0 & NE & 5850 & 720 & 5 & 0.70 & 13.50 & CK \\
\hline $11-13$ & 926 & 143 & 412 & 17 & 60 & 200 & SEE & 5220 & 930 & 5 & 0.70 & $13.9 \mathrm{~s}$ & oK \\
\hline $10-13$ & 55.6 & 135 & 39.0 & 19 & 8.0 & 150 & NE & 4900 & 60.0 & 5 & 0.70 & $13.5 \mathrm{~s}$ & $\mathrm{OK}$ \\
\hline 913 & 520 & 153 & 37.4 & 21 & 200 & 180 & $\mathrm{NE}$ & 1900 & 540 & 5 & $0 \pi 0$ & 14,00 & $C K$ \\
\hline [:13 & 43.6 & 126 & 35.0 & 23 & 9.6 & 170 & NE & 230 & 48.0 & 5 & 0.70 & 19.42 & OK \\
\hline $7: 13$ & $\$ 70$ & [1].] & 343 & 23 & 110 & 150 & NE & 60 & 450 & 5 & 0.70 & 12.80 & OK \\
\hline t:13 & 200 & 103 & 336 & $2 s$ & 200 & 170 & SEE & 0.0 & 440 & 5 & $a .70$ & $12 . \%$ & oK \\
\hline s:13 & 48.6 & 11.6 & 34.8 & $n 2$ & 110 & ts. & $\mathrm{NE}$ & 00 & 45.0 & 5 & 0.70 & 12.70 & $\mathrm{OK}$ \\
\hline 4:13 & +90 & 108 & 39.4 & 21 & 110 & 30.0 & NT & 90 & 470 & 5 & 9.70 & 12.5 & $6 \%$ \\
\hline 3:13 & 20 & 6.7 & 35.2 & 20 & 260 & $t \leqslant 0$ & NE & 0.6 & 4) 0 & 4 & 0.70 & 12.35 & OK \\
\hline 2:13 & 500 & 105 & 35.8 & 20 & 100 & 190 & NE & 00 & 43.0 & 5 & 0.70 & $12.3 \mathrm{~s}$ & $\mathrm{Co}$ \\
\hline $1: 13$ & 500 & 109 & 393 & 20 & 200 & 150 & $\mathrm{xE}$ & 00 & 480 & 3 & 0.70 & 12.90 & ox \\
\hline 6.13 & 526 & 416 & 370 & 19 & 90 & 180 & NE & 0.0 & 200 & 5 & 0.70 & 12.95 & OK \\
\hline 2313 & 530 & 119 & 37.7 & 19 & 100 & 200 & $\mathrm{NE}$ & 90 & 900 & 5 & 0.70 & 12.90 & $\phi \%$ \\
\hline 22.15 & 546 & 127 & 38.5 & 16 & 80 & 270 & SEE & 0.0 & 520 & 4 & 0.70 & $12.2 n$ & $\mathrm{CK}$ \\
\hline $21-13$ & 540 & 139 & 38.6 & 20 & 80 & 14.0 & $\mathrm{NE}$ & 00 & 52.0 & 4 & 0.70 & 12.9 & $C \%$ \\
\hline
\end{tabular}

betar

National Weather Service - Building a Weather-Ready Nation

$f y$ rop 


\section{Jarbo Gap RAWS - The Day Of}

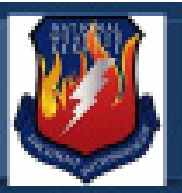

Weather Conditions for JBGCl

Observations Prior to: 11/09/2018 06:00 PST

\begin{tabular}{|c|c|c|c|c|c|c|c|c|c|c|c|c|c|}
\hline $\lim$ & $x_{n=1}$ & Pism & 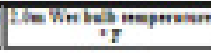 & 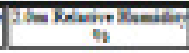 & 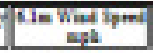 & Them & Hensanta & 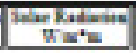 & 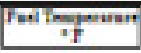 & 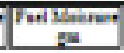 & 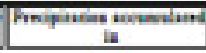 & 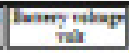 & 8 \\
\hline $5: 13$ & 50.0 & 6.9 & 35.2 & 17 & 290 & 45.0 & NE & 0.0 & 49.0 & 4 & 0.70 & 12.80 & Cautioe \\
\hline $4: 13$ & 50.0 & 6.9 & 35.2 & 17 & 28.0 & 47.0 & NE & 0.0 & 49.0 & 4 & 0.70 & 12.80 & OK \\
\hline $3: 13$ & 51.0 & 6.4 & 35.7 & 16 & 28.0 & 41.0 & NE & 0.0 & 50.0 & 4 & 0.70 & 12.80 & OK \\
\hline $2: 13$ & 52.0 & 5.8 & 36.1 & 15 & 27.0 & 48.0 & NE & 0.0 & 51.0 & 4 & 0.70 & 12.80 & OK \\
\hline $1: 13$ & 52.0 & 5.8 & 36.1 & 15 & 28.0 & 45.0 & NE & 0.0 & 51.0 & 4 & 0.70 & 12.90 & OK \\
\hline $0: 13$ & 52.0 & 4.3 & 35.9 & 14 & 25.0 & 48.0 & NE & 0.0 & 51.0 & 4 & 0.70 & 12.90 & OK \\
\hline $23: 13$ & 53.0 & 5.1 & 36.6 & 14 & 27.0 & 43.0 & $\mathrm{NE}$ & 0.0 & 51.0 & 4 & 0.70 & 12.90 & OK \\
\hline $22: 13$ & 53.0 & 5.1 & 36.6 & 14 & 220 & 39.0 & NDE & 0.0 & 51.0 & 4 & 0.70 & 12.90 & OK \\
\hline $21: 13$ & 54.0 & 4.3 & 37.0 & 13 & 22.0 & 36.0 & $\mathrm{NE}$ & 0.0 & 52.0 & 5 & 0.70 & 13.00 & OK \\
\hline $20: 13$ & 55.0 & 3.4 & 37.4 & 12 & 19.0 & 34.0 & $\mathrm{NDE}$ & 0.0 & 52.0 & 5 & 0.70 & 13.00 & OK \\
\hline $19: 13$ & $\$ 6.0$ & 4.1 & 38.0 & 12 & 18.0 & 30.0 & $\mathrm{NDE}$ & 0.0 & 53.0 & 5 & 0.70 & 13.00 & OK \\
\hline $18: 13$ & 57.0 & 4.9 & 33.6 & 12 & 15.0 & 27.0 & $\mathrm{NNE}$ & 0.0 & 54.0 & 5 & 0.70 & 13.10 & OK \\
\hline $17: 13$ & 58.0 & 3.8 & 39.0 & 11 & 13.0 & 23.0 & $\mathrm{NNE}$ & 9.0 & 55.0 & 5 & 0.70 & 13.30 & OK \\
\hline $16: 13$ & 60.0 & 7.3 & 40.5 & 12 & 8.0 & 25.0 & $\mathrm{NE}$ & $\$ 7.0$ & 58.0 & 5 & 0.70 & 13.50 & OK \\
\hline $15: 13$ & 61.0 & 8.0 & 41.1 & 12 & 100 & 28.0 & $\mathrm{NE}$ & 2540 & 60.0 & 5 & 0.70 & 13.70 & OK \\
\hline $14: 13$ & 63.0 & 7.7 & 42.0 & 11 & 150 & 24.0 & $\mathrm{NE}$ & 4340 & 67.0 & 5 & 0.70 & 14.40 & OK \\
\hline $13: 13$ & 61.0 & 8.0 & 41.1 & 12 & 120 & 32.0 & $\mathrm{NE}$ & 473.0 & 63.0 & 5 & 0.70 & 13.50 & OK \\
\hline $12: 13$ & 60.0 & 9.0 & 40.8 & 13 & 16.0 & 33.0 & $\mathrm{NNE}$ & 5560 & 64.0 & 5 & 0,70 & 13.60 & OK \\
\hline $11: 13$ & 58.0 & 9.1 & 39.8 & 14 & 140 & 29.0 & NNE & 525.0 & 61.0 & 5 & 0.70 & 13.80 & OK \\
\hline $10: 12$ & 55.0 & 9.7 & 28.2 & 16 & 18.0 & 30. & $M F$ & 4340 & 58.0 & 5 & 0.70 & 13.70 & OK \\
\hline $9: 13$ & 53.0 & 9.4 & 37.2 & 17 & 140 & 21.0 & NNE & 152.0 & 55.0 & 5 & 0.70 & 13.70 & OK \\
\hline S.12 & 510 & an & 36.1 & 18. & 60 & 250 & NAT & 52.0 & 51.0 & 5 & 0.70 & 13.90 & OK \\
\hline & & & & & & & & 7.0 & 46.0 & 5 & 0.70 & 12.80 & OK \\
\hline $6: 13$ & 48.0 & 12.0 & 35.0 & 23 & 18.0 & 40.0 & NNE & 0.0 & 46.0 & 5 & 0.70 & 12.70 & OK \\
\hline & & & & & 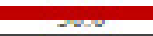 & $7+20$ & 14 & 0.0 & 47.0 & 5 & 0.70 & 12.80 & OK \\
\hline
\end{tabular}

WㅁN

National Weather Service - Building a Weather-Ready Nation

f $y$ rog 


\section{Jarbo Gap RAWS - Burned Over}

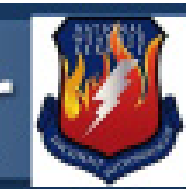

Weather Conditions for JBGCl
Observations Prior to: 11/10/2018 04:00 PST

\begin{tabular}{|c|c|c|c|c|c|c|c|c|c|c|c|c|c|}
\hline (1) & 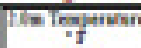 & 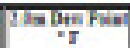 & 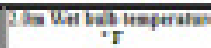 & 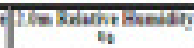 & 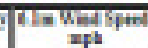 & 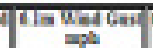 & 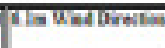 & 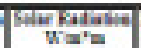 & 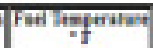 & 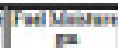 & 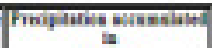 & 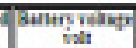 & $\begin{array}{l}\text { gann } \\
\text { Cwartal }\end{array}$ \\
\hline $3: 13$ & 46.0 & 14.7 & 34.5 & 28 & 6.0 & 10.0 & $\mathrm{E}$ & 0.0 & 45.0 & 5 & 0.70 & 12.80 & OK \\
\hline 2:13 & 47.0 & 14.8 & 35.1 & 27 & 6.0 & 11.0 & E & 0.0 & 46.0 & 5 & 0.70 & 12.80 & OK \\
\hline $1: 13$ & 49.0 & 15.6 & 36.3 & 26 & 5.0 & 10.0 & $\mathbf{E}$ & 0.0 & 47.0 & 5 & 0.70 & 12.80 & OK \\
\hline 0.13 & 49.0 & 15.6 & 36.3 & 26 & 5.0 & 9.0 & ESE & 0.0 & 48.0 & 5 & 0.70 & 12.90 & OK \\
\hline $23: 13$ & 500 & 15.6 & 36.8 & 25 & 4.0 & 11.0 & ESE & 0.0 & 49.0 & 5 & 0.70 & 12.90 & OK \\
\hline $22-13$ & 51.0 & 17.3 & 37.8 & 26 & 3.0 & 7.0 & ESE & 0.0 & 49.0 & 5 & 0.70 & 12.90 & OK \\
\hline $21: 13$ & 52.0 & 19.1 & 38.7 & 27 & 3.0 & 5.0 & $\mathbf{E}$ & 0.0 & 50.0 & 5 & 0.70 & 12.90 & $\mathrm{OK}$ \\
\hline $20: 13$ & 54.0 & 19.0 & 39.7 & 25 & 3.0 & 4.0 & $\mathrm{E}$ & 0.0 & 520 & 5 & 0.70 & 12.90 & OK \\
\hline $19: 13$ & 55.0 & 21.6 & 40.8 & 27 & 20 & 3.0 & $\mathrm{E}$ & 0.0 & 53.0 & 5 & 0.70 & 13.00 & OK \\
\hline $18: 13$ & 57.0 & 139 & 40.1 & 18 & 0.0 & 2.0 & & 0.0 & 53.0 & 5 & 0.70 & 13.10 & OK \\
\hline $17: 13$ & 58.0 & 12.1 & 40.3 & 16 & 2.0 & 4.0 & WSW & 6.0 & 55.0 & 5 & 0.70 & 13.20 & OK \\
\hline $16: 13$ & 59.0 & 99 & 40.4 & 14 & 2.0 & 4.0 & $5 w$ & 23.0 & 57.0 & 5 & 0.70 & 13.30 & OK \\
\hline $15: 13$ & 60.0 & 10.7 & 41.0 & 14 & 3.0 & 6.0 & WSW & 65.0 & 59.0 & 5 & 0.70 & 13.60 & OK \\
\hline $14: 13$ & 62.0 & 12.3 & 42.3 & 14 & 4.0 & 10.0 & E & 72.0 & 620 & 5 & 0.70 & 14.00 & OK \\
\hline $18-12$ & 610 & 115 & 416 & 14 & 60 & 120 & $\mathrm{~F}$ & 100 & 610 & 5 & n. 0.70 & 13.60 & OK \\
\hline $12-13$ & 60.0 & 122 & 41.3 & 15 & 6.0 & 15.0 & $\mathrm{E}$ & 80.0 & 620 & 5 & 0.70 & 14.20 & Caution \\
\hline $11: 13$ & 57.0 & 11.3 & 39.6 & 16 & 7.0 & 17,0 & $\mathbf{E}$ & 35.0 & 58.0 & 5 & 0.70 & 13.30 & Caution \\
\hline $10: 13$ & 57.0 & 11.3 & 39.6 & 16 & 10.0 & 21.0 & $\mathrm{E}$ & 143.0 & 38.0 & 6 & 0.70 & 13,60 & Caution \\
\hline 9.13 & 58.0 & 135 & 40.5 & 17 & 13.0 & 27.0 & $\mathrm{E}$ & 50.0 & 61.0 & 6 & 0.70 & 13.80 & Caution \\
\hline 8:13 & 83.0 & 18.4 & 52.5 & 9 & 18.0 & 72.0 & E & 52.0 & 105.0 & 5 & 0.70 & 13.00 & Caution \\
\hline $7: 13$ & 49.0 & 8.6 & 35.0 & 19 & 28.0 & 46.0 & $\mathrm{NE}$ & 12.0 & 48.0 & 4 & 0.70 & 12.90 & Caution \\
\hline $6: 13$ & 49.0 & 7.4 & 34.8 & 18 & 30.0 & 46.0 & $\mathrm{NE}$ & 0.0 & 48.0 & 4 & 0.70 & 12.70 & Caution \\
\hline $5: 13$ & 50.0 & 69 & 35.2 & 17 & 29.0 & 45.0 & NE & 0.0 & 49.0 & 4 & 0.70 & 12.80 & Caution \\
\hline$m^{\prime}$ & J00 & 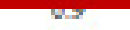 & ברית9 & 71 & 2000 & $7 \pi$ & se & 0.0 & 7900 & & orvo & 12.000 & $0 x$ \\
\hline $3: 13$ & 51.0 & 6.4 & 35.7 & 16 & 28.0 & 41.0 & NE & 0.0 & 50.0 & 4 & 0.70 & 12.80 & OK \\
\hline
\end{tabular}

WNN

National Weather Service - Building a Weather-Ready Nation

f $y$ rog 


\section{The next few days}

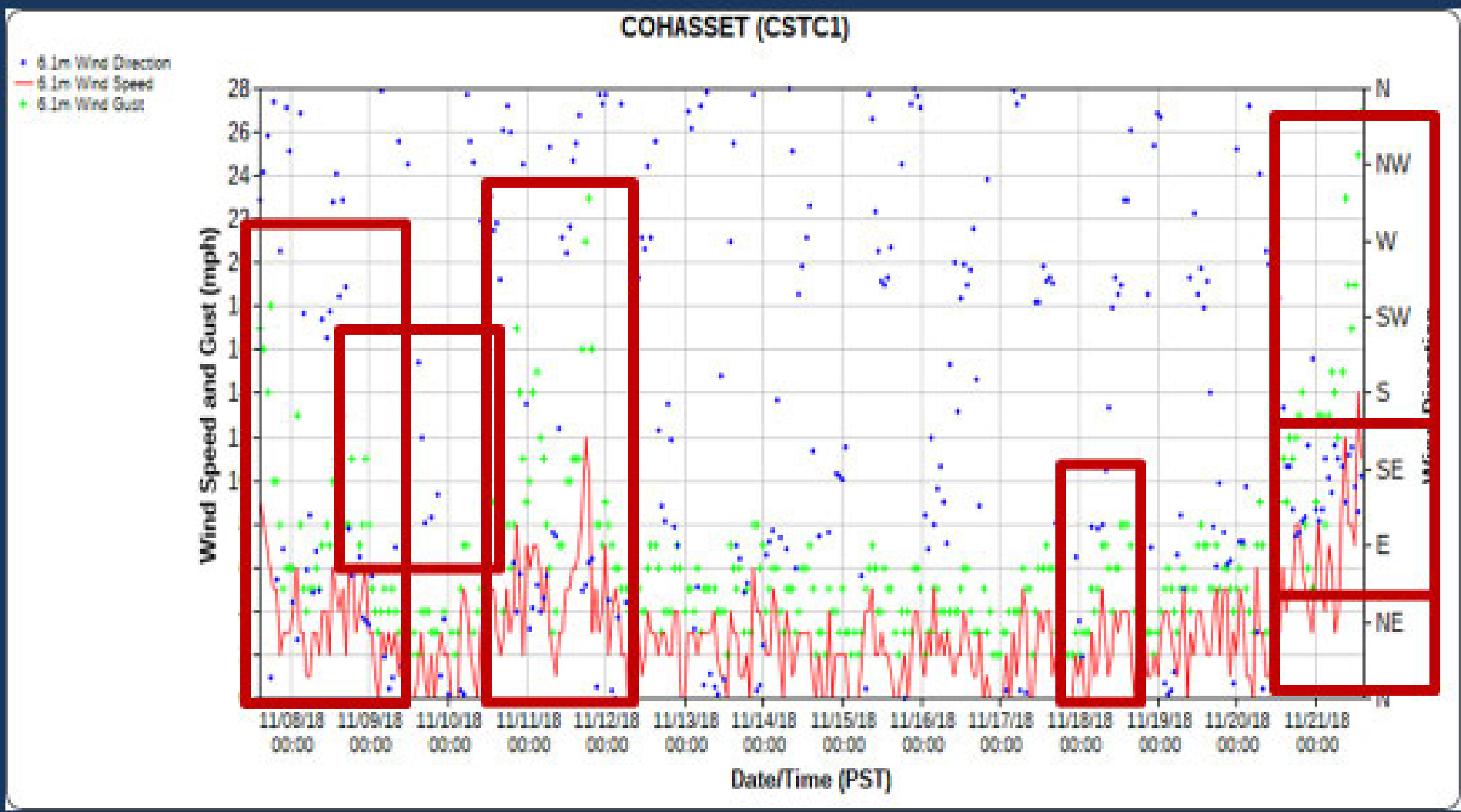

W:

National Weather Service - Building a Weather-Ready Nation

$f y$ Yoy 


\section{Thank you!}
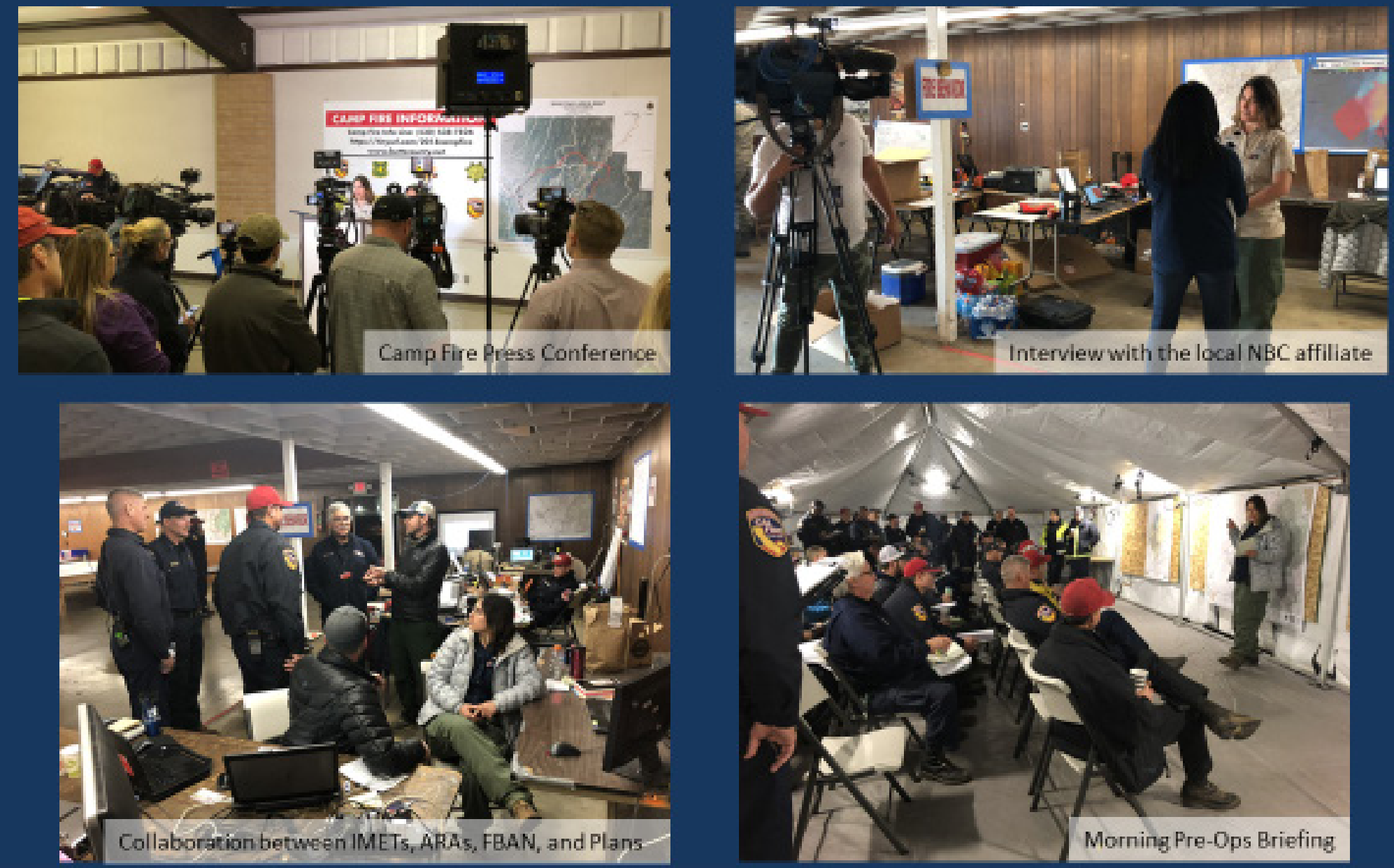

W:N

National Weather Service - Building a Weather-Ready Nation

$f y$ yoy 


\section{Appendix E. Identified Successes and Future Improvements to Data Collection and Analysis Methods}

\section{Data Collection Successes:}

1. Rapid deployment and initiation of data collection ensured the collection of uncontaminated data (before repopulation) and enabled the completion of the technical discussions (TDs) with first responders before the onset of the next fire season.

2. Perishable data, including AVL and PPD dashboard camera recordings, provided essential details to enable the timeline reconstruction.

\section{Recommendations Related to Picture Sharing during Technical Discussions:}

1. Record picture time and relevant attributes during the TDs to enable the use of the data even if the picture is not ultimately shared.

2. Obtain a letter of support from the fire chief giving permission to first responders to share images during the TDs.

3. Collect pictures/videos during the TDs, since success in obtaining the footage after the TDs was limited.

4. Confirm the capability to receive pictures and video from both Android and Apple devices during TDs.

\section{Recommendations for Future Data Collection:}

1. Collect badge numbers/identifiers for law enforcement to facilitate connecting TDs to radio $\log$ data.

2. Utilize a $360^{\circ}$ camera for post-fire drive-through. Conduct scene drive-through as soon as it is safe and does not interfere with firefighting operations.

3. Collect data from electric utility, communication, and alarm companies. Data from digital doorbells, if they can be obtained, would also be useful. Remote weather stations could help to quantify fire spread.

4. Mine social media early. Extensive photos and videos available from social media can be a valuable supplement to technical discussions, and deeper searching of this information may extend the reach of data collection.

5. Deploy experienced scribes with WUI fire backgrounds, including incident-specific backgrounds such as participation in preliminary reconnaissance. This would provide continuity for notetaking and database integration.

6. If incident size allows, collect DINS pictures of undamaged structures. 


\section{Appendix F. Fire Spread Data}

This appendix contains a line list of all fire observation data points collected in this study. ${ }^{27}$ To aid the reader, data is divided into 15 focus regions, as indicated in Figure 23. Each region has been sorted by the time of observation. The regions are ordered in the general fire progression sequence. Column titles are defined and described in Section 7.4.1 and Table 6.

Concow see page 257

Pentz Road see page 263

Feather River Hospital .................................see page 280

Wagstaff Road ..........................................see page 285

Bille Road ...................................................see page 289

Elliott Road and Nunneley Road ...................see page 293

Pearson Road and Buschmann Road ..............see page 299

Clark Road .................................................see page 308

Skyway.......................................................see page 324

Neal Road .................................................see page 340

Butte Creek Canyon ....................................see page 345

Valley View Drive ....................................see page 347

Foothills ...................................................see page 349

Nelson Bar Road ........................................see page 353

Magalia and Coutolenc Road ........................see page 358

${ }^{27}$ Some data points appear to be duplicates. This occurs when similar observations were made by different sources and/or multiple photographs were taken at the same time or in quick succession. 


\begin{tabular}{|c|c|c|c|c|c|c|c|c|c|c|c|c|}
\hline \multicolumn{13}{|c|}{ Concow } \\
\hline Source \# & Date & Time & $\begin{array}{l}\text { Time } \\
\text { Source }\end{array}$ & $\begin{array}{l}\text { Obs } \\
\text { Window } \\
\text { (min) }\end{array}$ & Latitude & Longitude & $\begin{array}{l}\text { Location } \\
\text { Source }\end{array}$ & Info Source & Fire Behavior Observations & $\begin{array}{l}\text { Type } \\
\text { of } \\
\text { Fire }\end{array}$ & $\begin{array}{l}\text { Residual } \\
\text { Fire? }\end{array}$ & SSI \\
\hline $911-001-1$ & $11 / 8$ & $06: 25$ & $911-001-1$ & 0 & 39.814610 & -121.434004 & Origin & $911-001-1$ & 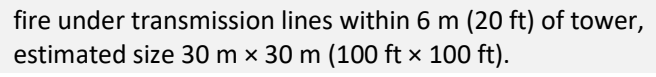 & V & & \\
\hline $911-002-1$ & $11 / 8$ & 06:31 & $911-002-1$ & 0 & 39.814610 & -121.434004 & Origin & $911-002-1$ & $\begin{array}{l}\text { wildfire in the Feather River Canyon area, Hwy } 70 \text { above } \\
\text { Poe Dam }\end{array}$ & V & & \\
\hline 911-004-1 & $11 / 8$ & 06:39 & $911-004-1$ & 0 & 39.814610 & -121.434004 & Origin & $911-004-1$ & spot fire started on Hwy 70 near Pulga Caltrans yard & v & & \\
\hline TD-028 & $11 / 8$ & 06:44 & Radio Log & 0 & 39.814610 & -121.434004 & Origin & TD & initial report of conditions & V & & \\
\hline VTD-28 & $11 / 8$ & $06: 45$ & Photo & 0 & 39.807822 & -121.482963 & Photo & Photo & $\begin{array}{l}\text { second power line ignition determined near } \\
\text { intersection of Rim Rd and Concow Rd }\end{array}$ & V & & \\
\hline TD-029 & $11 / 8$ & $06: 46$ & AVL & 976 & 39.803302 & -121.449305 & AVL & TD & fire threatening structures & $\mathrm{V}$ & & \\
\hline TD-028 & $11 / 8$ & $06: 47$ & Photo & 0 & 39.814328 & -121.434041 & Photo & Photo & Initial view of fire & V & & \\
\hline TD-005 & $11 / 8$ & $06: 47$ & Photo & 0 & 39.812603 & -121.434844 & Photo & Photo & $\begin{array}{l}\text { first view of fire; well established spot fire, } 30 \mathrm{~m}(100 \mathrm{ft}) \\
\text { smoke plume }\end{array}$ & v & & \\
\hline TD-028 & $11 / 8$ & $06: 58$ & AVL & 14 & 39.806103 & -121.451330 & Inferred & TD & fire already in and above Pulga & $\mathrm{V}$ & & \\
\hline $911-006-1$ & $11 / 8$ & 07:03 & $911-006-1$ & 0 & 39.807822 & -121.482963 & VTD-28 & $911-006-1$ & fire up slope from Concow Rd & $\mathrm{V}$ & & \\
\hline $911-009-1$ & $11 / 8$ & 07:05 & $911-009-1$ & 0 & 39.807822 & -121.482963 & VTD-28 & $911-009-1$ & $\begin{array}{l}\text { "can see fire on the mountain from my house, looking } \\
\text { north" }\end{array}$ & V & & \\
\hline TD-028 & $11 / 8$ & 07:10 & Radio Log & 0 & 39.807060 & -121.456750 & Inferred & TD & 80 ha to 120 ha (200 ac to $300 \mathrm{ac}$ ), rapid rate of spread & $\mathrm{V}$ & & \\
\hline TD-028 & $11 / 8$ & 07:15 & TD & 0 & 39.807060 & -121.456750 & TD & TD & $\begin{array}{l}\text { fire really got established in Flea Canyon, no vegetation } \\
\text { left, sent embers }\end{array}$ & $\mathrm{v}$ & & \\
\hline TD-028 & $11 / 8$ & 07:15 & Photo & 0 & 39.808530 & -121.447729 & Photo & Photo & can see flames up canyon from bridge & $\mathrm{v}$ & & \\
\hline TD-028 & $11 / 8$ & 07:15 & Photo & 0 & 39.808012 & -121.453297 & Photo & Photo & $\begin{array}{l}\text { fire has spread SW from origin into the canyon above } \\
\text { Pulga }\end{array}$ & V & & \\
\hline TD-028 & $11 / 8$ & 07:16 & Photo & 0 & 39.805433 & -121.451328 & Photo & Photo & $\begin{array}{l}\text { fire has spread SW from origin into the canyon above } \\
\text { Pulga }\end{array}$ & $\mathrm{V}$ & & \\
\hline TD-028 & $11 / 8$ & 07:16 & Photo & 0 & 39.806295 & -121.446234 & Photo & Photo & $\begin{array}{l}\text { glow of fire expanding along ridgeline; fire backing } \\
\text { down hillside toward river and Pulga }\end{array}$ & v & & \\
\hline TD-028 & $11 / 8$ & 07:16 & Photo & 0 & 39.806295 & -121.446234 & Photo & Photo & $\begin{array}{l}\text { fire along ridgeline and backing down hillside toward } \\
\text { river and Pulga }\end{array}$ & $\mathrm{V}$ & & \\
\hline TD-005 & $11 / 8$ & 07:16 & Photo & 0 & 39.808024 & -121.458911 & Photo & Photo & $\begin{array}{l}\text { massive billowing smoke cloud rising from Flea Valley } \\
\text { area }\end{array}$ & V & & \\
\hline TD-005 & $11 / 8$ & 07:20 & $\mathrm{AVL}$ & 0 & 39.794959 & -121.473990 & TD & TD & spot fires to west of Rim Rd & $S$ & & \\
\hline TD-028 & $11 / 8$ & 07:23 & Photo & 0 & 39.807797 & -121.440873 & Photo & Photo & $\begin{array}{l}\text { active vegetation fire, wind pushing fire up slope W, } \\
\text { WSW; fire extending up slope and well beyond ridge to } \\
\text { W }\end{array}$ & $\mathrm{v}$ & & \\
\hline TD-013 & $11 / 8$ & $07: 24$ & TD & 0 & 39.766468 & -121.537037 & TD & TD & $\begin{array}{l}\text { multiple (5) small spot fires } 3 \mathrm{~m} \times 3 \mathrm{~m}(10 \mathrm{ft} \times 10 \mathrm{ft}) \\
\text { visible on east facing slopes }\end{array}$ & S & & \\
\hline TD-005 & $11 / 8$ & $07: 24$ & Photo & 0 & 39.794663 & -121.473829 & Photo & Photo & $\begin{array}{l}\text { large, well established spot fire, } 0.1 \text { ha to } 0.2 \text { ha } \\
(0.25 \text { ac to } 0.5 \mathrm{ac})\end{array}$ & $S$ & & \\
\hline
\end{tabular}




\begin{tabular}{|c|c|c|c|c|c|c|c|c|c|c|c|c|}
\hline \multicolumn{13}{|c|}{ Concow } \\
\hline Source \# & Date & Time & $\begin{array}{l}\text { Time } \\
\text { Source }\end{array}$ & $\begin{array}{l}\text { Obs } \\
\text { Window } \\
\text { (min) }\end{array}$ & Latitude & Longitude & $\begin{array}{l}\text { Location } \\
\text { Source }\end{array}$ & Info Source & Fire Behavior Observations & $\begin{array}{l}\text { Type } \\
\text { of } \\
\text { Fire }\end{array}$ & $\begin{array}{l}\text { Residual } \\
\text { Fire? }\end{array}$ & SSI \\
\hline TD-005 & $11 / 8$ & 07:24 & Photo & 0 & 39.793910 & -121.473667 & Photo & Photo & spot fire & $\mathrm{s}$ & & \\
\hline TD-062 & $11 / 8$ & 07:25 & AVL & 7 & 39.788116 & -121.495713 & TD & TD & $\begin{array}{l}\text { see spots below down in Concow; homes start to catch } \\
\text { fire }\end{array}$ & $\mathrm{R}$ & & \\
\hline TD-143 & $11 / 8$ & 07:29 & Photo & 0 & 39.813105 & -121.534893 & Photo & Photo & flames visible on ridge top & v & & \\
\hline TD-143 & $11 / 8$ & 07:29 & Photo & 0 & 39.813105 & -121.534893 & Photo & Photo & flames visible on ridge top & V & & \\
\hline TD-013 & $11 / 8$ & 07:30 & Inferred & 10 & 39.777564 & -121.508483 & TD & TD & $\begin{array}{l}\text { observe } 6 \mathrm{~m} \times 6 \mathrm{~m}(20 \mathrm{ft} \times 20 \mathrm{ft}) \text { spot fire at house. fire } \\
\text { pulling upwind toward house }\end{array}$ & $S$ & & \\
\hline TD-110 & $11 / 8$ & 07:30 & Inferred & 15 & 39.761408 & -121.532027 & TD & TD & $\begin{array}{l}0.1 \text { ha }(0.25 \text { ac) spot fires in Concow creek just before } \\
\text { lake }\end{array}$ & $S$ & & \\
\hline $911-037-1$ & $11 / 8$ & 07:30 & $911-037-1$ & 0 & 39.789147 & -121.516244 & $911-037-1$ & $911-037-1$ & fire in the yard & $S$ & & \\
\hline TD-005 & $11 / 8$ & 07:32 & video & 0 & 39.793738 & -121.470504 & video & video & $\begin{array}{l}\text { Spot fire }[240 \mathrm{~m}(800 \mathrm{ft})] \text { from road to the } \\
\text { east/northeast }\end{array}$ & $S$ & & \\
\hline TD-005 & $11 / 8$ & 07:32 & video & 0 & 39.793824 & -121.474035 & video & video & spot fire on west side of Rim Rd & $\mathrm{s}$ & & \\
\hline TD-005 & $11 / 8$ & 07:32 & Photo & 0 & 39.794180 & -121.473630 & Photo & Photo & $\begin{array}{l}\text { spot fires have grown to several ac, spreading up slope, } \\
\text { consuming draw }\end{array}$ & $\mathrm{v}$ & & \\
\hline TD-005 & $11 / 8$ & 07:32 & Photo & 0 & 39.794612 & -121.470229 & Photo & Photo & significant flames, pines torching on ridgetop & v & & \\
\hline $911-040-1$ & $11 / 8$ & 07:33 & $911-040-1$ & 0 & 39.787712 & -121.529838 & $911-040-1$ & $911-040-1$ & fire in the yard & $S$ & & \\
\hline $911-042-2$ & $11 / 8$ & 07:34 & $911-042-2$ & 0 & 39.793533 & -121.510031 & $911-042-2$ & $911-042-2$ & fire, I think it's blocking the road & $\mathrm{S}$ & & \\
\hline TD-005 & $11 / 8$ & 07:35 & AVL & 0 & 39.784595 & -121.507358 & TD & TD & spot fire 3 ha (10 ac) and growing & S & & \\
\hline $911-046-1$ & $11 / 8$ & $07: 36$ & $911-046-1$ & 0 & 39.792422 & -121.510804 & $911-046-1$ & $911-046-1$ & fire actively coming onto property & $S$ & & \\
\hline TD-103 & $11 / 8$ & 07:38 & AVL & 0 & 39.760993 & -121.538608 & TD & TD & spot fires on west side of Concow Rd & $S$ & & \\
\hline $911-048-1$ & $11 / 8$ & 07:38 & $911-048-1$ & 0 & 39.809499 & -121.554749 & Inferred & $911-048-1$ & $\begin{array}{l}\text { new flames just below Sawmill Peak, it just started on } \\
\text { the Paradise side. Smoke started coming up and I just } \\
\text { started seeing flames. }\end{array}$ & S & & \\
\hline TD-013 & $11 / 8$ & 07:40 & Inferred & 10 & 39.786661 & -121.521587 & TD & TD & spot fire on both sides of Hoffman Rd & $S$ & & \\
\hline 911-053-1 & $11 / 8$ & 07:43 & $911-053-1$ & 0 & 39.786513 & -121.530355 & 911-053-1 & $911-053-1$ & fire at end of driveway, can see the flames & $\mathrm{S}$ & & \\
\hline TD-103 & $11 / 8$ & 07:45 & AVL & 4 & 39.776592 & -121.508305 & AVL & TD & fire at Concow Rd & V & & \\
\hline TD-103 & $11 / 8$ & 07:45 & AVL & 4 & 39.776592 & -121.508305 & AVL & TD & vegetation fire expanding around area & V & & \\
\hline $911-057-1$ & $11 / 8$ & 07:45 & $911-057-1$ & 0 & 39.785441 & -121.531678 & $911-057-1$ & $911-057-1$ & fire & $S$ & & \\
\hline $911-058-1$ & $11 / 8$ & 07:45 & $911-058-1$ & 0 & 39.807461 & -121.551843 & Inferred & $911-058-1$ & 4 to 5 spot fires visible on Sawmill Peak & $\mathrm{S}$ & & \\
\hline TD-005 & $11 / 8$ & 07:47 & AVL & 0 & 39.774950 & -121.532180 & TD & TD & 3 spot fires growing very fast & S & & \\
\hline $911-060-2$ & $11 / 8$ & 07:47 & $911-060-2$ & 0 & 39.810031 & -121.558001 & Inferred & $911-060-2$ & multiple spot fires on Paradise side of ridge & $S$ & & \\
\hline TD-103 & $11 / 8$ & 07:49 & AVL & 7 & 39.781743 & -121.505542 & AVL & TD & car on fire, brush on fire & 0 & & \\
\hline TD-110 & $11 / 8$ & 07:49 & Inferred & 26 & 39.776615 & -121.508305 & TD & TD & edge of fire & v & & \\
\hline TD-013 & $11 / 8$ & 07:50 & Radio Log & 0 & 39.796821 & -121.542241 & Radio Log & TD & $\begin{array}{l}10 \text { to } 15 \text { large spot fires } 0.8 \text { ha to } 1.2 \text { ha ( } 2 \text { ac to } 3 \text { ac) } \\
\text { each on back side of Sawmill Peak; Jordan Hill Rd }\end{array}$ & S & & \\
\hline 911-1024-1 & $11 / 8$ & 07:50 & 911-1024-1 & 0 & 39.789460 & -121.560302 & 911-1024-1 & 911-1024-1 & huge fire, a little above mid-range on the mountains & $\mathrm{V}$ & & \\
\hline
\end{tabular}




\begin{tabular}{|c|c|c|c|c|c|c|c|c|c|c|c|c|}
\hline \multicolumn{13}{|c|}{ Concow } \\
\hline Source \# & Date & Time & $\begin{array}{l}\text { Time } \\
\text { Source }\end{array}$ & $\begin{array}{l}\text { Obs } \\
\text { Window } \\
\text { (min) }\end{array}$ & Latitude & Longitude & $\begin{array}{l}\text { Location } \\
\text { Source }\end{array}$ & Info Source & Fire Behavior Observations & $\begin{array}{l}\text { Type } \\
\text { of } \\
\text { Fire }\end{array}$ & $\begin{array}{l}\text { Residual } \\
\text { Fire? }\end{array}$ & SSI \\
\hline 911-069-1 & $11 / 8$ & 07:50 & $911-069-1$ & 0 & 39.786405 & -121.530504 & Inferred & 911-069-1 & big fire on Hog Ranch & $\mathrm{V}$ & & \\
\hline $911-075-1$ & $11 / 8$ & 07:52 & $911-075-1$ & 0 & 39.794115 & -121.501841 & $911-075-1$ & $911-075-1$ & $\begin{array}{l}\text { completely engulfed in flames, totally on fire } \\
\text { surrounded by flames }\end{array}$ & 0 & & \\
\hline TD-013 & $11 / 8$ & 07:53 & Inferred & 7 & 39.804518 & -121.514083 & TD & TD & spots up above Concow Rd, to north & $\mathrm{s}$ & & \\
\hline TD-013 & $11 / 8$ & 07:53 & Inferred & 7 & 39.786533 & -121.521528 & TD & TD & $\begin{array}{l}\text { spot fires on Hoffman have merged now; fire blowing } \\
\text { across road }\end{array}$ & $\mathrm{s}$ & & \\
\hline 911-078-1 & $11 / 8$ & 07:53 & 911-078-1 & 0 & 39.760673 & -121.556378 & 911-078-1 & 911-078-1 & can see flames, just started, spreading really fast & $\mathrm{s}$ & & \\
\hline TD-006 & $11 / 8$ & 07:54 & Photo & 0 & 39.817593 & -121.544129 & Photo & Photo & northern flank & V & & \\
\hline TD-008 & $11 / 8$ & 07:55 & AVL & 0 & 39.769124 & -121.528701 & TD & TD & $\begin{array}{l}\text { several spot fires (approximately } 3 \text { ) across Concow } \\
\text { reservoir, each } 10 \text { ha ( } 25 \mathrm{ac} \text { ) and growing fast }\end{array}$ & $\mathrm{s}$ & & \\
\hline TD-008 & $11 / 8$ & 07:56 & $\mathrm{AVL}$ & 0 & 39.787362 & -121.482267 & TD & TD & fire coming down ridge from Concow Rd & $\mathrm{V}$ & & \\
\hline $911-086-1$ & $11 / 8$ & 07:58 & $911-086-1$ & 0 & 39.764600 & -121.557414 & $911-086-1$ & $911-086-1$ & can see spot fire & $\mathrm{S}$ & & \\
\hline TD-013 & $11 / 8$ & 08:00 & Inferred & 0 & 39.783360 & -121.510174 & TD & TD & $\begin{array}{l}\text { small patch of green between Hoffman Rd and the lake, } \\
\text { fire all around }\end{array}$ & $\mathrm{V}$ & & \\
\hline TD-013 & $11 / 8$ & 08:00 & Inferred & 17 & 39.783767 & -121.510606 & TD & TD & vehicles are catching fire & 0 & & \\
\hline TD-013 & $11 / 8$ & $08: 00$ & Inferred & 25 & 39.784056 & -121.509764 & TD & TD & 4 to 5 vehicles are burning & $\mathrm{O}$ & & \\
\hline TD-013 & $11 / 8$ & 08:00 & Inferred & 25 & 39.783138 & -121.507260 & TD & TD & 3 to 4 homes fully involved; propane tanks exploding & $\mathrm{R}$ & & \\
\hline TD-008 & $11 / 8$ & 08:01 & Inferred & 168 & 39.776915 & -121.508721 & TD & TD & edge of fire & $\mathrm{v}$ & & \\
\hline TD-008 & $11 / 8$ & 08:01 & AVL & 29 & 39.776259 & -121.508022 & AVL & TD & $\begin{array}{l}\text { flame front too intense to pass, burning vehicles in } \\
\text { road. Crown, timber, brush } 3 \mathrm{~m} \text { to } 4.6 \mathrm{~m} \text { ( } 10 \mathrm{ft} \text { to } 15 \mathrm{ft}) \text {, } \\
18 \mathrm{~m} \text { to } 24 \mathrm{~m}(60 \mathrm{ft} \text { to } 80 \mathrm{ft} \text { ) flames }\end{array}$ & 0 & & \\
\hline TD-040 & $11 / 8$ & 08:04 & Photo & 0 & 39.811170 & -121.539192 & Photo & Photo & fire burning on east side of Sawmill Peak & V & & \\
\hline TD-040 & $11 / 8$ & 08:04 & Photo & 0 & 39.811900 & -121.547225 & Photo & Photo & large fire burning on SE side of Sawmill Peak & $\mathrm{v}$ & & \\
\hline TD-058 & $11 / 8$ & 08:05 & Inferred & 0 & 39.808726 & -121.555181 & TD & TD & $\begin{array}{l}\text { can see fire on Sawmill Peak from the lookout on Old } \\
\text { Skyway }\end{array}$ & $\mathrm{V}$ & & \\
\hline $911-111-1$ & $11 / 8$ & 08:11 & $911-111-1$ & 0 & 39.794030 & -121.513173 & $911-111-1$ & $911-111-1$ & surrounded by flames on top of hill & 0 & & \\
\hline $911-113-1$ & $11 / 8$ & 08:12 & $911-113-1$ & 0 & 39.788647 & -121.518099 & $911-113-1$ & $911-113-1$ & whole property in flames & 0 & & \\
\hline TD-009 & $11 / 8$ & 08:15 & AVL & 0 & 39.787733 & -121.472717 & AVL & TD & fire burning across Rim Rd & $\mathrm{v}$ & & \\
\hline TD-009 & $11 / 8$ & 08:15 & AVL & 0 & 39.770628 & -121.526467 & TD & TD & $\begin{array}{l}\text { fire appears to be across Concow Lake - large spots, not } \\
\text { continuous fire line }\end{array}$ & S & & \\
\hline TD-110 & $11 / 8$ & 08:15 & TD-062 & 15 & 39.782642 & -121.505838 & TD & TD & $\begin{array}{l}\text { intense fire conditions; flames horizontal over Hoffman } \\
\text { Rd; untenable conditions }\end{array}$ & $\mathrm{v}$ & & \\
\hline TD-110 & $11 / 8$ & 08:15 & Inferred & 15 & 39.782032 & -121.505655 & TD & TD & $\begin{array}{l}\text { embers blowing across roadway; sketchy to drive } \\
\text { through but not crazy }\end{array}$ & $\mathrm{v}$ & & \\
\hline TD-110 & $11 / 8$ & 08:15 & Inferred & 15 & 39.783722 & -121.507093 & TD & TD & trees torching down Hoffman Rd & V & & \\
\hline 911-120-1 & $11 / 8$ & 08:18 & $911-120-1$ & 0 & 39.794115 & -121.501841 & $911-120-1$ & $911-120-1$ & surrounded by fire & 0 & & \\
\hline
\end{tabular}




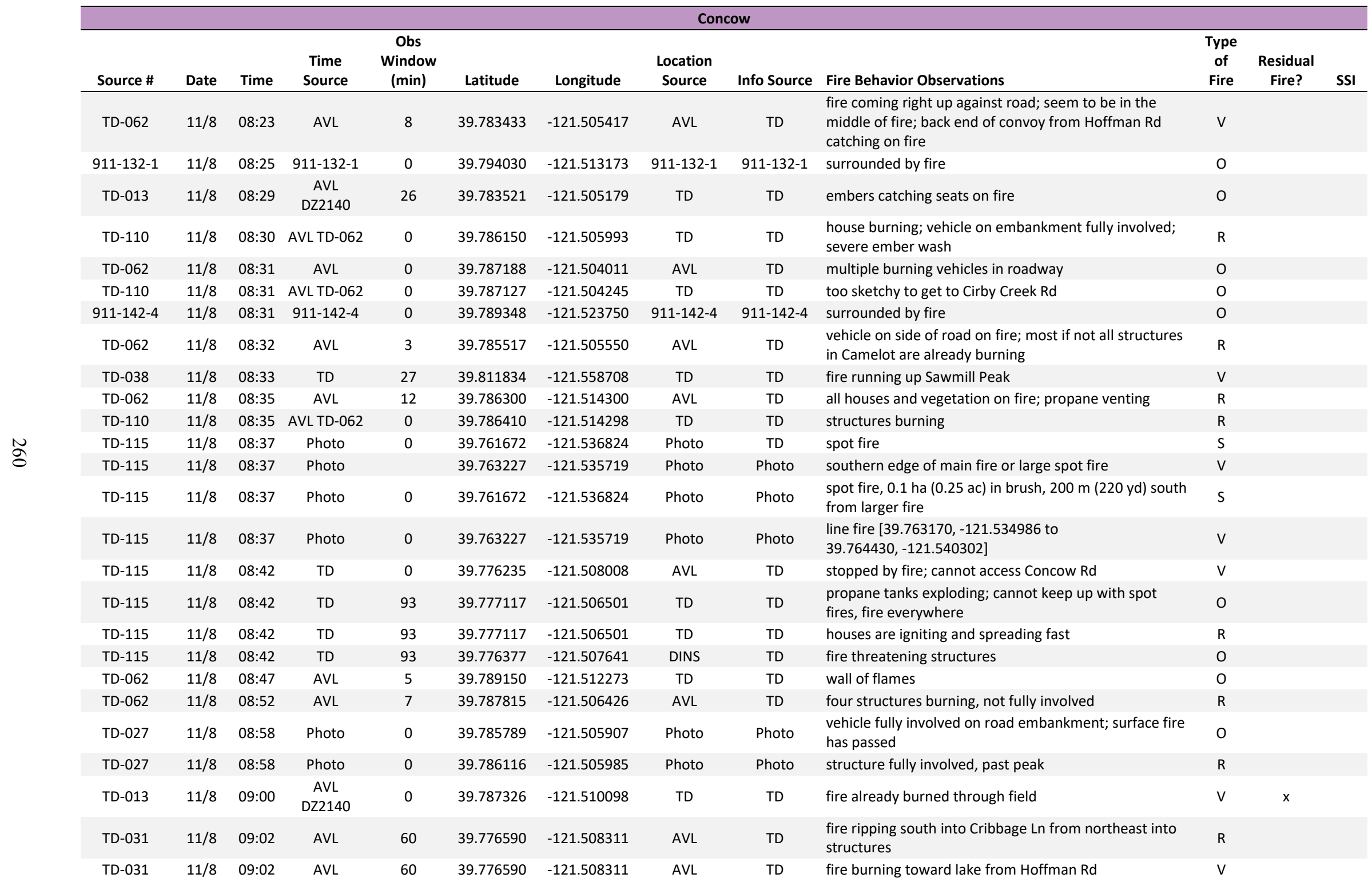




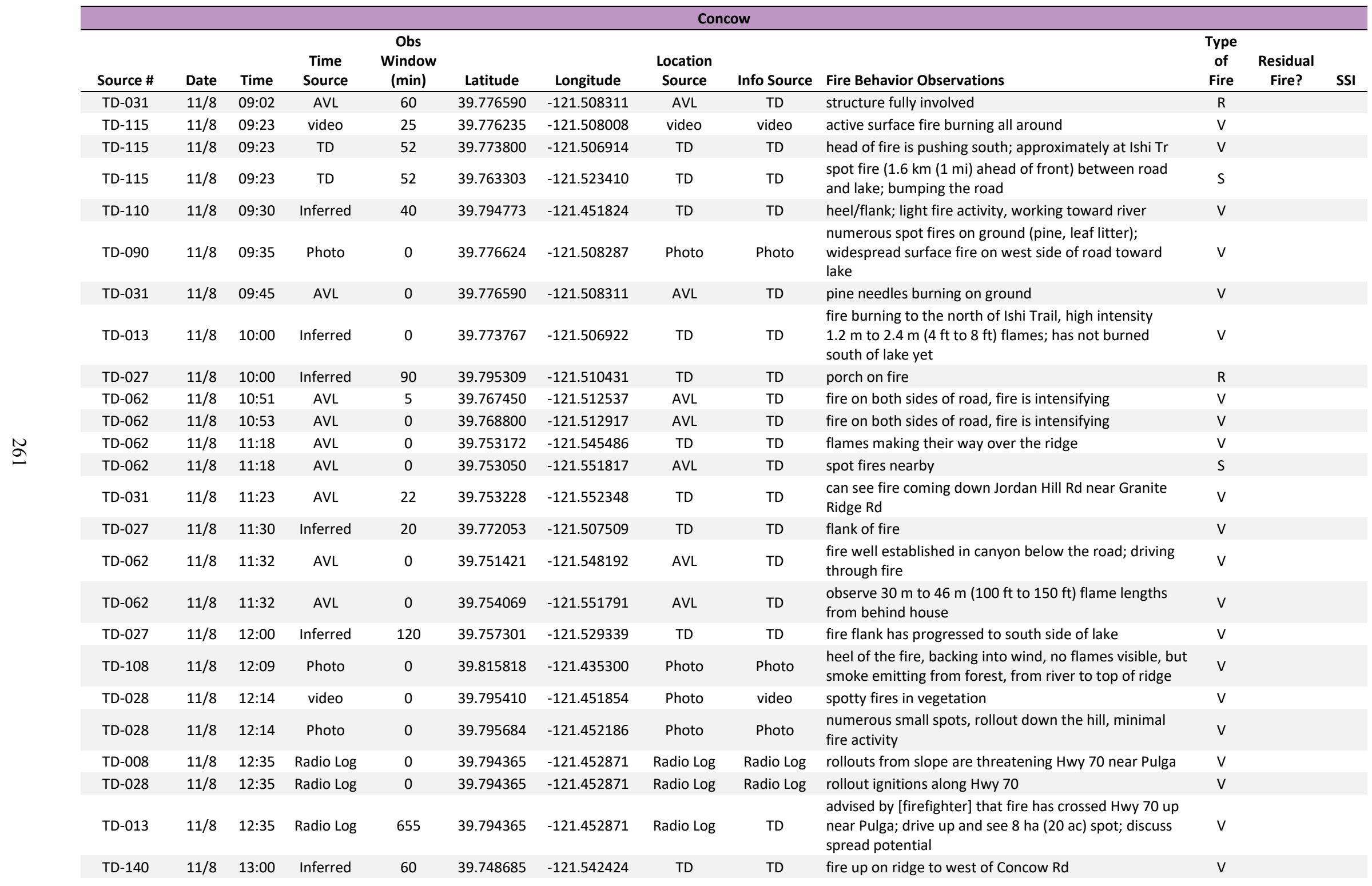




\begin{tabular}{|c|c|c|c|c|c|c|c|c|c|c|c|c|}
\hline \multicolumn{13}{|c|}{ Concow } \\
\hline Source \# & Date & Time & $\begin{array}{l}\text { Time } \\
\text { Source }\end{array}$ & $\begin{array}{c}\text { Obs } \\
\text { Window } \\
\text { (min) }\end{array}$ & Latitude & Longitude & $\begin{array}{l}\text { Location } \\
\text { Source }\end{array}$ & Info Source & Fire Behavior Observations & $\begin{array}{c}\text { Type } \\
\text { of } \\
\text { Fire }\end{array}$ & $\begin{array}{l}\text { Residual } \\
\text { Fire? }\end{array}$ & SSI \\
\hline TD-028 & $11 / 8$ & $23: 10$ & Radio Log & 0 & 39.787050 & -121.450567 & $A V L$ & Radio Log & $\begin{array}{l}\text { one slop over towards the river, starting to make runs, } \\
\text { but hung up in rocks below the roadway }\end{array}$ & V & & \\
\hline TD-028 & $11 / 9$ & $00: 28$ & Radio Log & 0 & 39.758168 & -121.476278 & AVL & Radio Log & $\begin{array}{l}\text { Fire rolls below Hwy } 70 \text { (east); fire well established } 1.6 \\
\mathrm{~km} \text { to } 3.2 \mathrm{~km} \text { ( } 1 \mathrm{mi} \text { to } 2 \mathrm{mi} \text { ) below Station } 36 \text {; drove } \\
\text { through fire to return to station }\end{array}$ & V & & \\
\hline TD-029 & $11 / 9$ & $00: 28$ & AVL & 0 & 39.761067 & -121.479133 & AVL & TD & [fire reached trigger point] & $\mathrm{V}$ & & \\
\hline TD-028 & $11 / 9$ & 03:07 & Photo & 0 & 39.749792 & -121.500913 & Photo & Photo & fire on ridge top & $\mathrm{V}$ & & \\
\hline
\end{tabular}




\begin{tabular}{|c|c|c|c|c|c|c|c|c|c|c|c|c|}
\hline \multicolumn{13}{|c|}{ Pentz Road } \\
\hline Source \# & Date & Time & $\begin{array}{c}\text { Time } \\
\text { Source }\end{array}$ & $\begin{array}{l}\text { Obs } \\
\text { Window } \\
\text { (min) }\end{array}$ & Latitude & Longitude & $\begin{array}{c}\text { Location } \\
\text { Source }\end{array}$ & Info Source & Fire Behavior Observations & $\begin{array}{l}\text { Type } \\
\text { of } \\
\text { Fire }\end{array}$ & $\begin{array}{l}\text { Residual } \\
\text { Fire? }\end{array}$ & SSI \\
\hline TD-063 & $11 / 8$ & 07:49 & $911-064-1$ & 0 & 39.754064 & -121.570775 & 911-064-1 & TD & spot fire & $\mathrm{S}$ & & \\
\hline $911-064-1$ & $11 / 8$ & 07:49 & $911-064-1$ & 0 & 39.754132 & -121.570864 & $911-064-1$ & $911-064-1$ & fire in yard & $\mathrm{S}$ & & \\
\hline TD-023 & $11 / 8$ & 07:50 & Inferred & 60 & 39.788645 & -121.576042 & TD & TD & 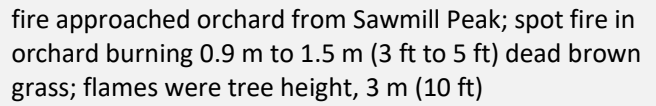 & v & & \\
\hline 911-066-1 & $11 / 8$ & $07: 50$ & 911-066-1 & 0 & 39.754563 & -121.570015 & Inferred & 911-066-1 & fire just started very close to us & $\mathrm{s}$ & & \\
\hline 911-071-1 & $11 / 8$ & 07:51 & 911-071-1 & 0 & 39.754132 & -121.570864 & 911-071-1 & 911-071-1 & fire in yard getting bigger by the second & $\mathrm{s}$ & & \\
\hline $911-074-1$ & $11 / 8$ & 07:52 & $911-074-1$ & 0 & 39.788694 & -121.576035 & Inferred & $911-074-1$ & huge fire in orchard & $S$ & & \\
\hline 911-1026-1 & $11 / 8$ & $07: 52$ & $911-1026-1$ & 0 & 39.774496 & -121.576350 & $911-1026-1$ & $911-1026-1$ & little fire here, probably going to spread & $S$ & & \\
\hline $911-1027-4$ & $11 / 8$ & $07: 52$ & $911-1027-4$ & 0 & 39.783271 & -121.570245 & $911-1027-4$ & $911-1027-4$ & spot fire starting & $\mathrm{s}$ & & \\
\hline $911-077-3$ & $11 / 8$ & $07: 53$ & $911-077-3$ & 0 & 39.778763 & -121.577193 & $911-077-3$ & $911-077-3$ & vegetation fire in side yard & $\mathrm{s}$ & & \\
\hline 911-082-1 & $11 / 8$ & $07: 56$ & 911-082-1 & 0 & 39.788579 & -121.576068 & Inferred & 911-082-1 & fire in Noble Orchard & $\mathrm{s}$ & & \\
\hline $911-084-1$ & $11 / 8$ & 07:56 & $911-084-1$ & 0 & 39.755072 & -121.569579 & Inferred & $911-084-1$ & fire behind home on Riverview & $S$ & & \\
\hline $911-085-2$ & $11 / 8$ & 07:57 & $911-085-2$ & 0 & 39.765917 & -121.576704 & $911-085-2$ & $911-085-2$ & burning sticks falling from sky & 0 & & \\
\hline TD-021 & $11 / 8$ & 07:58 & Radio Log & 35 & 39.788734 & -121.576054 & TD & TD & $\begin{array}{l}\text { find spot fire } 6 \mathrm{~m} \times 6 \mathrm{~m}(20 \mathrm{ft} \times 20 \mathrm{ft}) \text { in apple orchard; } \\
\text { no other fire visible }\end{array}$ & $S$ & & \\
\hline TD-023 & $11 / 8$ & 07:58 & TD-021 & 52 & 39.788316 & -121.576915 & TD & TD & orchard still on fire & V & & \\
\hline $911-086-3$ & $11 / 8$ & 07:58 & $911-086-3$ & 0 & 39.762973 & -121.567732 & Inferred & $911-086-3$ & fire coming up the hill by the back cottages & V & & \\
\hline $911-086-4$ & $11 / 8$ & $07: 58$ & $911-086-4$ & 0 & 39.788622 & -121.576136 & Inferred & $911-086-4$ & fire burning like mad & $\mathrm{s}$ & & \\
\hline 911-088-1 & $11 / 8$ & $07: 59$ & 911-088-1 & 0 & 39.774704 & -121.569142 & 911-088-1 & 911-088-1 & major flames behind house & V & & \\
\hline TD-061 & $11 / 8$ & $08: 00$ & Inferred & 8 & 39.781375 & -121.579608 & TD & TD & spot fire & $\mathrm{s}$ & & \\
\hline TD-042 & $11 / 8$ & 08:00 & Inferred & 40 & 39.789651 & -121.573591 & TD & TD & spot off Dean behind the orchard & $S$ & & \\
\hline 911-1034-2 & $11 / 8$ & 08:00 & $911-1034-2$ & 0 & 39.783199 & -121.576113 & Inferred & $911-1034-2$ & spot fire in field behind house & S & & \\
\hline 911-1035-1 & $11 / 8$ & $08: 00$ & $911-1035-1$ & 0 & 39.762078 & -121.568099 & Inferred & 911-1035-1 & fire within feet of structures & $\mathrm{V}$ & & \\
\hline TD-063 & $11 / 8$ & 08:02 & PPD video & 15 & 39.755087 & -121.569543 & PPD video & $\begin{array}{l}\text { TD, PPD } \\
\text { video }\end{array}$ & spot fire coming up from canyon & $\mathrm{S}$ & & \\
\hline 911-1040-1 & $11 / 8$ & 08:02 & $911-1040-1$ & 0 & 39.782604 & -121.570423 & $911-1040-1$ & $911-1040-1$ & spot fire & $S$ & & \\
\hline PPD-01 & $11 / 8$ & $08: 02$ & PPD-01 & 0 & 39.754989 & -121.569479 & video & video & spot fire & $\mathrm{s}$ & & \\
\hline $911-095-1$ & $11 / 8$ & 08:02 & $911-095-1$ & 0 & 39.769079 & -121.576232 & Inferred & $911-095-1$ & fire is behind the church & $S$ & & \\
\hline $911-098-1$ & $11 / 8$ & 08:04 & $911-098-1$ & 0 & 39.769217 & -121.576368 & Inferred & $911-098-1$ & fire in back of lot & $S$ & & \\
\hline TD-024 & $11 / 8$ & 08:05 & TD & 0 & 39.783767 & -121.573596 & TD & TD & spot fire & $\mathrm{s}$ & & \\
\hline $911-100-1$ & $11 / 8$ & 08:06 & $911-100-1$ & 0 & 39.769217 & -121.576368 & Inferred & $911-100-1$ & fire burning in dry grass & $S$ & & \\
\hline TD-022 & $11 / 8$ & 08:08 & Inferred & 0 & 39.788320 & -121.576828 & TD & TD & spot fire & S & & \\
\hline TD-040 & $11 / 8$ & $08: 08$ & Inferred & 28 & 39.788570 & -121.576044 & TD & TD & $\begin{array}{l}\text { spot is } 0.4 \text { ha to } 0.6 \text { ha ( } 1 \text { ac to } 1.5 \text { ac); no embers from } \\
\text { main fire, just from orchard }\end{array}$ & $S$ & & \\
\hline $911-104-1$ & $11 / 8$ & 08:09 & $911-104-1$ & 0 & 39.754121 & -121.570879 & $911-104-1$ & $911-104-1$ & fire burning on property & $S$ & & \\
\hline $911-1046-4$ & $11 / 8$ & 08:09 & 911-1046-4 & 0 & 39.778723 & -121.574071 & $911-1046-4$ & $911-1046-4$ & fire in mobile home park storage area & 0 & & \\
\hline
\end{tabular}




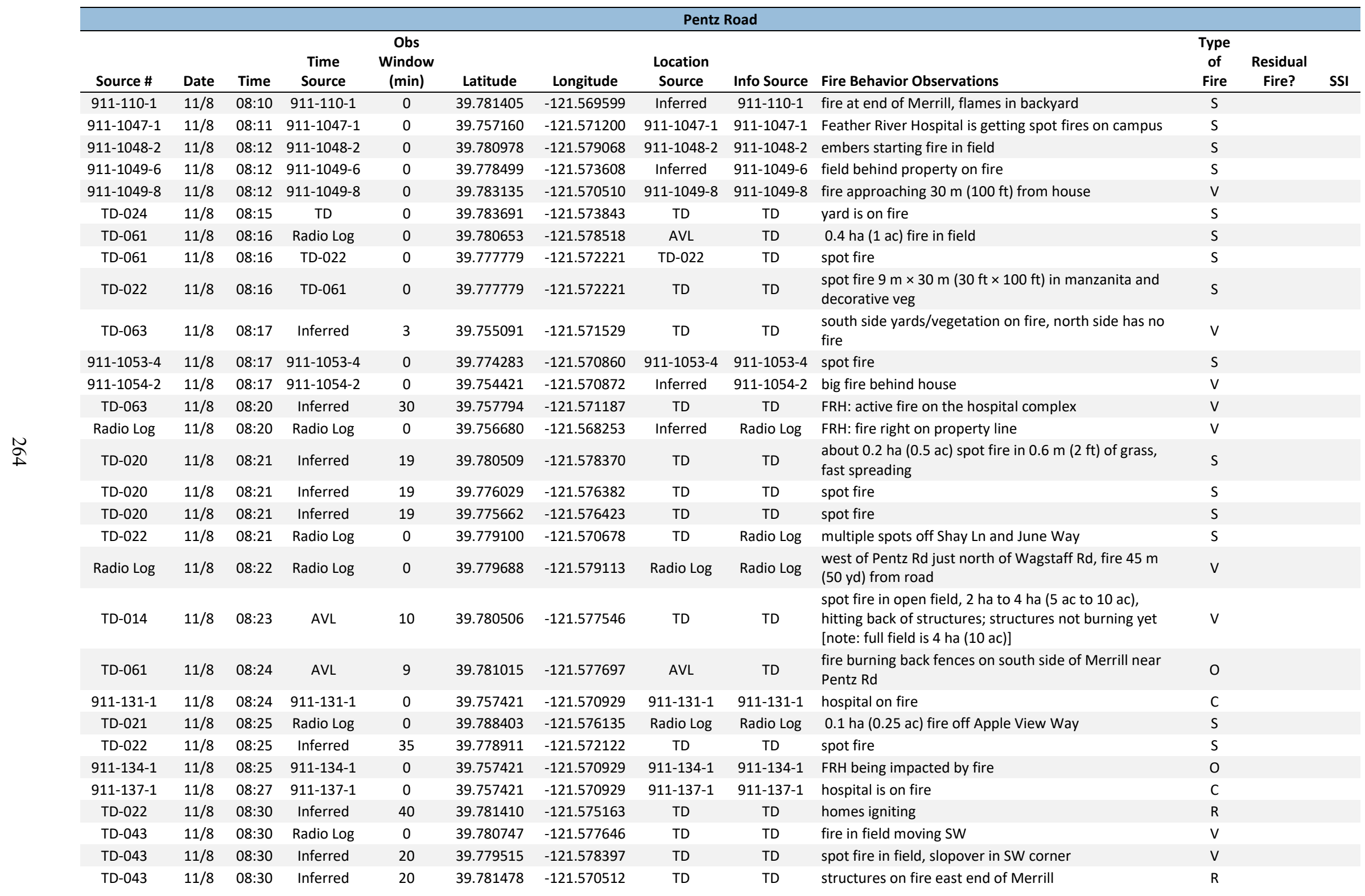




\begin{tabular}{|c|c|c|c|c|c|c|c|c|c|c|c|c|}
\hline & & & & & & & Pentz & Road & & & & \\
\hline Source \# & Date & Time & $\begin{array}{l}\text { Time } \\
\text { Source }\end{array}$ & $\begin{array}{c}\text { Obs } \\
\text { Window } \\
\text { (min) }\end{array}$ & Latitude & Longitude & $\begin{array}{l}\text { Location } \\
\text { Source }\end{array}$ & Info Source & Fire Behavior Observations & $\begin{array}{c}\text { Type } \\
\text { of } \\
\text { Fire }\end{array}$ & $\begin{array}{l}\text { Residual } \\
\text { Fire? }\end{array}$ & SSI \\
\hline TD-143 & $11 / 8$ & $08: 30$ & Inferred & 30 & 39.754738 & -121.572356 & TD & TD & fire both sides of road; propane exploding & $\mathrm{R}$ & & \\
\hline 911-141-1 & $11 / 8$ & $08: 31$ & 911-141-1 & 0 & 39.785706 & -121.578449 & 911-141-1 & 911-141-1 & fire in backyard & $\mathrm{s}$ & & \\
\hline TD-045 & $11 / 8$ & $08: 32$ & AVL & 5 & 39.780430 & -121.578750 & $\mathrm{AVL}$ & TD & Spot fire & $S$ & & \\
\hline $911-144-1$ & $11 / 8$ & $08: 32$ & $911-144-1$ & 0 & 39.783750 & -121.573598 & $911-144-1$ & $911-144-1$ & fire in yard & $\mathrm{S}$ & & \\
\hline TD-038 & $11 / 8$ & 08:33 & TD & 27 & 39.797136 & -121.566670 & TD & TD & see spot fire down in canyon & $S$ & & \\
\hline TD-021 & $11 / 8$ & $08: 33$ & TD & 27 & 39.788256 & -121.576047 & TD & TD & $\begin{array}{l}\text { spot fires igniting all over }(10+) \text { the field } 1 \mathrm{~min} \text { to } 2 \mathrm{~min} \\
\text { after wind increase }\end{array}$ & $\mathrm{S}$ & & \\
\hline TD-143 & $11 / 8$ & $08: 33$ & Photo & 0 & 39.780859 & -121.578891 & Photo & TD & field on fire & $\mathrm{V}$ & & \\
\hline TD-143 & $11 / 8$ & 08:33 & Photo & 0 & 39.780316 & -121.578891 & Photo & Photo & $\begin{array}{l}\text { grass field is burning toward Pentz Rd; } 50 \mathrm{~m} \text { ( } 55 \mathrm{yd} \text { ) east } \\
\text { of roadway }\end{array}$ & V & & \\
\hline TD-061 & $11 / 8$ & $08: 35$ & AVL & 13 & 39.779658 & -121.579541 & TD & TD & fire is spotting across Pentz Rd & $\mathrm{s}$ & & \\
\hline TD-040 & $11 / 8$ & $08: 36$ & Inferred & 0 & 39.786979 & -121.572546 & TD & TD & spots starting along Dean Rd & $\mathrm{s}$ & & \\
\hline TD-040 & $11 / 8$ & 08:36 & Inferred & 114 & 39.788598 & -121.573930 & TD & TD & active fire burning in grass behind Chapman Ln & $\mathrm{S}$ & & \\
\hline TD-040 & $11 / 8$ & $08: 36$ & Inferred & 114 & 39.788866 & -121.572862 & TD & TD & $\begin{array}{l}\text { propane tanks exploding, fire all around in heavy } \\
\text { vegetation and pine needles }\end{array}$ & V & & \\
\hline TD-040 & $11 / 8$ & 08:36 & Inferred & 114 & 39.787130 & -121.574843 & TD & TD & vegetation fire on lot; ember ignitions & V & & \\
\hline Radio Log & $11 / 8$ & 08:36 & Radio Log & 0 & 39.757060 & -121.571208 & Radio Log & Radio Log & fire within $3 \mathrm{~m}(10 \mathrm{ft})$ of $\mathrm{FRH}$ & $\mathrm{V}$ & & \\
\hline TD-005 & $11 / 8$ & $08: 37$ & AVL & 0 & 39.748583 & -121.572400 & AVL & TD & ember storm & 0 & & \\
\hline TD-005 & $11 / 8$ & $08: 37$ & AVL & 0 & 39.752744 & -121.572523 & AVL & TD & spot fire on west side of road & $\mathrm{s}$ & & \\
\hline TD-005 & $11 / 8$ & 08:37 & AVL & 0 & 39.754633 & -121.572426 & AVL & TD & fire on east side of Pentz Rd about to hit Riverview Dr & V & & \\
\hline TD-014 & $11 / 8$ & $08: 37$ & Radio Log & 0 & 39.756607 & -121.568242 & Radio Log & Radio Log & active torching behind FRH & V & & \\
\hline TD-005 & $11 / 8$ & $08: 38$ & $\mathrm{AVL}$ & 0 & 39.754891 & -121.571911 & TD & TD & fire in front yard & $S$ & & \\
\hline TD-005 & $11 / 8$ & 08:38 & AVL & 65 & 39.755100 & -121.571617 & AVL & TD & $\begin{array}{l}\text { spots growing bigger than backpump size in seconds, } \\
\text { and flames blowtorching, ember shower, all yards } \\
\text { burning. Decorative stuff in yards burning that normally } \\
\text { doesn't burn }\end{array}$ & $\mathrm{S}$ & & \\
\hline TD-014 & $11 / 8$ & 08:38 & AVL & 17 & 39.756387 & -121.568888 & TD & TD & FRH: fully involved buildings & C & & \\
\hline TD-014 & $11 / 8$ & $08: 38$ & AVL & 17 & 39.756620 & -121.571889 & TD & TD & FRH: fire on patio of $O B$ unit & 0 & & \\
\hline TD-045 & $11 / 8$ & 08:38 & $\mathrm{AVL}$ & 11 & 39.779757 & -121.575467 & AVL & TD & spot fire & $S$ & & \\
\hline $911-159-1$ & $11 / 8$ & 08:38 & $911-159-1$ & 0 & 39.782928 & -121.576918 & $911-159-1$ & $911-159-1$ & "giant" fire & $\mathrm{S}$ & & \\
\hline PPD-02 & $11 / 8$ & 08:39 & PPD-02 & 1 & 39.781406 & -121.581052 & video & video & spot fire; isolated smoke column rising from here & $\mathrm{S}$ & & \\
\hline TD-014 & $11 / 8$ & $08: 40$ & Radio Log & 0 & 39.756195 & -121.572080 & $\mathrm{AVL}$ & TD & FRH: fire on one of the patios at the hospital & 0 & & \\
\hline TD-014 & $11 / 8$ & 08:40 & Radio Log & 0 & 39.777786 & -121.579607 & Radio Log & Radio Log & multiple spot fires [in area of] Pentz Rd / Wagstaff Rd & $\mathrm{s}$ & & \\
\hline TD-084 & $11 / 8$ & 08:40 & AVL & 6 & 39.752380 & -121.572450 & AVL & TD & $\begin{array}{l}\text { a few spots on west side, } 10 \text { spot fires on east side of } \\
\text { Pentz Rd }\end{array}$ & $\mathrm{S}$ & & \\
\hline TD-016 & $11 / 8$ & 08:40 & Inferred & 5 & 39.752554 & -121.572109 & TD & TD & spot fires all along east side Pentz Rd & $\mathrm{S}$ & & \\
\hline TD-042 & $11 / 8$ & $08: 40$ & Inferred & 0 & 39.786896 & -121.574839 & TD & TD & fire all along Dean Rd & 0 & & \\
\hline
\end{tabular}




\begin{tabular}{|c|c|c|c|c|c|c|c|c|c|c|c|c|}
\hline \multicolumn{13}{|c|}{ Pentz Road } \\
\hline Source \# & Date & Time & $\begin{array}{l}\text { Time } \\
\text { Source }\end{array}$ & $\begin{array}{c}\text { Obs } \\
\text { Window } \\
\text { (min) }\end{array}$ & Latitude & Longitude & $\begin{array}{l}\text { Location } \\
\text { Source }\end{array}$ & Info Source & Fire Behavior Observations & $\begin{array}{c}\text { Type } \\
\text { of } \\
\text { Fire }\end{array}$ & $\begin{array}{l}\text { Residual } \\
\text { Fire? }\end{array}$ & SSI \\
\hline TD-042 & $11 / 8$ & 08:40 & Inferred & 0 & 39.778477 & -121.577106 & TD & TD & $\begin{array}{l}\text { half of mobile homes in Ridgewood mobile home park } \\
\text { are on fire }\end{array}$ & $\mathrm{R}$ & & \\
\hline PPD-02 & $11 / 8$ & 08:41 & PPD-02 & 0 & 39.781406 & -121.581052 & video & video & spot fire & $\mathrm{S}$ & & \\
\hline $911-170-1$ & $11 / 8$ & 08:43 & $911-170-1$ & 0 & 39.795278 & -121.574962 & $911-170-1$ & $911-170-1$ & structure on fire & $\mathrm{R}$ & & \\
\hline PPD-02 & $11 / 8$ & 08:43 & PPD-02 & 0 & 39.779087 & -121.577092 & Radio & Radio & $\begin{array}{l}\text { Ridgewood mobile home park; fires directly behind, } \\
\text { homes becoming involved }\end{array}$ & $\mathrm{R}$ & & \\
\hline TD-209 & $11 / 8$ & 08:44 & AVL & 2 & 39.745602 & -121.572362 & $\mathrm{AVL}$ & TD & glowing embers falling & 0 & & \\
\hline $911-174-1$ & $11 / 8$ & $08: 44$ & $911-174-1$ & 0 & 39.768492 & -121.583432 & $911-174-1$ & $911-174-1$ & fence on fire & 0 & & \\
\hline PPD-02 & $11 / 8$ & 08:44 & PPD-02 & 0 & 39.778876 & -121.575801 & Radio & Radio & north end of park is becoming involved (Ridgeway MHP) & $\mathrm{R}$ & & \\
\hline TD-064 & $11 / 8$ & 08:45 & Inferred & 15 & 39.778683 & -121.575499 & TD & TD & fire is hitting gas mains & 0 & & \\
\hline TD-064 & $11 / 8$ & 08:45 & Inferred & 15 & 39.778299 & -121.575586 & TD & TD & $\begin{array}{l}\text { fire moving deeper into Ridgewood MHP down both } \\
\text { rows }\end{array}$ & $\mathrm{R}$ & & \\
\hline TD-064 & $11 / 8$ & 08:45 & Inferred & 15 & 39.777563 & -121.576324 & TD & TD & $\begin{array}{l}\text { additional mobile homes in Ponderosa MHP catch on } \\
\text { fire }\end{array}$ & $\mathrm{R}$ & & \\
\hline TD-016 & $11 / 8$ & 08:45 & TD & 0 & 39.750708 & -121.572527 & TD & TD & encounter wall of fire & 0 & & \\
\hline TD-084 & $11 / 8$ & 08:46 & AVL & 127 & 39.753868 & -121.572262 & AVL & TD & bumpers of cars igniting & 0 & & \\
\hline TD-084 & $11 / 8$ & 08:46 & AVL & 127 & 39.753868 & -121.572262 & AVL & TD & fire threatening structures & 0 & & \\
\hline TD-084 & $11 / 8$ & 08:46 & AVL & 127 & 39.753392 & -121.572678 & AVL & TD & fire threatening structures & 0 & & \\
\hline TD-209 & $11 / 8$ & 08:46 & $A V L$ & 17 & 39.751665 & -121.570313 & AVL & TD & flames coming from the canyon & $\mathrm{v}$ & & \\
\hline TD-067 & $11 / 8$ & $08: 46$ & Inferred & 20 & 39.778443 & -121.578823 & TD & TD & Ridgewood MHP, portions are burning & $\mathrm{R}$ & & \\
\hline $911-178-3$ & $11 / 8$ & 08:46 & $911-178-3$ & 0 & 39.772408 & -121.568428 & $911-178-3$ & $911-178-3$ & residential alarm company reporting fire alarm & $\mathrm{R}$ & & \\
\hline $911-179-1$ & $11 / 8$ & 08:46 & $911-179-1$ & 0 & 39.757048 & -121.571191 & $911-179-1$ & 911-179-1 & hospital fire alarm & C & & \\
\hline TD-045 & $11 / 8$ & 08:47 & AVL & 0 & 39.779343 & -121.576061 & $\mathrm{AVL}$ & TD & two houses to south of field cannot be saved & $\mathrm{R}$ & & \\
\hline TD-103 & $11 / 8$ & $08: 47$ & AVL & 148 & 39.755683 & -121.571747 & AVL & TD & fire approaches from east & V & & \\
\hline TD-103 & $11 / 8$ & 08:47 & AVL & 148 & 39.753133 & -121.572216 & TD & TD & fire all around; all homes involved & $\mathrm{R}$ & & \\
\hline TD-103 & $11 / 8$ & 08:47 & AVL & 148 & 39.756426 & -121.571397 & TD & TD & FRH: Cancer center catches fire & C & & \\
\hline TD-122 & $11 / 8$ & 08:47 & AVL & 1 & 39.742333 & -121.572883 & AVL & TD & edge of fire & 0 & & \\
\hline VTD-17 & $11 / 8$ & $08: 47$ & TD & 3 & 39.756884 & -121.568212 & video & video & smoke coming from behind hospital & v & & \\
\hline TD-005 & $11 / 8$ & 08:48 & AVL & 0 & 39.755324 & -121.570642 & AVL & TD & house at end of street $50 \%$ involved & $\mathrm{R}$ & & \\
\hline TD-061 & $11 / 8$ & 08:48 & AVL & 5 & 39.781479 & -121.573042 & AVL & TD & civilian POV igniting on seat & 0 & & \\
\hline TD-061 & $11 / 8$ & 08:48 & AVL & 9 & 39.779620 & -121.570612 & TD & TD & fire impacting homes along Shay $\operatorname{Ln}$ & 0 & & \\
\hline TD-061 & $11 / 8$ & 08:48 & AVL & 9 & 39.782423 & -121.571996 & TD & TD & multiple spot fires & S & & \\
\hline TD-123 & $11 / 8$ & 08:48 & AVL & 0 & 39.747928 & -121.572361 & AVL & TD & can hear propane tanks exploding & 0 & & \\
\hline TD-109 & $11 / 8$ & 08:49 & AVL & 26 & 39.752233 & -121.572483 & AVL & TD & $\begin{array}{l}\text { fire both sides of Pentz Rd; east side of Pentz Rd more } \\
\text { involved }\end{array}$ & 0 & & \\
\hline TD-122 & $11 / 8$ & 08:49 & AVL & 48 & 39.751221 & -121.572481 & AVL & TD & flames hundreds of feet long coming out of canyon & $\mathrm{v}$ & & \\
\hline TD-123 & $11 / 8$ & 08:49 & AVL & 60 & 39.750897 & -121.572404 & AVL & TD & everything is on fire & 0 & & \\
\hline
\end{tabular}




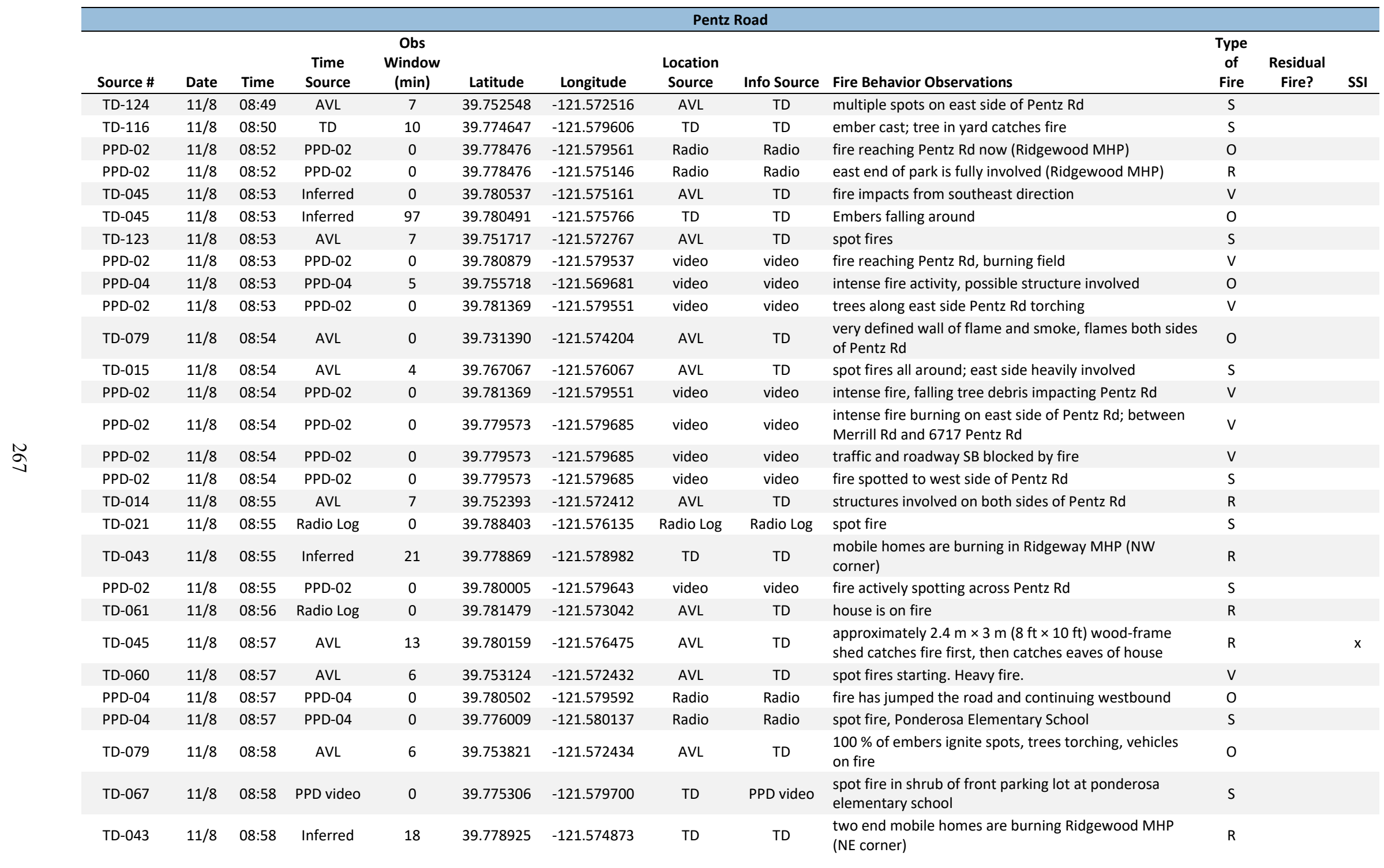




\begin{tabular}{|c|c|c|c|c|c|c|c|c|c|c|c|c|}
\hline & & & & & & & Pentz & Road & & & & \\
\hline Source \# & Date & Time & $\begin{array}{l}\text { Time } \\
\text { Source }\end{array}$ & $\begin{array}{l}\text { Obs } \\
\text { Window } \\
\text { (min) }\end{array}$ & Latitude & Longitude & $\begin{array}{l}\text { Location } \\
\text { Source }\end{array}$ & Info Source & Fire Behavior Observations & $\begin{array}{l}\text { Type } \\
\text { of } \\
\text { Fire }\end{array}$ & $\begin{array}{l}\text { Residual } \\
\text { Fire? }\end{array}$ & SSI \\
\hline TD-043 & $11 / 8$ & $08: 58$ & Inferred & 18 & 39.778472 & -121.576890 & TD & TD & $\begin{array}{l}\text { mobile homes burning; pass through fire twice in } \\
\text { mobile home park to escape back to Pentz Rd } \\
\text { (Ridgewood Mobile Home Park) }\end{array}$ & $\mathrm{R}$ & & \\
\hline PPD-02 & $11 / 8$ & 08:58 & PPD-02 & 0 & 39.776008 & -121.580095 & Radio & Radio & $\begin{array}{l}\text { Spot fire ponderosa school, large shrub in the front } \\
\text { parking lot }\end{array}$ & S & & \\
\hline TD-085 & $11 / 8$ & 08:59 & AVL & 0 & 39.777336 & -121.577799 & AVL & TD & $\begin{array}{l}\text { Ponderosa mobile home park burning; sending ember } \\
\text { showers }\end{array}$ & $\mathrm{R}$ & & \\
\hline TD-085 & $11 / 8$ & $08: 59$ & AVL & 40 & 39.778433 & -121.578792 & AVL & TD & all mobile homes on fire (Ridgewood MHP) & $\mathrm{R}$ & & \\
\hline TD-061 & $11 / 8$ & 09:00 & AVL & 6 & 39.779389 & -121.573230 & TD & TD & large spot fire & $\mathrm{S}$ & & \\
\hline TD-061 & $11 / 8$ & 09:00 & AVL & 22 & 39.781731 & -121.577049 & TD & TD & homes on north side of Merrill are igniting & $\mathrm{R}$ & & \\
\hline TD-015 & $11 / 8$ & 09:00 & AVL & 5 & 39.762633 & -121.574733 & AVL & TD & spot fires all around & $\mathrm{S}$ & & \\
\hline TD-129 & $11 / 8$ & 09:00 & AVL & 8 & 39.746117 & -121.572233 & AVL & TD & $\begin{array}{l}\text { fire crossing Pentz Rd from east to west between } \\
\text { Stearns Rd and Pearson Rd }\end{array}$ & 0 & & \\
\hline TD-016 & $11 / 8$ & 09:00 & TD & 0 & 39.752369 & -121.572747 & TD & TD & $\begin{array}{l}\text { fire quickly spotting to west side of Pentz Rd, many } \\
\text { spots starting up }\end{array}$ & $S$ & & \\
\hline TD-016 & $11 / 8$ & 09:00 & Inferred & 120 & 39.750918 & -121.574006 & TD & TD & fire threatening structures & 0 & & \\
\hline TD-016 & $11 / 8$ & 09:00 & Inferred & 120 & 39.753051 & -121.574265 & TD & TD & garage on structure igniting & $\mathrm{R}$ & & \\
\hline TD-016 & $11 / 8$ & 09:00 & Inferred & 120 & 39.751490 & -121.575348 & TD & TD & spot fire in Pearson Rd drainage, chased out by fire & $\mathrm{s}$ & & \\
\hline TD-021 & $11 / 8$ & 09:00 & Inferred & 18 & 39.774029 & -121.579626 & TD & TD & $\begin{array}{l}\text { fire actively hitting/crossing Pentz Rd between Wagstaff } \\
R d \text { and Bille Rd }\end{array}$ & 0 & & \\
\hline TD-116 & $11 / 8$ & 09:00 & TD & 23 & 39.769654 & -121.580470 & TD & TD & heavy ember cast & 0 & & \\
\hline TD-043 & $11 / 8$ & 09:00 & $\begin{array}{l}\text { TD-085, TD- } \\
022\end{array}$ & 30 & 39.777779 & -121.579642 & TD & TD & pine trees igniting at intersection & $\mathrm{v}$ & & \\
\hline TD-023 & $11 / 8$ & 09:00 & Inferred & 180 & 39.788541 & -121.576674 & TD & TD & observed fire whirl form & 0 & & \\
\hline TD-023 & $11 / 8$ & 09:00 & TD & 0 & 39.788042 & -121.577199 & TD & TD & fence ignites; house and garage catch fire & R & & \\
\hline TD-023 & $11 / 8$ & 09:00 & Inferred & 180 & 39.788088 & -121.577237 & TD & TD & concern about structure collapsing as it burns & $\mathrm{R}$ & & \\
\hline TD-103 & $11 / 8$ & 09:00 & Photo & 0 & 39.755455 & -121.571546 & Photo & Photo & fence and vegetation burning, threatening structure & 0 & & \\
\hline VTD-23 & $11 / 8$ & 09:01 & Inferred & 0 & 39.759349 & -121.572781 & video & video & first hot embers start landing on windshield & 0 & & \\
\hline PPD-02 & $11 / 8$ & 09:01 & PPD-02 & 0 & 39.778583 & -121.579579 & Radio & Radio & fire threatening vehicles & 0 & & \\
\hline TD-020 & $11 / 8$ & 09:02 & Inferred & 0 & 39.757028 & -121.571208 & TD & TD & ember cast & 0 & & \\
\hline $911-208-1$ & $11 / 8$ & 09:02 & $911-208-1$ & 0 & 39.757023 & -121.571290 & $911-208-1$ & 911-208-1 & fire alarm & C & & \\
\hline VTD-23 & $11 / 8$ & 09:03 & Inferred & 20 & 39.760734 & -121.573395 & video & video & first spot fire & $\mathrm{s}$ & & \\
\hline VTD-23 & $11 / 8$ & 09:03 & Inferred & 20 & 39.760734 & -121.573395 & video & video & $\begin{array}{l}\text { multiple spot fires in area along Pentz Rd at Vineyard; } \\
\text { both sides road }\end{array}$ & $\mathrm{S}$ & & \\
\hline TD-209 & $11 / 8$ & 09:03 & Photo & 0 & 39.753452 & -121.572392 & Photo & Photo & $\begin{array}{l}\text { vegetation fire, burning surface and up ladder fuels } \\
\text { both sides of Pentz Rd }\end{array}$ & v & & \\
\hline
\end{tabular}




\begin{tabular}{|c|c|c|c|c|c|c|c|c|c|c|c|c|}
\hline \multicolumn{13}{|c|}{ Pentz Road } \\
\hline Source \# & Date & Time & $\begin{array}{l}\text { Time } \\
\text { Source }\end{array}$ & $\begin{array}{l}\text { Obs } \\
\text { Window } \\
\text { (min) }\end{array}$ & Latitude & Longitude & $\begin{array}{l}\text { Location } \\
\text { Source }\end{array}$ & Info Source & Fire Behavior Observations & $\begin{array}{l}\text { Type } \\
\text { of } \\
\text { Fire }\end{array}$ & $\begin{array}{l}\text { Residual } \\
\text { Fire? }\end{array}$ & SSI \\
\hline TD-079 & $11 / 8$ & 09:04 & AVL & 32 & 39.765269 & -121.574923 & AVL & TD & $\begin{array}{l}100 \% \text { of embers ignite spots, trees torching, vehicles } \\
\text { on fire, people's hair igniting, dangerous fire, flames } \\
\text { going sideways; tire on engine melting }\end{array}$ & 0 & & \\
\hline $911-210-1$ & $11 / 8$ & 09:04 & $911-210-1$ & 0 & 39.758893 & -121.570887 & $911-210-1$ & $911-210-1$ & fire alarm & C & & \\
\hline VTD-17 & $11 / 8$ & 09:05 & TD & 0 & 39.758293 & -121.571793 & video & video & light embers start trickling down & 0 & & \\
\hline VTD-17 & $11 / 8$ & 09:05 & Inferred & 9 & 39.755064 & -121.572370 & video & video & fire burning on west side Pentz Rd & $\mathrm{v}$ & & \\
\hline PPD-05 & $11 / 8$ & 09:05 & PPD-05 & 0 & 39.757758 & -121.571137 & video & video & light ember cast blowing from the West & 0 & & \\
\hline $911-216-1$ & $11 / 8$ & 09:07 & $911-216-1$ & 0 & 39.775077 & -121.581572 & $911-216-1$ & $911-216-1$ & fence on fire & 0 & & \\
\hline PPD-05 & $11 / 8$ & 09:08 & PPD-05 & 2 & 39.757758 & -121.571137 & video & video & $\begin{array}{l}\text { heavy ember shower, embers exploding and skittering } \\
\text { across pavement }\end{array}$ & 0 & & \\
\hline PPD-05 & $11 / 8$ & 09:09 & PPD-05 & 0 & 39.757834 & -121.571099 & video & video & multiple spot fire ignition in mulch & $\mathrm{s}$ & & \\
\hline TD-045 & $11 / 8$ & 09:10 & $\mathrm{AVL}$ & 33 & 39.780190 & -121.576040 & $\mathrm{AVL}$ & TD & $\begin{array}{l}\text { Fire spread from neighbor's shed to fence to shed } \\
{[3 \mathrm{~m} \times 4.6 \mathrm{~m}(10 \mathrm{ft} \times 15 \mathrm{ft}) \text { shed] }}\end{array}$ & $\mathrm{R}$ & & \\
\hline PPD-02 & $11 / 8$ & 09:10 & PPD-02 & 0 & 39.787945 & -121.577869 & video & video & spot fire & $\mathrm{S}$ & & \\
\hline PPD-02 & $11 / 8$ & 09:10 & PPD-02 & 0 & 39.788858 & -121.578773 & video & video & multiple spot fires on north side of Apple View Way & S & & \\
\hline $911-221-2$ & $11 / 8$ & 09:11 & $911-221-2$ & 0 & 39.766771 & -121.575815 & $911-221-2$ & $911-221-2$ & roadway blocked by fire & $\mathrm{o}$ & & \\
\hline PPD-05 & $11 / 8$ & 09:11 & PPD-05 & 0 & 39.761954 & -121.573972 & Inferred & Radio & pretty involved fire in area & 0 & & \\
\hline TD-015 & $11 / 8$ & 09:12 & AVL & 11 & 39.766611 & -121.576095 & AVL & TD & fire through east side of Pentz Rd - structures on fire & $\mathrm{R}$ & & \\
\hline TD-015 & $11 / 8$ & 09:12 & Inferred & 9 & 39.766809 & -121.575783 & AVL & TD & $\begin{array}{l}\text { active fire; trees torching, and spot fires on west side of } \\
\text { Pentz Rd }\end{array}$ & v & & \\
\hline PPD-05 & $11 / 8$ & 09:12 & PPD-05 & 0 & 39.757892 & -121.571664 & video & Radio & $\begin{array}{l}\text { FRH: firestorm, fire threatening all around all the } \\
\text { buildings including gas tanks and oxygen }\end{array}$ & 0 & & \\
\hline TD-209 & $11 / 8$ & 09:14 & AVL & 120 & 39.751393 & -121.574283 & AVL & TD & fire threatening structures & 0 & & \\
\hline TD-129 & $11 / 8$ & 09:14 & Inferred & 36 & 39.752390 & -121.575420 & TD & TD & $\begin{array}{l}\text { fire spotted behind (west) homes on Chaney Ln; spot } \\
\text { fire getting sucked back to the main fire to the east }\end{array}$ & $\mathrm{s}$ & & \\
\hline TD-129 & $11 / 8$ & 09:14 & Inferred & 36 & 39.751244 & -121.574768 & Imagery & TD & burning vegetation threatening structures & v & & \\
\hline TD-090 & $11 / 8$ & 09:15 & AVL & 7 & 39.757795 & -121.572302 & AVL & TD & fire on the west side of Pentz Rd by the hospital & v & & \\
\hline TD-016 & $11 / 8$ & 09:15 & Inferred & 192 & 39.757568 & -121.570270 & TD & TD & FRH: attic fire in structure & C & & \\
\hline VTD-17 & $11 / 8$ & 09:15 & Inferred & 8 & 39.756180 & -121.572572 & video & video & $\begin{array}{l}\text { surface fire burning all of west side of Pentz Rd at } \\
\text { southern hospital driveway }\end{array}$ & $\mathrm{v}$ & & \\
\hline VTD-17 & $11 / 8$ & 09:15 & Inferred & 8 & 39.753918 & -121.572393 & video & video & $\begin{array}{l}\text { active fires both sides of Pentz Rd between hospital and } \\
\text { Chaney Ln }\end{array}$ & 0 & & \\
\hline VTD-17 & $11 / 8$ & 09:15 & Inferred & 8 & 39.750940 & -121.572532 & video & video & southern extent of fire & 0 & & \\
\hline TD-209 & $11 / 8$ & 09:16 & AVL & 26 & 39.751694 & -121.574025 & AVL & AVL, TD & fire threatening structures & 0 & & \\
\hline $911-230-5$ & $11 / 8$ & 09:16 & $911-230-5$ & 0 & 39.766771 & -121.575815 & $911-230-5$ & $911-230-5$ & ambulances on fire & 0 & & \\
\hline TD-109 & $11 / 8$ & 09:17 & AVL & 45 & 39.756683 & -121.570967 & AVL & TD & FRH: HVAC is on fire & C & & \\
\hline $911-232-1$ & $11 / 8$ & 09:17 & $911-232-1$ & 0 & 39.766778 & -121.575835 & $911-232-1$ & $911-232-1$ & ambulance on fire & 0 & & \\
\hline
\end{tabular}




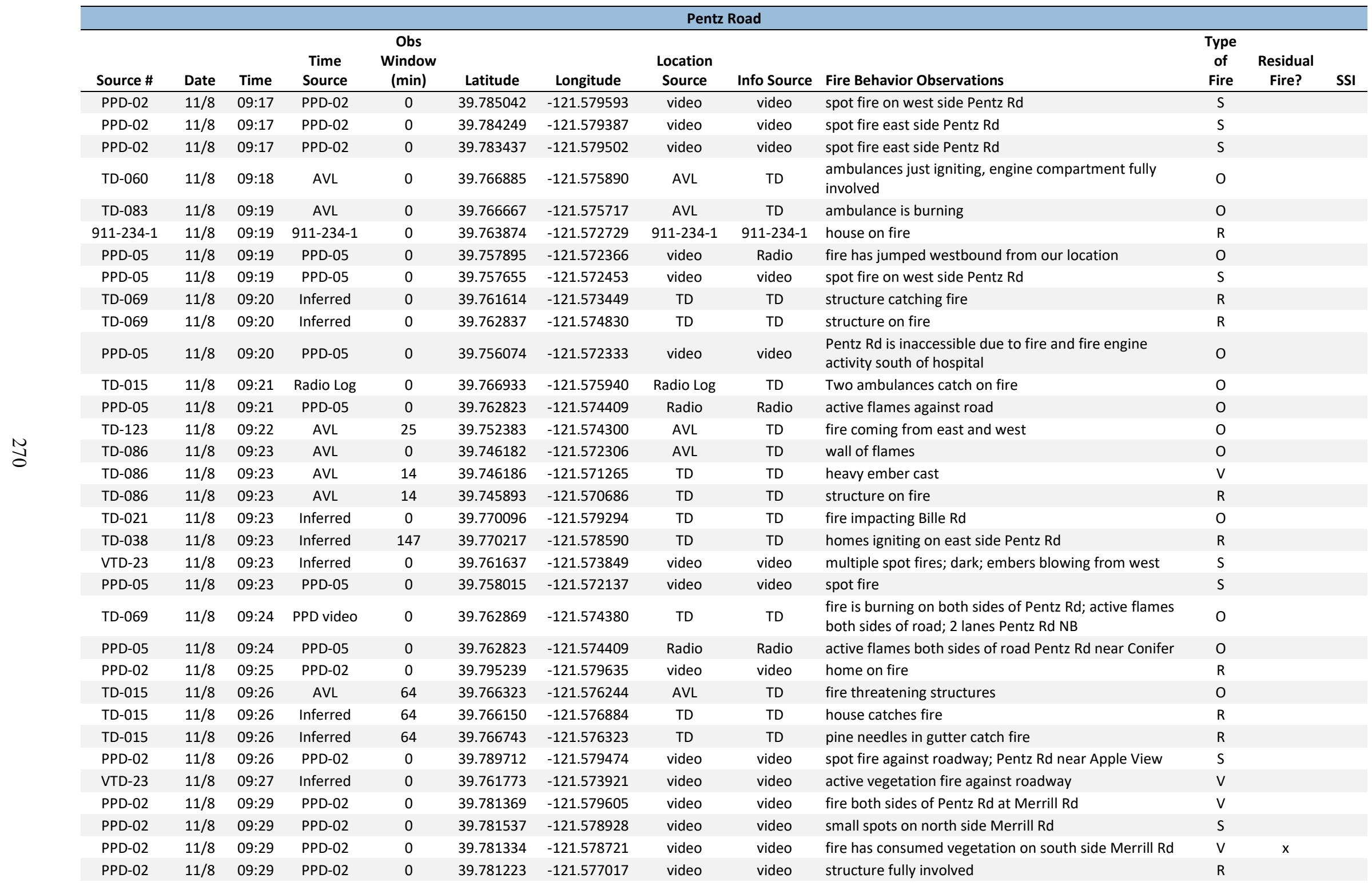




\begin{tabular}{|c|c|c|c|c|c|c|c|c|c|c|c|c|}
\hline \multicolumn{13}{|c|}{ Pentz Road } \\
\hline Source \# & Date & Time & $\begin{array}{l}\text { Time } \\
\text { Source }\end{array}$ & $\begin{array}{l}\text { Obs } \\
\text { Window } \\
\text { (min) }\end{array}$ & Latitude & Longitude & $\begin{array}{l}\text { Location } \\
\text { Source }\end{array}$ & Info Source & Fire Behavior Observations & $\begin{array}{l}\text { Type } \\
\text { of } \\
\text { Fire }\end{array}$ & $\begin{array}{l}\text { Residual } \\
\text { Fire? }\end{array}$ & SSI \\
\hline TD-089 & $11 / 8$ & 09:30 & Photo & 0 & 39.767950 & -121.577067 & $\mathrm{AVL}$ & TD & structure fully involved & $\mathrm{R}$ & & \\
\hline TD-009 & $11 / 8$ & 09:30 & $\mathrm{AVL}$ & 2 & 39.743570 & -121.572478 & $\mathrm{AVL}$ & TD & fire blowing across Pentz Rd & 0 & & \\
\hline PPD-02 & $11 / 8$ & 09:30 & PPD-02 & 0 & 39.782082 & -121.577407 & video & video & structure on fire & $\mathrm{R}$ & & \\
\hline TD-124 & $11 / 8$ & 09:31 & AVL & 6 & 39.757258 & -121.570255 & AVL & TD & $\begin{array}{l}\text { FRH: fire in corner in the eaves and gutters; landscaping } \\
\text { is on fire }\end{array}$ & C & & \\
\hline PPD-02 & $11 / 8$ & 09:31 & PPD-02 & 0 & 39.781419 & -121.580089 & video & video & small spot in pine needles & S & & \\
\hline PPD-02 & $11 / 8$ & 09:31 & PPD-02 & 0 & 39.781101 & -121.580289 & video & video & spot fire in yard & $\mathrm{s}$ & & \\
\hline PPD-02 & $11 / 8$ & 09:31 & PPD-02 & 0 & 39.781414 & -121.581390 & video & video & spot fire at west end of Merrill Rd & $S$ & & \\
\hline PPD-05 & $11 / 8$ & 09:32 & PPD-05 & 0 & 39.757756 & -121.572212 & video & video & spot fire & S & & \\
\hline TD-014 & $11 / 8$ & $09: 33$ & Radio Log & 0 & 39.758933 & -121.572683 & AVL & Radio Log & fire has burned past hospital & 0 & & \\
\hline PPD-05 & $11 / 8$ & 09:33 & PPD-05 & 0 & 39.758749 & -121.571922 & video & video & detached garage burning good, past peak & $\mathrm{R}$ & & \\
\hline PPD-05 & $11 / 8$ & 09:33 & PPD-05 & 0 & 39.762858 & -121.574370 & Radio & Radio & fire starting to impact vehicles & 0 & & \\
\hline PPD-02 & $11 / 8$ & 09:33 & PPD-02 & 0 & 39.781575 & -121.579407 & video & video & vegetation burning; large spot & S & & \\
\hline VTD-23 & $11 / 8$ & 09:34 & Inferred & 3 & 39.752515 & -121.572429 & video & video & $\begin{array}{l}\text { heavy fire both sides of Pentz Rd; very hot, heavy } \\
\text { ember wash; most structures fully involved }\end{array}$ & $\mathrm{R}$ & & \\
\hline TD-060 & $11 / 8$ & 09:35 & AVL & 0 & 39.769717 & -121.579117 & AVL & TD & fire burning around intersection & 0 & & \\
\hline TD-060 & $11 / 8$ & $09: 35$ & AVL & 17 & 39.769252 & -121.579192 & AVL & TD & mobile homes beginning to ignite (Eden Roc Estates) & $\mathrm{R}$ & & \\
\hline TD-079 & $11 / 8$ & 09:36 & AVL & 18 & 39.769867 & -121.579350 & AVL & TD & fire threatening structures & 0 & & \\
\hline PPD-05 & $11 / 8$ & 09:36 & PPD-05 & 0 & 39.757860 & -121.571753 & video & video & $\begin{array}{l}\text { multiple spot fires igniting in vegetation all around } \\
\text { parking lot }\end{array}$ & S & & \\
\hline VTD-23 & $11 / 8$ & 09:37 & Inferred & 0 & 39.749160 & -121.572480 & video & video & southern edge of fire & 0 & & \\
\hline PPD-05 & $11 / 8$ & 09:37 & PPD-05 & 0 & 39.757926 & -121.571072 & video & video & $\begin{array}{l}\text { FRH: HVAC support building flames showing from } \\
\text { second story }\end{array}$ & C & & \\
\hline TD-122 & $11 / 8$ & $09: 38$ & AVL & 0 & 39.747796 & -121.572477 & AVL & TD & fire has crossed Pentz Rd at Pearson Rd & 0 & & \\
\hline TD-124 & $11 / 8$ & 09:38 & AVL & 4 & 39.757917 & -121.570564 & AVL & TD & FRH: dumpsters on fire & 0 & & \\
\hline TD-020 & $11 / 8$ & 09:38 & AVL TD-124 & 4 & 39.757952 & -121.570552 & TD & TD & FRH: fire in dumpster & 0 & & \\
\hline VTD-21 & $11 / 8$ & 09:38 & Inferred & 15 & 39.750413 & -121.572531 & video & video & $\begin{array}{l}\text { heavy fire, everything burning both sides of road; debris } \\
\text { in roadway; wind blowing to east, lots of embers; dark, } \\
\text { smoky, visibility } 0 \mathrm{~m} \text { to } 60 \mathrm{~m} \text { ( } 0 \mathrm{ft} \text { to } 200 \mathrm{ft} \text { ) }\end{array}$ & $\mathrm{R}$ & & \\
\hline VTD-21 & $11 / 8$ & 09:38 & Inferred & 15 & 39.747756 & -121.572415 & video & video & intersection of Pentz Rd and Pearson Rd is fully involved & $\mathrm{R}$ & & \\
\hline PPD-05 & $11 / 8$ & 09:39 & PPD-05 & 0 & 39.761632 & -121.573828 & VTD-23 & video & fire north of hospital on both sides of Pentz Rd & 0 & & \\
\hline TD-005 & $11 / 8$ & 09:42 & Photo & 0 & 39.755060 & -121.573043 & Photo & Photo & $\begin{array}{l}\text { multiple structures on Fickett } L n \text { are fully involved, } \\
\text { abundant spot fires on surface vegetation }\end{array}$ & $\mathrm{R}$ & & \\
\hline TD-005 & $11 / 8$ & 09:43 & Photo & 34 & 39.756577 & -121.572070 & AVL & TD & $\begin{array}{l}\text { FRH: One section of fence on fire; small spot fire against } \\
\text { building in alcoves of Birth Day Place }\end{array}$ & 0 & & \\
\hline TD-045 & $11 / 8$ & 09:43 & AVL & 30 & 39.780721 & -121.576607 & AVL & TD & $\begin{array}{l}\text { Structure starting to catch on D side. Can see fire } \\
\text { affecting houses on Merrill Rd }\end{array}$ & $\mathrm{R}$ & & \\
\hline
\end{tabular}




\begin{tabular}{|c|c|c|c|c|c|c|c|c|c|c|c|c|}
\hline \multicolumn{13}{|c|}{ Pentz Road } \\
\hline Source \# & Date & Time & $\begin{array}{l}\text { Time } \\
\text { Source }\end{array}$ & $\begin{array}{c}\text { Obs } \\
\text { Window } \\
\text { (min) }\end{array}$ & Latitude & Longitude & $\begin{array}{l}\text { Location } \\
\text { Source }\end{array}$ & Info Source & Fire Behavior Observations & $\begin{array}{c}\text { Type } \\
\text { of } \\
\text { Fire }\end{array}$ & $\begin{array}{l}\text { Residual } \\
\text { Fire? }\end{array}$ & SSI \\
\hline TD-085 & $11 / 8$ & 09:43 & AVL & 36 & 39.784150 & -121.579283 & AVL & TD & $\begin{array}{l}\text { Beyond Fitness is igniting, Children's Community } \\
\text { Charter School is burning }\end{array}$ & C & & \\
\hline TD-020 & $11 / 8$ & 09:43 & TD-005 & 34 & 39.756672 & -121.571922 & TD & TD & FRH: fence and patio at hospital Birth Day Place burning & 0 & & \\
\hline TD-209 & $11 / 8$ & 09:44 & AVL & 50 & 39.751311 & -121.574426 & AVL & AVL, TD & fire threatening structures & $\mathrm{o}$ & & \\
\hline TD-005 & $11 / 8$ & 09:44 & Photo & 0 & 39.756763 & -121.571943 & Photo & Photo & $\begin{array}{l}\text { active fire in vegetation, torching juniper trees against } \\
\text { Birth Day Place, spewing firebrands }\end{array}$ & v & & \\
\hline TD-090 & $11 / 8$ & $09: 45$ & AVL & 55 & 39.760733 & -121.573417 & AVL & TD & vehicles being driven while on fire & 0 & & \\
\hline TD-090 & $11 / 8$ & 09:45 & AVL & 55 & 39.767474 & -121.576503 & TD & TD & $\begin{array}{l}\text { mobile home park burning; already consumed [could be } \\
\text { either MHP between FRH and Bille Rd] }\end{array}$ & $\mathrm{R}$ & $\mathrm{x}$ & \\
\hline PPD-05 & $11 / 8$ & 09:49 & PPD-05 & 0 & 39.769679 & -121.583588 & Radio & Radio & active flames, about $14 \mathrm{~m}$ ( $15 \mathrm{yd}$ ) from the roadway & V & & \\
\hline TD-021 & $11 / 8$ & 09:50 & PPD video & 0 & 39.769469 & -121.583071 & TD & TD & $\begin{array}{l}\text { fire impacting Bille Rd and vehicles abandoned/stuck on } \\
\text { road }\end{array}$ & 0 & & \\
\hline TD-060 & $11 / 8$ & $09: 52$ & AVL & 21 & 39.769467 & -121.580750 & AVL & TD & cars igniting on Bille Rd. Home catching fire. & $\mathrm{R}$ & & \\
\hline TD-063 & $11 / 8$ & 09:53 & PPD video & 7 & 39.751151 & -121.572527 & PPD video & $\begin{array}{l}\text { TD, PPD } \\
\text { video }\end{array}$ & $\begin{array}{l}\text { everything on fire on Pentz Rd between hospital and } \\
\text { Chaney Ln }\end{array}$ & $\mathrm{R}$ & & \\
\hline TD-079 & $11 / 8$ & 09:54 & AVL & 19 & 39.769519 & -121.580796 & AVL & TD & pickup on fire a few hundred yards down Bille Rd & 0 & & \\
\hline TD-103 & $11 / 8$ & 09:55 & Photo & 0 & 39.755630 & -121.571731 & Photo & Photo & $\begin{array}{l}\text { structure fully involved; interior fire, flames through } \\
\text { roof; roof partially collapsed }\end{array}$ & C & & \\
\hline TD-086 & $11 / 8$ & 09:57 & AVL & 0 & 39.731332 & -121.574204 & AVL & TD & fire is burning north of Malibu $\mathrm{Dr}$ & 0 & & \\
\hline PPD-05 & $11 / 8$ & 09:57 & PPD-05 & 0 & 39.756385 & -121.572306 & video & video & FRH: steady stream of explosions around the hospital & 0 & & \\
\hline PPD-05 & $11 / 8$ & 09:59 & PPD-05 & 0 & 39.762860 & -121.574108 & Inferred & Radio & $\begin{array}{l}\text { street completely burnt on one side, dodging intense } \\
\text { fire }\end{array}$ & 0 & & \\
\hline TD-021 & $11 / 8$ & $10: 00$ & TD & 30 & 39.769267 & -121.579100 & TD & TD & Eden Roc Estates mobile homes ignite and burn quickly & $\mathrm{R}$ & & \\
\hline TD-040 & $11 / 8$ & 10:00 & Inferred & 60 & 39.778033 & -121.580294 & TD & TD & spot fires in grass field & S & & \\
\hline TD-040 & $11 / 8$ & $10: 00$ & Inferred & 60 & 39.781358 & -121.579556 & TD & TD & car half on fire & 0 & & \\
\hline TD-020 & $11 / 8$ & 10:05 & TD-124 & 30 & 39.756420 & -121.571413 & TD & TD & FRH: fire at cancer center & C & & \\
\hline PPD-05 & $11 / 8$ & 10:05 & PPD-05 & 0 & 39.763657 & -121.574109 & Radio & Radio & most houses are burnt down & R & $x$ & \\
\hline TD-124 & $11 / 8$ & 10:07 & AVL & 27 & 39.756409 & -121.571416 & AVL & TD & FRH: fire in attic/ceiling of cancer building & C & & \\
\hline TD-086 & $11 / 8$ & 10:07 & Inferred & 113 & 39.725281 & -121.564342 & TD & TD & active fire & 0 & & \\
\hline TD-109 & $11 / 8$ & $10: 13$ & AVL & 76 & 39.761656 & -121.568042 & AVL & TD & homes on south side of retirement home are involved & $\mathrm{R}$ & & \\
\hline TD-109 & $11 / 8$ & $10: 13$ & AVL & 76 & 39.762085 & -121.568911 & AVL & TD & fire threatening structures & 0 & & \\
\hline TD-060 & $11 / 8$ & $10: 14$ & $A V L$ & 0 & 39.770350 & -121.579432 & AVL & TD & fire threatening structures & 0 & & \\
\hline TD-020 & $11 / 8$ & 10:15 & AVL TD-109 & 75 & 39.762061 & -121.568979 & TD & TD & $\begin{array}{l}\text { small fire on roof of main care facility of Canyon View } \\
\text { Dr }\end{array}$ & C & & \\
\hline PPD-02 & $11 / 8$ & 10:16 & PPD-02 & 0 & 39.768937 & -121.578861 & Radio & Radio & $\begin{array}{l}\text { Eden Roc mobile home park is going up near Pentz Rd, } \\
\text { it's not safe here }\end{array}$ & $R$ & & \\
\hline
\end{tabular}




\begin{tabular}{|c|c|c|c|c|c|c|c|c|c|c|c|c|}
\hline \multicolumn{13}{|c|}{ Pentz Road } \\
\hline Source \# & Date & Time & $\begin{array}{l}\text { Time } \\
\text { Source }\end{array}$ & $\begin{array}{l}\text { Obs } \\
\text { Window } \\
\text { (min) }\end{array}$ & Latitude & Longitude & $\begin{array}{l}\text { Location } \\
\text { Source }\end{array}$ & Info Source & Fire Behavior Observations & $\begin{array}{l}\text { Type } \\
\text { of } \\
\text { Fire }\end{array}$ & $\begin{array}{l}\text { Residual } \\
\text { Fire? }\end{array}$ & SSI \\
\hline TD-079 & $11 / 8$ & $10: 18$ & $\mathrm{AVL}$ & 5 & 39.788367 & -121.579600 & $\mathrm{AVL}$ & TD & $\begin{array}{l}15 \mathrm{~m} \times 15 \mathrm{~m}(50 \mathrm{ft} \times 50 \mathrm{ft}) \text { spot fire near Paradise Ridge } \\
\text { Southern Baptist Church }\end{array}$ & S & & \\
\hline TD-005 & $11 / 8$ & $10: 20$ & AVL & 32 & 39.762063 & -121.568917 & AVL & TD & $\begin{array}{l}\text { Bark mulch against building on fire; OSB under vinyl just } \\
\text { ignited, rapid fire growth }\end{array}$ & $\mathrm{R}$ & & \\
\hline TD-103 & $11 / 8$ & $10: 20$ & Photo & 0 & 39.755630 & -121.571731 & Photo & Photo & building past peak, mostly collapsed; vehicle burning & C & & \\
\hline TD-060 & $11 / 8$ & $10: 24$ & AVL & 6 & 39.793595 & -121.579631 & AVL & TD & $\begin{array}{l}\text { spot fires on east side of Pentz Rd, spotting around } \\
\text { structures }\end{array}$ & $\mathrm{S}$ & & \\
\hline TD-079 & $11 / 8$ & $10: 29$ & AVL & 20 & 39.793604 & -121.576854 & AVL & TD & $\begin{array}{l}\text { fire burning eastern homes down side streets towards } \\
\text { canyon }\end{array}$ & $\mathrm{R}$ & & \\
\hline TD-060 & $11 / 8$ & 10:30 & $\mathrm{AVL}$ & 19 & 39.791225 & -121.579133 & AVL & TD & fire threatening structures & 0 & & \\
\hline TD-015 & $11 / 8$ & $10: 30$ & TD-111 & 0 & 39.766467 & -121.577179 & TD & TD & fire threatening structures & 0 & & \\
\hline TD-015 & $11 / 8$ & $10: 30$ & AVL & 2 & 39.767364 & -121.576325 & AVL & TD & bed of pickup truck on Pentz Rd catches fire & 0 & & \\
\hline TD-040 & $11 / 8$ & $10: 30$ & Inferred & 108 & 39.788632 & -121.577414 & TD & TD & structure is half involved & $\mathrm{R}$ & & \\
\hline TD-040 & $11 / 8$ & $10: 30$ & Inferred & 108 & 39.788626 & -121.577069 & TD & TD & two structures $3 / 4$ involved & $\mathrm{R}$ & & \\
\hline TD-111 & $11 / 8$ & $10: 30$ & Inferred & 38 & 39.766160 & -121.576893 & TD & TD & structure on fire & $\mathrm{R}$ & & \\
\hline TD-209 & $11 / 8$ & 10:37 & AVL & 34 & 39.751171 & -121.573979 & AVL & $A V L, T D$ & fire threatening structures & 0 & & \\
\hline TD-005 & $11 / 8$ & 10:38 & Photo & 0 & 39.761630 & -121.568072 & Photo & Photo & all condos burned to foundation, burned down already & $\mathrm{R}$ & $\mathrm{x}$ & \\
\hline TD-037 & $11 / 8$ & $10: 38$ & video & 0 & 39.753660 & -121.572389 & TD & video & structures burning past-peak, limited active surface fire & $\mathrm{R}$ & $\mathrm{x}$ & \\
\hline TD-037 & $11 / 8$ & $10: 38$ & Photo & 0 & 39.750212 & -121.572508 & Photo & Photo & $\begin{array}{l}\text { structures fully involved, some burned to framing, some } \\
\text { burned to ground; all surface and vegetative fuels are } \\
\text { consumed }\end{array}$ & $\mathrm{R}$ & & \\
\hline TD-005 & $11 / 8$ & $10: 38$ & Photo & 0 & 39.761568 & -121.567984 & Photo & Photo & $\begin{array}{l}\text { Canyon View Dr detached homes are all burned to } \\
\text { foundation, some active flaming }\end{array}$ & $\mathrm{R}$ & $x$ & \\
\hline TD-037 & $11 / 8$ & $10: 39$ & video & 0 & 39.746135 & -121.572316 & TD & video & $\begin{array}{l}\text { Pentz Rd south of Pearson Rd; structures fully involved; } \\
\text { active vegetation fire and sideways embers }\end{array}$ & $\mathrm{R}$ & & \\
\hline TD-037 & $11 / 8$ & $10: 39$ & Photo & 0 & 39.748188 & -121.572426 & Photo & Photo & $\begin{array}{l}\text { nearly all structures fully involved both sides of Pentz } \\
\text { Rd; heavy fire all around, ember showers }\end{array}$ & $\mathrm{R}$ & & \\
\hline TD-005 & $11 / 8$ & $10: 39$ & Photo & 0 & 39.761568 & -121.567984 & Photo & Photo & $\begin{array}{l}\text { Canyon View Dr detached homes are all burned to } \\
\text { foundation, some active flaming }\end{array}$ & $\mathrm{R}$ & $x$ & \\
\hline TD-045 & $11 / 8$ & $10: 45$ & $\mathrm{AVL}$ & 50 & 39.781248 & -121.575876 & AVL & TD & structure beginning to burn in gable vent & $\mathrm{R}$ & & \\
\hline TD-037 & $11 / 8$ & 10:47 & video & 0 & 39.733619 & -121.568055 & TD & video & $\begin{array}{l}\text { numerous intensely burning (primarily vegetation) spot } \\
\text { fires all around; ember cast; explosions }\end{array}$ & $\mathrm{s}$ & & \\
\hline TD-037 & $11 / 8$ & 10:47 & Photo & 0 & 39.733931 & -121.568085 & Photo & Photo & $\begin{array}{l}\text { numerous significant spot fires all around; burning } \\
\text { trees, fences, plants. Possibly a few structures burning. }\end{array}$ & V & & \\
\hline TD-083 & $11 / 8$ & $10: 49$ & AVL & 3 & 39.791450 & -121.579650 & AVL & TD & many spot fires along west side of Pentz Rd & $\mathrm{s}$ & & \\
\hline TD-089 & $11 / 8$ & $10: 49$ & $\mathrm{AVL}$ & 22 & 39.788396 & -121.580532 & AVL & TD & $\begin{array}{l}0.1 \text { ha }(0.25 \mathrm{ac}) \text { spot in field at Paradise Ridge Southern } \\
\text { Baptist Church }\end{array}$ & $S$ & & \\
\hline TD-037 & $11 / 8$ & $10: 50$ & video & 0 & 39.733619 & -121.568055 & TD & video & surrounded by fire & $\mathrm{V}$ & & \\
\hline
\end{tabular}




\begin{tabular}{|c|c|c|c|c|c|c|c|c|c|c|c|c|}
\hline \multicolumn{13}{|c|}{ Pentz Road } \\
\hline Source \# & Date & Time & $\begin{array}{l}\text { Time } \\
\text { Source }\end{array}$ & $\begin{array}{l}\text { Obs } \\
\text { Window } \\
\text { (min) }\end{array}$ & Latitude & Longitude & $\begin{array}{l}\text { Location } \\
\text { Source }\end{array}$ & Info Source & Fire Behavior Observations & $\begin{array}{l}\text { Type } \\
\text { of } \\
\text { Fire }\end{array}$ & $\begin{array}{l}\text { Residual } \\
\text { Fire? }\end{array}$ & SSI \\
\hline TD-020 & $11 / 8$ & $10: 50$ & AVL TD-090 & 0 & 39.731352 & -121.574192 & TD & TD & north of Malibu Dr, fire already burned through & 0 & $\mathrm{x}$ & \\
\hline TD-037 & $11 / 8$ & $10: 50$ & Photo & 0 & 39.733525 & -121.568163 & Photo & Photo & $\begin{array}{l}\text { significant vegetation fire burning up against structure, } \\
\text { significant ember showers blowing in air and across } \\
\text { roadway }\end{array}$ & v & & \\
\hline TD-005 & $11 / 8$ & $10: 52$ & video & 3 & 39.760983 & -121.568917 & video & video & building burning out of eaves and under structure & C & & \\
\hline TD-079 & $11 / 8$ & $10: 52$ & AVL & 10 & 39.787783 & -121.580200 & AVL & TD & $\begin{array}{l}\text { Paradise Ridge Southern Baptist Church: new small spot } \\
\text { at church; fire came and wrapped around church; fire } \\
\text { established behind (to the west) of church; big fire } \\
\text { spreading north }\end{array}$ & $\mathrm{s}$ & & \\
\hline TD-090 & $11 / 8$ & $10: 52$ & Photo & 0 & 39.743611 & -121.572686 & Photo & Photo & $\begin{array}{l}\text { vegetation fires, ember showers, most houses fully } \\
\text { involved }\end{array}$ & $\mathrm{R}$ & & \\
\hline TD-005 & $11 / 8$ & $10: 55$ & Photo & 0 & 39.760248 & -121.569305 & Photo & Photo & FRH: multiple auxiliary hospital buildings are burning & C & & \\
\hline TD-005 & $11 / 8$ & 10:56 & AVL & 32 & 39.759968 & -121.571728 & TD & TD & $\begin{array}{l}\text { On Del Rio Way structures all burned, skeletons } \\
\text { collapsed. Looked like fire burned from Pentz Rd toward } \\
\text { canyon based on burn levels on Del Rio Way (ones } \\
\text { closer to Pentz Rd were more burned) }\end{array}$ & $\mathrm{R}$ & $x$ & \\
\hline TD-005 & $11 / 8$ & 10:56 & AVL & 32 & 39.760826 & -121.572071 & TD & TD & $\begin{array}{l}\text { fire in yards, fences on fire, burning toward homes, } 1 \\
\text { structure involved on street so far. Trees and poles on } \\
\text { fire. Continual spot fires and still an ember shower. }\end{array}$ & $\mathrm{R}$ & & \\
\hline TD-021 & $11 / 8$ & 11:00 & TD & 0 & 39.769425 & -121.582995 & TD & TD & Bille Rd is blocked by burning vehicles & 0 & & \\
\hline TD-014 & $11 / 8$ & 11:05 & Radio Log & 0 & 39.775552 & -121.579660 & AVL & Radio Log & Ponderosa Elementary School: school buildings on fire & c & & \\
\hline TD-060 & $11 / 8$ & 11:06 & AVL & 63 & 39.790041 & -121.580393 & AVL & TD & fire wrapped around Sweetbriar (S, W, N sides) & 0 & & \\
\hline TD-060 & $11 / 8$ & 11:06 & AVL & 0 & 39.789826 & -121.579918 & AVL & TD & $\begin{array}{l}\text { structure } 10 \% \text { to } 15 \% \text { involved in eaves. Huge pine } \\
\text { tree torching. }\end{array}$ & $\mathrm{R}$ & & \\
\hline TD-060 & $11 / 8$ & 11:06 & AVL & 63 & 39.789825 & -121.580428 & AVL & TD & first house ignites second house via radiation & $\mathrm{R}$ & & $x$ \\
\hline TD-079 & $11 / 8$ & 11:09 & AVL & 0 & 39.789145 & -121.580767 & TD & TD & Mulberry Ln - already burning, unsavable & $\mathrm{R}$ & & \\
\hline TD-083 & $11 / 8$ & 11:09 & AVL & 0 & 39.790045 & -121.580482 & AVL & TD & $\begin{array}{l}\text { fire to south of yards, not crowning but burning good. } \\
\text { Main fire coming from south }\end{array}$ & v & & \\
\hline TD-079 & $11 / 8$ & 11:09 & AVL & 49 & 39.789919 & -121.581164 & AVL & TD & $\begin{array}{l}\text { several structures igniting. Heavy brush and propane } \\
\text { tanks; large propane tank exploded }\end{array}$ & $\mathrm{R}$ & & \\
\hline TD-079 & $11 / 8$ & 11:09 & AVL & 49 & 39.790953 & -121.580883 & TD & TD & Blue spruce mobile estates burning and popping & $\mathrm{R}$ & & \\
\hline TD-009 & $11 / 8$ & 11:11 & AVL & 22 & 39.784373 & -121.578907 & AVL & TD & $\begin{array}{l}\text { Beyond Fitness gym building is on fire. Vegetation in } \\
\text { parking lot has burned. }\end{array}$ & C & & \\
\hline TD-009 & $11 / 8$ & 11:11 & AVL & 22 & 39.784157 & -121.578748 & $\mathrm{AVL}$ & TD & Children's Community Charter School building is on fire & C & & \\
\hline TD-209 & $11 / 8$ & 11:13 & Photo & 0 & 39.751028 & -121.572999 & Photo & Photo & structure burned to foundation, minimal flaming rubble & $\mathrm{R}$ & $x$ & \\
\hline TD-103 & $11 / 8$ & 11:14 & Photo & 0 & 39.755255 & -121.571109 & Photo & Photo & structure fully involved & $\mathrm{R}$ & & \\
\hline TD-103 & $11 / 8$ & $11: 15$ & Photo & 0 & 39.755255 & -121.571109 & Photo & Photo & structure fully involved & $\mathrm{R}$ & & \\
\hline
\end{tabular}




\begin{tabular}{|c|c|c|c|c|c|c|c|c|c|c|c|c|}
\hline \multicolumn{13}{|c|}{ Pentz Road } \\
\hline Source \# & Date & Time & $\begin{array}{l}\text { Time } \\
\text { Source }\end{array}$ & $\begin{array}{c}\text { Obs } \\
\text { Window } \\
\text { (min) }\end{array}$ & Latitude & Longitude & $\begin{array}{l}\text { Location } \\
\text { Source }\end{array}$ & Info Source & Fire Behavior Observations & $\begin{array}{l}\text { Type } \\
\text { of } \\
\text { Fire }\end{array}$ & $\begin{array}{l}\text { Residual } \\
\text { Fire? }\end{array}$ & SSI \\
\hline TD-015 & $11 / 8$ & 11:16 & AVL & 6 & 39.770043 & -121.579220 & AVL & TD & $\begin{array}{l}\text { fire all around. Eden Roc mobile home park had already } \\
\text { burned }\end{array}$ & 0 & & \\
\hline TD-209 & $11 / 8$ & 11:16 & Photo & 0 & 39.747588 & -121.572049 & Photo & Photo & structure fully involved & $\mathrm{R}$ & & \\
\hline TD-209 & $11 / 8$ & $11: 16$ & Photo & 0 & 39.747295 & -121.571934 & Photo & Photo & structure fully involved & $\mathrm{R}$ & & \\
\hline TD-209 & $11 / 8$ & 11:17 & $\mathrm{AVL}$ & 119 & 39.746880 & -121.572846 & $\mathrm{AVL}$ & TD & vehicle and house burning; main fire front had passed & $\mathrm{R}$ & & \\
\hline TD-209 & $11 / 8$ & 11:17 & Photo & 0 & 39.747588 & -121.572049 & Photo & Photo & structure fully involved & $\mathrm{R}$ & & \\
\hline TD-111 & $11 / 8$ & 11:19 & Inferred & 31 & 39.757874 & -121.570428 & TD & TD & FRH: lower portion of hospital on fire & C & & \\
\hline PPD-08 & $11 / 8$ & $11: 21$ & PPD-08 & 0 & 39.765284 & -121.574279 & Radio & Radio & area is a complete loss, unable to locate any structures & $\mathrm{R}$ & $\mathrm{x}$ & \\
\hline TD-069 & $11 / 8$ & $11: 22$ & Inferred & 118 & 39.757641 & -121.570452 & TD & TD & FRH: lower hospital building is on fire & C & & \\
\hline TD-009 & $11 / 8$ & $11: 26$ & Photo & 0 & 39.784836 & -121.579135 & AVL & Photo & Beyond Fitness gym building is on fire & C & & \\
\hline TD-009 & $11 / 8$ & 11:26 & Photo & 0 & 39.784830 & -121.579112 & Photo & Photo & $\begin{array}{l}\text { significant fire from roof of Beyond Fitness, } 30 \% \text { well } \\
\text { involved }\end{array}$ & C & & \\
\hline TD-009 & $11 / 8$ & $11: 26$ & Photo & 0 & 39.784830 & -121.579112 & Photo & Photo & $\begin{array}{l}\text { significant fire from roof of Beyond Fitness, } 30 \% \text { well } \\
\text { involved }\end{array}$ & C & & \\
\hline TD-209 & $11 / 8$ & $11: 27$ & Photo & 0 & 39.746797 & -121.572834 & Photo & Photo & $\begin{array}{l}\text { structure fully involved, threatening neighboring } \\
\text { structure }\end{array}$ & $\mathrm{R}$ & & \\
\hline TD-209 & $11 / 8$ & $11: 27$ & Photo & 0 & 39.746797 & -121.572834 & Photo & Photo & $\begin{array}{l}\text { structure fully involved, threatening neighboring } \\
\text { structure }\end{array}$ & $\mathrm{R}$ & & \\
\hline TD-209 & $11 / 8$ & $11: 28$ & Photo & 0 & 39.746797 & -121.572834 & Photo & Photo & $\begin{array}{l}\text { structure fully involved, threatening neighboring } \\
\text { structure }\end{array}$ & $\mathrm{R}$ & & \\
\hline TD-005 & $11 / 8$ & $11: 29$ & $\mathrm{AVL}$ & 1036 & 39.757529 & -121.570494 & TD & TD & $\begin{array}{l}\text { FRH: attic fire getting established, everything around } \\
\text { hospital on fire now }\end{array}$ & C & & \\
\hline TD-015 & $11 / 8$ & $11: 30$ & AVL & 0 & 39.775666 & -121.579589 & AVL & TD & part of Ponderosa Elementary School on fire & C & & \\
\hline TD-109 & $11 / 8$ & 11:30 & AVL & 414 & 39.757557 & -121.570446 & AVL & TD & $\begin{array}{l}\text { FRH: fire in roof of cardiology center; fire flaring up } \\
\text { through roof trenches }\end{array}$ & C & & \\
\hline TD-086 & $11 / 8$ & $11: 30$ & Inferred & 30 & 39.724904 & -121.565004 & Imagery & TD & burned over; push out quick safety zone & v & & \\
\hline TD-009 & $11 / 8$ & $11: 33$ & AVL & 17 & 39.783334 & -121.581026 & $A V L$ & TD & some structures burned & $\mathrm{R}$ & $x$ & \\
\hline TD-041 & $11 / 8$ & $11: 40$ & Inferred & 0 & 39.797653 & -121.581882 & TD & TD & houses on Gate Ln are igniting, spreading south & $\mathrm{R}$ & & \\
\hline TD-103 & $11 / 8$ & $11: 43$ & Photo & 0 & 39.757697 & -121.570238 & Photo & Photo & FRH: heavy smoke from outpatient wing of hospital & C & & \\
\hline TD-103 & $11 / 8$ & $11: 43$ & $\mathrm{AVL}$ & 64 & 39.756622 & -121.569851 & $\mathrm{AVL}$ & TD & FRH: see smoke in attic; patient room on fire & C & & \\
\hline TD-103 & $11 / 8$ & 11:43 & Photo & 0 & 39.757691 & -121.570134 & Photo & Photo & FRH: heavy smoke from cardiology wing & C & & \\
\hline TD-118 & $11 / 8$ & 11:45 & AVL SCK2 & 15 & 39.719126 & -121.578404 & TD & TD & fire both sides of the road & v & & \\
\hline TD-084 & $11 / 8$ & 11:50 & AVL & 66 & 39.787853 & -121.580120 & AVL & TD & $\begin{array}{l}\text { fire still on east side of Pentz Rd in area of Paradise } \\
\text { Ridge Southern Baptist Church; pine needles in engine } \\
\text { grill igniting; fire spotting overhead from south to north }\end{array}$ & v & & \\
\hline TD-089 & $11 / 8$ & $11: 50$ & AVL & 55 & 39.787833 & -121.580733 & AVL & TD & $\begin{array}{l}\text { pine needles and fence burning; fire established in area } \\
\text { around Paradise Ridge Southern Baptist Church }\end{array}$ & 0 & & \\
\hline
\end{tabular}




\begin{tabular}{|c|c|c|c|c|c|c|c|c|c|c|c|c|}
\hline & & & & & & & Pent: & Road & & & & \\
\hline Source \# & Date & Time & $\begin{array}{l}\text { Time } \\
\text { Source }\end{array}$ & $\begin{array}{l}\text { Obs } \\
\text { Window } \\
\text { (min) }\end{array}$ & Latitude & Longitude & $\begin{array}{l}\text { Location } \\
\text { Source }\end{array}$ & Info Source & Fire Behavior Observations & $\begin{array}{l}\text { Type } \\
\text { of } \\
\text { Fire }\end{array}$ & $\begin{array}{l}\text { Residual } \\
\text { Fire? }\end{array}$ & SSI \\
\hline TD-086 & $11 / 8$ & 11:55 & $\begin{array}{c}\text { AVL } \\
\text { DZ2140 }\end{array}$ & 35 & 39.723258 & -121.570702 & TD & TD & fire in grass bumping and hopping dozer line & v & & \\
\hline TD-086 & $11 / 8$ & 11:55 & $\begin{array}{c}\text { AVL } \\
\text { DZ2140 }\end{array}$ & 35 & 39.725171 & -121.569298 & TD & TD & two homes on fire & $\mathrm{R}$ & & \\
\hline TD-086 & $11 / 8$ & 11:55 & $\begin{array}{c}\text { AVL } \\
\text { DZ2140 }\end{array}$ & 35 & 39.719984 & -121.571226 & TD & TD & $6 \mathrm{~m}(20 \mathrm{ft})$ wall of fire from canyon to east & v & & \\
\hline TD-079 & $11 / 8$ & $12: 00$ & AVL & 5 & 39.788050 & -121.579683 & AVL & TD & multiple structures on Sweetbriar Ln burning & $\mathrm{R}$ & & \\
\hline TD-118 & $11 / 8$ & 12:00 & Inferred & 175 & 39.769334 & -121.582557 & TD & TD & $\begin{array}{l}\text { vehicles burned (horse trailer, delivery truck, fifth wheel } \\
\text { with truck) }\end{array}$ & 0 & & \\
\hline TD-103 & $11 / 8$ & 12:01 & Photo & 0 & 39.756641 & -121.569861 & Photo & Photo & $\begin{array}{l}\text { FRH: fire in Family Health Center is out, some damage } \\
\text { to exam room, exterior wall }\end{array}$ & C & $\mathrm{x}$ & \\
\hline TD-060 & $11 / 8$ & 12:09 & AVL & 0 & 39.790041 & -121.580393 & AVL & TD & multiple structures on fire at this time & $\mathrm{R}$ & & \\
\hline TD-021 & $11 / 8$ & 12:15 & TD & 45 & 39.775927 & -121.580895 & TD & TD & $\begin{array}{l}\text { Ponderosa Elementary School; portable buildings have } \\
\text { already burned; cafeteria is on fire }\end{array}$ & C & & \\
\hline PPD-08 & $11 / 8$ & $12: 16$ & PPD-08 & 0 & 39.711137 & -121.576335 & Radio & Radio & fire at this location & 0 & & \\
\hline TD-043 & $11 / 8$ & 12:18 & Inferred & 2 & 39.778454 & -121.578432 & TD & TD & Ridgewood MHP is burned down & $\mathrm{R}$ & $\mathrm{x}$ & \\
\hline TD-085 & $11 / 8$ & $12: 23$ & AVL & 87 & 39.792706 & -121.579473 & AVL & TD & flame front already through & $\mathrm{o}$ & $\mathrm{x}$ & \\
\hline TD-020 & $11 / 8$ & $12: 47$ & Radio Log & 0 & 39.757701 & -121.570451 & TD & TD & FRH: fire in wing of hospital; building smoking & C & & \\
\hline TD-089 & $11 / 8$ & $12: 51$ & AVL & 15 & 39.790200 & -121.581183 & AVL & TD & $\begin{array}{l}\text { Blue Spruce Mobile Estates caught on fire; house caught } \\
\text { fire from mobile home park; burning inside and deck } \\
\text { and fence }\end{array}$ & $\mathrm{R}$ & & $\mathrm{x}$ \\
\hline TD-103 & $11 / 8$ & $12: 55$ & AVL & 614 & 39.757525 & -121.570484 & AVL & TD & $\begin{array}{l}\text { FRH: wind directed straight down hallway, would flare } \\
\text { up trench cuts in roof }\end{array}$ & C & & \\
\hline TD-086 & $11 / 8$ & $12: 57$ & $\begin{array}{c}\text { AVL } \\
\text { DZ2140 }\end{array}$ & 46 & 39.719889 & -121.572750 & Imagery & TD & fires spotting over dozer lines & v & & \\
\hline TD-084 & $11 / 8$ & 13:01 & AVL & 50 & 39.788270 & -121.578327 & TD & TD & $\begin{array}{l}\text { houses on fire on Apple View Way, fire front already } \\
\text { came through }\end{array}$ & $\mathrm{R}$ & & \\
\hline TD-084 & $11 / 8$ & $13: 01$ & AVL & 50 & 39.788123 & -121.576972 & TD & TD & fire threatening structures & 0 & & \\
\hline TD-121 & $11 / 8$ & 13:10 & AVL TD-086 & 50 & 39.711107 & -121.576331 & Photo & TD & fire north of here & 0 & & \\
\hline TD-121 & $11 / 8$ & 13:10 & AVL TD-086 & 50 & 39.720269 & -121.573876 & TD & TD & large spot fire in area & $\mathrm{S}$ & & \\
\hline TD-121 & $11 / 8$ & $13: 10$ & AVL TD-086 & 50 & 39.724597 & -121.571336 & TD & TD & main fire line, fire north of here & 0 & & \\
\hline TD-089 & $11 / 8$ & 13:12 & AVL & 40 & 39.788243 & -121.578347 & AVL & TD & garage on fire & $\mathrm{R}$ & & \\
\hline TD-014 & $11 / 8$ & $13: 24$ & Radio Log & 0 & 39.758244 & -121.571631 & $A V L$ & Radio Log & FRH: fire at the hospital threatening main building & C & & \\
\hline TD-009 & $11 / 8$ & $13: 29$ & AVL & 5 & 39.784373 & -121.578907 & AVL & TD & $\begin{array}{l}\text { Beyond Fitness gym and Children's Community Charter } \\
\text { School building burned to the ground }\end{array}$ & C & $\mathrm{x}$ & \\
\hline TD-042 & $11 / 8$ & $13: 30$ & TD & 0 & 39.798129 & -121.580125 & TD & TD & structures around are burning & $\mathrm{R}$ & & \\
\hline TD-014 & $11 / 8$ & $13: 36$ & Radio Log & 0 & 39.758244 & -121.571631 & AVL & Radio Log & $\begin{array}{l}\text { FRH: hospital building well involved, beginning to } \\
\text { threaten the main hospital }\end{array}$ & C & & \\
\hline
\end{tabular}




\begin{tabular}{|c|c|c|c|c|c|c|c|c|c|c|c|c|}
\hline \multicolumn{13}{|c|}{ Pentz Road } \\
\hline Source \# & Date & Time & $\begin{array}{l}\text { Time } \\
\text { Source }\end{array}$ & $\begin{array}{c}\text { Obs } \\
\text { Window } \\
\text { (min) }\end{array}$ & Latitude & Longitude & $\begin{array}{l}\text { Location } \\
\text { Source }\end{array}$ & Info Source & Fire Behavior Observations & $\begin{array}{c}\text { Type } \\
\text { of } \\
\text { Fire }\end{array}$ & $\begin{array}{l}\text { Residual } \\
\text { Fire? }\end{array}$ & SSI \\
\hline TD-086 & $11 / 8$ & $13: 43$ & $\begin{array}{c}\text { AVL } \\
\text { DZ2140 }\end{array}$ & 17 & 39.718267 & -121.576245 & TD & TD & fire burning between houses and reservoir & v & & \\
\hline TD-130 & $11 / 8$ & $13: 46$ & Photo & 0 & 39.747756 & -121.572455 & Photo & Photo & $\begin{array}{l}\text { most structures burned to foundation, minimal active } \\
\text { spots of fire in rubble }\end{array}$ & $\mathrm{R}$ & $x$ & \\
\hline TD-130 & $11 / 8$ & $13: 46$ & Photo & 0 & 39.752969 & -121.572436 & Photo & Photo & $\begin{array}{l}\text { fire has burned through; minimal spotty fires limited to } \\
\text { stumps, power poles, and rubble }\end{array}$ & $\mathrm{R}$ & $\mathrm{x}$ & \\
\hline TD-130 & $11 / 8$ & $13: 46$ & Photo & 0 & 39.757240 & -121.572800 & Photo & Photo & structure fully involved & C & & \\
\hline TD-130 & $11 / 8$ & $13: 46$ & Photo & 0 & 39.757959 & -121.572638 & Photo & Photo & active fire on parcel, collapsed structure & $\mathrm{R}$ & & \\
\hline TD-130 & $11 / 8$ & $13: 46$ & Photo & 0 & 39.757709 & -121.570509 & Photo & Photo & FRH: significant flames from roof of cardiology building & C & & \\
\hline TD-130 & $11 / 8$ & $13: 46$ & Photo & 0 & 39.757915 & -121.569736 & Photo & Photo & $\begin{array}{l}\text { FRH: surface fuels, a vehicle, a dumpster already } \\
\text { consumed; no hot spots }\end{array}$ & 0 & $\mathrm{x}$ & \\
\hline TD-069 & $11 / 8$ & $13: 47$ & Inferred & 53 & 39.769375 & -121.582833 & TD & TD & cars actively burning blocking Bille Rd & 0 & & \\
\hline TD-069 & $11 / 8$ & $13: 47$ & Inferred & 53 & 39.775952 & -121.580888 & TD & TD & Ponderosa Elementary School cafeteria burning & C & & \\
\hline TD-130 & $11 / 8$ & 13:49 & video & 0 & 39.756547 & -121.572775 & video & video & $\begin{array}{l}\text { multiple structures fully involved west side of Pentz Rd } \\
\text { at hospital }\end{array}$ & $\mathrm{R}$ & & \\
\hline TD-112 & $11 / 8$ & $13: 50$ & Inferred & 370 & 39.757455 & -121.570619 & TD & TD & FRH: hospital is well involved & C & & \\
\hline TD-130 & $11 / 8$ & $13: 51$ & AVL & 319 & 39.757572 & -121.570474 & TD & TD & FRH: building burning inside & C & & \\
\hline TD-042 & $11 / 8$ & $13: 54$ & Photo & 0 & 39.784826 & -121.579119 & TD & TD & Beyond Fitness is burned down & C & $\mathrm{x}$ & \\
\hline TD-103 & $11 / 8$ & $13: 55$ & Photo & 0 & 39.757639 & -121.570544 & Photo & Photo & $\begin{array}{l}\text { FRH: portion of cardiology building fully involved; } \\
\text { flames coming from trench cuts in the roof }\end{array}$ & C & & \\
\hline TD-115 & $11 / 8$ & $14: 00$ & video & 0 & 39.716162 & -121.577602 & video & TD, video & into heavy, active fire, both sides of Pentz Rd; embers & 0 & & \\
\hline TD-086 & $11 / 8$ & $14: 00$ & TD & 0 & 39.714723 & -121.572826 & TD & TD & explore on east side of reservoir; fire wrapping to south & v & & \\
\hline TD-121 & $11 / 8$ & $14: 00$ & Inferred & 60 & 39.720796 & -121.576504 & TD & TD & fire spotting across Lago Vista to west side & $\mathrm{S}$ & & \\
\hline TD-121 & $11 / 8$ & $14: 00$ & Inferred & 180 & 39.711257 & -121.577644 & TD & TD & numerous spot fires & $S$ & & \\
\hline TD-121 & $11 / 8$ & $14: 00$ & Inferred & 180 & 39.704804 & -121.577658 & TD & TD & fire spreading south, threatening structures & V & & \\
\hline TD-121 & $11 / 8$ & $14: 00$ & Inferred & 180 & 39.702946 & -121.581588 & TD & TD & fire spreading south, threatening structures & $\mathrm{V}$ & & \\
\hline TD-121 & $11 / 8$ & $14: 00$ & Inferred & 180 & 39.701096 & -121.580489 & TD & TD & fire spreading south, threatening structures & v & & \\
\hline TD-115 & $11 / 8$ & $14: 00$ & Photo & 0 & 39.716173 & -121.577630 & Photo & Photo & large spot, active vegetation fire both sides of Pentz Rd & V & & \\
\hline TD-115 & $11 / 8$ & $14: 00$ & Photo & 0 & 39.717529 & -121.577953 & Photo & Photo & large spot, active vegetation fire both sides of Pentz Rd & $\mathrm{v}$ & & \\
\hline TD-103 & $11 / 8$ & $14: 00$ & Photo & 0 & 39.757606 & -121.570566 & Photo & Photo & $\begin{array}{l}\text { FRH: flames coming from roof trenches of cardiology } \\
\text { building }\end{array}$ & C & & \\
\hline TD-103 & $11 / 8$ & $14: 07$ & Photo & 0 & 39.757606 & -121.570566 & Photo & Photo & $\begin{array}{l}\text { FRH: flames coming from roof trenches of cardiology } \\
\text { building }\end{array}$ & C & & \\
\hline TD-103 & $11 / 8$ & $14: 08$ & Photo & 0 & 39.757606 & -121.570566 & Photo & Photo & $\begin{array}{l}\text { FRH: flames coming from roof trenches of cardiology } \\
\text { building }\end{array}$ & C & & \\
\hline TD-069 & $11 / 8$ & $14: 44$ & Inferred & 0 & 39.770044 & -121.584035 & TD & TD & cars burning on Bille Rd, but passable & 0 & & \\
\hline TD-055 & $11 / 8$ & $15: 00$ & TD & 180 & 39.757641 & -121.570478 & TD & TD & FRH: building burning & C & & \\
\hline
\end{tabular}




\begin{tabular}{|c|c|c|c|c|c|c|c|c|c|c|c|c|}
\hline \multicolumn{13}{|c|}{ Pentz Road } \\
\hline Source \# & Date & Time & $\begin{array}{l}\text { Time } \\
\text { Source }\end{array}$ & $\begin{array}{l}\text { Obs } \\
\text { Window } \\
\text { (min) }\end{array}$ & Latitude & Longitude & $\begin{array}{l}\text { Location } \\
\text { Source }\end{array}$ & Info Source & Fire Behavior Observations & $\begin{array}{l}\text { Type } \\
\text { of } \\
\text { Fire }\end{array}$ & $\begin{array}{l}\text { Residual } \\
\text { Fire? }\end{array}$ & SSI \\
\hline TD-042 & $11 / 8$ & $15: 00$ & Inferred & 90 & 39.775888 & -121.580945 & TD & TD & cafeteria burning at Ponderosa Elementary School & $\mathrm{C}$ & & \\
\hline TD-121 & $11 / 8$ & 15:00 & TD & 0 & 39.710573 & -121.583814 & TD & TD & fire moving $S, S W$ along drainage & V & & \\
\hline TD-016 & $11 / 8$ & 15:03 & Radio Log & 0 & 39.775647 & -121.579575 & Radio Log & Radio Log & "Ponderosa school off Pentz Rd is being impacted" & V & & \\
\hline TD-111 & $11 / 8$ & 15:04 & Photo & 0 & 39.797205 & -121.580949 & TD & TD & a few homes burning Gate Ln / Candlewood Ct & $\mathrm{R}$ & & \\
\hline VTD-07 & $11 / 8$ & 15:04 & Inferred & 66 & 39.712567 & -121.576952 & video & video & $\begin{array}{l}\text { structure on fire; } 3 \mathrm{~m}(10 \mathrm{ft}) \text { flames coming from the } \\
\text { roof; wind } 4.5 \mathrm{~m} / \mathrm{s} \text { to } 6.7 \mathrm{~m} / \mathrm{s}(10 \mathrm{mi} / \mathrm{h} \text { to } 15 \mathrm{mi} / \mathrm{h}) \text { from } \\
\text { east }\end{array}$ & $\mathrm{R}$ & & \\
\hline VTD-07 & $11 / 8$ & 15:04 & Inferred & 66 & 39.706858 & -121.584489 & video & video & plume coming from canyon & V & & \\
\hline VTD-07 & $11 / 8$ & 15:04 & Inferred & 66 & 39.712561 & -121.577010 & video & video & $\begin{array}{l}\text { structure on fire; }>4.6 \mathrm{~m} \mathrm{(} 15 \mathrm{ft} \text { ) flames, second story } \\
\text { well-involved, some surface fuels have burned through } \\
\text { in mulch bed }\end{array}$ & $\mathrm{R}$ & & \\
\hline VTD-07 & $11 / 8$ & 15:04 & Inferred & 66 & 39.712602 & -121.577603 & video & video & surface fuels, grass, on empty lot have burned & $\mathrm{v}$ & $\mathrm{x}$ & \\
\hline VTD-19 & $11 / 8$ & 15:04 & Inferred & 112 & 39.712543 & -121.576949 & video & video & Sierra del Sol, fully involved & $\mathrm{R}$ & & \\
\hline TD-112 & $11 / 8$ & 15:10 & Photo & 0 & 39.757671 & -121.570531 & Photo & Photo & $\begin{array}{l}\text { FRH: cardiology building on fire; north wing is partially } \\
\text { collapsed }\end{array}$ & C & & \\
\hline TD-130 & $11 / 8$ & $15: 34$ & Photo & 0 & 39.757743 & -121.570617 & Photo & Photo & FRH: cardiology burning & C & & \\
\hline TD-130 & $11 / 8$ & $15: 34$ & Photo & 0 & 39.757912 & -121.571109 & Photo & Photo & FRH: HVAC unit on roof flaming & 0 & & \\
\hline TD-037 & $11 / 8$ & $15: 42$ & video & 0 & 39.733617 & -121.568052 & video & video & structure completely finished burning & $\mathrm{R}$ & $\mathrm{x}$ & \\
\hline TD-020 & $11 / 8$ & $15: 42$ & Radio Log & 0 & 39.712526 & -121.577291 & Radio Log & Radio Log & fire threatening structures & 0 & & \\
\hline TD-020 & $11 / 8$ & $15: 42$ & Radio Log & 0 & 39.775980 & -121.580433 & Radio Log & Radio Log & fire threatening structures & 0 & & \\
\hline TD-037 & $11 / 8$ & $15: 42$ & Photo & 0 & 39.733705 & -121.567769 & Photo & Photo & structures in area destroyed, burned to foundation & $\mathrm{R}$ & $x$ & \\
\hline VTD-27 & $11 / 8$ & $15: 52$ & Inferred & 40 & 39.717451 & -121.578455 & video & video & structure fully involved & $\mathrm{R}$ & & \\
\hline VTD-27 & $11 / 8$ & $15: 52$ & Inferred & 40 & 39.718178 & -121.579263 & video & video & structure past peak fully involved, collapsing & $\mathrm{R}$ & $x$ & \\
\hline VTD-27 & $11 / 8$ & $15: 52$ & Inferred & 40 & 39.718012 & -121.578557 & video & video & vegetation already burned; trees torched & v & $x$ & \\
\hline VTD-27 & $11 / 8$ & $15: 52$ & Inferred & 40 & 39.717826 & -121.578984 & video & video & garden vegetation burned and smoking & V & $x$ & \\
\hline VTD-27 & $11 / 8$ & $15: 52$ & Inferred & 40 & 39.718286 & -121.578636 & video & video & structure burned, collapsed, light flames remaining & $\mathrm{R}$ & $\mathrm{x}$ & \\
\hline VTD-27 & $11 / 8$ & $15: 52$ & Inferred & 40 & 39.716415 & -121.577987 & video & video & $\begin{array}{l}\text { detached garage } 9 \mathrm{~m} \times 15 \mathrm{~m}(30 \mathrm{ft} \times 50 \mathrm{ft}) \text { burned to } \\
\text { foundation }\end{array}$ & 0 & $x$ & \\
\hline VTD-27 & $11 / 8$ & $15: 52$ & Inferred & 40 & 39.713107 & -121.576374 & video & video & $\begin{array}{l}\text { active flames in dense vegetation, torching trees; big } \\
\text { burst of energy, flaming debris and embers }\end{array}$ & v & & \\
\hline VTD-27 & $11 / 8$ & $15: 52$ & Inferred & 40 & 39.712557 & -121.576959 & video & video & $\begin{array}{l}\text { structure fire; past peak, roof collapsed, walls standing, } \\
\text { still burning }\end{array}$ & $\mathrm{R}$ & & \\
\hline VTD-27 & $11 / 8$ & $15: 52$ & Inferred & 40 & 39.712217 & -121.576982 & video & video & active vegetation fire & $\mathrm{S}$ & & \\
\hline TD-023 & $11 / 8$ & $16: 00$ & TD & 0 & 39.788612 & -121.577937 & TD & TD & ground fire creeping to structure and deck post on fire & $\mathrm{R}$ & & \\
\hline TD-023 & $11 / 8$ & 16:00 & TD & 0 & 39.790936 & -121.578637 & TD & TD & shed building at orchard caught fire and burned down & 0 & & \\
\hline TD-087 & $11 / 8$ & $16: 16$ & AVL & 41 & 39.711083 & -121.576217 & AVL & TD & fire both sides of Pentz Rd & v & & \\
\hline VTD-27 & $11 / 8$ & $16: 17$ & Inferred & 15 & 39.711696 & -121.571141 & video & video & increase in fire activity to east & 0 & & \\
\hline
\end{tabular}




\begin{tabular}{|c|c|c|c|c|c|c|c|c|c|c|c|c|}
\hline \multicolumn{13}{|c|}{ Pentz Road } \\
\hline Source \# & Date & Time & $\begin{array}{c}\text { Time } \\
\text { Source }\end{array}$ & $\begin{array}{c}\text { Obs } \\
\text { Window } \\
\text { (min) }\end{array}$ & Latitude & Longitude & $\begin{array}{c}\text { Location } \\
\text { Source }\end{array}$ & Info Source & Fire Behavior Observations & $\begin{array}{c}\text { Type } \\
\text { of } \\
\text { Fire } \\
\end{array}$ & $\begin{array}{l}\text { Residual } \\
\text { Fire? }\end{array}$ & SSI \\
\hline TD-209 & $11 / 8$ & $16: 22$ & AVL & 52 & 39.741773 & -121.568128 & AVL & TD & some houses damaged & $\mathrm{R}$ & $\mathrm{x}$ & \\
\hline TD-209 & $11 / 8$ & $16: 22$ & $\mathrm{AVL}$ & 38 & 39.743583 & -121.569417 & $\mathrm{AVL}$ & TD & hot spots around structures & 0 & $x$ & \\
\hline TD-209 & $11 / 8$ & $16: 30$ & Photo & 0 & 39.743515 & -121.570061 & Photo & Photo & shed is burned to ground, no active flames & 0 & $x$ & \\
\hline TD-209 & $11 / 8$ & $16: 30$ & Photo & 0 & 39.743562 & -121.569871 & Photo & Photo & fence has burned & 0 & $x$ & \\
\hline TD-005 & $11 / 8$ & $16: 44$ & Photo & 0 & 39.757705 & -121.570434 & Photo & Photo & $\begin{array}{l}\text { FRH: north portion of cardiology mostly burnt down, } \\
\text { reduced fire activity }\end{array}$ & C & & \\
\hline TD-209 & $11 / 8$ & $16: 45$ & Photo & 0 & 39.743543 & -121.569951 & Photo & Photo & few smoking hot spots, no active flames & 0 & $x$ & \\
\hline TD-209 & $11 / 8$ & $16: 45$ & Photo & 0 & 39.743558 & -121.569830 & Photo & Photo & wood retaining wall, mulch, vegetation; burned & 0 & $\mathrm{x}$ & \\
\hline TD-209 & $11 / 8$ & $16: 45$ & Photo & 0 & 39.743666 & -121.569786 & Photo & Photo & structure burned to foundation & $\mathrm{R}$ & $\mathrm{x}$ & \\
\hline TD-209 & $11 / 8$ & $16: 45$ & Photo & 0 & 39.743485 & -121.569201 & Photo & Photo & $\begin{array}{l}\text { structure burned to foundation, surface fuels on parcel } \\
\text { burned }\end{array}$ & $\mathrm{R}$ & $x$ & \\
\hline TD-209 & $11 / 8$ & $16: 45$ & Photo & 0 & 39.743750 & -121.568824 & Photo & Photo & structure fully involved & $\mathrm{R}$ & & \\
\hline TD-209 & $11 / 8$ & $16: 45$ & Photo & 0 & 39.743471 & -121.568726 & Photo & Photo & structure burned to foundation & $\mathrm{R}$ & $\mathrm{x}$ & \\
\hline TD-209 & $11 / 8$ & $16: 45$ & Photo & 0 & 39.743250 & -121.569726 & Photo & Photo & structure burned to foundation & $\mathrm{R}$ & $\mathrm{x}$ & \\
\hline TD-005 & $11 / 8$ & $16: 57$ & Photo & 0 & 39.757302 & -121.570408 & Photo & Photo & $\begin{array}{l}\text { FRH: cardiology, most fire activity on NW corner, } \\
\text { burning in rubble }\end{array}$ & C & & \\
\hline TD-087 & $11 / 8$ & $16: 59$ & AVL & 53 & 39.720333 & -121.577045 & AVL & TD & spot fires everywhere & $S$ & & \\
\hline TD-043 & $11 / 8$ & $17: 00$ & TD & 90 & 39.774975 & -121.580130 & TD & TD & Fire, Ponderosa Elementary School & C & & \\
\hline TD-121 & $11 / 8$ & $17: 00$ & TD & 30 & 39.711122 & -121.576252 & TD & TD & fire blows across Pentz Rd at the reservoir & v & & \\
\hline TD-121 & $11 / 8$ & $17: 00$ & Inferred & 30 & 39.709784 & -121.576015 & TD & TD & $\begin{array}{l}\text { fuels are black, but fire catches a house and spreads to } \\
\text { other structures }\end{array}$ & $\mathrm{R}$ & & \\
\hline TD-055 & $11 / 8$ & $17: 49$ & Photo & 0 & 39.757746 & -121.570627 & Photo & Photo & FRH: cardiology partially collapsed, still flaming & C & $\mathrm{x}$ & \\
\hline TD-055 & $11 / 8$ & $17: 50$ & Photo & 0 & 39.757641 & -121.570478 & Photo & TD & $\begin{array}{l}\text { FRH: lower hospital building is still burning, burned } \\
\text { down in sections }\end{array}$ & C & & \\
\hline TD-043 & $11 / 8$ & $18: 10$ & Photo & 0 & 39.776017 & -121.580848 & TD & TD & Ponderosa Elementary School cafeteria on fire & C & & \\
\hline TD-014 & $11 / 8$ & $18: 23$ & AVL & 40 & 39.786946 & -121.574589 & AVL & TD & houses on Dean Rd are pretty much gone & $\mathrm{R}$ & $\mathrm{x}$ & \\
\hline TD-109 & $11 / 8$ & $18: 26$ & AVL & 1 & 39.769673 & -121.583495 & AVL & TD & cars still burning on Bille Rd & 0 & & \\
\hline TD-103 & $11 / 8$ & $18: 26$ & Photo & 0 & 39.757728 & -121.570570 & Photo & Photo & FRH: cardiology portion is flaming rubble & C & $\mathrm{x}$ & \\
\hline TD-055 & $11 / 8$ & $18: 30$ & TD & 0 & 39.783865 & -121.578938 & TD & TD & $\begin{array}{l}\text { Children's Community Charter School: main building } \\
\text { burned; office building is not burned }\end{array}$ & c & $\mathrm{x}$ & \\
\hline TD-103 & $11 / 8$ & 23:40 & AVL & 440 & 39.757995 & -121.571050 & AVL & TD & FRH: maintenance shed roof on fire & c & & \\
\hline TD-103 & $11 / 8$ & 23:40 & AVL & 440 & 39.757525 & -121.570484 & AVL & TD & FRH: interior fire threatening main building & C & & \\
\hline TD-103 & $11 / 9$ & $00: 21$ & Photo & 0 & 39.757891 & -121.571183 & Photo & Photo & FRH: hot spots inside cardiology building & C & $\mathrm{x}$ & \\
\hline TD-103 & $11 / 9$ & 07:10 & $\mathrm{AVL}$ & 257 & 39.757995 & -121.571050 & AVL & TD & FRH: maintenance shed roof on fire & C & & \\
\hline
\end{tabular}




\begin{tabular}{|c|c|c|c|c|c|c|c|c|c|c|c|c|}
\hline \multicolumn{13}{|c|}{ Feather River Hospital } \\
\hline Source \# & Date & Time & $\begin{array}{l}\text { Time } \\
\text { Source }\end{array}$ & $\begin{array}{c}\text { Obs } \\
\text { Window } \\
\text { (min) }\end{array}$ & Latitude & Longitude & $\begin{array}{l}\text { Location } \\
\text { Source }\end{array}$ & Info Source & Fire Behavior Observations & $\begin{array}{c}\text { Type } \\
\text { of } \\
\text { Fire }\end{array}$ & $\begin{array}{l}\text { Residual } \\
\text { Fire? }\end{array}$ & SSI \\
\hline TD-063 & $11 / 8$ & 07:49 & $911-064-1$ & 0 & 39.754064 & -121.570775 & $911-064-1$ & TD & spot fire & $\mathrm{S}$ & & \\
\hline $911-064-1$ & $11 / 8$ & 07:49 & $911-064-1$ & 0 & 39.754132 & -121.570864 & $911-064-1$ & $911-064-1$ & fire in yard & $\mathrm{S}$ & & \\
\hline $911-066-1$ & $11 / 8$ & 07:50 & 911-066-1 & 0 & 39.754563 & -121.570015 & Inferred & 911-066-1 & fire just started very close to us & $\mathrm{s}$ & & \\
\hline $911-071-1$ & $11 / 8$ & 07:51 & $911-071-1$ & 0 & 39.754132 & -121.570864 & $911-071-1$ & $911-071-1$ & fire in yard getting bigger by the second & $\mathrm{S}$ & & \\
\hline 911-084-1 & $11 / 8$ & 07:56 & 911-084-1 & 0 & 39.755072 & -121.569579 & Inferred & 911-084-1 & fire behind home on Riverview $\mathrm{Dr}$ & $\mathrm{s}$ & & \\
\hline $911-086-3$ & $11 / 8$ & 07:58 & $911-086-3$ & 0 & 39.762973 & -121.567732 & Inferred & $911-086-3$ & fire coming up the hill by the back cottages & V & & \\
\hline 911-1035-1 & $11 / 8$ & 08:00 & $911-1035-1$ & 0 & 39.762078 & -121.568099 & Inferred & $911-1035-1$ & fire within feet of structures & V & & \\
\hline TD-063 & $11 / 8$ & 08:02 & PPD video & 15 & 39.755087 & -121.569543 & PPD video & $\begin{array}{l}\text { TD, PPD } \\
\text { video }\end{array}$ & spot fire coming up from canyon & $\mathrm{s}$ & & \\
\hline PPD-01 & $11 / 8$ & 08:02 & PPD-01 & 0 & 39.754989 & -121.569479 & video & video & spot fire & $\mathrm{s}$ & & \\
\hline $911-104-1$ & $11 / 8$ & 08:09 & $911-104-1$ & 0 & 39.754121 & -121.570879 & $911-104-1$ & $911-104-1$ & fire burning on property & $\mathrm{S}$ & & \\
\hline 911-1047-1 & $11 / 8$ & 08:11 & 911-1047-1 & 0 & 39.757160 & -121.571200 & 911-1047-1 & 911-1047-1 & Feather River Hospital is getting spot fires on campus & $\mathrm{s}$ & & \\
\hline TD-063 & $11 / 8$ & 08:17 & Inferred & 3 & 39.755091 & -121.571529 & TD & TD & $\begin{array}{l}\text { south side yards/vegetation on fire, north side has no } \\
\text { fire }\end{array}$ & V & & \\
\hline 911-1054-2 & $11 / 8$ & 08:17 & $911-1054-2$ & 0 & 39.754421 & -121.570872 & Inferred & $911-1054-2$ & big fire behind house & $\mathrm{V}$ & & \\
\hline TD-063 & $11 / 8$ & 08:20 & Inferred & 30 & 39.757794 & -121.571187 & TD & TD & FRH: active fire on the hospital complex & V & & \\
\hline Radio Log & $11 / 8$ & $08: 20$ & Radio Log & 0 & 39.756680 & -121.568253 & Inferred & Radio Log & FRH: fire right on property line & V & & \\
\hline $911-131-1$ & $11 / 8$ & $08: 24$ & $911-131-1$ & 0 & 39.757421 & -121.570929 & $911-131-1$ & 911-131-1 & hospital on fire & C & & \\
\hline 911-134-1 & $11 / 8$ & $08: 25$ & $911-134-1$ & 0 & 39.757421 & -121.570929 & $911-134-1$ & $911-134-1$ & FRH being impacted by fire & 0 & & \\
\hline $911-137-1$ & $11 / 8$ & $08: 27$ & 911-137-1 & 0 & 39.757421 & -121.570929 & 911-137-1 & $911-137-1$ & hospital is on fire & C & & \\
\hline TD-143 & $11 / 8$ & $08: 30$ & Inferred & 30 & 39.754738 & -121.572356 & TD & TD & fire both sides of road; propane exploding & $\mathrm{R}$ & & \\
\hline Radio Log & $11 / 8$ & $08: 36$ & Radio Log & 0 & 39.757060 & -121.571208 & Radio Log & Radio Log & fire within $3 \mathrm{~m}(10 \mathrm{ft})$ of $\mathrm{FRH}$ & V & & \\
\hline TD-005 & $11 / 8$ & 08:37 & AVL & 0 & 39.754633 & -121.572426 & AVL & TD & fire on east side of Pentz Rd about to hit Riverview $\mathrm{Dr}$ & $\mathrm{V}$ & & \\
\hline TD-014 & $11 / 8$ & 08:37 & Radio Log & 0 & 39.756607 & -121.568242 & Radio Log & Radio Log & active torching behind FRH & V & & \\
\hline TD-005 & $11 / 8$ & 08:38 & AVL & 0 & 39.754891 & -121.571911 & TD & TD & fire in front yard & S & & \\
\hline TD-005 & $11 / 8$ & 08:38 & AVL & 65 & 39.755100 & -121.571617 & AVL & TD & $\begin{array}{l}\text { Spots growing bigger than backpump size in seconds, } \\
\text { and flames blowtorching, ember shower, all yards } \\
\text { burning. Decorative stuff in yards burning that normally } \\
\text { doesn't burn }\end{array}$ & $\mathrm{S}$ & & \\
\hline TD-014 & $11 / 8$ & 08:38 & AVL & 17 & 39.756387 & -121.568888 & TD & TD & FRH: fully involved buildings & C & & \\
\hline TD-014 & $11 / 8$ & 08:38 & $\mathrm{AVL}$ & 17 & 39.756620 & -121.571889 & TD & TD & FRH: fire on patio of $O B$ unit & 0 & & \\
\hline TD-014 & $11 / 8$ & 08:40 & Radio Log & 0 & 39.756195 & -121.572080 & AVL & TD & FRH: fire on one of the patios at the hospital & 0 & & \\
\hline $911-179-1$ & $11 / 8$ & 08:46 & $911-179-1$ & 0 & 39.757048 & -121.571191 & $911-179-1$ & $911-179-1$ & hospital fire alarm & C & & \\
\hline TD-103 & $11 / 8$ & 08:47 & AVL & 148 & 39.755683 & -121.571747 & AVL & TD & fire approaches from east & V & & \\
\hline TD-103 & $11 / 8$ & $08: 47$ & AVL & 148 & 39.756426 & -121.571397 & TD & TD & FRH: Cancer center catches fire & C & & \\
\hline VTD-17 & $11 / 8$ & $08: 47$ & TD & 3 & 39.756884 & -121.568212 & video & video & smoke coming from behind hospital & V & & \\
\hline TD-005 & $11 / 8$ & $08: 48$ & AVL & 0 & 39.755324 & -121.570642 & AVL & TD & house at end of street $50 \%$ involved & $\mathrm{R}$ & & \\
\hline
\end{tabular}




\begin{tabular}{|c|c|c|c|c|c|c|c|c|c|c|c|c|}
\hline \multicolumn{13}{|c|}{ Feather River Hospital } \\
\hline Source \# & Date & Time & $\begin{array}{l}\text { Time } \\
\text { Source }\end{array}$ & $\begin{array}{c}\text { Obs } \\
\text { Window } \\
\text { (min) }\end{array}$ & Latitude & Longitude & $\begin{array}{l}\text { Location } \\
\text { Source }\end{array}$ & Info Source & Fire Behavior Observations & $\begin{array}{c}\text { Type } \\
\text { of } \\
\text { Fire }\end{array}$ & $\begin{array}{l}\text { Residual } \\
\text { Fire? }\end{array}$ & SSI \\
\hline PPD-04 & $11 / 8$ & 08:53 & PPD-04 & 5 & 39.755718 & -121.569681 & video & video & intense fire activity, possible structure involved & 0 & & \\
\hline TD-103 & $11 / 8$ & 09:00 & Photo & 0 & 39.755455 & -121.571546 & Photo & Photo & fence and vegetation burning, threatening structure & 0 & & \\
\hline TD-020 & $11 / 8$ & 09:02 & Inferred & 0 & 39.757028 & -121.571208 & TD & TD & ember cast & 0 & & \\
\hline 911-208-1 & $11 / 8$ & 09:02 & 911-208-1 & 0 & 39.757023 & -121.571290 & 911-208-1 & 911-208-1 & fire alarm & C & & \\
\hline 911-210-1 & $11 / 8$ & 09:04 & 911-210-1 & 0 & 39.758893 & -121.570887 & $911-210-1$ & 911-210-1 & fire alarm & C & & \\
\hline VTD-17 & $11 / 8$ & 09:05 & TD & 0 & 39.758293 & -121.571793 & video & video & light embers start trickling down & 0 & & \\
\hline VTD-17 & $11 / 8$ & 09:05 & Inferred & 9 & 39.755064 & -121.572370 & video & video & fire burning on west side Pentz Rd & V & & \\
\hline PPD-05 & $11 / 8$ & 09:05 & PPD-05 & 0 & 39.757758 & -121.571137 & video & video & light ember cast blowing from the west & 0 & & \\
\hline PPD-05 & $11 / 8$ & 09:08 & PPD-05 & 2 & 39.757758 & -121.571137 & video & video & $\begin{array}{l}\text { heavy ember shower, embers exploding and skittering } \\
\text { across pavement }\end{array}$ & 0 & & \\
\hline PPD-05 & $11 / 8$ & 09:09 & PPD-05 & 0 & 39.757834 & -121.571099 & video & video & multiple spot fire ignition in mulch & $\mathrm{s}$ & & \\
\hline PPD-05 & $11 / 8$ & 09:12 & PPD-05 & 0 & 39.757892 & -121.571664 & video & Radio & $\begin{array}{l}\text { FRH: firestorm, fire threatening all around all the } \\
\text { buildings including gas tanks and oxygen }\end{array}$ & 0 & & \\
\hline TD-090 & $11 / 8$ & 09:15 & $\mathrm{AVL}$ & 7 & 39.757795 & -121.572302 & AVL & TD & fire on the west side of Pentz Rd by the hospital & $\mathrm{V}$ & & \\
\hline TD-016 & $11 / 8$ & 09:15 & Inferred & 192 & 39.757568 & -121.570270 & TD & TD & FRH: attic fire in structure & C & & \\
\hline VTD-17 & $11 / 8$ & 09:15 & Inferred & 8 & 39.756180 & -121.572572 & video & video & $\begin{array}{l}\text { surface fire burning all of west side of Pentz Rd at } \\
\text { southern hospital driveway }\end{array}$ & V & & \\
\hline TD-109 & $11 / 8$ & 09:17 & AVL & 45 & 39.756683 & -121.570967 & AVL & TD & FRH: HVAC is on fire & C & & \\
\hline PPD-05 & $11 / 8$ & 09:19 & PPD-05 & 0 & 39.757895 & -121.572366 & video & Radio & fire has jumped westbound from our location & 0 & & \\
\hline PPD-05 & $11 / 8$ & 09:19 & PPD-05 & 0 & 39.757655 & -121.572453 & video & video & spot fire on west side Pentz Rd & $S$ & & \\
\hline PPD-05 & $11 / 8$ & 09:20 & PPD-05 & 0 & 39.756074 & -121.572333 & video & video & $\begin{array}{l}\text { Pentz Rd is inaccessible due to fire and fire engine } \\
\text { activity south of hospital }\end{array}$ & 0 & & \\
\hline TD-124 & $11 / 8$ & 09:22 & AVL & 81 & 39.757193 & -121.570698 & AVL & TD & FRH: passage connecting two buildings is $1 / 4$ involved & C & & \\
\hline PPD-05 & $11 / 8$ & 09:23 & PPD-05 & 0 & 39.758015 & -121.572137 & video & video & spot fire & S & & \\
\hline TD-124 & $11 / 8$ & 09:31 & AVL & 6 & 39.757258 & -121.570255 & AVL & TD & $\begin{array}{l}\text { FRH: fire in corner in the eaves and gutters; landscaping } \\
\text { is on fire }\end{array}$ & C & & \\
\hline PPD-05 & $11 / 8$ & 09:32 & PPD-05 & 0 & 39.757756 & -121.572212 & video & video & spot fire & $\mathrm{S}$ & & \\
\hline TD-014 & $11 / 8$ & 09:33 & Radio Log & 0 & 39.758933 & -121.572683 & $\mathrm{AVL}$ & Radio Log & fire has burned past hospital & 0 & & \\
\hline PPD-05 & $11 / 8$ & 09:33 & PPD-05 & 0 & 39.758749 & -121.571922 & video & video & detached garage burning good, past peak & $\mathrm{R}$ & & \\
\hline PPD-05 & $11 / 8$ & 09:36 & PPD-05 & 0 & 39.757860 & -121.571753 & video & video & $\begin{array}{l}\text { multiple spot fires igniting in vegetation all around } \\
\text { parking lot }\end{array}$ & $\mathrm{S}$ & & \\
\hline PPD-05 & $11 / 8$ & 09:37 & PPD-05 & 0 & 39.757926 & -121.571072 & video & video & $\begin{array}{l}\text { FRH: HVAC support building flames showing from } \\
\text { second story }\end{array}$ & C & & \\
\hline TD-124 & $11 / 8$ & 09:38 & AVL & 4 & 39.757917 & -121.570564 & AVL & TD & FRH: dumpsters on fire & 0 & & \\
\hline TD-020 & $11 / 8$ & 09:38 & AVL TD-124 & 4 & 39.757952 & -121.570552 & TD & TD & FRH: fire in dumpster & 0 & & \\
\hline TD-005 & $11 / 8$ & 09:43 & Photo & 34 & 39.756577 & -121.572070 & $A V L$ & TD & $\begin{array}{l}\text { FRH: One section of fence on fire; small spot fire against } \\
\text { building in alcoves of Birth Day Place }\end{array}$ & 0 & & \\
\hline
\end{tabular}




\begin{tabular}{|c|c|c|c|c|c|c|c|c|c|c|c|c|}
\hline \multicolumn{13}{|c|}{ Feather River Hospital } \\
\hline Source \# & Date & Time & $\begin{array}{l}\text { Time } \\
\text { Source }\end{array}$ & $\begin{array}{c}\text { Obs } \\
\text { Window } \\
\text { (min) }\end{array}$ & Latitude & Longitude & $\begin{array}{l}\text { Location } \\
\text { Source }\end{array}$ & Info Source & Fire Behavior Observations & $\begin{array}{c}\text { Type } \\
\text { of } \\
\text { Fire }\end{array}$ & $\begin{array}{l}\text { Residual } \\
\text { Fire? }\end{array}$ & SSI \\
\hline TD-020 & $11 / 8$ & 09:43 & TD-005 & 34 & 39.756672 & -121.571922 & TD & TD & FRH: fence and patio at hospital Birth Day Place burning & 0 & & \\
\hline TD-005 & $11 / 8$ & 09:44 & Photo & 0 & 39.756763 & -121.571943 & Photo & Photo & $\begin{array}{l}\text { active fire in vegetation, torching juniper trees against } \\
\text { Birth Day Place, spewing firebrands }\end{array}$ & $\mathrm{v}$ & & \\
\hline TD-103 & $11 / 8$ & 09:55 & Photo & 0 & 39.755630 & -121.571731 & Photo & Photo & $\begin{array}{l}\text { structure fully involved; interior fire, flames through } \\
\text { roof; roof partially collapsed }\end{array}$ & C & & \\
\hline PPD-05 & $11 / 8$ & $09: 57$ & PPD-05 & 0 & 39.756385 & -121.572306 & video & video & FRH: steady stream of explosions around the hospital & 0 & & \\
\hline TD-020 & $11 / 8$ & $10: 05$ & TD-124 & 30 & 39.756420 & -121.571413 & TD & TD & FRH: fire at cancer center & C & & \\
\hline TD-124 & $11 / 8$ & 10:07 & AVL & 27 & 39.756409 & -121.571416 & AVL & TD & FRH: fire in attic/ceiling of cancer building & C & & \\
\hline TD-109 & $11 / 8$ & $10: 13$ & AVL & 76 & 39.761656 & -121.568042 & AVL & TD & homes on south side of retirement home are involved & $\mathrm{R}$ & & \\
\hline TD-109 & $11 / 8$ & $10: 13$ & AVL & 76 & 39.762085 & -121.568911 & AVL & TD & fire threatening structures & 0 & & \\
\hline TD-020 & $11 / 8$ & $10: 15$ & AVL TD-109 & 75 & 39.762061 & -121.568979 & TD & TD & $\begin{array}{l}\text { small fire on roof of main care facility of Canyon View } \\
\text { Dr }\end{array}$ & C & & \\
\hline TD-005 & $11 / 8$ & $10: 20$ & AVL & 32 & 39.762063 & -121.568917 & $\mathrm{AVL}$ & TD & $\begin{array}{l}\text { Bark mulch against building on fire; OSB under vinyl just } \\
\text { ignited, rapid fire growth }\end{array}$ & $\mathrm{R}$ & & \\
\hline TD-103 & $11 / 8$ & $10: 20$ & Photo & 0 & 39.755630 & -121.571731 & Photo & Photo & building past peak, mostly collapsed; vehicle burning & C & & \\
\hline TD-005 & $11 / 8$ & $10: 38$ & Photo & 0 & 39.761630 & -121.568072 & Photo & Photo & all condos burned to foundation, burned down already & $\mathrm{R}$ & $\mathrm{x}$ & \\
\hline TD-005 & $11 / 8$ & $10: 38$ & Photo & 0 & 39.761568 & -121.567984 & Photo & Photo & $\begin{array}{l}\text { Canyon View Dr detached homes are all burned to } \\
\text { foundation, some active flaming }\end{array}$ & $\mathrm{R}$ & $\mathrm{x}$ & \\
\hline TD-005 & $11 / 8$ & $10: 39$ & Photo & 0 & 39.761568 & -121.567984 & Photo & Photo & $\begin{array}{l}\text { Canyon View Dr detached homes are all burned to } \\
\text { foundation, some active flaming }\end{array}$ & $\mathrm{R}$ & $\mathrm{x}$ & \\
\hline TD-005 & $11 / 8$ & $10: 52$ & video & 3 & 39.760983 & -121.568917 & video & video & building burning out of eaves and under structure & C & & \\
\hline TD-005 & $11 / 8$ & $10: 55$ & Photo & 0 & 39.760248 & -121.569305 & Photo & Photo & FRH: multiple auxiliary hospital buildings are burning & C & & \\
\hline TD-103 & $11 / 8$ & $11: 14$ & Photo & 0 & 39.755255 & -121.571109 & Photo & Photo & structure fully involved & $\mathrm{R}$ & & \\
\hline TD-103 & $11 / 8$ & $11: 15$ & Photo & 0 & 39.755255 & -121.571109 & Photo & Photo & structure fully involved & $\mathrm{R}$ & & \\
\hline TD-111 & $11 / 8$ & $11: 19$ & Inferred & 31 & 39.757874 & -121.570428 & TD & TD & FRH: lower portion of hospital on fire & C & & \\
\hline TD-069 & $11 / 8$ & $11: 22$ & Inferred & 118 & 39.757641 & -121.570452 & TD & TD & FRH: lower hospital building is on fire & C & & \\
\hline TD-005 & $11 / 8$ & $11: 29$ & AVL & 1036 & 39.757529 & -121.570494 & TD & TD & $\begin{array}{l}\text { FRH: attic fire getting established, everything around } \\
\text { hospital on fire now }\end{array}$ & C & & \\
\hline TD-109 & $11 / 8$ & $11: 30$ & AVL & 414 & 39.757557 & -121.570446 & AVL & TD & $\begin{array}{l}\text { FRH: fire in roof of cardiology center; fire flaring up } \\
\text { through roof trenches }\end{array}$ & C & & \\
\hline TD-103 & $11 / 8$ & $11: 43$ & Photo & 0 & 39.757697 & -121.570238 & Photo & Photo & FRH: heavy smoke from outpatient wing of hospital & C & & \\
\hline TD-103 & $11 / 8$ & $11: 43$ & AVL & 64 & 39.756622 & -121.569851 & AVL & TD & FRH: see smoke in attic; patient room on fire & C & & \\
\hline TD-103 & $11 / 8$ & $11: 43$ & Photo & 0 & 39.757691 & -121.570134 & Photo & Photo & FRH: heavy smoke from cardiology wing & C & & \\
\hline TD-103 & $11 / 8$ & $12: 01$ & Photo & 0 & 39.756641 & -121.569861 & Photo & Photo & $\begin{array}{l}\text { FRH: fire in Family Health Center is out, some damage } \\
\text { to exam room, exterior wall }\end{array}$ & C & $\mathrm{x}$ & \\
\hline TD-020 & $11 / 8$ & $12: 47$ & Radio Log & 0 & 39.757701 & -121.570451 & TD & TD & FRH: fire in wing of hospital; building smoking & C & & \\
\hline
\end{tabular}




\begin{tabular}{|c|c|c|c|c|c|c|c|c|c|c|c|c|}
\hline & & & & & & & Feather $\mathbf{R i}$ & r Hospital & & & & \\
\hline Source \# & Date & Time & $\begin{array}{c}\text { Time } \\
\text { Source }\end{array}$ & $\begin{array}{c}\text { Obs } \\
\text { Window } \\
\text { (min) }\end{array}$ & Latitude & Longitude & $\begin{array}{c}\text { Location } \\
\text { Source } \\
\end{array}$ & Info Source & Fire Behavior Observations & $\begin{array}{c}\text { Type } \\
\text { of } \\
\text { Fire }\end{array}$ & $\begin{array}{l}\text { Residual } \\
\text { Fire? }\end{array}$ & SSI \\
\hline TD-103 & $11 / 8$ & $12: 55$ & AVL & 614 & 39.757525 & -121.570484 & AVL & TD & $\begin{array}{l}\text { FRH: wind directed straight down hallway, would flare } \\
\text { up trench cuts in roof }\end{array}$ & C & & \\
\hline TD-014 & $11 / 8$ & $13: 24$ & Radio Log & 0 & 39.758244 & -121.571631 & AVL & Radio Log & FRH: fire at the hospital threatening main building & c & & \\
\hline TD-014 & $11 / 8$ & $13: 36$ & Radio Log & 0 & 39.758244 & -121.571631 & $A V L$ & Radio Log & $\begin{array}{l}\text { FRH: hospital building well involved, beginning to } \\
\text { threaten the main hospital }\end{array}$ & C & & \\
\hline TD-130 & $11 / 8$ & 13:46 & Photo & 0 & 39.757240 & -121.572800 & Photo & Photo & structure fully involved & c & & \\
\hline TD-130 & $11 / 8$ & $13: 46$ & Photo & 0 & 39.757959 & -121.572638 & Photo & Photo & active fire on parcel, collapsed structure & $\mathrm{R}$ & & \\
\hline TD-130 & $11 / 8$ & $13: 46$ & Photo & 0 & 39.757709 & -121.570509 & Photo & Photo & FRH: significant flames from roof of cardiology building & C & & \\
\hline TD-130 & $11 / 8$ & $13: 46$ & Photo & 0 & 39.757915 & -121.569736 & Photo & Photo & $\begin{array}{l}\text { FRH: surface fuels, a vehicle, a dumpster already } \\
\text { consumed; no hot spots }\end{array}$ & 0 & $\mathrm{x}$ & \\
\hline TD-130 & $11 / 8$ & $13: 49$ & video & 0 & 39.756547 & -121.572775 & video & video & $\begin{array}{l}\text { multiple structures fully involved west side of Pentz Rd } \\
\text { at hospital }\end{array}$ & $\mathrm{R}$ & & \\
\hline TD-112 & $11 / 8$ & $13: 50$ & Inferred & 370 & 39.757455 & -121.570619 & TD & TD & FRH: hospital is well involved & c & & \\
\hline TD-130 & $11 / 8$ & 13:51 & AVL & 319 & 39.757572 & -121.570474 & TD & TD & FRH: building burning inside & C & & \\
\hline TD-103 & $11 / 8$ & $13: 55$ & Photo & 0 & 39.757639 & -121.570544 & Photo & Photo & $\begin{array}{l}\text { FRH: portion of cardiology building fully involved; } \\
\text { flames coming from trench cuts in the roof }\end{array}$ & C & & \\
\hline TD-103 & $11 / 8$ & $14: 00$ & Photo & 0 & 39.757606 & -121.570566 & Photo & Photo & $\begin{array}{l}\text { FRH: flames coming from roof trenches of cardiology } \\
\text { building }\end{array}$ & C & & \\
\hline TD-103 & $11 / 8$ & 14:07 & Photo & 0 & 39.757606 & -121.570566 & Photo & Photo & $\begin{array}{l}\text { FRH: flames coming from roof trenches of cardiology } \\
\text { building }\end{array}$ & C & & \\
\hline TD-103 & $11 / 8$ & $14: 08$ & Photo & 0 & 39.757606 & -121.570566 & Photo & Photo & $\begin{array}{l}\text { FRH: flames coming from roof trenches of cardiology } \\
\text { building }\end{array}$ & C & & \\
\hline TD-055 & $11 / 8$ & $15: 00$ & TD & 180 & 39.757641 & -121.570478 & TD & TD & FRH: building burning & C & & \\
\hline TD-112 & $11 / 8$ & $15: 10$ & Photo & 0 & 39.757671 & -121.570531 & Photo & Photo & $\begin{array}{l}\text { FRH: cardiology building on fire; north wing is partially } \\
\text { collapsed }\end{array}$ & C & & \\
\hline TD-130 & $11 / 8$ & $15: 34$ & Photo & 0 & 39.757743 & -121.570617 & Photo & Photo & FRH: cardiology burning & C & & \\
\hline TD-130 & $11 / 8$ & $15: 34$ & Photo & 0 & 39.757912 & -121.571109 & Photo & Photo & FRH: HVAC unit on roof flaming & 0 & & \\
\hline TD-005 & $11 / 8$ & $16: 44$ & Photo & 0 & 39.757705 & -121.570434 & Photo & Photo & $\begin{array}{l}\text { FRH: north portion of cardiology mostly burnt down, } \\
\text { reduced fire activity }\end{array}$ & C & & \\
\hline TD-005 & $11 / 8$ & $16: 57$ & Photo & 0 & 39.757302 & -121.570408 & Photo & Photo & $\begin{array}{l}\text { FRH: cardiology, most fire activity on NW corner, } \\
\text { burning in rubble }\end{array}$ & C & & \\
\hline TD-055 & $11 / 8$ & $17: 49$ & Photo & 0 & 39.757746 & -121.570627 & Photo & Photo & FRH: cardiology partially collapsed, still flaming & C & $\mathrm{x}$ & \\
\hline TD-055 & $11 / 8$ & $17: 50$ & Photo & 0 & 39.757641 & -121.570478 & Photo & TD & $\begin{array}{l}\text { FRH: lower hospital building is still burning, burned } \\
\text { down in sections }\end{array}$ & C & & \\
\hline TD-103 & $11 / 8$ & $18: 26$ & Photo & 0 & 39.757728 & -121.570570 & Photo & Photo & FRH: cardiology portion is flaming rubble & C & $x$ & \\
\hline TD-103 & $11 / 8$ & 23:40 & AVL & 440 & 39.757995 & -121.571050 & AVL & TD & FRH: maintenance shed roof on fire & C & & \\
\hline TD-103 & $11 / 8$ & $23: 40$ & AVL & 440 & 39.757525 & -121.570484 & AVL & TD & FRH: interior fire threatening main building & C & & \\
\hline
\end{tabular}


Feather River Hospital

Obs

\begin{tabular}{|c|c|c|c|c|c|c|c|c|c|c|c|c|}
\hline Source \# & Date & Time & $\begin{array}{l}\text { Time } \\
\text { Source }\end{array}$ & $\begin{array}{c}\text { Obs } \\
\text { Window } \\
\text { (min) }\end{array}$ & Latitude & Longitude & $\begin{array}{c}\text { Location } \\
\text { Source }\end{array}$ & Info Source & Fire Behavior Observations & $\begin{array}{c}\text { Type } \\
\text { of } \\
\text { Fire }\end{array}$ & $\begin{array}{c}\text { Residual } \\
\text { Fire? }\end{array}$ & SSI \\
\hline TD-103 & $11 / 9$ & $00: 21$ & Photo & 0 & 39.757891 & -121.571183 & Photo & Photo & FRH: hot spots inside cardiology building & $\mathrm{C}$ & $\mathrm{x}$ & \\
\hline TD-103 & $11 / 9$ & 07:10 & AVL & 257 & 39.757995 & -121.571050 & AVL & TD & FRH: maintenance shed roof on fire & c & & \\
\hline
\end{tabular}




\begin{tabular}{|c|c|c|c|c|c|c|c|c|c|c|c|c|}
\hline \multicolumn{13}{|c|}{ Wagstaff Road } \\
\hline Source \# & Date & Time & $\begin{array}{l}\text { Time } \\
\text { Source }\end{array}$ & $\begin{array}{l}\text { Obs } \\
\text { Window } \\
\text { (min) }\end{array}$ & Latitude & Longitude & $\begin{array}{l}\text { Location } \\
\text { Source }\end{array}$ & Info Source & Fire Behavior Observations & $\begin{array}{l}\text { Type } \\
\text { of } \\
\text { Fire }\end{array}$ & $\begin{array}{l}\text { Residual } \\
\text { Fire? }\end{array}$ & SSI \\
\hline $911-077-3$ & $11 / 8$ & 07:53 & $911-077-3$ & 0 & 39.778763 & -121.577193 & $911-077-3$ & $911-077-3$ & vegetation fire in side yard & $\mathrm{S}$ & & \\
\hline 911-129-1 & $11 / 8$ & $08: 24$ & $911-129-1$ & 0 & 39.777911 & -121.598330 & $911-129-1$ & $911-129-1$ & fire & $\mathrm{s}$ & & \\
\hline TD-064 & $11 / 8$ & 08:30 & Inferred & 14 & 39.778184 & -121.585895 & TD & TD & $\begin{array}{l}\text { notice spot fires on north side of Wagstaff Rd between } \\
\text { Clark Rd and Pentz Rd }\end{array}$ & $\mathrm{S}$ & & \\
\hline $911-141-2$ & $11 / 8$ & 08:31 & $911-141-2$ & 0 & 39.775971 & -121.600466 & $911-141-2$ & $911-141-2$ & house on fire & $\mathrm{R}$ & & \\
\hline $911-157-1$ & $11 / 8$ & 08:37 & $911-157-1$ & 0 & 39.776591 & -121.588145 & $911-157-1$ & $911-157-1$ & field behind Kmart on fire & S & & \\
\hline TD-067 & $11 / 8$ & 08:38 & $911-158-1$ & 0 & 39.779476 & -121.587807 & TD & $\begin{array}{l}\text { TD, 911- } \\
158-1\end{array}$ & spot fire & $\mathrm{S}$ & & \\
\hline $911-158-1$ & $11 / 8$ & 08:38 & $911-158-1$ & 0 & 39.779450 & -121.587721 & $911-158-1$ & $911-158-1$ & spot fire in grass, just started, small but still burning & S & & \\
\hline $911-162-1$ & $11 / 8$ & 08:39 & $911-162-1$ & 0 & 39.778220 & -121.604211 & Inferred & $911-162-1$ & flames on bike path & S & & \\
\hline $911-163-1$ & $11 / 8$ & 08:39 & $911-163-1$ & 0 & 39.784007 & -121.612384 & Inferred & $911-163-1$ & $\begin{array}{l}\text { smoke coming out of Little Butte Creek Canyon, just } \\
\text { started, somewhere about Lucky Ln }\end{array}$ & S & & \\
\hline TD-014 & $11 / 8$ & 08:40 & Radio Log & 0 & 39.777786 & -121.579607 & Radio Log & Radio Log & multiple spot fires [in area of] Pentz Rd / Wagstaff Rd & $\mathrm{s}$ & & \\
\hline TD-075 & $11 / 8$ & 08:40 & Inferred & 6 & 39.777730 & -121.590638 & TD & TD & noticed embers flying through air & 0 & & \\
\hline TD-067 & $11 / 8$ & 08:40 & Inferred & 6 & 39.779476 & -121.587807 & TD & TD & smaller spot fire in grass behind church & $\mathrm{S}$ & & \\
\hline TD-042 & $11 / 8$ & 08:40 & Inferred & 0 & 39.778477 & -121.577106 & TD & TD & $\begin{array}{l}\text { half of mobile homes in Ridgewood mobile home park } \\
\text { are on fire }\end{array}$ & $\mathrm{R}$ & & \\
\hline $911-169-1$ & $11 / 8$ & 08:43 & $911-169-1$ & 0 & 39.777959 & -121.603210 & $911-169-1$ & $911-169-1$ & fire behind the house & $\mathrm{S}$ & & \\
\hline PPD-02 & $11 / 8$ & 08:43 & PPD-02 & 0 & 39.778604 & -121.588499 & Radio & Radio & $\begin{array}{l}\text { large tree on fire between Wagstaff Rd and Della Ln by } \\
\text { the school district office }\end{array}$ & $\mathrm{s}$ & & \\
\hline PPD-02 & $11 / 8$ & 08:43 & PPD-02 & 0 & 39.779087 & -121.577092 & Radio & Radio & $\begin{array}{l}\text { Ridgewood mobile home park; fires directly behind, } \\
\text { homes becoming involved }\end{array}$ & $\mathrm{R}$ & & \\
\hline TD-067 & $11 / 8$ & 08:46 & PPD video & 0 & 39.776799 & -121.588842 & TD & TD & $\begin{array}{l}\text { observed fully involved pine tree on south side } \\
\text { Wagstaff Rd }\end{array}$ & S & & \\
\hline TD-067 & $11 / 8$ & 08:46 & Inferred & 20 & 39.778443 & -121.578823 & TD & TD & Ridgewood MHP, portions are burning & $\mathrm{R}$ & & \\
\hline PPD-02 & $11 / 8$ & 08:46 & PPD-02 & 0 & 39.777473 & -121.588112 & Radio & Radio & spot fire; large tree and field involved & $S$ & & \\
\hline $911-178-2$ & $11 / 8$ & 08:46 & $911-178-2$ & 0 & 39.778331 & -121.603978 & Inferred & $911-178-2$ & fire on the bike path behind house & S & & \\
\hline TD-053 & $11 / 8$ & 08:50 & Inferred & 10 & 39.777706 & -121.594897 & TD & TD & houses burning, trees burning on north side & $\mathrm{R}$ & & \\
\hline PPD-02 & $11 / 8$ & 08:52 & PPD-02 & 0 & 39.778476 & -121.579561 & Radio & Radio & fire reaching Pentz Rd now (Ridgewood MHP) & 0 & & \\
\hline TD-043 & $11 / 8$ & 08:55 & Inferred & 21 & 39.778869 & -121.578982 & TD & TD & $\begin{array}{l}\text { mobile homes are burning in Ridgeway MHP (NW } \\
\text { corner) }\end{array}$ & $\mathrm{R}$ & & \\
\hline TD-043 & $11 / 8$ & 08:58 & Inferred & 18 & 39.778472 & -121.576890 & TD & TD & $\begin{array}{l}\text { mobile homes burning; pass through fire twice in } \\
\text { mobile home park to escape back to Pentz Rd } \\
\text { (Ridgewood Mobile Home Park) }\end{array}$ & $\mathrm{R}$ & & \\
\hline TD-085 & $11 / 8$ & 08:59 & AVL & 0 & 39.777336 & -121.577799 & AVL & TD & $\begin{array}{l}\text { Ponderosa mobile home park burning; sending ember } \\
\text { showers }\end{array}$ & $\mathrm{R}$ & & \\
\hline TD-085 & $11 / 8$ & 08:59 & AVL & 40 & 39.778433 & -121.578792 & AVL & TD & all mobile homes on fire (Ridgewood MHP) & $\mathrm{R}$ & & \\
\hline
\end{tabular}




\begin{tabular}{|c|c|c|c|c|c|c|c|c|c|c|c|c|}
\hline \multicolumn{13}{|c|}{ Wagstaff Road } \\
\hline Source \# & Date & Time & $\begin{array}{l}\text { Time } \\
\text { Source }\end{array}$ & $\begin{array}{c}\text { Obs } \\
\text { Window } \\
\text { (min) }\end{array}$ & Latitude & Longitude & $\begin{array}{l}\text { Location } \\
\text { Source }\end{array}$ & Info Source & Fire Behavior Observations & $\begin{array}{c}\text { Type } \\
\text { of } \\
\text { Fire }\end{array}$ & $\begin{array}{l}\text { Residual } \\
\text { Fire? }\end{array}$ & SSI \\
\hline TD-043 & $11 / 8$ & 09:00 & $\begin{array}{l}\text { TD-085, TD- } \\
022\end{array}$ & 30 & 39.777779 & -121.579642 & TD & TD & pine trees igniting at intersection & V & & \\
\hline TD-053 & $11 / 8$ & 09:00 & Inferred & 0 & 39.776337 & -121.588374 & TD & TD & fire east of Kmart & $\mathrm{R}$ & & \\
\hline PPD-02 & $11 / 8$ & 09:01 & PPD-02 & 0 & 39.778583 & -121.579579 & Radio & Radio & fire threatening vehicles & 0 & & \\
\hline TD-042 & $11 / 8$ & 09:15 & Inferred & 68 & 39.777646 & -121.603153 & TD & TD & numerous spot fires closer to Skyway & $\mathrm{S}$ & & \\
\hline TD-017 & $11 / 8$ & 09:17 & AVL & 103 & 39.777667 & -121.598330 & TD & TD & $\begin{array}{l}\text { Fire now spotting, pinching Wagstaff Rd between Clark } \\
\text { Rd and Skyway }\end{array}$ & $S$ & & \\
\hline TD-111 & $11 / 8$ & 09:21 & Radio Log & 0 & 39.777657 & -121.606241 & TD & Radio Log & $\begin{array}{l}\text { Skyway at Wagstaff about to be threatened, multiple } \\
\text { cars on fire in the area }\end{array}$ & 0 & & \\
\hline TD-111 & $11 / 8$ & 09:21 & Inferred & 0 & 39.777667 & -121.604621 & TD & TD & $\begin{array}{l}\text { well-established spot fire off Wagstaff Rd near the bike } \\
\text { path }\end{array}$ & $\mathrm{s}$ & & \\
\hline VTD-18 & $11 / 8$ & 09:28 & TD & 0 & 39.776810 & -121.588771 & video & video & tall pine tree bark burning along the entire trunk & $\mathrm{v}$ & & \\
\hline TD-052 & $11 / 8$ & 09:28 & Photo & 0 & 39.778000 & -121.590473 & Photo & Photo & $\begin{array}{l}\text { fire has burned up bark of tall pine tree behind (east) } \\
\text { Savemart }\end{array}$ & $\mathrm{v}$ & $\mathrm{x}$ & \\
\hline TD-017 & $11 / 8$ & 09:30 & Radio Log & 0 & 39.777731 & -121.590543 & Radio Log & Radio Log & $\begin{array}{l}\text { fire is well established [in area around] Clark Rd and } \\
\text { Wagstaff Rd }\end{array}$ & 0 & & \\
\hline TD-127 & $11 / 8$ & 09:30 & Inferred & 30 & 39.777987 & -121.598007 & TD & TD & $\begin{array}{l}\text { fire is burning from the NE into area of Rocky Ln and } \\
\text { Wagstaff Rd }\end{array}$ & 0 & & \\
\hline VTD-18 & $11 / 8$ & 09:30 & TD & 0 & 39.777301 & -121.587854 & video & video & $\begin{array}{l}\text { smoke plume rising from east of commercial buildings } \\
\text { (estimated source location) }\end{array}$ & 0 & & \\
\hline VTD-18 & $11 / 8$ & 09:32 & TD & 0 & 39.776068 & -121.588136 & video & video & $\begin{array}{l}\text { orange glow coming from east of commercial buildings } \\
\text { (estimated source location) }\end{array}$ & 0 & & \\
\hline TD-127 & $11 / 8$ & 09:37 & Radio Log & 0 & 39.777659 & -121.604169 & Radio Log & Radio Log & structures burning; vehicles about to get overrun & $\mathrm{R}$ & & \\
\hline TD-055 & $11 / 8$ & 09:40 & Radio Log & 0 & 39.777682 & -121.602032 & Radio Log & Radio Log & several structures threatened/involved & $\mathrm{R}$ & & \\
\hline VTD-18 & $11 / 8$ & 09:43 & TD & 0 & 39.775481 & -121.588899 & video & video & $\begin{array}{l}30 \mathrm{~m}(100 \mathrm{ft}) \text { tall pine tree torches in } 22 \mathrm{~s} \text {; starts off } \\
\text { major fire behind buildings }\end{array}$ & 0 & & \\
\hline TD-058 & $11 / 8$ & 09:44 & video & 0 & 39.775481 & -121.588899 & video & TD, video & trees torching & $\mathrm{v}$ & & \\
\hline TD-052 & $11 / 8$ & 09:44 & Photo & 0 & 39.775554 & -121.588966 & Photo & Photo & $\begin{array}{l}\text { very tall pine torching tree behind Savemart (Paradise } \\
\text { Plaza) }\end{array}$ & $\mathrm{v}$ & & \\
\hline TD-127 & $11 / 8$ & 09:47 & Radio Log & 0 & 39.777659 & -121.604169 & Radio Log & Radio Log & fire coming across Wagstaff Rd & 0 & & \\
\hline TD-127 & $11 / 8$ & 09:57 & Photo & 0 & 39.778025 & -121.602808 & Photo & Photo & $\begin{array}{l}\text { structure, surface fuels, vehicle all fully involved on } \\
\text { single parcel }\end{array}$ & $\mathrm{R}$ & & \\
\hline TD-040 & $11 / 8$ & $10: 00$ & Inferred & 60 & 39.778033 & -121.580294 & TD & TD & spot fires in grass field & $\mathrm{s}$ & & \\
\hline TD-014 & $11 / 8$ & $10: 15$ & AVL & 2 & 39.777724 & -121.598370 & AVL & TD & lots of fire, structures burning both sides of Wagstaff $R d$ & $\mathrm{R}$ & & \\
\hline TD-022 & $11 / 8$ & $10: 15$ & TD & 0 & 39.775663 & -121.605361 & TD & TD & area fully involved in fire; fire coming from $\mathrm{N}$ and $\mathrm{E}$ & 0 & & \\
\hline TD-022 & $11 / 8$ & $10: 15$ & Inferred & 45 & 39.775663 & -121.605361 & TD & TD & heavy vegetation is burning & V & & \\
\hline TD-127 & $11 / 8$ & $10: 17$ & Photo & 0 & 39.777662 & -121.603050 & Photo & Photo & $\begin{array}{l}\text { all structures fully involved around Wagstaff Rd/Oak } \\
\text { Way; everything burning, swirling ember showers }\end{array}$ & $\mathrm{R}$ & & \\
\hline
\end{tabular}




\begin{tabular}{|c|c|c|c|c|c|c|c|c|c|c|c|c|}
\hline \multicolumn{13}{|c|}{ Wagstaff Road } \\
\hline Source \# & Date & Time & $\begin{array}{l}\text { Time } \\
\text { Source }\end{array}$ & $\begin{array}{c}\text { Obs } \\
\text { Window } \\
\text { (min) }\end{array}$ & Latitude & Longitude & $\begin{array}{l}\text { Location } \\
\text { Source }\end{array}$ & Info Source & Fire Behavior Observations & $\begin{array}{c}\text { Type } \\
\text { of } \\
\text { Fire }\end{array}$ & $\begin{array}{l}\text { Residual } \\
\text { Fire? }\end{array}$ & SSI \\
\hline TD-055 & $11 / 8$ & $10: 22$ & Photo & 0 & 39.776884 & -121.588480 & Photo & Photo & structure burning well in garage & $\mathrm{R}$ & & \\
\hline TD-055 & $11 / 8$ & 10:22 & Photo & 0 & 39.776875 & -121.588445 & Photo & Photo & $\begin{array}{l}\text { attached garage of duplex fully involved, burning } \\
\text { through roof }\end{array}$ & $\mathrm{R}$ & & \\
\hline TD-127 & $11 / 8$ & $10: 40$ & Photo & 0 & 39.777289 & -121.603059 & Photo & Photo & fire burning up against roadway, both sides of road & 0 & & \\
\hline VTD-26 & $11 / 8$ & 10:43 & Inferred & 0 & 39.778228 & -121.601723 & video & video & structure fully involved & $\mathrm{R}$ & & \\
\hline VTD-26 & $11 / 8$ & 10:43 & Inferred & 0 & 39.778058 & -121.602160 & video & video & structures burned to foundation & $\mathrm{R}$ & $\mathrm{x}$ & \\
\hline VTD-13 & $11 / 8$ & 10:44 & video & 0 & 39.777680 & -121.603036 & video & video & $\begin{array}{l}\text { multiple structures fully involved; homes to the west on } \\
\text { north side, some have collapsed }\end{array}$ & $\mathrm{R}$ & & \\
\hline VTD-13 & $11 / 8$ & 10:44 & video & 0 & 39.777680 & -121.603036 & video & video & 1212 Wagstaff Rd and west on south side are burning & $\mathrm{R}$ & & \\
\hline VTD-26 & $11 / 8$ & 10:44 & Inferred & 0 & 39.783304 & -121.612575 & $\begin{array}{l}\text { video, } \\
\text { LANDSAT }\end{array}$ & video & large plume rising from canyon to west & S & & \\
\hline VTD-26 & $11 / 8$ & 10:46 & Inferred & 0 & 39.777369 & -121.604218 & video & video & structures burning on Berkshire Ave near Wagstaff Rd & $\mathrm{R}$ & & \\
\hline TD-127 & $11 / 8$ & 10:57 & Radio Log & 0 & 39.776749 & -121.603057 & Inferred & Radio Log & fire heavily impacting Oak Way and towards Bille Rd & 0 & & \\
\hline TD-017 & $11 / 8$ & 11:03 & AVL & 3 & 39.780343 & -121.609252 & AVL & TD & $\begin{array}{l}\text { Heavy fire and embers, embers entering vehicle door. } \\
\text { Everything burning all around }\end{array}$ & 0 & & \\
\hline TD-127 & $11 / 8$ & 11:30 & Inferred & 30 & 39.778239 & -121.608737 & TD & TD & heavy fire & 0 & & \\
\hline TD-017 & $11 / 8$ & 11:34 & AVL & 116 & 39.776363 & -121.589966 & AVL & TD & $\begin{array}{l}\text { Kmart threatened, front side of Kmart shrubs catching } \\
\text { fire. }\end{array}$ & S & & \\
\hline TD-015 & $11 / 8$ & 11:35 & AVL & 123 & 39.776164 & -121.587283 & TD & TD & fire around Kmart shopping center & 0 & & \\
\hline PPD-08 & $11 / 8$ & 11:44 & PPD-08 & 0 & 39.778894 & -121.589724 & video & video & spot fire on both sides of Clark Rd & S & & \\
\hline PPD-08 & $11 / 8$ & 11:44 & PPD-08 & 0 & 39.779241 & -121.589570 & video & video & spot fire on east side Clark Rd & $S$ & & \\
\hline PPD-08 & $11 / 8$ & 11:58 & PPD-08 & 0 & 39.779241 & -121.589570 & video & video & spot fire on both sides Clark Rd & $\mathrm{S}$ & & \\
\hline PPD-08 & $11 / 8$ & 11:58 & PPD-08 & 0 & 39.778648 & -121.590200 & video & video & spot fire west side Clark Rd & S & & \\
\hline TD-127 & $11 / 8$ & 12:00 & Radio Log & 0 & 39.777628 & -121.606319 & Radio Log & Radio Log & multiple gas stations being impacted by fire & C & & \\
\hline PPD-08 & $11 / 8$ & 12:00 & PPD-08 & 0 & 39.777640 & -121.589221 & video & video & spot fire & S & & \\
\hline TD-043 & $11 / 8$ & $12: 18$ & Inferred & 2 & 39.778454 & -121.578432 & TD & TD & Ridgewood MHP is burned down & $\mathrm{R}$ & $\mathrm{x}$ & \\
\hline VTD-18 & $11 / 8$ & 12:22 & TD & 0 & 39.776348 & -121.591675 & video & video & 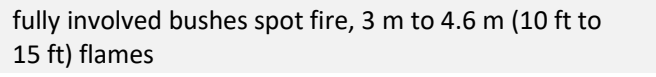 & S & & \\
\hline TD-127 & $11 / 8$ & $12: 24$ & Radio Log & 0 & 39.777646 & -121.606300 & Radio Log & Radio Log & fire on Skyway at Bille Rd and Wagstaff Rd & 0 & & \\
\hline TD-127 & $11 / 8$ & $12: 30$ & Radio Log & 0 & 39.777627 & -121.606305 & Radio Log & Radio Log & heavy fire impacting Skyway at Wagstaff Rd & 0 & & \\
\hline TD-100 & $11 / 8$ & $12: 30$ & Inferred & 0 & 39.778919 & -121.613265 & TD & TD & Waggoner Rd, Wagstaff Rd impacted with fire & 0 & & \\
\hline VTD-18 & $11 / 8$ & $12: 30$ & TD & 0 & 39.778248 & -121.590467 & Photo & Photo & spot fire, bushes/vegetation & S & & \\
\hline VTD-18 & $11 / 8$ & $12: 30$ & TD & 0 & 39.778062 & -121.591908 & Photo & Photo & heavy fire, multiple structures burning & $\mathrm{R}$ & & \\
\hline VTD-18 & $11 / 8$ & 12:47 & TD & 0 & 39.776198 & -121.591813 & Photo & video & juniper bush spot fire & S & & \\
\hline VTD-18 & $11 / 8$ & 13:13 & TD & 0 & 39.777167 & -121.588813 & video & video & $\begin{array}{l}\text { all structures behind Savemart are past peak, fully } \\
\text { involved, partially collapsed }\end{array}$ & $\mathrm{R}$ & $\mathrm{x}$ & \\
\hline TD-065 & $11 / 8$ & $14: 25$ & Inferred & 31 & 39.778005 & -121.590758 & TD & TD & fire threatening structure; fire into siding & c & & \\
\hline
\end{tabular}




\begin{tabular}{|c|c|c|c|c|c|c|c|c|c|c|c|c|}
\hline \multicolumn{13}{|c|}{ Wagstaff Road } \\
\hline Source \# & Date & Time & $\begin{array}{l}\text { Time } \\
\text { Source }\end{array}$ & $\begin{array}{c}\text { Obs } \\
\text { Window } \\
\text { (min) }\end{array}$ & Latitude & Longitude & $\begin{array}{l}\text { Location } \\
\text { Source }\end{array}$ & Info Source & Fire Behavior Observations & $\begin{array}{c}\text { Type } \\
\text { of } \\
\text { Fire }\end{array}$ & $\begin{array}{l}\text { Residual } \\
\text { Fire? }\end{array}$ & SSI \\
\hline TD-043 & $11 / 8$ & $14: 30$ & TD & 150 & 39.776522 & -121.590402 & TD & TD & fire around Kmart & 0 & & \\
\hline TD-205 & $11 / 8$ & $16: 45$ & AVL & 4 & 39.777534 & -121.604897 & AVL & TD & a few hot spots & 0 & & \\
\hline TD-207 & $11 / 8$ & $16: 49$ & AVL & 0 & 39.777648 & -121.596977 & AVL & TD & all burnt up & 0 & $\mathrm{x}$ & \\
\hline TD-207 & $11 / 8$ & $16: 52$ & AVL & 76 & 39.779170 & -121.585533 & AVL & TD & fire threatening structure & 0 & & \\
\hline TD-065 & $11 / 8$ & $16: 52$ & AVL TD-207 & 173 & 39.779150 & -121.585548 & AVL TD-207 & TD & fire threatening structure & 0 & & \\
\hline TD-205 & $11 / 8$ & $16: 54$ & $\mathrm{AVL}$ & 31 & 39.777383 & -121.612533 & AVL & TD & Fire getting under floor & $\mathrm{R}$ & & \\
\hline TD-114 & $11 / 8$ & $17: 14$ & $\begin{array}{c}\text { AVL } \\
\text { Bus1403 }\end{array}$ & 0 & 39.776164 & -121.590290 & TD & TD & fire behind the Kmart & 0 & & \\
\hline TD-108 & $11 / 8$ & $17: 56$ & Inferred & 81 & 39.777827 & -121.595673 & TD & TD & $\begin{array}{l}\text { scouting on foot Wagstaff Rd between Moss } \operatorname{Ln} \text { and } \\
\text { Apollo Ln; fire growing very fast }\end{array}$ & $\mathrm{v}$ & & \\
\hline TD-207 & $11 / 8$ & $18: 09$ & AVL & 96 & 39.780415 & -121.585751 & AVL & TD & fire threatening structure & 0 & & \\
\hline TD-108 & $11 / 8$ & $18: 34$ & Photo & 0 & 39.777827 & -121.595673 & Photo & Photo & $\begin{array}{l}1359 \text { Wagstaff Rd standing; structures on south side } \\
\text { Wagstaff Rd are burned down }\end{array}$ & $\mathrm{R}$ & $\mathrm{x}$ & \\
\hline TD-108 & $11 / 8$ & $18: 34$ & Photo & 0 & 39.777303 & -121.595404 & Photo & Photo & structure burned to foundation, flaming & $\mathrm{R}$ & $x$ & \\
\hline TD-014 & $11 / 8$ & 19:14 & Radio Log & 0 & 39.780941 & -121.627902 & Radio Log & Radio Log & fire in the wall of structure & $\mathrm{R}$ & & \\
\hline TD-127 & $11 / 8$ & 19:19 & Radio Log & 0 & 39.780959 & -121.627915 & TD & Radio Log & fire in wall of structure & $\mathrm{R}$ & & \\
\hline TD-200 & $11 / 8$ & $21: 52$ & $\mathrm{AVL}$ & 20 & 39.776750 & -121.626883 & AVL & TD & thought there was attic fire, siding on fire & $\mathrm{R}$ & & \\
\hline TD-202 & $11 / 8$ & 21:52 & AVL & 20 & 39.776462 & -121.626754 & TD & TD & siding of structure burning & $\mathrm{R}$ & & \\
\hline
\end{tabular}




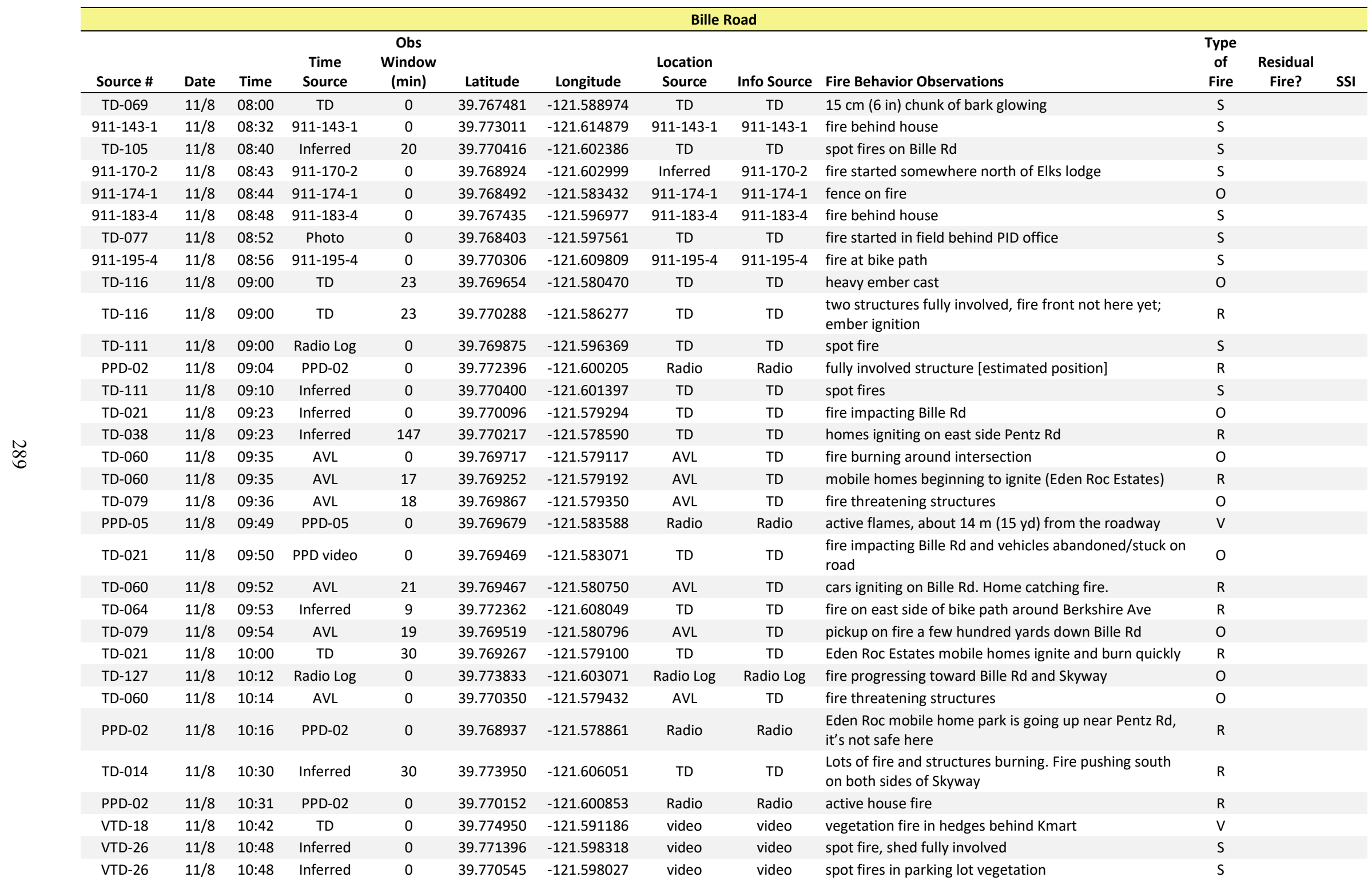




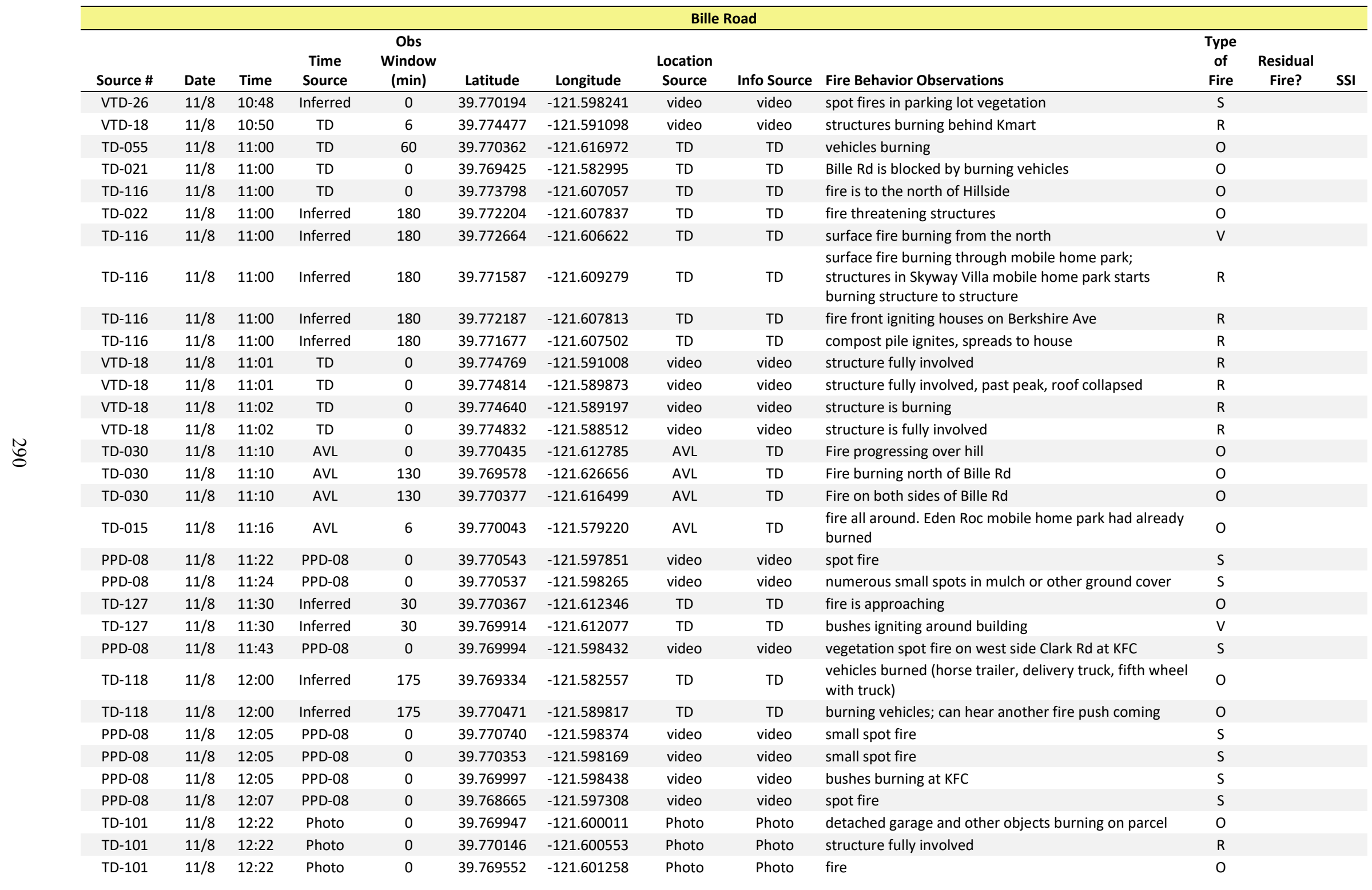




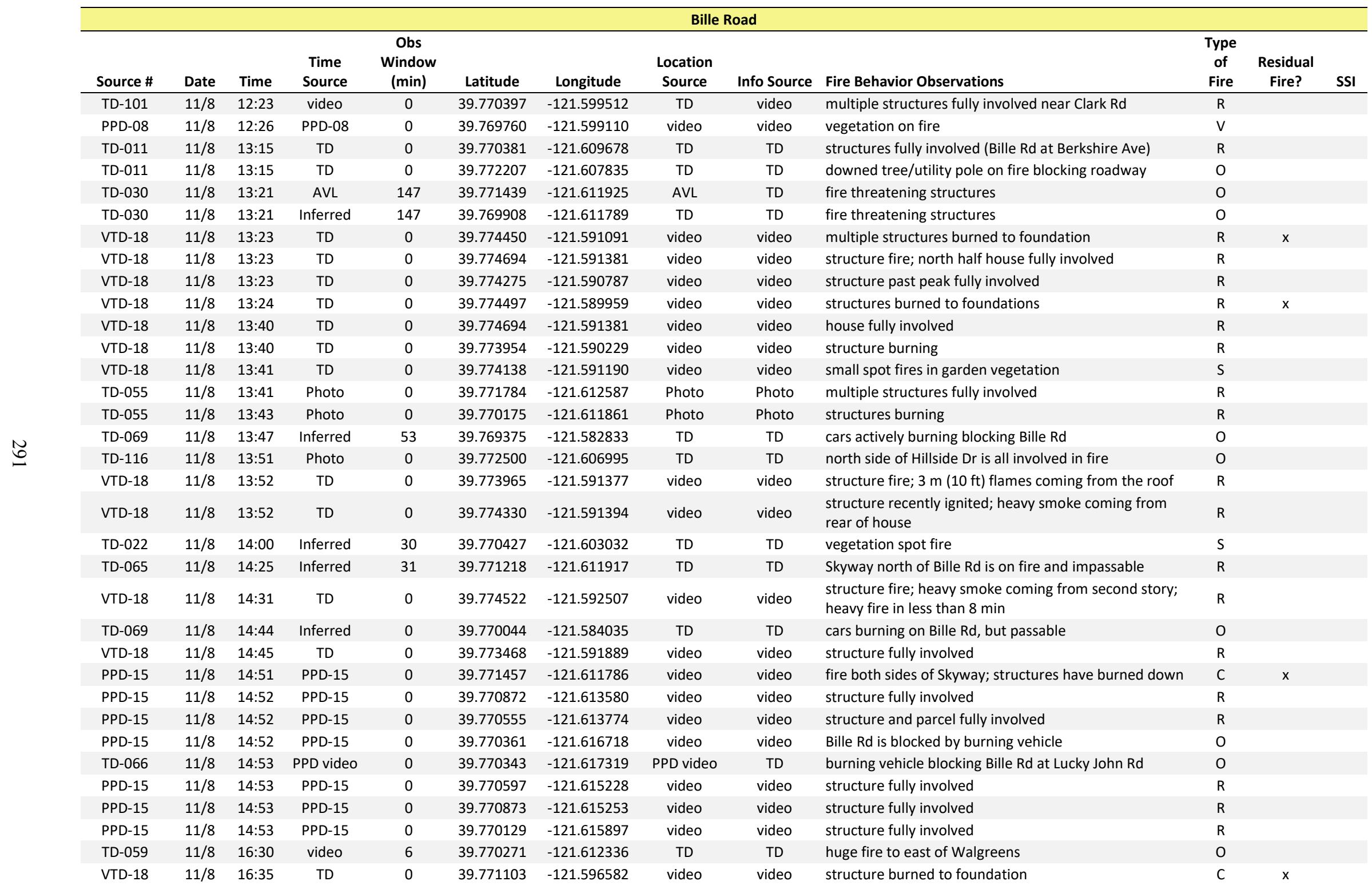




\begin{tabular}{|c|c|c|c|c|c|c|c|c|c|c|c|c|}
\hline \multicolumn{13}{|c|}{ Bille Road } \\
\hline Source \# & Date & Time & $\begin{array}{l}\text { Time } \\
\text { Source }\end{array}$ & $\begin{array}{c}\text { Obs } \\
\text { Window } \\
\text { (min) }\end{array}$ & Latitude & Longitude & $\begin{array}{l}\text { Location } \\
\text { Source }\end{array}$ & Info Source & Fire Behavior Observations & $\begin{array}{c}\text { Type } \\
\text { of } \\
\text { Fire }\end{array}$ & $\begin{array}{l}\text { Residual } \\
\text { Fire? }\end{array}$ & SSI \\
\hline VTD-18 & $11 / 8$ & $16: 36$ & TD & 0 & 39.770643 & -121.597097 & video & video & structure past-peak fully involved & $\mathrm{C}$ & & \\
\hline VTD-18 & $11 / 8$ & $16: 36$ & TD & 0 & 39.770225 & -121.597559 & video & video & structure burned to foundation & C & $\mathrm{x}$ & \\
\hline VTD-18 & $11 / 8$ & $16: 36$ & TD & 0 & 39.769903 & -121.597894 & video & video & $\begin{array}{l}\text { structure unburned, small vegetation spot fires against } \\
\text { building }\end{array}$ & $S$ & & \\
\hline TD-014 & $11 / 8$ & $16: 47$ & AVL & 6 & 39.769445 & -121.635538 & AVL & TD & $\begin{array}{l}\text { Fire well established in canyon, } 90 \mathrm{~m}(300 \mathrm{ft}) \text { flame } \\
\text { lengths }\end{array}$ & $\mathrm{v}$ & & \\
\hline TD-014 & $11 / 8$ & $16: 47$ & AVL & 6 & 39.767688 & -121.630753 & TD & TD & structures burning & $\mathrm{R}$ & & \\
\hline TD-127 & $11 / 8$ & $17: 14$ & Photo & 0 & 39.770370 & -121.616153 & Photo & Photo & $\begin{array}{l}\text { most structures around are fully involved, some burned } \\
\text { down, two standing; light breeze blowing embers }\end{array}$ & $\mathrm{R}$ & & \\
\hline TD-127 & $11 / 8$ & $17: 26$ & Radio Log & 0 & 39.770442 & -121.612302 & Radio Log & Radio Log & commercial structures all along Skyway are threatened & 0 & & \\
\hline TD-044 & $11 / 8$ & $17: 30$ & TD & 30 & 39.768639 & -121.634940 & TD & TD & everything on fire, trees crowning & $\mathrm{R}$ & & \\
\hline TD-111 & $11 / 8$ & $18: 00$ & TD & 60 & 39.768675 & -121.631355 & TD & TD & ember blizzard, wind blow torching flames & 0 & & \\
\hline TD-111 & $11 / 8$ & 18:00 & TD & 60 & 39.768736 & -121.636156 & TD & TD & Cliff Dr homes are all burned down & $\mathrm{R}$ & $\mathrm{x}$ & \\
\hline TD-109 & $11 / 8$ & $18: 26$ & AVL & 1 & 39.769673 & -121.583495 & AVL & TD & cars still burning on Bille Rd & 0 & & \\
\hline TD-205 & $11 / 8$ & $18: 58$ & AVL & 17 & 39.770053 & -121.614600 & AVL & TD & Fire in eaves of structure & $\mathrm{R}$ & & \\
\hline TD-015 & $11 / 8$ & $22: 40$ & AVL & 24 & 39.769117 & -121.627217 & AVL & TD & area already burned & 0 & $x$ & \\
\hline TD-008 & $11 / 8$ & $23: 27$ & AVL & 0 & 39.770467 & -121.590317 & AVL & Radio Log & fire threatening structures & 0 & & \\
\hline
\end{tabular}




\begin{tabular}{|c|c|c|c|c|c|c|c|c|c|c|c|c|}
\hline \multicolumn{13}{|c|}{ Elliott Road and Nunneley Road } \\
\hline Source \# & Date & Time & $\begin{array}{l}\text { Time } \\
\text { Source }\end{array}$ & $\begin{array}{c}\text { Obs } \\
\text { Window } \\
\text { (min) }\end{array}$ & Latitude & Longitude & $\begin{array}{l}\text { Location } \\
\text { Source }\end{array}$ & Info Source & Fire Behavior Observations & $\begin{array}{c}\text { Type } \\
\text { of } \\
\text { Fire }\end{array}$ & $\begin{array}{l}\text { Residual } \\
\text { Fire? }\end{array}$ & SSI \\
\hline $\begin{array}{l}911-1030- \\
10\end{array}$ & $11 / 8$ & 07:57 & $\begin{array}{l}911-1030- \\
10\end{array}$ & 0 & 39.756975 & -121.601220 & $\begin{array}{l}911-1030- \\
10\end{array}$ & $\begin{array}{l}911-1030- \\
10\end{array}$ & spot fire & $\mathrm{s}$ & & \\
\hline TD-074 & $11 / 8$ & 08:00 & TD & 0 & 39.759491 & -121.606635 & TD & TD & embers as large as a matchbox landing & 0 & & \\
\hline TD-069 & $11 / 8$ & 08:00 & TD & 15 & 39.762326 & -121.588917 & TD & TD & structure burning on east side Sawmill Rd & $\mathrm{R}$ & & \\
\hline TD-035 & $11 / 8$ & 08:02 & PPD video & 0 & 39.755929 & -121.604485 & TD & TD & spot fire 1100 block Nunneley Rd & $\mathrm{s}$ & & \\
\hline TD-067 & $11 / 8$ & 08:02 & PPD video & 0 & 39.756710 & -121.600997 & TD & $\begin{array}{l}\text { TD, PPD } \\
\text { video }\end{array}$ & spot fire & $\mathrm{s}$ & & \\
\hline PPD-01 & $11 / 8$ & 08:02 & PPD-01 & 1 & 39.756866 & -121.601153 & Radio & Radio & spot fire on Nunneley Rd near Jubilee Ln & $\mathrm{s}$ & & \\
\hline 911-1041-1 & $11 / 8$ & 08:03 & 911-1041-1 & 0 & 39.757744 & -121.598390 & Inferred & 911-1041-1 & spot fire & $\mathrm{s}$ & & \\
\hline TD-067 & $11 / 8$ & $08: 10$ & TD & 0 & 39.756710 & -121.600997 & TD & TD & $\begin{array}{l}\text { spot fire, large tree burning, flames }>1.8 \mathrm{~m}(6 \mathrm{ft}) \text {; pine } \\
\text { needles built up around vacant house }\end{array}$ & $\mathrm{s}$ & & \\
\hline 911-1051-1 & $11 / 8$ & $08: 14$ & 911-1051-1 & 0 & 39.757744 & -121.598390 & Inferred & 911-1051-1 & spot fire off Ingalls between Elliott Rd and Nunneley Rd & $\mathrm{S}$ & & \\
\hline TD-065 & $11 / 8$ & 08:15 & Inferred & 0 & 39.759502 & -121.606653 & TD & TD & ember showers & 0 & & \\
\hline $911-127-1$ & $11 / 8$ & $08: 23$ & $911-127-1$ & 0 & 39.756904 & -121.579291 & $911-127-1$ & $911-127-1$ & flames at the end of the road & s & & \\
\hline $911-148-1$ & $11 / 8$ & $08: 33$ & $911-148-1$ & 0 & 39.756937 & -121.585673 & $911-148-1$ & $911-148-1$ & fire & $\mathrm{S}$ & & \\
\hline 911-156-1 & $11 / 8$ & $08: 37$ & $911-156-1$ & 0 & 39.761662 & -121.585077 & $911-156-1$ & $911-156-1$ & spot fire & $\mathrm{S}$ & & \\
\hline TD-013 & $11 / 8$ & 08:40 & TD & 0 & 39.762184 & -121.588998 & TD & TD & $\begin{array}{l}\text { fire burning on Sawmill Rd; civilian report of "trees on } \\
\text { fire" }\end{array}$ & V & & \\
\hline TD-015 & $11 / 8$ & $08: 44$ & AVL & 0 & 39.760739 & -121.586951 & AVL & TD & $\begin{array}{l}0.2 \text { ha to } 0.4 \text { ha }(0.5 \text { ac to } 1.0 \mathrm{ac}) \text { spot fire in grass field } \\
\text { behind houses }\end{array}$ & $S$ & & \\
\hline $911-186-1$ & $11 / 8$ & $08: 49$ & $911-186-1$ & 0 & 39.759977 & -121.581872 & $911-186-1$ & $911-186-1$ & fire & $\mathrm{s}$ & & \\
\hline PPD-04 & $11 / 8$ & $08: 55$ & PPD-04 & 0 & 39.755913 & -121.589026 & Radio & Radio & spot fire & $\mathrm{s}$ & & \\
\hline 911-195-1 & $11 / 8$ & 08:56 & $911-195-1$ & 0 & 39.755966 & -121.588986 & $911-195-1$ & $911-195-1$ & spot fire & $\mathrm{s}$ & & \\
\hline $911-230-2$ & $11 / 8$ & 09:16 & $911-230-2$ & 0 & 39.755942 & -121.599648 & $911-230-2$ & $911-230-2$ & fire in the yard & $\mathrm{S}$ & & \\
\hline $911-230-4$ & $11 / 8$ & 09:16 & $911-230-4$ & 0 & 39.761000 & -121.588637 & $911-230-4$ & $911-230-4$ & residential fire alarm & $\mathrm{R}$ & & \\
\hline TD-070 & $11 / 8$ & 10:08 & PPD video & 0 & 39.756933 & -121.589059 & TD & TD & $\begin{array}{l}\text { Sawmill Rd impassable north of Nunneley Rd; fire } \\
\text { crossing roadway }\end{array}$ & 0 & & \\
\hline TD-070 & $11 / 8$ & 10:08 & PPD video & 0 & 39.757517 & -121.588760 & TD & TD & structures on east side Sawmill Rd burning & $\mathrm{R}$ & & \\
\hline PPD-05 & $11 / 8$ & 10:08 & PPD-05 & 0 & 39.755929 & -121.589011 & Radio & Radio & $\begin{array}{l}\text { active fire Sawmill Rd and Nunneley Rd on the NE } \\
\text { corner }\end{array}$ & 0 & & \\
\hline PPD-02 & $11 / 8$ & $10: 22$ & PPD-02 & 0 & 39.757446 & -121.606495 & Radio & Radio & north of Nunneley Rd east of Clark Rd is catching on fire & 0 & & \\
\hline TD-112 & $11 / 8$ & $10: 25$ & Inferred & 54 & 39.757000 & -121.594773 & TD & TD & spot fire & S & & \\
\hline TD-112 & $11 / 8$ & $10: 25$ & Inferred & 54 & 39.755915 & -121.593703 & TD & TD & encounter spot fire at Middle Libby Rd and Nunneley Rd & S & & \\
\hline TD-123 & $11 / 8$ & 10:44 & AVL & 0 & 39.757417 & -121.589000 & AVL & TD & fire on Sawmill Rd at Sir Ct & 0 & & \\
\hline TD-068 & $11 / 8$ & 10:50 & PPD video & 0 & 39.761569 & -121.603057 & TD & TD & fire behind (east) of Safeway & 0 & & \\
\hline PPD-02 & $11 / 8$ & 10:50 & PPD-02 & 0 & 39.760515 & -121.603216 & Radio & Radio & fire is right behind Safeway & 0 & & \\
\hline VTD-26 & $11 / 8$ & 10:55 & Inferred & 0 & 39.762665 & -121.605019 & video & video & spot fire & S & & \\
\hline
\end{tabular}




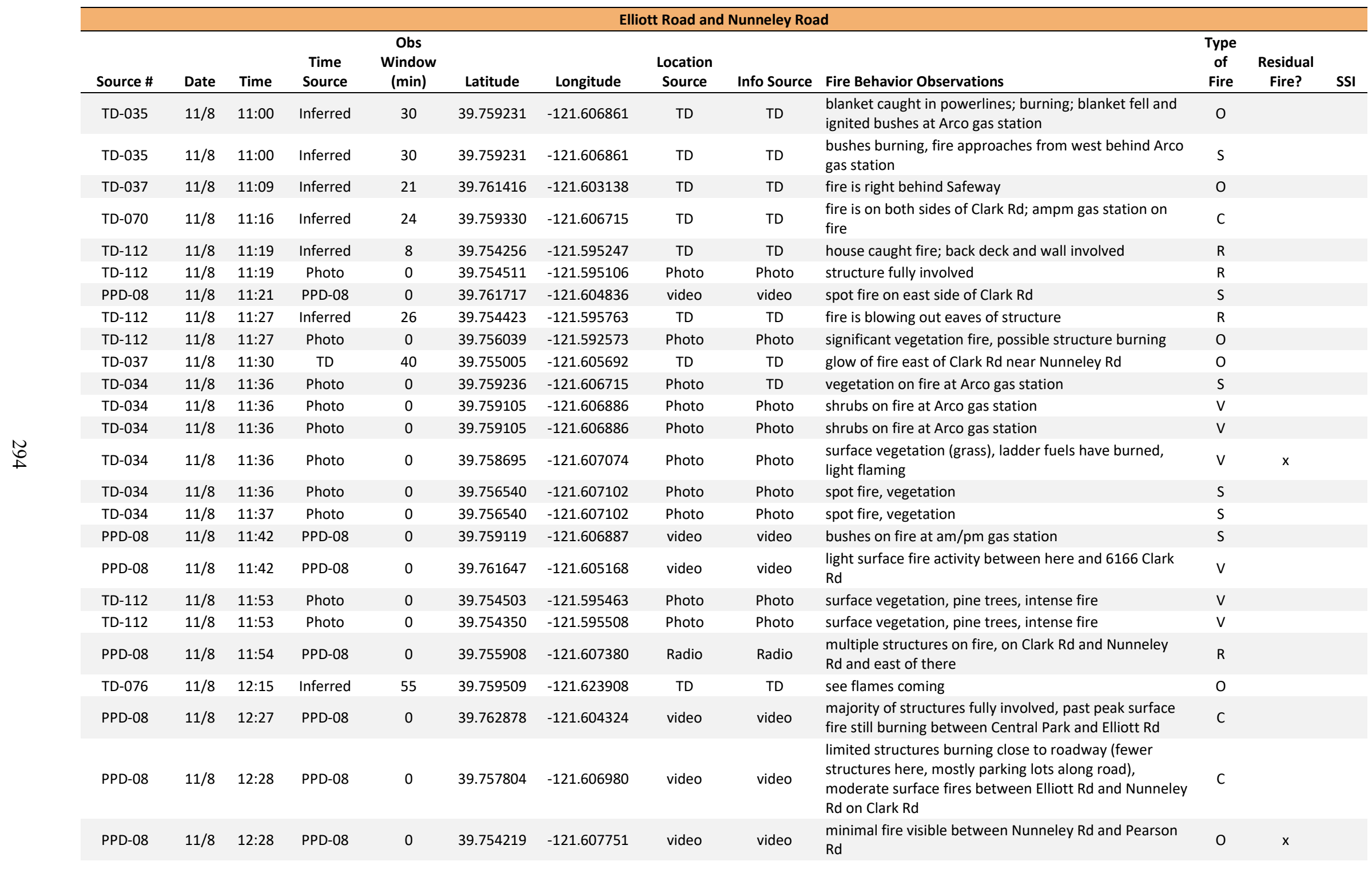




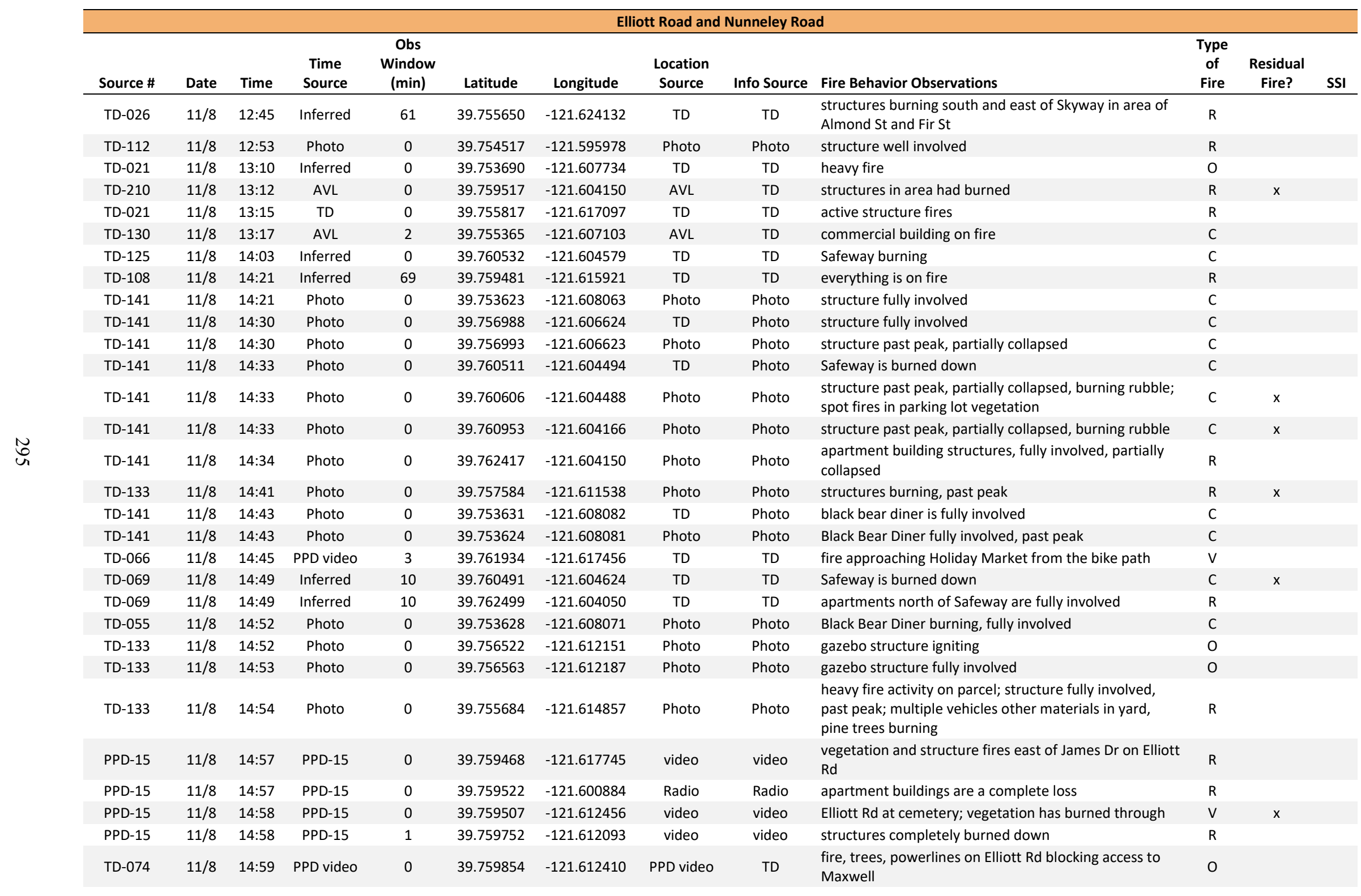




\begin{tabular}{|c|c|c|c|c|c|c|c|c|c|c|c|c|}
\hline \multicolumn{13}{|c|}{ Elliott Road and Nunneley Road } \\
\hline Source \# & Date & Time & $\begin{array}{l}\text { Time } \\
\text { Source }\end{array}$ & $\begin{array}{c}\text { Obs } \\
\text { Window } \\
\text { (min) }\end{array}$ & Latitude & Longitude & $\begin{array}{l}\text { Location } \\
\text { Source }\end{array}$ & Info Source & Fire Behavior Observations & $\begin{array}{l}\text { Type } \\
\text { of } \\
\text { Fire }\end{array}$ & $\begin{array}{l}\text { Residual } \\
\text { Fire? }\end{array}$ & SSI \\
\hline TD-069 & $11 / 8$ & $14: 59$ & Inferred & 9 & 39.756274 & -121.608330 & TD & TD & commercial structure burning & $\mathrm{C}$ & & \\
\hline TD-069 & $11 / 8$ & $14: 59$ & Inferred & 9 & 39.756825 & -121.608287 & TD & TD & mulch fire up against structure & $S$ & & \\
\hline TD-066 & $11 / 8$ & 15:01 & PPD video & 1 & 39.759464 & -121.617161 & PPD video & TD & intense fire on Elliott Rd at James Dr and Camino Ln & $\mathrm{R}$ & & \\
\hline PPD-15 & $11 / 8$ & 15:02 & PPD-15 & 0 & 39.755688 & -121.624108 & video & video & $\begin{array}{l}\text { most structures fully involved on Almond St and Fir St } \\
\text { east of Almond St ( } 5800 \text { Almond St to Cedar St and } \\
\text { Fir St east toward Black Olive Dr) }\end{array}$ & $\mathrm{R}$ & & \\
\hline TD-074 & $11 / 8$ & $15: 03$ & PPD video & 0 & 39.759934 & -121.611901 & PPD video & TD & all structures on east side of Maxwell Dr on fire & $\mathrm{R}$ & & \\
\hline TD-132 & $11 / 8$ & 15:04 & Photo & 0 & 39.755740 & -121.623420 & Photo & Photo & $\begin{array}{l}\text { significant widespread flames and glow; numerous } \\
\text { structures burning }\end{array}$ & $\mathrm{R}$ & & \\
\hline TD-015 & $11 / 8$ & $15: 14$ & AVL & 0 & 39.761600 & -121.612471 & AVL & TD & Paradise HS; fire threatening school & $\mathrm{V}$ & & \\
\hline TD-132 & $11 / 8$ & $15: 27$ & Inferred & 333 & 39.762794 & -121.613079 & TD & TD & Paradise HS: mobile classrooms are burning & C & & \\
\hline TD-132 & $11 / 8$ & 15:27 & Inferred & 333 & 39.762356 & -121.613341 & TD & TD & fire spreading crown to crown and along surface fuels & V & & \\
\hline TD-132 & $11 / 8$ & $15: 27$ & Inferred & 333 & 39.762288 & -121.612969 & TD & TD & Paradise HS: roof fire on auto shop & C & & \\
\hline TD-132 & $11 / 8$ & $15: 27$ & Inferred & 333 & 39.761014 & -121.613212 & TD & TD & Paradise HS: put out fire on roof of main building & C & & \\
\hline TD-141 & $11 / 8$ & 15:27 & Inferred & 303 & 39.762787 & -121.613067 & TD & TD & Paradise HS: all but one portable classroom is burning & C & & \\
\hline TD-141 & $11 / 8$ & 15:27 & Inferred & 303 & 39.762342 & -121.612973 & TD & TD & Paradise HS: fire on the roof & C & & \\
\hline TD-135 & $11 / 8$ & $15: 30$ & Inferred & 930 & 39.757657 & -121.624599 & TD & TD & $\begin{array}{l}\text { Starbucks; fire } 15 \mathrm{~m} \text { to } 18 \mathrm{~m} \text { ( } 50 \mathrm{ft} \text { to } 60 \mathrm{ft} \text { ) away from } \\
\text { structure, spotting into mulch }\end{array}$ & C & & \\
\hline TD-135 & $11 / 8$ & $15: 30$ & Inferred & 930 & 39.756602 & -121.625067 & TD & TD & $\begin{array}{l}\text { structures burning, flames coming from house vents; } \\
\text { exposure to other buildings }\end{array}$ & $\mathrm{R}$ & & \\
\hline TD-135 & $11 / 8$ & $15: 30$ & Inferred & 930 & 39.757657 & -121.624599 & TD & TD & shed and fence on fire near Starbucks & 0 & & \\
\hline TD-209 & $11 / 8$ & $15: 37$ & Photo & 0 & 39.753610 & -121.608070 & Photo & Photo & Black Bear Diner collapsed, flaming rubble & C & $\mathrm{x}$ & \\
\hline TD-124 & $11 / 8$ & $15: 39$ & $\mathrm{AVL}$ & 67 & 39.759717 & -121.607450 & $\mathrm{AVL}$ & TD & roof of Rite Aid on fire & C & & \\
\hline TD-132 & $11 / 8$ & $15: 51$ & Photo & 0 & 39.762335 & -121.612969 & TD & TD & Paradise HS: air vent on roof is on fire & C & & \\
\hline TD-133 & $11 / 8$ & $15: 51$ & Photo & 0 & 39.762512 & -121.611997 & Photo & Photo & structure burned to foundation, flaming rubble & $\mathrm{R}$ & $\mathrm{x}$ & \\
\hline TD-133 & $11 / 8$ & 15:51 & Photo & 0 & 39.762723 & -121.612058 & Photo & Photo & $\begin{array}{l}\text { multiple structures burned to foundation; east side } \\
\text { Maxwell Dr }\end{array}$ & $\mathrm{R}$ & $\mathrm{x}$ & \\
\hline TD-014 & $11 / 8$ & $15: 52$ & AVL & 0 & 39.758205 & -121.624762 & AVL & TD & fire everywhere, downtown beginning to burn & C & & \\
\hline TD-122 & $11 / 8$ & $15: 53$ & AVL & 53 & 39.759783 & -121.606883 & AVL & TD & fire on roof of Rite Aid & C & & \\
\hline TD-142 & $11 / 8$ & 16:00 & TD & 0 & 39.758900 & -121.624674 & TD & TD & tree is burning & v & & \\
\hline TD-141 & $11 / 8$ & $16: 02$ & Photo & 0 & 39.762976 & -121.613469 & Photo & Photo & $\begin{array}{l}\text { wooded areas are burning around field; structures are } \\
\text { burned to ground }\end{array}$ & $\mathrm{R}$ & & \\
\hline TD-141 & $11 / 8$ & 16:03 & Photo & 0 & 39.762275 & -121.613743 & Photo & Photo & spot fires in pine litter & $\mathrm{s}$ & & \\
\hline TD-141 & $11 / 8$ & 16:04 & Photo & 0 & 39.762758 & -121.613054 & Photo & Photo & $\begin{array}{l}\text { Paradise High School portable classrooms (6) are fully } \\
\text { involved }\end{array}$ & C & & \\
\hline TD-141 & $11 / 8$ & $16: 05$ & Photo & 0 & 39.762758 & -121.613054 & Photo & Photo & $\begin{array}{l}\text { Paradise High School portable classrooms (6) are fully } \\
\text { involved }\end{array}$ & C & & \\
\hline
\end{tabular}




\begin{tabular}{|c|c|c|c|c|c|c|c|c|c|c|c|c|}
\hline \multicolumn{13}{|c|}{ Elliott Road and Nunneley Road } \\
\hline Source \# & Date & Time & $\begin{array}{l}\text { Time } \\
\text { Source }\end{array}$ & $\begin{array}{l}\text { Obs } \\
\text { Window } \\
\text { (min) }\end{array}$ & Latitude & Longitude & $\begin{array}{l}\text { Location } \\
\text { Source }\end{array}$ & Info Source & Fire Behavior Observations & $\begin{array}{l}\text { Type } \\
\text { of } \\
\text { Fire }\end{array}$ & $\begin{array}{l}\text { Residual } \\
\text { Fire? }\end{array}$ & SSI \\
\hline TD-141 & $11 / 8$ & 16:05 & Photo & 0 & 39.762496 & -121.611981 & Photo & Photo & collapsed structure, burning & $\mathrm{R}$ & & \\
\hline TD-142 & $11 / 8$ & $16: 22$ & video & 0 & 39.756073 & -121.626177 & TD & video & commercial structures burning downtown & C & & \\
\hline TD-142 & $11 / 8$ & $16: 30$ & Inferred & 1020 & 39.758900 & -121.624674 & TD & TD & fire moving toward building from west and north & 0 & & \\
\hline TD-142 & $11 / 8$ & $16: 30$ & Inferred & 1020 & 39.757057 & -121.625073 & TD & TD & fire threatening structures & 0 & & \\
\hline TD-142 & $11 / 8$ & $16: 30$ & Inferred & 1020 & 39.757666 & -121.624595 & TD & TD & fire threatening structures & 0 & & \\
\hline TD-142 & $11 / 8$ & $16: 30$ & Inferred & 1020 & 39.759241 & -121.624497 & TD & TD & pine needles burning in garden bed & v & & \\
\hline TD-142 & $11 / 8$ & $16: 30$ & Inferred & 1020 & 39.759449 & -121.623921 & TD & TD & fire threatening structures & 0 & & \\
\hline TD-141 & $11 / 8$ & $16: 33$ & Photo & 0 & 39.760608 & -121.612078 & Photo & Photo & $\begin{array}{l}\text { structures burned to foundation on Maxwell Dr, } \\
\text { minimal flames }\end{array}$ & $\mathrm{R}$ & $\mathrm{x}$ & \\
\hline TD-141 & $11 / 8$ & $16: 33$ & Photo & 0 & 39.760068 & -121.612153 & Photo & Photo & $\begin{array}{l}\text { structures burned to foundation on Maxwell Dr, } \\
\text { minimal flames }\end{array}$ & $\mathrm{R}$ & $x$ & \\
\hline TD-141 & $11 / 8$ & $16: 33$ & Photo & 0 & 39.760382 & -121.611976 & Photo & Photo & $\begin{array}{l}\text { structures on east side Maxwell, Pleasant to Elliott Rd, } \\
\text { are burned to foundation, minimal active flames in } \\
\text { rubble }\end{array}$ & $\mathrm{R}$ & $\mathrm{x}$ & \\
\hline VTD-18 & $11 / 8$ & $16: 36$ & TD & 0 & 39.755914 & -121.607415 & video & video & $\begin{array}{l}\text { structures on east side Clark Rd (west side unknown } \\
\text { can't see in video) south of Elk Ln through town } \\
\text { basically all burned to foundations; very little active } \\
\text { burning }\end{array}$ & C & $\mathrm{x}$ & \\
\hline VTD-18 & $11 / 8$ & 16:37 & TD & 0 & 39.762073 & -121.604368 & video & video & a few structures collapsed and still burning & C & $x$ & \\
\hline VTD-18 & $11 / 8$ & 16:37 & TD & 0 & 39.760879 & -121.604259 & video & video & Safeway et al.; post-peak burning & C & $\mathrm{x}$ & \\
\hline TD-142 & $11 / 8$ & $16: 48$ & Photo & 0 & 39.755732 & -121.626176 & Photo & Photo & commercial structures burning & C & & \\
\hline TD-141 & $11 / 8$ & $16: 51$ & Photo & 0 & 39.760266 & -121.612498 & Photo & Photo & $\begin{array}{l}\text { all structures east side of Maxwell Dr between Elliott Rd } \\
\text { and Pleasant Ln are burned to foundation, minimal } \\
\text { flaming rubble }\end{array}$ & $\mathrm{R}$ & $\mathrm{x}$ & \\
\hline TD-201 & $11 / 8$ & $16: 54$ & Photo & 0 & 39.760367 & -121.605250 & Photo & Photo & Safeway is burned down & C & $\mathrm{x}$ & \\
\hline TD-201 & $11 / 8$ & $16: 54$ & Photo & 0 & 39.760190 & -121.605599 & Photo & Photo & $\begin{array}{l}\text { commercial structure collapsed, flaming rubble and } \\
\text { structure }\end{array}$ & C & $\mathrm{x}$ & \\
\hline TD-030 & $11 / 8$ & 17:07 & AVL & 0 & 39.760827 & -121.604738 & AVL & TD & Safeway burned & C & & \\
\hline TD-142 & $11 / 8$ & $17: 21$ & Photo & 0 & 39.759080 & -121.624529 & Photo & Photo & Building fully involved & C & & \\
\hline TD-142 & $11 / 8$ & $17: 25$ & Photo & 0 & 39.759087 & -121.624545 & Photo & Photo & structure fully involved & C & & \\
\hline TD-142 & $11 / 8$ & $17: 26$ & Photo & 0 & 39.758735 & -121.624156 & Photo & Photo & $\begin{array}{l}\text { fire coming from roof of structure; brands blowing } \\
\text { down street }\end{array}$ & C & & \\
\hline TD-142 & $11 / 8$ & $17: 26$ & Photo & 0 & 39.759188 & -121.623589 & Photo & Photo & Valero gas station fully involved & C & & \\
\hline TD-141 & $11 / 8$ & $17: 28$ & Photo & 0 & 39.763318 & -121.612705 & Photo & Photo & $\begin{array}{l}\text { structure burned to foundation, still flaming; small } \\
\text { spots around; power pole burning }\end{array}$ & $\mathrm{R}$ & $\mathrm{x}$ & \\
\hline TD-141 & $11 / 8$ & $17: 28$ & Photo & 0 & 39.762870 & -121.613055 & Photo & Photo & portable classrooms are burned down, flaming rubble & C & $\mathrm{x}$ & \\
\hline TD-141 & $11 / 8$ & $17: 28$ & Photo & 0 & 39.763862 & -121.612147 & Photo & Photo & structure burning & $\mathrm{R}$ & & \\
\hline
\end{tabular}




\begin{tabular}{|c|c|c|c|c|c|c|c|c|c|c|c|c|}
\hline \multicolumn{13}{|c|}{ Elliott Road and Nunneley Road } \\
\hline Source \# & Date & Time & $\begin{array}{c}\text { Time } \\
\text { Source }\end{array}$ & $\begin{array}{c}\text { Obs } \\
\text { Window } \\
\text { (min) }\end{array}$ & Latitude & Longitude & $\begin{array}{l}\text { Location } \\
\text { Source }\end{array}$ & Info Source & Fire Behavior Observations & $\begin{array}{c}\text { Type } \\
\text { of } \\
\text { Fire } \\
\end{array}$ & $\begin{array}{l}\text { Residual } \\
\text { Fire? }\end{array}$ & SSI \\
\hline TD-142 & $11 / 8$ & $17: 34$ & Photo & 0 & 39.758725 & -121.624129 & Photo & Photo & $\begin{array}{l}\text { Building fully involved; parked vehicle igniting from } \\
\text { exposure; brands blow down street to the south }\end{array}$ & c & & \\
\hline TD-209 & $11 / 8$ & $17: 39$ & AVL & 0 & 39.760711 & -121.604421 & AVL & TD & Safeway is already burned & C & $\mathrm{x}$ & \\
\hline TD-015 & $11 / 8$ & $17: 50$ & AVL & 0 & 39.760851 & -121.605862 & $A V L$ & TD & Safeway is all burned down & C & $x$ & \\
\hline TD-014 & $11 / 8$ & $17: 52$ & Radio Log & 0 & 39.757515 & -121.625300 & Radio Log & Radio Log & heavy fire in downtown area & C & & \\
\hline TD-127 & $11 / 8$ & $17: 55$ & AVL TD-015 & 4 & 39.761883 & -121.612383 & AVL TD-015 & TD & fire at Paradise HS & C & & \\
\hline TD-142 & $11 / 8$ & $17: 56$ & Photo & 0 & 39.757734 & -121.625757 & Photo & Photo & flames against building & 0 & & \\
\hline TD-201 & $11 / 8$ & $18: 15$ & Photo & 0 & 39.759188 & -121.623566 & Photo & Photo & structure burned to foundation, flaming rubble & C & $\mathrm{x}$ & \\
\hline TD-201 & $11 / 8$ & $18: 15$ & Photo & 0 & 39.758726 & -121.624034 & Photo & Photo & structures fully involved & C & & \\
\hline TD-124 & $11 / 8$ & $18: 42$ & AVL & 57 & 39.760281 & -121.621220 & AVL & TD & $\begin{array}{l}\text { Achieve Charter School behind St Thomas More Church } \\
\text { is on fire }\end{array}$ & C & & \\
\hline TD-030 & $11 / 8$ & 20:01 & AVL & 13 & 39.756650 & -121.625883 & AVL & TD & fire threatening structures & 0 & & \\
\hline TD-124 & $11 / 8$ & 20:03 & AVL & 0 & 39.760281 & -121.621220 & AVL & TD & Achieve Charter School is burned down & C & & \\
\hline TD-141 & $11 / 8$ & $20: 30$ & TD & 0 & 39.759965 & -121.613029 & TD & TD & $\begin{array}{l}\text { First Assembly of God church ignites; outbuilding } \\
\text { catches first }\end{array}$ & C & & \\
\hline TD-132 & $11 / 8$ & 21:00 & Inferred & 0 & 39.760017 & -121.613065 & TD & TD & light smoke from eaves of First Assembly of God church & C & & \\
\hline TD-141 & $11 / 8$ & 21:09 & Photo & 0 & 39.759965 & -121.613029 & TD & Photo & First Assembly of God building well involved & C & & \\
\hline TD-141 & $11 / 8$ & 21:09 & Photo & 0 & 39.760018 & -121.613041 & Photo & Photo & $\begin{array}{l}\text { First Assembly of God Church, structure fully involved, } \\
\text { collapsed }\end{array}$ & C & & \\
\hline TD-132 & $11 / 8$ & $22: 30$ & TD & 0 & 39.759267 & -121.608170 & TD & TD & spot fires and burning fences & 0 & & \\
\hline TD-132 & $11 / 8$ & $22: 30$ & TD & 0 & 39.759261 & -121.608486 & TD & TD & spot fires and burning fences & 0 & & \\
\hline TD-014 & $11 / 9$ & 01:42 & Radio Log & 0 & 39.759915 & -121.587527 & Radio Log & Radio Log & structure just igniting & $\mathrm{R}$ & & \\
\hline TD-030 & $11 / 9$ & 09:54 & $\mathrm{AVL}$ & 59 & 39.758167 & -121.608467 & AVL & TD & Shadowbrook Apartments complex on fire & $\mathrm{R}$ & & \\
\hline TD-111 & $11 / 9$ & $09: 54$ & AVL TD-030 & 59 & 39.758166 & -121.608866 & AVL TD-030 & TD & Shadowbrook Apartments on fire & $\mathrm{R}$ & & \\
\hline
\end{tabular}




\begin{tabular}{|c|c|c|c|c|c|c|c|c|c|c|c|c|}
\hline \multicolumn{13}{|c|}{ Pearson Road and Buschmann Road } \\
\hline Source \# & Date & Time & $\begin{array}{l}\text { Time } \\
\text { Source }\end{array}$ & $\begin{array}{c}\text { Obs } \\
\text { Window } \\
\text { (min) }\end{array}$ & Latitude & Longitude & $\begin{array}{l}\text { Location } \\
\text { Source }\end{array}$ & Info Source & Fire Behavior Observations & $\begin{array}{c}\text { Type } \\
\text { of } \\
\text { Fire }\end{array}$ & $\begin{array}{l}\text { Residual } \\
\text { Fire? }\end{array}$ & SSI \\
\hline TD-054 & $11 / 8$ & 08:15 & Inferred & 15 & 39.751620 & -121.611114 & TD & TD & $\begin{array}{l}\text { report of flames visible in the area of Paradise } \\
\text { Elementary School }\end{array}$ & 0 & & \\
\hline TD-100 & $11 / 8$ & 08:30 & TD & 0 & 39.735180 & -121.604409 & TD & TD & $\begin{array}{l}\text { spot fire too big to engage, est. about } 12 \mathrm{ha}(30 \mathrm{ac}) \text {; } \\
\text { established in drainage }\end{array}$ & S & & \\
\hline TD-005 & $11 / 8$ & $08: 37$ & AVL & 0 & 39.748583 & -121.572400 & AVL & TD & ember storm & 0 & & \\
\hline TD-123 & $11 / 8$ & $08: 48$ & AVL & 0 & 39.747928 & -121.572361 & AVL & TD & can hear propane tanks exploding & 0 & & \\
\hline TD-034 & $11 / 8$ & 08:56 & video & 0 & 39.750277 & -121.577827 & video & video & can hear ammunition and propane tank explosions & 0 & & \\
\hline TD-036 & $11 / 8$ & 08:56 & Inferred & 0 & 39.750614 & -121.577492 & TD & TD & can hear propane tanks exploding & 0 & & \\
\hline TD-129 & $11 / 8$ & 09:00 & AVL & 8 & 39.746117 & -121.572233 & AVL & TD & $\begin{array}{l}\text { fire crossing Pentz Rd from east to west between } \\
\text { Stearns Rd and Pearson Rd }\end{array}$ & 0 & & \\
\hline TD-037 & $11 / 8$ & 09:00 & Inferred & 20 & 39.748922 & -121.576071 & TD & TD & spot fire just becoming established in drainage & $\mathrm{s}$ & & \\
\hline TD-037 & $11 / 8$ & 09:00 & Inferred & 20 & 39.748218 & -121.578745 & TD & TD & can see spot fire on south side Pearson $R d$ at Stearns $R d$ & $\mathrm{~S}$ & & \\
\hline TD-100 & $11 / 8$ & 09:00 & TD & 0 & 39.749657 & -121.576802 & TD & TD & spot fires down in Pearson Rd drainage & $\mathrm{S}$ & & \\
\hline TD-100 & $11 / 8$ & 09:00 & Inferred & 30 & 39.732782 & -121.606831 & TD & TD & growing spot fire, well established in canyon & $S$ & & \\
\hline TD-068 & $11 / 8$ & 09:15 & Inferred & 15 & 39.750791 & -121.576813 & TD & TD & $\begin{array}{l}6 \mathrm{~m} \text { to } 9 \mathrm{~m}(20 \mathrm{ft} \text { to } 30 \mathrm{ft}) \text { flames in Pearson } \mathrm{Rd} \\
\text { drainage }\end{array}$ & V & & \\
\hline TD-087 & $11 / 8$ & 09:20 & AVL & 9 & 39.748617 & -121.585400 & AVL & TD & $\begin{array}{l}\text { spot fire, } 6 \mathrm{~m} \times 6 \mathrm{~m}(20 \mathrm{ft} \times 20 \mathrm{ft}) \text {, in pine needles and } \\
\text { litter; in a draw with green ivy }\end{array}$ & $\mathrm{S}$ & & \\
\hline TD-077 & $11 / 8$ & 09:20 & Inferred & 0 & 39.733280 & -121.604288 & TD & TD & see flames on ridge to east of Clark Rd & $\mathrm{v}$ & & \\
\hline TD-086 & $11 / 8$ & $09: 23$ & AVL & 0 & 39.746182 & -121.572306 & AVL & TD & wall of flames & 0 & & \\
\hline TD-037 & $11 / 8$ & 09:26 & Radio Log & 0 & 39.750215 & -121.576830 & Radio Log & Radio Log & $\begin{array}{l}\text { fire established on Pentz Rd at the curves down in the } \\
\text { drainage }\end{array}$ & $\mathrm{v}$ & & \\
\hline TD-037 & $11 / 8$ & 09:30 & Inferred & 0 & 39.748658 & -121.585273 & TD & TD & well-involved spot fire & $\mathrm{s}$ & & \\
\hline TD-087 & $11 / 8$ & 09:32 & AVL & 0 & 39.748633 & -121.583300 & AVL & TD & spot fires & $\mathrm{s}$ & & \\
\hline TD-111 & $11 / 8$ & 09:36 & Inferred & 14 & 39.751269 & -121.585639 & TD & TD & several homes burning along Henson Rd & $\mathrm{R}$ & & \\
\hline VTD-23 & $11 / 8$ & 09:37 & Inferred & 0 & 39.749160 & -121.572480 & video & video & southern edge of fire & 0 & & \\
\hline TD-122 & $11 / 8$ & 09:38 & AVL & 0 & 39.747796 & -121.572477 & AVL & TD & fire has crossed Pentz Rd at Pearson Rd & 0 & & \\
\hline VTD-21 & $11 / 8$ & 09:38 & Inferred & 15 & 39.747756 & -121.572415 & video & video & intersection of Pentz Rd and Pearson Rd is fully involved & $\mathrm{R}$ & & \\
\hline VTD-23 & $11 / 8$ & 09:38 & Inferred & 0 & 39.748730 & -121.574785 & video & video & large active spot, estimated 0.1 ha $(0.25 \mathrm{ac})$ & s & & \\
\hline VTD-23 & $11 / 8$ & 09:38 & Inferred & 0 & 39.750825 & -121.576730 & video & video & $\begin{array}{l}\text { moderate to heavy surface fire, single tree torching, } \\
\text { heavy ember shower through the curve }\end{array}$ & v & & \\
\hline TD-037 & $11 / 8$ & 09:38 & Photo & 0 & 39.748730 & -121.579461 & Photo & Photo & spot fire in vegetation & $\mathrm{s}$ & & \\
\hline VTD-24 & $11 / 8$ & $09: 40$ & AVL TD-122 & 0 & 39.750715 & -121.576335 & video & video & heavy fire in Pearson Rd drainage & $\mathrm{V}$ & & \\
\hline VTD-24 & $11 / 8$ & 09:40 & AVL TD-122 & 0 & 39.750233 & -121.577845 & video & video & heavy fire both sides of roadway & v & & \\
\hline TD-122 & $11 / 8$ & 09:41 & AVL & 19 & 39.749679 & -121.578103 & AVL & TD & $\begin{array}{l}\text { fire had cleaned ground fuels; fire overtakes engine; } \\
\text { engine is torched, blew diesel tank vents }\end{array}$ & $\mathrm{v}$ & & \\
\hline
\end{tabular}




\begin{tabular}{|c|c|c|c|c|c|c|c|c|c|c|c|c|}
\hline & & & & & & Pear & on Road and & Buschmann R & oad & & & \\
\hline Source \# & Date & Time & $\begin{array}{l}\text { Time } \\
\text { Source }\end{array}$ & $\begin{array}{c}\text { Obs } \\
\text { Window } \\
\text { (min) }\end{array}$ & Latitude & Longitude & $\begin{array}{l}\text { Location } \\
\text { Source }\end{array}$ & Info Source & Fire Behavior Observations & $\begin{array}{l}\text { Type } \\
\text { of } \\
\text { Fire }\end{array}$ & $\begin{array}{l}\text { Residual } \\
\text { Fire? }\end{array}$ & SSI \\
\hline TD-122 & $11 / 8$ & 09:41 & AVL & 19 & 39.749679 & -121.578103 & AVL & TD & $\begin{array}{l}\text { debris in back of pickup truck catches fire; ember } \\
\text { shower across window }\end{array}$ & 0 & & \\
\hline TD-122 & $11 / 8$ & 09:41 & AVL & 19 & 39.749679 & -121.578103 & AVL & TD & cars in front of engine are on fire & 0 & & \\
\hline TD-122 & $11 / 8$ & 09:41 & AVL & 19 & 39.749679 & -121.578103 & AVL & TD & $\begin{array}{l}\text { ground fuels are being totally consumed, torched to } \\
\text { limbs }\end{array}$ & v & & \\
\hline VTD-23 & $11 / 8$ & 09:41 & Inferred & 0 & 39.750100 & -121.577967 & video & video & $\begin{array}{l}\text { heavy surface fire, torching trees, ember showers sound } \\
\text { like pebbles }\end{array}$ & v & & \\
\hline VTD-23 & $11 / 8$ & 09:43 & Inferred & 0 & 39.750100 & -121.577967 & video & video & heavy ember shower pelting vehicle & 0 & & \\
\hline TD-087 & $11 / 8$ & 09:45 & AVL & 19 & 39.748651 & -121.580080 & AVL & TD & $\begin{array}{l}\text { Structures begin igniting from pine needles. Propane } \\
\text { explosions. Vehicles melting. Large spot fire, } 9 \mathrm{~m} \times 12 \mathrm{~m} \\
(30 \mathrm{ft} \times 40 \mathrm{ft}) \text {, in grass. }\end{array}$ & $\mathrm{R}$ & & \\
\hline VTD-16 & $11 / 8$ & 09:51 & video & 0 & 39.749496 & -121.575422 & AVL E2362 & video & heavy vegetation fire, heavy ember shower & V & & \\
\hline TD-129 & $11 / 8$ & 09:53 & Inferred & 0 & 39.750425 & -121.575918 & TD & TD & some cars next to $\mathrm{CHP}$ vehicle are burning & 0 & & \\
\hline TD-129 & $11 / 8$ & 09:53 & video & 0 & 39.748000 & -121.574350 & video & video & everything on fire, extensive ember cast & 0 & & \\
\hline PPD-05 & $11 / 8$ & $09: 53$ & PPD-05 & 0 & 39.749656 & -121.575513 & Radio & Radio & $\begin{array}{l}\text { CHP and SO units have disabled vehicles surrounded by } \\
\text { fire }\end{array}$ & 0 & & \\
\hline TD-129 & $11 / 8$ & $10: 00$ & Inferred & 0 & 39.749487 & -121.578186 & Imagery & TD & yellow VW burning & 0 & & \\
\hline TD-129 & $11 / 8$ & $10: 00$ & Inferred & 0 & 39.748639 & -121.579731 & Imagery & TD & vehicles burning & 0 & & \\
\hline TD-037 & $11 / 8$ & $10: 00$ & Inferred & 15 & 39.748578 & -121.579618 & TD & TD & white car coming from Stearns Rd catches fire & 0 & & \\
\hline TD-070 & $11 / 8$ & $10: 00$ & Inferred & 0 & 39.748619 & -121.588873 & TD & TD & $\begin{array}{l}\text { Pearson Rd blocked by fire across roadway at Sawmill } \\
\text { Rd }\end{array}$ & 0 & & \\
\hline VTD-02 & $11 / 8$ & $10: 00$ & TD & 600 & 39.747395 & -121.615048 & TD & TD & numerous spot fires around property; ember showers & $\mathrm{s}$ & & \\
\hline PPD-05 & $11 / 8$ & $10: 00$ & PPD-05 & 0 & 39.751719 & -121.597887 & Radio & Radio & fire on Angel Dr south of Pearson Rd & $\mathrm{R}$ & & \\
\hline TD-123 & $11 / 8$ & 10:04 & $\mathrm{AVL}$ & 14 & 39.748583 & -121.581067 & AVL & TD & area on fire & 0 & & \\
\hline VTD-23 & $11 / 8$ & 10:05 & Inferred & 8 & 39.748943 & -121.580613 & video & video & structure fully involved & $\mathrm{R}$ & & \\
\hline TD-087 & $11 / 8$ & 10:06 & AVL & 16 & 39.748321 & -121.581274 & AVL & TD & $\begin{array}{l}\text { all structures nearby are burning. Quarter-sized ember } \\
\text { showers. }\end{array}$ & $\mathrm{R}$ & & \\
\hline TD-087 & $11 / 8$ & $10: 18$ & AVL & 0 & 39.748650 & -121.581250 & AVL & TD & fire front is passed & 0 & & \\
\hline TD-064 & $11 / 8$ & $10: 18$ & Inferred & 162 & 39.748575 & -121.621579 & TD & TD & can hear propane tanks exploding & 0 & & \\
\hline TD-020 & $11 / 8$ & $10: 25$ & TD-087 & 10 & 39.748635 & -121.579991 & TD & TD & $\begin{array}{l}\text { fire everywhere; visibility } 30 \mathrm{~m} \text { to } 60 \mathrm{~m} \text { (100 ft to } 200 \mathrm{ft} \text { ) } \\
\text { (Pearson Rd east of Edgewood Ln) }\end{array}$ & 0 & & \\
\hline TD-020 & $11 / 8$ & $10: 25$ & TD-087 & 10 & 39.744923 & -121.593080 & TD & TD & scattered structure fires and woodpiles burning & $\mathrm{R}$ & & \\
\hline TD-087 & $11 / 8$ & $10: 26$ & AVL & 0 & 39.750733 & -121.576833 & AVL & TD & $\begin{array}{l}\text { area was already destroyed by push of fire. Burned law } \\
\text { enforcement vehicle in roadway }\end{array}$ & $\mathrm{v}$ & $x$ & \\
\hline PPD-02 & $11 / 8$ & $10: 32$ & PPD-02 & 0 & 39.748595 & -121.607750 & Radio & Radio & fire is overtaking vehicles on Clark Rd & 0 & & \\
\hline TD-037 & $11 / 8$ & $10: 39$ & video & 0 & 39.746135 & -121.572316 & TD & video & $\begin{array}{l}\text { Pentz Rd south of Pearson Rd; structures fully involved; } \\
\text { active vegetation fire and sideways embers }\end{array}$ & $\mathrm{R}$ & & \\
\hline
\end{tabular}




\begin{tabular}{|c|c|c|c|c|c|c|c|c|c|c|c|c|}
\hline & & & & & & Pear & on Road an & Buschmann R & oad & & & \\
\hline Source \# & Date & Time & $\begin{array}{l}\text { Time } \\
\text { Source }\end{array}$ & $\begin{array}{l}\text { Obs } \\
\text { Window } \\
\text { (min) }\end{array}$ & Latitude & Longitude & $\begin{array}{c}\text { Location } \\
\text { Source }\end{array}$ & Info Source & Fire Behavior Observations & $\begin{array}{l}\text { Type } \\
\text { of } \\
\text { Fire }\end{array}$ & $\begin{array}{l}\text { Residual } \\
\text { Fire? }\end{array}$ & SSI \\
\hline TD-037 & $11 / 8$ & $10: 39$ & Photo & 0 & 39.748188 & -121.572426 & Photo & Photo & $\begin{array}{l}\text { nearly all structures fully involved both sides of Pentz } \\
\text { Rd; heavy fire all around, ember showers }\end{array}$ & $R$ & & \\
\hline TD-034 & $11 / 8$ & $10: 45$ & TD & 0 & 39.749521 & -121.606715 & TD & TD & $\begin{array}{l}\text { conditions deteriorate; field caught fire, wind blowing } \\
\text { flames like blowtorch; spot fires and trees igniting; } \\
\text { embers blowing across street }\end{array}$ & 0 & & \\
\hline TD-065 & $11 / 8$ & $10: 46$ & Inferred & 100 & 39.748784 & -121.607914 & TD & TD & $\begin{array}{l}\text { fire has jumped to west side of Clark Rd at Buschmann } \\
\text { Rd }\end{array}$ & v & & \\
\hline TD-065 & $11 / 8$ & $10: 46$ & Inferred & 100 & 39.750525 & -121.614713 & TD & TD & $\begin{array}{l}\text { spot fires and structures burning in general area of } \\
\text { Pearson Rd and Buschmann Rd between Scottwood Rd } \\
\text { and Clark Rd }\end{array}$ & C & & \\
\hline TD-015 & $11 / 8$ & $10: 50$ & AVL & 0 & 39.747100 & -121.574617 & AVL & TD & houses fully involved, $50 \%$ to the ground & $\mathrm{R}$ & & \\
\hline TD-015 & $11 / 8$ & $10: 52$ & $A V L$ & 0 & 39.750807 & -121.576820 & AVL & TD & fire had previously consumed Dry Creek drainage & $\mathrm{v}$ & $x$ & \\
\hline TD-037 & $11 / 8$ & $10: 56$ & Photo & 0 & 39.750824 & -121.576556 & Photo & Photo & $\begin{array}{l}\text { vegetative fuels have been consumed; spot fires and } \\
\text { structure still burning }\end{array}$ & $\mathrm{R}$ & $x$ & \\
\hline TD-015 & $11 / 8$ & $10: 57$ & AVL & 0 & 39.748617 & -121.587000 & AVL & TD & burning vehicle and trailer & 0 & & \\
\hline TD-124 & $11 / 8$ & $11: 02$ & AVL & 206 & 39.748107 & -121.592907 & AVL & TD & structures on fire & $\mathrm{R}$ & & \\
\hline TD-124 & $11 / 8$ & $11: 02$ & AVL & 206 & 39.749410 & -121.592821 & AVL & TD & structures on fire & $\mathrm{R}$ & & \\
\hline TD-037 & $11 / 8$ & $11: 02$ & Inferred & 5 & 39.748626 & -121.587423 & Photo & TD & fully involved pickup and trailer & 0 & & \\
\hline TD-020 & $11 / 8$ & 11:02 & Inferred & 63 & 39.752255 & -121.598279 & TD & TD & $\begin{array}{l}\text { spot fires, various structures involved, along Pearson } \mathrm{Rd} \\
\text { in area of Angel } \mathrm{Dr}\end{array}$ & $\mathrm{R}$ & & \\
\hline TD-130 & $11 / 8$ & $11: 10$ & Photo & 0 & 39.748794 & -121.593510 & Photo & Photo & multiple small spot fires in needles/leaf litter & $\mathrm{s}$ & & \\
\hline TD-130 & $11 / 8$ & $11: 10$ & Photo & 0 & 39.750899 & -121.593249 & Photo & Photo & $\begin{array}{l}\text { significant fire; everything burning; vegetation, fences, } \\
\text { structures }\end{array}$ & $\mathrm{R}$ & & \\
\hline TD-130 & $11 / 8$ & $11: 12$ & video & 0 & 39.748799 & -121.593244 & video & video & $\begin{array}{l}\text { surface fire in pine needles at } S \text { Libby Rd and Pearson } \\
\text { Rd }\end{array}$ & v & & \\
\hline TD-130 & $11 / 8$ & $11: 12$ & video & 0 & 39.750824 & -121.593269 & video & video & $\begin{array}{l}\text { heavy fire on Stonehurst Dr; structure, fence, power } \\
\text { pole fully involved }\end{array}$ & $\mathrm{R}$ & & \\
\hline TD-130 & $11 / 8$ & $11: 12$ & $A V L$ & 10 & 39.752286 & -121.598100 & AVL & TD & $\begin{array}{l}\text { Pearson Rd between Station } 82 \text { and Ace Hardware; not } \\
\text { fully involved yet, but fire present }\end{array}$ & $\mathrm{R}$ & & \\
\hline TD-209 & $11 / 8$ & $11: 16$ & Photo & 0 & 39.747588 & -121.572049 & Photo & Photo & structure fully involved & $\mathrm{R}$ & & \\
\hline TD-209 & $11 / 8$ & $11: 16$ & Photo & 0 & 39.747295 & -121.571934 & Photo & Photo & structure fully involved & $\mathrm{R}$ & & \\
\hline TD-124 & $11 / 8$ & $11: 17$ & AVL & 191 & 39.748567 & -121.594117 & $A V L$ & TD & $\begin{array}{l}\text { fire all around; propane tanks exploding approximately } \\
1 \text { per min }\end{array}$ & 0 & & \\
\hline TD-209 & $11 / 8$ & 11:17 & AVL & 119 & 39.746880 & -121.572846 & AVL & TD & vehicle and house burning; main fire front had passed & $\mathrm{R}$ & & \\
\hline TD-209 & $11 / 8$ & $11: 17$ & Photo & 0 & 39.747588 & -121.572049 & Photo & Photo & structure fully involved & $\mathrm{R}$ & & \\
\hline TD-209 & $11 / 8$ & $11: 27$ & Photo & 0 & 39.746797 & -121.572834 & Photo & Photo & $\begin{array}{l}\text { structure fully involved, threatening neighboring } \\
\text { structure }\end{array}$ & $\mathrm{R}$ & & \\
\hline
\end{tabular}




\begin{tabular}{|c|c|c|c|c|c|c|c|c|c|c|c|c|}
\hline \multicolumn{13}{|c|}{ Pearson Road and Buschmann Road } \\
\hline Source \# & Date & Time & $\begin{array}{l}\text { Time } \\
\text { Source }\end{array}$ & $\begin{array}{c}\text { Obs } \\
\text { Window } \\
\text { (min) }\end{array}$ & Latitude & Longitude & $\begin{array}{l}\text { Location } \\
\text { Source }\end{array}$ & Info Source & Fire Behavior Observations & $\begin{array}{c}\text { Type } \\
\text { of } \\
\text { Fire }\end{array}$ & $\begin{array}{l}\text { Residual } \\
\text { Fire? }\end{array}$ & SSI \\
\hline TD-209 & $11 / 8$ & $11: 27$ & Photo & 0 & 39.746797 & -121.572834 & Photo & Photo & $\begin{array}{l}\text { structure fully involved, threatening neighboring } \\
\text { structure }\end{array}$ & $\mathrm{R}$ & & \\
\hline TD-209 & $11 / 8$ & $11: 28$ & Photo & 0 & 39.746797 & -121.572834 & Photo & Photo & $\begin{array}{l}\text { structure fully involved, threatening neighboring } \\
\text { structure }\end{array}$ & $\mathrm{R}$ & & \\
\hline TD-035 & $11 / 8$ & $11: 30$ & Inferred & 90 & 39.749298 & -121.607732 & TD & TD & $\begin{array}{l}\text { PGE yard bush pile: blow torching the road at } \\
\text { Buschmann Rd; Clark Rd impassable }\end{array}$ & 0 & & \\
\hline TD-037 & $11 / 8$ & $11: 30$ & TD & 40 & 39.747360 & -121.593116 & TD & TD & $\begin{array}{l}\text { houses on east side of Pearson Rd / L Libby Rd are } \\
\text { burning }\end{array}$ & $\mathrm{R}$ & & \\
\hline PPD-08 & $11 / 8$ & $11: 32$ & PPD-08 & 0 & 39.748590 & -121.607695 & Radio & Radio & fire getting really close to the roadway & 0 & & \\
\hline TD-123 & $11 / 8$ & $11: 34$ & Inferred & 15 & 39.749543 & -121.594237 & TD & TD & $\begin{array}{l}\text { Enchanted Forest mobile home park on fire; moving } \\
\text { towards west }\end{array}$ & $\mathrm{R}$ & & \\
\hline TD-123 & $11 / 8$ & $11: 34$ & Inferred & 15 & 39.748534 & -121.593692 & TD & TD & power pole on fire & 0 & & \\
\hline PPD-08 & $11 / 8$ & $11: 39$ & PPD-08 & 0 & 39.751943 & -121.607344 & Radio & Radio & fire coming up to Pearson Rd and Clark Rd & 0 & & \\
\hline TD-130 & $11 / 8$ & $11: 45$ & video & 0 & 39.752808 & -121.605317 & video & video & $\begin{array}{l}\text { spot fires on north side of Pearson Rd at Brookview } \\
\text { Way }\end{array}$ & $\mathrm{s}$ & & \\
\hline TD-130 & $11 / 8$ & $11: 45$ & Photo & 0 & 39.752761 & -121.605406 & Photo & Photo & $\begin{array}{l}\text { area of ground fire in heavy brush; blowing brands; } \\
\text { flames up to } 4.6 \mathrm{~m}(15 \mathrm{ft})\end{array}$ & $\mathrm{V}$ & & \\
\hline TD-130 & $11 / 8$ & $11: 45$ & Photo & 0 & 39.750398 & -121.607079 & Photo & Photo & $\begin{array}{l}\text { field and vegetation south of Ace Hardware is burning } \\
\text { up to fence and Clark Rd }\end{array}$ & $\mathrm{v}$ & & \\
\hline TD-130 & $11 / 8$ & 11:45 & Photo & 0 & 39.749080 & -121.608090 & Photo & Photo & $\begin{array}{l}\text { mulch/slash piles at Buschmann Rd and Clark Rd are } \\
\text { burning }\end{array}$ & 0 & & \\
\hline TD-130 & $11 / 8$ & 11:45 & Photo & 0 & 39.748598 & -121.607111 & Photo & Photo & widespread heavy fire; surface vegetation, trees & v & & \\
\hline TD-130 & $11 / 8$ & $11: 49$ & video & 0 & 39.748638 & -121.607720 & video & video & $\begin{array}{l}\text { fire still burning on both sides of Clark Rd at Buschmann } \\
\text { Rd, fire past peak }\end{array}$ & $\mathrm{V}$ & $\mathrm{x}$ & \\
\hline TD-111 & $11 / 8$ & $11: 50$ & Inferred & 30 & 39.748592 & -121.588628 & TD & TD & Pearson burning & 0 & & \\
\hline TD-130 & $11 / 8$ & 11:52 & AVL & 24 & 39.751002 & -121.606774 & $\mathrm{AVL}$ & TD & storage units burning at Ace Hardware & C & & \\
\hline TD-123 & $11 / 8$ & $11: 53$ & $\mathrm{AVL}$ & 0 & 39.747467 & -121.584433 & AVL & TD & fire all around & 0 & & \\
\hline PPD-08 & $11 / 8$ & $11: 53$ & PPD-08 & 0 & 39.748594 & -121.607721 & Radio & Radio & Clark Rd SB south of Buschmann Rd is engulfed in fire & 0 & & \\
\hline TD-037 & $11 / 8$ & $12: 00$ & Inferred & 60 & 39.752251 & -121.599985 & TD & TD & $\begin{array}{l}\text { fire has burned through Pearson Rd between Middle } \\
\text { Libby Rd and Clark Rd }\end{array}$ & $\mathrm{R}$ & $\mathrm{x}$ & \\
\hline TD-037 & $11 / 8$ & $12: 00$ & Inferred & 60 & 39.752978 & -121.607091 & TD & TD & $\begin{array}{l}\text { mobile homes on east side Clark Rd at Black Bear Diner } \\
\text { are burning }\end{array}$ & $\mathrm{R}$ & & \\
\hline TD-037 & $11 / 8$ & $12: 00$ & Inferred & 60 & 39.752603 & -121.607241 & TD & TD & fire getting established at Mobil gas station & C & & \\
\hline TD-037 & $11 / 8$ & $12: 00$ & Inferred & 60 & 39.749580 & -121.594577 & TD & TD & fire is approaching from west & 0 & & \\
\hline TD-074 & $11 / 8$ & $12: 00$ & TD & 0 & 39.749511 & -121.607724 & TD & TD & $\begin{array}{l}\text { flames across Clark Rd between Pearson Rd and } \\
\text { Buschmann Rd }\end{array}$ & 0 & & \\
\hline TD-130 & $11 / 8$ & $12: 00$ & Photo & 0 & 39.751054 & -121.606542 & Photo & Photo & $\begin{array}{l}\text { heavy vegetation fire, trees torching, ember showers } \\
\text { after trees torch }\end{array}$ & v & & \\
\hline
\end{tabular}




\begin{tabular}{|c|c|c|c|c|c|c|c|c|c|c|c|c|}
\hline \multicolumn{13}{|c|}{ Pearson Road and Buschmann Road } \\
\hline Source \# & Date & Time & $\begin{array}{l}\text { Time } \\
\text { Source }\end{array}$ & $\begin{array}{l}\text { Obs } \\
\text { Window } \\
\text { (min) }\end{array}$ & Latitude & Longitude & $\begin{array}{l}\text { Location } \\
\text { Source }\end{array}$ & Info Source & Fire Behavior Observations & $\begin{array}{l}\text { Type } \\
\text { of } \\
\text { Fire }\end{array}$ & $\begin{array}{l}\text { Residual } \\
\text { Fire? }\end{array}$ & SSI \\
\hline TD-014 & $11 / 8$ & $12: 03$ & $\mathrm{AVL}$ & 0 & 39.749694 & -121.594513 & TD & TD & Enchanted Forest mobile home park fully involved & $\mathrm{R}$ & & \\
\hline TD-014 & $11 / 8$ & $12: 05$ & Radio Log & 0 & 39.752283 & -121.595019 & Radio Log & Radio Log & $\begin{array}{l}\text { significant fire activity both sides of road; barely } \\
\text { passable }\end{array}$ & 0 & & \\
\hline TD-020 & $11 / 8$ & $12: 05$ & Inferred & 43 & 39.733797 & -121.593789 & TD & TD & fire burning at end of S Libby Rd & $\mathrm{R}$ & & \\
\hline TD-014 & $11 / 8$ & $12: 11$ & $\mathrm{AVL}$ & 5 & 39.736441 & -121.593781 & AVL & TD & $\begin{array}{l}\text { Timber still burning good. Structure already burned to } \\
\text { ground. One structure collapsed in road. }\end{array}$ & $\mathrm{R}$ & & \\
\hline TD-210 & $11 / 8$ & 12:11 & AVL & 9 & 39.751967 & -121.606617 & AVL & TD & fire threatening Ace Hardware & 0 & & \\
\hline TD-210 & $11 / 8$ & $12: 14$ & Photo & 0 & 39.751996 & -121.606674 & Photo & Photo & $\begin{array}{l}\text { fire to NE corner of Ace Hardware; vegetation, fence, } \\
\text { and power poles burning }\end{array}$ & 0 & & \\
\hline TD-210 & $11 / 8$ & $12: 14$ & Photo & 0 & 39.752052 & -121.606484 & Photo & Photo & vegetation fire, flaring up, torching & $\mathrm{v}$ & & \\
\hline TD-123 & $11 / 8$ & $12: 18$ & $\mathrm{AVL}$ & 7 & 39.733267 & -121.593917 & $\mathrm{AVL}$ & TD & structures burned in open area & $\mathrm{R}$ & & \\
\hline TD-111 & $11 / 8$ & $12: 26$ & Inferred & 7 & 39.752229 & -121.593818 & TD & TD & structures burning at Pearson Rd and Middle Libby Rd & $\mathrm{R}$ & & \\
\hline TD-123 & $11 / 8$ & $12: 27$ & AVL & 37 & 39.724088 & -121.594940 & TD & TD & trees on fire & V & & \\
\hline PPD-08 & $11 / 8$ & $12: 29$ & PPD-08 & 0 & 39.751950 & -121.609656 & video & video & spot fire south side of Pearson Rd & $\mathrm{S}$ & & \\
\hline PPD-08 & $11 / 8$ & $12: 29$ & PPD-08 & 0 & 39.752580 & -121.610136 & video & video & spot fire north side of Pearson Rd & $S$ & & \\
\hline PPD-08 & $11 / 8$ & $12: 29$ & PPD-08 & 0 & 39.752078 & -121.610783 & video & video & spot fire south side of Pearson Rd & $\mathrm{s}$ & & \\
\hline TD-111 & $11 / 8$ & $12: 33$ & AVL TD-123 & 32 & 39.737834 & -121.593800 & TD & TD & all structures on fire in area & $\mathrm{R}$ & & \\
\hline TD-130 & $11 / 8$ & $12: 35$ & AVL & 0 & 39.749694 & -121.593762 & AVL & TD & everything on fire & 0 & & \\
\hline TD-130 & $11 / 8$ & $12: 36$ & video & 0 & 39.751277 & -121.600907 & video & video & $\begin{array}{l}\text { between Garden View } \mathrm{Ln} \text { and Glen Cir at Pearson Rd; all } \\
\text { but } 1 \text { structure fully involved; heavy vegetation fire; } \\
\text { visibility zero }\end{array}$ & $\mathrm{R}$ & & \\
\hline TD-130 & $11 / 8$ & $12: 36$ & Photo & 0 & 39.749859 & -121.600915 & Photo & Photo & $\begin{array}{l}\text { Newland Rd is a furnace - very intense fire; everything } \\
\text { burning; all structures and vegetation intense flames, } \\
\text { fully involved, burning debris in roadway; dark, windy, } \\
\text { heavy ember showers }\end{array}$ & $\mathrm{R}$ & & \\
\hline TD-130 & $11 / 8$ & $12: 36$ & Photo & 0 & 39.752266 & -121.602376 & Photo & Photo & all structures fully involved, parcels completely burning & $\mathrm{R}$ & & \\
\hline TD-130 & $11 / 8$ & $12: 36$ & Photo & 0 & 39.752223 & -121.605562 & Photo & Photo & $\begin{array}{l}\text { vegetation past peak, still burning; consumed } \\
\text { throughout drainage, burning right up to roadway and } \\
\text { Ace Hardware parking lot }\end{array}$ & v & & \\
\hline TD-130 & $11 / 8$ & $12: 39$ & video & 0 & 39.749956 & -121.607664 & video & video & $\begin{array}{l}\text { Clark Rd between Pearson Rd and Village Pkwy; fire on } \\
\text { east side of Clark Rd [video does not show west side] }\end{array}$ & 0 & & \\
\hline TD-020 & $11 / 8$ & $12: 48$ & Inferred & 0 & 39.747683 & -121.593784 & Inferred & TD & all structures burning & $\mathrm{R}$ & & \\
\hline TD-210 & $11 / 8$ & $12: 53$ & video & 0 & 39.752278 & -121.599278 & video & video & $\begin{array}{l}\text { everything both sides fully involved on Pearson Rd at } \\
\text { Tamarack Way }\end{array}$ & $\mathrm{R}$ & & \\
\hline TD-210 & $11 / 8$ & $12: 53$ & Photo & 0 & 39.752265 & -121.597610 & Photo & Photo & $\begin{array}{l}\text { structures fully involved, surface fuels, trees burning; } \\
\text { one structure standing with no fire visible }\end{array}$ & $\mathrm{R}$ & & \\
\hline TD-210 & $11 / 8$ & $12: 53$ & Photo & 0 & 39.750401 & -121.593744 & Photo & Photo & $\begin{array}{l}\text { surface fuels past peak, still active flaming, everything } \\
\text { burning; structures fully involved }\end{array}$ & $\mathrm{R}$ & & \\
\hline
\end{tabular}




\begin{tabular}{|c|c|c|c|c|c|c|c|c|c|c|c|c|}
\hline & \multicolumn{12}{|c|}{ Pearson Road and Buschmann Road } \\
\hline & Date & Time & $\begin{array}{l}\text { Time } \\
\text { Source }\end{array}$ & $\begin{array}{c}\text { Obs } \\
\text { Window } \\
\text { (min) }\end{array}$ & Latitude & Longitude & $\begin{array}{l}\text { Location } \\
\text { Source }\end{array}$ & Info Source & Fire Behavior Observations & $\begin{array}{c}\text { Type } \\
\text { of } \\
\text { Fire }\end{array}$ & $\begin{array}{l}\text { Residual } \\
\text { Fire? }\end{array}$ & SSI \\
\hline TD-210 & $11 / 8$ & $12: 54$ & video & 0 & 39.750778 & -121.593731 & video & video & $\begin{array}{l}\text { everything both sides fully involved on Pearson Rd at } \\
\text { Stonehurst } \mathrm{Dr}\end{array}$ & $\mathrm{R}$ & & \\
\hline TD-064 & $11 / 8$ & $13: 10$ & Inferred & 50 & 39.753717 & -121.623441 & TD & TD & $\begin{array}{l}\text { park across street from PPD is burning; } 10 \mathrm{~cm} \text { to } 13 \mathrm{~cm} \\
\text { ( } 4 \text { in to } 5 \text { in) diameter embers falling }\end{array}$ & v & & \\
\hline TD-014 & $11 / 8$ & $13: 15$ & AVL & 0 & 39.750721 & -121.576646 & AVL & TD & areas burning a second time & $\mathrm{v}$ & & \\
\hline TD-130 & $11 / 8$ & $13: 21$ & AVL & 0 & 39.752601 & -121.607492 & AVL & TD & Mobil gas station on fire & C & & \\
\hline TD-014 & $11 / 8$ & $13: 23$ & Radio Log & 0 & 39.748125 & -121.609620 & Radio Log & Radio Log & fire in the building & $\mathrm{R}$ & & \\
\hline TD-112 & $11 / 8$ & $13: 23$ & Radio Log & 0 & 39.748140 & -121.609663 & Radio Log & Radio Log & structure on fire & $\mathrm{R}$ & & \\
\hline TD-112 & $11 / 8$ & 13:25 & Radio Log & 0 & 39.748140 & -121.609663 & Radio Log & Radio Log & apartments: 3 complexes well involved & $\mathrm{R}$ & & \\
\hline TD-112 & $11 / 8$ & $13: 25$ & Inferred & 8 & 39.747739 & -121.609668 & Radio Log & TD & Half of apartment complex fully involved & $\mathrm{R}$ & & \\
\hline TD-021 & $11 / 8$ & $13: 30$ & Inferred & 0 & 39.753746 & -121.624623 & TD & TD & fire has already burned around area of Station 81 & 0 & $\mathrm{x}$ & \\
\hline TD-209 & $11 / 8$ & $13: 41$ & Photo & 0 & 39.748519 & -121.582307 & Photo & Photo & $\begin{array}{l}\text { minimal fire activity limited to burning rubble; surface } \\
\text { fuels and abandoned vehicles have finished burning }\end{array}$ & $\mathrm{R}$ & $x$ & \\
\hline TD-123 & $11 / 8$ & $13: 46$ & $A V L$ & 42 & 39.751025 & -121.607178 & AVL & TD & back of Ace Hardware on fire; PVC stacks on fire & C & & \\
\hline TD-130 & $11 / 8$ & $13: 46$ & Photo & 0 & 39.750527 & -121.576059 & Photo & Photo & $\begin{array}{l}\text { all surface fuels and vegetation and abandoned vehicles } \\
\text { finished burning }\end{array}$ & 0 & $x$ & \\
\hline TD-130 & $11 / 8$ & $13: 46$ & Photo & 0 & 39.747756 & -121.572455 & Photo & Photo & $\begin{array}{l}\text { most structures burned to foundation, minimal active } \\
\text { spots of fire in rubble }\end{array}$ & $\mathrm{R}$ & $x$ & \\
\hline TD-209 & $11 / 8$ & $13: 59$ & $A V L$ & 4 & 39.748595 & -121.589830 & $\mathrm{AVL}$ & TD & houses are already burned down; nothing to protect & $\mathrm{R}$ & $\mathrm{x}$ & \\
\hline TD-064 & $11 / 8$ & $14: 00$ & Inferred & 0 & 39.753933 & -121.623996 & TD & TD & fire threatening structures & 0 & & \\
\hline TD-209 & $11 / 8$ & $14: 03$ & AVL & 7 & 39.749643 & -121.594508 & AVL & TD & $\begin{array}{l}\text { fire had already gone through Enchanted Forest mobile } \\
\text { home park }\end{array}$ & $\mathrm{R}$ & $x$ & \\
\hline TD-009 & $11 / 8$ & $14: 10$ & $\mathrm{AVL}$ & 0 & 39.749867 & -121.602550 & AVL & TD & house is burned down & $\mathrm{R}$ & $\mathrm{x}$ & \\
\hline TD-209 & $11 / 8$ & $14: 12$ & Photo & 0 & 39.749421 & -121.593324 & Photo & Photo & structures burned to foundation; flaming rubble & $\mathrm{R}$ & $x$ & \\
\hline TD-209 & $11 / 8$ & $14: 12$ & Photo & 0 & 39.749148 & -121.594168 & Photo & Photo & structures burned to foundation; flaming rubble & $\mathrm{R}$ & $x$ & \\
\hline TD-209 & $11 / 8$ & $14: 13$ & Photo & 0 & 39.752306 & -121.595087 & Photo & Photo & $\begin{array}{l}\text { structure burned down, fire out, surface vegetation } \\
\text { consumed }\end{array}$ & $\mathrm{R}$ & $x$ & \\
\hline TD-209 & $11 / 8$ & $14: 13$ & Photo & 0 & 39.752011 & -121.595371 & Photo & Photo & structure burned to foundation, minimal flaming rubble & $\mathrm{R}$ & $\mathrm{x}$ & \\
\hline TD-209 & $11 / 8$ & $14: 13$ & Photo & 0 & 39.752004 & -121.596833 & Photo & Photo & structure post peak, collapsed, still burning & $\mathrm{R}$ & $\mathrm{x}$ & \\
\hline TD-209 & $11 / 8$ & $14: 13$ & Photo & 0 & 39.752034 & -121.596325 & Photo & Photo & structure burned to foundation & $\mathrm{R}$ & $\mathrm{x}$ & \\
\hline TD-209 & $11 / 8$ & $14: 13$ & Photo & 0 & 39.752635 & -121.596030 & Photo & Photo & structure burned to foundation & $\mathrm{R}$ & $x$ & \\
\hline TD-209 & $11 / 8$ & $14: 13$ & Photo & 0 & 39.752261 & -121.602313 & Photo & Photo & $\begin{array}{l}\text { structures in area burned to foundation along Pearson } \\
\mathrm{Rd} \text {; minimal fire, burning rubble }\end{array}$ & $\mathrm{R}$ & $\mathrm{x}$ & \\
\hline TD-209 & $11 / 8$ & $14: 14$ & AVL & 0 & 39.751829 & -121.607361 & $A V L$ & TD & everything around Ace Hardware is burned & 0 & $x$ & \\
\hline TD-209 & $11 / 8$ & $14: 14$ & Photo & 0 & 39.752486 & -121.608038 & Photo & Photo & $\begin{array}{l}\text { widespread surface fires (burning rubble from new } \\
\text { sheds for sale), power pole burning }\end{array}$ & 0 & & \\
\hline TD-142 & $11 / 8$ & $14: 19$ & Inferred & 0 & 39.749320 & -121.607702 & TD & TD & fire on both sides of Clark Rd & 0 & & \\
\hline
\end{tabular}




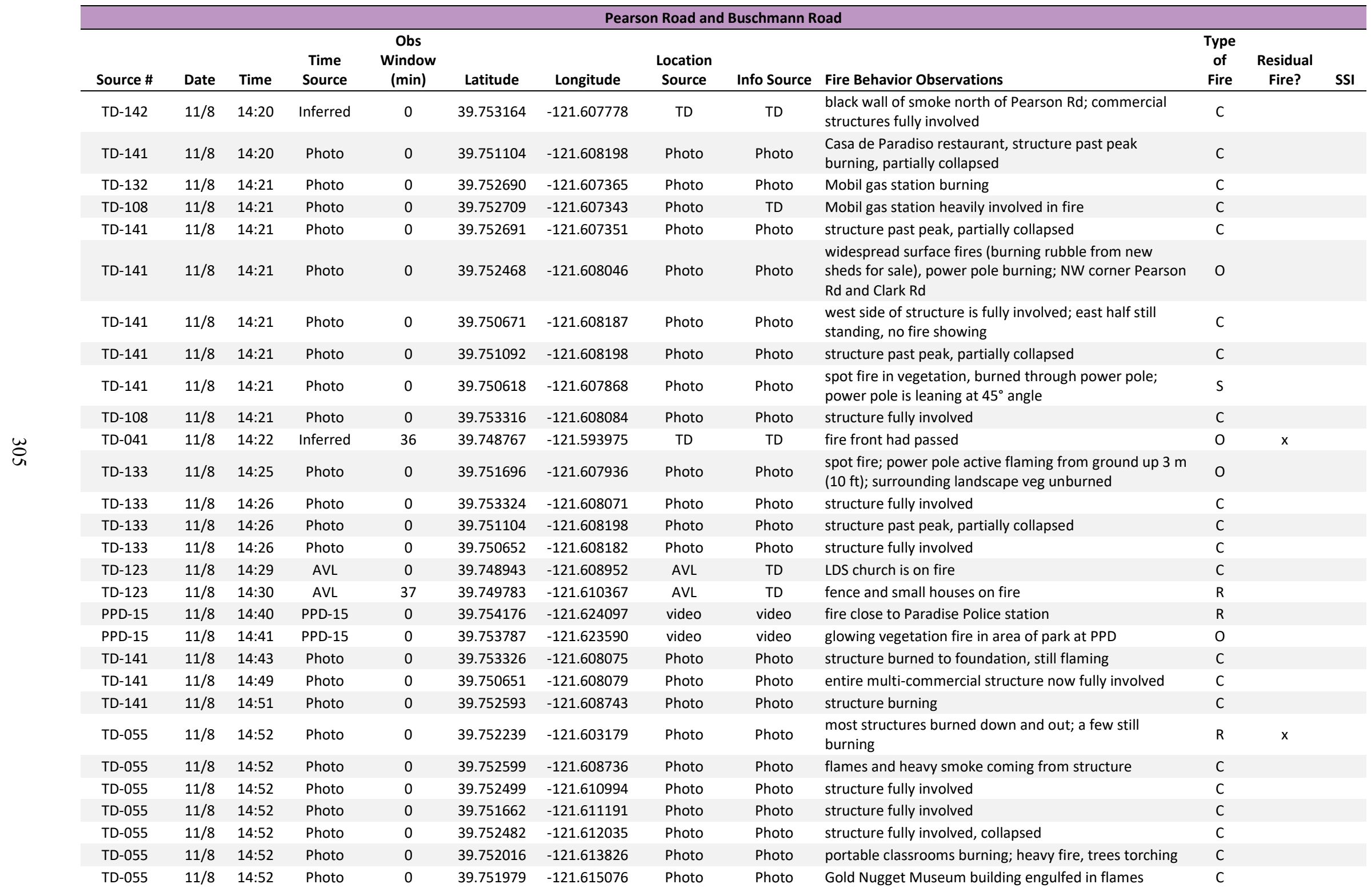




\begin{tabular}{|c|c|c|c|c|c|c|c|c|c|c|c|c|}
\hline \multicolumn{13}{|c|}{ Pearson Road and Buschmann Road } \\
\hline Source \# & Date & Time & $\begin{array}{l}\text { Time } \\
\text { Source }\end{array}$ & $\begin{array}{l}\text { Obs } \\
\text { Window } \\
\text { (min) }\end{array}$ & Latitude & Longitude & $\begin{array}{l}\text { Location } \\
\text { Source }\end{array}$ & Info Source & Fire Behavior Observations & $\begin{array}{l}\text { Type } \\
\text { of } \\
\text { Fire }\end{array}$ & $\begin{array}{l}\text { Residual } \\
\text { Fire? }\end{array}$ & SSI \\
\hline TD-055 & $11 / 8$ & 14:52 & Photo & 0 & 39.752370 & -121.616212 & Photo & Photo & vehicle in carport fully involved & 0 & & \\
\hline TD-055 & $11 / 8$ & 14:52 & Photo & 0 & 39.752372 & -121.618063 & Photo & Photo & entire hillside of vegetation burning, intense heat & $\mathrm{V}$ & & \\
\hline TD-055 & $11 / 8$ & 14:52 & Photo & 0 & 39.752084 & -121.622065 & Photo & Photo & $\begin{array}{l}\text { multiple structures fully involved both sides of Pearson } \\
\text { Rd; fire burning everywhere; significant ember wash }\end{array}$ & $\mathrm{R}$ & & \\
\hline TD-055 & $11 / 8$ & 14:52 & Photo & 0 & 39.752878 & -121.625259 & Photo & Photo & heavy fire on roof/facade of structure & C & & \\
\hline PPD-15 & $11 / 8$ & 14:52 & PPD-15 & 0 & 39.752085 & -121.621935 & Radio & Radio & area is all engulfed & 0 & & \\
\hline TD-101 & $11 / 8$ & 14:53 & Photo & 0 & 39.752820 & -121.625090 & Photo & Photo & 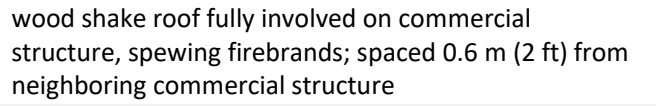 & C & & \\
\hline TD-101 & $11 / 8$ & $14: 53$ & Photo & 0 & 39.752579 & -121.625413 & Photo & Photo & vegetation spot fire & $\mathrm{s}$ & & \\
\hline TD-069 & $11 / 8$ & 14:59 & Inferred & 9 & 39.751606 & -121.611468 & TD & TD & Paradise Elementary School actively burning & C & & \\
\hline TD-069 & $11 / 8$ & 14:59 & Inferred & 9 & 39.752026 & -121.613836 & TD & TD & Intermediate school portables are on fire & C & & \\
\hline TD-069 & $11 / 8$ & 14:59 & Inferred & 9 & 39.751978 & -121.615056 & TD & TD & museum is on fire & c & & \\
\hline TD-069 & $11 / 8$ & 14:59 & Inferred & 9 & 39.752176 & -121.619057 & TD & TD & wall of flames across Pearson Rd & 0 & & \\
\hline TD-141 & $11 / 8$ & 15:02 & Photo & 0 & 39.752185 & -121.619487 & Photo & Photo & vegetation fire both sides of Pearson Rd; ember shower & $\mathrm{v}$ & & \\
\hline TD-141 & $11 / 8$ & 15:02 & Photo & 0 & 39.752439 & -121.621501 & Photo & Photo & structure fully involved; parcel vegetation burning & $\mathrm{R}$ & & \\
\hline TD-141 & $11 / 8$ & 15:02 & Photo & 0 & 39.751853 & -121.622340 & Photo & Photo & structure fully involved; parcel vegetation burning & C & & \\
\hline TD-141 & $11 / 8$ & 15:02 & Photo & 0 & 39.752401 & -121.622137 & Photo & Photo & $\begin{array}{l}\text { Craig Memorial Congregational Church burning, fully } \\
\text { involved }\end{array}$ & C & & \\
\hline TD-141 & $11 / 8$ & 15:02 & Photo & 0 & 39.752367 & -121.622944 & Photo & Photo & structure fully involved; parcel vegetation burning & $\mathrm{R}$ & & \\
\hline TD-141 & $11 / 8$ & 15:02 & Photo & 0 & 39.752359 & -121.622703 & Photo & Photo & structure fully involved & $\mathrm{R}$ & & \\
\hline TD-141 & $11 / 8$ & 15:02 & Photo & 0 & 39.752329 & -121.623198 & Photo & Photo & $\begin{array}{l}\text { structure fully involved, pickup truck burning, all } \\
\text { vegetation burning, tree limbs torched and glowing }\end{array}$ & $\mathrm{R}$ & & \\
\hline TD-132 & $11 / 8$ & 15:03 & video & 0 & 39.752108 & -121.622341 & Photo & video & $\begin{array}{l}\text { structures fully involved, ember showers bouncing } \\
\text { down street, spot fires }\end{array}$ & $\mathrm{R}$ & & \\
\hline PPD-15 & $11 / 8$ & 15:03 & PPD-15 & 0 & 39.753279 & -121.624885 & video & video & spot fire & $\mathrm{s}$ & & \\
\hline PPD-15 & $11 / 8$ & 15:03 & PPD-15 & 0 & 39.752810 & -121.625117 & video & video & commercial structures on fire & C & & \\
\hline TD-132 & $11 / 8$ & 15:03 & Photo & 0 & 39.751917 & -121.625193 & Photo & Photo & area burning, possible structures involved & 0 & & \\
\hline TD-132 & $11 / 8$ & 15:03 & Photo & 0 & 39.752086 & -121.622581 & Photo & Photo & $\begin{array}{l}\text { all structures fully involved and widespread vegetation } \\
\text { fire (flaming, past peak), both sides of Pearson Rd } \\
\text { between College Hill Rd and Black Olive Dr }\end{array}$ & $\mathrm{R}$ & & \\
\hline TD-132 & $11 / 8$ & 15:03 & Photo & 0 & 39.752816 & -121.625085 & Photo & Photo & structure fully involved & $\mathrm{R}$ & & \\
\hline TD-132 & $11 / 8$ & 15:03 & Photo & 0 & 39.752877 & -121.625252 & Photo & Photo & $\begin{array}{l}\text { structure igniting in eaves and roof due to neighboring } \\
\text { structure on fire }\end{array}$ & $\mathrm{R}$ & & $\mathrm{x}$ \\
\hline TD-132 & $11 / 8$ & 15:04 & Photo & 0 & 39.755875 & -121.626673 & Photo & Photo & $\begin{array}{l}\text { smoke coming from commercial structure; small spot } \\
\text { fire in vegetation also burning against structure }\end{array}$ & c & & \\
\hline TD-123 & $11 / 8$ & 15:07 & AVL & 0 & 39.748943 & -121.608952 & AVL & TD & LDS church is fully involved & c & & \\
\hline
\end{tabular}




\begin{tabular}{|c|c|c|c|c|c|c|c|c|c|c|c|c|}
\hline \multicolumn{13}{|c|}{ Pearson Road and Buschmann Road } \\
\hline Source \# & Date & Time & $\begin{array}{l}\text { Time } \\
\text { Source }\end{array}$ & $\begin{array}{c}\text { Obs } \\
\text { Window } \\
\text { (min) }\end{array}$ & Latitude & Longitude & $\begin{array}{l}\text { Location } \\
\text { Source }\end{array}$ & Info Source & Fire Behavior Observations & $\begin{array}{c}\text { Type } \\
\text { of } \\
\text { Fire }\end{array}$ & $\begin{array}{l}\text { Residual } \\
\text { Fire? }\end{array}$ & SSI \\
\hline TD-101 & $11 / 8$ & $15: 07$ & Photo & 0 & 39.748625 & -121.585894 & Photo & Photo & $\begin{array}{l}\text { area burned over, buildings destroyed, few spots of fire } \\
\text { remaining }\end{array}$ & $\mathrm{R}$ & $x$ & \\
\hline PPD-15 & $11 / 8$ & $15: 20$ & PPD-15 & 0 & 39.755830 & -121.626766 & video & video & fully involved commercial building; no other fire around & C & & \\
\hline TD-101 & $11 / 8$ & $15: 28$ & Photo & 0 & 39.748721 & -121.583197 & Photo & Photo & $\begin{array}{l}\text { Pearson Rd: Butte View Ter to Sawmill Rd, area burned } \\
\text { over, buildings destroyed, few spots of fire remaining }\end{array}$ & $\mathrm{R}$ & $x$ & \\
\hline TD-101 & $11 / 8$ & $15: 31$ & Photo & 0 & 39.751795 & -121.593330 & Photo & Photo & $\begin{array}{l}\text { structure burned to foundation, minimal flames in } \\
\text { rubble; parcel vegetation burnt, no flames }\end{array}$ & $\mathrm{R}$ & $\mathrm{x}$ & \\
\hline TD-209 & $11 / 8$ & $15: 38$ & AVL & 23 & 39.746537 & -121.611519 & TD & TD & fire coming from first floor & $\mathrm{R}$ & & \\
\hline TD-209 & $11 / 8$ & $15: 38$ & AVL & 23 & 39.746313 & -121.611514 & TD & TD & column of building ignites & $\mathrm{R}$ & & \\
\hline PPD-15 & $11 / 8$ & $15: 40$ & PPD-15 & 0 & 39.755102 & -121.627327 & video & video & $\begin{array}{l}\text { waves of embers blowing along roadway, both sides, } \\
\text { large, golf ball-sized and bouncing }\end{array}$ & 0 & & \\
\hline PPD-15 & $11 / 8$ & $15: 41$ & PPD-15 & 0 & 39.753501 & -121.627061 & video & video & vegetation on entire lot is burning intense & V & & \\
\hline PPD-15 & $11 / 8$ & $15: 41$ & PPD-15 & 0 & 39.752964 & -121.626219 & video & video & $\begin{array}{l}\text { multiple small spots along south side of Pearson Rd } \\
\text { between Skyway and Black Olive Dr }\end{array}$ & $\mathrm{S}$ & & \\
\hline PPD-15 & $11 / 8$ & $15: 41$ & PPD-15 & 0 & 39.752847 & -121.625119 & video & video & $\begin{array}{l}\text { fully involved structures on north side Pearson Rd; no } \\
\text { fire on south side of street }\end{array}$ & C & & \\
\hline PPD-15 & $11 / 8$ & $15: 41$ & PPD-15 & 2 & 39.752202 & -121.615930 & video & video & $\begin{array}{l}\text { fire has burned through everything on Pearson Rd east } \\
\text { of Black Olive Dr; } 33 \text { \% each of burned to foundation, } \\
\text { fully involved, and still standing; Black Olive Dr to Clark } \\
\mathrm{Rd}\end{array}$ & C & & \\
\hline VTD-18 & $11 / 8$ & $16: 40$ & TD & 0 & 39.748948 & -121.608932 & video & video & church past-peak fully involved, not collapsed yet & C & $x$ & \\
\hline TD-142 & $11 / 8$ & $16: 48$ & Photo & 0 & 39.755732 & -121.626176 & Photo & Photo & commercial structures burning & C & & \\
\hline TD-111 & $11 / 8$ & $16: 50$ & TD & 0 & 39.753842 & -121.624697 & TD & TD & fire around Station 81 & 0 & & \\
\hline TD-065 & $11 / 8$ & $17: 38$ & TD & 0 & 39.752202 & -121.612108 & TD & TD & Paradise Elementary is burned down & $\mathrm{C}$ & & \\
\hline TD-209 & $11 / 8$ & $17: 50$ & AVL & 53 & 39.746050 & -121.611217 & AVL & TD & $\begin{array}{l}\text { Paradise Community Village Apartments burned down / } \\
\text { fully involved }\end{array}$ & R & & \\
\hline TD-209 & $11 / 8$ & $17: 55$ & Photo & 0 & 39.746214 & -121.611519 & Photo & Photo & $\begin{array}{l}\text { structure fully involved, past peak, partially collapsed; } \\
\text { other apartment structures beginning to burn }\end{array}$ & $\mathrm{R}$ & & \\
\hline
\end{tabular}




\begin{tabular}{|c|c|c|c|c|c|c|c|c|c|c|c|c|}
\hline & & & & & & & Clark & Road & & & & \\
\hline Source \# & Date & Time & $\begin{array}{l}\text { Time } \\
\text { Source }\end{array}$ & $\begin{array}{c}\text { Obs } \\
\text { Window } \\
\text { (min) }\end{array}$ & Latitude & Longitude & $\begin{array}{l}\text { Location } \\
\text { Source }\end{array}$ & Info Source & Fire Behavior Observations & $\begin{array}{c}\text { Type } \\
\text { of } \\
\text { Fire }\end{array}$ & $\begin{array}{l}\text { Residual } \\
\text { Fire? }\end{array}$ & SSI \\
\hline TD-035 & $11 / 8$ & 07:45 & Inferred & 0 & 39.735414 & -121.610263 & TD & TD & hot embers falling & 0 & & \\
\hline TD-074 & $11 / 8$ & 08:00 & TD & 0 & 39.759491 & -121.606635 & TD & TD & embers as large as a matchbox landing & 0 & & \\
\hline TD-015 & $11 / 8$ & $08: 15$ & TD & 0 & 39.784464 & -121.587998 & TD & TD & spot fire & S & & \\
\hline TD-065 & $11 / 8$ & 08:15 & Inferred & 0 & 39.759502 & -121.606653 & TD & TD & ember showers & 0 & & \\
\hline TD-100 & $11 / 8$ & $08: 30$ & TD & 0 & 39.735180 & -121.604409 & TD & TD & $\begin{array}{l}\text { spot fire too big to engage, est. about } 12 \mathrm{ha}(30 \mathrm{ac}) \text {; } \\
\text { established in drainage }\end{array}$ & $S$ & & \\
\hline VTD-09 & $11 / 8$ & $08: 30$ & TD & 0 & 39.784384 & -121.589144 & video & video & spot fire in Apple Tree Village mobile home park & $\mathrm{S}$ & & \\
\hline VTD-09 & $11 / 8$ & 08:30 & TD & 0 & 39.783043 & -121.588983 & video & video & spot fire in Apple Tree Village mobile home park & $S$ & & \\
\hline VTD-09 & $11 / 8$ & 08:30 & TD & 0 & 39.784803 & -121.590610 & video & video & spot fire in Apple Tree Village mobile home park & $\mathrm{S}$ & & \\
\hline 911-142-1 & $11 / 8$ & 08:31 & $911-142-1$ & 0 & 39.796563 & -121.585649 & 911-142-1 & 911-142-1 & spot fire & $\mathrm{s}$ & & \\
\hline $911-142-2$ & $11 / 8$ & 08:31 & $911-142-2$ & 0 & 39.796563 & -121.585649 & $911-142-2$ & $911-142-2$ & spot fire & $\mathrm{S}$ & & \\
\hline TD-058 & $11 / 8$ & $08: 35$ & Inferred & 26 & 39.793050 & -121.584948 & TD & TD & trees on fire & v & & \\
\hline $911-152-1$ & $11 / 8$ & $08: 35$ & $911-152-1$ & 0 & 39.796563 & -121.585649 & $911-152-1$ & $911-152-1$ & spot fire & $S$ & & \\
\hline $911-153-1$ & $11 / 8$ & $08: 35$ & $911-153-1$ & 0 & 39.796563 & -121.585649 & $911-153-1$ & 911-153-1 & spot fire & $S$ & & \\
\hline $911-155-1$ & $11 / 8$ & $08: 36$ & $911-155-1$ & 0 & 39.796563 & -121.585649 & $911-155-1$ & $911-155-1$ & fire & $S$ & & \\
\hline $911-157-1$ & $11 / 8$ & $08: 37$ & $911-157-1$ & 0 & 39.776591 & -121.588145 & $911-157-1$ & $911-157-1$ & field behind Kmart on fire & $S$ & & \\
\hline TD-067 & $11 / 8$ & $08: 38$ & $911-158-1$ & 0 & 39.779476 & -121.587807 & TD & $\begin{array}{c}\text { TD, 911- } \\
158-1\end{array}$ & spot fire & $\mathrm{S}$ & & \\
\hline $911-158-1$ & $11 / 8$ & $08: 38$ & 911-158-1 & 0 & 39.779450 & -121.587721 & $911-158-1$ & $911-158-1$ & spot fire in grass, just started, small but still burning & $\mathrm{s}$ & & \\
\hline $911-161-2$ & $11 / 8$ & $08: 39$ & $911-161-2$ & 0 & 39.784800 & -121.587090 & $911-161-2$ & $911-161-2$ & fire is right next door & 0 & & \\
\hline TD-075 & $11 / 8$ & 08:40 & Inferred & 6 & 39.777730 & -121.590638 & TD & TD & noticed embers flying through air & 0 & & \\
\hline TD-067 & $11 / 8$ & 08:40 & Inferred & 6 & 39.779476 & -121.587807 & TD & TD & smaller spot fire in grass behind church & S & & \\
\hline TD-105 & $11 / 8$ & $08: 40$ & Inferred & 20 & 39.733599 & -121.612989 & TD & TD & fire spotting across Clark Rd & $\mathrm{S}$ & & \\
\hline TD-105 & $11 / 8$ & 08:40 & Inferred & 20 & 39.733599 & -121.612989 & TD & TD & structure burning & $\mathrm{R}$ & & \\
\hline 911-164-1 & $11 / 8$ & 08:40 & $911-164-1$ & 0 & 39.797065 & -121.585487 & $911-164-1$ & $911-164-1$ & fire & $\mathrm{S}$ & & \\
\hline PPD-02 & $11 / 8$ & 08:43 & PPD-02 & 0 & 39.778604 & -121.588499 & Radio & Radio & $\begin{array}{l}\text { large tree on fire between Wagstaff Rd and Della Ln by } \\
\text { the school district office }\end{array}$ & $\mathrm{S}$ & & \\
\hline TD-067 & $11 / 8$ & 08:46 & PPD video & 0 & 39.776799 & -121.588842 & TD & TD & $\begin{array}{l}\text { observed fully involved pine tree on south side } \\
\text { Wagstaff Rd }\end{array}$ & $S$ & & \\
\hline PPD-02 & $11 / 8$ & 08:46 & PPD-02 & 0 & 39.777473 & -121.588112 & Radio & Radio & spot fire; large tree and field involved & $S$ & & \\
\hline TD-077 & $11 / 8$ & 08:52 & Photo & 0 & 39.768403 & -121.597561 & TD & TD & fire started in field behind PID office & $\mathrm{S}$ & & \\
\hline $911-188-2$ & $11 / 8$ & $08: 52$ & $911-188-2$ & 0 & 39.773441 & -121.597718 & $911-188-2$ & $911-188-2$ & fire in playground? Trees at school behind church & $\mathrm{S}$ & & \\
\hline $911-201-1$ & $11 / 8$ & 08:59 & 911-201-1 & 0 & 39.742037 & -121.603353 & Inferred & 911-201-1 & fire behind house & $\mathrm{S}$ & & \\
\hline TD-111 & $11 / 8$ & 09:00 & Radio Log & 0 & 39.769875 & -121.596369 & TD & TD & spot fire & $\mathrm{S}$ & & \\
\hline TD-100 & $11 / 8$ & 09:00 & Inferred & 30 & 39.732782 & -121.606831 & TD & TD & growing spot fire, well established in canyon & $S$ & & \\
\hline TD-053 & $11 / 8$ & 09:00 & Inferred & 0 & 39.776337 & -121.588374 & TD & TD & fire east of Kmart & $\mathrm{R}$ & & \\
\hline
\end{tabular}




\begin{tabular}{|c|c|c|c|c|c|c|c|c|c|c|c|c|}
\hline & & & & & & & Clark & Road & & & & \\
\hline Source \# & Date & Time & $\begin{array}{l}\text { Time } \\
\text { Source }\end{array}$ & $\begin{array}{c}\text { Obs } \\
\text { Window } \\
\text { (min) }\end{array}$ & Latitude & Longitude & $\begin{array}{l}\text { Location } \\
\text { Source }\end{array}$ & Info Source & Fire Behavior Observations & $\begin{array}{c}\text { Type } \\
\text { of } \\
\text { Fire }\end{array}$ & $\begin{array}{l}\text { Residual } \\
\text { Fire? }\end{array}$ & SSI \\
\hline TD-017 & $11 / 8$ & 09:17 & AVL & 8 & 39.773662 & -121.598186 & Radio Log & TD & $\begin{array}{l}\text { Fire spotting on west side of Clark Rd, about } 0.4 \text { ha } \\
(1 \mathrm{ac}), \text { timber/litter fuel }\end{array}$ & $\mathrm{s}$ & & \\
\hline TD-077 & $11 / 8$ & $09: 20$ & Inferred & 0 & 39.733280 & -121.604288 & TD & TD & see flames on ridge to east of Clark Rd & $\mathrm{v}$ & & \\
\hline VTD-18 & $11 / 8$ & 09:28 & TD & 0 & 39.776810 & -121.588771 & video & video & tall pine tree bark burning along the entire trunk & $\mathrm{v}$ & & \\
\hline TD-052 & $11 / 8$ & 09:28 & Photo & 0 & 39.778000 & -121.590473 & Photo & Photo & $\begin{array}{l}\text { fire has burned up bark of tall pine tree behind (east) } \\
\text { Savemart }\end{array}$ & v & $x$ & \\
\hline TD-017 & $11 / 8$ & 09:30 & Radio Log & 0 & 39.777731 & -121.590543 & Radio Log & Radio Log & $\begin{array}{l}\text { fire is well established [in area around] Clark Rd and } \\
\text { Wagstaff Rd }\end{array}$ & 0 & & \\
\hline TD-017 & $11 / 8$ & 09:30 & Radio Log & 0 & 39.773662 & -121.598186 & Radio Log & Radio Log & $\begin{array}{l}\text { fire [in area of] Clark Rd and Bille Rd from the Paradise } \\
\text { Alliance Church working its way south }\end{array}$ & 0 & & \\
\hline TD-034 & $11 / 8$ & 09:30 & TD & 120 & 39.739841 & -121.605311 & TD & TD & fire coming from S and SE into Lanser Dr area & v & & \\
\hline VTD-18 & $11 / 8$ & 09:30 & TD & 0 & 39.777301 & -121.587854 & video & video & $\begin{array}{l}\text { smoke plume rising from east of commercial buildings } \\
\text { (estimated source location) }\end{array}$ & 0 & & \\
\hline VTD-18 & $11 / 8$ & 09:32 & TD & 0 & 39.776068 & -121.588136 & video & video & $\begin{array}{l}\text { orange glow coming from east of commercial buildings } \\
\text { (estimated source location) }\end{array}$ & 0 & & \\
\hline VTD-18 & $11 / 8$ & 09:43 & TD & 0 & 39.775481 & -121.588899 & video & video & $\begin{array}{l}30 \mathrm{~m}(100 \mathrm{ft}) \text { tall pine tree torches in } 22 \mathrm{~s} \text {; starts off } \\
\text { major fire behind buildings }\end{array}$ & 0 & & \\
\hline TD-058 & $11 / 8$ & 09:44 & video & 0 & 39.775481 & -121.588899 & video & TD, video & trees torching & V & & \\
\hline TD-052 & $11 / 8$ & 09:44 & Photo & 0 & 39.775554 & -121.588966 & Photo & Photo & $\begin{array}{l}\text { very tall pine torching tree behind Savemart (Paradise } \\
\text { Plaza) }\end{array}$ & $\mathrm{v}$ & & \\
\hline PPD-05 & $11 / 8$ & 09:52 & PPD-05 & 0 & 39.767647 & -121.602779 & Radio & Radio & fire in the area of the medical complex & $\mathrm{S}$ & & \\
\hline TD-014 & $11 / 8$ & $10: 00$ & AVL & 0 & 39.722754 & -121.612149 & $A V L$ & Radio Log & approximate fire edge & 0 & & \\
\hline TD-049 & $11 / 8$ & $10: 00$ & Inferred & 15 & 39.742633 & -121.607625 & TD & TD & fire on both sides of road; saw fire tornadoes & $\mathrm{v}$ & & \\
\hline TD-009 & $11 / 8$ & 10:02 & AVL & 0 & 39.738600 & -121.612133 & AVL & TD & fire burning on west side of Clark Rd & v & & \\
\hline TD-009 & $11 / 8$ & 10:04 & AVL & 6 & 39.765638 & -121.602173 & PPD video & TD & fire on both sides of Clark Rd, buildings and vegetation & C & & \\
\hline TD-041 & $11 / 8$ & 10:17 & Inferred & 0 & 39.736709 & -121.612867 & Inferred & TD & $\begin{array}{l}\text { fire just hit; vehicles are burning; flames fully or } \\
\text { partially blocking roadway }\end{array}$ & 0 & & \\
\hline TD-043 & $11 / 8$ & 10:17 & Photo & 0 & 39.785498 & -121.590364 & TD & TD & fire is burning around Station 35 & v & & \\
\hline TD-065 & $11 / 8$ & $10: 18$ & PPD video & 0 & 39.737657 & -121.612787 & TD & TD & bad fire across roadway & 0 & & \\
\hline PPD-02 & $11 / 8$ & $10: 18$ & PPD-02 & 0 & 39.725403 & -121.611852 & Radio & Radio & fire encroaching roadway & $\mathrm{O}$ & & \\
\hline ST9220C & $11 / 8$ & $10: 21$ & Radio Log & 0 & 39.742008 & -121.607632 & $\begin{array}{l}\text { Radio Log, } \\
\text { TD-041 }\end{array}$ & Radio Log & fire is impacting line of traffic on Clark Rd & 0 & & \\
\hline TD-055 & $11 / 8$ & $10: 22$ & Photo & 0 & 39.776884 & -121.588480 & Photo & Photo & structure burning well in garage & $\mathrm{R}$ & & \\
\hline TD-055 & $11 / 8$ & $10: 22$ & Photo & 0 & 39.776875 & -121.588445 & Photo & Photo & $\begin{array}{l}\text { attached garage of duplex fully involved, burning } \\
\text { through roof }\end{array}$ & $\mathrm{R}$ & & \\
\hline PPD-02 & $11 / 8$ & $10: 22$ & PPD-02 & 0 & 39.757446 & -121.606495 & Radio & Radio & north of Nunneley Rd east of Clark Rd is catching on fire & 0 & & \\
\hline TD-110 & $11 / 8$ & $10: 30$ & Inferred & 10 & 39.721618 & -121.612018 & TD-130 & TD & fire on Clark Rd at Airport Rd & $\mathrm{v}$ & & \\
\hline
\end{tabular}




\begin{tabular}{|c|c|c|c|c|c|c|c|c|c|c|c|c|}
\hline \multicolumn{13}{|c|}{ Clark Road } \\
\hline Source \# & Date & Time & $\begin{array}{l}\text { Time } \\
\text { Source }\end{array}$ & $\begin{array}{l}\text { Obs } \\
\text { Window } \\
\text { (min) }\end{array}$ & Latitude & Longitude & $\begin{array}{l}\text { Location } \\
\text { Source }\end{array}$ & Info Source & Fire Behavior Observations & $\begin{array}{l}\text { Type } \\
\text { of } \\
\text { Fire }\end{array}$ & $\begin{array}{l}\text { Residual } \\
\text { Fire? }\end{array}$ & SSI \\
\hline TD-100 & $11 / 8$ & $10: 30$ & TD & 0 & 39.729041 & -121.613179 & TD & TD & spot fires starting on west side of Clark Rd & $\mathrm{s}$ & & \\
\hline PPD-02 & $11 / 8$ & $10: 32$ & PPD-02 & 0 & 39.748595 & -121.607750 & Radio & Radio & fire is overtaking vehicles on Clark Rd & 0 & & \\
\hline TD-041 & $11 / 8$ & 10:35 & TD & 0 & 39.764877 & -121.602483 & TD & TD & $\begin{array}{l}\text { fire is hitting roadway from east; McDonalds just caught } \\
\text { fire }\end{array}$ & C & & \\
\hline TD-058 & $11 / 8$ & 10:35 & Inferred & 0 & 39.765523 & -121.602372 & TD & TD & everything beginning to burn, house on fire & $\mathrm{R}$ & & \\
\hline TD-110 & $11 / 8$ & $10: 40$ & Inferred & 90 & 39.742807 & -121.607651 & TD & TD & all structures are burning & $\mathrm{R}$ & & \\
\hline TD-100 & $11 / 8$ & $10: 40$ & Inferred & 80 & 39.725062 & -121.617719 & TD & TD & area being impacted by spot fires & $\mathrm{S}$ & & \\
\hline VTD-18 & $11 / 8$ & $10: 42$ & TD & 0 & 39.774950 & -121.591186 & video & video & vegetation fire in hedges behind Kmart & v & & \\
\hline VTD-13 & $11 / 8$ & $10: 43$ & Inferred & 0 & 39.783425 & -121.588258 & video & video & spot fire; RV fully involved in storage lot; Kilcrease Cir & 0 & & \\
\hline VTD-13 & $11 / 8$ & $10: 43$ & Inferred & 0 & 39.781345 & -121.589181 & video & video & spot fire & S & & \\
\hline VTD-13 & $11 / 8$ & $10: 43$ & Inferred & 0 & 39.780446 & -121.589681 & video & video & spot fire & $\mathrm{s}$ & & \\
\hline TD-061 & $11 / 8$ & $10: 45$ & Radio Log & 0 & 39.785487 & -121.586511 & Radio Log & Radio Log & $\begin{array}{l}\text { fire is on the [west] side of Clark Rd; Station } 35 \text { and Pine } \\
\text { Springs Mobile Home Park are being impacted }\end{array}$ & 0 & & \\
\hline TD-034 & $11 / 8$ & 10:45 & TD & 0 & 39.749521 & -121.606715 & TD & TD & $\begin{array}{l}\text { conditions deteriorate; field caught fire, wind blowing } \\
\text { flames like blowtorch; spot fires and trees igniting; } \\
\text { embers blowing across street }\end{array}$ & 0 & & \\
\hline TD-065 & $11 / 8$ & $10: 46$ & Inferred & 100 & 39.748784 & -121.607914 & TD & TD & $\begin{array}{l}\text { fire has jumped to west side of Clark Rd at Buschmann } \\
\text { Rd }\end{array}$ & v & & \\
\hline PPD-02 & $11 / 8$ & 10:46 & PPD-02 & 0 & 39.728219 & -121.612847 & Radio & Radio & $\begin{array}{l}\text { fire both sides of roadway, more intense on east side; } \\
\text { roadway is passable one lane }\end{array}$ & v & & \\
\hline VTD-26 & $11 / 8$ & $10: 48$ & Inferred & 0 & 39.771396 & -121.598318 & video & video & spot fire, shed fully involved & $\mathrm{S}$ & & \\
\hline VTD-26 & $11 / 8$ & $10: 48$ & Inferred & 0 & 39.770545 & -121.598027 & video & video & spot fires in parking lot vegetation & $S$ & & \\
\hline VTD-26 & $11 / 8$ & $10: 48$ & Inferred & 0 & 39.770194 & -121.598241 & video & video & spot fires in parking lot vegetation & $S$ & & \\
\hline TD-068 & $11 / 8$ & $10: 50$ & PPD video & 0 & 39.761569 & -121.603057 & TD & TD & fire behind (east) of Safeway & 0 & & \\
\hline VTD-18 & $11 / 8$ & $10: 50$ & TD & 6 & 39.774477 & -121.591098 & video & video & structures burning behind Kmart & $\mathrm{R}$ & & \\
\hline VTD-26 & $11 / 8$ & $10: 50$ & Inferred & 0 & 39.766707 & -121.601342 & video & video & $\begin{array}{l}\text { spot fires burning } 0.1 \text { ha }(0.25 \mathrm{ac}) \text {, light fire activity fine } \\
\text { fuels have already burned }\end{array}$ & s & & \\
\hline PPD-02 & $11 / 8$ & $10: 50$ & PPD-02 & 0 & 39.760515 & -121.603216 & Radio & Radio & fire is right behind Safeway & 0 & & \\
\hline VTD-26 & $11 / 8$ & 10:51 & Inferred & 0 & 39.766295 & -121.602245 & video & video & structure burned to foundation, active flames & $\mathrm{R}$ & $x$ & \\
\hline VTD-26 & $11 / 8$ & $10: 51$ & Inferred & 0 & 39.766089 & -121.601953 & video & video & landscape timbers flaming & 0 & & \\
\hline TD-130 & $11 / 8$ & $10: 51$ & Photo & 0 & 39.722505 & -121.611752 & Photo & Photo & grass field on east side Clark Rd already burned & v & $x$ & \\
\hline TD-130 & $11 / 8$ & $10: 51$ & Photo & 0 & 39.724433 & -121.612262 & Photo & Photo & $\begin{array}{l}\text { southern edge of fire burning in brush and grass, west } \\
\text { side of Clark Rd; past peak, still active fire; fire burning } \\
\text { up against road }\end{array}$ & v & & \\
\hline TD-130 & $11 / 8$ & $10: 51$ & Photo & 0 & 39.726234 & -121.612631 & Photo & Photo & $\begin{array}{l}\text { finger of fire burning on west side of Clark Rd between } \\
\text { Meadowsong and Round Valley Ranch Rd }\end{array}$ & v & & \\
\hline
\end{tabular}




\begin{tabular}{|c|c|c|c|c|c|c|c|c|c|c|c|c|}
\hline \multicolumn{13}{|c|}{ Clark Road } \\
\hline Source \# & Date & Time & $\begin{array}{l}\text { Time } \\
\text { Source }\end{array}$ & $\begin{array}{c}\text { Obs } \\
\text { Window } \\
\text { (min) }\end{array}$ & Latitude & Longitude & $\begin{array}{l}\text { Location } \\
\text { Source }\end{array}$ & Info Source & Fire Behavior Observations & $\begin{array}{c}\text { Type } \\
\text { of } \\
\text { Fire } \\
\end{array}$ & $\begin{array}{l}\text { Residual } \\
\text { Fire? }\end{array}$ & SSI \\
\hline TD-130 & $11 / 8$ & $10: 51$ & Photo & 0 & 39.727207 & -121.611371 & Photo & Photo & $\begin{array}{l}\text { field on east side Clark Rd, past peak burning, still active } \\
\text { spot fires on heavier fuels }\end{array}$ & $\mathrm{v}$ & $\mathrm{x}$ & \\
\hline PPD-02 & $11 / 8$ & $10: 51$ & PPD-02 & 0 & 39.728219 & -121.612847 & Radio & Radio & fire both sides, but is good enough to get through & 0 & & \\
\hline TD-210 & $11 / 8$ & $10: 52$ & AVL & 0 & 39.717203 & -121.607983 & TD-130 & TD & $\begin{array}{l}\text { flames coming from the east towards Clark Rd between } \\
\text { Airport Rd and Round Valley Ranch Rd }\end{array}$ & $\mathrm{V}$ & & \\
\hline VTD-26 & $11 / 8$ & $10: 52$ & Inferred & 0 & 39.765300 & -121.601231 & video & video & well established fire & 0 & & \\
\hline VTD-26 & $11 / 8$ & $10: 52$ & Inferred & 0 & 39.766009 & -121.603098 & video & video & well established fire & 0 & & \\
\hline TD-130 & $11 / 8$ & $10: 53$ & video & 0 & 39.722405 & -121.612190 & video & video & $\begin{array}{l}\text { fire on east side of Clark Rd north of Meadow Song Dr; } \\
\text { nothing really active }\end{array}$ & V & & \\
\hline TD-130 & $11 / 8$ & $10: 53$ & video & 0 & 39.723850 & -121.612007 & video & video & $\begin{array}{l}\text { fire on west side of Clark Rd north of Meadow Song Dr; } \\
\text { not really active }\end{array}$ & V & & \\
\hline VTD-26 & $11 / 8$ & $10: 53$ & Inferred & 0 & 39.765221 & -121.603485 & video & video & structure burning & $\mathrm{R}$ & & \\
\hline VTD-26 & $11 / 8$ & $10: 53$ & Inferred & 0 & 39.764829 & -121.603491 & video & video & $\begin{array}{l}\text { structure early stages of burning from roof, heavy fire } \\
\text { on parcel }\end{array}$ & $\mathrm{R}$ & & \\
\hline VTD-26 & $11 / 8$ & $10: 54$ & Inferred & 0 & 39.764186 & -121.603065 & video & video & structure past peak fully involved & C & & \\
\hline TD-041 & $11 / 8$ & $10: 55$ & Inferred & 0 & 39.785506 & -121.590472 & TD & TD & ground fuels already burned & V & $\mathrm{x}$ & \\
\hline TD-041 & $11 / 8$ & $10: 55$ & Inferred & 0 & 39.784688 & -121.592314 & TD & TD & $\begin{array}{l}\text { one mobile home on fire in Apple Tree Village mobile } \\
\text { homes }\end{array}$ & $\mathrm{R}$ & & \\
\hline VTD-26 & $11 / 8$ & $10: 55$ & Inferred & 0 & 39.762665 & -121.605019 & video & video & spot fire & $\mathrm{s}$ & & \\
\hline TD-034 & $11 / 8$ & 10:57 & TD-130 & 15 & 39.733372 & -121.612600 & TD & TD & fire burned over Clark Rd & 0 & & \\
\hline TD-009 & $11 / 8$ & $10: 59$ & AVL & 4 & 39.785387 & -121.590390 & AVL & TD & fire already burned around Station 35 & v & $\mathrm{x}$ & \\
\hline TD-009 & $11 / 8$ & $10: 59$ & AVL & 4 & 39.783878 & -121.590787 & TD & TD & Apple Tree Village Mobile Home Park actively burning & $\mathrm{R}$ & & \\
\hline TD-035 & $11 / 8$ & 11:00 & Inferred & 30 & 39.759231 & -121.606861 & TD & TD & $\begin{array}{l}\text { blanket caught in powerlines; burning; blanket fell and } \\
\text { ignited bushes at Arco gas station }\end{array}$ & 0 & & \\
\hline TD-035 & $11 / 8$ & $11: 00$ & Inferred & 30 & 39.759231 & -121.606861 & TD & TD & $\begin{array}{l}\text { bushes burning, fire approaches from west behind Arco } \\
\text { gas station }\end{array}$ & $S$ & & \\
\hline TD-041 & $11 / 8$ & 11:00 & Inferred & 0 & 39.784688 & -121.592314 & TD & TD & 10 mobile homes are burning & $\mathrm{R}$ & & \\
\hline TD-100 & $11 / 8$ & $11: 00$ & Inferred & 15 & 39.728204 & -121.612917 & TD & TD & 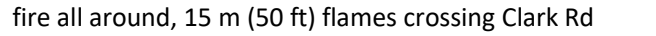 & 0 & & \\
\hline VTD-18 & $11 / 8$ & 11:01 & TD & 0 & 39.774769 & -121.591008 & video & video & structure fully involved & $\mathrm{R}$ & & \\
\hline VTD-18 & $11 / 8$ & 11:01 & TD & 0 & 39.774814 & -121.589873 & video & video & structure fully involved, past peak, roof collapsed & $\mathrm{R}$ & & \\
\hline VTD-18 & $11 / 8$ & $11: 02$ & TD & 0 & 39.774640 & -121.589197 & video & video & structure is burning & $\mathrm{R}$ & & \\
\hline VTD-18 & $11 / 8$ & 11:02 & TD & 0 & 39.774832 & -121.588512 & video & video & structure is fully involved & $\mathrm{R}$ & & \\
\hline TD-211 & $11 / 8$ & 11:08 & AVL & 83 & 39.739484 & -121.610608 & $\mathrm{AVL}$ & TD & fire coming up from drainage; fire both sides of Clark Rd & $\mathrm{v}$ & & \\
\hline TD-037 & $11 / 8$ & 11:09 & Inferred & 21 & 39.761416 & -121.603138 & TD & TD & fire is right behind Safeway & $\mathrm{O}$ & & \\
\hline TD-037 & $11 / 8$ & 11:09 & Inferred & 21 & 39.766955 & -121.600744 & TD & TD & $\begin{array}{l}\text { spotty fire along Clark Rd between Safeway and CMA } \\
\text { Church }\end{array}$ & $\mathrm{S}$ & & \\
\hline
\end{tabular}




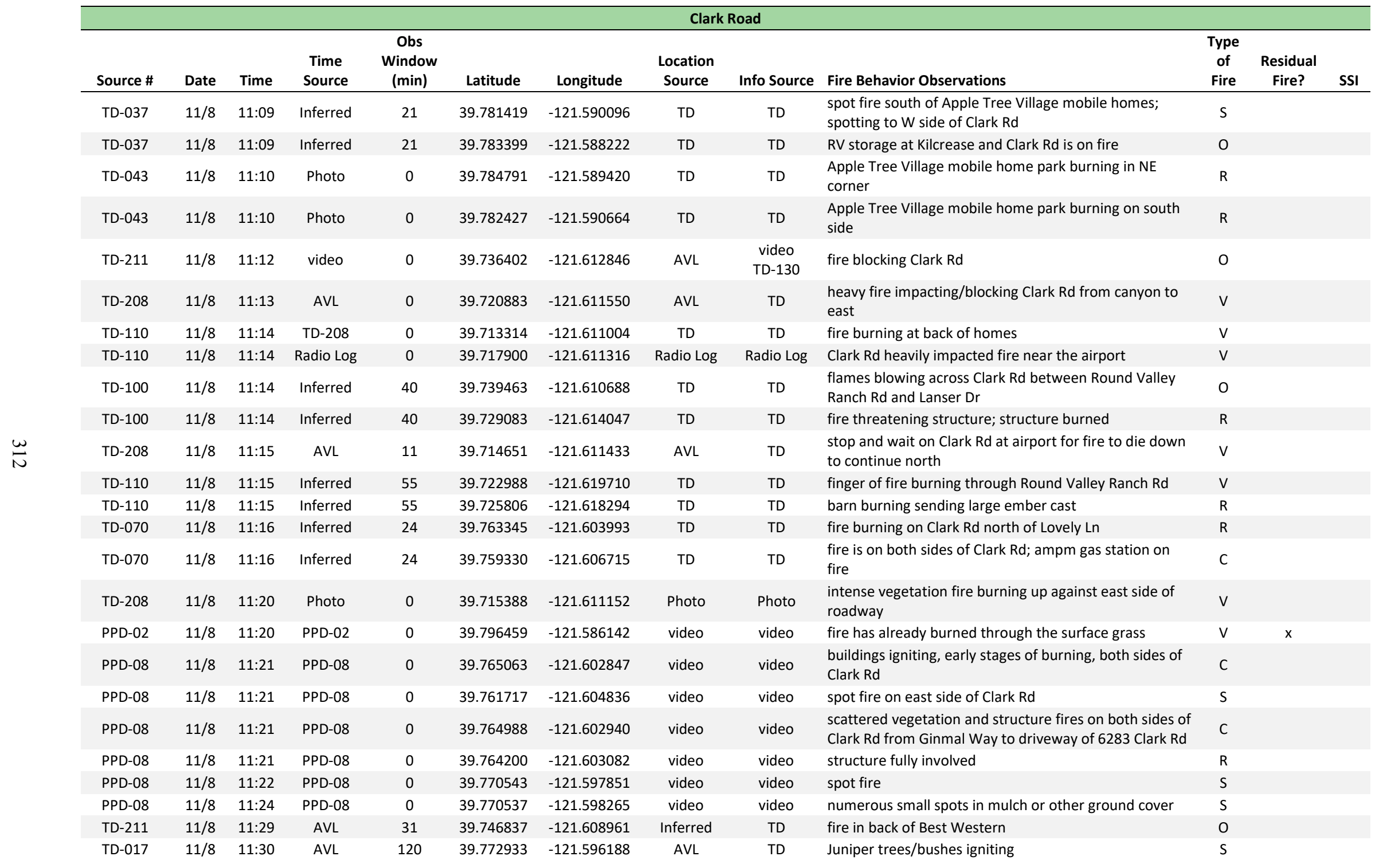




\begin{tabular}{|c|c|c|c|c|c|c|c|c|c|c|c|c|}
\hline \multicolumn{13}{|c|}{ Clark Road } \\
\hline Source \# & Date & Time & $\begin{array}{l}\text { Time } \\
\text { Source }\end{array}$ & $\begin{array}{l}\text { Obs } \\
\text { Window } \\
\text { (min) }\end{array}$ & Latitude & Longitude & $\begin{array}{l}\text { Location } \\
\text { Source }\end{array}$ & Info Source & Fire Behavior Observations & $\begin{array}{l}\text { Type } \\
\text { of } \\
\text { Fire }\end{array}$ & $\begin{array}{l}\text { Residual } \\
\text { Fire? }\end{array}$ & SSI \\
\hline TD-208 & $11 / 8$ & 11:30 & AVL & 4 & 39.738883 & -121.611750 & AVL & TD & $\begin{array}{l}\text { stop and wait for fire front to cross Clark Rd; drive } \\
\text { through fire; fire everywhere; foam line on engine } \\
\text { burned up }\end{array}$ & v & & \\
\hline TD-035 & $11 / 8$ & 11:30 & Inferred & 90 & 39.749298 & -121.607732 & TD & TD & $\begin{array}{l}\text { PGE yard bush pile: blow torching the road at } \\
\text { Buschmann Rd; Clark Rd impassable }\end{array}$ & 0 & & \\
\hline TD-035 & $11 / 8$ & 11:30 & Inferred & 90 & 39.743165 & -121.607652 & TD & TD & fire across roadway & 0 & & \\
\hline TD-037 & $11 / 8$ & $11: 30$ & TD & 40 & 39.785750 & -121.589174 & TD & TD & vegetation fire near the Station 35 (east) & v & & \\
\hline TD-037 & $11 / 8$ & 11:30 & TD & 40 & 39.755005 & -121.605692 & TD & TD & glow of fire east of Clark Rd near Nunneley Rd & 0 & & \\
\hline PPD-08 & $11 / 8$ & 11:32 & PPD-08 & 0 & 39.748590 & -121.607695 & Radio & Radio & fire getting really close to the roadway & 0 & & \\
\hline TD-017 & $11 / 8$ & 11:34 & AVL & 116 & 39.776363 & -121.589966 & $\mathrm{AVL}$ & TD & $\begin{array}{l}\text { Kmart threatened, front side of Kmart shrubs catching } \\
\text { fire. }\end{array}$ & $S$ & & \\
\hline TD-015 & $11 / 8$ & 11:35 & AVL & 123 & 39.776164 & -121.587283 & TD & TD & fire around Kmart shopping center & 0 & & \\
\hline TD-034 & $11 / 8$ & 11:36 & Photo & 0 & 39.759236 & -121.606715 & Photo & TD & vegetation on fire at Arco gas station & $S$ & & \\
\hline TD-034 & $11 / 8$ & 11:36 & Photo & 0 & 39.759105 & -121.606886 & Photo & Photo & shrubs on fire at Arco gas station & $\mathrm{V}$ & & \\
\hline TD-034 & $11 / 8$ & 11:36 & Photo & 0 & 39.759105 & -121.606886 & Photo & Photo & shrubs on fire at Arco gas station & v & & \\
\hline TD-034 & $11 / 8$ & 11:36 & Photo & 0 & 39.758695 & -121.607074 & Photo & Photo & $\begin{array}{l}\text { surface vegetation (grass), ladder fuels have burned, } \\
\text { light flaming }\end{array}$ & v & $\mathrm{x}$ & \\
\hline TD-034 & $11 / 8$ & 11:36 & Photo & 0 & 39.756540 & -121.607102 & Photo & Photo & spot fire, vegetation & S & & \\
\hline TD-208 & $11 / 8$ & 11:37 & $\mathrm{AVL}$ & 63 & 39.746617 & -121.608183 & AVL & TD & vegetation and structures nearby are burning & $\mathrm{R}$ & & \\
\hline TD-034 & $11 / 8$ & 11:37 & Photo & 0 & 39.756540 & -121.607102 & Photo & Photo & spot fire, vegetation & $S$ & & \\
\hline PPD-08 & $11 / 8$ & 11:39 & PPD-08 & 0 & 39.751943 & -121.607344 & Radio & Radio & fire coming up to Pearson Rd and Clark Rd & 0 & & \\
\hline TD-041 & $11 / 8$ & 11:40 & Inferred & 0 & 39.797653 & -121.581882 & TD & TD & houses on Gate Ln are igniting, spreading south & $\mathrm{R}$ & & \\
\hline PPD-08 & $11 / 8$ & 11:42 & PPD-08 & 0 & 39.759119 & -121.606887 & video & video & bushes on fire at am $/ \mathrm{pm}$ gas station & $\mathrm{S}$ & & \\
\hline PPD-08 & $11 / 8$ & 11:42 & PPD-08 & 0 & 39.761647 & -121.605168 & video & video & $\begin{array}{l}\text { light surface fire activity between here and } 6166 \text { Clark } \\
\text { Rd }\end{array}$ & V & & \\
\hline PPD-08 & $11 / 8$ & 11:42 & PPD-08 & 0 & 39.764169 & -121.603084 & video & video & structure fully involved & $\mathrm{R}$ & & \\
\hline PPD-08 & $11 / 8$ & 11:42 & PPD-08 & 0 & 39.764624 & -121.603185 & video & video & heavy fire activity, both sides of Clark Rd & C & & \\
\hline PPD-08 & $11 / 8$ & 11:43 & PPD-08 & 0 & 39.765112 & -121.602815 & video & video & $\begin{array}{l}\text { structures both sides Clark Rd fully involved at Central } \\
\text { Park Dr }\end{array}$ & C & & \\
\hline PPD-08 & $11 / 8$ & 11:43 & PPD-08 & 0 & 39.769994 & -121.598432 & video & video & vegetation spot fire on west side Clark Rd at KFC & $S$ & & \\
\hline PPD-08 & $11 / 8$ & 11:44 & PPD-08 & 0 & 39.778894 & -121.589724 & video & video & spot fire on both sides of Clark Rd & S & & \\
\hline PPD-08 & $11 / 8$ & 11:44 & PPD-08 & 0 & 39.779241 & -121.589570 & video & video & spot fire on east side Clark Rd & s & & \\
\hline PPD-08 & $11 / 8$ & 11:44 & PPD-08 & 0 & 39.781161 & -121.588972 & video & video & $\begin{array}{l}\text { moderate fire west side of Clark Rd between Jones Ln } \\
\text { and Mayhew Ln }\end{array}$ & $\mathrm{O}$ & & \\
\hline TD-130 & $11 / 8$ & 11:45 & video & 0 & 39.752808 & -121.605317 & video & video & $\begin{array}{l}\text { spot fires on north side of Pearson Rd at Brookview } \\
\text { Way }\end{array}$ & S & & \\
\hline
\end{tabular}




\begin{tabular}{|c|c|c|c|c|c|c|c|c|c|c|c|c|}
\hline \multicolumn{13}{|c|}{ Clark Road } \\
\hline Source \# & Date & Time & $\begin{array}{l}\text { Time } \\
\text { Source }\end{array}$ & $\begin{array}{c}\text { Obs } \\
\text { Window } \\
\text { (min) }\end{array}$ & Latitude & Longitude & $\begin{array}{l}\text { Location } \\
\text { Source }\end{array}$ & Info Source & Fire Behavior Observations & $\begin{array}{l}\text { Type } \\
\text { of } \\
\text { Fire }\end{array}$ & $\begin{array}{l}\text { Residual } \\
\text { Fire? }\end{array}$ & SSI \\
\hline TD-130 & $11 / 8$ & 11:45 & Photo & 0 & 39.752761 & -121.605406 & Photo & Photo & $\begin{array}{l}\text { area of ground fire in heavy brush; blowing brands; } \\
\text { flames up to } 4.6 \mathrm{~m} \text { (15ft) }\end{array}$ & v & & \\
\hline TD-130 & $11 / 8$ & 11:45 & Photo & 0 & 39.750398 & -121.607079 & Photo & Photo & $\begin{array}{l}\text { field and vegetation south of Ace Hardware is burning } \\
\text { up to fence and Clark Rd }\end{array}$ & v & & \\
\hline TD-130 & $11 / 8$ & 11:45 & Photo & 0 & 39.749080 & -121.608090 & Photo & Photo & $\begin{array}{l}\text { mulch/slash piles at Buschmann Rd and Clark Rd are } \\
\text { burning }\end{array}$ & 0 & & \\
\hline TD-130 & $11 / 8$ & $11: 45$ & Photo & 0 & 39.748598 & -121.607111 & Photo & Photo & widespread heavy fire; surface vegetation, trees & $\mathrm{V}$ & & \\
\hline PPD-08 & $11 / 8$ & 11:45 & PPD-08 & 0 & 39.783211 & -121.587706 & video & video & fire both sides of Clark Rd at Kilcrease Cir & 0 & & \\
\hline PPD-08 & $11 / 8$ & 11:45 & PPD-08 & 0 & 39.787001 & -121.585706 & video & video & spot fire; fence burning east side of Clark Rd & s & & \\
\hline PPD-08 & $11 / 8$ & $11: 45$ & PPD-08 & 0 & 39.789105 & -121.585285 & video & video & spot fire east side Clark Rd & $\mathrm{s}$ & & \\
\hline PPD-08 & $11 / 8$ & 11:45 & PPD-08 & 0 & 39.789631 & -121.585398 & video & video & spot fire east side Clark Rd & $S$ & & \\
\hline PPD-08 & $11 / 8$ & 11:45 & PPD-08 & 0 & 39.790221 & -121.585838 & video & video & yard and fence on west side Clark Rd lots of fire & 0 & & \\
\hline PPD-08 & $11 / 8$ & $11: 45$ & PPD-08 & 0 & 39.790549 & -121.585444 & video & video & spot fire on fence east side Clark Rd at Frankie & $\mathrm{S}$ & & \\
\hline PPD-08 & $11 / 8$ & 11:45 & PPD-08 & 0 & 39.792145 & -121.585029 & video & video & fire on east side of Clark Rd & 0 & & \\
\hline PPD-08 & $11 / 8$ & 11:46 & PPD-08 & 0 & 39.795540 & -121.584477 & video & video & surface spot fire east side Clark Rd & S & & \\
\hline TD-130 & $11 / 8$ & $11: 49$ & video & 0 & 39.748638 & -121.607720 & video & video & $\begin{array}{l}\text { fire still burning on both sides of Clark Rd at Buschmann } \\
\text { Rd, fire past peak }\end{array}$ & $\mathrm{v}$ & $\mathrm{x}$ & \\
\hline TD-130 & $11 / 8$ & $11: 52$ & AVL & 24 & 39.751002 & -121.606774 & AVL & TD & storage units burning at Ace Hardware & C & & \\
\hline PPD-10 & $11 / 8$ & 11:53 & PPD-10 & 0 & 39.799650 & -121.584492 & video & video & spot fire & S & & \\
\hline PPD-08 & $11 / 8$ & 11:53 & PPD-08 & 0 & 39.748594 & -121.607721 & Radio & Radio & Clark Rd SB south of Buschmann Rd is engulfed in fire & 0 & & \\
\hline TD-100 & $11 / 8$ & 11:54 & Photo & 7 & 39.733511 & -121.612977 & TD & Photo & structure, past peak, fully involved & $\mathrm{R}$ & & \\
\hline TD-101 & $11 / 8$ & $11: 54$ & Photo & 0 & 39.733162 & -121.612876 & Photo & Photo & $\begin{array}{l}\text { past peak, post-fire front vegetation fire, heavy fuels } \\
\text { still burning; structures fully involved, outbuildings } \\
\text { collapsed and burning }\end{array}$ & $\mathrm{R}$ & & \\
\hline PPD-08 & $11 / 8$ & 11:54 & PPD-08 & 0 & 39.755908 & -121.607380 & Radio & Radio & $\begin{array}{l}\text { multiple structures on fire, on Clark Rd and Nunneley } \\
\text { Rd and east of there }\end{array}$ & $\mathrm{R}$ & & \\
\hline PPD-12 & $11 / 8$ & $11: 56$ & PPD-12 & 0 & 39.799928 & -121.585323 & video & video & fire behind storage facility & 0 & & \\
\hline PPD-12 & $11 / 8$ & $11: 56$ & PPD-12 & 0 & 39.799126 & -121.586712 & video & video & spot fire & $\mathrm{s}$ & & \\
\hline PPD-08 & $11 / 8$ & 11:56 & PPD-08 & 0 & 39.792757 & -121.585194 & video & video & fire spotted to west side of Clark Rd & S & & \\
\hline PPD-08 & $11 / 8$ & 11:57 & PPD-08 & 0 & 39.790782 & -121.585722 & video & video & $\begin{array}{l}\text { fire on west side of Clark Rd has spread to north side of } \\
\text { Pheasant Ridge Dr }\end{array}$ & 0 & & \\
\hline PPD-08 & $11 / 8$ & 11:57 & PPD-08 & 0 & 39.789676 & -121.585782 & video & video & $\begin{array}{l}\text { heavy vegetation fire both sides Clark Rd between } \\
\text { Franke Ln and Eaglet Way }\end{array}$ & v & & \\
\hline PPD-08 & $11 / 8$ & $11: 57$ & PPD-08 & 1 & 39.784281 & -121.586722 & video & video & $\begin{array}{l}\text { heavy fire both sides of Clark Rd between Kimberly Ln } \\
\text { and Adams Rd }\end{array}$ & 0 & & \\
\hline PPD-08 & $11 / 8$ & 11:57 & PPD-08 & 1 & 39.781323 & -121.589097 & video & video & $\begin{array}{l}\text { heavy fire on west side Clark Rd between Adams Rd and } \\
\text { Jones } \operatorname{Ln}\end{array}$ & 0 & & \\
\hline
\end{tabular}




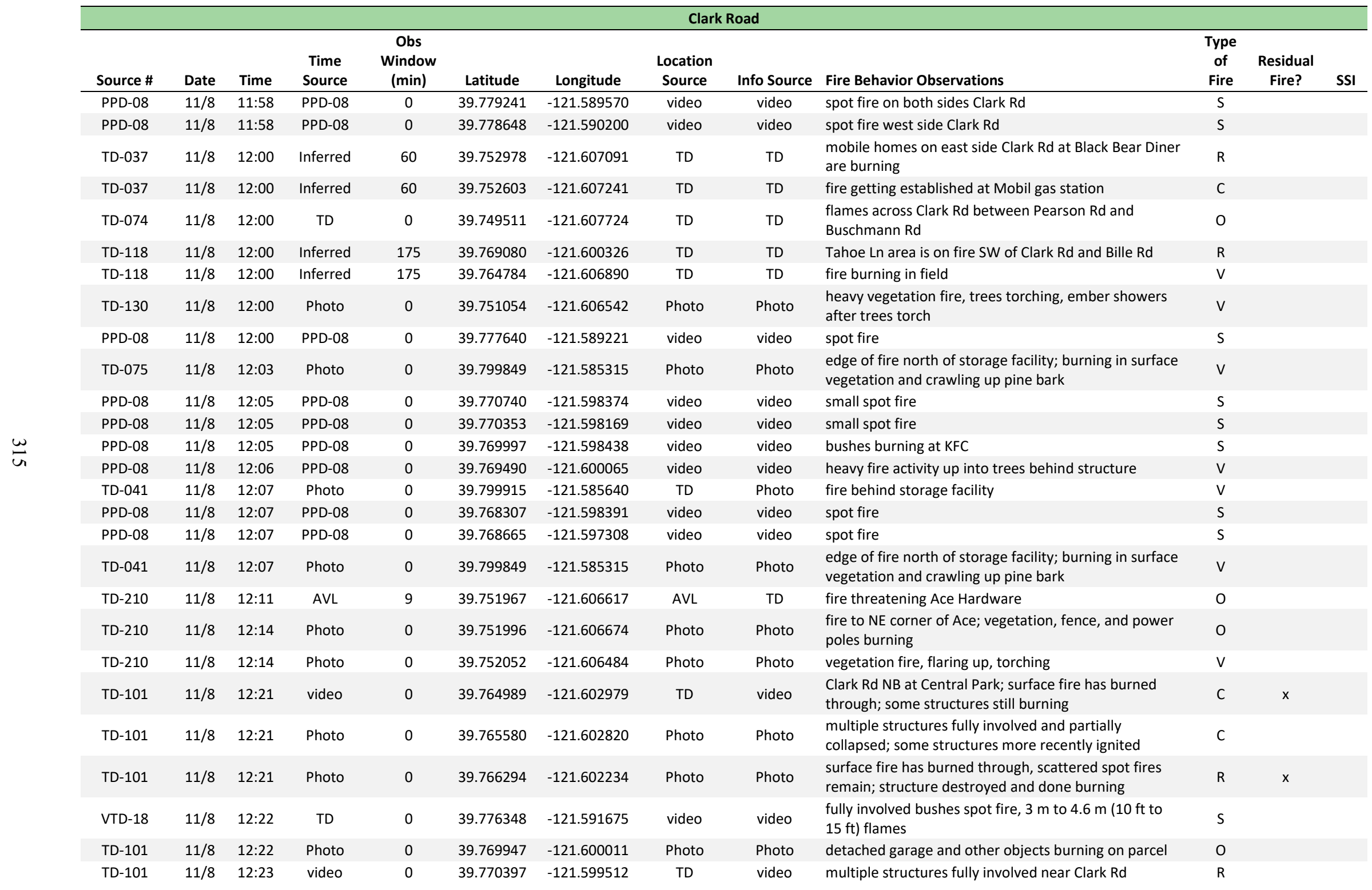




\begin{tabular}{|c|c|c|c|c|c|c|c|c|c|c|c|c|}
\hline & & & & & & & Clark & Road & & & & \\
\hline Source \# & Date & Time & $\begin{array}{l}\text { Time } \\
\text { Source }\end{array}$ & $\begin{array}{l}\text { Obs } \\
\text { Window } \\
\text { (min) }\end{array}$ & Latitude & Longitude & $\begin{array}{l}\text { Location } \\
\text { Source }\end{array}$ & Info Source & Fire Behavior Observations & $\begin{array}{l}\text { Type } \\
\text { of } \\
\text { Fire }\end{array}$ & $\begin{array}{l}\text { Residual } \\
\text { Fire? }\end{array}$ & SSI \\
\hline PPD-08 & $11 / 8$ & $12: 25$ & PPD-08 & 0 & 39.714572 & -121.611551 & Radio & Radio & Clark Rd past the airport, it clears up, its barely passable & $\mathrm{V}$ & & \\
\hline PPD-08 & $11 / 8$ & 12:26 & PPD-08 & 0 & 39.769760 & -121.599110 & video & video & vegetation on fire & V & & \\
\hline PPD-08 & $11 / 8$ & $12: 27$ & PPD-08 & 0 & 39.762878 & -121.604324 & video & video & $\begin{array}{l}\text { majority of structures fully involved, past peak surface } \\
\text { fire still burning between Central Park and Elliott Rd }\end{array}$ & C & & \\
\hline PPD-08 & $11 / 8$ & $12: 28$ & PPD-08 & 0 & 39.757804 & -121.606980 & video & video & $\begin{array}{l}\text { limited structures burning close to roadway (fewer } \\
\text { structures here, mostly parking lots along road), } \\
\text { moderate surface fires between Elliott Rd and Nunneley } \\
\text { Rd on Clark Rd }\end{array}$ & C & & \\
\hline PPD-08 & $11 / 8$ & $12: 28$ & PPD-08 & 0 & 39.754219 & -121.607751 & video & video & $\begin{array}{l}\text { minimal fire visible between Nunneley Rd and Pearson } \\
\text { Rd }\end{array}$ & $\mathrm{O}$ & $\mathrm{x}$ & \\
\hline PPD-08 & $11 / 8$ & $12: 29$ & PPD-08 & 0 & 39.751950 & -121.609656 & video & video & spot fire south side of Pearson Rd & S & & \\
\hline PPD-08 & $11 / 8$ & $12: 29$ & PPD-08 & 0 & 39.752580 & -121.610136 & video & video & spot fire north side of Pearson Rd & $\mathrm{S}$ & & \\
\hline VTD-18 & $11 / 8$ & $12: 30$ & TD & 0 & 39.778248 & -121.590467 & Photo & Photo & spot fire, bushes/vegetation & $\mathrm{S}$ & & \\
\hline VTD-18 & $11 / 8$ & $12: 30$ & TD & 0 & 39.778062 & -121.591908 & Photo & Photo & heavy fire, multiple structures burning & $\mathrm{R}$ & & \\
\hline TD-211 & $11 / 8$ & $12: 31$ & AVL & 80 & 39.725607 & -121.617260 & AVL & TD & fire coming from both sides Round Valley Ranch Rd & V & & \\
\hline TD-211 & $11 / 8$ & $12: 31$ & AVL & 80 & 39.725129 & -121.617635 & TD & TD & fire threatening structures & 0 & & \\
\hline TD-208 & $11 / 8$ & $12: 32$ & Photo & 0 & 39.746996 & -121.608046 & Photo & Photo & structure fully involved & $\mathrm{R}$ & & \\
\hline TD-208 & $11 / 8$ & $12: 32$ & Photo & 0 & 39.746174 & -121.608155 & Photo & Photo & spot fire & S & & \\
\hline TD-208 & $11 / 8$ & $12: 32$ & Photo & 0 & 39.746861 & -121.608476 & Photo & Photo & $\begin{array}{l}\text { heavy vegetation fire; numerous spot fires north side of } \\
\text { Best Western; wind gusty from east, blowing embers }\end{array}$ & v & & \\
\hline VTD-15 & $11 / 8$ & $12: 36$ & video & 2 & 39.740809 & -121.608013 & video & video & $\begin{array}{l}\text { everything burning, past peak, Clark Rd between } \\
\text { Buschmann Rd and Old Clark Rd (South) }\end{array}$ & 0 & $\mathrm{x}$ & \\
\hline TD-130 & $11 / 8$ & $12: 36$ & Photo & 0 & 39.752223 & -121.605562 & Photo & Photo & $\begin{array}{l}\text { vegetation past peak, still burning; consumed } \\
\text { throughout drainage, burning right up to roadway and } \\
\text { Ace Hardware parking lot }\end{array}$ & V & & \\
\hline TD-130 & $11 / 8$ & $12: 39$ & video & 0 & 39.749956 & -121.607664 & video & video & $\begin{array}{l}\text { Clark Rd between Pearson Rd and Village Pkwy; fire on } \\
\text { east side of Clark Rd [video does not show west side] }\end{array}$ & 0 & & \\
\hline VTD-06 & $11 / 8$ & $12: 43$ & video & 0 & 39.716547 & -121.611489 & video & video & $\begin{array}{l}\text { fire burning through guardrail posts; burning branches } \\
\text { in roadway }\end{array}$ & 0 & & \\
\hline VTD-06 & $11 / 8$ & $12: 44$ & video & 0 & 39.714643 & -121.611293 & video & video & heavy fire on Good View Dr, structures burning & $\mathrm{R}$ & & \\
\hline VTD-06 & $11 / 8$ & $12: 44$ & video & 0 & 39.713455 & -121.610877 & video & video & structures fully involved & $\mathrm{R}$ & & \\
\hline VTD-06 & $11 / 8$ & $12: 45$ & Inferred & 0 & 39.712525 & -121.614676 & video & video & $\begin{array}{l}\text { heavy vegetation fire near airport, } 30 \mathrm{~m}(100 \mathrm{ft}) \text { flames, } \\
\text { across canyon from Clark Rd }\end{array}$ & V & & \\
\hline VTD-18 & $11 / 8$ & $12: 47$ & TD & 0 & 39.776198 & -121.591813 & Photo & video & juniper bush spot fire & S & & \\
\hline TD-015 & $11 / 8$ & 12:53 & AVL & 0 & 39.780467 & -121.589150 & AVL & TD & fire all around & 0 & & \\
\hline TD-130 & $11 / 8$ & 12:57 & AVL & 3 & 39.741383 & -121.606783 & AVL & TD & house is gone & $\mathrm{R}$ & $\mathrm{x}$ & \\
\hline TD-208 & $11 / 8$ & $12: 57$ & AVL & 2 & 39.741283 & -121.607000 & AVL & TD & structure $1 / 2$ involved & $\mathrm{R}$ & & \\
\hline
\end{tabular}




\begin{tabular}{|c|c|c|c|c|c|c|c|c|c|c|c|c|}
\hline \multicolumn{13}{|c|}{ Clark Road } \\
\hline Source \# & Date & Time & $\begin{array}{l}\text { Time } \\
\text { Source }\end{array}$ & $\begin{array}{c}\text { Obs } \\
\text { Window } \\
\text { (min) }\end{array}$ & Latitude & Longitude & $\begin{array}{l}\text { Location } \\
\text { Source }\end{array}$ & Info Source & Fire Behavior Observations & $\begin{array}{c}\text { Type } \\
\text { of } \\
\text { Fire }\end{array}$ & $\begin{array}{l}\text { Residual } \\
\text { Fire? }\end{array}$ & SSI \\
\hline TD-035 & $11 / 8$ & $13: 00$ & Inferred & 60 & 39.717701 & -121.611365 & TD & TD & $\begin{array}{l}\text { fire activity made evacuation route dicey near the } \\
\text { airport }\end{array}$ & V & & \\
\hline TD-038 & $11 / 8$ & $13: 00$ & Inferred & 10 & 39.768540 & -121.599650 & TD & TD & fire blowing across Clark Rd; driving through flames & 0 & & \\
\hline TD-041 & $11 / 8$ & 13:10 & Inferred & 0 & 39.798287 & -121.585027 & TD & TD & fire in tree & V & & \\
\hline TD-041 & $11 / 8$ & $13: 10$ & Inferred & 50 & 39.798494 & -121.585064 & TD & TD & spotty fires around area & $\mathrm{s}$ & & \\
\hline TD-021 & $11 / 8$ & $13: 10$ & Inferred & 0 & 39.753690 & -121.607734 & TD & TD & heavy fire & 0 & & \\
\hline TD-210 & $11 / 8$ & 13:12 & AVL & 0 & 39.759517 & -121.604150 & AVL & TD & structures in area had burned & $\mathrm{R}$ & $x$ & \\
\hline VTD-18 & $11 / 8$ & $13: 13$ & TD & 0 & 39.777167 & -121.588813 & video & video & $\begin{array}{l}\text { all structures behind Savemart are past peak, fully } \\
\text { involved, partially collapsed }\end{array}$ & $\mathrm{R}$ & $x$ & \\
\hline TD-011 & $11 / 8$ & 13:15 & TD & 15 & 39.764868 & -121.603000 & TD & TD & structures on Clark Rd are burning & $\mathrm{R}$ & & \\
\hline TD-130 & $11 / 8$ & 13:17 & AVL & 2 & 39.755365 & -121.607103 & AVL & TD & commercial building on fire & C & & \\
\hline TD-208 & $11 / 8$ & $13: 20$ & AVL & 0 & 39.714651 & -121.611433 & AVL & TD & fire edge & V & & \\
\hline TD-130 & $11 / 8$ & $13: 21$ & AVL & 0 & 39.752601 & -121.607492 & AVL & TD & Mobil gas station on fire & C & & \\
\hline TD-067 & $11 / 8$ & $13: 22$ & PPD video & 0 & 39.799159 & -121.586737 & TD & TD & fire coming up Bader Mine Rd from canyon & V & & \\
\hline PPD-13 & $11 / 8$ & $13: 22$ & PPD-13 & 0 & 39.798207 & -121.586070 & video & video & spot fire & $\mathrm{s}$ & & \\
\hline PPD-13 & $11 / 8$ & $13: 22$ & PPD-13 & 0 & 39.799188 & -121.583946 & video & video & main fire north of here & 0 & & \\
\hline PPD-13 & $11 / 8$ & $13: 22$ & PPD-13 & 0 & 39.799765 & -121.586140 & video & video & spot fire & $\mathrm{s}$ & & \\
\hline TD-014 & $11 / 8$ & $13: 23$ & Radio Log & 0 & 39.748125 & -121.609620 & Radio Log & Radio Log & fire in the building & $\mathrm{R}$ & & \\
\hline TD-112 & $11 / 8$ & $13: 23$ & Radio Log & 0 & 39.748140 & -121.609663 & Radio Log & Radio Log & structure on fire & $\mathrm{R}$ & & \\
\hline TD-041 & $11 / 8$ & $13: 23$ & Photo & 23 & 39.798089 & -121.585145 & TD & TD & Optimo restaurant has just caught fire & C & & \\
\hline VTD-18 & $11 / 8$ & $13: 23$ & TD & 0 & 39.774450 & -121.591091 & video & video & multiple structures burned to foundation & $\mathrm{R}$ & $x$ & \\
\hline VTD-18 & $11 / 8$ & $13: 23$ & TD & 0 & 39.774694 & -121.591381 & video & video & structure fire; north half house fully involved & $\mathrm{R}$ & & \\
\hline VTD-18 & $11 / 8$ & $13: 23$ & TD & 0 & 39.774275 & -121.590787 & video & video & structure past peak fully involved & $\mathrm{R}$ & & \\
\hline VTD-18 & $11 / 8$ & $13: 24$ & TD & 0 & 39.774497 & -121.589959 & video & video & structures burned to foundations & $\mathrm{R}$ & $\mathrm{x}$ & \\
\hline TD-112 & $11 / 8$ & $13: 25$ & Radio Log & 0 & 39.748140 & -121.609663 & Radio Log & Radio Log & apartments: 3 complexes well involved & $\mathrm{R}$ & & \\
\hline TD-112 & $11 / 8$ & $13: 25$ & Inferred & 8 & 39.747739 & -121.609668 & Radio Log & TD & half of apartment complex fully involved & $\mathrm{R}$ & & \\
\hline TD-127 & $11 / 8$ & $13: 27$ & Radio Log & 0 & 39.798250 & -121.585384 & Radio Log & Radio Log & heavy fire conditions & 0 & & \\
\hline TD-127 & $11 / 8$ & 13:36 & Photo & 0 & 39.799451 & -121.584237 & Photo & Photo & heavy fire, fully involved structure and vegetation & $\mathrm{R}$ & & \\
\hline TD-127 & $11 / 8$ & 13:36 & Photo & 0 & 39.799247 & -121.584012 & Photo & Photo & vegetation and structure fully involved & $\mathrm{R}$ & & \\
\hline VTD-18 & $11 / 8$ & $13: 40$ & TD & 0 & 39.774694 & -121.591381 & video & video & house fully involved & $\mathrm{R}$ & & \\
\hline VTD-18 & $11 / 8$ & $13: 40$ & TD & 0 & 39.773954 & -121.590229 & video & video & structure burning & $\mathrm{R}$ & & \\
\hline VTD-18 & $11 / 8$ & 13:41 & TD & 0 & 39.774138 & -121.591190 & video & video & small spot fires in garden vegetation & $\mathrm{S}$ & & \\
\hline TD-123 & $11 / 8$ & 13:46 & $\mathrm{AVL}$ & 42 & 39.751025 & -121.607178 & AVL & TD & back of Ace Hardware on fire; PVC stacks on fire & C & & \\
\hline TD-127 & $11 / 8$ & $13: 46$ & Photo & 0 & 39.799357 & -121.584105 & Photo & Photo & structure past peak, fully involved & $\mathrm{R}$ & & \\
\hline TD-127 & $11 / 8$ & $13: 46$ & Photo & 0 & 39.798653 & -121.584304 & Photo & Photo & pine tree; trunk/bark burning to the top & v & & \\
\hline TD-041 & $11 / 8$ & $13: 50$ & Photo & 0 & 39.799357 & -121.584105 & Photo & Photo & structure past peak, fully involved & $\mathrm{R}$ & & \\
\hline
\end{tabular}




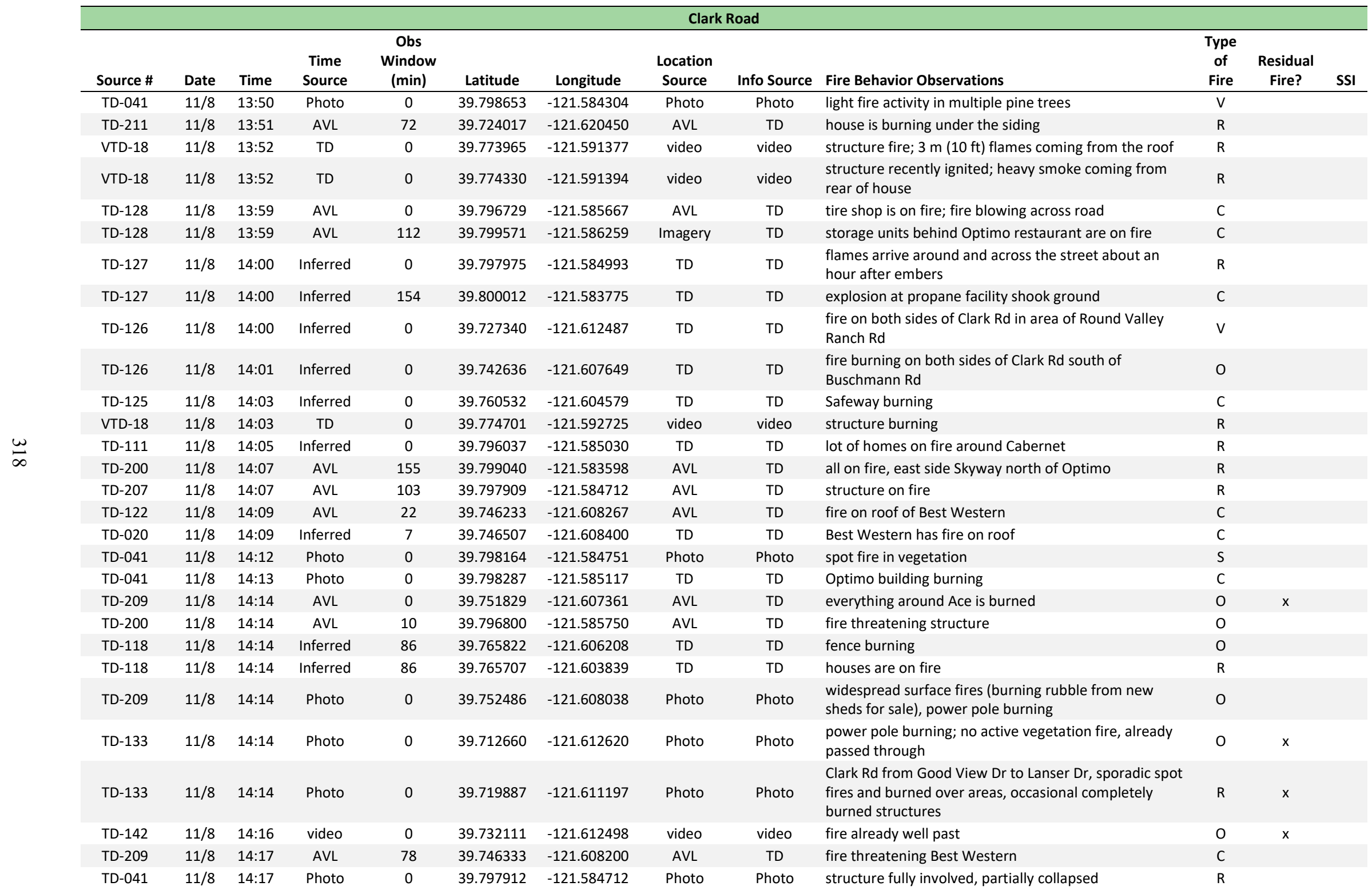




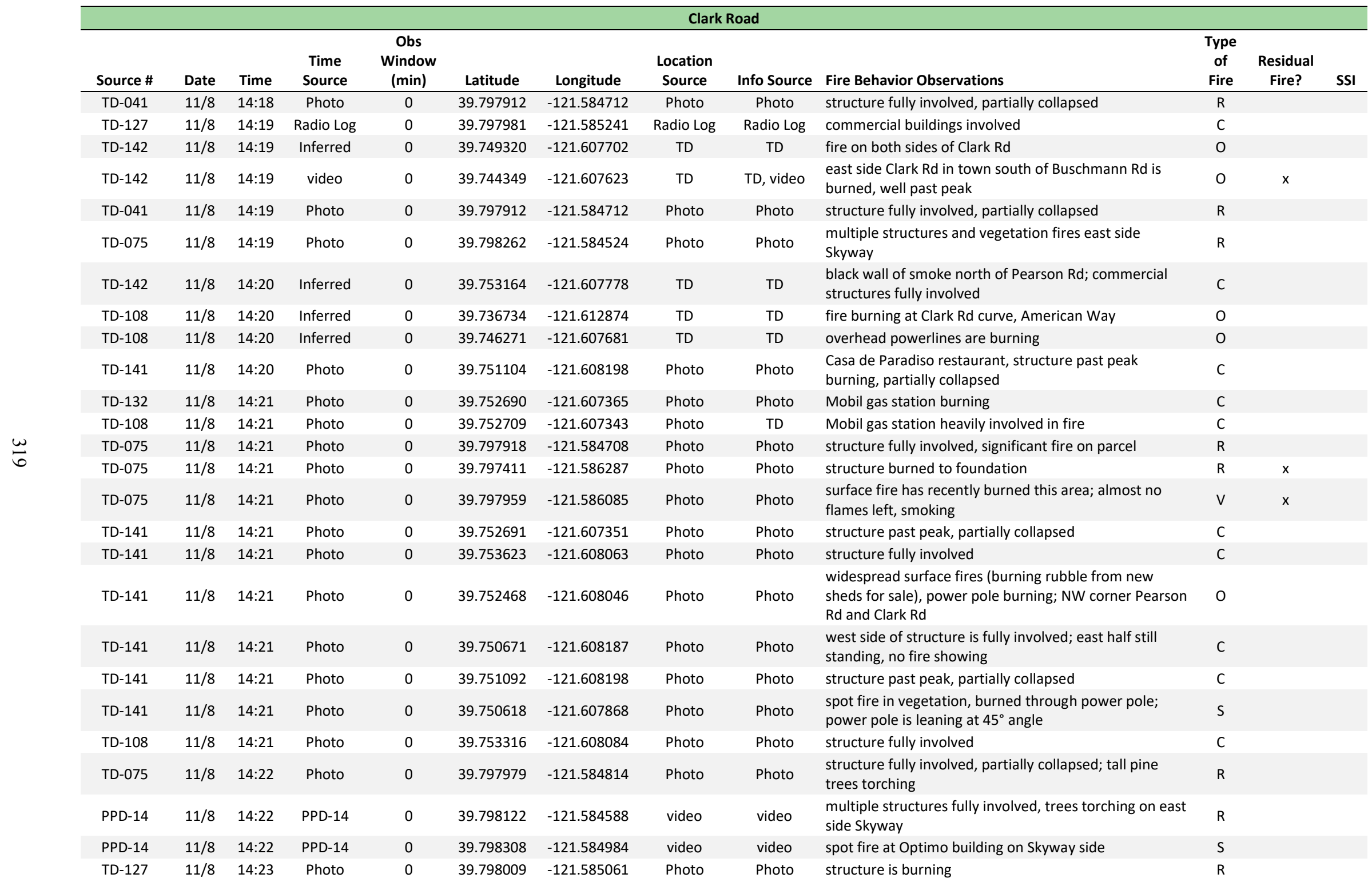




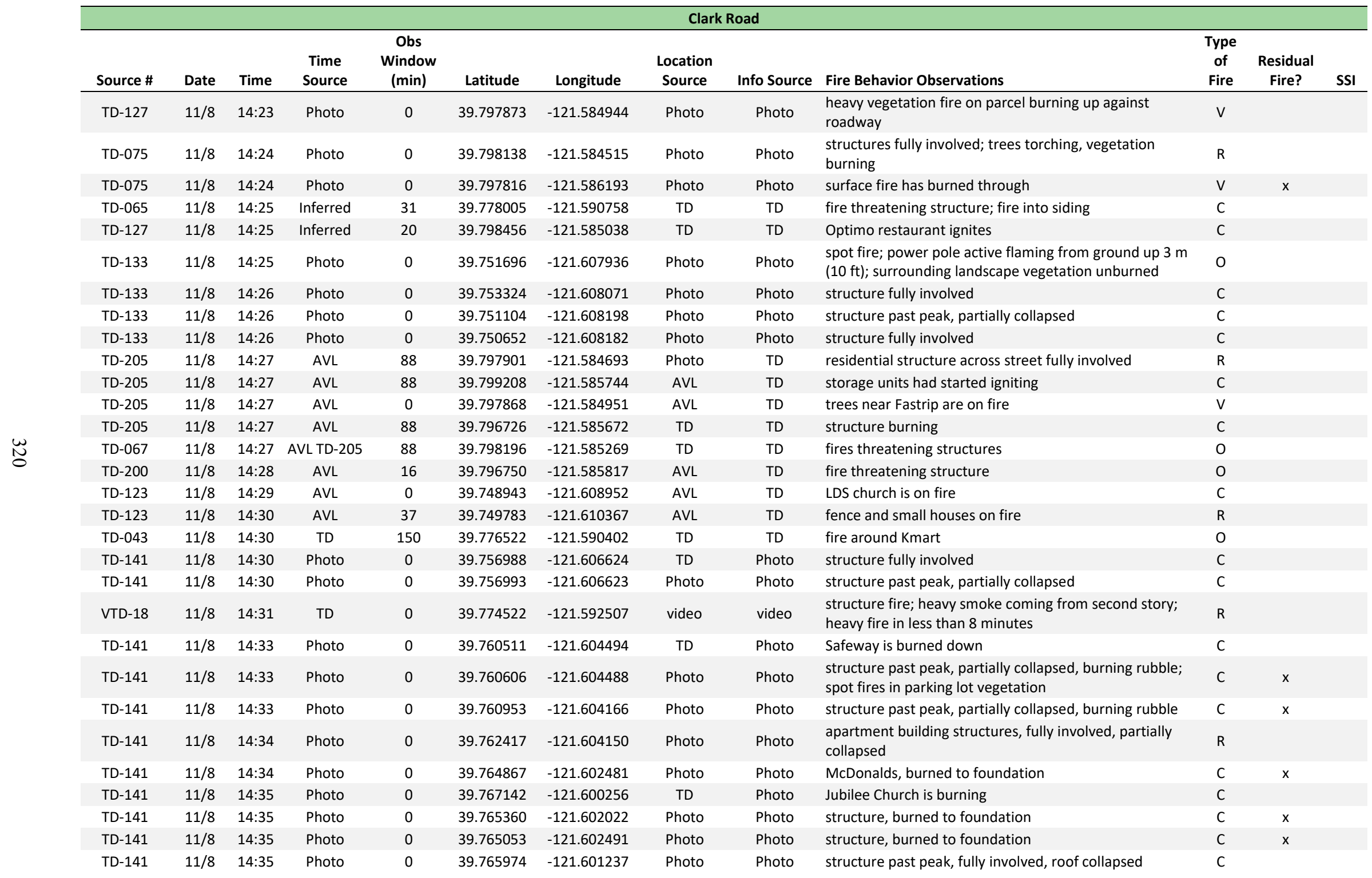




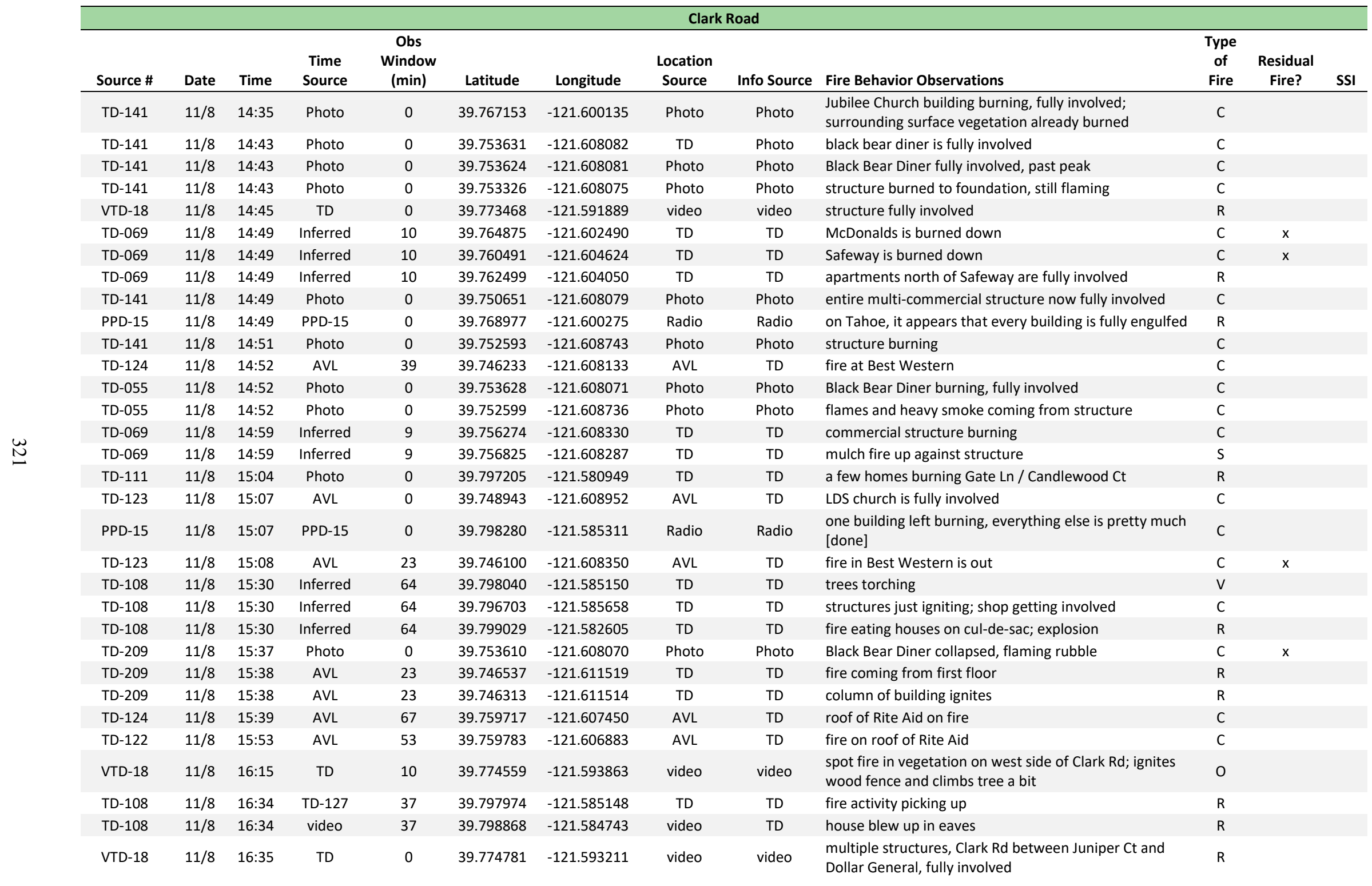




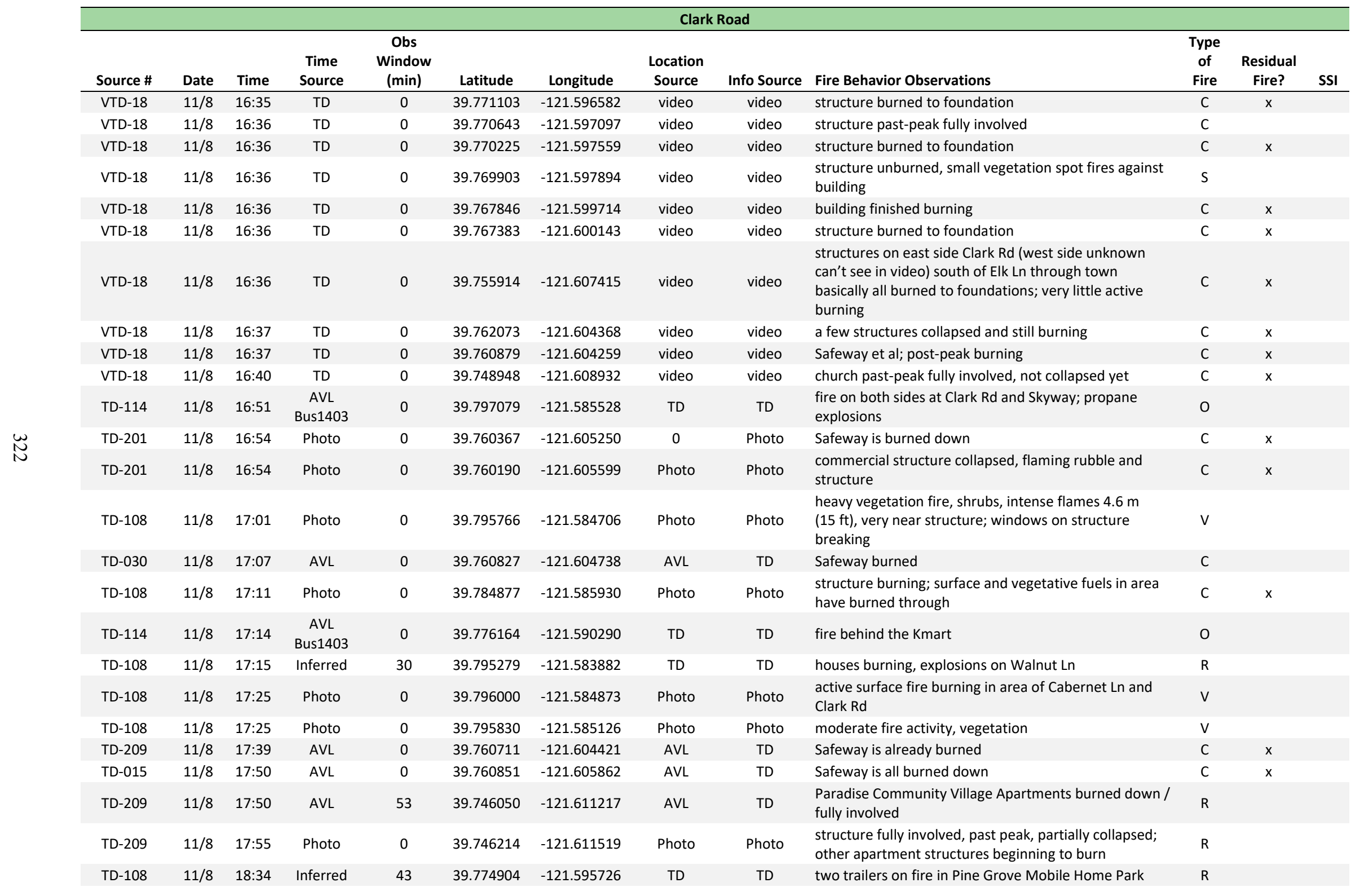




\begin{tabular}{|c|c|c|c|c|c|c|c|c|c|c|c|c|}
\hline \multicolumn{13}{|c|}{ Clark Road } \\
\hline Source \# & Date & Time & $\begin{array}{l}\text { Time } \\
\text { Source }\end{array}$ & $\begin{array}{c}\text { Obs } \\
\text { Window } \\
\text { (min) }\end{array}$ & Latitude & Longitude & $\begin{array}{l}\text { Location } \\
\text { Source }\end{array}$ & Info Source & Fire Behavior Observations & $\begin{array}{c}\text { Type } \\
\text { of } \\
\text { Fire }\end{array}$ & $\begin{array}{l}\text { Residual } \\
\text { Fire? }\end{array}$ & SS \\
\hline TD-108 & $11 / 8$ & $18: 34$ & Inferred & 43 & 39.774688 & -121.595782 & TD & TD & shed on fire & 0 & & \\
\hline TD-114 & $11 / 8$ & 19:00 & TD-108 & 0 & 39.775446 & -121.595472 & TD & TD & $\begin{array}{l}\text { Pine Grove mobile home park started to burn, then } \\
\text { really got going }\end{array}$ & $\mathrm{R}$ & & \\
\hline TD-108 & $11 / 8$ & 19:17 & video & 0 & 39.775905 & -121.595636 & video & TD & $\begin{array}{l}\text { mobile homes burning structure to structure; very hot; } \\
\text { propane exploding (Pine Grove mobile home park) }\end{array}$ & $\mathrm{R}$ & & $\mathrm{x}$ \\
\hline TD-108 & $11 / 8$ & 19:17 & Photo & 0 & 39.776002 & -121.595330 & Photo & Photo & $\begin{array}{l}\text { multiple mobile homes are fully involved ( } \mathrm{N} \text { and } \mathrm{W} \text { of } \\
\text { here); Pine Grove Mobile Home Park }\end{array}$ & $\mathrm{R}$ & & \\
\hline TD-014 & $11 / 8$ & $19: 20$ & Radio Log & 0 & 39.785083 & -121.588100 & AVL & Radio Log & power pole burning & 0 & & \\
\hline TD-014 & $11 / 8$ & 19:56 & Radio Log & 0 & 39.785014 & -121.586988 & Radio Log & Radio Log & $\begin{array}{l}\text { tree burning at Clark Rd and Forest Service Rd that is } \\
\text { going to burn up and fall }\end{array}$ & $\mathrm{v}$ & & \\
\hline TD-108 & $11 / 8$ & $20: 00$ & Inferred & 720 & 39.774725 & -121.594158 & TD & TD & fire threatening structures & v & & \\
\hline TD-205 & $11 / 8$ & $20: 12$ & AVL & 21 & 39.774510 & -121.594461 & AVL & TD & boat on fire next to house, fire into eaves of house & $\mathrm{R}$ & & \\
\hline TD-205 & $11 / 8$ & $20: 35$ & $A V L$ & 28 & 39.773648 & -121.596940 & $A V L$ & TD & shed smoldering behind Paradise Alliance Church & $\mathrm{O}$ & & \\
\hline TD-108 & $11 / 8$ & $20: 43$ & Photo & 0 & 39.774774 & -121.593208 & Photo & Photo & structure fully involved & $\mathrm{R}$ & & \\
\hline TD-108 & $11 / 8$ & $20: 43$ & Photo & 0 & 39.774780 & -121.593192 & Photo & Photo & structure fully involved & $\mathrm{R}$ & & \\
\hline TD-108 & $11 / 8$ & $20: 44$ & video & 0 & 39.775374 & -121.594823 & video & video & Pine Grove mobile home park fully involved & $\mathrm{R}$ & & \\
\hline TD-108 & $11 / 8$ & $20: 44$ & Photo & 0 & 39.775512 & -121.595483 & Photo & Photo & $\begin{array}{l}\text { majority of mobile homes are fully involved in Pine } \\
\text { Grove Mobile Home Park }\end{array}$ & $\mathrm{R}$ & & \\
\hline TD-207 & $11 / 8$ & $20: 50$ & AVL & 29 & 39.774495 & -121.594446 & AVL & TD & shed engulfed & 0 & & \\
\hline TD-132 & $11 / 8$ & $22: 30$ & TD & 0 & 39.759267 & -121.608170 & TD & TD & spot fires and burning fences & 0 & & \\
\hline TD-132 & $11 / 8$ & $22: 30$ & TD & 0 & 39.759261 & -121.608486 & TD & TD & spot fires and burning fences & 0 & & \\
\hline TD-022 & $11 / 9$ & 01:47 & Radio Log & 0 & 39.758799 & -121.606396 & TD & TD & fire threatening Masonic Lodge & C & & \\
\hline TD-110 & $11 / 9$ & 01:47 & Radio Log & 0 & 39.759056 & -121.606371 & Radio Log & TD & $\begin{array}{l}\text { Lisa's family pharmacy, smoke from attic; one engine, } \\
\text { worried about Masonic Lodge }\end{array}$ & C & & \\
\hline TD-030 & $11 / 9$ & 09:54 & AVL & 59 & 39.758167 & -121.608467 & AVL & TD & Shadowbrook Apartments complex on fire & $\mathrm{R}$ & & \\
\hline TD-111 & $11 / 9$ & 09:54 & AVL TD-030 & 59 & 39.758166 & -121.608866 & AVL TD-030 & TD & Shadowbrook apartments on fire & $\mathrm{R}$ & & \\
\hline TD-041 & $11 / 9$ & $10: 21$ & Photo & 0 & 39.785029 & -121.586608 & Photo & Photo & $\begin{array}{l}\text { multiple structures burned and destroyed, Clark Rd and } \\
\text { Forest Service Rd }\end{array}$ & C & $x$ & \\
\hline
\end{tabular}




\begin{tabular}{|c|c|c|c|c|c|c|c|c|c|c|c|c|}
\hline \multicolumn{13}{|c|}{ Skyway } \\
\hline Source \# & Date & Time & $\begin{array}{l}\text { Time } \\
\text { Source }\end{array}$ & $\begin{array}{c}\text { Obs } \\
\text { Window } \\
\text { (min) }\end{array}$ & Latitude & Longitude & $\begin{array}{l}\text { Location } \\
\text { Source }\end{array}$ & Info Source & Fire Behavior Observations & $\begin{array}{c}\text { Type } \\
\text { of } \\
\text { Fire }\end{array}$ & $\begin{array}{l}\text { Residual } \\
\text { Fire? }\end{array}$ & SSI \\
\hline 911-092-1 & $11 / 8$ & 08:01 & 911-092-1 & 0 & 39.804374 & -121.578145 & Inferred & 911-092-1 & spot fires on west side of canyon by Sawmill Peak & $\mathrm{S}$ & & \\
\hline 911-128-1 & $11 / 8$ & $08: 24$ & 911-128-1 & 0 & 39.781580 & -121.598282 & $911-128-1$ & 911-128-1 & fire started on bike path & $\mathrm{s}$ & & \\
\hline TD-113 & $11 / 8$ & 08:30 & TD & 30 & 39.785046 & -121.606910 & TD & TD & 3 to 4 spot fires down in canyon & $\mathrm{s}$ & & \\
\hline 911-142-1 & $11 / 8$ & 08:31 & $911-142-1$ & 0 & 39.796563 & -121.585649 & $911-142-1$ & $911-142-1$ & spot fire & $\mathrm{s}$ & & \\
\hline $911-142-2$ & $11 / 8$ & 08:31 & $911-142-2$ & 0 & 39.796563 & -121.585649 & $911-142-2$ & $911-142-2$ & spot fire & $S$ & & \\
\hline VTD-12 & $11 / 8$ & $08: 35$ & 911-152-1 & 84 & 39.794571 & -121.586945 & video & video & large spot fires & $\mathrm{s}$ & & \\
\hline VTD-12 & $11 / 8$ & 08:35 & Inferred & 84 & 39.790099 & -121.591535 & Inferred & TD & fire everywhere & 0 & & \\
\hline $911-152-1$ & $11 / 8$ & 08:35 & $911-152-1$ & 0 & 39.796563 & -121.585649 & $911-152-1$ & $911-152-1$ & spot fire & $\mathrm{s}$ & & \\
\hline $911-153-1$ & $11 / 8$ & 08:35 & $911-153-1$ & 0 & 39.796563 & -121.585649 & $911-153-1$ & $911-153-1$ & spot fire & S & & \\
\hline $911-154-1$ & $11 / 8$ & 08:35 & 911-154-1 & 0 & 39.795122 & -121.587174 & 911-154-1 & 911-154-1 & fire; it's huge & $\mathrm{s}$ & & \\
\hline 911-155-1 & $11 / 8$ & 08:36 & $911-155-1$ & 0 & 39.796563 & -121.585649 & $911-155-1$ & $911-155-1$ & fire & $\mathrm{s}$ & & \\
\hline $911-162-1$ & $11 / 8$ & 08:39 & 911-162-1 & 0 & 39.778220 & -121.604211 & Inferred & 911-162-1 & flames on bike path & $\mathrm{s}$ & & \\
\hline 911-164-1 & $11 / 8$ & 08:40 & 911-164-1 & 0 & 39.797065 & -121.585487 & 911-164-1 & 911-164-1 & fire & $\mathrm{s}$ & & \\
\hline TD-006 & $11 / 8$ & 08:41 & Radio Log & 0 & 39.804814 & -121.578638 & TD & TD & spot fires in Old Magalia & $\mathrm{s}$ & & \\
\hline TD-111 & $11 / 8$ & 08:41 & Inferred & 4 & 39.749885 & -121.653210 & TD & TD & $\begin{array}{l}\text { fire had clearly spotted over Paradise, can see smoke in } \\
\text { canyon }\end{array}$ & S & & \\
\hline $911-165-1$ & $11 / 8$ & $08: 42$ & $911-165-1$ & 0 & 39.795419 & -121.586980 & $911-165-1$ & $911-165-1$ & $0.1 \mathrm{ha}(0.25 \mathrm{ac})$ spot fire & $\mathrm{s}$ & & \\
\hline $911-167-1$ & $11 / 8$ & $08: 42$ & 911-167-1 & 0 & 39.796045 & -121.586709 & Inferred & 911-167-1 & fire across the street getting big & $\mathrm{s}$ & & \\
\hline $911-171-1$ & $11 / 8$ & $08: 43$ & $911-171-1$ & 0 & 39.796239 & -121.586660 & $911-171-1$ & $911-171-1$ & fire burning on west side of Skyway & $S$ & & \\
\hline $911-178-2$ & $11 / 8$ & $08: 46$ & $911-178-2$ & 0 & 39.778331 & -121.603978 & Inferred & $911-178-2$ & fire on the bike path behind house & S & & \\
\hline $911-182-1$ & $11 / 8$ & $08: 48$ & $911-182-1$ & 0 & 39.749224 & -121.653849 & $911-182-1$ & $911-182-1$ & $\begin{array}{l}\text { spot fire started near creek, white smoke coming from } \\
\text { the canyon right now }\end{array}$ & $\mathrm{s}$ & & \\
\hline $911-183-2$ & $11 / 8$ & 08:48 & $911-183-2$ & 0 & 39.784771 & -121.604407 & $911-183-2$ & $911-183-2$ & fire is next door & $\mathrm{s}$ & & \\
\hline $911-186-2$ & $11 / 8$ & 08:49 & $911-186-2$ & 0 & 39.772120 & -121.611882 & $911-186-2$ & $911-186-2$ & spot fire right up to road & 0 & & \\
\hline TD-006 & $11 / 8$ & 08:51 & $\mathrm{AVL}$ & 0 & 39.751079 & -121.655498 & AVL H901 & TD & spot fire in Butte Creek Canyon & $S$ & & \\
\hline $911-188-1$ & $11 / 8$ & $08: 52$ & $911-188-1$ & 0 & 39.787740 & -121.591175 & Inferred & $911-188-1$ & $0.1 \mathrm{ha}(0.25 \mathrm{ac})$ spot fire & $\mathrm{S}$ & & \\
\hline 911-195-4 & $11 / 8$ & 08:56 & 911-195-4 & 0 & 39.770306 & -121.609809 & 911-195-4 & 911-195-4 & fire at bike path & $\mathrm{s}$ & & \\
\hline $911-200-1$ & $11 / 8$ & 08:57 & $911-200-1$ & 0 & 39.751090 & -121.652243 & Inferred & 911-200-1 & spot fire kind of by Valley View $\mathrm{Dr}$ & $\mathrm{s}$ & & \\
\hline $911-202-1$ & $11 / 8$ & 08:59 & $911-202-1$ & 0 & 39.750171 & -121.651946 & Inferred & $911-202-1$ & spot fire visible, just started, rapid spread & $S$ & & \\
\hline TD-064 & $11 / 8$ & 09:00 & Inferred & 30 & 39.795743 & -121.586371 & TD & TD & $\begin{array}{l}\text { bike path and Skyway fully involved in fire, both sides of } \\
\text { Skyway }\end{array}$ & v & & \\
\hline TD-064 & $11 / 8$ & 09:00 & Inferred & 30 & 39.788627 & -121.591629 & TD & TD & $\begin{array}{l}\text { fire still to east of bike path south of Bel Air Dr, north of } \\
\text { Station } 35\end{array}$ & 0 & & \\
\hline TD-038 & $11 / 8$ & 09:00 & TD & 0 & 39.746843 & -121.653427 & TD & TD & fire in backyard on Russell Dr & $\mathrm{s}$ & & \\
\hline $911-204-1$ & $11 / 8$ & 09:00 & $911-204-1$ & 0 & 39.750408 & -121.652292 & Inferred & 911-204-1 & spot fire just started & S & & \\
\hline 911-205-1 & $11 / 8$ & 09:01 & $911-205-1$ & 0 & 39.783018 & -121.604111 & 911-205-1 & 911-205-1 & fire & $\mathrm{s}$ & & \\
\hline
\end{tabular}




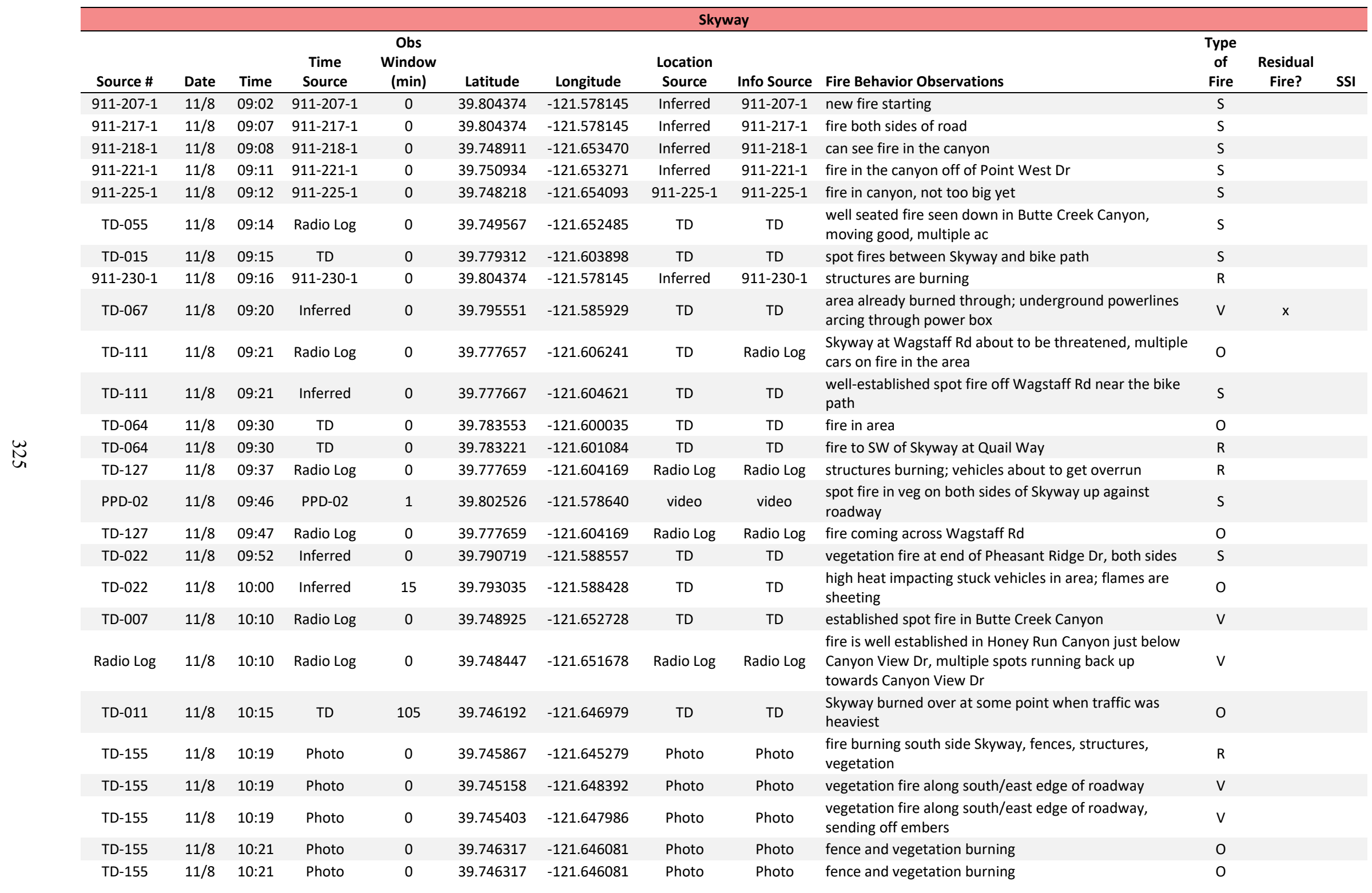




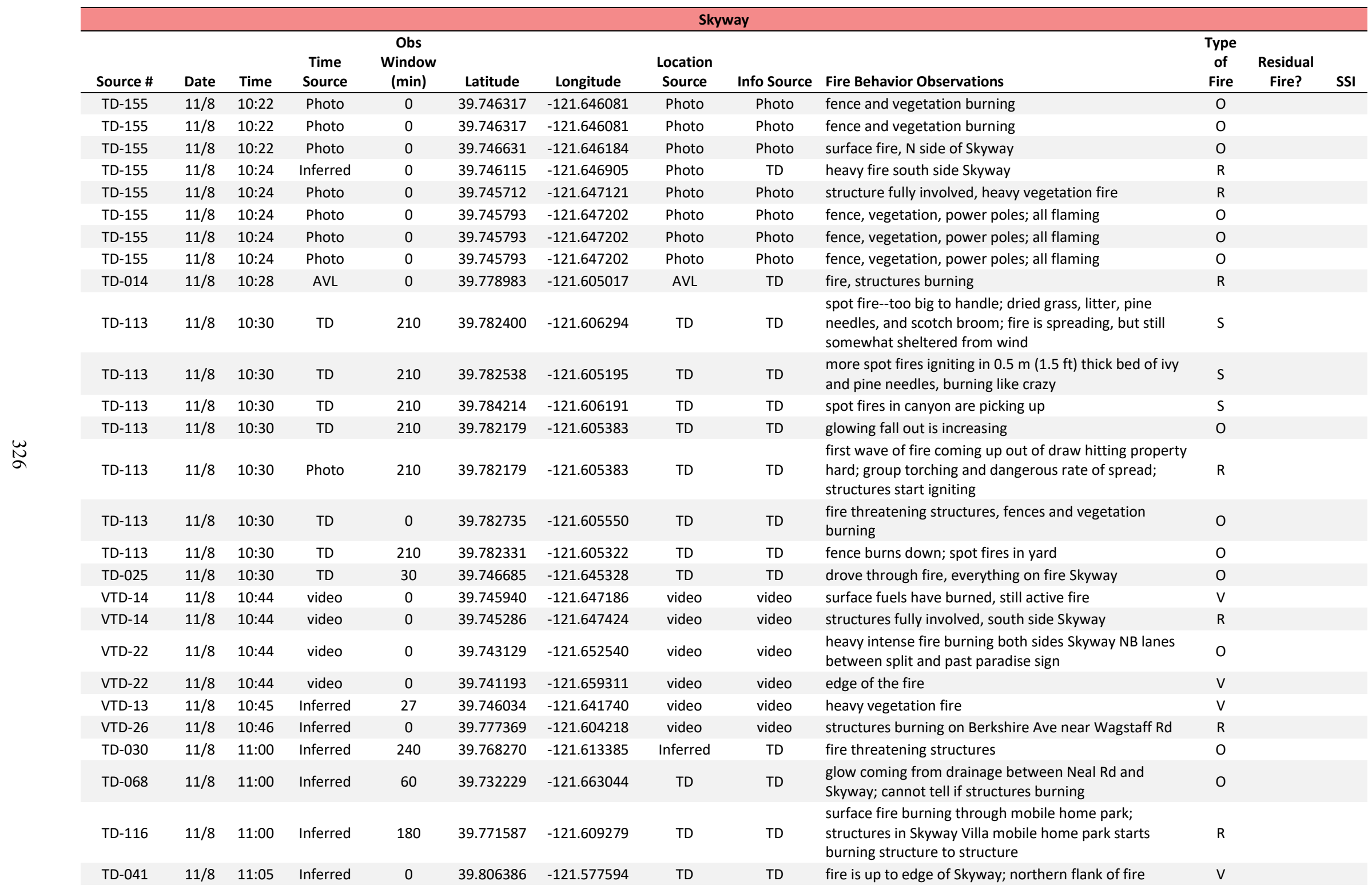




\begin{tabular}{|c|c|c|c|c|c|c|c|c|c|c|c|c|}
\hline \multicolumn{13}{|c|}{ Skyway } \\
\hline Source \# & Date & Time & $\begin{array}{l}\text { Time } \\
\text { Source }\end{array}$ & $\begin{array}{c}\text { Obs } \\
\text { Window } \\
\text { (min) }\end{array}$ & Latitude & Longitude & $\begin{array}{l}\text { Location } \\
\text { Source }\end{array}$ & Info Source & Fire Behavior Observations & $\begin{array}{c}\text { Type } \\
\text { of } \\
\text { Fire }\end{array}$ & $\begin{array}{l}\text { Residual } \\
\text { Fire? }\end{array}$ & SSI \\
\hline TD-030 & $11 / 8$ & $11: 10$ & AVL & 0 & 39.770435 & -121.612785 & AVL & TD & Fire progressing over hill & 0 & & \\
\hline VTD-13 & $11 / 8$ & 11:12 & video & 0 & 39.746378 & -121.644063 & video & video & south side Skyway heavy fire & v & & \\
\hline VTD-13 & $11 / 8$ & 11:13 & video & 0 & 39.744576 & -121.651387 & video & video & $\begin{array}{l}\text { heavy fire, structures fully involved, both sides roadway } \\
\text { between Skyway split and Skyway Crossroad }\end{array}$ & $\mathrm{R}$ & & \\
\hline VTD-26 & $11 / 8$ & 11:15 & Inferred & 125 & 39.747108 & -121.642189 & video & video & $\begin{array}{l}\text { area north of Skyway and west of health center is } \\
\text { burning, vegetation and structures }\end{array}$ & $\mathrm{R}$ & & \\
\hline VTD-26 & $11 / 8$ & 11:15 & Inferred & 125 & 39.745380 & -121.648033 & video & video & $\begin{array}{l}\text { vegetation south of split is past peak; most structures } \\
\text { fully involved; traffic flowing }\end{array}$ & $\mathrm{R}$ & & \\
\hline VTD-26 & $11 / 8$ & 11:15 & Inferred & 125 & 39.740964 & -121.656543 & video & video & Welcome to Paradise sign is half on fire, still standing & 0 & & \\
\hline VTD-26 & $11 / 8$ & 11:15 & Inferred & 125 & 39.741140 & -121.664146 & video & video & western extent of fire; traffic full speed SB in NB lanes & $\mathrm{V}$ & & \\
\hline PPD-02 & $11 / 8$ & $11: 20$ & PPD-02 & 0 & 39.796459 & -121.586142 & video & video & fire has already burned through the surface grass & $\mathrm{v}$ & $\mathrm{x}$ & \\
\hline PPD-02 & $11 / 8$ & $11: 20$ & PPD-02 & 0 & 39.795864 & -121.586268 & video & video & surface fire & V & & \\
\hline TD-041 & $11 / 8$ & 11:25 & PPD video & 0 & 39.795367 & -121.586539 & PPD video & TD & heavy fire on Skyway to the south of Clark Rd & 0 & & \\
\hline TD-011 & $11 / 8$ & 11:30 & TD & 0 & 39.746172 & -121.647081 & TD & TD & Skyway split is fully involved both sides & 0 & & \\
\hline TD-127 & $11 / 8$ & $11: 30$ & Inferred & 30 & 39.770367 & -121.612346 & TD & TD & fire is approaching & 0 & & \\
\hline TD-127 & $11 / 8$ & $11: 30$ & Inferred & 30 & 39.769914 & -121.612077 & TD & TD & bushes igniting around building & v & & \\
\hline PPD-08 & $11 / 8$ & $11: 37$ & PPD-08 & 0 & 39.790076 & -121.591541 & Radio & Radio & trapped by fire, Skyway at Coldren Rd & 0 & & \\
\hline TD-058 & $11 / 8$ & 11:38 & video & 0 & 39.746616 & -121.645514 & TD & TD, video & everything on fire; trees, cars, houses, telephone poles & $\mathrm{R}$ & & \\
\hline TD-058 & $11 / 8$ & $11: 38$ & video & 0 & 39.746579 & -121.645738 & video & video & scattered small surface fires both sides Skyway & $S$ & & \\
\hline TD-058 & $11 / 8$ & 11:38 & video & 0 & 39.746530 & -121.647086 & video & video & active vegetation fire north side Skyway & v & & \\
\hline TD-058 & $11 / 8$ & $11: 38$ & video & 0 & 39.745815 & -121.646890 & video & video & $\begin{array}{l}\text { heavy active vegetation fire in drainage on east side } \\
\text { Skyway }\end{array}$ & $\mathrm{v}$ & & \\
\hline TD-058 & $11 / 8$ & $11: 38$ & video & 0 & 39.744497 & -121.651252 & video & video & structures burning in middle of Skyway split & $\mathrm{R}$ & & \\
\hline TD-058 & $11 / 8$ & $11: 38$ & video & 0 & 39.741067 & -121.655847 & video & video & $\begin{array}{l}\text { scattered small surface fires both sides Skyway at } \\
\text { Crossroad and welcome sign }\end{array}$ & $\mathrm{v}$ & & \\
\hline TD-058 & $11 / 8$ & $11: 40$ & AVL & 0 & 39.740969 & -121.656546 & TD & TD & welcome to paradise sign is on fire & 0 & & \\
\hline PPD-08 & $11 / 8$ & 11:46 & PPD-08 & 0 & 39.775576 & -121.608944 & Radio & Radio & $\begin{array}{l}8000 \text { block Skyway about } 90 \mathrm{~m} \text { (100 yd) from being } \\
\text { overtaken [by fire] }\end{array}$ & 0 & & \\
\hline PPD-10 & $11 / 8$ & $11: 53$ & PPD-10 & 0 & 39.801315 & -121.582699 & video & video & large flames & 0 & & \\
\hline PPD-10 & $11 / 8$ & $11: 53$ & PPD-10 & 0 & 39.799650 & -121.584492 & video & video & spot fire & $\mathrm{S}$ & & \\
\hline PPD-12 & $11 / 8$ & $11: 56$ & PPD-12 & 0 & 39.799928 & -121.585323 & video & video & fire behind storage facility & 0 & & \\
\hline PPD-12 & $11 / 8$ & 11:56 & PPD-12 & 0 & 39.799126 & -121.586712 & video & video & spot fire & S & & \\
\hline TD-127 & $11 / 8$ & $12: 00$ & Inferred & 0 & 39.773464 & -121.610827 & TD & TD & $\begin{array}{l}\text { intense heat, fire; everything burning between Bille Rd } \\
\text { and Wagstaff Rd }\end{array}$ & $\mathrm{R}$ & & \\
\hline TD-127 & $11 / 8$ & $12: 00$ & Radio Log & 0 & 39.777628 & -121.606319 & Radio Log & Radio Log & multiple gas stations being impacted by fire & C & & \\
\hline TD-075 & $11 / 8$ & 12:03 & Photo & 0 & 39.799849 & -121.585315 & Photo & Photo & $\begin{array}{l}\text { edge of fire north of storage facility; burning in surface } \\
\text { vegetation and crawling up pine bark }\end{array}$ & $\mathrm{v}$ & & \\
\hline
\end{tabular}




\begin{tabular}{|c|c|c|c|c|c|c|c|c|c|c|c|c|}
\hline & & & & & & & Sky & vay & & & & \\
\hline Source \# & Date & Time & $\begin{array}{l}\text { Time } \\
\text { Source }\end{array}$ & $\begin{array}{l}\text { Obs } \\
\text { Window } \\
\text { (min) }\end{array}$ & Latitude & Longitude & $\begin{array}{l}\text { Location } \\
\text { Source }\end{array}$ & Info Source & Fire Behavior Observations & $\begin{array}{l}\text { Type } \\
\text { of } \\
\text { Fire }\end{array}$ & $\begin{array}{l}\text { Residual } \\
\text { Fire? }\end{array}$ & SSI \\
\hline TD-041 & $11 / 8$ & $12: 07$ & Photo & 0 & 39.799915 & -121.585640 & TD & Photo & fire behind storage facility & $\mathrm{V}$ & & \\
\hline TD-041 & $11 / 8$ & $12: 07$ & Photo & 0 & 39.799849 & -121.585315 & Photo & Photo & $\begin{array}{l}\text { edge of fire north of storage facility; burning in surface } \\
\text { vegetation and crawling up pine bark }\end{array}$ & v & & \\
\hline TD-079 & $11 / 8$ & $12: 10$ & AVL & 0 & 39.804683 & -121.577867 & AVL & TD & everything on fire driving up Skyway - both sides of road & 0 & & \\
\hline TD-070 & $11 / 8$ & $12: 12$ & Inferred & 112 & 39.745699 & -121.643270 & TD & TD & $\begin{array}{l}\text { structures burning on south side of Skyway; huge } \\
\text { flames }\end{array}$ & $\mathrm{R}$ & & \\
\hline TD-070 & $11 / 8$ & $12: 12$ & Inferred & 112 & 39.749073 & -121.639910 & TD & TD & $\begin{array}{l}\text { fire increasing from the north from the canyon behind } \\
\text { buildings }\end{array}$ & V & & \\
\hline TD-076 & $11 / 8$ & $12: 15$ & Inferred & 55 & 39.759509 & -121.623908 & TD & TD & see flames coming & 0 & & \\
\hline TD-060 & $11 / 8$ & $12: 18$ & AVL & 0 & 39.812633 & -121.575716 & AVL & TD & spot fire down in canyon & $\mathrm{s}$ & & \\
\hline TD-009 & $11 / 8$ & $12: 18$ & AVL & 0 & 39.810739 & -121.577389 & AVL & TD & estimated flank of the fire & 0 & & \\
\hline TD-083 & $11 / 8$ & $12: 21$ & AVL & 0 & 39.803900 & -121.581867 & AVL & TD & $\begin{array}{l}\text { fire on south side of Ishi, only one fire on north side } \\
\text { (detached garage on fire, mobile home burning under } \\
\text { floor) }\end{array}$ & $\mathrm{R}$ & & \\
\hline PPD-08 & $11 / 8$ & $12: 22$ & PPD-08 & 0 & 39.781516 & -121.602519 & Radio & Radio & crowning fire activity all to the west side & v & & \\
\hline TD-127 & $11 / 8$ & $12: 24$ & Radio Log & 0 & 39.777646 & -121.606300 & Radio Log & Radio Log & fire on Skyway at Bille Rd and Wagstaff Rd & 0 & & \\
\hline TD-060 & $11 / 8$ & $12: 27$ & AVL & 14 & 39.808500 & -121.579350 & AVL & TD & $\begin{array}{l}\text { Fire hit old fire station in Old Magalia and trees pretty } \\
\text { hard. Pine needles on metal roof ignite. }\end{array}$ & V & & \\
\hline TD-079 & $11 / 8$ & $12: 28$ & AVL & 16 & 39.803254 & -121.583125 & AVL & TD & $\begin{array}{l}\text { side panel of house on fire, houses igniting by ember } \\
\text { ignitions }\end{array}$ & $\mathrm{R}$ & & \\
\hline TD-066 & $11 / 8$ & $12: 30$ & Inferred & 15 & 39.750780 & -121.631565 & TD & TD & $\begin{array}{l}\text { spot fires along Skyway between Neal Rd and Pearson } \\
\text { Rd }\end{array}$ & S & & \\
\hline TD-127 & $11 / 8$ & $12: 30$ & Radio Log & 0 & 39.777627 & -121.606305 & Radio Log & Radio Log & heavy fire impacting Skyway at Wagstaff Rd & 0 & & \\
\hline TD-127 & $11 / 8$ & $12: 30$ & Inferred & 30 & 39.783505 & -121.600093 & TD & TD & fire closing in, both sides of roadway & 0 & & \\
\hline TD-127 & $11 / 8$ & $12: 45$ & Inferred & 15 & 39.788929 & -121.592443 & TD & TD & intense fire between Wagstaff Rd and Clark Rd & 0 & & \\
\hline TD-026 & $11 / 8$ & $12: 45$ & Inferred & 61 & 39.755650 & -121.624132 & TD & TD & $\begin{array}{l}\text { structures burning south and east of Skyway in area of } \\
\text { Almond St and Fir St }\end{array}$ & $\mathrm{R}$ & & \\
\hline TD-026 & $11 / 8$ & $12: 45$ & Inferred & 61 & 39.746394 & -121.643901 & TD & TD & $\begin{array}{l}\text { fire on both sides, fully involved, roofs on fire; pitch } \\
\text { black; area of Skyway and Princeton }\end{array}$ & $\mathrm{R}$ & & \\
\hline TD-026 & $11 / 8$ & $12: 45$ & Inferred & 61 & 39.744031 & -121.652480 & TD & TD & $\begin{array}{l}\text { fire burning between the Skyway split, Skyway } \\
\text { Crossroad }\end{array}$ & 0 & & \\
\hline TD-026 & $11 / 8$ & $12: 45$ & Inferred & 15 & 39.740962 & -121.656543 & TD & TD & "Welcome to Paradise" sign was burning & 0 & & \\
\hline TD-079 & $11 / 8$ & $12: 46$ & AVL & 20 & 39.802787 & -121.585373 & AVL & TD & grass fires, not all homes burning yet & V & & \\
\hline TD-012 & $11 / 8$ & $12: 52$ & Radio Log & 0 & 39.785725 & -121.607162 & TD & Radio Log & fire & 0 & & \\
\hline TD-200 & $11 / 8$ & $12: 55$ & AVL & 6 & 39.781840 & -121.602229 & AVL & TD & $\begin{array}{l}\text { Both sides of Skyway on fire (vehicles and houses } \\
\text { burning); between Wagstaff Rd and Quail Way }\end{array}$ & $\mathrm{R}$ & & \\
\hline TD-205 & $11 / 8$ & $13: 00$ & AVL & 19 & 39.783058 & -121.600700 & AVL & TD & Fire on both sides of Skyway & 0 & & \\
\hline
\end{tabular}




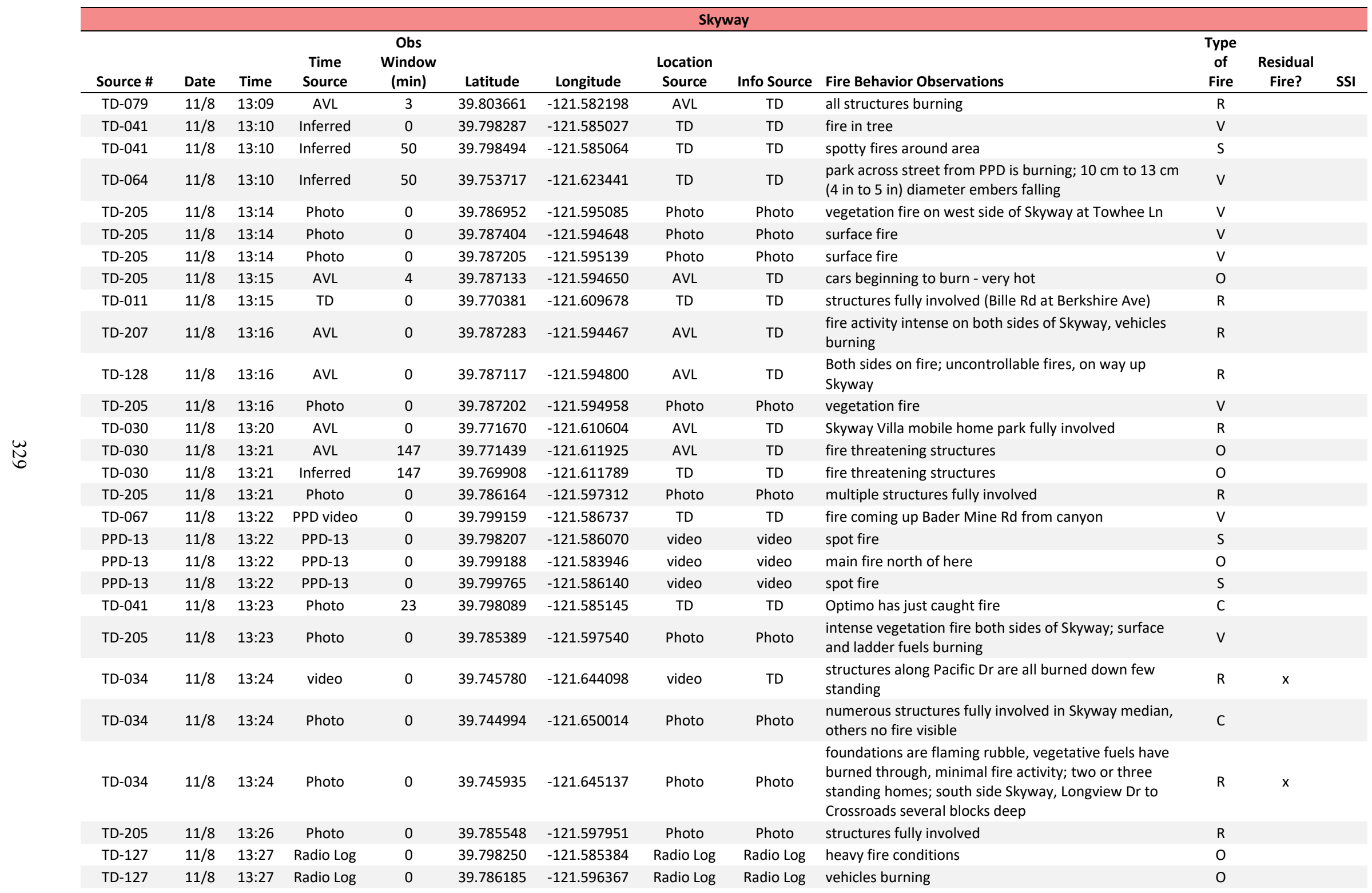




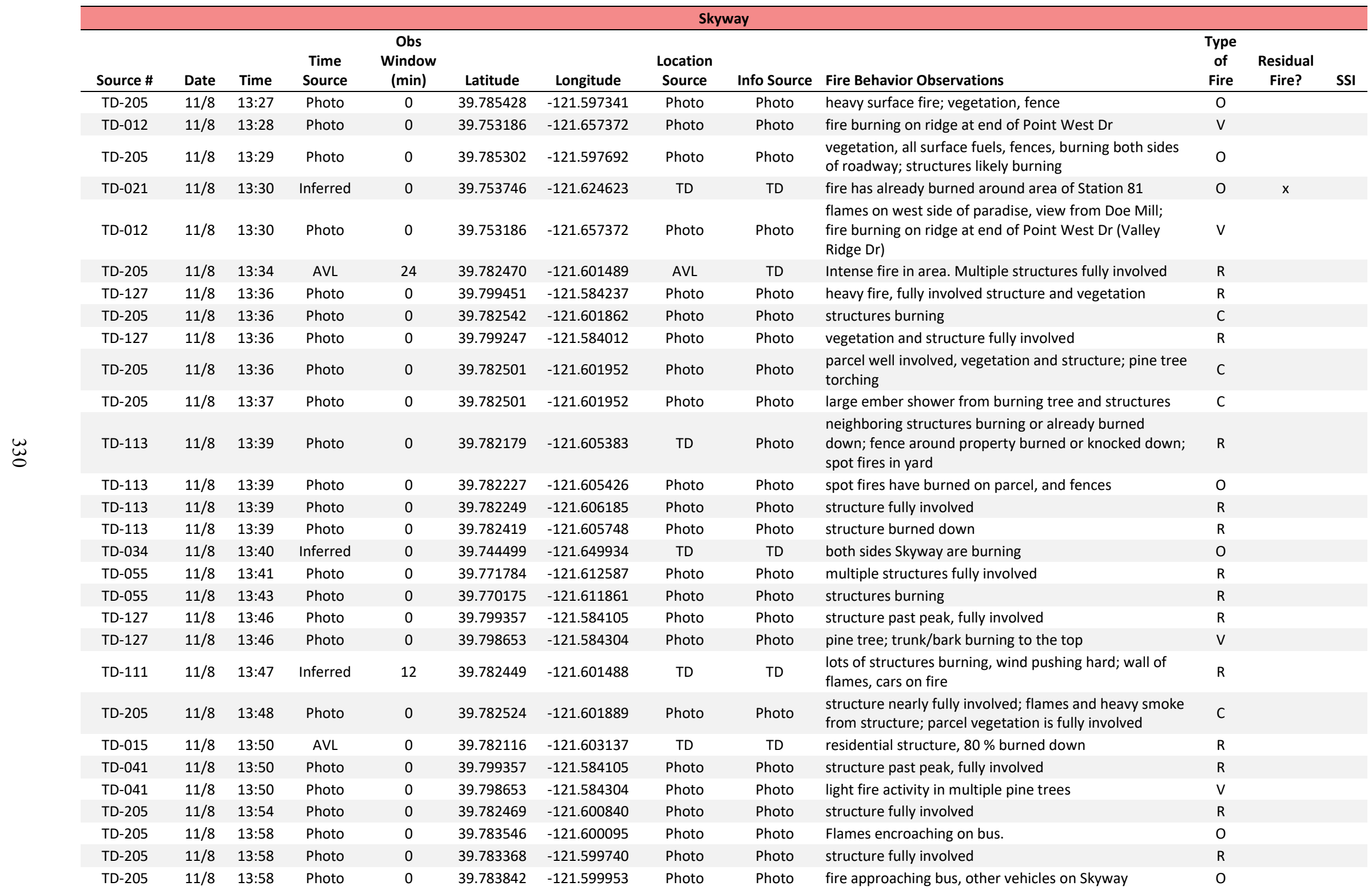




\begin{tabular}{|c|c|c|c|c|c|c|c|c|c|c|c|c|}
\hline \multicolumn{13}{|c|}{ Skyway } \\
\hline Source \# & Date & Time & $\begin{array}{l}\text { Time } \\
\text { Source }\end{array}$ & $\begin{array}{c}\text { Obs } \\
\text { Window } \\
\text { (min) }\end{array}$ & Latitude & Longitude & $\begin{array}{l}\text { Location } \\
\text { Source }\end{array}$ & Info Source & Fire Behavior Observations & $\begin{array}{c}\text { Type } \\
\text { of } \\
\text { Fire }\end{array}$ & $\begin{array}{l}\text { Residual } \\
\text { Fire? }\end{array}$ & SSI \\
\hline TD-205 & $11 / 8$ & $13: 58$ & Photo & 0 & 39.783366 & -121.599697 & Photo & Photo & structure and parcel fully involved & $\mathrm{R}$ & & \\
\hline TD-128 & $11 / 8$ & $13: 59$ & AVL & 0 & 39.796729 & -121.585667 & AVL & TD & tire shop is on fire; fire blowing across road & C & & \\
\hline TD-128 & $11 / 8$ & $13: 59$ & AVL & 112 & 39.799571 & -121.586259 & Imagery & TD & storage units behind Optimo are on fire & C & & \\
\hline TD-128 & $11 / 8$ & $14: 00$ & video & 0 & 39.782943 & -121.600878 & video & video & $\begin{array}{l}\text { heavy fire along Skyway, visibility } 3 \mathrm{~m}(10 \mathrm{ft}) \text {, } \\
\text { abandoned vehicles burning }\end{array}$ & 0 & & \\
\hline TD-064 & $11 / 8$ & $14: 00$ & Inferred & 0 & 39.753933 & -121.623996 & TD & TD & fire threatening structures & 0 & & \\
\hline TD-064 & $11 / 8$ & $14: 00$ & Inferred & 0 & 39.749477 & -121.633848 & TD & TD & back of town hall (woodpile) on fire & 0 & & \\
\hline TD-127 & $11 / 8$ & $14: 00$ & Inferred & 0 & 39.797975 & -121.584993 & TD & TD & $\begin{array}{l}\text { flames arrive around and across the street about an } \\
\text { hour after embers }\end{array}$ & $\mathrm{R}$ & & \\
\hline TD-127 & $11 / 8$ & $14: 00$ & Inferred & 154 & 39.800012 & -121.583775 & TD & TD & explosion at propane facility shook ground & C & & \\
\hline TD-113 & $11 / 8$ & $14: 00$ & TD & 300 & 39.782179 & -121.605383 & TD & TD & $\begin{array}{l}\text { fire kicked back up; second wave of fire came along } \\
\text { Skyway from NE; definitely more intense }\end{array}$ & V & & \\
\hline TD-113 & $11 / 8$ & $14: 00$ & TD & 300 & 39.782235 & -121.605061 & TD & TD & homes burning, embers flying all around & $\mathrm{R}$ & & \\
\hline TD-113 & $11 / 8$ & $14: 00$ & TD & 300 & 39.781855 & -121.605058 & TD & TD & vegetation fires, fences burning & 0 & & \\
\hline TD-113 & $11 / 8$ & 14:00 & TD & 300 & 39.782053 & -121.604395 & TD & TD & neighborhood burning & $\mathrm{R}$ & & \\
\hline TD-117 & $11 / 8$ & $14: 00$ & TD & 0 & 39.742833 & -121.673188 & TD & TD & 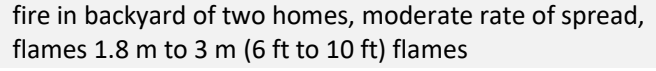 & $\mathrm{v}$ & & \\
\hline TD-117 & $11 / 8$ & $14: 00$ & Inferred & 120 & 39.739125 & -121.670044 & TD & TD & 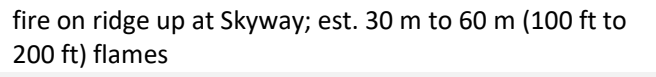 & V & & \\
\hline TD-128 & $11 / 8$ & $14: 00$ & Photo & 0 & 39.783378 & -121.600301 & Photo & Photo & $\begin{array}{l}\text { intense wind driven fires in trees, ground, buildings, } \\
\text { vehicles, brands blowing }\end{array}$ & $\mathrm{R}$ & & \\
\hline TD-205 & $11 / 8$ & 14:01 & Photo & 0 & 39.788443 & -121.592501 & Photo & Photo & structure fully involved & $\mathrm{R}$ & & \\
\hline TD-205 & $11 / 8$ & 14:01 & Photo & 0 & 39.788485 & -121.592362 & Photo & Photo & structure fully involved & $\mathrm{R}$ & & \\
\hline TD-111 & $11 / 8$ & $14: 05$ & Inferred & 0 & 39.796037 & -121.585030 & TD & TD & lot of homes on fire around Cabernet & $\mathrm{R}$ & & \\
\hline TD-200 & $11 / 8$ & 14:07 & AVL & 155 & 39.799040 & -121.583598 & AVL & TD & all on fire, east side Skyway north of Optimo & $\mathrm{R}$ & & \\
\hline TD-207 & $11 / 8$ & 14:07 & AVL & 103 & 39.797909 & -121.584712 & AVL & TD & structure on fire & $\mathrm{R}$ & & \\
\hline TD-017 & $11 / 8$ & 14:08 & AVL & 36 & 39.768554 & -121.612910 & AVL & TD & Very patchy fire spots west side of Skyway & $S$ & & \\
\hline VTD-20 & $11 / 8$ & $14: 10$ & TD & 0 & 39.730506 & -121.671658 & video & video & spot fires along ridge & v & & \\
\hline VTD-20 & $11 / 8$ & $14: 11$ & TD & 0 & 39.744807 & -121.650901 & video & video & past-peak, but still active fires within the Skyway split & 0 & & \\
\hline TD-041 & $11 / 8$ & $14: 12$ & Photo & 0 & 39.798164 & -121.584751 & Photo & Photo & spot fire in vegetation & $\mathrm{S}$ & & \\
\hline TD-041 & $11 / 8$ & $14: 13$ & Photo & 0 & 39.798287 & -121.585117 & TD & TD & Optimo building burning & C & & \\
\hline TD-200 & $11 / 8$ & 14:14 & $\mathrm{AVL}$ & 10 & 39.796800 & -121.585750 & AVL & TD & fire threatening structure & 0 & & \\
\hline TD-118 & $11 / 8$ & 14:14 & Inferred & 86 & 39.745187 & -121.650915 & TD & TD & fire on both sides; buildings burning & $\mathrm{R}$ & & \\
\hline TD-205 & $11 / 8$ & 14:17 & AVL & 4 & 39.786539 & -121.596865 & AVL & TD & $\begin{array}{l}\text { Wing of Heritage Assisted Living building on fire. Cars } \\
\text { on fire. }\end{array}$ & C & & \\
\hline TD-041 & $11 / 8$ & 14:17 & Photo & 0 & 39.797912 & -121.584712 & Photo & Photo & structure fully involved, partially collapsed & $\mathrm{R}$ & & \\
\hline TD-128 & $11 / 8$ & $14: 18$ & Photo & 0 & 39.797912 & -121.584712 & Photo & Photo & structure fully involved, partially collapsed & $\mathrm{R}$ & & \\
\hline
\end{tabular}




\begin{tabular}{|c|c|c|c|c|c|c|c|c|c|c|c|c|}
\hline \multicolumn{13}{|c|}{ Skyway } \\
\hline Source \# & Date & Time & $\begin{array}{l}\text { Time } \\
\text { Source }\end{array}$ & $\begin{array}{l}\text { Obs } \\
\text { Window } \\
\text { (min) }\end{array}$ & Latitude & Longitude & $\begin{array}{l}\text { Location } \\
\text { Source }\end{array}$ & Info Source & Fire Behavior Observations & $\begin{array}{l}\text { Type } \\
\text { of } \\
\text { Fire }\end{array}$ & $\begin{array}{l}\text { Residual } \\
\text { Fire? }\end{array}$ & SSI \\
\hline TD-127 & $11 / 8$ & $14: 19$ & Radio Log & 0 & 39.797981 & -121.585241 & Radio Log & Radio Log & commercial buildings involved & C & & \\
\hline TD-041 & $11 / 8$ & 14:19 & Photo & 0 & 39.797912 & -121.584712 & Photo & Photo & structure fully involved, partially collapsed & $\mathrm{R}$ & & \\
\hline TD-075 & $11 / 8$ & 14:19 & Photo & 0 & 39.798262 & -121.584524 & Photo & Photo & $\begin{array}{l}\text { multiple structures and vegetation fires east side } \\
\text { Skyway }\end{array}$ & $\mathrm{R}$ & & \\
\hline TD-075 & $11 / 8$ & $14: 21$ & Photo & 0 & 39.797918 & -121.584708 & Photo & Photo & structure fully involved, significant fire on parcel & $\mathrm{R}$ & & \\
\hline TD-075 & $11 / 8$ & $14: 21$ & Photo & 0 & 39.797411 & -121.586287 & Photo & Photo & structure burned to foundation & $\mathrm{R}$ & $\mathrm{x}$ & \\
\hline TD-075 & $11 / 8$ & $14: 21$ & Photo & 0 & 39.797959 & -121.586085 & Photo & Photo & $\begin{array}{l}\text { surface fire has recently burned this area; almost no } \\
\text { flames left, smoking }\end{array}$ & V & $\mathrm{x}$ & \\
\hline TD-075 & $11 / 8$ & $14: 22$ & Photo & 0 & 39.797979 & -121.584814 & Photo & Photo & $\begin{array}{l}\text { structure fully involved, partially collapsed; tall pine } \\
\text { trees torching }\end{array}$ & $\mathrm{R}$ & & \\
\hline PPD-14 & $11 / 8$ & $14: 22$ & PPD-14 & 0 & 39.798122 & -121.584588 & video & video & $\begin{array}{l}\text { multiple structures fully involved, trees torching on east } \\
\text { side Skyway }\end{array}$ & $\mathrm{R}$ & & \\
\hline PPD-14 & $11 / 8$ & $14: 22$ & PPD-14 & 0 & 39.798308 & -121.584984 & video & video & spot fire at Optimo building on Skyway side & $\mathrm{s}$ & & \\
\hline TD-127 & $11 / 8$ & $14: 23$ & Photo & 0 & 39.798009 & -121.585061 & Photo & Photo & structure is burning & $\mathrm{R}$ & & \\
\hline TD-127 & $11 / 8$ & $14: 23$ & Photo & 0 & 39.797873 & -121.584944 & Photo & Photo & $\begin{array}{l}\text { heavy vegetation fire on parcel burning up against } \\
\text { roadway }\end{array}$ & V & & \\
\hline TD-055 & $11 / 8$ & $14: 24$ & video & 0 & 39.775836 & -121.608634 & TD & TD & area has burned through & $\mathrm{v}$ & $\mathrm{x}$ & \\
\hline TD-075 & $11 / 8$ & $14: 24$ & Photo & 0 & 39.798138 & -121.584515 & Photo & Photo & $\begin{array}{l}\text { structures fully involved; trees torching, vegetation } \\
\text { burning }\end{array}$ & $\mathrm{R}$ & & \\
\hline TD-075 & $11 / 8$ & $14: 24$ & Photo & 0 & 39.797816 & -121.586193 & Photo & Photo & surface fire has burned through & $\mathrm{v}$ & $\mathrm{x}$ & \\
\hline TD-055 & $11 / 8$ & $14: 24$ & Photo & 0 & 39.775296 & -121.609345 & Photo & Photo & $\begin{array}{l}\text { all structures burned to foundation, still flaming; } \\
\text { virtually all fine surface fuels consumed }\end{array}$ & $\mathrm{R}$ & $\mathrm{x}$ & \\
\hline TD-055 & $11 / 8$ & $14: 24$ & Photo & 0 & 39.776049 & -121.608272 & Photo & Photo & all structures burned to foundation, still flaming & $\mathrm{R}$ & $\mathrm{x}$ & \\
\hline TD-011 & $11 / 8$ & $14: 25$ & TD & 0 & 39.750641 & -121.635344 & TD & TD & structures behind town hall, and fence, are on fire & $\mathrm{R}$ & & \\
\hline TD-011 & $11 / 8$ & $14: 25$ & TD & 5 & 39.739506 & -121.667166 & TD & TD & $\begin{array}{l}\text { drive down Skyway; it has burned over already and is } \\
\text { safe }\end{array}$ & $\mathrm{V}$ & $\mathrm{x}$ & \\
\hline TD-065 & $11 / 8$ & $14: 25$ & Inferred & 31 & 39.771218 & -121.611917 & TD & TD & Skyway north of Bille Rd is on fire and impassable & $\mathrm{R}$ & & \\
\hline TD-127 & $11 / 8$ & $14: 25$ & Inferred & 20 & 39.798456 & -121.585038 & TD & TD & Optimo restaurant ignites & C & & \\
\hline TD-055 & $11 / 8$ & $14: 25$ & Photo & 0 & 39.779039 & -121.604930 & Photo & Photo & $\begin{array}{l}\text { widespread, active vegetation fire; fine fuels are mostly } \\
\text { gone, larger fuels burning including up in trees, power } \\
\text { poles; flames } 0.6 \mathrm{~m}(2 \mathrm{ft}) \text {, past peak }\end{array}$ & $\mathrm{v}$ & & \\
\hline TD-055 & $11 / 8$ & $14: 26$ & video & 0 & 39.782367 & -121.601552 & TD & TD & $\begin{array}{l}\text { motorhome in roadway, fully engulfed; exploded when } \\
\text { trying to get past }\end{array}$ & 0 & & \\
\hline TD-055 & $11 / 8$ & $14: 26$ & Photo & 0 & 39.780294 & -121.603733 & Photo & Photo & $\begin{array}{l}\text { vegetation is burned through; structures still fully } \\
\text { involved }\end{array}$ & $\mathrm{R}$ & & \\
\hline TD-205 & $11 / 8$ & $14: 27$ & AVL & 88 & 39.797901 & -121.584693 & Photo & TD & residential structure across street fully involved & $\mathrm{R}$ & & \\
\hline TD-205 & $11 / 8$ & $14: 27$ & AVL & 88 & 39.799208 & -121.585744 & AVL & TD & Storage units had started igniting & C & & \\
\hline
\end{tabular}




\begin{tabular}{|c|c|c|c|c|c|c|c|c|c|c|c|c|}
\hline & & & & & & & Sky & & & & & \\
\hline & & & & Obs & & & & & & Type & & \\
\hline Source \# & Date & Time & $\begin{array}{c}\text { Time } \\
\text { Source }\end{array}$ & $\begin{array}{l}\text { Window } \\
\text { (min) }\end{array}$ & Latitude & Longitude & $\begin{array}{l}\text { Location } \\
\text { Source }\end{array}$ & Info Source & Fire Behavior Observations & $\begin{array}{c}\text { of } \\
\text { Fire }\end{array}$ & $\begin{array}{l}\text { Residual } \\
\text { Fire? }\end{array}$ & SSI \\
\hline TD-205 & $11 / 8$ & $14: 27$ & $\mathrm{AVL}$ & 0 & 39.797868 & -121.584951 & $\mathrm{AVL}$ & TD & Trees near Fastrip are on fire & $\mathrm{V}$ & & \\
\hline TD-205 & $11 / 8$ & $14: 27$ & AVL & 88 & 39.796726 & -121.585672 & TD & TD & structure burning & C & & \\
\hline TD-067 & $11 / 8$ & $14: 27$ & AVL TD-205 & 88 & 39.798196 & -121.585269 & TD & TD & fires threatening structures & 0 & & \\
\hline TD-200 & $11 / 8$ & $14: 28$ & $\mathrm{AVL}$ & 16 & 39.796750 & -121.585817 & AVL & TD & fire threatening structure & 0 & & \\
\hline TD-055 & $11 / 8$ & $14: 29$ & Photo & 0 & 39.781634 & -121.602452 & Photo & Photo & $\begin{array}{l}\text { all structures fully involved; vegetation past peak, still } \\
\text { burning }\end{array}$ & $\mathrm{R}$ & & \\
\hline TD-064 & $11 / 8$ & $14: 30$ & TD & 120 & 39.763003 & -121.620340 & TD & TD & spot fires & $\mathrm{s}$ & & \\
\hline PPD-15 & $11 / 8$ & $14: 37$ & PPD-15 & 0 & 39.749428 & -121.633775 & Radio & Radio & $\begin{array}{l}\text { town hall looks like it's about to catch on fire now; } \\
\text { fence is catching the west side of the building }\end{array}$ & 0 & & \\
\hline TD-015 & $11 / 8$ & $14: 39$ & $\begin{array}{l}\text { AVL, PPD } \\
\text { video }\end{array}$ & 0 & 39.749517 & -121.634467 & AVL & TD & Town Hall; fence on fire & 0 & & \\
\hline TD-071 & $11 / 8$ & $14: 40$ & PPD video & 0 & 39.762973 & -121.620371 & TD & TD & fire near Holiday Market, trees ignited & v & & \\
\hline PPD-15 & $11 / 8$ & $14: 40$ & PPD-15 & 0 & 39.754176 & -121.624097 & video & video & fire close to Paradise Police station & $\mathrm{R}$ & & \\
\hline PPD-15 & $11 / 8$ & $14: 41$ & PPD-15 & 0 & 39.753787 & -121.623590 & video & video & glowing vegetation fire in area of park at PPD & 0 & & \\
\hline TD-076 & $11 / 8$ & $14: 43$ & Photo & 0 & 39.745718 & -121.638429 & Photo & Photo & structure fully involved & C & & \\
\hline TD-076 & $11 / 8$ & $14: 43$ & Photo & 0 & 39.745798 & -121.638920 & Photo & Photo & $\begin{array}{l}\text { active vegetation fire, surface fuels and pine trees } \\
\text { torching }\end{array}$ & v & & \\
\hline TD-127 & $11 / 8$ & $14: 44$ & video & 0 & 39.791231 & -121.591078 & video & video & Skyway at Bel Air Dr; structure fully involved & $\mathrm{R}$ & & \\
\hline TD-076 & $11 / 8$ & $14: 44$ & Photo & 0 & 39.745625 & -121.639440 & Photo & Photo & structure fully involved & $\mathrm{R}$ & & \\
\hline TD-127 & $11 / 8$ & $14: 44$ & Photo & 0 & 39.791224 & -121.591043 & Photo & Photo & $\begin{array}{l}\text { structure fully involved, ignited and torched pine tree } \\
\text { up against building }\end{array}$ & c & & \\
\hline TD-066 & $11 / 8$ & $14: 45$ & PPD video & 3 & 39.761934 & -121.617456 & TD & TD & fire approaching Holiday Market from the bike path & $\mathrm{v}$ & & \\
\hline TD-127 & $11 / 8$ & $14: 45$ & Radio Log & 0 & 39.788747 & -121.592689 & Radio Log & Radio Log & $\begin{array}{l}\text { abandoned vehicles on Skyway between Clark Rd and } \\
\text { Wagstaff Rd are all burning }\end{array}$ & 0 & & \\
\hline TD-113 & $11 / 8$ & $14: 45$ & Photo & 0 & 39.781975 & -121.605559 & Photo & Photo & shed/outbuilding fully involved & 0 & & \\
\hline TD-127 & $11 / 8$ & $14: 46$ & Photo & 0 & 39.784795 & -121.598416 & Photo & Photo & $\begin{array}{l}\text { numerous residential and commercial structures all } \\
\text { around fully involved, past peak but active burning }\end{array}$ & C & & \\
\hline PPD-15 & $11 / 8$ & $14: 49$ & PPD-15 & 0 & 39.767912 & -121.613218 & video & video & fire approaching the building & 0 & & \\
\hline PPD-15 & $11 / 8$ & 14:51 & PPD-15 & 0 & 39.771457 & -121.611786 & video & video & fire both sides of Skyway; structures have burned down & $c$ & $\mathrm{x}$ & \\
\hline TD-055 & $11 / 8$ & $14: 52$ & Photo & 0 & 39.752878 & -121.625259 & Photo & Photo & heavy fire on roof/facade of structure & C & & \\
\hline TD-101 & $11 / 8$ & $14: 53$ & Photo & 0 & 39.752820 & -121.625090 & Photo & Photo & $\begin{array}{l}\text { wood shake roof fully involved on commercial } \\
\text { structure, spewing firebrands; spaced } 0.6 \mathrm{~m}(2 \mathrm{ft}) \text { from } \\
\text { neighboring commercial structure }\end{array}$ & C & & \\
\hline TD-101 & $11 / 8$ & $14: 53$ & Photo & 0 & 39.752579 & -121.625413 & Photo & Photo & vegetation spot fire & $\mathrm{s}$ & & \\
\hline TD-015 & $11 / 8$ & $14: 54$ & AVL & 13 & 39.749203 & -121.634276 & AVL & AVL & $\begin{array}{l}\text { Town Hall; woodpile on fire approximately } 18 \mathrm{~m}^{3} \\
\text { ( } 5 \text { cords) of firewood, debris around. Shrubs and } \\
\text { junipers are torching. }\end{array}$ & 0 & & \\
\hline
\end{tabular}




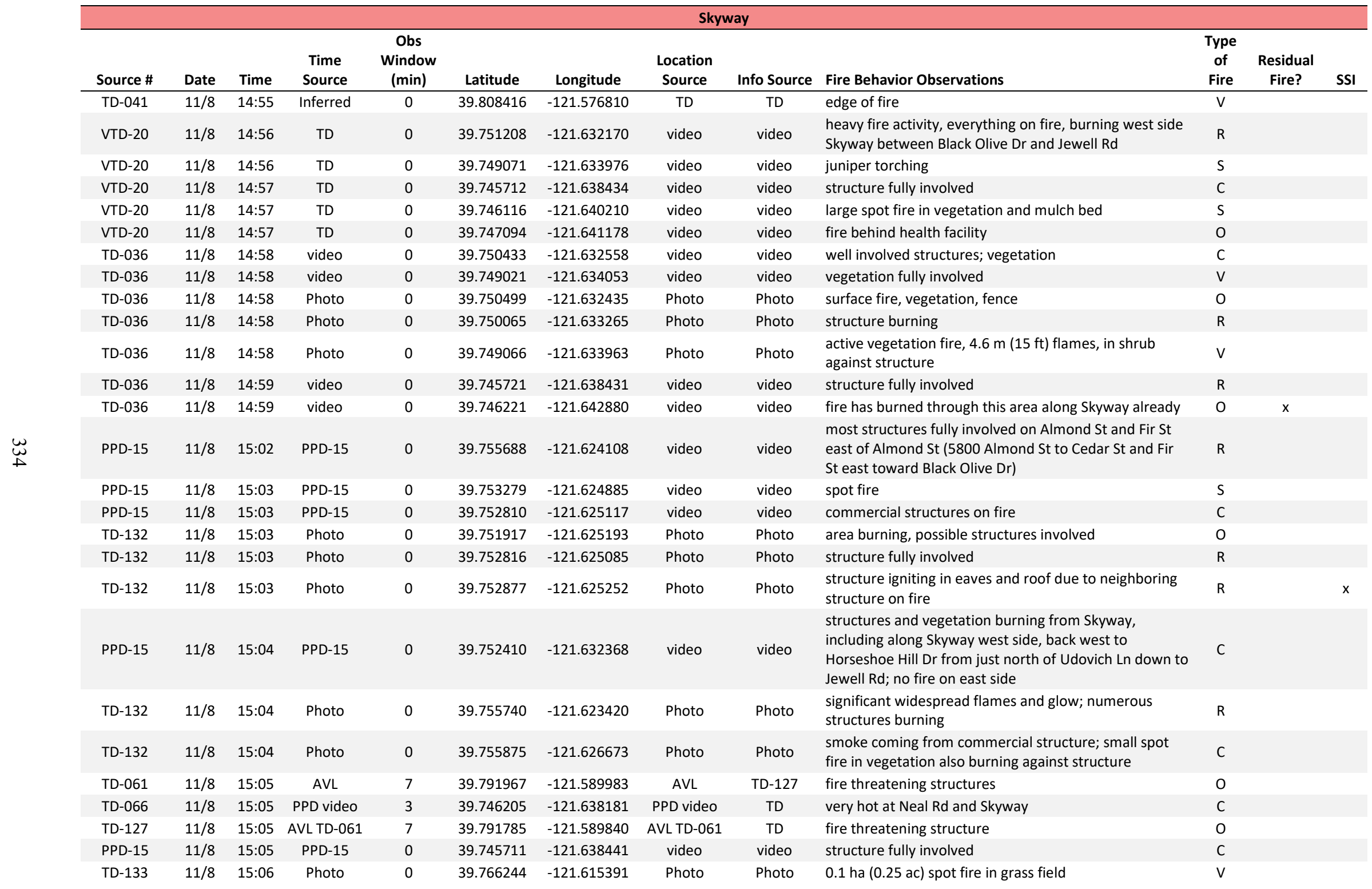




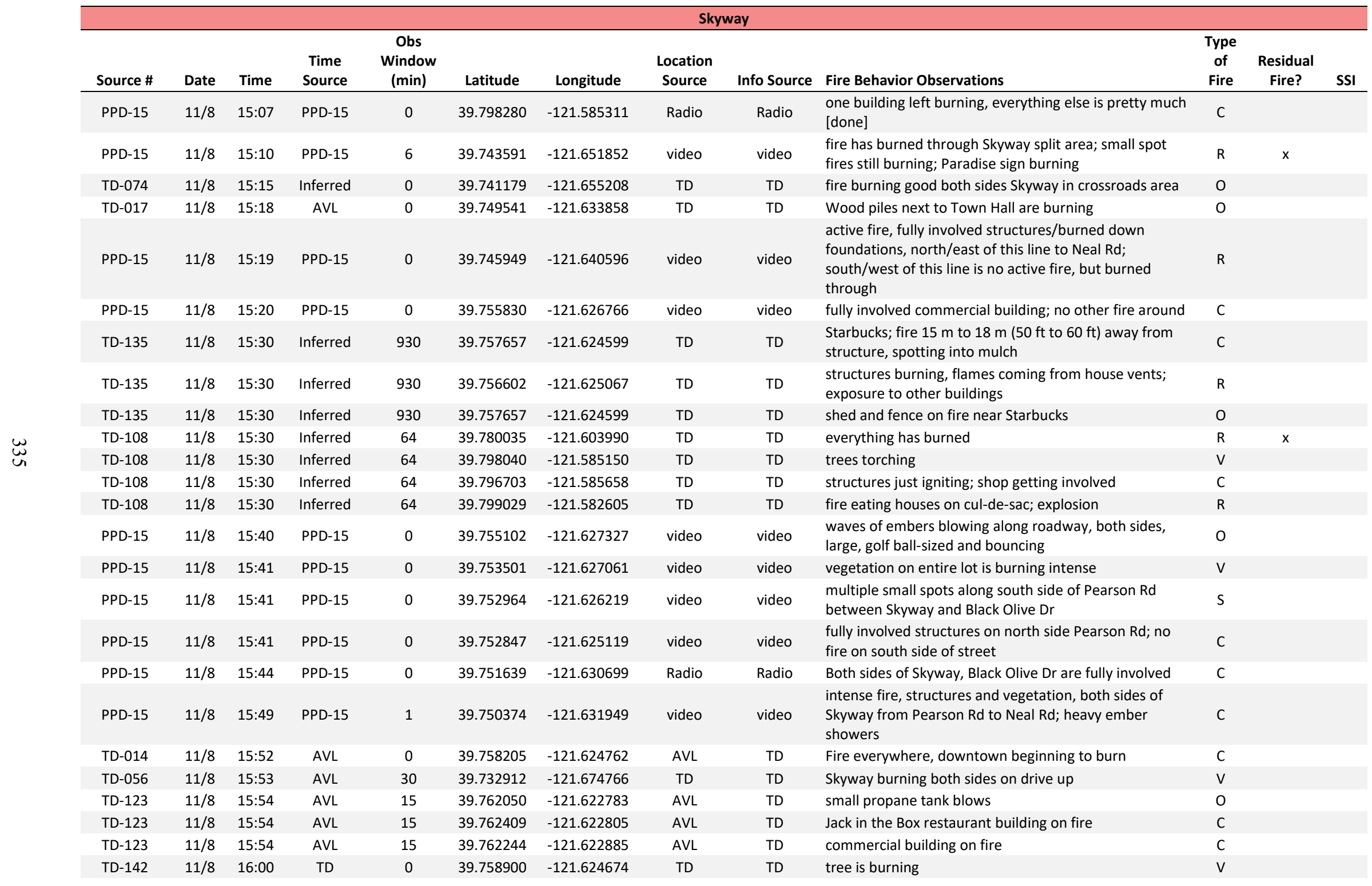




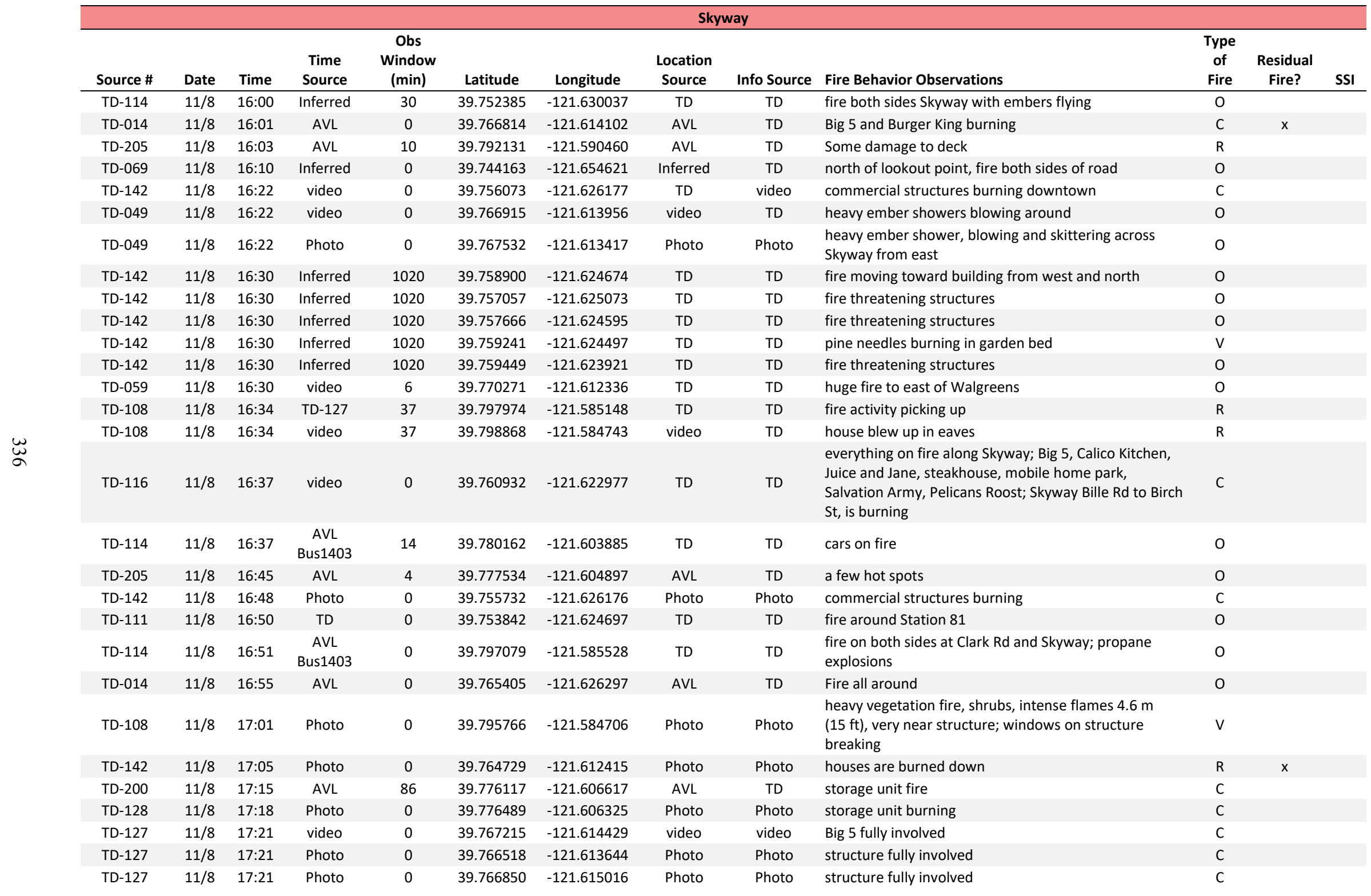




\begin{tabular}{|c|c|c|c|c|c|c|c|c|c|c|c|c|}
\hline \multicolumn{13}{|c|}{ Skyway } \\
\hline Source \# & Date & Time & $\begin{array}{l}\text { Time } \\
\text { Source }\end{array}$ & $\begin{array}{c}\text { Obs } \\
\text { Window } \\
\text { (min) }\end{array}$ & Latitude & Longitude & $\begin{array}{l}\text { Location } \\
\text { Source }\end{array}$ & Info Source & Fire Behavior Observations & $\begin{array}{c}\text { Type } \\
\text { of } \\
\text { Fire }\end{array}$ & $\begin{array}{l}\text { Residual } \\
\text { Fire? }\end{array}$ & SSI \\
\hline TD-127 & $11 / 8$ & $17: 21$ & Photo & 0 & 39.767247 & -121.614411 & Photo & Photo & structure fully involved & C & & \\
\hline TD-142 & $11 / 8$ & $17: 21$ & Photo & 0 & 39.759080 & -121.624529 & Photo & Photo & Building fully involved & C & & \\
\hline TD-127 & $11 / 8$ & $17: 23$ & Photo & 0 & 39.765146 & -121.618438 & Photo & Photo & structure fully involved & C & & \\
\hline TD-127 & $11 / 8$ & $17: 23$ & Photo & 0 & 39.765591 & -121.617992 & Photo & Photo & structure burned to foundation, glowing rubble & C & $\mathrm{x}$ & \\
\hline TD-127 & $11 / 8$ & $17: 23$ & Photo & 0 & 39.765814 & -121.617348 & Photo & Photo & structure fully involved & C & & \\
\hline TD-127 & $11 / 8$ & $17: 23$ & Photo & 0 & 39.765429 & -121.617552 & Photo & Photo & $\begin{array}{l}\text { numerous spot fires in roadside vegetation, garden } \\
\text { beds; embers skittering and blowing around }\end{array}$ & $S$ & & \\
\hline TD-108 & $11 / 8$ & $17: 25$ & Photo & 0 & 39.796000 & -121.584873 & Photo & Photo & $\begin{array}{l}\text { active surface fire burning in area of Cabernet } L n \text { and } \\
\text { Clark Rd }\end{array}$ & V & & \\
\hline TD-108 & $11 / 8$ & $17: 25$ & Photo & 0 & 39.795830 & -121.585126 & Photo & Photo & moderate fire activity, vegetation & $\mathrm{v}$ & & \\
\hline TD-142 & $11 / 8$ & $17: 25$ & Photo & 0 & 39.759087 & -121.624545 & Photo & Photo & structure fully involved & C & & \\
\hline TD-127 & $11 / 8$ & $17: 26$ & Radio Log & 0 & 39.770442 & -121.612302 & Radio Log & Radio Log & commercial structures all along Skyway are threatened & 0 & & \\
\hline TD-142 & $11 / 8$ & $17: 26$ & Photo & 0 & 39.758735 & -121.624156 & Photo & Photo & $\begin{array}{l}\text { fire coming from roof of structure; brands blowing } \\
\text { down street }\end{array}$ & C & & \\
\hline TD-142 & $11 / 8$ & $17: 26$ & Photo & 0 & 39.759188 & -121.623589 & Photo & Photo & Valero gas station fully involved & C & & \\
\hline TD-030 & $11 / 8$ & $17: 30$ & AVL & 11 & 39.763750 & -121.620917 & AVL & TD & fire threatening structures & 0 & & \\
\hline TD-201 & $11 / 8$ & $17: 33$ & Photo & 0 & 39.784355 & -121.598993 & Photo & Photo & $\begin{array}{l}\text { Skyway from Rocky } L n \text { to Kemen } L n \text {, burned over, spot } \\
\text { fires, most houses burning rubble or nearly out }\end{array}$ & $\mathrm{R}$ & $\mathrm{x}$ & \\
\hline TD-127 & $11 / 8$ & $17: 34$ & Photo & 0 & 39.765037 & -121.618873 & Photo & Photo & $\begin{array}{l}\text { Salvation Army, neighboring structures, fully involved; } \\
\text { embers lofting and blowing down road }\end{array}$ & C & & \\
\hline TD-142 & $11 / 8$ & $17: 34$ & Photo & 0 & 39.758725 & -121.624129 & Photo & Photo & $\begin{array}{l}\text { building fully involved; parked vehicle igniting from } \\
\text { exposure; brands blow down street to the South }\end{array}$ & C & & \\
\hline TD-030 & $11 / 8$ & $17: 42$ & AVL & 30 & 39.762550 & -121.620517 & AVL & TD & fire threatening structures & 0 & & \\
\hline TD-201 & $11 / 8$ & $17: 45$ & $\mathrm{AVL}$ & 40 & 39.762561 & -121.622127 & AVL & TD & $\begin{array}{l}\text { downtown commercial buildings are burning or } \\
\text { catching }\end{array}$ & C & & \\
\hline TD-108 & $11 / 8$ & $17: 49$ & video & 0 & 39.780637 & -121.603462 & TD & video & all structures burned down, still flaming & $\mathrm{R}$ & $\mathrm{x}$ & \\
\hline TD-108 & $11 / 8$ & $17: 49$ & Inferred & 7 & 39.772367 & -121.611390 & TD & TD & $\begin{array}{l}\text { Skyway Wagstaff Rd to Bille Rd nothing to be saved, } \\
\text { most structures gone }\end{array}$ & C & $\mathrm{x}$ & \\
\hline TD-108 & $11 / 8$ & $17: 49$ & Photo & 0 & 39.779683 & -121.604313 & Photo & Photo & $\begin{array}{l}\text { Skyway from Montna Dr to Wagstaff Rd, burned over, } \\
\text { spot fires, most houses burning rubble or nearly out }\end{array}$ & $\mathrm{R}$ & $\mathrm{x}$ & \\
\hline TD-014 & $11 / 8$ & $17: 52$ & Radio Log & 0 & 39.757515 & -121.625300 & Radio Log & Radio Log & heavy fire in downtown area & C & & \\
\hline TD-201 & $11 / 8$ & $17: 54$ & Photo & 0 & 39.765542 & -121.616143 & Photo & Photo & structure fully involved, partially collapsed & $\mathrm{R}$ & & \\
\hline TD-201 & $11 / 8$ & $17: 54$ & Photo & 0 & 39.766063 & -121.616652 & Photo & Photo & $\begin{array}{l}\text { multiple structures on north side of Skyway burned to } \\
\text { foundation }\end{array}$ & $\mathrm{R}$ & $x$ & \\
\hline TD-201 & $11 / 8$ & $17: 55$ & Photo & 0 & 39.765104 & -121.617327 & Photo & Photo & structure fully involved & C & & \\
\hline TD-108 & $11 / 8$ & $17: 56$ & Photo & 0 & 39.767139 & -121.613792 & Photo & Photo & Skyway at Maxwell; structures past peak, fully involved & C & $\mathrm{x}$ & \\
\hline TD-142 & $11 / 8$ & $17: 56$ & Photo & 0 & 39.757734 & -121.625757 & Photo & Photo & flames against building & 0 & & \\
\hline
\end{tabular}




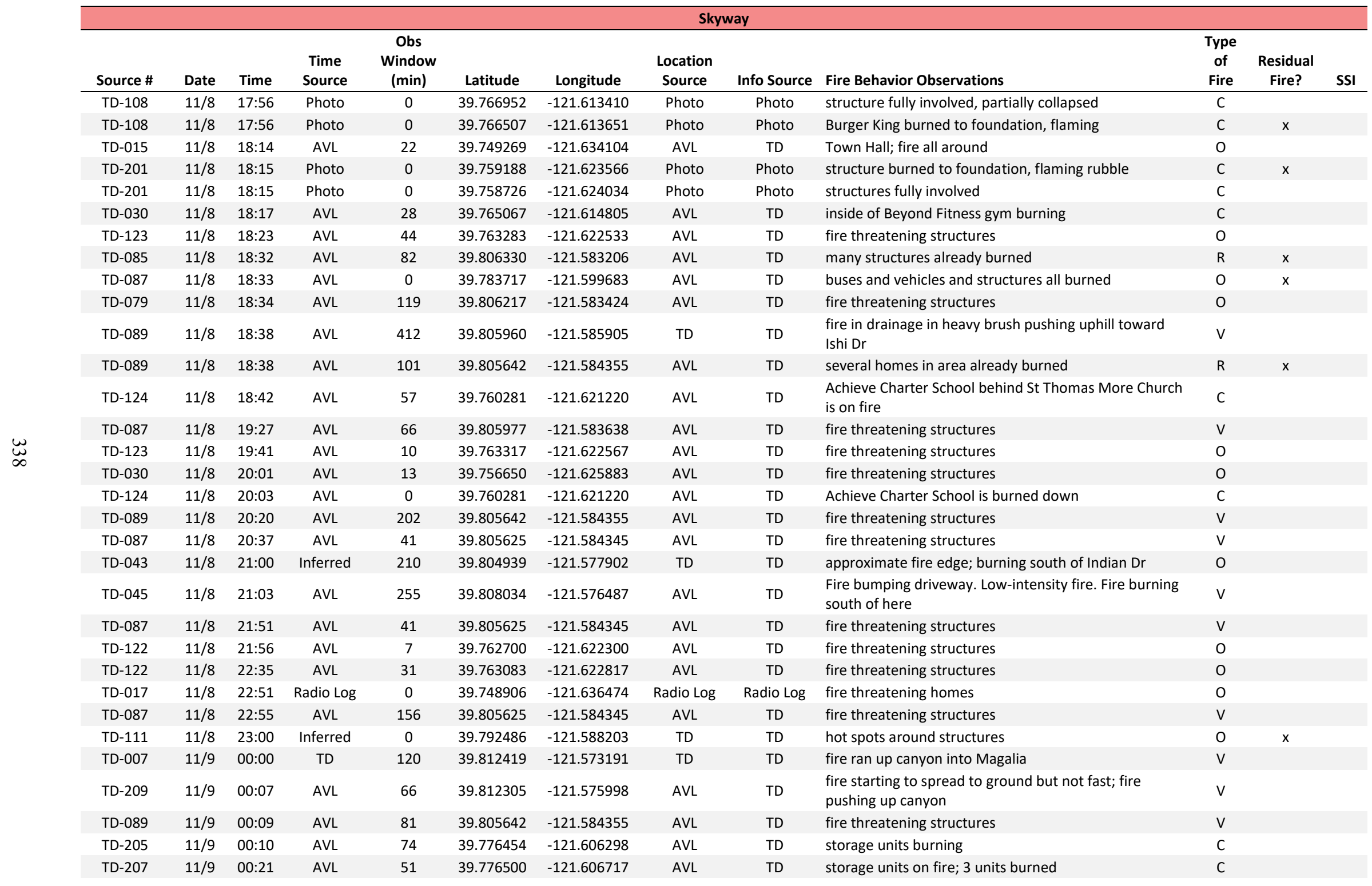




\begin{tabular}{|c|c|c|c|c|c|c|c|c|c|c|c|c|}
\hline \multicolumn{13}{|c|}{ Skyway } \\
\hline Source \# & Date & Time & $\begin{array}{l}\text { Time } \\
\text { Source }\end{array}$ & $\begin{array}{l}\text { Obs } \\
\text { Window } \\
\text { (min) }\end{array}$ & Latitude & Longitude & $\begin{array}{l}\text { Location } \\
\text { Source }\end{array}$ & Info Source & Fire Behavior Observations & $\begin{array}{c}\text { Type } \\
\text { of } \\
\text { Fire }\end{array}$ & $\begin{array}{l}\text { Residual } \\
\text { Fire? }\end{array}$ & SSI \\
\hline TD-061 & $11 / 9$ & $00: 53$ & AVL & 24 & 39.812883 & -121.578283 & AVL & TD & $\begin{array}{l}\text { main fire front blew straight across Skyway at } \\
\text { Coutolenc, estimated } 22 \mathrm{~m} / \mathrm{s}(50 \mathrm{mi} / \mathrm{h}) \text {. Wood } \\
\text { guardrails igniting. }\end{array}$ & $\mathrm{v}$ & & \\
\hline TD-125 & $11 / 9$ & $00: 53$ & TD-061 & 24 & 39.812793 & -121.578158 & TD & TD & $\begin{array}{l}\text { fire coming up from canyon, strong wind; softball size } \\
\text { embers; embers igniting houses }\end{array}$ & $\mathrm{R}$ & & \\
\hline TD-115 & $11 / 9$ & 01:00 & Inferred & 60 & 39.812751 & -121.578417 & TD & TD & hit wall of fire on Coutolenc Rd & 0 & & \\
\hline TD-115 & $11 / 9$ & 01:00 & Inferred & 60 & 39.812152 & -121.578021 & TD & TD & structure burning & C & & \\
\hline TD-126 & $11 / 9$ & 01:00 & TD & $\begin{array}{c}59.99999 \\
9\end{array}$ & 39.812768 & -121.578424 & TD & TD & fire spreads west and north of Skyway & v & & \\
\hline TD-045 & $11 / 9$ & 01:19 & AVL & 120 & 39.812594 & -121.578472 & AVL & TD & $\begin{array}{l}\text { Lots of spots. Tree stands torching. Fire came roaring up } \\
\text { from the canyon. Spotting below Skyway and into Old } \\
\text { Magalia }\end{array}$ & $\mathrm{v}$ & & \\
\hline TD-043 & $11 / 9$ & 01:30 & Inferred & 0 & 39.807558 & -121.579823 & TD & TD & lots of scattered spot fires & $\mathrm{S}$ & & \\
\hline TD-087 & $11 / 9$ & 01:33 & AVL & 113 & 39.808001 & -121.578911 & AVL & TD & $\begin{array}{l}\text { fire hits crazy from water station. Fire pushed from the } \\
\text { dam }\end{array}$ & $\mathrm{v}$ & & \\
\hline TD-089 & $11 / 9$ & 01:44 & $A V L$ & 102 & 39.809900 & -121.583985 & TD & TD & $\begin{array}{l}\text { big push of fire from east; fire also came up drainage } \\
\text { from west }\end{array}$ & $\mathrm{v}$ & & \\
\hline TD-207 & $11 / 9$ & 01:49 & AVL & 266 & 39.776500 & -121.606917 & AVL & TD & storage units on fire; 3 units burned & C & & \\
\hline TD-089 & $11 / 9$ & $03: 29$ & AVL & 97 & 39.805642 & -121.584355 & AVL & TD & fire threatening structures & $\mathrm{V}$ & & \\
\hline TD-087 & $11 / 9$ & 03:34 & AVL & 181 & 39.805625 & -121.584345 & AVL & TD & fire threatening structures & $\mathrm{v}$ & & \\
\hline TD-079 & $11 / 9$ & 05:14 & AVL & 209 & 39.805047 & -121.584566 & AVL & TD & $\begin{array}{l}\text { fire creeping up from canyon. Fire behavior had } \\
\text { reduced; just residual fire from before }\end{array}$ & $\mathrm{v}$ & & \\
\hline TD-132 & $11 / 9$ & 08:35 & TD & 45 & 39.773699 & -121.609622 & Photo & TD & 3 storage units fully involved & C & & \\
\hline TD-132 & $11 / 9$ & $09: 20$ & Photo & 0 & 39.773532 & -121.610107 & Photo & Photo & storage units, smoking, but no fire showing & C & $\mathrm{x}$ & \\
\hline
\end{tabular}




\begin{tabular}{|c|c|c|c|c|c|c|c|c|c|c|c|c|}
\hline & & & & & & & Neal & load & & & & \\
\hline Source \# & Date & Time & $\begin{array}{l}\text { Time } \\
\text { Source }\end{array}$ & $\begin{array}{c}\text { Obs } \\
\text { Window } \\
\text { (min) }\end{array}$ & Latitude & Longitude & $\begin{array}{l}\text { Location } \\
\text { Source }\end{array}$ & Info Source & Fire Behavior Observations & $\begin{array}{c}\text { Type } \\
\text { of } \\
\text { Fire }\end{array}$ & $\begin{array}{l}\text { Residual } \\
\text { Fire? }\end{array}$ & SSI \\
\hline TD-104 & $11 / 8$ & 08:30 & TD & 0 & 39.734419 & -121.628216 & TD & TD & $\begin{array}{l}\text { fire in canyon burning westward into backyards at end } \\
\text { of Eldridge } D r\end{array}$ & $\mathrm{v}$ & & \\
\hline TD-104 & $11 / 8$ & 09:00 & TD & 0 & 39.732695 & -121.631406 & TD & TD & backyard igniting; embers and ash falling & $\mathrm{v}$ & & \\
\hline TD-106 & $11 / 8$ & $10: 30$ & Inferred & 0 & 39.728016 & -121.655837 & TD & TD & fire front not here yet, just spots & $\mathrm{s}$ & & \\
\hline TD-106 & $11 / 8$ & 10:30 & Inferred & 420 & 39.727639 & -121.657419 & TD & TD & spot fires & $\mathrm{S}$ & & \\
\hline PPD-02 & $11 / 8$ & 10:57 & PPD-02 & 0 & 39.727458 & -121.655529 & Radio & Radio & flames coming up Red Sky Ln & 0 & & \\
\hline TD-068 & $11 / 8$ & 11:00 & Inferred & 60 & 39.732229 & -121.663044 & TD & TD & $\begin{array}{l}\text { glow coming from drainage between Neal Rd and } \\
\text { Skyway; cannot tell if structures burning }\end{array}$ & 0 & & \\
\hline TD-078 & $11 / 8$ & $11: 00$ & Inferred & 30 & 39.727544 & -121.655506 & TD & TD & small spot fires on Neal Rd & $\mathrm{s}$ & & \\
\hline TD-053 & $11 / 8$ & 11:00 & Inferred & 30 & 39.727514 & -121.655504 & TD & TD & fire coming over Neal Rd & 0 & & \\
\hline TD-053 & $11 / 8$ & $11: 00$ & Inferred & 30 & 39.728220 & -121.656609 & TD & TD & fire on NW side of Neal Rd & 0 & & \\
\hline PPD-08 & $11 / 8$ & 11:28 & PPD-08 & 0 & 39.727459 & -121.655531 & Radio & Radio & $\begin{array}{l}\text { flames are getting much closer to Neal Rd now up from } \\
\text { big sky }\end{array}$ & v & & \\
\hline PPD-08 & $11 / 8$ & $11: 29$ & PPD-08 & 0 & 39.727459 & -121.655531 & Radio & Radio & flames are getting really close to Neal Rd & $\mathrm{v}$ & & \\
\hline TD-066 & $11 / 8$ & 11:30 & TD & 0 & 39.729972 & -121.652711 & TD & TD & fire activity both sides of Neal Rd north of Wayland Rd & 0 & & \\
\hline TD-073 & $11 / 8$ & $11: 30$ & Inferred & 60 & 39.727998 & -121.655696 & TD & TD & $\begin{array}{l}\text { fire west side of Neal Rd; in area of Red Sky Ln and } \\
\text { Bayleaf } L n\end{array}$ & 0 & & \\
\hline TD-205 & $11 / 8$ & $11: 42$ & Photo & 0 & 39.726142 & -121.666917 & Photo & Photo & can see fire on ridge & $\mathrm{v}$ & & \\
\hline TD-205 & $11 / 8$ & 11:42 & Photo & 0 & 39.729143 & -121.661931 & Photo & Photo & extensive line of fire burning on ridge & v & & \\
\hline TD-205 & $11 / 8$ & 11:42 & Photo & 0 & 39.729143 & -121.661931 & Photo & Photo & extensive line of fire burning on ridge & $\mathrm{v}$ & & \\
\hline PPD-08 & $11 / 8$ & 11:48 & PPD-08 & 0 & 39.737026 & -121.648791 & Radio & Radio & $\begin{array}{l}\text { Neal Rd at Roe Rd, fire about } 14 \mathrm{~m} \text { to } 18 \mathrm{~m} \text { ( } 15 \mathrm{yd} \text { to } \\
20 \mathrm{yd} \text { ) from the road }\end{array}$ & 0 & & \\
\hline TD-091 & $11 / 8$ & $11: 53$ & AVL & 30 & 39.728161 & -121.656972 & AVL & TD & fire is bumping behind these structures; fire in drainage & v & & \\
\hline TD-066 & $11 / 8$ & 12:00 & TD & 10 & 39.737919 & -121.647952 & TD & TD & fire all around & 0 & & \\
\hline TD-106 & $11 / 8$ & $12: 00$ & $\begin{array}{l}\text { TD-205, } \\
\text { PPD video }\end{array}$ & 0 & 39.727586 & -121.655546 & TD & TD & fire front came all around & 0 & & \\
\hline TD-073 & $11 / 8$ & 12:04 & PPD video & 0 & 39.727499 & -121.655527 & TD & TD & fire at Wayland and Neal Rd & v & & \\
\hline TD-128 & $11 / 8$ & 12:07 & AVL & 0 & 39.732850 & -121.651417 & $\mathrm{AVL}$ & TD & fire is backing up hill toward subdivision (from SW) & v & & \\
\hline TD-014 & $11 / 8$ & 12:08 & Radio Log & 0 & 39.736998 & -121.648789 & Radio Log & Radio Log & $\begin{array}{l}\text { multiple vehicles being overrun by fire on Neal Rd and } \\
\text { Roe Rd area }\end{array}$ & 0 & & \\
\hline TD-205 & $11 / 8$ & 12:09 & AVL & 18 & 39.732763 & -121.653864 & AVL & TD & $\begin{array}{l}\text { fire to south of street - getting into back yards; intense } \\
\text { fire activity }\end{array}$ & $\mathrm{v}$ & & \\
\hline TD-205 & $11 / 8$ & 12:09 & Photo & 4 & 39.732763 & -121.653864 & Photo & Photo & fire in backyard & v & & \\
\hline TD-207 & $11 / 8$ & 12:09 & AVL & 13 & 39.732783 & -121.654217 & AVL & TD & fire behind structures & v & & \\
\hline TD-205 & $11 / 8$ & 12:09 & Photo & 0 & 39.732369 & -121.654058 & Photo & Photo & 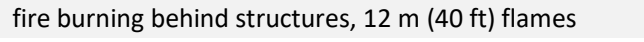 & v & & \\
\hline TD-205 & $11 / 8$ & 12:13 & Photo & 0 & 39.732492 & -121.654469 & Photo & Photo & $\begin{array}{l}\text { vegetation fire, trees torching; possible structure } \\
\text { burning }\end{array}$ & 0 & & \\
\hline
\end{tabular}




\begin{tabular}{|c|c|c|c|c|c|c|c|c|c|c|c|c|}
\hline \multicolumn{13}{|c|}{ Neal Road } \\
\hline Source \# & Date & Time & $\begin{array}{l}\text { Time } \\
\text { Source }\end{array}$ & $\begin{array}{l}\text { Obs } \\
\text { Window } \\
\text { (min) }\end{array}$ & Latitude & Longitude & $\begin{array}{l}\text { Location } \\
\text { Source }\end{array}$ & Info Source & Fire Behavior Observations & $\begin{array}{l}\text { Type } \\
\text { of } \\
\text { Fire }\end{array}$ & $\begin{array}{l}\text { Residual } \\
\text { Fire? }\end{array}$ & SSI \\
\hline PPD-08 & $11 / 8$ & $12: 13$ & PPD-08 & 0 & 39.730861 & -121.652047 & Radio & Radio & $\begin{array}{l}\text { lower Neal Rd north of Wayland Rd, fires crossing the } \\
\text { road }\end{array}$ & 0 & & \\
\hline PPD-08 & $11 / 8$ & $12: 17$ & PPD-08 & 0 & 39.736913 & -121.648907 & Radio & Radio & [3000 blk] flames almost to road & 0 & & \\
\hline TD-050 & $11 / 8$ & $12: 20$ & Inferred & 0 & 39.738122 & -121.647717 & TD & TD & $\begin{array}{l}\text { burning both sides of road; truck and utility trailer on } \\
\text { fire }\end{array}$ & 0 & & \\
\hline TD-091 & $11 / 8$ & $12: 23$ & AVL & 96 & 39.729684 & -121.654360 & AVL & TD & fire jumping dozer lines & $\mathrm{V}$ & & \\
\hline TD-205 & $11 / 8$ & $12: 23$ & Photo & 0 & 39.731907 & -121.655013 & Photo & Photo & fire approaching homes, threatening structures & 0 & & \\
\hline TD-092 & $11 / 8$ & $12: 25$ & AVL & 8 & 39.728496 & -121.657367 & AVL & TD & fire burning east towards Neal Rd & $\mathrm{o}$ & & \\
\hline TD-200 & $11 / 8$ & $12: 28$ & AVL & 0 & 39.741621 & -121.643231 & AVL & TD & fire everywhere on Neal Rd & 0 & & \\
\hline PPD-08 & $11 / 8$ & $12: 29$ & PPD-08 & 0 & 39.729943 & -121.652728 & Radio & Radio & $\begin{array}{l}\text { fire was right up against the road just inside the town } \\
\text { limits }\end{array}$ & 0 & & \\
\hline PPD-08 & $11 / 8$ & 12:31 & PPD-08 & 0 & 39.738838 & -121.646886 & Radio & Radio & fire is now crossing Neal Rd eastbound south of Jay $L n$ & 0 & & \\
\hline TD-092 & $11 / 8$ & $12: 36$ & AVL & 42 & 39.729796 & -121.658576 & AVL & TD & fire was bumping up to barn, tree on fire & V & & \\
\hline VTD-05 & $11 / 8$ & $13: 00$ & Inferred & 60 & 39.723699 & -121.660086 & video & video & fire burning up out of canyon spreading south & $\mathrm{v}$ & & \\
\hline VTD-05 & $11 / 8$ & $13: 00$ & Inferred & 60 & 39.723281 & -121.660694 & video & video & fire burning in canyon & v & & \\
\hline VTD-05 & $11 / 8$ & $13: 00$ & Inferred & 60 & 39.723386 & -121.661749 & video & video & past peak veg fire in canyon & $\mathrm{v}$ & & \\
\hline VTD-05 & $11 / 8$ & $13: 00$ & Inferred & 60 & 39.722642 & -121.662549 & video & video & fire in canyon & $\mathrm{v}$ & & \\
\hline TD-091 & $11 / 8$ & $13: 27$ & AVL & 32 & 39.729774 & -121.653727 & TD & TD & burning vehicle threatening structure & 0 & & \\
\hline TD-104 & $11 / 8$ & $13: 43$ & Photo & 0 & 39.732815 & -121.632743 & Photo & Photo & $\begin{array}{l}\text { significant fire at end of Eldridge Dr; vegetation, } \\
\text { possibly structures burning }\end{array}$ & 0 & & \\
\hline TD-104 & $11 / 8$ & $13: 44$ & Photo & 0 & 39.732592 & -121.632862 & Photo & Photo & structure fully involved & $\mathrm{R}$ & & \\
\hline TD-104 & $11 / 8$ & $13: 44$ & Photo & 0 & 39.732596 & -121.633190 & Photo & TD, Photo & $\begin{array}{l}\text { huge propane tank, deck engulfed, too far gone; } \\
\text { propane fell through deck and relief valve blew and } \\
\text { deck exploded; structures on fire }\end{array}$ & $\mathrm{R}$ & & \\
\hline TD-104 & $11 / 8$ & $13: 44$ & Photo & 0 & 39.732596 & -121.632857 & Photo & TD, Photo & structure fully involved & $\mathrm{R}$ & & \\
\hline TD-104 & $11 / 8$ & $13: 44$ & Photo & 0 & 39.732592 & -121.632862 & Photo & Photo & structure fully involved & $\mathrm{R}$ & & \\
\hline TD-104 & $11 / 8$ & $13: 44$ & Photo & 0 & 39.732577 & -121.633146 & Photo & Photo & structure burning & $\mathrm{R}$ & & \\
\hline TD-104 & $11 / 8$ & $13: 45$ & Photo & 0 & 39.732815 & -121.632743 & Photo & Photo & fire down end of Eldridge $\mathrm{Dr}$ & $\mathrm{v}$ & & \\
\hline TD-092 & $11 / 8$ & $13: 52$ & $\mathrm{AVL}$ & 9 & 39.730500 & -121.651600 & AVL & TD & burning vehicle threatening structure & 0 & & \\
\hline TD-104 & $11 / 8$ & $14: 00$ & Inferred & 120 & 39.732707 & -121.636506 & TD & TD & fire approaching from west & v & & \\
\hline TD-104 & $11 / 8$ & $14: 00$ & Inferred & 120 & 39.732579 & -121.636446 & TD & TD & $\begin{array}{l}180 \mathrm{~mm} \times 25 \mathrm{~mm} \times 6 \mathrm{~mm}(7 \mathrm{in} \times 1 \mathrm{in} \times 0.25 \mathrm{in}) \text { flaming } \\
\text { bark ember }\end{array}$ & 0 & & \\
\hline TD-104 & $11 / 8$ & $14: 00$ & Inferred & 120 & 39.732524 & -121.640887 & TD & TD & fire in canyon & $\mathrm{v}$ & & \\
\hline TD-104 & $11 / 8$ & $14: 00$ & Inferred & 120 & 39.732902 & -121.640698 & TD & TD & $\begin{array}{l}\text { hearing rumble of a freight train, rumbling of jet engine; } \\
\text { severe fire activity from canyon }\end{array}$ & $\mathrm{v}$ & & \\
\hline
\end{tabular}




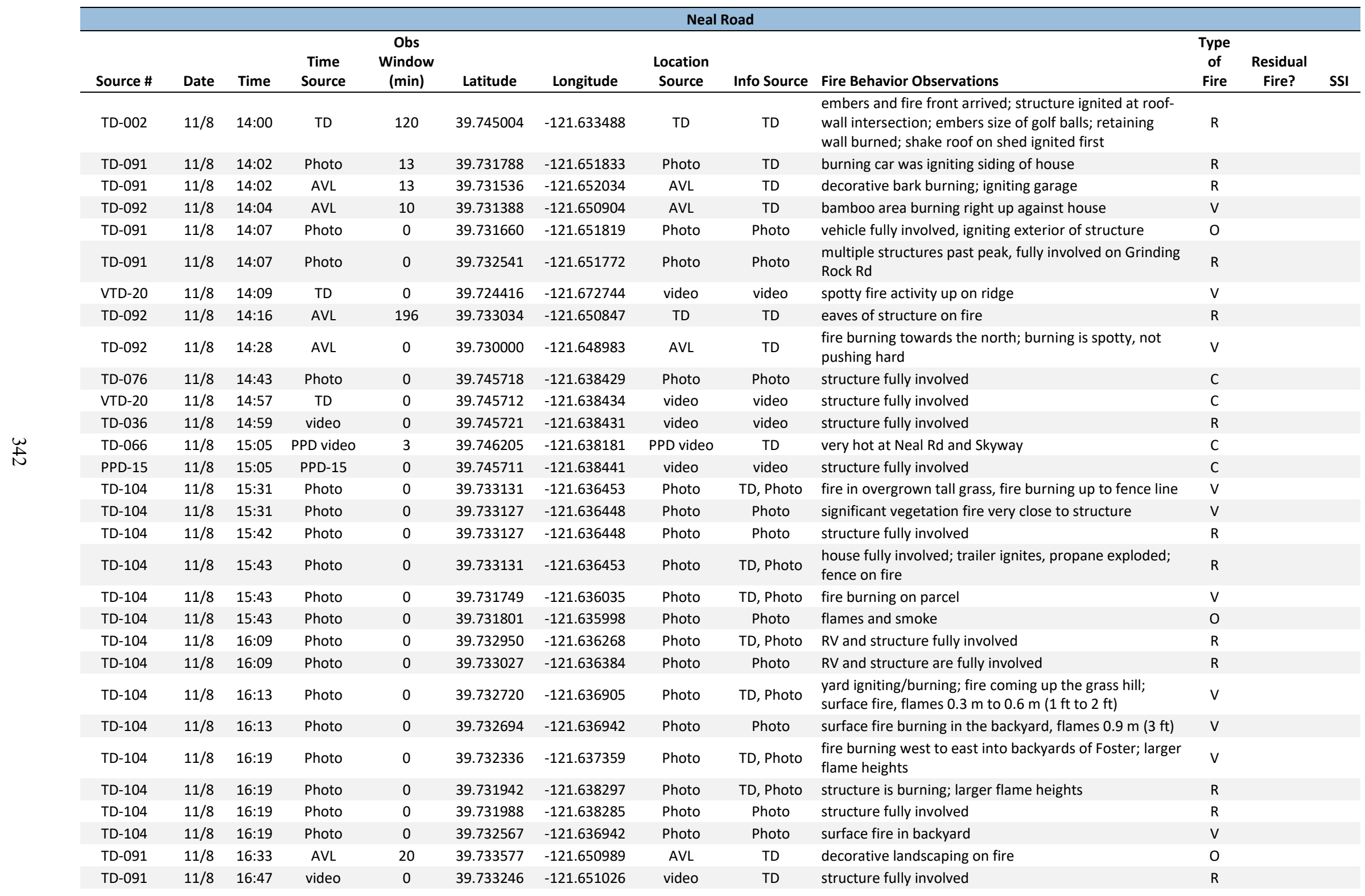




\begin{tabular}{|c|c|c|c|c|c|c|c|c|c|c|c|c|}
\hline \multicolumn{13}{|c|}{ Neal Road } \\
\hline Source \# & Date & Time & $\begin{array}{l}\text { Time } \\
\text { Source }\end{array}$ & $\begin{array}{c}\text { Obs } \\
\text { Window } \\
\text { (min) }\end{array}$ & Latitude & Longitude & $\begin{array}{l}\text { Location } \\
\text { Source }\end{array}$ & Info Source & Fire Behavior Observations & $\begin{array}{c}\text { Type } \\
\text { of } \\
\text { Fire }\end{array}$ & $\begin{array}{l}\text { Residual } \\
\text { Fire? }\end{array}$ & SSI \\
\hline TD-091 & $11 / 8$ & $16: 47$ & Photo & 0 & 39.733241 & -121.651070 & Photo & Photo & structure fully involved & $\mathrm{R}$ & & \\
\hline TD-091 & $11 / 8$ & $16: 47$ & Photo & 0 & 39.733571 & -121.651349 & Photo & Photo & structure fully involved & $\mathrm{R}$ & & \\
\hline TD-091 & $11 / 8$ & $16: 55$ & AVL & 6 & 39.733933 & -121.651551 & AVL & TD & fire threatening structure & $\mathrm{V}$ & & \\
\hline TD-091 & $11 / 8$ & 17:09 & AVL & 5 & 39.734971 & -121.650106 & AVL & TD & landscape bark burned into subfloor vents & $\mathrm{R}$ & & \\
\hline TD-091 & $11 / 8$ & $17: 18$ & AVL & 0 & 39.735367 & -121.650817 & AVL & TD & landscaping on fire; igniting structures & $\mathrm{R}$ & & \\
\hline TD-091 & $11 / 8$ & $17: 21$ & video & 4 & 39.735417 & -121.650183 & AVL & TD & garage fully involved; ground fuels igniting & $\mathrm{R}$ & & \\
\hline TD-091 & $11 / 8$ & $17: 23$ & Photo & 0 & 39.735602 & -121.650187 & Photo & Photo & $\begin{array}{l}\text { detached garage fully involved, significant exposure to } \\
\text { main structure }\end{array}$ & 0 & & $\mathrm{x}$ \\
\hline TD-091 & $11 / 8$ & $17: 23$ & Photo & 0 & 39.735428 & -121.650086 & Photo & Photo & numerous small vegetation spot fires on parcel & $\mathrm{s}$ & & \\
\hline TD-091 & $11 / 8$ & $17: 25$ & Photo & 0 & 39.735602 & -121.650187 & Photo & Photo & $\begin{array}{l}\text { detached garage fully involved, significant exposure to } \\
\text { main structure; eaves smoking }\end{array}$ & 0 & & \\
\hline TD-106 & $11 / 8$ & $17: 30$ & Inferred & 15 & 39.727616 & -121.654990 & TD & TD & $\begin{array}{l}\text { surrounded by fire, both sides of Neal Rd; miserable } \\
\text { trying to make it out of area }\end{array}$ & $\mathrm{R}$ & & \\
\hline TD-091 & $11 / 8$ & $17: 39$ & AVL & 35 & 39.727008 & -121.654899 & AVL & TD & heavy fire activity & 0 & & \\
\hline TD-091 & $11 / 8$ & $17: 39$ & AVL & 35 & 39.727703 & -121.655095 & AVL & TD & fire pushing in from the north east & 0 & & \\
\hline TD-104 & $11 / 8$ & 18:09 & Photo & 0 & 39.731620 & -121.636002 & Photo & TD, Photo & $\begin{array}{l}\text { fire burning primarily on east side Foster Rd one small } \\
\text { spot on west side }\end{array}$ & 0 & & \\
\hline TD-104 & $11 / 8$ & 18:09 & Photo & 0 & 39.731741 & -121.635985 & Photo & Photo & possible structure burning & 0 & & \\
\hline TD-104 & $11 / 8$ & 19:00 & & 60 & 39.732574 & -121.635377 & Photo & Inferred & two structures burning & $\mathrm{R}$ & & \\
\hline TD-104 & $11 / 8$ & 19:25 & Photo & 0 & 39.732616 & -121.634653 & Photo & TD, Photo & structure fully involved & $\mathrm{R}$ & & \\
\hline TD-104 & $11 / 8$ & 19:25 & Photo & 0 & 39.732559 & -121.634654 & Photo & Photo & structure fully involved & $\mathrm{R}$ & & \\
\hline TD-104 & $11 / 8$ & $20: 20$ & Photo & 0 & 39.732556 & -121.635578 & Photo & Photo & Structure on Eldridge Dr burning & $\mathrm{R}$ & & \\
\hline TD-104 & $11 / 8$ & $21: 29$ & Photo & 0 & 39.732184 & -121.636817 & Photo & TD, Photo & structure igniting & $\mathrm{R}$ & & \\
\hline TD-104 & $11 / 8$ & $23: 17$ & Photo & 0 & 39.732284 & -121.636929 & Photo & TD, Photo & $\begin{array}{l}\text { garage is well involved; wood roof structure, concrete } \\
\text { building; fence and boat are threatened/igniting }\end{array}$ & 0 & & \\
\hline TD-104 & $11 / 8$ & 23:17 & Photo & 0 & 39.732188 & -121.636807 & Photo & TD, Photo & garage fully involved & 0 & & \\
\hline TD-104 & $11 / 8$ & 23:17 & Photo & 0 & 39.732316 & -121.636503 & Photo & TD, Photo & structure is smoking and about to ignite & $\mathrm{R}$ & & \\
\hline TD-104 & $11 / 8$ & $23: 17$ & Photo & 0 & 39.732228 & -121.636919 & Photo & Photo & structure fully involved & $\mathrm{R}$ & & \\
\hline TD-104 & $11 / 9$ & 00:04 & Photo & 0 & 39.732221 & -121.636437 & Photo & TD, Photo & $\begin{array}{l}\text { fence and vegetation (oleander) burning up against } \\
\text { structure }\end{array}$ & v & & \\
\hline TD-104 & $11 / 9$ & 00:04 & Photo & 0 & 39.732221 & -121.636437 & Photo & Photo & $\begin{array}{l}\text { fence and vegetation (oleander) burning up against } \\
\text { structure }\end{array}$ & V & & \\
\hline TD-104 & $11 / 9$ & $00: 30$ & Photo & 0 & 39.732313 & -121.636505 & Photo & TD, Photo & structure burning & $\mathrm{R}$ & & \\
\hline TD-104 & $11 / 9$ & 00:30 & Photo & 0 & 39.732322 & -121.636507 & Photo & Photo & structure igniting; flames through the roof & $\mathrm{R}$ & & \\
\hline TD-104 & $11 / 9$ & $00: 42$ & Photo & 0 & 39.732313 & -121.636505 & Photo & TD, Photo & $\begin{array}{l}\text { structure well involved; burning up in roof; burned from } \\
\text { south to north }\end{array}$ & $\mathrm{R}$ & & \\
\hline TD-104 & $11 / 9$ & $00: 42$ & Photo & 0 & 39.732322 & -121.636507 & Photo & Photo & structure well involved; flames through the roof & $\mathrm{R}$ & & \\
\hline
\end{tabular}




\begin{tabular}{|c|c|c|c|c|c|c|c|c|c|c|c|c|}
\hline \multicolumn{13}{|c|}{ Neal Road } \\
\hline Source \# & Date & Time & $\begin{array}{l}\text { Time } \\
\text { Source }\end{array}$ & $\begin{array}{c}\text { Obs } \\
\text { Window } \\
\text { (min) }\end{array}$ & Latitude & Longitude & $\begin{array}{c}\text { Location } \\
\text { Source }\end{array}$ & Info Source & Fire Behavior Observations & $\begin{array}{c}\text { Type } \\
\text { of } \\
\text { Fire }\end{array}$ & $\begin{array}{c}\text { Residual } \\
\text { Fire? }\end{array}$ & SSI \\
\hline TD-104 & $11 / 9$ & $00: 43$ & Photo & 0 & 39.732322 & -121.636507 & Photo & Photo & structure well involved; flames through the roof & $\mathrm{R}$ & & \\
\hline TD-104 & $11 / 9$ & 00:45 & Photo & 0 & 39.732322 & -121.636507 & Photo & Photo & $\begin{array}{l}\text { structure well involved; flames through the roof; } \\
\text { generating firebrands }\end{array}$ & $\mathrm{R}$ & & \\
\hline TD-104 & $11 / 9$ & $00: 48$ & Photo & 0 & 39.732313 & -121.636505 & Photo & TD, Photo & $\begin{array}{l}\text { house collapsed, wall fell and ignited fence on north } \\
\text { side }\end{array}$ & $\mathrm{R}$ & & \\
\hline TD-104 & $11 / 9$ & $00: 48$ & Photo & 0 & 39.732322 & -121.636507 & Photo & Photo & structure fully involved & $\mathrm{R}$ & & \\
\hline
\end{tabular}




\begin{tabular}{|c|c|c|c|c|c|c|c|c|c|c|c|c|}
\hline \multicolumn{13}{|c|}{ Butte Creek Canyon and Lower Skyway } \\
\hline Source \# & Date & Time & $\begin{array}{l}\text { Time } \\
\text { Source }\end{array}$ & $\begin{array}{l}\text { Obs } \\
\text { Window } \\
\text { (min) }\end{array}$ & Latitude & Longitude & $\begin{array}{l}\text { Location } \\
\text { Source }\end{array}$ & Info Source & Fire Behavior Observations & $\begin{array}{c}\text { Type } \\
\text { of } \\
\text { Fire }\end{array}$ & $\begin{array}{l}\text { Residual } \\
\text { Fire? }\end{array}$ & SSI \\
\hline $911-223-1$ & $11 / 8$ & 09:11 & $911-223-1$ & 0 & 39.735791 & -121.687568 & Inferred & $911-223-1$ & fire about a mile beyond covered bridge & $S$ & & \\
\hline TD-014 & $11 / 8$ & 10:55 & Radio Log & 0 & 39.724188 & -121.692273 & $\begin{array}{l}\text { Radio Log, } \\
\text { Imagery }\end{array}$ & Radio Log & vehicle fire with threat to vegetation & 0 & & \\
\hline TD-026 & $11 / 8$ & $12: 45$ & Inferred & 15 & 39.724188 & -121.692273 & TD & TD & $\begin{array}{l}\text { pickup truck, SB in NB lanes has already burned; had } \\
\text { previously caught fire and was abandoned }\end{array}$ & 0 & $\mathrm{x}$ & \\
\hline Radio Log & $11 / 8$ & 13:02 & Radio Log & 0 & 39.729033 & -121.704007 & Radio Log & Radio Log & $\begin{array}{l}\text { spot fires on both sides of Honey Run, Centerville and } \\
\text { Honey Run }\end{array}$ & $\mathrm{S}$ & & \\
\hline TD-117 & $11 / 8$ & $14: 00$ & TD & 0 & 39.742833 & -121.673188 & TD & TD & $\begin{array}{l}\text { fire in backyard of two homes, moderate rate of spread, } \\
\text { flames } 1.8 \mathrm{~m} \text { to } 3 \mathrm{~m} \mathrm{(} 6 \mathrm{ft} \text { to } 10 \mathrm{ft} \text { ) flames }\end{array}$ & v & & \\
\hline TD-117 & $11 / 8$ & $14: 00$ & Inferred & 120 & 39.744503 & -121.680751 & TD & TD & $\begin{array}{l}\text { fire on ridge in Honey Run canyon; est. } 30 \mathrm{~m} \text { to } 60 \mathrm{~m} \\
(100 \mathrm{ft} \text { to } 200 \mathrm{ft} \text { ) flames }\end{array}$ & V & & \\
\hline TD-117 & $11 / 8$ & $14: 00$ & Inferred & 120 & 39.739515 & -121.678863 & TD & TD & ember showers & 0 & & \\
\hline TD-117 & $11 / 8$ & 14:00 & Inferred & 120 & 39.741952 & -121.678063 & TD & TD & fire threatening structure & 0 & & \\
\hline TD-007 & $11 / 8$ & $15: 40$ & TD-012 & 80 & 39.777748 & -121.690993 & TD & TD & spot fires in the Doe Creek area & $\mathrm{s}$ & & \\
\hline TD-117 & $11 / 8$ & 16:00 & Inferred & 300 & 39.736583 & -121.684689 & TD & TD & $\begin{array}{l}\text { fire spotting on homes down canyon; fire fronts are } \\
\text { joining }\end{array}$ & 0 & & \\
\hline TD-117 & $11 / 8$ & 16:00 & Inferred & 300 & 39.748322 & -121.686532 & TD & TD & fire moving quickly on Centerville Rd & 0 & & \\
\hline TD-117 & $11 / 8$ & 16:00 & Inferred & 300 & 39.732949 & -121.693106 & TD & TD & $\begin{array}{l}\text { fire coming down, merging from ridgelines pinching } \\
\text { Honey Run Rd; homes burning both sides of road }\end{array}$ & $\mathrm{R}$ & & \\
\hline TD-117 & $11 / 8$ & 16:00 & Inferred & 300 & 39.717714 & -121.719930 & TD & TD & chicken coop on fire; propane explosion & 0 & & \\
\hline TD-117 & $11 / 8$ & $16: 00$ & Inferred & 300 & 39.717714 & -121.719930 & TD & TD & $\begin{array}{l}\text { quick moving fire fronts, merging again from the } \\
\text { ridgelines }\end{array}$ & 0 & & \\
\hline TD-117 & $11 / 8$ & 16:00 & Inferred & 300 & 39.717714 & -121.719930 & TD & TD & fire both sides of the road & 0 & & \\
\hline TD-114 & $11 / 8$ & $16: 00$ & Inferred & 0 & 39.714896 & -121.709757 & TD & TD & fire near Tuscan Ridge & $\mathrm{V}$ & & \\
\hline TD-076 & $11 / 8$ & 16:34 & Photo & 0 & 39.762416 & -121.679481 & Photo & Photo & $\begin{array}{l}4 \text { ha to } 8 \text { ha }(10 \text { ac to } 20 \mathrm{ac} \text { ) spot fire in Butte Creek } \\
\text { Canyon }\end{array}$ & s & & \\
\hline TD-012 & $11 / 8$ & $18: 12$ & Radio Log & 0 & 39.774467 & -121.685367 & $A V L$ & TD & 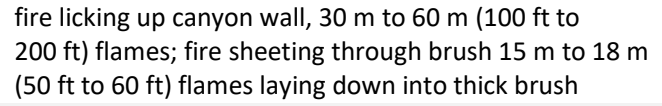 & v & & \\
\hline TD-201 & $11 / 8$ & $20: 17$ & AVL & 0 & 39.693348 & -121.758855 & TD & TD & $\begin{array}{l}\text { fire is approaching Hwy } 99 \text { near Skyway [line between } \\
\text { Spanish Garden Dr and Estates Dr] }\end{array}$ & V & & \\
\hline TD-009 & $11 / 8$ & $21: 00$ & Radio Log & 0 & 39.778893 & -121.682500 & Radio Log & Radio Log & $\begin{array}{l}\text { fire has moved to top of Doe Mill Ridge; hard push } \\
\text { through Buzztail/Wilder Rd }\end{array}$ & $\mathrm{O}$ & & \\
\hline TD-201 & $11 / 8$ & 21:04 & $\mathrm{AVL}$ & 146 & 39.693348 & -121.758855 & AVL & TD & edge of fire line & v & & \\
\hline TD-117 & $11 / 8$ & 21:07 & Radio Log & 0 & 39.717714 & -121.719930 & Radio Log & Radio Log & $\begin{array}{l}\text { Honey run to Centerville has all been impacted many } \\
\text { structures lost }\end{array}$ & $\mathrm{R}$ & & \\
\hline TD-009 & $11 / 8$ & 21:08 & Radio Log & 0 & 39.714953 & -121.724329 & Radio Log & Radio Log & $\begin{array}{l}\text { fire overcomes any containment or defense in Honey } \\
\text { Run Canyon }\end{array}$ & $\mathrm{O}$ & & \\
\hline
\end{tabular}




\begin{tabular}{|c|c|c|c|c|c|c|c|c|c|c|c|c|}
\hline \multicolumn{13}{|c|}{ Butte Creek Canyon and Lower Skyway } \\
\hline Source \# & Date & Time & $\begin{array}{l}\text { Time } \\
\text { Source }\end{array}$ & $\begin{array}{c}\text { Obs } \\
\text { Window } \\
\text { (min) }\end{array}$ & Latitude & Longitude & $\begin{array}{l}\text { Location } \\
\text { Source }\end{array}$ & Info Source & Fire Behavior Observations & $\begin{array}{c}\text { Type } \\
\text { of } \\
\text { Fire }\end{array}$ & $\begin{array}{l}\text { Residual } \\
\text { Fire? }\end{array}$ & SSI \\
\hline TD-091 & $11 / 8$ & $21: 28$ & AVL & 226 & 39.693891 & -121.757183 & AVL & TD & perimeter of fire & $\mathrm{V}$ & & \\
\hline TD-201 & $11 / 8$ & 21:40 & Radio Log & 0 & 39.687153 & -121.762226 & Radio Log & TD & edge of fire line & $\mathrm{V}$ & & \\
\hline TD-117 & $11 / 8$ & 22:00 & Inferred & 300 & 39.722532 & -121.753911 & TD & TD & fire front coming down the hill toward the west & 0 & & \\
\hline TD-009 & $11 / 8$ & 22:02 & Radio Log & 0 & 39.747231 & -121.752331 & Radio Log & Radio Log & $\begin{array}{l}\text { fire has moved up out of Stilson Canyon, coming up } \\
\text { over Old Humboldt Rd approaching Hwy } 32 \text { at the lower } \\
\text { end by the powerlines }\end{array}$ & V & & \\
\hline TD-012 & $11 / 8$ & 22:02 & Radio Log & 0 & 39.746706 & -121.754674 & Radio Log & TD & $\begin{array}{l}\text { fire moved up out of Stilson Canyon, spotting over } \\
\text { Humboldt Rd }\end{array}$ & $\mathrm{v}$ & & \\
\hline TD-009 & $11 / 8$ & 22:06 & Radio Log & 0 & 39.740790 & -121.766486 & Inferred & Radio Log & $\begin{array}{l}\text { fire is pushing down to lower Humboldt Rd near Hwy } 32 \\
\text { in Yosemite Dr area }\end{array}$ & $\mathrm{v}$ & & \\
\hline TD-012 & $11 / 8$ & 22:34 & AVL & 90 & 39.747309 & -121.752984 & AVL & TD & fire slops over Humboldt Rd into tall grass & $\mathrm{v}$ & & \\
\hline TD-009 & $11 / 8$ & 23:22 & AVL & 192 & 39.749204 & -121.746987 & AVL & TD & lower fire activity & V & & \\
\hline TD-201 & $11 / 8$ & 23:32 & AVL & 10 & 39.703904 & -121.756177 & Inferred & TD & subdivision is catching fire & $\mathrm{R}$ & & \\
\hline TD-201 & $11 / 9$ & 00:00 & AVL & 13 & 39.706787 & -121.739586 & AVL & TD & subdivision is catching fire & $\mathrm{R}$ & & \\
\hline
\end{tabular}




\begin{tabular}{|c|c|c|c|c|c|c|c|c|c|c|c|c|}
\hline \multicolumn{13}{|c|}{ Valley View Drive } \\
\hline Source \# & Date & Time & $\begin{array}{l}\text { Time } \\
\text { Source }\end{array}$ & $\begin{array}{c}\text { Obs } \\
\text { Window } \\
\text { (min) }\end{array}$ & Latitude & Longitude & $\begin{array}{l}\text { Location } \\
\text { Source }\end{array}$ & Info Source & Fire Behavior Observations & $\begin{array}{l}\text { Type } \\
\text { of } \\
\text { Fire }\end{array}$ & $\begin{array}{l}\text { Residual } \\
\text { Fire? }\end{array}$ & SSI \\
\hline TD-111 & $11 / 8$ & 08:41 & Inferred & 4 & 39.749885 & -121.653210 & TD & TD & $\begin{array}{l}\text { fire had clearly spotted over Paradise, can see smoke in } \\
\text { canyon }\end{array}$ & S & & \\
\hline $911-182-1$ & $11 / 8$ & 08:48 & $911-182-1$ & 0 & 39.749224 & -121.653849 & $911-182-1$ & $911-182-1$ & $\begin{array}{l}\text { spot fire started near creek, white smoke coming from } \\
\text { the canyon right now }\end{array}$ & $\mathrm{S}$ & & \\
\hline TD-006 & $11 / 8$ & $08: 51$ & AVL & 0 & 39.751079 & -121.655498 & AVL H901 & TD & spot fire in Butte Creek Canyon & $\mathrm{s}$ & & \\
\hline $911-200-1$ & $11 / 8$ & $08: 57$ & $911-200-1$ & 0 & 39.751090 & -121.652243 & Inferred & 911-200-1 & spot fire kind of by Valley View Dr & $\mathrm{s}$ & & \\
\hline $911-202-1$ & $11 / 8$ & 08:59 & $911-202-1$ & 0 & 39.750171 & -121.651946 & Inferred & $911-202-1$ & spot fire visible, just started, rapid spread & $S$ & & \\
\hline TD-038 & $11 / 8$ & 09:00 & TD & 0 & 39.746843 & -121.653427 & TD & TD & fire in backyard on Russell Dr & $S$ & & \\
\hline 911-204-1 & $11 / 8$ & 09:00 & $911-204-1$ & 0 & 39.750408 & -121.652292 & Inferred & 911-204-1 & spot fire just started & $\mathrm{s}$ & & \\
\hline $911-218-1$ & $11 / 8$ & 09:08 & $911-218-1$ & 0 & 39.748911 & -121.653470 & Inferred & $911-218-1$ & can see fire in the canyon & $\mathrm{S}$ & & \\
\hline $911-221-1$ & $11 / 8$ & 09:11 & $911-221-1$ & 0 & 39.750934 & -121.653271 & Inferred & $911-221-1$ & fire in the canyon off of Point West Dr & $S$ & & \\
\hline $911-225-1$ & $11 / 8$ & 09:12 & $911-225-1$ & 0 & 39.748218 & -121.654093 & $911-225-1$ & $911-225-1$ & fire in canyon, not too big yet & $S$ & & \\
\hline TD-055 & $11 / 8$ & 09:14 & Radio Log & 0 & 39.749567 & -121.652485 & TD & TD & $\begin{array}{l}\text { well seated fire seen down in Butte Creek Canyon, } \\
\text { moving good, multiple ac }\end{array}$ & S & & \\
\hline TD-007 & $11 / 8$ & 10:10 & Radio Log & 0 & 39.748925 & -121.652728 & TD & TD & established spot fire in Butte Creek Canyon & V & & \\
\hline Radio Log & $11 / 8$ & $10: 10$ & Radio Log & 0 & 39.748447 & -121.651678 & Radio Log & Radio Log & $\begin{array}{l}\text { fire is well established in Honey Run Canyon just below } \\
\text { Canyon View Dr, multiple spots running back up } \\
\text { towards Canyon View Dr }\end{array}$ & v & & \\
\hline TD-012 & $11 / 8$ & $13: 28$ & Photo & 0 & 39.753186 & -121.657372 & Photo & Photo & fire burning on ridge at end of Point West $\mathrm{Dr}$ & $\mathrm{v}$ & & \\
\hline TD-012 & $11 / 8$ & $13: 30$ & Photo & 0 & 39.753186 & -121.657372 & Photo & Photo & $\begin{array}{l}\text { flames on west side of paradise, view from Doe Mill Rd; } \\
\text { fire burning on ridge at end of Point West Dr (Valley } \\
\text { Ridge Dr) }\end{array}$ & $\mathrm{v}$ & & \\
\hline TD-044 & $11 / 8$ & $14: 30$ & TD & 30 & 39.758911 & -121.657097 & TD & TD & saw flames in canyon to west & $\mathrm{v}$ & & \\
\hline TD-123 & $11 / 8$ & $15: 54$ & AVL & 15 & 39.762050 & -121.622783 & AVL & TD & small propane tank blows & 0 & & \\
\hline TD-123 & $11 / 8$ & $15: 54$ & AVL & 15 & 39.762409 & -121.622805 & AVL & TD & Jack in the Box restaurant building on fire & C & & \\
\hline TD-123 & $11 / 8$ & $15: 54$ & AVL & 15 & 39.762244 & -121.622885 & AVL & TD & commercial building on fire & C & & \\
\hline TD-014 & $11 / 8$ & $16: 55$ & AVL & 0 & 39.765405 & -121.626297 & AVL & TD & Fire all around & 0 & & \\
\hline TD-020 & $11 / 8$ & $17: 00$ & Photo & 0 & 39.760163 & -121.647251 & Photo & Photo & $\begin{array}{l}\text { all but } 3 \text { structures are burned to foundation and } \\
\text { flaming; } 2 \text { standing, } 1 \text { other well-involved }\end{array}$ & $\mathrm{R}$ & $\mathrm{x}$ & \\
\hline TD-020 & $11 / 8$ & $17: 00$ & Photo & 0 & 39.760029 & -121.646928 & Photo & Photo & $\begin{array}{l}\text { structure well involved; landscaping vegetation on fire } \\
\text { or igniting }\end{array}$ & $\mathrm{R}$ & & \\
\hline TD-014 & $11 / 8$ & $17: 10$ & AVL & 35 & 39.762229 & -121.649664 & Radio Log & TD & fire making a hard run out of the canyon & $\mathrm{v}$ & & \\
\hline TD-201 & $11 / 8$ & $17: 45$ & $\mathrm{AVL}$ & 40 & 39.762561 & -121.622127 & AVL & TD & $\begin{array}{l}\text { downtown commercial buildings are burning or } \\
\text { catching }\end{array}$ & C & & \\
\hline TD-020 & $11 / 8$ & $17: 52$ & Radio Log & 59 & 39.760295 & -121.647590 & TD & TD & most structures burning on Valley Ridge $\mathrm{Dr}$ & $\mathrm{R}$ & & \\
\hline TD-020 & $11 / 8$ & $17: 52$ & Radio Log & 59 & 39.759942 & -121.647294 & TD & TD & fire threatening structures & 0 & & \\
\hline TD-020 & $11 / 8$ & $17: 52$ & Radio Log & 59 & 39.759829 & -121.647638 & TD & TD & bushes, fences on fire & 0 & & \\
\hline
\end{tabular}




\begin{tabular}{|c|c|c|c|c|c|c|c|c|c|c|c|c|}
\hline \multicolumn{13}{|c|}{ Valley View Drive } \\
\hline & & & & Obs & & & & & & Type & & \\
\hline Source \# & Date & Time & $\begin{array}{l}\text { Time } \\
\text { Source }\end{array}$ & $\begin{array}{c}\text { Window } \\
\text { (min) }\end{array}$ & Latitude & Longitude & $\begin{array}{l}\text { Location } \\
\text { Source }\end{array}$ & Info Source & Fire Behavior Observations & $\begin{array}{c}\text { of } \\
\text { Fire }\end{array}$ & $\begin{array}{l}\text { Residual } \\
\text { Fire? }\end{array}$ & SSI \\
\hline TD-123 & $11 / 8$ & $18: 23$ & AVL & 44 & 39.763283 & -121.622533 & $\mathrm{AVL}$ & TD & fire threatening structures & 0 & & \\
\hline TD-044 & $11 / 8$ & 19:00 & TD & 60 & 39.759285 & -121.644392 & TD & TD & $\begin{array}{l}\text { loose burning vegetation blowing against structure; } \\
\text { embers everywhere now }\end{array}$ & $\mathrm{v}$ & & \\
\hline TD-044 & $11 / 8$ & 19:00 & TD & 180 & 39.759363 & -121.645332 & TD & TD & putting out spot fires all over & $\mathrm{s}$ & & \\
\hline TD-044 & $11 / 8$ & 19:00 & TD & 180 & 39.759928 & -121.645674 & TD & TD & Fence to boat to house ignition & $\mathrm{R}$ & & \\
\hline TD-111 & $11 / 8$ & 19:00 & Inferred & 225 & 39.760085 & -121.647534 & TD & TD & fire threatening structure & 0 & & \\
\hline TD-123 & $11 / 8$ & 19:41 & $\mathrm{AVL}$ & 10 & 39.763317 & -121.622567 & AVL & TD & fire threatening structures & 0 & & \\
\hline TD-109 & $11 / 8$ & 19:51 & AVL & 103 & 39.761608 & -121.636388 & AVL & TD & a lot already on fire & $\mathrm{R}$ & & \\
\hline TD-123 & $11 / 8$ & 20:00 & AVL & 26 & 39.760050 & -121.647250 & AVL & AVL & fire threatening structures & 0 & & \\
\hline TD-123 & $11 / 8$ & $20: 59$ & AVL & 4 & 39.759167 & -121.647500 & AVL & TD & burned car in driveway & 0 & & \\
\hline TD-030 & $11 / 8$ & $21: 18$ & AVL & 28 & 39.760150 & -121.647250 & AVL & TD, Inferred & fire threatening structures & 0 & & \\
\hline TD-122 & $11 / 8$ & $21: 56$ & AVL & 7 & 39.762700 & -121.622300 & AVL & TD & fire threatening structures & 0 & & \\
\hline TD-044 & $11 / 8$ & $22: 30$ & TD & 0 & 39.759653 & -121.646100 & TD & TD & structure ignites from direct flames from wood pile & $\mathrm{R}$ & & \\
\hline TD-044 & $11 / 8$ & $22: 30$ & TD & 0 & 39.759597 & -121.646678 & TD & TD & structure ignites & $\mathrm{R}$ & & \\
\hline TD-122 & $11 / 8$ & 22:35 & AVL & 31 & 39.763083 & -121.622817 & AVL & TD & fire threatening structures & 0 & & \\
\hline TD-044 & $11 / 8$ & 23:00 & TD & 0 & 39.759855 & -121.645544 & TD & TD & sheds and fences burning & 0 & & \\
\hline TD-030 & $11 / 8$ & 23:27 & AVL & 450 & 39.760150 & -121.647250 & AVL & AVL & fire threatening structures & 0 & & \\
\hline TD-017 & $11 / 8$ & 23:47 & & 80 & 39.757412 & -121.644727 & TD & TD & fire threatening homes & 0 & & \\
\hline TD-017 & $11 / 8$ & $23: 47$ & & 80 & 39.756752 & -121.643697 & TD & TD & fires in the area & 0 & & \\
\hline
\end{tabular}




\begin{tabular}{|c|c|c|c|c|c|c|c|c|c|c|c|c|}
\hline & \multicolumn{12}{|c|}{ Foothills } \\
\hline & & & & Obs & & & & & & Type & & \\
\hline & Date & Time & $\begin{array}{l}\text { Time } \\
\text { Source }\end{array}$ & $\begin{array}{l}\text { Window } \\
\text { (min) }\end{array}$ & Latitude & Longitude & $\begin{array}{c}\text { Location } \\
\text { Source }\end{array}$ & Info Source & Fire Behavior Observations & $\begin{array}{c}\text { of } \\
\text { Fire }\end{array}$ & $\begin{array}{c}\text { Residual } \\
\text { Fire? }\end{array}$ & SSI \\
\hline \multirow{26}{*}{ w } & $11 / 8$ & $12: 27$ & PPD-08 & 0 & 39.721894 & -121.674285 & Inferred & Radio & fire & 0 & & \\
\hline & $11 / 8$ & $13: 00$ & Inferred & 60 & 39.699244 & -121.612972 & TD & TD & $\begin{array}{l}\text { fire across roadway; fire coming up slope burning over } \\
\text { road }\end{array}$ & v & & \\
\hline & $11 / 8$ & $13: 30$ & AVL & 0 & 39.695569 & -121.614212 & AVL & TD & approximate fire edge & 0 & & \\
\hline & $11 / 8$ & $13: 30$ & TD-054 & 40 & 39.692996 & -121.615581 & TD & TD & $\begin{array}{l}\text { see fire and smoke; stopped and turned around, sent } \\
\text { back to Butte College }\end{array}$ & $\mathrm{v}$ & & \\
\hline & $11 / 8$ & $14: 00$ & Inferred & 180 & 39.701096 & -121.580489 & TD & TD & fire spreading south, threatening structures & $\mathrm{v}$ & & \\
\hline & $11 / 8$ & $14: 08$ & Photo & 0 & 39.679630 & -121.610502 & Photo & Photo & can see fire on ridgetop to east of Clark Rd & V & & \\
\hline & $11 / 8$ & $14: 08$ & Photo & 0 & 39.683823 & -121.607416 & Photo & Photo & southern edge of fire, up on ridge & $\mathrm{V}$ & & \\
\hline & $11 / 8$ & $14: 09$ & Photo & 0 & 39.683823 & -121.607416 & Photo & Photo & fire up on ridge & v & & \\
\hline & $11 / 8$ & $14: 10$ & Photo & 0 & 39.695215 & -121.615773 & Photo & Photo & $\begin{array}{l}\text { lower intensity fire front, moving south in grass and } \\
\text { brush; limit of fire along Clark Rd }\end{array}$ & $\mathrm{v}$ & & \\
\hline & $11 / 8$ & $14: 11$ & Photo & 0 & 39.693195 & -121.615368 & Photo & TD & southern edge of fire; fire both sides of Clark Rd & $\mathrm{v}$ & & \\
\hline & $11 / 8$ & $14: 11$ & Photo & 0 & 39.693195 & -121.615368 & Photo & Photo & $\begin{array}{l}\text { encounter southern edge of fire; fire both sides of Clark } \\
R d\end{array}$ & 0 & & \\
\hline & $11 / 8$ & $14: 11$ & Photo & 0 & 39.693158 & -121.615411 & Photo & Photo & $\begin{array}{l}\text { spot fires burning against road; southern edge of main } \\
\text { fire burning lower intensity in grass }\end{array}$ & $\mathrm{v}$ & & \\
\hline & $11 / 8$ & $14: 12$ & Photo & 0 & 39.704519 & -121.609577 & Photo & Photo & oak woodland has burned through & $\mathrm{v}$ & $\mathrm{x}$ & \\
\hline & $11 / 8$ & $15: 00$ & TD-208 & 0 & 39.682207 & -121.619353 & TD & TD & wind shifted in afternoon and blew fire down canyon & $\mathrm{v}$ & & \\
\hline & $11 / 8$ & $15: 17$ & AVL & 2 & 39.679450 & -121.624567 & AVL & TD & $\begin{array}{l}\text { flames sheeting } 3 \mathrm{~m} \text { to } 4.6 \mathrm{~m} \text { ( } 10 \mathrm{ft} \text { to } 15 \mathrm{ft} \text { ); fire burned } \\
\text { over hood }\end{array}$ & $\mathrm{v}$ & & \\
\hline & $11 / 8$ & $15: 25$ & Photo & 0 & 39.695654 & -121.628735 & Photo & Photo & line of fire, nominally east to west & $\mathrm{v}$ & & \\
\hline & $11 / 8$ & $15: 28$ & AVL & 8 & 39.673320 & -121.624817 & AVL & TD & finger of fire & $\mathrm{v}$ & & \\
\hline & $11 / 8$ & $15: 28$ & AVL & 124 & 39.662638 & -121.628727 & AVL & TD & $\begin{array}{l}\text { igniting spots along west side of Clark Rd; several spots } \\
\text { about } 15 \mathrm{~m}(50 \mathrm{ft}) \text { off road }\end{array}$ & $\mathrm{S}$ & & \\
\hline & $11 / 8$ & $15: 29$ & Photo & 0 & 39.695654 & -121.628735 & Photo & Photo & observe short range down slope spotting & $\mathrm{s}$ & & \\
\hline & $11 / 8$ & $15: 30$ & Inferred & 0 & 39.695572 & -121.628333 & Photo & TD & fire is approaching from the north & $\mathrm{v}$ & & \\
\hline & $11 / 8$ & $15: 30$ & Inferred & 0 & 39.695572 & -121.628333 & Photo & TD & approximate fire line & V & & \\
\hline & $11 / 8$ & $15: 40$ & Photo & 0 & 39.692556 & -121.632043 & Photo & Photo & fire spreading in vegetation & v & & \\
\hline & $11 / 8$ & $15: 45$ & Inferred & 0 & 39.690847 & -121.628419 & TD & TD & fire hung up on ridge to north & $\mathrm{v}$ & & \\
\hline & $11 / 8$ & $15: 53$ & Photo & 0 & 39.693027 & -121.631477 & Photo & Photo & $\begin{array}{l}\text { fire has burned vegetation in field; stumps and logs still } \\
\text { burning }\end{array}$ & v & & \\
\hline & $11 / 8$ & $16: 14$ & AVL & 57 & 39.668315 & -121.615784 & AVL & TD & fire threatening structures & 0 & & \\
\hline & $11 / 8$ & $16: 30$ & Inferred & 270 & 39.697461 & -121.628272 & TD & TD & $\begin{array}{l}\text { fire up on ridge, coming downhill; extreme and variable } \\
\text { winds; fire spotting }\end{array}$ & v & & \\
\hline TD-119 & $11 / 8$ & $16: 33$ & Photo & 0 & 39.692447 & -121.625820 & Photo & Photo & $\begin{array}{l}\text { disorganized fire front burning downhill through grass } \\
\text { oak woodland; minimal flame heights }\end{array}$ & v & & \\
\hline
\end{tabular}




\begin{tabular}{|c|c|c|c|c|c|c|c|c|c|c|c|c|}
\hline & & & & & & & & hills & & & & \\
\hline Source \# & Date & Time & $\begin{array}{l}\text { Time } \\
\text { Source }\end{array}$ & $\begin{array}{c}\text { Obs } \\
\text { Window } \\
\text { (min) }\end{array}$ & Latitude & Longitude & $\begin{array}{l}\text { Location } \\
\text { Source }\end{array}$ & Info Source & Fire Behavior Observations & $\begin{array}{c}\text { Type } \\
\text { of } \\
\text { Fire }\end{array}$ & $\begin{array}{l}\text { Residual } \\
\text { Fire? }\end{array}$ & SSI \\
\hline TD-102 & $11 / 8$ & $16: 38$ & Photo & 0 & 39.692004 & -121.633525 & Photo & Photo & $\begin{array}{l}\text { flames burning downhill in grass oak woodland, east } \\
\text { toward structure }\end{array}$ & V & & \\
\hline TD-102 & $11 / 8$ & $16: 39$ & Photo & 0 & 39.692606 & -121.631818 & Photo & TD & large tree down, burning & V & & \\
\hline TD-102 & $11 / 8$ & $16: 39$ & Photo & 0 & 39.693027 & -121.631477 & Photo & Photo & $\begin{array}{l}\text { fire has burned vegetation in field; stumps and logs still } \\
\text { burning }\end{array}$ & V & $x$ & \\
\hline VTD-18 & $11 / 8$ & $16: 48$ & TD & 0 & 39.690713 & -121.619650 & video & video & $\begin{array}{l}\text { southern end of fire on west side Clark Rd; east side } \\
\text { burned already south of here }\end{array}$ & V & & \\
\hline VTD-18 & $11 / 8$ & $16: 49$ & TD & 0 & 39.686175 & -121.633755 & video & video & southern edge of main fire in vegetation (estimated) & $\mathrm{v}$ & & \\
\hline TD-120 & $11 / 8$ & $16: 55$ & Photo & 41 & 39.692265 & -121.629073 & TD & TD & shed burned & 0 & & \\
\hline TD-120 & $11 / 8$ & $17: 00$ & Photo & 0 & 39.691985 & -121.628919 & Photo & Photo & vegetation fire & V & & \\
\hline TD-120 & $11 / 8$ & $17: 00$ & Photo & 0 & 39.689585 & -121.630534 & Photo & Photo & disorganized fire front & V & & \\
\hline TD-211 & $11 / 8$ & $17: 03$ & AVL & 25 & 39.679420 & -121.627067 & $\mathrm{AVL}$ & TD & fire had already burned through Rattlesnake Flats Rd & $\mathrm{v}$ & $\mathrm{x}$ & \\
\hline TD-120 & $11 / 8$ & $17: 03$ & Photo & 0 & 39.693513 & -121.629937 & Photo & Photo & $\begin{array}{l}\text { surface fuels in area have burned through, glowing } \\
\text { remains, localized flaming }\end{array}$ & v & $x$ & \\
\hline TD-120 & $11 / 8$ & $17: 03$ & Photo & 0 & 39.692509 & -121.630674 & Photo & Photo & $\begin{array}{l}\text { surface fuels in area have burned through, glowing } \\
\text { remains, localized flaming }\end{array}$ & v & $\mathrm{x}$ & \\
\hline TD-102 & $11 / 8$ & $17: 15$ & AVL E2185 & 0 & 39.691312 & -121.629354 & TD & TD & fire gets very close & $\mathrm{v}$ & & \\
\hline TD-106 & $11 / 8$ & $17: 18$ & VTD-01 & 0 & 39.707698 & -121.677168 & video & TD & $\begin{array}{l}\text { fire all around roadway driving down Neal Rd; held up } \\
\text { by fire whirl for a minute }\end{array}$ & $\mathrm{v}$ & & \\
\hline VTD-01 & $11 / 8$ & $17: 18$ & Video & 0 & 39.707698 & -121.677168 & video & Twitter & fire whirl on Neal Rd & $\mathrm{v}$ & & \\
\hline TD-106 & $11 / 8$ & $17: 30$ & Inferred & 23 & 39.691565 & -121.694399 & TD & TD & fire is slope reversal, lining up with drainages & V & & \\
\hline TD-121 & $11 / 8$ & $17: 30$ & Inferred & 120 & 39.698313 & -121.584541 & TD & TD & fire is moving south quickly & 0 & & \\
\hline TD-121 & $11 / 8$ & $17: 30$ & Inferred & 120 & 39.689064 & -121.593182 & TD & TD & fire burning SW down ridge & v & & \\
\hline TD-119 & $11 / 8$ & $17: 36$ & Photo & 0 & 39.689512 & -121.630477 & Photo & Photo & increased fire activity, widespread across hillside & V & & \\
\hline TD-102 & $11 / 8$ & $17: 40$ & AVL E2185 & 0 & 39.668311 & -121.636192 & TD & TD & drove through fire & $\mathrm{v}$ & & \\
\hline TD-102 & $11 / 8$ & $17: 40$ & Inferred & 0 & 39.657612 & -121.647394 & TD & TD & fire had passed below and was burning in Cory Canyon & v & & \\
\hline TD-119 & $11 / 8$ & $17: 45$ & TD & 195 & 39.678369 & -121.634608 & TD & TD & detached garage burned, shed damaged & 0 & & \\
\hline TD-065 & $11 / 8$ & $17: 50$ & Inferred & 0 & 39.656833 & -121.646325 & TD & TD & fire is burning around Butte College & $\mathrm{v}$ & & \\
\hline TD-042 & $11 / 8$ & $18: 00$ & TD & 30 & 39.664504 & -121.742140 & TD & TD & fire crossing Hwy 99 & v & & \\
\hline TD-091 & $11 / 8$ & $18: 14$ & AVL & 13 & 39.674000 & -121.726967 & AVL & TD & $\begin{array}{l}\text { both sides of Neal Rd are already burned north of pull } \\
\text { out }\end{array}$ & v & $\mathrm{x}$ & \\
\hline TD-120 & $11 / 8$ & $18: 23$ & Photo & 0 & 39.679162 & -121.636959 & TD & TD & $\begin{array}{l}\text { fire burning from the west downhill towards structures; } \\
\text { burning in grass }\end{array}$ & v & & \\
\hline TD-120 & $11 / 8$ & $18: 26$ & Photo & 0 & 39.678149 & -121.638786 & Photo & Photo & vegetation fire & v & & \\
\hline TD-091 & $11 / 8$ & $18: 27$ & $\mathrm{AVL}$ & 24 & 39.669583 & -121.716700 & TD & TD & fire coming across valley from the east & v & & \\
\hline TD-120 & $11 / 8$ & $18: 27$ & Photo & 113 & 39.678184 & -121.639388 & TD & TD & fire near structure & v & & \\
\hline TD-120 & $11 / 8$ & $18: 27$ & Photo & 0 & 39.678149 & -121.638786 & Photo & Photo & vegetation fire, grass & v & & \\
\hline
\end{tabular}




\begin{tabular}{|c|c|c|c|c|c|c|c|c|c|c|c|c|}
\hline \multicolumn{13}{|c|}{ Foothills } \\
\hline Source \# & Date & Time & $\begin{array}{c}\text { Time } \\
\text { Source }\end{array}$ & $\begin{array}{l}\text { Obs } \\
\text { Window } \\
\text { (min) }\end{array}$ & Latitude & Longitude & $\begin{array}{l}\text { Location } \\
\text { Source }\end{array}$ & Info Source & Fire Behavior Observations & $\begin{array}{l}\text { Type } \\
\text { of } \\
\text { Fire }\end{array}$ & $\begin{array}{l}\text { Residual } \\
\text { Fire? }\end{array}$ & SSI \\
\hline TD-092 & $11 / 8$ & $18: 28$ & $\mathrm{AVL}$ & 23 & 39.673967 & -121.726883 & AVL & TD & fire coming across valley from the east & $\mathrm{V}$ & & \\
\hline TD-110 & $11 / 8$ & $18: 45$ & Inferred & 0 & 39.639898 & -121.628709 & TD & TD & $\begin{array}{l}\text { fire jumped Durham-Pentz Rd; limited resources and } \\
\text { burning away from houses, so let it go for now }\end{array}$ & V & & \\
\hline TD-076 & $11 / 8$ & 18:47 & Photo & 0 & 39.637289 & -121.697731 & Photo & Photo & fire south of Durham-Pentz Rd & v & & \\
\hline TD-071 & $11 / 8$ & 18:47 & TD-076 & 0 & 39.639288 & -121.696609 & Photo & TD & $\begin{array}{l}\text { fire both sides of Durham-Pentz Rd between } 99 \text { and } \\
\text { College }\end{array}$ & V & & \\
\hline TD-076 & $11 / 8$ & $18: 47$ & Photo & 0 & 39.636897 & -121.700941 & Photo & Photo & intense fire burning in grass & $\mathrm{V}$ & & \\
\hline TD-069 & $11 / 8$ & $18: 50$ & TD-064 & 0 & 39.655188 & -121.646304 & Inferred & TD & Butte College; hillside catches fire & v & & \\
\hline Radio Log & $11 / 8$ & $18: 50$ & Radio Log & 0 & 39.653679 & -121.728297 & Radio Log & Radio Log & $\begin{array}{l}\text { Fire is bumping Hwy } 99 \text { between Neal Rd and Durham- } \\
\text { Pentz Rd }\end{array}$ & V & & \\
\hline TD-064 & $11 / 8$ & $19: 00$ & Inferred & 0 & 39.655188 & -121.646304 & Inferred & TD & hillside at Butte College catches fire & $\mathrm{V}$ & & \\
\hline TD-106 & $11 / 8$ & 19:00 & Inferred & 0 & 39.661045 & -121.735427 & TD & TD & fire heading down hill, bumping Hwy 99 & V & & \\
\hline TD-102 & $11 / 8$ & 19:04 & Photo & 0 & 39.666830 & -121.644068 & Photo & Photo & active fire in vegetation & $\mathrm{V}$ & & \\
\hline TD-102 & $11 / 8$ & 19:04 & Photo & 0 & 39.665794 & -121.642383 & Photo & Photo & fire burning in grass on hillside above structures & v & & \\
\hline TD-201 & $11 / 8$ & 19:05 & Radio Log & 0 & 39.651152 & -121.727633 & Radio Log & $\begin{array}{l}\text { TD, Radio } \\
\text { Log }\end{array}$ & $\begin{array}{l}\text { Fire jumped Hwy } 99,0.8 \text { ha to } 1.2 \text { ha ( } 2 \text { ac to } 3 \text { ac); also } \\
\text { jumped Durham-Pentz Rd; wind driven from NE }\end{array}$ & $\mathrm{v}$ & & \\
\hline TD-201 & $11 / 8$ & 19:05 & Radio Log & 0 & 39.640100 & -121.710110 & Radio Log & Radio Log & $\begin{array}{l}\text { fire also jumped Durham-Pentz Rd into that triangle and } \\
\text { will be bumping Hwy } 99 \text { there as well }\end{array}$ & $\mathrm{v}$ & & \\
\hline TD-201 & $11 / 8$ & 19:05 & AVL & 0 & 39.658273 & -121.724358 & TD & TD & $\begin{array}{l}\text { fingery fire; } 11 \mathrm{~m} / \mathrm{s} \text { to } 13 \mathrm{~m} / \mathrm{s}(25 \mathrm{mi} / \mathrm{h} \text { to } 30 \mathrm{mi} / \mathrm{h}) \\
\text { winds; spotting fires in grass and jumping over Hwy } 99 \\
\text { in at least } 3 \text { places }\end{array}$ & $\mathrm{v}$ & & \\
\hline TD-211 & $11 / 8$ & 19:07 & AVL & 0 & 39.638700 & -121.681767 & AVL & TD & $\begin{array}{l}\text { fire burning up along Durham-Pentz Rd; drove through } \\
\text { flames blowing onto road }\end{array}$ & $\mathrm{V}$ & & \\
\hline TD-092 & $11 / 8$ & 19:07 & AVL & 0 & 39.659543 & -121.737382 & AVL & TD & slop over, fire burning on W side of Hwy 99 & $\mathrm{v}$ & & \\
\hline TD-091 & $11 / 8$ & 19:10 & AVL & 110 & 39.661225 & -121.744638 & $\mathrm{AVL}$ & TD & fire slop over Hwy 99 & v & & \\
\hline TD-106 & $11 / 8$ & 19:10 & AVL TD-091 & 110 & 39.659543 & -121.737382 & AVL TD-091 & TD & $\begin{array}{l}\text { fire slop over on south side Hwy 99; fire shoots through } \\
\text { underpass culvert }\end{array}$ & V & & \\
\hline TD-211 & $11 / 8$ & 19:14 & AVL & 0 & 39.657102 & -121.740002 & AVL & TD & fire burning on west side Hwy 99 & v & & \\
\hline TD-110 & $11 / 8$ & 19:24 & Radio Log & 0 & 39.631947 & -121.638452 & Imagery & Radio Log & $\begin{array}{l}\text { fire is about to jump Clark Rd, south of Durham-Pentz } \\
\text { Rd }\end{array}$ & $\mathrm{V}$ & & \\
\hline TD-102 & $11 / 8$ & $19: 24$ & Radio Log & 0 & 39.630269 & -121.638327 & TD & TD & $\begin{array}{l}\text { advised that fire is crossing Clark Rd at the Camelot } \\
\text { Horse Farm; residents had evacuated animals to the } \\
\text { farm }\end{array}$ & v & & \\
\hline TD-121 & $11 / 8$ & 19:30 & TD & 0 & 39.681618 & -121.572735 & TD & TD & fire threatening neighborhood & V & & \\
\hline VTD-01 & $11 / 8$ & 19:45 & Twitter & 0 & 39.664384 & -121.744302 & video & Twitter & fire spotting across Hwy 99 at Neal Rd & V & & \\
\hline TD-020 & $11 / 8$ & $20: 00$ & Inferred & 0 & 39.692918 & -121.580194 & TD & TD & active fireline & $\mathrm{V}$ & & \\
\hline TD-102 & $11 / 8$ & $20: 13$ & Photo & 0 & 39.639481 & -121.670731 & Photo & Photo & fire burning in grass north of Durham-Pentz Rd & $\mathrm{v}$ & & \\
\hline
\end{tabular}




\begin{tabular}{|c|c|c|c|c|c|c|c|c|c|c|c|c|}
\hline \multicolumn{13}{|c|}{ Foothills } \\
\hline & & & & Obs & & & & & & Type & & \\
\hline Source \# & Date & Time & $\begin{array}{l}\text { Time } \\
\text { Source }\end{array}$ & $\begin{array}{l}\text { Window } \\
\text { (min) }\end{array}$ & Latitude & Longitude & $\begin{array}{l}\text { Location } \\
\text { Source }\end{array}$ & Info Source & Fire Behavior Observations & $\begin{array}{c}\text { of } \\
\text { Fire }\end{array}$ & $\begin{array}{l}\text { Residual } \\
\text { Fire? }\end{array}$ & SSI \\
\hline TD-054 & $11 / 8$ & $20: 20$ & Photo & 0 & 39.651845 & -121.656006 & TD & TD & fire approaching ridge line & $\mathrm{V}$ & & \\
\hline TD-120 & $11 / 8$ & $20: 22$ & Inferred & 0 & 39.677156 & -121.635476 & TD & TD & shop fully involved & 0 & & \\
\hline TD-120 & $11 / 8$ & $20: 22$ & Photo & 0 & 39.678810 & -121.635421 & Photo & Photo & firing operation in grass above structure & $\mathrm{v}$ & & \\
\hline Radio Log & $11 / 8$ & $20: 27$ & Radio Log & 0 & 39.601640 & -121.662023 & Radio Log & Radio Log & $\begin{array}{l}\text { fire is at Hwy } 149 \text { and Shippee Rd, about to cross } \\
\text { Hwy } 149\end{array}$ & $\mathrm{v}$ & & \\
\hline TD-054 & $11 / 8$ & $20: 40$ & Photo & 0 & 39.648509 & -121.653927 & TD & TD & fire reaches Butte College, right up to concrete & $\mathrm{V}$ & & \\
\hline TD-121 & $11 / 8$ & 21:00 & TD & 120 & 39.697846 & -121.574343 & TD & TD & fire burned homes & $\mathrm{R}$ & & \\
\hline TD-102 & $11 / 8$ & $21: 12$ & Photo & 0 & 39.639993 & -121.664305 & Photo & Photo & $\begin{array}{l}\text { fire in grass burning against north side Durham-Pentz } \\
\text { Rd }\end{array}$ & $\mathrm{v}$ & & \\
\hline TD-102 & $11 / 8$ & 22:00 & TD & 60 & 39.656505 & -121.653190 & AVL & TD & structure burned & $\mathrm{R}$ & & \\
\hline TD-102 & $11 / 8$ & 22:00 & TD & 60 & 39.663508 & -121.644901 & $A V L$ & TD & structure burned & $\mathrm{R}$ & & \\
\hline Radio Log & $11 / 8$ & $22: 24$ & Radio Log & 0 & 39.601640 & -121.662023 & Radio Log & Radio Log & high probability of spots across Hwy 149 & v & & \\
\hline TD-102 & $11 / 8$ & $23: 18$ & Radio Log & 0 & 39.660557 & -121.652699 & Radio Log & Radio Log & small fire in the corner of structure & $\mathrm{R}$ & & \\
\hline TD-102 & $11 / 8$ & $23: 29$ & Inferred & 66 & 39.660557 & -121.652699 & TD & TD & small fire in structure & $\mathrm{R}$ & & \\
\hline TD-201 & $11 / 9$ & $00: 31$ & Radio Log & 0 & 39.655600 & -121.741876 & AVL & Radio Log & fire burning in wood facility & 0 & & \\
\hline Radio Log & $11 / 9$ & 01:15 & Radio Log & 0 & 39.601640 & -121.662023 & Radio Log & Radio Log & extent of fire; perimeter established & $v$ & & \\
\hline TD-201 & $11 / 9$ & 01:41 & Radio Log & 0 & 39.647250 & -121.662260 & Radio Log & Radio Log & imminent structure threat & 0 & & \\
\hline TD-102 & $11 / 9$ & 01:53 & Inferred & 333 & 39.648667 & -121.664614 & TD & TD & low creeping fire activity & v & & \\
\hline TD-102 & $11 / 9$ & $01: 53$ & Inferred & 333 & 39.648667 & -121.664614 & TD & TD & burning woodpiles & 0 & & \\
\hline
\end{tabular}




\begin{tabular}{|c|c|c|c|c|c|c|c|c|c|c|c|c|}
\hline \multicolumn{13}{|c|}{ Nelson Bar Road and Highway 70} \\
\hline Source \# & Date & Time & $\begin{array}{l}\text { Time } \\
\text { Source }\end{array}$ & $\begin{array}{c}\text { Obs } \\
\text { Window } \\
\text { (min) }\end{array}$ & Latitude & Longitude & $\begin{array}{l}\text { Location } \\
\text { Source }\end{array}$ & Info Source & Fire Behavior Observations & $\begin{array}{c}\text { Type } \\
\text { of } \\
\text { Fire }\end{array}$ & $\begin{array}{l}\text { Residual } \\
\text { Fire? }\end{array}$ & SSI \\
\hline TD-008 & $11 / 8$ & $11: 08$ & Radio Log & 0 & 39.710355 & -121.556751 & Radio Log & Radio Log & $\begin{array}{l}\text { fire established in canyon to point where river turns } \\
\text { into lake }\end{array}$ & V & & \\
\hline TD-108 & $11 / 8$ & $12: 25$ & Photo & 0 & 39.722200 & -121.551798 & Photo & Photo & southern extent of fire, burning in canyon & $\mathrm{V}$ & & \\
\hline TD-031 & $11 / 8$ & $12: 38$ & Photo & 0 & 39.732934 & -121.539099 & Photo & Photo & $\begin{array}{l}\text { massive gray smoke plume from main fire rising from } \\
\text { canyon }\end{array}$ & v & & \\
\hline TD-031 & $11 / 8$ & 13:00 & AVL & 11 & 39.743772 & -121.524825 & AVL & TD & Huge fire to north of Comfort Ln & $\mathrm{v}$ & & \\
\hline TD-013 & $11 / 8$ & 13:00 & Inferred & 0 & 39.736194 & -121.540577 & TD & TD & fire down in the canyons & V & & \\
\hline TD-013 & $11 / 8$ & $13: 00$ & Inferred & 300 & 39.720645 & -121.541835 & TD & TD & fire threatening structures & 0 & & \\
\hline TD-138 & $11 / 8$ & 13:00 & Inferred & 390 & 39.723426 & -121.542672 & TD & TD & low intensity fire backing down & v & & \\
\hline TD-137 & $11 / 8$ & $13: 53$ & Photo & 0 & 39.726779 & -121.549450 & Photo & Photo & fire burning NW of the pond, beyond ridge & V & & \\
\hline TD-137 & $11 / 8$ & $13: 53$ & Photo & 0 & 39.729353 & -121.549158 & Photo & Photo & smoke rising from canyon & V & & \\
\hline TD-062 & $11 / 8$ & 14:11 & $\mathrm{AVL}$ & 445 & 39.728383 & -121.540450 & $\mathrm{AVL}$ & TD & fire came from NE; destroyed 5 of 7 structures & $\mathrm{R}$ & & \\
\hline TD-140 & $11 / 8$ & 14:14 & video & 0 & 39.741429 & -121.526257 & video & TD & $\begin{array}{l}\text { fire is spotting ahead of main front, south toward } \\
\text { Nelson Bar Rd }\end{array}$ & $\mathrm{S}$ & & \\
\hline TD-140 & $11 / 8$ & 14:14 & Photo & 0 & 39.740353 & -121.526549 & Photo & Photo & $\begin{array}{l}\text { several spot fires burning in thick brush, pines; west } \\
\text { side of Concow Rd }\end{array}$ & $S$ & & \\
\hline TD-140 & $11 / 8$ & 14:14 & Photo & 0 & 39.742514 & -121.525605 & Photo & Photo & large flame lengths, active fire west of Concow Rd & v & & \\
\hline TD-140 & $11 / 8$ & 14:15 & Inferred & 165 & 39.733180 & -121.542777 & TD & TD & $\begin{array}{l}\text { fire is burning toward the SW in the drainage north of } \\
\text { Nelson Bar Rd }\end{array}$ & v & & \\
\hline TD-140 & $11 / 8$ & 14:15 & Inferred & 165 & 39.730634 & -121.544377 & TD & TD & fire burning toward Nelson Bar Rd from drainage & V & & \\
\hline TD-031 & $11 / 8$ & $14: 25$ & Photo & 0 & 39.733386 & -121.541970 & Photo & Photo & significant smoke plume rising from general area & V & & \\
\hline TD-027 & $11 / 8$ & $14: 40$ & Inferred & 0 & 39.742334 & -121.524345 & TD & TD & fire $60 \mathrm{~m} \mathrm{(200 \textrm {ft } ) \text { from structure }}$ & v & & \\
\hline TD-136 & $11 / 8$ & 14:55 & Photo & 0 & 39.733386 & -121.541970 & Photo & Photo & significant smoke plume rising from general area & V & & \\
\hline TD-136 & $11 / 8$ & 14:59 & Photo & 0 & 39.730005 & -121.548356 & Photo & Photo & large amount of smoke coming from canyon & V & & \\
\hline TD-136 & $11 / 8$ & 15:00 & Photo & 7 & 39.724755 & -121.538913 & Photo & Photo & view west along fire front & v & & \\
\hline TD-136 & $11 / 8$ & 15:03 & Photo & 0 & 39.724755 & -121.538913 & Photo & Photo & large amount of smoke coming from canyon & v & & \\
\hline TD-136 & $11 / 8$ & 15:07 & Photo & 0 & 39.728941 & -121.548790 & Photo & Photo & fire burning in canyon & v & & \\
\hline TD-027 & $11 / 8$ & $15: 40$ & video & 0 & 39.742334 & -121.524345 & TD & TD & pickup truck was burning, threatening house & 0 & & \\
\hline TD-027 & $11 / 8$ & $15: 40$ & Photo & 0 & 39.742220 & -121.524139 & Photo & Photo & vehicle fully involved next to structure & 0 & & \\
\hline TD-013 & $11 / 8$ & $15: 43$ & AVL E2364 & 0 & 39.730535 & -121.513448 & AVL E2364 & TD & fire threatening structures & 0 & & \\
\hline TD-027 & $11 / 8$ & $16: 00$ & TD & 0 & 39.738810 & -121.526594 & TD & TD & fire overruns property & $\mathrm{R}$ & & \\
\hline TD-027 & $11 / 8$ & $16: 22$ & Photo & 0 & 39.739538 & -121.525511 & Photo & Photo & $\begin{array}{l}\text { fire front burning through forested area; line oriented } \\
\text { east to west }\end{array}$ & v & & \\
\hline TD-027 & $11 / 8$ & $16: 30$ & TD & 0 & 39.739806 & -121.526244 & TD & TD & fire approaching Concow school & v & & \\
\hline TD-027 & $11 / 8$ & $17: 00$ & Inferred & 0 & 39.723704 & -121.544424 & TD & TD & $\begin{array}{l}\text { fire front approaching parallel to Nelson Bar Rd from } \\
\text { NW }\end{array}$ & v & & \\
\hline
\end{tabular}




\begin{tabular}{|c|c|c|c|c|c|c|c|c|c|c|c|c|}
\hline \multicolumn{13}{|c|}{ Nelson Bar Road and Highway 70} \\
\hline Source \# & Date & Time & $\begin{array}{l}\text { Time } \\
\text { Source }\end{array}$ & $\begin{array}{c}\text { Obs } \\
\text { Window } \\
\text { (min) }\end{array}$ & Latitude & Longitude & $\begin{array}{l}\text { Location } \\
\text { Source }\end{array}$ & Info Source & Fire Behavior Observations & $\begin{array}{l}\text { Type } \\
\text { of } \\
\text { Fire }\end{array}$ & $\begin{array}{l}\text { Residual } \\
\text { Fire? }\end{array}$ & SSI \\
\hline TD-136 & $11 / 8$ & 17:00 & TD & 0 & 39.730078 & -121.537927 & TD & TD & $\begin{array}{l}\text { fire approaches from the north; very intense, and fast, } \\
\text { lots of spot fires; burning through thick manzanita fuel }\end{array}$ & V & & \\
\hline TD-136 & $11 / 8$ & $17: 00$ & Inferred & 420 & 39.724929 & -121.538485 & TD & TD & fire on Nelson Bar Rd & V & & \\
\hline TD-140 & $11 / 8$ & $17: 00$ & TD & 0 & 39.723868 & -121.544055 & TD & TD & fire spotting across the flats & $\mathrm{S}$ & & \\
\hline TD-137 & $11 / 8$ & 17:06 & Photo & 0 & 39.721500 & -121.547443 & Photo & Photo & fire burning in drainage beyond ridge to west of pond & V & & \\
\hline TD-137 & $11 / 8$ & 17:06 & Photo & 0 & 39.721591 & -121.549953 & Photo & Photo & fire burning in canyon & V & & \\
\hline TD-137 & $11 / 8$ & $17: 12$ & Photo & 0 & 39.724355 & -121.545271 & Photo & Photo & fire front entering the field from the N/NW & V & & \\
\hline TD-137 & $11 / 8$ & $17: 12$ & Photo & 0 & 39.724404 & -121.545078 & Photo & Photo & low intensity line fires moving through grass & V & & \\
\hline TD-137 & $11 / 8$ & $17: 20$ & Photo & 0 & 39.723815 & -121.543971 & Photo & Photo & $\begin{array}{l}\text { fire front working through savannah down slope toward } \\
\text { pond }\end{array}$ & v & & \\
\hline TD-137 & $11 / 8$ & $17: 20$ & Photo & 0 & 39.723060 & -121.543448 & Photo & Photo & spot fire starts in field by the pond & $\mathrm{S}$ & & \\
\hline TD-137 & $11 / 8$ & $17: 20$ & Photo & 0 & 39.723128 & -121.543394 & Photo & Photo & spot fire in grass & $\mathrm{S}$ & & \\
\hline TD-137 & $11 / 8$ & $17: 20$ & Photo & 0 & 39.725463 & -121.545639 & Photo & Photo & main fire burning south through grass oak woodland & $\mathrm{V}$ & & \\
\hline TD-140 & $11 / 8$ & $17: 24$ & video & 0 & 39.724312 & -121.542186 & TD & TD & intense fire approaching structures & $\mathrm{v}$ & & \\
\hline TD-140 & $11 / 8$ & $17: 24$ & Photo & 0 & 39.726475 & -121.539972 & Photo & Photo & $\begin{array}{l}15 \mathrm{~m} \text { to } 30 \mathrm{~m} \text { ( } 50 \mathrm{ft} \text { to } 100 \mathrm{ft} \text { ) flames burning through } \\
\text { forest, spreading south toward Nelson Bar Rd }\end{array}$ & $\mathrm{v}$ & & \\
\hline TD-140 & $11 / 8$ & $17: 24$ & Photo & 0 & 39.724175 & -121.541637 & Photo & Photo & $\begin{array}{l}\text { significant fire front burning in vegetation up to } \\
\text { meadows and structures }\end{array}$ & V & & \\
\hline TD-140 & $11 / 8$ & $17: 29$ & video & 0 & 39.724737 & -121.538897 & TD & TD & fire rapidly impacting structures and Nelson Bar Rd & $\mathrm{v}$ & & \\
\hline TD-140 & $11 / 8$ & $17: 29$ & Photo & 0 & 39.724796 & -121.539567 & Photo & Photo & $\begin{array}{l}\text { numerous short-range spot fires, intense fire front } \\
\text { reaching Nelson Bar Rd, threatening structures }\end{array}$ & V & & \\
\hline TD-139 & $11 / 8$ & $17: 30$ & TD-140 & 30 & 39.727377 & -121.533871 & TD & TD & fire jumps Nelson Bar Rd by the school & V & & \\
\hline TD-139 & $11 / 8$ & $17: 30$ & Inferred & 210 & 39.709145 & -121.545065 & TD & TD & fire on west side of Nelson Bar Rd south of Lunt Rd & v & & \\
\hline TD-137 & $11 / 8$ & $17: 32$ & Photo & 0 & 39.722000 & -121.542103 & Photo & Photo & $\begin{array}{l}\text { fire burning through field down slope closer toward } \\
\text { structure }\end{array}$ & V & & \\
\hline TD-137 & $11 / 8$ & $17: 32$ & Photo & 0 & 39.722435 & -121.542043 & Photo & Photo & fire burning south downhill through grass & V & & \\
\hline TD-137 & $11 / 8$ & $17: 52$ & Photo & 0 & 39.722562 & -121.544111 & Photo & Photo & fire reaches pond & V & & \\
\hline TD-137 & $11 / 8$ & $17: 52$ & Photo & 0 & 39.722568 & -121.544233 & Photo & Photo & grass fire reaches pond & $\mathrm{v}$ & & \\
\hline TD-137 & $11 / 8$ & 18:00 & TD & 84 & 39.721413 & -121.541900 & TD & TD & burn out around structures & v & & \\
\hline TD-031 & $11 / 8$ & $18: 30$ & TD-140 & 30 & 39.727224 & -121.536955 & TD & TD & Fire blows over north side of Nelson Bar Rd & v & & \\
\hline TD-013 & $11 / 8$ & $18: 30$ & Inferred & 0 & 39.730563 & -121.530870 & TD & TD & $\begin{array}{l}\text { fire now up to Nelson Bar Rd and Concow school; new } \\
\text { goal to hold Hwy } 70\end{array}$ & v & & \\
\hline TD-140 & $11 / 8$ & $18: 30$ & TD & 0 & 39.736794 & -121.516785 & TD & TD & fire progressing south of Deadwood Rd & v & & \\
\hline TD-140 & $11 / 8$ & $18: 30$ & Inferred & 30 & 39.727309 & -121.533655 & TD & TD & fire spotting across Nelson Bar Rd & S & & \\
\hline TD-140 & $11 / 8$ & $18: 30$ & Inferred & 30 & 39.726214 & -121.536846 & TD & TD & structure is on fire & $\mathrm{R}$ & & \\
\hline TD-137 & $11 / 8$ & $18: 33$ & Photo & 0 & 39.721787 & -121.542269 & Photo & TD & fire approaching house & $\mathrm{v}$ & & \\
\hline
\end{tabular}




\begin{tabular}{|c|c|c|c|c|c|c|c|c|c|c|c|c|}
\hline & & & & & & & on Bar Road & and Highway & & & & \\
\hline Source \# & Date & Time & $\begin{array}{l}\text { Time } \\
\text { Source }\end{array}$ & $\begin{array}{c}\text { Obs } \\
\text { Window } \\
\text { (min) }\end{array}$ & Latitude & Longitude & $\begin{array}{l}\text { Location } \\
\text { Source }\end{array}$ & Info Source & Fire Behavior Observations & $\begin{array}{c}\text { Type } \\
\text { of } \\
\text { Fire }\end{array}$ & $\begin{array}{l}\text { Residual } \\
\text { Fire? }\end{array}$ & SSI \\
\hline TD-137 & $11 / 8$ & $18: 33$ & Photo & 0 & 39.721868 & -121.542289 & Photo & Photo & $\begin{array}{l}\text { fire burning through thick brush; } 6 \mathrm{~m}(20 \mathrm{ft}) \text { flames; } \\
\text { embers lofting }\end{array}$ & v & & \\
\hline TD-140 & $11 / 8$ & 19:15 & video & 0 & 39.723855 & -121.541314 & TD & TD & fire front has passed, spot fires around & $\mathrm{s}$ & & \\
\hline TD-140 & $11 / 8$ & 19:15 & Photo & 0 & 39.723829 & -121.541302 & Photo & Photo & $\begin{array}{l}\text { widespread scattered fires; fire front has passed } \\
\text { through; heavy fuels remain burning }\end{array}$ & 0 & & \\
\hline TD-137 & $11 / 8$ & $19: 30$ & TD & 210 & 39.729826 & -121.525793 & TD & TD & fire burning around the Concow pool & $\mathrm{V}$ & & \\
\hline TD-138 & $11 / 8$ & 19:30 & Inferred & 0 & 39.724681 & -121.538771 & TD & TD & fire bumps Nelson Bar Rd, spotting across & V & & \\
\hline TD-008 & $11 / 8$ & 20:00 & TD & 0 & 39.726344 & -121.531083 & TD & TD & $\begin{array}{l}\text { Fire made significant run up from Concow, spotted } \\
\text { across Nelson Bar Rd and school }\end{array}$ & V & & \\
\hline TD-139 & $11 / 8$ & $21: 00$ & TD & 0 & 39.724280 & -121.540569 & TD & TD & shed has burned down & 0 & $\mathrm{x}$ & \\
\hline TD-139 & $11 / 8$ & $21: 00$ & Inferred & 540 & 39.716273 & -121.521100 & TD & TD & fire bumping along Hwy 70 & $\mathrm{~V}$ & & \\
\hline TD-062 & $11 / 8$ & 22:05 & AVL & 0 & 39.721550 & -121.536683 & $A V L$ & TD & fire coming from ridge above N/NE & V & & \\
\hline TD-137 & $11 / 8$ & $23: 21$ & Photo & 0 & 39.729342 & -121.525624 & Photo & TD & heavy fire burning in vegetation around Concow pool & V & & \\
\hline TD-137 & $11 / 8$ & $23: 21$ & Photo & 0 & 39.729264 & -121.524825 & Photo & Photo & intense vegetation fire & V & & \\
\hline TD-013 & $11 / 9$ & 00:00 & TD-031 & 0 & 39.707357 & -121.534655 & TD & TD & main fire spots south across Lunt & V & & \\
\hline TD-027 & $11 / 9$ & 00:00 & Inferred & 300 & 39.685168 & -121.544534 & TD & TD & fire slopped over line south of Lunt Rd & V & & \\
\hline TD-136 & $11 / 9$ & 00:00 & TD & 0 & 39.724929 & -121.538485 & TD & TD & fire intensity has dropped & v & & \\
\hline TD-136 & $11 / 9$ & 00:00 & Inferred & 470 & 39.722445 & -121.527019 & TD & TD & fire creeping toward Shuman Ln & v & & \\
\hline TD-062 & $11 / 9$ & 00:01 & AVL & 0 & 39.706703 & -121.553878 & TD & TD & approximate fire edge & v & & \\
\hline TD-031 & $11 / 9$ & 00:07 & AVL & 293 & 39.704378 & -121.530668 & AVL & TD & $\begin{array}{l}\text { main fire came jumped } 6 \mathrm{~m}(20 \mathrm{ft}) \text { over Lunt Rd and } \\
\text { took off }\end{array}$ & V & & \\
\hline TD-062 & $11 / 9$ & $00: 47$ & AVL & 238 & 39.704400 & -121.530417 & AVL & TD & fire jumps line & v & & \\
\hline TD-008 & $11 / 9$ & 01:28 & Radio Log & 0 & 39.722908 & -121.532174 & Inferred & Radio Log & $\begin{array}{l}\text { fire is well established on the Hwy } 70 \text { side of Nelson Bar } \\
\text { Rd }\end{array}$ & v & & \\
\hline TD-027 & $11 / 9$ & 02:00 & TD-028 & 120 & 39.739166 & -121.495736 & TD & TD & fire front approaching Station 36 & $\mathrm{~V}$ & & \\
\hline TD-028 & $11 / 9$ & 02:19 & TD & 0 & 39.740270 & -121.496226 & Photo & TD & fire threatening structure & $\mathrm{v}$ & & \\
\hline TD-031 & $11 / 9$ & 03:29 & Photo & 0 & 39.704142 & -121.530384 & Photo & Photo & firing operation & v & & \\
\hline TD-008 & $11 / 9$ & 03:30 & TD-031 & 0 & 39.719866 & -121.531235 & TD & TD & fire grows south of Nelson Bar Rd, fire jumps line & V & & \\
\hline TD-031 & $11 / 9$ & 03:30 & Photo & 0 & 39.704378 & -121.530668 & AVL & Photo & vegetation fire & v & & \\
\hline TD-013 & $11 / 9$ & 03:30 & TD-031 & 25 & 39.707985 & -121.535131 & TD & TD & $\begin{array}{l}\text { spot fire Nelson Bar Rd/Concow Rd, spread jumped the } \\
\text { line; crossed Lunt Rd and drainage in } 10 \mathrm{~min} \text {, then died } \\
\text { on south face; winds } 18 \mathrm{~m} / \mathrm{s} \text { to } 22 \mathrm{~m} / \mathrm{s}(40 \mathrm{mi} / \mathrm{h} \text { to } \\
50 \mathrm{mi} / \mathrm{h} \text { ) flames laying down, brush fuel } 1.8 \mathrm{~m} \text { to } 3 \mathrm{~m} \\
\text { ( } 6 \mathrm{ft} \text { to } 10 \mathrm{ft} \text { ) }\end{array}$ & v & & \\
\hline TD-031 & $11 / 9$ & 03:55 & Photo & 0 & 39.704378 & -121.530668 & AVL & Photo & Big fire south of Lunt Rd & v & & \\
\hline TD-031 & $11 / 9$ & 03:55 & Photo & 0 & 39.703723 & -121.530324 & Photo & Photo & fire burning on south side Lunt Rd & $\mathrm{v}$ & & \\
\hline
\end{tabular}




\begin{tabular}{|c|c|c|c|c|c|c|c|c|c|c|c|c|}
\hline & & & & & & $\mathrm{Ne}$ & on Bar Roa & and Highway & & & & \\
\hline Source \# & Date & Time & $\begin{array}{l}\text { Time } \\
\text { Source }\end{array}$ & $\begin{array}{l}\text { Obs } \\
\text { Window } \\
\text { (min) }\end{array}$ & Latitude & Longitude & $\begin{array}{c}\text { Location } \\
\text { Source }\end{array}$ & Info Source & Fire Behavior Observations & $\begin{array}{l}\text { Type } \\
\text { of } \\
\text { Fire }\end{array}$ & $\begin{array}{l}\text { Residual } \\
\text { Fire? }\end{array}$ & SSI \\
\hline TD-031 & $11 / 9$ & 03:55 & Photo & 0 & 39.703456 & -121.530897 & Photo & Photo & $\begin{array}{l}\text { fire spotted and well established and running WSW } \\
\text { from Lunt Rd }\end{array}$ & V & & \\
\hline TD-008 & $11 / 9$ & 04:00 & TD-028 & 0 & 39.739151 & -121.495848 & TD & TD & $\begin{array}{l}\text { late night fire run impacts Station } 36 \text {, wind driven from } \\
\text { canyon }\end{array}$ & v & & \\
\hline TD-028 & $11 / 9$ & 04:00 & TD & 0 & 39.739156 & -121.495763 & AVL & TD & $\begin{array}{l}\text { Fire hit Station } 36 \text { from canyon to east and wrapped } \\
\text { around station from north. Fire both slope- and wind- } \\
\text { driven }\end{array}$ & v & & \\
\hline TD-028 & $11 / 9$ & 04:00 & TD & 0 & 39.722671 & -121.493224 & TD & TD & $\begin{array}{l}\text { fire pushed south to big bend mountain mobile home } \\
\text { park }\end{array}$ & V & & \\
\hline TD-013 & $11 / 9$ & 05:35 & Photo & 0 & 39.685985 & -121.540458 & Photo & Photo & intense fire line burning through forest up on ridge & $\mathrm{V}$ & & \\
\hline TD-136 & $11 / 9$ & 06:30 & Inferred & 80 & 39.722024 & -121.526158 & TD & TD & $\begin{array}{l}\text { sunrise causes fire intensity to pick up dramatically; } \\
\text { visibility decreases, suddenly everything is burning } \\
\text { again, trees, needles, houses }\end{array}$ & $\mathrm{R}$ & & \\
\hline TD-140 & $11 / 9$ & $06: 40$ & AVL & 0 & 39.725066 & -121.517156 & AVL & TD & fire is coming hard toward pool & $\mathrm{v}$ & & \\
\hline TD-140 & $11 / 9$ & 06:40 & Inferred & 40 & 39.727277 & -121.523958 & TD & TD & $\begin{array}{l}\text { fire burning across Pinkston Canyon Rd towards } \\
\text { Concow Rd; worried about getting pinched }\end{array}$ & $\mathrm{V}$ & & \\
\hline TD-140 & $11 / 9$ & $06: 40$ & Inferred & 40 & 39.722063 & -121.526952 & TD & TD & fire threatening structure & 0 & & \\
\hline TD-137 & $11 / 9$ & 07:09 & Photo & 0 & 39.720999 & -121.523302 & Photo & TD & $\begin{array}{l}\text { Shuman Ln; fire burning in area, but not intense, piles } \\
\text { of pine needles and slash debris }\end{array}$ & $\mathrm{v}$ & & \\
\hline TD-137 & $11 / 9$ & 07:09 & Photo & 0 & 39.720999 & -121.523302 & Photo & Photo & widespread vegetation surface fires & $\mathrm{v}$ & & \\
\hline TD-013 & $11 / 9$ & 07:20 & Photo & 20 & 39.725467 & -121.503032 & TD & TD & surrounded by heavy fire activity in vegetation & v & & \\
\hline TD-137 & $11 / 9$ & 07:20 & Inferred & 7 & 39.720999 & -121.523302 & Photo & TD & fire intensifies quickly & 0 & & \\
\hline TD-137 & $11 / 9$ & 07:20 & Inferred & 7 & 39.728044 & -121.525331 & TD & TD & roadway blocked by fire & 0 & & \\
\hline TD-140 & $11 / 9$ & 07:20 & TD-137 & 7 & 39.721039 & -121.523620 & TD & TD & $\begin{array}{l}\text { wind shift; fire starts coming down from west side, then } \\
\text { east side; both sides of Concow Rd are burning; Station } \\
37 \text { is hit hard }\end{array}$ & v & & \\
\hline TD-139 & $11 / 9$ & 07:20 & Inferred & 0 & 39.721190 & -121.524352 & TD & TD & fire approaches, wind increases, huge embers & 0 & & \\
\hline TD-013 & $11 / 9$ & 07:21 & Photo & 0 & 39.726078 & -121.502943 & Photo & Photo & vegetation fully involved & $\mathrm{v}$ & & \\
\hline TD-013 & $11 / 9$ & 07:22 & Photo & 0 & 39.726078 & -121.502943 & Photo & Photo & vegetation fully involved & v & & \\
\hline TD-140 & $11 / 9$ & 07:27 & Inferred & 20 & 39.718795 & -121.521428 & TD & TD & house fully involved & $\mathrm{R}$ & & \\
\hline TD-138 & $11 / 9$ & 07:27 & TD-137 & 21 & 39.727070 & -121.525007 & TD & TD & fire activity blew up & $\mathrm{v}$ & & \\
\hline TD-139 & $11 / 9$ & 07:30 & TD-140 & 90 & 39.716463 & -121.521202 & TD & TD & fire coming across $\mathrm{Hwy} 70$ & V & & \\
\hline TD-013 & $11 / 9$ & $07: 42$ & Photo & 0 & 39.725745 & -121.503254 & Photo & Photo & vegetation all around, surface fuels burning, glowing & V & & \\
\hline TD-140 & $11 / 9$ & 07:47 & video & 0 & 39.717375 & -121.519713 & video & TD & fire spots across $\mathrm{Hwy} 70$ at Concow Rd & $\mathrm{S}$ & & \\
\hline TD-140 & $11 / 9$ & 07:47 & Photo & 0 & 39.718327 & -121.518966 & Photo & Photo & fire on north side of Hwy 70 & v & & \\
\hline TD-140 & $11 / 9$ & 07:47 & Photo & 0 & 39.717118 & -121.520144 & Photo & Photo & spot fire on south side of Hwy 70 & $\mathrm{~S}$ & & \\
\hline TD-140 & $11 / 9$ & $07: 49$ & Photo & 0 & 39.716565 & -121.520843 & Photo & Photo & Spot fires on both side of Highway & $\mathrm{s}$ & & \\
\hline
\end{tabular}




\begin{tabular}{|c|c|c|c|c|c|c|c|c|c|c|c|c|}
\hline \multicolumn{13}{|c|}{ Nelson Bar Road and Highway 70} \\
\hline Source \# & Date & Time & $\begin{array}{l}\text { Time } \\
\text { Source }\end{array}$ & $\begin{array}{c}\text { Obs } \\
\text { Window } \\
\text { (min) }\end{array}$ & Latitude & Longitude & $\begin{array}{l}\text { Location } \\
\text { Source }\end{array}$ & Info Source & Fire Behavior Observations & $\begin{array}{c}\text { Type } \\
\text { of } \\
\text { Fire }\end{array}$ & $\begin{array}{l}\text { Residual } \\
\text { Fire? }\end{array}$ & SSI \\
\hline TD-136 & $11 / 9$ & 07:50 & Inferred & 0 & 39.719236 & -121.522166 & TD & TD & $\begin{array}{l}\text { drive out through fire across Concow Rd; engine takes } \\
\text { slight damage }\end{array}$ & 0 & & \\
\hline TD-137 & $11 / 9$ & 07:50 & Inferred & 0 & 39.727062 & -121.525020 & TD & TD & $\begin{array}{l}\text { wait at Concow Rd and Pinkston Canyon Rd; fire } \\
\text { intensity not as severe }\end{array}$ & 0 & & \\
\hline TD-136 & $11 / 9$ & 07:56 & Photo & 0 & 39.716264 & -121.520942 & Photo & TD & $\begin{array}{l}\text { Hwy } 70 \text { at Concow Rd; active fire burning along west } \\
\text { side Hwy } 70\end{array}$ & $\mathrm{v}$ & & \\
\hline TD-136 & $11 / 9$ & 07:56 & Photo & 0 & 39.717691 & -121.520010 & Photo & Photo & vegetation burning up against road; $6 \mathrm{~m}(20 \mathrm{ft})$ flames & $\mathrm{v}$ & & \\
\hline TD-031 & $11 / 9$ & $08: 20$ & Photo & 0 & 39.694825 & -121.531726 & Photo & Photo & $\begin{array}{l}\text { low intensity fire in shrub and grass west side Hwy } 70 \text {; } \\
\text { burn operation along roadway }\end{array}$ & $\mathrm{v}$ & & \\
\hline TD-140 & $11 / 9$ & $08: 27$ & Photo & 0 & 39.716962 & -121.521799 & Photo & Photo & $\begin{array}{l}\text { significant vegetation fire approaching Hwy } 70 \text { from } \\
\text { Concow Rd; light embers shower }\end{array}$ & $\mathrm{v}$ & & \\
\hline TD-140 & $11 / 9$ & $08: 40$ & video & 0 & 39.716256 & -121.521104 & video & TD & fire well established on South side Hwy 70 & $\mathrm{~V}$ & & \\
\hline TD-140 & $11 / 9$ & 08:40 & Photo & 0 & 39.716247 & -121.521073 & Photo & Photo & $\begin{array}{l}\text { well-established heavy fire on both sides of Hwy } 70 \text { at } \\
\text { Concow Rd }\end{array}$ & $\mathrm{v}$ & & \\
\hline TD-140 & $11 / 9$ & 08:55 & Photo & 0 & 39.714743 & -121.520527 & Photo & Photo & heavy fire heading south from Hwy 70 into Yankee Hill & $\mathrm{v}$ & & \\
\hline TD-140 & $11 / 9$ & 08:55 & Photo & 0 & 39.715309 & -121.520570 & Photo & Photo & intense vegetation fire activity; trees torching & $\mathrm{v}$ & & \\
\hline TD-138 & $11 / 9$ & 09:00 & Inferred & 0 & 39.710393 & -121.526320 & TD & TD & heavy fire activity along Hwy 70 & v & & \\
\hline TD-137 & $11 / 9$ & 09:01 & Inferred & 0 & 39.721146 & -121.523534 & TD & TD & Station 37 is burned down & C & $\mathrm{x}$ & \\
\hline TD-137 & $11 / 9$ & 09:02 & Photo & 0 & 39.716878 & -121.521218 & Photo & TD & fire had burned through area & 0 & $x$ & \\
\hline TD-137 & $11 / 9$ & 09:02 & Photo & 0 & 39.717100 & -121.521021 & Photo & Photo & surface fuels have burned, still glowing & $\mathrm{v}$ & $\mathrm{x}$ & \\
\hline
\end{tabular}




\begin{tabular}{|c|c|c|c|c|c|c|c|c|c|c|c|c|}
\hline \multicolumn{13}{|c|}{ Magalia and Coutolenc Road } \\
\hline Source \# & Date & Time & $\begin{array}{l}\text { Time } \\
\text { Source }\end{array}$ & $\begin{array}{c}\text { Obs } \\
\text { Window } \\
\text { (min) }\end{array}$ & Latitude & Longitude & $\begin{array}{l}\text { Location } \\
\text { Source }\end{array}$ & Info Source & Fire Behavior Observations & $\begin{array}{l}\text { Type } \\
\text { of } \\
\text { Fire }\end{array}$ & $\begin{array}{l}\text { Residual } \\
\text { Fire? }\end{array}$ & SSI \\
\hline $911-092-1$ & $11 / 8$ & 08:01 & $911-092-1$ & 0 & 39.804374 & -121.578145 & Inferred & $911-092-1$ & spot fires on west side of canyon by Sawmill Peak & $\mathrm{S}$ & & \\
\hline TD-006 & $11 / 8$ & $08: 41$ & Radio Log & 0 & 39.804814 & -121.578638 & TD & TD & spot fires in Old Magalia & $\mathrm{s}$ & & \\
\hline $911-207-1$ & $11 / 8$ & 09:02 & $911-207-1$ & 0 & 39.804374 & -121.578145 & Inferred & 911-207-1 & new fire starting & S & & \\
\hline $911-217-1$ & $11 / 8$ & 09:07 & $911-217-1$ & 0 & 39.804374 & -121.578145 & Inferred & $911-217-1$ & fire both sides of road & $\mathrm{S}$ & & \\
\hline $911-230-1$ & $11 / 8$ & 09:16 & $911-230-1$ & 0 & 39.804374 & -121.578145 & Inferred & $911-230-1$ & structures are burning & $\mathrm{R}$ & & \\
\hline $911-240-1$ & $11 / 8$ & 09:21 & $911-240-1$ & 0 & 39.712138 & -121.578005 & $911-240-1$ & $911-240-1$ & structure on fire & C & & \\
\hline $911-241-1$ & $11 / 8$ & 09:21 & $911-241-1$ & 0 & 39.712138 & -121.578005 & $911-241-1$ & $911-241-1$ & fire & C & & \\
\hline PPD-02 & $11 / 8$ & 09:46 & PPD-02 & 1 & 39.802526 & -121.578640 & video & video & $\begin{array}{l}\text { spot fire in vegetation on both sides of Skyway up } \\
\text { against roadway }\end{array}$ & $\mathrm{s}$ & & \\
\hline TD-041 & $11 / 8$ & 11:05 & Inferred & 0 & 39.806386 & -121.577594 & TD & TD & fire is up to edge of Skyway; northern flank of fire & v & & \\
\hline PPD-10 & $11 / 8$ & 11:53 & PPD-10 & 0 & 39.801315 & -121.582699 & video & video & large flames & 0 & & \\
\hline TD-079 & $11 / 8$ & 12:10 & $\mathrm{AVL}$ & 0 & 39.804683 & -121.577867 & AVL & TD & everything on fire driving up Skyway - both sides of road & 0 & & \\
\hline TD-060 & $11 / 8$ & 12:18 & AVL & 0 & 39.812633 & -121.575716 & AVL & TD & spot fire down in canyon & S & & \\
\hline TD-009 & $11 / 8$ & 12:18 & AVL & 0 & 39.810739 & -121.577389 & AVL & TD & estimated flank of the fire & 0 & & \\
\hline TD-083 & $11 / 8$ & $12: 21$ & AVL & 0 & 39.803900 & -121.581867 & AVL & TD & $\begin{array}{l}\text { fire on south side of Ishi Dr, only one fire on north side } \\
\text { (detached garage on fire, mobile home burning under } \\
\text { floor) }\end{array}$ & $\mathrm{R}$ & & \\
\hline TD-060 & $11 / 8$ & $12: 27$ & AVL & 14 & 39.808500 & -121.579350 & AVL & TD & $\begin{array}{l}\text { Fire hit old fire station in Old Magalia and trees pretty } \\
\text { hard. Pine needles on metal roof ignite. }\end{array}$ & V & & \\
\hline TD-079 & $11 / 8$ & $12: 28$ & $\mathrm{AVL}$ & 16 & 39.803254 & -121.583125 & AVL & TD & $\begin{array}{l}\text { side panel of house on fire, houses igniting by ember } \\
\text { ignitions }\end{array}$ & $\mathrm{R}$ & & \\
\hline TD-079 & $11 / 8$ & $12: 46$ & AVL & 20 & 39.802787 & -121.585373 & AVL & TD & grass fires, not all homes burning yet & $\mathrm{v}$ & & \\
\hline TD-060 & $11 / 8$ & $12: 56$ & AVL & 62 & 39.800715 & -121.600447 & AVL & TD & $\begin{array}{l}10 \text { structures fully involved, fire moving house to house } \\
\text { ( } S \text { side of Andover Dr) }\end{array}$ & $\mathrm{R}$ & & \\
\hline TD-060 & $11 / 8$ & $12: 56$ & AVL & 62 & 39.800954 & -121.598777 & AVL & TD & fire threatening structures & 0 & & \\
\hline TD-060 & $11 / 8$ & 12:56 & AVL & 62 & 39.800586 & -121.597584 & AVL & TD & 4 to 6 structures on fire & $\mathrm{R}$ & & \\
\hline TD-060 & $11 / 8$ & 12:56 & $\mathrm{AVL}$ & 62 & 39.808038 & -121.598450 & AVL & TD & fire threatening structures & 0 & & \\
\hline TD-060 & $11 / 8$ & $12: 58$ & Radio Log & 0 & 39.800960 & -121.597524 & AVL & Radio Log & fire at S Park Dr and Adrian Dr & 0 & & \\
\hline TD-040 & $11 / 8$ & 13:00 & Inferred & 540 & 39.798283 & -121.601389 & TD & TD & $\begin{array}{l}\text { some of first homes to ignite were on Achilles } \mathrm{Dr} \text { and } \\
\text { Andover } \mathrm{Dr}\end{array}$ & $\mathrm{R}$ & & \\
\hline TD-060 & $11 / 8$ & 13:03 & AVL & 8 & 39.799470 & -121.604749 & AVL & TD & flanking fire [in wildlands] behind homes on S Park Dr & $\mathrm{v}$ & & \\
\hline TD-079 & $11 / 8$ & 13:09 & AVL & 3 & 39.803661 & -121.582198 & AVL & TD & all structures burning & $\mathrm{R}$ & & \\
\hline TD-079 & $11 / 8$ & 13:24 & AVL & 13 & 39.798323 & -121.602435 & AVL & TD & some houses burning, could not access end of road & $\mathrm{R}$ & & \\
\hline TD-045 & $11 / 8$ & $13: 50$ & AVL & 16 & 39.799450 & -121.602817 & AVL & TD & active fire near structures & $\mathrm{v}$ & & \\
\hline TD-113 & $11 / 8$ & $14: 00$ & TD & 300 & 39.798536 & -121.597654 & TD & TD & fire burning upslope into Andover $\mathrm{Dr}$ & $\mathrm{v}$ & & \\
\hline TD-089 & $11 / 8$ & $14: 40$ & AVL & 172 & 39.795999 & -121.607217 & TD & TD & just a small slop over the access road & v & & \\
\hline TD-089 & $11 / 8$ & $14: 40$ & AVL & 172 & 39.791325 & -121.617666 & TD & TD & fire in drainage & $\mathrm{V}$ & & \\
\hline
\end{tabular}




\begin{tabular}{|c|c|c|c|c|c|c|c|c|c|c|c|c|}
\hline \multicolumn{13}{|c|}{ Magalia and Coutolenc Road } \\
\hline Source \# & Date & Time & $\begin{array}{l}\text { Time } \\
\text { Source }\end{array}$ & $\begin{array}{l}\text { Obs } \\
\text { Window } \\
\text { (min) }\end{array}$ & Latitude & Longitude & $\begin{array}{l}\text { Location } \\
\text { Source }\end{array}$ & Info Source & Fire Behavior Observations & $\begin{array}{c}\text { Type } \\
\text { of } \\
\text { Fire }\end{array}$ & $\begin{array}{l}\text { Residual } \\
\text { Fire? }\end{array}$ & SSI \\
\hline TD-079 & $11 / 8$ & $14: 42$ & $\mathrm{AVL}$ & 169 & 39.796295 & -121.606723 & TD & TD & active fire in drainage & $\mathrm{V}$ & & \\
\hline TD-084 & $11 / 8$ & $14: 48$ & AVL & 161 & 39.794128 & -121.623309 & TD & TD & fire in drainage & v & & \\
\hline TD-041 & $11 / 8$ & $14: 55$ & Inferred & 0 & 39.808416 & -121.576810 & TD & TD & edge of fire & $\mathrm{v}$ & & \\
\hline TD-085 & $11 / 8$ & $14: 57$ & AVL & 157 & 39.798757 & -121.603341 & AVL & TD & fire hung up in drainage & $\mathrm{v}$ & & \\
\hline TD-045 & $11 / 8$ & $15: 00$ & Inferred & 155 & 39.795334 & -121.608407 & TD & TD & Fire hung up on ridge behind houses & v & & \\
\hline TD-041 & $11 / 8$ & $15: 00$ & Inferred & 0 & 39.811869 & -121.590965 & TD & TD & $\begin{array}{l}\text { structures on east side of Andover Dr are already } \\
\text { burned to the ground }\end{array}$ & $\mathrm{R}$ & $\mathrm{x}$ & \\
\hline TD-126 & $11 / 8$ & $15: 00$ & TD & 480 & 39.797181 & -121.601162 & TD & TD & $\begin{array}{l}\text { wood piles, decks, fences, other detached combustibles } \\
\text { burning, threatening structures }\end{array}$ & 0 & & \\
\hline TD-060 & $11 / 8$ & $15: 04$ & AVL & 148 & 39.793906 & -121.613192 & AVL & TD & fire swung around below us & $\mathrm{v}$ & & \\
\hline TD-045 & $11 / 8$ & 15:05 & AVL & 150 & 39.797597 & -121.604738 & TD & TD & Light fire behavior. Creeping fire & $\mathrm{v}$ & & \\
\hline TD-100 & $11 / 8$ & $15: 45$ & Inferred & 15 & 39.808486 & -121.588058 & TD & TD & fire is burning on south side of dam and Andover $\mathrm{Dr}$ & $\mathrm{v}$ & & \\
\hline TD-143 & $11 / 8$ & $16: 30$ & Inferred & 36 & 39.813108 & -121.594710 & TD & TD & destroyed structures & $\mathrm{R}$ & $\mathrm{x}$ & \\
\hline TD-143 & $11 / 8$ & $17: 06$ & Photo & 39 & 39.800196 & -121.596171 & TD & TD & $\begin{array}{l}\text { house completely gone; well-past burning; firewood } \\
\text { pile is burning }\end{array}$ & $\mathrm{R}$ & $x$ & \\
\hline TD-114 & $11 / 8$ & $17: 14$ & TD & 166 & 39.815047 & -121.590572 & TD & TD & fire burning in area around SAV-MOR Foods & $\mathrm{v}$ & & \\
\hline TD-045 & $11 / 8$ & $17: 35$ & Inferred & 0 & 39.796955 & -121.616092 & TD & TD & $\begin{array}{l}\text { See well established } 6 \text { ha to } 8 \text { ha ( } 15 \text { ac to } 20 \text { ac) spot } \\
\text { fire }\end{array}$ & $\mathrm{s}$ & & \\
\hline TD-060 & $11 / 8$ & $17: 42$ & AVL & 33 & 39.802567 & -121.597617 & AVL & TD & fire threatening structures & 0 & & \\
\hline TD-060 & $11 / 8$ & $18: 17$ & AVL & 276 & 39.805100 & -121.595183 & AVL & TD & fire backing up hill, flanking & $\mathrm{v}$ & & \\
\hline TD-045 & $11 / 8$ & $18: 20$ & AVL & 156 & 39.804078 & -121.595806 & AVL & TD & Creeping fire behind structures & $\mathrm{v}$ & & \\
\hline TD-085 & $11 / 8$ & $18: 32$ & AVL & 82 & 39.806330 & -121.583206 & AVL & TD & many structures already burned & $\mathrm{R}$ & $\mathrm{x}$ & \\
\hline TD-079 & $11 / 8$ & $18: 34$ & AVL & 119 & 39.806217 & -121.583424 & AVL & TD & fire threatening structures & 0 & & \\
\hline TD-089 & $11 / 8$ & $18: 38$ & AVL & 412 & 39.805960 & -121.585905 & TD & TD & $\begin{array}{l}\text { fire in drainage in heavy brush pushing uphill toward } \\
\text { Ishi Dr }\end{array}$ & $\mathrm{v}$ & & \\
\hline TD-089 & $11 / 8$ & $18: 38$ & AVL & 101 & 39.805642 & -121.584355 & AVL & TD & several homes in area already burned & $\mathrm{R}$ & $\mathrm{x}$ & \\
\hline TD-014 & $11 / 8$ & 19:00 & AVL & 10 & 39.814181 & -121.592112 & AVL & TD & Significant fire push up draws & $\mathrm{v}$ & & \\
\hline TD-014 & $11 / 8$ & 19:00 & AVL & 10 & 39.811020 & -121.592326 & TD & TD & $\begin{array}{l}\text { Structures burning Andover } \mathrm{Dr} \text {, South Park } \mathrm{Dr} \text {, and } \\
\text { along Skyway by Rite Aid; unable to drive into South } \\
\text { Park Dr }\end{array}$ & $\mathrm{R}$ & & \\
\hline TD-143 & $11 / 8$ & 19:11 & Photo & 0 & 39.800181 & -121.596180 & Photo & Photo & structure burned to foundation; no active fire visible & $\mathrm{R}$ & $\mathrm{x}$ & \\
\hline TD-087 & $11 / 8$ & 19:27 & $\mathrm{AVL}$ & 66 & 39.805977 & -121.583638 & $A V L$ & TD & fire threatening structures & $\mathrm{v}$ & & \\
\hline TD-085 & $11 / 8$ & $20: 18$ & AVL & 12 & 39.803817 & -121.595483 & AVL & TD & some houses already affected & $\mathrm{R}$ & $\mathrm{x}$ & \\
\hline TD-089 & $11 / 8$ & $20: 20$ & AVL & 202 & 39.805642 & -121.584355 & AVL & TD & fire threatening structures & $\mathrm{v}$ & & \\
\hline TD-087 & $11 / 8$ & 20:37 & $A V L$ & 41 & 39.805625 & -121.584345 & AVL & TD & fire threatening structures & $\mathrm{v}$ & & \\
\hline TD-043 & $11 / 8$ & 21:00 & Inferred & 210 & 39.804939 & -121.577902 & TD & TD & approximate fire edge; burning south of Indian $\mathrm{Dr}$ & 0 & & \\
\hline
\end{tabular}




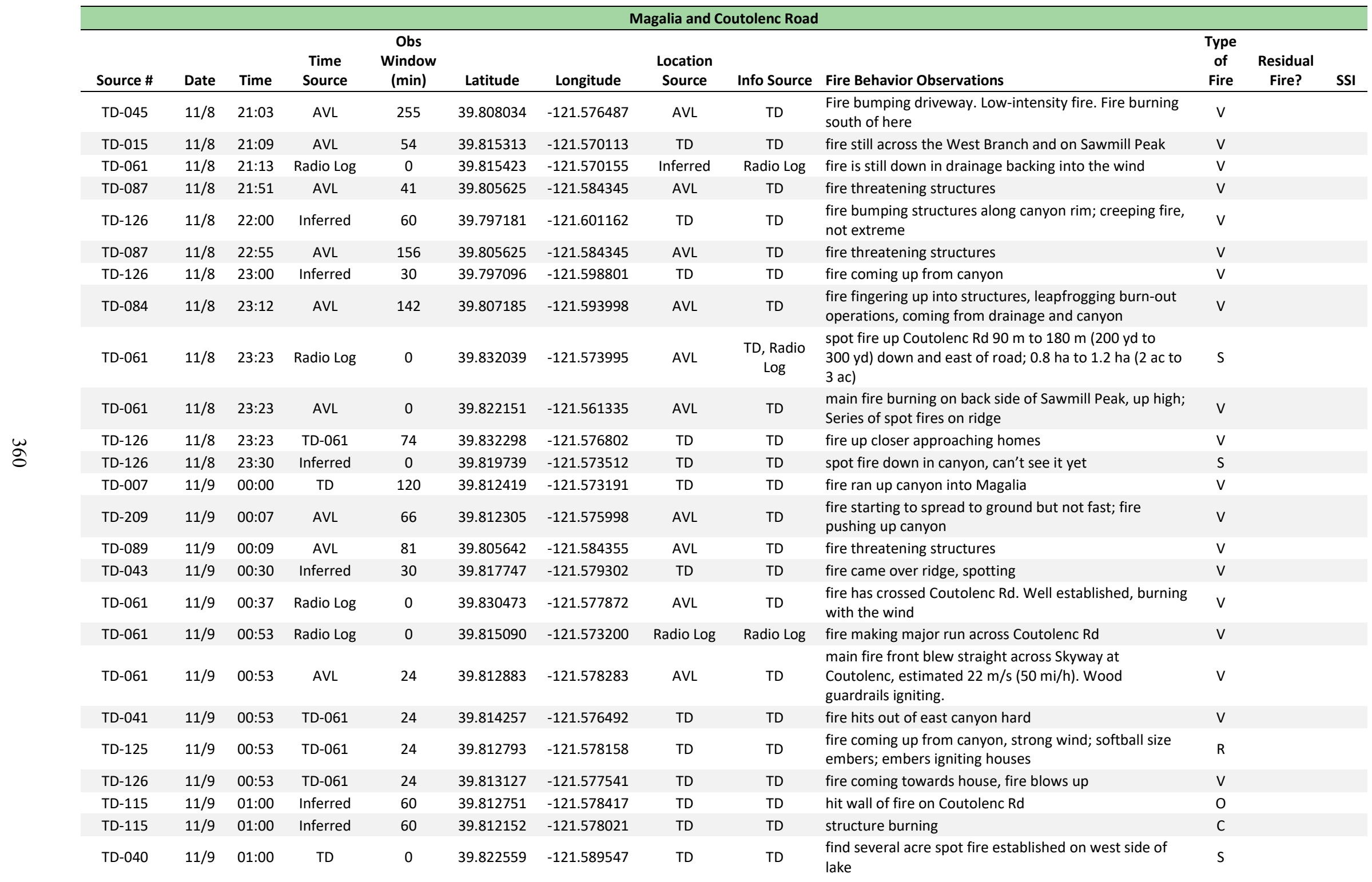




\begin{tabular}{|c|c|c|c|c|c|c|c|c|c|c|c|c|}
\hline & & & & & & & galia and C & utolenc Road & & & & \\
\hline Source \# & Date & Time & $\begin{array}{l}\text { Time } \\
\text { Source }\end{array}$ & $\begin{array}{l}\text { Obs } \\
\text { Window } \\
\text { (min) }\end{array}$ & Latitude & Longitude & $\begin{array}{l}\text { Location } \\
\text { Source }\end{array}$ & Info Source & Fire Behavior Observations & $\begin{array}{l}\text { Type } \\
\text { of } \\
\text { Fire }\end{array}$ & $\begin{array}{l}\text { Residual } \\
\text { Fire? }\end{array}$ & SSI \\
\hline TD-126 & $11 / 9$ & 01:00 & TD & 60 & 39.812768 & -121.578424 & TD & TD & fire spreads west and north of Skyway & $\mathrm{V}$ & & \\
\hline TD-126 & $11 / 9$ & 01:00 & Inferred & 60 & 39.813813 & -121.585729 & TD & TD & $\begin{array}{l}\text { fire burning both sides Skyway north of Dogtown Rd; } \\
\text { cannot get through }\end{array}$ & 0 & & \\
\hline TD-126 & $11 / 9$ & 01:00 & Inferred & 60 & 39.815439 & -121.589180 & TD & TD & fire working uphill towards Lakeridge Cir from lake & $\mathrm{v}$ & & \\
\hline TD-060 & $11 / 9$ & 01:03 & AVL & 32 & 39.807307 & -121.593886 & AVL & TD & $\begin{array}{l}300 \text { to } 400 \text { spot fires starting in S Park Dr, Andover Dr, } \\
\text { Endicot Cir, Altus Ct area. [fire came from Coutolenc Rd } \\
\text { blow-up]. Fire coming to north end of Andover Dr from } \\
\text { Little Butte Creek Canyon }\end{array}$ & $\mathrm{V}$ & & \\
\hline TD-041 & $11 / 9$ & 01:14 & Photo & 0 & 39.820733 & -121.587872 & TD & TD, Photo & fire spotting to east side of Dogtown Rd along lake & $\mathrm{s}$ & & \\
\hline TD-041 & $11 / 9$ & 01:14 & Photo & 0 & 39.820292 & -121.580220 & Photo & Photo & flames on the ridgetop & $\mathrm{V}$ & & \\
\hline TD-209 & $11 / 9$ & 01:17 & AVL & 0 & 39.815404 & -121.592327 & AVL & TD & fire not quite to road; spot fires throughout businesses & $\mathrm{s}$ & & \\
\hline TD-045 & $11 / 9$ & 01:18 & AVL & 0 & 39.811246 & -121.568248 & TD & TD & fire creeping down Sawmill Peak & v & & \\
\hline TD-045 & $11 / 9$ & 01:19 & AVL & 120 & 39.812594 & -121.578472 & AVL & TD & $\begin{array}{l}\text { Lots of spots. Tree stands torching. Fire came roaring up } \\
\text { from the canyon. Spotting below Skyway and into Old } \\
\text { Magalia }\end{array}$ & $\mathrm{V}$ & & \\
\hline TD-127 & $11 / 9$ & $01: 22$ & Photo & 0 & 39.815722 & -121.577526 & Photo & TD & $\begin{array}{l}\text { crown fire coming from the W Branch toward Coutolenc } \\
\text { Rd }\end{array}$ & V & & \\
\hline TD-127 & $11 / 9$ & $01: 22$ & Inferred & 27 & 39.821756 & -121.587876 & TD & TD & spot fires along west side Magalia Reservoir & $\mathrm{s}$ & & \\
\hline TD-127 & $11 / 9$ & 01:22 & Inferred & 27 & 39.817219 & -121.592681 & TD & TD & fire & 0 & & \\
\hline TD-127 & $11 / 9$ & 01:22 & Inferred & 27 & 39.812071 & -121.588898 & TD & TD & fire burning on Skyway/Dogtown Rd/dam & $\mathrm{V}$ & & \\
\hline TD-122 & $11 / 9$ & 01:23 & Photo & 17 & 39.818067 & -121.589767 & Photo & Photo & fire & $\mathrm{S}$ & & \\
\hline TD-041 & $11 / 9$ & $01: 23$ & Photo & 0 & 39.818286 & -121.589932 & TD & TD, Photo & spotty fire between Lakeridge Cir and Dogtown Rd & $\mathrm{S}$ & & \\
\hline TD-127 & $11 / 9$ & 01:23 & Photo & 0 & 39.816533 & -121.578257 & Photo & Photo & $30 \mathrm{~m}$ (100 ft) flames on the ridge & V & & \\
\hline TD-041 & $11 / 9$ & 01:23 & Photo & 0 & 39.818000 & -121.589667 & Photo & Photo & surface fire in leaf litter & $\mathrm{v}$ & & \\
\hline TD-043 & $11 / 9$ & 01:30 & Inferred & 0 & 39.807558 & -121.579823 & TD & TD & lots of scattered spot fires & $\mathrm{s}$ & & \\
\hline TD-087 & $11 / 9$ & 01:33 & $A V L$ & 113 & 39.808001 & -121.578911 & AVL & TD & $\begin{array}{l}\text { fire hits crazy from water station. Fire pushed from the } \\
\text { dam }\end{array}$ & $\mathrm{v}$ & & \\
\hline TD-040 & $11 / 9$ & 01:33 & Photo & 0 & 39.818406 & -121.590000 & TD & TD & fire spotting / spreading into Magalia & $\mathrm{s}$ & & \\
\hline TD-089 & $11 / 9$ & 01:44 & AVL & 102 & 39.809900 & -121.583985 & TD & TD & $\begin{array}{l}\text { big push of fire from east; fire also came up drainage } \\
\text { from west }\end{array}$ & $\mathrm{v}$ & & \\
\hline TD-127 & $11 / 9$ & 01:45 & TD & 0 & 39.817810 & -121.591917 & TD & TD & fire coming hard toward Coutolenc Rd & v & & \\
\hline TD-209 & $11 / 9$ & 01:48 & Photo & 0 & 39.819625 & -121.591566 & Photo & Photo & mass fire glow, significant fire from this area & V & & \\
\hline TD-209 & $11 / 9$ & 01:48 & Photo & 0 & 39.820000 & -121.590120 & Photo & Photo & significant fire, glow, coming from drainage & V & & \\
\hline TD-209 & $11 / 9$ & 01:48 & Photo & 0 & 39.818743 & -121.591089 & Photo & Photo & firebrand showers & 0 & & \\
\hline TD-061 & $11 / 9$ & 01:49 & Radio Log & 0 & 39.811425 & -121.587877 & Radio Log & Radio Log & $\begin{array}{l}\text { fire behavior is probably a } 22 \mathrm{~m} / \mathrm{s}(50 \mathrm{mi} / \mathrm{h} \text { ) wind } \\
\text { burning straight over to Andover } \mathrm{Dr}\end{array}$ & V & & \\
\hline TD-122 & $11 / 9$ & 01:50 & AVL & 309 & 39.816250 & -121.590383 & AVL & TD & Subway shop is burning, and propane is venting & c & & \\
\hline
\end{tabular}




\begin{tabular}{|c|c|c|c|c|c|c|c|c|c|c|c|c|}
\hline \multicolumn{13}{|c|}{ Magalia and Coutolenc Road } \\
\hline Source \# & Date & Time & $\begin{array}{l}\text { Time } \\
\text { Source }\end{array}$ & $\begin{array}{c}\text { Obs } \\
\text { Window } \\
\text { (min) }\end{array}$ & Latitude & Longitude & $\begin{array}{l}\text { Location } \\
\text { Source }\end{array}$ & Info Source & Fire Behavior Observations & $\begin{array}{c}\text { Type } \\
\text { of } \\
\text { Fire }\end{array}$ & $\begin{array}{l}\text { Residual } \\
\text { Fire? }\end{array}$ & SSI \\
\hline TD-040 & $11 / 9$ & 01:51 & Photo & 0 & 39.811214 & -121.590053 & TD & TD & $\begin{array}{l}\text { fire coming from little butte creek, north into Andover } \\
\text { Dr/Skyway }\end{array}$ & $\mathrm{v}$ & & \\
\hline TD-041 & $11 / 9$ & 01:51 & Photo & 0 & 39.818743 & -121.591089 & Photo & Photo & surface fire in pine/leaf litter & $\mathrm{v}$ & & \\
\hline TD-209 & $11 / 9$ & $01: 52$ & Photo & 0 & 39.819212 & -121.589838 & Photo & Photo & fire, orange glow coming from canyon & $\mathrm{v}$ & & \\
\hline TD-041 & $11 / 9$ & 01:53 & Photo & 0 & 39.819124 & -121.591425 & TD & TD, Photo & $\begin{array}{l}\text { ground fires moving fairly quickly; flare-ups and ember } \\
\text { cast from everything, } 100 \% \text { ignition }\end{array}$ & $\mathrm{v}$ & & \\
\hline TD-041 & $11 / 9$ & $01: 54$ & Photo & 0 & 39.818743 & -121.591089 & Photo & Photo & surface fire in pine/leaf litter; ladder fuels & $\mathrm{v}$ & & \\
\hline TD-041 & $11 / 9$ & 01:54 & Photo & 0 & 39.818198 & -121.590650 & Photo & Photo & vegetation fire & $\mathrm{V}$ & & \\
\hline TD-041 & $11 / 9$ & 01:57 & Photo & 0 & 39.818834 & -121.591188 & Photo & Photo & surface fire in pine/leaf litter; ladder fuels & $\mathrm{v}$ & & \\
\hline TD-109 & $11 / 9$ & 01:58 & $\mathrm{AVL}$ & 94 & 39.816167 & -121.590400 & $\mathrm{AVL}$ & TD & $\begin{array}{l}\text { Magalia Pines Baptist Church did catch fire at some } \\
\text { point }\end{array}$ & C & & \\
\hline TD-041 & $11 / 9$ & 01:58 & Photo & 0 & 39.818743 & -121.591089 & Photo & Photo & $\begin{array}{l}\text { surface fire in pine/leaf litter; ladder fuels; lots of small } \\
\text { embers through air and on road surface }\end{array}$ & $\mathrm{v}$ & & \\
\hline TD-061 & $11 / 9$ & 02:00 & AVL & 84 & 39.813922 & -121.592928 & AVL & TD & $\begin{array}{l}\text { all structures around here are burning; fire is burning } \\
\text { across the "fairway" }\end{array}$ & $\mathrm{R}$ & & \\
\hline TD-061 & $11 / 9$ & 02:00 & AVL & 84 & 39.815785 & -121.595632 & TD & TD & structure to structure fire spread & $\mathrm{R}$ & & $\mathrm{x}$ \\
\hline TD-060 & $11 / 9$ & 02:08 & AVL & 176 & 39.817592 & -121.591940 & $A V L$ & TD & $\begin{array}{l}\text { fire around us, burning in eaves of Donut shop; } \\
\text { unsavable }\end{array}$ & C & & \\
\hline TD-041 & $11 / 9$ & 02:09 & Photo & 0 & 39.818850 & -121.591692 & Photo & Photo & spot fire in parking lot vegetation & $\mathrm{s}$ & & \\
\hline TD-084 & $11 / 9$ & 02:10 & $\mathrm{AVL}$ & 174 & 39.817442 & -121.591647 & TD & TD & fire threatening structures & 0 & & \\
\hline TD-209 & $11 / 9$ & 02:11 & Photo & 0 & 39.820144 & -121.591938 & Photo & Photo & well-established vegetation fire & $\mathrm{v}$ & & \\
\hline TD-041 & $11 / 9$ & $02: 20$ & Photo & 0 & 39.819911 & -121.592060 & Photo & Photo & fire threatening structures & $\mathrm{v}$ & & \\
\hline TD-127 & $11 / 9$ & $02: 23$ & Photo & 0 & 39.817277 & -121.591326 & Photo & Photo & large flames from structure or torching trees & 0 & & \\
\hline TD-041 & $11 / 9$ & $02: 24$ & Photo & 0 & 39.818128 & -121.592764 & Photo & Photo & well established fire; possibly structures burning & 0 & & \\
\hline TD-041 & $11 / 9$ & $02: 28$ & Photo & 0 & 39.820144 & -121.591938 & Photo & Photo & well-established vegetation fire & $\mathrm{v}$ & & \\
\hline TD-041 & $11 / 9$ & 02:30 & TD & 60 & 39.806540 & -121.602037 & TD & TD & $\begin{array}{l}\text { sounds like war zone with explosions; fire came into W } \\
\text { Park area toward Pine Ridge School from east and south }\end{array}$ & $v$ & & \\
\hline TD-143 & $11 / 9$ & 02:30 & TD & 0 & 39.819394 & -121.590539 & TD & TD & fire approaching structure & $\mathrm{v}$ & & \\
\hline TD-041 & $11 / 9$ & $02: 36$ & Photo & 0 & 39.820266 & -121.592884 & Photo & Photo & well-established vegetation fire & v & & \\
\hline TD-127 & $11 / 9$ & 02:41 & Photo & 0 & 39.816879 & -121.592792 & Photo & Photo & structures fully involved; propane tanks venting & $\mathrm{R}$ & & \\
\hline TD-123 & $11 / 9$ & $02: 44$ & $\mathrm{AVL}$ & 0 & 39.820120 & -121.592755 & $A V L$ & TD & everything on fire & 0 & & \\
\hline TD-124 & $11 / 9$ & $02: 45$ & AVL & 0 & 39.823850 & -121.590583 & $A V L$ & TD & fire on both sides of Dogtown Rd & $\mathrm{v}$ & & \\
\hline TD-041 & $11 / 9$ & 02:51 & Photo & 0 & 39.820252 & -121.593127 & Photo & Photo & $\begin{array}{l}\text { heavy fire on parcel; vegetation, structure, fully } \\
\text { involved }\end{array}$ & $\mathrm{R}$ & & \\
\hline TD-123 & $11 / 9$ & 02:55 & $A V L$ & 73 & 39.822098 & -121.600180 & AVL & TD & houses on fire, propane tanks exploding & $\mathrm{R}$ & & \\
\hline TD-127 & $11 / 9$ & 03:09 & Photo & 0 & 39.817290 & -121.591744 & Photo & Photo & structure fully involved & c & & \\
\hline
\end{tabular}




\begin{tabular}{|c|c|c|c|c|c|c|c|c|c|c|c|c|}
\hline \multicolumn{13}{|c|}{ Magalia and Coutolenc Road } \\
\hline Source \# & Date & Time & $\begin{array}{l}\text { Time } \\
\text { Source }\end{array}$ & $\begin{array}{c}\text { Obs } \\
\text { Window } \\
\text { (min) }\end{array}$ & Latitude & Longitude & $\begin{array}{l}\text { Location } \\
\text { Source }\end{array}$ & Info Source & Fire Behavior Observations & $\begin{array}{c}\text { Type } \\
\text { of } \\
\text { Fire }\end{array}$ & $\begin{array}{l}\text { Residual } \\
\text { Fire? }\end{array}$ & SSI \\
\hline TD-041 & $11 / 9$ & 03:20 & Photo & 0 & 39.819299 & -121.593102 & Photo & Photo & $\begin{array}{l}\text { fence burning, pine tree torching, right up against } \\
\text { structure }\end{array}$ & 0 & & \\
\hline TD-041 & $11 / 9$ & 03:22 & Photo & 0 & 39.819299 & -121.593102 & Photo & Photo & structure igniting on eaves from fence and pine tree & $\mathrm{R}$ & & \\
\hline TD-089 & $11 / 9$ & 03:29 & AVL & 97 & 39.805642 & -121.584355 & AVL & TD & fire threatening structures & V & & \\
\hline TD-087 & $11 / 9$ & 03:34 & AVL & 181 & 39.805625 & -121.584345 & AVL & TD & fire threatening structures & V & & \\
\hline TD-009 & $11 / 9$ & 03:38 & AVL & 9 & 39.816263 & -121.592633 & AVL & TD & active structure fires & $\mathrm{R}$ & & \\
\hline TD-045 & $11 / 9$ & 03:41 & AVL & 0 & 39.814356 & -121.584692 & AVL & TD & $\begin{array}{l}\text { Area near the dam is destroyed, homes along Skyway } \\
\text { fully involved }\end{array}$ & $\mathrm{R}$ & & \\
\hline TD-045 & $11 / 9$ & 03:46 & AVL & 14 & 39.817283 & -121.592250 & AVL & TD & Fire still intense in area & 0 & & \\
\hline TD-041 & $11 / 9$ & 03:51 & Photo & 0 & 39.820402 & -121.594622 & Photo & Photo & $\begin{array}{l}\text { multiple parcels, structures, vegetation, vehicles, wood } \\
\text { piles, all fully involved }\end{array}$ & $\mathrm{R}$ & & \\
\hline TD-045 & $11 / 9$ & 04:04 & AVL & 5 & 39.818283 & -121.594317 & AVL & $\mathrm{AVL}$ & fire threatening structures & 0 & & \\
\hline TD-045 & $11 / 9$ & $04: 11$ & AVL & 30 & 39.818383 & -121.596650 & AVL & $\begin{array}{l}\text { AVL, TD, } \\
\text { Inferred }\end{array}$ & fire threatening structures & 0 & & \\
\hline TD-045 & $11 / 9$ & $04: 50$ & AVL & 5 & 39.818933 & -121.593550 & AVL & AVL & fire threatening structures & 0 & & \\
\hline TD-123 & $11 / 9$ & $04: 58$ & AVL & 44 & 39.814650 & -121.600083 & AVL & TD & fire threatening structures & 0 & & \\
\hline TD-124 & $11 / 9$ & 05:01 & AVL & 41 & 39.814383 & -121.599867 & AVL & TD & fire threatening structures & 0 & & \\
\hline TD-079 & $11 / 9$ & $05: 14$ & AVL & 209 & 39.805047 & -121.584566 & $\mathrm{AVL}$ & TD & $\begin{array}{l}\text { fire creeping up from canyon. Fire behavior had } \\
\text { reduced; just residual fire from before }\end{array}$ & v & & \\
\hline TD-089 & $11 / 9$ & $05: 15$ & AVL & 36 & 39.822211 & -121.594354 & AVL & TD & fire threatening structures & 0 & & \\
\hline TD-041 & $11 / 9$ & $05: 37$ & Photo & 0 & 39.823670 & -121.595660 & Photo & Photo & $\begin{array}{l}\text { structure fully involved, past peak; parcel mostly done } \\
\text { burning }\end{array}$ & $\mathrm{R}$ & & \\
\hline TD-041 & $11 / 9$ & 05:37 & Photo & 0 & 39.823412 & -121.594865 & Photo & Photo & $\begin{array}{l}\text { structure fully involved; detached garage/shed burned } \\
\text { to ground }\end{array}$ & $\mathrm{R}$ & & \\
\hline TD-084 & $11 / 9$ & 05:38 & AVL & 128 & 39.825109 & -121.597752 & AVL & TD & mobile home vinyl melting & $\mathrm{R}$ & & \\
\hline TD-084 & $11 / 9$ & $05: 38$ & AVL & 128 & 39.825782 & -121.596645 & AVL & TD & homes on fire & $\mathrm{R}$ & & \\
\hline TD-084 & $11 / 9$ & $05: 38$ & AVL & 128 & 39.825786 & -121.597587 & AVL & TD & house, needles on roof ignite & $\mathrm{R}$ & & \\
\hline TD-084 & $11 / 9$ & $05: 38$ & AVL & 128 & 39.822694 & -121.603184 & TD & TD & fire threatening structures & 0 & & \\
\hline TD-045 & $11 / 9$ & 05:41 & AVL & 63 & 39.817383 & -121.597117 & AVL & $\begin{array}{l}\text { AVL, TD, } \\
\text { Inferred }\end{array}$ & fire threatening structures & 0 & & \\
\hline TD-060 & $11 / 9$ & $05: 45$ & $\mathrm{AVL}$ & 78 & 39.825369 & -121.597549 & $\mathrm{AVL}$ & TD & fire threatening structures & 0 & & \\
\hline TD-127 & $11 / 9$ & $05: 52$ & Photo & 0 & 39.816839 & -121.598021 & Photo & Photo & $\begin{array}{l}\text { all structures north of Ponderosa; intense flaming, } \\
\text { burned to ground }\end{array}$ & C & & \\
\hline TD-209 & $11 / 9$ & $05: 59$ & Photo & 0 & 39.815479 & -121.600513 & Photo & Photo & structure fully involved & $\mathrm{R}$ & & \\
\hline TD-209 & $11 / 9$ & $06: 00$ & AVL & 5 & 39.815816 & -121.600570 & AVL & TD & houses engulfed; intense fire & $\mathrm{R}$ & & \\
\hline TD-209 & $11 / 9$ & $06: 00$ & AVL & 5 & 39.815590 & -121.600796 & AVL & TD & 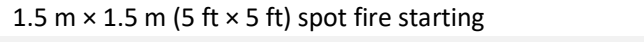 & S & & \\
\hline TD-209 & $11 / 9$ & $06: 00$ & AVL & 5 & 39.815590 & -121.600796 & AVL & TD & propane tank explodes & 0 & & \\
\hline
\end{tabular}




\begin{tabular}{|c|c|c|c|c|c|c|c|c|c|c|c|c|}
\hline \multicolumn{13}{|c|}{ Magalia and Coutolenc Road } \\
\hline & & & & Obs & & & & & & Type & & \\
\hline Source \# & Date & Time & $\begin{array}{l}\text { Time } \\
\text { Source }\end{array}$ & $\begin{array}{l}\text { Window } \\
\text { (min) }\end{array}$ & Latitude & Longitude & $\begin{array}{c}\text { Location } \\
\text { Source }\end{array}$ & Info Source & Fire Behavior Observations & $\begin{array}{c}\text { of } \\
\text { Fire }\end{array}$ & $\begin{array}{l}\text { Residual } \\
\text { Fire? }\end{array}$ & SSI \\
\hline TD-127 & $11 / 9$ & 06:00 & AVL TD-209 & 0 & 39.815590 & -121.600796 & AVL TD-209 & TD & fuel BLEVE & 0 & & \\
\hline TD-123 & $11 / 9$ & $06: 21$ & $\mathrm{AVL}$ & 374 & 39.843081 & -121.585436 & TD & TD & fire making run toward houses in Rosewood Dr area & $\mathrm{v}$ & & \\
\hline TD-124 & $11 / 9$ & $06: 30$ & AVL & 366 & 39.847069 & -121.584623 & AVL & TD & embers are still falling & 0 & & \\
\hline TD-087 & $11 / 9$ & 06:47 & AVL & 115 & 39.844457 & -121.583907 & TD & TD & $\begin{array}{l}\text { Fire creeping on side hill below streets. Multiple wood } \\
\text { pile fires }\end{array}$ & $\mathrm{v}$ & & \\
\hline TD-087 & $11 / 9$ & $06: 47$ & AVL & 115 & 39.846615 & -121.585351 & AVL & TD & fire threatening structures, woodpiles burning & 0 & & \\
\hline TD-128 & $11 / 9$ & 06:57 & Photo & 0 & 39.815019 & -121.601170 & Photo & Photo & fire & 0 & & \\
\hline TD-128 & $11 / 9$ & $06: 57$ & Photo & 0 & 39.815026 & -121.601606 & Photo & Photo & fence and vegetation burning & 0 & & \\
\hline TD-128 & $11 / 9$ & $06: 57$ & Photo & 0 & 39.815659 & -121.601912 & Photo & Photo & structure fully involved & $\mathrm{R}$ & & \\
\hline TD-128 & $11 / 9$ & $06: 57$ & Photo & 0 & 39.815426 & -121.601728 & Photo & Photo & structure fully involved & $\mathrm{R}$ & & \\
\hline TD-041 & $11 / 9$ & 07:00 & TD & 180 & 39.825494 & -121.596972 & TD & TD & intense fire activity; like furnace & 0 & & \\
\hline TD-064 & $11 / 9$ & 07:00 & TD & 30 & 39.807898 & -121.603846 & TD & TD & $\begin{array}{l}\text { houses burned down, some still burning; W Park } \\
\text { Dr/Ferguson Dr/Pueblo Dr loop }\end{array}$ & $\mathrm{R}$ & & \\
\hline TD-064 & $11 / 9$ & 07:00 & TD & 30 & 39.804668 & -121.599371 & TD & TD & intense burning, cannot pass due to fire & 0 & & \\
\hline TD-128 & $11 / 9$ & 07:05 & Photo & 0 & 39.815119 & -121.601366 & Photo & Photo & significant fire burning behind structure & 0 & & \\
\hline TD-060 & $11 / 9$ & 07:07 & $\mathrm{AVL}$ & 29 & 39.823059 & -121.600530 & AVL & TD & fire threatening structures & 0 & & \\
\hline TD-205 & $11 / 9$ & 07:09 & AVL & 2 & 39.816054 & -121.598818 & AVL & TD & Fire in crown on both sides of road & v & & \\
\hline TD-127 & $11 / 9$ & 07:10 & Inferred & 0 & 39.812606 & -121.597612 & TD & TD & $\begin{array}{l}\text { fire is flanking through S Park Dr area toward Pine Ridge } \\
\text { School }\end{array}$ & 0 & & \\
\hline TD-202 & $11 / 9$ & 07:20 & AVL & 4 & 39.813976 & -121.603160 & AVL & TD & $\begin{array}{l}\text { drove through serious fire to get to safety of Pine Ridge } \\
\text { School }\end{array}$ & 0 & & \\
\hline TD-128 & $11 / 9$ & 07:20 & AVL & 0 & 39.813992 & -121.603197 & AVL & TD & fire blowing across Compton Dr from west & v & & \\
\hline TD-127 & $11 / 9$ & 07:20 & Inferred & 0 & 39.812994 & -121.598349 & TD & TD & fire hits Pine Ridge School from the east & $\mathrm{v}$ & & \\
\hline TD-127 & $11 / 9$ & $07: 20$ & Inferred & 0 & 39.814422 & -121.604598 & TD & TD & fire coming into Ponderosa Dr from south & v & & \\
\hline TD-128 & $11 / 9$ & $07: 21$ & AVL & 84 & 39.813300 & -121.601309 & AVL & TD & 1 school building on fire, Pine Ridge School & C & & \\
\hline TD-207 & $11 / 9$ & $07: 23$ & AVL & 80 & 39.813000 & -121.600883 & AVL & TD & hotspots around Ponderosa Elementary School & 0 & $x$ & \\
\hline TD-205 & $11 / 9$ & $07: 24$ & AVL & 80 & 39.813333 & -121.600983 & AVL & TD & fire is surrounding the Pine Ridge School & 0 & & \\
\hline TD-205 & $11 / 9$ & $07: 24$ & AVL & 80 & 39.814391 & -121.603115 & AVL & TD & intense fire on north side of Pine Ridge School property & 0 & & \\
\hline TD-200 & $11 / 9$ & $07: 24$ & AVL & 80 & 39.812291 & -121.599922 & AVL & TD & fire coming hard & v & & \\
\hline TD-205 & $11 / 9$ & 07:32 & AVL & 20 & 39.813250 & -121.599966 & AVL & TD & $\begin{array}{l}\text { Pine Ridge School: portable classrooms are smoldering } \\
\text { and starting to ignite on corners }\end{array}$ & C & & \\
\hline TD-041 & $11 / 9$ & 07:46 & Photo & 0 & 39.814910 & -121.602640 & Photo & Photo & structure fully involved & $\mathrm{R}$ & & \\
\hline TD-205 & $11 / 9$ & 08:02 & AVL & 0 & 39.814416 & -121.603962 & AVL & TD & saw structures on Ponderosa igniting & $\mathrm{R}$ & & \\
\hline TD-041 & $11 / 9$ & $08: 18$ & Photo & 0 & 39.817729 & -121.602227 & Photo & Photo & structure fully involved & $\mathrm{R}$ & & \\
\hline TD-203 & $11 / 9$ & 09:33 & $\mathrm{AVL}$ & 8 & 39.815339 & -121.600087 & AVL & TD & all homes on Ponderosa Dr are engulfed & $\mathrm{R}$ & & \\
\hline TD-200 & $11 / 9$ & 09:40 & TD & 41 & 39.817395 & -121.605794 & TD & TD & fire too intense, everything engulfed & 0 & & \\
\hline TD-200 & $11 / 9$ & 09:44 & AVL & 16 & 39.815800 & -121.605350 & AVL & TD & propane tanks exploding; houses fully involved & $\mathrm{R}$ & & \\
\hline
\end{tabular}




\begin{tabular}{|c|c|c|c|c|c|c|c|c|c|c|c|c|}
\hline \multicolumn{13}{|c|}{ Magalia and Coutolenc Road } \\
\hline Source \# & Date & Time & $\begin{array}{l}\text { Time } \\
\text { Source }\end{array}$ & $\begin{array}{c}\text { Obs } \\
\text { Window } \\
\text { (min) }\end{array}$ & Latitude & Longitude & $\begin{array}{l}\text { Location } \\
\text { Source }\end{array}$ & Info Source & Fire Behavior Observations & $\begin{array}{c}\text { Type } \\
\text { of } \\
\text { Fire }\end{array}$ & $\begin{array}{l}\text { Residual } \\
\text { Fire? }\end{array}$ & SSI \\
\hline TD-205 & $11 / 9$ & 09:46 & video & 0 & 39.818750 & -121.596648 & AVL & video & $\begin{array}{l}\text { all structures on east side of Pineland Cir loop are } \\
\text { thoroughly burned down already }\end{array}$ & $\mathrm{R}$ & $x$ & \\
\hline TD-205 & $11 / 9$ & 09:46 & Photo & 0 & 39.818725 & -121.596641 & Photo & Photo & $\begin{array}{l}\text { all structures burned to foundation, minimal flaming } \\
\text { rubble }\end{array}$ & $\mathrm{R}$ & $\mathrm{x}$ & \\
\hline TD-200 & $11 / 9$ & $10: 21$ & AVL & 15 & 39.815617 & -121.605350 & AVL & TD & fire threatening to burn entire block & 0 & & \\
\hline TD-205 & $11 / 9$ & $10: 40$ & AVL & 0 & 39.814725 & -121.606477 & AVL & TD & Ponderosa Dr all on fire / houses burned down. & $\mathrm{R}$ & $\mathrm{x}$ & \\
\hline TD-205 & $11 / 9$ & $11: 15$ & AVL & 19 & 39.816778 & -121.609948 & AVL & TD & structure previously ignited/damaged & $\mathrm{R}$ & $\mathrm{x}$ & \\
\hline TD-205 & $11 / 9$ & $11: 15$ & AVL & 19 & 39.816613 & -121.609884 & TD & TD & house is burning & $\mathrm{R}$ & & \\
\hline TD-205 & $11 / 9$ & $11: 34$ & Photo & 0 & 39.816610 & -121.609938 & Photo & Photo & $\begin{array}{l}\text { structure collapsed, flaming; small vegetation spot fires } \\
\text { scattered around }\end{array}$ & $\mathrm{R}$ & $\mathrm{x}$ & \\
\hline TD-205 & $11 / 9$ & 11:57 & video & 51 & 39.816533 & -121.609500 & video & video & several structures fully involved & $\mathrm{R}$ & & \\
\hline TD-205 & $11 / 9$ & $11: 57$ & Photo & 0 & 39.816270 & -121.609521 & Photo & Photo & structure fully involved & $\mathrm{R}$ & & \\
\hline TD-207 & $11 / 9$ & $11: 58$ & AVL & 66 & 39.817467 & -121.608633 & AVL & TD & fire threatening structure & 0 & & \\
\hline TD-207 & $11 / 9$ & $11: 58$ & Photo & 0 & 39.816407 & -121.609367 & Photo & Photo & $\begin{array}{l}\text { multiple structures around fully involved or collapsed; } \\
\text { fire threatening surviving structure }\end{array}$ & $\mathrm{R}$ & & \\
\hline TD-128 & $11 / 9$ & $12: 00$ & Photo & 0 & 39.817941 & -121.608074 & Photo & Photo & multiple structures at end of cul-de-sac are burning & $\mathrm{R}$ & & \\
\hline TD-128 & $11 / 9$ & $12: 00$ & Photo & 0 & 39.817617 & -121.608670 & Photo & Photo & fire & 0 & & \\
\hline TD-205 & $11 / 9$ & $12: 36$ & Photo & 0 & 39.815972 & -121.608981 & Photo & Photo & structure fully involved & $\mathrm{R}$ & & \\
\hline TD-205 & $11 / 9$ & $12: 36$ & Photo & 0 & 39.816105 & -121.609292 & Photo & Photo & structure fully involved; propane/fuel tank venting & $\mathrm{R}$ & & \\
\hline TD-205 & $11 / 9$ & $12: 37$ & Photo & 0 & 39.816105 & -121.609292 & Photo & Photo & propane tank venting & 0 & & \\
\hline TD-207 & $11 / 9$ & 13:09 & $\mathrm{AVL}$ & 49 & 39.816967 & -121.609850 & $\mathrm{AVL}$ & TD & fire threatening structure & 0 & & \\
\hline TD-205 & $11 / 9$ & $13: 45$ & AVL & 14 & 39.816533 & -121.609500 & AVL & TD & fire threatening structures & 0 & & \\
\hline TD-207 & $11 / 9$ & 13:59 & AVL & 22 & 39.817200 & -121.609383 & AVL & TD & fire threatening structure & 0 & & \\
\hline TD-128 & $11 / 9$ & $14: 14$ & Photo & 0 & 39.817973 & -121.608184 & Photo & Photo & structures on Stetson Ct igniting & $\mathrm{R}$ & & \\
\hline TD-128 & $11 / 9$ & $14: 14$ & Photo & 0 & 39.817873 & -121.608503 & Photo & Photo & $\begin{array}{l}\text { structure ignited, fire becoming well established on } \\
\text { structure }\end{array}$ & $\mathrm{R}$ & & \\
\hline TD-128 & $11 / 9$ & $14: 14$ & Photo & 0 & 39.818227 & -121.607792 & Photo & Photo & $\begin{array}{l}\text { structure ignited, fire becoming well established on } \\
\text { structure }\end{array}$ & $\mathrm{R}$ & & \\
\hline TD-128 & $11 / 9$ & $14: 14$ & Photo & 0 & 39.818099 & -121.608342 & Photo & Photo & structure burning & $\mathrm{R}$ & & \\
\hline TD-128 & $11 / 9$ & $14: 14$ & Photo & 0 & 39.818250 & -121.608145 & Photo & Photo & structure burning & $\mathrm{R}$ & & \\
\hline TD-207 & $11 / 9$ & $14: 50$ & $\mathrm{AVL}$ & 70 & 39.817550 & -121.608567 & AVL & TD & fire threatening structure & 0 & & \\
\hline TD-205 & $11 / 9$ & $15: 26$ & AVL & 49 & 39.820177 & -121.604178 & AVL & $\begin{array}{l}\text { AVL, TD, } \\
\text { Inferred }\end{array}$ & fire threatening structures & 0 & & \\
\hline TD-205 & $11 / 9$ & $16: 23$ & AVL & 17 & 39.816533 & -121.609500 & AVL & TD & fire threatening structures & 0 & & \\
\hline TD-207 & $11 / 9$ & $16: 28$ & AVL & 101 & 39.816883 & -121.609867 & AVL & TD & fire threatening structure & 0 & & \\
\hline TD-205 & $11 / 9$ & $16: 55$ & AVL & 98 & 39.817400 & -121.607283 & AVL & $\begin{array}{l}\text { AVL, TD, } \\
\text { Inferred }\end{array}$ & fire threatening structures & 0 & & \\
\hline
\end{tabular}




\begin{tabular}{|c|c|c|c|c|c|c|c|c|c|c|c|c|}
\hline \multicolumn{13}{|c|}{ Magalia and Coutolenc Road } \\
\hline Source \# & Date & Time & $\begin{array}{l}\text { Time } \\
\text { Source }\end{array}$ & $\begin{array}{c}\text { Obs } \\
\text { Window } \\
\text { (min) }\end{array}$ & Latitude & Longitude & $\begin{array}{l}\text { Location } \\
\text { Source }\end{array}$ & Info Source & Fire Behavior Observations & $\begin{array}{c}\text { Type } \\
\text { of } \\
\text { Fire }\end{array}$ & $\begin{array}{l}\text { Residual } \\
\text { Fire? }\end{array}$ & SSI \\
\hline TD-207 & $11 / 9$ & $18: 15$ & AVL & 24 & 39.815650 & -121.605467 & AVL & TD & structure had burnt deck & $\mathrm{R}$ & $\mathrm{x}$ & \\
\hline TD-205 & $11 / 9$ & 19:40 & AVL & 73 & 39.816533 & -121.609500 & AVL & TD & fire threatening structures & 0 & & \\
\hline TD-082 & $11 / 9$ & & TD & 0 & 39.822323 & -121.607479 & TD & TD & structure fully involved & $\mathrm{R}$ & & \\
\hline TD-082 & $11 / 9$ & & TD & 0 & 39.821598 & -121.607799 & TD & TD & fire threatening structures & 0 & & \\
\hline TD-082 & $11 / 9$ & & TD & 0 & 39.821598 & -121.607799 & TD & TD & fire threatening structures & 0 & & \\
\hline
\end{tabular}




\section{Appendix G. Technical Discussion Comments}

Technical discussions often included statements or comments about the incident or WUI fire in general that were not directly related to establishing the incident timeline or linked to a specific observation. The comments came from a broad range of perspectives and contain a plethora of valuable observations from a range of different first responders.

The comments are included here as transcribed from the TD and include estimates of distances or lengths, generalized comments, and personal opinions.

The following are the ten categories used to sort the TD comments. Keywords were further used in each category to organize the TD comments.

1. Pre-Planning/Mitigation: efforts that are taken pre- or post-event to limit the loss of life and property in the event of a disaster. This includes egress, mitigation, notification, planning, and regulations.

2. Pre-Fire Hazard: any type of hazard that exists prior to and contributed to the wildfire event. This primarily consists of vegetation and fuel loads.

3. Fire Behavior: the way fuel ignites, flames develop, and fire spreads, including other related interactions of weather, topography, and fuels. This category includes but is not limited to ambient conditions, embers, flames, fire history, and vegetation.

4. Evacuation/ Notifications: protective actions in an emergency to help save lives of residents and first responders, for example by encouraging evacuations and limiting access to potentially dangerous or affected areas. This includes safety zones, planning, notifications, practice drills, egress, contraflow, hazards, and special needs.

5. Response: strategies of monitoring, confining, containing, point protection, and suppression in response to controlling a wildfire. This includes but is not limited to fire conditions, crews, firing methods, equipment, hazards, suppression, training, and water supply.

6. Operations: execution of a given set of tactical actions for containing/controlling a wildfire during the incident. This includes communication, coordination, equipment, resources related to needs, and availability.

7. High-Level/Other Agencies: coordination and mitigation efforts among federal, state, and local agencies. This includes but is not limited to multi-agency involvement or needs, coordination efforts, communications, and resource availability.

8. Equipment: equipment and personnel focusing on the use of specialized equipment, training, and tactics to effectively control, surround and eventually extinguish a wildfire.

9. Training: focused on quality of training, additional training needs, and equipment related to issues and preparedness throughout the event.

10. Other Responses: important comments that do not fall into the other nine categories. 
The following tables include TD comments related to Pre-Planning/Mitigation (Table 39), Pre-Fire Hazard (Table 40), and Fire Behavior (Table 41) as they relate to the fire progression theme presented in this report. The remaining categories will be presented within the relevant NIST Camp Fire report. 
Table 39. Pre-Planning/Mitigation Comments.

\begin{tabular}{|c|c|c|}
\hline TD & Keyword & Comments \\
\hline TD-084 & research & urban sprawl into areas with fire history \\
\hline TD-104 & resources & $\begin{array}{l}\text { need to provide more resources to both forest service and fire } \\
\text { prevention/mitigation; I would pay } \$ 100+\text { more in property tax } \\
\text { to support FD }\end{array}$ \\
\hline TD-128 & TRA & $\begin{array}{l}\text { Temporary Refuge Areas (TRAs) worked as they were } \\
\text { supposed to }\end{array}$ \\
\hline TD-055 & TRA & $\begin{array}{l}\text { TRAs were a plus, but concerned about where discussion is } \\
\text { going. Pre-planned TRA is not ideal, it was last resort in this } \\
\text { incident because so many people out on foot }\end{array}$ \\
\hline TD-055 & TRA & TRA is not a substitute for evacuation \\
\hline TD-085 & TRA & $\begin{array}{l}\text { big beneficial lesson = TRAs; saved hundreds to thousands; } \\
\text { make sure people know to get to them }\end{array}$ \\
\hline TD-074 & utilities & underground electric would be good \\
\hline TD-014 & utilities & underground utilities \\
\hline TD-017 & utilities & $\begin{array}{l}\text { underground power lines would be good; benefits would be } \\
\text { evacuations, trapped people, accessibility to locations and } \\
\text { reduced ignitions. }\end{array}$ \\
\hline TD-017 & vegetation & $\begin{array}{l}\text { roadway prep brush removal or grass buffer to remove roadside } \\
\text { flame impingement on traffic }\end{array}$ \\
\hline TD-017 & vegetation & $\begin{array}{l}\text { dry annual grass buildup along roadways. They're doing all this } \\
\text { work to upgrade Clark Rd but [they're] going to plant dry } \\
\text { annual grass along for erosion control that no one is going to } \\
\text { maintain/clear }\end{array}$ \\
\hline TD-017 & vegetation & $\begin{array}{l}\text { rural residents must be aware of fuel requirements for } \\
\text { protracted/extended evacuations }\end{array}$ \\
\hline TD-008 & vegetation & $\begin{array}{l}\text { brush grows back faster than new conifers, so untreated growth } \\
\text { since previous fires results in very heavy brush, too dense for } \\
\text { dozers }\end{array}$ \\
\hline TD-008 & vegetation & $\begin{array}{l}\text { Area around Concow is experiencing fuel-type conversion: } \\
\text { changing from timber to brush. Reentry of fire in high country } \\
\text { is preventing regrowth of conifers. }\end{array}$ \\
\hline TD-008 & vegetation & $\begin{array}{l}\text { Current landscape-level planning Butte county-wide all } \\
\text { interconnects: beginning to connect fuel breaks (extensive } \\
\text { county-wide fuel management projects) }\end{array}$ \\
\hline TD-084 & vegetation & $\begin{array}{l}\text { behind on vegetation management- }- \text { fire is probably the way to } \\
\text { keep up, but there are houses and people in between }\end{array}$ \\
\hline TD-084 & vegetation & $\begin{array}{l}\text { vegetation around house is a liability - but you want the veg for } \\
\text { appearance }\end{array}$ \\
\hline TD-090 & vegetation & $\begin{array}{l}\text { 1970s-80s.... Environmentalists protested logging and shut it } \\
\text { down; responsible logging would have resulted in significant } \\
\text { amounts of fuel removal and reduced fire intensity }\end{array}$ \\
\hline TD-090 & vegetation & you cannot control the wind, but you can reduce fuel loading \\
\hline
\end{tabular}




\begin{tabular}{|c|c|c|}
\hline TD & Keyword & Comments \\
\hline TD-090 & vegetation & $\begin{array}{l}\text { millions of board-feet of wood have gone to waste due to } \\
\text { disease, now it is fuel ready to burn }\end{array}$ \\
\hline TD-088 & vegetation & $\begin{array}{l}\text { dozers are portrayed as the devil regarding environmental } \\
\text { impact }\end{array}$ \\
\hline TD-211 & vegetation & need more fuel management \\
\hline TD-202 & vegetation & vegetation management not very good \\
\hline TD-069 & vegetation & $\begin{array}{l}\text { in previous generations Paradise was not as forested; there } \\
\text { should be regulations regarding vegetation in town }\end{array}$ \\
\hline TD-084 & vegetation & $\begin{array}{l}\text { fuel treatments worked when fire behavior / wind reduced on } \\
\text { day 2; understory and ladder fuel removal project ( } 3 \text { year } \\
\text { project) completed } 5 \text { years ago; shaded fuel break [Magalia, } \\
39.835482,-121.584838 \text {, TD-084-27] }\end{array}$ \\
\hline TD-104 & vegetation & need to clear vegetation along roadways \\
\hline TD-087 & vegetation & $\begin{array}{l}\text { unless more fuels projects are enacted CA climate going to } \\
\text { have more of these events }\end{array}$ \\
\hline TD-090 & vegetation & $\begin{array}{l}\text { the state needs to look at regulations to enforce fuel clearing } \\
\text { around homes }\end{array}$ \\
\hline TD-014 & vegetation & Road clearance of vegetation to avoid vehicle impingement \\
\hline TD-033 & vegetation & $\begin{array}{l}\text { need better vegetation fuel breaks off the roadways; roads were } \\
\text { not safe because of vegetation proximity }\end{array}$ \\
\hline TD-114 & vegetation & it's not that homes are too close, there is too much vegetation \\
\hline TD-090 & vegetation & $\begin{array}{l}\text { lots of environmental restrictions prevent vegetative fuel } \\
\text { management efforts }\end{array}$ \\
\hline TD-087 & vegetation & don't like the knee jerk reaction now for fuel management \\
\hline TD-127 & water & $\begin{array}{l}\text { protecting a parcel is a multi-faceted endeavor; power } \\
\text { generation, pumps and sprinklers for water, filling gutters with } \\
\text { water (plugs), landscape management, including live animals } \\
\text { for grazing }\end{array}$ \\
\hline TD-041 & water & $\begin{array}{l}\text { need built-in water testing, air testing, and new air filters } \\
\text { (station and on engines) are needed immediately at locations } \\
\text { that are still staffed; this lesson seems to be re-learned after } \\
\text { every fire event }\end{array}$ \\
\hline TD-143 & water & Del Oro system is on wells connected to PID by pipeline \\
\hline TD-143 & water & $\begin{array}{l}\text { all Del Oro tanks were topped off to within } 0.6 \mathrm{~m}(2 \mathrm{ft}) \text { from } \\
\text { the top before the fire }\end{array}$ \\
\hline TD-143 & water & $\begin{array}{l}\text { It was over a month before PID flushed their system; Del Oro } \\
\text { started flushing very soon }\end{array}$ \\
\hline TD-015 & WUI & $\begin{array}{l}\text { all existing infrastructure in county WUI areas is not adequate } \\
\text { for WUI }\end{array}$ \\
\hline TD-015 & WUI & $\begin{array}{l}\text { need a WUI "design fire" to evaluate worst case scenario for } \\
\text { preparedness and design }\end{array}$ \\
\hline
\end{tabular}


Table 40. Pre-Fire Hazard Comments.

\begin{tabular}{|c|c|c|}
\hline TD & Keyword & Comments \\
\hline TD-206 & clearance & 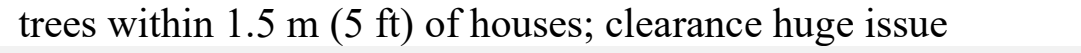 \\
\hline TD-011 & conditions & $\begin{array}{l}\text { if it was plastic...it melted; } 6 \text { major culverts (diameter of } 1.2 \mathrm{~m} \\
(48 \text { in)) plus } 60 \text { to } 100 \text { minor culverts }\end{array}$ \\
\hline TD-206 & $\begin{array}{l}\text { defensible } \\
\text { space }\end{array}$ & $\begin{array}{l}\text { domino effect from house to house; clearance huge issue ( } 3 \mathrm{~m} \\
\text { to } 6 \mathrm{~m}(10 \mathrm{ft} \text { to } 20 \mathrm{ft}) \text { between houses })\end{array}$ \\
\hline TD-015 & egress & long twisty roads as main travel routes \\
\hline TD-008 & embers & $\begin{array}{l}\text { Super dense continuous brush, } 2008 \text { fires put } 1000-\mathrm{hr} \text { fuels on } \\
\text { the ground contributing to long-range spotting }\end{array}$ \\
\hline TD-127 & fences & plastic fence slats burning \\
\hline TD-113 & fuel model & $\begin{array}{l}\text { typical California fuel model; extremely overgrown, thick, } \\
\text { cannot walk through it }\end{array}$ \\
\hline TD-035 & infrastructure & culverts under road burned all the way through \\
\hline TD-036 & infrastructure & $\begin{array}{l}\text { hundreds of plastic culverts burned out; both } 1.5 \mathrm{~m}(5 \mathrm{ft}) \text { and } \\
0.9 \mathrm{~m}(3 \mathrm{ft}) \text { diameters }\end{array}$ \\
\hline TD-036 & infrastructure & $\begin{array}{l}\text { culvert burned, including plastic } 413 \mathrm{kPa} \text { ( } 60 \mathrm{psi}) \text { gas line } \\
\text { inside - caused jet flame }\end{array}$ \\
\hline TD-017 & inspection & $\begin{array}{l}\text { ters in poorly maintained cars; need } \\
\text { on }\end{array}$ \\
\hline TD-123 & pine needles & dles and fuels away from houses \\
\hline TD-206 & pine needles & $\begin{array}{l}\text { ood siding, } 7 \mathrm{~cm} \text { to } 10 \mathrm{~cm} \text { ( } 3 \text { in to } 4 \mathrm{in} \text { ) } \\
\text { of }\end{array}$ \\
\hline TD-087 & pine needles & pine needles ignite structure and then structure takes off \\
\hline TD-016 & pine needles & $\begin{array}{l}\text { extensive needle cast, piles of needles eddying on decks, } \\
\text { gathering in roof valleys }\end{array}$ \\
\hline TD-079 & regulation & $\begin{array}{l}\text { neighborhood was super bushy, lots of trees, lack of } \\
\text { maintenance. Trees conducting fire to homes made it hard; } \\
\text { maintenance would have made big difference }\end{array}$ \\
\hline TD-084 & research & urban sprawl into areas with fire history \\
\hline TD-045 & $\mathrm{s}$ & \\
\hline TD-091 & et: & \\
\hline TD-017 & vegetation & \\
\hline TD-008 & vegetation & $\begin{array}{l}\text { extreme loading of } 1000-\mathrm{hr} \text { fuels. Estimated } 2.24 \mathrm{~kg} / \mathrm{m}^{2} \text { to } \\
3.36 \mathrm{~kg} / \mathrm{m}^{2}(10 \text { ton } / \text { ac to } 15 \text { ton } / \mathrm{ac} \text { ), estimated } 125 \% \text { timber } \\
\text { overstock. }\end{array}$ \\
\hline TD-045 & vegetati & pine needle drop a few days before and \\
\hline TD-090 & vegetation & $\begin{array}{l}\text { edles; lots of fuel - noticing thick ground fuels } \\
\text { n fires }\end{array}$ \\
\hline TD-128 & vegetation & \\
\hline TD-201 & vegetation & $\begin{array}{l}\text { 3...Station } 35 \text { was standing, covered with pine needles, } \\
\text { tters overflowing with needles from the wind prior to fire }\end{array}$ \\
\hline TD-035 & vegetatic & $\begin{array}{l}\text { Spring } 2018 \text { had lots of needle death; lots of Ponderosas in area } \\
\text { are diseased }\end{array}$ \\
\hline TD-127 & vegetation & too much fuel, overgrowth and dead timber \\
\hline
\end{tabular}




\begin{tabular}{|c|c|c|}
\hline TD & Keyword & Comments \\
\hline TD-023 & vegetation & $\begin{array}{l}0.9 \mathrm{~m} \text { to } 1.5 \mathrm{~m}(3 \mathrm{ft} \text { to } 5 \mathrm{ft}) \text { tall dead brown grass in orchard; } \\
\text { grass was mowed only at end of street }\end{array}$ \\
\hline TD-017 & vegetation & $\begin{array}{l}\text { dry annual grass buildup along roadways; they're doing all this } \\
\text { work to upgrade Clark Rd but they're going to plant dry annual } \\
\text { grass along for erosion control that no one is going to } \\
\text { maintain/clear }\end{array}$ \\
\hline TD-008 & vegetation & $\begin{array}{l}\text { brush grows back faster than new conifers, so untreated growth } \\
\text { since previous fires results in very heavy brush, too dense for } \\
\text { dozers }\end{array}$ \\
\hline TD-008 & vegetation & $\begin{array}{l}\text { area around Concow is experiencing fuel-type conversion: } \\
\text { changing from timber to brush; reentry of fire in high country } \\
\text { is preventing regrowth of conifers. }\end{array}$ \\
\hline TD-084 & vegetation & $\begin{array}{l}\text { vegetation around house is a liability - but you want the } \\
\text { vegetation for appearance }\end{array}$ \\
\hline TD-090 & vegetation & $\begin{array}{l}\text { 1970s-80s... Environmentalists protested logging and shut it } \\
\text { down; responsible logging would have resulted in significant } \\
\text { amounts of fuel removal and reduced fire intensity }\end{array}$ \\
\hline TD-090 & vegetation & you cannot control the wind, but you can reduce fuel loading \\
\hline TD-090 & vegetation & $\begin{array}{l}\text { millions of board-feet of wood have gone to waste due to } \\
\text { disease, now it is fuel ready to burn }\end{array}$ \\
\hline TD-014 & vegetation & road clearance of vegetation to avoid vehicle impingement \\
\hline TD-206 & visibility & visibility a big issue, especially with speed of incident \\
\hline TD-112 & wind & cleaned out gutters but the wind kept refilling them \\
\hline TD-035 & wind & $\begin{array}{l}\text { Pearson Rd; observed huge piles of needles deposited by wind; } \\
\text { needles piling against homes }\end{array}$ \\
\hline TD-127 & windows & plastic window frames melt and glass panes fall out \\
\hline
\end{tabular}


Table 41. Fire Behavior Comments.

\begin{tabular}{|c|c|c|}
\hline TD & Keyword & Comments \\
\hline TD-061 & conditions & underestimated fire behavior \\
\hline TD-012 & conditions & eerie still before the blow up \\
\hline TD-090 & conditions & extreme fire behavior; never saw anything like it \\
\hline TD-090 & conditions & complete blackness lasted about 10 minutes at a time \\
\hline TD-090 & conditions & $\begin{array}{l}\text { door handle on transport was hot to touch through gloves; } \\
\text { windows cracked from heat }\end{array}$ \\
\hline TD-006 & conditions & $\begin{array}{l}\text { visibility out of Chico [Airport] during most of event was } 0 \mathrm{~m} \\
\text { to } 400 \mathrm{~m}(0 \mathrm{mi} \text { to } 0.25 \mathrm{mi})\end{array}$ \\
\hline TD-006 & conditions & air attack was not very effective due to smoke and wind \\
\hline TD-203 & conditions & $\begin{array}{l}\text { fire moving so fast; had to reach into "toolbox" to come up with } \\
\text { creative ways to hold }\end{array}$ \\
\hline TD-203 & conditions & not much stopping fire on first night \\
\hline TD-011 & conditions & $\begin{array}{l}\text { if it was plastic...it melted; } 6 \text { major culverts (diameter } 1.2 \mathrm{~m} \\
\text { (48 in)) plus } 60 \text { to } 100 \text { minor culverts }\end{array}$ \\
\hline TD-076 & conditions & even with hours of notice, there still would have been casualties \\
\hline TD-022 & conditions & stopped being a vegetation fire when it hit Pentz Rd \\
\hline TD-113 & conditions & green vegetation was nuking \\
\hline TD-113 & conditions & felt like blow dryer right in the face \\
\hline TD-002 & conditions & $\begin{array}{l}\text { flames up to } 15 \mathrm{~m}(50 \mathrm{ft}) \text { high; } 22 \mathrm{~m} / \mathrm{s}(50 \mathrm{mi} / \mathrm{h}) \text { wind from } \\
\text { north; embers size of golf balls }\end{array}$ \\
\hline TD-090 & conditions & felt nothing could have been done to stop the fire \\
\hline TD-079 & conditions & ignition component near 100 \\
\hline TD-005 & conditions & $\begin{array}{l}\text { seemed like things became well involved or uncontrollable } \\
\text { faster than normal (all day long you see spot fire on roof, turn } \\
\text { around to get handline, turn back and structure is a quarter } \\
\text { involved. }\end{array}$ \\
\hline TD-014 & conditions & some areas were re-burned later in the day \\
\hline TD-017 & conditions & fuel, topography, and weather all aligned for this event. \\
\hline TD-113 & conditions & Poe Fire burned north during the day and south at night \\
\hline TD-056 & conditions & $\begin{array}{l}\text { visibility in Paradise was restricted, could see the bus in front } \\
\text { but not much further }\end{array}$ \\
\hline TD-020 & embers & $\begin{array}{l}\text { truck windshield broken by flying ember; dinner-plate-sized } \\
\text { chunk }\end{array}$ \\
\hline TD-014 & embers & embers were biggest issue. \\
\hline TD-017 & embers & $\begin{array}{l}\text { pine needles very susceptible to embers; there was significant } \\
\text { ember cast. }\end{array}$ \\
\hline TD-008 & embers & $\begin{array}{l}\text { super dense continuous brush, } 2008 \text { fires put } 1000 \text {-hr fuels on } \\
\text { the ground contributing to long-range spotting }\end{array}$ \\
\hline TD-087 & embers & quarter size ember showers \\
\hline TD-015 & embers & paper-sized embers landing in Chico (observed 19:00) \\
\hline TD-022 & embers & massive spotting, fire well established into vegetation \\
\hline
\end{tabular}




\begin{tabular}{|c|c|c|}
\hline TD & Keyword & Comments \\
\hline TD-022 & embers & after spotting, fire would back-fill into unburned areas \\
\hline TD-127 & embers & $\begin{array}{l}\text { only true fire front was overnight at Coutolenc, everything else } \\
\text { was spot fires }\end{array}$ \\
\hline TD-013 & embers & surprised by speed of initial growth of spot fires \\
\hline TD-027 & embers & fire spotting at least $400 \mathrm{~m}(0.25 \mathrm{mi})$ across Lake Oroville \\
\hline TD-110 & embers & ember wash from homes was heavy and long lasting \\
\hline TD-042 & embers & $\begin{array}{l}\text { spotty fire behavior allowed use of TRAs, unlike the Carr Fire } \\
\text { which was a wall of flame }\end{array}$ \\
\hline TD-002 & embers & $\begin{array}{l}\text { ember landed } 9 \mathrm{~m}(30 \mathrm{ft}) \text { up in tree and was glowing for } 2 \text { to } 3 \\
\text { days }\end{array}$ \\
\hline TD-026 & embers & glowing dime-sized embers landing on street as evacuating \\
\hline TD-026 & embers & pinecones catch fire and explode embers \\
\hline TD-006 & embers & $\begin{array}{l}\text { secondhand story: spot fire in juniper, went to get line, return } \\
\text { and fire had spread to attic and entire bush (on Merrill Ln) }\end{array}$ \\
\hline TD-063 & embers & some spot burns on the inside of vehicle from embers \\
\hline TD-100 & embers & spot fires could have been put out easily, all fires start small \\
\hline TD-014 & flames & $\begin{array}{l}91 \mathrm{~m}(300 \mathrm{ft}) \text { flame lengths burning out of the Honey Run } \\
\text { Canyon }\end{array}$ \\
\hline TD-008 & flames & $\begin{array}{l}\text { In Concow area, timber/brush } 3 \mathrm{~m} \text { to } 4.5 \mathrm{~m}(10 \mathrm{ft} \text { to } 15 \mathrm{ft}) \text { tall, } \\
18 \mathrm{~m} \text { to } 24 \mathrm{~m}(60 \mathrm{ft} \text { to } 80 \mathrm{ft}) \text { flames }\end{array}$ \\
\hline TD-079 & flames & $3 \mathrm{~m}$ to $4.5 \mathrm{~m}(10 \mathrm{ft}$ to $15 \mathrm{ft})$ flames laying to ground \\
\hline TD-084 & flames & $\begin{array}{l}\text { propane tanks exploding; } 150 \mathrm{~m}(500 \mathrm{ft}) \text { flame lengths } \\
\text { reigniting trees, fuels }\end{array}$ \\
\hline TD-084 & flames & $\begin{array}{l}90 \mathrm{~m}(300 \mathrm{ft}) \text { flame lengths off timber, } 6 \mathrm{~m} \text { to } 9 \mathrm{~m}(20 \mathrm{ft} \text { to } \\
30 \mathrm{ft}) \text { off brush; flames laying over with the wind; what } \\
\text { structure can survive this? }\end{array}$ \\
\hline TD-012 & flames & $\begin{array}{l}\text { houses feet with } 60 \mathrm{~m}(200 \mathrm{ft}) \text { clearance burned due to } \\
\text { horizontal flame lengths in wind }\end{array}$ \\
\hline TD-129 & hazards & falling trees may have knocked down power lines \\
\hline TD-011 & hazards & $\begin{array}{l}\text { Pearson } \mathrm{Rd} \text { and Skyway traffic light pole/signal sagged and } \\
\text { melted onto roadway (steel pole) }\end{array}$ \\
\hline TD-011 & hazards & $\begin{array}{l}\text { light pole arm at Pearson Rd and Recreation Dr deformed and } \\
\text { sagged }\end{array}$ \\
\hline TD-066 & hazards & power poles start burning at the bottom, middle, and cross tees \\
\hline TD-076 & hazards & melted/singed shirt sleeve on side of vehicle it was so hot \\
\hline TD-071 & hazards & powerlines down everywhere \\
\hline TD-110 & hazards & $\begin{array}{l}\text { surprised how fast power poles and lines came down in } \\
\text { Concow }\end{array}$ \\
\hline TD-126 & hazards & needles falling on homes would ignite \\
\hline TD-026 & hazards & wood chips still smoldering in yard on November 11 \\
\hline TD-090 & hazards & saw trees snapped off $6 \mathrm{~m}$ to $9 \mathrm{~m}(20 \mathrm{ft}$ to $30 \mathrm{ft})$ above ground \\
\hline TD-085 & hazards & put out fires on his vehicle multiple times \\
\hline
\end{tabular}




\begin{tabular}{|c|c|c|}
\hline TD & Keyword & Comments \\
\hline TD-069 & fire history & $\begin{array}{l}1936 \text { or } 1944 \text { fire in southern part of town with same burn scar } \\
\text { as } 2018 \text { fire }\end{array}$ \\
\hline TD-079 & fire history & $\begin{array}{l}\text { we were told at the Thomas Fire this was once in a career fire } \\
\text { behavior; followed by Carr; followed by Camp. }\end{array}$ \\
\hline TD-081 & fire history & wasn't like any other fire \\
\hline TD-085 & fire history & $\begin{array}{l}\text { thousands of structures burning, cars blocking access, } \\
\text { Armageddon-type behavior - civilians didn't help situation }\end{array}$ \\
\hline TD-089 & fire history & never seen this type of fire behavior in 17 -year career \\
\hline TD-061 & fire history & $\begin{array}{l}10 \text { years ago, [2008 Butte lightning fires] fire took } 3 \text { to } 4 \text { days } \\
\text { to progress from Concow to West Branch }\end{array}$ \\
\hline TD-079 & fire history & fire behavior similar to Carr Fire \\
\hline TD-060 & pine needles & pine needles blowing and igniting on roofs \\
\hline TD-087 & pine needles & pine needles ignite structure and then structure takes off \\
\hline TD-085 & conditions & number of runs and intensity were unprecedented \\
\hline TD-022 & structure & structure-to-structure fire spread \\
\hline TD-127 & structure & $\begin{array}{l}\text { fire front lasted about } 40 \text { minutes due to nearby structures } \\
\text { burning }\end{array}$ \\
\hline TD-127 & structure & $\begin{array}{l}\text { framed OSB houses under construction survived only because } \\
\text { no ground vegetation around }\end{array}$ \\
\hline TD-127 & structure & $\begin{array}{l}\text { composite materials can burn as severely as natural materials } \\
\text { (e.g., decking and wood) }\end{array}$ \\
\hline TD-026 & structure & $\begin{array}{l}\text { tile roof and } \$ 2000 \text { ember vents; wood eaves, cedar fence; } \\
\text { stucco survived but framing burned out }\end{array}$ \\
\hline TD-045 & structure & sheds may have caused many structures to ignite \\
\hline TD-106 & topography & $\begin{array}{l}\text { terrain did not help because there was a lot of lava cap rock, not } \\
\text { soil; hard to make line through the rocks }\end{array}$ \\
\hline TD-061 & topography & different fire behavior on lee-sides and drainages \\
\hline TD-012 & topography & $\begin{array}{l}\text { took only } 40 \text { minutes from fire crossing Butte Creek Island to } \\
\text { come up the walls of Doe Mill }\end{array}$ \\
\hline TD-037 & topography & $\begin{array}{l}\text { seems like structures in draws survived; fire blew right over } \\
\text { topography; } 2 \text { houses on Malibu Dr that survived are down in } \\
\text { draw }\end{array}$ \\
\hline TD-055 & topography & $\begin{array}{l}\text { Helltown had same terrain, same winds, but fire behavior was } \\
\text { different; if it had been the same, we would have died }\end{array}$ \\
\hline TD-014 & vegetation & ground fuels burned first, winds shifted, then burned up trees. \\
\hline TD-028 & vegetation & $\begin{array}{l}\text { vegetation fuel in Flea Canyon near Pulga probably contributed } \\
\text { to lots of embers when it burned quickly }\end{array}$ \\
\hline TD-084 & vegetation & $\begin{array}{l}\text { fuel treatments worked when fire behavior / wind reduced on } \\
\text { day } 2 \text {; understory and ladder fuel removal project ( } 3 \text { year } \\
\text { project) completed } 5 \text { years ago }\end{array}$ \\
\hline TD-100 & wind & wind howling, didn't shift until afternoon \\
\hline TD-079 & wind & $\begin{array}{l}\text { erratic winds } 7 \mathrm{~m} / \mathrm{s} \text { to } 9 \mathrm{~m} / \mathrm{s}(15 \mathrm{mi} / \mathrm{h} \text { to } 20 \mathrm{mi} / \mathrm{h}) \text {, gusts to } \\
13 \mathrm{~m} / \mathrm{s}(30 \mathrm{mi} / \mathrm{h})\end{array}$ \\
\hline
\end{tabular}




\begin{tabular}{|c|c|c|}
\hline TD & Keyword & Comments \\
\hline TD-087 & wind & purely wind driven with high fuel loading; terrain played a part \\
\hline TD-061 & wind & $\begin{array}{l}\text { wind driven fire; fuel wasn't grass or brush or timber - it was } \\
\text { houses }\end{array}$ \\
\hline TD-090 & wind & $\begin{array}{l}\text { wind blowing crazy, then would clear up a bit, back and forth } \\
\text { visibility }\end{array}$ \\
\hline TD-090 & wind & weird how the wind was shifting/spinning around \\
\hline TD-211 & wind & crazy wind speed; watched power poles snap from wind \\
\hline TD-091 & wind & winds were strong \\
\hline TD-092 & wind & nothing worked because of the wind \\
\hline TD-129 & wind & wind was blowing over trees \\
\hline TD-006 & wind & $\begin{array}{l}15 \mathrm{~m} / \mathrm{s} \text { to } 25 \mathrm{~m} / \mathrm{s}(30 \mathrm{kt} \text { to } 50 \mathrm{kt} \text { or } 34 \mathrm{mi} / \mathrm{h} \text { to } 57 \mathrm{mi} / \mathrm{h} \text { ) is critical } \\
\text { wind limit for fixed wing operations }\end{array}$ \\
\hline TD-006 & wind & $\begin{array}{l}\text { erratic winds shut down fixed wing operations around 08:00 on } \\
\text { November } 8\end{array}$ \\
\hline TD-041 & wind & erratic winds and smoke conditions constantly changing \\
\hline TD-076 & wind & winds were strong the whole day \\
\hline TD-086 & wind & $\begin{array}{l}\text { Butte is known for Jarbo winds; fire burning north all day will } \\
\text { switch and reverse more intense back toward the valley in the } \\
\text { afternoon }\end{array}$ \\
\hline TD-022 & wind & creeping fire, then flared up with wind gust \\
\hline TD-116 & wind & gusting winds caused bellowing effect on fire \\
\hline TD-043 & wind & $\begin{array}{l}\text { wind was strong enough to blow off helmet (in field at Merrill } \\
\text { Rd at 08:30 on November } 8 \text { ) }\end{array}$ \\
\hline TD-127 & wind & $\begin{array}{l}\text { called for rescue, but explosions and extreme fire behavior } \\
\text { prevented access; wind } 9 \mathrm{~m} / \mathrm{s} \text { to } 13 \mathrm{~m} / \mathrm{s}(20 \mathrm{mi} / \mathrm{h} \text { to } 30 \mathrm{mi} / \mathrm{h}) \text {, } \\
\text { bushels of pine needles burning }\end{array}$ \\
\hline TD-106 & wind & with wind, not a whole lot you can do with this fire \\
\hline TD-047 & wind & $\begin{array}{l}\text { lots of people don't know how close the fire came to burning } \\
\text { the whole county; wind shift could have blown it straight to } \\
\text { Oroville }\end{array}$ \\
\hline TD-081 & wind & $\begin{array}{l}\text { down-canyon winds normal for midnight ... morning to early } \\
\text { afternoon up canyon, then settles late evening, midnight to } \\
\text { 02:00 winds reverse strong; happened summer } 2018 \text { fire up in } \\
\text { Magalia, same thing during } 2008 \text { Concow fire }\end{array}$ \\
\hline TD-084 & wind & 2 to 3 city block diameter whirls \\
\hline TD-084 & wind & $\begin{array}{l}\text { hard to survive intense fire, }>27 \mathrm{~m} / \mathrm{s}(60 \mathrm{mi} / \mathrm{h}) \text { winds and } \\
\text { tornados - cannot defend }\end{array}$ \\
\hline
\end{tabular}


NIST Technical Note 2135

\title{
A Case Study of the Camp Fire - Fire Progression Timeline
}

\author{
Map Book
}

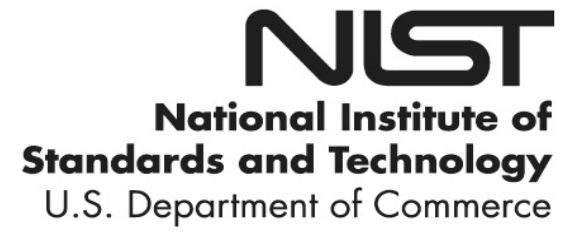




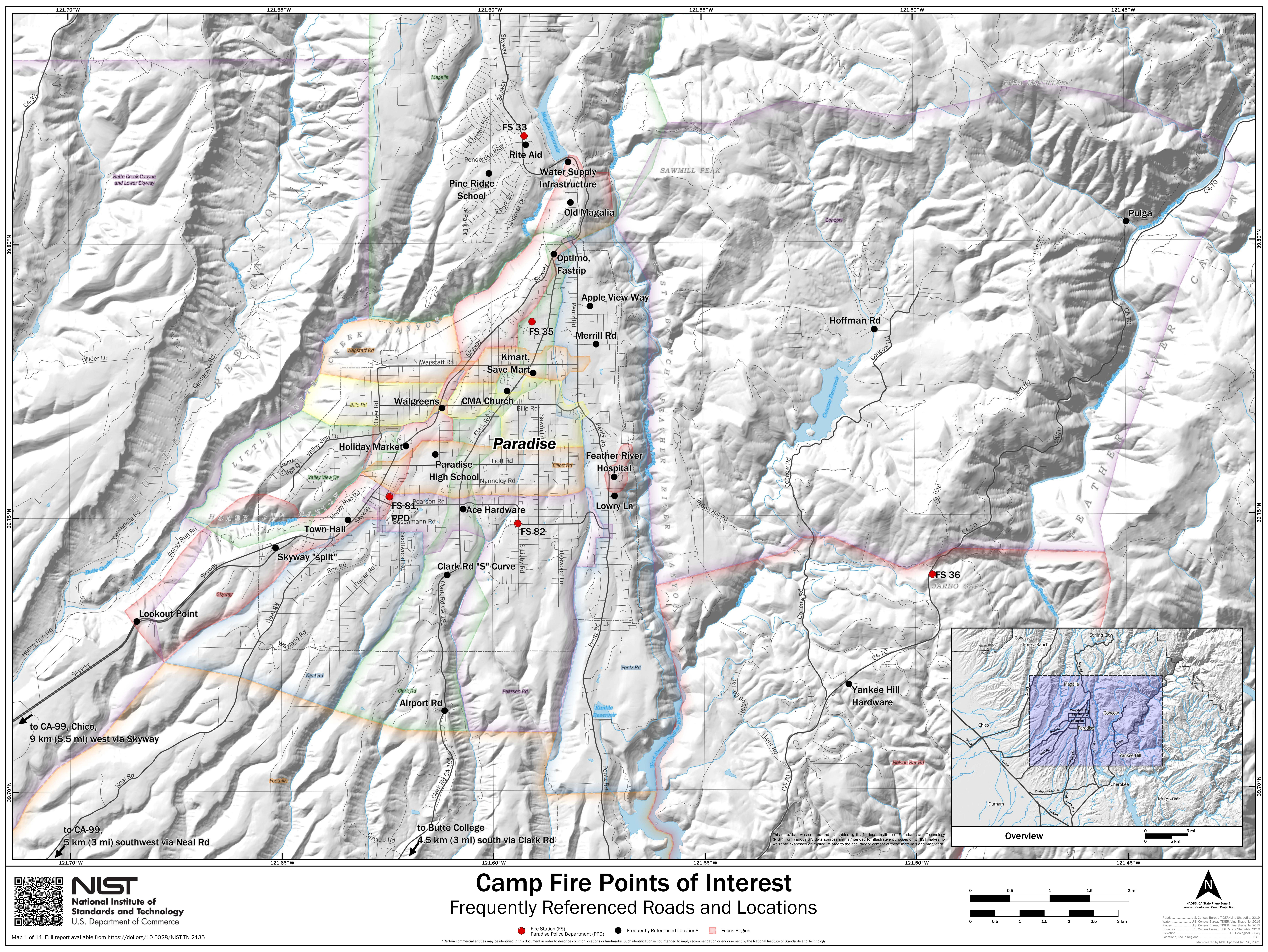




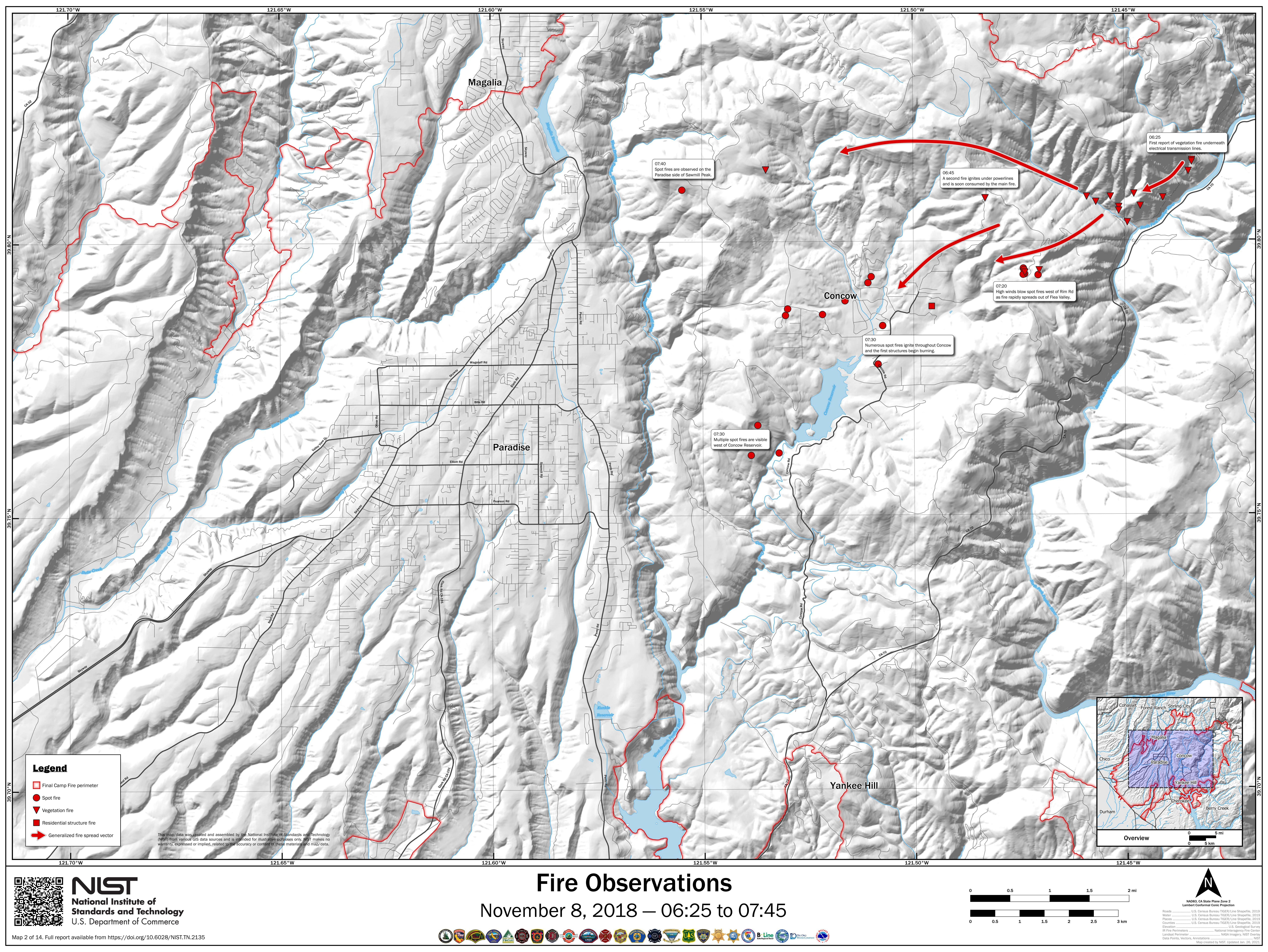




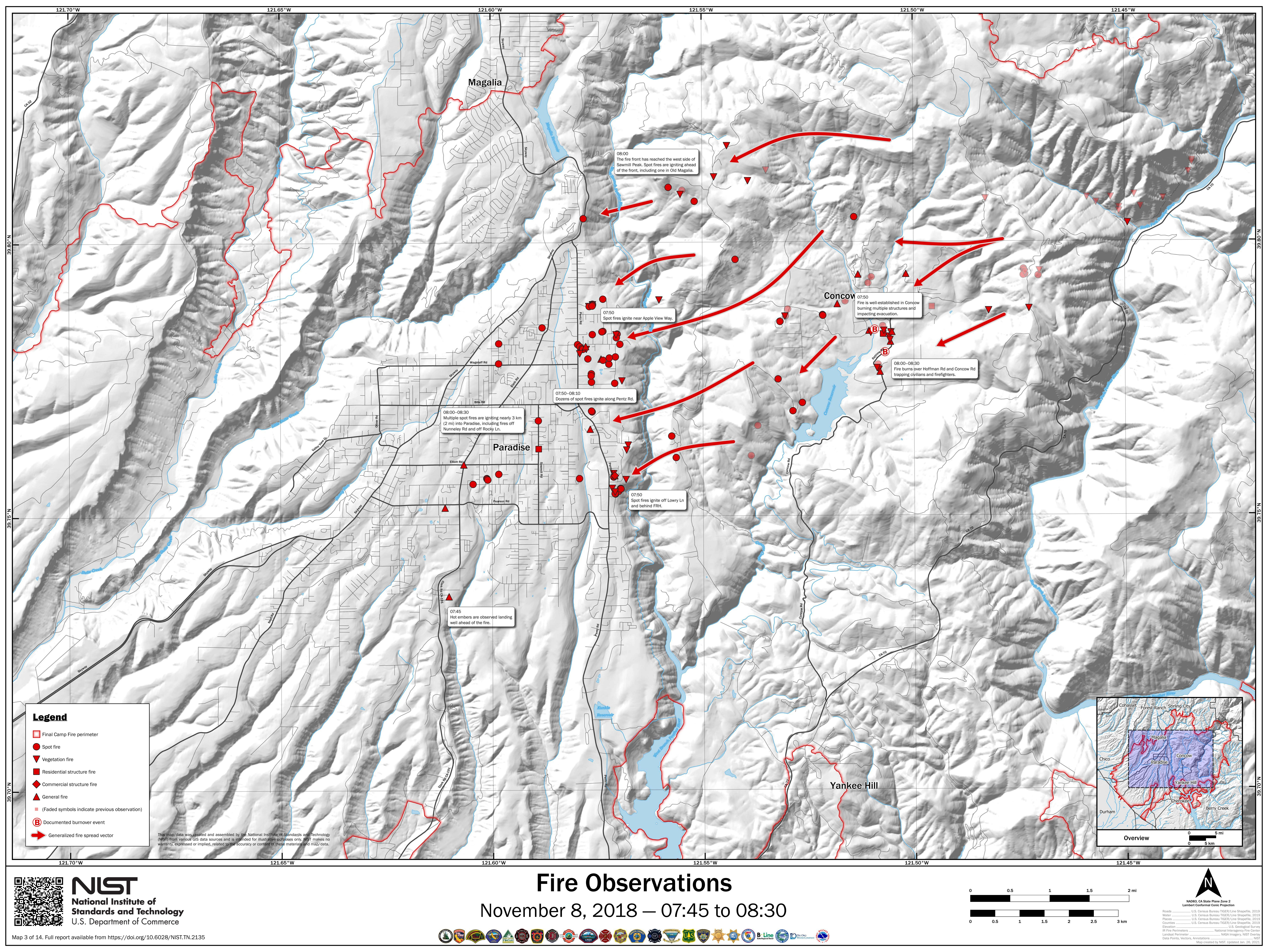




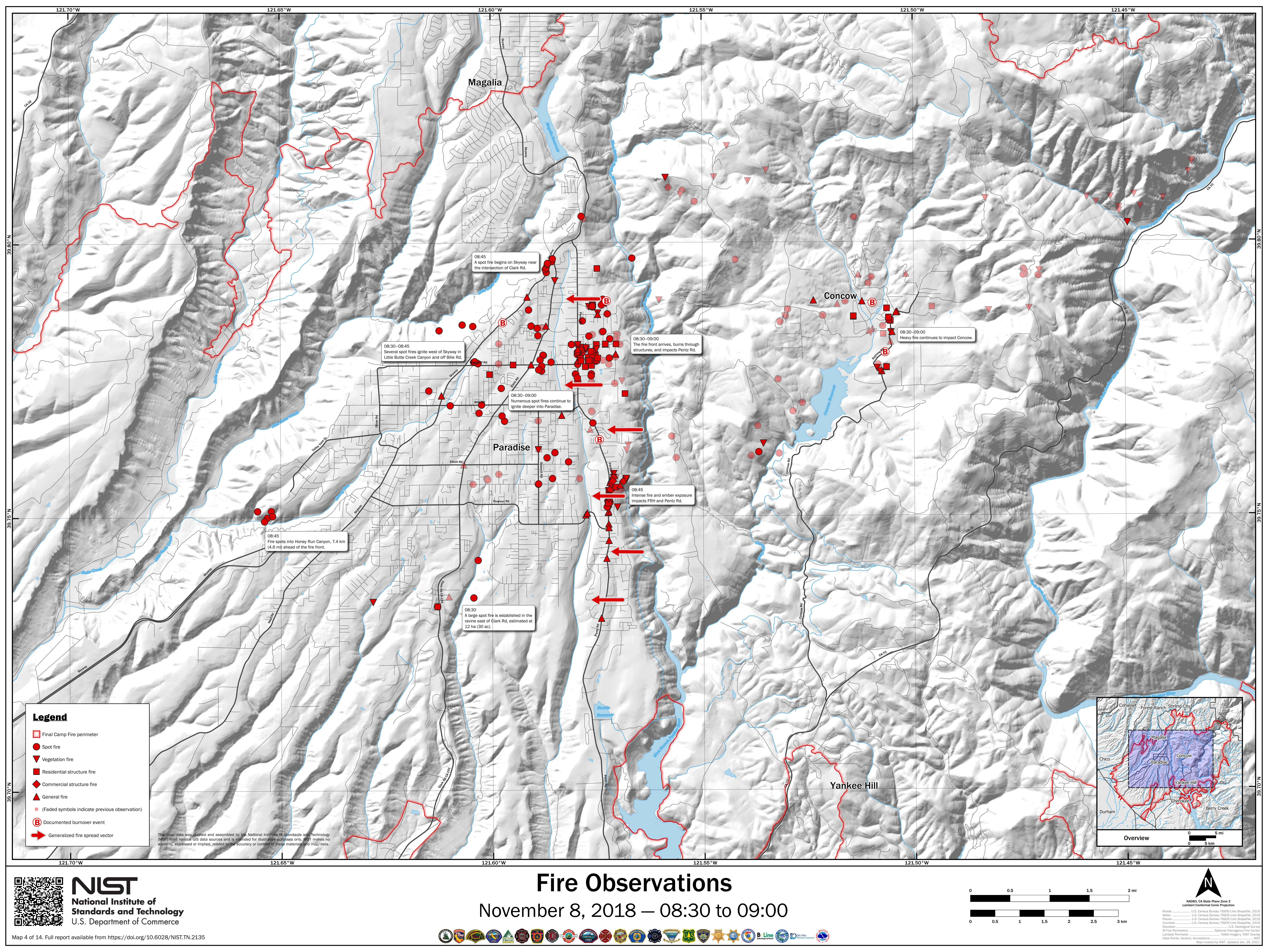




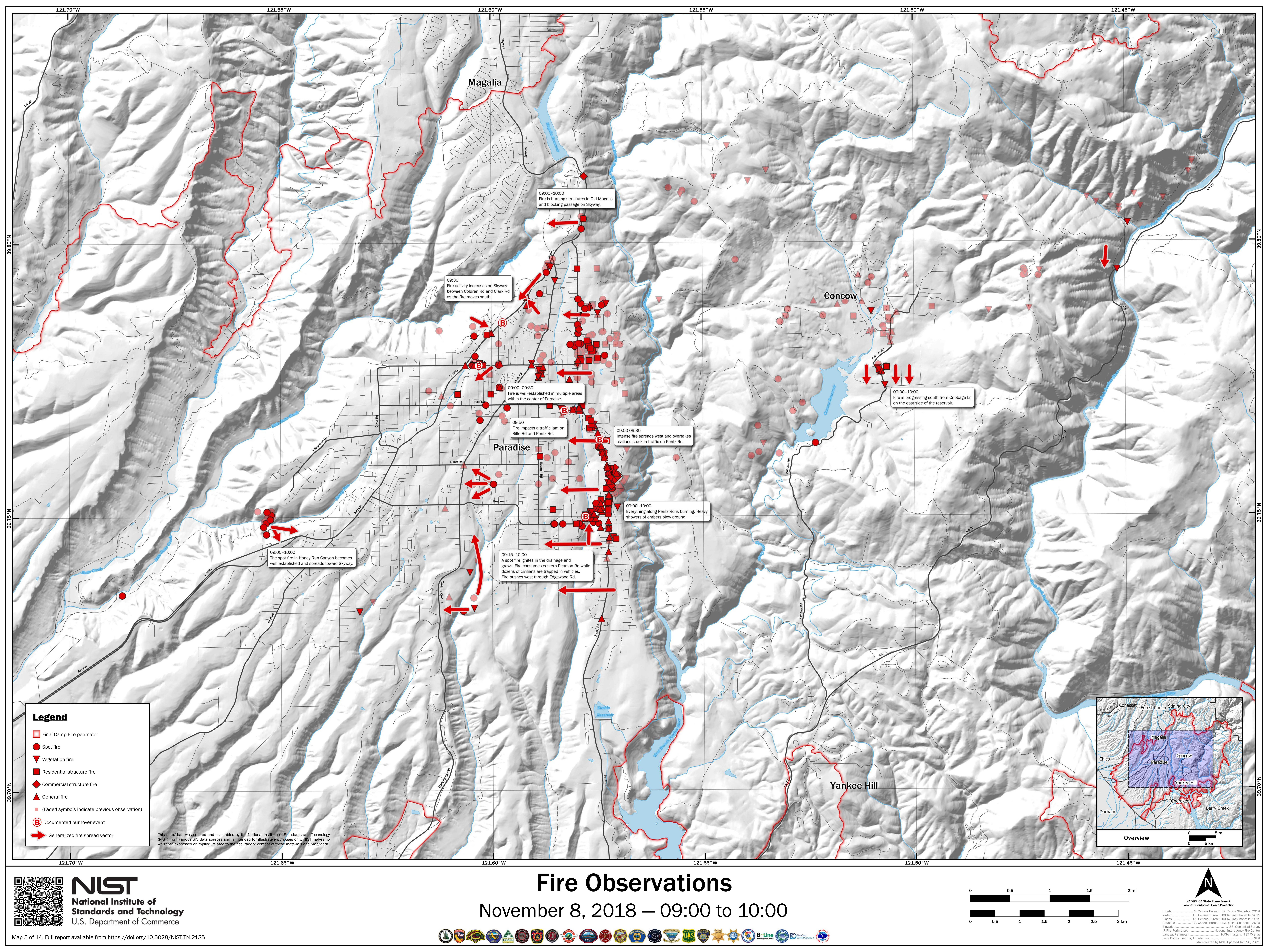




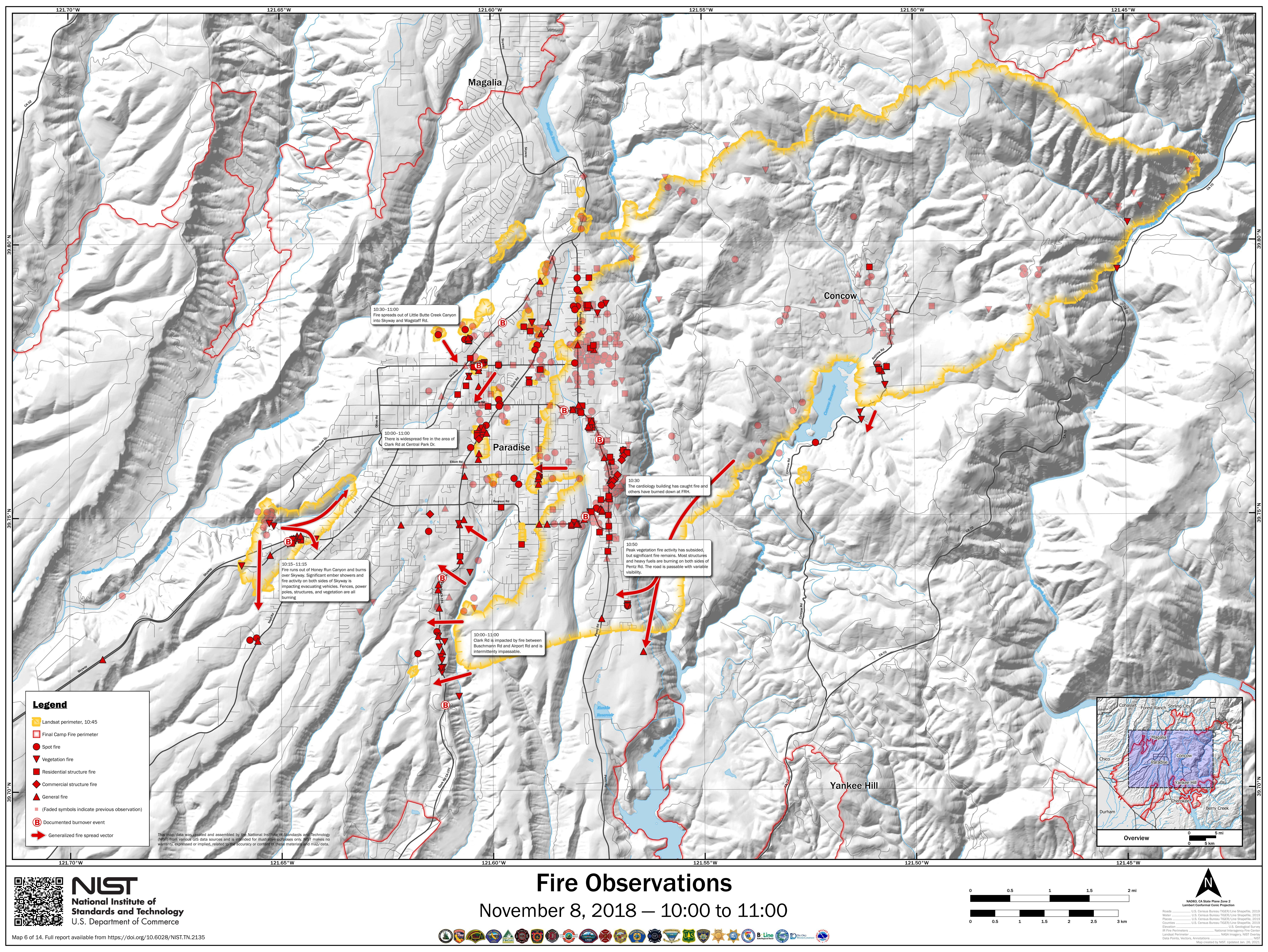




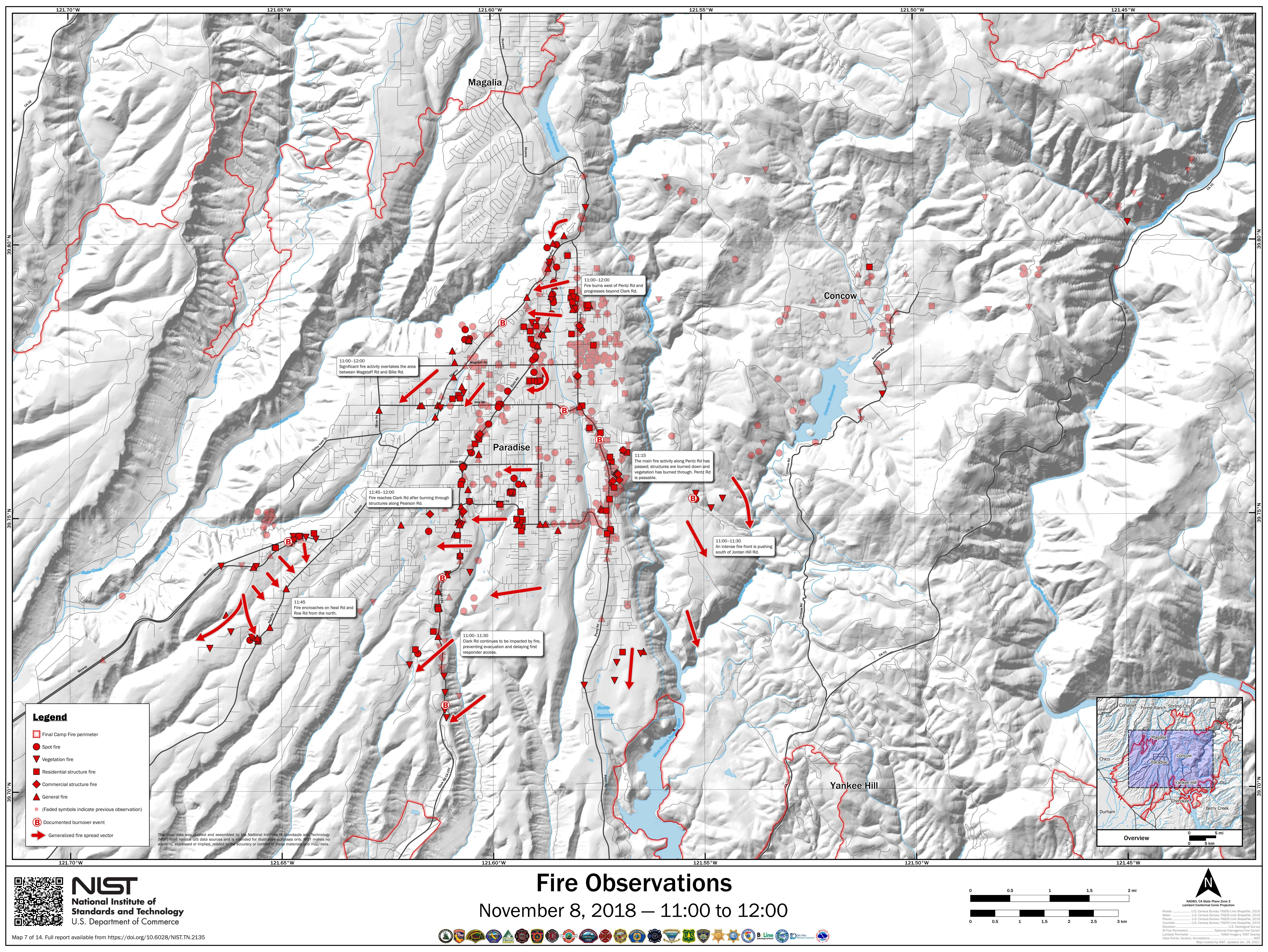




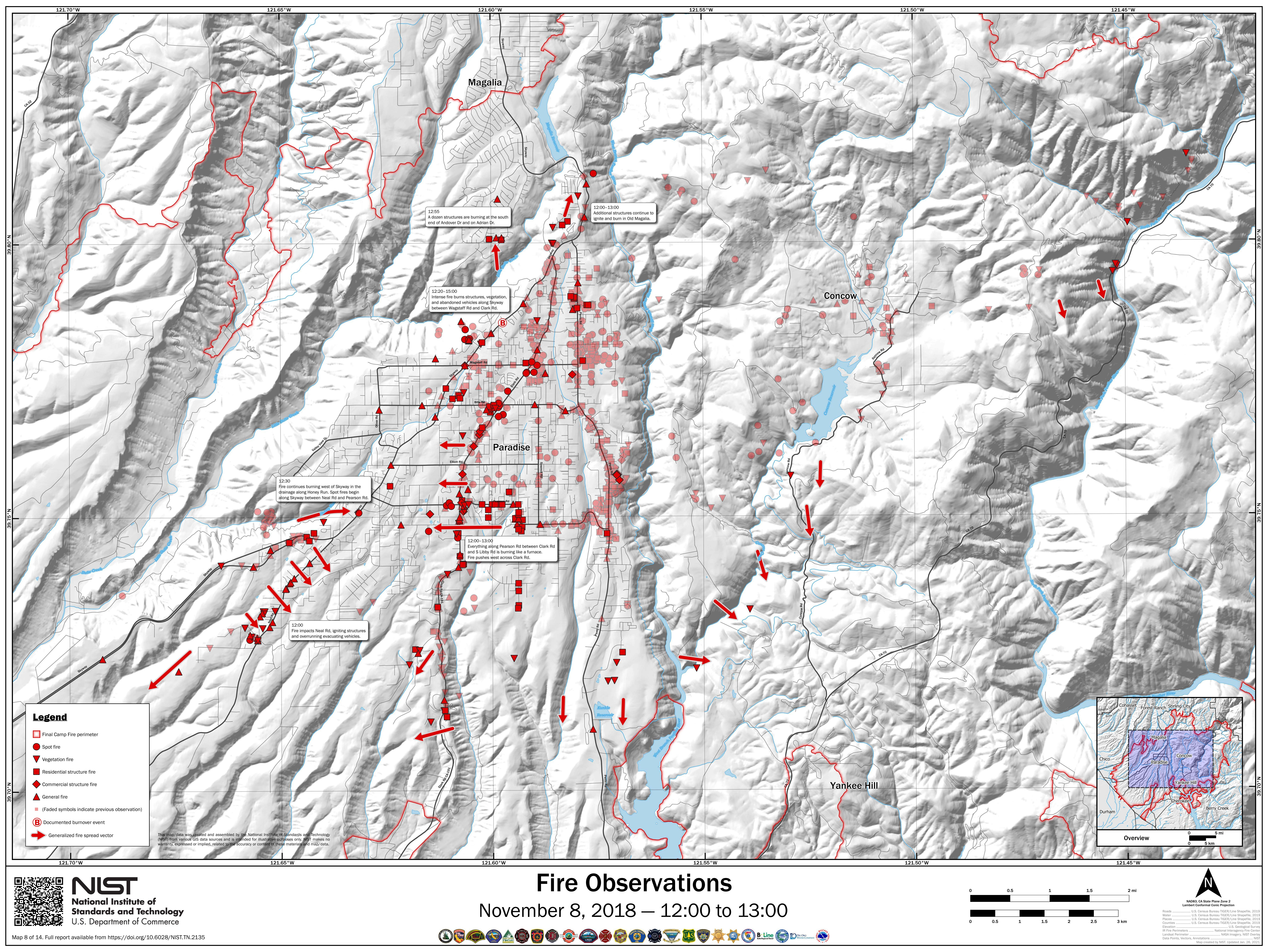




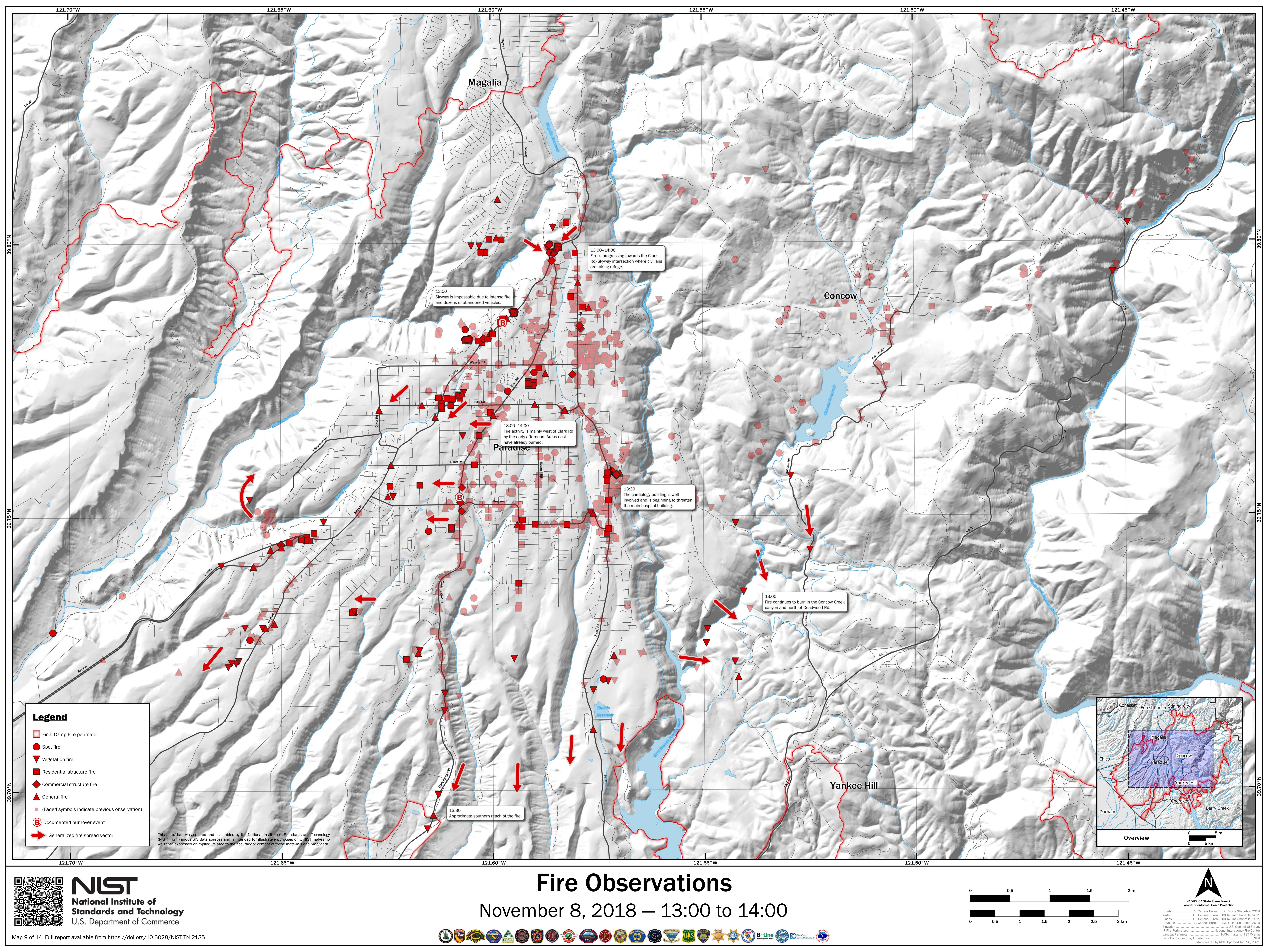




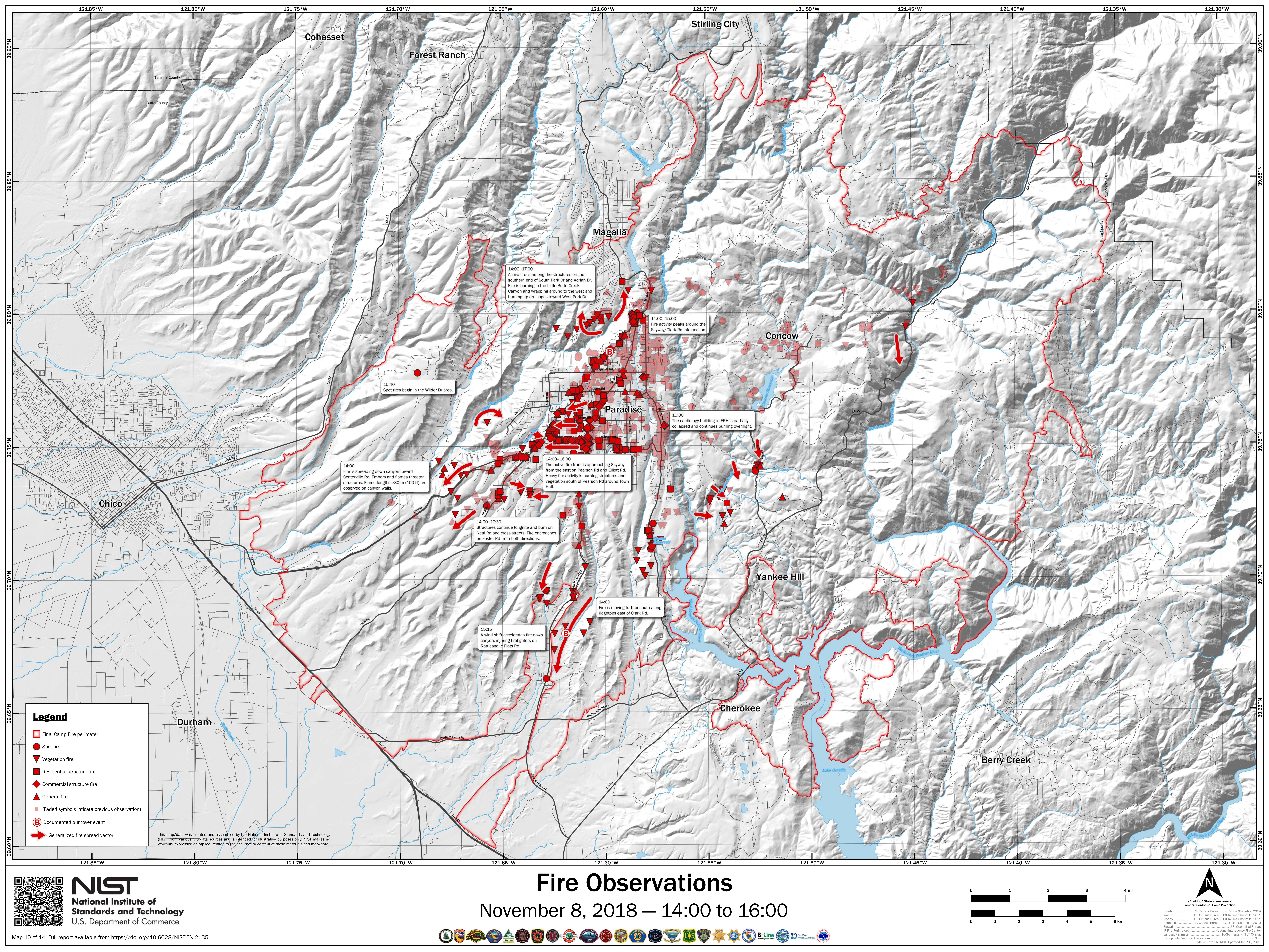




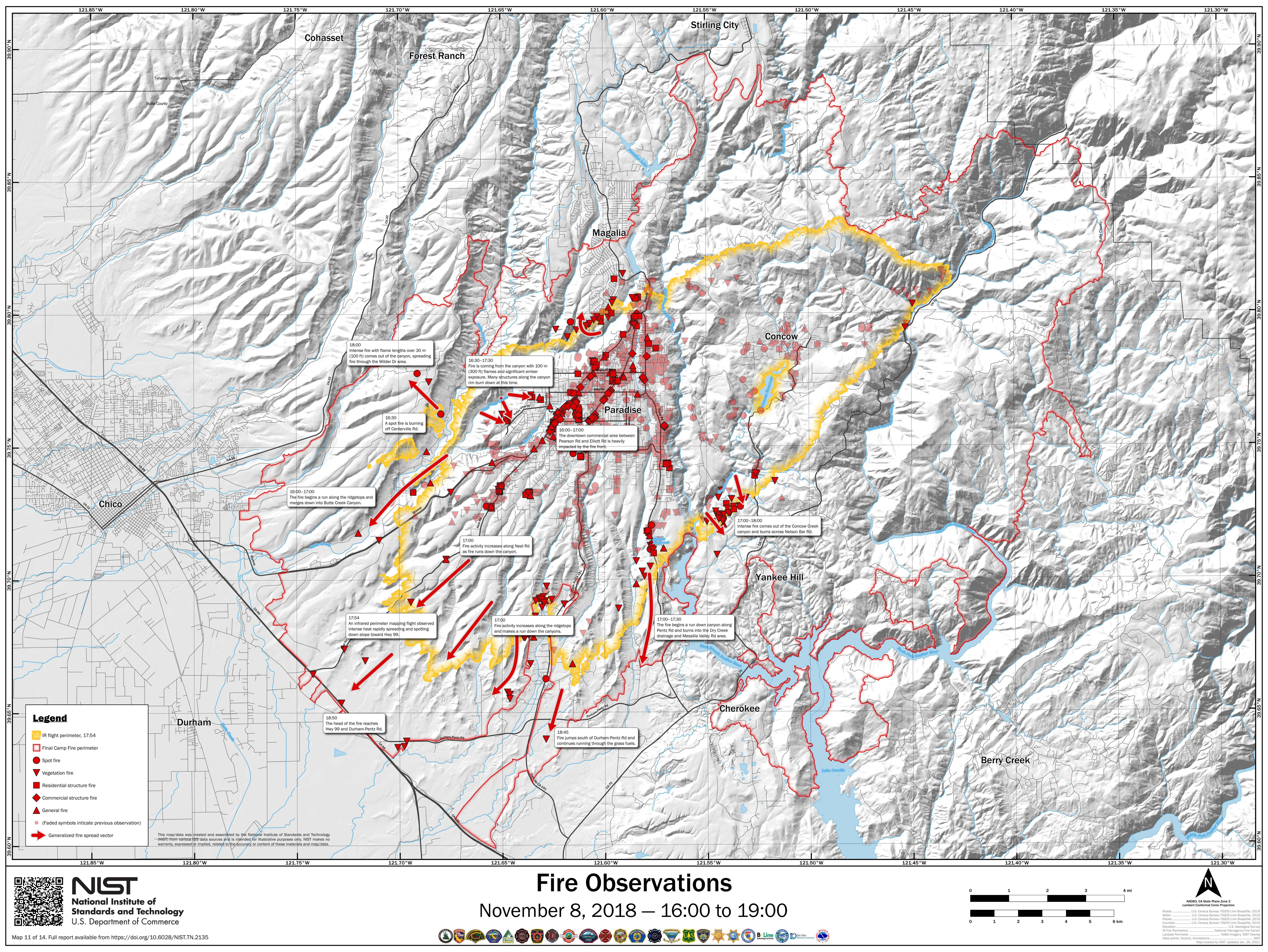




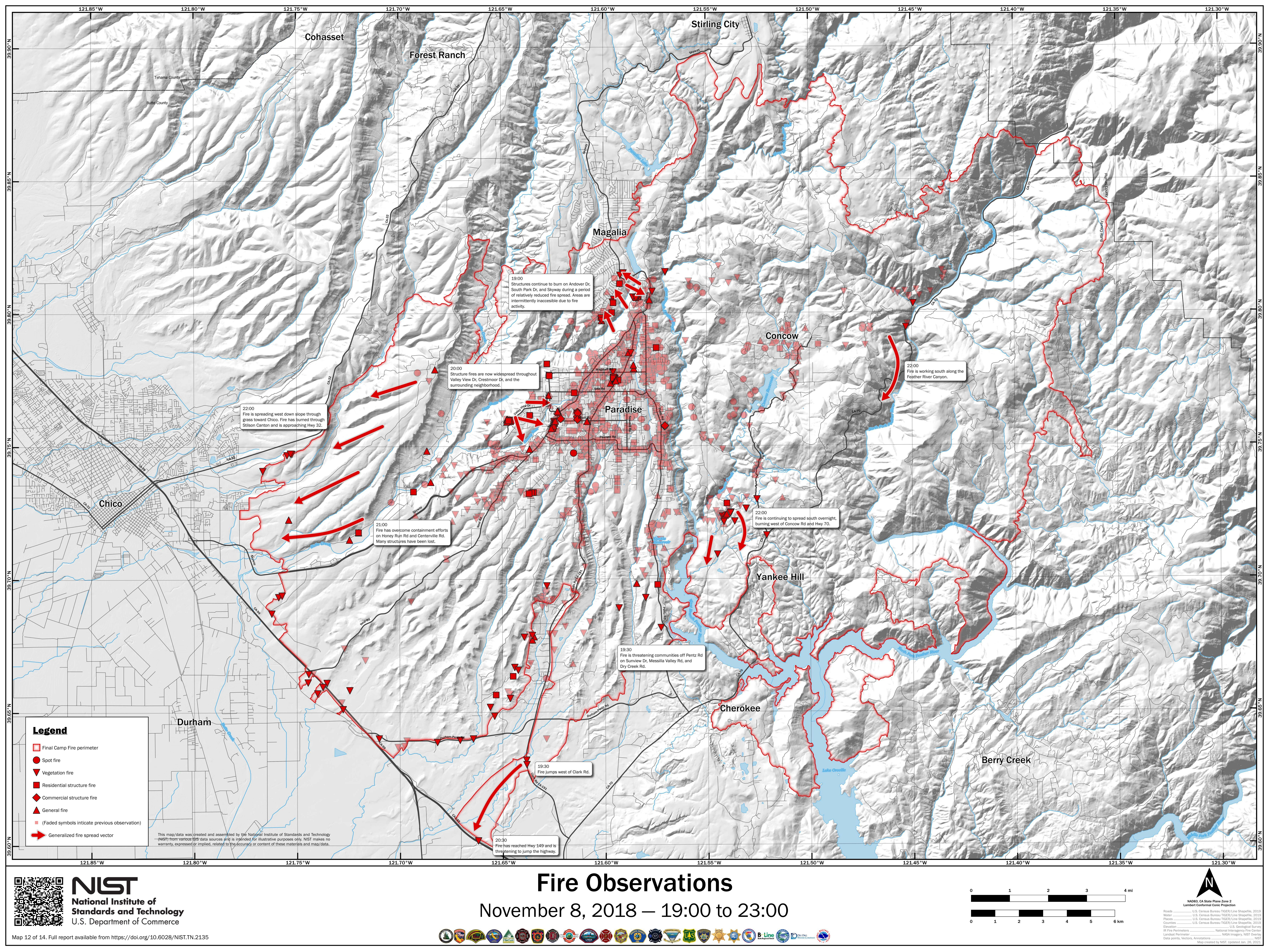




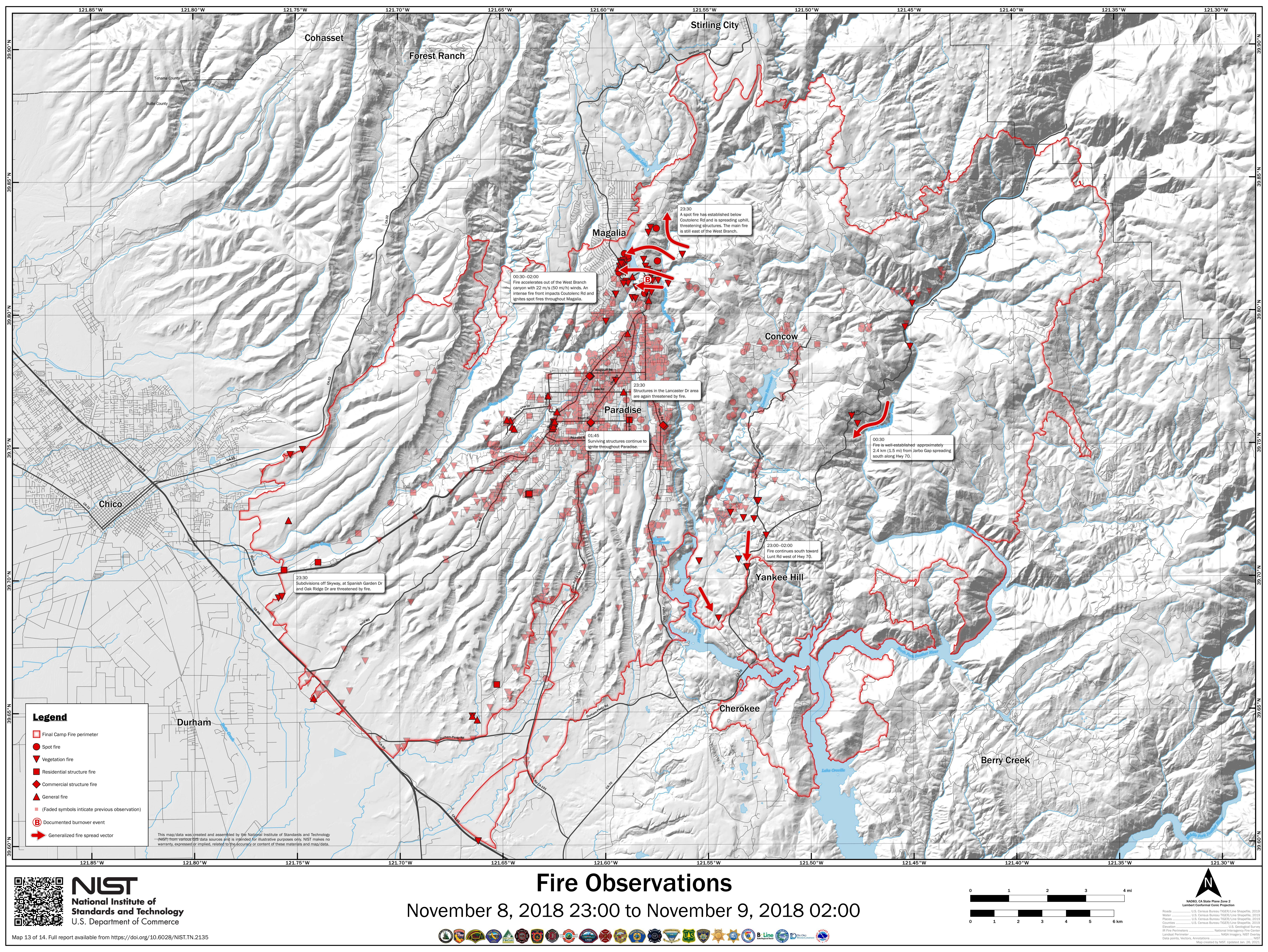




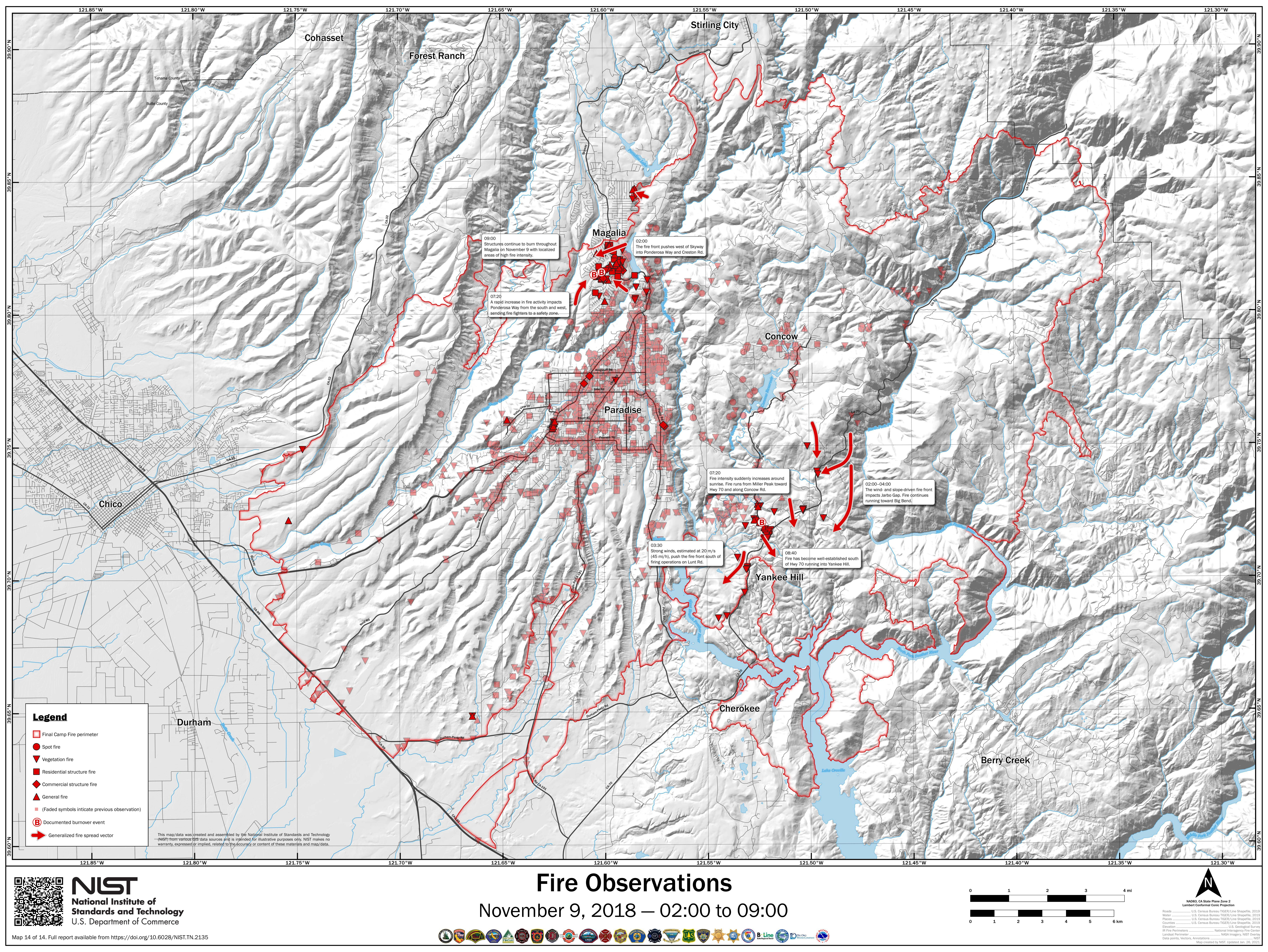

